\title{
Catálogo de las plantas vasculares de Chile
}

\section{Catalogue of the vascular plants of Chile}

\author{
Roberto Rodriguez ${ }^{1}$, Clodomiro Marticorena ${ }^{\dagger}$, Diego Alarcón ${ }^{3,4}$, Carlos Baeza ${ }^{1}$, Lohengrin \\ Cavieres ${ }^{3,4}$, Víctor L. Finot ${ }^{2}$, Nicol Fuentes ${ }^{1}$, Andrea Kiessling ${ }^{1}$, Maritza Mihoc ${ }^{3,4}$, Aníbal \\ Pauchard ${ }^{5}$, Eduardo Ruiz ${ }^{1}$, Paulina Sanchez ${ }^{5} \&$ Alicia Marticorena ${ }^{1 *}$
}

1Departamento de Botánica, Facultad de Ciencias Naturales y Oceanográficas, Universidad de Concepción, Casilla 160-C, Concepción, Chile.

2Departamento de Producción Animal, Facultad de Agronomía, Universidad de Concepción, Casilla 537, Chillán, Chile. ${ }^{3}$ Ecobiosis, Departamento de Botánica, Facultad de Ciencias Naturales y Oceanográficas, Universidad de Concepción, Casilla 160-C, Concepción, Chile.

${ }^{4}$ Instituto de Ecología y Biodiversidad (IEB), Casilla 653, Santiago, Chile.

${ }^{5}$ Laboratorio de Invasiones Biológicas, Facultad de Ciencias Forestales, Universidad de Concepción, Victoria 631, Concepción, Chile.

*amartic@udec.cl

\section{RESUMEN}

Se presenta un catálogo de las plantas vasculares que crecen en Chile. Está organizado por divisiones, Pteridophyta (Lycopodiopsida y Polypodiopsida), Pinophyta (Gnetopsida y Pinopsida) y Magnoliophyta (Liliopsida y Magnoliopsida), y dentro de cada grupo, las jerarquías taxonómicas (Familia, Género, Especies y taxones infraespecíficos) están ordenados alfabéticamente. Se incluye además un índice alfabético de géneros con indicación de la familia y grupo a que pertenecen. De acuerdo a este catálogo la flora de las plantas vasculares que crecen en Chile, comprende 186 familias, 1121 géneros y 5471 especies, de éstas, 4655 corresponden a especies nativas, de las cuales 2145 son endémicas de Chile y 816 las especies introducidas.

Palabras clave: Altitud, distribución geográfica, flora chilena, listado, origen.

\begin{abstract}
A catalog of vascular plants growing in Chile is presented. It is organized by divisions, Pteridophyta (Lycopodiopsida and Polypodiopsida), Pinophyta (Gnetopsida and Pinopsida) and Magnoliophyta (Liliopsida and Magnoliopsida), and within each group, the taxonomic hierarchies (Family, Genus, Species and infraspecific taxa) are arranged alphabetically. In accordance with this catalogue, the flora of vascular plants of Chile comprise 186 families, 1121 genera and 5471 species, 4655 species are native, 2145 of these are endemic to Chile and 816 species are introduced.
\end{abstract}

KEYwords: Checklist, Chilean flora, geographic distribution, elevation, origin.

\section{INTRODUCCIÓN}

La taxonomía, en lo que se refiere a la nomenclatura, está en constante revisión, provocando cambios en los nombres de los componentes de una flora. En muchos géneros de plantas vasculares chilenas, las especies son conocidas desde hace más de dos siglos, sin embargo, existe una gran cantidad de géneros que han sido recientemente revisados lo que ha repercutido en cambios nomenclaturales y variaciones en el número de los integrantes que comprenden las distintas jerarquías. Dado lo dinámico de esta disciplina, es preciso tomar conciencia de la necesidad de actualizar continuamente estos conocimientos debido a que constituyen la base para muchas otras disciplinas, siendo una herramienta fundamental al momento de evaluar el impacto ambiental de las actividades productivas sobre la flora del país.

El primer catálogo de la flora chilena lo publicó Federico Philippi (1881), debido a su antigüedad y por las citas de 
numerosos nombres de plantas que no existen en el país, actualmente está totalmente obsoleto. En dicho trabajo se incluyó información referente al nombre científico, autor de la especie, familia, citas bibliográficas y sinónimos para cada especie. Alrededor de un siglo después, Clodomiro Marticorena y Max Quezada (1985) publicaron el Catálogo de la flora vascular de Chile, actualizando de buena manera los nombres dados por Philippi y lo que se conocía taxonómicamente de la flora del país hasta esa fecha. Ese trabajo constituyó el primer intento de unificar y reunir todo el conocimiento disperso de la flora de Chile en una sola publicación, sirviendo como referente durante más de 20 años, y sintetizando la información sobre las clases, familias, géneros, especies, categorías infraespecíficas, autores y origen (nativo o introducido) para cada una de las especies de plantas vasculares presentes en el país.

Posterior a la publicación de estos trabajos han aparecido listas y catálogos regionales que fueron modificando algunos nombres de la flora chilena. Arroyo et al. (1990) contribuyen al conocimiento de la flora anual nativa de Chile continental, Henríquez et al. (1995) publican el Catálogo de la flora de la Región de Magallanes, luego Marticorena et al. (1998a, 1998b) el Catálogo de la flora vascular de Juan Fernández y el Catálogo de la flora vascular de la Región de Antofagasta, después Marticorena et al. (2001) publican el Catálogo de la Flora Vascular de la IV Región de Coquimbo, y por último Squeo et al. (2008) el Catálogo de la Flora Vascular de la Región de Atacama.

Con la aparición del Catálogo de las Plantas Vasculares del Cono Sur (Zuloaga et al. 2008) se actualizó gran parte del conocimiento taxonómico y la información de la distribución geográfica de las especies nativas e introducidas de Argentina, Sur de Brasil, Chile, Paraguay y Uruguay. Este catálogo ha sido de gran impacto en la aplicación correcta de los nombres para las plantas vasculares del Cono Sur de Sudamérica, considerando además del texto impreso, la continua corrección y actualización periódica de la base de datos del Instituto de Botánica Darwinion.

Desde el año 2008 a la fecha han aparecido nuevas publicaciones relacionadas a la flora, como tratamientos de familias de la Flora de Chile (Marticorena \& Rodríguez 2011), los estudios de distribución geográfica que amplían la presencia de algunas especies en otras regiones del país o en países vecinos, y tratamientos taxonómicos de familias y géneros que modifican el listado de especies nativas, endémicas e introducidas de Chile. Cabe destacar, la reciente publicación del libro Plants of Oceanic Islands. Evolution, Biogeography, and Conservation of the Flora of Juan Fernández (Robinson Crusoe) Archipelago (Stuessy et al. 2018), que permitió acceder a una detallada y actualizada revisión de los taxones presentes en el archipiélago, información que también ha sido incluida en este trabajo.

Un esfuerzo adicional permitió corregir, actualizar y depurar el registro de las especies introducidas en el país.
Nuevos registros, cambio en el estatus (origen) de algunas especies, corrección y validación del rango de distribución y la evaluación de la nomenclatura de estas especies permiten entregar el detalle a escala regional de este componente de la flora del país.

Dentro de las dificultades que se presentaron durante la realización del presente catálogo se encontraron varias especies cuya presencia en el país es dudosa, géneros que no han sido estudiados en su totalidad y que se desconoce su estado actual y nombres que no han podido ser corroborados por no poseer material de herbario disponible. Por ejemplo, las especies o combinaciones publicadas en revistas sin comité editorial y de difícil acceso, en su gran mayoría no han podido ser aceptadas. La imposibilidad, en algunos casos, de acceder a la publicación original, o bien la ausencia del material typus en los herbarios mencionados en los protólogos impidieron incluirlas.

El presente Catálogo de las Plantas Vasculares de Chile, constituye una nueva actualización, corrección y síntesis de la información taxonómica y geográfica de la flora de Chile incluyendo su territorio insular y la actual regionalización. Este nuevo catálogo viene a cubrir una necesidad nacional por saber qué especies crecen en el territorio, y se espera que sea también un incentivo para actualizar el conocimiento de grupos difíciles que no han sido tratados con nuevas técnicas y herramientas sistemáticas.

Como se señaló al comienzo, la taxonomía es dinámica, por lo que luego habrá que actualizar este catálogo, para esto, versiones actualizadas podrán ser consultadas en la página de la Facultad de Ciencias Naturales y Oceanográficas de la Universidad de Concepción en un intento de aportar al conocimiento y valorización de nuestro patrimonio a partir de esta disciplina.

\section{MATERIALES Y MÉTODOS}

El Catálogo de las plantas vasculares de Chile reúne la información de los taxones que se encuentran en Chile continental e insular (Archipiélago de Juan Fernández, Isla de Pascua e Islas Desventuradas).

La actualización de los niveles taxonómicos de división, clase, orden y familia siguen lo propuesto por Stevens (2001 en adelante). La actualización de los nombres científicos a nivel de especie se realizó utilizando toda la información bibliográfica disponible, tomando como base el Catálogo de las plantas vasculares de Chile (Marticorena \& Quezada 1985), Bibliografía botánica taxonómica de Chile (Marticorena 1992), Bibliografía botánica taxonómica de Chile, Suplemento 1 (Marticorena 1996), Catálogo del Cono Sur (Zuloaga et al. 2008), monografías y revisiones taxonómicas publicadas después de 2008 y que están relacionadas con cambios nomenclaturales en la flora chilena principalmente aquellos realizados en el marco del 
Proyecto Nueva Flora de Chile. Las abreviaturas de los nombres de los autores presentan el formato propuesto por Brummitt \& Powel (1992) seguido por The International Plant Names Index (IPNI).

De forma complementaria se revisaron especímenes de herbario, especialmente del Herbario de la Universidad de Concepción (CONC) y del Museo Nacional de Historia Natural (SGO). A raíz de estos estudios en este catálogo se incluye nueva información y en algunos casos se añaden notas para aclarar la nomenclatura y otra información relevante.

En cuanto a distribución geográfica, se actualizó con la nueva división administrativa del país agregando las nuevas regiones de Arica y Parinacota, Ñuble y Los Ríos, además se aclararon varias dudas con respecto a la presencia en Chile Continental e Insular de numerosas especies. Para cada una de las áreas se ha señalado con un acrónimo (Tabla 1). En cuanto al origen se consideraron tres categorías: nativas, endémicas de Chile e introducidas.

TABLA 1. Acrónimos utilizados para señalar cada una de las Regiones de Chile continental e insular. / Acronyms used to indicate each one of the Regions of continental and insular Chile.

\begin{tabular}{lc}
\hline REGIÓN & ACRÓNIMO \\
\hline Arica y Parinacota & AYP \\
Tarapacá & TAR \\
Antofagasta & ANT \\
Atacama & ATA \\
Coquimbo & COQ \\
Valparaíso & VAL \\
Metropolitana de Santiago & RME \\
Libertador Bernardo O’Higgins & LBO \\
Maule & MAU \\
Nuble & NUB \\
Biobío & BIO \\
Araucanía & ARA \\
Los Ríos & LRI \\
Los Lagos & LLA \\
Aisén & AIS \\
Magallanes & MAG \\
Juan Fernández & JFE \\
Isla de Pascua & IPA \\
Islas Desventuradas & IDE \\
\hline &
\end{tabular}

Finalmente, este catálogo incluye información sobre División, Clase, Familia, Género, Especie, y categorías infraespecíficas. Los nombres aceptados incluyen Autor(es), Sinónimos (considerando solo los nombres citados para
Chile), datos de Hábito (Árbol, Árbol pequeño, Arbusto, Subarbusto, Hierba), Ciclo de vida (anual, bienal, perenne), Estatus (endémico, nativo, introducido), Distribución en las regiones de Chile (según acrónimos), Rango altitudinal, presencia en Países vecinos (Argentina, Bolivia, Perú), Nombres vulgares en los casos que corresponda y Notas.

Para las plantas introducidas, el punto de partida fue la información que se obtuvo del Catálogo de la Flora Vascular de Chile (Marticorena \& Quezada 1985) y la base de datos del Laboratorio de Invasiones Biológicas de la Universidad de Concepción (LIB). A partir de esta información y de la incorporación de trabajos y publicaciones recientes en la materia, se corrige y depura el registro de especies introducidas en el país. En el presente catálogo, se compilan nuevos registros, se cambia el estatus (origen) de algunos taxones, y se corrige y valida el rango de distribución de estas especies en Chile continental e insular según la regionalización vigente. A su vez, y al igual que con las especies nativas, se evalúa y actualiza la nomenclatura, permitiéndonos entregar el detalle a escala regional de este componente de la flora del país. En este trabajo se detalla la misma información que para las especies nativas, a excepción de la información en relación a los sinónimos y su presencia en países vecinos.

El Anexo 1 contiene la lista alfabética de los géneros, con su correspondiente familia y clase.

Ejemplo del formato:

\section{ANACARDIACEAE}

\section{Schinus}

Schinus polygamus (Cav.) Cabrera

Sinónimos: Amyris polygama Cav., Schinus polygamus (Cav.) Cabrera var. chilensis F.A. Barkley, Schinus polygamus (Cav.) Cabrera fma. ovatus (Lindl.) Cabrera, Schinus dependens Ortega var. brevifolia Fenzl ex Engl., Schinus huyngan Kuntze, Schinus polygamus (Cav.) Cabrera var. parviflorus (Marchand) F.A. Barkley, Duvaua crenata Phil., Litrea crenata Phil., Schinus dependens Ortega var. parviflorus Marchand

Arbusto o árbol pequeño. Nativo.

Distribución: ATA, COQ, VAL, RME, LBO, MAU, NUB, BIO, ARA, LRI, LLA.

Rango altitudinal: 0-3200 m.

Países limítrofes: Argentina y Bolivia.

Nombre vulgar: Huingán.

Nota: Especie muy polimorfa, con variaciones especialmente en las hojas, lo que ha motivado la creación de variedades, subespecies y formas, las que han sido reunidas en una sola especie. 


\section{RESULTADOS}

De acuerdo a los registros, un total de 6 clases y 56 órdenes representan los niveles superiores de organización y se informa la presencia en el país de 5471 taxones distribuidos en 1121 géneros y 186 familias. Del total, 4655 corresponden a taxones nativos $(85,1 \%), 2145$ de ellos son endémicos de Chile $(39,2 \%)$, mientras que las introducidas suman 816 (14,9\%) (Tabla 2).

TABLA 2. Estadística de las plantas vasculares en la flora de Chile de acuerdo a su clase taxonómica. / Statistics of vascular plants of Chile, according to taxonomic class.

\begin{tabular}{lcccc}
\hline \multicolumn{1}{c}{ Clase } & ENdÉMICA & Nativa & INTRODUCIDA & TotAL \\
\hline Lycopodiopsida & 1 & 10 & 1 & 12 \\
Polypodiopsida & 55 & 94 & 4 & 153 \\
Gnetopsida & 2 & 4 & 0 & 6 \\
Pinopsida & 1 & 8 & 3 & 12 \\
Liliopsida & 401 & 617 & 216 & 1234 \\
Magnoliopsida & 1685 & 1777 & 592 & 4054 \\
Total & 2145 & 2510 & 816 & 5471 \\
\hline
\end{tabular}

Desde la publicación de Marticorena \& Quezada (1985), se han incorporado numerosos registros, tanto de especies nativas como de introducidas. Algunos ejemplos de los cambios que se presentan en este catálogo corresponden a: nivel de familia, la prevalencia de los nombres Apiaceae, Asteraceae y Brassicaceae, reemplazando el uso de los nombres de las familias Umbelliferae, Compositae y Cruciferae respectivamente. Fusión de algunas familias como Caesalpiniaceae y Mimosaceae cuyos representantes en Chile quedan reunidos bajo la familia Fabaceae; Ledocarpaceae y Vivianiaceae fusionadas bajo la familia Francoaceae; Flacourtiaceae quedando incluida bajo Salicaceae, la inclusión de Eucryphiaceae dentro de Cunoniaceae y Empetraceae y Epacridaceae dentro de Ericaceae. La segregación de géneros que quedan en familias independientes como Calceolariaceae que incluye a Calceolaria y Jovellana, Quillajaceae familia monotípica con Quillaja como único representante y Heliotropiaceae incluyendo a Heliotropium.

A nivel de género, el cambio de nombres como Pseudognaphalium, Austrolycopodium y Diphasium que reemplazan a los representantes chilenos de los géneros Gnaphalium y Lycopodium respectivamente. Nombres de géneros que han pasado a la sinonimia y por lo tanto deberían dejar de usarse en Chile como son: Mimulus (que pasa a ser Erythranthe), Mulinum y Laretia (que pasan a la sinonimia de Azorella), Satureja (cuyas especies quedaron entre los géneros Micromeria y Gardoquia) y Wendtia (que queda incluida bajo Balbisia). La segregación de especies en géneros independientes como Blumenbachia, Grausa, Nasa y Pinnasa antes incluidas en Loasa y, Amphiscirpus, Ficinia, Phylloscirpus, Rhodoscirpus y Zameioscirpus antes incluidos en Scirpus. La fusión de géneros como
Echinocactus, Eriosyce, Islaya, Neoporteria y Pyrrhocactus quedando incluidos en Eriosyce.

A nivel de especie, se presenta la sinonimia de numerosos taxones, nuevas combinaciones, revalidaciones y corrección en la denominación de otros. Se destaca la inclusión de especies nativas descritas en la última década como Alstroemeria marticorenae, Bipinnula gabriel, Chorizanthe novoana, Viola farkasiana y Weberbauerella chilensis y la incorporación de nuevos registros para la flora introducida como por ejemplo Dittrichia viscosa y Cotoneaster francheti entre varios otros.

Finalmente, para la entrega de la información de los rangos de distribución de especies nativas e introducidas ha sido fundamental el apoyo con material herborizado depositado en el Herbario de la Universidad de Concepción y el Herbario del Museo de Historia Natural, validando una vez más la importancia de estas entidades en la generación del conocimiento base de estas disciplinas.

La información de este catálogo se mantendrá actualizada periódicamente, en la medida en que surjan nuevos cambios taxonómicos o nuevos registros de plantas vasculares para Chile. En tal sentido, invitamos a colaborar con información que complemente este proceso de actualización, contactando al correo electrónico de correspondencia.

\section{AGRADECIMIENTOS}

Agradecemos a la Corporación Nacional Forestal (CONAF) por su iniciativa del VIII concurso del Fondo de Investigación del Bosque Nativo que financió el Proyecto $N^{\circ}$ 004/2016 "Actualización de la lista de las plantas nativas y endémicas de Chile", al Dr. Fernando Zuloaga del Instituto de Botánica 
Darwinion (Argentina) que entregó desinteresadamente la base de datos del catálogo del Cono Sur, pilar fundamental para lograr el objetivo del proyecto. A la Dra. Mary Kalin Arroyo de la Universidad de Chile por su constante apoyo y estímulo para el estudio de la flora de Chile. Nuestra gratitud a los colaboradores Nicolás García (Amaryllidaceae), Patricio Novoa (Orchidaceae) y Silvia Arroyo-Leuenberger (Leucocoryne) que revisaron los respectivos grupos. Nuestro agradecimiento a Gloria Rojas del Museo Nacional de Historia Natural (SGO) por las facilidades otorgadas en el estudio de las colecciones científicas, a Rosa Montero, Claudia Flores y Sonia Maldonado del Herbario de la Universidad de Concepción (CONC) por su constante labor con la organización del herbario.

\section{REFERENCIAS}

Arroyo, M.T.K., Marticorena, C., Muñoz, M. 1990. A checklist of the native annual flora of Continental Chile. Gayana Botánica 47: 119-135.

Brummitt, R.K., Powell, C.E. (eds.). 1992. Author of plant names. Royal Botanic Gardens, Kew. 732 pp.

Henríquez, J.M., Pisano, E., Marticorena, C. 1995. Catálogo de la flora vascular de Magallanes (XII ${ }^{\mathrm{a}}$ Región), Chile. Anales del Instituto de la Patagonia 23: 5-30.

Marticorena, C. 1992. Bibliografía Botánica Taxonómica de Chile. Monographs in Systematic Botany from the Missouri Botanical Garden 41: 1-587.

Marticorena, C. 1996. Bibliografía Botánica Taxonómica de Chile. Suplemento 1. Gayana Botánica 53(1): 1-263.

Marticorena, C., Matthei, O., Rodríguez, R., Arroyo, M.T.K., Muñoz, M., Squeo, F., Arancio, G. 1998b. Catálogo de la flora vascular de la Segunda Región (Región de Antofagasta), Chile. Gayana Botánica 55: 23-83.
Marticorena, C., Quezada, M. 1985. Catálogo de la flora vascular de Chile. Gayana Botánica 42: 1-157.

Marticorena, C., Rodríguez, R. (eds.). 2011. Flora de Chile 3(1). Misodendraceae a Zygophyllaceae. Ediciones Universidad de Concepción, Concepción, Chile. 148 pp.

Marticorena, C., Squeo, F.A., Arancio, G., Muñoz, M. 2001. Catálogo de la flora vascular de la IV Región de Coquimbo. En: Squeo, F.A., Arancio, G., Gutiérrez, J.R. (eds.), Libro Rojo de la flora nativa y de los sitios prioritarios para su conservación: Región de Coquimbo. Capítulo 7: 105-142.

Marticorena, C., Stuessy, T.F., Baeza, C. 1998a. Catalogue of the vascular flora of the Robinson Crusoe or Juan Fernández Islands, Chile. Gayana Botánica 55: 187-211.

Philippi, F. 1881. Catalogus plantarum vascularium chilensium adhuc descriptarum. Santiago de Chile. viii, $378 \mathrm{pp}$.

Squeo, F.A., Arroyo, M.T.K., Marticorena, A., Arancio, G., Muñoz, M., Negritto, M., Rojas, G., Rosas, M., Rodríguez, R., Humaña, A.M., Barrera, E., Marticorena, C. 2008. Catálogo de la Flora Vascular de la Región de Atacama. En: Squeo, F.A., Arancio, G., Gutiérrez, J.R. (eds.), Libro Rojo de la flora nativa y de los sitios prioritarios para su conservación: Región de Atacama. Capítulo 6: 97-120.

Stevens, P.F. 2001 onwards. Angiosperm Phylogeny Website. Version 14, July 2017. URL: http://www.mobot.org/ MOBOT/research/APweb/ Accedido: Mayo 18, 2018.

Stuessy, T.F., Crawford, D.J., López-Sepúlveda, P., Baeza, C.M., RuIz, E. (eds.). 2017. Plants of Oceanic Islands. Evolution, Biogeography, and Conservation of the Flora of the Juan Fernández (Robinson Crusoe) Archipelago. Cambridge University Press. 465 pp.

Zuloaga, F.O., Morrone, O., Belgrano, M.J. (eds.), Marticorena, C. (Chile), Marchesi, E. (Uruguay) (eds. asoc.). 2008. Catálogo de las Plantas Vasculares del Cono Sur (Argentina, Sur de Brasil, Chile, Paraguay y Uruguay). Monographs in Systematic Botany from the Missouri Botanical Garden 107 (3 vols.): i-xcvi, 1-3348. 


\section{CATÁLOGO TAXONÓMICO}

\section{PTERIDOPHYTA}

\section{LYCOPODIOPSIDA}

ISOETACEAE

\section{Isoetes}

Isoetes araucaniana Macluf \& Hickey

Hierba acuática. Perenne. Endémica.

Distribución: BIO, ARA.

Rango altitudinal: 800-1500 m.

Isoetes chubutiana Hickey, Macluf \& W.C. Taylor

Sinónimos: Isoetes valdiviensis H.P. Fuchs, nom. nud., Isoetes meyeri H.P. Fuchs, nom. nud.

Hierba acuática. Perenne. Nativa.

Distribución: BIO, LLA, AIS, MAG.

Rango altitudinal: 700-1300 m.

Países limítrofes: Argentina.

\section{Isoetes hieronymi $\mathrm{U}$. Weber}

Sinónimos: Isoetes argentina A.A. Eaton ex Palmer, nom. nud., Isoetes lechleri auct. non Mett.

Hierba acuática. Perenne. Nativa.

Distribución: COQ.

Rango altitudinal: $1000 \mathrm{~m}$.

Países limítrofes: Argentina.

Isoetes savatieri Franchet

Sinónimos: Calamaria savatieri (Franchet) Kuntze, Isoetes

lechleri Mett. var. savatieri (Franchet) L.D. Gómez

Hierba acuática. Perenne. Nativa.

Distribución: VAL, MAU, NUB, BIO, ARA, LLA, AIS, MAG.

Rango altitudinal: 0-200 m.

Países limítrofes: Argentina.

\section{LYCOPODIACEAE}

\section{Austrolycopodium}

Austrolycopodium alboffii (Rolleri) Holub

Sinónimos: Lycopodium alboffii Rolleri, Lycopodium magellanicum (P. Beauv.) Sw. var. nanum (Albov) Looser Hierba. Perenne. Nativa.

Distribución: LRI, LLA, AIS, MAG.

Rango altitudinal: 100-300 m.

Países limítrofes: Argentina.
Austrolycopodium confertum (Willd.) Holub

Sinónimos: Lycopodium confertum Willd., Lycopodium chonoticum Phil., Lycopodium confertum Willd. var. barrosii Looser, Lycopodium barrosii (Looser) Herter

Hierba. Perenne. Nativa.

Distribución: LRI, LLA, AIS, MAG.

Rango altitudinal: 500-1500 m.

Países limítrofes: Argentina.

Austrolycopodium erectum (Phil.) Holub

Sinónimos: Lycopodium erectum Phil., Lycopodium magellanicum (P. Beauv.) Sw. var. erectum (Phil.) Looser, Lycopodium looseri Herter

Hierba. Perenne. Nativa.

Distribución: ARA, LRI, LLA, MAG.

Rango altitudinal: 1200-2800 m.

Países limítrofes: Argentina y Bolivia.

Austrolycopodium magellanicum (P. Beauv.) Holub

Sinónimos: Lepidotis magellanica P. Beauv., Lycopodium magellanicum (P. Beauv.) Sw.

Hierba. Perenne. Nativa.

Distribución: BIO, ARA, LRI, LLA, AIS, MAG, JFE.

Rango altitudinal: 300-1600 m.

Países limítrofes: Argentina y Bolivia.

Nombre vulgar: Pinpinela.

Austrolycopodium paniculatum (Desv. ex Poir.) Holub Sinónimos: Lycopodium paniculatum Desv. ex Poir., Lycopodium dendromorphum Kunze

Hierba. Perenne. Nativa.

Distribución: BIO, ARA, LRI, LLA, AIS.

Rango altitudinal: 700-900 m.

Países limítrofes: Argentina.

Nombre vulgar: Palmita, pimpinela, licopodio, musgo, llanka-lawen.

\section{Diphasium}

Diphasium gayanum (J. Rémy) Holub

Sinónimos: Lycopodium gayanum J. Rémy, Lycopodium skottsbergii (Herter ex Nessel) Herter, Lycopodium scariosum G. Forst. var. gayanum (J. Remy) Nessel, Lycopodium scariosum auct. non G. Forst., Lycopodium jussiaei (jussieui) auct. non Desv.

Hierba. Perenne. Nativa.

Distribución: BIO, ARA, LRI, LLA, AIS, JFE.

Rango altitudinal: 300-1300 m.

Países limítrofes: Argentina.

Nombre vulgar: Palmita, pinpinela. 


\section{Huperzia}

Huperzia fuegiana (Roiv.) Holub

Sinónimos: Urostachys fuegianus (Roiv.) Herter, Lycopodium fuegianum Roiv., Urostachys selago (L.) Herter var. hessei Herter ex Nessel, Huperzia selago auct. non (L.) Schrank \& Mart., Lycopodium selago auct. non L. Hierba. Perenne. Nativa.

Distribución: AIS, MAG.

Rango altitudinal: 0-500 m.

Países limítrofes: Argentina.

\section{SELAGINELLACEAE}

\section{Selaginella}

Selaginella apoda (L.) Spring

Hierba. Anual o perenne. Introducida.

Distribución: BIO, LRI.

\section{POLYPODIOPSIDA}

\section{ASPLENIACEAE}

\section{Asplenium}

Asplenium dareoides Desv.

Sinónimos: Asplenium magellanicum Kaulf., Asplenium concisum Desv., Asplenium philippi Gand., Asplenium dareoides Desv. var. dentatum G. Kunkel

Hierba epífita o terrestre. Perenne. Nativa.

Distribución: COQ, VAL, LBO, MAU, NUB, BIO, ARA, LRI, LLA, AIS, MAG, JFE.

Rango altitudinal: 5-2000 m.

Países limítrofes: Argentina.

Nombre vulgar: Filu-lahuén.

Asplenium gilliesii Hook.

Sinónimos: Asplenium gilliesianum Hook. \& Grev.

Hierba saxícola. Perenne. Nativa.

Distribución: AYP.

Rango altitudinal: 4000-4000 m.

Países limítrofes: Argentina, Bolivia y Perú.

Asplenium macrosorum Bertero ex Colla

Hierba epífita o terrestre. Perenne. Endémica.

Distribución: JFE.

Rango altitudinal: 30-500 m.

Asplenium obtusatum G. Forst. var. obtusatum

Hierba. Perenne. Nativa.

Distribución: IPA, IDE.
Rango altitudinal: 2-190 m.

Asplenium obtusatum G. Forst. var. sphenoides (Kunze) C. Chr. ex Skottsb.

Sinónimos: Asplenium sphenoides Kunze, Asplenium chondrophyllum Bertero ex Colla, Asplenium consimile

J. Remy, Asplenium obliquum G. Forst. var. sphenoides (Kunze) Mett., Asplenium obliquum G. Forst. var. chondrophyllum (Bertero ex Colla) Mett.

Hierba. Perenne. Endémica.

Distribución: COQ, VAL, LBO, MAU, NUB, BIO, ARA, LRI, LLA, AIS, MAG, JFE.

Rango altitudinal: 2-500 m.

Asplenium patagonicum R.A. Rodr. \& R. Guzmán

Sinónimos: Asplenium longifolium Phil. ex Gotschl., nom. nud., Asplenium monanthes auct. non L.

Hierba terrestre o saxícola. Perenne. Endémica.

Distribución: ARA, LRI, LLA, MAG.

Rango altitudinal: 10-320 m.

\section{Asplenium peruvianum Desv.}

Sinónimos: Asplenium fragile C. Presl var. lomense Weath., Asplenium fragile C. Presl

Hierba saxícola. Perenne. Nativa.

Distribución: ANT.

Rango altitudinal: 200-200 m.

Países limítrofes: Argentina, Bolivia y Perú.

Asplenium polyodon G. Foster var. squamulosum (C. Chr.) R.A. Rodr.

Sinónimos: Asplenium adiantoides (L.) C. Chr. var. squamulosum C. Chr.

Hierba. Perenne. Endémica.

Distribución: IPA.

Rango altitudinal: 2-120 m.

Nombre vulgar: Nehe nehe.

Asplenium stellatum Colla

Sinónimos: Asplenium fernandezianum Kunze, Asplenium lunulatum Sw. var. stellatum (Colla) C. Chr.

Hierba. Perenne. Endémica.

Distribución: JFE.

Rango altitudinal: 90-1800 m.

Asplenium trilobum Cav.

Sinónimos: Asplenium trapezoides Sw., Asplenium parvulum Hook., Asplenium trilobum Cav. var. trapezoides (Sw.) G. Kunkel

Hierba epífita o terrestre. Perenne. Nativa.

Distribución: BIO, ARA, LRI, LLA, AIS.

Rango altitudinal: 5-600 m.

Países limítrofes: Argentina. 
Asplenium triphyllum C. Presl

Sinónimos: Asplenium imbricatum Hook. \& Grev.

Hierba saxícola. Perenne. Nativa.

Distribución: AYP, TAR, ANT, COQ.

Rango altitudinal: 4300-4500 m.

Países limítrofes: Argentina, Bolivia y Perú.

\section{Pleurosorus}

Pleurosorus papaverifolius (Kunze) Fée

Sinónimos: Gymnogramme papaverifolia Kunze, Pleurosorus inmersus Fée, Gymnogramma chilensis Brack., Pleurosorus papaverifolius (Kunze) Fée var. nana Villagrán, Pleurosorus papaverifolius (Kunze) Fée var. hirsuta Villagrán, Asplenium ciliatum C. Presl ex Bertero, Asplenium subglandulosum (Hook. \& Grev.) Salvo, Prada \& Díaz subsp. papaverifolium (Kunze) Salvo, Prada \& Díaz Hierba. Perenne. Nativa.

Distribución: COQ, VAL, RME, LBO, MAU, NUB, BIO, AIS, MAG.

Rango altitudinal: 100-1800 m.

Países limítrofes: Argentina.

\section{ATHYRIACEAE}

\section{Diplazium}

Diplazium fuenzalidae Espinosa

Sinónimos: Athyrium fuenzalidae (Espinosa) Gunckel, comb. illeg.

Hierba. Perenne. Endémica.

Distribución: IPA.

Rango altitudinal: 200-400 m.

Nombre vulgar: Nehe nehe.

\section{BLECHNACEAE}

\section{Blechnum}

Blechnum arcuatum J. Remy

Sinónimos: Blechnum bibreae Mett.

Hierba. Perenne. Nativa.

Distribución: MAU, NUB, BIO, ARA, LRI, LLA, AIS, MAG.

Rango altitudinal: 5-1300 m.

Países limítrofes: Argentina.

Blechnum asperum (Klotzsch) J.W. Sturm

Sinónimos: Lomaria aspera Klotzsch

Hierba. Perenne. Endémica.

Distribución: NUB, BIO, ARA, LRI, LLA.

Rango altitudinal: 15-415 m.
Blechnum blechnoides Keyserl.

Sinónimos: Lomaria leyboldtiana Phil., Blechnum valdiviense C. Chr., Blechnum leyboldtianum (Phil.) C. Chr., Lomaria blechnoides auct. non Bory, Spicanta leyboldtiana (Phil.) Kuntze

Hierba. Perenne. Endémica.

Distribución: MAU, NUB, BIO, ARA, LRI, LLA, AIS, MAG.

Rango altitudinal: 1-1100 m.

Nombre vulgar: Iquide.

Blechnum chilense (Kaulf.) Mett.

Sinónimos: Lomaria chilensis Kaulf., Lomaria gilliesii Hook. \& Grev., Lomaria reedii Phil., Blechnum gilliesii (Hook. \& Grev.) Mett., Blechnum reedii (Phil.) Espinosa, Blechnum chilense (Kaulf.) Mett. var. reedii (Phil.) Looser, Blechnum chilense (Kaulf.) Mett. fma. imbricatum Kunkel, Blechnum cordatum auct. non (Desv.) Hieron.

Subarbusto. Nativo.

Distribución: COQ, VAL, RME, LBO, MAU, NUB, BIO, ARA, LRI, LLA, AIS, MAG, JFE.

Rango altitudinal: 5-1500 m.

Países limítrofes: Argentina.

Nombre vulgar: Costilla de vaca, palmilla, quilquil, iquide.

Blechnum corralense Espinosa

Hierba. Perenne. Endémica.

Distribución: LRI, LLA.

Rango altitudinal: 15-1200 m.

Blechnum cycadifolium (Colla) J.W. Sturm

Sinónimos: Lomaria cycadifolia Colla, Lomaria lanuginosa Kunze, Blechnum lanuginosum (Kunze) J.W. Sturm, Blechnum magellanicum (Desv.) Mett. var. cycadifolium (Colla) C. Chr., Struthiopteris cycadifolia (Colla) Ching. Arbusto. Endémico.

Distribución: JFE.

Rango altitudinal: $180-1200 \mathrm{~m}$.

Blechnum hastatum Kaulf.

Sinónimos: Blechnum trilobum C. Presl, Blechnum ciliatum C. Presl, Lomaria hastata (Kaulf.) Kunze, Blechnum remotum C. Presl, Lomaria pubescens (Hook.) Kunze, Lomaria triloba (C. Presl) Fée, Blechnum hastatum Kaulf. var. minor Hook., Blechnum parvulum Phil., Blechnum australe L. var. triloba (C. Presl) Hieron., Blechnum australe L. var. hastata (Kaulf.) Hieron., Blechnum australe L. fma. trilobum (C. Presl) Rosenst., Blechnum auriculatum Cav. fma. remotum (C. Presl) C. Chr. \& Skottsb., Blechnum auriculatum Cav. fma. parvula (Phil.) C. Chr. \& Skottsb., Blechnum auriculatum Cav. var. trilobum (C. Presl) Osten \& Herter, Blechnum auriculatum Cav. var. hastatum (Kaulf.) Looser, Blechnum auriculatum Cav. var. parvulum (Phil.) Looser, Blechnum hastatum Kaulf. fma. alternatum 
G. Kunkel, Blechnum hastatum Kaulf. fma. punctatum (Looser) G. Kunkel, Blechnum hastatum Kaulf. var. trilobum (C. Presl) G. Kunkel, Blechnum brevifolium G. Kunkel, Blechnum brevifolium G. Kunkel subsp. parvulum (Phil.) Kunkel fma. imbricatum G. Kunkel, Blechnum brevifolium G. Kunkel var. valdiviense G. Kunkel, Blechnum brevifolium G. Kunkel subsp. parvulum (Phil.) G. Kunkel, Blechnum brevifolium G. Kunkel var. brevifolium fma. nervosum G. Kunkel, Blechnum brevifolium G. Kunkel var. brevifolium fma. semidecurrens G. Kunkel, Blechnum brevifolium G. Kunkel var. brevifolium fma. acuminatum G. Kunkel, Taenitis sagittaefera Bory, Mesothema remotum (C. Presl) C. Presl, Mesothema trilobum (C. Presl) C. Presl, Parablechnum ciliatum (C. Presl) C. Presl, Blechnopteris hastata (Kaulf.) Trevis., Struthiopteris hastata (Kaulf.) Trevis., Struthiopteris remota (C. Presl) Trevis., Struthiopteris triloba (C. Presl) Trevis., Spicanta hastata (Kaulf.) Kuntze, Blechnum auriculatum auct. non Cav., Mesothema hastatum (Kaulf.) C. Presl

Hierba. Perenne. Nativa.

Distribución: COQ, VAL, RME, LBO, MAU, NUB, BIO, ARA, LRI, LLA, JFE.

Rango altitudinal: 5-2500 m.

Países limítrofes: Argentina.

Nombre vulgar: Palmilla, quilquil, arriquilquil.

Blechnum longicauda C. Chr.

Hierba. Perenne. Endémica.

Distribución: JFE.

Rango altitudinal: 5-500 m.

Blechnum magellanicum (Desv.) Mett.

Sinónimos: Lomaria magellanica Desv., Lomaria setigera Gaudich., Blechnum magellanicum (Desv.) Mett. var. setigerum (Gaudich.) C. Chr., Blechnum magellanicum (Desv.) Mett. var. bipinnatifidum G. Kunkel

Arbusto. Nativo.

Distribución: MAU, NUB, BIO, ARA, LRI, LLA, AIS, MAG.

Rango altitudinal: 5-2200 m.

Países limítrofes: Argentina.

Nombre vulgar: Katalapi.

Blechnum microphyllum (Goldm.) C.V. Morton

Sinónimos: Lomaria microphylla Goldm., Lomaria australis Kunze, Lomaria gayana J. Remy, Blechnum gayanum (J. Remy) J.W. Sturm, Blechnum gayanum (J. Remy) J.W. Sturm fma. germainii (Hook.) Looser, Lomaria germainii Hook., Lomaria andicola Phil., Lomaria araucana Phil., Blechnum germanii (Hook.) H. Christ, Blechnum andicola (Phil.) C. Chr., Blechnum araucanum (Phil.) C. Chr., Blechnum poeppigianum J.W. Sturm

Hierba. Perenne. Nativa.
Distribución: RME, LBO, MAU, NUB, BIO, ARA, LRI, LLA.

Rango altitudinal: 5-2600 m.

Países limítrofes: Argentina.

Blechnum mochaenum G. Kunkel var. fernandezianum (Looser) de la Sota

Sinónimos: Blechnum blechnoides (Bory) Keyserl. var. fernandezianum Looser

Hierba. Perenne. Endémica.

Distribución: JFE.

Rango altitudinal: 100-1100 m.

Blechnum mochaenum $\mathrm{G}$. Kunkel var. mochaenum

Sinónimos: Lomaria lechleri T. Moore

Hierba. Perenne. Nativa.

Distribución: MAU, NUB, BIO, ARA, LRI, LLA, AIS, MAG, JFE.

Rango altitudinal: 5-1350 m.

Países limítrofes: Argentina.

Blechnum paschale (C. Chr.) Christenh

Sinónimos: Doodia paschalis C. Chr.

Hierba. Perenne. Endémica.

Distribución: IPA.

Rango altitudinal: 100-100 m.

Nombre vulgar: Nehe nehe.

Blechnum penna-marina (Poir.) Kuhn

Sinónimos: Polypodium penna-marina Poir., Blechnum alpinum Mett., Blechnum alpinum Mett. var. elongatum Mett., Blechnum uliginosum (Phil.) C. Chr., Blechnum penna-marina (Poir.) Kuhn var. uliginosa (Phil.) C. Chr., Blechnum penna-marina (Poir.) Kuhn fma. polypodioides (Desv. ex Gaudich.) C. Chr., Blechnum penna-marina (Poir.) Kuhn var. polypodioides (Desv. ex Gaudich.) Looser, Lomaria polypodioides Desv. ex Gaudich., Lomaria uliginosa Phil., Lomaria uliginosa Phil. var. magellanica Phil., Polypodium penna-marina Poir., Lomaria pennamarina (Poir.) Mett.

Hierba. Perenne. Nativa.

Distribución: ARA, LRI, LLA, AIS, MAG.

Rango altitudinal: 3-1500 m.

Países limítrofes: Argentina y Bolivia.

Nombre vulgar: Pinque.

Blechnum schottii (Colla) C. Chr.

Sinónimos: Lomaria schottii Colla, Lomaria bella Phil., Lomaria fernandeziana Phil.

Hierba trepadora. Perenne. Endémica.

Distribución: JFE.

Rango altitudinal: 50-820 m. 
Blechnum x rodriguezii Aguiar, Quintanilla \& Amigo Hierba. Perenne. Endémica.

Distribución: LRI, LLA.

Rango altitudinal: 150-585 m.

\section{CYSTOPTERIDACEAE}

\section{Cystopteris}

Cystopteris apiiformis Gand.

Sinónimos: Cystopteris fragilis (L.) Bernh. var. apiiformis (Gand.) C. Chr.

Hierba. Perenne. Nativa.

Distribución: AYP, COQ, VAL, RME, MAU, NUB, BIO, ARA, LRI, LLA, AIS, MAG, JFE.

Rango altitudinal: 0-3500 m.

Países limítrofes: Argentina.

\section{DAVALLIACEAE}

\section{Davallia}

Davallia solida (G. Forster) Sw.

Hierba. Perenne. Nativa.

Nota: La expedición Franco-Belga de 1934 (Tardieu-Blot 1936), reporta la presencia de esta especie para la Isla de Pascua. Sin embargo, esta especie nunca más ha sido encontrada.

\section{DENNSTAEDTIACEAE}

\section{Dennstaedtia}

Dennstaedtia glauca (Cav.) C. Chr. ex Looser

Sinónimos: Dicksonia lambertieana J. Remy, Davallia glauca Cav., Dennstaetia lambertyana (J. Remy) H. Christ Hierba. Perenne. Nativa.

Distribución: COQ, VAL, RME, LBO, MAU.

Rango altitudinal: 300-2360 m.

Países limítrofes: Argentina, Bolivia y Perú.

\section{Histiopteris}

Histiopteris incisa (Thunb.) J. Sm.

Sinónimos: Pteris incisa Thunb., Litobrochia incisa (Thunb.) C. Presl, Pteris flavescens Colla, Pteris patens Kunze, Pteris vespertilionis Labill. var. flavescens (Colla) J. Agardh, Litobrochia appendiculata (Kaulf.) J. Remy, Litobrochia patens (Kunze) J. Remy, Histiopteris incisa (Thunb.) J. Sm. var. flavescens (Colla) C. Chr., Pteris vespertilionis auct. non Labill.
Hierba. Perenne. Nativa.

Distribución: LLA, AIS, MAG, JFE.

Rango altitudinal: 5-580 m.

Países limítrofes: Perú.

\section{Hypolepis}

Hypolepis poeppigii (Kunze) R.A. Rodr.

Sinónimos: Polypodium poeppigii Kunze, Phegopteris poeppigii (Kunze) Fée ex J. Remy, Phegopteris sturmii Phil., Hypolepis rugosula (Labill.) J. Sm. var. poeppigii (Kunze) C. Chr. \& Skottsb., Cystopteris fragilis (L.) Bernh. var. pubescens Phil., Hypolepis poeppigiana Mett., Hypolepis chilensis Fée, Phegopteris poeppigii (Kunze)

Fée var. hirsuta Phil.

Hierba. Perenne. Nativa.

Distribución: COQ, VAL, RME, LBO, MAU, NUB, BIO, ARA, LRI, LLA, AIS, MAG, JFE.

Rango altitudinal: 25-650 m.

Países limítrofes: Argentina.

Nombre vulgar: Wilel-lawen, pesebre.

\section{Microlepia}

Microlepia strigosa (Thunb. ex Murray) C. Presl

Sinónimos: Trichomanes strigosus Thunb. ex Murray

Hierba. Perenne. Nativa.

Distribución: IPA.

Rango altitudinal: 100-300 m.

\section{DICKSONIACEAE}

\section{Dicksonia}

Dicksonia berteroana (Colla) Hook.

Sinónimos: Davallia berteroana Colla, Balantium berteroanum Kunze

Arbusto o árbol pequeño. Endémico.

Distribución: JFE.

Rango altitudinal: 200-700 m.

Dicksonia externa C. Chr. \& Skottsb.

Sinónimos: Dicksonia berteriana (Colla) Hook. var. virgata

C. Chr. \& Skottsb.

Arbusto o árbol pequeño. Endémico.

Distribución: JFE.

Rango altitudinal: 200-700 m.

\section{Lophosoria}

Lophosoria quadripinnata (J.F. Gmel.) C. Chr.

Sinónimos: Polypodium quadripinnatum J.F. Gmel., Polypodium pruinatum Sw., Polypodium cinereum Cav., 
Cyathea discolor Bory, Alsophila pruinata (Sw.) Kaulf. ex Kunze, Lophosoria pruinata (Sw.) C. Presl, Lophosoria quadripinnata (J.F. Gmel.) C. Chr. fma. viridifolia G. Kunkel

Subarbusto. Nativo.

Distribución: MAU, NUB, BIO, ARA, LRI, LLA, AIS, JFE. Rango altitudinal: 5-2000 m.

Países limítrofes: Argentina, Bolivia y Perú.

Nombre vulgar: Palmita, palmilla, helecho o palmita de Valdivia, ampe.

\section{Thyrsopteris}

\section{Thyrsopteris elegans Kunze}

Sinónimos: Dicksonia elegans (Kunze) Mett., Panicularia berteri Colla

Subarbusto. Endémico.

Distribución: JFE.

Rango altitudinal: 700-1000 m.

\section{DRYOPTERIDACEAE}

\section{Dryopteris}

Dryopteris filix-mas (L.) Schott

Hierba. Perenne. Introducida.

Distribución: LLA.

Dryopteris karwinskyana (Mett.) Kuntze

Sinónimos: Aspidium karwinskyanum Mett., Dryopteris espinosai Hicken, Thelypteris espinosae (Hicken) R.A. Rodr.

Hierba. Perenne. Nativa.

Distribución: IPA.

Rango altitudinal: $420 \mathrm{~m}$.

Nota: Considerado extinto en la Isla de Pascua por Jean-Yves Meyer (2013) porque no ha sido observado o recolectado desde hace más de 75 años.

\section{Elaphoglossum}

Elaphoglossum fonkii (Phil.) T. Moore

Sinónimos: Elaphoglossum mathewsii auct. non (Fée) T.

Moore, Acrostichum fonkii Phil.

Hierba saxícola. Perenne. Endémica.

Distribución: LRI, LLA.

Rango altitudinal: 0-800 m.

Elaphoglossum gayanum (Fée) T. Moore

Sinónimos: Acrostichum gayanum Fée

Hierba. Perenne. Nativa.

Distribución: ARA, LRI, LLA, AIS.

Rango altitudinal: 0-3000 m.
Países limítrofes: Argentina y Bolivia.

Elaphoglossum lindenii (Bory ex Fée) T. Moore

Sinónimos: Elaphoglossum squamatum auct. non. (Sw.)

T. Moore, Acrostichum squamosum Cav., Acrostichum

lindenii Bory ex Fée

Hierba. Perenne. Nativa.

Distribución: JFE.

Rango altitudinal: $400 \mathrm{~m}$.

Países limítrofes: Bolivia y Perú.

Elaphoglossum porteri Hicken

Sinónimos: Elaphoglossum rudolphii Espinosa

Hierba. Perenne. Nativa.

Distribución: LLA.

Rango altitudinal: 600-900 m.

Países limítrofes: Argentina.

Elaphoglossum skottsbergii Krajina

Sinónimos: Elaphoglossum gayanum auct. non (Fée) T.

Moore, Elaphoglossum tahitense auct. non Brack.

Hierba. Perenne. Endémica.

Distribución: IPA.

Rango altitudinal: 400-500 m.

\section{Megalastrum}

Megalastrum glabrius (C. Chr. \& Skottsb.) Sundue, Rouhan \& R.C. Moran

Sinónimos: Dryopteris inaequalifolia (Colla) C. Chr. var. glabrior C. Chr. \& Skottsb., Ctenitis inaequalifolia (Colla) Ching var. glabrior (C. Chr. \& Skottsb.) G. Kunkel, Megalastrum inaequalifolium (Colla) A.R. Sm. \& R.C. Moran var. glabrius (C. Chr. \& Skottsb.) R.A. Rodr.

Hierba. Perenne. Endémica.

Distribución: JFE.

Rango altitudinal: 200-600 m.

Megalastrum inaequalifolium (Colla) A.R. Sm. \& R.C. Moran

Sinónimos: Polypodium inaequalifolium Colla, Dryopteris villosa (L.) Kuntze var. berteroana (Hook.) C. Chr., Dryopteris skottsbergii C. Chr., Dryopteris inaequalifolia (Colla) C. Chr., Ctenitis inaequalifolia (Colla) Ching

Hierba. Perenne. Endémica.

Distribución: JFE.

Rango altitudinal: 200-600 m.

Megalastrum masafuerae Sundue, Rouhan \& R.C. Moran Hierba. Perenne. Endémica.

Distribución: JFE.

Rango altitudinal: $100 \mathrm{~m}$. 
Megalastrum spectabile (Kaulf.) A.R. Sm. \& R.C. Moran Sinónimos: Megalastrum spectabile (Kaulf.) A.R. Sm. \& R.C. Moran var. philippianum (C. Chr.) A.R. Sm. \& R.C. Moran, Polypodium spectabile Kaulf., Dryopteris spectabilis (Kaulf.) C. Chr., Ctenitis spectabilis (Kaulf.) G. Kunkel, Dryopteris spectabilis (Kaulf.) C. Chr. var. philippiana C. Chr., Ctenitis spectabilis (Kaulf.) G. Kunkel var. philippiana (C. Chr.) R.A. Rodr., Polypodium contractum Desv.

Hierba. Perenne. Nativa.

Distribución: COQ, VAL, LBO, MAU, NUB, BIO, ARA, LRI, LLA, AIS.

Rango altitudinal: 0-900 m.

Países limítrofes: Argentina.

Nombre vulgar: Pesebre.

\section{Polystichum}

Polystichum andinum Phil.

Hierba. Perenne. Nativa.

Distribución: RME, LBO, MAU, NUB, BIO, ARA, LRI, LLA, AIS, MAG.

Rango altitudinal: 0-4000 m.

Países limítrofes: Argentina.

Polystichum chilense (Christ) Diels var. chilense

Sinónimos: Polystichum bridgesii Schott, Aspidium aculeatum (L.) Sw. var. chilensis C. Chr., Aspidium bridgesii (Schott) J.W. Sturm, Aspidium paucicuspis J.W. Sturm, Polystichum aculeatum (L.) Schott var. chilense (H. Christ) C. Chr.

Hierba. Perenne. Nativa.

Distribución: MAU, NUB, BIO, ARA, LRI, LLA, AIS, MAG.

Rango altitudinal: 0-1300 m.

Países limítrofes: Argentina.

Nombre vulgar: Pelomén-lahuén.

Polystichum chilense (Christ) Diels var. dusenii (C. Chr.) Looser ex R.A. Rodr.

Sinónimos: Polystichum multifidum (Mett.) T. Moore var. dusenii C. Chr.

Hierba. Perenne. Nativa.

Distribución: LLA, AIS, MAG.

Rango altitudinal: 0-800 m.

Países limítrofes: Argentina.

\section{Polystichum fuentesii Espinosa}

Hierba. Perenne. Endémica.

Distribución: IPA.

Nota: Considerado extinto en la Isla de Pascua por Jean-Yves Meyer (2013) porque no ha sido observado o recolectado desde hace más de 75 años.
Polystichum multifidum (Mett.) T. Moore

Sinónimos: Polystichum multifidum (Mett.) T. Moore var. autranii Hicken, Aspidium multifidum Mett., Dryopteris metteniana Kuntze, Dicksonia andina Phil., Polystichum pearcei Phil., Polystichum nahuelhuapiense Diem, Aspidium pearcei (Phil.) F. Phil., Polystichum multifidum (Mett.) T. Moore var. pearcei (Phil.) R.A. Rodr.

Hierba. Perenne. Nativa.

Distribución: LRI, LLA, AIS, MAG.

Rango altitudinal: 0-1000 m.

Países limítrofes: Argentina.

Polystichum plicatum (Poepp. ex Kunze) Hicken Sinónimos: Polystichum elegans J. Remy, Polystichum mohrioides (Bory) C. Presl fma. genuina Hicken, Polystichum mohrioides (Bory) C. Presl fma. latifolia Hicken, Polystichum mohrioides (Bory) C. Presl var. elegans (J. Remy) C. Chr., Polystichum mohrioides (Bory) C. Presl var. plicatum (Poepp.) C. Chr., Aspidium plicatum Poepp. ex Kunze, Aspidium plicatum Poepp. ex Kunze var. laxum Kunze, Aspidium plicatum Poepp. ex Kunze var. rigidum Kunze, Aspidium elegans (J. Remy) J.W. Sturm Hierba. Perenne. Nativa.

Distribución: COQ, VAL, RME, LBO, MAU, NUB, BIO, ARA, LRI, LLA, AIS, MAG.

Rango altitudinal: 0-3500 m.

Países limítrofes: Argentina.

Polystichum subintegerrimum (Hook. \& Arn.) R.A. Rodr. Sinónimos: Polystichum brongniartianum J. Remy, Polystichum aculeatum (L.) Schott var. brongniartianum (J. Remy) C. Chr., Polystichum aculeatum (L.) Schott var. subintegerrimum (Hook. \& Arn.) C. Chr., Aspidium subintegerrimum Hook. \& Arn., Aspidium brongniartianum (J. Remy) J.W. Sturm

Hierba. Perenne. Endémica.

Distribución: NUB, BIO, ARA, LRI, LLA, AIS, MAG.

Rango altitudinal: 0-1100 m.

Polystichum tetragonum Fée

Sinónimos: Polystichum vestitum auct. non (G. Forst.) C. Presl

Hierba. Perenne. Endémica.

Distribución: JFE.

Rango altitudinal: $200 \mathrm{~m}$.

\section{Rumohra}

Rumohra adiantiformis (G. Forst.) Ching

Sinónimos: Polypodium adiantiforme G. Forst., Aspidium coriaceum Sw., Polystichum coriaceum Schott, Nephrodium duriusculum C. Presl, Polystichum adiantiforme (G. Forst.) J. Sm.

Hierba. Perenne. Nativa. 
Distribución: COQ, BIO, ARA, LRI, LLA, AIS, MAG.

Rango altitudinal: 0-1000 m.

Países limítrofes: Argentina, Bolivia y Perú.

Nombre vulgar: Pereq, calahuala, yerba del lagarto.

Rumohra berteroana (Colla) R.A. Rodr.

Sinónimos: Aspidium berterianum Colla, Aspidium flexum Kunze, Polystichum berterianum (Colla) C. Chr., Aspidium capense auct. non Willd.

Hierba. Perenne. Endémica.

Distribución: JFE.

Rango altitudinal: 200-1200 m.

\section{EQUISETACEAE}

\section{Equisetum}

Equisetum bogotense Kunth

Sinónimos: Equisetum flagelliforme Kunze, Equisetum flagelliferum Kunze ex Milde, Equisetum chilense C. Presl ex Milde, Equisetum rinihuense G. Kunkel

Hierba. Perenne. Nativa.

Distribución: AYP, TAR, ANT, ATA, COQ, VAL, RME, LBO, MAU, NUB, BIO, ARA, LRI, LLA, AIS.

Rango altitudinal: 10-3200 m.

Países limítrofes: Argentina, Bolivia y Perú.

Nombre vulgar: Limpia plata, yerba, yerba de la plata.

\section{Equisetum giganteum $\mathrm{L}$.}

Sinónimos: Equisetum poeppigianum Mett., Equisetum lechleri Milde, Equisetum tarapacanum Phil., Hippochaete gigantea (L.) Holub, Equisetum xylochaetum Mett.

Hierba. Perenne. Nativa.

Distribución: AYP, TAR, ARA.

Rango altitudinal: 20-2800 m.

Países limítrofes: Argentina, Bolivia y Perú.

Nombre vulgar: Cola de caballo, sojosojo.

Equisetum pyramidale Goldm.

Sinónimos: Equisetum ramosissimum Desf. var. scaberium Milde, Equisetum philippi Gand., Equisetum scandens J. Remy, Equisetum giganteum L. var. chilense Milde, Equisetum ramosissimum Desf. var. affine Milde, Equisetum araucanum Phil.

Hierba. Perenne. Endémica.

Distribución: ATA, COQ, VAL, RME, LBO, MAU, NUB, BIO, ARA.

Rango altitudinal: 10-2600 m.

Nombre vulgar: Cola de caballo.

\section{GLEICHENIACEAE}

\section{Sticherus}

Sticherus cryptocarpus (Hook.) Ching

Sinónimos: Dicranopteris cryptocarpa (Hook.) Looser, Gleichenia cryptocarpa Hook., Mertensia cryptocarpa (Hook.) J. Remy, Sticherus cryptocarpus (Hook.) Ching var. looserianus G. Kunkel

Hierba. Perenne. Nativa.

Distribución: BIO, ARA, LRI, LLA, AIS, MAG.

Rango altitudinal: 20-2200 m.

Países limítrofes: Argentina.

Nombre vulgar: Hierba loza, cola de gallo, ampe.

Sticherus lepidotus (R.A. Rodr.) R.A. Rodr. \& Ponce

Sinónimos: Gleichenia lepidota R.A Rodr.

Hierba. Perenne. Endémica.

Distribución: JFE.

Rango altitudinal: 500-1100 m.

Sticherus litoralis (Phil.) Nakai

Sinónimos: Mertensia litoralis Phil., Gleichenia litoralis (Phil.) C. Chr., Dicranopteris pedalis (Kaulf.) Looser var. litoralis (Phil.) Looser, Gleichenia pedalis (Kaulf.) Sprengel var. litoralis (Phil.) Looser, Dicranopteris litoralis (Phil.) Looser

Hierba. Perenne. Endémica.

Distribución: LRI, LLA, AIS, MAG.

Rango altitudinal: 3-1040 m.

Sticherus quadripartitus (Poir.) Ching

Sinónimos: Polypodium quadripartitum Poir., Gleichenia acutifolia Hook., Mertensia acutifolia (Hook.) J. Remy, Gleichenia bibreae Mett. ex Kuhn, Dicranopteris quadripartita (Poir.) Looser, Gleichenia quadripartita (Poir.) T. Moore, Mertensia magellanica Desv., Mertensia quadripartita (Poir.) Poir., Sticherus quadripartitus (Poir.) Ching fma. bipartitus G. Kunkel, Sticherus quadripartitus (Poir.) Ching fma. simplex G. Kunkel

Hierba. Perenne. Nativa.

Distribución: BIO, ARA, LRI, LLA, AIS, MAG, JFE.

Rango altitudinal: 0-1800 m.

Países limítrofes: Argentina.

Nombre vulgar: Yerba loza, palmita, pata de cucho.

Sticherus squamulosus (Desv.) Nakai var. gunckelianus (Looser) R.A. Rodr. \& Ponce

Sinónimos: Gleichenia squamulosa (Desv.) T. Moore var. gunckeliana (Looser) Duek, Dicranopteris squamulosa (Desv.) Looser var. gunckeliana Looser

Hierba trepadora. Perenne. Endémica.

Distribución: LRI, LLA.

Rango altitudinal: 0-100 m. 
Sticherus squamulosus (Desv.) Nakai var. squamulosus Sinónimos: Gleichenia pedalis (Kaulf.) Spreng., Dicranopteris pedalis (Kaulf.) Looser, Sticherus pedalis (Kaulf.) Ching, Gleichenia squamulosa (Desv.) T. Moore, Mertensia squamulosa Desv., Mertensia pedalis Kaulf., Mertensia oligocarpa Phil., Gleichenia oligocarpa (Phil.) C. Chr., Dicranopteris oligocarpa (Phil.) Looser, Sticherus oligocarpus (Phil.) Nakai, Sticherus squamulosus (Desv.) Nakai var. glaber (T. Moore) Nakai, Dicranopteris squamulosa (Desv.) Looser

Hierba. Perenne. Endémica.

Distribución: MAU, NUB, BIO, ARA, LRI, LLA, AIS, JFE. Rango altitudinal: 3-1500 m.

Nombre vulgar: Yerba loza, palmita, huedahue.

\section{HYMENOPHYLLACEAE}

\section{Hymenoglossum}

Hymenoglossum cruentum (Cav.) C. Presl

Sinónimos: Hymenophyllum cruentum Cav.

Hierba epífita. Perenne. Nativa.

Distribución: MAU, NUB, BIO, ARA, LRI, LLA, AIS, MAG, JFE.

Rango altitudinal: 0-900 m.

Países limítrofes: Argentina.

Nombre vulgar: Helecho película, sanguinaria, seda de la luma.

\section{Hymenophyllum}

Hymenophyllum caudiculatum Mart. var. productum (C. Presl) C. Chr.

Sinónimos: Hymenophyllum caudatum Bosch, Hymenophyllum patagonicum Gand., Sphaerocionium productum C. Presl, Mecodium caudiculatum (Mart.) Copel. fma. productum (C. Presl) G. Kunkel, Mecodium caudiculatum (Mart.) Copel. fma. nanum G. Kunkel Hierba epífita. Perenne. Nativa. Distribución: BIO, ARA, LRI, LLA, AIS, MAG, JFE. Rango altitudinal: 0-1500 m. Países limítrofes: Argentina.

Nombre vulgar: Pallante chilote.

\section{Hymenophyllum cuneatum Kunze var. cuneatum}

Sinónimos: Hymenophyllum cumingii C. Presl, Mecodium cuneatum (Kunze) Copel., Hymenophyllum polyanthos auct. non (Sw.) Sw.

Hierba epífita. Perenne. Endémica.

Distribución: ARA, LRI, LLA, AIS, MAG, JFE.

Rango altitudinal: 400-1000 m.
Hymenophyllum cuneatum Kunze var. rariforme C. Chr. \& Skottsb.

Sinónimos: Hymenophyllum terminale Phil., Hymenophyllum cuneatum Kunze fma. imbricata C. Chr. \& Skottsb., Mecodium cuneatum (Kunze) Copel. var. rariforme (C. Chr. \& Skottsb.) G. Kunkel

Hierba epífita. Perenne. Endémica.

Distribución: JFE.

Rango altitudinal: $300-500 \mathrm{~m}$.

Hymenophyllum darwinii Hook.f. ex Bosch

Sinónimos: Hymenophyllum abruptum Hook. var. brevifrons (Kunze) Franch., Hymenophyllum skottsbergii C.

Chr., Hymenophyllum rarum $\mathrm{R}$. Br. var. darwinii (Bosch) Neger

Hierba epífita o saxícola. Perenne. Nativa.

Distribución: MAU, NUB, BIO, ARA, LRI, LLA, AIS, MAG.

Rango altitudinal: 0-1200 m.

Países limítrofes: Argentina.

\section{Hymenophyllum dentatum Cav.}

Sinónimos: Hymenophyllum bridgesii Hook., Hymenophyllum trichocaulum Phil., Sphaerocionium bridgesii (Hook.) Klotzsch, Leptocionium dentatum (Cav.) Bosch, Meringium dentatum (Cav.) Copel.

Hierba epífita. Perenne. Nativa.

Distribución: BIO, ARA, LRI, LLA, AIS.

Rango altitudinal: 0-1600 m.

Países limítrofes: Argentina.

Nombre vulgar: Shushu-lahuén.

Hymenophyllum dicranotrichum (C. Presl) Hook. ex Sadeb.

Sinónimos: Hymenophyllum chiloense Hook., Leptocionium dicranotrichum C. Presl, Trichomanes spinulosum Phil.

Hierba. Perenne. Endémica.

Distribución: BIO, ARA, LRI, LLA, AIS.

Rango altitudinal: 0-600 m.

\section{Hymenophyllum falklandicum Baker}

Sinónimos: Hymenophyllum falklandicum Baker var. elongatum Diem \& J.S. Licht., Hymenophyllum glebarium H. Christ ex C. Chr., Hymenophyllum caespitosum auct. non Gaudich., Hymenophyllum falklandicum Baker var. falklandicum fma. andinum Diem \& J.S. Licht.

Hierba epífita. Perenne. Nativa.

Distribución: BIO, ARA, LRI, LLA, AIS, MAG, JFE.

Rango altitudinal: 0-1700 m.

Países limítrofes: Argentina.

Hymenophyllum ferrugineum Colla

Sinónimos: Hymenophyllum frankliniae Colenso, Hymenophyllum berteroi Hook., Sphaerocionium 
ferrugineum (Colla) Copel., Hymenophyllum ferrugineum Colla var. donatii Looser, Hymenophyllum subtilissimum Kunze

Hierba epífita o terrestre. Perenne. Nativa.

Distribución: ARA, LRI, LLA, AIS, MAG, JFE.

Rango altitudinal: 0-1400 m.

Países limítrofes: Argentina.

\section{Hymenophyllum fuciforme Sw.}

Sinónimos: Hymenophyllum semiteres Colla, Leptocionium fuciforme (Sw.) C. Presl, Mecodium fuciforme (Sw.) Copel. Hierba epífita o terrestre. Perenne. Nativa.

Distribución: MAU, NUB, BIO, ARA, LRI, LLA, AIS, MAG, JFE.

Rango altitudinal: 0-1200 m.

Países limítrofes: Argentina.

\section{Hymenophyllum krauseanum Phil.}

Sinónimos: Hymenophyllum magellanicum Willd. ex Kunze var. krauseanum (Phil.) C. Chr., Hymenophyllum dichotomum Cav. var. krauseanum (Phil.) C. Chr., Hymenophyllum plicatum Kaulf. var. krauseanum (Phil.) Looser, Meringium krauseanum (Phil.) G. Kunkel

Hierba epífita o saxícola. Perenne. Nativa.

Distribución: BIO, ARA, LRI, LLA, AIS, MAG.

Rango altitudinal: 0-1300 m.

Países limítrofes: Argentina.

Hymenophyllum nahuelhuapiense Diem \& J.S. Licht.

Hierba terrestre o saxícola. Perenne. Nativa.

Distribución: LLA, AIS, MAG.

Rango altitudinal: 200-800 m.

Países limítrofes: Argentina.

\section{Hymenophyllum pectinatum Cav.}

Hierba epífita o terrestre. Perenne. Nativa.

Distribución: MAU, NUB, BIO, ARA, LRI, LLA, AIS, MAG, JFE.

Rango altitudinal: 0-3600 m.

Países limítrofes: Argentina.

Hymenophyllum peltatum (Poir.) Desv.

Sinónimos: Trichomanes peltatum Poir., Hymenophyllum menziesii C. Presl, Hymenophyllum meyeri C. Presl, Hymenophyllum megachilum C. Presl, Hymenophyllum peltatum (Poir.) Desv. var. elongatum Diem \& J.S. Licht., Hymenophyllum mettenii Bosch, Hymenophyllum peltatum (Poir.) Desv. var. minor Diem \& J.S. Licht., Hymenophyllum peltatum (Poir.) Desv. var. patagonicum Diem \& J.S. Licht., Hymenophyllum unilaterale Bory, Hymenophyllum tunbrigense (L.) Sm. var. wilsoni (Hook.) Sadeb., Hymenophyllum wilsonii Hook.

Hierba epífita o saxícola. Perenne. Nativa.

Distribución: COQ, MAU, NUB, BIO, ARA, LRI, LLA,
AIS, MAG.

Rango altitudinal: 0-1400 m.

Países limítrofes: Argentina, Bolivia y Perú.

Hymenophyllum plicatum Kaulf.

Sinónimos: Ptychophyllum plicatum (Kaulf.) C. Presl, Hymenophyllum quadrifidum Phil., Hymenophyllum plicatum Kaulf. var. quadrifidum (Phil.) Looser, Meringium plicatum (Kaulf.) Copel., Hymenophyllum dichotomum auct. non Cav., Hymenophyllum nigricans Colla

Hierba epífita o terrestre. Perenne. Nativa.

Distribución: MAU, NUB, BIO, ARA, LRI, LLA, AIS, MAG, JFE.

Rango altitudinal: 0-800 m.

Países limítrofes: Argentina.

Hymenophyllum rugosum C. Chr. \& Skottsb.

Sinónimos: Hymenophyllum rugosum C. Chr. \& Skottsb. fma. lanceolatum C. Chr. \& Skottsb., Hymenophyllum tunbrigense auct. non (L.) Sm.

Hierba epífita o terrestre. Perenne. Endémica.

Distribución: JFE.

Rango altitudinal: 400-700 m.

Hymenophyllum secundum Hook. \& Grev.

Sinónimos: Hymenophyllum serra C. Presl, Meringium secundum (Hook. \& Grev.) Copel.

Hierba epífita o terrestre. Perenne. Nativa.

Distribución: LRI, LLA, AIS, MAG, JFE.

Rango altitudinal: 0-1200 m.

Países limítrofes: Argentina.

Hymenophyllum seselifolium C. Presl

Sinónimos: Didymoglossum magellanicum Desv., Hymenophyllum attenuatum Hook., Ptychophyllum magellanicum Klotzsch, Hymenophyllum bibraianum J.W. Sturm, Leptocionium attenuatum (Hook.) Bosch, Leptocionium magellanicum (Desv.) Bosch, Leptocionium seselifolium (C. Presl) Bosch, Meringium magellanicum (Desv.) Copel., Hymenophyllum magellanicum (Desv.) Willd. ex Kunze

Hierba epífita o terrestre. Perenne. Nativa.

Distribución: BIO, ARA, LRI, LLA, AIS, MAG.

Rango altitudinal: 0-1800 m.

Países limítrofes: Argentina.

Hymenophyllum tortuosum Hook. \& Grev.

Sinónimos: Myrmecostylum tortuosum (Hook. \& Grev.) C. Presl, Leptocionium tortuosum (Hook. \& Grev.) Bosch, Trichomanes beckeri E.H.L. Krause ex Phil., Hymenophyllum tortuosum Hook. \& Grev. var. beckeri (E.H.L. Krause ex Phil.) Espinosa, Hymenophyllum tortuosum Hook. \& Grev. var. bustillosii Espinosa, Meringium tortuosum (Hook. \& Grev.) Copel., Hymenophyllum tortuosum Hook. \& Grev. 
var. glomeratum Diem \& J.S. Licht.

Hierba epífita o terrestre. Perenne. Nativa.

Distribución: ARA, LRI, LLA, AIS, MAG, JFE.

Rango altitudinal: 0-1500 m.

Países limítrofes: Argentina.

Hymenophyllum tunbrigense (L.) Sm.

Sinónimos: Trichomanes tunbrigense L., Hymenophyllum antarcticum C. Presl, Hymenophyllum tunbrigense (L.) Sm. var. asperulum (Kunze) Diem \& J.S. Licht.

Hierba epífita o terrestre. Perenne. Nativa.

Distribución: LBO, MAU, NUB, BIO, ARA, LRI, LLA, AIS.

Rango altitudinal: 0-500 m.

Países limítrofes: Argentina.

Hymenophyllum umbratile Diem \& J.S. Licht.

Hierba epífita. Perenne. Nativa.

Distribución: LRI, LLA.

Rango altitudinal: 0-600 m.

Países limítrofes: Argentina.

\section{Serpyllopsis}

Serpyllopsis caespitosa (Gaudich.) C. Chr. var. caespitosa Sinónimos: Serpyllopsis caespitosa (Gaudich.) C. Chr. var. dusenii (H. Christ) C. Chr., Serpyllopsis caespitosa (Gaudich.) C. Chr. var. densifolia (Phil.) C. Chr., Serpyllopsis caespitosa (Gaudich.) C. Chr. var. elongata (Hook.) C. Chr., Hymenophyllum caespitosum Gaudich., Trichomanes caespitosum (Gaudich.) Hook.f., Leptocionium caespitosum C. Presl, Hymenophyllum dusenii H. Christ

Hierba. Perenne. Nativa.

Distribución: ARA, LRI, LLA, AIS, MAG.

Rango altitudinal: 0-1700 m.

Países limítrofes: Argentina.

Serpyllopsis caespitosa (Gaudich.) C. Chr. var. fernandeziana C. Chr. \& Skottsb.

Hierba terrestre o saxícola. Perenne. Endémica.

Distribución: JFE.

Rango altitudinal: 400-1400 m.

\section{Trichomanes}

Trichomanes exsectum Kunze

Sinónimos: Vandenboschia exsecta (Kunze) Copel., Polyphlebium exsectum (Kunze) Ebihara \& Dubuisson

Hierba epífita o saxícola. Perenne. Endémica.

Distribución: MAU, LRI, LLA, JFE.

Rango altitudinal: 0-600 m.

Trichomanes ingae C. Chr. \& Skottsb.

Sinónimos: Vandenboschia ingae (C. Chr. \& Skottsb.) Copel., Polyphlebium ingae (C. Chr. \& Skottsb.) Ebihara
\& Dubuisson

Hierba epífita o saxícola. Perenne. Endémica.

Distribución: JFE.

Rango altitudinal: 100-400 m.

Trichomanes philippianum J.W. Sturm

Sinónimos: Vandenboschia philippiana (J.W. Sturm)

Copel., Polyphlebium philippianum (J.W. Sturm) Ebihara \&

Dubuisson, Trichomanes dichotomum Phil.

Hierba epífita o saxícola. Perenne. Endémica.

Distribución: JFE.

Rango altitudinal: 500-700 m.

\section{MARSILEACEAE}

\section{Marsilea}

Marsilea mollis B.L. Rob. \& Fernald

Sinónimos: Marsilea punae de la Sota

Hierba acuática. Perenne. Nativa.

Distribución: COQ, VAL.

Rango altitudinal: 0-3500 m.

Países limítrofes: Argentina, Bolivia y Perú.

\section{Pilularia}

Pilularia americana A. Braun

Sinónimos: Pilularia valdiviana Phil. ex Baker, nom. nud.

Hierba acuática. Perenne. Nativa.

Distribución: COQ, VAL, RME, LBO, MAU, NUB, BIO, ARA, LRI.

Rango altitudinal: 0-100 m.

Países limítrofes: Argentina y Bolivia.

\section{OLEANDRACEAE}

\section{Arthropteris}

Arthropteris altescandens (Colla) J. Sm.

Sinónimos: Polypodium altescandens Colla, Polypodium procurrens Kunze, Nephrolepis altescandens (Colla) Baker Hierba trepadora. Perenne. Endémica.

Distribución: JFE.

Rango altitudinal: 0-700 m.

\section{OPHIOGLOSSACEAE}

\section{Botrychium}

Botrychium dusenii (H. Christ) Alston

Sinónimos: Botrychium ramosum Asch. var. patagonicum 
H. Christ, Botrychium lunaria (L.) Sw. var. dusenii H. Christ, Botrychium matricariaefolium A. Braun subsp. patagonicum (C. Chr.) R.T. Clausen

Hierba. Perenne. Nativa.

Distribución: RME, AIS, MAG.

Rango altitudinal: 0-900 m.

Países limítrofes: Argentina.

\section{Ophioglossum}

Ophioglossum crotalophoroides Walter

Sinónimos: Ophioglossum tuberosum Hook. \& Arn., Ophioglossum stipatum Miers ex Colla, Ophioglossum vulgatum L. var. crotalophoroides (Walter) D.C. Eaton

Hierba. Perenne. Nativa.

Distribución: VAL, RME, MAU, NUB, BIO, ARA, LRI, LLA.

Rango altitudinal: 0-1500 m.

Países limítrofes: Argentina, Bolivia y Perú.

Ophioglossum fernandezianum C. Chr.

Hierba. Perenne. Endémica.

Distribución: JFE.

Rango altitudinal: 0-300 m.

Ophioglossum melipillense J. Remy

Sinónimos: Ophioglossum lusitanicum L. subsp. coriaceum (A.Cunn.) R.T. Clausen

Hierba. Perenne. Nativa.

Distribución: VAL, RME, LBO, MAU.

Rango altitudinal: 0-1600 m.

Países limítrofes: Argentina.

\section{Ophioglossum reticulatum L.}

Sinónimos: Ophioglossum peruvianum C. Presl, Ophioglossum vulgatum L. var. reticulatum (L.) Luerss.

Hierba. Perenne. Nativa.

Distribución: IPA.

Rango altitudinal: 10-45 m.

Países limítrofes: Argentina, Bolivia y Perú.

Nombre vulgar: Tiapito.

\section{Ophioglossum vulgatum L.}

Sinónimos: Ophioglossum nudicaule L. var. robustum J.S. Licht., Ophioglossum valdivianum Phil., Ophioglossum vulgatum L. var. valdivianum (Phil.) J.S. Licht.

Hierba. Perenne. Nativa.

Distribución: LRI, LLA, AIS.

Rango altitudinal: 0-300 m.

Países limítrofes: Argentina.

Nombre vulgar: Huentru-lahuén.

\section{POLYPODIACEAE}

\section{Grammitis}

Grammitis magellanica Desv.

Sinónimos: Polypodium magellanicum (Desv.) J.W. Sturm, Polypodium magellanicum (Desv.) Copel., comb. illeg., Grammitis billardieri Willd. var. magellanica (Desv.) de la Sota, Polypodium gramineum auct. non Sw., Polypodium billardieri (Willd.) C. Chr. var. magellanicum (Desv.) C. Chr. Hierba epífita. Perenne. Nativa.

Distribución: BIO, ARA, LRI, LLA, AIS, MAG, JFE.

Rango altitudinal: $30-1600 \mathrm{~m}$.

Países limítrofes: Argentina.

Grammitis patagonica (C. Chr.) Parris

Sinónimos: Grammitis repanda Kunze ex Mett., Polypodium patagonicum C. Chr., Grammitis ciliata auct. non Colenso, Polypodium jungermannioides auct. non Klotzsch

Hierba epífita. Perenne. Nativa.

Distribución: LRI, LLA, AIS, MAG.

Rango altitudinal: 0-700 m.

Países limítrofes: Argentina.

Grammitis poeppigiana (Mett.) Pic. Serm.

Sinónimos: Polypodium poeppigianum Mett., Grammitis australis R. Br. var. nana (Brack.) Franch., Polypodium australe Mett. var. nanum Brack. ex Macloskie, Polypodium billardieri (Willd.) C. Chr. var. magellanicum (Desv.) C. Chr. fma. nanum (Brack.) Franch. ex Skottsb., Grammitis billardieri Willd. var. magellanica (Desv.) de la Sota fma. nana (Brack.) de la Sota, Grammitis magellanica Desv. fma. nana (Brack.) de la Sota ex T.R. Dudley, Grammitis nana auct. non Fée

Hierba epífita. Perenne. Nativa.

Distribución: ARA, LRI, LLA, AIS, MAG.

Rango altitudinal: 0-2000 m.

Países limítrofes: Argentina.

\section{Microsorum}

Microsorum scolopendria (Burm.f.) Copel.

Sinónimos: Polypodium scolopendria Burm.f., Polypodium phymatodes L., Polypodium fuentesii Hicken, Phymatodes scolopendria (Burm.f.) Ching, Phymatosorus scolopendria (Burm.f.) Pic.-Ser.

Hierba. Perenne. Nativa.

Distribución: IPA.

\section{Pleopeltis}

Pleopeltis macrocarpa (Bory ex Willd.) Kaulf.

Sinónimos: Polypodium macrocarpum Bory ex Willd., Polypodium lanceolatum L., Grammitis robusta Phil., 
Polypodium lanceolatum L. var. araucanum (Phil.) Looser, Phlebodium lanceolatum (L.) J. Sm., Drynaria lanceolata (L.) Fée, Drynaria macrocarpa (Bory ex Willd.) Fée, Lepicystis lanceolata (L.) Diels, Grammitis araucana Phil., Drynaria elongata auct. non Feé

Hierba epífita o terrestre. Perenne. Nativa.

Distribución: ANT, BIO, ARA, LRI, LLA, JFE.

Rango altitudinal: 0-2000 m.

Países limítrofes: Argentina y Bolivia.

Pleopeltis $x$ cerro-altoensis Danton \& Boudrie Hierba epífita. Perenne. Endémica.

Distribución: JFE.

\section{Polypodium}

Polypodium masafuerae Phil.

Sinónimos: Pleopeltis masafuerae (Phil.) de la Sota, Polypodium macrocarpum auct. non Presl

Hierba terrestre o saxícola. Perenne. Endémica.

Distribución: JFE.

Rango altitudinal: 0-600 m.

Polypodium pycnocarpum C. Chr.

Sinónimos: Polypodium squamatum Phil., Polypodium atacamense Baker ex Ball, Polypodium mollendense Maxon Hierba. Perenne. Nativa.

Distribución: ANT.

Países limítrofes: Argentina, Bolivia y Perú.

\section{Synammia}

Synammia espinosae (Weath.) G. Kunkel

Sinónimos: Polypodium espinosae Weath.

Hierba epífita o terrestre. Perenne. Endémica.

Distribución: ANT, ATA.

Rango altitudinal: 200-1000 m.

Synammia feuillei (Bertero) Copel.

Sinónimos: Grammitis triloba (Cav.) Desv., Polypodium glaucescens Bory, Synammia triloba (Cav.) C. Presl, Synammia skottsbergii G. Kunkel, Polypodium synammia (Fée ex J. Remy) C. Chr., Polypodium feuillei Bertero, Polypodium feuillei Bertero fma. trilobum (Cav.) Looser, PolypodiumfeuilleiBertero fma.simplex Looser, Polypodium feuillei Bertero fma. basiscopicum Looser, Polypodium feuillei Bertero var. feuillei fma. unilaterale G. Kunkel, Polypodium feuillei Bertero var. feuillei, Polypodium feuillei Bertero var. minor G. Kunkel, Synammia feuillei (Bertero) Copel. var. feuillei, Synammia feuillei (Bertero) Copel. var. feuillei fma. simplex (Looser) G. Kunkel, Synammia feuillei
(Bertero) Copel. var. feuillei fma. basiscopica (Looser) G. Kunkel, Synammia feuillei (Bertero) Copel. var. feuillei fma. unilaterale (G. Kunkel) G. Kunkel, Synammia feuillei (Bertero) Copel. var. feuillei fma. hastifolia (G. Kunkel) G. Kunkel, Synammia feuillei (Bertero) Copel. var. minor (G. Kunkel) G. Kunkel, Mecosorus trilobus (Cav.) Klotzsch, Goniophlebium synammia Fée ex J. Remy, Goniophlebium trilobum (Cav.) T. Moore, Polypodium trilobum auct. non Houtt., Goniophlebium californicum auct. non Fée, Polypodium feuillei Bertero var. ibañezii Looser, Synamia feuillei (Bertero) Copel. var. ibañezii (Looser) G. Kunkel, nom. illeg.

Hierba epífita o saxícola. Perenne. Nativa.

Distribución: COQ, VAL, LBO, MAU, NUB, BIO, ARA, LRI, LLA, AIS, MAG.

Rango altitudinal: 0-1200 m.

Países limítrofes: Argentina.

Nombre vulgar: Calahuala, hierba del lagarto, pillavilcún.

Synammia intermedia (Colla) G. Kunkel subsp. intermedia Sinónimos: Polypodium transluscens Kunze, Polypodium intermedium Colla, Polypodium intermedium Colla var. basicompositum C. Chr. \& Skottsb., Polypodium intermedium Colla var. fernandezianum Espinosa, Synammia intermedia (Colla) G. Kunkel subsp. masatierrae (C. Chr. \& Skottsb.) G. Kunkel, Goniophlebium translucens (Kunze) Fée

Hierba epífita. Perenne. Endémica.

Distribución: JFE.

Rango altitudinal: 0-500 m.

Synammia intermedia (Colla) G. Kunkel subsp. masafuerana (C. Chr. \& Skottsb.) G. Kunkel

Sinónimos: Polypodium intermedium Colla subsp. masafueranum C. Chr. \& Skottsb.

Hierba epífita. Perenne. Endémica.

Distribución: JFE.

Rango altitudinal: $200 \mathrm{~m}$.

\section{PSILOTACEAE}

\section{Psilotum}

Psilotum nudum (L.) P. Beauv.

Hierba. Perenne. Nativa.

Nota: La expedición Franco-Belga de 1934 (Tardieu-Blot 1936), reporta la presencia de esta especie para la Isla de Pascua. Sin embargo, esta especie nunca más ha sido encontrada. 


\section{PTERIDACEAE}

\section{Adiantum}

Adiantum capillus-veneris L.

Hierba. Perenne. Introducida.

Distribución: TAR, ATA, COQ, VAL, RME, LBO, MAU.

\section{Adiantum chilense Kaulf. var. chilense}

Sinónimos: Adiantum aethiopicum L. var. glabrum Kuntze, Adiantum mochaenum G. Kunkel

Hierba. Perenne. Nativa.

Distribución: TAR, ATA, COQ, VAL, RME, LBO, MAU, NUB, BIO, ARA, LRI, LLA, AIS, MAG, JFE.

Rango altitudinal: 0-1700 m.

Países limítrofes: Argentina.

Nombre vulgar: Doradilla, helecho de palo negro, palito negro, culantrillo.

Adiantum chilense Kaulf. var. hirsutum Hook. \& Grev. Sinónimos: Adiantum pubescens C. Presl, Adiantum glanduliferum Link, Adiantum pilosum Fée, Adiantum aethiopicum L. var. hirsutum (Hook. \& Grev.) Kuntze, Adiantum poiretii Wikstr. fma. hirsutum (Hook. \& Grev.) Hicken, Adiantum weatherbyanum Espinosa, Adiantum poiretii Wikstr. var. hirsutum (Hook. \& Grev.) R.M. Tryon, Adiantum thalictroides Willd. ex Schltdl. var. hirsutum (Hook. \& Grev.) De la Sota

Hierba. Perenne. Nativa.

Distribución: ANT, ATA, COQ, VAL, RME, LBO, MAU, NUB, BIO.

Rango altitudinal: 1700-3400 m.

Países limítrofes: Argentina y Perú.

Adiantum chilense Kaulf. var. scabrum (Kaulf.) Hicken Sinónimos: Adiantum scabrum Kaulf. var. scabrum, Adiantum aethiopicum L. var. scabrum (Kaulf.) Kuntze, Adiantum philippianum Espinosa, Adiantum scabrum Kaulf. var. philippianum (Espinosa) Looser, Adiantum glanduliferum auct. non Link

Hierba. Perenne. Nativa.

Distribución: COQ, VAL, RME, LBO, MAU, NUB, BIO, ARA, LRI.

Rango altitudinal: 0-2000 m.

Países limítrofes: Argentina.

\section{Adiantum excisum Kunze}

Sinónimos: Adiantum tenerum auct. non Sw.

Hierba. Perenne. Endémica.

Distribución: COQ, VAL, RME, LBO, MAU, NUB, BIO, ARA, LLA.

Rango altitudinal: 0-1700 m.
Adiantum gertrudis Espinosa

Hierba. Perenne. Endémica.

Distribución: COQ, VAL, RME.

Rango altitudinal: 0-1500 m.

Adiantum pearcei Phil.

Hierba. Perenne. Endémica.

Distribución: COQ, VAL, RME.

Rango altitudinal: 0-900 m.

Adiantum sulphureum Kaulf. var. majus Hook.

Sinónimos: Adiantum sulphureum Kaulf. var. cuneifolium Meigen, Adiantum sulfureum auct. non Kaulf.

Hierba. Perenne. Endémica.

Distribución: COQ, VAL, RME, LBO, MAU, NUB, BIO, ARA.

Rango altitudinal: 500-1000 m.

Adiantum sulphureum Kaulf. var. sulphureum

Sinónimos: Adiantum sulphureum Kaulf. var. minus Hook., Adiantum subsulphureum J. Remy, Adiantum aethiopicum L. var. sulphureum (Kaulf.) Kuntze, Adiantum sulphureum Kaulf. var. subsulphureum (J. Remy) Looser, Adiantum poiretii Wikstr. var. sulphureum (Kaulf.) R.M. Tryon, Adiantum chilense Kaulf. var. sulphureum (Hook.) Giúdice Hierba. Perenne. Nativa.

Distribución: COQ, VAL, RME, LBO, MAU, NUB, BIO, ARA, LRI, LLA, AIS.

Rango altitudinal: 0-1700 m.

Países limítrofes: Argentina.

\section{Argyrochosma}

Argyrochosma chilensis (J. Remy) Windham

Sinónimos: Pellaea chilensis (J. Remy) C. Chr., Notholaena chilensis (J. Remy) J.W. Sturm, Cincinalis chilensis J. Remy, Pellaea chilensis Fée, nom. nud.

Hierba. Perenne. Endémica.

Distribución: JFE.

Rango altitudinal: 0-500 m.

Argyrochosma nivea (Poir.) Windham

Sinónimos: Notholaena nivea (Poir.) Desv., Pellaea nivea (Poir.) Prantl, Pteris nivea Poir., Acrostichum albidulum Sw., Cincinalis nivea (Poir.) Desv., Gymnogramma nivea (Poir.) Mett., Cincinalis tarapacana Phil.

Hierba. Perenne. Nativa.

Distribución: AYP, TAR, ANT.

Rango altitudinal: 200-4000 m.

Países limítrofes: Argentina, Bolivia y Perú.

Nombre vulgar: Chujchu, qusupe. 


\section{Astrolepis}

Astrolepis sinuata (Lag. ex Sw.) D.M. Benham \& Windham Sinónimos: Cheilanthes sinuata (Lag. ex Sw.) Domin, Notholaena sinuata (Lag. ex Sw.) Kaulf., Acrostichum sinuatum Lag. ex Sw., Gymnogramma sinuata (Lag. ex Sw.) C. Presl

Hierba. Perenne. Nativa.

Distribución: TAR.

Rango altitudinal: 500-3000 m.

Países limítrofes: Argentina, Bolivia y Perú.

\section{Cheilanthes}

Cheilanthes arequipensis (Maxon) R.M. Tryon \& A. F. Tryon

Sinónimos: Notholaena arequipensis Maxon

Hierba. Perenne. Nativa.

Distribución: AYP, TAR.

Rango altitudinal: 2300-4000 m.

Países limítrofes: Argentina y Perú.

Cheilanthes glauca (Cav.) Mett.

Sinónimos: Cheilanthes chilensis Fée, Allosorus hirsutus C. Presl, Acrostichum glaucum Cav., Pteris glauca (Cav.) Cav., Pteris microphylla Colla, Pellaea hirsuta (C. Presl) Hook., Pellaea glauca (Cav.) J. Sm.

Hierba. Perenne. Nativa.

Distribución: COQ, VAL, RME, LBO, MAU, NUB, BIO, ARA, LLA, AIS.

Rango altitudinal: 0-1700 m.

Países limítrofes: Argentina.

Cheilanthes hypoleuca (Kunze) Mett.

Sinónimos: Notholaena tomentosa (Desv.) Desv., Cincinalis tomentosa Desv., Notholaena hypoleuca Kunze

Hierba. Perenne. Nativa.

Distribución: ANT, ATA, COQ, VAL, RME, LBO, MAU, NUB, BIO, ARA.

Rango altitudinal: 0-1500 m.

Países limítrofes: Argentina.

Nombre vulgar: Doradilla.

Cheilanthes mollis (Kunze) C. Presl

Sinónimos: Cheilanthes doradilla (Colla) Domin, Notholaena mollis Kunze, Notholaena doradilla Colla

Hierba. Perenne. Nativa.

Distribución: TAR, ANT, ATA, COQ, VAL, RME, LBO, LLA.

Rango altitudinal: 0-1300 m.

Países limítrofes: Perú.

Nombre vulgar: Doradilla.
Cheilanthes myriophylla Desv.

Sinónimos: Cheilanthes elegans Desv., Cheilanthes myriophylla Desv. var. elegans (Desv.) Hicken, Notholaena myriophylla J. Sm.

Hierba. Perenne. Nativa.

Distribución: AYP.

Rango altitudinal: 200-4000 m.

Países limítrofes: Argentina y Perú.

Cheilanthes pilosa Goldm.

Sinónimos: Cheilanthes macleanii Hook., Cheilanthes andina Hook.

Hierba. Perenne. Nativa.

Distribución: TAR.

Rango altitudinal: 800-4000 m.

Países limítrofes: Argentina, Bolivia y Perú.

Cheilanthes pruinata Kaulf.

Sinónimos: Cheilanthes mathewsii Kunze, Cheilanthes fasciculata Goldm., Cheilanthes micropteris auct. non Sw.

Hierba. Perenne. Nativa.

Distribución: AYP, TAR, ANT.

Rango altitudinal: 2000-4800 m.

Países limítrofes: Argentina, Bolivia y Perú.

Nombre vulgar: Chujchu, qusupe.

\section{Cryptogramma}

Cryptogramma fumariifolia (Phil. ex Baker) H. Christ Sinónimos: Cryptogramma crispa (L.) R. Br. var. chilensis (C. Chr.) Looser, Allosorus crispus Bernh. var. chilensis C. Chr., Pellaea fumariaefolia Phil. ex Baker, Allosorus fumariaefolius (Phil. ex Baker) Kuntze, Pellaea fumariifolia Phil.

Hierba. Perenne. Nativa.

Distribución: COQ, VAL, RME, LBO, MAU, NUB, BIO.

Rango altitudinal: 900-1400 m.

Países limítrofes: Argentina.

\section{Myriopteris}

Myriopteris aurea (Poir.) Grusz \& Windham

Sinónimos: Notholaena rufa C. Presl, Notholaena bonariensis (Willd.) C. Chr., Notholaena aurea (Poir.) Desv., Acrostichum bonariense Willd., Pteris aurea Poir., Cheilanthes bonariensis (Willd.) Proctor

Hierba. Perenne. Nativa.

Distribución: ANT.

Rango altitudinal: 600-4000 m.

Países limítrofes: Argentina y Perú. 


\section{Notholaena}

Notholaena sulphurea (Cav.) J. Sm.

Sinónimos: Notholaena lepida (Phil.) Looser, Pteris sulphurea Cav., Chrysochosma sulphurea (Cav.) Kümmerle, Cheilanthes lepida Phil.

Hierba. Perenne. Nativa.

Distribución: ATA.

Rango altitudinal: 200-2500 m.

Países limítrofes: Argentina, Bolivia y Perú.

\section{Pellaea}

Pellaea myrtillifolia Mett. ex Kuhn

Sinónimos: Allosorus andromedaefolius auct. non (Kaulf.) Kunze, Pellaea andromedaefolia auct. non (Kaulf.) Fée Hierba. Perenne. Endémica.

Distribución: ATA, COQ, VAL, RME, LBO.

Rango altitudinal: 100-2000 m.

Nombre vulgar: Coca, hierba coca, lendo del cerro.

\section{Pellaea ternifolia (Cav.) Link}

Sinónimos: Allosorus ternifolius Kunze ex Klotzsch, Pteris ternifolia Cav., Cheilanthes ternifolia (Cav.) T. Moore, Pteris tryphylla Bertero ex Colla, nom. nud.

Hierba. Perenne. Nativa.

Distribución: AYP, TAR, ANT, VAL, LBO, BIO, ARA, LRI.

Rango altitudinal: 200-4500 m.

Países limítrofes: Argentina, Bolivia y Perú.

Nombre vulgar: Qusupi, qusupe, yuquelahuén.

\section{Pteris}

Pteris berteroana J. Agardh

Sinónimos: Litobrochia berteroana (J. Agardh) Fée, Pteris comans G. Forst. var. berteroana, Pteris tenera auct. non Kaulf., Litobrochia decurrens auct. non C. Presl, Pteris comansauct. non G. Forst., Pteris incisa auct. non Thunb. Hierba. Perenne. Endémica.

Distribución: JFE.

Rango altitudinal: 0-500 m.

Pteris chilensis Desv.

Sinónimos: Pteris tenera Kaulf., Pteris fernandeziana Phil. Hierba. Perenne. Endémica.

Distribución: COQ, VAL, RME, LBO, MAU, NUB, BIO, ARA, LRI, JFE.

Rango altitudinal: 0-1400 m.

Pteris semiadnata Phil.

Sinónimos: Pteris marattiaefolia Hook., Pteris flexuosa auct. non Kaulf.

Hierba. Perenne. Nativa.

Distribución: BIO, ARA, LRI, LLA, AIS, MAG, JFE.
Rango altitudinal: $600-800 \mathrm{~m}$.

Países limítrofes: Argentina.

\section{Trismeria}

Trismeria trifoliata (L.) Diels

Sinónimos: Pityrogramma trifoliata (L.) R.M. Tryon, Acrostichum trifoliatum L.

Hierba. Perenne. Nativa.

Distribución: AYP, TAR.

Rango altitudinal: 0-2100 m.

Países limítrofes: Argentina, Bolivia y Perú.

\section{Vittaria}

Vittaria ensiformis Sw.

Sinónimos: Vittaria incurvata Cav., Vittaria elongata auct., non Sw., Vittaria costata auct. non Kunze

Hierba saxícola. Perenne. Nativa.

Distribución: IPA.

\section{SALVINIACEAE}

\section{Azolla}

Azolla filiculoides Lam.

Sinónimos: Azolla magellanica Willd., Azolla squamosa Molina, Azolla arbuscula Desv.

Hierba acuática. Anual. Nativa.

Distribución: AYP, TAR, ANT, ATA, COQ, VAL, RME, LBO, MAU, NUB, BIO, ARA, LRI, LLA, AIS.

Rango altitudinal: 5-3800 m.

Países limítrofes: Argentina, Bolivia y Perú.

Nombre vulgar: Flor del pato, tembladerilla, luchecillo, jupajupa.

\section{Salvinia}

Salvinia auriculata Aubl.

Hierba acuática. Perenne. Introducida.

Distribución: VAL.

\section{SCHIZAEACEAE}

\section{Schizaea}

Schizaea fistulosa Labill.

Sinónimos: Schizaea australis Gaudich., Schizaea palmata Hombr. \& Jacq., Schizaea chilensis Phil., Schizaea fistulosa Labill. var. australis (Gaudich.) Hook.f., Microschizaea fistulosa (Labill.) C.F. Reed, Schizaea valdiviana Phil. ex Hook. \& Baker 
Hierba. Perenne. Nativa.

Distribución: LRI, LLA, AIS, MAG.

Rango altitudinal: 0-1100 m.

Países limítrofes: Argentina.

\section{THELYPTERIDACEAE}

\section{Thelypteris}

Thelypteris argentina (Hieron.) Abbiatti

Sinónimos: Aspidium argentinum Hieron., Dryopteris argentina (Hieron.) C. Chr., Lastrea argentina (Hieron.) Copel., Aspidium rivulorum auct. non Link

Hierba. Perenne. Nativa.

Distribución: AYP, TAR, ANT, ATA, COQ, VAL, RME, LBO, MAU, BIO.

Rango altitudinal: 0-3300 m.

Países limítrofes: Argentina y Bolivia.

Nombre vulgar: Regalis.

Thelypteris dentata (Forssk.) E.P. St. John

Hierba. Perenne. Introducida.

Distribución: IPA.

Thelypteris interrupta (Willd.) K. Iwats.

Sinónimos: Aspidium gongylodes Schkuhr, Dryopteris gongylodes (Schkuhr) Kuntze, Polypodium tottum Thunb., Pteris interrupta Willd., Thelypteris totta (Thunb.) Schelpe Hierba. Perenne. Nativa.

Distribución: IPA.

Rango altitudinal: 0-900 m.

Países limítrofes: Argentina, Bolivia y Perú.

\section{WOODSIACEAE}

\section{Woodsia}

Woodsia montevidensis (Sprengel) Hieron.

Sinónimos: Dicksonia montevidensis Sprengel, Woodsia crenata (Kunze) Hieron.

Hierba. Perenne. Nativa.

Distribución: AYP.

Países limítrofes: Argentina, Bolivia y Perú.

\section{PINOPHYTA}

\section{GNETOPSIDA}

\section{EPHEDRACEAE}

\section{Ephedra}

Ephedra americana Humb. \& Bonpl. ex Willd.

Sinónimos: Ephedra breana Phil., Ephedra wraithiana I.M. Johnst., Ephedra americana Humb. \& Bonpl. ex Willd. var. humboldtii Stapf

Arbusto. Nativo.

Distribución: AYP, TAR, ANT, ATA, COQ.

Rango altitudinal: $500-4300 \mathrm{~m}$.

Países limítrofes: Argentina, Bolivia y Perú.

Nombre vulgar: Pingo-pingo.

Ephedra chilensis C. Presl

Sinónimos: Ephedra rupestris Benth., Ephedra frustillata Miers, Ephedra americana Humb. \& Bonpl. ex Willd. var. andina (Poepp. ex C.A. Mey.) Stapf, Ephedra andina Poepp. ex C.A. Mey., Ephedra andina Poepp. ex C.A.Mey. fma. abbreviata Stapf ex Skottsb., Ephedra araucana Phil., Ephedra bracteata Miers, Ephedra dumosa Miers, Ephedra monticola Miers, Ephedra nana Dusén, Ephedra patagonica Phil. ex Stapf, Ephedra americana Humb. \& Bonpl. ex Willd. var. rupestris (Benth.) Ball, Ephedra humilis Wedd., Ephedra andina Poepp. ex C.A. Mey. var. humilis Parlat.

Arbusto. Nativo.

Distribución: AYP, TAR, ANT, ATA, COQ, VAL, RME, LBO, MAU, NUB, BIO, ARA.

Rango altitudinal: 100-3000 m.

Países limítrofes: Argentina, Bolivia y Perú.

Nombre vulgar: Pingo-pingo, solupe, sulupe, transmontana

Ephedra gracilis Phil. ex Stapf

Arbusto. Endémico.

Distribución: ATA, COQ, VAL, RME.

Rango altitudinal: 10-1200 m.

Ephedra multiflora Phil. ex Stapf

Arbusto. Nativo.

Distribución: AYP, ANT, ATA.

Rango altitudinal: 2300-4000 m.

Países limítrofes: Argentina.

Nombre vulgar: Pingo-pingo.

Ephedra ochreata Miers

Sinónimos: Ephedra ochreata Miers var. striata Gillies ex Miers

Arbusto. Nativo.

Distribución: AIS.

Rango altitudinal: 389-389 m.

Países limítrofes: Argentina. 
Ephedra trifurcata Zoellner

Arbusto. Endémico.

Distribución: VAL.

Rango altitudinal: 200-300 m.

\section{PINOPSIDA}

\section{ARAUCARIACEAE}

Araucaria

Araucaria araucana (Molina) K. Koch

Sinónimos: Araucaria imbricata Pav., Columbea quadrifaria Salisb., Pinus araucana Molina, Dombeya chilensis Lam., Araucaria chilensis Mirb., Araucaria dombeyi Rich.

Árbol. Nativo.

Distribución: BIO, ARA, LRI.

Rango altitudinal: 600-1700 m.

Países limítrofes: Argentina.

Nombre vulgar: Araucaria, piñonero, pehuén.

\section{CUPRESSACEAE}

\section{Austrocedrus}

Austrocedrus chilensis (D. Don) Pic. Serm. \& Bizzarri Sinónimos: Austrocedrus chilensis (D. Don) Florin \& Boutelje, comb. illeg., Libocedrus chilensis (D. Don) Endl., Thuja andina Poepp., Thuja chilensis D. Don

Árbol. Nativo.

Distribución: VAL, RME, LBO, MAU, NUB, BIO, ARA, LRI, LLA.

Rango altitudinal: 250-1800 m.

Países limítrofes: Argentina.

Nombre vulgar: Ciprés de la cordillera, ciprés, len.

\section{Fitzroya}

Fitzroya cupressoides (Molina) I.M. Johnst.

Sinónimos: Fitzroya patagonica Hook.f. ex Lindl., Libocedrus cupressoides (Molina) Kuntze, Pinus cupressoides Molina

Árbol. Nativo.

Distribución: LRI, LLA.

Rango altitudinal: 100-1400 m.

Países limítrofes: Argentina.

Nombre vulgar: Alerce, lahuén, lahual.

\section{Pilgerodendron}

Pilgerodendron uviferum (D. Don) Florin

Sinónimos: Juniperus uvifera D. Don, Libocedrus tetragona (Hook.) Endl., Thuja tetragona Hook., Libocedrus uvifera (D. Don) Pilg.

Árbol. Nativo.

Distribución: LRI, LLA, AIS, MAG.

Rango altitudinal: 5-1300 m.

Países limítrofes: Argentina.

Nombre vulgar: Ciprés de las Guaitecas.

\section{PINACEAE}

\section{Pinus}

Pinus contorta Douglas ex Loudon

Árbol. Introducido.

Distribución: ARA, AIS.

Pinus pinaster Aiton

Árbol. Introducido.

Distribución: NUB, BIO.

Nombre vulgar: Pino marítimo.

Pinus radiata D. Don

Árbol. Introducido.

Distribución: VAL, LBO, MAU, NUB, BIO, ARA, LRI, LLA, JFE.

Nombre vulgar: Pino insigne.

\section{PODOCARPACEAE}

\section{Lepidothamnus}

Lepidothamnus fonkii Phil.

Sinónimos: Dacrydium foncki (Phil.) Ball

Arbusto. Nativo.

Distribución: LRI, LLA, AIS, MAG.

Rango altitudinal: 3-1300 m.

Países limítrofes: Argentina.

Nombre vulgar: Ciprés enano.

\section{Podocarpus}

Podocarpus nubigena Lindl.

Árbol. Nativo.

Distribución: ARA, LRI, LLA, AIS, MAG.

Rango altitudinal: 10-600 m.

Países limítrofes: Argentina.

Nombre vulgar: Mañío, mañío de hojas punzantes, pino amarillo. 
Podocarpus saligna D. Don

Sinónimos: Podocarpus chilinus Rich.

Árbol. Endémico.

Distribución: MAU, NUB, BIO, ARA, LRI, LLA.

Rango altitudinal: 10-900 m.

Nombre vulgar: Mañío de hojas largas, mañío.

\section{Prumnopitys}

Prumnopitys andina (Poepp. ex Endl.) de Laub. Sinónimos: Prumnopitys spicata (Poepp. ex Endl.) Molloy \& Muñoz-Schick, comb. illeg., Podocarpus andina Poepp. ex Endl., Prumnopitys elegans Phil., Podocarpus spicatus Poepp., Podocarpus valdiviana J. Nelson, Stachycarpus andina (Poepp. ex Endl.) Tiegh., Nageia andina (Poepp. ex Endl.) F. Muell.

Árbol. Nativo.

Distribución: MAU, NUB, BIO, ARA.

Rango altitudinal: 500-1300 m.

Países limítrofes: Argentina.

Nombre vulgar: Lleuque, uva de la cordillera.

\section{Saxegothaea}

Saxegothaea conspicua Lindl.

Sinónimos: Squamataxus albertiana J. Nelson

Árbol. Nativo.

Distribución: MAU, NUB, BIO, ARA, LRI, LLA, AIS.

Rango altitudinal: 100-1000 m.

Países limítrofes: Argentina.

Nombre vulgar: Mañío hembra, mañío.

\section{MAGNOLIOPHYTA}

\section{LILIOPSIDA}

\section{ALISMATACEAE}

Alisma

Alisma lanceolatum With. Hierba. Perenne. Introducida. Distribución: VAL, RME, LBO, MAU, NUB, BIO, ARA, LLA.

Alisma plantago-aquatica $\mathrm{L}$. Hierba. Perenne. Introducida.

Distribución: VAL, RME, LBO, MAU, NUB, BIO, ARA, LRI, LLA.

\section{Sagittaria}

Sagittaria montevidensis Cham. \& Schltdl. subsp. chilensis (Cham. \& Schltdl.) Bogin

Sinónimos: Sagittaria chilensis Cham. \& Schltdl., Sagittaria andina Phil.

Hierba. Perenne. Endémica.

Distribución: VAL, MAU, NUB, BIO, ARA, LRI, LLA.

Rango altitudinal: 0-1500 m.

Nombre vulgar: Lengua de vaca.

Sagittaria montevidensis Cham. \& Schltdl. subsp. montevidensis

Hierba acuática. Perenne. Nativa.

Distribución: BIO, LRI.

Países limítrofes: Argentina, Bolivia y Perú.

Sagittaria rhombifolia Cham.

Hierba acuática. Perenne. Nativa.

Distribución: LRI.

Países limítrofes: Argentina, Bolivia y Perú.

\section{ALSTROEMERIACEAE}

\section{Alstroemeria}

Alstroemeria achirae Muñoz-Schick \& Brinck

Hierba. Perenne. Endémica.

Distribución: MAU.

Rango altitudinal: 1500-1900 m.

Alstroemeria andina Phil. var. andina

Hierba. Perenne. Endémica.

Distribución: ATA, COQ.

Rango altitudinal: 2900-3700 m.

Alstroemeria andina Phil. var. venustula (Phil.) MuñozSchick

Sinónimos: Alstroemeria venustula Phil., Alstroemeria andina Phil. subsp. venustula (Phil.) Ehr. Bayer

Hierba. Perenne. Nativa.

Distribución: ATA, COQ.

Rango altitudinal: 2300-3700 m.

Países limítrofes: Argentina.

Alstroemeria angustifolia Herb. var. angustifolia

Sinónimos: Alstroemeria angustifolia Herb. var. conferta Herb., Alstroemeria angustifolia Herb. var. intermedia Herb., Alstroemeria angustifolia Herb. var. solliana Herb., Alstroemeria angustifolia Herb. var. acuminata Herb.

Hierba. Perenne. Endémica.

Distribución: ATA, COQ, VAL, RME, LBO.

Rango altitudinal: 0-1700 m. 
Alstroemeria angustifolia Herb. var. velutina (Ehr. Bayer) Muñoz-Schick

Sinónimos: Alstroemeria angustifolia Herb. subsp. velutina Ehr. Bayer

Hierba. Perenne. Endémica.

Distribución: COQ, VAL, RME.

Rango altitudinal: 500-2000 m.

Alstroemeria aurea Graham

Sinónimos: Alstroemeria aurantiaca D. Don, Alstroemeria mutabilis Kunze, Alstroemeria chiloensis Phil., Alstroemeria araucana Phil., Alstroemeria ligtu auct. non L., Alstroemeria stenopetala Phil.

Hierba. Perenne. Nativa.

Distribución: LBO, MAU, NUB, BIO, ARA, LRI, LLA, MAG.

Rango altitudinal: 200-1900 m.

Países limítrofes: Argentina.

Nombre vulgar: Liuto amarillo.

Nota: Introducida en Magallanes según E. Domínguez.

Alstroemeria citrina Phil.

Hierba. Perenne. Endémica.

Distribución: COQ, VAL.

Alstroemeria crispata Phil.

Hierba. Perenne. Endémica.

Distribución: ATA, COQ, VAL.

Rango altitudinal: 1100-3000 m.

Alstroemeria cummingiana Herb.

Sinónimos: Alstroemeria hookeri Lodd. subsp. cummingiana (Herb.) Ehr. Bayer

Hierba. Perenne. Endémica.

Distribución: COQ, VAL.

Rango altitudinal: 0-500 m.

Alstroemeria diluta Ehr. Bayer subsp. chrysantha Ehr. Bayer

Hierba. Perenne. Endémica.

Distribución: ATA, COQ, VAL.

Rango altitudinal: 0-400 m.

Alstroemeria diluta Ehr. Bayer subsp. diluta

Hierba. Perenne. Endémica.

Distribución: LBO, MAU.

Rango altitudinal: $300 \mathrm{~m}$.

\section{Alstroemeria exerens Meyen}

Sinónimos: Alstroemeria diazii Phil., Alstroemeria pallens

Phil., Alstroemeria exserens Meyen

Hierba. Perenne. Endémica.

Distribución: RME, LBO, MAU.

Rango altitudinal: 1500-2100 m.
Alstroemeria garaventae Ehr. Bayer

Hierba. Perenne. Endémica.

Distribución: VAL, RME.

Rango altitudinal: 1200-2000 m.

Alstroemeria graminea Phil.

Sinónimos: Taltalia graminea (Phil.) Ehr. Bayer

Hierba. Anual. Endémica.

Distribución: ANT, ATA.

Rango altitudinal: 0-500 m.

Alstroemeria hookeri Lodd. subsp. hookeri

Sinónimos: Alstroemeria rosea Hook., Alstroemeria hookeriana Schult.

Hierba. Perenne. Endémica.

Distribución: VAL, MAU, NUB, BIO.

Rango altitudinal: 0-300 m.

Alstroemeria hookeri Lodd. subsp. maculata Ehr. Bayer

Hierba. Perenne. Endémica.

Distribución: COQ.

Rango altitudinal: 0-100 m.

Alstroemeria hookeri Lodd. subsp. recumbens (Herb.) Ehr.

Bayer

Sinónimos: Alstroemeria recumbens Herb.

Hierba. Perenne. Endémica.

Distribución: COQ, VAL.

Rango altitudinal: 0-100 m.

Alstroemeria hookeri Lodd. subsp. sansebastiana C.M.

Baeza \& E. Ruiz

Hierba. Perenne. Endémica.

Distribución: NUB, BIO.

Rango altitudinal: 0-100 m.

Alstroemeria kingii Phil.

Hierba. Perenne. Endémica.

Distribución: ATA.

Rango altitudinal: 0-800 m.

Alstroemeria leporina Ehr. Bayer \& Grau

Sinónimos: Alstroemeria hirtella Phil.

Hierba. Perenne. Endémica.

Distribución: ATA, COQ.

Rango altitudinal: 900-2000 m.

Alstroemeria ligtu L. subsp. ligtu

Sinónimos: Alstroemeria flava Phil., Alstroemeria lothiana Utinet, Alstroemeria chilensis Lem., Alstroemeria haemantha Ruiz \& Pav.

Hierba. Perenne. Endémica.

Distribución: VAL, RME, LBO, MAU, NUB, BIO, ARA.

Rango altitudinal: 0-800 m.

Nombre vulgar: Liuto. 
Alstroemeria ligtu L. subsp. simsii (Spreng.) Ehr. Bayer Sinónimos: Alstroemeria haemantha auct. non Ruiz \& Pav., Alstroemeria simsii Spreng., Alstroemeria ciliata Poepp., Alstroemeria pulchella auct. non L.f., Alstroemeria pulchella L. f. var. pilosa Lindl., Alstroemeria haemantha Ruiz \& Pav. var. pilosa (Lindl.) Herb., Alstroemeria haemantha Ruiz \& Pav. var. simsiana Herb., Alstroemeria quillotensis Herb., Alstroemeria macraeana Herb., Alstroemeria aurea Graham var. valparadisiaca Herb., Alstroemeria aurea Meyen, hom. illeg., Alstroemeria dentata Klotzsch

Hierba. Perenne. Endémica.

Distribución: VAL, RME, LBO, MAU, BIO.

Rango altitudinal: 0-1800 m.

Alstroemeria ligtu L. subsp. splendens Muñoz-Schick Sinónimos: Alstroemeria ligtu L. subsp. incarnata Ehr. Bayer, nom. illeg.

Hierba. Perenne. Endémica.

Distribución: RME, LBO, MAU.

Rango altitudinal: 1100-1400 m.

Alstroemeria lutea Muñoz-Schick

Hierba. Perenne. Endémica.

Distribución: TAR.

Alstroemeria magnifica Herb. var. magenta (Ehr. Bayer) Muñoz-Schick

Sinónimos: Alstroemeria magenta Ehr. Bayer

Hierba. Perenne. Endémica.

Distribución: COQ, VAL.

Rango altitudinal: 0-700 m.

\section{Alstroemeria magnifica Herb. var. magnifica}

Sinónimos: Alstroemeria gayana Phil., Alstroemeria magnifica Herb. subsp. gayana (Phil.) Ehr. Bayer

Hierba. Perenne. Endémica.

Distribución: ATA, COQ, VAL, RME.

Rango altitudinal: 0-600 m.

Nombre vulgar: Lirio morado.

Alstroemeria magnifica Herb. var. sierrae (Muñoz) Muñoz-Schick

Sinónimos: Alstroemeria sierrae Muñoz

Hierba. Perenne. Endémica.

Distribución: COQ.

Alstroemeria magnifica Herb. var. tofoensis Muñoz-Schick Hierba. Perenne. Endémica.

Distribución: COQ.

Rango altitudinal: 600-700 m.

Alstroemeria marticorenae Negritto \& C.M. Baeza

Hierba. Perenne. Endémica.

Distribución: VAL.
Alstroemeria mollensis Muñoz-Schick \& Brinck

Hierba. Perenne. Endémica.

Distribución: COQ.

Rango altitudinal: 2000-2200 m.

Alstroemeria pallida Graham

Sinónimos: Alstroemeria albiflora C. Presl, Alstroemeria rosea Phil., Alstroemeria ligtu L. var. andina Phil., Alstroemeria nivalis Phil., hom. illeg., Alstroemeria nubigena Phil.

Hierba. Perenne. Endémica.

Distribución: COQ, VAL, RME.

Rango altitudinal: $1100-2800 \mathrm{~m}$.

Alstroemeria parvula Phil.

Hierba. Perenne. Endémica.

Distribución: VAL, RME.

Rango altitudinal: 2200-2600 m.

Alstroemeria patagonica Phil.

Sinónimos: Alstroemeria nana Rendle, Alstroemeria patagonica Phil. fma. biflora Ravenna, Alstroemeria pygmaea auct. non Herb.

Hierba. Perenne. Nativa.

Distribución: AIS, MAG.

Rango altitudinal: 0-1300 m.

Países limítrofes: Argentina.

Alstroemeria pelegrina $\mathrm{L}$.

Sinónimos: Alstroemeria amoena Salisb., Alstroemeria pelegrina L. var. albescens Herb., Alstroemeria gayana Phil. var. humilis Phil.

Hierba. Perenne. Endémica.

Distribución: COQ, VAL.

Rango altitudinal: 0-100 m.

Alstroemeria philippii Baker var. albicans Muñoz-Schick

Hierba. Perenne. Endémica.

Distribución: ATA.

Rango altitudinal: 300-400 m.

\section{Alstroemeria philippii Baker var. philippii}

Hierba. Perenne. Endémica.

Distribución: ATA, COQ.

Alstroemeria piperata A.R. Flores \& J.M. Watson

Hierba. Perenne. Endémica.

Distribución: VAL.

Rango altitudinal: 1200-1500 m.

Alstroemeria polyphylla Phil.

Hierba. Perenne. Endémica.

Distribución: ATA.

Rango altitudinal: 800-900 m. 
Alstroemeria presliana Herb. subsp. australis Ehr. Bayer Hierba. Perenne. Endémica.

Distribución: MAU, NUB, BIO, ARA.

Rango altitudinal: 200-1500 m.

Alstroemeria presliana Herb. subsp. presliana

Sinónimos: Alstroemeria chillanensis Grau \& Ehr. Bayer, Alstroemeria diazii auct. non Phil., Alstroemeria epulauquensis Ravenna

Hierba. Perenne. Nativa.

Distribución: LBO, MAU, NUB, BIO, ARA.

Rango altitudinal: 1300-2300 m.

Países limítrofes: Argentina.

Alstroemeria pseudospathulata Ehr. Bayer

Sinónimos: Alstroemeria crocea Phil., Alstroemeria lacrima-solis Ravenna, Alstroemeria spathulata auct. non C. Presl, Alstroemeria oxyphylla Ravenna, nom. illeg.

Hierba. Perenne. Nativa.

Distribución: LBO, MAU.

Rango altitudinal: 500-1500 m.

Países limítrofes: Argentina.

Alstroemeria pulchra Sims subsp. lavandulacea Ehr. Bayer Hierba. Perenne. Endémica.

Distribución: BIO, ARA.

Rango altitudinal: 200-300 m.

Alstroemeria pulchra Sims subsp. pulchra var. maxima Phil. Sinónimos: Alstroemeria magnifica Herb. subsp. maxima (Phil.) Ehr. Bayer, Alstroemeria spectabilis Ravenna

Hierba. Perenne. Endémica.

Distribución: COQ, VAL, RME.

Rango altitudinal: 0-400 m.

Alstroemeria pulchra Sims subsp. pulchra var. pulchra Sinónimos: Alstroemeria ligtu L. var. pulchra (Sims) Baker, Alstroemeria tricolor Hook., Alstroemeria flos-martinii Ker Gawl., Alstroemeria bicolor Hook.

Hierba. Perenne. Endémica.

Distribución: COQ, VAL, RME, LBO, MAU.

Rango altitudinal: 0-1000 m.

Nombre vulgar: Flor del águila, flor del traro.

Alstroemeria revoluta Ruiz \& Pav.

Sinónimos: Alstroemeria herbertiana Roem., Alstroemeria reflexa Roem., Alstroemeria inconspicua Phil.

Hierba. Perenne. Endémica.

Distribución: VAL, RME, LBO, MAU, NUB, BIO, ARA.

Rango altitudinal: 0-2500 m.

Alstroemeria schizanthoides Grau var. alba Muñoz-Schick Sinónimos: Alstroemeria modesta Phil.

Hierba. Perenne. Endémica.

Distribución: COQ.
Alstroemeria schizanthoides Grau var. schizanthoides

Hierba. Perenne. Endémica.

Distribución: ATA, COQ.

Rango altitudinal: 800-1900 m.

Alstroemeria spathulata C. Presl

Hierba. Perenne. Endémica.

Distribución: COQ, VAL, RME, LBO.

Rango altitudinal: 2000-3500 m.

Alstroemeria traudliae J.M. Watson \& A.R. Flores

Hierba. Perenne. Endémica.

Distribución: COQ.

Rango altitudinal: 300-350 m.

\section{Alstroemeria umbellata Meyen}

Sinónimos: Alstroemeria sericantha Schauer

Hierba. Perenne. Endémica.

Distribución: RME, LBO.

Rango altitudinal: 2000-3000 m.

Alstroemeria versicolor Ruiz \& Pav.

Sinónimos: Alstroemeria meyeniana Schauer, Alstroemeria tigrina Phil., Alstroemeria sotoana Phil., Alstroemeria xanthina Phil.

Hierba. Perenne. Endémica.

Distribución: RME, LBO, MAU, NUB, BIO, ARA.

Rango altitudinal: 200-2000 m.

\section{Alstroemeria violacea Phil.}

Sinónimos: Alstroemeria paupercula Phil., Alstroemeria violacea Knight \& Perry, nom. nud.

Hierba. Perenne. Nativa.

Distribución: TAR, ANT, ATA, COQ, VAL.

Rango altitudinal: 0-800 $\mathrm{m}$.

Países limítrofes: Perú.

Nombre vulgar: Lirio del campo.

Alstroemeria werdermannii Ehr. Bayer var. flavicans Muñoz-Schick

Hierba. Perenne. Endémica.

Distribución: ATA, COQ.

Rango altitudinal: 0-100 m.

Alstroemeria werdermannii Ehr. Bayer var. werdermannii Hierba. Perenne. Endémica.

Distribución: ATA, COQ.

Rango altitudinal: 0-100 m.

Alstroemeria zoellneri Ehr. Bayer

Hierba. Perenne. Endémica.

Distribución: VAL, RME.

Rango altitudinal: 1100-1800 m. 
Bomarea

Bomarea dulcis (Hook.) Beauverd

Sinónimos: Bomarea engleriana auct. non Kraenzl., Alstroemeria dulcis Hook.

Hierba. Perenne. Nativa.

Distribución: AYP.

Rango altitudinal: 2500-5200 m.

Países limítrofes: Bolivia y Perú.

Bomarea involucrosa (Herb.) Baker

Sinónimos: Collania involucrosa Herb.

Hierba. Perenne. Nativa.

Distribución: AYP.

Rango altitudinal: 3500-3700 m.

Países limítrofes: Bolivia y Perú.

Bomarea salsilla (L.) Herb.

Sinónimos: Alstroemeria salsilla L., Alstroemeria oculata Lodd., Bomarea oculata (Lodd.) M. Roem.

Hierba. Perenne. Nativa.

Distribución: VAL, RME, LBO, MAU, NUB, BIO, ARA.

Rango altitudinal: 0-300 m.

Países limítrofes: Bolivia.

Nombre vulgar: Salsilla, zalcilla.

\section{Leontochir}

Leontochir ovallei Phil. var. luteus Muñoz-Schick

Hierba. Perenne. Endémica.

Distribución: ATA.

\section{Leontochir ovallei Phil. var. ovallei}

Sinónimos: Bomarea ovallei (Phil.) Ravenna, Alstroemeria ovallei (Phil.) Hunz.

Hierba. Perenne. Endémica.

Distribución: ATA.

Rango altitudinal: 0-100 m.

Nombre vulgar: Garra de león.

\section{AMARYLLIDACEAE}

\section{Allium}

Allium vineale L. var. compactum (Thuill.) Coss. \& Germ. Hierba. Perenne. Introducida.

Distribución: ARA.

Allium vineale $\mathrm{L}$. var. vineale Hierba. Perenne. Introducida. Distribución: ARA.
Amaryllis

Amaryllis belladona L.

Hierba. Perenne. Introducida.

Distribución: VAL, MAU, JFE.

\section{Clinanthus}

Clinanthus humilis (Herb.) Meerow

Sinónimos: Stenomesson humile (Herb.) Baker, Clitanthes

humilis Herb., Stenomesson chilense Ravenna

Hierba. Perenne. Nativa.

Distribución: TAR.

Rango altitudinal: 3000-4200 m.

Países limítrofes: Argentina y Bolivia.

\section{Famatina}

Famatina andina (Phil.) Ravenna

Sinónimos: Rhodophiala andina Phil., Hippeastrum andinum (Phil.) Phil., Bathya andina (Phil.) Ravenna

Hierba. Perenne. Nativa.

Distribución: VAL, RME, LBO, MAU.

Países limítrofes: Argentina.

Famatina cisandina Ravenna

Hierba. Perenne. Endémica.

Distribución: RME, MAU.

Rango altitudinal: 1800-2200 m.

Famatina maulensis Ravenna

Sinónimos: Miltinea maulensis (Ravenna) Ravenna

Hierba. Perenne. Endémica.

Distribución: MAU.

Rango altitudinal: $1500 \mathrm{~m}$.

\section{Gethyum}

Gethyum atropurpureum Phil.

Sinónimos: Solaria atropurpurea (Phil.) Ravenna, Solaria major Reiche

Hierba. Perenne. Endémica.

Distribución: VAL, RME, LBO, MAU.

Gethyum cuspidatum (Harv. ex Baker) Muñoz-Schick Sinónimos: Solaria cuspidata (Harv. ex Baker) Ravenna, Ancrumia cuspidata Harv. ex Baker

Hierba. Perenne. Endémica.

Distribución: COQ, VAL.

Rango altitudinal: 100-200 m. 


\section{Gilliesia}

Gilliesia dimera Ravenna

Hierba. Perenne. Endémica.

Distribución: MAU.

Gilliesia graminea Lindl.

Sinónimos: Gilliesia curicana Ravenna, Gilliesia gaudichaudiana Kunth

Hierba. Perenne. Nativa.

Distribución: COQ, VAL, RME, LBO, MAU.

Rango altitudinal: 0-900 m.

Países limítrofes: Argentina.

Gilliesia isopetala Ravenna

Hierba. Perenne. Endémica.

Distribución: LBO.

Rango altitudinal: 1000-1700 m.

Gilliesia montana Poepp. \& Endl.

Sinónimos: Gilliesia monophylla Reiche, Miersia scalae

Gunckel, Gilliesia nahuelbutae Ravenna

Hierba. Perenne. Endémica.

Distribución: MAU, NUB, BIO, ARA.

Rango altitudinal: 0-1000 m.

\section{Ipheion}

Ipheion sessile (Phil.) Traub

Sinónimos: Brodiaea sessiliflora (Baker) Baker, Brodiaea sessilis (Phil.) F. Meigen, Milla sessiliflora Baker, Triteleia sessilis Phil., Tristagma sessile (Phil.) Traub, Tristagma leichtlinii (Baker) Ravenna, Milla leichtlinii Baker, Brodiaea leichtlinii (Baker) Baker, Tristagma leichtlinii (Baker) Traub, Triteleia leichtlinii (Baker) G. Nicholson Hierba. Perenne. Nativa.

Distribución: RME, MAU.

Rango altitudinal: 0-500 m.

Países limítrofes: Argentina.

\section{Latace}

Latace andina (Poepp.) Sassone fma. andina Sinónimos: Zoellnerallium andinum (Poepp.) Crosa, Nothoscordum andinum (Poepp.) Fuentes, Nothoscordum bivalve auct. non (L.) Britton, Nothoscordum brevispathum Phil., Nothoscordum sellowianum Kunth var. brevispathum (Phil.) Fuentes, Nothoscordum strictum Gay, Ornithogalum andinum Poepp., Nothoscordum poeppigii Fuentes, Latace volkmanni Phil., Leucocoryne volkmanni (Phil.) Engl.

Hierba. Perenne. Nativa.

Distribución: VAL, RME, LBO, LLA.

Rango altitudinal: 1500-3500 m.

Países limítrofes: Argentina.
Latace andina (Poepp.) Sassone fma. lutea (Ravenna)

Sassone

Sinónimos: Nothoscordum andinum (Poepp.) Fuentes fma. luteum Ravenna

Hierba. Perenne. Nativa.

Distribución: VAL, RME.

Rango altitudinal: 1500-3000 m.

Países limítrofes: Argentina.

Latace serenense (Ravenna) Sassone

Sinónimos: Nothoscordum serenense Ravenna

Hierba. Perenne. Endémica.

Distribución: ATA, COQ.

Rango altitudinal: $300-500 \mathrm{~m}$.

\section{Leucocoryne}

Leucocoryne alliacea Miers ex Lindl.

Sinónimos: Leucocoryne angustipetala Gay, Leucocoryne reflexa Grau

Hierba. Perenne. Endémica.

Distribución: COQ, VAL, RME, LBO, MAU, NUB, BIO, ARA, LLA.

Rango altitudinal: 900-2200 m.

Leucocoryne angosturae Ravenna

Hierba. Perenne. Endémica.

Distribución: RME.

Leucocoryne appendiculata Phil.

Hierba. Perenne. Endémica.

Distribución: AYP, TAR, ANT, ATA.

Rango altitudinal: 400-800 m.

Leucocoryne arrayanensis Ravenna

Hierba. Perenne. Endémica.

Distribución: RME.

Rango altitudinal: 1700-2500 m.

Leucocoryne candida Ravenna

Hierba. Perenne. Endémica.

Distribución: LBO.

Rango altitudinal: 700-800 m.

Leucocoryne codehuensis Ravenna

Hierba. Perenne. Endémica.

Distribución: LBO.

Leucocoryne conconensis Ravenna

Hierba. Perenne. Endémica.

Distribución: VAL.

Rango altitudinal: 0-100 m. 
Leucocoryne conferta Zoellner

Hierba. Perenne. Endémica.

Distribución: COQ, VAL, LBO.

Rango altitudinal: 200-1200 m.

Leucocoryne connivens Phil.

Hierba. Perenne. Endémica.

Distribución: MAU.

Leucocoryne conostyla Ravenna

Hierba. Perenne. Endémica.

Distribución: COQ.

Leucocoryne coquimbensis F. Phil. var. alba Zoellner Hierba. Perenne. Endémica.

Distribución: COQ.

Leucocoryne coquimbensis F. Phil. var. coquimbensis Hierba. Perenne. Endémica.

Distribución: COQ, VAL.

\section{Leucocoryne coronata Ravenna}

Sinónimos: Leucocoryne narcissoides Phil., Pabellonia incrassata (Phil.) Quezada \& Martic., Stemmatium narcissoides Phil., Leucocoryne incrassata Phil., Chrysocoryne incrassata (Phil.) Zoellner

Hierba. Perenne. Endémica.

Distribución: ANT, ATA.

Leucocoryne curacavina Ravenna

Hierba. Perenne. Endémica.

Distribución: RME.

Leucocoryne dimorphopetala (Gay) Ravenna

Sinónimos: Tristagma dimorphopetala Gay, Leucocoryne gayii Baker

Hierba. Perenne. Endémica.

Distribución: ATA, COQ.

Leucocoryne editiana Ravenna

Hierba. Perenne. Endémica.

Distribución: COQ.

Rango altitudinal: $2200 \mathrm{~m}$.

Leucocoryne foetida Phil.

Sinónimos: Leucocoryne odorata Lindl.

Hierba. Perenne. Endémica.

Distribución: VAL, MAU.

Leucocoryne fragrantissima Ravenna

Hierba. Perenne. Endémica.

Distribución: RME.

Rango altitudinal: $1500 \mathrm{~m}$.
Leucocoryne fuscostriata Ravenna

Hierba. Perenne. Endémica.

Distribución: COQ.

Leucocoryne gilliesioides (Phil.) Ravenna

Sinónimos: Erinna gilliesioides Phil.

Hierba. Perenne. Endémica.

Distribución: RME.

Rango altitudinal: 1400-1600 m.

Leucocoryne inclinata Ravenna

Hierba. Perenne. Endémica.

Distribución: COQ.

Rango altitudinal: 800-1000 m.

Leucocoryne ixioides (Hook.) Lindl.

Sinónimos: Leucocoryne pauciflora Phil., Brodiaea ixioides

Hook.

Hierba. Perenne. Endémica.

Distribución: COQ, VAL, RME, LBO, MAU, NUB, BIO, ARA.

Rango altitudinal: 800-1100 m.

Leucocoryne leucogyna Ravenna

Hierba. Perenne. Endémica.

Distribución: VAL.

Leucocoryne lilacea Ravenna

Hierba. Perenne. Endémica.

Distribución: COQ, VAL.

Leucocoryne lurida Ravenna

Hierba. Perenne. Endémica.

Distribución: COQ.

Leucocoryne macropetala Phil.

Sinónimos: Pabellonia oxypetala (Phil.) Quezada \& Martic., Leucocoryne oxypetala Phil., Chrysocoryne oxypetala (Phil.) Zoellner

Hierba. Perenne. Endémica.

Distribución: ATA, COQ.

Rango altitudinal: $800 \mathrm{~m}$.

Leucocoryne maulensis Ravenna

Hierba. Perenne. Endémica.

Distribución: MAU.

Leucocoryne modesta Ravenna

Hierba. Perenne. Endémica.

Distribución: VAL.

Rango altitudinal: $1300 \mathrm{~m}$.

Leucocoryne mollensis Ravenna

Hierba. Perenne. Endémica. 
Distribución: COQ, VAL.

Rango altitudinal: 0-500 m.

Leucocoryne montana Phil. Hierba. Perenne. Endémica.

Distribución: VAL.

Leucocoryne pachystyla Ravenna

Hierba. Perenne. Endémica.

Distribución: VAL.

Leucocoryne porphyrea Ravenna

Hierba. Perenne. Endémica.

Distribución: COQ.

Rango altitudinal: 800-1500 m.

Leucocoryne praealta Ravenna

Hierba. Perenne. Endémica.

Distribución: VAL.

Rango altitudinal: 1000-1200 m.

\section{Leucocoryne purpurea Gay}

Sinónimos: Leucocoryne ixioides (Hook.) Lindl. var. purpurea (Gay) Baker

Hierba. Perenne. Endémica.

Distribución: ATA, COQ, VAL.

Leucocoryne quilimarina Ravenna

Hierba. Perenne. Endémica.

Distribución: COQ.

Rango altitudinal: 0-100 m.

Leucocoryne rungensis Ravenna

Hierba. Perenne. Endémica.

Distribución: RME.

Rango altitudinal: 900-1100 m.

\section{Leucocoryne simulans Ravenna}

Hierba. Perenne. Endémica.

Distribución: COQ.

Rango altitudinal: 1800-2000 m.

Leucocoryne subulata Ravenna

Hierba. Perenne. Endémica.

Distribución: RME.

Rango altitudinal: $2000 \mathrm{~m}$.

Leucocoryne taguataguensis Ravenna

Hierba. Perenne. Endémica.

Distribución: LBO.

Leucocoryne talinensis L. Mansur \& M. Cisternas Hierba. Perenne. Endémica.

Distribución: COQ.
Rango altitudinal: 200-300 m.

Leucocoryne tricornis Ravenna

Hierba. Perenne. Endémica.

Distribución: RME.

Rango altitudinal: $2000 \mathrm{~m}$.

Leucocoryne ungulifera Ravenna

Hierba. Perenne. Endémica.

Distribución: LBO.

Leucocoryne valparadisea Ravenna

Hierba. Perenne. Endémica.

Distribución: VAL.

Leucocoryne violacescens Phil.

Hierba. Perenne. Endémica.

Distribución: COQ, VAL, RME.

Leucocoryne vittata Ravenna

Hierba. Perenne. Endémica.

Distribución: COQ, VAL.

\section{Leucojum}

Leucojum vernum $\mathrm{L}$.

Hierba. Anual. Introducida.

Distribución: JFE.

\section{Miersia}

Miersia chilensis Lindl.

Sinónimos: Miersia major Kunth, Miersia rusbyi Britton, Miersia chilensis Lindl. var. bicolor Muñoz-Schick Hierba. Perenne. Endémica.

Distribución: COQ, VAL, RME, LBO, MAU, ARA.

Rango altitudinal: 0-200 m.

Miersia cornuta Phil.

Hierba. Perenne. Endémica.

Distribución: COQ, VAL.

Rango altitudinal: 700-900 m.

Miersia leporina Ravenna

Hierba. Perenne. Endémica.

Distribución: COQ, VAL, RME.

Rango altitudinal: $800 \mathrm{~m}$.

Miersia minor Kunth

Sinónimos: Miersia myodes Bertero

Hierba. Perenne. Endémica.

Distribución: RME, LBO, NUB, BIO, ARA.

Rango altitudinal: 220-600 m. 
Miersia tenuiseta Ravenna

Sinónimos: Miersia tenuiseta Ravenna fma. castanea Ravenna

Hierba. Perenne. Endémica.

Distribución: VAL, RME.

Rango altitudinal: 0-1000 m.

\section{Myostemma}

Myostemma advena (Ker Gawl.) Ravenna

Sinónimos: Amaryllis advena Ker Gawl., Hippeastrum hesperidius Herb. var. pallidum Herb., Hippeastrum pallidum (Herb.) Pax, Hippeastrum advenum (Ker Gawl.) Herb., Habranthus pallidus Lodd., Habenaria miniatus D. Don ex Sweet, Habranthus hesperius Herb., Amaryllis valparadisiaca Steud., Chlidanthus cumingii C. Presl, Rhodophiala advena (Ker Gawl.) Traub

Hierba. Perenne. Endémica.

Distribución: COQ, VAL, RME, NUB.

Rango altitudinal: $1400 \mathrm{~m}$.

Nombre vulgar: Añañuca.

Myostemma ananuca (Phil.) J.M. Watson \& A.R. Flores

Sinónimos: Hippeastrum ananuca Phil., Amaryllis ananuca (Phil.) Traub \& Moldenke, Rhodophiala ananuca (Phil.) Traub

Hierba. Perenne. Endémica.

Distribución: ANT, ATA, COQ.

Rango altitudinal: 0-500 m.

Nombre vulgar: Añañuca.

Myostemma araucana (Phil.) Ravenna

Sinónimos: Amaryllis araucana (Phil.) Traub \& Uphof, Hippeastrum araucanum Phil., Rhodophiala araucana (Phil.) Traub

Hierba. Perenne. Endémica.

Distribución: MAU, NUB, BIO, ARA.

Rango altitudinal: 900-1500 m.

Nombre vulgar: Añañuca.

Myostemma bagnoldii (Herb.) J.M. Watson \& A.R. Flores Sinónimos: Habranthus bagnoldii Herb., Hippeastrum bagnoldii (Herb.) Baker, Hippeastrum bagnoldii (Herb.) Baker var. minor Speg., Amaryllis bagnoldi (Herb.) D. Dietr., Rhodophiala bagnoldii (Herb.) Traub

Hierba. Perenne. Endémica.

Distribución: ANT, ATA, COQ.

Rango altitudinal: 0-600 m.

Nombre vulgar: Añañuca.

Myostemma berteroana (Phil.) Ravenna

Sinónimos: Hippeastrum berteroanum (Phil.) Baker, Amaryllis berteroana (Phil.) Traub \& Moldenke, Habranthus berteroanus Phil., Rhodophiala berteroana (Phil.) Traub
Hierba. Perenne. Endémica.

Distribución: LBO.

Nombre vulgar: Añañuca.

Myostemma maculata (L'Hér.) Ravenna

Sinónimos: Amaryllis maculata L'Hér., Rhodophiala maculata (L'Hér.) Ravenna

Hierba. Perenne. Endémica.

Distribución: ARA.

Rango altitudinal: 0-300 m.

Nombre vulgar: Añañuca.

Myostemma monantha Ravenna

Hierba. Perenne. Endémica.

Distribución: LBO, MAU.

Myostemma montana (Phil.) Ravenna

Sinónimos: Hippeastrum montanum (Phil.) Baker, Amaryllis montana (Phil.) Traub \& Uphof, Habranthus montanus Phil., Rhodophiala montana (Phil.) Traub

Hierba. Perenne. Endémica.

Distribución: MAU, ARA.

Nombre vulgar: Añañuca.

Myostemma phycelloides (Herb.) Ravenna

Sinónimos: Amaryllis phycelloides (Herb.) Steud., Habranthus phycelloides Herb., Hippeastrum phycelloides (Herb.) Baker, Phycella phycelloides (Herb.) Traub, Rhodophiala phycelloides (Herb.) Hunz.

Hierba. Perenne. Endémica.

Distribución: ATA, COQ, RME, MAU.

Rango altitudinal: 0-2200 m.

Nombre vulgar: Añañuca.

Myostemma tiltilensis (Traub \& Moldenke) Ravenna

Sinónimos: Hippeastrum laetum Phil., Amaryllis tiltilensis Traub \& Moldenke, Amaryllis laeta (Phil.) Traub \& Uphof, Rhodophiala tiltilensis (Traub \& Moldenke) Traub

Hierba. Perenne. Endémica.

Distribución: VAL, RME.

Nombre vulgar: Añañuca.

\section{Nothoscordum}

Nothoscordum flavescens Kunth

Hierba. Perenne. Endémica.

Distribución: VAL.

Nothoscordum gracile (Dryand. ex Aiton) Stearn

Sinónimos: Allium gracile Aiton, Maligia gracilis (Aiton)

Raf.

Hierba. Perenne. Nativa.

Distribución: COQ, VAL, RME, LBO, BIO, LLA.

Países limítrofes: Argentina y Bolivia. 
Nothoscordum gramineum (Sims) Beauverd

Sinónimos: Nothoscordum striatellum (Lindl.) Kunth, Ornithogalum gramineum Sims, Allium striatellum Lindl.

Hierba. Perenne. Nativa.

Distribución: VAL, RME, LBO, NUB, BIO, ARA, LRI.

Rango altitudinal: 0-500 m.

Países limítrofes: Argentina.

\section{Nothoscordum mahui Traub}

Hierba. Perenne. Endémica.

Distribución: RME.

Rango altitudinal: 300-400 m.

Nothoscordum nidulans Phil.

Hierba. Perenne. Endémica.

Distribución: RME.

Nothoscordum nublense Ravenna

Hierba. Perenne. Endémica.

Distribución: MAU, NUB, BIO, ARA, LLA.

\section{Phycella}

Phycella angustifolia Phil.

Sinónimos: Hippeastrum angustifolium (Phil.) Phil., comb. illeg., Amaryllis philippiana Traub \& Uphof

Hierba. Perenne. Endémica.

Distribución: VAL, RME.

Phycella australis Ravenna

Hierba. Perenne. Endémica.

Distribución: LBO, MAU, NUB, BIO.

Rango altitudinal: 0-500 $\mathrm{m}$.

Nombre vulgar: Amancay.

Phycella cyrtanthoides (Sims) Lindl.

Sinónimos: Hippeastrum igneum (Lindl.) Muñoz, Phycella

magnifica Herb., Amaryllis ignea Lindl., Amaryllis cyrtanthoides Sims, Amaryllis demissa Steud.

Hierba. Perenne. Endémica.

Distribución: COQ, VAL, RME, LBO, MAU, NUB, BIO, ARA.

Rango altitudinal: 1000-1500 m.

Phycella gayana (Kuntze) Traub

Sinónimos: Hippeastrum gayanum Kuntze, Amaryllis gayana (Kuntze) Traub \& Uphof

Hierba. Perenne. Endémica.

Distribución: RME.

\section{Phycella scarlatina Ravenna}

Hierba. Perenne. Endémica.

Distribución: COQ, RME.

Rango altitudinal: $2000 \mathrm{~m}$.
Placea

Placea amoena Phil.

Hierba. Perenne. Endémica.

Distribución: COQ, RME.

Rango altitudinal: 800-2000 m.

Placea arzae Phil.

Sinónimos: Placea germainii Phil. subsp. arzae (Phil.)

Ravenna

Hierba. Perenne. Endémica.

Distribución: VAL, RME, LBO.

Rango altitudinal: 300-2000 m.

Nombre vulgar: Macaya.

Placea davidii Ravenna

Hierba. Perenne. Endémica.

Distribución: RME.

Placea lutea Phil.

Sinónimos: Placea germainii Phil. subsp. lutea (Phil.)

Ravenna

Hierba. Perenne. Endémica.

Distribución: VAL.

Placea ornata Miers ex Lindl.

Sinónimos: Placea germainii Phil., Placea grandiflora

Lem.

Hierba. Perenne. Endémica.

Distribución: VAL, RME.

Rango altitudinal: 900-1700 m.

Nombre vulgar: Lagañosa.

\section{Pyrolirion}

Pyrolirion tubiflorum (L'Hér.) M. Roem.

Hierba. Perenne. Introducida.

Distribución: TAR.

\section{Rhodolirium}

Rhodolirium andicola (Poepp.) Ravenna

Sinónimos: Amaryllis andicola Poepp., Amaryllis purpurata (Phil.) Traub \& Uphof, Habranthus andicola (Poepp.) Herb., Hippeastrum andicola (Poepp.) Baker, Hippeastrum purpuratum Phil., Rhodophiala purpurata (Phil.) Traub, Zephyranthes andicola (Poepp.) Baker, Rhodophiala andicola (Poepp.) Traub

Hierba. Perenne. Nativa.

Distribución: MAU, NUB, BIO, ARA, LLA.

Rango altitudinal: $1200-1800 \mathrm{~m}$.

Países limítrofes: Argentina. 
Rhodolirium chilense (L'Hér.) Ravenna

Sinónimos: Amaryllis chilensis L'Hér., Hippeastrum chilense (L'Hér.) Baker, Habranthus chilensis (L'Hér.) Herb., Rhodophiala chilensis (L'Hér.) Traub, Rhodolirium speciosum (Herb.) Ravenna

Hierba. Perenne. Endémica.

Distribución: BIO.

Rango altitudinal: 0-100 m.

Rhodolirium fulgens (Hook. f.) Ravenna

Sinónimos: Hippeastrum fulgens (Hook. f.) Phil., Amaryllis fulgens (Hook. f.) Traub \& Uphof, Habranthus fulgens Hook. f., Rhodophiala fulgens (Hook. f.) Traub

Hierba. Perenne. Endémica.

Distribución: LLA.

Rhodolirium laetum (Phil.) Ravenna

Sinónimos: Rhodophiala laeta Phil., Rhodophiala uniflora Phil., Hippeastrum uniflorum (Phil.) Baker, Amaryllis uniflora (Phil.) Traub \& Uphof

Hierba. Perenne. Endémica.

Distribución: ANT, ATA.

Rango altitudinal: $1000 \mathrm{~m}$.

Rhodolirium montanum Phil.

Sinónimos: Amaryllis rhodolirion (Baker) Traub \& Uphof, Hippeastrum rhodolirion (Phil.) Baker, Rhodolirium andinum Phil., Rhodophiala rhodolirion (Baker) Traub, Amaryllis popetana (Phil.) Traub \& Uphof, Hippeastrum popetanum Phil., Rhodophiala popetana (Phil.) Traub

Hierba. Perenne. Nativa.

Distribución: RME, LBO, MAU.

Rango altitudinal: 2000-2700 m.

Países limítrofes: Argentina.

\section{Rhodophiala}

Rhodophiala bakeri (Phil.) Traub

Sinónimos: Amaryllis backeri (Phil.) Traub \& Moldenke, Habranthus bakeri Phil., Hippeastrum bakeri (Phil.) Traub \& Uphof, Amaryllis bakeri (Phil.) Traub \& Uphof

Hierba. Perenne. Endémica.

Distribución: MAU, ARA.

\section{Rhodophiala flava (Phil.) Traub}

Sinónimos: Hippeastrum solisii Phil., Amaryllis solisii (Phil.) Traub \& Uphof, Habranthus flavus Phil., Amaryllis flava (Phil.) Traub \& Uphof

Hierba. Perenne. Endémica.

Distribución: MAU, NUB.

Rhodophiala lineata (Phil.) Traub

Sinónimos: Hippeastrum lineatum (Phil.) Baker, Amaryllis lineata (Phil.) Traub \& Uphof, hom. illeg., Habranthus lineatus Phil.

Hierba. Perenne. Endémica.

Distribución: RME.

Rhodophiala moelleri (Phil.) Traub

Sinónimos: Hippeastrum moelleri Phil., Amaryllis moelleri

(Phil.) Traub \& Moldenke, Myostemma cautinensis Ravenna

Hierba. Perenne. Endémica.

Distribución: ARA.

Rango altitudinal: 900-1000 m.

Rhodophiala pratensis (Poepp.) Traub

Sinónimos: Amaryllis pratensis Poepp., Hippeastrum pratense (Poepp.) Baker, Rhodophiala speciosa (Herb.) Baker, Amaryllis atacamensis Traub \& Uphof, Habranthus speciosus Herb., Habranthus pratensis (Poepp.) Herb., Rhodophiala volckmannii Phil., Placea pratensis F. Phil., nom. nud., Rhodolirium speciosum (Herb.) Ravenna, Myostemma pratensis (Poepp.) Ravenna

Hierba. Perenne. Endémica.

Distribución: ANT, ATA, COQ, MAU, NUB, BIO, LLA.

Rango altitudinal: 0-200 m.

Rhodophiala rosea (Sweet) Traub

Sinónimos: Hippeastrum roseum (Sweet) Baker, Amaryllis barlowii Traub \& Moldenke, Habranthus roseus Sweet, Amaryllis rosea (Sweet) Traub \& Uphof, Zephyranthes purpurea Phil.

Hierba. Perenne. Endémica.

Distribución: LBO, MAU, NUB, BIO, ARA.

Rhodophiala splendens (Renjifo) Traub

Sinónimos: Hippeastrum splendens (Renjifo) Renjifo ex Phil., Amaryllis splendens (Renjifo) Traub \& Moldenke, Habranthus splendens Renjifo

Hierba. Perenne. Endémica.

Distribución: MAU.

\section{Solaria}

Solaria miersioides Phil.

Sinónimos: Solaria brevicoalita Ravenna

Hierba. Perenne. Nativa.

Distribución: COQ, RME, MAU, NUB.

Rango altitudinal: 900-2300 m.

Países limítrofes: Argentina.

\section{Speea}

Speea humilis (Phil.) Loes. ex E.H.L. Krause

Sinónimos: Speea triloba Ravenna

Hierba. Perenne. Endémica.

Distribución: VAL, RME, LBO. 


\section{Traubia}

Traubia modesta (Phil.) Ravenna

Sinónimos: Hippeastrum modestum (Phil.) Baker, Lapiedra chilensis F. Phil., Amaryllis modesta (Phil.) Traub \& Uphof, Traubia chilensis (F. Phil.) Moldenke, Rhodophiala modesta Phil.

Hierba. Perenne. Endémica.

Distribución: COQ, VAL, LBO.

Rango altitudinal: 0-100 m.

\section{Tristagma}

Tristagma ameghinoi (Speg.) Speg.

Sinónimos: Brodiaea ameghinoi Speg.

Hierba. Perenne. Nativa.

Distribución: MAU, AIS, MAG.

Rango altitudinal: 500-1500 m.

Países limítrofes: Argentina.

Tristagma berteroi (Kunth) S. Arroyo \& Sassone

Sinónimos: Brodiaea berteri (Kunth) Fuentes

Hierba. Perenne. Endémica.

Distribución: VAL.

Tristagma bivalve (Hook. ex Lindl.) Traub

Sinónimos: Triteleia bivalvis Hook. ex Lindley, Milla bivalvis (Lindl.) Baker, Hookera bivalvis (Hook. ex Lindl.)

Kuntze, Brodiaea bivalvis (Hook. ex Lindl.) Meigen, Ipheion bivalve (Hook. ex Lindl.) Traub, Tristagma brevipes (Kuntze) Traub, Triteleia brevipes Kuntze, Milla brevipes (Kuntze) Baker, Brodiaea brevipes (Kuntze) Baker, Hookera brevipes (Kuntze) Kuntze, Ipheion brevipes (Kuntze) Traub

Hierba. Perenne. Endémica.

Distribución: ATA, COQ, VAL, RME, LBO, MAU, NUB, BIO, ARA.

Rango altitudinal: 0-200 m.

Tristagma circinatum (Sandw.) Traub

Sinónimos: Brodiaea circinata Sandwith

Hierba. Perenne. Nativa.

Distribución: LBO.

Países limítrofes: Argentina.

Tristagma gracile (Phil.) Traub

Sinónimos: Triteleia gracilis Phil., Brodiaea philippiana Baker, Ipheion gracile (Phil.) Traub

Hierba. Perenne. Endémica.

Distribución: ARA.

Tristagma graminifolium (Phil.) Ravenna

Sinónimos: Garaventia graminifolia (Phil.) Looser, Nothoscordum graminifolium (Phil.) Traub, Steinmannia graminifolia F. Phil.

Hierba. Perenne. Endémica.

Distribución: VAL, RME.

Rango altitudinal: 600-700 m.

Tristagma nivale Poepp. fma. australe (Neger ex Dusén)

Ravenna

Sinónimos: Tristagma australe Neger ex Dusén

Hierba. Perenne. Nativa.

Distribución: MAG.

Rango altitudinal: 0-1000 m.

Países limítrofes: Argentina.

Tristagma nivale Poepp. fma. nivale

Sinónimos: Milla nivalis (Poepp.) Baker, Tristagma philippii Gandoger, Tristagma fragrans Ravenna

Hierba. Perenne. Nativa.

Distribución: COQ, VAL, RME, LBO, NUB, BIO, ARA, MAG.

Rango altitudinal: 300-3200 m.

Países limítrofes: Argentina.

Tristagma patagonicum (Baker) Traub

Sinónimos: Brodiaea patagonica (Baker) Baker, Milla patagonica Baker

Hierba. Perenne. Nativa.

Distribución: AIS.

Rango altitudinal: 0-2000 m.

Países limítrofes: Argentina.

Tristagma poeppigianum (Gay) Traub

Sinónimos: Triteleia poeppigiana Gay

Hierba. Perenne. Endémica.

Distribución: RME.

Rango altitudinal: $2400 \mathrm{~m}$.

Tristagma porrifolium (Poepp.) Traub

Sinónimos: Triteleia porrifolia Poeppig, Milla porrifolia (Poepp.) Baker, Brodiaea porrifolia (Poepp.) Meigen, Hookera porrifolia (Poepp.) Kuntze, Ipheion porrifolium (Poepp.) Traub

Hierba. Perenne. Endémica.

Distribución: VAL.

Tristagma violaceum (Kunth) Traub

Sinónimos: Triteleia violacea Kunth, Brodiaea violacea (Kunth) Baker, Ipheion violaceum (Kunth) Traub

Hierba. Perenne. Endémica.

Distribución: NUB. 


\section{APONOGETONACEAE}

Aponogeton

Aponogeton distachyos L.f.

Hierba. Perenne. Introducida.

Distribución: LLA.

\section{ARACEAE}

\section{Colocasia}

Colocasia esculenta (L.) Schott

Hierba. Perenne. Introducida.

Distribución: IPA.

Nombre vulgar: Taro (Rapa Nui).

\section{Landoltia}

Landoltia punctata (G. Mey.) Les \& D.J. Crawford Hierba acuática. Perenne. Introducida.

Distribución: MAG.

\section{Lemna}

\section{Lemna gibba L.}

Sinónimos: Lemna parodiana Giardelli

Hierba acuática. Anual. Nativa.

Distribución: TAR, ANT, COQ, VAL, RME, LBO, BIO, LLA.

Países limítrofes: Argentina, Bolivia y Perú.

\section{Lemna minuta Kunth}

Sinónimos: Lemna minima Kunth, nom. nud., Lemna minima Phil. ex Hegelm., hom. illeg., Lemna minuscula Herter, nom. illeg., Lemna valdiviana Phil. var. abbreviata Hegelm., Lemna valdiviana Phil. var. minima Hegelm. Hierba acuática. Perenne. Nativa.

Distribución: AYP, TAR, ANT, COQ, VAL, RME, LBO, MAU, NUB, BIO, ARA, LLA.

Países limítrofes: Argentina y Bolivia.

Nombre vulgar: Lenteja de agua.

Lemna valdiviana Phil.

Sinónimos: Lemna valdiviana Phil. var. platyclados Hegelm., Lemna valdiviana Phil. var. pellucida Hegelm., Lemna valdiviana Phil. var. robusta Hegelm.

Hierba acuática. Perenne. Nativa.

Distribución: TAR, VAL, RME, MAU, ARA, LLA.

Países limítrofes: Argentina, Bolivia y Perú.

Nombre vulgar: Lenteja de agua.

\section{Pistia}

Pistia stratiotes L.

Hierba acuática. Perenne. Introducida.

Distribución: VAL.

\section{Spirodela}

Spirodela intermedia W. Koch

Hierba acuática. Perenne. Nativa.

Distribución: VAL.

Países limítrofes: Argentina, Bolivia y Perú.

\section{Wolffia}

Wolffia brasiliensis Wedd.

Sinónimos: Wolffia papulifera C.H. Thomps., Wolffia punctata Griseb.

Hierba acuática. Perenne. Nativa.

Distribución: NUB.

Países limítrofes: Argentina y Bolivia.

Nombre vulgar: Lenteja de agua.

\section{Wolffiella}

Wolffiella oblonga (Phil.) Hegelm. Sinónimos: Lemna oblonga Phil., Wolffia oblonga (Phil.) Hegelm., Wolffia lingulata Hegelm. var. minor Hegelm. Hierba acuática. Perenne. Nativa.

Distribución: VAL, RME, MAU.

Países limítrofes: Argentina, Bolivia y Perú.

Nombre vulgar: Lenteja de agua.

\section{Zantedeschia}

Zantedeschia aethiopica (L.) Spreng.

Hierba. Perenne. Introducida.

Distribución: VAL, RME, LLA, JFE.

\author{
ARECACEAE \\ Juania \\ Juania australis (Mart.) Drude ex Hook. f. \\ Sinónimos: Ceroxylon australe Mart., Nunnezharia chonta \\ (Phil.) Kuntze, Morenia chonta Phil. \\ Árbol. Endémico. \\ Distribución: JFE. \\ Rango altitudinal: 200-800 m. \\ Nombre vulgar: Chonta, palma chonta.
}


Jubaea

Jubaea chilensis (Molina) Baill.

Sinónimos: Palma chilensis Molina, Cocos chilensis (Molina) Kunth, Micrococos chilensis (Molina) Phil., Jubaea spectabilis Kunth, Molinaea micrococos Bertero

Árbol. Endémico.

Distribución: COQ, VAL, RME, LBO, MAU.

Rango altitudinal: $300 \mathrm{~m}$.

Nombre vulgar: Palma Chilena.

\section{ASPARAGACEAE}

\section{Cordyline}

Cordyline terminalis (L.) Kunth

Arbusto. Introducido.

Distribución: IPA.

Nombre vulgar: Ti (Rapa Nui).

\section{Herreria}

Herreria stellata Ruiz \& Pav.

Sinónimos: Herreria verticillata Molina

Hierba trepadora. Perenne. Endémica.

Distribución: MAU, BIO, LLA.

Rango altitudinal: 0-700 m.

Nombre vulgar: Zarza.

\section{Oziroë}

Ozirö̈ acaulis (Baker) Speta

Sinónimos: Scilla acualis Baker

Hierba. Perenne. Nativa.

Distribución: AYP.

Rango altitudinal: 3000-4000 m.

Países limítrofes: Argentina y Bolivia.

Ozirö̈ arida (Poepp.) Speta

Sinónimos: Fortunatia arida (Poepp.) Ravenna, Ozirö̈ arida (Poepp.) Ravenna, Ornithogalum aridum Poepp., Ornithogalum chloroleucum Lindl., Scilla chloroleuca (Lindl.) Kunth, Ornithogalum chilense Phil., Ornithogalum biflorum (Ruiz \& Pav.) D. Don var. chloroleucum (Lindl.) Baker, Ozirö̈ chloroleuca (Poepp.) Speta

Hierba. Perenne. Endémica.

Distribución: COQ, VAL, RME, LBO, MAU, NUB, BIO, ARA.

Rango altitudinal: 0-200 m.

Ozirö̈ biflora (Ruiz \& Pav.) Speta

Sinónimos: Fortunatia biflora (Ruiz \& Pav.) J.F. Macbr., Camassia biflora (Ruiz \& Pav.) Cocucci, Scilla biflora Ruiz
\& Pav., Scilla triflora Phil., Ornithogalum biflorum (Ruiz \&

Pav.) D. Don

Hierba. Perenne. Nativa.

Distribución: TAR, ANT, ATA, COQ, VAL, RME, LBO.

Rango altitudinal: 0-900 m.

Países limítrofes: Bolivia.

Nombre vulgar: Lágrima de la virgen.

Ozirö̈ pomensis Ravenna

Sinónimos: Oziroë totorensis Ravenna

Hierba. Perenne. Nativa.

Distribución: TAR.

Rango altitudinal: 1800-3600 m.

Países limítrofes: Argentina y Bolivia.

\section{Trichopetalum}

Trichopetalum plumosum (Ruiz \& Pav.) J.F. Macbr. Sinónimos: Trichopetalum stellatum Lindl., Trichopetalum gracile Lindl., Anthericum plumosum Ruiz \& Pav., Bottionea thysanotoides Colla, Endocoma peruviana Raf., Endocoma parviflora Raf.

Hierba. Perenne. Endémica.

Distribución: COQ, VAL, RME, LBO, MAU, NUB, BIO, ARA.

Rango altitudinal: 0-1500 m.

Nombre vulgar: Flor de la plumilla.

\section{ASPHODELACEAE}

\section{Asphodelus}

Asphodelus fistulosus L.

Hierba. Perenne. Introducida.

Distribución: AYP, ATA.

\section{Pasithea}

Pasithea caerulea (Ruiz \& Pav.) D. Don

Sinónimos: Pasithea caerulea (Ruiz \& Pav.) D. Don var. grandiflora I.M. Johnst., Anthericum caeruleum Ruiz \& Pav.

Hierba. Perenne. Nativa.

Distribución: ANT, ATA, COQ, VAL, RME, LBO, MAU, NUB, BIO, ARA, LLA.

Rango altitudinal: 0-1000 m.

Países limítrofes: Perú.

Nombre vulgar: Flor del queltehue, azulillo. 


\section{ASTELIACEAE}

\section{Astelia}

Astelia pumila (G. Forst.) Gaudich.

Sinónimos: Astelia pumila (G. Forst.) R. Br., comb. illeg., Melanthium pumilum $\mathrm{G}$. Forst.

Hierba. Perenne. Nativa.

Distribución: LRI, LLA, AIS, MAG.

Rango altitudinal: 0-600 m.

Países limítrofes: Argentina.

\section{BROMELIACEAE}

\section{Deuterocohnia}

Deuterocohnia chrysantha (Phil.) Mez

Sinónimos: Pitcairnia chrysantha Phil.

Hierba. Perenne. Endémica.

Distribución: ANT, ATA.

Rango altitudinal: 0-800 m.

Nombre vulgar: Chagual del jote.

\section{Fascicularia}

Fascicularia bicolor (Ruiz \& Pav.) Mez subsp. bicolor Sinónimos: Fascicularia micrantha (Phil.) Mez, Fascicularia parviflora Mez, Bromelia bicolor Ruiz \& Pav., Billbergia bicolor (Ruiz \& Pav.) Schult. f., Rhodostachys bicolor (Ruiz \& Pav.) Benth. ex Hook. f. ex Baker, Rhodostachys micrantha Phil., Bromelia joinvillei E. Morren

Hierba epífita o terrestre. Perenne. Endémica.

Distribución: VAL, LBO, MAU, NUB, BIO, ARA, LRI, LLA, AIS.

Rango altitudinal: $600 \mathrm{~m}$.

Nombre vulgar: Chupalla.

Fascicularia bicolor (Ruiz \& Pav.) Mez subsp. canaliculata E.C. Nelson \& Zizka

Sinónimos: Fascicularia kirchhoffiana (Wittm.) Mez, Bromelia albobracteata Steud. ex Lechl., nom. nud., Rhodostachys albo-bracteata (Steud. ex Baker) Baker, Rhodostachys pitcairniifolia (B. Verl.) Benth. var. kirchoffiana Wittm.

Hierba epífita o terrestre. Perenne. Endémica.

Distribución: MAU, NUB, BIO, ARA, LRI, LLA, AIS.

Rango altitudinal: 0-100 m.

Nombre vulgar: Puñeñe.

\section{Greigia}

Greigia berteroi Skottsb.
Sinónimos: Hesperogreigia berteroi (Skottsb.) Skottsb.

Hierba. Perenne. Endémica.

Distribución: JFE.

Rango altitudinal: 600-700 m.

Greigia landbeckii (Lechl. ex Phil.) Phil. ex F. Phil.

Sinónimos: Bromelia landbeckii Lechl. ex Phil.

Hierba. Perenne. Endémica.

Distribución: BIO, LRI, LLA.

Rango altitudinal: 0-600 m.

Nombre vulgar: Nocha.

\section{Greigia pearcei Mez}

Hierba. Perenne. Endémica.

Distribución: BIO, LRI, LLA.

Rango altitudinal: 100-400 m.

Greigia sphacelata (Ruiz \& Pav.) Regel

Sinónimos: Billbergia sphacelata (Ruiz \& Pav.) Schult. f., Bromelia discolor Lindl., Bromelia crassa Steud., nom. nud., Bromelia clandestina Carrière, nom. nud., Bromelia sphacelata Ruiz \& Pav.

Hierba. Perenne. Endémica.

Distribución: MAU, NUB, BIO, ARA, LLA.

Rango altitudinal: 0-500 m.

Nombre vulgar: Chupón.

\section{Ochagavia}

Ochagavia andina (Phil.) Zizka, Trumpler \& Zoellner

Sinónimos: Rhodostachys andina Phil.

Hierba. Perenne. Endémica.

Distribución: LBO, MAU, NUB.

Rango altitudinal: $700-2500 \mathrm{~m}$.

Ochagavia carnea (Beer) L.B. Sm. \& Looser

Sinónimos: Ochagavia chamissonis (Mez) L.B. Sm. \& Looser, Rhodostachys chamissonis Mez, Bromelia longifolia auct. non Rudge, Bromelia lindleyana Lem., nom. illeg., Bromelia carnea Beer, Rhodostachys grandiflora Phil., Ruckia ellemeti Regel, Pourretia argentea Wittm., nom. nud., Rhodostachys carnea (Beer) Mez, Ochagavia grandiflora (Phil.) Mez

Hierba. Perenne. Endémica.

Distribución: VAL, LBO, MAU, NUB, BIO, ARA.

Rango altitudinal: 0-1100 m.

Nombre vulgar: Cardoncillo.

Ochagavia elegans Phil.

Sinónimos: Rhodostachys elegans (Phil.) Mez

Hierba. Perenne. Endémica.

Distribución: JFE.

Rango altitudinal: 0-600 m. Nombre vulgar: Chupón. 
Ochagavia litoralis (Phil.) Zizka, Trumpler \& Zoellner Sinónimos: Fascicularia litoralis (Phil.) Mez, Ochagavia lindleyana Mez, Placseptalia rebecae Espinosa, Fascicularia pitcairniifolia (B. Verl.) Mez, Hechtia pitcairniifolia B. Verl., Bromelia pitcairniifolia (B. Verl.) K. Koch, Rhodostachys pitcairniifolia (B. Verl.) Benth., Hechtia carnea Wittm., nom. nud., Rhodostachys litoralis Phil.

Hierba. Perenne. Endémica.

Distribución: COQ, VAL, LBO.

Rango altitudinal: 0-300 m.

Puya

Puya alpestris (Poepp.) Gay subsp. alpestris

Sinónimos: Pourretia alpestris Poepp., Puya whytei Hook. f., Puya pumila Ravenna, Pitcairnia coerulea auct. non Benth.

Hierba. Perenne. Endémica.

Distribución: COQ, VAL, RME, LBO, MAU, NUB, BIO, ARA.

Rango altitudinal: 1500-2000 m.

Puya alpestris (Poepp.) Gay subsp. zoellneri Zizka

Sinónimos: Puya coerulea auct. non Lindl., Puya whytei auct. non Hook.f., Pitcairnia alpestris L.H. Bailey, Puya berteroniana auct. non Mez

Hierba. Perenne. Endémica.

Distribución: COQ, VAL, RME, LBO, MAU.

\section{Puya berteroniana $\mathrm{Mez}$}

Sinónimos: Pitcairnia alpestris L.H. Bailey, nom. nud.

Hierba. Perenne. Endémica.

Distribución: COQ, VAL, RME, LBO.

Rango altitudinal: 0-2000 m.

Nombre vulgar: Chagual.

Nota: Según Zizka et al. (2013) esta especie sería un híbrido (Puya $x$ berteroniana Mez).

Puya boliviensis Baker

Sinónimos: Puya copiapina Phil.

Hierba. Perenne. Endémica.

Distribución: ANT, ATA.

Rango altitudinal: 1500-2500 m.

\section{Puya chilensis Molina}

Sinónimos: Puya quillotana W. Weber, Pourretia coarctata

Ruiz \& Pav., Pitcairnia chilensis Lodd., Puya suberosa

Molina, Puya gigantea Phil., Puya chilensis Molina var.

gigantea Baker ex Mez

Hierba. Perenne. Endémica.

Distribución: COQ, VAL, RME, LBO, BIO.

Rango altitudinal: 1000-2500 m.

Nombre vulgar: Puya.
Puya coerulea Lindl. var. coerulea

Sinónimos: Pourretia caerulea Miers, nom. nud., Pitcairnia coerulea (Lindl) Benth., Pitcairnia coerulea auct. non Benth., Puya violacea auct. non Mez

Hierba. Perenne. Endémica.

Distribución: COQ, VAL, RME, LBO.

Rango altitudinal: 500-2000 m.

Nombre vulgar: Chagualillo.

Puya coerulea Lindl. var. intermedia (L.B. Sm. \& Looser) L.B. Sm. \& Looser

Sinónimos: Puya paniculata Phil., Puya glabrata Phil. ex

Baker

Hierba. Perenne. Endémica.

Distribución: VAL, RME, LBO, MAU.

Rango altitudinal: 400-700 m.

Puya coerulea Lindl. var. monteroana (L.B. Sm. \& Looser) L.B. Sm. \& Looser

Sinónimos: Puya violacea (Brongn.) Mez var. monteroana L.B. Sm. \& Looser

Hierba. Perenne. Endémica.

Distribución: LBO.

Rango altitudinal: 1500-2500 m.

Puya coerulea Lindl. var. violacea (Brongn.) L.B. Sm. \& Looser

Sinónimos: Puya rubricaulis Steud., Pourretia rubricaulis

Miers, Pitcairnia violacea Brongn., Pourretia violacea

Linden, Puya violacea (Brongn.) Mez

Hierba. Perenne. Endémica.

Distribución: VAL, LBO, MAU.

Rango altitudinal: 400-1200 m.

Nombre vulgar: Chagual chico.

Puya gilmartiniae G.S. Varad. \& A.R. Flores

Hierba. Perenne. Endémica.

Distribución: COQ.

Rango altitudinal: 1500-2500 m.

Puya pumila Ravenna

Hierba. Perenne. Endémica.

Distribución: BIO.

Puya venusta Phil.

Sinónimos: Pitcairnia venusta (Phil.) Baker, Pitcairnia sphaerocephala Baker, Puya coquimbensis Mez, Puya gaudichaudii $\mathrm{Mez}$

Hierba. Perenne. Endémica.

Distribución: COQ, VAL.

Rango altitudinal: 1000-1500 m.

Nombre vulgar: Chagual. 


\section{Tillandsia}

Tillandsia geissei Phil.

Hierba epífita. Perenne. Endémica.

Distribución: ANT, ATA, COQ.

Rango altitudinal: 200-600 m.

Tillandsia landbeckii Phil.

Hierba epífita. Perenne. Nativa.

Distribución: AYP, TAR, ANT, ATA, COQ.

Rango altitudinal: 300-1500 m.

Países limítrofes: Perú.

Nombre vulgar: Calachunca.

Tillandsia marconae W. Till \& Vitek

Hierba epífita. Perenne. Nativa.

Distribución: AYP, TAR.

Rango altitudinal: 600-800 m.

Países limítrofes: Perú.

Tillandsia tragophoba M.O. Dillon

Hierba epífita. Perenne. Endémica.

Distribución: ANT.

Rango altitudinal: 200-500 m.

Tillandsia usneoides (L.) L.

Sinónimos: Renealmia usneoides L., Tillandsia usneoides (L.) L. var. ferruginea (André) Mez, Tillandsia usneoides (L.) L. fma. cretacea Mez, Tillandsia usneoides (L.) L. fma. ferruginea André

Hierba epífita. Perenne. Nativa.

Distribución: COQ, VAL, RME, MAU, NUB, BIO, ARA, LLA.

Rango altitudinal: 0-3300 m.

Países limítrofes: Argentina y Perú.

Nombre vulgar: Barbón, barbas de viejo.

Tillandsia virescens Ruiz \& Pav.

Sinónimos: Tillandsia capillaris Ruiz \& Pav. fma. virescens (Ruiz \& Pav.) L.B. Sm., Tillandsia propinqua Gay, Diaphoranthema virescens (Ruiz \& Pav.) Beer, Tillandsia stolpi Phil.

Hierba epífita. Perenne. Nativa.

Distribución: AYP, TAR, ATA, COQ, VAL, LBO.

Rango altitudinal: 450-4000 m.

Países limítrofes: Argentina, Bolivia y Perú.

Nombre vulgar: Calachunca.

\section{BUTOMACEAE}

Hydrocleys

Hydrocleys nymphoides (Willd.) Buchenau

Hierba acuática. Perenne. Introducida.

Distribución: VAL.

\section{COMMELINACEAE}

\section{Commelina}

Commelina diffusa Burm. f.

Hierba. Perenne. Introducida.

Distribución: IPA.

Commelina erecta L.

Hierba. Perenne. Introducida.

Distribución: ANT, COQ, RME.

\section{Tradescantia}

Tradescantia fluminensis Vell. Hierba. Perenne. Introducida.

Distribución: LRI, JFE.

\section{CORSIACEAE}

\section{Arachnitis}

Arachnitis uniflora Phil.

Hierba. Perenne. Nativa.

Distribución: RME, LBO, MAU, NUB, BIO, ARA, LRI, LLA, AIS, MAG.

Rango altitudinal: 0-1500 m.

Países limítrofes: Argentina.

Nombre vulgar: Flor de la araña.

\section{CYPERACEAE}

Amphiscirpus

Amphiscirpus nevadensis (S. Watson) Oteng-Yeb.

Sinónimos: Schoenoplectus nevadensis (S. Watson) Soják, Scirpus nevadensis S. Watson, Scirpus nevadensis S. Watson var. remireoides (Griseb.) Beetle, Scirpus remireoides Griseb., Isolepis oreophila Phil.

Hierba. Perenne. Nativa.

Distribución: MAG.

Rango altitudinal: 0-4000 m.

Países limítrofes: Argentina. 


\section{Bolboschoenus}

Bolboschoenus maritimus (L.) Palla

Hierba. Perenne. Introducida.

Distribución: LLA.

\section{Carex}

Carex acaulis d'Urv.

Hierba. Perenne. Nativa.

Distribución: MAG.

Rango altitudinal: 0-1000 m.

Países limítrofes: Argentina.

Carex acutata Boott

Sinónimos: Carex anwandteri Phil., Carex foeminea Steud. Hierba. Perenne. Endémica.

Distribución: ATA, VAL, MAU, NUB, BIO, ARA, LRI, LLA, AIS, MAG.

Rango altitudinal: 0-1100 m.

Carex aematorhyncha E. Desv. var. aematorhyncha

Sinónimos: Carex filiformis L. subsp. aematorrhyncha (E. Desv.) Kük.

Hierba. Perenne. Nativa.

Distribución: MAU, NUB, BIO, ARA, LLA, AIS, MAG.

Rango altitudinal: 0-1200 m.

Países limítrofes: Argentina.

Carex aematorhyncha E. Desv. var. corralensis (Phil.) Kük.

Sinónimos: Carex corralensis Phil., Carex filiforme auct. non Gooden.

Hierba. Perenne. Nativa.

Distribución: ARA, LRI, LLA, AIS, MAG.

Rango altitudinal: 0-900 m.

Países limítrofes: Argentina.

\section{Carex andersonii Boott}

Sinónimos: Carex eleopsammodes Steud.

Hierba. Perenne. Nativa.

Distribución: ARA, LLA, AIS, MAG.

Rango altitudinal: 0-900 m.

Países limítrofes: Argentina.

Carex andina Phil.

Hierba. Perenne. Nativa.

Distribución: COQ, VAL, RME, LBO, MAU, NUB, BIO,

ARA, LLA, AIS, MAG.

Rango altitudinal: 1200-3300 m.

Países limítrofes: Argentina.

Carex aphylla Kunth

Sinónimos: Carex ebracteata Phil.

Hierba. Perenne. Nativa.
Distribución: COQ, VAL, RME, LBO, MAU, NUB, BIO, ARA, LLA.

Rango altitudinal: 700-2700 m.

Países limítrofes: Argentina.

Carex araucana Phil.

Hierba. Perenne. Endémica.

Distribución: COQ, RME, LBO, MAU, NUB, BIO, ARA, LLA, AIS.

Carex argentina Barros

Hierba. Perenne. Nativa.

Distribución: RME, MAU.

Rango altitudinal: 1000-2600 m.

Países limítrofes: Argentina.

Carex atropicta Steud.

Sinónimos: Carex lechleri Phil., hom. illeg., Carex leporina auct. non L., p.p., Carex pampae Kalela, p.p., Carex peraltae Phil., Carex fuegina Phil.

Hierba. Perenne. Nativa.

Distribución: ATA, COQ, VAL, RME, AIS, MAG.

Rango altitudinal: 0-2500 m.

Países limítrofes: Argentina.

Carex austroamericana G.A. Wheeler

Sinónimos: Carex andina Phil. var. subabscondita Kük., p.p., Carex andina Phil. var. subabscondita auct. non Kük.

Hierba. Perenne. Nativa.

Distribución: MAG.

Rango altitudinal: 0-800 m.

Países limítrofes: Argentina.

Carex banksii Boott var. banksii

Sinónimos: Carex germana Boott, Carex trifida Franch., hom. illeg., Carex trifida Cav. var. franchetii Kurtz

Hierba. Perenne. Nativa.

Distribución: VAL, RME, LBO, MAU, NUB, BIO, ARA, LRI, LLA, AIS, MAG.

Rango altitudinal: 0-1900 m.

Países limítrofes: Argentina.

Carex banksii Boott var. fonkii (Phil.) Kük.

Sinónimos: Carex fonkii Phil.

Hierba. Perenne. Nativa.

Distribución: MAG.

Rango altitudinal: 0-1000 m.

Países limítrofes: Argentina.

Carex banksii Boott var. gilliesii (Phil.) Kük.

Sinónimos: Carex dessaueri Phil., Carex gilliesii Phil.

Hierba. Perenne. Endémica.

Distribución: RME.

Rango altitudinal: 2000-3000 m. 
Carex berteroana E. Desv.

Sinónimos: Carex setifolia Kunze ex Kunth var. pungens (Boeck.) Kük., Carex setifolia Kunze ex Kunth var. berteroana (E. Desv.) Gunckel, Carex pungens Boeck., Carex setifolia Kunze ex Kunth var. colchaguensis (Phil.) Kük., Carex colchaguensis Phil., Carex moelleri Phil. Hierba. Perenne. Endémica. Distribución: COQ, VAL, RME, LBO, MAU, NUB, BIO, ARA.

Rango altitudinal: 0-1500 m.

Carex berteroniana Steud.

Sinónimos: Carex paleata Boott

Hierba. Perenne. Endémica.

Distribución: JFE.

Rango altitudinal: 0-700 m.

Carex bonariensis Desf. ex Poir.

Hierba. Perenne. Nativa.

Distribución: VAL, BIO, ARA.

Rango altitudinal: 0-200 m.

Países limítrofes: Argentina, Bolivia y Perú.

Carex bracteosa Kunze ex Kunth

Hierba. Perenne. Endémica.

Distribución: VAL, RME, LBO, NUB, BIO, ARA, LRI.

Rango altitudinal: 0-800 m.

\section{Carex brongniartii Kunth}

Sinónimos: Carex hypoxanthus Steud.

Hierba. Perenne. Nativa.

Distribución: LBO, MAU, NUB, BIO, ARA, LLA.

Rango altitudinal: 0-700 m.

Países limítrofes: Argentina.

Carex caduca Boott

Sinónimos: Carex ortegae Phil., Carex caduca Boott var. ortegae (Phil.) Kük.

Hierba. Perenne. Nativa.

Distribución: LLA, AIS, MAG.

Rango altitudinal: 0-1500 m.

Países limítrofes: Argentina.

Carex camptoglochin V.I. Krecz.

Hierba. Perenne. Nativa.

Distribución: LLA, AIS, MAG.

Rango altitudinal: 0-500 m.

Países limítrofes: Argentina.

\section{Carex canescens L.}

Hierba. Perenne. Introducida.

Distribución: ARA, LRI, LLA, AIS, MAG.

Carex capitata $\mathrm{L}$.

Hierba. Perenne. Nativa.
Distribución: MAG.

Rango altitudinal: 0-1000 m.

Países limítrofes: Argentina.

Carex catamarcensis C.B. Clarke ex Kük.

Sinónimos: Carex latibracteolata Kük.

Hierba. Perenne. Nativa.

Distribución: COQ.

Rango altitudinal: 500-1000 m.

Países limítrofes: Argentina.

Carex chilensis Brongn. ex Duperrey

Sinónimos: Carex riparia Curtis var. chilensis (Brongn. ex Duperrey) Kük., Carex riparia Curtis subsp. chilensis (Brongn. ex Duperrey) Kük., Carex vacillans Steud.

Hierba. Perenne. Nativa.

Distribución: BIO, ARA, LRI, LLA, AIS.

Rango altitudinal: 0-500 m.

Países limítrofes: Argentina.

Carex chillanensis Phil.

Sinónimos: Carex melanolepis Phil.

Hierba. Perenne. Nativa.

Distribución: VAL, RME, MAU, NUB, BIO, AIS, MAG.

Rango altitudinal: 0-3500 m.

Países limítrofes: Argentina.

Carex darwinii Boott var. darwinii

Sinónimos: Carex incompta Franch.

Hierba. Perenne. Nativa.

Distribución: ARA, LRI, LLA, AIS, MAG.

Rango altitudinal: 0-1500 m.

Países limítrofes: Argentina.

Carex darwinii Boott var. serranoi (Phil.) Kük.

Sinónimos: Carex darwinii Boott var. robustior Kük., Carex serranoi Phil.

Hierba. Perenne. Endémica.

Distribución: LLA, AIS, MAG.

Rango altitudinal: 0-1500 m.

Carex darwinii Boott var. urolepis (Franch.) Kük.

Sinónimos: Carex darwinii Boott var. aristata C.B. Clarke ex Kük., Carex urolepis Franch.

Hierba. Perenne. Nativa.

Distribución: LLA, AIS, MAG.

Rango altitudinal: 0-200 $\mathrm{m}$.

Países limítrofes: Argentina.

Carex decidua Boott

Sinónimos: Carex decidua Boott var. minor Kük., Carex pedicellata Phil., Carex rahmeri Phil., Carex vulgaris R.E.

Fr. var. antucensis Kük.

Hierba. Perenne. Nativa.

Distribución: RME, LBO, MAU, NUB, BIO, ARA, LLA, 
AIS, MAG.

Rango altitudinal: 0-2400 m.

Países limítrofes: Argentina.

Carex distenta Kunze ex Kunth

Sinónimos: Carex fuscula d'Urv. var. distenta (Kuntze ex Kunth) Kük., Carex huitensis Steud., Carex indecora auct. non Kunth, Carex pseudopunctata Boeck.

Hierba. Perenne. Nativa.

Distribución: VAL, LBO, MAU, BIO, LLA, AIS, MAG.

Rango altitudinal: 0-700 m.

Países limítrofes: Argentina.

Carex excelsa Poepp. ex Kunth

Sinónimos: Carex lechleri Steud., Carex pseudocyperus L. subsp. haenkeana auct. non (J. Presl \& C. Presl) Kük., Carex pseudocyperus L. var. haenkeana (J. Presl \& C. Presl) Kük., Carex pseudocyperus L. var. lechleri Boott, Carex psilostachys Steud.

Hierba. Perenne. Nativa.

Distribución: COQ, VAL, RME, LBO, MAU, NUB, BIO, ARA, LLA, AIS.

Rango altitudinal: 0-1000 m.

Países limítrofes: Argentina.

Nombre vulgar: Cortadera.

Carex fernandezensis Mack. ex G.A. Wheeler

Hierba. Perenne. Endémica.

Distribución: JFE.

Rango altitudinal: 300-600 m.

Carex firmicaulis Kalela

Sinónimos: Carex andicola G.A. Wheeler, Carex nebularum Phil. fma. major (Kük.) Kük., Carex pycnostachya Kar. \& Kir. var. major Kük.

Hierba. Perenne. Nativa.

Distribución: COQ, LBO.

Rango altitudinal: 100-1300 m.

Países limítrofes: Argentina.

Carex fuscula d'Urv. var. fuscula fma. fuscula

Sinónimos: Carex hieronymi Boeck., Carex calbucana Phil., Carex fuscula d'Urv. var. hieronymi (Boeck.) Kük., Carex inconspicua Steud. var. fuscula (d'Urv.) Kük., Carex indecora Kunth var. humilis Kunth, Carex riparia auct. non Curtis, Carex valdiviana Phil., Carex fuscula d'Urv. f. elatior Kurtz

Hierba. Perenne. Nativa.

Distribución: COQ, RME, LBO, BIO, ARA, LRI, LLA, AIS, MAG.

Rango altitudinal: 0-1500 m.

Países limítrofes: Argentina.
Carex fuscula d'Urv. var. fuscula fma. indecora (Kunth)

Kük.

Sinónimos: Carex indecora Kunth

Hierba. Perenne. Nativa.

Distribución: LLA.

Países limítrofes: Argentina.

Carex fuscula d'Urv. var. pseudextensa Kük.

Hierba. Perenne. Endémica.

Distribución: LLA.

Carex gayana E. Desv. var. densa Kük.

Hierba. Perenne. Nativa.

Distribución: ATA, LBO, MAU, MAG.

Rango altitudinal: 0-3500 m.

Países limítrofes: Argentina y Perú.

Carex gayana E. Desv. var. gayana

Sinónimos: Carex nitens Phil.

Hierba. Perenne. Nativa.

Distribución: ANT, ATA, COQ, VAL, RME, LBO, MAU, NUB, BIO, ARA, AIS, MAG.

Rango altitudinal: 0-3500 m.

Países limítrofes: Argentina.

Carex gayana E. Desv. var. rufa Kük.

Sinónimos: Carex gayana E. Desv. var. taurina (Phil.)

Kük., Carex taurina Phil.

Hierba. Perenne. Nativa.

Distribución: COQ, VAL, RME.

Rango altitudinal: 500-2300 m.

Países limítrofes: Argentina.

Carex gayana E. Desv. var. schedonautos (Steud.) Kük.

Sinónimos: Carex schedonautos Steud.

Hierba. Perenne. Nativa.

Distribución: MAG.

Países limítrofes: Argentina.

Carex hookeri Kunth

Sinónimos: Carex beecheyana Boott ex E. Desv.

Hierba. Perenne. Endémica.

Distribución: VAL, RME, LBO, LLA.

Carex hypoleucos E. Desv.

Sinónimos: Carex nebularum Phil. var. kurtziana (Kük.)

Kük., Carex kurtziana Kük.

Hierba. Perenne. Nativa.

Distribución: RME, MAU, NUB, BIO, ARA, MAG.

Rango altitudinal: $1500-2300 \mathrm{~m}$.

Países limítrofes: Argentina. 
Carex inconspicua Steud.

Hierba. Perenne. Nativa.

Distribución: LBO, MAU, NUB, BIO, ARA, LRI, LLA.

Rango altitudinal: 0-2800 m.

Países limítrofes: Argentina.

Carex kingii (Boott) Reznicek

Sinónimos: Uncinia kingii Boott

Hierba. Perenne. Nativa.

Distribución: AIS, MAG.

Rango altitudinal: 700-1000 m.

Países limítrofes: Argentina.

Carex lamprocarpa Phil.

Hierba. Perenne. Endémica.

Distribución: BIO, ARA, LLA.

Rango altitudinal: 500-1000 m.

\section{Carex lateriflora Phil.}

Sinónimos: Carex involucrata Steud. ex Lechl., nom. nud., Carex trichodes Steud. ex Boott var. lateriflora (Phil.) Kük., Carex trichodes Steud. ex Boott var. major Kük., Carex reicheana Boeck.

Hierba. Perenne. Nativa.

Distribución: MAU, NUB, BIO, ARA, LLA.

Rango altitudinal: 1000-1500 m.

Países limítrofes: Argentina.

\section{Carex macloviana d'Urv. var. macloviana}

Sinónimos: Carex festiva Dewey, Carex inciso-dentata Steud., Carex ovalis auct. non Gooden., Carex propinqua Nees \& Meyen, Carex allomacros Steud., Carex macloviana d'Urv. fma. bracteata Kük., Carex pratensis Phil., hom. illeg. Hierba. Perenne. Nativa.

Distribución: COQ, VAL, RME, LBO, MAU, NUB, BIO, ARA, LRI, LLA, AIS, MAG.

Rango altitudinal: 0-3800 m.

Países limítrofes: Argentina.

Carex macloviana d'Urv. var. pseudoleporina Kük.

Sinónimos: Carex leporina auct. non L., p.p., Carex leporina L. var. elatior Boeck., Carex leucocarpa Phil.

Hierba. Perenne. Nativa.

Distribución: MAU, NUB, BIO, ARA, LRI, LLA, MAG.

Rango altitudinal: 0-1000 m.

Países limítrofes: Argentina.

Carex macloviana d'Urv. var. thermarum (Phil.) Kük.

Sinónimos: Carex macloviana d'Urv. var. incrassata Kük., Carex thermarum Phil.

Hierba. Perenne. Nativa.

Distribución: VAL, RME, MAU, NUB, BIO.

Rango altitudinal: 1000-2000 m.

Países limítrofes: Argentina.
Carex macrorrhiza Boeck.

Sinónimos: Carex macrorrhiza Boeck. var. simplex Kük., Carex bonplandii auct. non Kunth, Carex curvifolia Boeck., Carex hypoleucos auct. non E. Desv.

Hierba. Perenne. Nativa.

Distribución: TAR, RME.

Rango altitudinal: 2000-4200 m.

Países limítrofes: Argentina y Bolivia.

Carex macrosolen Steud.

Sinónimos: Carex macrocarpa Phil.

Hierba. Perenne. Nativa.

Distribución: MAG.

Rango altitudinal: 0-900 m.

Países limítrofes: Argentina.

Carex magellanica Lam.

Sinónimos: Carex atrata L. var. magellanica (Lam.)

Wahlenb., Carex cernua Phil., hom. illeg.

Hierba. Perenne. Nativa.

Distribución: LBO, MAU, NUB, BIO, ARA, LRI, LLA, AIS, MAG.

Rango altitudinal: 0-2200 m.

Países limítrofes: Argentina.

Carex malmei Kalela

Sinónimos: Carex atropicta Steud. var. platycarpa Phil. ex Kük.

Hierba. Perenne. Nativa.

Distribución: ATA, COQ, RME.

Rango altitudinal: 2600-4000 m

Países limítrofes: Argentina.

Carex maritima Gunnerus

Sinónimos: Carex incurva Lightf. var. misera (Phil.) Kük., Carex melanocystis E. Desv., Carex melanocystis E. Desv. var. misera (Phil.) Kük., Carex misera Phil.

Hierba. Perenne. Nativa.

Distribución: TAR, ANT, ATA, COQ, VAL, MAG.

Rango altitudinal: 200-4200 m.

Países limítrofes: Argentina y Bolivia.

Carex microglochin Wahlenb.

Hierba. Perenne. Nativa.

Distribución: ATA, COQ, AIS, MAG.

Rango altitudinal: 200-4100 m.

Países limítrofes: Argentina, Bolivia y Perú.

Carex minutissima Barros

Hierba. Perenne. Nativa.

Distribución: AIS, MAG.

Rango altitudinal: 500-1700 m.

Países limítrofes: Argentina. 
Carex molinae Phil.

Hierba. Perenne. Endémica.

Distribución: MAU.

Rango altitudinal: 2200-2400 m.

Carex moorei G.A. Wheeler

Hierba. Perenne. Nativa.

Distribución: MAG.

Rango altitudinal: 600-800 m.

Países limítrofes: Argentina.

Carex multispicata Kunze ex Kunth

Sinónimos: Carex acutata Boott var. multispicata (Kunze ex Kunth) Kük.

Hierba. Perenne. Endémica.

Distribución: BIO.

\section{Carex nebularum Phil.}

Sinónimos: Carex propinqua auct. non Nees \& Meyen, Carex pycnostachya auct. non Kar. \& Kir.

Hierba. Perenne. Nativa.

Distribución: RME, MAU, NUB, AIS.

Rango altitudinal: 1000-2200 m.

Países limítrofes: Argentina.

Carex ochrostachya Phil.

Hierba. Perenne. Endémica.

Distribución: MAU.

\section{Carex odontolepis Phil.}

Sinónimos: Carex banksii Boott var. odontolepis (Phil.)

Kük., Carex promaucana Phil.

Hierba. Perenne. Nativa.

Distribución: VAL, RME, LBO, NUB, ARA.

Rango altitudinal: $100-2300 \mathrm{~m}$.

Países limítrofes: Argentina.

Carex phalaroides Kunth

Sinónimos: Carex chlorolepis Steud., Carex schenkiana

Boeck., Uncinia phalaroides (Kunth) Nees

Hierba. Perenne. Nativa.

Distribución: VAL, BIO, ARA, LLA, JFE.

Rango altitudinal: 0-300 m.

Países limítrofes: Argentina y Bolivia.

Carex pisanoi G.A. Wheeler

Hierba. Perenne. Endémica.

Distribución: MAG.

Rango altitudinal: 0-500 m.

Carex pleioneura G.A. Wheeler

Hierba. Perenne. Nativa.

Distribución: AYP, TAR, COQ, RME.

Rango altitudinal: 1900-3400 m.

Países limítrofes: Argentina.
Carex poeppigii C.B. Clarke ex G.A. Wheeler

Sinónimos: Carex lamprocarpa Phil. var. rotundata Kük.

Hierba. Perenne. Endémica.

Distribución: BIO.

Carex pumila Thunb.

Hierba. Perenne. Introducida.

Distribución: LBO, MAU, BIO, LLA, AIS, MAG.

Carex reichei Kük.

Sinónimos: Carex aueri Kalela

Hierba. Perenne. Nativa.

Distribución: MAU, MAG.

Rango altitudinal: 0-2500 m.

Países limítrofes: Argentina.

Carex sagei Phil.

Sinónimos: Carex barrosii Nelmes, Carex flava L. subsp.

brevirostrata Kük.

Hierba. Perenne. Nativa.

Distribución: ARA, LLA, MAG.

Rango altitudinal: 0-500 $\mathrm{m}$.

Países limítrofes: Argentina.

Carex setifolia Kunze ex Kunth

Sinónimos: Carex pissisii Phil.

Hierba. Perenne. Nativa.

Distribución: COQ, VAL, RME, LBO, MAU.

Países limítrofes: Perú.

Carex sorianoi Barros

Hierba. Perenne. Nativa.

Distribución: MAG.

Rango altitudinal: 100-800 m.

Países limítrofes: Argentina.

Carex stuessyi G.A. Wheeler

Hierba. Perenne. Endémica.

Distribución: JFE.

Rango altitudinal: 900-1400 m.

Carex subantarctica Speg.

Sinónimos: Carex chubutensis C.B. Clarke

Hierba. Perenne. Nativa.

Distribución: AIS, MAG.

Rango altitudinal: 0-800 m.

Países limítrofes: Argentina.

Carex toroensis G.A. Wheeler

Hierba. Perenne. Endémica.

Distribución: MAG.

Rango altitudinal: 0-100 m. 
Carex trachycystis Griseb.

Sinónimos: Carex sororia auct. non Kunth

Hierba. Perenne. Nativa.

Distribución: BIO.

Rango altitudinal: 0-500 m.

Países limítrofes: Argentina.

Carex transandina G.A. Wheeler

Hierba. Perenne. Endémica.

Distribución: MAG.

Rango altitudinal: 300-600 m.

Carex trichodes Steud. ex Boott

Hierba. Perenne. Endémica.

Distribución: LLA.

Carex trifida Cav.

Sinónimos: Carex aristata auct. non R. Br.

Hierba. Perenne. Nativa.

Distribución: AIS, MAG.

Rango altitudinal: 0-500 m.

Países limítrofes: Argentina.

Carex vallis-pulchrae Phil. var. barrosiana G.A. Wheeler Hierba. Perenne. Nativa.

Distribución: MAG.

Rango altitudinal: 0-300 m.

Países limítrofes: Argentina.

Carex vallis-pulchrae Phil. var. vallis-pulchrae

Sinónimos: Carex castellanosii Barros

Hierba. Perenne. Nativa.

Distribución: ATA, COQ, RME, LBO, MAG.

Rango altitudinal: 2000-3800 m.

Países limítrofes: Argentina.

Carex werdermannii Gross

Hierba. Perenne. Endémica.

Distribución: LRI.

Rango altitudinal: $1000 \mathrm{~m}$.

\section{Carpha}

Carpha schoenoides Banks \& Sol. ex Hook. f.

Sinónimos: Carpha alpina R. Br. var. schoenoides (Banks \&

Sol. ex Hook. f.) Kük., Carpha viridis Phil.

Hierba. Perenne. Nativa.

Distribución: LLA, AIS, MAG.

Rango altitudinal: 0-800 m.

Países limítrofes: Argentina.

\section{Cyperus}

Cyperus aggregatus (Willd.) Endl.
Sinónimos: Cyperus flavomariscus Griseb., Didymia cyperomorpha Phil., Mariscus aggregatus Willd.

Hierba. Perenne. Nativa.

Distribución: BIO.

Rango altitudinal: 0-1000 m.

Países limítrofes: Argentina, Bolivia y Perú.

Cyperus brevifolius (Rottb.) Endl. ex Hassk.

Sinónimos: Kyllinga brevifolia Rottb.

Hierba. Perenne. Nativa.

Distribución: IPA.

Países limítrofes: Argentina.

Nombre vulgar: Hikukio’e (Rapa Nui).

Cyperus cyperoides (L.) Kuntze

Hierba. Perenne. Nativa.

Distribución: IPA.

Nombre vulgar: Hikukio’e (Rapa Nui).

Cyperus difformis L.

Hierba. Perenne. Introducida.

Distribución: LBO, MAU, NUB, BIO.

Cyperus eragrostis Lam. var. compactus (E. Desv.) Kük.

Sinónimos: Cyperus lutescens Phil., hom. illeg., Cyperus vegetus Willd. var. compactus E. Desv., Cyperus vegetus Willd. var. trigonus Kuntze

Hierba. Perenne. Nativa.

Distribución: ATA, COQ, VAL, RME, LBO, MAU, NUB, BIO, ARA, LRI, LLA, JFE, IPA.

Rango altitudinal: 0-200 m.

Países limítrofes: Argentina.

Nombre vulgar: Hikukio’e (Rapa Nui).

Cyperus eragrostis Lam. var. eragrostis

Sinónimos: Cyperus declinatus Moench, Cyperus vegetus

Willd., Cyperus eragrostis Lam. fma. latifrons Kük.

Hierba. Perenne. Nativa.

Distribución: ATA, COQ, VAL, RME, LBO, MAU, NUB, BIO, ARA, LLA, JFE.

Rango altitudinal: 0-2400 m.

Países limítrofes: Argentina, Bolivia y Perú.

Cyperus fraternus Kunth

Sinónimos: Cyperus reflexus Vahl var. fraternus (Kunth)

Kuntze

Hierba. Perenne. Nativa.

Distribución: MAU, NUB, BIO, ARA, LRI, LLA.

Países limítrofes: Argentina.

Cyperus grammicus Kunze ex Kunth

Sinónimos: Pycreus grammicus (Kunze ex Kunth) C.B. Clarke, Cyperus parvulus Steud.

Hierba. Perenne. Endémica. 
Distribución: MAU, NUB, BIO, ARA, LLA.

Rango altitudinal: 0-1000 m.

Cyperus involucratus Rott.

Hierba. Perenne. Introducida.

Distribución: ANT, RME, MAU, LLA.

\section{Cyperus laevigatus L.}

Hierba. Perenne. Introducida.

Distribución: AYP, TAR, ANT, COQ, MAU.

Rango altitudinal: 0-1000 m.

Cyperus lanceolatus Poir.

Sinónimos: Cyperus lepidus Phil.

Hierba. Perenne. Nativa.

Distribución: MAU.

Rango altitudinal: 0-1200 m.

Países limítrofes: Argentina y Bolivia.

Cyperus megapotamicus Kunth var. jaeggii (Boeck.) Kük. ex Barros

Sinónimos: Pycreus megapotamicus (Kunth) Nees var. jaeggii (Boeck.) Guagl., Cyperus jaeggii Boeck.

Hierba. Perenne. Nativa.

Distribución: NUB, BIO.

Rango altitudinal: 0-300 m.

Países limítrofes: Argentina y Bolivia.

Cyperus odoratus L.

Sinónimos: Cyperus flexuosus Vahl, Torulinium odoratum (L.) Hooper

Hierba. Perenne. Introducida.

Distribución: LBO, MAU, LRI.

Rango altitudinal: 0-1000 m.

\section{Cyperus poeppigii Kunth}

Sinónimos: Torulinium poeppigii (Kunth) C.B. Clarke

Hierba. Perenne. Endémica.

Distribución: RME, LBO.

Rango altitudinal: 0-100 m.

Cyperus polystachyos Rottb.

Hierba. Anual o perenne. Introducida.

Distribución: IPA.

Nombre vulgar: Hikukio'e (Rapa Nui).

\section{Cyperus reflexus Vahl}

Sinónimos: Cyperus haematostachys Steud.

Hierba. Perenne. Nativa.

Distribución: VAL, RME, LBO, MAU, NUB, BIO, ARA, LRI, LLA, JFE.

Rango altitudinal: 0-2200 m.

Países limítrofes: Argentina, Bolivia y Perú.

Nombre vulgar: Morcacho, ñocha.
Cyperus rigens J. Presl \& C. Presl

Sinónimos: Cyperus chilensis Boeck., Cyperus conceptionis Steud., Cyperus lacustris Phil., Cyperus laetus auct. non J. Presl \& C. Presl, Cyperus laetus J. Presl \& C. Presl var. conceptionis (Steud.) Kük., Mariscus conceptionis (Steud.)

C.B. Clarke, Cyperus paposanus Phil., Cyperus nocha Phil., Cyperus rancoanus Phil.

Hierba. Perenne. Nativa.

Distribución: AYP, ANT, RME, MAU, NUB, BIO, ARA, LLA.

Rango altitudinal: 0-1500 m.

Países limítrofes: Argentina y Bolivia.

Nombre vulgar: Ñocha, lleivún.

Cyperus rotundus L.

Sinónimos: Chlorocyperus rotundus (L.) Palla

Hierba. Perenne. Introducida.

Distribución: ATA, COQ, VAL, RME, MAU, BIO.

Rango altitudinal: 0-500 m.

Nombre vulgar: Coquillo.

Cyperus squarrosus L.

Sinónimos: Cyperus aristatus Rottb., nom. illeg.

Hierba. Anual. Introducida.

Distribución: COQ, RME, LBO, MAU, BIO, LRI.

Rango altitudinal: 0-2500 m.

Cyperus tweediei C.B. Clarke

Hierba. Anual o perenne. Nativa.

Distribución: VAL.

Rango altitudinal: 200-2700 m.

Países limítrofes: Argentina.

Cyperus virens Michx. var. montanus (Boeck.) Denton Sinónimos: Cyperus montanus Boeck., Cyperus uleanus Boeck.

Hierba. Perenne. Nativa.

Distribución: NUB.

Rango altitudinal: 0-500 m.

Países limítrofes: Argentina.

Cyperus virens Michx. var. virens

Sinónimos: Cyperus acutangulus Boeck., Cyperus vegetus Willd. var. acutangulus (Boeck.) Kuntze, Cyperus virens Michx. var. acutangulus (Boeck.) Kük.

Hierba. Perenne. Nativa.

Distribución: MAU, ARA.

Rango altitudinal: 0-2500 m.

Países limítrofes: Argentina y Bolivia.

Nombre vulgar: Cortadera, lleivún.

Cyperus volckmannii Phil.

Sinónimos: Cyperus araeus Phil.

Hierba. Anual. Endémica. 
Distribución: COQ, MAU.

Rango altitudinal: 0-800 m.

Cyperus xanthostachyus Steud.

Sinónimos: Cyperus lechlerii Steud.

Hierba. Perenne. Nativa.

Distribución: VAL, MAU, NUB, BIO, ARA, LRI, LLA,

AIS.

Rango altitudinal: 0-800 m.

Países limítrofes: Bolivia.

Nombre vulgar: Cortadera, ñocha.

\section{Eleocharis}

Eleocharis atacamensis Phil.

Hierba. Perenne. Nativa.

Distribución: ANT, ATA, COQ, NUB, LLA, MAG.

Rango altitudinal: 500-3600 m.

Países limítrofes: Argentina y Bolivia.

\section{Eleocharis bonariensis Nees}

Sinónimos: Eleocharis striatula E. Desv., Scirpus striatulus (E. Desv.) Griseb.

Hierba. Perenne. Nativa.

Distribución: ATA, COQ, VAL, RME, LBO, MAU, NUB, BIO, ARA, LRI.

Rango altitudinal: 0-3000 m.

Países limítrofes: Argentina.

Eleocharis cordillerana S. González, Guagl. \& Ruthsatz Hierba. Perenne. Endémica.

Distribución: LRI, LLA.

Rango altitudinal: 500-900 m.

Eleocharis dombeyana Kunth

Hierba. Perenne. Nativa.

Distribución: ATA, RME.

Rango altitudinal: 0-2500 m.

Países limítrofes: Argentina, Bolivia y Perú.

Eleocharis flavescens (Poir.) Urb.

Sinónimos: Scirpus flavescens Poir.

Hierba. Perenne. Nativa.

Distribución: RME, MAU, BIO.

Rango altitudinal: 0-400 m.

Países limítrofes: Argentina y Bolivia.

Eleocharis fuscopurpurea (Steud.) H. Pfeiff.

Sinónimos: Eleocharis melanocarpa Phil., Eleocharis vincentina Phil., Eleocharis vincentina Phil. var. arcuata (Kuntze) C.B. Clarke, Isolepis fuscopurpurea Steud., Scirpus desvauxii Phil.

Hierba. Perenne. Nativa.

Distribución: MAU, BIO, LRI, JFE.
Rango altitudinal: 0-2300 m.

Países limítrofes: Argentina.

Eleocharis lechleri Boeck.

Hierba. Perenne. Nativa.

Distribución: LRI, LLA.

Rango altitudinal: 400-900 m.

Países limítrofes: Argentina.

Eleocharis macrostachya Britton

Sinónimos: Eleocharis palustris auct. non (L.) R. Br., Scirpus palustris auct. non L.

Hierba. Perenne. Nativa.

Distribución: COQ, VAL, RME, LBO, MAU, NUB, BIO, ARA, LRI, LLA, AIS, MAG.

Rango altitudinal: 0-1700 m.

Países limítrofes: Argentina y Bolivia.

Eleocharis maculosa (Vahl) Roem. \& Schult.

Sinónimos: Scirpus maculosus Vahl

Hierba. Perenne. Nativa.

Distribución: VAL, MAU, NUB, LLA, JFE.

Rango altitudinal: 0-1200 m.

Países limítrofes: Argentina, Bolivia y Perú.

Eleocharis melanocephala E. Desv.

Sinónimos: Scirpus melanocephalus (E. Desv.) Griseb.

Hierba. Perenne. Nativa.

Distribución: VAL, MAU, NUB, BIO, ARA, LLA.

Países limítrofes: Argentina y Bolivia.

Eleocharis melanomphala C.B. Clarke

Hierba. Perenne. Nativa.

Distribución: RME.

Rango altitudinal: 1000-3500 m.

Países limítrofes: Argentina y Bolivia.

Eleocharis melanostachys (d'Urv.) C.B. Clarke

Sinónimos: Eleocharis litoralis Phil., Eleocharis valdiviana

Phil., Scirpus melanostachys d'Urv.

Hierba. Perenne. Nativa.

Distribución: ATA, RME, MAU, NUB, BIO, ARA, LRI, LLA, AIS, MAG.

Rango altitudinal: 0-2200 m.

Países limítrofes: Argentina y Perú.

Eleocharis montana (Kunth) Roem. \& Schult.

Sinónimos: Scirpus montanus Kunth

Hierba. Perenne. Nativa.

Distribución: MAU, NUB, BIO, ARA.

Rango altitudinal: 100-1000 m.

Países limítrofes: Argentina, Bolivia y Perú. 
Eleocharis pachycarpa E. Desv.

Sinónimos: Eleocharis dubia Phil., Eleocharis fuscosanguinea Boeck., Eleocharis lepida Phil., Eleocharis leptocaulis Steud., Eleocharis liocarpa Phil.

Hierba. Perenne. Nativa.

Distribución: COQ, VAL, RME, LBO, MAU, NUB, BIO, ARA, LRI, LLA, AIS, MAG.

Rango altitudinal: 0-2400 m.

Países limítrofes: Argentina.

Eleocharis pseudoalbibracteata S. González \& Guagl.

Sinónimos: Eleocharis albibracteata auct. non Nees \& Meyen ex Kunth

Hierba. Perenne. Nativa.

Distribución: TAR, ANT, ATA, COQ, RME, LBO, MAU, NUB, BIO, ARA, LLA, AIS, MAG, IPA.

Rango altitudinal: $400-4400 \mathrm{~m}$.

Países limítrofes: Argentina y Bolivia.

Eleocharis quinqueflora (Hartmann) O. Schwarz

Sinónimos: Scirpus quinqueflorus Hartmann, Isolepis andina Phil., Scirpus andinus Phil.

Hierba. Perenne. Nativa.

Distribución: ANT, ATA.

Rango altitudinal: 2200-4000 m.

Países limítrofes: Argentina y Perú.

Eleocharis radicans (Poir.) Kunth

Sinónimos: Eleocharis costulata Nees \& Meyen ex Kunth, Eleocharis rivularis Phil., Scirpus radicans Poir.

Hierba. Perenne. Nativa.

Distribución: VAL, RME, LBO, MAU, NUB, BIO, ARA, LLA.

Rango altitudinal: 0-2000 m.

Países limítrofes: Argentina, Bolivia y Perú.

Eleocharis tucumanensis Barros

Hierba. Perenne. Nativa.

Distribución: TAR, ANT, RME.

Rango altitudinal: 3900-4600 m.

Países limítrofes: Argentina y Bolivia.

Eleocharis uniflora Seberg

Sinónimos: Chillania pusilla Roiv.

Hierba. Perenne. Endémica.

Distribución: NUB.

\section{Ficinia}

Ficinia nodosa (Rottb.) Goetgh., Muasya \& D.A. Simpson Sinónimos: Scirpus molinianus Beetle, Isolepis nodosa (Rottb.) R. Br., Scirpus nodosus Rottb., Isolepis monocephala Steud.

Hierba. Perenne. Nativa.
Distribución: VAL, LBO, MAU, BIO, ARA, LLA, AIS, JFE.

\section{Isolepis}

Isolepis cernua (Vahl) Roem. \& Schult.

Sinónimos: Cyperus pumilio Steud., Isolepis erubescens Steud., Isolepis heterophylla Steud., Isolepis modesta Phil., Isolepis monostachya Phil., Isolepis purpurascens Steud., Schoenoplectus cernuus (Vahl) Hayek, Scirpus cernuus Vahl, Scirpus chloroticus Phil., Scirpus modestus (Phil.) F. Phil., Scirpus terminalis Phil., Scirpus aegialitis Phil.

Hierba. Anual. Nativa.

Distribución: AYP, TAR, ANT, COQ, VAL, RME, LBO, MAU, NUB, BIO, ARA, LLA, AIS, MAG, JFE.

Rango altitudinal: 0-2800 m.

Países limítrofes: Argentina, Bolivia y Perú.

Isolepis nigricans Kunth

Sinónimos: Cyperus urvilleanus Steud., Isolepis albescens E. Desv., Isolepis angachillensis Steud., Isolepis phaecocarpa Phil., hom. illeg., Isolepis ramulosa Steud., Isolepis vivipara Schrad. ex E. Desv., Scirpus angachilensis (Steud.) Boeck., Scirpus bridgesii Boeck., Scirpus constitutionis Phil., Scirpus didymostachyus Phil., Scirpus phaecarpus Phil., Scirpus albescens (E. Desv.) Phil., Isolepis nana Phil., Isolepis tristachya Phil., Scirpus trichocaulos Phil., Scirpus philipii C.B. Clarke

Hierba. Anual. Nativa.

Distribución: COQ, VAL, RME, LBO, MAU, NUB, BIO, ARA, LLA, AIS, MAG.

Rango altitudinal: 500-4000 m.

Países limítrofes: Argentina y Bolivia.

Isolepis ranko (Steud.) Vegetti

Sinónimos: Cyperus ranko Steud., Isolepis perpusilla Phil., hom. illeg., Scirpus philippii auct. non C.B. Clarke, Scirpus ranko (Steud.) Gunckel, Scirpus ranko (Steud.) Beetle, comb. illeg.

Hierba. Anual. Nativa.

Distribución: LRI.

Rango altitudinal: 0-1000 m.

Países limítrofes: Argentina.

Isolepis varians Steud.

Sinónimos: Isolepis valdiviae Steud., Scirpus varians (Steud.) Boeck., Isolepis valdiviae F. Phil. ex Boeck., nom. illeg.

Hierba. Anual. Nativa.

Distribución: BIO, ARA, LLA.

Rango altitudinal: $700-1200 \mathrm{~m}$.

Países limítrofes: Argentina. 


\section{Machaerina}

Machaerina scirpoidea (Steud.) T. Koyama

Sinónimos: Terobera scirpoidea Steud., Vincentia scirpoidea (Steud.) Boeck., Cladium scirpoideum (Steud.) Benth. \& Hook. f. ex Hemsl., Mariscus scirpoideus (Steud.) Kuntze, Agylla ensifolia Phil., Cladium ensifolium (F. Phil.) H. Pfeiff.

Hierba. Perenne. Endémica.

Distribución: JFE.

Rango altitudinal: 100-700 m.

\section{Oreobolus}

Oreobolus obtusangulus Gaudich.

Sinónimos: Gaimardia australis auct. non Gaudich., Oreobolus clandestinus Phil., Oreobolus obtusangulus Gaudich. fma. borealis Skottsb.

Hierba. Perenne. Nativa.

Distribución: NUB, BIO, ARA, LRI, LLA, AIS, MAG, JFE. Rango altitudinal: 0-1600 m.

Países limítrofes: Argentina, Bolivia y Perú.

\section{Phylloscirpus}

Phylloscirpus acaulis (Phil.) Goetgh. \& D.A. Simpson Sinónimos: Scirpus macrolepis Phil., Scirpus acaulis Phil., Scirpus atacamensis auct. non Phil., Scirpus nubigenus Phil., Scirpus sessiliflorus Phil.

Hierba. Perenne. Nativa.

Distribución: AYP, TAR, ANT, ATA, COQ, RME, LBO, MAU, NUB, BIO, ARA.

Rango altitudinal: 2000-3500 m.

Países limítrofes: Argentina, Bolivia y Perú.

Phylloscirpus boliviensis (Barros) Dhooge \& Goetgh.

Sinónimos: Scirpus boliviensis Barros

Hierba. Perenne. Nativa.

Distribución: TAR.

Rango altitudinal: 4100-4800 m.

Países limítrofes: Bolivia.

Phylloscirpus deserticola (Phil.) Dhooge \& Goetgh.

Sinónimos: Scirpus deserticola Phil.

Hierba. Perenne. Nativa.

Distribución: AYP, TAR, ANT, ATA, COQ, RME.

Rango altitudinal: 2000-4800 m.

Países limítrofes: Argentina y Bolivia.

\section{Rhodoscirpus}

Rhodoscirpus asper (J. Presl \& C. Presl) Léveillé-Bourret, Donadío \& J.R. Starr

Sinónimos: Scirpus asper J. Presl \& C. Presl, Scirpus brachycaulos Phil., Scirpus trachycaulos Phil.

Hierba. Perenne. Nativa.

Distribución: TAR, ANT, ATA, COQ, VAL, RME, LBO, MAU, NUB, BIO, ARA.

Rango altitudinal: 700-3200 m.

Países limítrofes: Argentina.

\section{Rhynchospora}

Rhynchospora brownii Roem. \& Schult. subsp. americana Guagl.

Sinónimos: Rhynchospora rugosa auct. non (Vahl) Gale

Hierba. Perenne. Nativa.

Distribución: ARA.

Rango altitudinal: 0-2700 m.

Países limítrofes: Argentina, Bolivia y Perú.

\section{Schoenoplectus}

Schoenoplectus americanus (Pers.) Volkart ex Schinz \& R. Keller

Sinónimos: Scirpus chilensis auct. non Nees \& Meyen, Scirpus americanus Pers.

Hierba. Perenne. Nativa.

Distribución: AYP, TAR, ANT, ATA, VAL, LBO, MAU, BIO, LLA.

Rango altitudinal: 0-2600 m.

Países limítrofes: Argentina, Bolivia y Perú.

Schoenoplectus californicus (C.A. Mey.) Soják var. californicus

Sinónimos: Elytrospermum californicus C.A. Mey., Malacochaete chilense Nees \& Meyen ex Boeck., Malacochaete oligostachya Phil. ex Boeck., Scirpus californicus (C.A. Mey.) Steud.

Hierba. Perenne. Nativa.

Distribución: AYP, TAR, ANT, ATA, COQ, VAL, RME, LBO, MAU, NUB, BIO, ARA, LLA, AIS, MAG, IPA.

Rango altitudinal: 0-2000 m.

Países limítrofes: Argentina y Bolivia.

Nombre vulgar: Totora, ngaatu (Rapa Nui).

Schoenoplectus californicus (C.A. Mey.) Soják var. spoliatus (Barros) Vegetti

Sinónimos: Dichromena atrosanguinea E. Desv.

Hierba. Perenne. Nativa.

Distribución: LLA, AIS.

Rango altitudinal: 500-1000 m.

Países limítrofes: Argentina.

Nombre vulgar: Totora.

Schoenoplectus californicus (C.A. Mey.) Soják var. tereticulmis (Steud.) Vegetti

Sinónimos: Scirpus californicus (C.A. Mey.) Steud. var. 
tereticulmis (Steud.) Beetle, Scirpus pseudotriqueter Steud., Scirpus riparius J. Presl \& C. Presl var. tereticulmis (Steud.) C.B. Clarke, Scirpus tereticulmis Steud.

Hierba. Perenne. Nativa.

Distribución: LLA, AIS, MAG.

Rango altitudinal: 0-500 m.

Países limítrofes: Argentina.

Nombre vulgar: Totora.

Schoenoplectus mucronatus (L.) Palla

Hierba. Perenne. Introducida.

Distribución: VAL, MAU, NUB, BIO.

Schoenoplectus pungens (Vahl) Palla var. badius (J. Presl \& C. Presl) S.G. Sm.

Sinónimos: Scirpus badius J. Presl \& C. Presl

Hierba. Perenne. Nativa.

Distribución: ATA, MAU, LLA.

Rango altitudinal: 0-1000 m.

Países limítrofes: Argentina.

Schoenoplectus pungens (Vahl) Palla var. longispicatus (Britton) S.G. Sm.

Sinónimos: Schoenoplectus americanus (Pers.) Volkart ex Schinz \& R. Keller subsp. longispicatus (Britton) Soják

Hierba. Perenne. Nativa.

Distribución: COQ.

Rango altitudinal: 0-500 m.

Países limítrofes: Argentina.

Schoenoplectus pungens (Vahl) Palla var. pungens

Sinónimos: Scirpus americanus Pers. var. pungens (Vahl)

Barros \& Osten, Scirpus pungens Vahl

Hierba. Perenne. Nativa.

Distribución: TAR, ANT, ATA, COQ, VAL, RME, LBO, MAU, BIO, LLA.

Rango altitudinal: 0-1400 m.

Países limítrofes: Argentina y Bolivia.

\section{Schoenus}

Schoenus andinus (Phil.) H. Pfeiff.

Sinónimos: Carpha andina Phil., Schoenus sodalium (Franch.) Phil.

Hierba. Perenne. Nativa.

Distribución: MAU, NUB, BIO, ARA, LLA, AIS, MAG.

Rango altitudinal: 200-1900 m.

Países limítrofes: Argentina.

\section{Schoenus antarcticus (Hook. f.) Dusén}

Sinónimos: Carpha antarctica (Hook. f.) C.B. Clarke, Chaetospora antarctica Hook. f., Elynanthus antarcticus (Hook. f.) Franch.

Hierba. Perenne. Nativa.

Distribución: LLA, AIS, MAG.
Rango altitudinal: $100-500 \mathrm{~m}$.

Países limítrofes: Argentina.

Schoenus nitens (R. Br.) Poir. subsp. krausei (Phil.) Kük.

Sinónimos: Schoenus krausei (Phil.) Gunckel, Isolepis

krausei Phil., Scirpus spadiceus Phil., hom. illeg.

Hierba. Perenne. Nativa.

Distribución: BIO, LRI, LLA.

Rango altitudinal: 0-300 m.

Países limítrofes: Argentina.

Schoenus rhynchosporoides (Steud.) Kük.

Sinónimos: Carpha laxa (Hook. f.) Macloskie, Carpha paniculata Phil., Chaetospora laxa Hook.f., Elynanthus laxus (Hook.f.) Macloskie

Hierba. Perenne. Nativa.

Distribución: MAU, LRI, LLA, AIS, MAG.

Rango altitudinal: 100-1000 m.

Países limítrofes: Argentina.

\section{Scirpus}

Scirpus angustisquamis Beetle

Hierba. Perenne. Endémica.

Distribución: ARA, LLA.

Scirpus melanocaulos Phil.

Hierba. Perenne. Endémica.

Distribución: LBO, LRI, LLA.

Rango altitudinal: 0-100 m.

Scirpus spegazzinianus Barros

Hierba. Perenne. Nativa.

Distribución: MAG.

Rango altitudinal: 0-600 m.

Países limítrofes: Argentina.

Uncinia

Uncinia andina G.A. Wheeler

Hierba. Perenne. Nativa.

Distribución: BIO, ARA.

Rango altitudinal: 700-1500 m.

Países limítrofes: Argentina.

Uncinia araucana G.A. Wheeler

Hierba. Perenne. Endémica.

Distribución: ARA.

Rango altitudinal: 1400-1700 m.

Uncinia aspericaulis G.A. Wheeler

Hierba. Perenne. Endémica.

Distribución: JFE.

Rango altitudinal: $900 \mathrm{~m}$. 
Uncinia austroamericana G.A. Wheeler

Sinónimos: Uncinia lechleriana auct. non Steud., Uncinia macrolepis auct. non Decne.

Hierba. Perenne. Nativa.

Distribución: MAG.

Rango altitudinal: 0-600 m.

Países limítrofes: Argentina.

Uncinia chilensis G.A. Wheeler

Hierba. Perenne. Nativa.

Distribución: BIO, ARA.

Rango altitudinal: 1000-1500 m.

Países limítrofes: Argentina.

Uncinia costata Kük.

Hierba. Perenne. Endémica.

Distribución: JFE.

Rango altitudinal: 0-300 m.

\section{Uncinia douglasii Boott}

Hierba. Perenne. Endémica.

Distribución: JFE.

Rango altitudinal: 200-600 m.

Uncinia erinacea (Cav.) Pers.

Sinónimos: Carex erinacea Cav., Uncinia longearistata

Steud., Uncinia macrotricha Franch., Uncinia erinacea

(Cav.) Pers. var. angustata Kük., Uncinia erinacea (Cav.)

Pers. var. longifolia (Kük.) C.B. Clarke, Uncinia longifolia

Kunth, Uncinia philippii Steud.

Hierba. Perenne. Endémica.

Distribución: MAU, NUB, BIO, ARA, LRI, LLA, AIS, MAG.

Rango altitudinal: 0-1000 m.

Uncinia lechleriana Steud.

Sinónimos: Uncinia brevicaulis auct. non (Thouars) Kunth, Uncinia macloviana auct. non Gaudich.

Hierba. Perenne. Nativa.

Distribución: LLA, AIS, MAG.

Rango altitudinal: 100-800 m.

Países limítrofes: Argentina.

Uncinia macloviana Gaudich.

Sinónimos: Carex delacosta Kuntze, Uncinia brevicaulis (Thouars) Kunth var. macloviana (Gaudich.) C.B. Clarke, Uncinia brevicaulis (Thouars) Kunth fma. montana (Phil.)

Kük., Uncinia montana Phil.

Hierba. Perenne. Nativa.

Distribución: RME, BIO, ARA, LRI, LLA, AIS, MAG, JFE.

Rango altitudinal: 0-900 m.

Países limítrofes: Argentina y Bolivia.
Uncinia macloviformis G.A. Wheeler

Hierba. Perenne. Endémica.

Distribución: JFE.

Rango altitudinal: 1100-1400 m.

Uncinia macrolepis Decne.

Sinónimos: Uncinia sinclairii auct. non Boott

Hierba. Perenne. Nativa.

Distribución: MAG.

Rango altitudinal: 0-200 m.

Países limítrofes: Argentina y Bolivia.

Uncinia macrophylla Steud.

Sinónimos: Uncinia bella Phil., Uncinia bracteosa Phil., Uncinia phalaroides auct. non (Kunth) Nees

Hierba. Perenne. Endémica.

Distribución: BIO, LRI.

Rango altitudinal: $100-1100 \mathrm{~m}$.

Uncinia multifaria Nees ex Boott

Sinónimos: Uncinia multifaria Nees ex Boott var. macrostachya (E. Desv.) C.B. Clarke

Hierba. Perenne. Endémica.

Distribución: MAU, NUB, BIO, ARA, LRI, LLA, JFE.

Rango altitudinal: 0-700 m.

Nombre vulgar: Quinquina.

\section{Uncinia negeri Kük.}

Hierba. Perenne. Nativa.

Distribución: ARA, LLA, AIS.

Rango altitudinal: 500-2000 m.

Países limítrofes: Argentina.

Uncinia phleoides (Cav.) Pers.

Sinónimos: Carex phleoides Cav., Uncinia lasiocarpa Steud. ex Boeck., Uncinia longifolia E. Desv., hom. illeg., Uncinia montteana Phil., Uncinia phleoides (Cav.) Pers. var. krausei Kük.

Hierba. Perenne. Nativa.

Distribución: COQ, VAL, RME, LBO, MAU, NUB, BIO, ARA, LRI, LLA, AIS, JFE.

Rango altitudinal: 0-2700 m.

Países limítrofes: Argentina, Bolivia y Perú.

Nombre vulgar: Quinquín.

Uncinia scabriuscula G.A. Wheeler

Sinónimos: Uncinia brevicaulis (Thouars) Kunth var. laticarpa Kük.

Hierba. Perenne. Nativa.

Distribución: ARA, LLA, AIS, JFE.

Rango altitudinal: 200-1500 m.

Países limítrofes: Argentina. 


\section{Uncinia setifolia Kunze}

Sinónimos: Carex pissisii Phil.

Hierba. Perenne. Endémica.

Distribución: COQ, VAL, RME, LBO, MAU.

Rango altitudinal: 0-2400 m.

Uncinia tenuis Poepp. ex Kunth

Sinónimos: Uncinia gracillis d'Urv., hom. illeg., Uncinia tenuis Poepp. ex Kunth fma. firmula Kük.

Hierba. Perenne. Nativa.

Distribución: ARA, LRI, LLA, AIS, MAG, JFE.

Rango altitudinal: 0-1500 m.

Países limítrofes: Argentina.

Uncinia trichocarpa C.A. Mey.

Sinónimos: Uncinia phleoides (Cav.) Pers. var. trichocarpa (C.A. Mey.) C.B. Clarke, Uncinia longispica Boeck., Uncinia urvillei Steud., Uncinia phleoides (Cav.) Pers. var. longispica (Boeck.) C.B. Clarke, Uncinia chlorostachya Phil., Uncinia loliacea Phil.

Hierba. Perenne. Endémica.

Distribución: COQ, VAL, RME, MAU, NUB, BIO, ARA, LRI, LLA.

Rango altitudinal: 0-500 m.

\section{Uncinia triquetra Kük.}

Sinónimos: Uncinia lechleriana Steud. var. triquetra (Kük.) Kük.

Hierba. Perenne. Nativa.

Distribución: ARA, LLA, AIS, MAG.

Rango altitudinal: 100-1300 m.

Países limítrofes: Argentina.

\section{Zameioscirpus}

Zameioscirpus atacamensis (Phil.) Dhooge \& Goetgh. Sinónimos: Scirpus atacamensis (Phil.) Boeck., Isolepis atacamensis Phil.

Hierba. Perenne. Nativa.

Distribución: TAR, ATA, COQ.

Rango altitudinal: 3200-4800 m.

Países limítrofes: Argentina y Bolivia.

Zameioscirpus gaimardiodes (E. Desv.) Dhooge \& Goetgh. Sinónimos: Carex gaimardioides E. Desv.

Hierba. Perenne. Nativa.

Distribución: ATA, COQ, LBO.

Rango altitudinal: 3100-4000 m.

Países limítrofes: Argentina.

Zameioscirpus muticus Dhooge \& Goetgh.

Hierba. Perenne. Nativa.

Distribución: TAR, ANT.

Rango altitudinal: 4100-4500 m.
Países limítrofes: Argentina y Bolivia.

\section{DIOSCOREACEAE}

\section{Dioscorea}

Dioscorea acerifolia Phil.

Hierba trepadora. Perenne. Endémica.

Distribución: LLA.

Dioscorea andina Phil.

Hierba trepadora. Perenne. Nativa.

Distribución: LBO, MAU, NUB, BIO, ARA.

Rango altitudinal: 0-1500 m.

Países limítrofes: Argentina.

Nombre vulgar: Papa cimarrona.

Dioscorea antucoana Uline ex R. Knuth

Hierba trepadora. Perenne. Endémica.

Distribución: BIO.

Dioscorea araucana Phil.

Hierba trepadora. Perenne. Endémica.

Distribución: BIO, ARA.

Rango altitudinal: $1500 \mathrm{~m}$.

Dioscorea aristolochiifolia Poepp.

Sinónimos: Dioscorea trichoneura Phil.

Hierba trepadora. Perenne. Endémica.

Distribución: VAL, RME.

Rango altitudinal: 0-500 m.

Dioscorea auriculata Poepp.

Sinónimos: Dioscorea acutifolia Phil., Dioscorea helicifolia

Kunth

Hierba trepadora. Perenne. Endémica.

Distribución: VAL, MAU, NUB, BIO, ARA, LLA.

Rango altitudinal: 0-700 $\mathrm{m}$.

Nombre vulgar: Name.

Dioscorea axilliflora Phil.

Hierba trepadora. Perenne. Endémica.

Distribución: ATA.

Dioscorea besseriana Kunth var. berteroi Uline ex R. Knuth Hierba trepadora. Perenne. Endémica.

Distribución: RME.

Dioscorea besseriana Kunth var. besseriana

Hierba trepadora. Perenne. Endémica.

Distribución: ANT, COQ, VAL, RME, LBO, MAU, BIO.

Rango altitudinal: 0-1000 m. 
Dioscorea biloba (Phil.) Caddick \& Wilkin subsp. biloba Sinónimos: Epipetrum bilobum Phil.

Hierba trepadora. Perenne. Endémica.

Distribución: ANT, COQ.

Rango altitudinal: 400-500 m.

Dioscorea biloba (Phil.) Caddick \& Wilkin subsp. coquimbana Viruel, Segarra \& L. Villar

Hierba trepadora. Perenne. Endémica.

Distribución: COQ.

Dioscorea brachybotrya Poepp. var. brachybotrya

Sinónimos: Dioscorea novemloba Steud. ex F. Phil., Dioscorea scandens Kunze ex Kunth, Dioscorea buchtienii R. Knuth

Hierba trepadora. Perenne. Nativa.

Distribución: LBO, MAU, NUB, BIO, ARA, LRI, LLA.

Rango altitudinal: 1500-1600 m.

Países limítrofes: Argentina.

Nombre vulgar: Poñi.

Dioscorea brachybotrya Poepp. var. germainii Uline ex R. Knuth

Hierba trepadora. Perenne. Endémica.

Distribución: LBO, MAU.

Rango altitudinal: 0-2000 m.

Dioscorea brachystachya Phil.

Hierba trepadora. Perenne. Endémica.

Distribución: BIO.

Dioscorea bridgesii Griseb. ex Kunth

Hierba trepadora. Perenne. Endémica.

Distribución: COQ, VAL, RME, LBO, MAU, NUB, BIO.

Rango altitudinal: 0-900 m.

Nombre vulgar: Papa cimarrona.

Dioscorea bryoniifolia Poepp.

Sinónimos: Dioscorea hederacea Miers ex Bertero

Hierba trepadora. Perenne. Endémica.

Distribución: COQ, VAL, RME.

Rango altitudinal: 0-500 m.

Nombre vulgar: Camisilla.

Dioscorea cissophylla Phil.

Hierba trepadora. Perenne. Endémica.

Distribución: LRI, LLA.

Rango altitudinal: 0-400 m.

Dioscorea fastigiata Gay

Sinónimos: Dioscorea cylindrostachya I.M. Johnst., Dioscorea thinophila Phil.

Hierba trepadora. Perenne. Endémica.

Distribución: ANT, ATA, COQ.
Rango altitudinal: 0-500 m.

Dioscorea gayi Phil.

Sinónimos: Dioscorea arenaria auct. non Kunth

Hierba trepadora. Perenne. Endémica.

Distribución: ATA.

Dioscorea geissei Phil.

Hierba trepadora. Perenne. Endémica.

Distribución: ATA.

Dioscorea gracilis Hook. ex Poepp.

Hierba trepadora. Perenne. Endémica.

Distribución: VAL.

Rango altitudinal: 0-500 m.

Dioscorea humifusa Poepp. var. gracilis (Hook. \& Arn.)

L.E. Navas

Hierba trepadora. Perenne. Endémica.

Distribución: COQ, VAL, RME, NUB.

Rango altitudinal: 0-200 m.

Dioscorea humifusa Poepp. var. humifusa

Sinónimos: Dioscorea nigrescens Phil.

Hierba trepadora. Perenne. Endémica.

Distribución: ATA, COQ, VAL, RME, LBO, MAU, NUB, BIO, ARA.

Rango altitudinal: 0-1500 m.

Nombre vulgar: Huanqui.

Dioscorea humilis Bertero ex Colla subsp. humilis

Sinónimos: Dioscorea pusilla Hook., Epipetrum humile (Bertero ex Colla) Phil.

Hierba. Perenne. Endémica.

Distribución: VAL, RME, LBO, MAU, BIO.

Rango altitudinal: 0-1500 m.

Dioscorea humilis Bertero ex Colla subsp. polyanthes (F. Phil.) Viruel, Segarra \& L. Villar

Sinónimos: Epipetrum polyanthes F. Phil., Dioscorea polyanthes (F. Phil.) Caddick \& Wilkin

Hierba. Perenne. Endémica.

Distribución: MAU.

Dioscorea litoralis Phil.

Hierba trepadora. Perenne. Endémica.

Distribución: VAL, BIO.

Rango altitudinal: 0-400 m.

Dioscorea longipes Phil.

Hierba trepadora. Perenne. Endémica.

Distribución: MAU, ARA.

Rango altitudinal: 100-200 m. 
Dioscorea modesta Phil.

Sinónimos: Dioscorea parvifolia Phil., Dioscorea aristolochiifolia Poepp. var. parvifolia (Phil.) L.E. Navas \& Erba

Hierba trepadora. Perenne. Endémica.

Distribución: VAL, RME, MAU.

Dioscorea nana Poepp.

Hierba trepadora. Perenne. Endémica.

Distribución: VAL, MAU, NUB, BIO, ARA, LRI.

Rango altitudinal: 100-1300 m.

Dioscorea obtusifolia Hook. \& Arn. var. obtusifolia

Hierba trepadora. Perenne. Endémica.

Distribución: RME.

Dioscorea obtusifolia Hook. \& Arn. var. philippii Uline ex R. Knuth

Hierba trepadora. Perenne. Endémica.

Distribución: RME.

Dioscorea oligophylla Phil.

Hierba trepadora. Perenne. Endémica.

Distribución: VAL, RME.

Dioscorea paupera Phil.

Hierba trepadora. Perenne. Endémica.

Distribución: ATA, COQ.

Dioscorea pedicellata Phil.

Hierba trepadora. Perenne. Endémica.

Distribución: COQ, RME, LBO, MAU, NUB, BIO, ARA.

Rango altitudinal: 0-1300 m.

Nombre vulgar: Papa cimarrona.

Dioscorea pencana Phil.

Hierba trepadora. Perenne. Endémica.

Distribución: BIO.

Rango altitudinal: 200-300 m.

\section{Dioscorea reticulata Gay}

Sinónimos: Dioscorea brachybotrya Poepp. var. reticulata (Gay) Uline ex R. Knuth, Dioscorea helicifolia auct. non Kunth, Dioscorea reticulata Gay var. nervosa (Phil.) L.E. Navas \& Erba, Dioscorea thermarum Phil., Dioscorea nervosa Phil., Dioscorea pedatifida Phil.

Hierba trepadora. Perenne. Nativa.

Distribución: LBO, MAU, NUB, BIO, ARA, LLA.

Rango altitudinal: 200-2300 m.

Países limítrofes: Argentina.

Nombre vulgar: Jabón del monte.

Dioscorea saxatilis Poepp.

Sinónimos: Dioscorea heterophylla Poepp., Dioscorea parviflora Phil., Dioscorea longifolia Phil., Dioscorea heterophylla Poepp. var. longifolia (Phil.) L.E. Navas \& Erba, Dioscorea linearis Bertero ex Colla, Dioscorea arenaria Kunth

Hierba trepadora. Perenne. Endémica.

Distribución: COQ, VAL, RME, LBO, MAU, NUB, BIO.

Rango altitudinal: 0-1400 m.

Nombre vulgar: Papa cimarrona.

Dioscorea stenocolpus Phil.

Hierba trepadora. Perenne. Endémica.

Distribución: MAU, NUB, BIO, ARA.

Dioscorea tenella Phil.

Hierba trepadora. Perenne. Endémica.

Distribución: ANT, COQ.

Rango altitudinal: 400-700 m.

Nombre vulgar: Papa cimarrona.

Dioscorea tenuis R. Knuth

Hierba trepadora. Perenne. Endémica.

Distribución: LLA.

Dioscorea uliginosa Phil.

Hierba trepadora. Perenne. Endémica.

Distribución: BIO, ARA.

Dioscorea valdiviensis R. Knuth

Hierba trepadora. Perenne. Endémica.

Distribución: ARA, LLA.

Dioscorea variifolia Bertero ex Colla

Sinónimos: Dioscorea acuminata Steud., Dioscorea microphylla Steud.

Hierba trepadora. Perenne. Endémica.

Distribución: COQ, VAL, RME, LBO, BIO, ARA.

Rango altitudinal: 0-700 $\mathrm{m}$.

Dioscorea volckmannii Phil.

Hierba trepadora. Perenne. Nativa.

Distribución: RME, LBO, MAU.

Rango altitudinal: $2300-3000 \mathrm{~m}$.

Países limítrofes: Argentina.

\section{HYDROCHARITACEAE}

Egeria

Egeria densa Planch.

Hierba acuática. Perenne. Introducida.

Distribución: VAL, RME, NUB, BIO, LRI, LLA. 


\section{Elodea}

Elodea potamogeton (Bertero) Espinosa

Sinónimos: Diplandra potamogeton Bertero, Anacharis potamogeton (Bertero) Vict., Anacharis chilensis Planch., Egeria chilensis (Planch.) Benth. \& Hook., Elodea chilensis (Planch.) Casp.

Hierba acuática. Perenne. Nativa.

Distribución: AYP, TAR, VAL, RME, MAU, NUB.

Rango altitudinal: 20-4450 m.

Países limítrofes: Bolivia y Perú.

\section{Limnobium}

Limnobium laevigatum (Humb. \& Bonpl. ex Willd.) Heine Hierba acuática. Perenne. Introducida.

Distribución: VAL, RME, BIO.

\section{IRIDACEAE}

\section{Calydorea}

Calydorea xiphioides (Poepp.) Espinosa

Sinónimos: Sisyrinchium xiphioides Poepp., Sisyrinchium grandiflorum Poepp., Sisyrinchium speciosum Hook., Calydorea speciosa (Hook.) Herb.

Hierba. Perenne. Endémica.

Distribución: COQ, VAL, LBO, MAU, BIO.

Rango altitudinal: 0-400 $\mathrm{m}$.

Nombre vulgar: Lahue.

\section{Crocosmia}

Crocosmia crocosmiiflora (Lemoine ex Burbidge \& Dean) N.E. Br.

Hierba. Perenne. Introducida.

Distribución: VAL, ARA, LLA, JFE.

\section{Herbertia}

Herbertia lahue (Molina) Goldblatt

Sinónimos: Trifurcia lahue (Molina) Goldblatt subsp. lahue, Alophia lahue (Molina) Espinosa, Ferraria lahue Molina Hierba. Perenne. Nativa.

Distribución: VAL, LBO, MAU, NUB, BIO, ARA, LRI, LLA, AIS, JFE.

Rango altitudinal: 0-400 m.

Países limítrofes: Argentina.

Nombre vulgar: Lahue.

Iris

Iris germanica L.
Hierba. Perenne. Introducida.

Distribución: JFE.

Iris pseudacorus L.

Hierba. Perenne. Introducida.

Distribución: LLA.

\section{Libertia}

Libertia chilensis (Molina) Gunckel

Sinónimos: Libertia elegans Poepp., Libertia formosa Graham, Libertia ixioides auct. non (G. Forst.) Spreng., Strumaria chilensis Molina, Libertia crassa Graham, Choeradodia chilensis Herb., Sisyrinchium fernandezianum Steud. \& Hochst., nom. nud., Libertia grandiflora Phil., Libertia formosa Graham var. crassa (Graham) Baker, Roterbe elegans Steud. ex Baker, nom. nud., Libertia chilensis Klotzsch ex Baker, nom. nud., Libertia formosa Graham var. grandiflora (Phil.) Johow, Libertia insignis Ravenna, Libertia umbellata Ravenna

Hierba. Perenne. Nativa.

Distribución: MAU, NUB, BIO, ARA, LRI, LLA, AIS, MAG, JFE.

Rango altitudinal: 0-1000 m.

Países limítrofes: Argentina.

Nombre vulgar: Calle-calle, tekel-tekel.

Libertia sessiliflora (Poepp.) Skottsb.

Sinónimos: Sisyrinchium sessiliflorum Poepp., Libertia caerulescens Kunth \& Bouché, Sisyrinchium huismo Dombey ex Baker, nom. nud., Sisyrinchium coerulescens F. Muell.

Hierba. Perenne. Endémica.

Distribución: VAL, LBO, MAU, NUB, BIO, ARA, LRI, LLA.

Rango altitudinal: 0-1000 m.

Nombre vulgar: Trique.

Libertia tricocca Phil.

Sinónimos: Libertia falcata Ravenna

Hierba. Perenne. Endémica.

Distribución: LBO, MAU, NUB, BIO, ARA, LRI, LLA.

Rango altitudinal: 0-1300 m.

Nombre vulgar: Trique.

\section{Mastigostyla}

Mastigostyla cyrtophylla I.M. Johnst.

Sinónimos: Cypella cyrtoophylla (I.M. Johnst.) Diels

Hierba. Perenne. Nativa.

Distribución: AYP, TAR, ANT.

Rango altitudinal: 2000-3800 m.

Países limítrofes: Perú. 


\section{Olsynium}

Olsynium biflorum (Thunb.) Goldblatt

Sinónimos: Galaxia narcissoides (Cav.) Willd., Phaiophleps biflora (Thunb.) R.C. Foster, Phaiophleps odoratissimum (Lindl.) Raf., Sisyrinchium odoratissimum Lindl., Solenomelus biflorus (Thunb.) Baker, Symphyostemon biflorus (Thunb.) Dusén, Symphyostemon narcissoides (Cav.) Miers ex Klatt, Symphyostemon odoratissimum (Lindl.) Miers, Symphyostemon patagonicum Speg., Gladiolus biflorus Thunb., Sisyrinchium narcissoides Cav., Phaiophleps patagonica (Speg.) R.C. Foster

Hierba. Perenne. Nativa.

Distribución: MAG.

Rango altitudinal: 0-1000 m.

Países limítrofes: Argentina.

Olsynium chrysochromum J.M. Watson \& A.R. Flores Sinónimos: Olsynium luteum (Phil.) Goldblatt, comb. illeg., Chamelum luteum Phil., hom. illeg.

Hierba. Perenne. Endémica.

Distribución: COQ, RME.

Rango altitudinal: 2000-3500 m.

Olsynium frigidum (Poepp.) Goldblatt

Sinónimos: Chamelum andinum (Phil.) Benth. \& Hook., Chamelum frigidum (Poepp.) Ravenna, Sisyrinchium andinum Phil., Sisyrinchium frigidum Poepp., Solenomelus andinus (Phil.) Baker, Solenomelus frigidus (Poepp.) Klatt, Susarium andinum (Phil.) Phil.

Hierba. Perenne. Nativa.

Distribución: VAL, RME, LBO, MAU, NUB, BIO, ARA.

Rango altitudinal: 1100-2700 m.

Países limítrofes: Argentina.

Olsynium junceum (E. Mey. ex C. Presl) Goldblatt subsp. colchaguense (Phil.) J.M. Watson \& A.R. Flores

Sinónimos: Sisyrinchium junceum E. Mey. ex C. Presl subsp. colchaguense (Phil.) R.A. Rodr., Sisyrinchium junceum E. Mey. ex C. Presl var. colchaguense (Phil.) Baker, Sisyrinchium colchaguense Phil., Sisyrinchium eleutherostemon Phil.

Hierba. Perenne. Endémica.

Distribución: LBO, MAU.

Rango altitudinal: 1500-2600 m.

Olsynium junceum (E. Mey. ex C. Presl) Goldblatt subsp. depauperatum (Phil.) R.A. Rodr. \& Martic.

Sinónimos: Sisyrinchium junceum E. Mey. ex C. Presl subsp. depauperatum (Phil.) R.A. Rodr., Sisyrinchium depauperatum Phil.

Hierba. Perenne. Endémica.

Distribución: COQ, LBO, MAU, NUB, BIO, ARA, LRI, LLA.
Rango altitudinal: 500-1500 m.

Olsynium junceum (E. Mey. ex C. Presl) Goldblatt subsp. junceum

Sinónimos: Sisyrinchium argentinense Hauman, Sisyrinchium junceum E. Mey. ex J. Presl, Sisyrinchium middletoni Baker, Sisyrinchium pauciflorum Phil., Sisyrinchium junciforme Poepp., Olsynium argentinense (Hauman) Ravenna, Sisyrinchium roseum Herb.

Hierba. Perenne. Nativa.

Distribución: ATA, COQ, VAL, RME, LBO, MAU, NUB, BIO, ARA, LLA, MAG.

Rango altitudinal: 200-3500 m.

Países limítrofes: Argentina, Bolivia y Perú.

Nombre vulgar: Huilmo.

Olsynium lyckholmi (Dusén) Goldblatt

Sinónimos: Phaiophleps biflora (Thunb.) R.C. Foster subsp. lyckholmi (Dusén) Goldblatt, Symphyostemon lyckholmi Dusén

Hierba. Perenne. Nativa.

Distribución: AIS, MAG.

Rango altitudinal: 0-1100 m.

Países limítrofes: Argentina.

Olsynium nigricans (Phil.) R.A. Rodr. \& Martic.

Sinónimos: Phaiophleps nigricans (Phil.) R.C. Foster, Susarium nigricans Phil., Sisyrinchium maulense Ravenna, Solenomelus nigricans (Phil.) Baker, Symphyostemon nigricans (Phil.) Benth. ex Baker

Hierba. Perenne. Endémica.

Distribución: COQ, LBO, MAU, NUB, BIO, ARA.

Rango altitudinal: 0-400 m.

Olsynium obscurum (Cav.) Goldblatt

Sinónimos: Galaxia obscura Cav., Ona obscura (Cav.)

Ravenna, Tapeinia obscura (Cav.) D.M. Moore

Hierba. Perenne. Nativa.

Distribución: AIS, MAG.

Rango altitudinal: $900 \mathrm{~m}$.

Países limítrofes: Argentina.

Olsynium philippii (Klatt) Goldblatt subsp. illapelinum (Phil.) J.M. Watson \& A.R. Flores

Sinónimos: Sisyrinchium illapelinum Phil., Sisyrinchium roseum Phil., hom. illeg., Sisyrinchium philippii Klatt subsp. illapelinum (Phil.) Rodr.

Hierba. Perenne. Endémica.

Distribución: COQ, VAL, RME, LBO.

Rango altitudinal: 1000-3200 m.

Olsynium philippii (Klatt) Goldblatt subsp. philippii Sinónimos: Sisyrinchium philippii Klatt, Sisyrinchium scabrum Phil., hom. illeg. 
Hierba. Perenne. Endémica.

Distribución: COQ, VAL, RME, LBO.

Rango altitudinal: 2000-3000 m.

Olsynium scirpoideum (Poepp.) Goldblatt subsp. leucanthum (Colla) R.A. Rodr. \& Martic.

Sinónimos: Sisyrinchium leucanthum Colla, Sisyrinchium scirpoideum Poepp. subsp. leucanthum (Colla) R.A. Rodr., Sisyrinchium bifolium Phil., Sisyrinchium stenophyllum Phil., Sisyrinchium nuno Colla var. leucanthum (Colla) Baker, Sisyrinchium filiforme Steud., nom. illeg.

Hierba. Perenne. Endémica.

Distribución: VAL, RME, LBO, BIO.

Rango altitudinal: 0-1300 m.

Olsynium scirpoideum (Poepp.) Goldblatt subsp. luridum (Ravenna) R.A. Rodr. \& Martic.

Sinónimos: Sisyrinchium scirpoideum Poepp. subsp. luridum (Ravenna) R.A. Rodr., Sisyrinchium luridum Ravenna

Hierba. Perenne. Nativa.

Distribución: NUB, BIO.

Rango altitudinal: 0-1500 m.

Países limítrofes: Argentina.

Olsynium scirpoideum (Poepp.) Goldblatt subsp. scirpeum (Phil.) R.A. Rodr. \& Martic.

Sinónimos: Sisyrinchium scirpoideum Poepp. subsp. scirpeum (Phil.) R.A. Rodr., Sisyrinchium scirpeum Phil., Sisyrinchium stenopetalum Phil.

Hierba. Perenne. Endémica.

Distribución: NUB.

Rango altitudinal: 500-1000 m.

Olsynium scirpoideum (Poepp.) Goldblatt subsp. scirpoideum

Sinónimos: Sisyrinchium scirpiforme Poepp., Sisyrinchium scirpoideum Poepp., Sisyrinchium asperulum Phil., Sisyrinchium berteroanum Phil., Sisyrinchium floribundum Phil., Sisyrinchium gracile Phil., Sisyrinchium junciforme Poepp. var. nivale Phil., Sisyrinchium strictum Phil., nom. nud., Sisyrinchium nivale Phil., Sisyrinchium junceum E. Mey. ex C. Presl var. scirpiforme (Poepp.) Baker, Sisyrinchium nuno Colla, Sisyrinchium nunna Steud., Sisyrinchium junceum E. Mey. ex C. Presl var. gracile (Phil.) Baker, Sisyrinchium junceum E. Mey. ex C. Presl var. asperulum (Phil.) Baker

Hierba. Perenne. Nativa.

Distribución: TAR, ANT, ATA, COQ, VAL, RME, LBO, MAU, NUB, BIO, ARA.

Rango altitudinal: 0-2300 m.

Países limítrofes: Bolivia y Perú.

Nombre vulgar: Huilmo.
Olsynium trinerve (Baker) R.A. Rodr. \& Martic.

Sinónimos: Sisyrinchium trinerve Baker

Hierba. Perenne. Nativa.

Distribución: AYP.

Rango altitudinal: 2500-4100 m.

Países limítrofes: Perú.

\section{Romulea}

Romulea rosea (L.) Eckl.

Hierba. Perenne. Introducida.

Distribución: VAL, MAU, BIO.

\section{Sisyrinchium}

Sisyrinchium arenarium Poepp. subsp. adenostemon (Phil.) Ravenna

Sinónimos: Sisyrinchium adenostemon Phil., Sisyrinchium pauperculum Phil.

Hierba. Perenne. Nativa.

Distribución: VAL, RME, LBO, MAU.

Rango altitudinal: 1000-3200 m.

Países limítrofes: Argentina.

Sisyrinchium arenarium Poepp. subsp. arenarium

Sinónimos: Sisyrinchium adenostemon Phil. subsp. microspathum (Phil.) Ravenna, Sisyrinchium arenarium Poepp. subsp. microspathum (Phil.) Ravenna, Sisyrinchium flexuosum Lindl., Sisyrinchium microspathum Phil., Sisyrinchium multiflorum Phil., Sisyrinchium nervosum Phil., Sisyrinchium oligostachyum Phil., Sisyrinchium striatum Sm. var. microspathum (Phil.) Speg., Sisyrinchium angustifolium Phil., Sisyrinchium antucense Ravenna, Sisyrinchium breviarmium Ravenna, Sisyrinchium limarinum Ravenna

Hierba. Perenne. Nativa.

Distribución: COQ, VAL, RME, LBO, MAU, NUB, BIO, ARA, AIS, MAG.

Rango altitudinal: 0-2500 m.

Países limítrofes: Argentina.

Sisyrinchium azureum Phil.

Hierba. Perenne. Nativa.

Distribución: ANT, ATA.

Países limítrofes: Argentina, Bolivia y Perú.

Sisyrinchium chilense Hook.

Sinónimos: Sisyrinchium iridifolium auct. non Kunth, Sisyrinchium iridifolium Kunth subsp. valdivianum (Phil.) Ravenna, Sisyrinchium scabrum Cham. \& Schltdl. var. exaltatum Klatt, Sisyrinchium uniflorum Gay ex Phil., Sisyrinchium ramosum Herb. var. chilense (Hook.) Herb., Sisyrinchium graminifolium auct. non Lindl., Sisyrinchium graminifolium Bertero ex Steud., Sisyrinchium arrayanicum 
Ravenna, Sisyrinchium micranthum Cav. subsp. valdivianum (Phil.) Ravenna, Sisyrinchium valdivianum Phil.

Hierba. Perenne. Nativa.

Distribución: ATA, COQ, VAL, RME, LBO, MAU, NUB, BIO, ARA, LRI, LLA, AIS, MAG.

Rango altitudinal: 0-3700 m.

Países limítrofes: Argentina, Bolivia y Perú.

Nombre vulgar: Clavelillo.

\section{Sisyrinchium cuspidatum Poepp.}

Sinónimos: Sisyrinchium convallium Ravenna, Sisyrinchium longifolium Phil., Sisyrinchium adenocarpum Steud., Sisyrinchium flexuosum Phil., p.p.

Hierba. Perenne. Nativa.

Distribución: ATA, COQ, VAL, RME, LBO, MAU, NUB, BIO, ARA.

Rango altitudinal: 0-2000 m.

Países limítrofes: Argentina.

\section{Sisyrinchium graminifolium Lindl.}

Sinónimos: Sisyrinchium graminifolium Lindl. var. maculatum (Hook.) Klatt, Sisyrinchium maculatum Hook., Sisyrinchium graminifolium Lindl. subsp. luteum (Bertero ex Steud.) R.A. Rodr., comb. illeg., Sisyrinchium luteum Bertero ex Steud., nom. nud., Sisyrinchium dasycarpum Phil., Sisyrinchium piligerum Phil., Sisyrinchium volckmanni Phil., Echthronema graminifolium (Lindl.) Herb., Sisyrinchium graminifolium Lindl. var. pumilum Lindl., Echthronema pumilum (Lindl.) Herb., Sisyrinchium tenuifolium Willd., Echthronema maculatum (Hook.) Herb., Sisyrinchium ascendens Poepp., Sisyrinchium graminifolium Lindl. var. ascendens (Poepp.) Baker, Sisyrinchium guttatum Moris, Sisyrinchium majale Link, Sisyrinchium pymaeum Klotzsch ex Klatt, nom. nud., Sisyrinchium tingens Steud., Sisyrinchium maipoanum Ravenna, Sisyrinchium orbiculatum Ravenna, Sisyrinchium valparadiseum Ravenna, Sisyrinchium gratissimum Ravenna, Sisyrinchium tofoense Ravenna, Sisyrinchium vestitum Ravenna

Hierba. Perenne. Nativa.

Distribución: ANT, ATA, COQ, VAL, RME, LBO, MAU, NUB, BIO, ARA.

Rango altitudinal: 0-1200 m.

Países limítrofes: Argentina.

Nombre vulgar: Ñuño.

Sisyrinchium micranthum Cav.

Hierba. Perenne. Introducida.

Distribución: IPA.

Sisyrinchium nanum Phil.

Sinónimos: Sisyrinchium graminifolium Lindl. subsp. nanum (Phil.) Ravenna

Hierba. Perenne. Nativa.

Distribución: LBO, MAU, LLA, AIS, MAG.
Rango altitudinal: $700-2300 \mathrm{~m}$.

Países limítrofes: Argentina.

Sisyrinchium patagonicum Phil. ex Baker

Sinónimos: Sisyrinchium lechleri Phil., Sisyrinchium nudicaule Phil., Sisyrinchium palenae Phil., Sisyrinchium rahmeri Phil., Sisyrinchium inclinatum Ravenna

Hierba. Perenne. Nativa.

Distribución: COQ, VAL, MAU, NUB, BIO, ARA, LRI, LLA, AIS, MAG.

Rango altitudinal: 0-2000 m.

Países limítrofes: Argentina.

Sisyrinchium pearcei Phil.

Hierba. Perenne. Endémica.

Distribución: ARA, LRI, LLA, AIS, MAG.

Rango altitudinal: 500-2000 m.

Sisyrinchium striatum Sm.

Sinónimos: Sisyrinchium bracteosum Phil., Bermudiana striata (Sm.) Moench, Marica striata (Sm.) Ker Gawl., Paneguia striata (Sm.) Raf., Spathirachis striata (Sm.) Klotzsch ex Klatt, Sisyrinchium spicatum Cav., Moraea sertata Jacq., Sisyrinchium lutescens Lodd., Sisyrinchium libertoides Steud., Sisyrinchium nigricans Gay, Sisyrinchium laevigatum Ravenna

Hierba. Perenne. Nativa.

Distribución: ATA, COQ, VAL, RME, LBO, MAU, NUB, BIO, ARA.

Rango altitudinal: 0-2500 m.

Países limítrofes: Argentina.

Nombre vulgar: Maicillo.

\section{Solenomelus}

Solenomelus pedunculatus (Gillies ex Hook.) Hochr.

Sinónimos: Sisyrinchium pedunculatum Gillies ex Hook., Sisyrinchium longistylum Lem., Sisyrinchium scabriusculum Steud., Solenomelus chilensis Miers

Hierba. Perenne. Endémica.

Distribución: COQ, VAL, RME, LBO, MAU, NUB, BIO, ARA, LRI.

Rango altitudinal: 0-1900 m.

Nombre vulgar: Maicillo.

Solenomelus segethii (Phil.) Kuntze

Sinónimos: Lechera sisyrinchium Griseb. ex Lechl., nom. nud., Susarium segethii (Phil.) Phil., Symphyostemon segethii (Phil.) Macloskie, Solenomelus sisyrinchium (Griseb.) Pax ex Diels, nom. illeg., Sisyrinchium segethi Phil., Solenomelus lechleri Baker

Hierba. Perenne. Nativa.

Distribución: COQ, VAL, RME, LBO, MAU, NUB, BIO, ARA, LRI, LLA, AIS, MAG. 
Rango altitudinal: 0-2700 m.

Países limítrofes: Argentina.

\section{Tapeinia}

Tapeinia pumila (G. Forst.) Baill.

Sinónimos: Ixia magellanica Lam., Ixia pumila G. Forst., Moraea magellanica (Lam.) Willd., Sisyrinchium pumilum (G. Forst.) Hook., Tapeinia magellanica (Lam.) Ker Gawl., Witsenia magellanica (Lam.) Pers., Witsenia pumila (G. Forst.) Vahl

Hierba. Perenne. Nativa.

Distribución: ARA, LRI, LLA, AIS, MAG.

Rango altitudinal: 0-1800 m.

Países limítrofes: Argentina.

\section{Tigridia}

Tigridia philippiana I.M. Johnst.

Hierba. Perenne. Endémica.

Distribución: TAR, ANT, ATA.

Rango altitudinal: 0-900 m.

\section{JUNCACEAE}

\section{Distichia}

\section{Distichia filamentosa Buchenau}

Sinónimos: Agapatea filamentosa Buchenau, nom. nud., Distichia filamentosa (Buchenau) Griseb., nom. illeg.

Hierba. Perenne. Nativa.

Distribución: AYP.

Rango altitudinal: 3500-4700 m.

Países limítrofes: Argentina.

Distichia muscoides Nees \& Meyen

Hierba. Perenne. Nativa.

Distribución: AYP, TAR, ANT.

Rango altitudinal: 3600-4600 m.

Países limítrofes: Argentina, Bolivia y Perú.

\section{Juncus}

Juncus acuminatus Michx. var. multiceps (Kunze ex Kunth) Barros

Sinónimos: Juncus multiceps Kuntze ex Kunth

Hierba. Perenne. Endémica.

Distribución: MAU, NUB, BIO, ARA, LLA.

Juncus acutus L. subsp. acutus var. decompositus Guss.

Hierba. Perenne. Endémica.

Distribución: ANT, COQ.

Rango altitudinal: $600 \mathrm{~m}$.
Juncus acutus L. subsp. leopoldii (Parl.) Snogerup

Sinónimos: Juncus acutus L. var. leopoldii (Parl.) Buchenau, Juncus leopoldii Parl.

Hierba. Perenne. Nativa.

Distribución: ANT, ATA, COQ, VAL, RME, LLA.

Rango altitudinal: 900-2400 m.

Países limítrofes: Argentina.

Juncus balticus Willd. subsp. andicola (Hook.) Snogerup Sinónimos: Juncus pictus Phil., Juncus andicola Hook., Juncus balticus Willd. var. pictus (Phil.) Griseb., Juncus conceptionis Steud., Juncus deserticola Phil., Juncus arcticus Willd. var. andicola (Hook.) Balslev

Hierba. Perenne. Nativa.

Distribución: ANT, ATA, COQ, RME, MAU, LRI, LLA.

Rango altitudinal: 0-4100 m.

Países limítrofes: Argentina y Bolivia.

Nombre vulgar: Hunquillo.

Juncus balticus Willd. subsp. mexicanus (Willd. ex Roem. \& Schult.) Kirschner

Sinónimos: Juncus balticus Willd. var. crassiculmis Buchenau ex Griseb., Juncus balticus Willd. var. mexicanus (Willd.) Kuntze, Juncus mexicanus Willd. ex Schult. \& Schult. f., Juncus crassiculmis (Buchenau) Herter, Juncus balticus Willd. var. columnaris Buchenau, Juncus arcticus Willd. var. mexicanus (Willd. ex Roem. \& Schult.) Balslev Hierba. Perenne. Nativa.

Distribución: ANT, ATA, COQ, VAL, RME, LBO, MAU, ARA, LRI, LLA, AIS, MAG.

Rango altitudinal: 0-3900 m.

Países limítrofes: Argentina y Bolivia.

Juncus bufonius L.

Sinónimos: Juncus bufonius L. var. genuinus Cout., nom. illeg., Juncus bufonius L. var. pumilio Griseb.

Hierba. Anual. Nativa.

Distribución: ANT, ATA, COQ, VAL, RME, LBO, MAU, NUB, BIO, ARA, LRI, LLA, AIS, MAG, JFE.

Rango altitudinal: 0-4100 m.

Países limítrofes: Argentina, Bolivia y Perú.

Nota: Introducida en el Archipiélago Juan Fernández.

Juncus bulbosus L.

Hierba. Perenne. Introducida.

Distribución: LLA.

Juncus capillaceus Lam.

Sinónimos: Juncus capillaceus Lam. var. montevidensis Buchenau, Juncus tenuifolius Steud.

Hierba. Perenne. Nativa.

Distribución: VAL, LBO, NUB, BIO, ARA, LRI, LLA, JFE.

Rango altitudinal: 0-3500 m.

Países limítrofes: Argentina, Bolivia y Perú. 
Juncus capitatus Weigel

Hierba. Anual. Introducida.

Distribución: MAU, NUB, BIO, ARA, LLA.

Juncus cyperoides Laharpe

Sinónimos: Juncus graminifolius E. Mey., Juncus rivularis Poepp. ex Steud.

Hierba. Perenne. Nativa.

Distribución: COQ, VAL, RME, LBO, MAU, NUB, BIO,

ARA, LRI, LLA, AIS, MAG.

Rango altitudinal: 0-3600 m.

Países limítrofes: Argentina, Bolivia y Perú.

Juncus dichotomus Elliot

Sinónimos: Juncus cognatus Kunth, Juncus tenuis A. Gray, hom. illeg., Juncus tenuis Willd. var. dichotomus (Elliott) Wood

Hierba. Perenne. Nativa.

Distribución: MAU, NUB, BIO, ARA.

Rango altitudinal: 0-2500 m.

Países limítrofes: Argentina y Bolivia.

Juncus diemii Barros

Hierba. Perenne. Nativa.

Distribución: LLA.

Países limítrofes: Argentina.

Juncus effusus L. var. effusus

Sinónimos: Juncus bogotensis Kunth, Juncus leersii auct. non T. Marsson

Hierba. Perenne. Nativa.

Distribución: MAU, NUB, BIO, ARA, LRI, LLA, AIS.

Rango altitudinal: 0-3700 m.

Países limítrofes: Argentina, Bolivia y Perú.

Juncus effusus L. var. subglomeratus DC.

Sinónimos: Juncus effusus L. var. compactus Lej. \& Courtois

Hierba. Perenne. Endémica.

Distribución: LLA, AIS.

Rango altitudinal: 0-100 m.

Juncus ernesti-barrosii Barros

Hierba. Perenne. Nativa.

Distribución: BIO.

Rango altitudinal: 0-1000 m.

Países limítrofes: Argentina.

Juncus filiformis L.

Hierba. Perenne. Introducida.

Distribución: VAL, RME, MAU.

Rango altitudinal: 90-900 m.
Juncus homalocaulis F. Muell. ex Benth.

Hierba. Perenne. Introducida.

Distribución: IPA.

Juncus imbricatus Laharpe

Sinónimos: Juncus capillaceus Lam. var. chilensis Buchenau, Juncus chamissonis Kunth, Juncus imbricatus Laharpe var. chamissonis (Kunth) Buchenau, Juncus imbricatus Laharpe var. lechleri (Steud.) Buchenau, Juncus lechleri Steud., Juncus spanianthus Steud., Juncus collinus Steud., Juncus multiflorus Bertero ex Steud., Juncus urvillei Steud., Juncus chamissonis Kunth fma. pusillus Buchenau Hierba. Perenne. Nativa.

Distribución: COQ, VAL, RME, LBO, MAU, NUB, BIO, ARA, LRI, LLA, JFE.

Rango altitudinal: 0-3800 m.

Países limítrofes: Argentina, Bolivia y Perú.

Juncus involucratus Steud. ex Buchenau

Hierba. Perenne. Nativa.

Distribución: MAU, BIO, LLA, AIS.

Países limítrofes: Argentina.

Juncus kraussii Hochst. subsp. austerus (Buchenau) Snogerup

Sinónimos: Juncus austerus Buchenau

Hierba. Perenne. Nativa.

Distribución: LLA.

Rango altitudinal: 0-500 m.

Países limítrofes: Argentina.

Juncus llanquihuensis Barros

Sinónimos: Juncus mendocinus Barros

Hierba. Perenne. Nativa.

Distribución: LLA.

Rango altitudinal: 0-1000 m.

Países limítrofes: Argentina.

Juncus microcephalus Kunth

Sinónimos: Juncus floribundus Kunth, Juncus luzuloxyphium Griseb., Juncus microcephalus Kunth var. floribundus (Kunth) Kunth, Juncus microcephalus Kunth var. intermedius Kunth, Juncus microcephalus Kunth var. typicus Buchenau, nom. illeg., Juncus microcephalus Kunth var. virens Griseb., Juncus sellowianus Kunth, Juncus microcephalus Kunth fma. conglobatus Barros, Juncus timotensis Barros, Juncus floribundus Phil., nom. illeg., Juncus rudis Kunth

Hierba. Perenne. Nativa.

Distribución: VAL, RME, LBO, MAU, NUB, BIO, ARA, LRI, LLA, AIS, MAG.

Rango altitudinal: 0-3000 m.

Países limítrofes: Argentina, Bolivia y Perú. 
Juncus pallescens Lam.

Sinónimos: Juncus dombeyanus J. Gay ex Laharpe, Juncus dombeyanus J. Gay ex Laharpe var. elatus Buchenau, Juncus dombeyanus J. Gay ex Laharpe var. pycnanthus Buchenau, Juncus dombeyanus J. Gay ex Laharpe var. typicus Buchenau, nom. illeg., Juncus commixtus Steud., Juncus proximus Steud., Juncus fernandezianus Steud., Juncus longifolius Steud., Juncus megakoleos Steud.

Hierba. Perenne. Nativa.

Distribución: ATA, COQ, VAL, RME, MAU, NUB, BIO, ARA, LLA, AIS, JFE.

Rango altitudinal: 0-2000 m.

Países limítrofes: Argentina, Bolivia y Perú.

Nombre vulgar: Hierba de la vaca.

Juncus planifolius $\mathrm{R}$. Br.

Hierba. Perenne. Introducida.

Distribución: MAU, BIO, ARA, LRI, LLA, AIS, JFE.

Juncus procerus E. Mey.

Sinónimos: Juncus valdiviae Steud.

Hierba. Perenne. Nativa.

Distribución: MAU, NUB, BIO, ARA, LRI, LLA, AIS, MAG, JFE.

Rango altitudinal: 0-1100 m.

Países limítrofes: Argentina.

Nombre vulgar: Junquillo.

Juncus scheuchzerioides Gaudich.

Sinónimos: Juncus capillaceus Hook., hom. illeg., Juncus exiguus Gaudich. ex Hook. f., Juncus inconspicuus d'Urv., Juncus pusillus auct. non Buchenau, Juncus scheuchzerioides Gaudich. var. inconspicuus (d'Urv.) Hook.

Hierba. Perenne. Nativa.

Distribución: ANT, ATA, COQ, VAL, RME, LBO, LRI, LLA, AIS, MAG.

Rango altitudinal: 0-2100 m.

Países limítrofes: Argentina.

Juncus stipulatus Nees \& Meyen

Sinónimos: Juncus chilensis Gay, Juncus corralensis Phil., Juncus depauperatus Phil., Juncus gayanus Steud., Juncus mandonii Buchenau, Juncus microcephalus Kunth var. pusillus E. Mey., Juncus oliganthus Phil., Juncus stipulatus Nees \& Meyen var. corralensis (Phil.) Buchenau, Juncus biflorus Phil.

Hierba. Perenne. Nativa.

Distribución: TAR, ANT, ATA, COQ, VAL, RME, LBO, MAU, NUB, BIO, ARA, LRI, LLA, AIS, MAG.

Rango altitudinal: 2000-4500 m.

Países limítrofes: Argentina, Bolivia y Perú.

Juncus tenuis Willd. var. congestus Engelm. ex Buchenau Sinónimos: Juncus occidentalis Wiegand, Juncus tenuis
Willd. var. occidentalis (Wiegand) Coville

Hierba. Perenne. Nativa.

Distribución: RME, MAU.

Países limítrofes: Argentina.

Juncus tenuis Willd. var. tenuis

Sinónimos: Juncus smithii Kunth, Juncus subtenuis Herter, Juncus tenuis Willd. var. multicornis E. Mey., Juncus tenuis Willd. var. williamsii Fernald

Hierba. Perenne. Nativa.

Distribución: VAL, MAU, BIO, LLA.

Rango altitudinal: 0-3000 m.

Países limítrofes: Argentina.

\section{Luzula}

Luzula alopecurus Desv.

Sinónimos: Juncodes alopecurus (Desv.) Kuntze, Juncoides alopecurus (Desv.) Macloskie, Luzula villosa Wikstr.

Hierba. Perenne. Nativa.

Distribución: ARA, LLA, AIS, MAG.

Rango altitudinal: 0-1600 m.

Países limítrofes: Argentina.

Luzula antarctica Hook. f.

Sinónimos: Juncodes antarcticus (Hook. f.) Kuntze, Juncoides antarcticum (Hook. f.) Macloskie

Hierba. Perenne. Nativa.

Distribución: MAG.

Rango altitudinal: 300-1000 m.

Países limítrofes: Argentina.

Luzula brachyphylla Phil.

Sinónimos: Luzula racemosa Desv. fma. brachyphylla (Phil.) Fuentes

Hierba. Perenne. Nativa.

Distribución: AIS, MAG.

Países limítrofes: Argentina.

Luzula campestris (L.) DC.

Hierba. Perenne. Introducida.

Distribución: MAU, BIO, LLA, MAG.

Luzula chilensis Nees \& Meyen ex Kunth

Sinónimos: Luzula rigida Phil., Juncodes chilense (Nees \& Meyen ex Kunth) Kuntze, Luzula chilensis Nees \& Meyen ex Kunth fma. rigida (Phil.) Fuentes

Hierba. Perenne. Nativa.

Distribución: COQ, VAL, RME, LBO, MAU, NUB, BIO, ARA, LRI, LLA, AIS, MAG.

Rango altitudinal: 400-3300 m.

Países limítrofes: Argentina. 
Luzula excelsa Buchenau

Sinónimos: Juncodes excelsum (Buchenau) Kuntze

Hierba. Perenne. Nativa.

Distribución: MAU, ARA, AIS, MAG.

Rango altitudinal: 1000-3500 m.

Países limítrofes: Argentina, Bolivia y Perú.

\section{Luzula leiboldii Buchenau}

Sinónimos: Juncodes leiboldii (Buchenau) Kuntze

Hierba. Perenne. Nativa.

Distribución: VAL, RME, MAU, BIO.

Rango altitudinal: 100-1200 m.

Países limítrofes: Argentina.

Luzula masafuerana Skottsb.

Hierba. Perenne. Endémica.

Distribución: JFE.

Rango altitudinal: 900-1400 m.

\section{Luzula parvula Barros}

Hierba. Perenne. Nativa.

Distribución: RME.

Rango altitudinal: 3300-3400 m.

Países limítrofes: Argentina.

Luzula racemosa Desv.

Sinónimos: Juncodes racemosum (Desv.) Kuntze, Luzula racemosa Desv. var. typica Buchenau

Hierba. Perenne. Nativa.

Distribución: COQ, VAL, RME, LBO, MAU, NUB, BIO,

ARA, LLA, AIS, MAG.

Rango altitudinal: 1500-4700 m.

Países limítrofes: Argentina, Bolivia y Perú.

\section{Luzula tristachya Desv.}

Sinónimos: Luzula campestris (L.) DC. var. tristachya (Desv.) Buchenau, Luzula pauciflora Phil.

Hierba. Perenne. Endémica.

Distribución: COQ, VAL, BIO, ARA, LLA.

Rango altitudinal: 100-600 m.

\section{Marsippospermum}

Marsippospermum grandiflorum (L. f.) Hook. f.

Sinónimos: Juncus grandiflorus L. f., Marsippospermum calyculatum Desv., hom. illeg., Rostkovia grandiflora (L. f.) Hook. f.

Hierba. Perenne. Nativa.

Distribución: NUB, ARA, LRI, LLA, AIS, MAG.

Rango altitudinal: 0-1000 m.

Países limítrofes: Argentina.
Marsippospermum philippii (Buchenau) Hauman

Sinónimos: Marsippospermum grandiflorum (L. f.) Hook.

f. var. philippii Buchenau, Rostkovia gracilis Phil., hom.

illeg., Rostkovia grandiflora (L. f.) Hook. f. var. philippii

(Buchenau) Hosseus

Hierba. Perenne. Nativa.

Distribución: NUB, BIO, ARA, LRI, LLA, AIS, MAG.

Rango altitudinal: 1500-2500 m.

Países limítrofes: Argentina.

Marsippospermum reichei Buchenau

Sinónimos: Rostkovia reichei (Buchenau) Hosseus

Hierba. Perenne. Nativa.

Distribución: LLA, AIS, MAG.

Rango altitudinal: 500-1100 m.

Países limítrofes: Argentina.

\section{Oxychloë}

Oxychloë andina Phil.

Sinónimos: Distichia andina (Phil.) Benth. \& Hook.

Hierba. Perenne. Nativa.

Distribución: AYP, TAR, ANT, ATA, COQ, RME.

Rango altitudinal: 3200-4500 m.

Países limítrofes: Argentina, Bolivia y Perú.

Oxychloë bisexualis Kuntze

Sinónimos: Andesia bisexualis (Kuntze) Hauman

Hierba. Perenne. Nativa.

Distribución: COQ, VAL, RME.

Rango altitudinal: 2800-4400 m.

Países limítrofes: Argentina.

Oxychloë haumaniana (Barros) Barros

Sinónimos: Andesia haumaniana Barros

Hierba. Perenne. Nativa.

Distribución: ATA, COQ.

Rango altitudinal: 3500-4500 m.

Países limítrofes: Argentina.

\section{Patosia}

Patosia clandestina (Phil.) Buchenau

Sinónimos: Oxychloë clandestina (Phil.) Hauman, Rostkovia clandestina Phil., Rostkovia brevifolia Phil., Oxychloë brevifolia (Phil.) Buchenau, Distichia clandestina (Phil.) Buchenau

Hierba. Perenne. Nativa.

Distribución: ANT, ATA, COQ, VAL, RME, MAU, NUB, BIO, ARA.

Rango altitudinal: 2700-4500 m. Países limítrofes: Argentina y Bolivia. 


\section{Rostkovia}

Rostkovia magellanica (Lam.) Hook. f.

Sinónimos: Juncus magellanicus Lam., Rostkovia sphaerocarpa Desv.

Hierba. Perenne. Nativa.

Distribución: LRI, LLA, AIS, MAG.

Rango altitudinal: 0-1500 m.

Países limítrofes: Argentina.

\section{JUNCAGINACEAE}

\section{Lilaea}

Lilaea scilloides (Poir.) Hauman

Sinónimos: Lilaea subulata Humb. \& Bonpl., Phalangium scilloides Poir.

Hierba. Anual. Nativa.

Distribución: RME, MAU, ARA, LLA, AIS, MAG.

Rango altitudinal: 0-4100 m.

Países limítrofes: Argentina y Perú.

\section{Tetroncium}

Tetroncium magellanicum Willd.

Hierba. Perenne. Nativa.

Distribución: ARA, LLA, AIS, MAG.

Rango altitudinal: 0-1300 m.

Países limítrofes: Argentina.

\section{Triglochin}

\section{Triglochin concinna Burtt Davy}

Sinónimos: Triglochin maritima L. var. altoandina Cabrera, Triglochin maritima L. var. deserticola Phil., Triglochin monanthos Speg.

Hierba. Perenne. Nativa.

Distribución: TAR, ANT, ATA, VAL, MAG.

Países limítrofes: Argentina.

\section{Triglochin palustris L.}

Sinónimos: Triglochin fonticola Phil., Triglochin andinum Phil.

Hierba. Perenne. Nativa.

Distribución: ANT, ATA, COQ, RME, MAU, LLA, MAG.

Países limítrofes: Argentina.

Triglochin striata Ruiz \& Pav.

Sinónimos: Triglochin montevidensis Spreng, Triglochin striata Ruiz \& Pav. var. filifolia Buchenau, Triglochin striata Ruiz \& Pav. var. montevidensis (Spreng.) Buchenau, Triglochin lechleri Steud., Triglochin litoreum Phil., Triglochin volckmanni Phil.
Hierba. Perenne. Nativa.

Distribución: TAR, ANT, ATA, COQ, VAL, RME, MAU, BIO, ARA, LLA, AIS.

Países limítrofes: Argentina.

\section{LUZURIAGACEAE}

\section{Luzuriaga}

Luzuriaga marginata (Gaertn.) Benth.

Sinónimos: Callixene marginata (Gaertn.) Lam., Enargea marginata Gaertn., Callixene magellanicum Raeusch.

Subarbusto. Nativo.

Distribución: LRI, LLA, AIS, MAG.

Rango altitudinal: 0-400 $\mathrm{m}$.

Países limítrofes: Argentina.

Luzuriaga polyphylla (Hook.) J.F. Macbr.

Sinónimos: Callixene polyphylla Hook., Luzuriaga erecta Kunth, Enargea polyphylla (Hook.) F. Muell.

Subarbusto trepador. Endémico.

Distribución: MAU, NUB, BIO, ARA, LRI, LLA, AIS, MAG.

Rango altitudinal: 0-800 m.

Nombre vulgar: Quilineja.

Luzuriaga radicans Ruiz \& Pav.

Sinónimos: Callixene radicans (Ruiz \& Pav.) Macloskie, Enargea radicans (Ruiz \& Pav.) F. Muell.

Subarbusto trepador. Nativo.

Distribución: LBO, MAU, NUB, BIO, ARA, LRI, LLA, AIS.

Rango altitudinal: 0-1200 m.

Países limítrofes: Argentina.

Nombre vulgar: Quilineja.

\section{ORCHIDACEAE}

\section{Bipinnula}

Bipinnula fimbriata (Poepp.) I.M. Johnst.

Sinónimos: Chloraea fimbriata Poepp., Bipinnula mystacina Lindl., Jouyella fimbriata (Poepp.) Szlach. \& Marg.

Hierba. Perenne. Endémica.

Distribución: COQ, VAL, RME, LBO, MAU.

Bipinnula gabriel P.A. Bravo \& G.M. Baeza

Hierba. Perenne. Endémica.

Distribución: MAU.

Bipinnula plumosa Lindl.

Sinónimos: Bipinnula philipporum Kraenzl., Bipinnula 
plumosa Lindl. var. philipporum (Krzl) Reiche, Jouyella philipporum (Kraenzl.) Szlach. \& Marg., Jouyella plumosa (Lindl.) Szlach. \& Marg.

Hierba. Perenne. Endémica.

Distribución: COQ, VAL, RME, LBO.

Bipinnula taltalensis I.M. Johnst.

Sinónimos: Jouyella taltalensis (I.M.Johnst.) Szlach. \& Marg.

Hierba. Perenne. Endémica.

Distribución: ANT.

Bipinnula volkmannii Kraenzl.

Hierba. Perenne. Endémica.

Distribución: NUB, BIO, ARA.

\section{Brachystele}

Brachystele unilateralis (Poir.) Schltr.

Sinónimos: Ophrys unilateralis Poir., Gyrostachys chilensis (A. Rich.) Kuntze, Gyrostachys unilateralis (Poir.) Kuntze, Spiranthes chilensis A. Rich., Spiranthes diuretica Lindl., Neottia diuretica Willd., Sarcoglottis diuretica (Willd.) W.H. Baxter, Epipactis diuretica (Willd.) Stokes, Spiranthes nuil A. Rich., Odontorrhynchus chilensis (A. Rich.) Garay, Odontorrhynchus domeykoanus Szlach., Odontorrhynchus erosus Szlach., Odontorrhynchus variabilis Garay

Hierba. Perenne. Nativa.

Distribución: COQ, VAL, RME, MAU, NUB, BIO, ARA, LRI, LLA.

Países limítrofes: Argentina.

Nombre vulgar: Nuil.

\section{Chloraea}

\section{Chloraea alpina Poepp.}

Sinónimos: Asarca alpina (Poepp.) Kuntze, Chloraea hookeriana Speg. \& Kraenzl., Chloraea ferruginea Speg \& Kraenzl., Chloraea xerophila Kraenzl., Chloraea perezmoreaui Garay, Chloraea cholilensis Speg. \& Kraenzl Hierba. Perenne. Nativa.

Distribución: RME, LBO, MAU, NUB, BIO, ARA, AIS.

Países limítrofes: Argentina.

Nombre vulgar: Tulipán del monte.

Chloraea barbata Lindl.

Sinónimos: Asarca barbata (Lindl.) Kuntze, Chloraea aurea Phil.

Hierba. Perenne. Nativa.

Distribución: VAL, RME, MAU, NUB, BIO, ARA.

Países limítrofes: Argentina.

Chloraea bidentata (Poepp. \& Endl.) M.N. Correa

Sinónimos: Asarca bidentata Poepp. \& Endl., Chloraea bicallosa Phil.

Hierba. Perenne. Nativa.

Distribución: MAU, NUB, BIO, ARA.

Países limítrofes: Argentina.

Chloraea bletioides Lindl.

Sinónimos: Chloraea ulanthoides Lindl., Asarca bletioides

(Lindl.) Kuntze, Chloraea grandis Kraenzl., Chloraea

affinis Lindl., Asarca affinis (Lindl.) Kuntze, Chloraea

ulanthoides Lindl. var affinis (Lindl.) Reiche, Chloraea

ulanthoides Lindl. var grandis (Kraenzl.) Reiche, Chloraea

lindleyi Poepp.

Hierba. Perenne. Endémica.

Distribución: VAL, RME, LBO, MAU, NUB.

Nombre vulgar: Lengua de loro.

Chloraea chrysantha Poepp.

Sinónimos: Asarca chrysantha (Poeep.) Kuntze, Asarca aurantiaca Lindl., Chloraea crocata Phil., Chloraea aurantiaca Lindl., Asarca speciosa Lindl.

Hierba. Perenne. Endémica.

Distribución: COQ, VAL, RME, LBO, MAU, NUB, BIO, ARA.

Nombre vulgar: Pico de loro.

Chloraea chrysochlora Phil.

Sinónimos: Asarca chrysochlora (Phil.) Kuntze, Chloraea collicensis Kraenzl., Chloraea hemichloris Kraenzl., Asarca lechleri (Lindl. ex Kraenzl.) Kunze, Chloraea lechleri Lindl. ex Kraenzl.

Hierba. Perenne. Nativa.

Distribución: BIO, ARA, LLA, AIS.

Países limítrofes: Argentina.

Chloraea crispa Lindl.

Sinónimos: Asarca crispa (Lindl.) Kuntze, Chloraea cygnea Phil., Asarca cygnea (Phil.) Kuntze, Chloraea spectabilis Phil., Asarca conspicua Kuntze

Hierba. Perenne. Endémica.

Distribución: MAU, NUB, BIO, ARA, LLA.

Nombre vulgar: Gavilú, pico de loro.

Chloraea cristata Lindl.

Sinónimos: Chloraea pogonata Phil., Asarca pogonata (Phil.) Kuntze

Hierba. Perenne. Endémica.

Distribución: COQ, VAL.

Chloraea cuneata Lindl.

Sinónimos: Asarca cuneata (Lindl.) Kuntze, Asarca obovata (Phil.) Kuntze, Chloraea obovata Phil., Chloraea nervosa Phil. ex Kraenzl.

Hierba. Perenne. Endémica.

Distribución: BIO, ARA, LRI. 
Chloraea disoides Lindl.

Sinónimos: Chileorchis disoides (Lindl.) Szlach., Asarca disodes (Lindl.) Kuntze, Chloraea picta Phil. ex Kraenzl., Chloraea disoides Lindl. var. picta (Phil. ex Kraenzl.) M.N. Correa

Hierba. Perenne. Endémica.

Distribución: VAL, RME, LBO, MAU, BIO, ARA.

Chloraea galeata Lindl.

Sinónimos: Asarca galeata (Lindl.) Kuntze, Asarca maculosa Poepp., Chloraea alaris Lindl., Chloraea secunda Phil., Chloraea suaveolens Phil., Asarca maculata Steud., Chloraea besseri Rchb.f., Chloraea berteroana Kraenzl., Asarca besseri (Rchb.f.) Kuntze, Chloraea rypaloglossa A. Rich., Asarca rhypaloglossa (A. Rich.) Kuntze

Hierba. Perenne. Endémica.

Distribución: LBO, MAU, NUB, BIO, ARA.

\section{Chloraea gaudichaudii Brongn.}

Sinónimos: Asarca gaudichaudii (Brongn.) Kuntze, Arethusa lutea Gaud., Epipactis lutea (Gaudich.) Steud., Chloraea fonki Phil. orth. mut., Asarca fonckii (Phil.) Kuntze orth. mut., Chloraea inconspicua Phil., Asarca inconspicua (Phil.) Kuntze, Chloraea falklandica Kraenzl., Chloraea gymnoglossa Phil., Asarca gymnoglossa (Phil.) Kuntze

Hierba. Perenne. Nativa.

Distribución: NUB, BIO, ARA, LRI, LLA, AIS, MAG.

Países limítrofes: Argentina.

Chloraea gavilu Lindl.

Sinónimos: Limodorum luteum Lam., Chloraea sceptrum Rchb.f., Epidendrum luteum (Lam.) Poir., Chloraea lutea (Wild.) Schltr., nom. illeg., Chloraea lindleyi Poepp., Chloraea semitensis Phil. ex Kraenzl., Chloraea lotensis Rolfe, Cymbidium luteum (Lam.) Willd.

Hierba. Perenne. Endémica.

Distribución: VAL, LBO, MAU, NUB, BIO, ARA, LRI.

Chloraea heteroglossa Rchb.f.

Sinónimos: Asarca heteroglossa (Rchb.f.) Kuntze

Hierba. Perenne. Endémica.

Distribución: VAL.

\section{Chloraea lamellata Lindl.}

Sinónimos: Asarca lamellata (Lindl.) Kuntze, Chloraea decipiens Poepp., Chloraea semibarbata Lindl., Asarca semibarbata (Lindl.) Kuntze, Chloraea semibarbata Lindl. ssp pearcei Kraenzl., Chloraea pearcei Phil., Asarca pearcei (Phil.) Kuntze

Hierba. Perenne. Endémica.

Distribución: LBO, NUB, BIO, ARA, LRI.

Chloraea longipetala Lindl.

Sinónimos: Asarca longipetala (Lindl.) Kuntze, Chloraea panduraeformis Phil., Chloraea multilamellata Phil. ex Kraenzl., Chloraea liliaceae Kraenzl., Chloraea reicheana Kraenzl.

Hierba. Perenne. Endémica.

Distribución: MAU, NUB, BIO, ARA, LLA.

Chloraea magellanica Hook. f.

Sinónimos: Asarca magellanica (Hook.f.) Kuntze, Chloraea bouganvilleana Franch., Chloraea spegazziniana Kraenzl., Chloraea hystrix Speg. \& Kraenzl., Chloraea leontoglossa Kraenzl. \& Speg., Chloraea kraenzliniana Hoehne

Hierba. Perenne. Nativa.

Distribución: MAU, NUB, BIO, ARA, LRI, LLA, AIS, MAG.

Países limítrofes: Argentina.

Chloraea multiflora Lindl.

Sinónimos: Asarca multiflora (Lindl.) Kuntze, Chloraea densa Rich., Chloraea campestris Poepp., Chloraea stenantha Kraenzl., Asarca densa (A. Rich.) Kuntze, Chloraea poeppigiana A. Rich., Asarca poeppigiana (A. Rich.) Kuntze, Chloraea pseudo-campestris Kraenzl., Chloraea decipiens Poepp.

Hierba. Perenne. Endémica.

Distribución: VAL, RME, LBO, MAU, NUB, BIO, ARA.

Nombre vulgar: Gavilú.

\section{Chloraea nudilabia Poepp.}

Sinónimos: Asarca nudilabia (Poepp.) Kuntze, Chloraea leucojiflora Kraenzl., Chloraea heteroglossa Rchb.f., Chloraea homopetala Phil.

Hierba. Perenne. Endémica.

Distribución: MAU, NUB, BIO, ARA.

Chloraea parviflora (Poepp.) Mourgues \& Novoa

Sinónimos: Asarca parviflora Poepp. Chloraea reflexa Phil., Chloraea reflexa Phil. var. latifolia Phil., Asarca reflexa (Phil.) Kuntze

Hierba. Perenne. Endémica.

Distribución: MAU, BIO.

Chloraea philippii Rchb.f.

Sinónimos: Asarca philippii (Rchb.f.) Kuntze, Chloraea lagunae-pacis Kraenzl., Chloraea lineata Phil. ex Kraenzl., Chloraea modesta Phil. ex Kraenzl.

Hierba. Perenne. Nativa.

Distribución: BIO, ARA, LLA, AIS.

Países limítrofes: Argentina.

\section{Chloraea prodigiosa Rchb.f.}

Sinónimos: Asarca prodigiosa (Rchb.f.) Kuntze, Chloraea calopogon Phil., Asarca calopogon (Phil.) Kuntze, Chloraea dasypogon Phil., Asarca dasypogon (Phil.) Kuntze

Hierba. Perenne. Endémica.

Distribución: RME, LBO, MAU. 
Chloraea speciosa Poepp.

Sinónimos: Chloraea gayana Rich., Asarca gayana (A. Rich.) Kuntze, Chloraea elwelsii Rolfe, Chloraea speciosa Poepp. fma. sterilis Kraenzl., Asarca insignis Kuntze, comb. illeg.

Hierba. Perenne. Nativa.

Distribución: BIO, ARA, LLA.

Países limítrofes: Argentina.

Chloraea virescens (Willd.) Lindl.

Sinónimos: Asarca patagonica (Phil.) Kuntze, Chloraea patagonica Phil., Chloraea pigichen Kuntze, Chloraea piquichen Lindl., Chloraea pleistodactyla Kraenzl. \& Speg., Cymbidium virescens Willd., Chloraea incisa Poepp., Chloraea odontoglossa A. Rich., Chloraea unguis-cati Rchb.f., Chloraea chlorosticta Phil., Asarca chlorosticta (Phil.) Kuntze, Asarca odontoglossa (A. Rich.) Kuntze, Asarca unguis-cati (Rchb.f.) Kuntze, Asarca incisa (Poepp.) Kuntze, Asarca fimbriata (Phil.) Kuntze, Chloraea fimbriata Phil., nom. illeg.

Hierba. Perenne. Nativa.

Distribución: BIO, ARA, LRI, LLA.

Países limítrofes: Argentina.

Nombre vulgar: Piquichén, pichiquén.

Chloraea viridiflora Poepp.

Sinónimos: Asarca viridiflora (Poepp.) Kuntze, Chloraea verrucosa Phil., Chloraea piquichen (Lam.) Lindl., Chloraea viridiflora Poepp. var. reticulata Reiche, Chloraea robusta Rolfe, Chloraea leontoglossa Kraenzl., nom. illeg., Asarca tuberculata Kuntze

Hierba. Perenne. Nativa.

Distribución: MAU, NUB, BIO.

Países limítrofes: Argentina.

Chloraea volkmannii Phil. ex Kraenzl.

Sinónimos: Chloraea lineata Phil. ex Kraenzl.

Hierba. Perenne. Endémica.

Distribución: BIO, ARA.

\section{Codonorchis}

Codonorchis lessonii (Brongn.) Lindl.

Sinónimos: Epipactis lessonii d'Urv., Calopogon lessonii (d’Urv.). Brong., Pogonia lessonii (D’Urv.) Rchb.f., Pogonia tetraphylla Poepp. \& Endl., Codonorchis tetraphylla (Poepp. \& Endl.) L.O.Williams, Codonorchis poeppigii Lindl., Pogonia lessonii (D’Urv.) Rchb.f. var. poeppigii Reiche, Codonorchis lessonii (Brong.) Lindl. var. poeppigii (Lindl.) Reiche, Codonorchis skottsbergii Kraenzl., Pogonia lessonii (D’Urv.) Rchb.f. var. skottsbergii Reiche, Codonorchis lessonii (Brong.) Lindl. var. skottsbergii (Kraenzl.) Reiche Hierba. Perenne. Nativa.
Distribución: MAU, NUB, BIO, ARA, LRI, LLA, AIS, MAG.

Países limítrofes: Argentina.

Nombre vulgar: Palomita, azucena.

\section{Correorchis}

Correorchis cylindrostachya (Poepp.) Szlach.

Sinónimos: Chloraea cylindrostachya Poepp., Asarca cylindrostachya (Poepp.) Kuntze, Chloraea papillosa Phil., Chloraea major Ravenna, Chloraea leptopetala Reiche

Hierba. Perenne. Nativa.

Distribución: VAL, RME, LBO, MAU, NUB, BIO, ARA, AIS.

Países limítrofes: Argentina.

\section{Gavilea}

Gavilea araucana (Phil.) M.N. Correa

Sinónimos: Asarca araucana Phil., Asarca araucana Phil. var. incisa Hauman, Gavilea araucana (Phil.) M.N. Correa var. incisa Hauman

Hierba. Perenne. Nativa.

Distribución: VAL, RME, MAU, NUB, BIO, ARA, LRI, LLA, AIS, MAG.

Países limítrofes: Argentina.

Gavilea australis (Skottsb.) M.N. Correa

Sinónimos: Asarca australis Skottsb., Asarca enigmatica Hauman

Hierba. Perenne. Nativa.

Distribución: AIS, MAG.

Países limítrofes: Argentina.

Gavilea cardioglossa (Reiche) Martic.

Sinónimos: Gavilea cardioglossa (Reiche) M.N. Correa, comb. illeg., Asarca cardioglossa Reiche

Hierba. Perenne. Endémica.

Distribución: ARA, LRI, LLA.

Gavilea chica (Speg. \& Kraenzl.) Chemisquy

Sinónimos: Chloraea chica Speg. \& Kraenzl., Chloraea kruegeri F. Phil. ex Kraenzl.

Hierba. Perenne. Nativa.

Distribución: COQ, VAL, RME, LBO, MAU, NUB, BIO, ARA, LLA, AIS, MAG.

Países limítrofes: Argentina.

Gavilea gladysiae Chemisquy

Hierba. Perenne. Nativa.

Distribución: MAG.

Países limítrofes: Argentina. 
Gavilea glandulifera (Poepp.) M.N. Correa

Sinónimos: Asarca appendiculata Phil. ex Kraenzl., Asarca glandulifera Poepp., Chloraea albo-rosea Kraenzl. \& Speg., Chloraea volucris Lindl., Gavilea auriculata Ravenna

Hierba. Perenne. Nativa.

Distribución: VAL, RME, LBO, MAU, NUB, BIO, ARA, LLA, AIS, MAG.

Países limítrofes: Argentina.

Gavilea insularis M.N. Correa

Hierba. Perenne. Endémica.

Distribución: JFE.

Gavilea kingii (Hook. f.) M.N. Correa

Sinónimos: Asarca kingii Hook.f., Chloraea kingii

Macloskie

Hierba. Perenne. Endémica.

Distribución: MAG.

Gavilea litoralis (Phil.) M.N. Correa

Sinónimos: Chloraea litoralis Phil., Asarca litoralis (Phil.) Kunze, Asarca litoralis (Phil.) Reiche, Asarca macroptera Kraenzl., Gavilea macroptera (Kraenzl.) M. N. Correa Hierba. Perenne. Nativa.

Distribución: ARA, LRI, LLA, AIS, MAG.

Países limítrofes: Argentina.

Gavilea longibracteata (Lind1.) Sparre ex L.E. Navas

Sinónimos: Chloraea longibracteata Lindl., Asarca longibracteata (Lind.) Kuntze, Asarca sinuata Lindl., Asarca longibracteata (Lindl.) Skottsb., comb. illeg., Asarca berteri Rchb.f., Asarca verrucosa A. Rich. ex Gay, Asarca spectabilis Phil., Chloraea semibarbata Lindl. ssp. spectabilis

Hierba. Perenne. Endémica.

Distribución: COQ, VAL, RME, LBO, MAU, NUB, BIO, ARA.

\section{Gavilea lutea (Pers.) M.N. Correa}

Sinónimos: Serapias lutea Comm. ex Pers., Asarca lutea (Comm. ex Pers.) Kuntze, Asarca lutea (Comm. ex Pers.) Skottsb., comb. illeg., Chloraea lutea (Comm. ex Pers.) Skottsb., Chloraea commersonii Brongn., nom. illeg., Asarca commersonii (Brongn.) Hook. f., comb. illeg., Asarca commersonii (Brongn.) Kuntze, comb. illeg., Gavilea acutiflora Poepp., Asarca acutiflora (Poepp.) Poepp. \& Endl., Asarca brachychila Phil., Asarca thermarum Phil. ex Kraenzl., Asarca tenuiflora Rolfe, Asarca acutifolia Steud. Hierba. Perenne. Nativa.

Distribución: NUB, BIO, ARA, LLA, AIS, MAG.

Países limítrofes: Argentina.

Gavilea odoratissima Poepp.

Sinónimos: Asarca odoratissima Poepp. \& Endl., Chloraea odoratissima (Poepp. \& Endl.) Macloskie, Asarca chrysostachya Phil., Asarca platyantha Kraenzl. auct. non Rchb.f., Asarca sulphurea Phil., Asarca ventanai Hauman Hierba. Perenne. Nativa.

Distribución: MAU, NUB, BIO, ARA, LRI, LLA, AIS.

Países limítrofes: Argentina.

Gavilea platyantha (Rchb.f.) Ormd.

Sinónimos: Asarca platyantha Rchb.f., Asarca glandulifera Poepp. var. illapelina Reiche, Gavilea glandulifera (Poepp.) M.N. Correa var. illapelina (Reiche) Novoa, J. Espejo, Cisternas, M. Rubio y Domínguez, comb. illeg.

Hierba. Perenne. Nativa.

Distribución: COQ, VAL.

Países limítrofes: Argentina.

\section{Gavilea supralabellata M.N. Correa}

Hierba. Perenne. Nativa.

Distribución: AIS, MAG.

Países limítrofes: Argentina.

Gavilea trullata Ormd.

Sinónimos: Asarca cardioglossa Reiche var. patagonica Garay, Gavilea cardioglossa (Reiche) Martic. var. patagonica (Garay) M.N.Correa

Hierba. Perenne. Nativa.

Distribución: LLA.

Países limítrofes: Argentina.

Gavilea venosa (Lam.) Garay \& Ormd.

Sinónimos: Limodorum venosum Lam., Gavilea leucantha Poepp. \& Endl., nom. illeg., Asarca leucantha Poepp. \& Endl., comb. illeg., Gavilea feuilleana (Kraenzl.) Lehnebach, Asarca feuilleana Kraenzl.

Hierba. Perenne. Endémica.

Distribución: MAU, NUB, BIO, ARA, LRI.

Gavilea wittei (Hicken) Ormd.

Sinónimos: Asarca patagonica Skottsb., hom. illeg., Chloraea wittei Hicken, Gavilea patagonica (Skottsb.) M.N. Correa

Hierba. Perenne. Nativa.

Distribución: AIS, MAG.

Países limítrofes: Argentina.

\section{Habenaria}

Habenaria pumila Poepp.

Sinónimos: Habenaria paucifolia Lindl., Habenaria germainii Phil., Habenaria uliginosa Phil., hom. illeg., Habenaria brachyceros Phil., nom. illeg.

Hierba. Perenne. Nativa.

Distribución: ATA, COQ, VAL, RME, LBO, MAU, NUB, BIO, ARA, LRI, LLA.

Países limítrofes: Argentina. 


\section{Myrosmodes}

Myrosmodes nervosa (Kraenzl.) Novoa, C. Vargas \& Cisternas

Sinónimos: Aa nervosa (Kraenzl.) Schltr., Altensteinia nervosa Kraenzl.

Hierba. Perenne. Endémica.

Distribución: AYP, TAR, ANT.

\section{Ulantha}

Ulantha apinnula (Gosewijn) Szlach. Sinónimos: Chloraea apinnula (Gosewijn) Szlach., Bipinnula apinnula Gosewijn

Hierba. Perenne. Endémica.

Distribución: MAU.

Ulantha grandiflora (Poepp.) Szlach.

Sinónimos: Asarca grandiflora (Poepp.) Kuntze, Chloraea grandiflora Poepp.

Hierba. Perenne. Endémica.

Distribución: MAU, NUB, BIO, ARA.

\section{PHILESIACEAE}

\section{Lapageria}

Lapageria rosea Ruiz \& Pav.

Arbusto trepador. Endémico.

Distribución: COQ, VAL, LBO, MAU, NUB, BIO, ARA, LRI, LLA.

Rango altitudinal: 0-400 m.

Nombre vulgar: Copihue.

\section{Philesia}

Philesia magellanica J.F. Gmel.

Sinónimos: Philesia buxifolia Lam.

Arbusto trepador. Nativo.

Distribución: LRI, LLA, AIS, MAG.

Rango altitudinal: 0-100 m.

Países limítrofes: Argentina.

Nombre vulgar: Coicopihue.

\section{POACEAE}

\section{Agropyron}

Agropyron cristatum (L.) Gaertn.

Hierba. Perenne. Introducida.

Distribución: MAG.
Agrostis

Agrostis arvensis Phil.

Hierba. Perenne. Endémica.

Distribución: BIO, LLA.

Rango altitudinal: 10-420 m.

Agrostis brachyathera Steud.

Hierba. Perenne. Nativa.

Distribución: MAU, NUB, BIO, AIS, MAG.

Rango altitudinal: 300-2200 m.

Países limítrofes: Argentina.

Agrostis breviculmis Hitchc.

Sinónimos: Agrostis nana (J. Presl) Kunth, Trichodium nanum J. Presl

Hierba. Perenne. Nativa.

Distribución: RME, MAU, BIO.

Rango altitudinal: 820-2800 m.

Países limítrofes: Argentina, Bolivia y Perú.

Agrostis capillaris L.

Hierba. Perenne. Introducida.

Distribución: COQ, VAL, RME, MAU, NUB, BIO, ARA, LRI, LLA, AIS, MAG.

Agrostis castellana Boiss. \& Reut.

Hierba. Perenne. Introducida.

Distribución: RME, MAU, NUB, BIO, ARA, LRI, LLA, AIS, MAG.

Agrostis gigantea Roth

Hierba. Perenne. Introducida.

Distribución: COQ, VAL, RME, LBO, NUB, BIO, ARA, LRI, LLA, AIS, MAG.

Agrostis glabra (J. Presl) Kunth var. glabra

Sinónimos: Trichodium glabrum J. Presl, Agrostis gayana

E. Desv., Agrostis andina Phil.

Hierba. Perenne. Nativa.

Distribución: COQ, VAL, RME, LBO, MAU, NUB, BIO, ARA, LLA, MAG.

Rango altitudinal: 170-3500 m.

Países limítrofes: Argentina.

Agrostis glabra (J. Presl) Kunth var. melanthes (Phil.) Rúgolo \& De Paula

Sinónimos: Agrostis melanthes Pilg., Calamagrostis laxiflora Phil.

Hierba. Perenne. Nativa.

Distribución: BIO, ARA, LLA, AIS.

Rango altitudinal: 45-2070 m.

Países limítrofes: Argentina. 
Agrostis idahoensis Nash

Hierba. Perenne. Nativa.

Distribución: MAU, NUB, LRI, LLA, MAG.

Rango altitudinal: 10-2200 m.

Países limítrofes: Argentina.

Nota: Especie de distribución disyunta en Norte y Sudamérica.

\section{Agrostis imberbis Phil.}

Sinónimos: Agrostis stenophylla Phil., Agrostis scotantha Phil.

Hierba. Perenne. Nativa.

Distribución: COQ, RME, LBO, MAU, NUB, BIO, ARA, AIS, MAG.

Rango altitudinal: 175-3200 m.

Países limítrofes: Argentina.

Agrostis inconspicua Kunze ex E. Desv.

Sinónimos: Agrostis airiformis Steud. ( A. airaeformis), Agrostis airoides Franch.

Hierba. Perenne. Nativa.

Distribución: VAL, RME, LBO, MAU, NUB, BIO, ARA, LRI, LLA, AIS, MAG.

Rango altitudinal: 10-2250 m.

Países limítrofes: Argentina.

Agrostis insularis Rúgolo \& A.M. Molina

Hierba. Perenne. Endémica.

Distribución: LLA.

Rango altitudinal: $25-30 \mathrm{~m}$.

Agrostis leptotricha E. Desv.

Sinónimos: Agrostis lechleri Steud.

Hierba. Perenne. Nativa.

Distribución: VAL, RME, LBO, MAU, NUB, BIO, ARA, LRI, LLA, AIS, MAG.

Rango altitudinal: 5-2300 m.

Países limítrofes: Argentina.

Agrostis masafuerana Pilg.

Hierba. Perenne. Endémica.

Distribución: JFE.

Rango altitudinal: 880-1350 m.

Agrostis mertensii Trin.

Sinónimos: Agrostis williamsii Phil., Agrostis poeppigiana Phil.

Hierba. Perenne. Nativa.

Distribución: VAL, RME, LBO, MAU, NUB, BIO, ARA, LRI, LLA, AIS, MAG.

Rango altitudinal: $15-2200 \mathrm{~m}$.

Países limítrofes: Argentina, Bolivia y Perú.
Agrostis meyenii Trin.

Sinónimos: Agrostis conferta Nees \& Meyen

Hierba. Perenne. Nativa.

Distribución: COQ, VAL, RME, LBO, MAU, NUB, BIO,

ARA, LRI, LLA, AIS, MAG.

Rango altitudinal: 15-3200 m.

Países limítrofes: Argentina y Bolivia.

Agrostis perennans (Walter) Tuck.

Sinónimos: Agrostis tenuifolia M. Bieb. var. fretensis Hook.f., Agrostis flavidula Steud., Agrostis aberrans Steud., Agrostis violacea Phil., Agrostis exarata Trin. var. angustifolia Hack., Agrostis canina L. var. grandiflora Hack. hom. illeg.

Hierba. Perenne. Nativa.

Distribución: MAU, NUB, BIO, ARA, LRI, LLA, MAG.

Rango altitudinal: $10-2200 \mathrm{~m}$.

Países limítrofes: Argentina, Bolivia y Perú.

Agrostis philippiana Rúgolo \& De Paula

Sinónimos: Agrostis clausa Phil. hom. illeg.

Hierba. Perenne. Nativa.

Distribución: RME, MAU, NUB, BIO, LRI, LLA, AIS, MAG.

Rango altitudinal: 10-2070 m.

Países limítrofes: Argentina.

Agrostis scabra Willd.

Hierba. Perenne. Introducida.

Distribución: MAU, BIO, ARA, LRI, LLA, AIS, MAG.

Agrostis serranoi Phil.

Sinónimos: Agrostis vaginata Phil., Agrostis delfini Phil., Agrostis oligoclada Phil., Agrostis fuegiana Hack., Agrostis aristata Phil.

Hierba. Perenne. Nativa.

Distribución: VAL, ARA, LRI, LLA, AIS, MAG.

Rango altitudinal: 25-2000 m.

Países limítrofes: Argentina.

Nombre vulgar: Ilusión.

Agrostis stolonifera L. var. palustris (Huds.) Farw.

Hierba. Perenne. Introducida.

Distribución: ANT, ATA, VAL, MAU, NUB, BIO, ARA, LRI, LLA, AIS, MAG.

Agrostis stolonifera L. var. stolonifera

Hierba. Perenne. Introducida.

Distribución: TAR, ATA, COQ, VAL, MAU, NUB, BIO, ARA, LRI, LLA, AIS, MAG, JFE, IPA.

Agrostis tolucensis Kunth

Hierba. Perenne. Nativa.

Distribución: AYP, TAR. 
Rango altitudinal: 3930-4750 m.

Países limítrofes: Argentina, Bolivia y Perú.

Agrostis uliginosa Phil.

Sinónimos: Agrostis paucinodis Hack.

Hierba. Perenne. Nativa.

Distribución: NUB, ARA, LRI, LLA, AIS, MAG.

Rango altitudinal: 10-1500 m.

Países limítrofes: Argentina.

Agrostis umbellata Colla

Sinónimos: Agrostis chilensis Trin., Agrostis canina var. umbellata (Colla) Kuntze, Agrostis glabra Hochst. ex E. Desv., Agrostis paradisiaca Steud., Agrostis patens Trin., Agrostis stricta Trin.

Hierba. Anual o perenne. Endémica.

Distribución: VAL, RME, LBO, BIO, AIS.

Rango altitudinal: 70-2000 m.

Agrostis vidalii Phil.

Hierba. Perenne. Nativa.

Distribución: LLA.

Rango altitudinal: 15-1250 m.

Países limítrofes: Argentina.

Agrostis vinealis Schreb.

Hierba. Perenne. Introducida.

Distribución: COQ.

\section{Aira}

Aira caryophyllea L.

Hierba. Anual. Introducida.

Distribución: ANT, COQ, VAL, RME, LBO, MAU, NUB, BIO, ARA, LRI, LLA, AIS, MAG, JFE.

Aira elegantissima Schur

Hierba. Anual. Introducida.

Distribución: VAL, ARA.

Aira praecox $\mathrm{L}$.

Hierba. Anual. Introducida.

Distribución: VAL, LLA, AIS, MAG, JFE.

\section{Alopecurus}

Alopecurus aequalis Sobol.

Hierba. Anual. Introducida.

Distribución: MAG.

Alopecurus geniculatus L. var. geniculatus

Hierba. Perenne. Introducida.

Distribución: MAG.
Alopecurus geniculatus L. var. patagonicus Parodi

Hierba. Anual. Nativa.

Distribución: AIS, MAG.

Rango altitudinal: 300-550 m.

Países limítrofes: Argentina.

Alopecurus heleochloides Hack.

Hierba. Anual. Endémica.

Distribución: COQ, RME, MAG.

Rango altitudinal: 25-3000 m.

Alopecurus lechleri Steud.

Sinónimos: Alopecurus antarcticus Lechler ex Steud., nom. illeg. como sin. de Alopecurus lechleri Steud., Alopecurus antarcticus Vahl var. lechleri (Steud.) Parodi

Hierba. Perenne. Endémica.

Distribución: LRI.

Rango altitudinal: 10-10 m.

Alopecurus magellanicus Lam. var. bracteatus (Phil.) Mariano

Sinónimos: Alopecurus bracteatus Phil., Alopecurus antarcticus Vahl var. bracteatus (Phil.) Parodi

Hierba. Perenne. Nativa.

Distribución: BIO, LRI, LLA, AIS, MAG.

Rango altitudinal: 5-800 m.

Países limítrofes: Argentina, Bolivia y Perú.

\section{Alopecurus magellanicus Lam. var. magellanicus}

Sinónimos: Alopecurus antarcticus Vahl, Alopecurus alpinus Sm. var. antarcticus (Vahl) Macloskie \& Dusén, Alopecurus alpinus Sm. fma. antarctica (Vahl) Hack., Alopecurus alpinus Sm. var. aristatus Hook fma., nom. nud. Hierba. Perenne. Nativa.

Distribución: BIO, ARA, LRI, LLA, AIS, MAG.

Rango altitudinal: 5-1750 m.

Países limítrofes: Argentina, Bolivia y Perú.

Alopecurus myosuroides Huds.

Hierba. Anual. Introducida.

Distribución: MAG.

Alopecurus pratensis L.

Hierba. Perenne. Introducida.

Distribución: ARA, LRI, LLA, AIS, MAG.

\section{Amelichloa}

Amelichloa brachychaeta (Godr.) Arriaga \& Barkworth Sinónimos: Stipa brachychaeta Godr., Nassella brachychaeta (Godr.) Barkworth, Achnatherum brachychaetum (Godr.) Barkworth, Jarava brachychaeta (Godr.) Peñail.

Hierba. Perenne. Nativa. 
Distribución: VAL, RME, LBO, MAU, BIO.

Rango altitudinal: 120-120 m.

Países limítrofes: Argentina y Perú.

Amelichloa brevipes (E. Desv.) Arriaga \& Barkworth Sinónimos: Stipa brevipes E. Desv., Jarava brevipes (E. Desv.) Peñail.

Hierba. Perenne. Nativa.

Distribución: RME, AIS, MAG.

Rango altitudinal: 100-3325 m.

Países limítrofes: Argentina.

Amelichloa caudata (Trin.) Arriaga \& Barkworth

Sinónimos: Stipa caudata Trin., Achnatherum caudatum

(Trin.) S.W.L. Jacobs \& J. Everett, Jarava caudata (Trin.)

Peñail., Stipa bertrandii Phil., Stipa amphicarpa Phil., Stipa

litoralis Phil.

Hierba. Perenne. Nativa.

Distribución: COQ, VAL, RME, LBO, BIO, ARA.

Rango altitudinal: 20-950 m.

Países limítrofes: Argentina.

\section{Ammophila}

Ammophila arenaria (L.) Link

Hierba. Perenne. Introducida.

Distribución: COQ, VAL, MAU, ARA, LLA, MAG.

\section{Amphibromus}

Amphibromus scabrivalvis (Trin.) Swallen

Sinónimos: Avena scabrivalvis Trin., Bromus holciformis

Steud. \& Hochst., Helictotrichon scabrivalvis (Trin.)

Renvoize

Hierba. Perenne. Nativa.

Distribución: VAL, MAU, NUB, BIO, ARA, LRI.

Rango altitudinal: 10-450 m.

Países limítrofes: Argentina, Bolivia y Perú.

\section{Anatherostipa}

Anatherostipa bomanii (Hauman) Peñail.

Sinónimos: Nicoraella bomanii (Hauman) Torres, Stipa

bomanii Hauman

Hierba. Perenne. Nativa.

Distribución: AYP, TAR, ANT.

Rango altitudinal: 3750-4550 m.

Países limítrofes: Argentina.

Anatherostipa hans-meyeri (Pilg.) Peñail.

Sinónimos: Stipa hans-meyeri Pilg.

Hierba. Perenne. Nativa.

Distribución: AYP.

Rango altitudinal: 4000-4200 m.
Países limítrofes: Bolivia y Perú.

Anatherostipa mucronata (Griseb.) F. Rojas

Sinónimos: Piptochaetium mucronatum Griseb.

Hierba. Perenne. Nativa.

Distribución: TAR, ANT.

Rango altitudinal: 3500-4500 m.

Países limítrofes: Argentina.

Anatherostipa rigidiseta (Pilg.) Peñail.

Sinónimos: Oryzopsis rigidiseta Pilg.

Hierba. Perenne. Nativa.

Distribución: AYP, TAR, ANT.

Rango altitudinal: 3890-4100 m.

Países limítrofes: Bolivia y Perú.

Anatherostipa venusta (Phil.) Peñail.

Sinónimos: Stipa venusta Phil., Nicoraella venusta (Phil.)

Torres

Hierba. Perenne. Endémica.

Distribución: AYP, TAR, ANT.

Rango altitudinal: 3400-4600 m.

Nombre vulgar: Vizcachera.

\section{Anthoxanthum}

Anthoxanthum altissimum (Steud.) Veldkamp

Sinónimos: Hierochloe altissima Steud.

Hierba. Perenne. Endémica.

Distribución: BIO, ARA, LRI, LLA, AIS.

Rango altitudinal: 5-780 m.

Nombre vulgar: Paja ratonera.

Anthoxanthum gunckelii (Parodi) Veldkamp

Sinónimos: Hierochloe gunckelii Parodi

Hierba. Perenne. Nativa.

Distribución: BIO, ARA, LRI, LLA.

Rango altitudinal: 5-280 m.

Países limítrofes: Argentina.

Nombre vulgar: Paja ratonera.

Anthoxanthum juncifolium (Hack.) Veldkamp

Sinónimos: Hierochloejuncifolia (Hack.) Parodi, Hierochloe utriculata (Ruiz \& Pav.) Kunth var. juncifolia Hack.

Hierba. Perenne. Nativa.

Distribución: ARA, LRI, LLA, AIS.

Rango altitudinal: 20-1900 m.

Países limítrofes: Argentina.

Anthoxanthum odoratum L.

Hierba. Perenne. Introducida.

Distribución: MAU, NUB, BIO, ARA, LRI, LLA, AIS, MAG, JFE. 
Anthoxanthum pusillum (Hack. ex Dusén) Veldkamp

Sinónimos: Hierochloe pusilla Hack. ex Dusén

Hierba. Perenne. Nativa.

Distribución: MAG.

Rango altitudinal: 100-900 m.

Países limítrofes: Argentina.

Anthoxanthum redolens (Vahl) P. Royen

Sinónimos: Hierochloe redolens (Vahl) Roem. et Schult., Holcus redolens Vahl, Avena redolens (Vahl) Pers., Melica magellanica Desr., Hierochloe antarctica (Labill.) R. Brown var. redolens (Vahl) Brongn., Hierochloe redolens (Vahl) Roem. \& Schult. var. magellanica (Hook.f.) Macloskie, Hierochloe magellanica Hook.f., Hierochloe sorianoi De Paula

Hierba. Perenne. Nativa.

Distribución: COQ, BIO, LRI, LLA, AIS, MAG.

Rango altitudinal: 10-1320 m.

Países limítrofes: Argentina, Bolivia y Perú.

Nombre vulgar: Paja ratonera.

Anthoxanthum spicatum (Parodi) Veldkamp

Sinónimos: Hierochloe spicata Parodi

Hierba. Perenne. Endémica.

Distribución: ARA, MAG.

Rango altitudinal: $950-950 \mathrm{~m}$.

Nombre vulgar: Paja ratonera.

Anthoxanthum utriculatum (Ruiz \& Pav.) Y. Schouten \& Veldkamp

Sinónimos: Hierochloe utriculata (Ruiz \& Pav.) Kunth, Torresia utriculata Ruiz \& Pav., Hierochloe utriculata (Ruiz $\&$ Pav.) Kunth var. minor Desv.

Hierba. Perenne. Nativa.

Distribución: RME, MAU, NUB, BIO, ARA, LRI, LLA.

Rango altitudinal: 2-2500 m.

Países limítrofes: Argentina.

Nombre vulgar: Paja ratonera.

\section{Apera}

Apera interrupta (L.) P. Beauv.

Hierba. Anual. Introducida.

Distribución: RME, ARA.

\section{Aristida}

Aristida adscensionis L.

Sinónimos: Aristida bromoides Kunth., Aristida dispersa var. nana Trin. \& Rupr., Aristida festucoides Steud. \& Hoscht., Aristida nana Steud., Chaetaria bromoides Roem. \& Schult., Chaetaria nana Nees ex Steud., Aristida humilis Kunth, Aristida adscensionis L. var. bromoides (Kunth) Henrard
Hierba. Anual. Nativa.

Distribución: AYP, TAR, ANT, ATA, COQ, VAL, RME.

Rango altitudinal: 25-3660 m.

Países limítrofes: Argentina, Bolivia y Perú.

Aristida pallens Cav. var. intermedia Trin. \& Rupr.

Sinónimos: Aristida pallens var. geminata Caro

Hierba. Perenne. Nativa.

Distribución: NUB, BIO, ARA.

Rango altitudinal: 0-300 m.

Países limítrofes: Argentina.

Nombre vulgar: Coirón.

Aristida pallens Cav. var. pallens

Sinónimos: Aristida glaberrima Steud., Aristida pallens var. genuina Trin. \& Rupr., Chetaria pallens (Cav.) P. Beauv.

Hierba. Perenne. Nativa.

Distribución: MAU, NUB, BIO, ARA.

Rango altitudinal: 0-300 m.

Países limítrofes: Argentina.

Nombre vulgar: Coirón.

Aristida spegazzinii Arechav.

Sinónimos: Aristida pampeana Speg., Aristida spegazzinii var. abbreviata Hack., Aristida spegazzinii fma. colorata Hack., Aristida spegazzinii var. genuina Hack., Aristida spegazzinii var. pallescens Hack.

Hierba. Perenne. Nativa.

Distribución: NUB, BIO, ARA.

Rango altitudinal: $65-1700 \mathrm{~m}$.

Países limítrofes: Argentina.

\section{Arrhenatherum}

Arrhenatherum elatius (L.) P.Beauv. ex J.Presl \& C.Presl var. bulbosum (Willd.) Spenn.

Hierba. Perenne. Introducida.

Distribución: VAL, NUB, BIO, ARA, LRI, LLA, AIS, MAG.

Arrhenatherum elatius (L.) P.Beauv. ex J.Presl \& C.Presl var. elatius

Hierba. Perenne. Introducida.

Distribución: RME, BIO, ARA, LRI, LLA.

\section{Arundo}

Arundo donax L.

Hierba. Perenne. Introducida.

Distribución: AYP, TAR, ANT, ATA, COQ, RME, LBO, MAU, NUB, BIO, ARA. 


\section{Austrostipa}

Austrostipa scabra (Lindl.) S.W.L. Jacobs \& J. Everett Hierba. Perenne. Introducida.

Distribución: IPA.

\section{Avena}

Avena barbata Pott ex Link

Hierba. Anual. Introducida.

Distribución: ANT, COQ, VAL, RME, LBO, MAU, NUB, BIO, ARA, LLA, JFE.

Avena fatua L.

Hierba. Anual. Introducida.

Distribución: COQ, VAL, RME, LBO, MAU, NUB, BIO, ARA, LRI, LLA, IPA.

Avena sativa L.

Hierba. Anual. Introducida.

Distribución: MAU, NUB, BIO, ARA, LLA, MAG.

Avena sterilis L.

Hierba. Anual. Introducida.

Distribución: RME.

Avena strigosa Schreb.

Hierba. Anual. Introducida.

Distribución: BIO, LLA.

\section{Avenella}

Avenella flexuosa (L.) Drejer

Sinónimos: Aira flexuosa L., Deschampsia flexuosa (L.) Nees, Deschampsia flexuosa (L.) Trin., Deschampsia tenella Phil. hom. illeg., Deschampsia philippii Macloskie, Aira vestita Steud., Deschampsia vestita (Steud.) Hauman, Deschampsia martinii Phil., Avenella flexuosa (L.) Parl.

Hierba. Perenne. Nativa.

Distribución: BIO, LLA, AIS, MAG.

Rango altitudinal: 5-1000 m.

Países limítrofes: Argentina.

\section{Axonopus}

Axonopus compressus (Sw.) P. Beauv.

Sinónimos: Axonopus paschalis (Stapf) Pilg., Paspalum paschale Stapf, Paspalum scoparium Flüggé var. oligostachyum Hack. ex Fuentes, Milium compressum Sw.

Hierba. Perenne. Nativa.

Distribución: IPA.

Rango altitudinal: 5-400 m.

Países limítrofes: Argentina, Bolivia y Perú.

Nombre vulgar: Heriki hare (Rapa Nui).

\section{Bothriochloa}

Bothriochloa barbinodis (Lag.) Herter

Sinónimos: Andropogon barbinodis Lag.

Hierba. Perenne. Nativa.

Distribución: TAR.

Rango altitudinal: 400-3000 m.

Países limítrofes: Argentina, Bolivia y Perú.

Bothriochloa ischaemum (L.) Keng

Hierba. Perenne. Introducida.

Distribución: IPA.

Bothriochloa laguroides (DC.) Herter

Sinónimos: Andropogon laguroides DC.

Hierba. Perenne. Introducida.

Distribución: VAL, MAU, NUB, BIO, ARA.

Rango altitudinal: 10-1000 m.

Nombre vulgar: Cola de zorro.

Bothriochloa saccharoides (Sw.) Rydb. subsp. australis Scrivanti

Hierba. Perenne. Nativa.

Distribución: VAL.

Rango altitudinal: 120-2600 m.

Países limítrofes: Argentina, Bolivia y Perú.

Nombre vulgar: Coirón.

Bothriochloa saccharoides (Sw.) Rydb. subsp. parvispiculus (Hitchc.) Davidse

Sinónimos: Andropogon saccharoides Sw. subsp. parvispiculus Hitchc., Andropogon cacharoides Sw. var. parvispiculus (Hitchc.) Standl., Bothriochloa saccharoides var. parvispiculus (Hitchc.) Tovar

Hierba. Perenne. Nativa.

Distribución: VAL.

Países limítrofes: Argentina, Bolivia y Perú.

Bothriochloa saccharoides (Sw.) Rydb. subsp. saccharoides Sinónimos: Andropogon saccharoides Sw., Andropogon berteronianus Steud.

Hierba. Perenne. Nativa.

Distribución: VAL, MAU, NUB, BIO, ARA.

Rango altitudinal: 10-740 m.

Países limítrofes: Argentina y Perú.

\section{Bouteloua}

Bouteloua simplex Lag.

Sinónimos: Chondrosum tenue P. Beauv. ex Kunth, Bouteloua tenuis (P. Beauv. ex Kunth) Griseb., Chondrosum humile P. Beauv. ex Kunth, Bouteloua tenuis var. humilis (P. Beauv. ex Kunth) Griseb., Bouteloua brachyanthera Phil., Bouteloua rahmeri Phil., Bouteloua simplex var. rahmeri 
(Phil.) Henrard

Hierba. Anual. Nativa.

Distribución: AYP, TAR, ANT.

Rango altitudinal: $2700-4000 \mathrm{~m}$.

Países limítrofes: Argentina, Bolivia y Perú.

\section{Brachypodium}

Brachypodium distachyon (L.) P. Beauv.

Hierba. Perenne. Introducida.

Distribución: COQ, VAL, LBO, MAU, BIO, JFE.

\section{Briza}

Briza maxima L.

Hierba. Anual. Introducida.

Distribución: ATA, VAL, RME, LBO, MAU, NUB, BIO, ARA, LRI, LLA, MAG, JFE.

\section{Briza minor L.}

Hierba. Anual. Introducida.

Distribución: ATA, COQ, VAL, RME, LBO, MAU, NUB, BIO, ARA, LRI, LLA, JFE, IPA.

\section{Bromelica}

Bromelica cepacea (Phil.) Nicora

Sinónimos: Festuca cepacea Phil., Melica cepacea (Phil.)

Scribn.

Hierba. Perenne. Nativa.

Distribución: RME, LBO, MAU, ARA.

Rango altitudinal: 1000-3500 m.

Países limítrofes: Argentina.

\section{Bromidium}

Bromidium anomalum (Trin.) Döll.

Sinónimos: Aira anomala Trin., Agrostis koelerioides E. Desv., Deyeuxia anomala (Trin.) Benth. \& Hook.f., Bromidium hygrometricum (Nees) Nees \& Meyen var. anomalum (Trin.) Kuntze, Agrostis anomala (Trin.) Herter, Koeleria chilensis Steud., nom. nud., Didymochaeta chilensis Steud.

Hierba. Anual. Nativa.

Distribución: COQ, VAL, RME, LBO, MAU, NUB, BIO, ARA, LRI.

Rango altitudinal: 10-900 m.

Países limítrofes: Argentina y Perú.

Bromidium trisetoides (Steud.) Rúgolo

Sinónimos: Agrostis trisetoides Steud.

Hierba. Anual. Endémica.

Distribución: COQ, MAU, NUB, BIO, ARA, LRI.

Rango altitudinal: 25-300 m.

\section{Bromus}

Bromus araucanus Phil.

Sinónimos: Bromus alpestris Steud.

Hierba. Perenne. Nativa.

Distribución: ARA, MAG.

Rango altitudinal: 600-900 m.

Países limítrofes: Argentina.

Bromus berteroanus Colla

Sinónimos: Trisetum hirtum Trin., Avena villosula Kunze ex E. Desv., Trisetum barbartum Steud., Bromus trinii E. Desv. var. micranthera E. Desv., Bromus trinii E. Desv. var. pallidiflora E. Desv., Bromus trinii E. Desv. var. manicata E. Desv., Bromus trinii E. Desv. var. stricta E. Desv., Bromus bicuspis Nees ex Steud., Danthonia pseudo-spicata Muell., Trisetum litorale Phil., Trisetum trinii (E. Desv.) LouisMarie var. pallidiflorus (E. Desv.) Louis-Marie, Trisetum trinii (E. Desv.) var. manicatum (E. Desv.) Louis-Marie, Trisetum trinii (E. Desv.) Louis-Marie var. micrantherum (E. Desv.) Louis-Marie, Trisetum trinii (E. Desv.) LouisMarie var. strictum (E. Desv.) Louis-Marie, Trisetum trinii (E. Desv.) Louis-Marie var. litorale (Phil.) Louis-Marie, Trisetobromus hirtus (Trin.) Nevski

Hierba. Anual. Nativa.

Distribución: AYP, ANT, ATA, COQ, VAL, RME, LBO, MAU, NUB, BIO, ARA, AIS, JFE.

Rango altitudinal: 5-1600 m.

Países limítrofes: Argentina, Bolivia y Perú.

Bromus burkartii Muñoz

Hierba. Perenne. Endémica.

Distribución: ARA.

Rango altitudinal: 1080-1490 m.

Bromus catharticus Vahl var. catharticus

Sinónimos: Bromus haenkeanus (J. Presl) Kunth, Ceratochloa haenkeana J. Presl, Bromus willdenowii Kunth var. haenkeanus, Bromus unioloides Kunth var. haenkeanus (J. Presl) Shear

Hierba. Anual, bienal o perenne. Nativa.

Distribución: AYP, TAR, ANT, ATA, COQ, VAL, RME, LBO, MAU, NUB, BIO, ARA, LRI, LLA, AIS, MAG, JFE, IPA.

Rango altitudinal: 5-4550 m.

Países limítrofes: Argentina, Bolivia y Perú.

Bromus catharticus Vahl var. elatus (E. Desv.) Planchuelo Sinónimos: Bromus cebadilla Steud., Bromus stamineus E. Desv., Bromus valdivianus Phil., Bromus unioloides fma. elatus (E. Desv.) Allen \& Thell. ex Kloos, Ceratochloa valdiviana (Phil.) Holub, Ceratochloa staminea (E. Desv.) Stace, Bromus catharticus subsp. stamineus (E. Desv.) Massa 
Hierba. Anual, bienal o perenne. Nativa.

Distribución: AYP, ANT, COQ, VAL, RME, LBO, MAU, NUB, BIO, ARA, LRI, LLA, AIS, MAG, JFE.

Rango altitudinal: 2-4680 m.

Países limítrofes: Argentina.

Nombre vulgar: Lanco, cebadilla, pasto del perro.

Nota: Introducida en el Archipiélago Juan Fernández.

\section{Bromus coloratus Steud.}

Sinónimos: Bromus patagonicus Phil., Bromus unioloides Kunth var. coloratus (Steud.) Pilg., Ceratochloa colorata (Steud.) Holub

Hierba. Perenne. Nativa. Distribución: RME, ARA, LRI, LLA, AIS, MAG.

Rango altitudinal: 25-1490 m.

Países limítrofes: Argentina.

Bromus erectus Huds.

Hierba. Perenne. Introducida.

Distribución: BIO, MAG.

\section{Bromus gunckelii Matthei}

Hierba. Anual. Endémica.

Distribución: AYP, TAR.

Rango altitudinal: 3100-3740 m.

\section{Bromus hordeaceus L.}

Hierba. Anual. Introducida.

Distribución: COQ, VAL, RME, LBO, MAU, NUB, BIO, ARA, LRI, LLA, AIS, MAG, JFE.

Bromus lanatus Kunth

Hierba. Perenne. Nativa.

Distribución: AYP, TAR.

Rango altitudinal: 4100-4720 m.

Países limítrofes: Argentina, Bolivia y Perú.

\section{Bromus lanceolatus Roth}

Hierba. Perenne. Introducida.

Distribución: MAU.

\section{Bromus lithobius Trin.}

Sinónimos: Bromus unioloides var. humilis E. Desv., Bromus chilensis Trin., Bromus fonckii Phil., Bromus scaber Phil., Bromus andinus Phil.

Hierba. Perenne. Nativa.

Distribución: COQ, VAL, RME, MAU, NUB, BIO, ARA, LRI, LLA, AIS, JFE.

Rango altitudinal: 2-1900 m.

Países limítrofes: Argentina.

Nota: Introducida en el Archipiélago Juan Fernández.

Bromus madritensis L.

Hierba. Anual. Introducida.
Distribución: COQ, VAL, MAU, ARA.

Bromus mango E. Desv.

Sinónimos: Ceratochloa mango (E. Desv.) Holub

Hierba. Perenne. Nativa.

Distribución: RME, ARA.

Rango altitudinal: 349-1490 m.

Países limítrofes: Argentina.

Nombre vulgar: Mango.

Bromus pellitus Hack.

Hierba. Perenne. Nativa.

Distribución: MAG.

Rango altitudinal: 800-900 m.

Países limítrofes: Argentina.

Bromus racemosus L.

Hierba. Anual. Introducida.

Distribución: LLA, MAG.

Bromus rigidus Roth

Hierba. Anual. Introducida.

Distribución: ATA, COQ, VAL, RME, LBO, MAU, NUB, BIO, ARA, LRI, LLA, AIS, JFE.

Bromus scoparius L.

Hierba. Anual. Introducida.

Distribución: VAL, RME, LBO, BIO.

Bromus secalinus L.

Hierba. Anual. Introducida.

Distribución: BIO, ARA, LRI, LLA, AIS, MAG.

Bromus setifolius J. Presl var. brevifolius Nees

Sinónimos: Bromus macranthos Meyen, Bromus macranthos Meyen ex E. Desv. var. macrantha

Hierba. Perenne. Nativa.

Distribución: ATA, COQ, VAL, RME, MAU, NUB, BIO, ARA, AIS, MAG.

Rango altitudinal: 15-3950 m.

Países limítrofes: Argentina.

Bromus setifolius J. Presl var. pictus (Hook.) Skottsb.

Sinónimos: Bromus pictus Hook.f., Bromus macranthos E. Desv. var. minor E. Desv., Bromus setifolius J. Presl var. pictus (Hook.f.) J.A. Cámara

Hierba. Perenne. Nativa.

Distribución: RME, MAG.

Rango altitudinal: 15-2500 m.

Países limítrofes: Argentina.

Bromus setifolius J. Presl var. setifolius

Sinónimos: Bromus macranthos Meyen var. setifolius (J. Presl) E. Desv. 
Hierba. Perenne. Nativa.

Distribución: ATA, COQ, VAL, RME, LBO, MAU, NUB, BIO, AIS, MAG.

Rango altitudinal: 80-3600 m.

Países limítrofes: Argentina.

Bromus squarrosus L.

Hierba. Anual. Introducida.

Distribución: RME, BIO, LLA.

Bromus stamineus E.Desv.

Hierba. Perenne. Introducida.

Distribución: ANT, COQ, VAL, RME, MAU, NUB, BIO,

ARA, LLA, MAG, JFE.

Bromus sterilis L.

Hierba. Anual. Introducida.

Distribución: VAL, RME, LBO, BIO, ARA, LLA, MAG.

\section{Bromus tectorum L.}

Hierba. Anual. Introducida.

Distribución: LBO, MAU, ARA, LLA.

Bromus tunicatus Phil.

Sinónimos: Bromus culmineus Phil.

Hierba. Perenne. Nativa.

Distribución: RME, LBO, MAU, NUB, BIO, ARA, AIS, MAG.

Rango altitudinal: 5-3600 m.

Países limítrofes: Argentina.

\section{Calotheca}

Calotheca brizoides (Lam.) Desv.

Sinónimos: Bromus brizoides Lam., Briza patula Phil., Chascolytrum brizoides (Lam.) Essi, Longhi-Wagner \& Souza-Chies

Hierba. Perenne. Nativa.

Distribución: LBO, MAU, NUB, BIO, ARA.

Rango altitudinal: 10-350 m.

Países limítrofes: Argentina.

\section{Catabrosa}

Catabrosa aquatica (L.) P. Beauv.

Hierba. Perenne. Introducida.

Distribución: MAG.

Catabrosa werdermannii (Pilg.) Nicora \& Rúgolo

Sinónimos: Phippsia werdermannii Pilg., Phippsia werdermannii Pilg. fma. minor Pilg., Phippsia weredermannii Pilg. fma. major Pilg.

Hierba. Perenne. Nativa.

Distribución: AYP, TAR, ANT, ATA, COQ.
Rango altitudinal: 1900-4700 m.

Países limítrofes: Argentina y Bolivia.

\section{Catapodium}

Catapodium rigidum (L.) C.E. Hubb.

Hierba. Anual. Introducida.

Distribución: COQ, VAL, RME, BIO, ARA, LRI, LLA, MAG.

\section{Cenchrus}

Cenchrus chilensis (E. Desv.) Morrone

Sinónimos: Gymnotrix chilensis E. Desv., Pennisetum chilense (E. Desv.) B.D. Jacks. ex R.R. Fr.

Hierba. Perenne. Nativa.

Distribución: TAR, ANT, ATA, COQ, VAL.

Rango altitudinal: 430-3300 m.

Países limítrofes: Argentina y Bolivia.

Cenchrus clandestinus (Hochst. ex Chiov.) Morrone

Hierba. Perenne. Introducida.

Distribución: ATA, COQ, VAL, RME, IPA.

Cenchrus echinatus L.

Hierba. Anual. Introducida.

Distribución: AYP, MAU, LRI, LLA, IPA.

Cenchrus longisetus M.C. Johnst.

Hierba. Perenne. Introducida.

Distribución: RME.

Cenchrus myosuroides Kunth

Hierba. Perenne. Introducida.

Distribución: AYP, TAR, ATA, MAU.

Cenchrus spinifex Cav.

Hierba. Anual o bienal. Nativa.

Distribución: AYP, TAR, ATA, MAU.

Rango altitudinal: 50-2700 m.

Países limítrofes: Argentina, Bolivia y Perú.

\section{Chascolytrum}

Chascolytrum koelerioides (Trin.) Essi, Longhi-Wagner \& Souza-Chies

Sinónimos: Gymnachne koelerioides (Trin.) Parodi, Rhombolytrum berteroanum E. Desv., Poa tenuiculmis Steud., Gymnachne jaffuelii Parodi, Poa philippii Steud., Poa koelerioides Trin.

Hierba. Perenne. Endémica.

Distribución: VAL, LBO, MAU, NUB, BIO, ARA, LRI.

Rango altitudinal: 5-1300 m. 
Chascolytrum rhomboideum (Link) L. Essi, LonghiWagner Souza Chies

Sinónimos: Rhombolytrum rhomboideum Link, Poa tumidula Steud., Rhombolytrum quinquenervium Phil.

Hierba. Perenne. Endémica.

Distribución: VAL, RME, LBO, MAU.

Rango altitudinal: 80-900 m.

Chascolytrum subaristatum (Lam.) Desv.

Sinónimos: Briza subaristata Lam., Calotheca stricta Hook. \& Arn., Briza stricta (Hook. \& Arn.) Steud., Briza violascens

Steud., Briza berteroniana Steud., Festuca commersonii Spreng., nom. illeg. illeg.

Hierba. Perenne. Nativa.

Distribución: COQ, VAL, RME, LBO, MAU, NUB, BIO, ARA, LRI, LLA, JFE.

Rango altitudinal: 0-1500 m.

Países limítrofes: Argentina y Bolivia.

\section{Chloris}

Chloris gayana Kunth

Hierba. Perenne. Introducida.

Distribución: IPA.

Chloris radiata (L.) Sw.

Hierba. Anual. Introducida.

Distribución: AYP.

Chloris virgata $\mathrm{Sw}$.

Hierba. Anual. Introducida.

Distribución: AYP.

Rango altitudinal: 50-840 m.

\section{Chusquea}

Chusquea argentina Parodi

Sinónimos: Chusquea culeou E. Desv. fma. longiramea Parodi

Hierba. Perenne. Nativa.

Distribución: LLA.

Rango altitudinal: 440-440 m.

Países limítrofes: Argentina.

Nombre vulgar: Coligüe, Colihue.

\section{Chusquea ciliata Phil.}

Hierba. Perenne. Endémica.

Distribución: VAL, RME.

Rango altitudinal: 400-400 m.

Chusquea culeou E. Desv.

Sinónimos: Chusquea andina Phil., Chusquea breviglumis Phil.

Hierba. Perenne. Nativa.
Distribución: COQ, VAL, LBO, MAU, NUB, BIO, ARA, LRI, LLA, AIS.

Rango altitudinal: 0-2060 m.

Países limítrofes: Argentina.

Nombre vulgar: Coligüe, colihue.

Chusquea cumingii Nees

Sinónimos: Chusquea parvifolia Phil.

Hierba. Perenne. Endémica.

Distribución: COQ, VAL, RME, LBO, MAU, NUB.

Rango altitudinal: 5-1600 m.

Nombre vulgar: Coligüe, Colihue, quila, quila chica, colihue de la zona central.

Chusquea fernandeziana Phil.

Hierba. Perenne. Endémica.

Distribución: JFE.

Rango altitudinal: 412-830 m.

Nombre vulgar: Colihue.

Chusquea macrostachya Phil.

Hierba. Perenne. Endémica.

Distribución: RME, LRI, LLA.

Rango altitudinal: 70-885 m.

Nombre vulgar: Quila, itihue, taihuén.

Chusquea montana Phil. fma. montana

Hierba. Perenne. Nativa.

Distribución: NUB, LRI, LLA, AIS.

Rango altitudinal: $60-2280 \mathrm{~m}$.

Países limítrofes: Argentina.

Nombre vulgar: Quila enana, tihuén.

Chusquea montana Phil. fma. nigricans (Phil.) Matthei

Sinónimos: Chusquea nigricans Phil.

Hierba. Perenne. Endémica.

Distribución: LRI, LLA, AIS.

Nombre vulgar: Quila enana.

Chusquea quila Kunth

Sinónimos: Nastus prolifer Desv., Chusquea quila var. laxiflora E. Desv., C. parvifolia Phil., C. parviflora Phil.

Hierba. Perenne. Endémica.

Distribución: LBO, MAU, NUB, BIO, ARA, LRI, LLA, AIS.

Rango altitudinal: 5-1600 m.

Nombre vulgar: Quila.

Chusquea uliginosa Phil.

Sinónimos: Chusquea tenuiflora Phil.

Hierba. Perenne. Endémica.

Distribución: LRI, LLA, AIS.

Rango altitudinal: 5-1500 m.

Nombre vulgar: Quila chica, quila de los ñadis. 
Chusquea valdiviensis E. Desv.

Hierba. Perenne. Nativa.

Distribución: NUB, BIO, ARA, LRI, LLA.

Rango altitudinal: 10-800 m.

Países limítrofes: Argentina.

Nombre vulgar: Quila, quila del sur, quila vutre.

\section{Coix}

Coix lacryma-jobi L.

Hierba. Anual. Introducida.

Distribución: IPA.

\section{Cortaderia}

Cortaderia araucana Stapf emend. Testoni \& Villamil Sinónimos: Cortaderia araucana Stapf, Cortaderia araucana Stapf var. fuenzalidae Acevedo, Cortaderia araucana Stapf var. skottsbergii Acevedo, Cortaderia longicauda Hack.

Hierba. Perenne. Nativa.

Distribución: COQ, VAL, RME, LBO, MAU, NUB, BIO, ARA, LRI, LLA, AIS.

Rango altitudinal: 5-2200 m.

Países limítrofes: Argentina.

Nombre vulgar: Cola de zorro.

Cortaderia egmontiana (Roem. \& Schult.) M. Lyle ex Connor

Sinónimos: Arundo egmontiana Roem. \& Schult., Calamagrostis patula Steud., Calamagrostis scirpiformis Phil., Cortaderia minima Conert, Cortaderia pilosa (d’Urv.) Hack., Cortaderia pilosa (d'Urv.) Hack. var. minima (Conert) Nicora, Poa phragmites Phil.

Hierba. Perenne. Nativa.

Distribución: RME, MAU, NUB, BIO, ARA, LLA, AIS, MAG.

Rango altitudinal: 10-2500 m.

Países limítrofes: Argentina.

Nombre vulgar: Cola de zorro.

Cortaderia selloana (Schult. \& Schult.f.) Asch. \& Graebn. emend. Testoni \& Villamil subsp. jubata (Lemoine) Testoni \& Villamil

Hierba. Perenne. Nativa.

Distribución: AYP, TAR, ANT, ATA, COQ.

Países limítrofes: Argentina.

Nombre vulgar: Cortadera.

Cortaderia selloana (Schult. \& Schult.f.) Asch. \& Graebn. emend. Testoni \& Villamil subsp. selloana

Sinónimos: Arundo selloana Schult. \& Schult.f.

Hierba. Perenne. Nativa.

Distribución: AYP, TAR, ANT, ATA, COQ, VAL, RME,
NUB, BIO, ARA, LLA, AIS, IPA.

Rango altitudinal: 10-3550 m.

Países limítrofes: Argentina y Bolivia.

Nombre vulgar: Cortadera.

Nota: Introducida en la Isla de Pascua.

Cortaderia speciosa (Nees \& Meyen) Stapf

Sinónimos: Gynerium speciosum Nees \& Meyen, Arundo quila Mol., Gynerium quila (Mol.) Nees \& Meyen, Gynerium argenteum Nees var. parviflorum E. Desv., Gynerium argenteum Nees var. strictum E. Desv., Gynerium atacamense Phil., Cortaderia rudiuscula Stapf, Moorea speciosa (Nees \& Meyen) Stapf, Cortaderia atacamensis (Phil.) Pilg., Cortaderia rudiuscula Stapfma. emend. Acevedo

Hierba. Perenne. Nativa.

Distribución: AYP, TAR, ANT, ATA, COQ, VAL, RME, LBO, MAU, NUB, BIO, ARA, IPA.

Rango altitudinal: $3450 \mathrm{~m}$.

Países limítrofes: Argentina, Bolivia y Perú.

Nombre vulgar: Espural, espuro.

\section{Corynephorus}

Corynephorus divaricatus (Pourr.) Breistr.

Hierba. Anual. Introducida.

Distribución: BIO.

\section{Cymbopogon}

Cymbopogon citratus (DC.) Stapf

Hierba. Perenne. Introducida.

Distribución: TAR.

\section{Cynodon}

Cynodon affinis Caro \& E.A. Sánchez

Sinónimos: Cynodon dactylon (L.) Pers. var. affinis (Caro \& E.A. Sánchez) Romero Zarco

Hierba. Perenne. Nativa.

Distribución: AYP, TAR, COQ, VAL, RME, NUB.

Rango altitudinal: 10-900 m.

Países limítrofes: Argentina y Perú.

Cynodon dactylon (L.) Pers.

Hierba. Perenne. Introducida.

Distribución: AYP, TAR, ANT, ATA, COQ, VAL, RME, LBO, MAU, NUB, BIO, IPA.

Nombre vulgar: Mati (Rapa Nui).

Cynodon nitidus Caro \& E.A. Sánchez

Hierba. Perenne. Endémica.

Distribución: AYP, TAR. 


\section{Cynosurus}

\section{Cynosurus cristatus L.}

Hierba. Perenne. Introducida.

Distribución: VAL, BIO, AIS, MAG.

Cynosurus echinatus L.

Hierba. Anual. Introducida.

Distribución: VAL, RME, LBO, MAU, NUB, BIO, ARA, LRI, LLA, AIS, MAG, JFE.

\section{Dactylis}

Dactylis glomerata L.

Hierba. Perenne. Introducida.

Distribución: VAL, RME, LBO, MAU, NUB, BIO, ARA, LRI, LLA, AIS, MAG, JFE.

\section{Danthonia}

Danthonia araucana Phil.

Hierba. Perenne. Endémica.

Distribución: VAL, LBO, MAU, NUB, BIO, ARA, LRI.

Rango altitudinal: 10-930 m.

Danthonia californica Boland. var. americana (Scribn.) Hitchc.

Sinónimos: Danthonia grandiflora Phil.

Hierba. Perenne. Nativa.

Distribución: MAU, NUB, BIO, ARA.

Rango altitudinal: 60-450 m.

Danthonia chilensis E. Desv. var. aureofulva (E. Desv.) C.M. Baeza

Sinónimos: Danthonia aureofulva E. Desv.

Hierba. Perenne. Endémica.

Distribución: VAL, LBO, MAU, NUB, BIO, ARA, LRI, LLA.

Rango altitudinal: 5-630 m.

Danthonia chilensis E. Desv. var. chilensis

Sinónimos: Avena ariguensis Steud.

Hierba. Perenne. Nativa.

Distribución: VAL, LBO, MAU, NUB, BIO, ARA, LRI, LLA, JFE.

Rango altitudinal: 10-820 m.

Países limítrofes: Argentina.

Danthonia chilensis E. Desv. var. glabriflora Nicora

Sinónimos: Danthonia calva Phil.

Hierba. Perenne. Nativa.

Distribución: LRI, LLA.

Rango altitudinal: 25-480 m.

Países limítrofes: Argentina.
Danthonia decumbens (L.) DC.

Hierba. Perenne. Introducida.

Distribución: LLA.

Danthonia malacantha (Steud.) Pilg.

Sinónimos: Trisetum malacanthum Steud., Danthonia collina Phil., Danthonia octoflora Phil., Danthonia oresigena Phil.

Hierba. Perenne. Endémica.

Distribución: COQ, VAL, LBO, MAU, NUB, BIO, ARA, LRI, JFE.

Rango altitudinal: 5-1700 m.

\section{Deschampsia}

Deschampsia airiformis (Steud.) Benth. \& Hook.f.

Sinónimos: Trisetum airiforme Steud., Agrostis desvauxii

Phil.

Hierba. Anual. Nativa.

Distribución: RME, NUB, ARA, AIS.

Rango altitudinal: 60-2200 m.

Países limítrofes: Argentina.

Deschampsia antarctica E. Desv.

Sinónimos: Aira antarctica Hook. fma. hom. illeg., Airidium elegantulum Steud., Deschampsia elegantula (Steud.) Parodi, Deschampsia fueguina Phil.

Hierba. Perenne. Nativa.

Distribución: MAU, MAG.

Rango altitudinal: 10-900 m.

Países limítrofes: Argentina.

Deschampsia berteroana (Kunth) Trin.

Sinónimos: Trisetum berteroanum Kunth, Aira berteroniana (Kunth) Steudel, Monandraira berteroana (Kunth) E. Desv., Deschampsia berteroana (Kunth) fma. Meigen, Deschampsia beroana (Kunth) Trin. var. parvispicula Parodi

Hierba. Anual. Nativa.

Distribución: COQ, VAL, RME, LBO, MAU, NUB, BIO.

Rango altitudinal: 10-3000 m.

Países limítrofes: Argentina.

Deschampsia caespitosa (L.) P. Beauv. var. caespitosa Sinónimos: Aira caespitosa L., Deschampsia andina Phil. Hierba. Perenne. Nativa.

Distribución: ATA, COQ, VAL, RME, MAU, NUB, BIO, ARA, LLA, AIS, MAG.

Rango altitudinal: 5-4200 m.

Países limítrofes: Argentina y Bolivia.

Deschampsia caespitosa (L.) P. Beauv. var. pulchra (Nees \& Meyen) Nicora

Sinónimos: Deschampsia pulchra Nees \& Meyen, Aira pulchra (Nees \& Meyen) Steud. 
Hierba. Perenne. Nativa.

Distribución: LBO, MAU, NUB, BIO.

Rango altitudinal: $1600-4000 \mathrm{~m}$.

Países limítrofes: Argentina.

Deschampsia cordilleranum Hauman

Hierba. Perenne. Nativa.

Distribución: COQ, RME.

Rango altitudinal: 3200-3500 m.

Países limítrofes: Argentina.

Deschampsia danthonioides (Trin.) Munro

Sinónimos: Aira danthonioides Trin.

Hierba. Anual. Nativa.

Distribución: COQ, LBO.

Rango altitudinal: 40-700 m.

Deschampsia elongata (Hook.) Munro

Sinónimos: Aira elongata Hook., Aira aciphylla Franch., Aira aciphylla Franch. var. pumila Franch., Deschampsia aciphylla (Franch.) Speg.

Hierba. Perenne. Nativa.

Distribución: COQ, ARA, AIS, MAG.

Rango altitudinal: 10-2800 m.

Países limítrofes: Argentina.

Deschampsia kingii (Hook.f.) E. Desv.

Sinónimos: Aira kingii Hook.f., Deschampsia kingii

(Hook.f.) Macloskie, Aira elatior Steud.

Hierba. Perenne. Nativa.

Distribución: ARA, AIS, MAG.

Rango altitudinal: 5-1300 m.

Países limítrofes: Argentina.

Deschampsia laxa Phil.

Sinónimos: Calamagrostis hirthii Phil.

Hierba. Perenne. Nativa.

Distribución: LLA, AIS, MAG.

Rango altitudinal: $10-485 \mathrm{~m}$.

Países limítrofes: Argentina.

Deschampsia looseriana Parodi var. looseriana

Hierba. Anual. Endémica.

Distribución: COQ, VAL, RME, LBO, MAU, BIO.

Rango altitudinal: 10-2475 m.

Deschampsia looseriana Parodi var. triandra Parodi

Hierba. Anual. Endémica.

Distribución: RME.

Rango altitudinal: 500-500 m.

Deschampsia micrantha Phil.

Hierba. Perenne. Endémica.

Distribución: COQ.
Rango altitudinal: $\mathrm{m}$.

Deschampsia monandra Parodi

Sinónimos: Deschampsia glauca (E. Desv.) Parodi, hom. illeg., Monandraira glauca E. Desv.

Hierba. Perenne. Endémica.

Distribución: VAL, RME, NUB, ARA.

Rango altitudinal: 45-3500 m.

Deschampsia parvula (Hook.f.) E. Desv.

Sinónimos: Aira parvula Hook.f., Trisetum parvulum

(Hook.f.) Speg., Deschampsia parvula (Hook.f.) Macloskie

Hierba. Perenne. Nativa.

Distribución: AIS, MAG.

Rango altitudinal: 20-1100 m.

Países limítrofes: Argentina.

Deschampsia patula (Phil.) Pilg. ex Skottsb.

Sinónimos: Monandraira patula Phil., Deschampsia

elegantula (Steud.) Parodi var. patula (Phil.) Parodi

Hierba. Perenne. Nativa.

Distribución: MAG.

Rango altitudinal: 10-900 m.

Países limítrofes: Argentina.

Deschampsia setacea (Huds.) Hack.

Hierba. Perenne. Introducida.

Distribución: COQ, VAL, RME.

Deschampsia venustula Parodi

Hierba. Perenne. Nativa.

Distribución: RME, MAU, MAG.

Rango altitudinal: 900-3400 m.

Países limítrofes: Argentina.

\section{Deyeuxia}

Deyeuxia breviaristata Wedd.

Sinónimos: Deyeuxia variegata Phil., Calamagrostis variegata (Phil.) Kuntze

Hierba. Perenne. Nativa.

Distribución: AYP, TAR, ANT, RME.

Rango altitudinal: $3700-4810 \mathrm{~m}$.

Países limítrofes: Argentina, Bolivia y Perú.

Nombre vulgar: Pasto vicuña.

Deyeuxia brevifolia J. Presl var. brevifolia

Sinónimos: Calamagrostis brevifolia (J. Presl) Steud.

Hierba. Perenne. Nativa.

Distribución: AYP, TAR, ANT.

Rango altitudinal: 3000-4700 m.

Países limítrofes: Argentina, Bolivia y Perú. 
Deyeuxia brevifolia J. Presl var. expansa Rúgolo \& Villav. Hierba. Perenne. Nativa.

Distribución: TAR.

Rango altitudinal: 3200-3900 m.

Países limítrofes: Bolivia y Perú.

Deyeuxia cabrerae (Parodi) Parodi var. aristulata Rúgolo \& Villav.

Sinónimos: Calamagrostis cabrerae Parodi var. aristulata (Rúgolo \& Villav.) Soreng

Hierba. Perenne. Nativa.

Distribución: ANT, ATA.

Rango altitudinal: 3200-4600 m.

Países limítrofes: Argentina y Bolivia.

Deyeuxia cabrerae (Parodi) Parodi var. cabrerae

Sinónimos: Calamagrostis cabrerae Parodi

Hierba. Perenne. Nativa.

Distribución: ANT.

Rango altitudinal: 3600-4200 m.

Países limítrofes: Argentina.

Deyeuxia cabrerae (Parodi) Parodi var. trichopoda Parodi ex Rúgolo

Sinónimos: Calamagrostis cabrerae Parodi var. trichopoda (Rúgolo) Soreng

Hierba. Perenne. Nativa.

Distribución: ANT, ATA.

Rango altitudinal: 3700-4570 m.

Países limítrofes: Argentina y Perú.

Deyeuxia chrysantha J. Presl var. chrysantha

Sinónimos: Calamagrostis nitida Hack.

Hierba. Perenne. Nativa.

Distribución: AYP, TAR, ANT, COQ.

Rango altitudinal: $3500-5000 \mathrm{~m}$.

Países limítrofes: Argentina, Bolivia y Perú.

Nombre vulgar: Sora.

Deyeuxia chrysantha J. Presl var. phalaroides (Wedd.) Villav.

Sinónimos: Deyeuxia phalaroides Wedd.

Hierba. Perenne. Nativa.

Distribución: AYP, TAR, ANT.

Rango altitudinal: 4100-5000 m.

Países limítrofes: Argentina, Bolivia y Perú.

Deyeuxia chrysophylla Phil.

Hierba. Perenne. Nativa.

Distribución: TAR, ANT, ATA.

Rango altitudinal: 3800-5300 m.

Países limítrofes: Argentina y Bolivia.
Deyeuxia chrysostachya E. Desv.

Sinónimos: Deyeuxia chrysostachya E. Desv. var. B E. Desv., Calamagrostis chrysostachya (E. Desv.) Kuntze, Calamagrostis chrysostachya (E. Desv.) Hack., Calamagrostis chrysostachya (E. Desv.) V.N. Vassil.

Hierba. Perenne. Nativa.

Distribución: ANT, COQ, VAL, RME.

Rango altitudinal: 3000-4000 m.

Países limítrofes: Argentina.

Deyeuxia crispa Rúgolo \& Villav.

Hierba. Perenne. Nativa.

Distribución: AYP, TAR, ANT.

Rango altitudinal: 4400-5000 m.

Países limítrofes: Argentina, Bolivia y Perú.

Nombre vulgar: Paja viscachera.

Deyeuxia curvula Wedd.

Sinónimos: Deyeuxia tenuifolia Phil., Calamagrostis tenuifolia (Phil.) R.E. Fr., Calamagrostis curvula (Wedd.)

Pilg.

Hierba. Perenne. Nativa.

Distribución: AYP, TAR, ANT.

Rango altitudinal: 2600-4900 m.

Países limítrofes: Argentina, Bolivia y Perú.

Nombre vulgar: Pasto vicuña.

Deyeuxia deserticola Phil. var. breviaristata Rúgolo \& Villav.

Sinónimos: Calamagrostis deserticola (Phil.) Phil. var. breviaristata (Rúgolo \& Villav.) Soreng

Hierba. Perenne. Nativa.

Distribución: AYP, ANT, ATA.

Rango altitudinal: 4300-4950 m.

Países limítrofes: Argentina y Bolivia.

Deyeuxia deserticola Phil. var. deserticola

Sinónimos: Calamagrostis deserticola (Phil.) Phil., Agrostis canescens Griseb., Deyeuxia trisetoides Phil.

Hierba. Perenne. Nativa.

Distribución: AYP, TAR, ANT, ATA.

Rango altitudinal: 2800-4900 m.

Países limítrofes: Argentina y Bolivia.

Deyeuxia diemii Rúgolo

Sinónimos: Calamagrostis diemii (Rúgolo) Soreng

Hierba. Perenne. Nativa.

Distribución: MAU.

Rango altitudinal: 1250-1950 m.

Países limítrofes: Argentina.

Deyeuxia eminens J. Presl var. discreta Rúgolo \& Villav. Sinónimos: Deyeuxia leiopoda Wedd. var. discreta Wedd., Calamagrostis eminens (J. Presl) Steud. var. discreta 
(Rúgolo \& Villav.) Soreng

Hierba. Perenne. Nativa.

Distribución: ANT.

Rango altitudinal: $3680-4000 \mathrm{~m}$.

Países limítrofes: Bolivia y Perú.

Deyeuxia eminens J. Presl var. eminens

Sinónimos: Calamagrostis eminens (J. Presl) Steud., Deyeuxia robusta Phil., Agrostis eminens (J. Presl) Griseb., Deyeuxia elegans Wedd., Deyeuxia polystachya Wedd., Deyeuxia arundinacea Phil., Calamagrostis robusta (Phil.) Phil.

Hierba. Perenne. Nativa.

Distribución: AYP, TAR, ANT, ATA, COQ.

Rango altitudinal: 3000-4730 m.

Países limítrofes: Argentina, Bolivia y Perú.

Nombre vulgar: Pasto huailla, huaya, chillagua, chillagua

blanda, iru, guaia, sora-sora.

Deyeuxia eminens J. Presl var. fulva (Griseb.) Rúgolo

Sinónimos: Deyeuxia laxiflora Phil., Calamagrostis eminens (J. Presl) Steud. var. fulva (Griseb.) Soreng

Hierba. Perenne. Nativa.

Distribución: ANT, ATA, COQ, RME.

Rango altitudinal: 3200-4200 m.

Países limítrofes: Argentina.

Nombre vulgar: Pasto de vega, cebadilla de vicuña.

Deyeuxia erythrostachya E. Desv. var. erythrostachya Sinónimos: Aira gayana Steud., Calamagrostis erythrostachya (E. Desv.) Hack., Stylagrostis erythrostachya (E. Desv.) Mez, Calamagrostis stipitata Hitchc., Calamagrostis gayana (Steud.) Soreng

Hierba. Perenne. Nativa. Distribución: COQ, VAL, RME, LBO, MAU, NUB, BIO, ARA, LRI, LLA, AIS, MAG.

Rango altitudinal: 550-4000 m.

Países limítrofes: Argentina.

Deyeuxia erythrostachya E. Desv. var. neuquenensis Rúgolo

Sinónimos: Calamagrostis gayana (Steud.) Soreng var. neuquenensis (Rúgolo) Soreng

Hierba. Perenne. Nativa.

Distribución: MAU, NUB.

Rango altitudinal: 2200-2500 m.

Países limítrofes: Argentina.

Deyeuxia filifolia Wedd.

Hierba. Perenne. Nativa.

Distribución: ANT.

Rango altitudinal: 2500-2500 m.

Países limítrofes: Argentina, Bolivia y Perú.
Deyeuxia hackelii (Lillo) Parodi

Sinónimos: Calamagrostis hackelii Lillo

Hierba. Perenne. Nativa.

Distribución: ANT.

Rango altitudinal: 3900-5000 m.

Países limítrofes: Argentina y Bolivia.

Deyeuxia heterophylla Wedd.

Sinónimos: Calamagrostis heterophylla (Wedd.) Pilg.

Hierba. Perenne. Nativa.

Distribución: AYP, TAR.

Rango altitudinal: 3520-4150 m

Países limítrofes: Argentina, Bolivia y Perú.

Nombre vulgar: Cebadilla.

Deyeuxia patagonica Speg.

Sinónimos: Calamagrostis patagonica (Speg.) Macloskie

Hierba. Perenne. Nativa.

Distribución: ARA.

Rango altitudinal: 1500-1500 m.

Países limítrofes: Argentina.

Deyeuxia poaeoides (Steud.) Rúgolo

Sinónimos: Calamagrostis poaeoides (Steud.) Hack., Calamagrostis fuegiana Speg., Calamagrostis magellanica

Phil.

Hierba. Perenne. Nativa.

Distribución: AIS, MAG.

Rango altitudinal: 0-1000 m.

Países limítrofes: Argentina, Bolivia y Perú.

Deyeuxia rigescens (J. Presl) Türpe

Sinónimos: Agrostis rigescens J. Presl

Hierba. Perenne. Nativa.

Distribución: AYP, TAR, ATA.

Rango altitudinal: 3500-4340 m.

Países limítrofes: Argentina, Bolivia y Perú.

Deyeuxia rigida Kunth

Sinónimos: Calamagrostis gusindei Pilg. ex Skottsb.

Hierba. Perenne. Nativa.

Distribución: AYP, TAR, ANT, AIS, MAG.

Rango altitudinal: 15-4680 m.

Países limítrofes: Argentina, Bolivia y Perú.

Deyeuxia spicigera J. Presl var. cephalotes (Wedd.) Rúgolo \& Villav.

Sinónimos: Deyeuxia cephalotes Wedd., Calamagrostis spicigera (J. Presl) Steud. var. cephalotes (Wedd.) Soreng

Hierba. Perenne. Nativa.

Distribución: TAR.

Rango altitudinal: 3750-4700 m.

Países limítrofes: Argentina, Bolivia y Perú. 
Deyeuxia spicigera J. Presl var. spicigera

Sinónimos: Calamagrostis spicigera (J. Presl.) Steud.

Hierba. Perenne. Nativa.

Distribución: AYP.

Rango altitudinal: 3600-5000 m.

Países limítrofes: Argentina, Bolivia y Perú.

Deyeuxia suka (Speg.) Parodi

Sinónimos: Calamagrostis suka Speg.

Hierba. Perenne. Nativa.

Distribución: LLA, AIS, MAG.

Rango altitudinal: 5-785 m.

Países limítrofes: Argentina.

Deyeuxia velutina Nees \& Meyen var. nardifolia (Griseb.) Rúgolo

Sinónimos: Agrostis nardifolia Griseb., Deyeuxia nardifolia

(Griseb.) Phil., Calamagrostis nardifolia (Griseb.) Hack.

Hierba. Perenne. Nativa.

Distribución: TAR, ANT, ATA, COQ.

Rango altitudinal: 3800-4700 m.

Países limítrofes: Argentina, Bolivia y Perú.

Deyeuxia velutina Nees \& Meyen var. velutina

Sinónimos: Calamagrostis velutina (Nees \& Meyen) Steud., Deyeuxia chilensis E. Desv., Deyeuxia agrostidea Phil.

Hierba. Perenne. Nativa.

Distribución: ANT, ATA, COQ, RME, LLA.

Rango altitudinal: 2300-4200 m.

Países limítrofes: Argentina.

Deyeuxia vicunarum Wedd.

Hierba. Perenne. Nativa.

Distribución: AYP.

Rango altitudinal: 3500-4860 m.

Países limítrofes: Argentina, Bolivia y Perú.

Deyeuxia viridiflavescens (Poir.) Kunth var. montevidensis (Nees) Cabrera \& Rúgolo

Sinónimos: Calamagrostis montevidensis Nees

Hierba. Perenne. Nativa.

Distribución: BIO, LRI.

Rango altitudinal: 5-2300 m.

Países limítrofes: Argentina, Bolivia y Perú.

Deyeuxia viridiflavescens (Poir.) Kunth var. viridiflavescens Sinónimos: Arundo viridiflavescens Poir.

Hierba. Perenne. Nativa.

Distribución: BIO, LRI.

Rango altitudinal: 10-200 m.

Países limítrofes: Argentina.

Deyeuxia viridis Phil.

Sinónimos: Calamagrostis nemoralis Phil., Calamagrostis nemoralis Phil. ex Kuntze, Deyeuxia nemoralis Phil.

Hierba. Perenne. Nativa.

Distribución: BIO, LRI, LLA, MAG.

Rango altitudinal: 10-820 m.

Países limítrofes: Argentina.

\section{Dichanthelium}

Dichanthelium sabulorum (Lam.) Gould \& Clark var. polycladum (E. Ekman) Zuloaga

Sinónimos: Panicum polycladum E. Ekman, Panicum pencanum Phil., Panicum sabulorum var. polycladum (E. Ekman) Palacios ex Burkart

Hierba. Perenne. Nativa.

Distribución: BIO.

Rango altitudinal: 10-10 m.

Países limítrofes: Argentina y Bolivia.

Dichanthelium sabulorum (Lam.) Gould \& Clark var. sabulorum

Sinónimos: Panicum sabulorum Lam., Panicum acutatum

Steud.

Hierba. Perenne. Nativa.

Distribución: MAU, BIO.

Rango altitudinal: 10-1460 m.

Países limítrofes: Argentina.

\section{Dichelachne}

Dichelachne crinita (L.f.) Hook.f.

Hierba. Perenne. Nativa.

Distribución: IPA.

Dichelachne micrantha (Cav.) Domin

Hierba. Perenne. Nativa.

Distribución: IPA.

\section{Dielsiochloa}

Dielsiochloa floribunda (Pilg.) Pilg.

Sinónimos: Trisetum floribundum Pilg.

Hierba. Perenne. Nativa.

Distribución: AYP, TAR, ANT.

Rango altitudinal: 4240-5250 m.

Países limítrofes: Argentina, Bolivia y Perú.

\section{Digitaria}

Digitaria aequiglumis (Hack. \& Arechav.) Parodi

Hierba. Anual. Introducida.

Distribución: MAU, NUB, BIO, ARA.

Digitaria ciliaris (Retz.) Koeler

Hierba. Anual. Nativa. 
Distribución: IPA.

Países limítrofes: Argentina.

Digitaria ischaemum (Schreb.) Muhl.

Hierba. Anual. Introducida.

Distribución: BIO, LLA.

Digitaria sanguinalis (L.) Scop.

Hierba. Anual. Introducida.

Distribución: ATA, COQ, VAL, RME, LBO, MAU, NUB,

BIO, ARA, LRI, LLA, JFE.

Digitaria setigera Roth ex Roemer et Schultes

Hierba. Anual. Introducida.

Distribución: IPA.

\section{Digitaria violascens Link}

Hierba. Anual. Introducida.

Distribución: VAL, IPA.

\section{Diplachne}

Diplachne fusca (L.) Kunth subsp. uninervia (J. Presl) P.M. Peterson \& N. Snow

Sinónimos: Megastachya uninervia J. Presl, Poa uninervia (J. Presl) Kunth, Diplachne verticillata Nees \& Meyen, Uralepis verticillata (Nees \& Meyen) Steud, Eragrostis uninervia (J. Presl) Steud., Brizopyrum uninervium (J. Presl) E. Fourn., Diplachne tarapacana Phil., Leptochloa uninervia (J. Presl.) Hitchc. \& Chase, Diplachne uninervia (J. Presl.) Parodi, Diplachne fusca var. uninervia (J. Presl.) P.M. Peterson \& N. Snow., Leptochloa fusca (L.) Kunth subsp. uninervia (J. Presl.) N.W. Snow

Hierba. Anual. Nativa.

Distribución: AYP, TAR, ANT, ATA, COQ, VAL.

Rango altitudinal: 20-1300 m.

Países limítrofes: Argentina, Bolivia y Perú.

\section{Distichlis}

Distichlis humilis Phil.

Sinónimos: Distichlis misera Phil., Distichlis spicata (L.) Greene var. humilis (Phil.) Kuntze

Hierba. Perenne. Nativa.

Distribución: AYP, TAR, ANT, ATA.

Rango altitudinal: 2310-4300 m.

Países limítrofes: Argentina, Bolivia y Perú.

Distichlis scoparia (Nees ex Kunth) Arechav.

Sinónimos: Poa scoparia Nees ex Kunth, Uniola scoparia (Nees ex Kunth) Steud.

Hierba. Perenne. Nativa.

Distribución: AYP, TAR, ANT, ATA, COQ, VAL, RME, BIO, ARA, LRI.
Rango altitudinal: 5-4200 m.

Países limítrofes: Argentina.

Distichlis spicata (L.) Greene

Sinónimos: Distichlis maritima Rafma., Distichlis deserticola Phil., Distichlis hirsuta Phil., Distichlis mendocina Phil., Distichlis hirta Phil., Distichlis spicata var. andina Beetle, Distichlis spicata var. stricta (Torr.) Scribn., Uniola sctricta Torr.

Hierba. Perenne. Nativa.

Distribución: AYP, TAR, ANT, ATA, COQ, VAL, RME, MAU, NUB, BIO, ARA, LRI, LLA.

Rango altitudinal: 5-3800 m.

Países limítrofes: Argentina, Bolivia y Perú.

\section{Echinochloa}

Echinochloa colona (L.) Link

Hierba. Anual. Introducida.

Distribución: COQ, VAL, RME, LBO, MAU, NUB, BIO, ARA, JFE.

Echinochloa crusgalli (L.) P.Beauv. var. crusgalli

Hierba. Anual. Introducida.

Distribución: COQ, VAL, RME, LBO, MAU, NUB, BIO, ARA, LRI.

Echinochloa crusgalli (L.) P.Beauv. var. mitis (Pursh) Peterm.

Hierba. Anual. Introducida.

Distribución: ATA, COQ, VAL, RME, MAU, NUB, BIO, ARA, LRI, LLA.

Echinochloa crusgalli (L.) P.Beauv. var. zelayensis (Kunt) Hitchc.

Hierba. Anual. Introducida.

Distribución: MAU.

Echinochloa crus-pavonis (Kunth) Schult.

Hierba. Anual. Introducida.

Distribución: AYP, TAR, COQ, VAL, RME, MAU, NUB, BIO, ARA.

\section{Ehrharta}

Ehrharta longiflora Sm.

Hierba. Anual. Introducida.

Distribución: VAL.

Rango altitudinal: 50-100 m.

Ehrharta stipoides Labill.

Hierba. Perenne. Introducida.

Distribución: IPA. 


\section{Eleusine}

Eleusine indica (L.) Gaertn.

Hierba. Anual. Introducida.

Distribución: IPA.

Eleusine tristachya (Lam.) Lam.

Hierba. Anual. Introducida.

Distribución: ANT, ATA, VAL, RME, MAU, BIO, ARA, LRI, LLA, JFE.

\section{Elymus}

Elymus angulatus J. Pres1

Sinónimos: Elymus agropyroides J. Presl, Elymus andinus Poepp. ex Trin., Elymus antarcticus Hook.f. var. fulvescens Kurtz, Elymus valdiviae Steud., Elymus asper Nees ex Steud., Elymus chonoticus Phil., Elymus corralensis Phil., Elymus gayanus E. Desv., Elymus gracilis Phil., Elymus latiglumis Phil., Elymus muticus Phil., Elymus oreophilus Phil., Elymus palenae Phil., Elymus paposanus Phil., Elymus pratensis Phil., Elymus rigescens Poepp. ex Trin., Elymus uniflorus Phil., Elymus vaginatus Phil., Hordeum valdiviae (Steud.) Schenck

Hierba. Perenne. Nativa.

Distribución: ANT, ATA, COQ, VAL, RME, LBO, MAU, NUB, BIO, ARA, LRI, LLA, AIS, MAG.

Rango altitudinal: 5-2800 m.

Países limítrofes: Argentina, Bolivia y Perú.

Elymus magellanicus (E. Desv.) A. Löve

Sinónimos: Triticum repens L. var. magellanicum E. Desv., Triticum magellanicum (E. Desv.) Speg., Agropyron magellanicum (E. Desv.) Hack., Triticum pubiflorum Steud., Triticum magellanicum (E. Desv.) Speg. var. pubiflorum (Steud.) Speg., Agropyron pubiflorum (Steud.) P. Candargy, Agropyron magellanicum (E. Desv.) Hack. var. pubiflorum (Steud.) Hauman \& Vanderv., Agropyron pubiflorum (Steud.) Parodi, Elytrigia pubiflora (Steud.) Tzvelev, Elymus glaucescens Seberg, Agropyron antarcticum Parodi, Agropyron fuegianum (Speg.) Kurtz var. brachyatherum Parodi, Agropyron fuegianum (Speg.) Kurtz var. polystachyum Parodi, Agropyron pubiflorum (Steud.) Parodi var. fragile Parodi

Hierba. Perenne. Nativa.

Distribución: RME, AIS, MAG.

Rango altitudinal: 10-1400 m.

Países limítrofes: Argentina.

Elymus patagonicus Speg.

Hierba. Perenne. Nativa.

Distribución: AIS.

Países limítrofes: Argentina.
Elymus repens (L.) Gould

Hierba. Perenne. Introducida.

Distribución: RME, ARA, LLA, MAG.

Elymus scabriglumis (Hack.) A. Löve

Sinónimos: Agropyron repens P. Beauv. var. scabriglume

Hack.

Hierba. Perenne. Nativa.

Distribución: ANT, LLA, AIS, MAG.

Rango altitudinal: 100-3300 m.

Países limítrofes: Argentina.

\section{Elytrigia}

Elytrigia repens (L.) Nevski

Hierba. Perenne. Introducida.

Distribución: RME, ARA, LRI, MAG.

\section{Enneapogon}

Enneapogon desvauxii P. Beauv.

Hierba. Perenne. Nativa.

Distribución: AYP, TAR, ANT.

Rango altitudinal: 2000-2580 m.

Países limítrofes: Argentina, Bolivia y Perú.

\section{Eragrostis}

Eragrostis atrovirens (Desf.) Trin. ex Steud.

Hierba. Perenne. Introducida.

Distribución: IPA.

Eragrostis attenuata Hitchc.

Sinónimos: Sporobolus scaber Phil.

Hierba. Perenne. Nativa.

Distribución: ANT, ATA.

Rango altitudinal: 610-610 m.

Países limítrofes: Perú.

Eragrostis curvula (Schrad.) Nees

Hierba. Perenne. Introducida.

Distribución: BIO, MAG.

Eragrostis kuschelii Skottsb.

Sinónimos: Eragrostis peruviana var. macranthera Skottsb.

Hierba. Perenne. Endémica.

Distribución: IDE.

Rango altitudinal: 5-100 m.

Eragrostis mexicana (Hornem.) Link subsp. virescens (J. Presl) S.D. Koch \& Sánchez Vega

Sinónimos: Eragrostis virescens J. Presl, Poa virescens (Presl) Kunth, Eragrostis chilensis (Moris) Nees, Poa 
chilensis Moris, Eragrostis scabra Phil., Eragrostis rahmeri Phil.

Hierba. Anual. Nativa.

Distribución: AYP, TAR, ANT, ATA, COQ, VAL, RME, LBO, MAU, NUB, BIO, ARA, LRI.

Rango altitudinal: $20-2500 \mathrm{~m}$.

Países limítrofes: Argentina, Bolivia y Perú.

Eragrostis nigricans (Kunth) Steud. var. nigricans

Sinónimos: Poa nigricans Kunth, Eragrostis subatra Jedwabn., Eragrostis tristis Jebwabn., Eragrostis nigricans Jebwabn. var. tristis

Hierba. Anual. Nativa.

Distribución: AYP, TAR, ANT.

Rango altitudinal: 2600-3800 m.

Países limítrofes: Argentina, Bolivia y Perú.

Eragrostis nigricans (Kunth) Steud. var. punensis Nicora Sinónimos: Eragrostis mexicana (Hornem.) Link subsp. mexicana

Hierba. Anual. Endémica.

Distribución: AYP, ANT, VAL.

Rango altitudinal: 2950-3800 m.

Eragrostis peruviana (Jacq.) Trin.

Sinónimos: Eragrostis deserticola Phil.

Hierba. Anual. Nativa.

Distribución: AYP, ANT, IDE.

Rango altitudinal: 500-3460 m.

Países limítrofes: Perú.

Eragrostis pilosa (L.) P. Beauv.

Hierba. Anual. Introducida.

Distribución: COQ, RME, MAU, MAG.

\section{Eragrostis polytricha Nees}

Hierba. Perenne. Nativa.

Distribución: RME, MAU, NUB, BIO, ARA, LRI.

Rango altitudinal: 10-1000 m.

Países limítrofes: Argentina y Bolivia.

Eragrostis pycnantha (Phil.) Nicora

Sinónimos: Poa pycnantha Phil.

Hierba. Perenne. Endémica.

Distribución: ATA.

Rango altitudinal: 140-140 m.

Eragrostis tenuifolia (A. Rich.) Hochst. ex Steud. Hierba. Anual. Introducida.

Distribución: IPA.

Eragrostis weberbaueri Pilg.

Hierba. Perenne. Nativa.

Distribución: AYP, TAR, ANT.
Rango altitudinal: 2100-3700 m.

Países limítrofes: Perú.

\section{Eremium}

Eremium erianthum (Phil.) Seberg \& Linde-Laursen

Sinónimos: Elymus erianthus Phil.

Hierba. Perenne. Nativa.

Distribución: COQ.

Rango altitudinal: 1800-1800 m.

Países limítrofes: Argentina.

\section{Eriochloa}

Eriochloa montevidensis Griseb.

Hierba. Perenne. Nativa.

Distribución: AYP.

Rango altitudinal: 50-840 m.

Países limítrofes: Argentina.

\section{Festuca}

Festuca acanthophylla E. Desv. var. acanthophylla Sinónimos: Festuca tunicata E. Desv., Festuca coiron Steud., Festuca berteroniana Steud., Festuca robusta Phil., Festuca thermarum Phil., Festuca desvauxii Phil., Festuca acuta Phil., Festuca desvauxii Phil. var. ampla St.-Yves, Festuca barrazae Muñoz

Hierba. Perenne. Nativa.

Distribución: ANT, COQ, VAL, RME, LBO, MAU, NUB, BIO, ARA, LRI, LLA, AIS, MAG.

Rango altitudinal: (50)900-2500 m.

Países limítrofes: Argentina.

Festuca acanthophylla E. Desv. var. scabriuscula (Phil.) J.C. Ospina, Aliscioni \& S. Denham

Sinónimos: Festuca scabriuscula Phil., Festuca robusta Phil. var. scabriuscula (Phil.) St.-Yves, Festuca asperata Phil., Festuca pascua Phil., Festuca steudelii Phil., Festuca morenensis Matthei

Hierba. Perenne. Nativa.

Distribución: ANT, RME, NUB, BIO, ARA, LRI.

Rango altitudinal: $700-2200 \mathrm{~m}$.

Países limítrofes: Argentina.

Festuca argentina (Speg.) Parodi

Sinónimos: Poa argentina Speg., Festuca cavallieri St.-Yves Hierba. Perenne. Nativa.

Distribución: AIS.

Rango altitudinal: 50-2200 m.

Países limítrofes: Argentina.

Festuca arundinacea Schreb.

Sinónimos: Festuca orthophylla Pilg. 
Hierba. Perenne. Introducida.

Distribución: AYP, TAR, ANT, ATA, COQ, VAL, RME, MAU, NUB, BIO, LLA, JFE.

Festuca chrysophylla Phil.

Sinónimos: Festuca deserticola Phil. var. chrysophylla (Phil.) St.-Yves, Festuca deserticola Phil. var. juncea St.Yves, Festuca juncea Phil., hom. illeg.

Hierba. Perenne. Nativa.

Distribución: AYP, TAR, ANT.

Rango altitudinal: 3200-4860 m.

Países limítrofes: Argentina, Bolivia y Perú.

Festuca cirrosa (Speg.) Parodi

Sinónimos: Festuca erecta d'Urv. var. cirrosa Speg.

Hierba. Perenne. Nativa.

Distribución: MAG.

Rango altitudinal: 5-175 m.

Países limítrofes: Argentina.

Festuca contracta Kirk

Sinónimos: Festuca erecta d'Urv., hom. illeg.

Hierba. Perenne. Nativa.

Distribución: MAG.

Rango altitudinal: 200-1050 m.

Países limítrofes: Argentina.

Festuca gracillima Hook.f. var. glacialis Rúgolo \& Nicora Hierba. Perenne. Nativa.

Distribución: MAG.

Rango altitudinal: 5-1300 m.

Países limítrofes: Argentina.

Festuca gracillima Hook.f. var. gracillima

Sinónimos: Festuca gracillima Hook. var. brevifolia Speg.

Hierba. Perenne. Nativa.

Distribución: NUB, AIS, MAG.

Rango altitudinal: 5-900 m.

Países limítrofes: Argentina.

Festuca hypsophyla Phil.

Sinónimos: Festuca deserticola Phil. var. hypsophyla (Phil.) St.-Yves

Hierba. Perenne. Nativa.

Distribución: AYP, TAR, ANT, ATA.

Rango altitudinal: 3200-4800 m.

Países limítrofes: Argentina, Bolivia y Perú.

Festuca juncifolia St.-Amans

Hierba. Perenne. Introducida.

Distribución: MAG.

Festuca kurtziana St.-Yves

Hierba. Perenne. Nativa.

Distribución: COQ, RME, MAU.
Rango altitudinal: 1630-2740 m.

Países limítrofes: Argentina.

Festuca magellanica Lam.

Hierba. Perenne. Nativa.

Distribución: COQ, VAL, RME, MAU, NUB, BIO, LLA, AIS, MAG.

Rango altitudinal: 5-3300 m.

Países limítrofes: Argentina.

Festuca monticola Phil.

Sinónimos: Festuca gracillima Hook. var. monticola (Phil.)

St.-Yves, Festuca subandina Phil.

Hierba. Perenne. Nativa.

Distribución: NUB, BIO, ARA, LRI, LLA, MAG.

Rango altitudinal: 5-1550 m.

Países limítrofes: Argentina.

Festuca ovina L. subsp. tenuifolia (Sibth.) Celak.

Hierba. Perenne. Introducida.

Distribución: MAG.

Festuca pallescens (St.-Yves) Parodi

Sinónimos: Festuca gracillima Hook. var. pallescens St.-

Yves

Hierba. Perenne. Nativa.

Distribución: AIS, MAG.

Rango altitudinal: $15-1700 \mathrm{~m}$.

Países limítrofes: Argentina.

Festuca panda Sw.

Hierba. Perenne. Endémica.

Distribución: AYP, COQ.

Rango altitudinal: 2900-3400 m.

Festuca purpurascens Banks \& Sol. ex Hook.f.

Sinónimos: Festuca purpurascens Banks \& Sol. ex Hook. var. submutica E. Desv., Festuca purpurascens Banks \& Sol. ex Hook. var. aristata E. Desv., Festuca insularis Steud., Festuca lechleriana Steud., Festuca platyphylla Steud., Festuca purpurascens Banks \& Sol. ex Hook. var. platyphylla (Steud.) St.-Yves, Festuca laxiflora Phil., hom. illeg., Festuca dumetorum Phil., hom. illeg., Festuca trachylepis Hack. ex Druce, Festuca philippii Becherer, nom. illeg., Festuca davilae Phil., Festuca glaucophylla Phil., Festuca serranoi Phil., Festuca purpurascens Banks \& Sol. ex Hook.f. fma. aristata St.-Yves, Festuca purpurascens Banks \& Sol. ex Hook.f. fma. scabriuscula St.-Yves

Hierba. Perenne. Nativa.

Distribución: RME, MAU, NUB, BIO, ARA, LRI, LLA, AIS, MAG.

Rango altitudinal: 5-1200 m.

Países limítrofes: Argentina. 
Festuca pyrogea Speg.

Hierba. Perenne. Nativa.

Distribución: RME, AIS, MAG.

Rango altitudinal: 100-1100 m.

Países limítrofes: Argentina.

Festuca rigescens (J. Presl) Kunth

Sinónimos: Diplachne rigescens Presl, Festuca deserticola Phil., Festuca paupera Phil., Festuca deserticola Phil. var. paupera (Phil.) St.-Yves

Hierba. Perenne. Nativa.

Distribución: AYP, TAR, ANT, COQ.

Rango altitudinal: 2500-4800 m.

Países limítrofes: Argentina.

Festuca rubra L.

Hierba. Perenne. Introducida.

Distribución: COQ, VAL, RME, AIS, MAG.

Festuca subantarctica Parodi

Sinónimos: Festuca commersonii Franch., hom. illeg.

Hierba. Perenne. Nativa.

Distribución: MAG.

Rango altitudinal: 5-175 m.

Países limítrofes: Argentina.

Festuca werdermannii St.-Yves

Hierba. Perenne. Nativa.

Distribución: ANT, ATA, COQ.

Rango altitudinal: $2800-4200 \mathrm{~m}$.

Países limítrofes: Argentina.

\section{Gastridium}

Gastridium phleoides (Nees \& Meyen) C.E. Hubb.

Hierba. Anual. Introducida.

Distribución: ATA, COQ, VAL, RME, LBO, MAU, NUB, BIO, ARA, LRI, LLA, JFE, IPA.

Gastridium ventricosum (Gouan) Schinz \& Thell.

Hierba. Anual. Introducida.

Distribución: IPA, JFE.

\section{Glyceria}

Glyceria fluitans (L.) R. Br.

Hierba. Perenne. Introducida.

Distribución: MAU, BIO, ARA, LRI, MAG.

Glyceria multiflora Steud.

Hierba. Perenne. Nativa.

Distribución: VAL, RME, MAU, NUB, BIO, ARA, LRI, LLA, AIS, MAG.

Rango altitudinal: 5-760 m.
Países limítrofes: Argentina y Bolivia.

\section{Gynerium}

Gynerium sagittatum (Aubl.) P. Beauv.

Hierba o subarbusto. Perenne. Introducida.

Distribución: TAR.

\section{Hainardia}

Hainardia cylindrica (Willd.) Greuter

Hierba. Anual. Introducida.

Distribución: VAL, NUB, BIO.

\section{Helictotrichon}

Helictotrichon bulbosum (Hitchc.) Parodi

Sinónimos: Trisetum bulbosum Hitchc.

Hierba. Perenne. Nativa.

Distribución: BIO.

Países limítrofes: Argentina.

\section{Holcus}

Holcus lanatus L.

Hierba. Anual. Introducida.

Distribución: COQ, VAL, RME, LBO, MAU, NUB, BIO, ARA, LRI, LLA, AIS, MAG.

\section{Hordeum}

Hordeum brachyatherum Phil.

Sinónimos: Critesion brachyatherum (Phil.)A. Löve

Hierba. Perenne. Endémica.

Distribución: COQ, VAL, MAU, MAG.

Rango altitudinal: 2-50 m.

Hordeum chilense Roem. \& Schult.

Sinónimos: Critesion chilense (Roem. \& Schult.) A. Löve, Hordeum chilense Brongn., nom. illeg., Hordeum secalinum Schreb. var. chilense (Brongn.) E. Desv., Hordeum pratense Huds. var. chilense (Brongn.) Macloskie, Hordeum pratense Huds. var. brongniartii Macloskie, Hordeum cylindricum Steud., Hordeum depauperatum Steud., Hordeum chilense Roem. \& Schult. var. pseudosecalinum Hauman, Hordeum chilense Roem. \& Schult. var. pilosum Nevski

Hierba. Perenne. Nativa.

Distribución: AYP, TAR, ANT, COQ, VAL, RME, LBO, MAU, NUB, BIO, ARA, LRI, LLA, AIS, MAG, JFE.

Rango altitudinal: 5-4200 m.

Países limítrofes: Argentina.

Nota: Introducida en el Archipiélago Juan Fernández. 
Hordeum comosum J. Presl

Hierba. Perenne. Nativa.

Distribución: AYP, TAR, ATA, COQ, VAL, RME, LBO, MAU, NUB, BIO, ARA, LRI, LLA, AIS, MAG.

Rango altitudinal: 5-4300 m.

Países limítrofes: Argentina y Bolivia.

Hordeum fuegianum Bothmer, N. Jacobsen \& R.R. Jorg. Hierba. Perenne. Nativa.

Distribución: MAG.

Rango altitudinal: 10-1000 m.

Países limítrofes: Argentina.

Hordeum hystrix Roth

Hierba. Perenne. Introducida.

Distribución: VAL, LBO, MAU, NUB.

Hordeum jubatum L.

Hierba. Perenne. Introducida.

Distribución: MAG.

Hordeum lechleri (Steud.) Schenck

Sinónimos: Critesion lechleri (Steud.) A. Löve, Elymus lechleri Steud

Hierba. Perenne. Nativa.

Distribución: AIS, MAG.

Rango altitudinal: 10-500 m.

Países limítrofes: Argentina.

Hordeum marinum Huds. subsp. gussoneanum (Parl.) Thell.

Hierba. Anual. Introducida.

Distribución: COQ, VAL, RME, LBO, MAU, BIO.

Hordeum marinum Huds. subsp. marinum

Hierba. Anual. Introducida.

Distribución: VAL, RME, MAU, BIO, ARA, LRI, LLA, AIS, MAG.

Hordeum murinum L. subsp. leporinum (Link.) Arcang. Hierba. Anual. Introducida.

Distribución: VAL, BIO.

Hordeum murinum L. subsp. murinum

Hierba. Anual. Introducida.

Distribución: ANT, ATA, COQ, VAL, RME, LBO, MAU, NUB, BIO, ARA, LRI, LLA, AIS, MAG, JFE, IPA.

Hordeum muticum J. Presl

Hierba. Perenne. Nativa.

Distribución: AYP, TAR, ANT, ATA, RME, LRI, LLA.

Rango altitudinal: 460-4040 m.

Países limítrofes: Argentina, Bolivia y Perú.
Hordeum parodii Covas

Sinónimos: Critesion parodii (Covas) A. Löve

Hierba. Perenne. Nativa.

Distribución: AIS, MAG.

Rango altitudinal: 10-200 m.

Países limítrofes: Argentina.

Hordeum patagonicum (Hauman) Covas subsp. magellanicum (Parodi \& Nicora) Bothmer, Giles \& N. Jacobsen

Sinónimos: Hordeum chilense Roem. \& Schult. var. magellanicum Parodi \& Nicora, Critesion magellanicum (Parodi \& Nicora) A. Löve

Hierba. Perenne. Nativa.

Distribución: ATA, RME, AIS, MAG.

Rango altitudinal: $150-700 \mathrm{~m}$.

Países limítrofes: Argentina.

Hordeum patagonicum (Hauman) Covas subsp. santacrucense (Parodi \& Nicora) Bothmer, Giles \& N. Jacobsen

Sinónimos: Hordeum santacrucense (Parodi \& Nicora), Critesion santacrucense (Parodi \& Nicora) Á. Löve

Hierba. Perenne. Nativa.

Distribución: AIS, MAG.

Rango altitudinal: $\mathrm{m}$.

Países limítrofes: Argentina.

Hordeum pubiflorum Hook.f. subsp. halophilum (Griseb.) Baden \& Bothmer

Sinónimos: Hordeum halophilum Griseb., Hordeum jubatum L. fma. versicolor Kuntze, Hordeum jubatum L. fma. violaceum Kuntze, Hordeum jubatum fma. viride Kuntze

Hierba. Perenne. Nativa.

Distribución: ANT, ATA, COQ, RME, LBO, BIO, AIS, MAG.

Rango altitudinal: 20-4170 m.

Países limítrofes: Argentina y Bolivia.

Hordeum pubiflorum Hook.f. subsp. pubiflorum

Hierba. Perenne. Nativa.

Distribución: RME, MAU, BIO, MAG.

Rango altitudinal: 15-3500 m.

Países limítrofes: Argentina.

Hordeum vulgare L.

Hierba. Anual. Introducida.

Distribución: ATA, COQ, RME, BIO, ARA.

\section{Imperata}

Imperata brasiliensis Trin.

Sinónimos: Imperata arundinacea Cirillo var. americana 
Hierba. Perenne. Nativa.

Distribución: NUB.

Países limítrofes: Argentina, Bolivia y Perú.

Nombre vulgar: Paja colorada.

Imperata condensata Steud.

Sinónimos: Imperata arundinacea Cirillo var. condensata

(Steud.) Hack., Imperata cylindrica (L.) Raeusch. var. condensata (Steud.) Hack.

Hierba. Perenne. Nativa.

Distribución: ATA, COQ, VAL, RME, MAU, NUB, BIO, ARA, LRI.

Rango altitudinal: 10-2233 m.

Países limítrofes: Argentina y Bolivia.

Nombre vulgar: maicillo.

Imperata parodii Acevedo Hierba. Perenne. Endémica.

Distribución: ARA.

\section{Jarava}

Jarava annua (Mez) Peñail.

Sinónimos: Stipa annua Mez

Hierba. Anual. Nativa.

Distribución: AYP, TAR, ANT.

Rango altitudinal: 100-3700 m.

Países limítrofes: Perú.

Jarava ichu Ruiz \& Pav. var. pungens (Nees \& Meyen) Ciald.

Hierba. Perenne. Nativa.

Distribución: AYP.

Rango altitudinal: 4040-4040 m.

Países limítrofes: Argentina, Bolivia y Perú.

Jarava leptostachya (Griseb.) F. Rojas

Sinónimos: Stipa leptostachya Griseb.

Hierba. Perenne. Nativa.

Distribución: AYP, TAR, ANT.

Rango altitudinal: 3300-4040 m.

Países limítrofes: Argentina y Bolivia.

Nombre vulgar: Paja amarilla.

Jarava neaei (Nees ex Steud.) Peñail.

Sinónimos: Stipa neaei Nees ex Steud., Stipa bella Phil.

Hierba. Perenne. Nativa.

Distribución: COQ, RME, MAU, AIS.

Rango altitudinal: 1000-2700 m.

Países limítrofes: Argentina.

Jarava plumosa (Spreng.) S.W.L. Jacobs \& Everett

Sinónimos: Calamagrostis plumosa Spreng., Stipa tenuiflora Phil., Stipa papposa Nees, nom. illeg.

Hierba. Perenne. Nativa.
Distribución: ATA, COQ, VAL, LBO, MAU, NUB, BIO, ARA.

Rango altitudinal: 5-900 m.

Países limítrofes: Argentina.

Jarava plumosula (Nees ex Steud.) F. Rojas

Sinónimos: Stipa plumosula Nees ex Steud., Stipa plumosa

Trin.

Hierba. Perenne. Nativa.

Distribución: ANT, ATA, COQ, VAL, RME.

Rango altitudinal: 10-3500 m.

Países limítrofes: Argentina, Bolivia y Perú.

Jarava pogonathera (E. Desv.) Peñail.

Sinónimos: Stipa pogonathera E. Desv., Stipa buchtienii

Hack.

Hierba. Perenne. Nativa.

Distribución: ANT, ATA, COQ, VAL, RME, MAU.

Rango altitudinal: 720-3700 m.

Países limítrofes: Argentina.

Jarava psylantha (Speg.) Peñail.

Sinónimos: Stipa psylantha Speg.

Hierba. Perenne. Nativa.

Distribución: AIS, MAG.

Rango altitudinal: 150-300 m.

Países limítrofes: Argentina.

Jarava pungionata (Caro \& E.A. Sánchez) Matthei

Sinónimos: Stipa pungionata Caro \& E.A. Sánchez

Hierba. Perenne. Nativa.

Distribución: AYP, TAR, ANT.

Rango altitudinal: $3725-4150 \mathrm{~m}$.

Países limítrofes: Argentina.

Jarava scabrifolia (Torres) Peñail.

Sinónimos: Stipa scabrifolia Torres, Jarava mattheii F.

Rojas

Hierba. Perenne. Nativa.

Distribución: ANT.

Rango altitudinal: 4000-4000 m.

Países limítrofes: Argentina y Bolivia.

Jarava subaristata (Matthei) Matthei

Sinónimos: Stipa leptostachya Griseb. var. subaristata Matthei, Stipa subaristata (Matthei) Caro \& E.A. Sánchez

Hierba. Perenne. Nativa.

Distribución: AYP, TAR.

Rango altitudinal: 1870-4040 m.

Países limítrofes: Argentina.

Jarava tortuosa (E. Desv.) Peñail.

Sinónimos: Stipa tortuosa E. Desv.

Hierba. Perenne. Endémica. 
Distribución: ANT, ATA, COQ.

Rango altitudinal: 10-900 m.

\section{Koeleria}

Koeleria fueguina Calderón ex Nicora

Hierba. Perenne. Nativa.

Distribución: MAU, NUB, AIS, MAG.

Rango altitudinal: 400-1600 m.

Países limítrofes: Argentina.

Koeleria kurtzii Hack. emend. A.M. Molina

Sinónimos: Trisetum subaristatum E. Desv.

Hierba. Perenne. Nativa.

Distribución: TAR, RME, MAU, MAG.

Rango altitudinal: 3400-4300 m.

Países limítrofes: Argentina, Bolivia y Perú.

\section{Lachnagrostis}

Lachnagrostis filiformis (G. Forst.) Trin.

Sinónimos: Agrostis avenacea J.F. Gmel.

Hierba. Anual o perenne. Nativa.

Distribución: VAL, MAU, LLA, IPA.

Países limítrofes: Argentina.

Nombre vulgar: Tuere heu (Rapa Nui).

Nota: Introducida en el continente: regiones de Valparaíso,

Maule y Los Lagos.

\section{Lagurus}

Lagurus ovatus L.

Hierba. Anual. Introducida.

Distribución: COQ, VAL, LBO, MAU, NUB, BIO, ARA, LRI, MAG.

\section{Lamarckia}

Lamarckia aurea (L.) Moench

Hierba. Anual. Introducida.

Distribución: ATA, COQ, VAL, RME.

\section{Leptophyllochloa}

Leptophyllochloa micrathera (E. Desv.) C.E. Calderón ex Nicora

Sinónimos: Trisetum micratherum E. Desv., Koeleria micrathera (E. Desv.) Griseb., Koeleria philippiana E. Desv., Trisetum depauperatum Phil., Trisetum brachyatherum Phil., Trisetum laxiflorum Phil., Trisetum laxum Phil., Trisetum nemorosum Phil.

Hierba. Perenne. Nativa.

Distribución: MAU, NUB, BIO, ARA, LRI, LLA, JFE.

Rango altitudinal: 25-1200 m.
Países limítrofes: Argentina.

Nota: Introducida en el Archipiélago Juan Fernández.

\section{Lepturus}

Lepturus repens (G. Forst.) $\mathrm{R}$. Br.

Hierba. Anual. Introducida.

Distribución: IPA.

\section{Leymus}

Leymus arenarius (L.) Hochst.

Hierba. Perenne. Introducida.

Distribución: VAL, MAG.

\section{Lolium}

Lolium multiflorum Lam.

Hierba. Anual o bienal. Introducida.

Distribución: AYP, TAR, ANT, ATA, COQ, VAL, RME, LBO, MAU, NUB, BIO, ARA, LRI, LLA, MAG, JFE.

Lolium perenne L.

Hierba. Perenne. Introducida.

Distribución: ATA, COQ, VAL, RME, LBO, MAU, NUB, BIO, ARA, LRI, LLA, AIS, MAG, JFE, IPA.

Lolium rigidum Gaudin

Hierba. Anual. Introducida.

Distribución: COQ, VAL, RME, LBO, BIO, ARA, LRI, MAG.

\section{Lolium temulentum L.}

Hierba. Anual. Introducida.

Distribución: COQ, VAL, RME, BIO, ARA, LRI, LLA.

\section{Megalachne}

Megalachne berteroniana Steud.

Sinónimos: Bromus megalachne Pilg., Pantathera fernandeziana Phil., Bromus fernandezianus Phil., Pantathera avenacea Phil.

Hierba. Perenne. Endémica.

Distribución: JFE.

Rango altitudinal: 180-670 m.

Megalachne masafuerana (Skottsb. \& Pilg.) Matthei Sinónimos: Bromus masafueranus Skottsb. \& Pilg. Hierba. Perenne. Endémica.

Distribución: JFE.

Rango altitudinal: 320-1100 m. 
Megalachne robinsoniana $\mathrm{C}$. Peña

Hierba. Perenne. Endémica.

Distribución: JFE.

Rango altitudinal: $300-400 \mathrm{~m}$.

\section{Megathyrsus}

Megathyrsus maximus (Jacq.) B. K. Simon \& S. W. L. Jacobs var. pubiglumis (K. Schum.) B. K. Simon \& S. W. L. Jacobs

Hierba. Perenne. Introducida.

Distribución: IPA.

\section{Melica}

Melica argentata $\mathrm{E}$. Desv.

Sinónimos: Melica glabra Steud., Melica ampla Phil., Melica nitida Phil., Melica tortuosa Phil., Melica argentata var. breviglumis Papp, Melica violacea var. argentata Papp Hierba. Perenne. Endémica.

Distribución: ANT, COQ, VAL, RME, LBO, MAU.

Rango altitudinal: 15-2200 m.

Melica commersonnii Nees ex Steud.

Sinónimos: Melica commutata Steud., Melica violacea Cav. var. pallida E. Desv., Melica violacea Cav. var. commersonii (Nees ex Steud.) Papp, Melica violacea Cav. var. commutata (Steud.) Papp

Hierba. Perenne. Endémica.

Distribución: COQ, VAL, RME, LBO, MAU, NUB, BIO.

Rango altitudinal: 15-1900 m.

\section{Melica longiflora Steud.}

Sinónimos: Melica flava Nees ex Steud., Maelica laxiflora E. Desv., Melica laxiflora E. Desv. var. hirsuta E. Desv., Melica hirta Phil., Melica exaltata Phil., Melica berteroana Phil., Melica berteroana fma. violacea Papp, Melica berteroana Phil. var. exaltata (Phil.) Papp, Melica berteroana Phil. var. pilosula Papp, Melica flava Nees ex Steud. var. violacea Papp, Melica laxiflora E. Desv. var. glabra Papp, Melica laxiflora E. Desv. var. hirta Papp, Melica laxiflora E. Desv. var. pilosula Papp, Melica laxiflora fma. hirta (Phil.) Hempel

Hierba. Perenne. Endémica.

Distribución: COQ, VAL, RME, LBO, MAU.

Rango altitudinal: 20-1300 m.

Melica mollis Phil.

Hierba. Perenne. Endémica.

Distribución: ATA, COQ.

Rango altitudinal: $340 \mathrm{~m}$.

Melica paulsenii Phil.

Sinónimos: Melica littoralis Phil. var. paulsenii (Phil.)
Papp, Melica littoralis Phil. var. werdermannii Papp

Hierba. Perenne. Endémica.

Distribución: COQ, VAL, RME, MAU.

Rango altitudinal: $50-700 \mathrm{~m}$.

Melica poecilantha E. Desv.

Sinónimos: Melica poecilantha E. Desv. var. umbrosa E.

Desv.

Hierba. Perenne. Endémica.

Distribución: COQ.

Rango altitudinal: 500-1200 m.

Melica violacea Cav.

Sinónimos: Melica alata Nees ex Steud., Melica filiculmis

E. Desv., Melica valdiviana Phil., Melica alata Nees ex Steud. var. filiculmis (E. Desv.) Papp, Melica alata Nees ex Steud. var. mollis Papp, Melica violacea Cav. fma. mollis (Papp) Hempel

Hierba. Perenne. Endémica.

Distribución: COQ, VAL, RME, LBO, MAU, NUB, BIO, ARA, LRI.

Rango altitudinal: 5-2000 m.

\section{Melinis}

Melinis minutiflora $\mathrm{P}$. Beauv. Hierba. Perenne. Introducida. Distribución: IPA.

Melinis repens (Willd.) Zizka

Hierba. Perenne. Introducida.

Distribución: IPA.

\section{Microchloa}

Microchloa indica (L. f.) P. Beauv.

Hierba. Perenne. Introducida.

Distribución: AYP.

Microchloa kunthii Desv.

Hierba. Perenne. Nativa.

Distribución: AYP, TAR.

Rango altitudinal: $3220-3220 \mathrm{~m}$.

Países limítrofes: Argentina, Bolivia y Perú.

\section{Miscanthus}

Miscanthus sinensis Andersson

Hierba. Perenne. Introducida.

Distribución: MAU. 


\section{Muhlenbergia}

Muhlenbergia asperifolia (Nees \& Meyen ex Trin.) Parodi Sinónimos: Vilfa asperifolia Nees \& Meyen ex Trin., Sporobolus copiapinus Phil.

Hierba. Perenne. Nativa.

Distribución: AYP, TAR, ANT, ATA, COQ, RME.

Rango altitudinal: 100-4700 m.

Países limítrofes: Argentina y Bolivia.

Muhlenbergia fastigiata (J. Presl) Henrard

Sinónimos: Sporobolus fastigiatus J. Presl

Hierba. Perenne. Nativa.

Distribución: AYP.

Rango altitudinal: 3300-4300 m.

Países limítrofes: Argentina, Bolivia y Perú.

Muhlenbergia peruviana (P. Beauv.) Steud.

Sinónimos: Clomena peruviana $\mathrm{P}$. Beauv.

Hierba. Anual. Nativa.

Distribución: AYP, TAR, ANT, MAU.

Rango altitudinal: 2250-4040 m.

Países limítrofes: Argentina, Bolivia y Perú.

\section{Munroa}

\section{Munroa andina Phil.}

Sinónimos: Hemimunroa andina (Phil.) Parodi, Munroa multiflora Phil.

Hierba. Anual. Nativa.

Distribución: TAR, ANT.

Rango altitudinal: 2700-4000 m.

Países limítrofes: Argentina y Bolivia.

\section{Munroa argentina Griseb.}

Hierba. Anual. Nativa.

Distribución: ANT.

Rango altitudinal: 2820-3800 m.

Países limítrofes: Argentina y Bolivia.

Munroa decumbens Phil.

Hierba. Anual. Nativa.

Distribución: AYP, ANT.

Rango altitudinal: 2850-3660 m.

Países limítrofes: Argentina, Bolivia y Perú.

\section{Nassella}

Nassella arcuata (R.E. Fr.) Torres Sinónimos: Stipa arcuata R.E. Fr. Hierba. Perenne. Nativa. Distribución: AYP, TAR, ANT.

Rango altitudinal: 400-4500 m. Países limítrofes: Argentina y Bolivia.
Nassella asplundii Hitchc.

Hierba. Perenne. Nativa.

Distribución: AYP, TAR.

Rango altitudinal: $3600-4000 \mathrm{~m}$.

Países limítrofes: Bolivia y Perú.

Nassella barbinodis (Phil.) Muñoz-Schick, Ciald. \& Morrone

Sinónimos: Stipa barbinodis Phil.

Hierba. Perenne. Endémica.

Distribución: NUB, BIO, ARA, LLA.

Rango altitudinal: 60-280 m.

Nassella caespitosa Griseb.

Hierba. Perenne. Nativa.

Distribución: ANT.

Rango altitudinal: 4120-4120 m.

Países limítrofes: Argentina y Perú.

Nassella chilensis (Trin.) E. Desv. var. chilensis

Sinónimos: Urachne chilensis Trin., Piptatherum ligleyanum

Nees, Urachne major Trin. \& Rupr., Nassella major (Trin.

\& Rupr.) E. Desv., Nassella ramosa E. Desv., Nassella sadae Phil., Nassella landbeckii Phil., Nassella landbackii Phil. var. eremophila Phil., Nassella laxiflora Phil., Nassella planifolia Phil.Nassella floribunda Phil., Nassella obscura fma. Phil.

Hierba. Perenne. Nativa.

Distribución: AYP, ANT, COQ, VAL, RME, LBO, MAU, NUB, BIO, ARA.

Rango altitudinal: 2700-5000 m.

Países limítrofes: Argentina.

Nombre vulgar: Coirón, Coironcillo, Nudillo.

Nassella chilensis (Trin.) E. Desv. var. juncea (Phil.) Muñoz-Schick

Sinónimos: Nassella juncea Phil.

Hierba. Perenne. Endémica.

Distribución: COQ, RME, LBO, BIO, ARA, LRI.

Rango altitudinal: 20-925 m.

Nassella coquimbensis (Matthei) Peñail.

Sinónimos: Stipa coquimbensis Matthei

Hierba. Perenne. Endémica.

Distribución: COQ.

Rango altitudinal: $60-350 \mathrm{~m}$.

Nassella duriuscula (Phil.) Barkworth

Sinónimos: Stipa duriuscula Phil.

Hierba. Perenne. Endémica.

Distribución: ATA, COQ, VAL, RME, LBO, MAU, NUB, BIO, ARA, LRI.

Rango altitudinal: 15-1000 m. 
Nassella elata (Speg.) Torres

Sinónimos: Stipa caespitosa (Griseb.) Speg. var. elata Speg. Hierba. Perenne. Nativa.

Distribución: ATA.

Rango altitudinal: 2200-3000 m.

Países limítrofes: Argentina y Bolivia.

Nassella filiculmis (Delile) Barkworth

Sinónimos: Stipa filiculmis Delile, Stipa leucogluma Steud., Stipa trichocaulos Phil.

Hierba. Perenne. Nativa.

Distribución: LBO, NUB, BIO, ARA, LRI.

Rango altitudinal: 5-1200 m.

Países limítrofes: Argentina.

Nassella gibba (Phil.) Muñoz-Schick

Sinónimos: Piptochaetium gibbum Phil., Nassella exserta Phil. var. asperata Parodi

Hierba. Perenne. Endémica.

Distribución: VAL, RME, LBO, MAU, NUB.

Rango altitudinal: $15-1000 \mathrm{~m}$.

Nassella gigantea (Steud.) Muñoz-Schick

Sinónimos: Urachne gigantea Steud., Nassella exserta Phil., Nassella fuscescens Phil., Nassella melanocarpa Phil., Nassella pugae Phil.

Hierba. Perenne. Nativa.

Distribución: COQ, VAL, RME, LBO, MAU, NUB, BIO,

ARA, LRI, LLA, AIS.

Rango altitudinal: 5-1800 m.

Países limítrofes: Argentina.

Nassella hirtifolia (Hitchc.) Barkworth

Sinónimos: Stipa hirtifolia Hitchc.

Hierba. Perenne. Endémica.

Distribución: ATA, COQ, VAL, RME, LBO.

Rango altitudinal: $20-1650 \mathrm{~m}$.

Nassella lachnophylla (Trin.) Barkworth

Sinónimos: Stipa lachnophylla Trin., Stipa cumingiana var. lachnophylla (Trin.) Trin. \& Rupr., Stipa cumingiana Trin., Stipa laxa E. Desv., Stipa leiocarpa Nees ex Steud., Stipa hirta Phil.

Hierba. Perenne. Endémica.

Distribución: COQ, VAL, RME, LBO, MAU, ARA.

Rango altitudinal: 10-1000 m.

Nassella laevissima (Phil.) Barkworth

Sinónimos: Piptochaetium laevissimum Phil., Stipa laevissima (Phil.) Speg., Nassella longearistata Phil., Piptochaetium collinum Phil., Stipa breviculmis Hitchc.

Hierba. Perenne. Nativa.

Distribución: COQ, VAL, RME, LBO, MAU, NUB, BIO, ARA, LLA, AIS, JFE.
Rango altitudinal: 5-2500 m.

Países limítrofes: Argentina.

Nota: Introducida en el Archipiélago Juan Fernández.

Nassella longiglumis (Phil.) Barkworth

Sinónimos: Stipa longiglumis Phil.

Hierba. Perenne. Nativa.

Distribución: COQ, LBO, MAU, NUB.

Rango altitudinal: 60-700 m.

Países limítrofes: Argentina.

Nassella macrathera (Phil.) Barkworth

Sinónimos: Stipa macrathera Phil., Stipa fernandeziana Phil., hom. illeg. non Steud. 1854, Stipa rudolphii Speg.

Hierba. Perenne. Endémica.

Distribución: COQ, RME, MAU, NUB, BIO, ARA, LRI, JFE.

Rango altitudinal: 2-2000 m.

Nassella manicata (E. Desv.) Barkworth

Sinónimos: Stipa manicata E. Desv.

Hierba. Perenne. Nativa.

Distribución: ATA, COQ, VAL, RME, LBO, MAU, NUB, BIO, ARA, LRI.

Rango altitudinal: 10-2800 m.

Nassella meyeniana (Trin. \& Rupr.) Parodi

Sinónimos: Urachne meyeniana Trin. \& Rupr.

Hierba. Perenne. Nativa.

Distribución: AYP.

Países limítrofes: Argentina, Bolivia y Perú.

Nassella nardoides (Phil.) Barkworth

Sinónimos: Danthonia nardoides Phil., Stipa nardoides (Phil.) Hack. ex Hitchc

Hierba. Perenne. Nativa.

Distribución: AYP, TAR, ANT, ATA.

Rango altitudinal: 3000-4900 m.

Países limítrofes: Argentina, Bolivia y Perú.

Nassella neesiana (Trin. \& Rupr.) Barkworth

Sinónimos: Stipa neesiana Trin. \& Rupr., Stipa neesiana Trin. \& Rupr. var. chilensis Trin. \& Rupr., Stipa neesiana Trin. \& Rupr. var. fernandeziana Trin. \& Rupr., Stipa fernandeziana (Trin. \& Rupr.) Steud., Stipa longiflora Steud., Stipa trachysperma Phil., Stipa contracta Phil., Stipa hispida Phil.

Hierba. Perenne. Nativa.

Distribución: ATA, COQ, VAL, RME, LBO, MAU, NUB, BIO, ARA, LRI, LLA, JFE.

Rango altitudinal: 5-1100 m.

Países limítrofes: Argentina, Bolivia y Perú.

Nombre vulgar: flechilla.

Nota: Introducida en el Archipiélago Juan Fernández. 
Nassella parodii (Matthei) Barkworth

Sinónimos: Stipa parodii Matthei

Hierba. Perenne. Endémica.

Distribución: LBO, NUB, BIO.

Rango altitudinal: 5-370 m.

Nassella pfisteri (Matthei) Barkworth

Sinónimos: Stipa pfisteri Matthei

Hierba. Perenne. Endémica.

Distribución: COQ, MAU, NUB.

Rango altitudinal: 60-350 m.

Nassella philippii (Steud.) Barkworth

Sinónimos: Stipa philippii Steud., Stipa lenta Hitchc.

Hierba. Perenne. Nativa.

Distribución: MAU, NUB, BIO, ARA, LRI, LLA.

Rango altitudinal: $65-450 \mathrm{~m}$.

Países limítrofes: Argentina.

Nassella poeppigiana (Trin. \& Rupr.) Barkworth

Sinónimos: Stipa poeppigiana Trin. \& Rupr., Stipa amethystina Steud., Nassella amethystina (Steud.)

Barkworth, Stipa pratensis Phil., Stipa collina Phil., Stipa curicoana Phil., Stipa julietii Phil., Stipa montana Phil.

Hierba. Perenne. Nativa.

Distribución: COQ, VAL, LBO, MAU, NUB, BIO, ARA, LRI.

Rango altitudinal: 10-1700 m.

Países limítrofes: Argentina.

Nombre vulgar: Quilmén, fechilla.

Nassella pubiflora (Trin. \& Rupr.) E. Desv.

Sinónimos: Urachne pubiflora Trin. \& Rupr.

Hierba. Perenne. Nativa.

Distribución: AYP, TAR.

Rango altitudinal: 2950-4000 m.

Países limítrofes: Argentina, Bolivia y Perú.

Nombre vulgar: Taj-taja.

Nassella pungens E. Desv.

Sinónimos: Nassella humilis Phil., Nassella johnstonii

Parodi

Hierba. Perenne. Endémica.

Distribución: AYP, TAR, ANT, ATA, COQ, RME.

Rango altitudinal: 5-1000 m.

Nassella rupestris (Phil.) Torres

Sinónimos: Stipa rupestris Phil.

Hierba. Perenne. Nativa.

Distribución: AYP, TAR, ANT.

Rango altitudinal: 3200-4600 m.

Países limítrofes: Argentina y Bolivia.

Nassella tenuis (Phil.) Barkworth

Sinónimos: Stipa tenuis Phil.
Hierba. Perenne. Nativa.

Distribución: AYP, TAR, ANT, BIO, ARA.

Países limítrofes: Argentina.

Nicoraepoa

Nicoraepoa andina (Trin.) Soreng \& L.J. Gillespie

Sinónimos: Poa andina Trin., Deschampsia latifolia Phil.,

Poa aristata Phil., Poa acrochaeta Hack.

Hierba. Perenne. Nativa.

Distribución: BIO, ARA, LRI.

Rango altitudinal: 935-2600 m.

Países limítrofes: Argentina.

Nicoraepoa chonotica (Phil.) Soreng \& L.J. Gillespie

Sinónimos: Poa chonotica Phil., Poa latifolia Phil., Poa robusta Phil., Poa borchersii Phil., Poa chubutensis Speg.,

Poa berningeri Pilg.

Hierba. Perenne. Nativa.

Distribución: NUB, ARA, LLA, AIS, MAG.

Rango altitudinal: $10-2700 \mathrm{~m}$.

Países limítrofes: Argentina.

Nicoraepoa pugionifolia (Speg.) Soreng \& L.J. Gillespie

Sinónimos: Poa pugionifolia Speg., Poa acutissima Pilg.

Hierba. Perenne. Nativa.

Distribución: MAG.

Rango altitudinal: 600-850 m.

Países limítrofes: Argentina.

Nicoraepoa robusta (Steud.) Soreng \& L.J. Gillespie Sinónimos: Poa robusta Steud., Festuca arenaria Lam., Poa arenicola St.-Ives

Hierba. Perenne. Nativa.

Distribución: AIS, MAG.

Rango altitudinal: 5-95 m.

Países limítrofes: Argentina.

Nicoraepoa subenervis (Hack.) Soreng \& L.J. Gillespie subsp. spegazziniana (Nicora) Soreng \& L.J. Gillespie

Sinónimos: Poa spegazziniana Parodi, Poa subenervis Hack. var. spegazziniana Nicora

Hierba. Perenne. Nativa.

Distribución: RME, LBO.

Rango altitudinal: 2390-2600 m.

Países limítrofes: Argentina.

Nicoraepoa subenervis (Hack.) Soreng \& L.J. Gillespie subsp. subenervis

Sinónimos: Poa subenervis Hack.

Hierba. Perenne. Nativa.

Distribución: RME, MAG.

Rango altitudinal: 720-900 m.

Países limítrofes: Argentina. 


\section{Ortachne}

Ortachne breviseta Hitchc.

Sinónimos: Stipa breviseta (Hitchc.) Martic. \& Quezada, nom. illeg., Stipa yatesensis Martic. \& Quezada

Hierba. Perenne. Nativa.

Distribución: LRI, LLA.

Rango altitudinal: 1200-1700 m.

Países limítrofes: Argentina.

Ortachne rariflora (Hook.f.) Hughes

Sinónimos: Muhlenbergia rariflora Hook.f., Ortachne retorta Nees ex Steud., Stipa rariflora (Hook.f.) Benth., Stipa retorta (Nees ex Steud.) Mez

Hierba. Perenne. Nativa.

Distribución: LLA, AIS, MAG.

Rango altitudinal: $15-1300 \mathrm{~m}$.

Países limítrofes: Argentina.

\section{Oryza}

\section{Oryza sativa L.}

Hierba. Anual. Introducida.

Distribución: RME, LBO, MAU, BIO.

\section{Panicum}

\section{Panicum capillare L.}

Hierba. Anual. Introducida.

Distribución: COQ, VAL, RME, MAU, NUB, BIO, ARA, LRI.

Panicum dichotomiflorum Michx.

Hierba. Anual. Introducida.

Distribución: RME, LBO, MAU, BIO.

\section{Panicum miliaceum L.}

Hierba. Anual. Introducida.

Distribución: NUB, BIO.

Panicum racemosum (P. Beauv.) Spreng.

Sinónimos: Monachne racemosa P. Beauv.

Hierba. Perenne. Nativa.

Distribución: MAU, BIO, ARA, LRI.

Países limítrofes: Argentina.

Panicum urvilleanum Kunth

Sinónimos: Monachne urvilleana (Kunth) Herter, Panicum reversipilum Steud., Panicum urvillianum Brongn.

Hierba. Perenne. Nativa.

Distribución: LBO, NUB, BIO, ARA, LRI.

Rango altitudinal: 5-140 m.

Países limítrofes: Argentina.

\section{Pappostipa}

Pappostipa atacamensis (Parodi) Romasch.

Sinónimos: Stipa atacamensis Parodi, Jarava atacamensis

(Parodi) Peñail.

Hierba. Perenne. Nativa.

Distribución: ANT, ATA, COQ, RME.

Rango altitudinal: 1900-4380 m.

Países limítrofes: Argentina.

Pappostipa chrysophylla (E. Desv.) Romasch.

Sinónimos: Stipa chrysophylla E. Desv., Stipa chrysophylla

E. Desv. var. major E. Desv., Stipa humilis Cav. fma. chrysophylla (E. Desv.) Kuntze, Stipa speciosa Trin. \& Rupr. subsp. chrysophylla (E. Desv.) Dusén, Jarava chrysophylla (E. Desv.) Peñail., Stipa chrysophylla E. Desv. var. minor E. Desv.

Hierba. Perenne. Nativa.

Distribución: AYP, TAR, ANT, ATA, COQ, VAL, RME, LBO, MAU.

Rango altitudinal: 470-4290 m.

Países limítrofes: Argentina.

Pappostipa frigida (Phil.) Romasch.

Sinónimos: Stipa frigida Phil., Jarava frigida (Phil.) F.

Rojas

Hierba. Perenne. Nativa.

Distribución: AYP, TAR, ANT, ATA, COQ, RME, MAU.

Rango altitudinal: 50-5000 m.

Países limítrofes: Argentina y Bolivia.

Nombre vulgar: pasto vicuña.

Pappostipa humilis (Cav.) Romasch.

Sinónimos: Stipa humilis Cav., Jarava humilis (Cav.)

Peñail.

Hierba. Perenne. Nativa.

Distribución: AIS, MAG.

Rango altitudinal: 15-800 m.

Países limítrofes: Argentina.

Nombre vulgar: Coirón, coirón amargo.

Pappostipa ibarii (Phil.) Romasch.

Sinónimos: Stipa ibarii Phil., Jarava ibarii (Phil.) Peñail.

Hierba. Perenne. Nativa.

Distribución: MAG.

Rango altitudinal: 100-900 m.

Países limítrofes: Argentina.

Nombre vulgar: Coirón enano.

Pappostipa nana (Speg.) Romasch.

Sinónimos: Stipa nana Speg., Jarava nana (Speg.) Peñail.

Hierba. Perenne. Nativa.

Distribución: AIS.

Rango altitudinal: 400-400 m.

Países limítrofes: Argentina. 
Pappostipa speciosa (Trin. \& Rupr.) Romasch.

Sinónimos: Stipa speciosa Trin. \& Rupr., Stipa humilis Cav. var. speciosa (Trin. \& Rupr.) Kuntze, Achnatherum speciosum (Trin. \& Rupr.) Barkworth

Hierba. Perenne. Nativa.

Distribución: AYP, TAR, ANT, ATA, COQ, VAL, RME, LBO, MAU, NUB, BIO, ARA, AIS, MAG.

Rango altitudinal: 5-4120 m.

Países limítrofes: Argentina y Bolivia.

Nombre vulgar: Pajonal.

Pappostipa vaginata (Phil.) Romasch.

Sinónimos: Stipa vaginata Phil., Jarava vaginata (Phil.) F. Rojas

Hierba. Perenne. Nativa.

Distribución: AYP, TAR, ANT, ATA, COQ, VAL, RME.

Rango altitudinal: $1100-4300 \mathrm{~m}$.

Países limítrofes: Argentina y Bolivia.

\section{Parapholis}

Parapholis incurva (L.) C.E. Hubb.

Hierba. Anual. Introducida.

Distribución: COQ, VAL, RME, BIO.

Parapholis strigosa (Dumort.) C.E. Hubb.

Hierba. Anual. Introducida.

Distribución: BIO, ARA, LLA.

\section{Paspalum}

Paspalum chilense Catanzaro \& G.H. Rua

Hierba. Perenne. Endémica.

Distribución: BIO, ARA, LRI.

Paspalum conjugatum P. J. Berg.

Hierba. Perenne. Introducida.

Distribución: IPA.

Paspalum dasypleurum Kuntze ex E. Desv.

Sinónimos: Paspalum cumingii Nees ex Steud., Paspalum pachyrrhizum Steud., Paspalum paradisiacum Steud.

Hierba. Perenne. Nativa.

Distribución: ATA, VAL, RME, MAU, NUB, BIO, ARA, LRI, LLA, JFE.

Rango altitudinal: 5-1200 m.

Países limítrofes: Argentina.

Nombre vulgar: Chépica.

Nota: Introducida en el Archipiélago Juan Fernández.

Paspalum dilatatum Poir. ex Lam.

Hierba. Perenne. Nativa.

Distribución: COQ, VAL, RME, LBO, MAU, NUB, BIO, ARA, LRI, IPA.
Rango altitudinal: $30-1000 \mathrm{~m}$.

Países limítrofes: Argentina y Bolivia.

Nombre vulgar: Chépica gigante.

Nota: Introducida en la Isla de Pascua.

Paspalum distichum L.

Hierba. Perenne. Introducida.

Distribución: AYP, ANT, VAL, RME, LBO, MAU, NUB, BIO, ARA, LRI, JFE.

Paspalum forsterianum Flüggé

Hierba. Perenne. Endémica.

Distribución: IPA.

Nombre vulgar: Herike hare (Rapa Nui).

Paspalum minus E. Fourn.

Hierba. Perenne. Nativa.

Distribución: ARA, LRI.

Rango altitudinal: 160-220 m.

Países limítrofes: Argentina, Bolivia y Perú.

Paspalum notatum Flüggé var. saurae Parodi

Hierba. Perenne. Nativa.

Distribución: IPA.

Países limítrofes: Argentina, Bolivia y Perú.

Paspalum orbiculare G. Forst.

Hierba. Perenne. Introducida.

Distribución: IPA.

Rango altitudinal: 25-100 m.

Paspalum plicatulum Michx.

Hierba. Perenne. Nativa.

Distribución: MAU.

Rango altitudinal: 1000-1000 m.

Países limítrofes: Argentina, Bolivia y Perú.

Paspalum urvillei Steud.

Hierba. Perenne. Nativa.

Distribución: COQ, MAU, NUB, BIO, ARA, LRI.

Rango altitudinal: 10-1500 m.

Países limítrofes: Argentina y Bolivia.

Paspalum vaginatum Sw.

Sinónimos: Paspalum gayanum E. Desv.

Hierba. Perenne. Nativa.

Distribución: TAR, ANT, ATA, COQ, VAL, RME, MAU, NUB, BIO, ARA, LRI, LLA.

Rango altitudinal: 20-2000 m.

Países limítrofes: Argentina, Bolivia y Perú.

Nombre vulgar: Chépica. 


\section{Phalaris}

Phalaris amethystina Trin.

Sinónimos: Phalaris berteroniana Steud., Phalaris robinsoniana Nees ex Steud., Phalaris colchaguensis Phil., Phalaridanta robinsoniana (Steud.) St.-Lég.

Hierba. Anual. Endémica.

Distribución: COQ, VAL, RME, LBO, MAU, NUB, BIO, ARA, LLA, JFE.

Rango altitudinal: 40-1000 m.

Nota: Introducida en el Archipiélago Juan Fernández.

Phalaris angusta Nees ex Trin.

Sinónimos: Phalaris chilensis J. Presl.

Hierba. Anual. Nativa.

Distribución: VAL, MAU, NUB, BIO, ARA, LRI, LLA, JFE.

Rango altitudinal: 10-175 m.

Países limítrofes: Argentina, Bolivia y Perú.

Nota: Introducida en el Archipiélago Juan Fernández.

Phalaris aquatica L.

Hierba. Perenne. Introducida.

Distribución: AYP, COQ, VAL, RME, LBO, MAU, NUB, BIO, ARA, MAG.

\section{Phalaris arundinacea L.}

Hierba. Anual. Introducida.

Distribución: LLA, MAG.

Phalaris canariensis L.

Hierba. Anual. Introducida.

Distribución: ANT, ATA, COQ, VAL, RME, LBO, MAU,

NUB, BIO, ARA, LRI, MAG.

Phalaris caroliniana Walter

Hierba. Anual. Introducida.

Distribución: VAL.

Phalaris coerulescens Desf.

Hierba. Perenne. Introducida.

Distribución: BIO.

Phalaris minor Retz.

Hierba. Anual. Introducida.

Distribución: COQ, BIO.

Phalaris paradoxa $\mathrm{L}$.

Hierba. Anual. Introducida.

Distribución: LBO.

\section{Phleum}

Phleum alpinum L.
Hierba. Perenne. Nativa.

Distribución: COQ, VAL, RME, LBO, MAU, NUB, BIO, ARA, LLA, AIS, MAG.

Países limítrofes: Argentina.

Phleum pratense L.

Hierba. Perenne. Introducida.

Distribución: RME, MAU, NUB, BIO, ARA, LRI, LLA, AIS, MAG.

\section{Phragmites}

Phragmites australis (Cav.) Trin. ex Steud.

Sinónimos: Arundo australis Cav., Phragmites communis Trin., Phragmites phragmites (L.) H. Karst., Phragmites phragmites (L.) Speg., Phtagmites dioicus Hack. ex Hicken, Phragmites dioica Hack. ex Conert

Hierba. Perenne. Introducida.

Distribución: TAR, ANT, ATA, COQ, VAL, RME, MAU, NUB, BIO, ARA, LRI.

Rango altitudinal: 5-2390 m.

Nombre vulgar: Carrizo.

\section{Piptatherum}

Piptatherum miliaceum (L.) Coss.

Hierba. Perenne. Introducida.

Distribución: VAL, RME, MAG.

\section{Piptochaetium}

Piptochaetium angolense Phil.

Hierba. Perenne. Endémica.

Distribución: COQ, VAL, RME, LBO, MAU, NUB, BIO, ARA.

Rango altitudinal: 10-740 m.

Piptochaetium bicolor (Vahl) E. Desv.

Sinónimos: Stipa bicolor Vahl, Stipa megalantha Steud.

Hierba. Perenne. Nativa.

Distribución: VAL, RME, LBO, MAU, NUB, BIO, ARA, LRI, JFE.

Rango altitudinal: $10-1100 \mathrm{~m}$.

Países limítrofes: Argentina.

Piptochaetium depressum (Steud.) C. Peña

Sinónimos: Urachne depressa Steud., Piptochaetium verrucosum Phil., Piptochaetium humile Phil., Piptochaetium granulatum Phil., Piptochaetium moelleri Phil.

Hierba. Perenne. Endémica.

Distribución: COQ, VAL, RME, LBO, MAU, NUB, BIO, ARA, LRI.

Rango altitudinal: 0-1500 m. 
Piptochaetium fuscum (Nees ex Steud.) Barkworth, Cialdella \& Gandhi

Sinónimos: Urachne fusca Steud., Piptochaetium purpuratum Phil., Piptochaetium pallidum Phil. ex Griseb., Piptochaetium macrocarpum Phil.

Hierba. Perenne. Nativa.

Distribución: COQ, VAL, RME, LBO, MAU, NUB, BIO, ARA.

Rango altitudinal: 10-1100 m.

Piptochaetium hirtum Phil.

Sinónimos: Piptochaetium brevifolium Phil.

Hierba. Perenne. Nativa.

Distribución: RME.

Países limítrofes: Argentina.

Piptochaetium montevidense (Spreng.) Parodi

Sinónimos: Caryochloa montevidensis Spreng., Piptochaetium tuberculatum E. Desv., Oryzopsis tuberculata (E. Desv.) Speg., Urachne depressa Steud., Piptochaetium verrucosum Phil., Oryzopsis verruculosa (Phil.) Speg., Oryzopsis verrucosa (Phil.) Speg., Piptochaetium humile Phil., Piptochetium moelleri Phil.

Hierba. Perenne. Nativa.

Distribución: COQ, VAL, RME, LBO, MAU, NUB, BIO, ARA, LRI, LLA.

Rango altitudinal: 5-1500 m.

Países limítrofes: Argentina, Bolivia y Perú.

Piptochaetium panicoides (Lam.) E. Desv.

Sinónimos: Stipa panicoides Lam., Piptochaetium subnudum Phil.

Hierba. Perenne. Nativa.

Distribución: RME, MAU, NUB, BIO, ARA, LRI.

Rango altitudinal: $15-1400 \mathrm{~m}$.

Países limítrofes: Argentina, Bolivia y Perú.

Piptochaetium stipoides (Trin. \& Rupr.) Hack.

Sinónimos: Urachne stipoides Trin. \& Rupr., Piptochaetium cuspidatum Phil.

Hierba. Perenne. Nativa.

Distribución: VAL, RME, LBO, MAU, NUB, BIO, ARA, LRI.

Rango altitudinal: 10-300 m.

Países limítrofes: Argentina.

\section{Poa}

Poa acinaciphylla E. Desv.

Sinónimos: Poa villaroellii Phil.

Hierba. Perenne. Endémica.

Distribución: COQ, VAL, RME.

Rango altitudinal: 2500-3700 m.
Poa alopecurus (Gaudich. ex Mirb.) Kunth subsp. alopecurus

Sinónimos: Arundo alopecurus Gaudich.

Hierba. Perenne. Nativa.

Distribución: ARA, LLA, AIS, MAG.

Rango altitudinal: 20-1080 m.

Países limítrofes: Argentina.

Poa alopecurus (Gaudich. ex Mirb.) Kunth subsp. fuegiana (Hook.f.) D.M. Moore \& Dogg.

Sinónimos: Festuca fuegiana Hook.f., Poa fuegiana (Hook.f.) Hack., Festuca fuegiana Hook.f. var. vivipara Hook., Aira superbiens Steud., Poa superbiens (Steud.) Hauman \& Parodi, Deyeuxia vivipara Phil., Festuca pogonantha Franch., Poa pogonantha (Franch.) Parodi, Poa fuegiana (Hook.f.) Hack. var. involucrata Hack., Poa commersonii Franch.

Hierba. Perenne. Nativa.

Distribución: ARA, LRI, LLA, AIS, MAG.

Rango altitudinal: 3-1300 m.

Países limítrofes: Argentina.

Poa alopecurus (Gaudich. ex Mirb.) Kunth subsp. shuka (Speg.) Giussani \& Soreng

Sinónimos: Festuca shuka Speg., Poa shuka (Speg.) Parodi

Hierba. Perenne. Nativa.

Distribución: MAG.

Países limítrofes: Argentina.

Poa androgyna Hack.

Hierba. Perenne. Nativa.

Distribución: AYP.

Rango altitudinal: 3400-4156 m.

Países limítrofes: Bolivia.

\section{Poa annua L.}

Hierba. Anual. Introducida.

Distribución: TAR, ANT, COQ, VAL, RME, LBO, MAU, NUB, BIO, ARA, LRI, LLA, AIS, MAG, JFE, IPA.

Poa atropidiformis Hack.

Sinónimos: Dissanthelium atropidiforme (Hack.) Soreng

Hierba. Perenne. Nativa.

Distribución: MAG.

Rango altitudinal: 3-1300 m.

Países limítrofes: Argentina.

Poa bonariensis (Lam.) Kunth

Sinónimos: Festuca bonariensis Lam., Schenodorus bonariensis (Lam.) Roem. \& Schult.

Hierba. Perenne. Nativa.

Distribución: ANT, ATA, COQ, VAL, RME, LBO, MAU, NUB, BIO, ARA, LLA, MAG.

Rango altitudinal: 10-1400 m.

Países limítrofes: Argentina y Bolivia. 
Poa bulbosa L. subsp. bulbosa

Hierba. Perenne. Introducida.

Distribución: MAG.

Poa bulbosa L. subsp. vivipara (Koeler) Arcang.

Hierba. Perenne. Introducida.

Distribución: MAG.

\section{Poa compressa L.}

Hierba. Perenne. Introducida.

Distribución: ARA, LLA, MAG.

Poa cumingii Trin.

Sinónimos: Distichlis ammobia Phil., Distichlis volkmannii Phil., Poa conformis Nees ex Steud., Poa curva Nees ex Steud., Poa dialystostachya Phil., Poa phalaroides Nees ex Steud., Poa stachyodes Phil.

Hierba. Perenne. Endémica.

Distribución: COQ, VAL, MAU, NUB, BIO, ARA, LRI, LLA.

Rango altitudinal: 3-350 m.

Poa darwiniana Parodi

Hierba. Perenne. Nativa.

Distribución: MAG.

Países limítrofes: Argentina.

Poa denudata Steud.

Sinónimos: Koeleria rigidula Steud., Trisetum rigidulum (Steud.) Domin, Poa vaginiflora Steud., Poa vaginifolia Steud. ex Lechler, Poa vaginiformis Steud. ex fma. Phil., Poa chiloensis Phil., Poa fonckii Phil., Poa araucana Phil., Poa eligulata Hack.

Hierba. Perenne. Nativa.

Distribución: COQ, VAL, RME, LBO, MAU, NUB, BIO, ARA, LRI, LLA, AIS.

Rango altitudinal: 1-2750 m.

Países limítrofes: Argentina.

Poa flabellata (Lam.) Raspail

Sinónimos: Festuca flabellata Lam., Poa flabellata Hook.f., Parodiochloa flabellata (Lam.) C.E. Hubb.

Hierba. Perenne. Nativa.

Distribución: MAG.

Países limítrofes: Argentina.

Poa gayana E. Desv.

Hierba. Perenne. Nativa.

Distribución: COQ, VAL, RME, LBO, MAU, NUB.

Rango altitudinal: 470-3400 m.

Países limítrofes: Argentina.

Poa glauca Vahl

Hierba. Perenne. Introducida.
Distribución: AIS, MAG.

Poa gymnantha Pilg.

Hierba. Perenne. Nativa.

Distribución: AYP, TAR.

Rango altitudinal: 4250-4720 m.

Países limítrofes: Argentina, Bolivia y Perú.

Poa hachadoensis Nicora var. hachadoensis

Hierba. Perenne. Nativa.

Distribución: BIO, ARA.

Rango altitudinal: 1284-1430 m.

Países limítrofes: Argentina.

Poa hachadoensis Nicora var. pilosa Nicora

Hierba. Perenne. Nativa.

Distribución: LBO.

Países limítrofes: Argentina.

Poa holciformis J. Presl

Sinónimos: Koeleria poaeoides Nees ex Steud., Festuca elliotii Hack., Poa chilensis Trin., Poa chilensis Trin. var. robustior Phil.

Hierba. Perenne. Nativa.

Distribución: COQ, VAL, RME, LBO, MAU, NUB, BIO, ARA.

Rango altitudinal: 1200-3800 m.

Países limítrofes: Argentina.

Poa humillima Pilg.

Sinónimos: Poa humillima Pilg. var. exserta Hack. ex

Buchtien

Hierba. Perenne. Nativa.

Distribución: AYP, ANT.

Rango altitudinal: 4500-4925 m.

Países limítrofes: Argentina, Bolivia y Perú.

Poa infirma Kunth

Hierba. Anual. Introducida.

Distribución: VAL, RME.

Poa kurtzii R.E. Fr.

Hierba. Perenne. Nativa.

Distribución: AYP, TAR.

Rango altitudinal: 4000-4680 m.

Países limítrofes: Argentina, Bolivia y Perú.

Poa laetevirens R.E. Fr.

Sinónimos: Poa nana Phil., Poa atacamensis Parodi, Puccinellia atacamensis (Parodi) Soreng

Hierba. Perenne. Nativa.

Distribución: AYP, TAR.

Rango altitudinal: 4078-4550 m.

Países limítrofes: Argentina, Bolivia y Perú. 
Poa lanuginosa Poir. var. lanuginosa

Sinónimos: Poa magellanica Phil. ex Macloskie

Hierba. Perenne. Nativa.

Distribución: ANT, COQ, VAL, RME, LBO, MAU, NUB, BIO, ARA, LLA, MAG.

Rango altitudinal: 10-3500 m.

Países limítrofes: Argentina.

Poa lanuginosa Poir. var. patagonica (Phil.) Giussani \& Soreng

Sinónimos: Poa patagonica Phil.

Hierba. Perenne. Nativa.

Distribución: MAG.

Rango altitudinal: 110-110 m.

Países limítrofes: Argentina.

Poa lepidula (Nees \& Meyen) Soreng \& L.J. Gillespie Sinónimos: Anthochloa lepidula Nees \& Meyen

Hierba. Perenne. Nativa.

Distribución: AYP, TAR, ANT.

Rango altitudinal: 4000-5000 m.

Países limítrofes: Argentina, Bolivia y Perú.

Poa ligularis Nees ex Steud.

Sinónimos: Poa denudata Steud. var. minor Ball

Hierba. Perenne. Nativa.

Distribución: BIO, AIS.

Rango altitudinal: 230-930 m.

Países limítrofes: Argentina.

Poa lilloi Hack.

Hierba. Perenne. Nativa.

Distribución: AYP.

Rango altitudinal: 4250-4250 m.

Países limítrofes: Argentina.

Poa mendocina Nicora \& F.A. Roig

Hierba. Perenne. Nativa.

Distribución: RME.

Rango altitudinal: 3325-3325 m.

Países limítrofes: Argentina.

Poa nemoralis L.

Hierba. Perenne. Introducida.

Distribución: RME, ARA, AIS, MAG.

Poa obvallata Steud.

Sinónimos: Deyeuxia vulcanica Phil., Poa julietii Phil., Poa pachypogon Nees, Poa subaristata Phil., Poa tristigmatica E. Desv.

Hierba. Perenne. Nativa.

Distribución: VAL, RME, LBO, MAU, NUB, BIO, ARA, LRI, LLA, AIS.

Rango altitudinal: 210-2600 m.
Países limítrofes: Argentina.

Poa palustris L.

Hierba. Perenne. Introducida.

Distribución: VAL, RME, MAG.

Poa paposana Phil.

Hierba. Perenne. Endémica.

Distribución: ANT, ATA, COQ, VAL, RME.

Rango altitudinal: 30-820 m.

Poa parviceps Hack.

Hierba. Perenne. Nativa.

Distribución: ANT.

Rango altitudinal: 4395-4395 m.

Países limítrofes: Argentina.

Poa pearsonii Reeder

Hierba. Perenne. Nativa.

Distribución: AYP.

Países limítrofes: Argentina, Bolivia y Perú.

Poa perligulata Pilg.

Hierba. Perenne. Nativa.

Distribución: AYP, TAR.

Rango altitudinal: 4340-4460 m.

Países limítrofes: Argentina, Bolivia y Perú.

Poa pfisteri Soreng

Hierba. Perenne. Endémica.

Distribución: BIO.

Rango altitudinal: 200-300 m.

Poa planifolia Kuntze

Sinónimos: Colpodium planifolium (Kuntze) K. Schum., Poa chilensis Trin. var. planifolia (Kuntze) Haumann

Hierba. Perenne. Nativa.

Distribución: RME.

Rango altitudinal: 2750-3230 m.

Países limítrofes: Argentina.

Poa pratensis L. subsp. alpigena (Lindm.) Hiitonen

Hierba. Perenne. Introducida.

Distribución: MAG.

Poa pratensis L. subsp. pratensis

Hierba. Perenne. Introducida.

Distribución: ATA, COQ, VAL, RME, LBO, MAU, NUB, BIO, ARA, LRI, LLA, AIS, MAG, JFE.

Poa scaberula Hook.f.

Sinónimos: Poa dactyliformis Steud.

Hierba. Perenne. Nativa.

Distribución: ANT, ATA, AIS, MAG. 
Rango altitudinal: 95-4200 m.

Países limítrofes: Argentina, Bolivia y Perú.

Poa schoenoides Phil.

Hierba. Perenne. Endémica.

Distribución: LRI.

Poa secunda J. Presl

Sinónimos: Poa fulvescens Trin., Festuca patagonica Phil., Festuca spianantha Phil., Poa fallens Pilg.

Hierba. Perenne. Nativa.

Distribución: VAL, RME, LBO, AIS, MAG.

Rango altitudinal: 200-2600 m.

Países limítrofes: Argentina.

Poa serpaiana Refulio

Sinónimos: Dissanthelium peruvianum (Nees \& Meyen)

Pilg., Phalaridium peruvianum Nees \& Meyen

Hierba. Anual. Nativa.

Distribución: AYP.

Rango altitudinal: 4450-4450 m.

Países limítrofes: Argentina, Bolivia y Perú.

Poa spiciformis (Steud.) Hauman \& Parodi var. ibarii (Phil.) Giussani

Sinónimos: Poa ibari var. ibari Phil., Poa rigidifolia Steud. var. ibarii (Phil.) Giussani

Hierba. Perenne. Nativa.

Distribución: MAG.

Rango altitudinal: 5-900 m.

Países limítrofes: Argentina.

Poa spiciformis (Steud.) Hauman \& Parodi var. spiciformis Sinónimos: Aira spiciformis Steud., Koeleria sterilis Steud., Poa poecila Phil.

Hierba. Perenne. Nativa.

Distribución: RME, AIS, MAG.

Rango altitudinal: 5-1400 m.

Países limítrofes: Argentina.

Poa stenantha Trin.

Sinónimos: Poa chorizantha E. Desv.

Hierba. Perenne. Nativa.

Distribución: NUB, ARA, AIS, MAG.

Rango altitudinal: 670-2200 m.

Poa trachyantha Hack.

Hierba. Perenne. Endémica.

Distribución: AIS.

Poa tricolor Nees ex Steud.

Hierba. Perenne. Endémica.

Distribución: VAL.
Poa trivialis L.

Hierba. Perenne. Introducida.

Distribución: VAL, RME, MAU, NUB, BIO, LRI, LLA, MAG.

Poa yaganica Speg.

Sinónimos: Poa breviculmis Pilg., Poa chrysantha Lindm.

Hierba. Perenne. Nativa.

Distribución: MAG.

Rango altitudinal: 50-170 m.

Países limítrofes: Argentina.

\section{Podagrostis}

Podagrostis sesquiflora (E. Desv.) Nicora

Sinónimos: Agrostis sesquiflora E. Desv., Deyeuxia sesquiflora (E. Desv.) Benth. \& Hook.f. ex W.D. Jacks., Briza sesquiflora (E. Desv.) Pilg.

Hierba. Perenne. Nativa.

Distribución: MAU, NUB, BIO, ARA, LRI.

Rango altitudinal: 1000-2400 m.

Países limítrofes: Argentina.

\section{Podophorus}

Podophorus bromoides Phil.

Hierba. Perenne. Endémica.

Distribución: JFE.

Rango altitudinal: 0-500 m.

Nota: Extinta.

\section{Polypogon}

Polypogon australis Brongn.

Sinónimos: Polypogon chonoticus Hook.f., Polypogon crinitus Trin., hom. illeg. non(Schreb.) Nutt. 1818, Polypogon littoralis var. crinitus Kuntze, Polypogon interruptus var. crinitus (Kuntze) Hack., Polypogon radicans Steud.

Hierba. Perenne. Nativa.

Distribución: AYP, TAR, ANT, ATA, COQ, VAL, RME, LBO, MAU, NUB, BIO, ARA, LRI, LLA, AIS, JFE.

Rango altitudinal: $10-4000 \mathrm{~m}$.

Países limítrofes: Argentina.

Nota: Introducida en el Archipiélago Juan Fernández.

Polypogon cachinalensis Phil.

Hierba. Perenne. Endémica.

Distribución: ANT, COQ.

Rango altitudinal: 2600-3000 m.

Polypogon chilensis (Kunth) Pilg.

Sinónimos: Chaetotropis chilensis Kunth, Chaetotropis latifolia Phil.

Hierba. Anual. Nativa.

Distribución: ATA, VAL, NUB, BIO, LRI, LLA, JFE. 
Rango altitudinal: 5-700 m.

Países limítrofes: Argentina.

Nota: Introducida en el Archipiélago Juan Fernández.

Polypogon elongatus Kunth var. elongatus

Sinónimos: Polypogon affinis Brongn.

Hierba. Perenne. Nativa.

Distribución: ATA, VAL, RME, NUB, LRI, LLA, AIS.

Rango altitudinal: 400-850 m.

Países limítrofes: Argentina, Bolivia y Perú.

Polypogon elongatus Kunth var. strictus E. Desv.

Hierba. Perenne. Endémica.

Distribución: RME, LRI, LLA.

Rango altitudinal: 5-200 m.

Polypogon exasperatus (Trin.) Renvoize var. exasperatus Sinónimos: Agrostis exasperata Trin., Chaetotropis exasperata (Trin.) Björkman, Agrostis asperigluma Steud., Chaetotropis asperigluma (Steud.) Nicora, Chaetotropis araucana Phil., Agrostis exasperata Trin. var. viridis Kuntze, Agrostis speeiana $\mathrm{Mez}$

Hierba. Perenne. Nativa.

Distribución: RME, MAU, NUB, BIO, ARA, LRI, LLA, MAG, JFE.

Rango altitudinal: 5-2250 m.

Países limítrofes: Argentina, Bolivia y Perú.

Polypogon exasperatus (Trin.) Renvoize var. kuntzei (Mez) Finot

Sinónimos: Agrostis kuntze Mez, Agrostis exasperata Trin. var. purpurascens Kuntze

Hierba. Perenne. Nativa.

Distribución: COQ, RME.

Rango altitudinal: 2000-2800 m.

Países limítrofes: Argentina.

\section{Polypogon imberbis (Phil.) Johow}

Sinónimos: Nowodworskya imberbis Phil., Chaetotropis imberbis (Phil.) Björkman, Polypogon imberbis (Phil.) Johow fma. aristata Skottsb.

Hierba. Perenne. Nativa.

Distribución: MAU, ARA, LRI, LLA, JFE.

Rango altitudinal: 5-100 m.

Países limítrofes: Argentina.

Nota: Introducida en el Archipiélago Juan Fernández.

\section{Polypogon interruptus Kunth}

Sinónimos: Polypogon interruptus Kunth var. breviaristatus

E. Desv., Polypogon interruptus Kunth var. longearistata

E. Desv., Polypogon microstachys Phil., Polypogon tarapacanus Phil., Polypogon brachyatherus Phil., Polypogon breviaristatus Phil., Polypogon purpurascens Phil.

Hierba. Perenne. Nativa.
Distribución: AYP, TAR, ANT, ATA, COQ, VAL, RME, LBO, MAU, NUB, BIO, LLA.

Rango altitudinal: $10-3850 \mathrm{~m}$.

Países limítrofes: Argentina, Bolivia y Perú.

Polypogon linearis Trin.

Sinónimos: Polypogon longiflorus Nees ex Steud., nom. nud., Polypogon longiflorus Nees ex Steud., Polypogon longiflorus Nees ex Trin.

Hierba. Anual. Endémica.

Distribución: COQ, VAL, RME, LBO, MAU, BIO.

Rango altitudinal: 20-740 m.

Polypogon magellanicus (Lam.) Finot

Sinónimos: Agrostis magellanica Lam., Agrostis antarctica Hook.f., Agrostis magellanica Lam. var. antarctica (Hook.f.) Franch., Agrostis magellanica Lam. var. antarctica (Hook.f.) Pilg., Agrostis cognata Steud., Agrostis magellanica Lam. var. cognata (Steud.) Macloskie \& Dusén, Agrostis chonotica Phil., Agrostis araucana Phil., Agrostis macrathera Phil., Agrostis rinihuensis Phil., Vilfa magellanica (Lam.) P. Beauv.

Hierba. Perenne. Nativa.

Distribución: LRI, LLA, AIS, MAG.

Rango altitudinal: 10-1200 m.

Países limítrofes: Argentina.

Polypogon maritimus Willd.

Hierba. Anual. Introducida.

Distribución: VAL, BIO.

Polypogon monspeliensis (L.) Desf.

Hierba. Anual. Introducida.

Distribución: AYP, ANT, ATA, COQ, VAL, RME, LBO, MAU, NUB, BIO, ARA, LRI, LLA, AIS, JFE.

Polypogon viridis (Gouan) Breistr.

Hierba. Perenne. Introducida.

Distribución: AYP, TAR, ANT, COQ, VAL, RME, LBO, BIO, ARA, LLA.

\section{Puccinellia}

Puccinellia argentinensis (Hack.) Parodi

Sinónimos: Atropis argentinensis Hack.

Hierba. Perenne. Nativa.

Distribución: ATA.

Rango altitudinal: 2000-4000 m.

Países limítrofes: Argentina.

Puccinellia biflora (Steud.) Parodi

Sinónimos: Festuca biflora Steud., Atropis biflora (Steud.)

St.-Yves \& Camus

Hierba. Perenne. Nativa.

Distribución: MAG. 
Rango altitudinal: 0-15 m.

Países limítrofes: Argentina.

Puccinellia frigida (Phil.) I.M. Johnst.

Sinónimos: Catabrosa frigida Phil., Poa eremophila Phil., Poa oresigena Phil., Puccinellia oresigena (Phil.) Hitchc., Poa hypsophila Phil., Puccinellia hypsophila (Phil.) Parodi ex Espinosa, Puccinellia hypsophila (Phil.) Parodi ex Nicora, Poa pumila Phil., Poa taltalensis Pilg.

Hierba. Perenne. Nativa.

Distribución: AYP, TAR, ANT, ATA, COQ.

Rango altitudinal: 2300-4500 m.

Países limítrofes: Argentina y Bolivia.

Puccinellia glaucescens (Phil.) Parodi

Sinónimos: Catabrosa glaucescens Phil., Puccinellia johnstonii Muñoz

Hierba. Perenne. Nativa.

Distribución: COQ, VAL, RME, BIO, LLA, AIS, MAG.

Rango altitudinal: 5-3000 m.

Países limítrofes: Argentina.

Puccinellia magellanica (Hook.f.) Parodi

Sinónimos: Catabrosa magellanica Hook.f., Atropis magellanica (Hook.f.) E. Desv., Glyceria magellanica (Hook.f.) Benth., Glyceria fuegiana Speg., Atropis laxa Pilg., Puccinellia laxa (Pilg.) Parodi

Hierba. Perenne. Nativa.

Distribución: LLA, MAG.

Rango altitudinal: 0-90 m.

Países limítrofes: Argentina.

Puccinellia preslii (Hack.) Ponert

Sinónimos: Catabrosa tenuifolia J. Presl, Aira tenuifolia (J. Presl) Steud., Glyceria tenuifolia (J. Presl) Steud. nom. illeg., Atropis preslii (J. Presl) Hauman, Atropis tenuifolia (J. Presl) Hauman nom. illeg., Atropis tenuifolia (J. Presl) Speg. nom. illeg., Puccinellia tenuifolia (J. Presl) Parodi, nom. illeg., Puccinellia parodi Nicora nom. illeg.

Hierba. Perenne. Nativa.

Distribución: ATA.

Rango altitudinal: 4000-4000 m.

Países limítrofes: Argentina.

Puccinellia pusilla (Hack.) Parodi

Sinónimos: Atropis preslii Hack. subsp. pusiilla Hack.

Hierba. Perenne. Nativa.

Distribución: MAG.

Rango altitudinal: 5-130 m.

Países limítrofes: Argentina.

Puccinellia skottsbergii (Pilg.) Parodi

Sinónimos: Atropis skottsbergii Pilg.

Hierba. Perenne. Nativa.
Distribución: MAG.

Países limítrofes: Argentina.

\section{Relchela}

Relchela panicoides Steud.

Sinónimos: Panicum oligostachyum Steud., Agrostis asperula Phil., Agrostis corralensis Phil., Agrostis limonias Phil.

Hierba. Perenne. Nativa.

Distribución: VAL, MAU, NUB, BIO, ARA, LRI, LLA.

Rango altitudinal: 10-1460 m.

Países limítrofes: Argentina.

\section{Rostraria}

Rostraria cristata (L.) Tzvelev

Hierba. Anual. Introducida.

Distribución: TAR, COQ, VAL, RME, LBO, MAU, MAG, IPA.

Rostraria trachyantha (Phil.) Tzvelev ex Soreng

Sinónimos: Koeleria trachyantha Phil., Raimundochloa trachyantha (Phil.) A.M. Molina, Parodiochloa trachyantha

(Phil.) A.M. Molina

Hierba. Anual. Nativa.

Distribución: ANT, ATA, COQ, VAL.

Rango altitudinal: 25-550 m.

Países limítrofes: Perú.

\section{Rytidosperma}

Rytidosperma lechleri Steud.

Sinónimos: Danthonia glabra Phil., Rytidosperma glabrum (Phil.) Nicora, Notodanthonia lechleri (Steud.) Veldkamp

Hierba. Perenne. Nativa.

Distribución: COQ, VAL, RME, MAU, NUB, BIO, ARA, LRI, LLA.

Rango altitudinal: 800-3300 m.

Países limítrofes: Argentina.

Rytidosperma paschale (Pilg.) C.M. Baeza

Sinónimos: Danthonia paschalis Pilg.

Hierba. Perenne. Endémica.

Distribución: IPA.

Rango altitudinal: 10-10 m.

Rytidosperma pictum (Nees \& Meyen) Nicora var. bimucronata Nicora

Sinónimos: Notodanthonia picta (Nees \& Meyen) Veldkamp var. bimucronata (Nicora) Veldkamp

Hierba acuática. Perenne. Nativa.

Distribución: BIO, AIS.

Países limítrofes: Argentina. 
Rytidosperma pictum (Nees \& Meyen) Nicora var. pictum Sinónimos: Danthonia picta Nees \& Meyen, Notodanthonia picta (Nees \& Meyen) Veldkamp

Hierba. Perenne. Nativa.

Distribución: COQ, VAL, RME, LBO, MAU, NUB, BIO, ARA, LRI, LLA, AIS, MAG.

Rango altitudinal: 170-3020 m.

Países limítrofes: Argentina.

\section{Rytidosperma quirihuense C.M. Baeza}

Hierba. Perenne. Endémica.

Distribución: VAL, NUB.

Rango altitudinal: $355-390 \mathrm{~m}$.

Rytidosperma violaceum (E. Desv.) Nicora

Sinónimos: Danthonia violacea E. Desv., Notodanthonia violacea (E. Desv.) Veldkamp

Hierba. Perenne. Nativa.

Distribución: VAL, RME, LBO, MAU, NUB, BIO, ARA, LLA.

Rango altitudinal: 150-4000 m.

Países limítrofes: Argentina.

Rytidosperma virescens (E. Desv.) Nicora

Sinónimos: Danthonia virescens E. Desv., Danthonia andina Phil., Danthonia werdermanni Pilg., Notodanthonia virescens (E. Desv.) Veldkamp var. virescens

Hierba. Perenne. Nativa.

Distribución: COQ, VAL, RME, LBO, MAU, NUB, BIO, ARA, LLA, AIS, MAG.

Rango altitudinal: 20-2900 m.

Países limítrofes: Argentina.

\section{Saccharum}

\section{Saccharum oficinarum L.}

Hierba. Perenne. Introducida.

Distribución: IPA.

\section{Schismus}

Schismus arabicus Nees

Hierba. Anual. Introducida.

Distribución: COQ, VAL.

Schismus barbatus (L.) Thell.

Hierba. Anual. Introducida.

Distribución: ATA, COQ, VAL, RME.

\section{Schizachyrium}

Schizachyrium sanguineum (Retz.) Alston

Hierba. Perenne. Introducida.

Distribución: VAL, RME, BIO.

\section{Schyzachyrium}

Schyzachyrium spicatum (Spreng.) Herter

Sinónimos: Deyeuxia spicata Spreng.

Hierba. Perenne. Nativa.

Distribución: BIO.

Rango altitudinal: 750-750 m.

Países limítrofes: Argentina y Bolivia.

Nombre vulgar: Pasto escoba.

\section{Setaria}

Setaria palmifolia (Koenig) Stapf

Hierba. Perenne. Introducida.

Distribución: IPA.

Setaria parviflora (Poir.) Kerguélen var. brachytricha Pensiero

Sinónimos: Panicum brachytrichum Steud. ex Lechler, Setaria brachytricha (Steud. ex Lechler) Mez

Hierba. Perenne. Nativa.

Distribución: BIO, ARA, LRI, LLA.

Rango altitudinal: $10-130 \mathrm{~m}$.

Países limítrofes: Argentina.

Setaria parviflora (Poir.) Kerguélen var. parviflora

Hierba. Perenne. Introducida.

Distribución: ATA, COQ, VAL, LBO, MAU, NUB, BIO, ARA, LLA, JFE, IPA.

Setaria pumila (Poir.) Roem. \& Schult.

Hierba. Anual. Introducida.

Distribución: TAR, ATA, VAL, RME, MAU, BIO.

Setaria sphacelata (Schumach.) Stapf \& C. E. Hubb. ex M. B. Moss

Hierba. Perenne. Introducida.

Distribución: IPA.

Setaria verticillata (L.) P. Beauv.

Hierba. Anual. Introducida.

Distribución: AYP, TAR, ANT, ATA, COQ, VAL, RME, BIO, ARA.

Setaria viridis (L.) P. Beauv.

Hierba. Anual. Introducida.

Distribución: ANT, ATA, VAL, RME, BIO.

\section{Sorghum}

Sorghum bicolor (L.) Moench.

Hierba. Anual o perenne. Introducida.

Distribución: IPA. 
Sorghum halepense (L.) Pers.

Hierba. Perenne. Introducida.

Distribución: AYP, TAR, ANT, ATA, COQ, VAL, RME, LBO, NUB, BIO, ARA, MAG, IPA.

Nombre vulgar: Toroko (Rapa Nui).

\section{Sporobolus}

Sporobolus densiflorus (Brongn.) P.M. Peterson \& Saarela Sinónimos: Chauvinia chilensis Steud., Spartina densiflora Brongn.

Hierba. Perenne. Nativa.

Distribución: VAL, LBO, MAU, NUB, BIO, ARA, LRI,

LLA.

Rango altitudinal: 5-150 m.

Países limítrofes: Argentina.

Sporobolus indicus (L.) R. Br.

Hierba. Perenne. Introducida.

Distribución: IPA.

Nombre vulgar: Here hoi (Rapa Nui).

Sporobolus virginicus (L.) Kunth

Sinónimos: Agrostis virginica L.

Hierba. Perenne. Introducida.

Distribución: AYP, TAR.

Rango altitudinal: 50-340 m.

\section{Stenotaphrum}

Stenotaphrum secundatum (Walter) Kuntze

Hierba. Perenne. Introducida.

Distribución: AYP, TAR, BIO, LRI, LLA.

\section{Taeniatherum}

Taeniatherum caput-medusae (L.) Nevski

Hierba. Anual. Introducida.

Distribución: LBO, MAU.

\section{Trichoneura}

\section{Trichoneura weberbaueri Pilg.}

Hierba. Anual. Nativa.

Distribución: AYP.

Rango altitudinal: 2100-2276 m.

Países limítrofes: Perú.

\section{Tripogon}

Tripogon nicorae Rúgolo \& A.S. Vega

Hierba. Perenne. Nativa.

Distribución: AYP, TAR.

Rango altitudinal: 2950-3200 m.
Países limítrofes: Argentina, Bolivia y Perú.

Tripogon spicatus (Nees) Ekman

Sinónimos: Bromus spicatus Nees

Hierba. Perenne. Nativa.

Distribución: AYP, TAR.

Rango altitudinal: 2900-3100 m.

Países limítrofes: Argentina, Bolivia y Perú.

\section{Trisetum}

Trisetum ambiguum Rúgolo \& Nicora

Hierba. Perenne. Nativa.

Distribución: MAG.

Rango altitudinal: 350-900 m.

Países limítrofes: Argentina.

Trisetum barbinode Trin.

Sinónimos: Trisetum hirtiflorum Hack.

Hierba. Perenne. Nativa.

Distribución: RME, MAU, NUB, BIO, ARA.

Rango altitudinal: 550-3500 m.

Países limítrofes: Argentina.

Trisetum caudulatum Trin.

Sinónimos: Trisetum chromostachyum E. Desv., Trisetum heteronymum Steud., Trisetum variabile E. Desv., Trisetum variabile E. Desv. var. flavescens E. Desv., Trisetum variabile E. Desv. var. virescens E. Desv., Trisetum malacophyllum Steud, Trisetum splendidulum Steud., Trisetum chiloense Phil., Trisetum variabile E. Desv. var. chiloense (Phil.) Louis-Marie, Trisetum monticola Phil., Trisetum ochrostachyum Phil., Trisetum vidalii Phil., Trisetum variabile E. Desv. var. vidalii (Phil.) Louis-Marie, Trisetum lechleri (Steud.) Nicora, Koeleria lechleri Steud.

Hierba. Perenne. Nativa.

Distribución: ANT, COQ, VAL, RME, LBO, MAU, NUB, BIO, ARA, LRI, LLA, AIS, MAG, JFE.

Rango altitudinal: 1170-3500 m.

Países limítrofes: Argentina.

Nota: Introducida en el Archipiélago Juan Fernández.

Trisetum cernuum Trin.

Sinónimos: Avena leptostachys Hook.f., Trisetum fraudulentum Steud.

Hierba. Perenne. Nativa.

Distribución: ARA, LRI, LLA, AIS, MAG.

Rango altitudinal: 150-1550 m.

Países limítrofes: Argentina.

Trisetum flavescens (L.) P. Beauv.

Hierba. Perenne. Introducida.

Distribución: MAG. 
Trisetum johnstonii (Louis-Marie) Finot subsp. johnstonii Sinónimos: Trisetum oreophilum Louis-Marie var. johnstonii Louis-Marie

Hierba. Perenne. Nativa.

Distribución: ATA, COQ, RME.

Rango altitudinal: 3000-4300 m.

Países limítrofes: Argentina.

Trisetum johnstonii (Louis-Marie) Finot subsp. mattheii (Finot) Finot

Sinónimos: Trisetum matthei Finot

Hierba. Perenne. Endémica.

Distribución: AYP.

Rango altitudinal: 4100-4100 m.

Trisetum longiglume Hack.

Sinónimos: Trisetum andicola Louis-Marie, Deschampsia andicola (Louis-Marie) Valencia

Hierba. Perenne. Nativa.

Distribución: RME.

Rango altitudinal: 2000-4000 m.

Países limítrofes: Argentina.

Trisetum nancaguense Finot

Hierba. Perenne. Endémica.

Distribución: RME, LBO, MAU, BIO.

Rango altitudinal: 45-2450 m.

Trisetum preslei (Kunth) E. Desv.

Sinónimos: Avena preslei Kunth

Hierba. Perenne. Nativa.

Distribución: ATA, COQ, VAL, RME, MAU, NUB, BIO, ARA, AIS.

Rango altitudinal: 1300-3800 m.

Países limítrofes: Argentina.

Trisetum pyramidatum Louis-Marie ex Finot

Hierba. Perenne. Nativa.

Distribución: RME, MAU, NUB, BIO, ARA, AIS, MAG.

Rango altitudinal: 5-540 m.

Países limítrofes: Argentina.

Trisetum spicatum (L.) K. Richt. subsp. cumingii (Nees ex Steud.) Finot

Sinónimos: Trisetum spicatum (L.) K. Richt. var. cumingii (Nees ex Steud.) Finot, Koeleria cumingii Nees ex Steud., Trisetum cumingii (Nees ex Steud.) Nicora, Trisetum malacophyllum Phil., Trisetum mollifolium Louis-Marie

Hierba. Perenne. Nativa.

Distribución: MAU, NUB, LLA, AIS, MAG.

Rango altitudinal: 150-1460 m.

Países limítrofes: Argentina.

Trisetum spicatum (L.) K. Richt. subsp. dianthemum (Louis-Marie) Finot
Sinónimos: Trisetum dianthemum (Louis-Marie) Finot, Trisetum spicatum var. dianthemum Louis-Marie, Trisetum biflorum Phil.

Hierba. Perenne. Nativa.

Distribución: BIO, LRI, LLA, MAG.

Rango altitudinal: 3-200 m.

Países limítrofes: Argentina.

Trisetum spicatum (L.) K. Richt. subsp. phleoides (d'Urv.) Macloskie

Sinónimos: Avena phleoides d'Urv., Trisetum hirsutum

Phil., Trisetum spicatum var. hirsutum (Phil.) Louis-Marie,

Trisetum phleoides

Hierba. Perenne. Nativa.

Distribución: MAU, NUB, BIO, AIS, MAG.

Rango altitudinal: 80-1460 m.

Países limítrofes: Argentina.

Trisetum spicatum (L.) K. Richt. subsp. spicatum Sinónimos: Aira spicata L., Trisetum andinum Phil.

Hierba. Perenne. Nativa.

Distribución: VAL, RME, LBO, MAU, NUB, BIO, ARA, LRI, LLA, AIS, MAG.

Rango altitudinal: 5-2500 m.

Países limítrofes: Argentina, Bolivia y Perú.

Triticum

Triticum aestivum $\mathrm{L}$.

Hierba. Anual. Introducida.

Distribución: IPA.

\section{Vahlodea}

Vahlodea atropurpurea (Wahlenb.) Fr. ex Hartm.

Sinónimos: Aira atropurpurea Wahlenb., Deschampsia atropurpurea (Wahlenb.) Schleele, Aira magellanica Hook.f., Aira atropurpurea Whalenb. var. magellanica (Hook.f.) Skottsb., Vahlodea atropurpurea (Wahlenb.) Fr. ex Hartm. subsp. magellanica (Hook.f.) Hyl., Vahlodea magellanica (Hook.f.) Tzvelev, Deschampsia brachyphylla Phil.

Hierba. Perenne. Nativa.

Distribución: RME, LRI, LLA, AIS, MAG.

Rango altitudinal: $150-2000 \mathrm{~m}$.

Países limítrofes: Argentina.

\section{Vulpia}

Vulpia antucensis Trin.

Sinónimos: Festuca antucensis (Trin.) Steud., Festuca eriolepis E. Desv., Vulpia eriolepis (E. Desv.) C.H. Blom Hierba. Anual. Nativa.

Distribución: ANT, COQ, VAL, RME, LBO, MAU, NUB, 
BIO, ARA, LLA, AIS.

Rango altitudinal: 15-2800 m.

Países limítrofes: Argentina.

Nombre vulgar: pasto sedilla.

Vulpia bromoides (L.) Gray

Hierba. Anual. Introducida.

Distribución: ATA, COQ, VAL, RME, LBO, MAU, NUB, BIO, ARA, LRI, LLA, AIS, MAG, JFE.

Vulpia muralis (Kunth) Nees

Hierba. Anual. Introducida.

Distribución: COQ, VAL, RME, BIO, ARA, JFE.

Vulpia myuros (L.) C.C.Gmel. fma. megalura (Nutt.) Stace \& R. Cotton

Sinónimos: Vulpia myuros (L.) C.C. Gmel. var. hirsuta Hack.

Hierba. Anual. Introducida.

Distribución: ANT, COQ, VAL, RME, LBO, MAU, NUB, BIO, ARA, LRI, JFE, IPA.

Vulpia myuros (L.) C.C.Gmel. fma. myuros

Hierba. Anual. Introducida.

Distribución: AYP, ANT, COQ, VAL, RME, LBO, MAU, NUB, BIO, ARA, LLA, MAG, IPA.

Vulpia octoflora (Walter) Rydb.

Sinónimos: Festuca octoflora Walter, Vulpia antofagastensis

Parodi

Hierba. Anual. Nativa.

Distribución: AYP, ANT, COQ.

Rango altitudinal: $30-500 \mathrm{~m}$.

Países limítrofes: Argentina.

Nombre vulgar: pasto sedilla.

Zea

Zea mays L.

Hierba. Anual. Introducida.

Distribución: IPA.

\section{PONTEDERIACEAE}

\section{Eichhornia}

Eichhornia crassipes (Mart.) Solms

Hierba acuática. Perenne. Introducida.

Distribución: ATA, COQ, VAL, BIO.

\section{POTAMOGETONACEAE}

Potamogeton

Potamogeton ferrugineus Hagstr.

Hierba acuática. Perenne. Nativa.

Distribución: AIS.

Rango altitudinal: 100-1000 m.

Países limítrofes: Argentina, Bolivia y Perú.

Potamogeton gayi A. Benn.

Sinónimos: Potamogeton burkartii Horn ex Tur

Hierba acuática. Perenne. Nativa.

Distribución: ARA.

Rango altitudinal: 0-1200 m.

Países limítrofes: Argentina y Bolivia.

Potamogeton illinoensis Morong

Sinónimos: Potamogeton dunicola Tur, Potamogeton pedersenii Tur

Hierba acuática. Perenne. Nativa.

Distribución: VAL, ARA, LLA, MAG.

Rango altitudinal: 0-1000 m.

Países limítrofes: Argentina, Bolivia y Perú.

Potamogeton linguatus Hagstr.

Sinónimos: Potamogeton badiovirens Hagstr., Potamogeton natans auct. non L., Potamogeton montanus C. Presl

Hierba acuática. Perenne. Nativa.

Distribución: NUB, BIO, ARA, LRI, LLA, AIS, MAG.

Rango altitudinal: 0-1300 m.

Países limítrofes: Argentina.

Potamogeton montevidensis A. Benn.

Hierba acuática. Perenne. Nativa.

Distribución: BIO.

Rango altitudinal: 0-3000 m.

Países limítrofes: Argentina.

Potamogeton pusillus L.

Sinónimos: Potamogeton berteroanus Phil., Potamogeton aschersonii A. Benn., Potamogeton pusillus L. var. longepedunculatus Hicken, Potamogeton tenuifolius F. Phil., Potamogeton uruguayensis A. Benn. \& Graebn., Potamogeton pusillus L. var. argentinus A. Benn.

Hierba acuática. Anual o bienal. Introducida.

Distribución: ANT, ATA, VAL, RME, LBO, MAU, NUB, BIO, ARA, LRI.

Rango altitudinal: 0-2000 m.

Nombre vulgar: Espiga de agua.

Potamogeton spirilliformis Hagstr.

Sinónimos: Potamogeton reniacoensis Sparre

Hierba acuática. Perenne. Nativa. 
Distribución: VAL.

Rango altitudinal: 0-500 m.

Países limítrofes: Argentina.

\section{Stuckenia}

Stuckenia filiformis (Pers.) Boehm. subsp. alpina (Blytt) R.R. Haynes, Les \& M. Král

Sinónimos: Potamogeton strictus Phil., Potamogeton aulacophyllum K. Schum., Potamogeton strictus Phil. var. magellanicus Hagstr., Potamogeton juncifolius A. Kern. ex C. Fritsch, Potamogeton marinus L. fma. alpinus Blytt Hierba acuática. Perenne. Nativa.

Distribución: AYP, TAR, ANT, ATA, COQ, BIO, MAG.

Rango altitudinal: 200-4000 m.

Países limítrofes: Argentina y Bolivia.

Stuckenia pectinata (L.) Börner

Sinónimos: Potamogeton diffusus (Hagstr.) Herter, Potamogeton pectinatus L. var. diffusus Hagstr., Potamogeton pectinatus L., Coleogeton pectinatus (L.) Les \& R.R. Haynes

Hierba acuática. Perenne. Nativa.

Distribución: ATA, COQ, VAL, RME, MAU, BIO.

Rango altitudinal: 0-4000 m.

Países limítrofes: Argentina y Bolivia.

Stuckenia striata (Ruiz \& Pav.) Holub

Sinónimos: Potamogeton australis F. Phil., Potamogeton dissimilis A. Benn., Potamogeton pectinatus L. var. striatus (Ruiz \& Pav.) Hagstr., Potamogeton pectinatus L. var. ungulatus Hagstr., Coleogeton striatus (Ruiz \& Pav.) Les \& R.R. Haynes, Potamogeton striatus Ruiz \& Pav.

Hierba acuática. Perenne. Nativa.

Distribución: VAL, RME, LLA.

Rango altitudinal: 0-4000 m.

Países limítrofes: Argentina y Perú.

Nombre vulgar: Nori.

\section{Zannichellia}

\section{Zannichellia palustris L.}

Hierba acuática. Perenne. Introducida.

Distribución: ANT, ATA, COQ, VAL, RME, LBO, MAU, MAG.

Rango altitudinal: 0-4400 m.

\section{RESTIONACEAE}

\section{Apodasmia}

Apodasmia chilensis (Gay) B.G. Briggs \& L.A.S. Johnson Sinónimos: Leptocarpus chilensis (Gay) Mast., Schoenodum chilense Gay, Calopsis chilensis (Gay) Steud.

Hierba. Perenne. Endémica.

Distribución: BIO, ARA, LRI, LLA, AIS, MAG.

Nombre vulgar: Canutillo.

\section{Gaimardia}

Gaimardia australis Gaudich.

Sinónimos: Gaimardia pusilla Gaudich.

Hierba. Perenne. Nativa.

Distribución: LRI, LLA, AIS, MAG.

Rango altitudinal: 0-300 m.

Países limítrofes: Argentina.

Nombre vulgar: Pasto de turbal.

\section{RUPPIACEAE}

Ruppia

Ruppia filifolia (Phil.) Skottsb.

Sinónimos: Potamogeton filifolius Phil., Ruppia obtusa Hagstr., Ruppia obtusa Hagstr. var. repens Hagstr., Ruppia andina Phil.

Hierba acuática. Perenne. Nativa.

Distribución: AYP, TAR, ANT, ATA, MAG.

Rango altitudinal: 0-4400 m.

Países limítrofes: Argentina, Bolivia y Perú.

Nombre vulgar: Pelo de marisma.

\section{Ruppia maritima $\mathrm{L}$.}

Sinónimos: Ruppia maritima L. var. rostrata C. Agardh, Ruppia maritima L. subsp. rostellata (Koch ex Rchb.) Asch. \& Graebn., Ruppia rostellata Koch ex Rchb.

Hierba acuática. Perenne. Nativa.

Distribución: ANT, ATA, COQ, VAL, ARA.

Rango altitudinal: 0-500 $\mathrm{m}$.

Países limítrofes: Argentina, Bolivia y Perú.

\section{TECOPHILAEACEAE}

\section{Conanthera}

Conanthera bifolia Ruiz \& Pav.

Sinónimos: Conanthera passeriflora Ravenna, Conanthera passeriflora Ravenna fma. lilacina Ravenna, Conanthera passeriflora Ravenna fma. nocticolor Ravenna, Conanthera passeriflora Ravenna fma. coelestis Ravenna, Conanthera passeriflora Ravenna fma. melananthera Ravenna, Conanthera passeriflora Ravenna fma. immaculata Ravenna, Sisyrinchium illmu Molina Hierba. Perenne. Endémica. Distribución: VAL, RME, LBO, MAU, NUB, BIO, ARA. 
Rango altitudinal: 1000-1500 m.

Nombre vulgar: Flor de la viuda.

Conanthera campanulata Lindl.

Sinónimos: Cummingia campanulata D. Don, Conanthera bifolia auct. non Ruiz \& Pav., Conanthera simsii Sweet, Cummingia tenella D. Don, Conanthera variegata Fenzl ex Reichardt, Conanthera tenella (Kunth) Ravenna, Conanthera alba Grau, Conanthera sabulosa Ravenna Hierba. Perenne. Endémica.

Distribución: TAR, ANT, COQ, VAL, RME, MAU, NUB, BIO, ARA.

Rango altitudinal: 0-3200 m.

Conanthera parvula (Phil.) Muñoz-Schick

Sinónimos: Conanthera johowii Espinosa, Conanthera minima Grau, Cummingia parvula Phil.

Hierba. Perenne. Endémica.

Distribución: VAL, LBO, MAU, NUB, BIO, ARA.

Rango altitudinal: 100-500 m.

Conanthera trimaculata (D. Don) F. Meigen

Hierba. Perenne. Endémica.

Distribución: VAL, RME, LBO, NUB.

Rango altitudinal: 0-800 m.

Conanthera urceolata Ravenna

Hierba. Perenne. Endémica.

Distribución: ATA.

Rango altitudinal: 0-100 m.

Tecophilaea

Tecophilaea cyanocrocus Leyb.

Sinónimos: Zephyra cyanocrocus (Leyb.) Ravenna

Hierba. Perenne. Endémica.

Distribución: RME.

Rango altitudinal: 700-900 m.

Tecophilaea violiflora Bertero ex Colla fma. polyantha Skottsb.

Hierba. Perenne. Endémica.

Distribución: COQ.

Nota: Citada para Chile (Marticorena \& Quezada, 1985) sin

mencionar ejemplar de referencia.

Tecophilaea violiflora Bertero ex Colla fma. violiflora

Sinónimos: Zephyra violiflora (Bertero ex Colla) Ravenna

Hierba. Perenne. Endémica.

Distribución: COQ, VAL, RME.

Rango altitudinal: 0-800 m.

Nombre vulgar: Violeta de la cordillera.

\section{Zephyra}

Zephyra compacta C. Ehrh.

Hierba. Perenne. Endémica.

Distribución: ATA, COQ.

Rango altitudinal: 0-500 m.

Zephyra elegans D. Don

Sinónimos: Zephyra amoena D. Don, Dicolus caerulescens

Phil.

Hierba. Perenne. Endémica.

Distribución: TAR, ANT, ATA, COQ.

Rango altitudinal: 0-800 m.

Nombre vulgar: Argentina.

\section{TYPHACEAE}

Typha

Typha angustifolia L.

Hierba. Perenne. Introducida.

Distribución: AYP, TAR, VAL, MAU, NUB, BIO, ARA, LRI.

Typha domingensis Pers.

Hierba. Perenne. Introducida.

Distribución: TAR, ANT, VAL, NUB, BIO, ARA.

\section{ZOSTERACEAE}

\section{Zostera}

Zostera chilensis (J. Kuo) S.W.L. Jacobs \& D.H. Les

Sinónimos: Heterozostera chilensis J. Kuo

Hierba. Perenne. Endémica.

Distribución: ATA, COQ.

Rango altitudinal: 0-200 m.

Nombre vulgar: Seba de mar.

\section{MAGNOLIOPSIDA}

\section{ACANTHACEAE}

\section{Dicliptera}

Dicliptera paposana Phil. Hierba. Perenne. Endémica. Distribución: ANT. 


\section{Stenandrium}

Stenandrium dulce (Cav.) Nees

Sinónimos: Gerardia dulcis (Cav.) S.F. Blake, Ruellia

dulcis Cav., Nierembergia prunellifolia Dunal

Hierba. Perenne. Nativa.

Distribución: COQ, VAL, RME, LBO, MAU, NUB, BIO, ARA.

Rango altitudinal: 0-3000 m.

Países limítrofes: Argentina, Bolivia y Perú.

\section{AEXTOXICACEAE}

\section{Aextoxicon}

Aextoxicon punctatum Ruiz \& Pav.

Árbol. Nativo.

Distribución: COQ, VAL, LBO, MAU, NUB, BIO, ARA, LRI, LLA.

Rango altitudinal: 0-1800 m.

Países limítrofes: Argentina.

Nombre vulgar: Olivillo, palo muerto, tique, teque, aceitunillo.

\section{AIZOACEAE}

\section{Carpobrotus}

Carpobrotus chilensis (Molina) N.E. Br.

Sinónimos: Mesembryanthemum chilense Molina, Carpobrotus aequilaterus auct. non (Haw.) N.E. Br.

Hierba. Perenne. Nativa.

Distribución: ANT, ATA, COQ, VAL, LBO, MAU, NUB, BIO, ARA, LRI, JFE.

Rango altitudinal: 0-500 m.

Países limítrofes: Argentina.

Nombre vulgar: Doca.

Carpobrotus edulis (L.) N.E. Br.

Hierba. Anual. Introducida.

Distribución: VAL, MAU, BIO, LRI.

\section{Galenia}

Galenia pubescens (Eckl. \& Zeyh.) Druce

Hierba. Perenne. Introducida.

Distribución: COQ, VAL.

\section{Mesembryanthemum}

Mesembryanthemum crystallinum L.

Hierba. Anual. Introducida.
Distribución: ANT, ATA, COQ, VAL.

Mesembryanthemum nodiflorum $\mathrm{L}$.

Hierba. Anual. Introducida.

Distribución: ATA, COQ.

\section{Sesuvium}

Sesuvium portulacastrum (L.) L.

Hierba. Perenne. Introducida.

Distribución: AYP.

\section{Tetragonia}

Tetragonia angustifolia Barnéoud

Arbusto. Endémico.

Distribución: TAR, ANT, ATA, COQ.

Rango altitudinal: 0-1200 m.

Tetragonia copiapina Phil.

Hierba. Anual. Endémica.

Distribución: ANT, ATA, COQ.

Rango altitudinal: 0-900 m.

Tetragonia espinosae Muñoz

Hierba. Anual. Endémica.

Distribución: ANT, ATA, COQ.

Rango altitudinal: 0-600 m.

Tetragonia macrocarpa Phil.

Sinónimos: Tetragonia pusilla Phil.

Hierba. Anual. Endémica.

Distribución: ANT, ATA, COQ, IDE.

Rango altitudinal: 0-1500 m.

Tetragonia maritima Barnéoud

Arbusto. Endémico.

Distribución: ANT, ATA, COQ.

Rango altitudinal: 0-1300 m.

Tetragonia microcarpa Phil.

Sinónimos: Tetragonia macrocarpa Phil. var. microcarpa (Phil.) Reiche, Tetragonia tenella I.M. Johnst., Tetragonia trigona Phil., Tetragonia kuntzei J. Buchw. ex Kuntze

Hierba. Anual. Nativa.

Distribución: AYP, TAR, ANT, ATA.

Rango altitudinal: 0-3000 m.

Países limítrofes: Perú.

Tetragonia ovata Phil.

Sinónimos: Tetragonia robusta Phil.

Hierba. Anual. Endémica.

Distribución: AYP, TAR, ANT, ATA, COQ.

Rango altitudinal: 0-700 m. 
Tetragonia pedunculata Phil.

Hierba. Anual. Nativa.

Distribución: ATA.

Rango altitudinal: 0-600 m.

Países limítrofes: Perú.

\section{Tetragonia tetragonoides (Pall.) Kuntze}

Hierba. Anual. Nativa.

Distribución: ATA, COQ, VAL, LBO, MAU, BIO, LRI, LLA, JFE, IPA, IDE.

Países limítrofes: Argentina.

Nota: Taylor (1996) señala que es nativa en Australia, Nueva Zelanda, Japón, Argentina y Chile dispersada por corrientes oceánicas, mientras que Prescott (1984) señala que es nativa sólo de Australia y Nueva Zelanda.

\section{Trianthema}

Trianthema portulacastrum L.

Hierba. Anual. Introducida.

Distribución: IPA.

\section{AMARANTHACEAE}

\section{Alternanthera}

Alternanthera halimifolia (Lam.) Standl. ex Pittier

Sinónimos: Achyranthes halimifolia Lam.

Hierba. Perenne. Nativa.

Distribución: AYP, TAR, ATA.

Rango altitudinal: 0-500 m.

Países limítrofes: Perú.

Alternanthera philoxeroides (Mart.) Griseb.

Hierba acuática. Perenne. Introducida.

Distribución: VAL.

Alternanthera porrigens (Jacq.) Kuntze

Sinónimos: Alternanthera junciflora (J. Remy) I.M. Johnst., Achyranthes porringens Jacq.

Hierba. Perenne. Nativa.

Distribución: AYP, TAR, ANT, ATA, VAL.

Rango altitudinal: 0-600 m.

Países limítrofes: Bolivia y Perú.

\section{Amaranthus}

Amaranthus albus L.

Hierba. Anual. Introducida.

Distribución: COQ, RME.

Amaranthus asplundii Thell.

Sinónimos: Amaranthus affinis Thell., Amaranthus buchtienianus Thell.

Hierba. Anual. Nativa.

Distribución: LLA.

Rango altitudinal: $2400-3600 \mathrm{~m}$.

Países limítrofes: Argentina y Bolivia.

Amaranthus blitum L. subsp. emarginatus (Moq. ex Uline et W.L. Bray) Carretero, Muñoz Garm. \& Pedrol

Hierba. Anual. Introducida.

Distribución: TAR, ANT.

Amaranthus deflexus L.

Hierba. Perenne. Introducida.

Distribución: ANT, ATA, COQ, VAL, RME, LBO, MAU, NUB, BIO, ARA, LRI, LLA, MAG, JFE.

Amaranthus hybridus L. subsp. cruentus (L.) Thell.

Hierba. Anual. Introducida.

Distribución: RME, MAU, BIO.

Amaranthus hybridus L. subsp. hybridus

Hierba. Anual. Introducida.

Distribución: AYP, TAR, ANT, ATA, COQ, VAL, RME, LBO, MAU, NUB, BIO, ARA, LRI, LLA, JFE.

Amaranthus looseri Suess.

Hierba. Anual. Endémica.

Distribución: VAL, RME.

Rango altitudinal: $500 \mathrm{~m}$.

Amaranthus retroflexus L.

Hierba. Anual. Introducida.

Distribución: AYP, TAR, ANT, ATA, COQ, VAL, RME, MAU, NUB, BIO, ARA.

Amaranthus viridis L.

Hierba. Perenne. Introducida.

Distribución: ATA, COQ, ARA.

\section{Gomphrena}

Gomphrena meyeniana Walp.

Hierba. Perenne. Nativa.

Distribución: AYP, TAR, ANT.

Rango altitudinal: 2000-4500 m.

Países limítrofes: Argentina, Bolivia y Perú.

Gomphrena umbellata J. Remy

Sinónimos: Xeraea umbellata (J. Remy) Kuntze

Hierba. Anual. Nativa.

Distribución: TAR.

Rango altitudinal: 3000-4000 m.

Países limítrofes: Argentina, Bolivia y Perú. 


\section{ANACARDIACEAE}

\section{Haplorhus}

Haplorhus peruviana Engl.

Árbol. Nativo.

Distribución: AYP, TAR.

Rango altitudinal: 0-1000 m.

Países limítrofes: Perú.

Nombre vulgar: Carza.

\section{Lithrea}

Lithrea caustica (Molina) Hook. \& Arn.

Sinónimos: Lithraea caustica (Molina) Hook. \& Arn. var. pilosa Engl., Laurus caustica Molina, Lithraea caustica (Molina) Hook. \& Arn. fma. pilosa (Engl.) Cabrera, Persea caustica (Molina) Spreng., Lithrea venenosa Miers, nom. nud., Rhus caustica Hook. \& Arn., Lithrea caustica (Molina) Hook. \& Arn. var. glabra Engler

Árbol. Endémico.

Distribución: ATA, COQ, VAL, RME, LBO, MAU, NUB, BIO, ARA, LRI.

Rango altitudinal: 0-2800 m.

Nombre vulgar: Litre.

\section{Schinus}

\section{Schinus areira L.}

Sinónimos: Schinus molle L. var. areira (L.) DC., Schinus huingan Molina, Schinus bituminoides Salisb., Schinus molle L. var. huingan (Molina) Marchand

Árbol. Nativo.

Distribución: AYP, TAR, ANT, ATA, COQ, VAL, RME.

Rango altitudinal: 0-3500 m.

Países limítrofes: Argentina, Bolivia y Perú.

Nombre vulgar: Molle, pimiento, pimentero.

\section{Schinus kauselii F.A. Barkley}

Arbusto o árbol pequeño. Endémico.

Distribución: VAL, RME, MAU.

Rango altitudinal: 1400-1800 m.

Schinus latifolius (Gillies ex Lindl.) Engl.

Sinónimos: Litrea molle auct. non L., Duvaua latifolia Gillies ex Lindl., Schinus dependens Ortega var. latifolia Marchand, Schinus chilensis Marchand var. glabra Marchand, Duvaua dependens (Ortega) DC. var gamma Hook., Duvaua velutina Turcz., Schinus chilensis Marchand, Schinus latifolius (Gillies ex Lindl.) Engler var. tomentosus Fenzl ex Engler, Schinus velutinus (Turcz.) I.M. Johnst.

Árbol. Endémico.

Distribución: COQ, VAL, RME, LBO, MAU.

Rango altitudinal: 0-1500 m.

Nombre vulgar: Molle.
Schinus marchandii F.A. Barkley

Arbusto. Nativo.

Distribución: AIS.

Rango altitudinal: 0-900 m.

Países limítrofes: Argentina.

Schinus montanus (Phil.) Engl.

Sinónimos: Lithraea montana Phil.

Arbusto. Endémico.

Distribución: VAL, RME, LBO.

Rango altitudinal: 0-2500 m.

Schinus patagonicus (Phil.) I.M. Johnst. ex Cabrera var. crenuloides (F.A. Barkley) F.A. Barkley

Sinónimos: Schinus montanus (Phil.) Engl. var. crenuloides

F.A. Barkley

Arbusto. Endémico.

Distribución: MAU, NUB, BIO, ARA.

Rango altitudinal: 0-1000 m.

Nombre vulgar: Litrecillo.

Schinus patagonicus (Phil.) I.M. Johnst. ex Cabrera var. patagonicus

Sinónimos: Litrea patagonica Phil., Schinus crenatus Engl., Lithraea montana Phil. var. patagonica Phil., Duvaua patagonica Phil., Schinus montana (Phil.) Engl. var. patagonica Reiche, Duvaua dependens (Ortega) DC. var. patagonica Phil.

Arbusto o árbol pequeño. Nativo.

Distribución: VAL, RME, LBO, MAU, NUB, BIO, ARA, LLA, AIS.

Rango altitudinal: 0-2000 m.

Países limítrofes: Argentina.

Nombre vulgar: Laura, litrecillo.

Schinus polygamus (Cav.) Cabrera

Sinónimos: Amyris polygama Cav., Schinus polygamus (Cav.) Cabrera var. chilensis F.A. Barkley, Schinus polygamus (Cav.) Cabrera fma. ovatus (Lindl.) Cabrera, Schinus dependens Ortega var. brevifolia Fenzl ex Engl., Schinus huyngan Kuntze, Schinus polygamus (Cav.) Cabrera var. parviflorus (Marchand) F.A. Barkley, Duvaua crenata Phil., Litrea crenata Phil., Schinus dependens Ortega var. parviflorus Marchand

Arbusto o árbol pequeño. Nativo.

Distribución: ATA, COQ, VAL, RME, LBO, MAU, NUB, BIO, ARA, LRI, LLA.

Rango altitudinal: 0-3200 m.

Países limítrofes: Argentina y Bolivia.

Nombre vulgar: Huingán.

Nota: Especie muy polimorfa, con variaciones especialmente en las hojas, lo que ha motivado la creación de variedades, subespecies y formas. Han sido reunidas en una sola especie. 


\section{APIACEAE}

Ammi

Ammi majus L.

Hierba. Anual. Introducida.

Distribución: RME, LRI, LLA.

Ammi visnaga (L.) Lam.

Hierba. Anual o bienal. Introducida.

Distribución: COQ, VAL, RME, LBO, MAU, ARA, JFE.

\section{Anethum}

Anethum graveolens L.

Hierba. Anual. Introducida.

Distribución: JFE.

\section{Anthriscus}

Anthriscus caucalis M. Bieb.

Hierba. Anual. Introducida.

Distribución: VAL, RME, LBO, MAU, BIO.

Anthriscus sylvestris (L.) Hoffm.

Hierba. Bienal. Introducida.

Distribución: MAG.

\section{Apium}

Apium chilense Hook. \& Arn.

Sinónimos: Apium flexuosum Phil., Ligusticum dumetorum Phil.

Hierba. Perenne. Endémica.

Distribución: ANT, ATA, VAL, RME, LBO, MAU, JFE.

Rango altitudinal: 0-1500 m.

\section{Apium fernandezianum Johow}

Hierba. Perenne. Endémica.

Distribución: JFE.

\section{Apium graveolens $\mathrm{L}$.}

Hierba. Bienal. Introducida.

Distribución: ANT, LRI, LLA.

Apium humile (Phil.) Reiche

Sinónimos: Ligusticum humile Phil.

Hierba. Perenne. Endémica.

Distribución: RME.

Apium nodiflorum (L.) Lag.

Hierba. Perenne. Introducida.

Distribución: ATA, COQ, VAL, MAU, NUB, BIO, ARA.
Apium panul (Bertero ex DC.) Reiche

Sinónimos: Ligusticum pansil Bertero ex DC., Ligusticum nemorosum Phil., Ligusticum landbeckii Phil., Ligusticum apioides Phil., Carum panul (Bertero ex DC.) Griseb., Apium andinum Phil., Apium apioides (Phil.) Reiche, Apium philippii H. Wolff, Apium angustilobum (Phil.) Reiche, Apium panul (Bertero ex DC.) Reiche var. araucanum (Phil.) Reiche, Apium peucedanoides (C. Presl ex DC.) Reiche, Apium peucedanoides (C. Presl ex DC.) Reiche var. tenuifolium (C. Presl ex DC.) H. Wolff, Pimpinella araucana Phil., Ligusticum peucedanoides C. Presl ex DC., Pimpinella andina Phil., Ligusticum angustilobum Phil., Ligusticum cahuilense Phil. ex sched., Pimpinella macrophylla Phil., Pimpinella molleri Phil., Pimpinella navarri Phil., Pimpinella peteroana Phil., Pimpinella vidali Phil.

Hierba. Perenne. Nativa.

Distribución: ANT, ATA, COQ, VAL, RME, LBO, MAU, NUB, BIO, ARA, LLA.

Rango altitudinal: 0-2600 m.

Países limítrofes: Argentina.

Nombre vulgar: Panul.

Apium pimpinellifolium (Phil.) Reiche

Sinónimos: Ligusticum pimpinellifolium Phil.

Hierba. Perenne. Endémica.

Distribución: LBO.

Apium prostratum Labill.

Sinónimos: Apium maclovianum Gand., Apium dunicola Pontiroli, Apium australe Thouars var. latisectum H. Wolff, Wydleria humilis Phil., Apium australe Thouars

Hierba. Perenne. Nativa.

Distribución: TAR, ANT, ATA, COQ, RME, MAU, BIO, LRI, LLA, AIS, MAG, JFE, IPA.

Rango altitudinal: 0-100 m.

Países limítrofes: Argentina.

Nombre vulgar: Rapa.

\section{Asteriscium}

Asteriscium aemocarpon Clos

Sinónimos: Asteriscium ramosissimum Phil., Asteriscium verrucosum Meyen, Asteriscium haemocarpum Clos var. chlorocarpum Phil.

Hierba. Anual. Endémica.

Distribución: COQ, RME, LBO.

Rango altitudinal: 2100-3500 m.

Asteriscium chilense Cham. \& Schltdl.

Sinónimos: Eryngium tricuspidatum Dombey, Asteriscium poeppigii DC., Asteriscium chilense Cham. \& Schltdl. var. haenkei DC., Asteriscium pozoides Clos

Hierba. Perenne. Endémica.

Distribución: ANT, ATA, COQ, VAL, RME, LBO, MAU, 
NUB, BIO, ARA, LRI.

Rango altitudinal: $100-2500 \mathrm{~m}$.

Nombre vulgar: Anicillo, huaralao, muchu, colecilla.

Asteriscium closii (Kuntze) Mathias \& Constance

Sinónimos: Dipterygia closii Kuntze, Bustillosia chilensis

Clos, Asteriscium pungens Drude, Bustillosia chilensis Clos var. setacea Phil.

Hierba. Anual. Endémica.

Distribución: ANT, ATA, COQ.

Rango altitudinal: 0-2000 m.

Asteriscium vidali Phil.

Hierba. Perenne. Endémica.

Distribución: ATA.

Rango altitudinal: 0-400 m.

\section{Azorella}

Azorella acaulis (Cav.) Drude

Sinónimos: Huanaca acaulis Cav., Lechleria palmata Phil., Huanaca bergii Hieron., Huanaca geraniifolia DC., Huanaca cavanillesii DC., Spananthe huanaca (Spreng.) Lag., Oenanthe huanaca Spreng.

Hierba. Perenne. Nativa.

Distribución: AIS, MAG.

Rango altitudinal: 0-1300 m.

Países limítrofes: Argentina.

Azorella albovaginata (Gillies \& Hook.) G.M. Plunkett \& A.N. Nicolas var. pauciflorum (Reiche) G.M. Plunkett \& A.N. Nicolas

Sinónimos: Mulinum albovaginatum Gillies \& Hook. var. pauciflorum (Reiche) J.C. Zech, Mulinum pauciflorum Reiche, Azorellopsis trisecta $\mathrm{H}$. Wolff, Mulinum reichei $\mathrm{H}$. Wolff

Hierba. Perenne. Endémica.

Distribución: LBO, MAU.

Rango altitudinal: 0-1000 m.

Azorella ameghinoi Speg.

Sinónimos: Azorella transverse-striata Hauman

Hierba. Perenne. Nativa.

Distribución: AIS, MAG.

Rango altitudinal: 200-2500 m.

Países limítrofes: Argentina.

Nombre vulgar: Llareta.

Azorella andina (Phil.) Drude

Sinónimos: Trisciadium andinum Phil., Huanaca andina (Phil.) Phil., Azorella trilobata Dusén, Schizeilema trilobatum (Dusén) Domin

Hierba. Perenne. Nativa.

Distribución: BIO, ARA, MAG.
Rango altitudinal: 600-2800 m.

Países limítrofes: Argentina.

Azorella atacamensis G.M. Plunkett \& A.N. Nicolas

Sinónimos: Mulinum crassifolium Phil. non Azorella Pers.

Subarbusto. Nativo.

Distribución: TAR, ANT, ATA.

Rango altitudinal: 3700-4500 m.

Países limítrofes: Argentina.

Azorella biloba (Schltdl.) Wedd.

Sinónimos: Fragosa biloba Schltdl., Azorella lehmannii

Hieron.

Subarbusto. Nativo.

Distribución: ANT.

Rango altitudinal: 2500-5000 m.

Países limítrofes: Argentina, Bolivia y Perú.

Nombre vulgar: Llareta.

Azorella boelckei (Mathias \& Constance) G.M. Plunkett \& A.N. Nicolas

Sinónimos: Huanaca boelckei Mathias \& Constance

Hierba. Perenne. Nativa.

Distribución: LLA, AIS.

Rango altitudinal: 1000-2000 m.

Países limítrofes: Argentina.

Azorella burkartii (Mathias \& Constance) G.M. Plunkett \& A.N. Nicolas

Sinónimos: Huanaca burkartii Mathias \& Constance

Hierba. Perenne. Nativa.

Distribución: ARA, MAG.

Rango altitudinal: $800-2500 \mathrm{~m}$.

Países limítrofes: Argentina.

Azorella compacta Phil.

Sinónimos: Azorella columnaris H. Wolff, Azorella yareta Hauman, Azorella prismatoclada Domin, Laretia compacta (Phil.) Reiche

Subarbusto. Nativo.

Distribución: AYP, TAR, ANT, ATA.

Rango altitudinal: 3500-5200 m.

Países limítrofes: Argentina, Bolivia y Perú.

Nombre vulgar: Llareta, yareta.

Azorella concolor Rendle

Sinónimos: Mulinum valentini Speg., Mulinum lycopodiopsis Speg.

Subarbusto. Nativo.

Distribución: MAG.

Rango altitudinal: 300-1400 m.

Países limítrofes: Argentina. 
Azorella crassipes Phil.

Subarbusto. Nativo.

Distribución: BIO.

Rango altitudinal: 1700-2000 m.

Países limítrofes: Argentina.

Nombre vulgar: Llareta.

Azorella cryptantha (Clos) Reiche

Sinónimos: Mulinum integrifolium Hieron., Mulinum

cryptanthum Clos

Subarbusto. Nativo.

Distribución: ATA, COQ.

Rango altitudinal: 2500-4300 m.

Países limítrofes: Argentina.

Nombre vulgar: Llareta.

\section{Azorella diversifolia Clos}

Sinónimos: Pozoa incisa Griseb., Azorella incisa (Griseb.)

Wedd. Azorella diversifolia Clos var. antillanca J.C. Zech

Hierba. Perenne. Nativa.

Distribución: MAU, NUB, BIO, ARA, LRI, LLA.

Rango altitudinal: 1000-3500 m.

Países limítrofes: Argentina.

Azorella filamentosa Lam.

Sinónimos: Chamitis integrifolia Gaertn., Azorella chamitis Pers.

Hierba. Perenne. Nativa.

Distribución: MAG.

Rango altitudinal: 0-900 m.

Países limítrofes: Argentina.

Azorella fuegiana Speg.

Sinónimos: Azorella mesetae Skottsb., Azorella dusenii $\mathrm{H}$.

Wolff

Hierba. Perenne. Nativa.

Distribución: MAG.

Rango altitudinal: 0-1500 m.

Países limítrofes: Argentina.

Azorella lycopodioides Gaudich.

Sinónimos: Azorella nervosa Phil., Azorella laevigata Phil., Azorella clandestina Phil., Azorella vaginata Phil., Azorella lycopodioides Gaudich. var. compacta Phil., Azorella philippi Gand., Azorella concolor auct. non Rendle

Subarbusto. Nativo.

Distribución: VAL, LBO, MAU, NUB, BIO, ARA, LLA, AIS, MAG.

Rango altitudinal: 0-2500 m.

Países limítrofes: Argentina.

Nombre vulgar: Llareta.

Azorella madreporica Clos

Sinónimos: Azorella bolacina Clos, Azorella piligera Phil.,
Azorella muscoides Phil., Azorella obtusiloba Phil.

Subarbusto. Nativo.

Distribución: ATA, COQ, VAL, RME, LBO, ARA.

Rango altitudinal: 1800-3600 m.

Países limítrofes: Argentina.

Nombre vulgar: Llareta.

\section{Azorella monantha Clos}

Sinónimos: Azorella cespitosa auct. non Cav., Azorella hookeriana Clos, Azorella apoda A. Gray, Azorella sessiliflora Phil., Azorella bryoides Phil., Azorella nucamentacea (Phil.) Hauman, Apleura nucamentacea Phil., Azorella glacialis Phil.

Subarbusto. Nativo.

Distribución: COQ, RME, LBO, MAU, NUB, BIO, ARA, AIS, MAG.

Rango altitudinal: 0-3000 m.

Países limítrofes: Argentina.

Nombre vulgar: Llareta.

Azorella monteroi S. Martínez \& Constance

Hierba. Perenne. Endémica.

Distribución: BIO, ARA.

Rango altitudinal: $1800 \mathrm{~m}$.

Azorella nivalis Phil.

Sinónimos: Mulinum leptacanthum Phil., Mulinum patagonicum Speg.

Subarbusto. Nativo.

Distribución: ARA, LLA.

Rango altitudinal: 1400-2600 m.

Países limítrofes: Argentina.

Azorella patagonica Speg.

Sinónimos: Azorella patagonica Speg. var. compacta Speg., Azorella plantaginea Speg.

Hierba. Perenne. Nativa.

Distribución: MAG.

Rango altitudinal: 0-1000 m.

Países limítrofes: Argentina.

Azorella prolifera (Cav.) G.M. Plunkett \& A.N. Nicolas Sinónimos: Mulinum spinosum (Cav.) Pers., Selinum spinosum Cav., Selinum proliferum Cav., Mulinum proliferum (Cav.) Pers., Mulinum laxum Phil., Mulinum leoninum Lorentz, Mulinum chillanense Phil., Mulinum ovalleanum Phil., Mulinum spinosum (Cav.) Pers. var. leoninum Kuntze, Mulinum spinosum (Cav.) Pers. var. quinquepartitum Kuntze, Mulinum spinosum (Cav.) Pers. var. trispinescens Kuntze, Mulinum gandogeri M. Hiroe, Mulinum spinosum (Cav.) Pers. var. longeinvolucrata Hicken, Mulinum spinosum (Cav.) Pers. var. proliferum (Cav.) Kuntze, Mulinum spinosum (Cav.) Pers. var. chillanense (Phil.) Reiche, Mulinum spinosum (Cav.) Pers. 
var. laxum (Phil.) Reiche, Mulinum hirsutum Phil.

Arbusto. Nativo.

Distribución: ATA, COQ, VAL, RME, LBO, MAU, NUB, BIO, ARA, AIS, MAG.

Rango altitudinal: 0-1500 m.

Países limítrofes: Argentina y Bolivia.

Nombre vulgar: Neneo, mata barrosa, dichillo, hierba de la culebra, hierba negra, chila, espinillo, churquecillo.

Azorella ranunculus d'Urv.

Sinónimos: Schizeilema ranunculus (d'Urv.) Domin, Pozoa ranunculus (d'Urv.) Hook.f.

Hierba. Perenne. Nativa.

Distribución: LLA, AIS, MAG.

Rango altitudinal: 0-900 m.

Países limítrofes: Argentina.

Azorella ruizii G.M. Plunkett \& A.N. Nicolas

Sinónimos: Selinum acaule Cav., Mulinum acaule (Cav.)

Pers., Laretia acaulis (Cav.) Gillies \& Hook.

Subarbusto. Nativo.

Distribución: ATA, COQ, VAL, RME, LBO, MAU.

Rango altitudinal: 2000-3500 m.

Países limítrofes: Argentina.

Nombre vulgar: Llareta.

Azorella selago Hook.f.

Sinónimos: Azorella selago Hook.f. var. compacta Albov, Azorella selago Hook.f. var. pulvinaris Albov, Azorella antipoda Gand., Azorella maquariensis Orchard

Subarbusto. Nativo.

Distribución: AIS, MAG.

Rango altitudinal: 0-1000 m.

Países limítrofes: Argentina.

Nombre vulgar: Llareta.

Azorella spinosa (Ruiz \& Pav.) Pers.

Sinónimos: Fragosa spinosa Ruiz \& Pav., Mulinum cuneatum Hook. \& Arn., Azorella pectinata Phil., Mulinum clandestinum Phil.

Hierba. Perenne. Endémica.

Distribución: COQ, VAL, RME, LBO, MAU, NUB, BIO, ARA, LLA.

Rango altitudinal: 0-2000 m.

\section{Azorella trifoliolata Clos}

Sinónimos: Azorella gayana Phil., Azorella depauperata Phil., Azorella pinnatiloba Gand.

Hierba. Perenne. Nativa.

Distribución: ANT, ATA, COQ, RME, BIO, ARA, LRI, LLA, AIS, MAG.

Rango altitudinal: 500-3500 m.

Países limítrofes: Argentina.
Azorella trifurcata (Gaertn.) Pers.

Sinónimos: Chamitis trifurcata Gaertn., Azorella cespitosa Cav., Bolax gilliesii Hook., Azorella gilliesii (Hook.) Hook. \& Arn., Azorella utriculata Griseb., Azorella rahmeri Phil., Azorella albida Phil., Azorella crassifolia Pers., Chamitis tricuspidata Gaertn.

Subarbusto. Nativo.

Distribución: ATA, RME, LBO, MAU, NUB, BIO, ARA, AIS, MAG.

Rango altitudinal: 0-3500 m.

Países limítrofes: Argentina.

Nombre vulgar: Llareta.

Azorella ulicina (Gillies \& Hook.) G.M. Plunkett \& A.N. Nicolas

Sinónimos: Mulinum ulicinum Gillies \& Hook.

Subarbusto. Nativo.

Distribución: ANT.

Rango altitudinal: 4100-4700 m.

Países limítrofes: Argentina y Bolivia.

\section{Bolax}

Bolax caespitosa Hombr. \& Jacq. ex Decne.

Sinónimos: Azorella bovei Speg., Azorella gummifera Poir., Bolax bovei (Speg.) Dusén

Subarbusto. Nativo.

Distribución: LLA, AIS, MAG.

Rango altitudinal: 0-1500 m.

Países limítrofes: Argentina.

Bolax gummifera (Lam.) Spreng.

Sinónimos: Hydrocotyle gummifera Lam., Bolax columnifer Gand., Bolax glebaria Comm. ex Gaudich., Azorella glebaria (Comm. ex Gaudich.) A. Gray, Bolax complicatus Spreng.

Subarbusto. Nativo.

Distribución: MAG.

Rango altitudinal: 0-3500 m.

Países limítrofes: Argentina.

\section{Bowlesia}

Bowlesia incana Ruiz \& Pav.

Sinónimos: Bowlesia geraniifolia Cham. \& Schltdl., Bowlesia nodiflora DC., Bowlesia rotundifolia Phil., Bowlesia tenera Spreng., Bowlesia incana Ruiz \& Pav. fma. tenera Urb.

Hierba. Anual. Nativa.

Distribución: ANT, COQ, VAL, RME, LBO, MAU, BIO.

Rango altitudinal: 0-1000 m.

Países limítrofes: Argentina. 
Bowlesia lobata Ruiz \& Pav.

Sinónimos: Bowlesia acutiloba H. Wolff, Bowlesia acutangula Benth., Drusa acutangula (Benth.) Drude

Hierba. Perenne. Nativa.

Distribución: TAR.

Rango altitudinal: 1300-4600 m.

Países limítrofes: Argentina, Bolivia y Perú.

Bowlesia macrophysa Zoellner

Hierba. Anual. Endémica.

Distribución: COQ.

Rango altitudinal: $2900 \mathrm{~m}$.

Bowlesia paposana I.M. Johnst.

Hierba. Anual. Endémica.

Distribución: AYP, TAR, ANT.

Rango altitudinal: 3000-3500 m.

\section{Bowlesia sodiroana $\mathrm{H}$. Wolff}

Hierba. Anual. Nativa.

Distribución: COQ.

Rango altitudinal: 200-500 m.

Países limítrofes: Bolivia y Perú.

Bowlesia tropaeolifolia Gillies \& Hook.

Sinónimos: Bowlesia tropaeolifolia Gillies \& Hook. var. gayana Domin, Bowlesia tropaeolifolia Gillies \& Hook. var. heterophylla Speg., Bowlesia tropaeolifolia Gillies \& Hook. var. patagonica Speg., Bowlesia cirrosa Phil., Bowlesia pulchella Wedd., Bowlesia flexilis Meyen, Bowlesia tropaeolifolia Gillies \& Hook. var. cirrosa (Phil.) Reiche

Hierba. Perenne. Nativa.

Distribución: AYP, TAR, ANT, COQ, VAL, RME, LBO, MAU, NUB, BIO, ARA, LLA, AIS, MAG.

Rango altitudinal: 100-4500 m.

Países limítrofes: Argentina, Bolivia y Perú.

Nombre vulgar: Barba de gato.

\section{Bowlesia uncinata Colla}

Sinónimos: Bowlesia tropaeolifolia Gillies \& Hook. var. tripartita Hook. \& Arn., Bowlesia tripartita (Hook. \& Arn.) Clos, Bowlesia reichei Phil., Bowlesia tripartita (Hook. \& Arn.) Clos var. reichei (Phil.) Reiche, Bowlesia axilliflora Phil., Bowlesia tripartita (Hook. \& Arn.) Clos var. axilliflora (Phil.) Reiche, Bowlesia dumetorum Phil., Bowlesia tripartita (Hook. \& Arn.) Clos var. dumertorum (Phil.) Reiche, Bowlesia tripartita (Hook. \& Arn.) Clos var. triloba Reiche, Bowlesia macrosperma H. Wolff

Hierba. Anual. Endémica.

Distribución: ATA, COQ, VAL, RME, LBO, MAU, BIO.

Rango altitudinal: 700-2000 m.

\section{Centella}

Centella asiatica (L.) Urb.

Sinónimos: Hydrocotyle asiatica L., Hydrocotyle triflora

Ruiz \& Pav., Centella triflora (Ruiz \& Pav.) Nannf.

Hierba. Perenne. Nativa.

Distribución: MAU, BIO, ARA, LRI, LLA, AIS, MAG, JFE.

Rango altitudinal: 10-600 m.

Países limítrofes: Argentina, Bolivia y Perú.

\section{Conium}

Conium maculatum $\mathrm{L}$.

Hierba. Anual o bienal. Introducida.

Distribución: COQ, VAL, RME, LBO, MAU, NUB, BIO, ARA, LRI, LLA, MAG, JFE.

\section{Coriandrum}

Coriandrum sativum $\mathrm{L}$.

Hierba. Anual. Introducida.

Distribución: LLA, JFE.

\section{Cyclospermum}

Cyclospermum laciniatum (DC.) Constance

Sinónimos: Helosciadium laciniatum DC., Helosciadium laciniatum DC. var. humile Hook. \& Arn., Helosciadium gracile Clos, Apium laciniatum (DC.) Urb. var. gracile (Clos) Reiche, Apium laciniatum (DC.) Urb. var. hispidulum H. Wolff, Helosciadium deserticolum Phil., Apium laciniatum (DC.) Urb. fma. deserticolum H. Wolff, Helosciadium biternatum Phil., Apium biternatum (Phil.) Reiche

Hierba. Anual. Nativa.

Distribución: TAR, ANT, ATA, COQ, VAL, RME, LBO, BIO, ARA.

Rango altitudinal: 0-1600 m.

Países limítrofes: Perú.

Cyclospermum leptophyllum (Pers.) Sprague

Sinónimos: Apium leptophyllum (Pers.) F. Muell., Pimpinella leptophylla Pers., Helosciadium leptophyllum (Pers.) DC., Apium ammi Urb., Apium ranunculifolium auct. non Kunth, Apium laciniatum (DC.) Urb. fma. elatius (Hook. \& Arn.) H. Wolff, Apium ranunculifolium (DC.) Reiche, comb. illeg., Helosciadium ranunculifolium DC., Helosciadium laciniatum DC. var. elatius Hook. \& Arn., Apium ammi Urb. var. genuinum H. Wolff, Apium ammi Urb. fma. filamentosum (Kuntze) H. Wolff, Apium ammi Urb. var. filamentosum Kuntze, Apium ammi Urb. fma. nanum Kuntze, Apium ammi Urb. fma. pedunculata Chodat, Apium ammi Urb. var. leptophyllum (Pers.) Kuntze 
Hierba. Anual. Nativa.

Distribución: ATA, COQ, VAL, RME, MAU, NUB, BIO, ARA, LRI, JFE, IPA.

Rango altitudinal: 0-4000 m.

Países limítrofes: Argentina, Bolivia y Perú.

Nota: Introducida en el Archipiélago Juan Fernández.

\section{Daucus}

Daucus carota L.

Hierba. Anual o bienal. Introducida.

Distribución: VAL, RME, LBO, MAU, NUB, BIO, ARA, LRI, LLA, IPA.

Daucus montanus Humb. \& Bonpl. ex Spreng.

Sinónimos: Daucus toriloides DC., Daucus australis Poepp. Hierba. Anual o bienal. Nativa.

Distribución: ANT, COQ, VAL, MAU, LLA, AIS, MAG, JFE.

Rango altitudinal: 0-3000 m.

Países limítrofes: Argentina, Bolivia y Perú.

Nota: Introducida en el Archipiélago Juan Fernández.

Daucus pusillus Michx.

Sinónimos: Daucus scaber Larrañaga, Daucus montevidensis Link ex Spreng., Daucus hispidifolius Clos

Hierba. Anual. Introducida.

Distribución: COQ, VAL, RME, LBO, MAU, BIO, LLA, AIS.

Rango altitudinal: 0-2300 m.

\section{Diposis}

Diposis bulbocastanum DC.

Hierba. Perenne. Endémica.

Distribución: COQ, VAL, RME, LBO.

Rango altitudinal: 500-2500 m.

\section{Domeykoa}

Domeykoa andina Saldivia \& Faúndez

Hierba. Anual o perenne. Endémica.

Distribución: TAR.

Rango altitudinal: 2650-3120 m.

Domeykoa oppositifolia Phil.

Hierba. Anual. Endémica.

Distribución: ANT, ATA.

Rango altitudinal: 100-1000 m.

Domeykoa perennis I.M. Johnst.

Hierba. Perenne. Endémica.

Distribución: ANT, ATA.

Rango altitudinal: 0-200 m.

\section{Eremocharis}

Eremocharis confinis I.M. Johnst.

Subarbusto. Nativo.

Distribución: AYP.

Rango altitudinal: 3100-3200 m.

Países limítrofes: Perú.

Eremocharis fruticosa Phil.

Sinónimos: Eremocharis flexuosa Phil., Dipterygia philippiana Kuntze

Arbusto. Endémico.

Distribución: TAR, ANT, ATA.

Rango altitudinal: 100-1800 m.

\section{Eryngium}

Eryngium anomalum Hook. \& Arn.

Hierba. Perenne. Endémica.

Distribución: ATA, COQ, VAL.

Rango altitudinal: $100 \mathrm{~m}$.

Eryngium bupleuroides Hook. \& Arn.

Arbusto o árbol pequeño. Endémico.

Distribución: JFE.

Rango altitudinal: 400-900 m.

Eryngium cardosii Clos

Hierba. Perenne. Endémica.

Distribución: BIO.

Rango altitudinal: 100-200 m.

Eryngium coquimbanum Phil. ex Urb.

Hierba. Anual. Endémica.

Distribución: ATA, COQ.

Rango altitudinal: 0-500 m.

Eryngium depressum Hook. \& Arn. Sinónimos: Eryngium arvense Phil.

Hierba. Perenne. Endémica.

Distribución: VAL, RME, LBO, MAU, NUB, BIO, ARA, LLA.

Rango altitudinal: 100-1000 m.

Nombre vulgar: Caucha.

Eryngium fernandezianum Skottsb.

Arbusto. Endémico.

Distribución: JFE.

Rango altitudinal: 300-500 m.

Nota: Probable híbrido entre E. bupleuroides y E. inaccessum.

Eryngium humifusum Clos

Sinónimos: Eryngium pratense Phil. var. depressum Phil., Eryngium pratense Phil., Eryngium humifusum Clos var. 
pratense (Phil.) Reiche

Hierba. Perenne. Endémica.

Distribución: BIO, ARA, LRI.

Rango altitudinal: 0-1400 m.

Eryngium inaccessum Skottsb.

Arbusto. Endémico.

Distribución: JFE.

Rango altitudinal: 0-300 m.

Eryngium macracanthum Phil.

Hierba. Anual. Endémica.

Distribución: ATA.

Rango altitudinal: 0-200 m.

Eryngium paniculatum Cav. \& Dombey ex F. Delaroche Sinónimos: Eryngium paniculatum Cav. \& Dombey ex F. Delaroche var. chilensis DC.

Hierba. Perenne. Nativa.

Distribución: COQ, VAL, RME, LBO, MAU, NUB, BIO, ARA, LRI, LLA.

Rango altitudinal: 100-1000 m.

Países limítrofes: Argentina.

Nombre vulgar: Cardoncillo, chupalla, quisco, pitillo.

Eryngium polyrhizum Clos

Hierba. Anual. Endémica.

Distribución: NUB, BIO.

Rango altitudinal: 200-300 m.

Eryngium pseudojunceum Clos

Sinónimos: Eryngium fistulosum Phil., Eryngium crantzioides Griseb., Eryngium pseudojunceum Clos var. crantzioides (Griseb.) Reiche, Eryngium pseudojunceum Clos var. fistulosum (Phil.) Reiche

Hierba. Perenne. Nativa.

Distribución: VAL, NUB, BIO, ARA, LRI, LLA.

Rango altitudinal: $0-1500 \mathrm{~m}$.

Países limítrofes: Argentina.

Eryngium pulchellum Phil.

Hierba. Anual. Endémica.

Distribución: ANT, ATA, COQ, VAL.

Rango altitudinal: 0-600 m.

Eryngium rostratum Cav.

Sinónimos: Eryngium rostratum Cav. var. diversifolium

Hierba. Perenne. Endémica.

Distribución: VAL, LBO, MAU, NUB, BIO, ARA.

Rango altitudinal: 0-700 m.

Nombre vulgar: Caucha, cardilla.

Eryngium sarcophyllum Hook. \& Arn. Arbusto o árbol pequeño. Endémico.
Distribución: JFE.

Rango altitudinal: 0-500 m.

Nota: Extinta.

\section{Foeniculum}

Foeniculum vulgare Mill.

Hierba. Perenne. Introducida.

Distribución: AYP, TAR, ANT, ATA, COQ, VAL, RME, LBO, MAU, NUB, BIO, ARA, LLA, JFE.

\section{Gymnophyton}

Gymnophyton flexuosum Clos

Sinónimos: Dipterygia flexuosa Kuntze, Asteriscium flexuosum Drude, Gymnophyton kingii Phil., Dipterygia kingii Kuntze, Gymnophyton robustum Clos var. kingii Reiche

Arbusto. Endémico.

Distribución: ANT, ATA, COQ.

Rango altitudinal: $800-2600 \mathrm{~m}$.

Gymnophyton foliosum Phil.

Sinónimos: Dipterygia foliosa Kuntze

Arbusto. Endémico.

Distribución: TAR, ANT, ATA, COQ.

Rango altitudinal: $0-400 \mathrm{~m}$.

Gymnophyton isatidicarpum (C. Presl ex DC.) Mathias \& Constance

Sinónimos: Mulinum isatidicarpum C. Presl ex DC., Dipterygia isatidicarpa C. Presl ex DC., Asteriscium isatidicarpum Hook. \& Arn., Gymnophyton spinescens Phil., Dipterygia spinescens Kuntze, Asteriscium spinescens Drude

Arbusto. Endémico.

Distribución: COQ, VAL, RME, LBO.

Rango altitudinal: 800-3500 m.

\section{Gymnophyton robustum Clos}

Sinónimos: Asteriscium robustum Baill.

Arbusto. Endémico.

Distribución: TAR, ATA, COQ.

Rango altitudinal: 400-2500 m.

Nombre vulgar: Bíobio.

Gymnophyton spinosissimum Phil.

Sinónimos: Dipterygia spinosissima Kuntze, Asteriscium spinosissimum Drude

Arbusto. Endémico.

Distribución: ANT, ATA, COQ.

Rango altitudinal: 2800-4500 m. 


\section{Homalocarpus}

Homalocarpus bowlesioides Hook. \& Arn.

Sinónimos: Bowlesia elegans Clos, Bowlesia elata Clos, Bowlesia cana Phil.

Hierba. Anual. Endémica.

Distribución: ATA, COQ, VAL, RME.

Rango altitudinal: 900-1900 m.

Homalocarpus dichotomus (Poepp. ex DC.) Mathias \& Constance

Sinónimos: Bowlesia dichotoma Poepp. ex DC., Bowlesia dichotoma Poepp. ex DC. var. albo-squamata Phil., Bowlesia dichotoma Poepp. ex DC. var. chrysocarpa Phil., Bowlesia multiradiata Colla

Hierba. Anual. Endémica.

Distribución: ATA, COQ, VAL, RME, LBO.

Rango altitudinal: 400-3000 m.

Homalocarpus digitatus (Phil.) Mathias \& Constance Sinónimos: Bowlesia dichotoma Poepp. ex DC. var. digitata (Phil.) Domin, Bowlesia digitata Phil.

Hierba. Anual. Endémica.

Distribución: ATA.

Rango altitudinal: 800-1100 m.

Homalocarpus dissectus Mathias \& Constance

Hierba. Anual. Endémica.

Distribución: COQ, VAL, RME.

Rango altitudinal: 100-1400 m.

Homalocarpus integerrimus (Turcz.) Mathias \& Constance Sinónimos: Bowlesia integerrima Turcz., Bowlesia dichotoma Poepp. ex DC. var. integerrima Domin

Hierba. Anual. Endémica.

Distribución: ANT, ATA, COQ, LBO.

Rango altitudinal: 100-1000 m.

Homalocarpus nigripetalus (Clos) Mathias \& Constance Sinónimos: Bowlesia nigripetala Clos

Hierba. Anual. Endémica.

Distribución: COQ, VAL, RME.

Rango altitudinal: 200-2000 m.

\section{Hydrocotyle}

Hydrocotyle bonariensis Lam.

Sinónimos: Hydrocotyle umbellata L. var. bonariensis (Lam.) Roem. \& Schult., Hydrocotyle multiflora Ruiz \& Pav.

Hierba. Perenne. Nativa.

Distribución: AYP, TAR, COQ, VAL, BIO.

Rango altitudinal: 0-2500 m.

Países limítrofes: Argentina y Perú.
Hydrocotyle chamaemorus Cham. \& Schltdl.

Sinónimos: Hydrocotyle araucana Phil., Hydrocotyle araucana Phil. var. patagonica Speg., Hydrocotyle carrerae Phil., Hydrocotyle rahmeri Phil., Hydrocotyle valdiviana Phil., Hydrocotyle chamaemorus Cham. \& Schltdl. var. valdiviana Reiche, Hydrocotyle skottsbergii Gand.

Hierba. Perenne. Nativa.

Distribución: NUB, BIO, ARA, LRI, LLA, AIS, MAG.

Rango altitudinal: 0-2500 m.

Países limítrofes: Argentina.

Nombre vulgar: Malva del monte.

Hydrocotyle cryptocarpa Speg.

Hierba. Perenne. Nativa.

Distribución: COQ, LBO, NUB, ARA.

Rango altitudinal: 0-200 m.

Países limítrofes: Argentina.

Hydrocotyle indecora DC.

Sinónimos: Hydrocotyle bonplandii A. Rich. var. chilensis DC., Hydrocotyle marchantioides Clos

Hierba. Perenne. Nativa.

Distribución: COQ, MAU, NUB, BIO, ARA, LRI, LLA, AIS.

Rango altitudinal: 500-1000 m.

Países limítrofes: Argentina.

Hydrocotyle modesta Cham. \& Schltdl.

Sinónimos: Hydrocotyle modesta Cham. \& Schltdl. var. repens Clos

Hierba. Perenne. Nativa.

Distribución: VAL, RME, LBO, MAU, NUB, BIO, ARA, LLA.

Rango altitudinal: 0-1200 m.

Países limítrofes: Argentina.

Hydrocotyle poeppigii DC.

Sinónimos: Hydrocotyle lechleri Phil., Hydrocotyle uliginosa Phil.

Hierba. Perenne. Endémica.

Distribución: NUB, BIO, ARA, LRI, LLA, AIS.

Rango altitudinal: 0-1100 m.

Hydrocotyle ranunculoides L.f.

Sinónimos: Hydrocotyle batrachoides DC., Hydrocotyle ranunculoides L. var. lobata Urb., Hydrocotyle ranunculoides L. var. inciso-crenata Urb.

Hierba. Perenne. Nativa.

Distribución: COQ, VAL, RME, LBO, MAU, NUB, BIO, ARA, LRI.

Rango altitudinal: 0-3500 m.

Países limítrofes: Argentina y Perú.

Nombre vulgar: Hierba de la plata, tangue. 
Hydrocotyle umbellata L.

Hierba. Perenne. Nativa.

Distribución: TAR, VAL, BIO.

Rango altitudinal: 0-1500 m.

Países limítrofes: Perú.

Hydrocotyle verticillata Thunb.

Sinónimos: Hydrocotyle volckmanni Phil., Hydrocotyle verticillata Thunb. var. pluriradiata Urb.

Hierba. Perenne. Nativa.

Distribución: RME, LBO, MAU, BIO.

Rango altitudinal: 0-800 m.

Países limítrofes: Argentina y Perú.

\section{Levisticum}

Levisticum officinale W.D.J. Koch

Hierba. Perenne. Introducida.

Distribución: LLA, MAG.

\section{Lilaeopsis}

Lilaeopsis macloviana (Gand.) A.W. Hill

Sinónimos: Crantzia macloviana Gand., Lilaeopsis andina A.W. Hill, Lilaeopsis andina A.W. Hill var. multivittata A.W. Hill, Lilaeopsis sinuata A.W. Hill, Crantzia lineata (Michx.) Nutt. var. subulata Wedd., Lilaeopsis lineata Green

Hierba. Perenne. Nativa.

Distribución: AYP, TAR, ANT, ATA, COQ, VAL, RME, BIO, ARA, LRI, LLA, AIS, MAG.

Rango altitudinal: 0-4700 $\mathrm{m}$.

Países limítrofes: Argentina, Bolivia y Perú.

Nombre vulgar: Isru.

\section{Oreomyrrhis}

Oreomyrrhis hookeri Mathias \& Constance

Sinónimos: Azorella daucoides d'Urv., Oreomyrrhis daucoides auct. non Urb.

Hierba. Perenne. Nativa.

Distribución: MAG.

Rango altitudinal: 0-200 m.

Países limítrofes: Argentina y Bolivia.

\section{Osmorhiza}

Osmorhiza chilensis Hook. \& Arn.

Sinónimos: Osmorhiza berteroi DC., Osmorhiza berteroi DC. var. gracilior Phil., Schudia chilensis Molina ex Clos Hierba. Perenne. Nativa. Distribución: COQ, VAL, RME, LBO, MAU, NUB, BIO, ARA, LRI, LLA, AIS, MAG.

Rango altitudinal: 0-2500 m.
Países limítrofes: Argentina.

Nombre vulgar: Asta de cabra.

Osmorhiza depauperata Phil.

Sinónimos: Osmorhiza obtusa (J.M. Coult. \& Rose)

Fernald, Washingtonia obtusa J.M. Coult. \& Rose

Hierba. Perenne. Nativa.

Distribución: BIO, MAG.

Rango altitudinal: 0-2500 m.

Países limítrofes: Argentina.

Osmorhiza glabrata Phil.

Sinónimos: Myrrhis renjifoana Phil., Uraspermum glabratum (Phil.) Kuntze, Elleimataenia renjifoana (Phil.)

Koso-Poliansky

Hierba. Perenne. Nativa.

Distribución: RME, LBO, MAU, NUB, BIO, ARA.

Rango altitudinal: 1500-2000 m.

Países limítrofes: Argentina.

\section{Pastinaca}

Pastinaca sativa L.

Hierba. Bienal. Introducida.

Distribución: RME, MAU, BIO, ARA, LLA, AIS.

\section{Petroselinum}

Petroselinum crispum (Mill.) A.W.Hill.

Hierba. Bienal. Introducida.

Distribución: VAL, JFE.

\section{Pozoa}

Pozoa coriacea Lag.

Sinónimos: Pozoa hydrocotylifolia Bridges, Azorella coriacea (Lag.) Kuntze, Azorella hydrocotylifolia (Bridges) Macloskie, Pozoa denticulata Meyen

Hierba. Perenne. Nativa.

Distribución: COQ, VAL, RME, LBO, MAU, NUB, BIO, ARA.

Rango altitudinal: 1000-4000 m.

Países limítrofes: Argentina.

Nombre vulgar: Anislao.

Pozoa volcanica Mathias \& Constance

Sinónimos: Azorella volcanica $\mathrm{M}$. Hiroe

Hierba. Perenne. Nativa.

Distribución: MAU, NUB, BIO, ARA, LRI.

Rango altitudinal: 1200-2400 m.

Países limítrofes: Argentina. 


\section{Sanicula}

Sanicula crassicaulis Poepp. ex DC.

Sinónimos: Sanicula liberta auct. non Cham. \& Schltdl.

Hierba. Perenne. Nativa.

Distribución: COQ, VAL, RME, LBO, MAU, NUB, BIO,

ARA, LRI, JFE.

Rango altitudinal: 500-1000 m.

Países limítrofes: Argentina.

Nombre vulgar: Pata de león.

Sanicula graveolens Poepp. ex DC.

Sinónimos: Sanicula macrorhiza Bertero ex Colla, Sanicula macrorhiza Bertero ex Colla var. andina Meigen

Hierba. Perenne. Nativa.

Distribución: COQ, VAL, RME, LBO, MAU, NUB, BIO, ARA, AIS.

Rango altitudinal: 1500-3000 m.

Países limítrofes: Argentina.

Nombre vulgar: Pata de león.

\section{Scandix}

Scandix pecten-veneris L.

Hierba. Anual. Introducida.

Distribución: RME, LBO, MAU, NUB, BIO, ARA.

Seseli

Seseli libanotis (L.) Koch

Hierba. Bienal. Introducida.

Distribución: BIO.

\section{Sium}

Sium latifolium L.

Hierba. Perenne. Introducida.

Distribución: ATA, COQ, VAL.

\section{Torilis}

Torilis arvensis (Huds.) Link

Hierba. Anual. Introducida.

Distribución: MAU, NUB, BIO.

Torilis nodosa (L.) Gaertn.

Hierba. Anual. Introducida.

Distribución: COQ, VAL, RME, LBO, MAU, BIO, ARA, JFE.

\section{APOCYNACEAE}

\section{Asclepias}

Asclepias curassavica L.

Hierba. Perenne. Introducida.

Distribución: AYP, TAR, IPA.

\section{Catharanthus}

Catharanthus roseus (L.) G. Don

Hierba. Perenne. Introducida.

Distribución: IPA.

\section{Diplolepis}

Diplolepis biflora (Phil.) Hechem \& C. Ezcurra

Sinónimos: Diplolepis nummulariifolia (Hook. \& Arn.) Liede \& Rapini var. biflora (Phil.) Hechem \& C. Ezcurra, Cynoctonum biflorum Phil., Cynanchum nummulariifolium Hook. \& Arn. var. biflorum (Phil.) Reiche, Vincetoxicum biflorum (Phil.) Kuntze

Hierba. Perenne. Nativa.

Distribución: VAL, RME, BIO, ARA.

Rango altitudinal: 1000-2500 m.

Países limítrofes: Argentina.

Diplolepis boerhaviifolia (Hook. \& Arn.) Liede \& Rapini Sinónimos: Cynanchum boerhaviifolium Hook. \& Arn., Cynoctonum boerhaviifolium (Hook. \& Arn.) Decne., Oxypetalum parvifolium Phil., hom. illeg., Schizostemma kingii Phil., Vincetoxicon biflorum (Phil.) Kuntze Subarbusto trepador. Endémico.

Distribución: ANT, ATA, COQ, VAL, RME.

Rango altitudinal: 0-800 m.

Nombre vulgar: Pehuendum, pahueldum.

Diplolepis geminiflora (Decne.) Liede \& Rapini Sinónimos: Astephanus geminiflorus Decne.

Arbusto trepador. Endémico.

Distribución: ANT, ATA, COQ, VAL, RME.

Rango altitudinal: 0-1800 m.

Nombre vulgar: Azahar de quissco, azahar, cuerdecilla, cordelillo, lichilahuén, voquicillo.

Diplolepis hieronymi (Lorentz) Liede \& Rapini Sinónimos: Astephanus hieronymi (Lorentz) Malme, Cynanchum fallax Hicken, Cynanchum hieronymi (Lorentz) Hicken, Astephanus fallax (Hicken) T. Mey., Grisebachiella hieronymi Lorentz

Arbusto. Nativo.

Distribución: MAU.

Rango altitudinal: 600-1800 m.

Países limítrofes: Argentina. 
Diplolepis menziesii Schult.f.

Arbusto trepador. Endémico.

Distribución: COQ, VAL, RME, LBO, MAU.

Rango altitudinal: $300-900 \mathrm{~m}$.

Nombre vulgar: Voquicillo, voqui amarillo.

Diplolepis mucronata (Decne.) Hechem \& C. Ezcurra

Sinónimos: Cynanchum chilense (Phil.) Malme, Holostemma chilense Phil., Cynoctonum mucronatum Decne., Cynanchum mucronatum (Decne.) Reiche, comb. illeg., Vincetoxicum mucronatum (Decne.) Kuntze

Hierba trepadora. Perenne. Nativa.

Distribución: COQ, VAL, RME, LBO, NUB.

Rango altitudinal: 800-2000 m.

Países limítrofes: Argentina.

Nombre vulgar: Voqui.

Diplolepis myrtifolia (Hook. \& Arn.) Hechem \& C. Ezcurra Sinónimos: Cynanchum myrtifolium Hook. \& Arn., Cynoctonum myrtifolium (Hook. \& Arn.) Decne., Cynoctonum nemorosum Phil., Vincetoxicum nemorosum (Phil.) Kuntze

Subarbusto trepador. Endémico.

Distribución: ARA, LRI.

Rango altitudinal: 0-900 m.

Nombre vulgar: Hierba del tricao.

Diplolepis nummulariifolia (Hook. \& Arn.) Liede \& Rapini Sinónimos: Cynanchum patagonicum (Phil.) Malme, Cynoctonum nummulariifolium (Hook. \& Arn.) Decne., Cynoctonum undulatum Decne., Cynanchum nanum Skottsb., hom. illeg., Cynoctonum patagonicum Phil., Vincetoxicum patagonicum (Phil.) Kuntze, Cynanchum undulatum (Decne.) K. Schum., Cynanchum nummulariifolium Hook. \& Arn., Vincetoxicum nummularifolium (Hook. \& Arn.) Kuntze, Vincetoxicum undulatum (Decne.) Kuntze, Cynanchum andinum Liede, Cynanchum nanissimum Liede, nom. illeg., Cynanchum nanellum P.T. Li

Arbusto o subarbusto. Nativo.

Distribución: COQ, VAL, RME, LBO, MAU, NUB, BIO, ARA, LRI.

Rango altitudinal: 700-3000 m.

Países limítrofes: Argentina.

Diplolepis pachyphylla (Decne.) Hechem \& C. Ezcurra Sinónimos: Cynanchum acutifolium (Phil.) Reiche, Cynanchum pachyphyllum (Decne.) K. Schum., Cynoctonum acutifolium Phil., Cynoctonum pachyphyllum Decne., Cynoctonum chiloense Decne., Cynanchum lancifolium Hook. \& Arn., hom. illeg., Vincetoxicum chiloense (Decne.) Kuntze, Vincetoxicum pachyphyllum (Decne.) Kuntze, Cynanchum chiloense (Decne.) Malme

Hierba trepadora. Perenne. Nativa.

Distribución: MAU, NUB, BIO, ARA, LRI, LLA, AIS.

Rango altitudinal: 100-500 m.

Países limítrofes: Argentina.
Nombre vulgar: Pahueldin, pahueldum, pahueldun.

Diplolepis viridis (Phil.) Hechem \& C. Ezcurra

Sinónimos: Cynanchum deserticola A.R. Flores \& J.M.

Watson, Cynoctonum viride Phil., Cynanchum viride (Phil.)

Reiche, nom. illeg., Cynanchum atacamense Liede

Arbusto. Endémico.

Distribución: ANT, ATA, COQ.

Rango altitudinal: 0-1300 m.

\section{Elytropus}

Elytropus chilensis (A. DC.) Müll. Arg.

Sinónimos: Echites chilensis A. DC., Echites ptarmicus Poepp., Echites heterophyllus Miq., Elytropus ptarmica

(Poepp.) Miers, Vinca sternutetoria Poepp. ex Reiche., Elytropus heterophyllus Miers, Elytropus pubescens Miers

Arbusto trepador. Nativo.

Distribución: LBO, MAU, NUB, BIO, ARA, LRI, LLA, AIS.

Rango altitudinal: 0-1000 m.

Países limítrofes: Argentina.

Nombre vulgar: Poroto del campo, quilmay, voqui.

\section{Philibertia}

Philibertia candolleana (Hook. \& Arn.) Goyder

Sinónimos: Brachylepis candolleana Hook. \& Arn., Astephanus cordifolius Phil., Mitostigma cordifolium (Phil.)

E. Fourn., Aphanostelma candolleanum (Hook. \& Arn.) Malme, Melinia candolleana (Hook. \& Arn.) Decne.

Subarbusto trepador. Nativo.

Distribución: RME.

Rango altitudinal: 0-2000 m.

Países limítrofes: Argentina.

Philibertia solanoides Kunth

Sinónimos: Blepharodon rahmeri Phil., Philibertia rahmeri

(Phil.) Malme

Subarbusto trepador. Nativo.

Distribución: AYP, TAR, ANT.

Rango altitudinal: 2000-4500 m.

Países limítrofes: Bolivia y Perú.

\section{Skytanthus}

Skytanthus acutus Meyen

Sinónimos: Scytalanthus acutus Walp., Neriandra angustifolia DC.

Arbusto. Endémico.

Distribución: ANT, ATA, COQ.

Rango altitudinal: 0-800 $\mathrm{m}$.

Nombre vulgar: Cuerno, cuerno de cabra, monte de burro, cuernecillo. 


\section{Tweedia}

Tweedia andina (Phil.) G.H. Rua

Sinónimos: Tweedia hookeri (Decne.) Malme, Oxypetalum andinum Phil., Oxypetalum hookeri Decne., Oxypetalum mölleri Phil.

Subarbusto trepador. Endémico.

Distribución: VAL, RME, LBO, MAU, NUB, BIO, ARA.

Rango altitudinal: 0-1000 m.

Nombre vulgar: Voquicillo.

Tweedia birostrata (Hook. \& Arn.) Hook. \& Arn.

Sinónimos: Tweedia confertiflora (Decne.) Malme, Tweedia obliquifolia (Colla) Malme, Cynanchum birostratum Hook. \& Arn., Gonolobus obliquifolius Colla, Gonolobus voquicillo Colla, Oxypetalum saxatile Decne., Oxypetalum confertiflorum Decne., Oxypetalum brevipes Phil., Gothofreda birostrata (Hook. \& Arn.) Kuntze, Gothofreda obliquifolia (Colla) Kuntze, Gothofreda confertiflora (Decne.) Kuntze, Gothofreda brevipes (Phil.) Kuntze, Oxypetalum angustifolium Phil., Tweedia brevipes (Phil.) Malme

Subarbusto trepador. Endémico.

Distribución: ANT, ATA, COQ, VAL, RME, LBO, MAU, NUB, BIO.

Rango altitudinal: 0-1700 m.

Nombre vulgar: Voquicillo.

Tweedia stipitata G.H. Rua \& Liede

Subarbusto trepador. Endémico.

Distribución: COQ, VAL, RME.

Rango altitudinal: 0-800 m.

\section{Vinca}

Vinca major L.

Hierba. Perenne. Introducida.

Distribución: ANT, COQ, VAL, RME, LBO, MAU, NUB, BIO, ARA, LRI, LLA, JFE.

\section{ARALIACEAE}

\section{Hedera}

\section{Hedera helix L.}

Arbusto trepador. Introducido.

Distribución: BIO, ARA, LRI, LLA.

Nombre vulgar: Hiedra.

\section{Raukaua}

Raukaua laetevirens (Gay) Frodin Sinónimos: Aralia laetevirens Gay, Aralia paniculata Phil.,
Cheirodendron laetevirens (Gay) Seem., Pseudopanax laetevirens (Gay) Dusén, comb. illeg., Pseudopanax laetevirens (Gay) Franchet

Arbusto o árbol pequeño. Nativo.

Distribución: MAU, NUB, BIO, ARA, LRI, LLA, AIS, MAG.

Rango altitudinal: 0-1500 m.

Países limítrofes: Argentina.

Nombre vulgar: Sauco cimarrón, sauco del diablo.

Raukaua valdiviensis (Gay) Frodin

Sinónimos: Aralia valdiviensis Gay, Aralia valdiviensis Gay, Pseudopanax valdiviensis (Gay) Seem. ex Harms, Pseudopanax valdiviensis (Gay) Seem. ex Harms

Arbusto trepador. Endémico.

Distribución: MAU, NUB, BIO, ARA, LRI, LLA.

Rango altitudinal: 0-500 m.

Nombre vulgar: Curaco, traumén, voquinaranjillo, hueldahuca.

\section{ARISTOLOCHIACEAE}

\section{Aristolochia}

Aristolochia bridgesii (Klotzsch) Duch.

Sinónimos: Aristolochia pearcei Phil., Howardia bridgesii

Klotzsch

Hierba. Perenne. Endémica.

Distribución: ATA, COQ, RME.

Rango altitudinal: 900-1300 m.

Nombre vulgar: Oreja de zorro amarilla.

Aristolochia chilensis Bridges ex Lindl. Sinónimos: Aristolochia setigera Klotzsch

Hierba. Perenne. Endémica.

Distribución: ANT, ATA, COQ, VAL, RME.

Rango altitudinal: 0-1500 m.

Nombre vulgar: Oreja de zorro, hierba de la Virgen María, clon.

\section{Lactoris}

Lactoris fernandeziana Phil.

Arbusto. Endémico.

Distribución: JFE.

Rango altitudinal: $500 \mathrm{~m}$.

\section{ASTERACEAE}

\section{Abrotanella}

Abrotanella emarginata (Gaudich.) Cass. 
Sinónimos: Oligosporus emarginatus Gaudich.

Hierba. Perenne. Nativa.

Distribución: AIS, MAG.

Rango altitudinal: 0-1000 m.

Países limítrofes: Argentina.

Abrotanella linearifolia A. Gray

Hierba. Perenne. Endémica.

Distribución: LLA, AIS, MAG, JFE.

Rango altitudinal: 0-1400 m.

Abrotanella purpurea Swenson

Hierba. Perenne. Endémica.

Distribución: LLA, AIS, MAG.

Rango altitudinal: 0-800 m.

Abrotanella submarginata A. Gray

Hierba. Perenne. Endémica.

Distribución: MAG.

Rango altitudinal: 0-700 m.

\section{Abrotanella trichoachaenia Cabrera}

Hierba. Perenne. Nativa.

Distribución: AIS, MAG.

Rango altitudinal: 800-1600 m.

Países limítrofes: Argentina.

Abrotanella trilobata Swenson

Hierba. Perenne. Nativa.

Distribución: MAG.

Rango altitudinal: 400-800 m.

Países limítrofes: Argentina.

\section{Achillea}

Achillea millefolium L.

Hierba. Perenne. Introducida.

Distribución: COQ, RME, LBO, MAU, NUB, BIO, ARA, LRI, LLA, AIS, MAG.

\section{Achillea ptarmica L.}

Hierba. Perenne. Introducida.

Distribución: LLA.

\section{Achyrocline}

\section{Achyrocline tomentosa Rusby}

Sinónimos: Achyrocline polycephala Rusby

Subarbusto. Nativo.

Distribución: AYP.

Rango altitudinal: 700-3600 m.

Países limítrofes: Argentina y Bolivia.

\section{Acmella}

Acmella glaberrima (Hassl.) R.K. Jansen

Sinónimos: Spilanthes glaberrima Hassl.

Hierba. Perenne. Introducida.

Distribución: MAU.

Rango altitudinal: 0-500 m.

\section{Acrisione}

Acrisione cymosa (J. Remy) B. Nord.

Sinónimos: Senecio cymosus J. Remy, Senecio lechleri Sch. Bip. nom. Nud.

Arbusto o árbol pequeño. Endémico.

Distribución: VAL, BIO, ARA, LRI, LLA, AIS.

Rango altitudinal: 0-1100 m.

Nombre vulgar: Matico, para ná.

Acrisione denticulata (Hook. \& Arn.) B. Nord. var. denticulata

Sinónimos: Senecio yegua (Colla) Cabrera var. yegua, Cacalia denticulata Hook. \& Arn., Danaa yegua Colla, Senecio denticulatus (Hook. \& Arn.) DC., hom. illeg., Senecio ovalifolius Turcz., Senecio rancaguensis J. Remy, Senecio yegua (Colla) Cabrera var. depilis (Phil.) Cabrera Arbusto. Nativo.

Distribución: COQ, VAL, RME, LBO, MAU, NUB, BIO, ARA, LRI, LLA.

Rango altitudinal: 700-900 m.

Países limítrofes: Argentina.

Nombre vulgar: Palpalen, palo de yegua.

Acrisione denticulata (Hook. \& Arn.) B. Nord. var. pilota (Phil.) B. Nord.

Sinónimos: Senecio denticulatus (Hook. \& Arn.) DC. var. pilotus Phil., Senecio yegua (Colla) Cabrera var. pilotus (Phil.) Cabrera

Arbusto. Endémico.

Distribución: COQ, VAL, RME, LBO, MAU, NUB, BIO, ARA, LLA.

Rango altitudinal: 0-1200 m.

\section{Adenocaulon}

Adenocaulon chilense Less.

Sinónimos: Adenocaulon lechleri Sch. Bip., Boerhavia nudicaulis Phil.

Hierba. Perenne. Nativa.

Distribución: VAL, MAU, NUB, BIO, ARA, LRI, LLA, AIS, MAG.

Rango altitudinal: 0-1000 m.

Países limítrofes: Argentina. 


\section{Ageratum}

Ageratum conyzoides L.

Hierba. Anual o perenne. Introducida.

Distribución: IPA.

Agoseris

Agoseris chilensis (Less.) Greene

Sinónimos: Macrorhynchus chilensis Less., Troximon

chilense (Less.) A. Gray

Hierba. Perenne. Endémica.

Distribución: COQ, VAL, RME, LBO.

Rango altitudinal: 0-1100 m.

Nombre vulgar: Yesquilla.

Agoseris coronopifolia (d'Urv.) K.L. Chambers ex D.M. Moore

Sinónimos: Agoseris australis (Phil.) Macloskie, Agoseris pumila (Gaudich.) Macloskie, Macrorhynchus australis Phil., Macrorhynchus elatus Phil., Macrorhynchus poeppigii DC., Macrorhynchus pumilum (Gaudich.) DC., Taraxacum coronopifolium d'Urv., Taraxacum pumilum Gaudich., Agoseris poeppigii (DC.) Greene, Troximon coronopifolius (d'Urv.) Cabrera, Troximon poepigii (DC.) De Wild., Troximon pumilum (Gaudich.) De Wild.

Hierba. Perenne. Nativa.

Distribución: COQ, VAL, RME, NUB, ARA, LRI, LLA, AIS, MAG.

Rango altitudinal: 0-800 m.

Países limítrofes: Argentina.

\section{Aldama}

Aldama adenotricha (S.F. Blake) E.E. Schill. \& Panero Sinónimos: Viguiera adenotricha S.F. Blake

Hierba. Anual. Endémica.

Distribución: COQ.

Aldama atacamensis (Phil.) E.E. Schill. \& Panero Sinónimos: Viguiera atacamensis Phil., Viguiera linearis Reiche, Rhysolepis atacamensis (Phil.) H. Rob. \& A.J. Moore

Subarbusto. Endémico.

Distribución: AYP, TAR, ANT.

Rango altitudinal: 2800-2900 m.

Aldama helianthoides (Rich.) E.E. Schill. \& Panero Sinónimos: Viguiera pazensis Rusby, Flourensia atacamensis (Phil.) Reiche, Helianthus atacamensis Phil., Sanvitalia helianthoides Rich., Rhysolepis helianthoides (Rich.) H. Rob. \& A.J. Moore

Hierba. Perenne. Nativa.

Distribución: TAR.
Rango altitudinal: 2000-3500 m.

Países limítrofes: Argentina, Bolivia y Perú.

Nombre vulgar: Sorona.

Aldama revoluta (Meyen) E.E. Schill. \& Panero

Sinónimos: Viguiera revoluta (Meyen) S.F. Blake, Flourensia corymbosa DC., Flourensia corymbosa DC. var. araucana (Phil.) Reiche, Helianthus araucanus Phil., Helianthus revolutus Meyen, Viguiera corymbosa (DC.) Blake, Viguiera poeppigii A. Gray, nom. illeg., Viguiera gayana (Phil.) Cabrera ex Espinosa, nom. illeg., Flourensia gayana (Phil.) Reiche, Helianthus gayanus Phil.

Hierba o subarbusto. Perenne. Nativa.

Distribución: AYP, TAR, ATA, COQ, RME, LBO, MAU, NUB, BIO.

Rango altitudinal: 0-1200 m.

Países limítrofes: Argentina.

Nombre vulgar: Botón de oro del monte, china del campo, maravilla.

\section{Amblyopappus}

Amblyopappus pusillus Hook. \& Arn. var. pauciflorus (Phil.) Reiche

Sinónimos: Amblyopappus pauciflorus Phil.

Hierba. Anual. Endémica.

Distribución: ATA.

Nombre vulgar: Manzanilla.

Amblyopappus pusillus Hook. \& Arn. var. pusillus

Sinónimos: Aroma tenuifolia Nutt., Infantea chilensis J.

Remy

Hierba. Anual. Endémica.

Distribución: ANT, ATA, COQ, JFE.

Rango altitudinal: 0-200 m.

Nombre vulgar: Manzanilla.

Nota: Introducida en el Archipiélago Juan Fernández.

\section{Ambrosia}

Ambrosia arborescens Mill.

Arbusto. Introducido.

Distribución: COQ.

Ambrosia artemisioides Meyen \& Walp. ex Meyen Sinónimos: Franseria fruticosa Phil., Franseria meyeniana Sch. Bip.

Arbusto. Nativo.

Distribución: AYP, TAR, ANT.

Rango altitudinal: 1700-4600 m.

Países limítrofes: Bolivia y Perú.

Nombre vulgar: Tikara, pikara, cadillo, monte verde, tola negra, pegapega, lipelipe. 
Ambrosia chamissonis (Less.) Greene

Hierba. Perenne. Introducida.

Distribución: COQ, VAL, LBO, MAU, NUB, BIO, ARA, LRI, LLA.

Ambrosia elatior L.

Hierba. Anual. Introducida.

Distribución: MAU, NUB, BIO.

Ambrosia peruviana Willd.

Hierba. Anual. Introducida.

Distribución: AYP, TAR.

Ambrosia tenuifolia Spreng.

Hierba. Perenne. Introducida.

Distribución: BIO.

\section{Anaphalis}

Anaphalis chilensis Reiche

Sinónimos: Helichrysum chilense Hook. \& Arn.

Hierba. Perenne. Endémica.

Distribución: VAL, RME, LBO, MAU, NUB, BIO, ARA.

Rango altitudinal: 500-800 m.

\section{Antennaria}

Antennaria chilensis J. Remy var. chilensis

Hierba. Perenne. Nativa.

Distribución: COQ, VAL, RME, LBO, MAU, NUB, BIO, ARA, AIS, MAG.

Rango altitudinal: 1600-3000 m.

Países limítrofes: Argentina.

Antennaria chilensis J. Remy var. magellanica (Sch. Bip.)

Reiche

Sinónimos: Antennaria magellanica Sch. Bip.

Hierba. Perenne. Nativa.

Distribución: MAG.

Rango altitudinal: 0-1000 m.

Países limítrofes: Argentina.

\section{Anthemis}

Anthemis arvensis L.

Hierba. Anual o bienal. Introducida.

Distribución: RME, LBO, NUB, BIO, ARA, LLA.

Anthemis cotula L.

Hierba. Anual. Introducida.

Distribución: TAR, ANT, ATA, COQ, VAL, RME, LBO, MAU, NUB, BIO, ARA, LRI, LLA, MAG, JFE.

\section{Aphyllocladus}

Aphyllocladus denticulatus (J. Remy) Cabrera var. calvus (Phil.) Cabrera

Sinónimos: Jobaphes virgatus Phil. var. calvus Phil.

Arbusto. Endémico.

Distribución: AYP, TAR.

Rango altitudinal: 2500-2800 m.

Aphyllocladus denticulatus (J. Remy) Cabrera var. denticulatus

Sinónimos: Cyclolepis denticulata J. Remy, Jobaphes virgatus Phil., Plazia virgata (Phil.) O. Hoffm.

Arbusto. Endémico.

Distribución: ATA.

Rango altitudinal: 700-2700 m.

Nombre vulgar: Piyaya sureña, monte blanco.

\section{Arctium}

Arctium minus (Hill) Bernh.

Hierba. Bienal. Introducida.

Distribución: VAL, RME, LBO, BIO, ARA, LLA.

\section{Arctotheca}

Arctotheca calendula (L.) Levyns

Hierba. Anual o perenne. Introducida.

Distribución: LBO, MAU, NUB, BIO, ARA.

\section{Argyranthemum}

Argyranthemum frutescens (L.) Sch. Bip.

Subarbusto. Introducido.

Distribución: COQ, RME.

Arnica

Arnica angustifolia Vahl

Hierba. Perenne. Introducida.

Distribución: LLA.

\section{Artemisia}

Artemisia absinthium L.

Subarbusto. Introducido.

Distribución: VAL, MAU, NUB, BIO, ARA, LRI, LLA, MAG, JFE.

Artemisia copa Phil. var. copa

Arbusto o árbol pequeño. Nativo.

Distribución: AYP, TAR, ANT, ATA, VAL.

Rango altitudinal: 3000-4700 m. 
Países limítrofes: Argentina.

Nombre vulgar: Copa, kopa, salvia blanca.

Artemisia copa Phil. var. trifida Acevedo

Arbusto. Endémico.

Distribución: ANT.

Rango altitudinal: $2400 \mathrm{~m}$.

Artemisia magellanica Sch. Bip.

Hierba. Perenne. Nativa.

Distribución: MAG.

Rango altitudinal: 0-1500 m.

Países limítrofes: Argentina.

Artemisia verlotorum Lamotte

Hierba. Perenne. Introducida.

Distribución: MAU.

\section{Baccharis}

Baccharis acaulis (Wedd. ex R.E. Fr.) Cabrera

Sinónimos: Heterothalamus acaulis Wedd. ex R.E. Fr., Pseudobaccharis acaulis (Wedd. ex R.E. Fr.) Cabrera, Psila caespitosa Phil., Baccharis acaulis (Wedd. ex R.E. Fr.) Malag., nom. illeg.

Hierba. Perenne. Nativa.

Distribución: TAR, ANT.

Rango altitudinal: 3300-3700 m.

Países limítrofes: Argentina y Bolivia.

Nombre vulgar: Mamañika, qatari, anojarpsike, psike de perro.

Baccharis alnifolia Meyen \& Walp.

Arbusto. Nativo.

Distribución: AYP, TAR, ANT.

Rango altitudinal: 3000-3800 m.

Países limítrofes: Perú.

Nombre vulgar: Chilca blanca, pichana, monte.

Baccharis boliviensis (Wedd.) Cabrera

Sinónimos: Baccharis boliviensis (Wedd.) Cuatrec., comb. illeg., Heterothalamus boliviensis Wedd., Pseudobaccharis boliviensis (Wedd.) Cabrera, Psila boliviensis (Wedd.) Cabrera, Baccharis boliviensis (Wedd.) Malag., comb. illeg. Arbusto. Nativo.

Distribución: AYP, TAR, ANT, ATA, COQ.

Rango altitudinal: 1500-4700 m.

Países limítrofes: Argentina, Bolivia y Perú.

Nombre vulgar: Tolilla, tolita, tola chica, monte de paloma, tola amarilla, tola hembra.

Baccharis caespitosa (Ruiz \& Pav.) Pers. Sinónimos: Molina caespitosa Ruiz \& Pav. Subarbusto. Nativo.
Distribución: AYP, TAR, ANT, LBO.

Rango altitudinal: 3500-4000 m.

Países limítrofes: Argentina, Bolivia y Perú.

Baccharis calliprinos Griseb.

Sinónimos: Pingraea scandens (Ruiz \& Pav.) F.H. Hellwig,

Baccharis petiolata DC., Baccharis petiolata DC. var. rotundifolia Phil., Baccharis scandens auct. non (Ruiz \& Pav.) Pers., Molina scandens Ruiz \& Pav., Baccharis salicifolia (Ruiz \& Pav.) Pers. subsp. calliprinos (Griseb.) Joch.Müll., Baccharis scandens (Ruiz \& Pav.) Pers.

Arbusto. Nativo.

Distribución: TAR, ANT.

Rango altitudinal: 1400-3500 m.

Países limítrofes: Argentina y Perú.

Nombre vulgar: Chilca, chillka, suncho, pichana, sangayo.

Baccharis concava (Ruiz \& Pav.) Pers.

Sinónimos: Baccharis macraei Hook. \& Arn. var. intermedia Heering, Molina concava Ruiz \& Pav.

Arbusto. Endémico.

Distribución: BIO.

Rango altitudinal: 0-300 m.

Nombre vulgar: Vautro, gaultro, guauchu.

Baccharis cymosa Phil.

Sinónimos: Pingraea cymosa (Phil.) F.H. Hellwig

Arbusto. Endémico.

Distribución: LRI.

Rango altitudinal: 1000-1300 m.

Baccharis darwinii Hook. \& Arn.

Sinónimos: Neomolina darwinii (Hook. \& Arn.) F.H. Hellwig, nom. illeg., Baccharis angulata Griseb. var. gracilis Heering

Subarbusto. Nativo.

Distribución: LLA, AIS.

Rango altitudinal: 0-3500 m.

Países limítrofes: Argentina.

Baccharis elaeoides J. Remy

Arbusto. Nativo.

Distribución: LRI, LLA.

Rango altitudinal: 0-3000 m.

Países limítrofes: Argentina.

Baccharis genistelloides (Lam.) Pers.

Sinónimos: Molina venosa Ruiz \& Pav., Baccharis venosa (Ruiz \& Pav.) Pers.

Subarbusto. Nativo.

Distribución: TAR.

Rango altitudinal: $3900 \mathrm{~m}$.

Países limítrofes: Bolivia y Perú. 
Baccharis glutinosa Pers.

Sinónimos: Baccharis angustifolia (Cass.) Desf., nom. illeg., Baccharis pingraea DC. var. angustissima DC., Baccharis pingraea DC. var. pingraea, Baccharis pingraea DC. fma. latifolia DC., Baccharis serrulata (Lam.) Pers. var. pingraea (DC.) Baker, Baccharis viscosa (Ruiz \& Pav.) Kuntze, comb. illeg., Molina viscosa Ruiz \& Pav., Pingraea viscosa (Ruiz \& Pav.) F.H. Hellwig, Baccharis huydobriana J. Remy p.p., Baccharis litoralis Phil., Baccharis longipes Kunze ex DC. var. angustissima Phil., Baccharis glutinosa Pers. var. angustissima (DC.) Giuliano, Baccharis pingraea DC. var. latifolia DC., nom. illeg.

Hierba. Perenne. Nativa.

Distribución: ANT, ATA, COQ, VAL, RME, LBO, MAU, NUB, BIO, ARA, LLA.

Rango altitudinal: 0-2500 m.

Países limítrofes: Argentina, Bolivia y Perú.

Nombre vulgar: Chilca, chilquilla.

Baccharis intermedia DC.

Sinónimos: Baccharis gayana Phil., Baccharis volckmannii Phil.

Arbusto. Endémico.

Distribución: COQ, VAL, RME, LBO.

Rango altitudinal: 0-3000 m.

Baccharis juncea (Cass.) Desf.

Sinónimos: Arrhenachne juncea Cass.

Hierba. Perenne. Nativa.

Distribución: AYP, TAR, ANT, ATA, COQ, VAL, RME, MAU, LRI, LLA, AIS.

Rango altitudinal: 0-3500 m.

Países limítrofes: Argentina y Bolivia.

Nombre vulgar: Suncho, pasto loco, totora, chukchuka, mutumutu.

Baccharis linearis (Ruiz \& Pav.) Pers. subsp. linearis Sinónimos: Baccharis lingulata Kunze ex Less., Baccharis linifolia Meyen, Baccharis rosmarinifolia Hook. \& Arn., Molina linearis Ruiz \& Pav., Baccharis montteana Phil. Arbusto. Nativo.

Distribución: ATA, COQ, VAL, RME, LBO, MAU, NUB, BIO, ARA, LLA.

Rango altitudinal: 0-3000 m.

Países limítrofes: Argentina.

Nombre vulgar: Romerillo, romero, romero de la tierra.

Baccharis linearis (Ruiz \& Pav.) Pers. subsp. pycnocephala F.H. Hellwig

Sinónimos: Baccharis callistemoides Walp., Baccharis rosmarinifolia Hook. \& Arn. var. callistemoides (Walp.) Heering ex Reiche, Baccharis rosmarinifolia Hook. \& Arn. var. subsinuata DC., Baccharis subandina Phil., Baccharis rosmarinifolia Hook. \& Arn. var. subandina (Phil.) Heering
Arbusto. Nativo.

Distribución: VAL, LBO, MAU, NUB, BIO, ARA, LRI.

Rango altitudinal: 0-1700 m.

Países limítrofes: Argentina.

Baccharis lycioides J. Remy

Sinónimos: Baccharis negeri Heering, Baccharis valdiviana Phil.

Arbusto. Nativo.

Distribución: MAU, NUB, BIO, ARA, LRI, LLA.

Rango altitudinal: 0-1500 m.

Países limítrofes: Argentina.

Nombre vulgar: Romerillo.

Baccharis macraei Hook. \& Arn.

Sinónimos: Baccharis macraei Hook. \& Arn. var. lucida Heering

Arbusto. Endémico.

Distribución: COQ, VAL, RME, LBO.

Rango altitudinal: 0-500 m.

Baccharis magellanica (Lam.) Pers.

Sinónimos: Baccharis tricuneata (L.f.) Pers. var. magellanica (Lam.) Cuatrec., Conyza magellanica Lam.

Arbusto. Nativo.

Distribución: MAU, NUB, BIO, ARA, LRI, LLA, AIS, MAG.

Rango altitudinal: 0-3500 m.

Países limítrofes: Argentina.

Baccharis mylodontis F.H. Hellwig

Arbusto. Endémico.

Distribución: MAG.

Rango altitudinal: 0-500 m.

Baccharis neaei DC.

Sinónimos: Baccharis bezanilleana J. Remy, Baccharis bezanilleana J. Remy var. solisii (Phil.) Reiche, Baccharis rhetinodes Meyen \& Walp., Baccharis solieri J. Remy, Baccharis solisii Phil., Baccharis talcareguensis Heering ex Reiche, Baccharis solieri J. Remy var. williamsii (Phil.) Heering, Baccharis williamsii F. Phil. ex Phil.

Arbusto. Nativo.

Distribución: COQ, VAL, RME, LBO, MAU, NUB, BIO, ARA, LRI.

Rango altitudinal: 0-3200 m.

Países limítrofes: Argentina.

Nombre vulgar: Romerillo del monte.

Baccharis nivalis (Wedd.) Sch. Bip. ex Phil.

Sinónimos: Palenia delfinii Phil., Heterothalamus nivalis Wedd., Lucilia dioica Phil.

Hierba. Perenne. Nativa.

Distribución: NUB, ARA, LRI, LLA, AIS, MAG. 
Rango altitudinal: 500-3500 m.

Países limítrofes: Argentina.

Baccharis obovata Hook. \& Arn.

Sinónimos: Baccharis umbelliformis DC., Baccharis foliosa Hook. \& Arn., Baccharis obovata Hook. \& Arn. subsp. umbelliformis (DC.) F.H. Hellwig, Baccharis umbelliformis DC. fma. frigida Heering, nom. illeg., Baccharis umbelliformis DC. var. typica Heering, nom. illeg., Baccharis umbelliformis DC. var. vulgaris Heering, Baccharis umbelliformis DC. var. $B$

Arbusto. Nativo.

Distribución: VAL, RME, LBO, MAU, NUB, BIO, ARA, LRI, LLA, AIS.

Rango altitudinal: 0-3000 m.

Países limítrofes: Argentina.

Nombre vulgar: Chilca, vautro.

Baccharis paniculata DC.

Sinónimos: Baccharis philippii Heering, Neomolina paniculata (DC.) F.H. Hellwig, nom. illeg., Baccharis floribunda Phil., hom. illeg., Baccharis leptocephala Phil., hom. illeg., Nardophyllum paniculatum Phil.

Arbusto. Endémico.

Distribución:ATA, COQ, VAL, RME,LBO,MAU,NUB,BIO.

Rango altitudinal: 0-1000 m.

Baccharis patagonica Hook. \& Arn.

Sinónimos: Baccharis cuneifolia (Lam.) DC., hom. illeg., Conyza cuneifolia Lam.

Arbusto. Nativo.

Distribución: LBO, MAU, NUB, BIO, ARA, LRI, LLA, AIS, MAG, JFE.

Rango altitudinal: 0-3000 m.

Países limítrofes: Argentina.

Baccharis pilcensis F.H. Hellwig

Arbusto. Endémico.

Distribución: MAU, BIO.

Rango altitudinal: 1600-2200 m.

Baccharis poeppigiana DC. subsp. austropedicellata F.H. Hellwig

Arbusto. Nativo.

Distribución: RME, LBO, MAU, BIO.

Rango altitudinal: 2000-2500 m.

Países limítrofes: Argentina.

Baccharis poeppigiana DC. subsp. ocellata (Phil.) F.H. Hellwig

Sinónimos: Baccharis ocellata Phil., Baccharis umbelliformis DC. var. ocellata (Phil.) Heering ex Reiche Arbusto. Nativo.

Distribución: LBO, MAU, NUB, BIO.
Rango altitudinal: 1000-2000 m.

Países limítrofes: Argentina.

Baccharis poeppigiana DC. subsp. poeppigiana

Sinónimos: Baccharis obovata Hook. \& Arn. var. poeppigiana (DC.) Cabrera, Baccharis umbelliformis DC. var. poeppigiana (DC.) Heering ex Reiche, Baccharis pedicellata DC.

Arbusto. Endémico.

Distribución: COQ, VAL, RME.

Rango altitudinal: 2000-3000 m.

Nombre vulgar: Chilca cordillerana.

Baccharis pycnantha Phil.

Sinónimos: Pingraea pycnantha (Phil.) F.H. Hellwig

Arbusto. Endémico.

Distribución: ATA.

Baccharis racemosa (Ruiz \& Pav.) DC.

Sinónimos: Baccharis eupatorioides Hook. \& Arn., Baccharis racemosa (Ruiz \& Pav.) DC. var. eupatorioides (Hook. \& Arn.) Heering ex Reiche, comb. illeg., Molina racemosa Ruiz \& Pav., Neomolina racemosa (Ruiz \& Pav.) Hellwig, Baccharis fastigiata Phil. ex Reiche, Baccharis racemosa (Ruiz \& Pav.) DC. var. angolensis Kuntze, Baccharis racemosa (Ruiz \& Pav.) DC. var. eupatorioides (Hook. \& Arn.) Kuntze, Baccharis rigida Hook. \& Arn., Baccharis racemosa (Ruiz \& Pav.) DC. var. typica Heering, nom. illeg., Baccharis eupatorioides Hook. \& Arn. var. B, Baccharis eupatorioides Hook. \& Arn. var. gama, Baccharis ovata Hook. \& Arn.

Arbusto. Nativo.

Distribución: VAL, RME, LBO, MAU, NUB, BIO, ARA, LRI, LLA.

Rango altitudinal: 0-3000 m.

Países limítrofes: Argentina.

Nombre vulgar: Chilca.

Baccharis rhomboidalis J. Remy

Sinónimos: Baccharis rhomboidalis J. Remy subsp. truncata (Phil.) F.H. Hellwig, Baccharis involucrata Phil., Baccharis nemorosa Phil., Baccharis rhomboidalis J. Remy var. nemorosa (Phil.) Heering ex Reiche

Arbusto. Endémico.

Distribución: ATA, VAL, RME, LBO, MAU, NUB, BIO, ARA, LRI.

Rango altitudinal: 0-3000 m.

Baccharis sagittalis (Less.) DC.

Sinónimos: Molina sagittalis Less., Pingraea sagittalis (Less.) F.H. Hellwig

Subarbusto. Nativo.

Distribución: TAR, ATA, COQ, VAL, RME, LBO, MAU, NUB, BIO, ARA, LRI, LLA, AIS. 
Rango altitudinal: 0-2400 m.

Países limítrofes: Argentina y Bolivia.

Nombre vulgar: Verbena de tres esquinas.

Baccharis salicifolia (Ruiz \& Pav.) Pers.

Sinónimos: Baccharis longipes Kunze ex DC., Baccharis marginalis DC. var. longipes (Kunze ex DC.) Heering, Baccharis viscosa (Ruiz \& Pav.) Kuntze var. nigricans Kuntze, Molina salicifolia Ruiz \& Pav., Baccharis confertifolia Bertero ex Colla, Baccharis kraussei Heering ex Reiche, Baccharis marginalis DC., Baccharis pallida Heering ex Reiche, Pingraea marginalis (DC.) F.H. Hellwig, Pingraea salicifolia (Ruiz \& Pav.) F.H. Hellwig, Baccharis chilquilla DC., nom. illeg., Baccharis araucana Phil., Baccharis cuervii Phil., Baccharis glutinosa Pers. var. incisa Heering, Baccharis huydobriana J. Remy, Baccharis linifolia Phil., hom. illeg., Baccharis marginalis DC. var. araucana (Phil.) Heering, Baccharis marginalis DC. var. linifolia (Phil.) Heering, Baccharis sphaerocephala Hook. \& Arn. var. krausei (Heering) Malag., comb. illeg.

Arbusto. Nativo.

Distribución: AYP, TAR, ANT, ATA, COQ, VAL, RME, LBO, MAU, NUB, BIO, ARA, LRI, LLA.

Rango altitudinal: 0-3500 $\mathrm{m}$.

Países limítrofes: Argentina, Bolivia y Perú.

Nombre vulgar: Chilca, chilquilla, chilquilla del río, suncho, culpío, radín.

Baccharis sessilifolia DC.

Subarbusto. Endémico.

Distribución: VAL, MAU, BIO.

Rango altitudinal: 0-500 m.

Baccharis spartioides (Hook. \& Arn. ex DC.) J. Remy

Sinónimos: Baccharis sarophora Phil., Heterothalamus spartioides Hook. \& Arn. ex DC., Pseudobaccharis spartioides (Hook. \& Arn. ex DC.) Cabrera, Psila spartioides (Hook. \& Arn. ex DC.) Cabrera

Arbusto. Nativo.

Distribución: ATA, COQ.

Rango altitudinal: 0-3000 m.

Países limítrofes: Argentina.

Nombre vulgar: Escoba, hierba de la escoba, pichana.

Baccharis sphaerocephala Hook. \& Arn.

Sinónimos: Pingraea sphaerocephala (Hook. \& Arn.) F.H. Hellwig, Baccharis radin Phil.

Arbusto. Endémico.

Distribución: BIO, ARA, LRI, LLA.

Rango altitudinal: 0-700 m.

Nombre vulgar: Rari.

Baccharis taltalensis I.M. Johnst.

Sinónimos: Neomolina taltalensis (I.M. Johnst.) F.H.
Hellwig, nom. illeg.

Subarbusto. Endémico.

Distribución: ANT, ATA.

Rango altitudinal: 300-900 m.

Baccharis tola Phil. subsp. santelicis (Phil.) Joch. Müller var. chrysophylla (F.H. Hellwig) Joch. Müller

Sinónimos: Baccharis santelicis Phil. subsp. chrysophylla F.H. Hellwig

Arbusto. Nativo.

Distribución: AYP, TAR.

Rango altitudinal: 3000-4600 m.

Países limítrofes: Bolivia.

Baccharis tola Phil. subsp. santelicis (Phil.) Joch. Müller var. incarum (Wedd.) Joch. Müller

Sinónimos: Baccharis santelicis Phil., Baccharis muicrophylla Kunth var. incarum Wedd., Baccharis incarum Wedd.

Arbusto. Nativo.

Distribución: AYP, TAR, ANT.

Rango altitudinal: 1900-4800 m.

Países limítrofes: Argentina, Bolivia y Perú.

Nombre vulgar: Ñaka, lejía, tola lejía, ñakat'ula.

Baccharis tola Phil. subsp. tola var. tola

Sinónimos: Baccharis incarum (Wedd.) Perkins var. lejia (Phil.) Cabrera, Baccharis tola Phil. var. lejia (Phil.) Reiche, Baccharis lejia Phil.

Arbusto. Nativo.

Distribución: ANT, ATA.

Rango altitudinal: 2200-4500 m.

Países limítrofes: Argentina y Bolivia.

Nombre vulgar: Lejia, tola, leña lejía, loire, ñaka.

Baccharis tola Phil. subsp. tola var. viscosissima (Kuntze) Joch. Müller

Sinónimos: Baccharis magellanica (Lam.) Pers. var. viscosissima Kuntze, Baccharis tola Phil. subsp. altiplanicola F.H. Hellwig, Baccharis tola Phil. var. viscosissima (Kuntze) Joch.Müll.

Arbusto. Nativo.

Distribución: TAR, ANT.

Rango altitudinal: 3100-4500 m.

Países limítrofes: Argentina y Bolivia.

Nombre vulgar: Tolita, chachakoma de burro.

Baccharis vernalis F.H. Hellwig

Sinónimos: Baccharis concava (Ruiz \& Pav.) Pers. var. floribunda Heering

Arbusto. Endémico.

Distribución: ATA, COQ, VAL, LBO, MAU, NUB, BIO.

Rango altitudinal: 0-700 m. 
Baccharis zoellneri F.H. Hellwig subsp. minor F.H. Hellwig

Arbusto. Endémico.

Distribución: BIO, ARA.

Rango altitudinal: 800-1400 m.

Baccharis zoellneri F.H. Hellwig subsp. zoellneri

Arbusto. Nativo.

Distribución: ARA, LRI, LLA, AIS, MAG.

Rango altitudinal: 0-1300 m.

Países limítrofes: Argentina.

\section{Bahia}

Bahia ambrosioides Lag.

Sinónimos: Achyropappus maritimus Poepp. ex DC., nom. nud., Stylesia ambrosioides (Lag.) Nutt., Stylesia puberula Nutt., Eriophyllum ambrosioides (Lag.) Kuntze

Subarbusto. Endémico.

Distribución: TAR, ANT, ATA, COQ, VAL, RME, LBO, MAU, NUB, BIO, JFE.

Rango altitudinal: 0-600 m.

Nombre vulgar: Chamicilla, manzanilla cimarroma, chamiza blanca.

Nota: Introducida en el Archipiélago Juan Fernández.

\section{Bellis}

\section{Bellis perennis L.}

Hierba. Perenne. Introducida.

Distribución: COQ, VAL, RME, LBO, MAU, NUB, BIO, ARA, LRI, LLA, MAG.

\section{Belloa}

Belloa chilensis (Hook. \& Arn.) J. Remy

Sinónimos: Chevreulia nivea Phil., Gnaphalium andicola Kuntze, hom. illeg., Lucilia araucana Phil., Lucilia chilensis Hook. \& Arn., Lucilia chilensis Poepp. \& Endl., hom. illeg., Lucilia frigida Reiche, nom. illeg., Lucilia nivea (Phil.) Cabrera

Hierba. Perenne. Nativa.

Distribución: TAR, RME, LBO, MAU, NUB, BIO, ARA, LLA.

Rango altitudinal: 900-2000 m.

Países limítrofes: Argentina.

\section{Bidens}

Bidens aurea (Aiton) Sherff

Hierba. Perenne. Introducida.

Distribución: TAR, ANT, ATA, COQ, VAL, RME, LBO, MAU, NUB, BIO, LRI, LLA, IPA.
Bidens laevis (L.) Britton, Sterns \& Poggenb.

Hierba. Perenne. Introducida.

Distribución: ANT, VAL, RME, LBO, MAU, NUB, BIO, ARA, LLA.

Bidens pilosa L. var. alausensis (Kunth) Sherff

Sinónimos: Bidens alausensis Kunth, Bidens valparadisiaca Colla, Bidens chilensis DC.

Hierba. Anual. Nativa.

Distribución: TAR, COQ, VAL, RME, LBO, BIO, JFE.

Rango altitudinal: 0-2800 m.

Países limítrofes: Bolivia y Perú.

Bidens pilosa L. var. apiifolia (DC.) Sherff

Sinónimos: Bidens chilensis DC. var. apiifolia DC.

Hierba. Anual. Endémica.

Distribución: ATA, COQ, VAL, RME, LBO.

Rango altitudinal: 0-1300 m.

Bidens pilosa L. var. pilosa

Hierba. Anual. Introducida.

Distribución: AYP, TAR, ANT, ATA, COQ, VAL, RME, LBO, MAU, NUB, BIO, ARA, JFE, IPA.

Bidens pseudocosmos Sherff

Hierba. Anual. Nativa.

Distribución: ANT, COQ.

Rango altitudinal: $2900-3400 \mathrm{~m}$.

Países limítrofes: Argentina, Bolivia y Perú.

Nombre vulgar: Amor seco.

Bidens subalternans DC.

Sinónimos: Bidens quadrangularis DC.

Hierba. Anual. Nativa.

Distribución: AYP, TAR, ANT.

Rango altitudinal: 0-1500 m.

Países limítrofes: Argentina y Bolivia.

Bidens triplinervia Kunth var. macrantha (Wedd.) Sherff

Sinónimos: Bidens macrantha Griseb., Bidens humilis

Wedd. var. macrantha Wedd.

Hierba. Perenne. Nativa.

Distribución: AYP, TAR, ANT.

Rango altitudinal: 1000-3300 m.

Países limítrofes: Argentina, Bolivia y Perú.

Nombre vulgar: Flor amarilla.

Bidens triplinervia Kunth var. triplinervia

Sinónimos: Bidens pedunculata Phil.

Hierba. Perenne. Nativa.

Distribución: AYP.

Rango altitudinal: 2000-2500 m.

Países limítrofes: Argentina, Bolivia y Perú. 


\section{Blennosperma}

Blennosperma chilense Less.

Sinónimos: Soliva radiata Poepp. ex Less., Unxia anthemidifolia Bertero ex Colla, Unxia anthemidifolia Bertero ex Less., Apalus anthemifolius (Bertero ex Colla) DC.

Hierba. Anual. Endémica.

Distribución: VAL, RME, LBO, MAU, NUB, BIO, ARA.

Rango altitudinal: 0-1700 m.

\section{Brachyclados}

Brachyclados caespitosus (Phil.) Speg.

Sinónimos: Brachyclados obtusifolius Kuntze, Brachyclados pygmaeus Kuntze, Lavidia caespitosa Phil.

Subarbusto. Nativo.

Distribución: MAG.

Rango altitudinal: 0-500 m.

Países limítrofes: Argentina.

Brachyclados lycioides D. Don

Sinónimos: Baucis lavandulifolia Phil., Brachyclados involutus Kuntze, Brachyclados macrocephalus Kuntze

Arbusto. Nativo.

Distribución: COQ, VAL.

Rango altitudinal: 0-2000 m.

Países limítrofes: Argentina.

\section{Calendula}

Calendula arvensis L.

Hierba. Anual. Introducida.

Distribución: COQ, VAL, RME, BIO.

\section{Calendula officinalis L.}

Hierba. Anual o bienal. Introducida.

Distribución: COQ, VAL, RME, BIO, JFE.

Calendula tripterocarpa Rupr.

Hierba. Anual. Introducida.

Distribución: COQ.

\section{Calopappus}

\section{Calopappus acerosus Meyen}

Sinónimos: Nassauvia remyana Wedd., Calopappus acanthifolius J. Remy, Nassauvia acanthifolia (J. Remy) G.F. Grandjot, Nassauvia acerosa (Meyen) Wedd.

Hierba. Perenne. Endémica.

Distribución: COQ, VAL, RME, LBO, MAU.

Rango altitudinal: 2300-3200 m.

\section{Calyptocarpus}

Calyptocarpus vialis Less.

Hierba. Perenne. Introducida.

Distribución: IPA.

\section{Carduus}

\section{Carduus nutans L.}

Hierba. Bienal. Introducida.

Distribución: VAL, RME, ARA.

Carduus pycnocephalus L.

Hierba. Anual o bienal. Introducida.

Distribución: COQ, VAL, RME, LBO, MAU, NUB, BIO, ARA, LRI, LLA, JFE.

Carduus tenuiflorus Curtis

Hierba. Anual o bienal. Introducida.

Distribución: VAL.

Carduus thoermeri Weinm.

Hierba. Anual. Introducida.

Distribución: VAL, RME, LBO, ARA, AIS, MAG.

\section{Carthamus}

\section{Carthamus lanatus L.}

Hierba. Anual. Introducida.

Distribución: COQ, VAL, RME, LBO, MAU, NUB, BIO, ARA, JFE.

\section{Carthamus tinctorius L.}

Hierba. Anual. Introducida.

Distribución: COQ, RME, BIO.

\section{Centaurea}

Centaurea atacamensis (Reiche) I.M. Johnst.

Sinónimos: Centaurea floccosa Hook. \& Arn. var. atacamensis Reiche, Centaurea atacamensis (Reiche) Ravenna, comb. illeg.

Arbusto. Endémico.

Distribución: ANT, ATA, VAL.

Rango altitudinal: 0-100 m.

Centaurea benedicta (L.) L.

Hierba. Anual. Introducida.

Distribución: VAL, RME, MAU.

Centaurea bulbosa Hook. \& Arn.

Sinónimos: Centaurea dianthoides J. Remy

Hierba. Perenne. Endémica. 
Distribución: COQ, VAL, BIO, ARA, LLA.

Rango altitudinal: 0-700 m.

Centaurea cachinalensis Phil.

Arbusto. Endémico.

Distribución: ANT, ATA, COQ.

Rango altitudinal: 0-2800 m.

\section{Centaurea calcitrapa L.}

Hierba. Anual o bienal. Introducida.

Distribución: VAL, RME, LBO, MAU, NUB, BIO, ARA, LRI, LLA.

Centaurea chilensis Hook. \& Arn. var. breviloba DC.

Subarbusto. Endémico.

Distribución: COQ, VAL.

Centaurea chilensis Hook. \& Arn. var. chilensis

Subarbusto. Endémico.

Distribución: ATA, COQ, VAL, RME, LBO.

Rango altitudinal: 1500-3500 m.

Nombre vulgar: Hierba o flor del minero.

Centaurea chilensis Hook. \& Arn. var. stenolepis Phil.

Subarbusto. Endémico.

Distribución: ATA, COQ.

Rango altitudinal: 0-100 m.

Centaurea cyanus L.

Hierba. Anual. Introducida.

Distribución: RME, AIS.

Centaurea floccosa Hook. \& Arn.

Sinónimos: Centaurea illapelina Phil.

Subarbusto. Endémico.

Distribución: ATA, COQ, VAL.

Rango altitudinal: 0-2900 m.

Centaurea gayana J. Remy

Hierba. Perenne. Endémica.

Distribución: ATA, COQ.

Centaurea jacea L.

Hierba. Perenne. Introducida.

Distribución: ARA.

\section{Centaurea melitensis L.}

Hierba. Anual o bienal. Introducida.

Distribución: AYP, TAR, ANT, ATA, COQ, VAL, RME, LBO, MAU, NUB, BIO, ARA, LRI, LLA, MAG, JFE, IPA.

Centaurea monocephala J. Remy

Hierba. Perenne. Endémica.

Distribución: BIO.
Centaurea nigra L.

Hierba. Perenne. Introducida.

Distribución: ARA.

Centaurea solstitialis L.

Hierba. Anual o bienal. Introducida.

Distribución: VAL, RME, LBO, MAU.

\section{Centaurodendron}

Centaurodendron dracaenoides Johow

Sinónimos: Plectocephalus dracaenoides (Johow) F.H.

Hellwig

Arbusto o árbol pequeño. Endémico.

Distribución: JFE.

Rango altitudinal: 0-500 m.

Centaurodendron palmiforme Skottsb.

Arbusto o árbol pequeño. Endémico.

Distribución: JFE.

Rango altitudinal: 0-500 m.

\section{Centipeda}

Centipeda elatinoides (Less.) Benth. \& Hook.f. ex O. Hoffm. Sinónimos: Myriogyne elatinoides Less.

Hierba. Perenne. Nativa.

Distribución: COQ, LBO, MAU, NUB, BIO, ARA, LRI, LLA.

Rango altitudinal: 500-1000 m.

Países limítrofes: Argentina.

Nombre vulgar: Pedorilla, peorrilla.

\section{Chaetanthera}

Chaetanthera albiflora (Phil.) A.M.R. Davies

Sinónimos: Chaetanthera linearis Poepp. ex Less. var. albiflora Phil., Chaetanthera linearis Poepp. ex Less. var. taltalensis I.M. Johnst., Chaetanthera microphylla (Cass.) Hook. \& Arn. var. albiflora (Phil.) Cabrera, Chaetanthera linifolia Bertero ex Less. var. albiflora Phil., Chaetanthera albiflora Phil., nom. illeg.

Hierba. Anual. Endémica.

Distribución: ANT, ATA, COQ, VAL.

Rango altitudinal: 1600-1800 m.

Chaetanthera chilensis (Willd.) DC. var. chilensis Sinónimos: Chaetanthera chilensis (Willd.) DC. var. argentea (Phil.) Cabrera, Chaetanthera chilensis (Willd.) DC. var. involucrata (Phil.) Cabrera, Chaetanthera argentea D. Don, p.p. Chaetanthera argentea Phil., hom. illeg., Chaetanthera collina Phil., Chaetanthera eryngioides D. Don, Chaetanthera grandiflora Steud., Chaetanthera nana Phil., Chaetanthera sericea Lag., Chaetanthera serrata Ruiz \& Pav. var. argentea (Phil.) Reiche, Chaetanthera 
serrata Ruiz \& Pav. var. nana (Phil.) Reiche, Chaetanthera sublignosa Kuntze, Perdicium chilense Willd., Chaetanthera involucrata Phil., Chaetanthera tenuifolia D. Don var. eryngioides (D. Don) Hook. \& Arn.

Hierba. Perenne. Nativa.

Distribución: COQ, VAL, RME, LBO, MAU, NUB, BIO, ARA.

Rango altitudinal: 0-2500 m.

Países limítrofes: Argentina.

Chaetanthera chilensis (Willd.) DC. var. tenuifolia (D. Don) Cabrera

Sinónimos: Chaetanthera argentea D. Don, p.p., Chaetanthera tenuifolia D. Don

Hierba. Perenne. Nativa.

Distribución: COQ, VAL, LBO, MAU, NUB, BIO.

Países limítrofes: Argentina.

Chaetanthera ciliata Ruiz \& Pav.

Hierba. Anual. Endémica.

Distribución: VAL, RME, LBO, MAU, NUB, BIO, ARA.

Rango altitudinal: 0-1200 m.

Chaetanthera depauperata (Hook. \& Arn.) A.M.R. Davies Sinónimos: Chaetanthera linifolia Bertero ex Less. var. depauperata (Hook. \& Arn.) DC., Chaetanthera leptocephala Cabrera, Chaetanthera microphylla (Cass.) Hook. \& Arn. var. depauperata Hook. \& Arn.

Hierba. Anual. Endémica.

Distribución: ATA, COQ, VAL, RME.

Rango altitudinal: 700-2900 m.

Chaetanthera elegans Phil. var. elegans

Sinónimos: Chaetanthera elata Phil., Chaetanthera brachylepis Phil., Chaetanthera valdiviana Phil., Chaetanthera humilis Phil., Chaetanthera serrata Ruiz \& Pav. var. humilis (Phil.) Reiche, Chaetanthera volckmanni Phil.

Hierba. Perenne. Nativa.

Distribución: LBO, MAU, NUB, BIO, ARA, LLA.

Rango altitudinal: 1500-2000 m.

Países limítrofes: Argentina.

Nombre vulgar: China.

Chaetanthera elegans Phil. var. pratensis (Phil.) Cabrera Sinónimos: Chaetanthera andina Phil., Chaetanthera andina Phil. var. pratensis (Phil.) Reiche, Chaetanthera araucana Phil., Chaetanthera comata Phil., Chaetanthera elegans Phil. var. andina (Phil.) Cabrera, Chaetanthera foliosa Phil., Chaetanthera montana Phil., Chaetanthera pratensis Phil.

Hierba. Perenne. Nativa.

Distribución: MAU, NUB, BIO, ARA.

Países limítrofes: Argentina.
Chaetanthera elegans Phil. var. pulchra Cabrera

Hierba. Perenne. Nativa.

Distribución: MAU, NUB, BIO, ARA.

Países limítrofes: Argentina.

Chaetanthera euphrasioides (DC.) F. Meigen

Sinónimos: Chaetanthera debilis Meyen \& Walp., Elachia euphrasioides DC., Chaetanthera euphrasioides Reiche var. spinulosa (Phil.) Reiche, Elachia spinulosa Phil., Chaetanthera euphrasioides Reiche, hom. illeg., Tylloma euphrasioides (DC.) Wedd.

Hierba. Anual. Nativa.

Distribución: COQ, VAL, RME, LBO, MAU, BIO.

Rango altitudinal: 1200-3700 m.

Países limítrofes: Argentina.

Chaetanthera flabellata D. Don

Sinónimos: Chaetanthera multicaulis DC. var. prostata DC., Chaetanthera prostrata D. Don, Elachia euphrasioides Deless. non DC., hom. illeg., Chaetanthera flabellata D. Don var. prostrata (D. Don) Hook. \& Arn.

Hierba. Anual. Endémica.

Distribución: VAL, RME, MAU.

Rango altitudinal: 1600-2600 m.

Chaetanthera flabellifolia Cabrera

Sinónimos: Pachylaena elegans Phil.

Hierba. Anual. Endémica.

Distribución: COQ.

Rango altitudinal: 3000-3500 m.

Chaetanthera frayjorgensis A.M.R. Davies

Sinónimos: Tylloma brachylepis Phil., Tylloma glabratum

DC. var. brachylepis (Phil.) Reiche, Tylloma glabratum

DC. var. microphyllum Phil.

Hierba. Anual. Endémica.

Distribución: ATA, COQ.

Rango altitudinal: 0-500 $\mathrm{m}$.

Chaetanthera glabrata (DC.) F. Meigen

Sinónimos: Tylloma glabratum DC., Tylloma glabratum DC. var. rotundifolium (Phil.) Reiche, Tylloma glabratum DC. var. stolpi (Phil.) Reiche, Tylloma glabratum DC. var. strictum (Phil.) Reiche, Tylloma rotundifolium Phil., Tylloma stolpi Phil.

Hierba. Anual o perenne. Endémica.

Distribución: ANT, ATA, COQ, VAL, RME, LBO.

Rango altitudinal: 0-3000 m.

Chaetanthera glandulosa J. Remy var. glandulosa

Sinónimos: Tiltilia pungens Phil. ex Reiche, nom. nud.

Subarbusto. Endémico.

Distribución: COQ, VAL, RME.

Rango altitudinal: 1000-3000 m. 
Chaetanthera glandulosa J. Remy var. gracilis A.M.R. Davies

Subarbusto. Endémico.

Distribución: VAL.

Rango altitudinal: 1000-2000 m.

Chaetanthera incana Poepp. ex Less.

Sinónimos: Chaetanthera incana Poepp. ex Less. var. spathulata DC., Chaetanthera obtusata Phil., Chaetanthera scariosa D. Don, Chaetanthera spathulata Poepp. ex Less., Chaetanthera chilensis Hook. \& Arn., hom. illeg.

Hierba. Anual. Endémica.

Distribución: COQ, VAL, RME.

Rango altitudinal: 0-500 m.

Chaetanthera kalinae A.M.R. Davies

Hierba. Anual. Endémica.

Distribución: ATA, COQ.

Rango altitudinal: 2300-3100 m.

Chaetanthera lanata (Phil.) I.M. Johnst.

Sinónimos: Chaetanthera philippii B.L. Rob., Chondrochilus grandiflorus Phil., Chondrochilus involucratus Phil., Chondrochilus lanatus Phil., Tylloma lanatum Phil., Tylloma involucratum (Phil.) Reiche

Hierba. Perenne. Nativa.

Distribución: ANT, ATA, COQ, VAL, RME.

Rango altitudinal: 2600-3900 m.

Países limítrofes: Argentina.

Chaetanthera limbata (D. Don) Less.

Sinónimos: Chaetanthera schroederi G.F. Grandjot \& K. Grandjot, Tylloma ciliatum Phil., Tylloma eurylepis Phil., Tylloma glabratum DC. var. eurylepis (Phil.) Reiche, Tylloma limbatum D. Don, Tylloma strictum Phil.

Hierba. Anual. Nativa.

Distribución: ANT, ATA, COQ, VAL, RME, LBO.

Rango altitudinal: 0-2500 m.

Países limítrofes: Argentina.

Chaetanthera linearis Poepp. ex Less.

Sinónimos: Chaetanthera kunthiana Less. p.p., Chaetanthera linearifolia Poepp. ex Steud., nom. nud.

Hierba. Anual. Endémica.

Distribución: AYP, ANT, ATA, COQ, VAL, RME, LBO, MAU.

Rango altitudinal: 0-2000 m.

Chaetanthera microphylla (Cass.) Hook. \& Arn.

Sinónimos: Chaetanthera linifolia Bertero ex Less., Chaetanthera salsoloides (D. Don) Kuntze, Cherina microphylla Cass., Onoseris linifolia Bertero, nom. nud., Euthrixia salsoloides D. Don, Chaetanthera delicatula Phil., Chaetanthera pentapetala Phil., Euthrixia affinis D. Don
Hierba. Anual. Nativa.

Distribución: ATA, COQ, VAL, RME, LBO, MAU, NUB, BIO.

Rango altitudinal: 0-1600 m.

Países limítrofes: Argentina.

Chaetanthera moenchioides Less.

Sinónimos: Chaetanthera moenchioides Less. var. pauciflora F. Meigen, Chaetanthera moenchioides Less. var. sulphurea F. Meigen, Chaetanthera tenuifolia Deless., hom. illeg., Chaetanthera albicans Bertero, nom. nud.

Hierba. Anual. Nativa.

Distribución: ATA, COQ, VAL, RME, LBO, MAU, NUB, BIO, ARA, LLA.

Rango altitudinal: 0-2300 m.

Países limítrofes: Argentina.

Chaetanthera multicaulis DC.

Hierba. Anual. Endémica.

Distribución: VAL, RME, LBO.

Rango altitudinal: 0-1500 m.

Chaetanthera perpusilla (Wedd.) Anderb. \& S.E. Freire

Sinónimos: Chaetanthera aymarae Martic. \& Quezada, Luciliopsis perpusilla Wedd.

Hierba. Anual. Nativa.

Distribución: AYP, TAR.

Rango altitudinal: 2200-3300 m.

Países limítrofes: Bolivia.

Nombre vulgar: Pasto de lluvia.

Chaetanthera peruviana A. Gray

Hierba. Anual. Nativa.

Distribución: AYP.

Rango altitudinal: 2700-3900 m.

Países limítrofes: Perú.

Chaetanthera pubescens A.M.R. Davies

Hierba. Anual. Endémica.

Distribución: ATA, COQ.

Rango altitudinal: 600-3500 m.

Chaetanthera ramosissima D. Don

Sinónimos: Chaetanthera tenella Less. var. tenella, Chaetanthera berteriana Colla, hom. illeg., Minythodes umbellata Phil., Chaetanthera kunthiana Less. p.p

Hierba. Anual. Endémica.

Distribución: ATA, COQ, VAL, RME, LBO, MAU.

Rango altitudinal: 0-1000 m.

Chaetanthera renifolia (J. Remy) Cabrera

Sinónimos: Chaetanthera crenata (Phil.) F. Meigen, comb. illeg., Chondrochilus crenatus Phil., Elachia renifolia J. Remy, Tylloma renifolium (J. Remy) Wedd. 
Hierba. Anual. Endémica.

Distribución: RME.

Rango altitudinal: 2000-4000 m.

Chaetanthera serrata Ruiz \& Pav.

Sinónimos: Chaetanthera spinulosa Cass., Proselia serrata

(Ruiz \& Pav.) D. Don

Hierba. Perenne. Endémica.

Distribución: VAL, RME, LBO, MAU, NUB, BIO, ARA, LRI.

Rango altitudinal: 0-1500 m.

\section{Chaetanthera spathulifolia Cabrera}

Sinónimos: Carmelita spathulata Phil., Chaetanthera spathulata (Phil.) Hauman, comb. illeg.

Hierba. Perenne. Nativa.

Distribución: COQ, VAL.

Rango altitudinal: 2700-4100 m.

Países limítrofes: Argentina.

Chaetanthera splendens (J. Remy) B.L. Rob.

Sinónimos: Elachia splendens J. Remy, Tylloma splendens (J. Remy) Wedd.

Hierba. Anual. Nativa.

Distribución: COQ, RME.

Rango altitudinal: 2500-4000 m.

Países limítrofes: Argentina.

Chaetanthera taltalensis (Cabrera) A.M.R. Davies

Sinónimos: Chaetanthera tenella Less. var. taltalensis Cabrera

Hierba. Anual. Endémica.

Distribución: ANT, ATA, COQ.

Rango altitudinal: 0-500 m.

Chaetanthera villosa D. Don

Sinónimos: Carmelita formosa Gay ex DC.

Hierba. Perenne. Nativa.

Distribución: RME, LBO, MAU, NUB, BIO, ARA.

Rango altitudinal: 1000-3000 m.

Países limítrofes: Argentina.

\section{Chaptalia}

Chaptalia exscapa (Pers.) Baker var. chilensis (DC.) Burkart

Sinónimos: Gerbera chilensis (DC.) Sch. Bip., Thyrsanthema chilensis (DC.) Kuntze, Loxodon chilensis DC.

Hierba. Perenne. Endémica.

Distribución: VAL, RME, LBO, MAU, NUB, BIO, ARA.

Rango altitudinal: 0-500 $\mathrm{m}$.

\section{Chersodoma}

Chersodoma arequipensis (Cuatrec.) Cuatrec.

Sinónimos: Senecio arequipensis Cuatrec., Chersodoma

longipedicellata Ricardi \& Martic.

Subarbusto. Nativo.

Distribución: AYP, TAR, ANT.

Rango altitudinal: 3200-3700 m.

Países limítrofes: Perú.

Nombre vulgar: Chachakoma blanca, coquilla.

Chersodoma candida Phil.

Sinónimos: Senecio chersodomus Reiche, nom. nud., Senecio oxyodon Phil.

Arbusto. Nativo.

Distribución: AYP, TAR, ANT.

Rango altitudinal: 3600-4200 m.

Países limítrofes: Argentina y Bolivia.

Chersodoma jodopappa (Sch. Bip.) Cabrera

Sinónimos: Senecio jodopappus Sch. Bip. ex Wedd., nom. illeg., Senecio jodopappus Sch. Bip.

Arbusto. Nativo.

Distribución: AYP, TAR, ANT.

Rango altitudinal: 3000-4300 m.

Países limítrofes: Argentina, Bolivia y Perú.

Nombre vulgar: Chachakoma blanca, poq'ot'ula, coquilla.

\section{Chevreulia}

Chevreulia diemii Cabrera

Hierba. Perenne. Nativa.

Distribución: MAU, ARA, LLA.

Rango altitudinal: 0-1600 m.

Países limítrofes: Argentina.

Chevreulia lycopodioides (d'Urv.) DC.

Sinónimos: Gnaphalium lycopodioides d'Urv.

Hierba. Perenne. Nativa.

Distribución: ARA, LLA.

Rango altitudinal: 0-500 m.

Países limítrofes: Argentina.

Chevreulia pusilla DC.

Sinónimos: Chevreulia lanceolata J. Remy

Hierba. Perenne. Nativa.

Distribución: VAL, LBO, NUB, BIO, ARA, LRI, LLA.

Rango altitudinal: 0-500 m.

Países limítrofes: Argentina.

Chevreulia sarmentosa (Pers.) S.F. Blake

Sinónimos: Chevreulia stolonifera Cass., nom. illeg., Chevreulia thouarsii J. Remy, nom. illeg., Tussilago sarmentosa Pers., Chaptalia sarmentosa (Pers.) S.F. Blake 
Hierba. Perenne. Nativa.

Distribución: BIO, ARA, LRI, LLA.

Rango altitudinal: 0-1700 m.

Países limítrofes: Argentina y Bolivia.

Nombre vulgar: Pasto dulce.

\section{Chiliotrichum}

Chiliotrichum diffusum (G. Forst.) Kuntze

Sinónimos: Amellus diffusus G. Forst., Aster magellanicus Spreng., hom. illeg., Chiliotrichum rosmarinifolium Less., Chiliotrichum amelloideum Cass., nom. illeg., Chiliotrichum amelloideum Cass., nom. illeg. var. lanceolatum Nees, Chiliotrichum amelloideum Cass., nom. illeg. var. rosmarinifolium (Less.) Nees, Chiliotrichum diffusum (G. Forst.) Kuntze var. angustifolium Speg., Chiliotrichum diffusum (G. Forst.) Kuntze var. media Speg., Chiliotrichum longifolium Phil., Chiliotrichum virgatum Phil., Chiliotrichum feliciae Hombr. \& Jacq., Chiliotrichum angustifolium Phil., Chiliotrichum tenue Phil., Tropidolepis diffusa (G. Forst.) Tausch, Chiliotrichum amelloideum Cass., nom. illeg. var. diffusum (G. Forst.) Nees, Chiliotrichum diffusum (G. Forst.) Kuntze fma. typica Speg., nom. illeg. Arbusto. Nativo.

Distribución: LBO, MAU, NUB, BIO, ARA, LLA, AIS, MAG.

Rango altitudinal: 0-2700 m.

Países limítrofes: Argentina.

Nombre vulgar: Fascine, romerillo.

Chiliotrichum fuegianum (O. Hoffm.) Bonifacino Sinónimos: Chiliophyllum fuegianum O. Hoffm.

Arbusto. Nativo.

Distribución: MAG.

Rango altitudinal: 0-300 m.

Países limítrofes: Argentina.

\section{Chrysanthemoides}

Chrysanthemoides monilifera (L.) Norl.

Arbusto. Introducido.

Distribución: VAL, RME.

\section{Chrysanthemum}

\section{Chrysanthemum coronarium $\mathrm{L}$.}

Hierba. Anual. Introducida.

Distribución: ATA, COQ, VAL, MAU, BIO, JFE.

Chrysanthemum segetum $\mathrm{L}$.

Hierba. Anual. Introducida.

Distribución: LLA.

\section{Chuquiraga}

Chuquiraga atacamensis Kuntze

Sinónimos: Chuquiraga glabra Phil., nom. illeg.

Arbusto. Nativo.

Distribución: AYP, TAR, ANT, ATA.

Rango altitudinal: 3000-4500 m.

Países limítrofes: Argentina y Bolivia.

Nombre vulgar: Tajtará, quebraolla, azafrán, lengua de gallo, rezongón.

Chuquiraga kuschelii Acevedo

Arbusto. Endémico.

Distribución: AYP.

Rango altitudinal: 2900-3900 m.

\section{Chuquiraga oppositifolia D. Don}

Sinónimos: Barnadesia flavescens Meyen, Chuquiraga alpina Poepp. ex Less., Chuquiraga chrysantha Field \& Gardner, Chuquiraga oppositifolia D. Don var. angustifolia Ces., Chuquiraga oppositifolia D. Don var. macrantha J. Remy

Arbusto. Nativo.

Distribución: COQ, VAL, RME, LBO, MAU.

Rango altitudinal: $1500-2500 \mathrm{~m}$.

Países limítrofes: Argentina.

Nombre vulgar: Hierba blanca.

Chuquiraga spinosa Less. subsp. australis C. Ezcurra

Arbusto. Nativo.

Distribución: ANT, ATA.

Rango altitudinal: 3500-4500 m.

Países limítrofes: Argentina y Bolivia.

Nombre vulgar: Ch'ana, chinchillawa macho.

Chuquiraga spinosa Less. subsp. rotundifolia (Wedd.) C. Ezcurra

Sinónimos: Chuquiraga rotundifolia Wedd.

Hierba. Perenne. Nativa.

Distribución: AYP, TAR, ANT.

Rango altitudinal: 3500-4500 m.

Países limítrofes: Bolivia y Perú.

Chuquiraga ulicina (Hook. \& Arn.) Hook. \& Arn. subsp. acicularis (D. Don) C. Ezcurra

Sinónimos: Chuquiraga acicularis D. Don, Chuquiraga revoluta Fielding \& Gardner

Arbusto. Endémico.

Distribución: ATA, COQ, VAL, RME.

Rango altitudinal: 0-1200 m.

Chuquiraga ulicina (Hook. \& Arn.) Hook. \& Arn. subsp. ulicina

Sinónimos: Chuquiraga incana D. Don, Chuquiraga 
ulicina (Hook. \& Arn.) Hook. \& Arn. var. incana (Phil.) I.M. Johnst., Barnadesia ulicina Hook. \& Arn., Chuquiraga incana Phil., nom. illeg.

Arbusto. Endémico.

Distribución: TAR, ANT, ATA, COQ.

Rango altitudinal: 0-1700 m.

Nombre vulgar: Hierba de la yesca, araña de la ballena.

\section{Cichorium}

Cichorium intybus L.

Hierba. Anual o bienal. Introducida.

Distribución: ATA, COQ, VAL, RME, LBO, MAU, NUB, BIO, ARA, LRI, LLA, MAG, JFE, IPA.

\section{Cirsium}

Cirsium arvense (L.) Scop.

Hierba. Anual. Introducida.

Distribución: VAL, RME, NUB, BIO, ARA, AIS, MAG.

Cirsium vulgare (Savi) Ten.

Hierba. Anual o bienal. Introducida.

Distribución: COQ, VAL, RME, LBO, MAU, NUB, BIO, ARA, LRI, LLA, AIS, MAG, JFE, IPA.

\section{Cladanthus}

Cladanthus mixtus (L.) Chevall.

Hierba. Anual. Introducida.

Distribución: VAL, BIO.

\section{Coleostephus}

Coleostephus myconis (L.) Cass.

Hierba. Anual. Introducida.

Distribución: MAU, ARA, AIS.

\section{Conyza}

Conyza andina J. Remy

Sinónimos: Conyza dumetorum Phil., Conyza hirtella (DC.) Martic., nom. illeg., Conyza arvensis Phil., Erigeron hirtellus DC.

Hierba. Perenne. Endémica.

Distribución: COQ, VAL, RME.

Rango altitudinal: 0-500 m.

Conyza arabidifolia J. Remy

Sinónimos: Conyza paulsenii Phil., Conyza asperula Phil., Conyza coxi Phil.

Hierba. Perenne. Endémica.

Distribución: VAL, RME, LBO.

Rango altitudinal: 1500-2000 m.
Conyza bonariensis (L.) Cronquist var. angustifolia (Cabrera) Cabrera

Sinónimos: Conyza linearis DC., Erigeron bonariensis L. var. angustifolius Cabrera

Hierba. Anual. Nativa.

Distribución: VAL.

Rango altitudinal: 0-3000 m.

Países limítrofes: Argentina.

Conyza bonariensis (L.) Cronquist var. bonariensis

Sinónimos: Conyza hispida Kunth, Conyza plebeja Phil., Erigeron bonariensis L., Erigeron bonariensis L. fma. grisea Chodat, Marsea bonariensis (L.) V.M. Badillo

Hierba. Anual. Nativa.

Distribución: AYP, TAR, ANT, ATA, COQ, VAL, RME, LBO, MAU, NUB, BIO, ARA, LLA, AIS, MAG, JFE, IPA. Rango altitudinal: 0-2000 m.

Países limítrofes: Argentina, Bolivia y Perú.

Nombre vulgar: Puringa hiva (Rapa Nui).

Nota: Introducida en el Archipiélago Juan Fernández y en la Isla de Pascua.

Conyza bustillosiana J. Remy

Hierba. Anual. Endémica.

Distribución: VAL, RME.

Conyza copiapina Phil.

Hierba. Anual. Endémica.

Distribución: ATA.

Rango altitudinal: 200-1500 m.

Conyza depilis Phil.

Hierba. Perenne. Endémica.

Distribución: BIO.

Rango altitudinal: 0-500 m.

Conyza deserticola Phil.

Hierba. Perenne. Nativa.

Distribución: AYP, TAR, ANT.

Rango altitudinal: 2000-4400 m.

Países limítrofes: Argentina, Bolivia y Perú.

Nombre vulgar: Maransela, anojarjinchu, oreja de perro.

Conyza foliosa Phil.

Hierba. Perenne. Endémica.

Distribución: ARA.

Conyza gayana Phil.

Sinónimos: Conyza consanguinea Phil., Erigeron consanguineus (Phil.) Cabrera, Conyza araucana Phil., Conyza canescens Phil., Conyza monticola Phil., Conyza vulgaris Phil., hom. illeg., Erigeron stenophyllus Hook. \& Arn.

Hierba. Perenne. Endémica. 
Distribución: COQ, VAL, RME, LBO, MAU, NUB, BIO, ARA, LLA, MAG.

Rango altitudinal: 0-500 m.

Conyza glabrata Phil.

Hierba. Anual o bienal. Endémica.

Distribución: RME.

Rango altitudinal: $1000 \mathrm{~m}$.

\section{Conyza larrainiana J. Remy}

Sinónimos: Conyza conglomerata Phil., Conyza pratensis Phil., Erigeron larrainianus (J. Remy) Cabrera

Hierba o subarbusto. Perenne. Nativa.

Distribución: LLA, AIS, MAG.

Rango altitudinal: 500-1000 m.

Países limítrofes: Argentina.

\section{Conyza lateralis Phil.}

Hierba. Perenne. Endémica.

Distribución: COQ, RME.

Rango altitudinal: 500-600 m.

Conyza lechleri (Sch. Bip.) Cabrera

Sinónimos: Erigeron lechleri Sch. Bip.

Hierba. Anual. Nativa.

Distribución: LLA, MAG.

Rango altitudinal: 500-2100 m.

Países limítrofes: Argentina.

Conyza pencana Phil.

Hierba. Perenne. Endémica.

Distribución: BIO.

Conyza primulifolia (Lam.) Cuatrec. \& Lourteig

Sinónimos: Conyza chilensis Spreng., Conyza scabiosaefolia J. Remy, Conyza yungasensis Rusby, Erigeron chilensis (Spreng.) D. Don ex G. Don, Conyza myosotifolia Kunth, Inula primulifolia Lam., Marsea chilensis (Spreng.) Kuntze, Marsea chilensis (Spreng.) V.M. Badillo, nom. illeg., Conyza chilensis Spreng. var. integrifolia Phil.

Hierba. Bienal. Nativa.

Distribución: MAU, NUB, BIO, ARA, LRI, LLA.

Rango altitudinal: 0-2000 m.

Países limítrofes: Argentina.

Conyza spiculosa (Hook. \& Arn.) Zardini

Sinónimos: Conyza colinensis Phil., Conyza patens Phil., Erigeron colinensis Phil., Erigeron spiculosus Hook. \& Arn., Erigeron spinulosum Hook. \& Arn. var. umbrosa Phil. Hierba. Perenne. Endémica.

Distribución: VAL, RME, MAU.

Nombre vulgar: Huilmo.
Conyza stenophylla Phil.

Sinónimos: Conyza armeriifolia Phil., Conyza linifolia Phil., hom. illeg., Erigeron flagellifolius Cabrera

Hierba. Perenne. Endémica.

Distribución: MAU, NUB, BIO, ARA, LLA.

Rango altitudinal: 100-1000 m.

Conyza suffruticosa Phil.

Hierba. Perenne. Nativa.

Distribución: RME.

Países limítrofes: Bolivia.

Conyza sumatrensis (Retz.) E. Walker var. leiotheca (S.F. Blake) Pruski \& G. Sancho

Sinónimos: Conyza bilbaoana J. Remy, Conyza bonariensis (L.) Cronquist var. leiotheca (S.F. Blake) Cuatrec., Conyza elata Kunth \& Bouché, Conyza myriocephala J. Remy, Erigeron bilbaoanus (J. Remy) Cabrera, Erigeron bonariensis L. var. floribundum (Kunth) Cuatrec., Erigeron bonariensis L. var. leiothecus S.F. Blake, Erigeron floribundus (Kunth) Sch. Bip., Marsea bonariensis (L.) V.M. Badillo var. leiotheca (S.F. Blake) V.M. Badillo, Conyza floribunda Kunth, Conyza sumatrensis (Retz.) E. Walker var. floribunda (Kunth) J.B. Marshall

Hierba. Anual. Nativa.

Distribución: ATA, COQ, VAL, RME, LBO, MAU, NUB, BIO, ARA, LRI, LLA, AIS.

Rango altitudinal: 0-2500 m.

Países limítrofes: Argentina y Bolivia.

Conyza tenera Phil.

Hierba. Perenne. Endémica.

Distribución: VAL.

Conyza thermarum Phil.

Sinónimos: Erigeron thermarum (Phil.) Cabrera

Hierba. Perenne. Endémica.

Distribución: NUB, BIO, ARA.

Rango altitudinal: 1000-2500 m.

Conyza valdiviana Phil.

Hierba. Perenne. Endémica.

Distribución: LLA.

\section{Coreopsis}

Coreopsis suaveolens Sherff

Subarbusto. Endémico.

Distribución: AYP, TAR.

Rango altitudinal: 3400-3800 m.

Nombre vulgar: Flor amarilla, chirichiri, chilile. 


\section{Cotula}

Cotula australis (Sieber ex Spreng.) Hook. f.

Hierba. Anual. Introducida.

Distribución: COQ, VAL, RME, LBO, MAU, NUB, BIO, ARA, JFE, IPA, IDE.

\section{Cotula coronopifolia L.}

Hierba. Perenne. Introducida.

Distribución: ANT, ATA, COQ, VAL, RME, LBO, MAU, NUB, BIO, ARA, LRI, LLA, JFE.

\section{Cotula mexicana (DC.) Cabrera}

Sinónimos: Cotula minuta (L.f.) Schinz, nom. illeg., Hippia minuta L.f., Lancisia minuta (L.f.) Rydb., Soliva mexicana DC., Soliva minuta (L.f.) Sweet

Hierba. Anual. Nativa.

Distribución: AYP, TAR, ANT, COQ.

Rango altitudinal: 3500-4000 m.

Países limítrofes: Argentina, Bolivia y Perú.

Nombre vulgar: Pichipichi, champa, t'champa.

\section{Crepis}

Crepis capillaris (L.) Wallr.

Hierba. Anual. Introducida.

Distribución: ATA, VAL, RME, LBO, MAU, NUB, BIO, ARA, LRI, LLA, AIS, MAG, JFE, IPA.

\section{Crepis pulchra L.}

Hierba. Anual. Introducida.

Distribución: LBO, MAU, NUB, BIO.

Crepis setosa Haller f.

Hierba. Anual. Introducida.

Distribución: ARA.

Crepis vesicaria L. subsp. taraxacifolia (Thuill.) Thell. ex Schinz \& R. Keller

Hierba. Anual o perenne. Introducida.

Distribución: BIO, ARA.

\section{Cuatrecasasiella}

Cuatrecasasiella argentina (Cabrera) H. Rob.

Sinónimos: Luciliopsis argentina Cabrera

Hierba. Perenne. Nativa.

Distribución: AYP, TAR, ANT.

Rango altitudinal: 2500-4300 m.

Países limítrofes: Argentina y Bolivia.

\section{Cynara}

\section{Cynara cardunculus L.}

Hierba. Perenne. Introducida.

Distribución: COQ, VAL, RME, LBO, MAU, NUB, BIO, JFE, IPA.

\section{Dasyphyllum}

Dasyphyllum diacanthoides (Less.) Cabrera

Sinónimos: Chuquiraga leucoxylon Poepp. ex Less., Flotovia diacanthoides Less., Piptocarpha diacanthoides Hook. \& Arn.

Árbol. Nativo.

Distribución: MAU, NUB, BIO, ARA, LRI, LLA.

Rango altitudinal: 500-1500 m.

Países limítrofes: Argentina.

Nombre vulgar: Palo blanco, palo santo, tayu, trevo, tallu.

Dasyphyllum excelsum (D. Don) Cabrera

Sinónimos: Chuquiraga excelsa D. Don, Flotovia excelsa (D. Don) DC., Piptocarpha excelsa (D. Don) Hook. \& Arn.

Árbol. Endémico.

Distribución: VAL, RME, LBO.

Rango altitudinal: 0-1000 m.

Nombre vulgar: Palo santo.

\section{Delairea}

Delairea odorata Lem.

Hierba. Perenne. Introducida.

Distribución: VAL, NUB, BIO, LRI, JFE.

\section{Dendroseris}

Dendroseris berteroana (Decne.) Hook. \& Arn.

Sinónimos: Dendroseris pinnata (Bertero ex Decne.) Hook. \& Arn. var. insignis (Bertero) Johow, Phoenicoseris berteriana (Decne.) Skottsb., Rea beteriana Decne., Rea pinnata Bertero ex Decne. var. insignis Bertero

Arbusto o árbol pequeño. Endémico.

Distribución: JFE.

Rango altitudinal: 0-500 m.

Nombre vulgar: Colecillo, col.

Dendroseris gigantea Johow

Árbol. Endémico.

Distribución: JFE.

Rango altitudinal: 0-500 m.

Nombre vulgar: Colecillo, col.

Dendroseris litoralis Skottsb.

Arbusto o árbol pequeño. Endémico.

Distribución: JFE.

Rango altitudinal: 0-500 m.

Nombre vulgar: Colecillo, col. 
Dendroseris macrantha (Bertero ex Decne.) Skottsb. Sinónimos: Rea macrantha Bertero ex Decne.

Arbusto o árbol pequeño. Endémico.

Distribución: JFE.

Rango altitudinal: 0-500 m.

Nombre vulgar: Colecillo, col.

\section{Dendroseris macrophylla D. Don}

Arbusto o árbol pequeño. Endémico.

Distribución: JFE.

Rango altitudinal: 0-500 m.

Nombre vulgar: Colecillo, col.

Dendroseris marginata (Bertero ex Decne.) Hook. \& Arn. Sinónimos: Dendroseris macrophylla $\mathrm{D}$. Don var. marginata (Bertero ex Decne.) Johow, Rea marginata Bertero ex Decne.

Arbusto o árbol pequeño. Endémico.

Distribución: JFE.

Rango altitudinal: 0-500 m.

Nombre vulgar: Colecillo, col.

Dendroseris micrantha (Bertero ex Decne.) Hook. \& Arn. Sinónimos: Rea micrantha Bertero ex Decne., Rea longifolia Phil. ex Reiche

Arbusto o árbol pequeño. Endémico.

Distribución: JFE.

Rango altitudinal: 0-500 m.

Nombre vulgar: Colecillo, col.

Dendroseris neriifolia (Decne.) Hook. \& Arn.

Sinónimos: Rea leucantha Bertero, Rea neriifolia Decne.

Árbol. Endémico.

Distribución: JFE.

Rango altitudinal: 0-500 m.

Nombre vulgar: Colecillo, col.

Dendroseris pinnata (Bertero ex Decne.) Hook. \& Arn.

Sinónimos: Phoenicoseris pinnata (Bertero ex Decne.)

Skottsb., Rea pinnata Bertero ex Decne.

Arbusto o árbol pequeño. Endémico.

Distribución: JFE.

Rango altitudinal: 0-500 m.

Nombre vulgar: Colecillo, col.

Dendroseris pruinata (Johow) Skottsb.

Sinónimos: Dendroseris micrantha (Bertero ex Decne.) Hook. \& Arn. var. pruinata Johow, Rea pruinata (Johow) Skottsb.

Arbusto o árbol pequeño. Endémico.

Distribución: JFE.

Rango altitudinal: 0-500 m.

Nombre vulgar: Colecillo, col.
Dendroseris regia Skottsb.

Arbusto o árbol pequeño. Endémico.

Distribución: JFE.

Rango altitudinal: 0-500 m.

Nombre vulgar: Colecillo, col.

\section{Diplostephium}

Diplostephium cinereum Cuatrec.

Arbusto. Nativo.

Distribución: AYP, TAR.

Rango altitudinal: 3800-4400 m.

Países limítrofes: Bolivia y Perú.

Nombre vulgar: Koa, koba, koya, hembra.

Diplostephium meyenii Wedd.

Sinónimos: Aster trachyticus Phil.

Arbusto. Nativo.

Distribución: AYP, TAR, ANT.

Rango altitudinal: 3000-3900 m.

Países limítrofes: Perú.

Nombre vulgar: Tola, tola del alma, leña quebrolla, manzanillón.

Diplostephium tacorense Hieron.

Arbusto. Nativo.

Distribución: ATA.

Rango altitudinal: 3000-4000 m.

Países limítrofes: Perú.

\section{Dittrichia}

Dittrichia viscosa (L.) Greuter

Arbusto. Introducido.

Distribución: VAL.

\section{Doniophyton}

Doniophyton anomalum (D. Don) Kurtz

Sinónimos: Chuquiraga anomala D. Don, Chuquiraga patagonica Phil., Doniophyton andicolum Wedd., Doniophyton patagonicum (Phil.) Hieron.

Subarbusto. Nativo.

Distribución: RME, ARA.

Rango altitudinal: 0-1800 m.

Países limítrofes: Argentina.

Doniophyton weddellii Katinas \& Stuessy

Subarbusto. Nativo.

Distribución: ANT, ATA, COQ, RME.

Rango altitudinal: 1900-4000 m.

Países limítrofes: Argentina. 


\section{Eclipta}

Eclipta prostrata (L.) L.

Hierba. Anual. Introducida.

Distribución: VAL, MAU.

\section{Encelia}

Encelia canescens Lam. var. canescens

Arbusto o subarbusto. Nativo.

Distribución: AYP, TAR, ANT, ATA, COQ.

Rango altitudinal: 0-1500 m.

Países limítrofes: Bolivia y Perú.

Encelia canescens Lam. var. oblongifolia (DC.) S.F. Blake Sinónimos: Encelia oblongifolia DC.

Subarbusto. Endémico.

Distribución: TAR, ANT, ATA, COQ.

Rango altitudinal: 0-2700 m.

Nombre vulgar: Coronilla del fraile, incienso.

Encelia canescens Lam. var. parvifolia (Kunth) Ball

Sinónimos: Encelia canescens Lam. var. lanuginosa I.M. Johnst., Encelia canescens Lam. var. tomentosa (Walp.) Ball, Encelia parvifolia Kunth, Encelia tomentosa Walp.

Subarbusto. Nativo.

Distribución: TAR, ANT, ATA, COQ.

Rango altitudinal: 0-3000 m.

Países limítrofes: Perú.

Nombre vulgar: Coronilla del fraile, incienso, hormiguero.

\section{Erechtites}

Erechtites leptanthus (Phil.) Cabrera

Sinónimos: Senecio leptanthus Phil.

Hierba. Anual. Endémica.

Distribución: ANT, ATA.

Rango altitudinal: 0-800 m.

\section{Eriachaenium}

Eriachaenium magellanicum Sch. Bip.

Hierba. Perenne. Nativa.

Distribución: MAG.

Rango altitudinal: 0-1000 m.

Países limítrofes: Argentina.

\section{Erigeron}

Erigeron andicola DC.

Sinónimos: Erigeron araucanus Phil., Erigeron ciliaris Phil., Erigeron andinus Phil., Erigeron biflorus Phil., Aster bellidiastrum Nees ex Walp., hom. illeg.

Hierba. Perenne. Nativa.
Distribución: COQ, VAL, RME, LBO, MAU, NUB, BIO, ARA, AIS, MAG.

Rango altitudinal: 500-4000 m.

Países limítrofes: Argentina.

Erigeron campanensis Valdeb., Lowrey \& Stuessy

Subarbusto. Endémico.

Distribución: VAL.

Rango altitudinal: 1500-2000 m.

Erigeron cinereus Hook. \& Arn.

Sinónimos: Erigeron poeppigii DC.

Hierba. Perenne. Nativa.

Distribución: VAL, RME, MAU, NUB, BIO, ARA, AIS, MAG.

Rango altitudinal: 500-3000 m.

Países limítrofes: Argentina.

Erigeron fasciculatus Colla

Sinónimos: Haplopappus hispidulus DC., Aster breviflorus Phil., Aster litoralis Phil., Erigeron berterianus DC., Erigeron subandinus Phil.

Subarbusto. Endémico.

Distribución: COQ, VAL.

Rango altitudinal: 0-1500 m.

Nombre vulgar: Escabiosa.

Erigeron fernandezius (Colla) Harling

Sinónimos: Erigeron fernandezianus (Colla) Solbrig, nom.

illeg., Erigeron fruticosum DC., Terranea fernandezia Colla

Hierba o subarbusto. Perenne. Endémica.

Distribución: JFE.

Rango altitudinal: 0-500 m.

Erigeron gilliesii (Hook. \& Arn.) Cabrera

Sinónimos: Aster albertii Phil., Aster gayanus DC., Aster gilliesii Hook. \& Arn., Astradelphus chilensis J. Remy, Erigeron pratensis Phil., Erigeron remyanus Wedd., Gusmania chilensis J. Remy

Hierba. Perenne. Nativa.

Distribución: VAL, RME, LBO, MAU, NUB, BIO, ARA, LLA, MAG.

Rango altitudinal: 800-2000 m.

Países limítrofes: Argentina.

Erigeron illapelinus Phil.

Hierba. Perenne. Nativa.

Distribución: COQ.

Rango altitudinal: 2400-3000 m.

Países limítrofes: Argentina.

Erigeron ingae Skottsb.

Sinónimos: Erigeron ingae Skottsb. var. innocentium Skottsb., Erigeron turricola Skottsb. 
Subarbusto. Endémico.

Distribución: JFE.

Erigeron karvinskianus DC.

Hierba. Perenne. Introducida.

Distribución: VAL, RME, BIO, LRI.

Erigeron leptopetalus Phil.

Sinónimos: Erigeron brevicaulis Phil., Erigeron nubigenus Phil.

Subarbusto. Nativo.

Distribución: ATA, COQ, RME, MAU, NUB, LLA, AIS, MAG.

Rango altitudinal: 0-4000 m.

Países limítrofes: Argentina.

Erigeron luteoviridis Skottsb.

Subarbusto. Endémico.

Distribución: JFE.

Rango altitudinal: 0-500 m.

Erigeron luxurians (Skottsb.) Solbrig

Sinónimos: Erigeron litoralis (Phil.) Skottsb. var. luxurians

Skottsb.

Subarbusto. Endémico.

Distribución: COQ, VAL.

Rango altitudinal: 0-700 m.

Erigeron myosotis Pers.

Sinónimos: Erigeron fernandezii Phil., Erigeron ibari Phil., Erigeron lacarensis Phil., Erigeron myosotis Pers. var. elongatum Sch. Bip., Erigeron myosotis Pers. subsp. polymorphoides Vierh., Erigeron myosotis Pers. subsp. pseudomagellanicus Vierh., Erigeron myosotis Pers. fma. spithameus Vierh., Erigeron philippii Sch. Bip. ex Wedd., Erigeron philippii Sch. Bip. ex Wedd. fma. densehirsutus Vierh., Erigeron philippii Sch. Bip. ex Wedd. fma. sparsehirsutus Vierh., Erigeron philippii Sch. Bip. ex Wedd. fma. tragopogonoides Skottsb. ex Vierh., Erigeron platylepis Vierh., Erigeron sullivanii Hook.f. var. magellanicum Sch. Bip., Erigeron angustifolius Phil., Erigeron polyphyllum Phil., Erigeron glabratus Reiche, hom. illeg.

Hierba. Perenne. Nativa.

Distribución: COQ, RME, LBO, MAU, NUB, BIO, ARA, LLA, AIS, MAG.

Rango altitudinal: 0-1000 m.

Países limítrofes: Argentina.

Erigeron othonnifolius Hook. \& Arn.

Sinónimos: Aster prostratus Phil., Erigeron vidali Phil.

Subarbusto. Endémico.

Distribución: VAL, MAU, BIO.

Rango altitudinal: 0-300 m.
Erigeron patagonicus Phil.

Hierba. Perenne. Nativa.

Distribución: AIS, MAG.

Rango altitudinal: 0-500 m.

Países limítrofes: Argentina.

Erigeron pulcher Phil.

Hierba. Perenne. Nativa.

Distribución: VAL, RME.

Rango altitudinal: 2700-3200 m.

Países limítrofes: Argentina.

Erigeron rosulatus Wedd.

Sinónimos: Erigeron brittonianus Rusby, Erigeron pulvinatus Wedd.

Hierba. Perenne. Nativa.

Distribución: AYP.

Rango altitudinal: 4000-4500 m.

Países limítrofes: Argentina, Bolivia y Perú.

Erigeron rupicola Phil.

Subarbusto. Endémico.

Distribución: JFE.

Rango altitudinal: 0-500 m.

Erigeron stuessyi Valdeb.

Subarbusto. Endémico.

Distribución: JFE.

Rango altitudinal: 900-950 m.

\section{Eupatorium}

Eupatorium glechonophyllum Less.

Sinónimos: Ageratina glechonophylla (Less.) R.M. King \&

H. Rob., Eupatorium remyanum Phil., Ageratina remyana (Phil.) R.M. King \& H. Rob.

Arbusto. Nativo.

Distribución: ANT, COQ, VAL, RME, LBO, MAU, NUB, BIO.

Rango altitudinal: 0-200 m.

Países limítrofes: Bolivia y Perú.

Nombre vulgar: Barba de viejo, barbón.

Eupatorium salvium Colla

Sinónimos: Aristeguietia salvia (Colla) R.M. King \& H.

Rob.

Arbusto. Endémico.

Distribución: COQ, VAL, RME, LBO, MAU, NUB, BIO.

Rango altitudinal: 0-200 m.

Nombre vulgar: Pegajosa, salvia macho, pega. 


\section{Facelis}

Facelis plumosa (Wedd.) Sch. Bip.

Sinónimos: Lucilia plumosa Wedd.

Hierba. Anual. Nativa.

Distribución: AYP.

Rango altitudinal: 2800-4500 m.

Países limítrofes: Argentina, Bolivia y Perú.

Facelis retusa (Lam.) Sch. Bip.

Sinónimos: Facelis retusa (Lam.) Sch. Bip. var. patula Beauverd, Facelis apiculata Cass., nom. illeg., Gnaphalium retusum Lam., Leptalea apiculata (Cass.) D. Don ex Hook. \& Arn., Facelis retusa (Lam.) Sch. Bip. var. andicola (Nees) Beauverd, Helichrysum retusum Spreng., Pteropogon chilense Fisch. \& Meyer, nom. nud., Pteropogon andicola Ness, Facelis retusa (Lam.) Sch. Bip. fma. gigantea Beauverd, Facelis retusa (Lam.) Sch. Bip. var. candelabrum Beauverd, Facelis retusa (Lam.) Sch. Bip. fma. laxa Beauverd, Facelis retusa (Lam.) Sch. Bip. fma. congesta Beauverd, Facelis retusa (Lam.) Sch. Bip. fma. planifolia Beauverd, Facelis retusa (Lam.) Sch. Bip. fma. nana Beauverd

Hierba. Anual. Nativa.

Distribución: ANT, COQ, VAL, RME, LBO, MAU, NUB, BIO, ARA.

Rango altitudinal: 0-1000 m.

Países limítrofes: Argentina.

\section{Flaveria}

Flaveria bidentis (L.) Kuntze

Sinónimos: Ethulia bidentis L., Eupatorium chilense Molina, Flaveria capitata Juss. ex Sm., Flaveria chilensis (Molina) J.F. Gmel., Flaveria contrayerba (Cav.) Pers., Milleria chiloensis Juss., nom. nud., Milleria contrayerba Cav., Flaveria bidentis (L.) B.L. Rob., comb. illeg.

Hierba. Anual. Nativa.

Distribución: AYP, TAR, ANT, ATA, COQ, VAL, RME, LBO.

Rango altitudinal: 0-3000 m.

Países limítrofes: Argentina, Bolivia y Perú.

Nombre vulgar: Contrahierba, dasdaqui, daudá, mata gusanos, sinapaya, monte colorado.

\section{Flaveria haumanii Dimitri \& Orfila}

Sinónimos: Flaveria bidentis (L.) Kuntze var. angustifolia Kuntze

Hierba. Anual. Nativa.

Distribución: TAR, ANT, ATA.

Rango altitudinal: 0-1500 m.

Países limítrofes: Argentina.

\section{Flourensia}

Flourensia thurifera (Molina) DC.

Sinónimos: Helianthus thurifera Molina, Diomedea thurifera (Molina) Bertero ex Colla, Helianthus glutinosus Hook. \& Arn., Flourensia besseriana Hook. \& Arn., Helianthus besserianus (Meyen \& Walp.) Benth. \& Hook., Flourensia thurifera (Molina) DC. var. lanceolata J. Remy Arbusto. Endémico.

Distribución: ATA, COQ, VAL, RME.

Rango altitudinal: 400-1000 m.

Nombre vulgar: Incienso, maravilla del campo.

\section{Gaillardia}

Gaillardia aristata Pursh

Hierba. Perenne. Introducida.

Distribución: TAR.

\section{Galinsoga}

\section{Galinsoga parviflora Cav.}

Sinónimos: Galinsoga quinqueradiata Ruiz \& Pav., nom. illeg., Wiborgia parviflora (Cav.) Kunth

Hierba. Anual. Nativa.

Distribución: AYP, TAR, ANT, ATA, COQ, VAL, RME, LBO, MAU, NUB, BIO, ARA, LRI, LLA, JFE, IPA.

Rango altitudinal: 0-2500 m.

Países limítrofes: Argentina, Bolivia y Perú.

Nombre vulgar: Pacoyuyo, miri vaihi (Rapa Nui).

Nota: Introducida en la Isla de Pascua.

\section{Gamochaeta}

Gamochaeta aliena (Hook. \& Arn.) Cabrera

Sinónimos: Gnaphalium alienum Hook. \& Arn., Gnaphalium stachydifolium Lam. var. alienum (Hook. \& Arn.) Reiche

Hierba. Perenne. Endémica.

Distribución: COQ, LBO, MAU, NUB, BIO, LLA.

Rango altitudinal: 0-500 m.

Gamochaeta alpina (Poepp. \& Endl.) S.E Freire \& Anderb. Sinónimos: Gamochaetopsis alpina (Poepp. \& Endl.) Anderb. \& S.E. Freire, Laennecia alpina Poepp., Lucilia alpina (Poepp.) Cabrera

Hierba. Perenne. Nativa.

Distribución: ARA, LLA.

Rango altitudinal: 1200-1900 m.

Países limítrofes: Argentina.

Gamochaeta americana (Mill.) Wedd.

Sinónimos: Gnaphalium americanum Mill., Gnaphalium purpureum L. var. americaum (Mill.) Klatt, Gnaphalium spicatum Mill. var chonoticum Hook.f. 
Hierba. Bienal o perenne. Nativa.

Distribución: AYP, COQ, VAL, RME, LBO, MAU, NUB, BIO, ARA, LRI, LLA, AIS, MAG, JFE, IPA.

Rango altitudinal: 0-3200 m.

Países limítrofes: Argentina, Bolivia y Perú.

Nota: Introducida en el Archipiélago de Juan Fernández y en la Isla de Pascua.

\section{Gamochaeta andina (Phil.) Cabrera}

Sinónimos: Gnaphalium andinum Phil., Gnaphalium petraeum Phil.

Hierba. Perenne. Endémica.

Distribución: RME, MAU, BIO.

Rango altitudinal: 2400-2700 m.

Gamochaeta axillaris (J. Remy) Cabrera

Sinónimos: Gnaphalium axillare J. Remy, Gnaphalium stachydifolium Lam. var. axillare (J. Remy) Reiche

Hierba. Perenne. Endémica.

Distribución: RME.

Rango altitudinal: 1700-2000 m.

\section{Gamochaeta chamissonis (DC.) Cabrera}

Sinónimos: Gamochaeta polybotrya (Phil.) Cabrera, Gamochaeta julietii (Phil.) Anderb., Gamochaeta serranoi (Phil.) Cabrera, Gnaphalium chamissonis DC., Gnaphalium fernandezianum Phil., Gnaphalium julietii Phil., Gnaphalium polybotryum Phil., Gnaphalium purpureum L. var. chamissonis (DC.) Klatt, Gnaphalium purpureum L. var. julietii (Phil.) Reiche, Gnaphalium serranoi Phil., Gamochaeta fernandeziana (Phil.) Anderb., Gnaphalium suffruticosum Phil., Gamochaeta suffruticosa (Phil.) Anderb. Hierba. Perenne. Nativa.

Distribución: COQ, VAL, RME, LBO, MAU, NUB, BIO, ARA, LLA, AIS, MAG, JFE.

Rango altitudinal: 1000-1800 m.

Países limítrofes: Argentina.

Gamochaeta depilata (Phil.) Cabrera

Sinónimos: Gnaphalium depilatum Phil., Gnaphalium obscurum Phil.

Hierba. Perenne. Nativa.

Distribución: VAL, MAU, NUB, BIO, ARA, AIS.

Rango altitudinal: 500-1000 m.

Países limítrofes: Argentina.

\section{Gamochaeta deserticola Cabrera}

Hierba. Perenne. Nativa.

Distribución: TAR, ANT, COQ, VAL, RME, BIO, ARA, MAG.

Rango altitudinal: 3000-4000 m.

Países limítrofes: Argentina y Bolivia.
Gamochaeta falcata (Lam.) Cabrera

Hierba. Perenne. Nativa.

Distribución: MAU, NUB, BIO, ARA.

Rango altitudinal: 950-1940 m.

Países limítrofes: Argentina.

Gamochaeta filaginea (DC.) Cabrera

Sinónimos: Gnaphalium filaginea DC., Gamochaeta berteriana (DC.) Cabrera, Gnaphalium berterianum DC., Gnaphalium stachydifolium Lam. var. berterianum (DC.)

Klatt, Gnaphalium bellidifolium Phil.

Hierba. Perenne. Nativa.

Distribución: VAL, RME, MAU, NUB, BIO.

Rango altitudinal: 0-300 m.

Gamochaeta humilis Wedd.

Hierba. Perenne. Nativa.

Distribución: ANT.

Países limítrofes: Bolivia y Perú.

Gamochaeta neuquensis Cabrera

Hierba. Perenne. Nativa.

Distribución: RME, ARA, MAG.

Rango altitudinal: 500-1500 m.

Países limítrofes: Argentina.

Gamochaeta nivalis Cabrera

Sinónimos: Gnaphalium nivale Phil., hom. illeg.

Hierba. Perenne. Nativa.

Distribución: VAL, RME, MAU, NUB, BIO, ARA, LLA, AIS, MAG.

Rango altitudinal: 800-3000 m.

Países limítrofes: Argentina.

Gamochaeta oligantha (Phil.) L.E. Navas

Sinónimos: Gnaphalium oliganthum Phil., Gamochaeta monticola (Phil. ex Reiche) Cabrera, Gnaphalium monticola Phil. ex Reiche

Hierba. Anual. Nativa.

Distribución: COQ, VAL, RME, MAU.

Rango altitudinal: 500-2000 m.

Países limítrofes: Argentina.

Gamochaeta procumbens (Phil.) Cabrera

Sinónimos: Gnaphalium procumbens Phil.

Hierba. Perenne. Endémica.

Distribución: LBO, MAU, NUB, MAG.

Rango altitudinal: 900-1500 m.

Gamochaeta purpurea (L.) Cabrera

Hierba. Anual. Introducida.

Distribución: IPA. 
Gamochaeta ramosa S.E. Freire, N. Bayón \& C.M. Baeza Sinónimos: Gnaphalium ramosum Phil., nom. illeg. Hierba. Anual. Endémica.

Distribución: COQ, VAL, RME, LBO, MAU.

Rango altitudinal: 0-3000 m.

\section{Gamochaeta serpyllifolia Wedd.}

Sinónimos: Gamochaeta munnozii Cabrera, nom. illeg., Gnaphalium serpyllifolium J. Remy, hom. illeg.

Hierba. Perenne. Nativa.

Distribución: RME, LBO, MAU, NUB, BIO, ARA, AIS.

Rango altitudinal: 1000-1500 m.

Países limítrofes: Argentina.

Gamochaeta simplicicaulis (Willd. ex Spreng.) Cabrera

Sinónimos: Gnaphalium purpureum L. var. simplicicaule (Willd. ex Spreng.) Klatt, Gnaphalium simplicicaule Willd. ex Spreng.

Hierba. Anual. Nativa.

Distribución: VAL, RME, MAU, NUB, BIO, ARA, LRI, LLA, AIS, MAG, JFE.

Rango altitudinal: 0-3700 m.

Países limítrofes: Argentina.

Gamochaeta spiciformis (Sch. Bip.) Cabrera

Sinónimos: Gamochaeta foliosa (Phil.) Anderb., Gnaphalium foliosum Phil., Gamochaeta peteroana (Phil.) Anderb., Gnaphalium mucronatum Phil., nom. illeg., Gnaphalium peteroanum Phil., Gnaphalium purpureum L. var. mucronatum (Phil.) Skottsb., Gnaphalium spiciforme Sch. Bip., Gamochaeta chilensis Deble

Hierba. Perenne. Nativa.

Distribución: COQ, VAL, RME, LBO, MAU, NUB, BIO, ARA, LRI, LLA, AIS, MAG.

Rango altitudinal: 200-1500 m.

Países limítrofes: Argentina.

Gamochaeta stachydifolia (Lam.) Cabrera

Sinónimos: Gnaphalium purpureum L. var. stachydifolium (Lam.) Baker, Gnaphalium stachydifolium Lam., Gnaphalium agreste Phil.

Hierba. Perenne. Nativa.

Distribución: VAL, RME, BIO, LRI, JFE.

Rango altitudinal: 400-1800 m.

Países limítrofes: Argentina.

Nota: Introducida en el Archipiélago Juan Fernández.

Gamochaeta subfalcata (Cabrera) Cabrera

Sinónimos: Gnaphalium subfalcatum Cabrera

Hierba. Perenne. Nativa.

Distribución: COQ, VAL, RME, MAU, BIO.

Rango altitudinal: 0-4100 m.

Países limítrofes: Argentina.
Gamochaeta valparadisea (Phil.) Anderb.

Sinónimos: Gnaphalium valparadiseum Phil.

Hierba. Perenne. Endémica.

Distribución: COQ, VAL, MAU.

Rango altitudinal: 0-300 m.

Gamochaeta villaroelii (Phil.) Cabrera

Sinónimos: Gnaphalium villaroelii Phil.

Hierba. Perenne. Endémica.

Distribución: COQ, VAL, RME, NUB.

\section{Gochnatia}

Gochnatia foliolosa (D. Don) D. Don ex Hook. \& Arn. var. fascicularis (D. Don) Cabrera

Sinónimos: Gochnatia fascicularis (D. Don) D. Don ex Hook. \& Arn., Gochnatia multiflora F. Phil., Pentaphorus fascicularis D. Don

Arbusto. Endémico.

Distribución: VAL, RME, LBO, MAU, NUB, BIO, ARA.

Rango altitudinal: 0-1200 m.

Nombre vulgar: Mira.

Gochnatia foliolosa (D. Don) D. Don ex Hook. \& Arn. var. foliolosa

Sinónimos: Gochnatia australis Phil., Gochnatia berteroana Phil., Gochnatia cuspidata Phil., Gochnatia integerrima Phil., Gochnatia laxiflora Phil., Gochnatia litoralis Phil., Gochnatia pyrifolia (D. Don) D. Don ex Hook. \& Arn., Gochnatia racemosa Phil., Gochnatia rigida D. Don ex Hook. \& Arn., Pentaphorus foliolosus D. Don, Pentaphorus pyrifolius D. Don

Arbusto. Endémico.

Distribución: ATA, COQ, VAL, RME, LBO, MAU, NUB, BIO, ARA, LLA.

Rango altitudinal: 0-1200 m.

Nombre vulgar: Mira, mira-mira.

\section{Grindelia}

Grindelia chiloensis (Cornel.) Cabrera

Sinónimos: Grindelia foliosa D. Don ex Hook. \& Arn., Haplopappus hoorebekia DC., nom. illeg., Hoorebekia chiloense Cornel.

Subarbusto. Nativo.

Distribución: VAL, RME, LBO, MAU, NUB, BIO, ARA, LLA.

Rango altitudinal: 0-3000 m.

Países limítrofes: Argentina.

Grindelia glutinosa (Cav.) Mart.

Sinónimos: Aster glutinosus Cav., Grindelia glutinosa (Cav.) Dunal, nom. illeg., Grindelia montana Phil.

Subarbusto. Nativo. 
Distribución: AYP, TAR.

Rango altitudinal: $500 \mathrm{~m}$.

Países limítrofes: Perú.

Grindelia tarapacana Phil.

Sinónimos: Grindelia obovata Rusby

Arbusto. Nativo.

Distribución: AYP, TAR.

Rango altitudinal: $2500 \mathrm{~m}$.

Países limítrofes: Perú.

Nombre vulgar: Chiñechinchillawa, keñakeña, bailahuén.

\section{Gutierrezia}

Gutierrezia baccharoides Sch. Bip.

Subarbusto. Nativo.

Distribución: AIS, MAG.

Rango altitudinal: 0-4000 m.

Países limítrofes: Argentina.

Gutierrezia espinosae Acevedo

Arbusto. Endémico.

Distribución: TAR, ANT, ATA, COQ.

Rango altitudinal: 0-1000 m.

Gutierrezia gayana (J. Remy) Reiche

Sinónimos: Brachyris gayana (J. Remy) J. Remy, Odontocarpha gayana J. Remy

Arbusto. Endémico.

Distribución: ATA, COQ.

Rango altitudinal: 0-1400 m.

Nombre vulgar: Monte amarillo.

Gutierrezia neaeana (DC.) Sch. Bip. ex S.F. Blake

Sinónimos: Brachyris neaeana DC.

Arbusto. Endémico.

Distribución: ATA.

Rango altitudinal: 2500-4000 m.

Gutierrezia resinosa (Hook. \& Arn.) S.F. Blake

Sinónimos: Brachyris floribunda Phil., Brachyris paniculata DC., Galinsoga resinosa Hook. \& Arn., Gutierrezia compacta Phil., Gutierrezia laricifolia D. Don, Odontocarpha poeppigii DC.

Arbusto. Endémico.

Distribución: COQ, VAL, RME, LBO.

Rango altitudinal: 0-1200 m.

Nombre vulgar: Delgadilla, monte amarillo, pichanilla, pichana.

Gutierrezia taltalensis Phil.

Sinónimos: Gutierrezia copiapina Phil.

Arbusto. Endémico.

Distribución: ANT, ATA.

Rango altitudinal: 0-1000 m.

\section{Guynesomia}

Guynesomia scoparia (Phil.) Bonifacino \& Sancho

Sinónimos: Hinterhubera scoparia (Phil.) Cabrera, Nardophyllum scoparium Phil.

Arbusto. Endémico.

Distribución: ATA, COQ.

Rango altitudinal: 1400-3000 m.

Gypothamnium

Gypothamnium pinifolium Phil.

Sinónimos: Plazia pinnifolia (Phil.) O. Hoffm.

Arbusto. Endémico.

Distribución: ANT, ATA.

Rango altitudinal: 0-500 m.

Nombre vulgar: Palo de yote.

\section{Haplopappus}

Haplopappus angustifolius (DC.) Reiche subsp. angustifolius Sinónimos: Haplopappus durus Reiche, Pyrrocoma angustifolia DC., Pyrrocoma rigida Phil., Aster atenes Kuntze, Aster sternbergii Kuntze

Arbusto. Endémico.

Distribución: ATA, COQ.

Rango altitudinal: 0-1500 m.

Nombre vulgar: Bailahuen.

Haplopappus angustifolius (DC.) Reiche subsp. saxatilis (J. Remy) Klingenb.

Sinónimos: Haplopappus saxatilis (Remy) Reiche, Haplopappus sphacelatus (Phil.) Reiche, Pyrrocoma saxatilis J. Remy, Aster saxatilis (J. Remy) Kuntze, Haplodiscus sphacelatus Phil.

Arbusto. Endémico.

Distribución: COQ, RME, MAU.

Rango altitudinal: 400-1700 m.

Haplopappus anthylloides Meyen \& Walp.

Sinónimos: Haplopappus radicans J. Remy, Aster anthylloides (Meyen \& Walp.) Kuntze, Aster radicans (J.

Remy) Kuntze

Arbusto. Nativo.

Distribución: VAL, RME, LBO, MAU.

Rango altitudinal: 700-3000 m.

Países limítrofes: Argentina.

Haplopappus arbutoides J. Remy

Sinónimos: Aster arbutoides (J. Remy) Kuntze, Haplopappus obovatus Phil., Haplopappus baccharidifolius Phil., Haplopappus zanartui (Phil.) Reiche, Haplodiscus zanartui Phil.

Subarbusto. Nativo. 
Distribución: COQ, VAL, LBO, MAU, NUB, BIO, ARA.

Rango altitudinal: 700-2400 m.

Países limítrofes: Argentina.

Haplopappus baylahuen J. Remy subsp. baylahuen Sinónimos: Haplopappus lastarrianus J. Remy, Haplopappus medicinalis Phil., Aster baylahuen (J. Remy) Kuntze, Aster lastarrianus (J. Remy) Kuntze, Haplopappus domeykoi Phil., Haplopappus fluehmannii Phil.

Arbusto. Nativo.

Distribución: ATA, COQ.

Rango altitudinal: 2700-3500 m.

Países limítrofes: Argentina.

Nombre vulgar: Bailahuen.

Haplopappus baylahuen J. Remy subsp. fluehmannii (Phil.) Klingenb.

Sinónimos: Haplopappus fluehmannii Phil.

Arbusto. Endémico.

Distribución: ATA.

Rango altitudinal: 2400-3700 m.

Nombre vulgar: Bailahuen.

Haplopappus bezanillanus (J. Remy) Reiche

Sinónimos: Pyrrocoma bezanillana J. Remy, Aster bezanillanus Kuntze

Subarbusto. Endémico.

Distribución: COQ.

Rango altitudinal: $300-2800 \mathrm{~m}$.

Haplopappus bustillosianus J. Remy

Sinónimos: Aster bustillosianus (J. Remy) Kuntze, Haplopappus australis Phil., Haplopappus patagonicus Phil., Haplopappus subandinus Phil.

Subarbusto. Nativo.

Distribución: MAU, NUB, BIO, ARA, LLA.

Rango altitudinal: $1500 \mathrm{~m}$.

Países limítrofes: Argentina.

Haplopappus cerberoanus (J. Remy) Reiche subsp. cerberoanus

Sinónimos: Pyrrocoma cerberoana J. Remy, Aster cerberoanus (J. Remy) Kuntze

Arbusto. Nativo.

Distribución: ATA, COQ.

Rango altitudinal: 0-1000 m.

Países limítrofes: Perú.

Haplopappus cerberoanus (J. Remy) Reiche subsp. elquianus Klingenb.

Arbusto. Endémico.

Distribución: COQ.

Rango altitudinal: 800-2000 m.
Haplopappus chrysanthemifolius (Less.) DC.

Sinónimos: Haplopappus berteri DC., Haplopappus leucanthemifolius Phil., Grindelia glutinosa Bertero, Andromachia alternifolia Kuntze, Diplopappus chrysanthemifolius Less.

Arbusto. Endémico.

Distribución: COQ, VAL, RME, LBO, MAU, NUB, BIO.

Rango altitudinal: 0-200 m.

Haplopappus coquimbensis (Hook. \& Arn.) Klingenb.

Sinónimos: Haplopappus acanthodon Phil., Haplopappus hirsutus Phil., Haplopappus hirtellus Phil. var. hirsutus (Phil.) Reiche, Diplopappus coquimbensis Hook. \& Arn., Haplopappus hirtellus Phil., Aster hirtellus (Phil.) Kuntze, Haplopappus limarensis Phil., Haplopappus hirtellus Phil. var. limarensis Reiche, Haplopappus vidalii Phil., Haplodiscus elatus Phil., Haplopappus elatus (Phil.) Reiche Arbusto. Endémico.

Distribución: ATA, COQ, VAL, LBO.

Rango altitudinal: 10-1000 m.

\section{Haplopappus decurrens J. Remy}

Sinónimos: Aster remyanus Kuntze

Arbusto. Endémico.

Distribución: COQ, VAL, RME, LBO.

Rango altitudinal: 0-2000 m.

Haplopappus deserticolus Phil.

Sinónimos: Haplopappus involucratus Phil., Haplopappus rengifoanus Phil.

Arbusto. Endémico.

Distribución: ANT, ATA, COQ.

Rango altitudinal: 0-700 m.

Haplopappus diplopappus J. Remy subsp. diplopappus Sinónimos: Aster diplopappus (J. Remy) Kuntze, Haplopappus pallidus Phil., Haplopappus heterophysus Phil.,Haplopappus marginalis Phil. var. heterophysus (Phil.) Reiche, Haplopappus peteroanus Phil., Haplopappus reticulatus Phil., Aster venosus Kuntze

Subarbusto. Nativo.

Distribución: LBO, MAU.

Rango altitudinal: 800-3540 m.

Países limítrofes: Argentina.

Nombre vulgar: Blanquillo.

Haplopappus diplopappus J. Remy subsp. villosus (Phil.) Klingenb.

Sinónimos: Haplopappus villosus Phil., Aster villiger Kuntze

Subarbusto. Nativo.

Distribución: VAL, RME, LBO, MAU.

Rango altitudinal: 1000-3000 m.

Países limítrofes: Argentina. 
Haplopappus donianus (Hook. \& Arn.) Reiche

Sinónimos: Diplopappus donianus Hook. \& Arn., Haplodiscus tenuifolius Phil., Haplodiscus exserens Phil., Haplopappus canescens (Phil.) Reiche var. exserens Reiche Arbusto. Endémico.

Distribución: VAL, LBO, MAU, BIO.

Rango altitudinal: 0-600 m.

Haplopappus foliosus (Hook. \& Arn.) Hook. \& Arn. Sinónimos: Aster polyphyllus (Phil.) Kuntze, Aster foliosus (DC.) Kuntze, Diplopappus foliosus Hook. \& Arn., Haplopappus foliosus DC., Haplodiscus polyphyllus Phil., Haplopappus phyllophorus Reiche, Haplodiscus densifolius Phil.

Arbusto. Endémico.

Distribución: ATA, COQ, VAL, RME, LBO, MAU.

Rango altitudinal: 0-750 m.

Nombre vulgar: Cuerno de cabra, palo negro.

Haplopappus glabratus Phil.

Sinónimos: Haplopappus arbutoides J. Remy var. glabratus (Phil.) Reiche, Aster glabratus (Phil.) Kuntze

Subarbusto. Nativo.

Distribución: VAL, RME, LBO, MAU.

Rango altitudinal: 1600-3300 m.

Países limítrofes: Argentina.

Haplopappus glutinosus Cass.

Sinónimos: Aster senebierifolius Kuntze, nom. illeg., Diplopappus coronopifolius Less., nom. illeg., Haplopappus coronopifolius (Less.) DC., nom. illeg.

Arbusto. Nativo.

Distribución: VAL, LBO, MAU, NUB, BIO, ARA, LRI, LLA, AIS.

Rango altitudinal: 10-2500 m.

Países limítrofes: Argentina.

Nombre vulgar: Buchú.

Haplopappus grindelioides (Less.) DC.

Sinónimos: Aster marginalis (Phil.) Kuntze, Haplopappus marginalis Phil., Haplopappus corniculatus Phil., Haplopappus heterocomus Phil., Haplopappus reflexus Phil., Diplopappus grindelioides Less., Aster reversus Kuntze, Aster grindelioides (Less.) Kuntze

Subarbusto. Nativo.

Distribución: RME, LBO, MAU, NUB, BIO, ARA.

Rango altitudinal: 600-2500 m.

Países limítrofes: Argentina.

Haplopappus humilis (Phil.) Reiche

Sinónimos: Haplodiscus humilis Phil.

Arbusto. Endémico.

Distribución: RME, LBO, MAU, NUB.

Rango altitudinal: 160-1100 m.
Haplopappus integerrimus (Hook. \& Arn.) H.M. Hall

Sinónimos: Haplopappus acerosus (Bertero) Phil., Haplopappus pulchellus DC. var. elongaus J. Remy, Grindelia acerosa Bertero ex Phil., nom. nud., Diplopappus integerrimus Hook. \& Arn., Steriphe acerosa (Bertero ex Phil.) Phil.

Arbusto. Endémico.

Distribución: COQ, VAL, RME.

Rango altitudinal: 500-2000 m.

Haplopappus linifolius (Phil.) Reiche

Sinónimos: Pyrrhocoma linifolia Phil., Aster linoides

Kuntze

Arbusto. Endémico.

Distribución: ATA, COQ.

Rango altitudinal: 1800-2200 m.

Haplopappus litoralis Phil.

Arbusto. Endémico.

Distribución: COQ, VAL.

Rango altitudinal: 0-700 m.

Haplopappus macrocephalus (Poepp. ex Less.) DC.

Sinónimos: Haplopappus caespitosus Nutt., Diplopappus macrocephalus Poepp. ex Less., Aster macrocephalus (Poepp. ex Less.) Kuntze, Haplopappus scaposus J. Remy, Haplopappus spinulosus Phil., Haplopappus serrulatus Reiche, Aster spinuliger Kuntze

Subarbusto. Endémico.

Distribución: VAL, RME, LBO, MAU, NUB, BIO, ARA.

Rango altitudinal: 100-2000 m.

Haplopappus maulinus Klingenb.

Arbusto. Endémico.

Distribución: MAU, BIO.

Rango altitudinal: 400-2300 m.

Haplopappus meyenii Walp.

Sinónimos: Haplopappus foliosus DC. subsp. meyenii (Walp.) Klingenb., Aster meyenii (Walp.) Kuntze

Subarbusto. Endémico.

Distribución: COQ.

Rango altitudinal: 0-400 m.

Haplopappus mucronatus (Hook. \& Arn.) Hook. \& Arn. ex B.D. Jacks.

Sinónimos: Baccharis mucronata Hook. \& Arn., hom. illeg., Haplopappus fonckii Phil., Haplopappus hookerianus DC., Haplopappus ilicifolius J. Remy, Diplopappus mucronatus Hook. \& Arn., Baccharis hookeriana DC., Aster ilicifolius (J. Remy) Kuntze, Haplopappus axilliflorus Phil., Haplopappus ilicifolius J. Remy var. platylepis (Phil.) Reiche, Haplopappus platylepis Phil., Haplopappus macraenus (Remy) Reiche, Pyrrocoma macraena Remy, 
Aster macraenus (Remy) Kuntze, Aplopappus macraenus Gray, comb. inval.

Arbusto. Endémico.

Distribución: ATA, COQ, VAL.

Rango altitudinal: 0-900 m.

Haplopappus multifolius Phil. ex Reiche subsp. baccharidiformis Klingenb.

Arbusto. Endémico.

Distribución: RME.

Rango altitudinal: $1800 \mathrm{~m}$.

Haplopappus multifolius Phil. ex Reiche subsp. multifolius Sinónimos: Haplopappus rotundifolius H.M. Hall, Pyrrocoma foliosa Phil., Aster multifolius (Phil. ex Reiche) Kuntze, Diplopappus foliolosus Hook. \& Arn., Diplopappus ilicifolius Hook. \& Arn.

Arbusto. Nativo.

Distribución: COQ, VAL, RME.

Rango altitudinal: 700-3200 m.

Países limítrofes: Argentina.

Haplopappus multifolius Phil. ex Reiche subsp. ovalifolius Klingenb.

Arbusto. Endémico.

Distribución: VAL, RME.

Rango altitudinal: 1300-3200 m.

Haplopappus nahuelbutae Klingenb.

Subarbusto. Endémico.

Distribución: BIO, ARA.

Rango altitudinal: 100-1460 m.

\section{Haplopappus ochagavianus Phil.}

Sinónimos: Haplopappus tiltilensis (Phil.) Reiche, Aster ochayaviensis Kuntze, Haplopappus reicheanus H.M. Hall, Haplopappus vernicosus Phil. ex Reiche

Arbusto. Endémico.

Distribución: COQ, VAL, RME.

Rango altitudinal: 100-2200 m.

\section{Haplopappus parvifolius (DC.) Gay}

Sinónimos: Pyrrocoma parvifolia DC., Aster parvifolius (DC.) Kuntze

Subarbusto. Endémico.

Distribución: ATA, COQ.

Rango altitudinal: 0-1800 m.

Nombre vulgar: Crespilla.

Haplopappus paucidentatus Phil.

Sinónimos: Aster oligodontus Kuntze, Haplopappus glutinosus (Less.) DC., hom. illeg., Diplopappus glutinosus Less., Aster glutinosus (Less.) Kuntze, Haplopappua prostratus Phil.
Subarbusto. Nativo.

Distribución: MAU, NUB, BIO, ARA, LLA.

Rango altitudinal: 950-2000 m.

Países limítrofes: Argentina.

Haplopappus philippii (Kuntze) H.M. Hall

Sinónimos: Haplopappus paniculatus Phil., Aster philippii

Kuntze, Haplopappus breviradiatus Reiche

Arbusto. Endémico.

Distribución: ATA, COQ, VAL.

Rango altitudinal: 0-500 m.

Haplopappus pinea (Phil.) Reiche

Sinónimos: Pyrrhocoma pinea Phil., Aster pineus (Phil.)

Kuntze

Arbusto. Endémico.

Distribución: COQ, VAL.

Rango altitudinal: 2000-2400 m.

Haplopappus pinnatifidus Nutt.

Sinónimos: Haplopappus setigerus (Phil.) Meigen, Pyrrocoma nuttalli J. Remy, nom. illeg., Aster andinus Kuntze, Diplopappus setiger Hook. \& Arn., Pyrrocoma setigera Phil., Aster setiger (Phil.) Kuntze

Arbusto. Endémico.

Distribución: COQ, VAL, RME, LBO, MAU.

Rango altitudinal: 550-1200 m.

Haplopappus poeppigianus (Hook. \& Arn.) A. Gray

Sinónimos: Diplopappus poeppigianus Hook. \& Arn., Haplodiscus polycladus Phil., Haplopappus argenteus Steud., Haplodiscus polycladus Phil., Haplopappus canescens (Phil.) Reiche, Grindelia canescens Bertero, Pyrrocoma canescens Phil., Aster griseus Kuntze

Arbusto. Endémico.

Distribución: VAL, RME, LBO.

Rango altitudinal: 0-1000 m.

Haplopappus pulchellus DC.

Sinónimos: Aster valparaisanus Kuntze

Arbusto. Endémico.

Distribución: COQ, VAL, RME, LBO, MAU.

Rango altitudinal: $300-1600 \mathrm{~m}$.

Haplopappus punctatus (Willd.) H.M. Hall

Sinónimos: Haplopappus chamissonis (Less.) DC., Conyza punctata Willd., Diplopappus chamissonis Less., Diplopappus punctatus Less. ex DC., Aster adalbertii Kuntze, Haplopappus corymbosus (Phil.) Reiche, Haplopappus rosmarinifolius Reiche, Steriphe corymbosa Phil., Aster pedunculosus (J. Remy) Kuntze, Haplopappus pedunculosus J. Remy, Haplopappus integerrimus (Hook. \& Arn.) H.M. Hall var. punctatus (Willd.) G.K. Br. \& W.D. Clark 
Arbusto. Endémico.

Distribución: RME, LBO, MAU, BIO.

Rango altitudinal: 100-1600 m.

Haplopappus pusillus Klingenb.

Sinónimos: Diplopappus bellidifolius Hook. \& Arn., Haplopappus cuneifolius Nutt., Aster cuneifolius (Nutt.) Kuntze

Arbusto. Nativo.

Distribución: COQ, VAL, RME.

Rango altitudinal: $3300 \mathrm{~m}$.

Países limítrofes: Argentina.

Haplopappus racemiger Klingenb.

Arbusto. Endémico.

Distribución: ATA, COQ.

Rango altitudinal: 30-560 m.

Haplopappus remyanus Wedd.

Sinónimos: Haplopappus prinophyllus Phil., Pyrrocoma ilicifolia J. Remy, Aster remyanus (Wedd.) Kuntze, Haplodiscus vernicosus Phil., Haplopappus latifolius (Phil.) Reiche, Haplodiscus latifolius Phil., Haplodiscus vernicosus Phil., Haplodiscus vernicosus Phil. var. geissei Phil., Haplodiscus kingii Phil., Haplopappus kingii (Phil.) Reiche

Arbusto. Endémico.

Distribución: ATA, COQ, VAL, RME, LBO.

Rango altitudinal: 300-2500 m.

Nombre vulgar: Bailahuen.

Haplopappus rengifoanus J. Remy

Sinónimos: Aster rengifoanus (J. Remy) Kuntze, Haplodiscus pachyphyllus Phil.

Arbusto. Endémico.

Distribución: ANT, ATA, COQ.

Rango altitudinal: 100-700 m.

Haplopappus retinervius (Kuntze) Klingenb.

Sinónimos: Aster retinervius Kuntze, Pyrrhocoma reticulata Phil., Haplopappus reticulatus (Phil.) Reiche nom. illeg., Haplopappus ischnos (Phil.) Reiche, Haplodiscus ischnos Phil., Haplodiscus landbecki Phil.

Arbusto. Endémico.

Distribución: COQ, VAL.

Rango altitudinal: 500-1800 m.

Haplopappus rigidus Phil.

Sinónimos: Haplopappus villanuevae Phil., Aster atacamensis Kuntze, nom. illeg.

Arbusto. Nativo.

Distribución: ANT, ATA, COQ.

Rango altitudinal: 2500-4000 m.

Países limítrofes: Argentina.
Nombre vulgar: Bailahuen, gualavina, chajchajra.

Haplopappus rosulatus H.M. Hall

Subarbusto. Endémico.

Distribución: ANT, ATA, COQ.

Haplopappus schumannii (Kuntze) G.K. Br. \& W.D. Clark Sinónimos: Haplopappus armerioides Phil., Haplopappus poeppigianus (Hook. \& Arn.) A. Gray var. radiatus A. Gray, Haplopappus sericeus Phil., Aster schumannii Kuntze, Steriphe navarri Phil.

Arbusto. Endémico.

Distribución: VAL, RME.

Rango altitudinal: 1400-3000 m.

Haplopappus scrobiculatus (Nees) DC.

Sinónimos: Aster densifolius (J. Remy) Kuntze, Aster scrobiculatus (Nees) Kuntze, Diplopappus cuneatus Hook. \& Arn., Diplopappus scrobiculatus Nees, Haplopappus densifolius J. Remy, Perezia spathulata Phil., hom. illeg.

Arbusto. Nativo.

Distribución: COQ, VAL, RME, LBO, MAU, NUB, BIO, ARA.

Rango altitudinal: 2600-3700 m.

Países limítrofes: Argentina.

Haplopappus setulosus Klingenb.

Arbusto. Endémico.

Distribución: MAU, NUB.

Rango altitudinal: $250 \mathrm{~m}$.

Haplopappus stelliger J. Remy

Sinónimos: Aster stelliger (J. Remy) Kuntze, Haplopappus denticulatus (Phil.) Reiche, Pyrrocoma denticulata Phil., Aster denticulatus (Phil.) Kuntze

Arbusto. Endémico.

Distribución: COQ.

Haplopappus stolpii Phil.

Arbusto. Endémico.

Distribución: RME, MAU, NUB, BIO, ARA.

Rango altitudinal: 50-700 m.

Haplopappus taeda Reiche

Sinónimos: Haplodiscus peteroanus Phil., Haplopappus graveolens (Phil.) Reiche, Haplodiscus graveolens Phil. Arbusto. Endémico.

Distribución: VAL, RME, LBO, MAU.

Rango altitudinal: $300-2000 \mathrm{~m}$.

Haplopappus uncinatus Phil.

Sinónimos: Haplopappus candolei Phil., Haplopappus uncinatus Phil. var. candolei (Phil.) Reiche, Diplopappus canescens Hook. \& Arn., Aster uncinatus (Phil.) Kuntze 
Arbusto. Endémico.

Distribución: COQ, VAL, RME, LBO, MAU.

Rango altitudinal: 0-2500 m.

Haplopappus undulatus Klingenb.

Arbusto. Endémico.

Distribución: COQ, VAL, RME.

Rango altitudinal: 2000-3500 m.

Haplopappus valparadisiacus Klingenb.

Sinónimos: Diplopappus inuloides Hook. \& Arn., Haplopappus berteroi var. lanceolatus DC., Haplopappus formosus Phil.

Arbusto. Endémico.

Distribución: COQ, VAL, RME, LBO.

Rango altitudinal: 10-60 m.

Haplopappus velutinus J. Remy subsp. illinitus (Phil.) Klingenb.

Sinónimos: Haplopappus illinitus Phil., Aster illinitus (Phil.) Kuntze, Haplopappus glutinosus Cass. var. illinitus (Phil.) Reiche

Arbusto. Endémico.

Distribución: LBO, MAU.

Rango altitudinal: $800 \mathrm{~m}$.

Haplopappus velutinus J. Remy subsp. longipes (Phil.) Klingenb.

Sinónimos: Haplodiscus longiscapus Phil., Haplopappus longipes (Phil.) Reiche, Pyrrocoma longipes Phil., Aster longipes (Phil.) Kuntze

Arbusto. Endémico.

Distribución: LBO, MAU.

Rango altitudinal: 800-2300 m.

Haplopappus velutinus J. Remy subsp. velutinus

Sinónimos: Haplopappus virgatus Phil., Haplopappus longiscapus Phil., Haplopappus stenophyllus Phil., Haplopappus fallax (Phil.) Reiche, Haplodiscus fallax Phil., Aster gayanus Kuntze, Aster scopiformis Phil., Diplopappus glutinosus Hook. \& Arn., nom. illeg.

Arbusto. Nativo.

Distribución: COQ, VAL, RME, LBO, MAU.

Rango altitudinal: 1300-2100 m.

Países limítrofes: Argentina.

Haplopappus vicuniensis Klingenb.

Arbusto. Endémico.

Distribución: COQ.

\section{Hedypnois}

Hedypnois cretica (L.) Dum. Cours. Hierba. Anual. Introducida.
Distribución: COQ, VAL, LBO, MAU, NUB, BIO, ARA.

Hedypnois rhagadioloides (L.) F.W. Schmidt

Hierba. Anual. Introducida.

Distribución: COQ, VAL, MAU, BIO, ARA.

\section{Helenium}

Helenium aromaticum (Hook.) L.H. Bailey

Sinónimos: Cephalophora aromatica (Hook.) Schrad., Cephalophora collina Phil., Cephalophora lanceolata Phil., Cephalophora tenera Cass., Graemia aromatica Hook., Helenium collinum (Phil.) F. Meigen, Gaillardia aromatica (Hook.) Baill.

Hierba. Anual o perenne. Nativa.

Distribución: ATA, COQ, VAL, RME, LBO, MAU.

Rango altitudinal: 0-1200 m.

Países limítrofes: Perú.

Nombre vulgar: Manzanilla del campo.

\section{Helenium atacamense Cabrera}

Sinónimos: Cephalophora litoralis Phil.

Hierba. Anual o bienal. Endémica.

Distribución: ANT, ATA, COQ.

Rango altitudinal: 0-800 m.

Helenium glaucum (Cav.) Stuntz

Sinónimos: Cephalophora berteroana Phil., Cephalophora borchersii Phil., Cephalophora foliosa Phil., Cephalophora glauca Cav., Cephalophora gracilis Phil., Cephalophora plantaginea DC., Cephalophora plantaginea DC. var. spathulata (F. Phil.) Reiche, Cephalophora punctata Klatt, Cephalophora rigida Phil., Cephalophora spathulata F. Phil., Cephalophora stolpii Phil., Heleniastrum glaucum (Cav.) Kuntze, Gaillardia glauca (Cav.) Baill., Helenium borchersii (Phil.) Cabrera, Helenium foliosum (Phil.) Cabrera, Helenium gracile (Phil.) Cabrera, Hymenopappus glaucus (Cav.) Spreng., Helenium plantagineum (DC.) J.F. Macbr.

Hierba. Perenne. Endémica.

Distribución: COQ, VAL, RME, LBO, MAU, NUB, BIO, ARA, LLA.

Rango altitudinal: 0-800 m.

Nombre vulgar: Poquil.

Helenium insulare (Phil.) Cabrera

Sinónimos: Actinea insularis (Phil.) Kuntze, Cephalophora insularis Phil.

Hierba. Bienal o perenne. Endémica.

Distribución: BIO.

Rango altitudinal: 0-100 m. 
Helenium ovallense Bierner

Hierba. Anual o bienal. Endémica.

Distribución: COQ.

Rango altitudinal: 200-400 m.

Helenium urmenetae (Phil.) Cabrera var. leguiffei (Phil.) Bierner

Sinónimos: Cephalophora leguiffei Phil., Cephalophora peraltae Phil., Helenium leguiffei (Phil.) J.F. Macbr.

Hierba. Anual o bienal. Endémica.

Distribución: ATA, COQ.

Rango altitudinal: 300-1300 m.

Helenium urmenetae (Phil.) Cabrera var. urmenetae Sinónimos: Cephalophora setigera Phil., Cephalophora urmenatae Phil., Helenium longiaristatum (Phil.) Cabrera Hierba. Anual o bienal. Endémica.

Distribución: ANT, ATA, COQ, RME.

Rango altitudinal: 0-300 $\mathrm{m}$.

\section{Helenium vallenariense (Phil.) Bierner}

Sinónimos: Cephalophora vallenariense Phil.

Hierba. Anual o bienal. Endémica.

Distribución: ATA, COQ.

Rango altitudinal: 400-1200 m.

\section{Helianthus}

\section{Helianthus tuberosus L.}

Hierba. Perenne. Introducida.

Distribución: VAL, RME, LBO, MAU, NUB, BIO, ARA, LLA.

\section{Helminthotheca}

Helminthotheca echioides (L.) Holub

Hierba. Anual. Introducida.

Distribución: TAR, ATA, COQ, VAL, RME, LBO, MAU, BIO, ARA, LLA.

\section{Helogyne}

\section{Helogyne apaloidea Nutt.}

Sinónimos: Brachyandra tenuifolia (Phil.) Reiche, Leto tenuifolia Phil.

Arbusto. Nativo.

Distribución: AYP, TAR.

Rango altitudinal: 700-3200 m.

Países limítrofes: Perú.

Nombre vulgar: Chilisaya, tola.

Helogyne macrogyne (Phil.) B.L. Rob. Sinónimos: Brachyandra macrogyne Phil. Arbusto. Endémico.
Distribución: AYP, TAR, ANT.

Rango altitudinal: 2000-3800 m.

Nombre vulgar: Tíkara.

\section{Heterosperma}

Heterosperma nanum (Nutt.) Sherff

Sinónimos: Bidens involucrata Phil., Heterosperma involucratum (Phil.) Reiche, Microdonta nana Nutt.

Hierba. Anual. Nativa.

Distribución: AYP, TAR, ANT.

Rango altitudinal: 1000-4000 m.

Países limítrofes: Argentina, Bolivia y Perú.

Heterosperma ovatifolium Cav.

Sinónimos: Heterosperma pinnatum Kunth var. ovatifolium (Cav.) Kuntze

Hierba. Anual. Nativa.

Distribución: TAR.

Rango altitudinal: 500-3000 m.

Países limítrofes: Argentina, Bolivia y Perú.

\section{Hieracium}

Hieracium antarcticum d'Urv.

Sinónimos: Hieracium antarcticum d'Urv. var. myosotidifolium (Sch. Bip.) Sleumer, Hieracium andinum Phil., Hieracium gracile Hook. subsp. andinum (Phil.) Zahn, Hieracium gracile Hook. subsp. antarcticum (d'Urv.) Zahn, Hieracium gracile Hook. subsp. myosotidifolium (Sch. Bip.) Zahn, Hieracium magellanicum Sch. Bip., Hieracium myostidifolium Sch. Bip., Hieracium philippii Albov, Hieracium triste Macloskie, hom. illeg., Pilosella magellanica (Sch. Bip.) F.W. Schultz \& Sch. Bip., Pilosella myosotidifolia (Sch. Bip.) F.W. Schultz \& Sch. Bip.

Hierba. Anual. Nativa.

Distribución: ARA, LLA, AIS, MAG.

Rango altitudinal: 0-2000 m.

Países limítrofes: Argentina.

Hieracium aurantiacum L.

Hierba. Perenne. Introducida.

Distribución: LLA, MAG.

Hieracium chilense Less.

Sinónimos: Hieracium gayanum Arv.-Touv., Hieracium orthotrichum R.E. Fr., Pilosella chilensis (Less.) F.W. Schultz \& Sch. Bip., Pilosella orthotricha (R.E. Fr.) F.W. Schultz \& Sch. Bip.

Hierba. Perenne. Nativa.

Distribución: RME, LBO, MAU, NUB, BIO, ARA, LLA, AIS, MAG.

Rango altitudinal: 500-1500 m.

Países limítrofes: Argentina y Perú. 
Hieracium glaucifolium Poepp. ex Froel.

Sinónimos: Hieracium chilense Ball, Pilosella glaucifolia (Poepp. ex Froel.) F.W. Schultz \& Sch. Bip., Hieracium chilense Skottsb., hom. illeg.

Hierba. Perenne. Nativa.

Distribución: MAU, NUB, BIO, ARA, LLA, AIS.

Rango altitudinal: 500-2000 m.

Países limítrofes: Argentina.

\section{Hieracium patagonicum Hook.f.}

Sinónimos: Hieracium chilense Less. var. navarinum Zahn, Hieracium poeppigianum Zahn, Pilosella patagonica (Hook.f.) F.W. Schultz \& Sch. Bip.

Hierba. Perenne. Nativa.

Distribución: LBO, MAU, NUB, BIO, ARA, LLA, MAG.

Rango altitudinal: 0-1000 m.

Países limítrofes: Argentina.

Hieracium pilosella L. subsp. euronotum Nägeli \& Peter Hierba. Perenne. Introducida.

Distribución: MAG.

Hieracium praealtum Vill. ex Gochnat

Hierba. Perenne. Introducida.

Distribución: MAG.

\section{Hypochaeris}

Hypochaeris acaulis (J. Remy) Britton

Sinónimos: Achyrophorus acaulis J. Remy

Hierba. Perenne. Nativa.

Distribución: COQ, RME, MAU, NUB, BIO, ARA.

Rango altitudinal: 1400-3000 m.

Países limítrofes: Argentina.

Hypochaeris apargioides Hook. \& Arn.

Sinónimos: Hypochaeris berteri Colla, Achyrophorus apargioides (Hook. \& Arn.) DC.

Hierba. Perenne. Endémica.

Distribución: VAL, RME, LBO, MAU, NUB, BIO, ARA.

Rango altitudinal: 500-2000 m.

Nombre vulgar: Escorzonera.

Hypochaeris arenaria Gaudich.

Sinónimos: Achyrophorus andinus DC., Achyrophorus arenarius (Gaudich.) DC., Achyrophorus humilis Phil., Hypochaeris arenaria Gaudich. var. andina (DC.) Cabrera, Hypochaeris andina (DC.) Benth. \& Hook. ex Griseb., Hypochaeris humilis (Phil.) Reiche, Hypochaeris pygmaea Phil., Leontodon arenarius (Gaudich.) Albov, Hypochaeris psychrophila (Wedd.) Reiche, Seriola andina DC., nom. illeg., Achyrophorus psychrophilus Wedd., Hypochaeris andina (DC.) Benth. \& Hook. ex Griseb. var. laciniata Phil. Hierba. Perenne. Nativa.
Distribución: VAL, ARA, LLA, AIS, MAG.

Rango altitudinal: 0-2400 m.

Países limítrofes: Argentina.

Hypochaeris chondrilloides (A. Gray) Cabrera

Sinónimos: Achyrophorus chondrilloides A. Gray, Achyrophorus deserticola Phil., Achyrophorus glaucus Phil., Oreophila chondrilloides D. Don ex A. Gray, nom. illeg., Hypochaeris glauca (Phil.) Reiche, comb. illeg., Oreophila chondrilloides Hook. \& Arn., nom. nud., Hypochaeris glabrata Phil.

Hierba. Perenne. Nativa.

Distribución: AYP, ANT, ATA, COQ, VAL, RME.

Rango altitudinal: 0-3500 m.

Países limítrofes: Argentina y Bolivia.

Nombre vulgar: Lokoche, romaza.

Hypochaeris clarionoides (J. Remy) Reiche

Sinónimos: Achyrophorus clarionoides J. Remy, Achyrophorus microphyllus J. Remy, Hypochaeris clarionoides (J. Remy) Reiche var. microphylla (J. Remy) Cabrera, Hypochaeris tenuifolia (Hook. \& Arn.) Griseb. var. clarionoides (J. Remy) Bortiri, Hypochaeris microphylla (J. Remy) Reiche, Hypochaeris nana Phil.

Hierba. Perenne. Nativa.

Distribución: COQ, VAL, RME, MAG.

Rango altitudinal: 2500-3400 m.

Países limítrofes: Argentina.

Hypochaeris cupressorum F. Phil.

Hierba. Perenne. Endémica.

Distribución: RME, LBO, MAU.

Rango altitudinal: 1000-2000 m.

Hypochaeris deserticola Phil.

Hierba. Perenne. Endémica.

Distribución: ATA.

Hypochaeris eremophila Cabrera

Sinónimos: Distoecha taraxacoides Phil.

Hierba. Perenne. Nativa.

Distribución: AYP, TAR, ANT.

Rango altitudinal: 2800-4700 m.

Países limítrofes: Argentina y Bolivia.

Hypochaeris foliosa (Phil.) Reiche Sinónimos: Achyrophorus foliosus Phil.

Hierba. Perenne. Endémica.

Distribución: ANT.

Rango altitudinal: 0-500 m.

Hypochaeris gayana (DC.) Cabrera

Sinónimos: Achyrophorus tenuifolius (Hook. \& Arn.) DC. var. gayanus DC. 
Hierba. Perenne. Nativa.

Distribución: RME, MAU, NUB, BIO, ARA.

Rango altitudinal: 0-2500 m.

Países limítrofes: Argentina.

Hypochaeris glabra L.

Hierba. Anual. Introducida.

Distribución: COQ, VAL, RME, LBO, MAU, NUB, ARA, MAG, JFE, IPA.

Hypochaeris grandidentata (Phil.) Reiche

Sinónimos: Achyrophorus grandidentatus Phil.

Hierba. Perenne. Endémica.

Distribución: ANT, ATA.

Rango altitudinal: 200-2500 m.

Nombre vulgar: Cerrajilla, renca.

Hypochaeris hispidula Phil.

Hierba. Perenne. Endémica.

Distribución: LLA.

Rango altitudinal: 0-100 m.

Hypochaeris incana (Hook. \& Arn.) Macloskie var. incana Sinónimos: Achyrophorus incanus (Hook. \& Arn.) Sch. Bip., Seriola incana Hook. \& Arn.

Hierba. Perenne. Nativa.

Distribución: ARA, AIS, MAG.

Rango altitudinal: 0-1500 m.

Países limítrofes: Argentina.

Hypochaeris incana (Hook. \& Arn.) Macloskie var. integrifolia (Sch. Bip.) Cabrera

Sinónimos: Achyrophorus coronopifolius Sch. Bip., Hypochaeris arenaria Gaudich. var. coronopifolia (Sch. Bip.) Speg., Hypochaeris ibari Phil., Leontodon coronopifolium (Sch. Bip.) Comm. ex Albov, Hypochaeris coronopifolia (Sch. Bip.) Franch.

Hierba. Perenne. Nativa.

Distribución: MAG.

Rango altitudinal: 0-1000 m.

Países limítrofes: Argentina.

Hypochaeris laciniosa Phil.

Hierba. Perenne. Endémica.

Distribución: BIO.

Rango altitudinal: 0-100 m.

Hypochaeris lessingii (Sch. Bip.) Reiche

Sinónimos: Achyrophorus lessingii Sch. Bip.

Hierba. Perenne. Endémica.

Distribución: BIO, ARA.

Rango altitudinal: 2000-2500 m.
Hypochaeris melanolepis Phil.

Hierba. Perenne. Endémica.

Distribución: VAL.

Rango altitudinal: 1500-2500 m.

Hypochaeris meyeniana (Walp.) Benth. \& Hook.f. ex Griseb. Sinónimos: Oreophila meyeniana Walp., Achyrophorus meyenianus (Walp.) Walp.

Hierba. Perenne. Nativa.

Distribución: AYP, TAR.

Rango altitudinal: 3300-3900 m.

Países limítrofes: Perú.

Hypochaeris montana (Phil.) Reiche

Sinónimos: Achyrophorus montanus Phil.

Hierba. Perenne. Nativa.

Distribución: RME.

Rango altitudinal: 1800-4000 m.

Países limítrofes: Argentina.

Hypochaeris nahuelvutae Phil.

Hierba. Perenne. Endémica.

Distribución: ARA.

Rango altitudinal: 1500-2500 m.

Hypochaeris palustris (Phil.) De Wild.

Sinónimos: Achyrophorus palustris Phil.

Hierba. Perenne. Nativa.

Distribución: MAU, NUB, BIO, ARA, LRI, LLA, AIS, MAG.

Rango altitudinal: 0-2100 m.

Países limítrofes: Argentina.

Hypochaeris pilosa Reiche

Sinónimos: Hypochaeris hirta Phil.

Hierba. Perenne. Endémica.

Distribución: BIO, ARA.

Rango altitudinal: 0-500 $\mathrm{m}$.

Hypochaeris radicata $\mathrm{L}$.

Hierba. Perenne. Introducida.

Distribución: COQ, VAL, RME, MAU, NUB, BIO, ARA, LRI, LLA, AIS, MAG, JFE.

Hypochaeris scorzonerae (DC.) F. Muell. var. glabrata (DC.) Reiche

Sinónimos: Achyrophorus scorzonerae DC. var. glabrata

DC., Hypochaeris chrysantha Poepp. ex DC., Oreophila

taraxacoides Don, Seriola taraxacoides (Don) Hook. \& Arn., Achyrophorus chrysanthus DC.

Hierba. Perenne. Endémica.

Distribución: ANT, ATA, COQ, VAL, RME, LBO.

Rango altitudinal: 0-500 $\mathrm{m}$. 
Hypochaeris scorzonerae (DC.) F. Muell. var. ramosa (DC.) Reiche

Sinónimos: Achyrophorus scorzonerae DC. var. ramosa DC. Hierba. Perenne. Endémica.

Distribución: VAL.

Rango altitudinal: 0-500 m.

Hypochaeris scorzonerae (DC.) F. Muell. var. scorzonerae Sinónimos: Hypochaeris sonchoides Kunth, Achyrophorus scorzonerae DC.

Hierba. Perenne. Endémica.

Distribución: ANT, ATA, COQ, VAL, RME, LBO.

Rango altitudinal: 0-2000 m.

Nombre vulgar: Escorzonera.

Hypochaeris spathulata (J. Remy) Reiche var. chiloensis (J. Remy) Reiche

Sinónimos: Achyrophorus spathulatus J. Remy var. chiloensis J. Remy

Hierba. Perenne. Endémica.

Distribución: LBO, LLA.

Rango altitudinal: 0-500 m.

Hypochaeris spathulata (J. Remy) Reiche var. spathulata Sinónimos: Achyrophorus spathulatus J. Remy

Hierba. Perenne. Endémica.

Distribución: LBO, MAU, NUB, BIO, ARA, LRI, LLA, AIS, MAG.

Rango altitudinal: 0-800 m.

\section{Hypochaeris taraxacoides Ball}

Hierba. Perenne. Nativa.

Distribución: AYP, TAR, ANT.

Rango altitudinal: 2600-5000 m.

Países limítrofes: Argentina, Bolivia y Perú.

Nombre vulgar: Psiñe de burro, jap'epsike, waripsike.

Hypochaeris tenerifolia (J. Remy) Dusén

Sinónimos: Achyrophorus tenerifolius J. Remy

Hierba. Perenne. Nativa.

Distribución: BIO, ARA, LLA, MAG.

Rango altitudinal: 0-1500 m.

Países limítrofes: Argentina.

Hypochaeris tenuifolia (Hook. \& Arn.) Griseb. var. eurylepis (Phil.) Cabrera

Sinónimos: Achyrophorus araucanus Phil., Achyrophorus odoratus (Poepp. \& Endl.) Walp., Oreophila odorata Poepp. \& Endl., Hypochaeris eurylepis Phil., Hypochaeris odorata (Poepp. \& Endl.) Benth. \& Hook.f. var. eurylepis (Phil.) Reiche, Hypochaeris odorata (Poepp. \& Endl.) Benth. \& Hook.f.

Hierba. Perenne. Nativa.

Distribución: LBO, MAU, NUB, BIO, ARA, LLA.
Rango altitudinal: 2000-3000 m.

Países limítrofes: Argentina.

Hypochaeris tenuifolia (Hook. \& Arn.) Griseb. var. linearifolia (DC.) Bortiri

Sinónimos: Achyrophorus graminifolius Phil., nom. nud., Achyrophorus tenuifolius (Hook. \& Arn.) DC. var. linearifolius DC., Hypochaeris graminifolia Phil., Achyrophorus angustissimus Phil.

Hierba. Perenne. Nativa.

Distribución: RME, LBO, MAU.

Rango altitudinal: 1500-2000 m.

Países limítrofes: Argentina.

Hypochaeris tenuifolia (Hook. \& Arn.) Griseb. var. tenuifolia

Sinónimos: Achyrophorus tenuifolius (Hook. \& Arn.) DC., Seriola tenuifolia Hook. \& Arn., Hypochaeris spinuligera (Phil.) Reiche, Hypochaeris volckmannii (Phil.) Phil., Oreophila tenuifolia D. Don ex Hook. \& Arn., nom. illeg., Achyrophorus tenuifolius (Hook. \& Arn.) DC. var. neaeanus DC., Achyrophorus spinuliger Phil., Achyrophorus volckmannii Phil.

Hierba. Perenne. Nativa.

Distribución: COQ, VAL, RME, LBO, MAU, NUB, BIO, ARA, LLA, AIS, MAG.

Rango altitudinal: 1300-3200 m.

Países limítrofes: Argentina.

Nombre vulgar: Escorzonera.

Hypochaeris thermarum Phil.

Hierba. Perenne. Endémica.

Distribución: MAU.

Rango altitudinal: 2500-3400 m.

Hypochaeris thrincioides (J. Remy) Reiche

Sinónimos: Achyrophorus brevicaulis Phil., Achyrophorus philippi Sch. Bip. ex Reiche

Hierba. Perenne. Endémica.

Distribución: COQ, VAL, RME, LBO, MAU, NUB, BIO, ARA, LLA.

Rango altitudinal: 0-1000 m.

Hypochaeris toltensis Reiche

Sinónimos: Hypochaeris grandiflora F. Phil.

Hierba. Perenne. Endémica.

Distribución: ARA.

Rango altitudinal: 0-500 m.

Jungia

Jungia polita Griseb.

Arbusto o subarbusto. Nativo.

Distribución: TAR. 
Países limítrofes: Argentina y Perú.

Nota: No hay registros en herbarios nacionales. Duplicados en GH, NY, US, recolectados por Shepard en la Provincia de Tarapacá (TAR). Ver Harling, 1995. Acta Regiae Soc. Litt. Gothob., Bot. 4:5-133.

\section{Kieslingia}

Kieslingia chilensis Faúndez, Saldivia \& A.E. Martic.

Arbusto. Endémico.

Distribución: ATA.

Rango altitudinal: 1600-2500 m.

\section{Lactuca}

\section{Lactuca sativa L.}

Hierba. Anual o bienal. Introducida.

Distribución: AYP, RME.

\section{Lactuca serriola L.}

Hierba. Anual o bienal. Introducida.

Distribución: ANT, ATA, COQ, VAL, RME, LBO, MAU, NUB, BIO, ARA.

\section{Lactuca virosa $\mathrm{L}$.}

Hierba. Anual o bienal. Introducida.

Distribución: RME, LBO, MAU, NUB, BIO, ARA.

\section{Laennecia}

Laennecia artemisioides (Meyen \& Walp.) G.L. Nesom Sinónimos: Conyza artemisioides Meyen \& Walp., Conyza andicola Phil., Erigeron artemisioides (Meyen \& Walp.) Sch. Bip., Marsea artemisiaefolia (Meyen \& Walp.) Kuntze Hierba. Anual. Nativa.

Distribución: AYP, TAR, ANT, RME.

Rango altitudinal: $3500-4500 \mathrm{~m}$.

Países limítrofes: Argentina y Bolivia.

\section{Lagenophora}

Lagenophora hariotii Franch.

Sinónimos: Lagenifera hariotii (Franch.) T.R. Dudley, comb. illeg., Lagenophora hirsuta auct. non Less.

Hierba. Perenne. Nativa.

Distribución: MAU, NUB, BIO, ARA, LRI, LLA, AIS, MAG, JFE.

Rango altitudinal: 0-1500 m.

Países limítrofes: Argentina.

Lagenophora hirsuta Poepp. ex Less.

Sinónimos: Lagenophora commersonii Cass. var. hirsuta (Poepp. ex Less.) Hook.f.

Hierba. Perenne. Nativa.
Distribución: RME, MAU, NUB, BIO, ARA, LRI, LLA, AIS, MAG.

Rango altitudinal: 500-1500 m.

Países limítrofes: Argentina.

Lagenophora nudicaulis (Comm. ex Lam.) Dusén

Sinónimos: Aster nudicaulis Comm. ex Lam., Bellis magellanica DC., Calendula magellanica Willd., Lagenifera nudicaulis (Comm. ex Lam.) T.R. Dudley, Lagenophora commersonii Cass., Lagenophora purpurascens Phil.

Hierba. Perenne. Nativa.

Distribución: LBO, MAU, NUB, BIO, ARA, LLA, AIS, MAG.

Rango altitudinal: 0-2200 m.

Países limítrofes: Argentina.

\section{Lapsana}

Lapsana communis $\mathrm{L}$.

Hierba. Anual. Introducida.

Distribución: COQ, VAL, RME, LBO, MAU, NUB, BIO, ARA, LRI, LLA, AIS, JFE.

\section{Lasthenia}

Lasthenia kunthii (Less.) Hook. \& Arn.

Sinónimos: Hymenatherum kunthii Less., Lasthenia bridgesii (Poepp. \& Endl.) Steud., Lasthenia chilensis Steud., nom. nud., Lasthenia obtusifolia Cass., Lasthenia obtusifolia Cass. var. bridgesii (Poepp. \& Endl.) DC., Rancagua bridgesii Poepp. \& Endl., Rancagua feuillei (Bertero ex Colla) Poepp. $\&$ Endl., Tagetes feuillei Bertero ex Colla

Hierba. Anual. Nativa.

Distribución: COQ, VAL, RME, LBO, MAU, NUB, BIO, ARA, MAG.

Rango altitudinal: 0-1000 m.

Países limítrofes: Argentina.

Nombre vulgar: Rancagua.

\section{Leontodon}

Leontodon autumnalis L.

Hierba. Perenne. Introducida.

Distribución: VAL, MAG.

Leontodon hirtus L.

Hierba. Perenne. Introducida.

Distribución: VAL, NUB, BIO, LRI, LLA.

Leontodon saxatilis Lam.

Hierba. Perenne. Introducida.

Distribución: VAL, LBO, MAU, NUB, BIO, ARA, LRI, LLA. 


\section{Lepidophyllum}

Lepidophyllum cupressiforme (Lam.) Cass.

Sinónimos: Baccharis cupressiformis (Lam.) Pers., Conyza cupressiformis Lam., Gutierrezia cupressiformis (Lam.) Sch. Bip., Athanasia cupressiformis (Lam.) Comm. ex Cass., Brachyridium cupressiforme (Lam.) Meisn., nom. illeg., Grindelia cupressiformis (Lam.) Sch. Bip. ex Reiche Arbusto. Nativo.

Distribución: MAG.

Rango altitudinal: 0-500 m.

Países limítrofes: Argentina.

\section{Leptinella}

Leptinella scariosa Cass.

Sinónimos: Cotula acaenoides (Hook. \& Arn.) Alb., Cotula hombroni Franch., Cotula scariosa (Cass.) Franch., Leptinella acaenoides Hook. \& Arn.

Hierba. Perenne. Nativa.

Distribución: LRI, LLA, AIS, MAG.

Rango altitudinal: 0-1000 m.

Países limítrofes: Argentina.

\section{Leptocarpha}

Leptocarpha rivularis DC.

Arbusto. Endémico.

Distribución: MAU, NUB, BIO, ARA, LRI, LLA.

Rango altitudinal: 0-1000 m.

Nombre vulgar: Palo negro.

\section{Leucanthemum}

Leucanthemum vulgare Lam.

Hierba. Perenne. Introducida.

Distribución: RME, LBO, MAU, NUB, BIO, ARA, LRI, LLA, MAG.

\section{Leucheria}

Leucheria achillaeifolia Hook. \& Arn.

Sinónimos: Chabraea fragans Phil., Lasiorhiza anthemidifolia (Phil.) Kuntze, Lasiorhiza fragans (Phil.) Kuntze, Lasiorhiza achillaefolia (Hook. \& Arn.) Macloskie, Lasiorhiza ibari (Phil.) Macloskie, Leuceria anthemidifolia Phil., Leuceria ibari Phil.

Hierba. Perenne. Nativa.

Distribución: MAU, NUB, BIO, ARA, AIS, MAG.

Rango altitudinal: 0-2000 m.

Países limítrofes: Argentina.

Leucheria amoena Phil.

Hierba. Perenne. Nativa.
Distribución: LBO, MAU.

Rango altitudinal: 1000-2000 m.

Países limítrofes: Argentina.

Leucheria apiifolia Phil.

Hierba. Perenne. Endémica.

Distribución: MAU.

Rango altitudinal: $2500 \mathrm{~m}$.

Leucheria bridgesii Hook. \& Arn.

Sinónimos: Chabraea pulchella Phil., Lasiorhiza pulchella

(Phil.) Kuntze, comb. illeg., Leuceria microcephala Reiche

Hierba. Perenne. Endémica.

Distribución: COQ, VAL, RME, LBO.

Rango altitudinal: 1000-3300 m.

Leucheria candidissima D. Don

Sinónimos: Chabraea candidissima (D. Don) DC., Lasiorhiza candidissima (D. Don) Macloskie, Leuceria candidissima D. Don fma. subintegra Skottsb., Leuceria laciniata Hook. \& Arn.

Hierba. Perenne. Nativa.

Distribución: RME, MAU.

Rango altitudinal: 2000-3200 m.

Países limítrofes: Argentina.

Leucheria cerberoana J. Remy

Sinónimos: Leuceria glabrata Phil.

Hierba. Anual. Endémica.

Distribución: ANT, ATA, COQ, VAL, RME.

Rango altitudinal: 0-1100 m.

Leucheria coerulescens J. Remy

Sinónimos: Leucheria aurita Phil.

Hierba. Perenne. Nativa.

Distribución: NUB, ARA, LRI.

Rango altitudinal: 0-1000 m.

Países limítrofes: Argentina.

\section{Leucheria congesta D. Don}

Sinónimos: Chabraea canescens Phil., Lasiorhiza glomerulata Kuntze, Leuceria canescens (Phil.) Reiche, Leuceria glomerulata (Kuntze) K. Schum., Leuceria sonchoides Phil.

Hierba. Perenne. Nativa.

Distribución: COQ, VAL, RME.

Rango altitudinal: 2500-3000 m.

Países limítrofes: Argentina.

Leucheria cumingii Hook. \& Arn.

Sinónimos: Chabraea modesta Phil., Leuceria debilis Phil., Leuceria modesta (Phil.) Reiche

Hierba. Anual. Endémica.

Distribución: ANT, ATA, COQ.

Rango altitudinal: 0-500 $\mathrm{m}$. 
Leucheria daucifolia (D. Don) Crisci

Sinónimos: Ptilurus daucifolius D. Don, Chabraea daucifolia (D. Don) Wedd., Chabraea laciniata Wedd.

Hierba. Perenne. Nativa.

Distribución: AYP, TAR.

Rango altitudinal: 2600-4800 m.

Países limítrofes: Bolivia y Perú.

\section{Leucheria floribunda DC.}

Sinónimos: Eizaguirrea candollei J. Remy, nom. illeg., Eizaguirrea cirsioides Phil., Eizaguirrea sonchifolia Turcz., Lasiorhiza floribunda (DC.) Kuntze, Leuceria racemosa Phil., Leuceria sonchifolia (Turcz.) Reiche

Hierba. Perenne. Nativa.

Distribución: COQ, VAL, RME, LBO, MAU.

Rango altitudinal: 2000-3000 m.

Países limítrofes: Argentina.

Leucheria garciana J. Remy

Hierba. Perenne. Endémica.

Distribución: LBO, MAU.

Rango altitudinal: $2500 \mathrm{~m}$.

Leucheria gayana (J. Remy) Reiche

Sinónimos: Chabraea gayana J. Remy, Leuceria nudicaulis Phil., Leuceria popetana Phil.

Hierba. Perenne. Nativa.

Distribución: VAL, RME, LBO, MAU.

Rango altitudinal: 1800-3000 m.

Países limítrofes: Argentina.

Leucheria gilliesii Hook. \& Arn.

Sinónimos: Leuceria hieracioides D. Don, hom. illeg., Leuceria nivea Phil.

Hierba. Perenne. Nativa.

Distribución: RME, MAU, ARA.

Rango altitudinal: 1900-2500 m.

Países limítrofes: Argentina.

Leucheria glabriuscula (Phil.) Reiche

Sinónimos: Chabraea glabriuscula Phil.

Hierba. Anual. Endémica.

Distribución: RME.

Rango altitudinal: $1000 \mathrm{~m}$.

Leucheria glacialis (Poepp. ex Less.) Reiche

Sinónimos: Chabraea glacialis (Poepp. ex Less.) DC., Lasiorhiza glacialis Poepp. ex Less., Leuceria araucana Phil., Leuceria discolor Phil., Leuceria glacialis (Poepp. ex Less.) Reiche var. longifolia (Phil.) Cabrera, Leuceria longifolia Phil., Leuceria pauciflora Phil., Leuceria thermarum (Phil.) Reiche var. araucana (Phil.) Reiche Hierba. Perenne. Nativa.

Distribución: MAU, NUB, BIO, ARA, LRI, LLA, AIS.
Rango altitudinal: 0-2600 m.

Países limítrofes: Argentina.

Leucheria glandulosa D. Don

Sinónimos: Chabraea elongata Bertero ex Colla, Chabraea glandulosa (D. Don) DC., Lasiorhiza glandulosa (D. Don)

DC., Leuceria peduncularis J. Remy

Hierba. Perenne. Endémica.

Distribución: COQ, VAL, RME, LBO, BIO.

Rango altitudinal: 600-2000 m.

Leucheria graui Katinas, M.C. Tellería \& Crisci

Hierba. Perenne. Endémica.

Distribución: MAU.

Rango altitudinal: 2200-2400 m.

Leucheria hahnii Franch.

Sinónimos: Chabraea integrifolia Phil., hom. illeg., Lasiorhiza hahnii (Franch.) Macloskie, Leuceria fuegina Phil., Leucheria gossypina Hook. \& Arn. var. integrifolia Sch. Bip., Leucheria gossypina Hook. \& Arn. var. pinnatifida Sch. Bip., Lasiorhiza fueguiana (Phil.) Kuntze, Leucheria integrifolia (Phil.) Reiche ex B.L. Rob., Chabraea suaveolens (d'Urv.) DC. var. pinnatifida Sch. Bip., nom. nud., Chabraea suaveolens (d’Urv.) DC. var. integrifolia Sch. Bip., nom. nud.

Hierba. Perenne. Nativa.

Distribución: AIS, MAG.

Rango altitudinal: 0-1600 m.

Países limítrofes: Argentina.

Leucheria hieracioides Cass.

Sinónimos: Lasiorhiza acanthoides (D. Don) Kuntze, Lasiorhiza hieracioides (Cass.) Kuntze, Leuceria acanthoides D. Don, Leuceria divaricata D. Don, Chabraea prenanthoides Bertero

Hierba. Perenne. Endémica.

Distribución: VAL, RME, LBO, MAU.

Rango altitudinal: 0-2200 m.

Leucheria leontopodioides (Kuntze) K. Schum.

Sinónimos: Lasiorhiza leontopodioides Kuntze

Hierba. Perenne. Nativa.

Distribución: MAG.

Rango altitudinal: 0-1500 m.

Países limítrofes: Argentina.

Leucheria lithospermifolia (Less.) Reiche subsp. integrifolia (Phil.) Grau \& Zinnecker

Sinónimos: Leucheria integrifolia (Phil.) Crisci, Chabraea integrifolia Phil.

Hierba. Perenne. Nativa.

Distribución: MAU, NUB, BIO.

Rango altitudinal: 1000-1500 m. 
Leucheria lithospermifolia (Poepp. ex Less.) Reiche subsp. lithospermifolia

Sinónimos: Chabraea lithospermifolia (Poepp. ex Less.) DC., Lasiorhiza lithospermifolia Poepp. ex Less., Leuchaeria volcanica Hook. \& Arn.

Hierba. Perenne. Nativa.

Distribución: MAU, NUB, BIO, ARA.

Rango altitudinal: 1400-2000 m.

Países limítrofes: Argentina.

Leucheria magna Phil.

Sinónimos: Lasiorhiza stricta (Phil.) Macloskie, Leuceria stricta Phil.

Hierba. Perenne. Nativa.

Distribución: ARA, AIS.

Rango altitudinal: 0-1000 m.

Países limítrofes: Argentina.

Leucheria meladensis Katinas, Crisci \& A.E. Martic.

Hierba. Perenne. Endémica.

Distribución: MAU.

Rango altitudinal: 1000-1100 m.

Leucheria menana J. Remy

Hierba. Anual. Endémica.

Distribución: ATA, COQ.

Rango altitudinal: 0-500 m.

Leucheria millefolium Dusén \& Skottsb.

Hierba. Perenne. Nativa.

Distribución: MAU, NUB, BIO, ARA, AIS, MAG.

Rango altitudinal: 0-2500 m.

Países limítrofes: Argentina.

Leucheria multiflora Phil.

Hierba. Perenne. Endémica.

Distribución: COQ, VAL, RME, LBO.

Rango altitudinal: 0-500 m.

Leucheria nutans (J. Remy) Reiche

Sinónimos: Chabraea nutans J. Remy, Chabraea poeppigii Phil., Clybatis volkmanii Phil., Lasiorhiza nutans (J. Remy)

Kuntze

Hierba. Perenne. Nativa.

Distribución: NUB, BIO, ARA.

Rango altitudinal: 1300-2000 m.

Países limítrofes: Argentina.

Leucheria oligocephala J. Remy

Sinónimos: Trixis senecioides Hook.

Hierba. Anual. Endémica.

Distribución: VAL, RME, LBO.

Rango altitudinal: 0-1000 m.
Leucheria paniculata Poepp. ex Less.

Hierba. Perenne. Nativa.

Distribución: RME, NUB, BIO, ARA, MAG.

Rango altitudinal: 0-2800 m.

Países limítrofes: Argentina.

Leucheria papillosa Cabrera

Hierba. Perenne. Nativa.

Distribución: BIO, ARA, LRI, LLA, AIS.

Rango altitudinal: 1000-2000 m.

Países limítrofes: Argentina.

Leucheria polyclados (J. Remy) Reiche

Sinónimos: Chabraea polyclados J. Remy

Hierba. Perenne. Endémica.

Distribución: ATA.

Rango altitudinal: 3000-3100 m.

Leucheria pteropogon (Griseb.) Cabrera

Sinónimos: Senecio pteropogon Griseb.

Hierba. Perenne. Nativa.

Distribución: ANT.

Rango altitudinal: $3500-0 \mathrm{~m}$.

Países limítrofes: Argentina.

Leucheria purpurea (Vahl) Hook. \& Arn.

Sinónimos: Chabraea purpurea (Vahl) DC., Perdicium purpureum Vahl, Lasiorhiza purpurea (Vahl) Less., Leuceria purpurea (Vahl) S. Moore ex Rendle

Hierba. Perenne. Nativa.

Distribución: MAG.

Rango altitudinal: 500-1000 m.

Países limítrofes: Argentina.

Leucheria rosea Poepp. ex Less.

Sinónimos: Lasiorhiza rosea Less. var. albiflora Kuntze, Lasiorhiza rosea Less. var. andryaloides (DC.) Kuntze, comb. illeg., Leuceria andryaloides DC., nom. illeg., Leucheria lepida Phil.

Hierba. Perenne. Nativa.

Distribución: VAL, RME, LBO, MAU.

Rango altitudinal: 1000-2000 m.

Países limítrofes: Argentina.

Leucheria runcinata D. Don

Sinónimos: Leucheria landbeckii (Phil.) Reiche, Chabraea barrasiana J. Remy, Chabraea concinna Phil., Chabraea coquimbana Phil., Chabraea landbeckii Phil., Chabraea oligocephala Phil., Chabraea runcinata (D. Don) Hook., Chabraea tenerifolia Phil., Leuceria barrasiana (J. Remy) Reiche, comb. illeg., Leuceria barrasiana (J. Remy) Reiche var. tenerifolia (Phil.) Reiche, Leuceria coquimbana (Phil.) Reiche, Leuceria meyeniana Walp., Leuceria paucicapitata Reiche, Leucheria tenerifolia (Phil.) Phil., Leuceria 
concinna (Phil.) Reiche, Leuceria barrasiana (J. Remy) F. Meigen, comb. illeg.

Hierba. Perenne. Nativa.

Distribución: ATA, COQ, VAL, RME, LBO, MAU, NUB.

Rango altitudinal: 3000-0 m.

Países limítrofes: Argentina.

Nombre vulgar: Blanquillo.

Leucheria salina (J. Remy) Hieron. subsp. salina

Sinónimos: Chabraea salina J. Remy, Chabraea salinasi Phil. var. bipinnatifida Phil., Lasiorhiza salina (J. Remy) Kuntze, Leuceria salina (J. Remy) Dusén, comb. illeg., Leuceria salina (J. Remy) Reiche

Hierba. Perenne. Nativa.

Distribución: ATA, COQ, VAL, RME.

Rango altitudinal: 2000-4500 m.

Países limítrofes: Argentina.

Leucheria salina (J. Remy) Hieron. subsp. zöllneri Crisci Hierba. Perenne. Nativa.

Distribución: COQ, RME, LBO.

Rango altitudinal: $3000 \mathrm{~m}$.

Países limítrofes: Argentina.

\section{Leucheria scrobiculata D. Don}

Sinónimos: Chabraea glabra DC., Chabraea scrobiculata (D. Don) DC., Chabraea scrobiculata (D. Don) DC. var. pentacephala Phil., Lasiorhiza glabra (DC.) Kuntze, Lasiorhiza scrobiculata (D. Don) Kuntze, Leuceria scrobiculata D. Don var. glabra (DC.) Hauman, Mimela pedicularifolia Phil.

Hierba. Perenne. Nativa.

Distribución: VAL, RME, LBO.

Rango altitudinal: 1900-3500 m.

Países limítrofes: Argentina.

Leucheria senecioides Hook. \& Arn.

Sinónimos: Lasiorhiza cinerea (D. Don) Less., Chabraea abbreviata Bertero ex Colla, Chabraea cinerea (D. Don) DC., Lasiorhiza senecioides (Hook. \& Arn.) Kuntze, Lenceria abbreviata (Bertero) Steud., Leuceria cinerea D. Don, Leuceria senecioides Hook. \& Arn. var. purpurescens DC.

Hierba. Perenne. Endémica.

Distribución: COQ, VAL, RME, LBO, MAU, NUB, BIO, ARA.

Rango altitudinal: 0-500 m.

Leucheria tenuis Less.

Sinónimos: Chabraea berteroniana Steud., Chabraea tenuior Bertero ex Colla

Hierba. Anual. Endémica.

Distribución: COQ, VAL, RME, LBO, ARA.

Rango altitudinal: 900-2000 m.
Leucheria thermarum (Phil.) Phil.

Sinónimos: Chabraea thermarum Phil., Leuceria thermarum (Phil.) Reiche, nom. illeg.

Hierba. Perenne. Nativa.

Distribución: NUB, ARA, LRI, LLA, AIS.

Rango altitudinal: 0-1000 m.

Países limítrofes: Argentina.

\section{Leucheria tomentosa (Less.) Crisci}

Sinónimos: Chabraea tomentosa (Less.) DC., Lasiorhiza pulchella (D. Don) Steud., Lasiorhiza tomentosa Less., Leuceria eriochlaena J. Remy, Leuceria pulchella D. Don

Hierba. Perenne. Endémica.

Distribución: COQ, VAL, RME, MAU.

Rango altitudinal: 0-500 $\mathrm{m}$.

Leucheria viscida (Bertero ex Colla) Crisci

Sinónimos: Chabraea rosea DC., Chabraea viscida Bertero ex Colla, Chabraea viscosa Bertero ex DC., nom. nud., Lasiorhiza philippiana Kuntze, Lasiorhiza rosea Less., Leuceria chillanensis Reiche, Leuceria glandulosa Phil., nom. illeg., Leuceria leucomalla Phil., Leuceria neaei DC., Leuceria rosea (Less.) Reiche

Hierba. Perenne. Nativa.

Distribución: COQ, VAL, RME, LBO, MAU, NUB, BIO, ARA.

Rango altitudinal: 0-3000 m.

Países limítrofes: Argentina.

\section{Leunisia}

Leunisia laeta Phil.

Arbusto. Nativo.

Distribución: COQ, VAL.

Rango altitudinal: 2000-3000 m.

\section{Logfia}

Logfia gallica (L.) Coss. \& Germ.

Hierba. Anual. Introducida.

Distribución: COQ, VAL, RME, LBO, MAU, NUB, BIO, ARA.

\section{Lophopappus}

Lophopappus cuneatus R.E. Fr.

Arbusto. Nativo.

Distribución: TAR.

Rango altitudinal: 2800-4000 m.

Países limítrofes: Argentina y Bolivia.

Lophopappus foliosus Rusby

Sinónimos: Proustia foliosa (Rusby) Ferreyra

Arbusto. Nativo. 
Distribución: AYP, TAR.

Rango altitudinal: 3000-4000 m.

Países limítrofes: Argentina, Bolivia y Perú.

Lophopappus tarapacanus (Phil.) Cabrera

Sinónimos: Gochnatia tarapacana Phil.

Arbusto. Nativo.

Distribución: AYP, TAR.

Rango altitudinal: 2200-4700 m.

Nombre vulgar: Tajana, tagtaga, chari, moñe, leñadura.

\section{Lucilia}

Lucilia eriophora J. Remy

Hierba. Perenne. Endémica.

Distribución: VAL, RME, LBO, ARA.

Rango altitudinal: 1000-1500 m.

\section{Lycapsus}

Lycapsus tenuifolius Phil.

Sinónimos: Alomia tenuifolia (Phil.) Benth. \& Hook.f. ex Reiche

Subarbusto. Endémico.

Distribución: IDE.

Rango altitudinal: 0-500 m.

\section{Macrachaenium}

\section{Macrachaenium gracile Hook.f.}

Sinónimos: Macrachaenium foliosum Albov

Hierba. Perenne. Nativa.

Distribución: BIO, ARA, LRI, LLA, AIS, MAG.

Rango altitudinal: 0-1000 m.

Países limítrofes: Argentina.

\section{Madia}

Madia chilensis (Nutt.) Reiche

Sinónimos: Madariopsis chilensis Nutt.

Hierba. Anual. Endémica.

Distribución: COQ, VAL, RME, LBO, MAU, NUB, BIO, ARA, LLA, MAG.

Rango altitudinal: 10-2500 m.

Nombre vulgar: Madia, madi, melosa.

\section{Madia sativa Molina}

Sinónimos: Madia viscosa Cav.

Hierba. Anual. Nativa.

Distribución: ATA, COQ, VAL, RME, LBO, MAU, NUB, BIO, ARA, LRI, LLA, AIS, MAG, JFE.

Rango altitudinal: 0-1300 m.

Países limítrofes: Argentina.

Nombre vulgar: Madi, melosa.
Nota: Introducida en el Archipiélago Juan Fernández.

\section{Malacothrix}

Malacothrix clevelandii A. Gray

Hierba. Anual. Introducida.

Distribución: ATA, COQ.

Rango altitudinal: 10-1000 m.

Malacothrix coulteri A. Gray

Hierba. Anual. Introducida.

Distribución: COQ.

\section{Marticorenia}

Marticorenia foliosa (Phil.) Crisci

Sinónimos: Leuceria foliosa Phil., Lasiorhiza foliosa (Phil.)

Kuntze

Arbusto. Endémico.

Distribución: ATA, VAL, RME.

Rango altitudinal: 2700-3300 m.

\section{Matricaria}

Matricaria chamomilla L.

Hierba. Anual. Introducida.

Distribución: ANT, COQ, VAL, RME, LBO, MAU, NUB, BIO, ARA, LLA, JFE.

Matricaria discoidea DC.

Hierba. Anual. Introducida.

Distribución: VAL, RME, LBO, MAU, NUB, BIO, ARA, LLA, AIS, MAG.

\section{Micropsis}

Micropsis nana DC.

Sinónimos: Lasiophyton pusillum Hook. \& Arn.

Hierba. Anual. Endémica.

Distribución: COQ, VAL, RME, LBO, MAU, NUB, BIO, ARA, JFE.

Rango altitudinal: 300-2500 m.

Nota: Introducida en el Archipiélago Juan Fernández.

\section{Microseris}

Microseris pygmaea D. Don

Hierba. Anual o perenne. Introducida.

Distribución: ANT, ATA, COQ, VAL, RME, LBO, MAU, BIO, ARA. 
Mikania

Mikania mendocina Phil.

Hierba trepadora. Perenne. Nativa.

Distribución: LBO, MAU, NUB, BIO, ARA.

Rango altitudinal: 500-1000 m.

Países limítrofes: Argentina.

\section{Mniodes}

Mniodes coarctata Cuatrec.

Hierba. Perenne. Nativa.

Distribución: AYP.

Rango altitudinal: $4600 \mathrm{~m}$.

Países limítrofes: Perú.

Mniodes piptolepis (Wedd.) S.E. Freire, Chemisquy, Anderb. \& Urtubey

Sinónimos: Belloa piptolepis (Wedd.) Cabrera, Gnaphalium piptolepis (Wedd.) Griseb., Lucilia piptolepis Wedd., Merope piptolepis Wedd., Luciliocline piptolepis (Wedd.)

M.O. Dillon \& Sagást.

Hierba. Perenne. Nativa.

Distribución: TAR.

Rango altitudinal: 3200-4500 m.

Países limítrofes: Argentina, Bolivia y Perú.

Mniodes schultzii (Wedd.) S.E. Freire, Chemisquy, Anderb. \& Urtubey

Sinónimos: Belloa schultzii (Wedd.) Cabrera, Gnaphalium schultzii (Wedd.) Cabrera, Lucilia schultzii (Wedd.) A. Gray, Merope schultzii Wedd., Luciliocline schultzii (Wedd.) M.O. Dillon \& Sagást.

Hierba. Perenne. Nativa.

Distribución: TAR, ANT.

Rango altitudinal: 3900-5000 m.

Países limítrofes: Argentina, Bolivia y Perú.

Nombre vulgar: Yaretilla.

\section{Moscharia}

Moscharia pinnatifida Ruiz \& Pav.

Hierba. Anual. Endémica.

Distribución: ATA, COQ, VAL, RME, LBO, MAU, NUB.

Rango altitudinal: 0-2000 m.

Nombre vulgar: Almizcle.

Moscharia solbrigii Crisci

Hierba. Anual. Endémica.

Distribución: COQ.

Rango altitudinal: 300-500 m.

\section{Mutisia}

Mutisia acerosa Less.

Sinónimos: Mutisia parviflora J. Remy, Mutisia ulicina D.

Don

Arbusto. Nativo.

Distribución: COQ, VAL, RME, LBO, MAU, NUB.

Rango altitudinal: 1200-3000 m.

Países limítrofes: Argentina.

Nombre vulgar: Romerillo de cordillera.

Mutisia acuminata Ruiz \& Pav. var. hirsuta (Meyen) Cabrera

Sinónimos: Mutisia viciaefolia Cav. var. hirsuta (Meyen)

Wedd., Mutisia hirsuta Meyen

Arbusto trepador. Nativo.

Distribución: AYP, TAR.

Rango altitudinal: 2500-3500 m.

Países limítrofes: Bolivia y Perú.

Mutisia araucana Phil.

Subarbusto trepador. Endémico.

Distribución: BIO, ARA.

Rango altitudinal: 800-1400 m.

Mutisia brachyantha Phil.

Subarbusto. Endémico.

Distribución: COQ, VAL, RME, LBO, MAU, NUB, BIO, ARA.

Rango altitudinal: $1200 \mathrm{~m}$.

Mutisia cana Poepp.

Sinónimos: Mutisia glauca J. Remy, Mutisia polyphylla Phil., Mutisia reticulata Phil., Mutisia volckmanni Phil., Mutisia glauca Phil.

Arbusto trepador. Endémico.

Distribución: ATA, COQ, VAL, RME.

Rango altitudinal: 1000-2000 m.

Nombre vulgar: Granadilla.

Mutisia decurrens Cav. var. decurrens

Sinónimos: Aplophyllum decurrens (Cav.) Cass., Mutisia decurrens Cav. var. andina Phil.

Subarbusto trepador. Nativo.

Distribución: LBO, MAU, NUB, BIO, ARA, AIS.

Rango altitudinal: 0-1000 m.

Países limítrofes: Argentina.

Mutisia decurrens Cav. var. patagonica (Phil.) S.F. Blake Sinónimos: Mutisia patagonica Phil.

Subarbusto trepador. Nativo.

Distribución: NUB.

Rango altitudinal: 0-1000 m.

Países limítrofes: Argentina. 
Mutisia hamata Reiche

Sinónimos: Mutisia microphylla Phil., hom. illeg.

Subarbusto trepador. Nativo.

Distribución: AYP, TAR, ANT.

Rango altitudinal: 2500-4500 m.

Países limítrofes: Argentina y Bolivia.

Mutisia ilicifolia Hook. var. decandolleana (Phil. ex Reiche) Cabrera

Sinónimos: Mutisia candolleana Phil., Mutisia decandolleana Phil.

Arbusto trepador. Endémico.

Distribución: COQ, VAL, RME, LBO, MAU.

Rango altitudinal: 200-2000 m.

\section{Mutisia ilicifolia Hook. var. ilicifolia}

Sinónimos: Aplophyllum ilicifolium (Cav.) Cass., Mutisia breviflora Phil., Mutisia consobrina Phil., Mutisia eriocephala Phil., Mutisia grossedentata Phil., Mutisia ilicifolia Hook., Mutisia ilicifolia Hook. var. cavanillesii DC., Mutisia involucrata Phil. var. consobrina Phil.

Arbusto trepador. Endémico.

Distribución: COQ, VAL, RME, LBO, MAU, NUB.

Rango altitudinal: 1000-1800 m.

Nombre vulgar: Clavel del campo, grasilla, flor de granada, hierba del jote, flor de la canela.

Mutisia involucrata Phil.

Subarbusto. Endémico.

Distribución: VAL, RME, LBO, MAU.

Rango altitudinal: 300-1700 m.

Mutisia lanigera Wedd.

Subarbusto. Nativo.

Distribución: AYP, TAR, ANT.

Rango altitudinal: $4000 \mathrm{~m}$.

Países limítrofes: Bolivia y Perú.

Nombre vulgar: Chirchirkuma, chinkachinka, wichakaña.

Mutisia latifolia D. Don fma. bracteata (J. Remy) Cabrera Sinónimos: Mutisia bracteata J. Remy

Arbusto trepador. Endémico.

Distribución: COQ, VAL.

Rango altitudinal: 0-600 m.

Mutisia latifolia D. Don fma. latifolia

Arbusto trepador. Endémico.

Distribución: COQ, VAL, RME, LBO, NUB.

Rango altitudinal: 0-2400 m.

Mutisia ledifolia Decne. ex Wedd.

Arbusto. Nativo.

Distribución: AYP, TAR, ANT.

Rango altitudinal: 3000-4200 m.
Países limítrofes: Argentina, Bolivia y Perú.

Nombre vulgar: Quinchamale, chinchirkoma, tola negra, kaputula, tola romero.

Mutisia linearifolia Cav.

Sinónimos: Aplophyllum linearifolium (Cav.) Cass.

Arbusto. Nativo.

Distribución: RME, LBO, MAU, NUB.

Rango altitudinal: 0-1000 m.

Países limítrofes: Argentina.

Mutisia macrophylla Phil.

Subarbusto. Endémico.

Distribución: NUB.

Rango altitudinal: 200-500 m.

Mutisia oligodon Poepp. \& Endl.

Sinónimos: Mutisia gayana J. Remy, Mutisia meyeniana J.

Remy ex Phil.

Subarbusto trepador. Nativo.

Distribución: NUB, BIO, ARA.

Rango altitudinal: 0-1000 m.

Países limítrofes: Argentina.

Mutisia rosea Poepp. ex Less.

Sinónimos: Mutisia alba Phil., Mutisia berteriana Endl. ex Poepp., Mutisia berterii DC., Mutisia landbeckii Phil., Mutisia subulata Ruiz \& Pav. var. rosea (Less.) Ruiz \& Pav. Subarbusto trepador. Endémico.

Distribución: COQ, VAL, RME, LBO, MAU, BIO.

Rango altitudinal: 1000-2000 m.

Mutisia sinuata Cav.

Sinónimos: Guariruma sinuatum (Cav.) Cass., Mutisia dentata Phil., Mutisia popetana Phil., Mutisia sanguinea Meyen, Mutisia sinuata Cav. var. brachycephala Phil., Mutisia sinuata Cav. var. taraxacifolia (Less.) Kuntze, Mutisia taraxacifolia Less., Mutisia taraxacifolia Less. var. integerrima Phil.

Arbusto trepador. Nativo.

Distribución: ATA, COQ, VAL, RME, LBO, MAU.

Rango altitudinal: 1700-3500 m.

Países limítrofes: Argentina.

Mutisia spectabilis Phil.

Subarbusto. Endémico.

Distribución: COQ, VAL.

Rango altitudinal: 1300-2800 m.

Nombre vulgar: Clavel del aire.

Mutisia spinosa Ruiz \& Pav. var. pulchella (Speg.) Cabrera Sinónimos: Mutisia bridgesii Endl. ex Poepp. \& Endl., Mutisia pulchella Speg., Mutisia retusa J. Remy, Mutisia retusa J. Remy var. pulchella (Speg.) Skottsb. 
Subarbusto trepador. Nativo.

Distribución: MAU, NUB, BIO, ARA, LRI, LLA, AIS.

Rango altitudinal: 0-1000 m.

Países limítrofes: Argentina.

Nombre vulgar: Clavel del campo, flor de la estrella.

Mutisia spinosa Ruiz \& Pav. var. spinosa

Sinónimos: Mutisia auriculata Poepp. ex Less., Mutisia hastata Bertero ex DC., nom. nud., Mutisia ilicifolia Hook. var. truncata (D. Don) DC., Mutisia retusa J. Remy var. glaberrima Phil., Mutisia truncata D. Don

Subarbusto trepador. Nativo.

Distribución: MAU, NUB, BIO, ARA, LRI, LLA, AIS.

Rango altitudinal: 0-1000 m.

Países limítrofes: Argentina.

Nombre vulgar: Clavel del campo, flor de la estrella.

Mutisia splendens Renjifo

Subarbusto. Endémico.

Distribución: VAL, RME.

\section{Mutisia subspinosa Cav.}

Sinónimos: Guariruma subspinosum (Cav.) Cass.

Subarbusto. Nativo.

Distribución: ATA, NUB.

Rango altitudinal: 1500-2500 m.

Países limítrofes: Argentina.

Mutisia subulata Ruiz \& Pav. fma. rosmarinifolia (Poepp. \& Endl.) Cabrera

Sinónimos: Mutisia linearifolia Hook., hom. illeg., Mutisia gracilis Meyen, Mutisia hookeri Meyen, Mutisia subulata Ruiz \& Pav. var. major Hook. \& Arn., Mutisia hookeri Meyen var. rosmarinifolia Poepp. \& Endl., Mutisia elegans Phil., Mutisia subulata Ruiz \& Pav. var. gracilis (Meyen) Walp., Mutisia linearifolia Cav. var. hookeri (Meyen) Reiche Subarbusto trepador. Nativo.

Distribución: COQ, VAL, RME, LBO, MAU, NUB, BIO.

Rango altitudinal: $1700-3000 \mathrm{~m}$.

Países limítrofes: Bolivia.

Mutisia subulata Ruiz \& Pav. fma. subulata

Sinónimos: Guariruma inflexum (Cav.) Cass., Mutisia hookeri Meyen var. scandens Poepp. \& Endl., Mutisia inflexa Cav., Mutisia inflexa Cav. var. imberbis Poepp. \& Endl., Mutisia inflexa Cav. var. melanopoga Poepp. \& Endl., Mutisia subulata Ruiz \& Pav. var. cavanillessii Hook. \& Arn., Mutisia versicolor Phil.

Subarbusto trepador. Nativo.

Distribución: COQ, VAL, RME, LBO, MAU, NUB, BIO, ARA.

Rango altitudinal: 0-500 m.

Países limítrofes: Argentina.
Mutisia tridens Poepp. ex Less.

Subarbusto. Endémico.

Distribución: BIO.

\section{Nardophyllum}

Nardophyllum bryoides (Lam.) Cabrera

Sinónimos: Anactinia hookeri J. Remy, nom. illeg., Nardophyllum obtusifolium Hook. \& Arn., Baccharis bryoides (Lam.) Pers., Chiliotrichum darwinii Hook.f., Chiliotrichum humile Hook.f., Chiliotrichum kingii Hook.f., Conyza bryoides Lam., Microchaete humilis (Hook.f.) Sch. Bip., Nardophyllum darwinii (Hook.f.) A. Gray, Nardophyllum humile (Hook.f.) A. Gray, Nardophyllum kingii (Hook.f.) A. Gray, Nardophyllum parvifolium Phil., Dolichogyne parvifolia Phil. ex Kuntze

Arbusto. Nativo.

Distribución: AIS, MAG.

Rango altitudinal: 0-1200 m.

Países limítrofes: Argentina.

Nardophyllum chiliotrichioides (J. Remy) A. Gray

Sinónimos: Dolichogyne chiliotrichioides J. Remy

Arbusto. Nativo.

Distribución: COQ, VAL, RME, LBO.

Rango altitudinal: 0-3800 m.

Países limítrofes: Argentina.

Nardophyllum genistoides (Phil.) A. Gray Sinónimos: Dolichogyne genistoides Phil.

Arbusto. Endémico.

Distribución: VAL, RME.

Nardophyllum lanatum (Meyen) Cabrera

Sinónimos: Barnadesia lanata Meyen, Dolichogyne candollei J. Remy, nom. illeg., Dolichogyne gnaphalioides DC., Gochnatia revoluta D. Don ex Hook. \& Arn., Nardophyllum candollei (J. Remy) F. Meigen, comb. illeg., Nardophyllum revolutum (D. Don ex Hook. \& Arn.) Hook. \& Arn.

Arbusto. Endémico.

Distribución: ATA, COQ, VAL, RME, LBO.

Rango altitudinal: 1200-3200 m.

Nombre vulgar: Macabeo.

\section{Nassauvia}

Nassauvia aculeata (Less.) Poepp. \& Endl. var. aculeata Sinónimos: Nassauvia aculeata (Less.) Poepp. \& Endl. var. spinosa (D. Don) Cabrera, Nassauvia diazii (Phil.) Reiche, Nassauvia latifolia (Phil.) F. Meigen, Nassauvia spinosa (D. Don) Reiche, comb. illeg., Panargyrum diazii Phil., Panargyrum latifolium Phil., Panargyrum pectinatum Phil., Panargyrum spinosum D. Don, Penthanthus aculeatus Less. 
Hierba. Perenne. Nativa.

Distribución: VAL, RME, LBO, MAU, NUB, BIO, ARA, MAG.

Rango altitudinal: 1500-2500 m.

Países limítrofes: Argentina.

Nassauvia aculeata (Less.) Poepp. \& Endl. var. azorelloides (Speg.) Cabrera

Sinónimos: Nassauvia abbreviata (Hook. \& Arn.) Dusén, Nassauvia abbreviata (Hook. \& Arn.) Dusén var. azorelloides Speg., Nassauvia abbreviata (Hook. \& Arn.) Dusén var. subspinosa (Phil.) Macloskie, Nassauvia subspinosa (Phil.) Albov, Panargyrum abbreviatum Hook. \& Arn., Panargyrum subspinosum Phil.

Hierba. Perenne. Nativa.

Distribución: AIS, MAG.

Rango altitudinal: 0-1000 m.

Países limítrofes: Argentina.

Nassauvia aculeata (Less.) Poepp. \& Endl. var. robusta (Cabrera) Cabrera

Sinónimos: Nassauvia abbreviata (Hook. \& Arn.) Dusén var. robusta Cabrera

Hierba. Perenne. Nativa.

Distribución: AIS, MAG.

Rango altitudinal: 0-1000 m.

Países limítrofes: Argentina.

Nassauvia argentea Phil.

Sinónimos: Nassauvia revoluta D. Don var. argentea (Phil.)

Hosseus

Hierba. Perenne. Nativa.

Distribución: NUB, ARA, LRI.

Rango altitudinal: 1500-2000 m.

Países limítrofes: Argentina.

Nassauvia axillaris (Lag. ex Lindl.) D. Don

Sinónimos: Acanthophyllum axillare (Lag. ex Lindl.) Hook. \& Arn., Strongyloma axillare (Lag. ex Lindl.) DC., Triptilion axillare Lag. ex Lindl.

Arbusto. Nativo.

Distribución: COQ, VAL, RME.

Rango altitudinal: 1000-4600 m.

Países limítrofes: Argentina y Bolivia.

Nassauvia coronipappa M.T.K. Arroyo \& Martic.

Hierba. Perenne. Endémica.

Distribución: MAG.

Rango altitudinal: 800-1100 m.

Nassauvia cumingii Hook. \& Arn.

Sinónimos: Nassauvia glabrata Phil., Nassauvia macracantha DC., Nassauvia macracantha DC. var. glabrata (Phil.) Reiche, Nassauvia macracantha DC. var. spicata (J. Remy) Hauman, Nassauvia spicata J. Remy, Nassauvia spinosa Phil., Nassauvia suaveolens D. Don, hom. illeg.

Hierba. Perenne. Nativa.

Distribución: COQ, VAL, RME, LBO, MAU.

Rango altitudinal: 2700-4000 m.

Países limítrofes: Argentina.

Nassauvia darwinii (Hook. \& Arn.) O. Hoffm. \& Dusén Sinónimos: Nassauvia candollei Macloskie, Nassauvia darwinii (Hook. \& Arn.) O. Hoffm. \& Dusén var. laxa (Phil.) Skottsb., Nassauvia lagascae (DC.) Reiche, hom. illeg., Nassauvia laxa (Phil.) Speg., Panargyrum darwinii Hook. \& Arn., Panargyrum lagascae DC., Panargyrum laxum Phil.

Hierba. Perenne. Nativa.

Distribución: AIS, MAG.

Rango altitudinal: 0-1000 m.

Países limítrofes: Argentina.

Nassauvia dentata Griseb.

Sinónimos: Nassauvia cespitosa Wedd., Nassauvia patula Phil.

Hierba. Perenne. Nativa.

Distribución: RME, BIO, ARA, LRI, LLA, AIS, MAG.

Rango altitudinal: 1200-2100 m.

Países limítrofes: Argentina.

Nassauvia digitata Wedd.

Sinónimos: Nassauvia lycopodioides Phil.

Hierba. Perenne. Nativa.

Distribución: MAU, NUB, BIO.

Rango altitudinal: 2000-2500 m.

Países limítrofes: Argentina.

Nassauvia dusenii O. Hoffm.

Hierba. Perenne. Nativa.

Distribución: AIS, MAG.

Rango altitudinal: 0-1000 m.

Países limítrofes: Argentina.

Nassauvia glomerata (D. Don) Wedd.

Sinónimos: Panargyrum densifolium Phil., Panargyrum glomeratum D. Don

Hierba. Perenne. Nativa.

Distribución: RME, LBO, MAU, BIO.

Rango altitudinal: 2500-3500 m.

Países limítrofes: Argentina.

Nassauvia glomerulosa (Lag. ex Lindl.) D. Don

Sinónimos: Nassauvia glomerulosa (Lag. ex Lindl.) D. Don fma. struthionum (Phil.) Skottsb., Nassauvia struthionum (Phil.) Speg., Strongyloma glomerulosum (Lag. ex Lindl.) DC., Strongyloma struthionum Phil., Triptilion glomerulosum Lag. ex Lindl., Nassauvia maeviae Cabrera 
Arbusto. Nativo.

Distribución: RME, MAG.

Rango altitudinal: 0-1500 m.

Países limítrofes: Argentina.

Nassauvia lagascae (D. Don) F. Meigen var. globosa Skottsb.

Hierba. Perenne. Nativa.

Distribución: MAG.

Rango altitudinal: 500-1000 m.

Países limítrofes: Argentina.

Nassauvia lagascae (D. Don) F. Meigen var. lagascae

Sinónimos: Caloptilion lagascae (D. Don) Hook. \& Arn., Nassauvia lanata Reiche, Portalesia procumbens Meyen, Sphaerocephalus lagascae D. Don

Hierba. Perenne. Nativa.

Distribución: COQ, VAL, RME, LBO, MAU, ARA, LRI, MAG.

Rango altitudinal: 3000-4000 m.

Países limítrofes: Argentina.

Nassauvia lagascae (D. Don) F. Meigen var. lanata (Phil.) Skottsb.

Sinónimos: Caloptilion lagascae (D. Don) Hook. \& Arn. var. lanata Phil., Nassauvia humilis Phil., Nassauvia lanata Reiche var. lanigera (Phil.) Reiche, Nassauvia lanigera Phil.

Hierba. Perenne. Nativa.

Distribución: MAU, NUB, BIO, ARA, LRI, LLA, AIS, MAG.

Rango altitudinal: 1000-3000 m.

Países limítrofes: Argentina.

Nassauvia latissima Skottsb.

Hierba. Perenne. Nativa.

Distribución: MAG.

Rango altitudinal: 0-500 m.

Países limítrofes: Argentina.

Nassauvia looseri Cabrera

Sinónimos: Panargyrum heterophyllum Phil., Panargyrum acerosum Phil., Nassauvia heterophylla (Phil.) Reiche

Hierba. Perenne. Endémica.

Distribución: RME.

Rango altitudinal: 2500-3000 m.

Nassauvia magellanica J.F. Gmel.

Sinónimos: Nassauvia suaveolens Willd.

Hierba. Perenne. Nativa.

Distribución: MAG.

Rango altitudinal: 0-1000 m.

Países limítrofes: Argentina.
Nassauvia pinnigera D. Don

Sinónimos: Nassauvia multiflora Meyen

Hierba. Perenne. Nativa.

Distribución: VAL, RME, LBO, MAU.

Rango altitudinal: 3000-4000 m.

Países limítrofes: Argentina.

\section{Nassauvia pulcherrima Cabrera}

Hierba. Perenne. Nativa.

Distribución: LRI.

Rango altitudinal: 1800-2000 m.

Países limítrofes: Argentina.

Nassauvia pygmaea (Cass.) Hook.f. var. intermedia (Phil.) Cabrera

Sinónimos: Nassauvia intermedia Phil., Nassauvia pumila Poepp. \& Endl., Nassauvia pumila Poepp. \& Endl. var. intermedia (Phil.) Reiche

Hierba. Perenne. Nativa.

Distribución: NUB, BIO, ARA, LLA.

Rango altitudinal: 1500-2000 m.

Países limítrofes: Argentina.

Nassauvia pygmaea (Cass.) Hook.f. var. pygmaea

Sinónimos: Nassauvia nordenskjoldii O. Hoffm. ex Dusén, Nassauvia pumila Poepp. \& Endl. var. nordenskjoldii (O. Hoffm. ex Dusén) Reiche, Triachne pygmaea Cass.

Hierba. Perenne. Nativa.

Distribución: VAL, NUB, BIO, ARA, AIS, MAG.

Rango altitudinal: 0-1000 m.

Países limítrofes: Argentina.

Nassauvia pyramidalis Meyen

Sinónimos: Nassauvia macracantha DC. var. pungens (Phil.) Hauman, Nassauvia pungens Phil.

Hierba. Perenne. Nativa.

Distribución: RME, LBO, MAU, BIO.

Rango altitudinal: 2000-2700 m.

Países limítrofes: Argentina.

Nassauvia ramosissima DC.

Hierba. Perenne. Endémica.

Distribución: LBO, MAU, LRI, LLA.

Rango altitudinal: 600-2000 m.

Nassauvia revoluta D. Don

Sinónimos: Nassauvia brevifolia Phil., Nassauvia nivalis Poepp. ex Less., Nassauvia nivalis Poepp. \& Endl. var. brevifolia (Phil.) Reiche, Nassauvia nivalis Poepp. \& Endl. var. sericea Phil., Nassauvia revoluta D. Don var. nivalis (Poepp. ex Less.) Hosseus, Nassauvia sericea Phil.

Subarbusto. Nativo.

Distribución: RME, LBO, MAU, NUB, BIO, ARA, LRI, LLA, AIS, MAG. 
Rango altitudinal: 1000-4000 m.

Países limítrofes: Argentina.

Nombre vulgar: Cadislao, calahuala.

Nassauvia sprengelioides DC.

Sinónimos: Nassauvia araucana Phil.

Hierba. Perenne. Nativa.

Distribución: MAU, NUB, BIO, ARA.

Rango altitudinal: 2000-3000 m.

Países limítrofes: Argentina.

Nombre vulgar: Hierba de la culebra.

Nassauvia uniflora (D. Don) Hauman

Sinónimos: Nassauvia oligocephala (DC.) Wedd., Panargyrum oligocephalum DC., Panargyrum uniflorum D. Don

Hierba. Perenne. Nativa.

Distribución: COQ, VAL, RME.

Rango altitudinal: 2800-4000 m.

Países limítrofes: Argentina.

\section{Noticastrum}

Noticastrum adscendens DC.

Sinónimos: Noticastrum pradense (Phil.) Phil., Aster adscendens (DC.) Reiche, Aster pradensis Phil., Diplopappus sericeus Less. var. glandulosa Hook. \& Arn., Noticastrum glandulosum Phil., Noticastrum sanfurgi Phil. Hierba. Perenne. Endémica.

Distribución: VAL, RME, LBO, MAU.

Rango altitudinal: 0-1000 m.

\section{Noticastrum antucense Phil.}

Sinónimos: Aster antucensis (Phil.) Kuntze, Aster erectus (J. Remy) Kuntze var. antucensis (Phil.) Reiche

Hierba. Perenne. Endémica.

Distribución: BIO, ARA, LRI, LLA.

Rango altitudinal: 100-300 m.

Noticastrum erectum J. Remy

Sinónimos: Aster erectus (J. Remy) Kuntze, Aster erectus (J. Remy) Reiche

Hierba. Perenne. Endémica.

Distribución: MAU, NUB, BIO, ARA, LLA.

Rango altitudinal: $100-1000 \mathrm{~m}$.

\section{Noticastrum eriophorum J. Remy}

Sinónimos: Aster eriophorus (J. Remy) Kuntze, Aster eriophorus (J. Remy) Reiche, Aster leucopappus (Phil.) Reiche, Leucopsis harveyi Baker, Leucopsis sericea (Less.) Baker var. eriophora (J. Remy) Baker, Noticastrum leucopappum Phil.

Hierba. Perenne. Endémica.
Distribución: VAL, LBO, MAU, NUB, BIO, ARA, LRI.

Rango altitudinal: 0-1300 m.

Noticastrum sericeum (Less.) Less. ex Phil.

Sinónimos: Aster albus (Phil.) Reiche, comb. illeg., Aster albus (Phil.) Kuntze, Aster haplopappus (J. Remy) Kuntze, comb. illeg., Aster haplopappus (J. Remy) Reiche, Aster marginatus Kunth var. tomentosus Wedd., Aster nitens Kuntze, Aster notosericeus Griseb., Aster sericeus (Less.) Nees, Diplopappus sericeus Less., Noticastrum philippii Sch. Bip., nom. nud., Haplopappus sericeus (Less.) DC., Leucopsis sericea (Less.) Baker, Noticastrum album Phil., Noticastrum haplopappus J. Remy, nom. illeg.

Hierba. Perenne. Nativa.

Distribución: COQ, VAL, RME, LBO, MAU, NUB, BIO, ARA, LRI.

Rango altitudinal: 0-1500 m.

Países limítrofes: Argentina.

\section{Notopappus}

Notopappus andinus (Phil.) Klingenb.

Sinónimos: Grindeliaandina (Phil.)Phil., Chrysophthalmum andinum Phil., Helianthus australis Phil.

Subarbusto. Endémico.

Distribución: MAU.

Notopappus chryseus (Kuntze) Klingenb. var. discoides Tortosa \& A. Bartoli

Sinónimos: Aster chryseus Kuntze, Haplopappus chrysocephalus Reiche, Haplopappus chryseus (Kuntze) Cabrera, Pyrrocoma aurea Phil., Grindelia prunelloides (Poepp. ex Less.) A. Bartoli \& Tortosa var. discoides Tortosa \& A. Bartoli

Subarbusto. Nativo.

Distribución: MAU.

Rango altitudinal: 2300-2700 m.

Países limítrofes: Argentina.

Notopappus pectinatus (Phil.) Klingenb.

Sinónimos: Aster anethifolius (Phil.) Kuntze, Grindelia anethifolia (Phil.) A. Bartoli \& Tortosa, Aster pectinatus (Phil.) Kuntze, Diplopappus pinnatifidus Hook. \& Arn., hom. illeg., Haplopappus anethifolius Phil., Haplopappus moyanoi Speg., Haplopappus pectinatus Phil. var. anethifolius (Phil.) Reiche, Haplopappus pectinatus Phil., Haplopappus araucanus Phil.

Arbusto. Nativo.

Distribución: MAU, NUB, BIO, ARA.

Rango altitudinal: 500-1000 m.

Países limítrofes: Argentina. 
Notopappus prunelloides (Poepp. ex Less.) Klingenb. Sinónimos: Aster prunelloides (Poepp. ex Less.) Kuntze, Haplopappus prunelloides (Poepp. ex Less.) DC., Diplopappus prunelloides Poepp. ex Less., Haplopappus prunelloides (Poepp. ex Less.) DC. var. sphaerocephalus Reiche, Grindelia prunelloides (Poepp. ex Less.) A. Bartoli \& Tortosa, Haplopappus bellidifolius Phil. var. brachylepis (Phil.) Reiche, Haplopappus brachylepis Phil.

Hierba o subarbusto. Perenne. Nativa.

Distribución: MAU, NUB, BIO, ARA, LLA.

Rango altitudinal: 500-1700 m.

Países limítrofes: Argentina.

\section{Ocyroe}

Ocyroe armata (Wedd.) Bonifacino

Sinónimos: Dolichogyne armata Wedd., Ocyroe spinosa Phil., Nardophyllum armatum (Wedd.) Reiche

Arbusto. Nativo.

Distribución: ANT.

Rango altitudinal: 2800-4600 m.

Países limítrofes: Argentina y Bolivia.

\section{Onopordum}

Onopordum acanthium L.

Hierba. Bienal. Introducida.

Distribución: RME, ARA.

\section{Ophryosporus}

Ophryosporus anomalus R.M. King \& H. Rob.

Sinónimos: Piqueria cumingii B.L. Rob., hom. illeg.

Arbusto. Nativo.

Distribución: TAR, ANT.

Rango altitudinal: 0-200 m.

Países limítrofes: Perú.

Ophryosporus floribundus (DC.) R.M. King \& H. Rob.

Sinónimos: Piqueria floribunda DC.

Arbusto. Nativo.

Distribución: AYP, TAR, ANT.

Países limítrofes: Perú.

Ophryosporus heptanthus (Sch.Bip. ex Wedd.) R.M. King \& H. Rob.

Sinónimos: Eupatorium heptanthus (Sch. Bip. ex Baker) R.M. King \& H. Rob., Ophryosporus origanoides (Meyen \& Walp.) Hieron., Eupatorium origanoides Meyen \& Walp. Arbusto. Nativo.

Distribución: AYP, TAR.

Rango altitudinal: 2800-3320 m.

Países limítrofes: Bolivia, Perú.
Ophryosporus hoppii (B.L. Rob.) R.M. King \& H. Rob. Sinónimos: Trychionolepis hoppii B.L. Rob.

Arbusto. Nativo.

Distribución: AYP, TAR, ANT.

Rango altitudinal: 300-3200 m.

Países limítrofes: Perú.

Ophryosporus johnstonii B.L. Rob.

Arbusto. Endémico.

Distribución: ATA.

Rango altitudinal: 1200-1300 m.

Ophryosporus paradoxus (Hook. \& Arn.) Benth. \& Hook. ex B.D. Jacks.

Sinónimos: Eupatorium paradoxus Hook. \& Arn.

Arbusto. Endémico.

Distribución: ANT, ATA, COQ, VAL, RME.

Rango altitudinal: 0-1800 m.

Ophryosporus pinifolius (Phil.) R.M. King \& H. Rob. Sinónimos: Stevia pinifolia Phil., Piqueria pinifolia (Phil.) Hieron. ex B.L. Rob.

Arbusto. Nativo.

Distribución: AYP, TAR, ANT.

Rango altitudinal: 3000-3500 m.

Países limítrofes: Perú.

Nombre vulgar: Sapama.

Ophryosporus triangularis Meyen

Sinónimos: Eupatorium foliolosum DC., Ophryosporus

foliolosus (DC.) Reiche

Arbusto. Endémico.

Distribución: AYP, TAR, ANT, ATA, COQ.

Rango altitudinal: 0-3400 m.

Nombre vulgar: Rabo de zorro.

\section{Oriastrum}

Oriastrum acerosum (J. Remy) Phil. var. acerosum

Sinónimos: Chaetanthera acerosa (J. Remy) Benth. \& Hook.f. ex Griseb. var. acerosa, Chaetanthera pallida (Phil.) Hauman, Egania acerosa J. Remy, Egania pallida Phil., Oriastrum incanum Phil., Oriastrum parviflorum Phil., Oriastrum uncinatum Phil., Oriastrum pallidum (Phil.) Phil., Oriastrum pusillum Poepp. \& Endl. var. uncinatum (Phil.) Reiche

Hierba. Anual. Nativa.

Distribución: ATA, COQ, VAL, RME.

Rango altitudinal: 2800-4000 m.

Países limítrofes: Argentina.

Oriastrum acerosum (J. Remy) Phil. var. dasycarpum Cabrera

Hierba. Anual. Nativa. 
Distribución: COQ.

Rango altitudinal: $3600-4000 \mathrm{~m}$.

Países limítrofes: Argentina.

Oriastrum achenohirsutum (Tombesi) A.M.R. Davies Sinónimos: Chaetanthera pulvinata (Phil.) Hauman var. acheno-hirsutum Tombesi, Chaetanthera acheno-hirsuta (Tombesi) M.T.K. Arroyo, A.M.R. Davies \& Till-Bottraud Hierba. Anual. Nativa.

Distribución: ATA.

Rango altitudinal: 3900-4100 m.

Países limítrofes: Argentina.

Oriastrum apiculatum (J. Remy) A.M.R. Davies

Sinónimos: Chaetanthera apiculata (J. Remy) F. Meigen, Chaetanthera lanigera Phil., Egania apiculata J. Remy, Oriastrum albicaule Phil. var. albicaule, Oriastrum albicaule Phil. var. nivale (Phil.) Reiche, Oriastrum nivale Phil.

Hierba. Anual. Nativa.

Distribución: COQ, VAL, RME, LBO, MAU, NUB.

Rango altitudinal: 3000-3300 m.

Países limítrofes: Argentina.

Oriastrum chilense (J. Remy) Wedd.

Sinónimos: Aldunantea chilensis J. Remy, Chaetanthera pusilla (D. Don) Hook. \& Arn., Oriastrum pusillum Reiche, hom. illeg. var. uncinatum Reiche, Tylloma pusillum D. Don, Oriastrum pusillum Reiche, hom. illeg.

Hierba. Anual. Nativa.

Distribución: COQ, RME.

Rango altitudinal: 2100-3800 m.

Países limítrofes: Argentina.

Oriastrum dioicum (J. Remy) Phil.

Sinónimos: Chaetanthera dioica (J. Remy) B.L. Rob., Egania dioica J. Remy

Hierba. Anual. Nativa.

Distribución: ANT, COQ, RME.

Rango altitudinal: 3000-5000 m.

Países limítrofes: Argentina.

Oriastrum gnaphalioides (J. Remy) Wedd.

Sinónimos: Aldunantea gnaphalioides J. Remy, Chaetanthera gnaphalioides (J. Remy) I.M. Johnst., Chondrochilus parvifolius Phil., Oriastrum albiflorum (Phil.) Reiche, Oriastrum leucocephalum Phil., Tylloma albiflorum Phil.

Hierba. Anual. Nativa.

Distribución: ANT, ATA, COQ, VAL, RME.

Rango altitudinal: $3000-4000 \mathrm{~m}$.

Países limítrofes: Argentina.
Oriastrum lycopodioides (J. Remy) Wedd.

Sinónimos: Aldunantea lycopodioides J. Remy, Chaetanthera lycopodioides (J. Remy) Cabrera, Oriastrum gayi Phil., Oriastrum glabriusculum Phil., Oriastrum lycopodioides (J. Remy) Wedd. var. glabriusculum (Phil.)

Reiche

Hierba. Anual. Nativa.

Distribución: COQ, VAL, LBO.

Rango altitudinal: 3000-3900 m.

Países limítrofes: Argentina.

Oriastrum minutum (Phil.) Nicola, S.E. Freire \& Ariza

Sinónimos: Chaetanthera minuta (Phil.) Cabrera, Oriastrum gossypinum Phil., Tylloma minutum Phil., Tylloma gnaphalioides Phil.

Hierba. Anual. Nativa.

Distribución: ANT, ATA, COQ, VAL.

Rango altitudinal: 3000-4000 m.

Países limítrofes: Argentina.

Oriastrum pulvinatum Phil. var. polymallum (Phil.) Hicken Sinónimos: Chaetanthera pulvinata (Phil.) Hauman var. polymalla (Phil.) Hicken, Chaetanthera acerosa auct. non (J. Remy) Bonpl. \& Humb., Oriastrum polymallum Phil., Oriastrum tontalensis A.M.R. Davies

Hierba. Anual. Nativa.

Distribución: TAR, COQ.

Rango altitudinal: 3000-4600 m.

Países limítrofes: Argentina.

Oriastrum pulvinatum Phil. var. pulvinatum

Sinónimos: Chaetanthera pulvinata (Phil.) Hauman var. pulvinata

Hierba. Anual. Nativa.

Distribución: TAR, ANT, ATA, COQ.

Rango altitudinal: 2800-4500 m.

Países limítrofes: Argentina.

Oriastrum pusillum Poepp. \& Endl.

Sinónimos: Chaetanthera planiseta Cabrera

Hierba. Anual. Endémica.

Distribución: COQ, VAL, RME.

Rango altitudinal: 2300-3400 m.

Oriastrum revolutum (Phil.) A.M.R. Davies

Sinónimos: Chaetanthera revoluta (Phil.) Cabrera, Egania appressa Phil., Egania revoluta Phil., Oriastrum dioicum (J. Remy) Phil. var. revolutum (Phil.) Reiche

Hierba. Anual. Nativa.

Distribución: AYP, TAR, ANT, ATA.

Rango altitudinal: $3500-4600 \mathrm{~m}$.

Países limítrofes: Argentina y Bolivia.

Nombre vulgar: Keúche, tieuchi, comida de perdiz. 
Oriastrum sphaeroidale Reiche

Sinónimos: Chaetanthera sphaeroidalis (Reiche) Hicken, Chaetanthera pulvinata (Phil.) Hauman var. acuminatibracteata Hauman

Hierba. Anual. Nativa.

Distribución: ANT, ATA, COQ.

Rango altitudinal: 3200-5000 m.

Países limítrofes: Argentina.

Nombre vulgar: Flor de la puna.

Oriastrum tarapacensis A.M.R. Davies

Hierba. Perenne. Endémica.

Distribución: AYP, TAR.

Rango altitudinal: 4100-4600 m.

Oriastrum werdermannii A.M.R. Davies

Hierba. Anual. Endémica.

Distribución: COQ.

Rango altitudinal: 0-1000 m.

\section{Oxyphyllum}

Oxyphyllum ulicinum Phil.

Arbusto. Endémico.

Distribución: ANT, ATA.

\section{Pachylaena}

Pachylaena atriplicifolia D. Don ex Hook. \& Arn. Sinónimos: Chionoptera gayophyta DC., Pachylaena gayophyta (DC.) Hieron., Pachylaena rosea I.M. Johnst.

Hierba. Perenne. Nativa.

Distribución: ATA, COQ, VAL, RME, LBO, MAU.

Rango altitudinal: 1400-4000 m.

Países limítrofes: Argentina.

Nombre vulgar: Oreja de chancho, hierba santa.

\section{Parastrephia}

Parastrephia lepidophylla (Wedd.) Cabrera

Sinónimos: Parastrephia lepidophylla (Wedd.) Cabrera, Dolichogyne lepidophylla Wedd., Lepidophyllum tola Cabrera, nom. illeg.

Arbusto. Nativo.

Distribución: AYP, TAR, ANT.

Rango altitudinal: 3500-4500 m.

Países limítrofes: Argentina, Bolivia y Perú.

Nombre vulgar: Tola vaca, tola, sipu, chijarwaya, pulika, tola amarga, qiroqiro.

Parastrephia lucida (Meyen) Cabrera

Sinónimos: Baccharis lucida Meyen, Dolichogyne glabra Phil., Polycladus abietinus Phil., Lepidophyllum abietinum (Phil.) Reiche, Lepidophyllum lucidum (Meyen) Cabrera
Arbusto. Nativo.

Distribución: AYP, TAR, ANT.

Rango altitudinal: 2900-5000 m.

Países limítrofes: Argentina, Bolivia y Perú.

Nombre vulgar: Tola del rio, tola de agua, umatola, tola amarga, unutola.

Parastrephia quadrangularis (Meyen) Cabrera

Sinónimos: Baccharis quadrangularis Meyen, Polycladus cupressinus Phil., Lepidophyllum cupressinum (Phil.) Kuntze, Lepidophyllum meyenii A. Gray, nom. illeg., Lepidophyllum quadrangulare (Meyen) Benth. \& Hook.

Arbusto. Nativo.

Distribución: AYP, TAR, ANT.

Rango altitudinal: 3000-4700 m.

Países limítrofes: Argentina, Bolivia y Perú.

Nombre vulgar: Chacha, coba, pulika, tola amarilla.

Parastrephia teretiuscula (Kuntze) Cabrera

Sinónimos: Lepidophyllum teretiusculum Kuntze

Arbusto. Nativo.

Distribución: TAR, ANT.

Rango altitudinal: 3200-4200 m.

Países limítrofes: Bolivia.

Nombre vulgar: Chacha, coba, pulika, tola amarilla, kobatola.

\section{Pascalia}

Pascalia glauca Ortega

Sinónimos: Wedelia glauca (Ortega) O. Hoffm. ex Hicken, Helianthus copiapinus Phil., Wedelia copiapina (Phil.) Reiche, Wedelia glauca (Ortega) S.F. Blake, comb. illeg.

Hierba. Perenne. Nativa.

Distribución: ATA.

Rango altitudinal: 0-2000 m.

Países limítrofes: Argentina y Bolivia.

Nombre vulgar: Sunchillo, huilmo, huilmo copiapino.

\section{Perezia}

Perezia atacamensis (Phil.) Reiche

Sinónimos: Clarionea atacamensis Phil.

Hierba. Perenne. Nativa.

Distribución: TAR, ANT, ATA, COQ.

Rango altitudinal: 3500-5000 m.

Países limítrofes: Argentina.

Nombre vulgar: Marancel, aycha-aycha.

Perezia calophylla (Phil.) Reiche

Sinónimos: Homoeanthus calophyllus Phil.

Hierba. Perenne. Nativa.

Distribución: LLA. 
Rango altitudinal: 1500-2000 m.

Países limítrofes: Argentina.

Perezia capito (Phil.) Reiche

Sinónimos: Homoeanthus capito Phil.

Hierba. Perenne. Nativa.

Distribución: LBO, MAU, NUB, BIO.

Rango altitudinal: 1500-2600 m.

Países limítrofes: Argentina.

Perezia carthamoides (D. Don) Hook. \& Arn.

Sinónimos: Clarionea carthamoides D. Don var. crispa (Meyen) Phil., Clarionea multicapitata J. Remy, Clarionea spectabilis Phil., Clarionea carthamoides D. Don, Perezia diversifolia Meyen, Perezia diversifolia Meyen var. crispa Meyen, Perezia multicapitata (J. Remy) Wedd.

Hierba. Perenne. Nativa.

Distribución: ATA, COQ, VAL, RME, LBO, MAU.

Rango altitudinal: 1800-3800 m.

Países limítrofes: Argentina.

Perezia ciliosa (Phil.) Reiche

Sinónimos: Clarionea ciliosa Phil.

Hierba. Perenne. Nativa.

Distribución: AYP, TAR, ANT.

Rango altitudinal: 2500-3000 m.

Países limítrofes: Argentina, Bolivia y Perú.

Nombre vulgar: Maransel hembra.

Perezia delicata Vuilleum.

Hierba. Perenne. Nativa.

Distribución: LLA.

Rango altitudinal: $1550 \mathrm{~m}$.

Países limítrofes: Argentina.

Perezia fonkii (Phil.) Reiche

Sinónimos: Clarionea affinis Phil., Clarionea fonkii Phil.

Hierba. Perenne. Nativa.

Distribución: NUB, BIO, ARA, LRI.

Rango altitudinal: 1000-2000 m.

Países limítrofes: Argentina.

Perezia lactucoides (Vahl) Less.

Sinónimos: Perezia lactucoides (Vahl) Less. subsp. palustris (Phil.) Vuilleum., Aster magellanicus Lam., Chaetanthera magellanica (Lam.) Spreng., Clarionea lactucoides (Vahl) D. Don, Perdicium lactucoides Vahl, Homoianthus magellanicus (Lam.) DC., Homoianthus palustris Phil., Perezia palustris (Phil.) Reiche, Homoianthus magellanicus (Lam.) DC. var. lactucoides (Vahl) Hook., Perdicium laevigatum Banks \& Sol. ex Hook.f., nom. nud.

Hierba. Perenne. Nativa.

Distribución: ARA, LRI, LLA, AIS, MAG.
Rango altitudinal: 0-1600 m.

Países limítrofes: Argentina.

Perezia linearis Less.

Sinónimos: Homoeanthus rigidus Phil., Homoianthus linearis (Less.) DC.

Hierba. Perenne. Nativa.

Distribución: LBO, MAU, NUB, BIO, ARA, AIS, MAG.

Rango altitudinal: 600-1600 m.

Países limítrofes: Argentina.

Perezia lyrata (J. Remy) Wedd.

Sinónimos: Clarionea pinnata Phil., Homoianthus gayanus

J. Remy, Homoianthus lyratus J. Remy, Perezia pinnata

(Phil.) Reiche

Hierba. Perenne. Endémica.

Distribución: LBO, MAU, NUB, BIO, ARA, LLA.

Rango altitudinal: $1500-2000 \mathrm{~m}$.

Perezia magellanica (L.f.) Lag.

Sinónimos: Clarionea elegans Phil., Clarionea magellanica (L.f.) Lag. ex DC., Perdicium magellanicum L.f., Perezia lagascae Cass., nom. illeg., Perezia magellanica (L.f.) Less., comb. illeg., Perezia elegans (Phil.) Albov, Perdicium sinuatum Banks \& Sol. ex Hook.f., nom. nud.

Hierba. Perenne. Nativa.

Distribución: LLA, AIS, MAG.

Rango altitudinal: 200-1400 m.

Países limítrofes: Argentina.

Perezia megalantha Speg.

Hierba. Perenne. Nativa.

Distribución: MAG.

Rango altitudinal: 1200-0 m.

Países limítrofes: Argentina.

Perezia multiflora (Humb. \& Bonpl.) Less.

Sinónimos: Chaetanthera multiflora Humb. \& Bonpl., Homanthis multiflorus (Humb. \& Bonpl.) Kunth, Homoianthus multiflorus (Humb. \& Bonpl.) DC.

Hierba. Perenne. Nativa.

Distribución: AYP.

Rango altitudinal: 1100-4900 m.

Países limítrofes: Argentina, Bolivia y Perú.

Perezia nutans Less.

Sinónimos: Perezia gayana DC., Perezia perfoliata J. Remy, Calorezia nutans (Less.) Panero, Perdicium nutans Poepp. ex Less., nom. nud.

Hierba. Perenne. Nativa.

Distribución: VAL, RME, LBO, MAU, NUB, BIO, ARA.

Rango altitudinal: 1000-2500 m.

Países limítrofes: Argentina. 
Perezia pedicularidifolia Less.

Sinónimos: Clarionea comosa Phil., Clarionea laciniata Phil., Clarionea parvifolia Phil., Clarionea variabilis Phil., Clarionea volkmanii Phil., Clarionea humilis Phil., Perezia laciniata (Phil.) Reiche, Perezia laciniata (Phil.) Reiche var. comosa (Phil.) Reiche, Homoeanthus variabilis Phil., Perezia pedicularidifolia Less. var. humilis (Phil.) Reiche, Perezia pedicularidifolia Less. var. parvifolia (Phil.) Reiche, Perezia variabilis (Phil.) Reiche, Perdicium pedicularidifolium Poepp. ex Less., nom. nud.

Hierba. Anual. Nativa.

Distribución: MAU, NUB, BIO, ARA, LRI, LLA, AIS.

Rango altitudinal: $1000-2200 \mathrm{~m}$.

Países limítrofes: Argentina.

Perezia pilifera (D. Don) Hook. \& Arn.

Sinónimos: Clarionea lechleri Sch. Bip., Clarionea pilifera D. Don, Homoeanthus humilis Phil., Perezia linearis Less. var. humilis (Phil.) Reiche, Perezia lechleri (Sch. Bip.) De Wild.

Hierba. Perenne. Nativa.

Distribución: COQ, VAL, RME, LBO, MAU, NUB, BIO, ARA, AIS, MAG.

Rango altitudinal: 1500-4300 m.

Países limítrofes: Argentina.

Perezia pinnatifida (Humb. \& Bonpl.) Wedd.

Sinónimos: Chaetanthera pinnatifida Humb. \& Bonpl.

Hierba. Perenne. Nativa.

Distribución: TAR.

Rango altitudinal: 3300-5000 m.

Países limítrofes: Argentina, Bolivia y Perú.

\section{Perezia poeppigii Less.}

Sinónimos: Clarionea caulescens Phil., Clarionea nana Phil., Clarionia virens D. Don, Clarionema virens (D. Don) Phil. var. humilis Phil., Homoeanthus remyanus Phil., Homoeanthus brevicaulis Phil., Homoianthus pristiphyllus J. Remy, Perezia pristiphylla (J. Remy) Wedd., Perezia virens (D. Don) Hook. \& Arn., Homoianthus brevicaulis Phil.

Hierba. Perenne. Endémica.

Distribución: COQ, VAL, RME, LBO, MAU.

Rango altitudinal: 1200-2900 m.

Perezia prenanthoides Less.

Sinónimos: Perezia brachylepis Phil., Calorezia prenanthoides (Less.) Panero

Hierba. Perenne. Nativa.

Distribución: NUB, ARA, LRI, LLA.

Rango altitudinal: $1200-2000 \mathrm{~m}$.

Países limítrofes: Argentina.

Nombre vulgar: Estrella de los Andes.
Perezia pungens (Humb. \& Bonpl.) Less.

Sinónimos: Perezia ciliaris D. Don ex Hook. \& Arn., Clarionea ciliaris (D. Don ex Hook. \& Arn.) DC., Chaetanthera pungens Humb. \& Bonpl., Homoeanthus pungens (Humb. \& Bonpl.) Spreng., Homanthis pungens (Humb. \& Bonpl.) Kunth, Clarionia pungens (Humb. \& Bonpl.) D. Don

Hierba. Perenne. Nativa.

Distribución: TAR, ANT, ATA.

Rango altitudinal: 2000-5000 m.

Países limítrofes: Argentina, Bolivia y Perú.

Nombre vulgar: Maransel, waji.

Perezia recurvata (Vahl) Less. subsp. beckii (Hook. \& Arn.) Cabrera

Sinónimos: Perezia beckii Hook. \& Arn., Homoeanthus pectinatus Phil., Perezia pectinata (Phil.) Reiche

Hierba. Perenne. Nativa.

Distribución: LBO, MAU, NUB, BIO, ARA, AIS, MAG.

Países limítrofes: Argentina.

Perezia recurvata (Vahl) Less. subsp. recurvata

Sinónimos: Chaetanthera recurvata (Vahl) Spreng., Clarionea recurvata (Vahl) D. Don, Perdicium recurvatum Vahl, Perezia doniana Less., Homoianthus donianus (Less.) J. Remy, Homoianthus inermis Meyen \& Walp., nom. illeg., Perezia reflexa Meyen, Clarionia recurvata (Vahl) D. Don, Clarionea reflexa (Meyen) Phil.

Hierba. Perenne. Nativa.

Distribución: RME, LBO, MAU, NUB, BIO, ARA, LLA, AIS, MAG.

Rango altitudinal: 0-3000 m.

Países limítrofes: Argentina.

Perezia recurvata (Vahl) Less. subsp. triceps (Phil.) Cabrera Sinónimos: Homoeanthus triceps Phil., Perezia triceps (Phil.) Reiche

Hierba. Perenne. Nativa.

Distribución: ARA.

Países limítrofes: Argentina.

Perezia spathulata (Lag. ex D. Don) Hook. \& Arn. Sinónimos: Clarionea spathulata Lag. ex D. Don, Perezia viscosa Poepp. ex Less., Homoianthus viscosus (Poepp. ex Less.) DC., Perdicium viscosum Poepp. ex Less., nom. nud., Homoianthus germaini Phil. ex Reiche, nom. nud. Hierba. Perenne. Nativa.

Distribución: BIO, ARA, LRI.

Rango altitudinal: 100-1200 m.

Países limítrofes: Argentina. 


\section{Perityle}

Perityle emoryi Torr.

Sinónimos: Closia cotula J. Remy var. elata (Phil.) Reiche, Closia discoidea Phil., Closia elata Phil., Laphamia emoryi (Torr.) Benth. \& Hook.f. ex Jacks., Perityle discoidea (Phil.) I.M. Johnst., Perityle emoryi Torr. var. elata (Phil.) I.M. Johnst., Closia anthemoides Phil., Closia brachypetala Phil., Closia chilensis Regel \& Körn., Closia cotula J. Remy, Closia digitata Phil., Closia elata Phil. var. nana Phil., Closia foliosa Phil., Closia pusilla Phil., Closia viridis Phil., Closia villosa Phil.

Hierba. Anual. Nativa. Distribución: AYP, TAR, ANT, ATA, COQ.

Rango altitudinal: 0-3600 m.

Países limítrofes: Perú.

\section{Picradeniopsis}

Picradeniopsis multiflora (Hook. \& Arn.) B.G. Baldwin Sinónimos: Bahia gilliesii A. Gray, Rothia intermedia Kuntze, Rothia pusilla (Wedd.) Kuntze, Schkuhria multiflora Hook. \& Arn.

Hierba. Anual. Nativa.

Distribución: AYP, TAR, ANT.

Rango altitudinal: 500-4500 m.

Países limítrofes: Argentina, Bolivia y Perú.

Nombre vulgar: Soiko de cabra, pasto de campo, manzanillón.

\section{Picris}

Picris echioides L.

Hierba. Anual. Introducida.

Distribución: AYP, ATA, COQ, VAL, RME, LBO, MAU, NUB, BIO, ARA, LRI, LLA, IPA.

\section{Picrosia}

Picrosia longifolia D. Don

Sinónimos: Picrosia australis Decne., Psilopogon albiflorus Phil., Tragopogon fritillarioides Less.

Hierba. Perenne. Nativa.

Distribución: TAR, BIO, ARA.

Rango altitudinal: 0-1000 m.

Países limítrofes: Argentina, Bolivia y Perú.

\section{Plazia}

Plazia cheiranthifolia (J. Remy) Wedd. Sinónimos: Aglaodendron cheiranthifolium J. Remy Arbusto. Nativo. Distribución: COQ.

Rango altitudinal: $2600-2800 \mathrm{~m}$.
Plazia daphnoides Wedd.

Arbusto. Nativo.

Distribución: AYP.

Rango altitudinal: 2600-4400 m.

Países limítrofes: Argentina, Bolivia y Perú.

Nombre vulgar: Chinchirkuma, koya macho, chajilla.

\section{Pleocarphus}

Pleocarphus revolutus D. Don

Sinónimos: Jungia dentata (D. Don) Reiche, Jungia revoluta (D. Don) Reiche, Jungia revoluta (D. Don) Reiche var. dentata (Phil.) Reiche, Pleocarphus dentatus Phil.

Arbusto. Endémico.

Distribución: ATA, COQ, VAL.

Rango altitudinal: 0-3000 m.

Nombre vulgar: Cola de ratón.

\section{Pluchea}

Pluchea chingoyo (Kunth) DC.

Sinónimos: Conyza chingoyo Kunth

Arbusto. Nativo.

Distribución: AYP, TAR, ANT.

Rango altitudinal: 1000-2500 m.

Países limítrofes: Perú.

Nombre vulgar: Chilca, chingoyo.

\section{Podanthus}

Podanthus mitiqui Lindl.

Sinónimos: Euxenia mitiqui DC.

Arbusto. Endémico.

Distribución: COQ, VAL, RME, LBO, MAU, NUB.

Rango altitudinal: 0-2000 $\mathrm{m}$.

Nombre vulgar: Mitique, mitriu.

Podanthus ovatifolius Lag.

Arbusto. Endémico.

Distribución: COQ, VAL, RME, LBO, MAU, NUB, BIO, ARA.

Rango altitudinal: 0-800 $\mathrm{m}$.

Nombre vulgar: Mitique, palo negro.

\section{Polyachyrus}

Polyachyrus annuus I.M. Johnst.

Hierba. Anual. Nativa.

Distribución: TAR, ANT, ATA, COQ.

Rango altitudinal: 0-700 $\mathrm{m}$.

Países limítrofes: Perú. 
Polyachyrus carduoides Phil.

Sinónimos: Polyachyrus foliosus Phil., Polyachyrus glabratus Phil., Polyachyrus latifolius Phil., Polyachyrus rigidus I.M. Johnst.

Subarbusto. Endémico.

Distribución: TAR, ANT, ATA, COQ, VAL.

Rango altitudinal: 800-3000 m.

Nombre vulgar: Renguilla, borlón de alforja, hediondilla, sokasoka.

Polyachyrus cinereus Ricardi \& Weldt

Subarbusto. Endémico.

Distribución: ANT, ATA, COQ.

Rango altitudinal: 0-800 m.

Polyachyrus fuscus (Meyen) Walp.

Sinónimos: Polyachyrus fuscus (Meyen) Walp. var. roseus (Phil.) Reiche, Polyachyrus roseus Phil., Diaphoranthus fuscus Meyen

Subarbusto. Nativo.

Distribución: AYP, TAR, ANT, ATA, COQ, VAL.

Rango altitudinal: 0-800 m.

Países limítrofes: Perú.

Polyachyrus gayi J. Remy

Subarbusto. Endémico.

Distribución: ATA, COQ.

Rango altitudinal: 0-500 m.

Polyachyrus poeppigii Kuntze ex Less. subsp. multifidus (D. Don) Ricardi \& Weldt

Sinónimos: Polyachyrus multifidus D. Don, Polyachyrus sanromani Phil., Polyachyrus selinoides Reiche

Subarbusto. Endémico.

Distribución: ANT, ATA.

Rango altitudinal: 0-500 m.

Polyachyrus poeppigii Kuntze ex Less. subsp. poeppigii Sinónimos: Polyachyrus calderensis Phil., Polyachyrus decurrens Lag. ex DC., Polyachyrus litoralis Phil., Polyachyrus macrotis Phil., Polyachyrus poeppigii Kuntze ex Less. var. litoralis (Phil.) Reiche, Polyachyrus tenuifolius Phil., Polyachyrus virgatus I.M. Johnst.

Subarbusto. Nativo.

Distribución: ANT, ATA, COQ, VAL, RME, LBO, MAU.

Rango altitudinal: 0-500 m.

Países limítrofes: Bolivia.

\section{Polyachyrus sphaerocephalus D. Don}

Sinónimos: Polyachyrus bridgesii Poepp. \& Endl., Polyachyrus tarapacanus Phil.

Subarbusto. Nativo.

Distribución: AYP, TAR, ANT.

Rango altitudinal: 0-4000 m.
Países limítrofes: Perú.

Nombre vulgar: Sokasoka.

\section{Porophyllum}

Porophyllum ruderale (Jacq.) Cass.

Sinónimos: Cacalia glandulosa Salisb., nom. illeg., Cacalia porophyllum L., Cacalia ruderalis (Jacq.) Sw., Kleinia porophyllum (L.) Willd., Kleinia ruderalis Jacq., Porophyllum ellipticum Cass., Porophyllum ellipticum Cass. var. genuinum Urb., nom. illeg., Porophyllum ellipticum Cass. var. intermedium DC., Porophyllum ellipticum Cass. var. ruderale (Jacq.) Urb., Porophyllum latifolium Benth., Porophyllum macrolepidium Malme, Porophyllum porophyllum (L.) Kuntze, comb. illeg., Porophyllum ruderale (Jacq.) Cass. var. angustifolium Hassl., Porophyllum ruderale (Jacq.) Cass. var. ellipticum (Cass.) A. Gray ex B.L. Rob., Porophyllum ruderale (Jacq.) Cass. var. glandulosum Chodat \& Hassl., Porophyllum ruderale (Jacq.) Cass. var. macrolepidium (Malme) Chodat \& Hassl., Porophyllum ruderale (Jacq.) Cass. fma. suffruticosum Chodat \& Hassl., Tagetes integrifolia Muschl.

Hierba. Perenne. Nativa.

Distribución: ANT.

Rango altitudinal: 0-2500 m.

Países limítrofes: Argentina, Bolivia y Perú.

\section{Proustia}

Proustia cuneifolia D. Don subsp. cinerea (Phil.) Luebert Sinónimos: Proustia cinerea Phil., Proustia cuneifolia D. Don fma. cinerea (Phil.) Fabris

Arbusto. Endémico.

Distribución: ATA, COQ, VAL, RME, MAU.

Rango altitudinal: 300-1200 m.

Proustia cuneifolia D. Don subsp. cuneifolia

Sinónimos: Proustia pungens Poepp. ex Less., Proustia pungens Poepp. ex Less. var. heterophylla Kuntze, Proustia cuneifolia D.Don var. integrifolia Hook. \& Arn., Proustia cuneifolia D.Don var. spinulosa Hook. \& Arn., Proustia pungens Poepp. ex Less. var. cuneifolia (D. Don) Wedd., Proustia cuneifolia D. Don fma. cuneifolia

Arbusto. Nativo.

Distribución: TAR, ANT, COQ, VAL, RME, LBO, MAU, NUB, BIO.

Rango altitudinal: 2000-3500 m.

Países limítrofes: Argentina, Bolivia y Perú.

Nombre vulgar: Huañil, pucana, tipia, palo de yegua.

Proustia cuneifolia D. Don subsp. tipia (Phil.) Luebert Sinónimos: Proustia tipia Phil., Proustia cuneifolia D. Don fma. tipia (Phil.) Fabris

Arbusto. Endémico. 
Distribución: TAR, ANT.

Rango altitudinal: 0-700 m.

Nombre vulgar: Tipia.

\section{Proustia pyrifolia DC.}

Sinónimos: Proustia pyrifolia DC. var. canescens DC., Proustia oblongifolia D. Don, Proustia glandulosa DC., Proustia pyrifolia DC. fma. glandulosa (DC.) Fabris

Arbusto. Endémico.

Distribución: COQ, VAL, RME, LBO, MAU, NUB, BIO, ARA, LRI, LLA.

Rango altitudinal: 200-1200 m.

Nombre vulgar: Parrila blanca, tola blanca, voqui blanco.

\section{Pseudognaphalium}

Pseudognaphalium aldunateoides (J. Remy) C. Monti, Bayón \& S.E. Freire

Sinónimos: Gnaphalium aldunateoides J. Remy, Gnaphalium diminutivum Phil., Gnaphalium perpusillum Phil., Gnaphalium phaeolepis Phil., Pseudognaphalium perpusillum (Phil.) C. Monti, Bayón \& S.E. Freire, Gnaphalium insulare Phil.

Hierba. Anual. Nativa.

Distribución: COQ, VAL, RME, LBO, MAU, NUB, BIO, ARA, LLA, AIS, JFE.

Rango altitudinal: 500-3700 m.

Países limítrofes: Argentina.

Nota: Introducida en el Archipiélago Juan Fernández.

Pseudognaphalium cabrerae (S.E. Freire) S.E. Freire, Bayón, Baeza, Giuliano \& C. Monti

Sinónimos: Gnaphalium philippii Cabrera, hom. illeg., Gnaphalium fastigiatum Phil., hom. illeg., Gnaphalium cabrerae S.E. Freire, nom. illeg., Pseudognaphalium cabrerae(S.E. Freire) Deble, nom. illeg., Pseudognaphalium fastigiatum Bayón, nom. illeg., Gnaphalium cabrerae S.E. Freire

Hierba. Perenne. Nativa.

Distribución: TAR, RME, MAU, ARA.

Rango altitudinal: 0-2000 m.

Países limítrofes: Argentina.

Pseudognaphalium cheiranthifolium (Lam.) Hilliard \& B.L. Burtt

Sinónimos: Gnaphalium cheiranthifolium Lam., Gnaphalium acutifolium Phil., Gnaphalium araucanum Phil., Gnaphalium citrinum Hook. \& Arn., Gnaphalium paniculatum Bertero ex Colla, Gnaphalium valdivianum Phil., Gnaphalium cheiranthifolium Lam. var. paniculatum (Bertero ex Colla) Skottsb.

Hierba. Perenne. Nativa.

Distribución: AYP, COQ, VAL, RME, LBO, MAU, NUB, BIO, ARA, LRI, LLA, JFE.
Rango altitudinal: 0-2500 m.

Países limítrofes: Argentina, Bolivia y Perú.

Nombre vulgar: Té de burro.

Nota: Introducida en el Archipiélago Juan Fernández.

Pseudognaphalium cymatoides (Kunze ex DC.) Anderb. Sinónimos: Gnaphalium moelleri Phil., Gnaphalium canum Phil., hom. illeg., Pseudognaphalium moelleri (Phil.) Anderb., Gnaphalium ulophyllum Hook. \& Arn., Gnaphalium cymathoides Kunze ex DC. var. glabrum Walp., Gnaphalium cymathoides Kunze ex DC., Gnaphalium cheiranthifolium Bertero, hom. illeg.

Hierba. Anual. Nativa.

Distribución: AYP, COQ, VAL, RME, LBO, MAU, NUB, BIO, ARA, LLA.

Rango altitudinal: 0-4000 m.

Países limítrofes: Argentina y Bolivia.

Nombre vulgar: Hierba de San Juan.

Pseudognaphalium gayanum (J. Remy) Anderb.

Sinónimos: Gnaphalium heterophyllum Phil., Gnaphalium heterotrichum Phil., Gnaphalium leucocephalum Phil., nom. illeg., Gnaphalium pseudohelichrysum Reiche, Gnaphalium gayanum J. Remy, Gnaphalium robustum Phil., Pseudognaphalium heterotrichum (Phil.) Anderb., Pseudognaphalium robustum (Phil.) Anderb., Hypelichrysum heterotrichum (Phil.) Kirp.

Hierba. Perenne. Endémica.

Distribución: AYP, TAR, ANT, ATA, COQ, VAL, RME, LBO, MAU, NUB, LLA, AIS, MAG.

Rango altitudinal: 0-3500 m.

Pseudognaphalium lacteum (Meyen \& Walp.) Anderb. Sinónimos: Gnaphalium lacteum Meyen \& Walp., Gnaphalium argyrolepis Phil.

Hierba. Perenne. Nativa.

Distribución: AYP, TAR, ANT, COQ, BIO.

Rango altitudinal: 2500-4600 m.

Países limítrofes: Argentina, Bolivia y Perú.

Nombre vulgar: Viravira, viravira blanca.

Pseudognaphalium landbeckii (Phil.) Anderb.

Sinónimos: Gnaphalium landbeckii Phil.

Hierba. Perenne. Endémica.

Distribución: VAL, RME, LBO, MAU.

Rango altitudinal: 0-1000 m.

Pseudognaphalium munoziae Bayón C. Monti \& S.E. Freire

Hierba. Perenne. Endémica.

Distribución: AYP.

Rango altitudinal: 3500-4200 m. 
Pseudognaphalium psilophyllum (Meyen \& Walp.) Anderb.

Sinónimos: Gnaphalium glandulosum Klatt, Gnaphalium psilophyllum Meyen \& Walp., Pseudognaphalium glandulosum (Klatt) Anderb.

Hierba. Perenne. Nativa.

Distribución: AYP, TAR, ANT, COQ, VAL, LBO, MAU, LLA.

Rango altitudinal: 800-4600 m.

Países limítrofes: Argentina y Bolivia.

Nombre vulgar: Viravira, chuncho viravira.

Pseudognaphalium remyanum (Phil.) Anderb.

Sinónimos: Gnaphalium remyanum Phil.

Hierba. Perenne. Nativa.

Distribución: RME.

Rango altitudinal: 500-1000 m.

Países limítrofes: Bolivia.

Pseudognaphalium tarapacanum (Phil.) Anderb.

Sinónimos: Gnaphalium tarapacanum Phil.

Hierba. Perenne. Nativa.

Distribución: AYP, TAR, ANT, COQ, RME, MAU, NUB,

BIO.

Rango altitudinal: 3000-4100 m.

Países limítrofes: Argentina.

Pseudognaphalium viravira (Molina) Anderb.

Sinónimos: Gnaphalium andicola Phil., Gnaphalium pratense Phil., Gnaphalium longifolium Phil., Gnaphalium subnudum Phil., Pseudognaphalium pratense (Phil.) Anderb., Gnaphalium coquimbense Phil., Gnaphalium illapelinum Phil. var. illapelinum, Gnaphalium viravira Molina, Pseudognaphalium coquimbense (Phil.) Anderb., Pseudognaphalium illapelinum (Phil.) Anderb., Gnaphalium viravira Less., hom. illeg., Pseudognaphalium andicola (Phil.) C. Monti, Bayón \& S.E. Freire

Hierba. Perenne. Nativa.

Distribución: AYP, TAR, ATA, COQ, VAL, RME, LBO, MAU, NUB, BIO, ARA, LLA, AIS, MAG.

Rango altitudinal: 0-4000 m.

Países limítrofes: Argentina.

Nombre vulgar: Hierba de la diuca, hierba de la vida, viravira.

\section{Psilocarphus}

\section{Psilocarphus brevissimus Nutt.}

Sinónimos: Psilocarphus globiferus Nutt.

Hierba. Anual. Nativa.

Distribución: COQ, VAL, RME, LBO, MAU, NUB, BIO, ARA.

Rango altitudinal: 300-3000 m.

Países limítrofes: Argentina.
Psilocarphus tenellus Nutt. var. globiferus (Bertero ex DC.) Morefield

Sinónimos: Benzanilla chilensis J. Remy, Micropus globiferus Bertero ex DC., Psilocarphus chilensis (J. Remy) A. Gray, Psilocarphus globiferus (Bertero ex DC.) Speg., comb. illeg., Psilocarphus berteri I.M. Johnst., Psilocarphus globiferus (Bertero ex DC.) Speg. var. minimus Cabrera Hierba. Anual. Endémica.

Distribución: COQ, VAL, RME, LBO.

Rango altitudinal: 0-1000 m.

\section{Schkuhria}

Schkuhria pinnata (Lam.) Kuntze ex Thell.

Sinónimos: Amblyopappus mendocina Phil., Schkuhria pinnata (Lam.) Kuntze ex Thell. var. abrotanoides (Roth) Cabrera, Schkuhria pinnata (Lam.) Kuntze ex Thell. var. octoaristata (DC.) Cabrera, Pectis pinnata Lam., Rothia pinnata (Lam.) Kuntze, Rothia pinnata (Lam.) Kuntze ex Thell. var. pallida Kuntze, Rothia pinnata (Lam.) Kuntze ex Thell. var. purpurascens Kuntze, Schkuhria abrotanoides Roth, Schkuhria abrotanoides Roth var. isopappa (Benth.) Hieron., Schkuhria abrotanoides Roth var. pomasquiensis Hieron., Schkuhria advena Thell., Schkuhria bonariensis Hook. \& Arn., Schkuhria coquimbana Phil., Schkuhria isopappa Benth., Schkuhria octoaristata DC., Schkuhria pinnata (Lam.) Kuntze ex Thell. var. typica Cabrera, nom. illeg.

Hierba. Anual. Nativa.

Distribución: AYP, TAR, COQ.

Rango altitudinal: 0-3000 m.

Países limítrofes: Argentina, Bolivia y Perú.

Nombre vulgar: Cachanlahuen cimarrón, canchalahua.

\section{Scolymus}

Scolymus hispanicus L.

Hierba. Perenne. Introducida.

Distribución: VAL.

\section{Senecio}

Senecio acanthifolius Hombr. \& Jacquinot

Sinónimos: Senecio acanthifolius Hombr. \& Jacquinot subsp. virens (Phil.) Cabrera \& Zardini, Senecio virens Phil., Iocenes acanthifolius (Hombr. \& Jacq.) Nord., Iocenes acanthifolius (Hombr. \& Jacq.) Nord. subsp. virens (Phil.) B. Nord., Senecio ombrophyllus Skottsb.

Hierba. Perenne. Nativa.

Distribución: LRI, LLA, AIS, MAG.

Rango altitudinal: 200-1200 m.

Países limítrofes: Argentina. 
Senecio adenophyllus Meyen \& Walp.

Arbusto. Nativo.

Distribución: AYP, TAR, ANT.

Rango altitudinal: 4200-4800 m.

Países limítrofes: Argentina, Bolivia y Perú.

Nombre vulgar: Tola hedionda, hachakoma del burro, tola del burro.

Senecio adenotrichius DC.

Sinónimos: Adenotrichia amplexicaulis Lindl., Heterolepis conyzoides Bertero ex DC.

Hierba. Perenne. Endémica.

Distribución: COQ, VAL, RME.

Rango altitudinal: 300-1200 m.

Senecio alcicornis Hook. \& Arn.

Sinónimos: Senecio chrysanthemoides Phil.

Arbusto. Endémico.

Distribución: ATA, COQ.

Rango altitudinal: 0-900 m.

Senecio algens Wedd.

Hierba. Perenne. Nativa.

Distribución: AYP, TAR, ANT.

Rango altitudinal: 4200-5200 m

Países limítrofes: Argentina, Bolivia y Perú.

Senecio alloeophyllus O. Hoffm.

Subarbusto. Nativo.

Distribución: MAG.

Rango altitudinal: 1300-1800 m.

Países limítrofes: Argentina.

\section{Senecio almeidae Phil.}

Arbusto o subarbusto. Endémico.

Distribución: ANT, ATA, COQ.

Rango altitudinal: 0-1300 m.

Senecio angulatus L.f.

Arbusto trepador. Introducido.

Distribución: TAR, COQ, VAL, RME, LBO, MAU.

Senecio angustissimus Phil.

Sinónimos: Senecio linariifolius Poepp. ex DC. var. angustissimus (Phil.) Speg., Senecio nahuelbutanus Phil.

Subarbusto. Nativo.

Distribución: MAU, NUB, BIO, ARA.

Rango altitudinal: $1700 \mathrm{~m}$.

Países limítrofes: Argentina.

Senecio anthemidiphyllus J. Remy

Sinónimos: Senecio campanae Phil., Senecio hakeifolius Hook. \& Arn. var. viscidus Hook. \& Arn., Senecio brachylepis Phil., Senecio psammophilus Phil., hom. illeg.
Arbusto. Nativo.

Distribución: ATA, COQ, VAL, RME, LBO.

Rango altitudinal: $2700 \mathrm{~m}$.

Países limítrofes: Argentina.

Senecio antofagastanus Cabrera

Subarbusto. Endémico.

Distribución: ANT.

Rango altitudinal: $1000 \mathrm{~m}$.

Senecio aquaticus Hill. subsp. aquaticus

Hierba. Perenne. Introducida.

Distribución: BIO, LLA.

Senecio aquaticus Hill. subsp. barbareifolius (Wimm. \& Grab.) Walters

Hierba. Perenne. Introducida.

Distribución: VAL, BIO, ARA, LRI, LLA.

Senecio argyreus Phil.

Subarbusto. Nativo.

Distribución: BIO, ARA, LLA, AIS, MAG.

Rango altitudinal: 1000-1800 m.

Países limítrofes: Argentina.

Senecio aristianus J. Remy

Sinónimos: Senecio guayacanensis Phil.

Subarbusto. Endémico.

Distribución: ATA, COQ, VAL.

Rango altitudinal: 0-300 m.

Senecio arleguianus J. Remy

Arbusto. Endémico.

Distribución: COQ.

Rango altitudinal: $1200 \mathrm{~m}$.

Senecio arnicoides Hook. \& Arn.

Sinónimos: Senecio plantagineus Bertero ex Colla, Aster plantagineus Poepp. ex DC.

Hierba. Perenne. Endémica.

Distribución: VAL, RME, LBO, NUB, BIO, ARA, LRI.

Rango altitudinal: $800 \mathrm{~m}$.

Senecio arnottii Hook.f.

Sinónimos: Senecio limbardioides Hook. \& Arn., hom. illeg., Senecio limbardioides Hook. \& Arn. var. beta Hook. \& Arn., Senecio arnottii Hook.f. var. major Macloskie Subarbusto. Nativo.

Distribución: LLA, MAG.

Rango altitudinal: 0-300 m.

Países limítrofes: Argentina. 
Senecio aspericaulis J. Remy

Sinónimos: Senecio hypsophilus Phil.

Subarbusto. Nativo.

Distribución: MAU, NUB, BIO.

Rango altitudinal: 2400-2800 m.

Países limítrofes: Argentina.

\section{Senecio atacamensis Phil.}

Arbusto. Nativo.

Distribución: AYP, TAR, ANT.

Rango altitudinal: $3100 \mathrm{~m}$.

Países limítrofes: Argentina.

Nombre vulgar: Mukuraka, chachacoma blanca, cacho de cabra, chachacoma del burro.

Senecio baccharidifolius Poepp. ex DC.

Subarbusto. Nativo.

Distribución: MAU, NUB, BIO, ARA, LLA.

Rango altitudinal: 1500-1600 m.

Países limítrofes: Argentina.

Senecio bahioides Hook. \& Arn.

Sinónimos: Senecio bahioides Hook. \& Arn. var. glaber Hook. \& Arn., Senecio bahioides Hook. \& Arn. var. lanosus Hook. \& Arn., Senecio irregularis Phil.

Arbusto. Endémico.

Distribución: ATA, COQ, VAL, RME.

Rango altitudinal: 0-1000 m.

Senecio balsamicus Phil.

Subarbusto. Endémico.

Distribución: ATA.

Rango altitudinal: $2700 \mathrm{~m}$.

\section{Senecio barbarae Cabrera}

Hierba. Perenne. Nativa.

Distribución: ANT.

Rango altitudinal: 4300-5000 m.

Países limítrofes: Argentina.

Senecio barrosianus Cabrera

Subarbusto. Endémico.

Distribución: MAU.

Rango altitudinal: 200-500 m.

\section{Senecio beaufilsii Kuntze}

Subarbusto. Nativo.

Distribución: MAG.

Rango altitudinal: 1500-1900 m.

Países limítrofes: Argentina.

Senecio behnii Ricardi \& Martic.

Subarbusto. Endémico.

Distribución: AYP, TAR.
Rango altitudinal: 3200-3300 m.

Nombre vulgar: Viravira.

Senecio benaventianus J. Remy

Subarbusto. Endémico.

Distribución: COQ.

Rango altitudinal: 200-2000 m.

Senecio berteroi (DC.) Pelser

Sinónimos: Robinsonia berteroi (DC.) Sanders, Stuessy \& Martic., Balbisia berteroi DC., Vendredia berterii (DC.)

Baillon, Rhetinodendron berteroi (DC.) Hemsl.

Arbusto. Endémico.

Distribución: JFE.

Rango altitudinal: 0-500 m.

Nota: Posiblemente extinta.

Senecio bipontinii Wedd.

Sinónimos: Senecio carnifolius Cabrera, Senecio sarcophyllus Phil., hom. illeg., Senecio schultzii Wedd., hom. illeg., Senecio julietii Phil.

Subarbusto. Endémico.

Distribución: MAU, NUB, BIO, ARA, LLA, AIS.

Rango altitudinal: $120-2520 \mathrm{~m}$.

Senecio botijae Ehrh.

Hierba. Perenne. Endémica.

Distribución: ANT.

Rango altitudinal: 500-1000 m.

Senecio brachylobus Phil.

Subarbusto. Endémico.

Distribución: ATA, COQ.

Rango altitudinal: $500 \mathrm{~m}$.

Senecio bracteolatus Hook. \& Arn. var. bracteolatus

Sinónimos: Senecio coxi Phil.

Arbusto. Nativo.

Distribución: BIO, ARA.

Rango altitudinal: 0-1400 m.

Países limítrofes: Argentina.

Senecio bracteolatus Hook. \& Arn. var. valderramae (Phil.) Cabrera

Sinónimos: Senecio valderramae Phil.

Arbusto. Nativo.

Distribución: ARA, LRI, LLA, MAG.

Rango altitudinal: 1000-1400 m.

Países limítrofes: Argentina.

Senecio breviscapus DC.

Sinónimos: Senecio acaulis Phil., Senecio chamaecephalus Wedd.

Hierba. Perenne. Nativa. 
Distribución: AYP, TAR, ANT, ATA, COQ, VAL, RME.

Rango altitudinal: 2600-4600 m.

Países limítrofes: Argentina, Bolivia y Perú.

Senecio bridgesii Hook. \& Arn.

Subarbusto. Endémico.

Distribución: COQ, VAL, RME.

Rango altitudinal: 0-3000 m.

Senecio brunonianus Hook. \& Arn.

Sinónimos: Senecio serenensis J. Remy

Subarbusto. Endémico.

Distribución: ATA, COQ, VAL.

Rango altitudinal: $100 \mathrm{~m}$.

Senecio buglossus Phil.

Sinónimos: Senecio limonius Phil., Senecio valdivianus Phil.

Hierba. Perenne. Endémica.

Distribución: BIO, ARA, LRI, LLA.

Rango altitudinal: 0-1400 m.

Nombre vulgar: Hualtata, lengua de vaca.

Senecio bustillosianus J. Remy var. borchersii (Phil.) Cabrera

Sinónimos: Senecio borchersii Phil.

Subarbusto. Endémico.

Distribución: VAL, RME.

Rango altitudinal: 1800-2200 m.

Senecio bustillosianus J. Remy var. bustillosianus

Sinónimos: Senecio schulzeanus Meigen

Subarbusto. Endémico.

Distribución: VAL, RME, LBO.

Rango altitudinal: 2600-2700 m.

Senecio cachinalensis Phil. var. cachinalensis

Sinónimos: Senecio breanus Phil., Senecio larrañagae Phil.

Arbusto. Endémico.

Distribución: ANT, ATA.

Rango altitudinal: 200-400 m.

Senecio cachinalensis Phil. var. copiapinus (Phil.) Cabrera Sinónimos: Senecio copiapinus Phil.

Arbusto. Endémico.

Distribución: ATA.

Senecio calocephalus Poepp.

Sinónimos: Senecio columbaria J. Remy

Hierba. Perenne. Endémica.

Distribución: NUB, BIO, ARA, LRI.

Rango altitudinal: 0-1500 m.
Senecio candidans DC.

Sinónimos: Brachypappus candicans (J. Vahl) Sch. Bip., Cacalia candicans Vahl, Culcitium gayanum J. Remy, Senecio culciremy Cuatrec.

Hierba. Perenne. Nativa.

Distribución: BIO, LLA, AIS, MAG.

Rango altitudinal: 0-500 m.

Países limítrofes: Argentina.

Senecio candollei Wedd.

Hierba. Perenne. Nativa.

Distribución: AYP.

Rango altitudinal: 3500-5000 m.

Países limítrofes: Argentina, Bolivia y Perú.

Nombre vulgar: Chukuchuku.

Senecio cerberoanus J. Remy var. cerberoanus

Sinónimos: Senecio berterianus DC. var. obtusus DC., Senecio phaedrus Phil.

Arbusto. Endémico.

Distribución: ATA, COQ, VAL.

Rango altitudinal: 0-800 m.

Senecio cerberoanus J. Remy var. lanatus Cabrera

Arbusto. Endémico.

Distribución: COQ.

Rango altitudinal: 0-800 m.

Senecio chamomillifolius Phil.

Subarbusto. Endémico.

Distribución: ATA.

Rango altitudinal: 0-1300 m.

Senecio chañaralensis Phil.

Arbusto. Endémico.

Distribución: ATA, COQ.

Rango altitudinal: 0-100 m.

Senecio chilensis Less. var. argophyllus (Phil.) Cabrera fma. argophyllus

Sinónimos: Senecio argophyllus Phil.

Subarbusto. Nativo.

Distribución: MAU, NUB, BIO, ARA.

Rango altitudinal: $2000 \mathrm{~m}$.

Países limítrofes: Argentina.

Senecio chilensis Less. var. argophyllus (Phil.) Cabrera fma. discoideus Cabrera

Subarbusto. Nativo.

Distribución: MAU.

Rango altitudinal: 1500-3000 m.

Países limítrofes: Argentina. 
Senecio chilensis Less. var. chilensis

Sinónimos: Senecio argenteus Kuntze ex DC., Senecio linearifolius Colla, Senecio phagnaloides DC.

Subarbusto. Nativo.

Distribución: VAL, RME, LBO, MAU, NUB, BIO, ARA, LRI, LLA.

Rango altitudinal: 200-1000 m.

Países limítrofes: Argentina.

\section{Senecio chillanensis Cabrera}

Subarbusto. Endémico.

Distribución: NUB, BIO, ARA.

Rango altitudinal: $700-1800 \mathrm{~m}$.

Senecio chionophilus Phil.

Sinónimos: Senecio vulcanicus Phil., hom. illeg.

Subarbusto. Nativo.

Distribución: MAU, NUB, BIO, ARA, LRI, LLA.

Rango altitudinal: 1500-2100 m.

Países limítrofes: Argentina.

Senecio chrysocomoides Hook. \& Arn.

Subarbusto. Nativo.

Distribución: AIS.

Rango altitudinal: 0-500 m.

Países limítrofes: Argentina.

Senecio chrysolepis Phil.

Sinónimos: Senecio juncalensis Phil.

Subarbusto. Nativo.

Distribución: TAR, ANT, ATA.

Rango altitudinal: 3400-4200 m.

Países limítrofes: Argentina y Bolivia.

Senecio clarioneifolius J. Remy

Subarbusto. Nativo.

Distribución: COQ, VAL, RME, LBO, MAU.

Rango altitudinal: 2300-3000 m.

Países limítrofes: Argentina.

Senecio coquimbensis Phil.

Sinónimos: Senecio berterianus DC., hom. illeg., Senecio glanduloso-hirtellus Reiche

Arbusto. Endémico.

Distribución: ATA, COQ.

Rango altitudinal: 100-700 m.

\section{Senecio coronopodiphyllus J. Remy}

Sinónimos: Metazanthus cacalioides Meyen

Subarbusto. Nativo.

Distribución: COQ, RME, LBO.

Rango altitudinal: 2500-3000 m.

Países limítrofes: Argentina.
Senecio corrugatus (Phil.) Pelser

Sinónimos: Robinsonia gayana Decne., Robinsonia corrugata Phil., Robinsonia longifolia Phil.

Arbusto. Endémico.

Distribución: JFE.

Rango altitudinal: 0-500 m.

Nombre vulgar: Resino.

Senecio coscayanus Ricardi \& Martic.

Arbusto. Endémico.

Distribución: TAR.

Rango altitudinal: $3200 \mathrm{~m}$.

Senecio covasii Cabrera

Subarbusto. Nativo.

Distribución: RME, MAU.

Rango altitudinal: 1800-2800 m.

Países limítrofes: Argentina.

Senecio crepidioides Phil.

Subarbusto. Endémico.

Distribución: ATA, COQ, VAL.

Rango altitudinal: 400-600 m.

Senecio crithmoides Hook. \& Arn.

Sinónimos: Senecio carnifolius Cabrera, Senecio diazii Phil., Senecio remyanus Phil., Senecio sarcophyllus Phil., hom. illeg., Senecio schultzii Wedd., hom. illeg., Senecio julietii Phil., Senecio iberidifolius Phil., p.p.

Subarbusto. Nativo.

Distribución: COQ, VAL, RME, MAU, NUB, BIO, ARA, LLA.

Rango altitudinal: 1700-4500 m.

Países limítrofes: Argentina.

Senecio crusoei Pelser

Sinónimos: Robinsonia gracilis Decne., Robinsonia micrantha Phil. ex Hemsl.

Arbusto. Endémico.

Distribución: JFE.

Rango altitudinal: 0-500 m.

Nombre vulgar: Resinillo.

Senecio ctenophyllus Phil.

Sinónimos: Senecio vittatus Reiche

Arbusto. Endémico.

Distribución: AYP, TAR, ANT.

Rango altitudinal: 1000-3000 m.

Nombre vulgar: Flor amarilla, monte manzanilla, tuksatuksa.

Senecio cumingii Hook. \& Arn. var. bracteosus (J. Remy) Cabrera

Sinónimos: Senecio bracteosus J. Remy 
Hierba. Perenne. Endémica.

Distribución: COQ, VAL.

Rango altitudinal: 0-600 m.

Senecio cumingii Hook. \& Arn. var. cumingii

Sinónimos: Senecio paralias Phil.

Hierba. Perenne. Nativa.

Distribución: COQ, VAL, RME, LBO.

Rango altitudinal: 0-600 m.

Países limítrofes: Perú.

Senecio cuneatus Hook.f.

Sinónimos: Senecio arenicola Reiche

Hierba. Perenne. Nativa.

Distribución: AIS, MAG.

Rango altitudinal: $600 \mathrm{~m}$.

Países limítrofes: Argentina.

Senecio darwinii Hook. \& Arn.

Sinónimos: Senecio darwinii Hook. \& Arn. var. laxus Hook.

\& Arn.

Subarbusto. Nativo.

Distribución: LLA, AIS, MAG.

Rango altitudinal: 0-2000 m.

Países limítrofes: Argentina.

Senecio davilae Phil.

Subarbusto. Endémico.

Distribución: VAL, RME.

Rango altitudinal: 600-3000 m.

Senecio depressus Hook. \& Arn.

Sinónimos: Culcitium depressum D. Don ex Hook. \& Arn., nom. nud., Senecio poeppigii Hook. \& Arn. var. condensatus Reiche

Subarbusto. Nativo.

Distribución: LBO, MAU.

Rango altitudinal: $3100 \mathrm{~m}$.

Países limítrofes: Argentina.

Senecio dichotomus Phil.

Subarbusto. Endémico.

Distribución: ANT.

Rango altitudinal: 0-2900 m.

\section{Senecio diemii Cabrera}

Hierba. Perenne. Nativa.

Distribución: ARA.

Rango altitudinal: $1900 \mathrm{~m}$.

Países limítrofes: Argentina.

Senecio digitatus Phil.

Hierba. Perenne. Nativa.

Distribución: TAR, ANT.
Rango altitudinal: 3500-4000 m.

Países limítrofes: Argentina.

Senecio donianus Hook. \& Arn.

Sinónimos: Senecio arachnoideus Phil., hom. illeg.

Subarbusto. Nativo.

Distribución: COQ, VAL, RME.

Rango altitudinal: 2700-4000 m.

Países limítrofes: Argentina.

Senecio dryophyllus Meyen \& Walp.

Sinónimos: Senecio tarapacanus Phil., Senecio amphibolus

Wedd., Senecio amphibolus Wedd. var. socialis (Wedd.)

Cabrera, Senecio socialis Wedd.

Subarbusto. Nativo.

Distribución: AYP, TAR, ANT.

Rango altitudinal: $3500-4500 \mathrm{~m}$.

Países limítrofes: Argentina, Bolivia y Perú.

Nombre vulgar: Wilaparpa, parpaparpa.

\section{Senecio elquiensis Cabrera}

Hierba o subarbusto. Perenne. Endémica.

Distribución: COQ.

Rango altitudinal: $800 \mathrm{~m}$.

Senecio eriophyton J. Remy

Arbusto. Nativo.

Distribución: ANT, ATA, COQ.

Rango altitudinal: 3500-4800 m.

Países limítrofes: Argentina.

Nombre vulgar: Chachacoma, cachacoma.

Senecio eruciformis J. Remy var. brachycephalus (Phil.) Cabrera

Sinónimos: Senecio rutaceus Phil. var. brachycephalus

Phil.

Subarbusto. Nativo.

Distribución: COQ, VAL, RME, MAU.

Rango altitudinal: 1200-3000 m.

Países limítrofes: Argentina.

Senecio eruciformis J. Remy var. eruciformis

Sinónimos: Senecio rutaceus Phil.

Subarbusto. Nativo.

Distribución: COQ, VAL, RME, MAU, NUB, BIO.

Rango altitudinal: 2200-2600 m.

Países limítrofes: Argentina.

Nombre vulgar: Nica.

Senecio espinosae Cabrera

Subarbusto. Endémico.

Distribución: MAU.

Rango altitudinal: $2500 \mathrm{~m}$. 
Senecio evenius (Phil.) Pelser

Sinónimos: Robinsonia evenia Phil.

Arbusto. Endémico.

Distribución: JFE.

Rango altitudinal: 0-500 m.

Senecio farinifer Hook. \& Arn.

Sinónimos: Senecio apricus Phil., Senecio belophyllus J. Remy, Senecio linariifolius Poepp. ex DC. var. longifolia Phil.

Subarbusto. Endémico.

Distribución: COQ, VAL, RME, MAU.

Rango altitudinal: 700-1600 m.

Senecio filaginoides DC.

Sinónimos: Senecio albolanatus Phil., hom. illeg., Senecio leuciscus Phil., Senecio leyboldtii Phil., Senecio meyenii Phil., Senecio sericeus Kuntze, p.p.

Arbusto. Nativo.

Distribución: NUB, MAG.

Rango altitudinal: 400-2700 m.

Países limítrofes: Argentina.

Senecio fistulosus Poepp. ex Less. var. fistulosus

Sinónimos: Senecio hualtata Bertero ex DC., Senecio amplus J. Remy, Senecio cordillerae Phil., Senecio dombeyanus DC., Senecio hualtata Bertero ex DC. var. variabilis (Phil.) Reiche, Senecio quillotensis Phil., Senecio variabilis Phil.

Hierba. Perenne. Nativa.

Distribución: COQ, VAL, RME, LBO, MAU, NUB, BIO, ARA, LRI, LLA, AIS.

Rango altitudinal: 1600-2400 m.

Países limítrofes: Argentina.

Nombre vulgar: Hualtata, lampazo, paco.

Senecio fistulosus Poepp. ex Less. var. ochroleucus (Hook. \& Arn.) Cabrera

Sinónimos: Senecio fistulosus Poepp. ex DC., nom. illeg., Senecio ochroleucus Hook. \& Arn.

Hierba. Perenne. Nativa.

Distribución: COQ, VAL, BIO, LRI.

Rango altitudinal: 1200-3500 m.

Países limítrofes: Argentina.

Senecio francisci Phil.

Arbusto. Nativo.

Distribución: COQ, VAL, RME, LBO, MAU.

Rango altitudinal: 1300-3500 m.

Países limítrofes: Argentina.

Senecio garaventai Cabrera

Subarbusto. Endémico.
Distribución: COQ, VAL.

Rango altitudinal: 1600-1900 m.

Senecio gayanus DC.

Sinónimos: Senecio soloanus Phil., Senecio sotoanus Phil.

Subarbusto. Endémico.

Distribución: RME, LBO, MAU.

Rango altitudinal: 700-1000 m.

Senecio gilliesii Hook. \& Arn.

Sinónimos: Cacalia candicans Poepp. ex DC., Cacalia nivea

Kuntze ex DC., Culcitium poeppigii DC., Senecio poeppigii

(DC.) Wedd., hom. illeg.

Hierba. Perenne. Nativa.

Distribución: LBO, MAU, BIO.

Rango altitudinal: 700-3200 m.

Países limítrofes: Argentina.

Senecio glaber Less.

Sinónimos: Senecio molinae Phil., Senecio ahrendsi Phil., Senecio delfinii Phil., Senecio fernandezi Phil., Senecio möelleri Phil., Senecio phyllocomus Phil., Senecio pratensis Phil., Senecio pratensis Phil. var. delfinii (Phil.) Reiche, Senecio glaber Less. var. pratensis (Phil.) Cabrera, Senecio tocornali Phil.

Subarbusto. Nativo.

Distribución: COQ, VAL, RME, LBO, MAU, NUB, BIO, ARA, LLA, AIS.

Rango altitudinal: 1100-2000 m.

Países limítrofes: Argentina.

Nombre vulgar: Chilquilla.

Senecio glabratus Hook. \& Arn.

Sinónimos: Senecio auriculatus Poepp. ex DC., Senecio berterianus Colla, Senecio valparadisiacus Colla, Senecio macrotus Kuntze ex Meyen

Subarbusto. Endémico.

Distribución: ATA, COQ, VAL, RME.

Rango altitudinal: 0-900 m.

Senecio gnidioides Phil. var. gilvus (Phil.) Cabrera

Sinónimos: Senecio gilvus Phil.

Subarbusto. Nativo.

Distribución: BIO, ARA, LRI.

Rango altitudinal: 1000-2500 m.

Países limítrofes: Argentina.

Senecio gnidioides Phil. var. gnidioides

Subarbusto. Nativo.

Distribución: RME, LBO, NUB, BIO, ARA, MAG.

Rango altitudinal: $1000-2500 \mathrm{~m}$.

Países limítrofes: Argentina. 
Senecio grandjotii Cabrera

Subarbusto. Nativo.

Distribución: RME.

Rango altitudinal: 3200-3800 m.

Países limítrofes: Argentina.

Senecio grindeliifolius DC.

Subarbusto. Nativo.

Distribución: RME.

Rango altitudinal: 2700-3000 m.

Países limítrofes: Argentina.

Senecio gunckelii Cabrera

Arbusto. Endémico.

Distribución: RME, LBO, MAU.

Rango altitudinal: $1500 \mathrm{~m}$.

Senecio haenkeanus Cuatrec.

Hierba. Perenne. Nativa.

Distribución: AYP.

Rango altitudinal: 4500-5000 m.

Países limítrofes: Perú.

Nombre vulgar: Chukuchuku.

Senecio haenkei DC.

Sinónimos: Senecio chionotus Phil.

Subarbusto. Nativo.

Distribución: ANT, ATA, COQ.

Rango altitudinal: 800-3500 m.

Países limítrofes: Argentina.

Senecio hakeifolius Bertero ex DC. var. hakeifolius

Sinónimos: Senecio hakeifolius Bertero ex DC. var. ochroleucus (Phil.) Reiche, Senecio leptophyllus Hook. \& Arn., Senecio ochroleucus Phil., hom. illeg., Senecio valparadisiensis J. Remy, Senecio platycodon Baker, p.p., Senecio linearilobus Bong. var. beta Hook. \& Arn.

Subarbusto. Endémico.

Distribución: ATA, COQ, VAL, RME, LBO.

Rango altitudinal: 100-3000 m.

Nombre vulgar: Pie de pajarito.

Senecio hakeifolius Bertero ex DC. var. vidalii (Phil.)

Reiche

Sinónimos: Senecio vidalii Phil.

Subarbusto. Endémico.

Distribución: ATA, COQ.

Rango altitudinal: $200 \mathrm{~m}$.

Senecio haloragis J. Remy var. glandulosus Cabrera

Subarbusto. Endémico.

Distribución: MAU.

Rango altitudinal: 0-100 m.
Senecio haloragis J. Remy var. haloragis

Sinónimos: Senecio germainii Phil.

Subarbusto. Endémico.

Distribución: LBO, MAU, NUB, BIO.

Rango altitudinal: 0-100 m.

Senecio helgae Cabrera

Hierba. Perenne. Nativa.

Distribución: ANT.

Rango altitudinal: 4000-4600 m.

Países limítrofes: Argentina.

Senecio hickenii Hauman

Subarbusto. Nativo.

Distribución: COQ, VAL.

Rango altitudinal: 3500-4000 m.

Países limítrofes: Argentina.

Senecio hieracium J. Remy

Sinónimos: Senecio pearcei Phil.

Hierba. Perenne. Nativa.

Distribución: MAU, NUB, BIO, ARA, LLA, AIS, MAG.

Rango altitudinal: 1200-2500 m.

Países limítrofes: Argentina.

Senecio hirsutulus Phil.

Arbusto o subarbusto. Endémico.

Distribución: ATA, COQ, VAL.

Rango altitudinal: $0-100 \mathrm{~m}$.

Senecio hirtus Cabrera

Sinónimos: Senecio crispus Phil., hom. illeg.

Arbusto. Endémico.

Distribución: ANT, ATA.

Rango altitudinal: 3500-4000 m.

Nombre vulgar: Chachacom.

Senecio humifusus (Hook.f.) Cabrera

Sinónimos: Senecio darwinii Hook. \& Arn. var. eradiatus

A. Gray

Hierba. Perenne. Nativa.

Distribución: MAG.

Rango altitudinal: 900-1000 m.

Países limítrofes: Argentina.

Senecio humillimus Sch. Bip. ex Wedd.

Hierba. Perenne. Nativa.

Distribución: AYP.

Rango altitudinal: 3500-4800 m.

Países limítrofes: Argentina, Bolivia y Perú.

Nombre vulgar: Pasto, k'jota. 
Senecio illapelinus Phil.

Subarbusto. Nativo.

Distribución: COQ, VAL.

Rango altitudinal: 3100-3600 m.

Países limítrofes: Argentina.

Senecio illinitus Phil.

Sinónimos: Senecio cervicornis Phil.

Subarbusto. Endémico.

Distribución: ANT, ATA, COQ, VAL, RME, MAU.

Rango altitudinal: 0-2000 m.

Senecio invalidus C. Jeffrey

Sinónimos: Senecio debilis Phil., hom. illeg.

Subarbusto. Endémico.

Distribución: LBO.

Rango altitudinal: 1100-1500 m.

Senecio isernii Phil.

Arbusto o subarbusto. Endémico.

Distribución: ATA, COQ.

Rango altitudinal: 0-100 m.

Senecio jacobeiformis J. Remy

Hierba o subarbusto. Perenne. Endémica.

Distribución: ANT, COQ.

Rango altitudinal: 0-2600 m.

Senecio jaffuelii Cabrera

Subarbusto. Nativo.

Distribución: RME.

Rango altitudinal: 1700-4500 m.

Países limítrofes: Argentina.

Senecio jarae Phil.

Hierba. Perenne. Nativa.

Distribución: AYP, TAR, ANT.

Rango altitudinal: 2400-5000 m.

Países limítrofes: Argentina, Bolivia y Perú.

Nombre vulgar: Romerillo.

Senecio jilesii Cabrera

Arbusto. Endémico.

Distribución: COQ.

Rango altitudinal: $2000 \mathrm{~m}$.

\section{Senecio johnstonianus Cabrera}

Subarbusto. Endémico.

Distribución: ATA.

Rango altitudinal: 2000-2700 m.

Senecio jorquerae Phil.

Subarbusto. Endémico.

Distribución: ATA.
Rango altitudinal: 3000-3500 m.

Senecio jungei Phil.

Arbusto. Endémico.

Distribución: COQ.

Rango altitudinal: 1500-2000 m.

Senecio kingii Hook.f.

Sinónimos: Senecio gymnocaulos Phil., Senecio subdiscoideus Sch. Bip. ex Wedd., Metazanthus grandiflorus Meyen, Senecio breviculus Phil., Senecio caespitosus Phil., Senecio kingii Hook.f. fma. subdiscoideus (Sch. Bip. ex Wedd.) Hosseus, Senecio purpuratus Phil., Senecio purpuratus Phil. var. subdiscoideus (Sch. Bip. ex Wedd.) Reiche, Senecio kingii Hook.f. var. paradoxus (Albov ex Kurtz) Cabrera

Hierba. Perenne. Nativa.

Distribución: VAL, RME, LBO, MAU, NUB, BIO, ARA, LLA, AIS, MAG.

Rango altitudinal: 100-3800 m.

Países limítrofes: Argentina.

Senecio laetevirens Phil.

Subarbusto. Nativo.

Distribución: VAL, RME.

Rango altitudinal: 2000-3200 m.

Países limítrofes: Argentina.

Senecio laevicaulis DC.

Sinónimos: Senecio holophyllus J. Remy

Subarbusto. Endémico.

Distribución: RME, LBO, MAU.

Rango altitudinal: $2500 \mathrm{~m}$.

Senecio landbeckii Phil.

Subarbusto. Endémico.

Distribución: LBO, MAU.

Rango altitudinal: $1500-2500 \mathrm{~m}$.

Senecio laseguei Hombr. \& Jacquinot

Sinónimos: Senecio danyausii Hombr. \& Jacquinot var. intermedius Sch. Bip., Senecio magellanicus Phil., hom. illeg., Senecio philippii De Wild.

Hierba. Perenne. Nativa.

Distribución: MAG.

Rango altitudinal: 100-300 m.

Países limítrofes: Argentina.

Senecio lastarrianus J. Remy

Sinónimos: Senecio baccharidifolius DC. var. angustifolius DC., Senecio nitidus Phil.

Subarbusto. Endémico.

Distribución: LBO, MAU, NUB.

Rango altitudinal: 900-2000 m. 
Senecio laucanus Ricardi \& Martic.

Hierba. Perenne. Endémica.

Distribución: AYP.

Rango altitudinal: 4200-4300 m.

Senecio leptocaulos Phil.

Subarbusto. Endémico.

Distribución: ATA, COQ, VAL, RME, LBO.

Rango altitudinal: 800-1600 m.

Senecio leucomallus A. Gray var. incisus A. Gray

Arbusto o subarbusto. Nativo.

Distribución: MAG.

Rango altitudinal: 0-1500 m.

Países limítrofes: Argentina.

Senecio leucomallus A. Gray var. leucomallus

Arbusto o subarbusto. Nativo.

Distribución: AIS, MAG.

Rango altitudinal: 0-500 m.

Países limítrofes: Argentina.

Senecio leucophyton Phil.

Subarbusto. Nativo.

Distribución: MAU.

Rango altitudinal: 1500-1800 m.

Países limítrofes: Argentina.

Senecio leucus Phil.

Arbusto. Nativo.

Distribución: ANT, ATA, COQ.

Rango altitudinal: 2500-3500 m.

Países limítrofes: Argentina.

Senecio linaresensis Soldano

Sinónimos: Senecio subdentatus Phil., hom. illeg.

Subarbusto. Endémico.

Distribución: MAU.

Rango altitudinal: 900-2000 m.

Senecio linariifolius Poepp. ex DC. var. aclonetus (Phil.) Cabrera

Sinónimos: Senecio aclonetus Phil., Senecio encelia J.

Remy, Senecio microcephalus Phil. var. aclonetus (Phil.)

Kuntze

Subarbusto. Endémico.

Distribución: MAU, NUB, BIO.

Rango altitudinal: 0-2200 m.

Senecio linariifolius Poepp. ex DC. var. heliophytoides (Phil.) Reiche

Sinónimos: Senecio heliophytoides Phil.

Subarbusto. Nativo.

Distribución: RME, MAU, NUB, BIO, ARA, LLA, AIS.
Rango altitudinal: 1200-2500 m.

Países limítrofes: Argentina.

Senecio linariifolius Poepp. ex DC. var. linariifolius

Sinónimos: Senecio promaucanus Phil.

Subarbusto. Nativo.

Distribución: LBO, MAU, NUB, BIO, ARA, AIS.

Rango altitudinal: 1000-2900 m.

Países limítrofes: Argentina.

Senecio lithostaurus Cabrera

Sinónimos: Senecio remyanus Phil. fma. eradiatus Kuntze

Subarbusto. Nativo.

Distribución: RME.

Rango altitudinal: 1500-3500 m.

Países limítrofes: Argentina.

Senecio looseri Cabrera

Subarbusto. Nativo.

Distribución: COQ, VAL, RME.

Rango altitudinal: 3000-5000 m.

Países limítrofes: Argentina.

Senecio lorentziella Hicken

Subarbusto. Nativo.

Distribución: ATA, COQ, VAL, RME.

Rango altitudinal: 2900-3500 m.

Países limítrofes: Argentina.

Senecio luridus Phil.

Arbusto. Endémico.

Distribución: ATA.

Rango altitudinal: $2400 \mathrm{~m}$.

Senecio madagascariensis Poir.

Hierba. Perenne. Introducida.

Distribución: COQ.

Senecio madariagae Phil.

Arbusto. Endémico.

Distribución: TAR, ANT.

Rango altitudinal: 0-3400 m.

Senecio magellanicus Hook. \& Arn.

Sinónimos: Senecio culcitenellus Cuatrec., Senecio vaginifolius Sch. Bip., Culcitium magellanicum (Hook. \& Arn.) Hombr. \& Jacquinot

Hierba. Perenne. Nativa.

Distribución: AIS, MAG.

Rango altitudinal: 200-1600 m.

Países limítrofes: Argentina.

Senecio mapuche Cabrera

Subarbusto. Endémico. 
Distribución: VAL, RME.

Rango altitudinal: 1800-2200 m.

Senecio martinensis Dusén

Hierba. Perenne. Nativa.

Distribución: AIS, MAG.

Rango altitudinal: 600-1200 m.

Países limítrofes: Argentina.

Senecio masafuerae (Skottsb.) Pelser

Sinónimos: Robinsonia masafuerae (Skottsb.) Pelser

Arbusto. Endémico.

Distribución: JFE.

Rango altitudinal: 0-500 m.

Senecio masatierrae Pelser

Sinónimos: Robinsonia macrocephala Decne.,

Symphyochaeta macrocephala (Decne.) Skottsb.

Arbusto o árbol pequeño. Endémico.

Distribución: JFE.

Rango altitudinal: 0-500 m.

Nombre vulgar: Incienso.

Nota: Extinta.

Senecio maulinus Reiche

Sinónimos: Senecio leucomallus Phil., hom. illeg.

Subarbusto. Endémico.

Distribución: LBO, MAU.

Rango altitudinal: 200-2800 m.

Senecio mesembrynus Cabrera

Sinónimos: Senecio bakeri Reiche

Subarbusto. Endémico.

Distribución: AIS, MAG.

Rango altitudinal: 0-100 m.

Senecio microcephalus Phil. var. angustifolius Cabrera Arbusto. Nativo.

Distribución: LLA.

Rango altitudinal: $300-800 \mathrm{~m}$.

Países limítrofes: Argentina.

Senecio microcephalus Phil. var. microcephalus

Arbusto. Nativo.

Distribución: NUB, LRI.

Rango altitudinal: $300-800 \mathrm{~m}$.

Países limítrofes: Argentina.

Senecio microphyllus Phil.

Sinónimos: Senecio hakeifolius Hook. \& Arn. var. adenophyllus Hook. \& Arn., Senecio gypsophilus Phil., Senecio bowenkampi Phil., Senecio alfalfalis Phil.

Arbusto. Nativo.

Distribución: COQ, VAL, RME, LBO, MAU.
Rango altitudinal: 1500-2300 m.

Países limítrofes: Argentina.

Senecio micropifolius DC.

Sinónimos: Senecio pelolepis Johnst.

Subarbusto. Endémico.

Distribución: ANT, ATA, COQ.

Rango altitudinal: 1900-4300 m.

Senecio microtis Phil.

Arbusto. Endémico.

Distribución: ATA.

Rango altitudinal: 0-3200 m.

Senecio minutifolius Phil.

Arbusto. Endémico.

Distribución: ATA, COQ, VAL, RME.

Rango altitudinal: 1600-3200 m.

Senecio miser Hook.f.

Sinónimos: Senecio ericoides Reiche, Senecio fueginus

Phil.

Subarbusto. Nativo.

Distribución: MAG.

Rango altitudinal: 100-1500 m.

Países limítrofes: Argentina.

Senecio monttianus J. Remy

Subarbusto. Endémico.

Distribución: AYP, COQ, RME, LBO, MAU.

Rango altitudinal: 2400-3000 m.

Senecio munnozii Cabrera

Subarbusto. Endémico.

Distribución: COQ.

Rango altitudinal: 0-100 m.

Senecio murinus Phil.

Subarbusto. Endémico.

Distribución: ATA, COQ, VAL.

Rango altitudinal: 400-1400 m.

Nombre vulgar: Hierba de los ratones, hierba zonza.

Senecio murorum J. Remy

Arbusto. Endémico.

Distribución: COQ, RME.

Rango altitudinal: 100-200 m.

Nombre vulgar: Monte azulillo.

Senecio myriophyllus Phil.

Arbusto o subarbusto. Endémico.

Distribución: ANT, ATA, COQ.

Rango altitudinal: 0-1200 m. 
Senecio neaei DC. var. incisus DC.

Sinónimos: Senecio sericeus Kuntze var. incisus (DC.)

Kuntze

Arbusto o subarbusto. Nativo.

Distribución: MAG.

Rango altitudinal: 0-2600 m.

Países limítrofes: Argentina.

\section{Senecio neaei DC. var. neaei}

Sinónimos: Senecio sericeus Kuntze var. neaei (DC.) Kuntze

Arbusto o subarbusto. Nativo.

Distribución: MAU, NUB, BIO, ARA, AIS.

Rango altitudinal: 300-1800 m.

Países limítrofes: Argentina.

Senecio nigrescens Hook. \& Arn.

Sinónimos: Senecio chamaedryfolius Less.

Hierba. Perenne. Endémica.

Distribución: MAU, NUB, BIO.

Rango altitudinal: $0-100 \mathrm{~m}$.

Nombre vulgar: Nilhue.

Senecio nublensis Soldano

Sinónimos: Senecio carnosus Phil., hom. illeg.

Subarbusto. Endémico.

Distribución: NUB, ARA, LLA.

Rango altitudinal: 0-1800 m.

Senecio nutans Sch. Bip.

Sinónimos: Senecio graveolens Wedd.

Arbusto. Nativo.

Distribución: AYP, TAR, ANT.

Rango altitudinal: 3500-5000 m.

Países limítrofes: Argentina, Bolivia y Perú.

Nombre vulgar: Tola hembra, chachacoma, chachakoma macho.

\section{Senecio obtectus Kuntze}

Subarbusto. Nativo.

Distribución: VAL, RME, LBO.

Rango altitudinal: 2200-2600 m.

Países limítrofes: Argentina.

Senecio oreinus Cabrera

Sinónimos: Senecio andicola Phil., hom. illeg., Senecio monticola Phil., hom. illeg.

Subarbusto. Nativo.

Distribución: ATA, COQ.

Rango altitudinal: 1700-3000 m.

Países limítrofes: Argentina.

Senecio oreophyton J. Remy

Sinónimos: Senecio medicinalis Phil.

Arbusto. Nativo.
Distribución: ANT, ATA, COQ.

Rango altitudinal: 3100-4000 m.

Países limítrofes: Argentina.

Nombre vulgar: Hierba del incordio, chachacoma.

Senecio otaeguianus Phil.

Subarbusto. Endémico.

Distribución: VAL.

Rango altitudinal: 0-100 m.

Senecio otites Kunze ex DC.

Sinónimos: Senecio chiloensis Phil., Senecio otophorus

Phil., nom. illeg.

Hierba. Perenne. Nativa.

Distribución: MAU, NUB, BIO, ARA, LRI, LLA, AIS.

Rango altitudinal: $600-1100 \mathrm{~m}$.

Países limítrofes: Argentina.

Nombre vulgar: Trompetilla, tutuco, trompón.

Senecio pachyphyllos J. Remy

Sinónimos: Senecio domeykoanus Phil., Senecio sedifolius

Phil.

Subarbusto. Nativo.

Distribución: RME, LBO, MAU, NUB, BIO, ARA.

Rango altitudinal: 1200-3200 m.

Países limítrofes: Argentina.

Senecio pappii Ricardi \& Martic.

Subarbusto. Endémico.

Distribución: AYP, ANT.

Rango altitudinal: 3200-3600 m.

Nombre vulgar: Kopa de cóndor, chachakoma blanca, pupusa.

\section{Senecio parodii Cabrera}

Hierba. Perenne. Nativa.

Distribución: BIO, ARA, LLA.

Rango altitudinal: $300-1200 \mathrm{~m}$.

Países limítrofes: Argentina.

Senecio patagonicus Hook. \& Arn. var. alyssoides (Sch. Bip.) Cabrera

Sinónimos: Senecio danyausii Hombr. \& Jacquinot var. alyssoides Sch. Bip., Senecio exilis Hombr. \& Jacquinot, Senecio floccidus Hombr. \& Jacquinot

Subarbusto. Nativo.

Distribución: AIS, MAG.

Rango altitudinal: 0-500 $\mathrm{m}$.

Países limítrofes: Argentina.

Senecio patagonicus Hook. \& Arn. var. andersonii (Hook.f.) Cabrera

Sinónimos: Senecio andersonii Hook.f., Senecio andersonii Hook.f. var. ß Hook.f., Senecio forsteri Phil. 
Subarbusto. Nativo.

Distribución: AIS, MAG.

Rango altitudinal: 100-900 m.

Países limítrofes: Argentina.

Senecio patagonicus Hook. \& Arn. var. lobatifolius (Hombr. \& Jacquinot) Cabrera

Sinónimos: Senecio danyausii Hombr. \& Jacquinot var. ß J. Remy, nom. illeg., Senecio danyausii Hombr. \& Jacquinot var. lobatifolia Hombr. \& Jacquinot, Senecio danyausii Hombr. \& Jacquinot var. trifurcatus Sch. Bip.

Subarbusto. Nativo.

Distribución: MAG.

Rango altitudinal: 0-500 m.

Países limítrofes: Argentina.

Senecio patagonicus Hook. \& Arn. var. patagonicus

Sinónimos: Senecio lechleri Phil., Senecio palenae Phil.

Subarbusto. Nativo.

Distribución: AIS, MAG.

Rango altitudinal: 200-1300 m.

Países limítrofes: Argentina.

Senecio paucidentatus DC. var. limbardioides (Hook. \& Arn.) Cabrera

Sinónimos: Senecio limbardioides Hook. \& Arn., Senecio olivaceus Phil.

Subarbusto. Endémico.

Distribución: VAL.

Rango altitudinal: 0-100 m.

Senecio paucidentatus DC. var. paucidentatus

Subarbusto. Endémico.

Distribución: COQ, VAL.

Rango altitudinal: 0-200 m.

Senecio pemehuensis Soldano

Sinónimos: Senecio scoparius Phil., hom. illeg.

Subarbusto. Endémico.

Distribución: BIO, ARA.

Rango altitudinal: $1400 \mathrm{~m}$.

Senecio pentaphyllus Phil.

Sinónimos: Senecio laciniosus Phil., Senecio navarri Phil., Senecio pentaphyllus Phil. var. navarri (Phil.) Reiche, Senecio schoenleini Meigen

Subarbusto. Endémico.

Distribución: VAL, RME, LBO.

Rango altitudinal: 2300-2500 m.

Senecio peripotamus C. Jeffrey

Sinónimos: Senecio rivularis J. Remy, hom. illeg.

Subarbusto. Endémico.

Distribución: COQ.
Rango altitudinal: 300-2700 m.

Senecio peteroanus Phil.

Subarbusto. Nativo.

Distribución: MAU, ARA.

Rango altitudinal: 1600-2100 m.

Países limítrofes: Argentina.

Senecio petrophyus Pelser

Sinónimos: Robinsonia saxatilis Danton

Arbusto. Endémico.

Distribución: JFE.

Rango altitudinal: $300 \mathrm{~m}$.

Senecio pfisteri Ricardi \& Martic.

Hierba. Perenne. Endémica.

Distribución: AYP, TAR, ANT.

Rango altitudinal: 4300-4400 m.

Senecio philippicus Regel \& Körn.

Sinónimos: Senecio paposanus Phil.

Arbusto. Endémico.

Distribución: ANT.

Rango altitudinal: 200-900 m.

Senecio philippii Sch. Bip. ex Wedd.

Sinónimos: Senecio ammophilus Phil., Senecio hirthi Phil.

Subarbusto. Nativo.

Distribución: LLA, AIS, MAG.

Rango altitudinal: 500-1000 m.

Países limítrofes: Argentina.

Senecio phylicifolius Poepp. ex DC.

Sinónimos: Cineraria phylicifolia Poepp. ex DC.

Subarbusto. Endémico.

Distribución: NUB, BIO, ARA.

Rango altitudinal: 200-2000 m.

Senecio phylloleptus Cuatrec.

Arbusto. Nativo.

Distribución: AYP.

Rango altitudinal: $3500 \mathrm{~m}$.

Países limítrofes: Bolivia y Perú.

Nombre vulgar: Flor amarilla.

Senecio pilquensis $\mathrm{H}$. Buek

Sinónimos: Senecio heterophyllus DC., hom. illeg., Senecio phyllomorphus Steud., Senecio porophylloides J. Remy

Subarbusto. Nativo.

Distribución: MAU, NUB, BIO, ARA, LRI.

Rango altitudinal: 900-1700 m.

Países limítrofes: Argentina. 
Senecio pissisi Phil.

Subarbusto. Nativo.

Distribución: ATA, COQ.

Rango altitudinal: 3000-4100 m.

Países limítrofes: Argentina.

Senecio planiflorus Kunze ex Cabrera

Sinónimos: Senecio littoralis Poepp. ex DC., nom. illeg., Senecio sinuatilobus DC. var. littoralis DC.

Arbusto. Endémico.

Distribución: COQ, VAL, RME, LBO, MAU.

Rango altitudinal: 0-700 m.

Senecio poeppigii Hook. \& Arn.

Sinónimos: Senecio dealbatus Phil., Senecio micropifolius DC. var. ß. monocephalus DC., Senecio williamsii Phil.

Subarbusto. Nativo.

Distribución: MAU, NUB, BIO, ARA, LLA, MAG.

Rango altitudinal: 1300-2000 m.

Países limítrofes: Argentina.

\section{Senecio polygaloides Phil}

Sinónimos: Senecio linariifolius Poepp. ex DC. var. tenuifolius DC., Senecio multibracteatus Phil., hom. illeg., Senecio linariifolius Poepp. ex DC. var. discoideus Kuntze Subarbusto. Nativo.

Distribución: COQ, VAL, RME, LBO, MAU, NUB, BIO, ARA, AIS.

Rango altitudinal: 2000-3100 m.

Países limítrofes: Argentina.

Senecio polyphyllus Kunze ex DC.

Sinónimos: Senecio tristis Phil. var. comberi Greenm.

Subarbusto. Nativo.

Distribución: LBO, MAU, NUB, BIO, ARA.

Rango altitudinal: $1700-2600 \mathrm{~m}$.

Países limítrofes: Argentina y Perú.

Senecio portalesianus J. Remy var. lanuginosus (Phil.) Cabrera

Sinónimos: Senecio antucensis Phil. var. lanuginosa Phil.

Subarbusto. Endémico.

Distribución: NUB, BIO, ARA.

Rango altitudinal: 1400-2500 m.

Senecio portalesianus J. Remy var. portalesianus

Sinónimos: Senecio antucensis Phil., Senecio polyphyllus

Kunze ex DC. var. antucensis (Phil.) Reiche, Senecio

ceratophyllus D. Don ex Hook. \& Arn. var. B nana D. Don

ex Hook. \& Arn.

Subarbusto. Nativo.

Distribución: NUB, BIO, ARA, LLA, AIS, MAG.

Rango altitudinal: $1500-2800 \mathrm{~m}$.

Países limítrofes: Argentina.
Senecio portulacoides J. Remy

Sinónimos: Senecio macer Phil.

Arbusto. Endémico.

Distribución: COQ.

Rango altitudinal: 1200-2800 m.

Senecio prenanthifolius Phil.

Sinónimos: Senecio ranconensis Sch. Bip. ex Phil., nom. nud., Senecio helianthoides Phil., Senecio ranconensis Sch.

Bip. ex Lechl., nom. nud.

Hierba. Perenne. Nativa.

Distribución: LBO, ARA, LRI, LLA.

Rango altitudinal: 1000-1500 m.

Países limítrofes: Argentina.

Senecio proteus J. Remy var. geissei (Phil.) Cabrera

Sinónimos: Senecio geissei Phil.

Arbusto. Endémico.

Distribución: ATA, COQ.

Rango altitudinal: $1200-1800 \mathrm{~m}$.

Senecio proteus J. Remy var. proteus

Sinónimos: Senecio bracteolatus Phil., Senecio foliolosus

Reiche, Senecio pinnatifidus Phil., Senecio stenophyllus

Phil.

Arbusto. Endémico.

Distribución: ATA, COQ.

Rango altitudinal: 800-3000 m.

Nombre vulgar: Pajarito, palito blanco.

Senecio pseudalmeidae Cabrera

Arbusto. Endémico.

Distribución: ANT.

Rango altitudinal: $300 \mathrm{~m}$.

Senecio pseuderucoides Cabrera

Arbusto. Endémico.

Distribución: RME.

Rango altitudinal: $1900 \mathrm{~m}$.

Senecio pubescens Phil.

Arbusto o subarbusto. Endémico.

Distribución: COQ.

Rango altitudinal: 1500-1600 m.

Senecio puchii Phil.

Subarbusto. Nativo.

Distribución: AYP, TAR, ANT.

Rango altitudinal: 4200-4800 m.

Países limítrofes: Argentina y Bolivia.

Nombre vulgar: Chachakoma, leña de tola, tola de piedra. 
Senecio pycnanthus Phil.

Sinónimos: Senecio pycnanthus Phil. var. brevifolia Phil.

Subarbusto. Endémico.

Distribución: MAU, NUB.

Rango altitudinal: 0-1200 m.

Senecio rahmeri Phil.

Subarbusto. Nativo.

Distribución: ANT, ATA.

Rango altitudinal: 4100-4300 m.

Países limítrofes: Argentina.

\section{Senecio reicheanus Cabrera}

Subarbusto. Nativo.

Distribución: AYP, TAR, ANT.

Rango altitudinal: $3600 \mathrm{~m}$.

Países limítrofes: Bolivia.

Senecio renjifoanus Phil.

Subarbusto. Nativo.

Distribución: RME.

Rango altitudinal: 1600-3300 m.

Países limítrofes: Argentina.

Senecio ricardii Martic. \& Quezada

Arbusto. Endémico.

Distribución: AYP, ATA.

Rango altitudinal: 3100-3400 m.

Senecio santelicis Phil.

Sinónimos: Senecio crispus Phil. var. santelisis (Phil.) Reiche

Arbusto. Nativo.

Distribución: ANT, ATA.

Rango altitudinal: 3500-4600 m.

Países limítrofes: Argentina.

Senecio santiagoensis Kuntze

Sinónimos: Senecio leucanthemifolius Phil.

Subarbusto. Endémico.

Distribución: RME.

Rango altitudinal: 2300-2500 m.

Senecio saxicola Wedd.

Subarbusto. Nativo.

Distribución: ATA.

Rango altitudinal: 200-300 m.

Países limítrofes: Perú.

Senecio schoenemannii Phil.

Subarbusto. Endémico.

Distribución: MAU.

Rango altitudinal: $1300 \mathrm{~m}$.
Senecio scopulorum Poepp.

Hierba o subarbusto. Perenne. Endémica.

Distribución: BIO.

Rango altitudinal: 900-1500 m.

Senecio scorzonerifolius Meyen \& Walp.

Sinónimos: Senecio armeriifolius Phil.

Hierba. Perenne. Nativa.

Distribución: AYP, TAR, ANT, ATA.

Rango altitudinal: 4400-4600 m.

Países limítrofes: Argentina y Perú.

Nombre vulgar: Romerillo chico.

Senecio segethii Phil.

Sinónimos: Senecio peraltae Phil.

Hierba. Perenne. Nativa.

Distribución: ATA, COQ.

Rango altitudinal: 2000-4100 m.

Países limítrofes: Argentina.

Senecio sericeonitens Speg.

Sinónimos: Senecio patagonicus Phil., hom. illeg.

Arbusto. Nativo.

Distribución: ARA, LLA, AIS, MAG.

Rango altitudinal: 700-2000 m.

Países limítrofes: Argentina.

Senecio serratifolius (Meyen \& Walp.) Cuatrec.

Sinónimos: Senecio cernuus Phil., hom. illeg.

Hierba. Perenne. Nativa.

Distribución: AYP, TAR, ANT.

Rango altitudinal: 4000-5000 m.

Países limítrofes: Argentina, Bolivia y Perú.

Senecio sinuatilobus DC.

Sinónimos: Senecio mollis Poepp. ex DC.

Arbusto. Endémico.

Distribución: COQ, VAL, RME, LBO, MAU.

Rango altitudinal: 0-1500 m.

Senecio skottsbergii Cabrera var. anomalus Cabrera

Subarbusto. Endémico.

Distribución: AIS.

Rango altitudinal: 0-100 m.

Senecio skottsbergii Cabrera var. skottsbergii

Subarbusto. Nativo.

Distribución: AIS, MAG.

Rango altitudinal: 600-1800 m.

Países limítrofes: Argentina.

Senecio smithii DC.

Sinónimos: Brachypappus smithii (DC.) Sch. Bip., Senecio verbascifolius Hombr. \& Jacquinot ex Decne, Senecio kurtzii Phil., Senecio punctarenicus Krause, Cineraria leucanthema 
Banks \& Sol. ex Walp.

Hierba. Perenne. Nativa.

Distribución: ARA, LRI, LLA, AIS, MAG.

Rango altitudinal: 0-2100 m.

Países limítrofes: Argentina.

\section{Senecio socompae Cabrera}

Subarbusto. Nativo.

Distribución: ANT.

Rango altitudinal: 3500-4000 m.

Países limítrofes: Argentina.

Senecio spinosus DC.

Arbusto. Nativo.

Distribución: AYP, TAR.

Rango altitudinal: 3400-4600 m.

Países limítrofes: Perú.

Nombre vulgar: Añawaya, kaylla, espina, tola de espino, té del cuerno.

Senecio subauritus Phil.

Subarbusto. Endémico.

Distribución: BIO, ARA.

Rango altitudinal: 900-1500 m.

\section{Senecio subpubescens Cabrera}

Subarbusto. Nativo.

Distribución: MAU, NUB, BIO, ARA, LRI, LLA, MAG.

Rango altitudinal: 1000-1700 m.

Países limítrofes: Argentina.

Senecio subulatus D. Don ex Hook. \& Arn. var. salsus (Griseb.) Cabrera

Sinónimos: Senecio diversifolius Phil., hom. illeg., Senecio salsus Griseb., Senecio subulatus D. Don ex Hook. \& Arn. var. diversifolius (Phil.) Cabrera

Arbusto. Nativo.

Distribución: AYP, TAR, ANT.

Rango altitudinal: 2500-4000 m.

Países limítrofes: Argentina y Bolivia.

Nombre vulgar: Chachakoma macho.

\section{Senecio subumbellatus Phil.}

Sinónimos: Senecio thermarum Phil., Senecio antirhinifolius Phil., Senecio linariifolius Poepp. ex DC. var. subdiscoideus DC., Senecio multicaulis Poepp., hom. illeg.

Subarbusto. Nativo.

Distribución: VAL, RME, LBO, MAU, NUB, BIO, ARA, LRI.

Rango altitudinal: 1500-3600 m.

Países limítrofes: Argentina.

Senecio sundtii Phil.

Subarbusto. Nativo.

Distribución: ANT, ATA.
Rango altitudinal: 3600-4700 m.

Países limítrofes: Argentina y Bolivia.

Senecio sylvaticus L.

Hierba. Anual. Introducida.

Distribución: VAL, MAU, NUB, BIO, ARA, LRI, LLA, AIS.

Senecio tacorensis Cabrera

Sinónimos: Senecio olivaceobracteatus Ricardi \& Martic.

Subarbusto. Nativo.

Distribución: AYP, TAR, ANT.

Rango altitudinal: $3500-4200 \mathrm{~m}$.

Países limítrofes: Bolivia y Perú.

Nombre vulgar: Koya blanca, monte blanco, payakoa, kpa de cóndor.

Senecio talquinus Phil.

Subarbusto. Endémico.

Distribución: MAU.

Rango altitudinal: $2100 \mathrm{~m}$.

Senecio tehuelches (Speg.) Cabrera

Sinónimos: Senecio miser Hook.f. var. tehuelches Speg.

Subarbusto. Nativo.

Distribución: AIS.

Rango altitudinal: 400-1000 m.

Países limítrofes: Argentina.

Senecio thurifer (Decne.) Pelser

Sinónimos: Robinsonia thurifera Decne.

Arbusto. Endémico.

Distribución: JFE.

Rango altitudinal: 0-500 m.

Senecio tinctolobus I.M. Johnst.

Subarbusto. Endémico.

Distribución: ATA, COQ.

Rango altitudinal: $3000-4300 \mathrm{~m}$.

Senecio tricuspidatus Hook. \& Arn. var. dentatus (Sch. Bip.) Cabrera

Sinónimos: Senecio ibari Phil., Senecio longipes Hook.f., Senecio longipes Hook.f. var. dentatus Sch. Bip., Senecio longipes Hook.f. var. integrifolius Sch. Bip.

Arbusto. Nativo.

Distribución: MAG.

Rango altitudinal: 0-1200 m.

Países limítrofes: Argentina.

Senecio tricuspidatus Hook. \& Arn. var. tricuspidatus Sinónimos: Senecio nordenskjöldii O. Hoffm., Senecio nordenskjöldii O. Hoffm. var. simplicior O. Hoffm. ex Dusén Arbusto. Nativo. 
Distribución: AIS, MAG.

Rango altitudinal: 0-1200 m.

Países limítrofes: Argentina.

Senecio trifidus Hook. \& Arn.

Sinónimos: Senecio demissus Phil.

Subarbusto. Nativo.

Distribución: RME.

Rango altitudinal: 2700-4000 m.

Países limítrofes: Argentina.

Senecio trifurcatus (G. Forst.) Less.

Sinónimos: Cineraria trifurcata (G. Forst.) Spreng., Senecio trifurcatus (G. Forst.) Less. var. pentadactylus (Phil.) Speg., Senecio trifurcatus (G. Forst.) Less. var. pisensis Sch. Bip. ex Wedd., Senecio pentadactylus Phil., Tussilago trifurcata G. Forst.

Hierba. Perenne. Nativa.

Distribución: ARA, LLA, AIS, MAG.

Rango altitudinal: 800-1600 m.

Países limítrofes: Argentina.

Senecio trifurcifolius Hieron.

Subarbusto. Nativo.

Distribución: AYP.

Rango altitudinal: 4200-5100 m.

Países limítrofes: Bolivia y Perú.

Senecio triodon Phil.

Sinónimos: Senecio baccharidifolius DC. var. subradiatus DC.

Subarbusto. Nativo.

Distribución: VAL, LBO, MAU, NUB, BIO, ARA, LRI, LLA, AIS, MAG.

Rango altitudinal: 900-2000 m.

Países limítrofes: Argentina.

Senecio tripinnatifidus Reiche

Subarbusto. Endémico.

Distribución: COQ, VAL.

Rango altitudinal: 1100-1300 m.

Senecio tristis Phil.

Sinónimos: Senecio consanguineus Phil., Senecio setulosus Phil.

Subarbusto. Nativo.

Distribución: RME, LBO, MAU, NUB, BIO, ARA.

Rango altitudinal: 1200-2100 m.

Países limítrofes: Argentina.

Senecio troncosii Phil.

Sinónimos: Senecio thinophilus Phil.

Hierba. Anual. Endémica.

Distribución: ANT, ATA.
Rango altitudinal: 0-1800 m.

Senecio viridis Phil. var. radiatus R.E. Fr.

Arbusto. Nativo.

Distribución: TAR, ANT.

Rango altitudinal: 2500-3700 m.

Países limítrofes: Argentina.

Senecio viridis Phil. var. viridis

Arbusto. Nativo.

Distribución: AYP, TAR, ANT.

Rango altitudinal: 3000-4400 m.

Países limítrofes: Argentina y Bolivia.

Nombre vulgar: Mocora, mocoraca.

Senecio viscosissimus Colla

Sinónimos: Senecio hakeaefolius Hook. \& Arn., Cineraria

humilis Poepp.

Subarbusto. Endémico.

Distribución: ANT, COQ, VAL, LBO.

Rango altitudinal: 0-400 m.

Senecio volckmannii Phil.

Sinónimos: Senecio rosmarinus Phil. var. ascotanensis (Phil.) Cabrera, Senecio rosmarinus Phil., Senecio ascotanensis Phil., Senecio doñae-annae Phil.

Subarbusto. Nativo.

Distribución: AYP, TAR, ANT, ATA, COQ.

Rango altitudinal: 3300-4500 m.

Países limítrofes: Argentina y Bolivia.

Nombre vulgar: Romero, pukachaki, pata colorada, kopa de cóndor, viravira.

\section{Senecio vulgaris $\mathrm{L}$.}

Hierba. Anual. Introducida.

Distribución: ANT, ATA, COQ, VAL, RME, LBO, MAU, NUB, BIO, ARA, LRI, LLA, MAG, JFE.

Senecio websteri Hook.f.

Sinónimos: Senecio websteri Hook.f. var. subdiscoideus A.

Gray

Hierba. Perenne. Nativa.

Distribución: MAG.

Rango altitudinal: 0-600 m.

Países limítrofes: Argentina.

Senecio werdermannii Greenm.

Sinónimos: Senecio modestus Phil., hom. illeg.

Subarbusto. Nativo.

Distribución: VAL, RME.

Rango altitudinal: 2000-3000 m.

Países limítrofes: Argentina. 
Senecio xerophilus Phil. var. deserticola (Cabrera) Cabrera Sinónimos: Senecio deserticola Cabrera, Senecio cremophilus Phil., hom. illeg., Senecio eremophilus Phil. Subarbusto. Endémico.

Distribución: ANT.

Rango altitudinal: $4500 \mathrm{~m}$.

\section{Senecio xerophilus Phil. var. xerophilus}

Subarbusto. Nativo.

Distribución: AYP, TAR, ANT.

Rango altitudinal: $3700-4700 \mathrm{~m}$.

Países limítrofes: Argentina.

Nombre vulgar: Romerillo, romerillo blanco.

Senecio zapahuirensis Martic. \& Quezada

Arbusto. Endémico.

Distribución: AYP, TAR.

Rango altitudinal: 2100-3000 m.

Senecio zoellneri Martic. \& Quezada

Sinónimos: Culcitium albifolium Zoellner

Hierba. Perenne. Nativa.

Distribución: AYP.

Rango altitudinal: 4000-5000 m.

Países limítrofes: Bolivia.

Nombre vulgar: Chukuchuku.

Senecio zosterifolius Hook. \& Arn.

Sinónimos: Senecio uliginosus Phil., Haplostichia stolonifera Phil., Senecio cotuloides Reiche, Senecio graminifolius Phil., Senecio potamogetonifolius Sch. Bip. ex Phil.

Hierba. Perenne. Nativa.

Distribución: VAL, NUB, BIO, ARA, LRI.

Rango altitudinal: 600-1500 m.

Países limítrofes: Argentina.

\section{Sigesbeckia}

Sigesbeckia serrata DC.

Sinónimos: Sigesbeckia jorullensis auct. non Kunth Hierba. Anual. Nativa.

Distribución: VAL, RME, NUB, BIO, ARA, LRI, LLA, AIS.

Rango altitudinal: 1300-2900 m.

Países limítrofes: Argentina y Perú.

\section{Silybum}

Silybum marianum (L.) Gaertn.

Hierba. Anual o bienal. Introducida.

Distribución: COQ, VAL, RME, LBO, MAU, NUB, BIO, ARA, LRI, LLA, JFE.

\section{Smallanthus}

Smallanthus connatus (Spreng.) H. Rob.

Hierba. Perenne. Introducida.

Distribución: VAL.

\section{Solidago}

Solidago argentinensis López Laph. \& Semple

Hierba. Perenne. Nativa.

Distribución: VAL.

Rango altitudinal: 1000-4000 m.

Países limítrofes: Argentina, Bolivia y Perú.

Solidago chilensis Meyen

Sinónimos: Solidago linearifolia DC., Solidago microglossa

DC. var. linearifolia (DC.) Baker, Aster sagei Phil.,

Solidago coquimbana Phil., Solidago floribunda Phil.,

Solidago laxiflora Phil., Solidago parviflora Phil., Solidago recta Phil., Solidago valdiviana Phil.

Hierba. Perenne. Nativa.

Distribución: TAR, ATA, COQ, VAL, RME, LBO, MAU, NUB, BIO, ARA, LRI, LLA, AIS, JFE.

Rango altitudinal: 0-2500 m.

Países limítrofes: Argentina.

Nombre vulgar: Fulel, huellen.

Nota: Introducida en el Archipiélago Juan Fernández.

Solidago patagonica Phil.

Hierba. Perenne. Endémica.

Distribución: AIS.

Rango altitudinal: 0-500 m.

\section{Soliva}

Soliva sessilis Ruiz \& Pav.

Sinónimos: Soliva microloma Phil., Soliva valdiviana Phil., Gymnostyles chilensis Spreng.

Hierba. Anual. Nativa.

Distribución: COQ, VAL, RME, LBO, MAU, NUB, BIO, ARA, LRI, LLA.

Rango altitudinal: 0-1500 m.

Países limítrofes: Argentina.

Nombre vulgar: Dicha.

Soliva stolonifera (Brot.) R. Br. ex Sweet

Sinónimos: Soliva urbica Phil.

Hierba. Anual. Nativa.

Distribución: RME, MAU, JFE.

Rango altitudinal: 0-500 m.

Países limítrofes: Argentina, Bolivia y Perú.

Nota: Introducida en el Archipiélago Juan Fernández. 
Sonchus

Sonchus arvensis L.

Hierba. Perenne. Introducida.

Distribución: MAG.

Sonchus asper (L.) Hill

Hierba. Anual o bienal. Introducida.

Distribución: AYP, TAR, ANT, ATA, COQ, VAL, RME, LBO, MAU, NUB, BIO, ARA, LRI, LLA, AIS, MAG, JFE, IPA, IDE.

\section{Sonchus oleraceus L.}

Hierba. Anual. Introducida.

Distribución: AYP, TAR, ANT, ATA, COQ, VAL, RME, LBO, MAU, NUB, BIO, LRI, LLA, AIS, MAG, JFE, IPA.

\section{Sonchus tenerrimus L.}

Hierba. Anual o bienal. Introducida.

Distribución: AYP, TAR, ANT, ATA, COQ, VAL, RME, LBO, MAU, NUB, BIO, ARA, LRI, LLA, MAG, JFE.

\section{Spilanthes}

\section{Spilanthes leiocarpa DC.}

Sinónimos: Ceratocephalus leiocarpus (DC.) Kuntze

Hierba. Perenne. Nativa.

Distribución: AYP.

Rango altitudinal: 200-300 m.

Países limítrofes: Perú.

\section{Spinoliva}

Spinoliva ilicifolia (Hook. \& Arn.) G.Sancho subsp. baccharoides (D.Don ex Hook. \& Arn.) G.Sancho Sinónimos: Proustia baccharoides D. Don ex Hook. \& Arn., Proustia ilicifolia Hook. \& Arn. fma. baccharoides (D. Don ex Hook. \& Arn.) Fabris

Arbusto. Endémico.

Distribución: ATA, COQ, VAL, RME, LBO.

Nombre vulgar: Huañil, olivillo.

Spinoliva ilicifolia (Hook. \& Arn.) G.Sancho subsp. ilicifolia

Sinónimos: Proustia pungens Poepp. ex Less. var. ilicifolia (Hook. \& Arn.) DC., Proustia olivillo Phil., Proustia reticulata Phil., Proustia ilicifolia Hook. \& Arn. fma. ilicifolia

Arbusto. Endémico.

Distribución: ATA, COQ, VAL, RME.

Rango altitudinal: 900-2000 m.

Nombre vulgar: Huañil, olivillo.

\section{Stevia}

Stevia philippiana Hieron.

Sinónimos: Stevia hyssopifolia Phil., hom. illeg., Stevia menthaefolia Phil., hom. illeg., Stevia hyssopifolia var. panulensis B.L. Rob. ex I.M. Johnst.; Porophyllum tarapacanum Zoellner

Subarbusto. Endémico.

Distribución: AYP, TAR, ANT, ATA.

Rango altitudinal: 780-3600 m.

Nombre vulgar: Mulumulu.

\section{Symphyotrichum}

Symphyotrichum glabrifolium (DC.) G.L. Nesom

Sinónimos: Aster vahlii (Gaudich.) Hook. \& Arn. var. australis (Phil.) Reiche, Erigeron australis Phil., Erigeron glabrifolius DC., Erigeron scorzoneraefolium J. Remy, Aster glabrifolius (DC.) Reiche

Hierba. Perenne. Nativa.

Distribución: MAU, NUB, BIO, ARA, LLA, AIS, MAG.

Rango altitudinal: $780-3600 \mathrm{~m}$.

Países limítrofes: Argentina.

Symphyotrichum patagonicum (Cabrera) G.L. Nesom

Sinónimos: Aster patagonicus Cabrera

Hierba. Perenne. Nativa.

Distribución: MAG.

Rango altitudinal: 250-350 m.

Países limítrofes: Argentina.

Symphyotrichum peteroanum (Phil.) G.L. Nesom Sinónimos: Aster peteroanus Phil., Aster vahlii (Gaudich.) Hook. \& Arn. var. latifolius Cabrera

Hierba. Perenne. Nativa.

Distribución: LBO, MAU, NUB, BIO, ARA, LLA.

Rango altitudinal: 1000-2200 m.

Países limítrofes: Argentina.

Symphyotrichum squamatum (Spreng.) G.L. Nesom Sinónimos: Aster exilis Elliott var. australis A. Gray, Aster moelleri (Phil.) Reiche, Baccharis asteroides Bertero ex Colla, Conyza berteroana Phil., Conyza squamata Spreng., Conyzanthus squamatus (Spreng.) Tamamsch., Erigeron depilis Phil., Erigeron semiamplexicaule Meyen, Aster squamatus (Spreng.) Hieron., Tripolium oliganthum Phil., Tripolium moelleri Phil., Tripolium conspicuum J. Remy, Aster asteroides (Bertero ex Colla) Rusby, comb. illeg., Symphyotrichum subulatum (Michx.) G.L. Nesom var. squamatum (Spreng.) S.D. Sundb.

Hierba. Perenne. Nativa.

Distribución: AYP, TAR, ATA, COQ, VAL, RME, LBO, MAU, NUB, BIO, ARA.

Rango altitudinal: 0-2500 m.

Países limítrofes: Argentina y Bolivia. 
Symphyotrichum vahlii (Gaudich.) G.L. Nesom

Sinónimos: Aster vahlii (Gaudich.) Hook. \& Arn. var. tenuifolius (Phil.) Cabrera, Aster vahlii (Gaudich.) Hook. \& Arn., Aster zosterifolius Reiche, Erigeron graminifolius Phil., Erigeron pugae Phil., Erigeron vahlii Gaudich., Symphyotrichum vahlii (Gaudich.) G.L. Nesom var. tenuifolium (Phil.) G.L. Nesom, Tripolium humile Phil., Tripolium tenuifolium Phil., Astradelphus calbucanus Phil., Erigeron tripolioides Phil.

Hierba. Perenne. Nativa.

Distribución: LBO, MAU, NUB, BIO, ARA, LRI, LLA, AIS, MAG.

Rango altitudinal: 0-1200 m.

Países limítrofes: Argentina.

\section{Tagetes}

\section{Tagetes biflora Cabrera}

Hierba. Anual. Nativa.

Distribución: ATA.

Rango altitudinal: 0-2500 m.

Países limítrofes: Argentina.

Tagetes minuta $\mathrm{L}$.

Sinónimos: Tagetes bonariensis Pers.

Hierba. Anual. Nativa.

Distribución: AYP, TAR, ANT, ATA, COQ, VAL, RME, LBO, MAU, NUB.

Rango altitudinal: 0-2500 m.

Países limítrofes: Argentina y Bolivia.

Nombre vulgar: Quinchihue, soyko, suyko blanco.

\section{Tagetes multiflora Kunth}

Hierba. Anual. Nativa.

Distribución: AYP, TAR, ANT, ATA.

Rango altitudinal: $1000-4500 \mathrm{~m}$.

Países limítrofes: Argentina, Bolivia y Perú.

Nombre vulgar: Soyko, sayko, té de burro.

\section{Tanacetum}

Tanacetum parthenium (L.) Sch. Bip.

Hierba. Perenne. Introducida.

Distribución: COQ, VAL, RME, LBO, MAU, NUB, BIO, ARA, LRI, LLA, AIS.

\section{Tanacetum vulgare $\mathrm{L}$.}

Hierba. Perenne. Introducida.

Distribución: RME, NUB, BIO, ARA, LRI, LLA, AIS, MAG.

\section{Taraxacum}

Taraxacum fernandezianum Dahlst. ex Skottsb.
Hierba. Perenne. Endémica.

Distribución: JFE.

Rango altitudinal: 0-4000 m.

Nota: La cita de Richards (1976) de su presencia en la

Región Metropolitana de Santiago se considera dudosa.

Taraxacum gilliesii Hook. \& Arn.

Sinónimos: Taraxacum ibari Phil., Taraxacum laevigatum

(Willd.) DC. var. magellanicum (Comm. ex Sch. Bip.)

Reiche, Taraxacum magellanicum Comm. ex Sch. Bip., Taraxacum magellanicum Comm. ex Sch. Bip. var. lobatum

Dahlst.

Hierba. Perenne. Nativa.

Distribución: MAG.

Rango altitudinal: 0-1000 m.

Países limítrofes: Argentina.

Taraxacum officinale F.H. Wigg.

Hierba. Perenne. Introducida.

Distribución: TAR, ANT, ATA, COQ, VAL, RME, LBO, MAU, NUB, BIO, ARA, LRI, LLA, AIS, MAG, JFE, IPA.

\section{Tessaria}

Tessaria absinthioides (Hook. \& Arn.) DC.

Sinónimos: Baccharis absinthioides Hook. \& Arn., Gynheteria incana Spreng., p.p., Pluchea absinthioides (Hook. \& Arn.) H. Rob. \& Cuatrec.

Arbusto. Nativo.

Distribución: AYP, TAR, ANT, ATA, COQ, VAL, RME, LBO, MAU, NUB, BIO.

Rango altitudinal: 0-3000 m.

Países limítrofes: Argentina, Bolivia y Perú.

Nombre vulgar: Brea, chilquilla, sorona, péril, callacozo, hierba de la zorra.

\section{Thamnoseris}

Thamnoseris lacerata (Phil.) F. Phil. fma. lacerata Sinónimos: Rea lacerata Phil.

Arbusto. Endémico.

Distribución: IDE.

Thamnoseris lacerata (Phil.) F. Phil. fma. obtusifolia Skottsb.

Arbusto. Endémico.

Distribución: IDE.

\section{Tolpis}

Tolpis barbata (L.) Gaertn.

Hierba. Anual. Introducida.

Distribución: RME, LBO, MAU, NUB, BIO, ARA. 
Tragopogon

Tragopogon dubius Scop.

Hierba. Anual o bienal. Introducida.

Distribución: MAU.

Tragopogon porrifolius L.

Hierba. Anual o bienal. Introducida.

Distribución: ANT, COQ, VAL, RME, LBO, BIO, AIS.

\section{Trichocline}

Trichocline aurea (D. Don) Reiche

Sinónimos: Bichenia aurea D. Don, Chaetanthera berteriana Less., Trichocline pedicularifolia Walp.

Hierba. Perenne. Endémica.

Distribución: COQ, VAL, RME, LBO, MAU, NUB, BIO, ARA.

Rango altitudinal: 0-1400 m.

Nombre vulgar: Hierba de la yesca, yerguilla.

Trichocline caulescens Phil.

Sinónimos: Onoseris lanata Phil., Trichocline nivea Phil., Trichocline stuebelii Phil., Chaetanthera crispa Phil.

Hierba. Perenne. Endémica.

Distribución: AYP, TAR, ANT.

Rango altitudinal: 1800-3500 m.

Nombre vulgar: Wanti, garra de león, bailabaila.

Trichocline cineraria (D. Don) Hook. \& Arn.

Sinónimos: Chaetanthera crenata J. Remy, Gerbera cineraria (D. Don) Kuntze, Leuceria contrayerba Kurtz, Trichocline contrayerba (Kurtz) Hauman, Trichocline crenata (J. Remy) Reiche, Bichenia cineraria D. Don, Bichenia crenata (J. Remy) Wedd.

Hierba. Perenne. Nativa.

Distribución: COQ, VAL.

Rango altitudinal: 1700-3400 m.

Países limítrofes: Argentina.

Trichocline dealbata (Hook. \& Arn.) Benth. \& Hook.f. ex Griseb.

Sinónimos: Chaetanthera dealbata Hook. \& Arn., Chaetanthera parviflora Phil.

Hierba. Perenne. Nativa.

Distribución: RME, LBO.

Rango altitudinal: 2000-3800 m.

Países limítrofes: Argentina.

Trichocline deserticola Zardini

Sinónimos: Trichocline spathulata (Phil.) Zardini, comb. illeg., Onoseris spathulata Phil.

Hierba. Perenne. Endémica.

Distribución: TAR, ANT.
Rango altitudinal: 3500-4000 m.

Nombre vulgar: Pastito plomo, botón.

\section{Tripleurospermum}

Tripleurospermum inodorum (L.) Sch. Bip.

Hierba. Anual. Introducida.

Distribución: RME, MAG.

\section{Triptilion}

Triptilion achilleae DC.

Sinónimos: Triptilion chilense Bertero ex DC., nom. nud., Triptilion dusenii O. Hoffm., Triptilion euphrasioides DC., Triptilion tenuifolium Phil.

Hierba. Anual. Nativa.

Distribución: RME, LBO, BIO, ARA, LLA.

Rango altitudinal: 0-1500 m.

Países limítrofes: Argentina.

Triptilion benaventei J. Remy

Hierba. Perenne. Endémica.

Distribución: BIO, ARA.

Rango altitudinal: 1000-1300 m.

Triptilion berteroi Phil.

Hierba. Anual. Endémica.

Distribución: RME, LBO, MAU, BIO.

Rango altitudinal: 1200-1600 m.

Triptilion capillatum (D. Don) Hook. \& Arn.

Sinónimos: Triptilion capillatum (D. Don) Hook. \& Arn. var. andinum (Phil.) Reiche, Triptilion capillatum (D. Don)

Hook. \& Arn. var. laxum (Phil.) Reiche, Nassauvia capillata D. Don, Triptilion andinum Phil., Triptilion laxum Phil.

Hierba. Anual. Nativa.

Distribución: COQ, VAL, RME, LBO.

Rango altitudinal: 300-2200 m.

Países limítrofes: Argentina.

Triptilion cordifolium Lag. ex Lindl.

Sinónimos: Nassauvia cordifolia (Lag. ex Lindl.) D. Don, comb. illeg., Triptilion maritimum Poepp. ex DC., nom. nud. Hierba. Anual. Endémica.

Distribución: COQ, VAL, RME, LBO.

Rango altitudinal: 0-500 m.

Nombre vulgar: Siempreviva del cerro.

Triptilion gibbosum J. Remy

Sinónimos: Triptilion compactum Phil., Triptilion pusillum

Phil.

Hierba. Anual. Endémica.

Distribución: ATA, COQ.

Rango altitudinal: 0-500 m. 
Triptilion spinosum Ruiz \& Pav.

Sinónimos: Triptilion bulbosum J. Remy, Triptilion diffusum D. Don, Triptilion digitatum Phil., Triptilion pectinatum Phil. var. millefolium (Phil.) Reiche, Triptilion pectinatum Phil., Triptilion ramulosum Phil., Triptilion spinosum Ruiz \& Pav. var. eriochlaenum DC., Triptilion spinosum Ruiz \& Pav. var. integrifolium (Phil.) Reiche, Triptilion spinosum Ruiz \& Pav. var. remyanum (Phil.) Reiche, Nassauvia spinosa (Ruiz \& Pav.) D. Don, Nassauvia diffusa D. Don, nom. illeg., Triptilion humile Phil., Triptilion integrifolium Phil., Triptilion laciniatum Willd., Triptilion millefolium Phil., Triptilion remyanum Phil.

Hierba. Perenne. Endémica.

Distribución: ANT, COQ, VAL, RME, LBO, MAU, NUB, BIO, ARA, LRI.

Rango altitudinal: 0-1500 m.

Nombre vulgar: Siempreviva.

\section{Trixis}

Trixis cacalioides (Kunth) D. Don

Sinónimos: Perdicium cacalioides Kunth

Arbusto. Nativo.

Distribución: AYP, TAR, ANT, ATA.

Rango altitudinal: 0-3000 m.

Países limítrofes: Argentina, Bolivia y Perú.

\section{Urmenetea}

Urmenetea atacamensis Phil.

Sinónimos: Onoseris atacamensis (Phil.) Hoffm.

Hierba. Perenne. Nativa.

Distribución: ANT, ATA.

Rango altitudinal: 2400-4000 m.

Países limítrofes: Argentina.

Nombre vulgar: Kótar, koka del desierto, coquilla, oreja de ratón.

\section{Urospermum}

Urospermum picroides (L.) F.W. Schmidt

Hierba. Anual. Introducida.

Distribución: COQ, VAL, RME.

\section{Verbesina}

Verbesina aurita Phil.

Hierba. Anual. Nativa.

Distribución: ANT, ATA.

Rango altitudinal: 2000-2500 m.

Países limítrofes: Argentina.

Verbesina encelioides (Cav.) Benth. \& Hook.f. ex A. Gray Sinónimos: Verbesina scabra Phil., hom. illeg., Ximenesia encelioides Cav., Verbesina encelioides (Cav.) Echegaray, comb. illeg.

Hierba. Anual. Nativa.

Distribución: ANT, ATA.

Rango altitudinal: 0-2500 m.

Países limítrofes: Argentina y Bolivia.

Nombre vulgar: Maravilla, flor amarilla, mirasol, mirasol chico.

Verbesina saubinetia Klatt

Hierba. Perenne. Endémica.

Distribución: COQ.

Rango altitudinal: 500-700 m.

\section{Villanova}

Villanova oppositifolia Lag.

Sinónimos: Vasquezia biternata Phil., Vasquezia oppositifolia (Lag.) S.F. Blake

Hierba. Anual. Nativa.

Distribución: ANT.

Rango altitudinal: 0-300 m.

Países limítrofes: Bolivia y Perú.

Villanova robusta Phil.

Hierba. Perenne. Endémica.

Distribución: AYP, TAR.

Rango altitudinal: 2800-3800 m.

\section{Volutaria}

Volutaria tubuliflora (Murb.) Sennen

Hierba. Anual. Introducida.

Distribución: ATA, COQ.

\section{Werneria}

Werneria aretioides Wedd.

Hierba. Perenne. Nativa.

Distribución: AYP, TAR, ANT.

Rango altitudinal: 4000-5000 m.

Países limítrofes: Argentina, Bolivia y Perú.

Werneria cochlearis Griseb.

Hierba. Perenne. Nativa.

Distribución: ANT.

Rango altitudinal: $4500 \mathrm{~m}$.

Países limítrofes: Argentina.

Werneria glaberrima Phil.

Hierba. Perenne. Nativa.

Distribución: AYP, TAR, ANT.

Rango altitudinal: 4200-4600 m. 
Países limítrofes: Bolivia.

Nombre vulgar: Maransel, comida de vizcacha.

Werneria heteroloba Wedd.

Sinónimos: Werneria heteroloba Wedd. fma. microcephala

Rockh.

Hierba. Perenne. Nativa.

Distribución: AYP, TAR, ANT, ATA, COQ.

Rango altitudinal: 3500-5000 m.

Países limítrofes: Argentina, Bolivia y Perú.

Nombre vulgar: Teqerere, pasto de bofedal.

Werneria pinnatifida J. Remy

Hierba. Perenne. Nativa.

Distribución: TAR, ANT, ATA, COQ.

Rango altitudinal: 3400-4450 m.

Países limítrofes: Argentina.

Werneria pygmaea Gillies ex Hook. \& Arn.

Sinónimos: Werneria denticulata S.F. Blake, Werneria brachypappa Phil., hom. illeg., Werneria rhizoma J. Remy, Werneria brachypappa Sch. Bip.

Hierba. Perenne. Nativa.

Distribución: AYP, TAR, ANT, ATA, COQ, VAL, RME.

Rango altitudinal: 2200-5000 m.

Países limítrofes: Argentina, Bolivia y Perú.

Nombre vulgar: Mamañika, qatari, anojarpsike, vega.

Werneria solivifolia Sch. Bip.

Hierba. Perenne. Nativa.

Distribución: AYP.

Rango altitudinal: 4000-4500 m.

Países limítrofes: Bolivia y Perú.

Werneria spathulata Wedd.

Hierba. Perenne. Nativa.

Distribución: AYP, TAR, ANT.

Rango altitudinal: 4000-4500 m.

Países limítrofes: Argentina y Bolivia.

Nombre vulgar: Pupusa, pupusa de agua.

\section{Xanthium}

Xanthium spinosum L.

Hierba. Anual. Introducida.

Distribución: ANT, ATA, COQ, VAL, RME, LBO, MAU, NUB, BIO, ARA, LRI, LLA, JFE.

\section{Xanthium strumarium L.}

Hierba. Anual. Introducida.

Distribución: ATA, COQ, RME, LBO, NUB, BIO.

\section{Xenophyllum}

Xenophyllum ciliolatum (A. Gray) V.A. Funk

Sinónimos: Werneria ciliolata A. Gray

Subarbusto. Nativo.

Distribución: AYP, TAR, ANT.

Rango altitudinal: 4000-5200 m.

Países limítrofes: Bolivia y Perú.

Nombre vulgar: Pupusa, poposa, yaretilla.

Xenophyllum incisum (Phil.) V.A. Funk

Sinónimos: Werneria incisa Phil.

Subarbusto. Nativo.

Distribución: AYP, TAR, ANT.

Rango altitudinal: 4300-4400 m.

Países limítrofes: Argentina.

Nombre vulgar: Pupusa del agua, pupusa del campo.

Xenophyllum juniperinum (Hieron.) J. Calvo

Sinónimos: Werneria juniperina Hieron.

Subarbusto. Nativo.

Distribución: AYP.

Rango altitudinal: 4100-5200 m.

Países limítrofes: Bolivia y Perú.

Xenophyllum poposum (Phil.) V.A. Funk

Sinónimos: Werneria poposa Phil.

Subarbusto. Nativo.

Distribución: AYP, TAR, ANT.

Rango altitudinal: $3500-5300 \mathrm{~m}$.

Países limítrofes: Argentina, Bolivia y Perú.

Nombre vulgar: Poposa, pupusa, jasuaso, asoaso, yareta.

Xenophyllum pseudodigitatum (Rockh.) V.A. Funk

Sinónimos: Werneria pseudodigitata Rockh.

Subarbusto. Nativo.

Distribución: AYP, TAR, ANT.

Rango altitudinal: 4000-5000 m.

Países limítrofes: Argentina.

Xenophyllum weddellii (Phil.) V.A. Funk

Sinónimos: Werneria weddellii Phil.

Subarbusto. Nativo.

Distribución: AYP, TAR, ANT.

Rango altitudinal: 4000-5000 m.

Países limítrofes: Bolivia y Perú.

Nombre vulgar: Poposa, pupusa, purapura.

\section{Yunquea}

Yunquea tenzii Skottsb.

Arbusto o árbol pequeño. Endémico.

Distribución: JFE.

Rango altitudinal: 0-500 m. 


\section{BALANOPHORACEAE}

\section{Ombrophytum}

Ombrophytum subterraneum (Aspl.) B. Hansen

Sinónimos: Juelia subterranea Aspl., Juelia lilloana Sleumer, Juelia meyeri Sleumer, Ombrophytum peruvianum auct. non Poepp. \& Endl.

Hierba parásita. Perenne. Nativa.

Distribución: AYP, TAR, ANT.

Rango altitudinal: 500-4000 m.

Países limítrofes: Argentina y Perú.

Nombre vulgar: Maíz del monte, sicha, pora.

\section{BASELLACEAE}

\section{Anredera}

Anredera cordifolia (Ten.) Steenis

Arbusto trepador. Introducido.

Distribución: VAL, IPA.

\section{BERBERIDACEAE}

\section{Berberis}

Berberis actinacantha Mart.

Sinónimos: Berberis brachyacantha Phil. ex Reiche, Berberis coquimbensis Muñoz, Berberis crispa Gay, Berberis florida Phil., Berberis hakeoides (Hook.f.) C.K. Schneid., Berberis variiflora C.K. Schneid., Berberis actinacantha Mart. var. crispa (Gay) Reiche, Berberis congestiflora Gay var. hakeoides Hook.f.

Arbusto. Endémico.

Distribución: ANT, COQ, VAL, RME, LBO, MAU, NUB, BIO, ARA, LLA.

Rango altitudinal: 100-1900 m.

Nombre vulgar: Michay.

Berberis chilensis Gillies ex Hook. \& Arn. var. brachybotria (Gay) Landrum

Sinónimos: Berberis brachybotria Gay, Berberis brachybotria Gay var. brevispina Reiche

Arbusto. Endémico.

Distribución: COQ, VAL, RME, LBO.

Rango altitudinal: 0-1500 m.

Berberis chilensis Gillies ex Hook. \& Arn. var. chilensis Sinónimos: Berberis diffusa Gay, Berberis ferox Gay, Berberis fragrans Phil. ex Reiche, Berberis chilensis Gillies ex Hook. var. diffusa (Gay) Reiche, Berberis chilensis Gillies ex Hook. var. ferox (Gay) Reiche, Berberis gayi K. Koch
Arbusto. Endémico.

Distribución: COQ, VAL, RME, LBO, MAU, NUB, BIO, ARA.

Rango altitudinal: 300-1600 m.

Nombre vulgar: Michay.

Berberis congestiflora Gay

Arbusto. Endémico.

Distribución: RME, ARA, LRI.

Rango altitudinal: 0-500 m.

Nombre vulgar: Michay.

Berberis corymbosa Hook. \& Arn.

Sinónimos: Berberis paniculata Phil., Berberis corymbosa Hook. \& Arn. var. paniculata (Phil.) Reiche

Arbusto o árbol pequeño. Endémico.

Distribución: JFE.

Rango altitudinal: 300-600 m.

Berberis darwinii Hook.

Sinónimos: Berberis costulata Gand., Berberis knightii (Lindl.) K. Koch, Mahonia knightii Lindl.

Arbusto. Nativo.

Distribución: RME, MAU, NUB, BIO, ARA, LRI, LLA, AIS.

Rango altitudinal: 0-1500 m.

Países limítrofes: Argentina.

Nombre vulgar: Michay, quelung.

Berberis empetrifolia Lam.

Sinónimos: Berberis mutabilis Phil., Berberis wawrana C.K. Schneid., Berberis empetrifolia Lam. var. magellanica C.K. Schneid.

Subarbusto. Nativo.

Distribución: COQ, VAL, RME, LBO, MAU, NUB, BIO, ARA, LLA, AIS, MAG.

Rango altitudinal: 0-3500 m.

Países limítrofes: Argentina.

Nombre vulgar: Zarcilla, monte negro, uva de la cordillera.

Berberis glomerata Hook. \& Arn.

Sinónimos: Berberis glomerata Hook. \& Arn. var. zahlbruckneriana (C.K. Schneid.) Ahrendt, Berberis zahlbruckneriana C.K. Schneid.

Arbusto. Endémico.

Distribución: COQ, VAL.

Rango altitudinal: 500-1000 m.

Berberis horrida Gay

Sinónimos: Berberis pilosifolia Ahrendt, Berberis actinacantha Mart. var. mollis Reiche, Berberis actinacantha Mart. var. horrida (Gay) Reiche

Arbusto. Endémico.

Distribución: VAL, RME, LBO, MAU, NUB, BIO. 
Rango altitudinal: 800-1000 m.

Nombre vulgar: Michay.

Berberis ilicifolia L.f.

Sinónimos: Berberis subantarctica Gand., Berberis

lagenaria Poir.

Arbusto o árbol pequeño. Nativo.

Distribución: LLA, AIS, MAG.

Rango altitudinal: 0-1000 m.

Países limítrofes: Argentina.

Nombre vulgar: Chelia.

Berberis litoralis Phil.

Arbusto o árbol pequeño. Endémico.

Distribución: ANT.

Rango altitudinal: 500-1000 m.

Nombre vulgar: Michay de Paposo.

Berberis masafuerana Skottsb.

Arbusto o árbol pequeño. Endémico.

Distribución: JFE.

Rango altitudinal: 200-1100 m.

Berberis microphylla $\mathrm{G}$. Forst.

Sinónimos: Berberis buxifolia Lam. var. antucoana (C.K. Schneid.) Orsi, Berberis buxifolia Lam., Berberis heterophylla Juss. ex Poir., Berberis inermis Pers., Berberis antucoana C.K. Schneid., Berberis buxifolia Lam. var. nuda C.K. Schneid., Berberis marginata Gay, Berberis spinosissima (Reiche) Ahrendt, Berberis buxifolia Lam. var. spinosissima Reiche, Berberis buxifolia Lam. var. papillosa C.K. Schneid., Berberis dulcis Sweet, Berberis buxifolia Lam. var. antarctica C.K. Schneid.

Arbusto. Nativo.

Distribución: RME, LBO, MAU, NUB, BIO, ARA, LRI, LLA, AIS, MAG.

Rango altitudinal: 0-2500 m.

Países limítrofes: Argentina.

Nombre vulgar: Calafate, michay, mulun.

\section{Berberis montana Gay}

Sinónimos: Berberis chillanensis (C.K. Schneid.) Sprague ex Bean, Berberis chillanensis (C.K. Schneid.) Sprague ex Bean var. hirsutipes Sprague, Berberis coletioides Lechl., Berberis polypetala Phil., Berberis montana Gay var. gracilis C.K. Schneid., Berberis montana Gay var. chillanensis C.K. Schneid., Berberis montana Gay var. coletioides (Lechl.) C.K. Schneid., Berberis buxifolia Lam. var. montana (Gay) Reiche, Berberis coletioides Lechl. var. gracilis (C.K. Schneid.) Ahrendt

Arbusto. Nativo.

Distribución: VAL, RME, LBO, MAU, NUB, BIO, ARA, LRI, LLA, AIS.

Rango altitudinal: 500-2700 m.
Países limítrofes: Argentina.

Nombre vulgar: Palo amarillo.

Berberis negeriana Tischler

Arbusto. Endémico.

Distribución: BIO.

Rango altitudinal: 200-300 m.

Berberis rotundifolia Poepp. \& Endl.

Sinónimos: Berberis philippii Ahrendt, Berberis polymorpha Phil.

Arbusto. Endémico.

Distribución: LBO, MAU, NUB, BIO, ARA, LLA.

Rango altitudinal: 200-2300 m.

Berberis serratodentata Lechl.

Sinónimos: Berberis pearcei Phil.

Arbusto. Nativo.

Distribución: NUB, BIO, ARA, LRI, LLA, AIS.

Rango altitudinal: 500-2000 m.

Países limítrofes: Argentina.

Nombre vulgar: Saloll.

Berberis trigona Kunze ex Poepp. \& Endl.

Sinónimos: Berberis linearifolia Phil., Berberis linearifolia

Phil. var. longifolia (Reiche) Ahrendt, Berberis grisebachii

Lechl., Berberis trigona Kunze ex Poepp. \& Endl. var. longifolia Reiche

Arbusto. Nativo.

Distribución: MAU, NUB, BIO, ARA, LRI, LLA, MAG.

Rango altitudinal: 500-1800 m.

Países limítrofes: Argentina.

Nombre vulgar: Calafate, michay.

Berberis valdiviana Phil.

Sinónimos: Berberis valdiviana Phil. var. gracilifolia Ahrendt

Arbusto o árbol pequeño. Endémico.

Distribución: RME, LBO, MAU, NUB, BIO, ARA, LRI.

Rango altitudinal: 0-1000 m.

Nombre vulgar: Clen, espina en cruz.

\section{BERBERIDOPSIDACEAE}

\section{Berberidopsis}

Berberidopsis corallina Hook.f.

Arbusto. Endémico.

Distribución: MAU, NUB, BIO, ARA, LRI, LLA.

Rango altitudinal: 100-600 m.

Nombre vulgar: Michay rojo. 


\section{BETULACEAE}

\section{Alnus}

Alnus glutinosa (L.) Gaertn.

Árbol. Introducido.

Distribución: COQ, RME, BIO, LLA.

Nombre vulgar: Aliso.

\section{BIGNONIACEAE}

\section{Argylia}

Argylia adscendens DC. var. adscendens

Sinónimos: Argylia huidobriana Clos, Argylia lutea Phil., Argylia viridis Phil. var. lutea (Phil.) Reiche

Hierba. Perenne. Endémica.

Distribución: COQ, VAL, RME, LBO.

Rango altitudinal: 900-3200 m.

Nombre vulgar: Triaca.

Argylia adscendens DC. var. viridis (Phil.) Gleisner \& Ricardi Sinónimos: Argylia viridis Phil.

Hierba. Perenne. Endémica.

Distribución: COQ, RME.

Rango altitudinal: 1800-2500 m.

\section{Argylia bifrons Phil.}

Hierba. Perenne. Endémica.

Distribución: ATA.

Rango altitudinal: 3000-3500 m.

\section{Argylia bustillosii Phil.}

Sinónimos: Argylia australis Phil., Argylia potentillifolia DC. var. australis (Phil.) Macloskie, comb. illeg., Argylia potentillifolia DC. var. australis (Phil.) Speg.

Subarbusto. Nativo.

Distribución: LBO, BIO.

Rango altitudinal: 800-2500 m.

Países limítrofes: Argentina.

Argylia checoensis (Meyen) I.M. Johnst.

Sinónimos: Oxalis checoensis Meyen, Argylia incana Phil., Argylia sitiens I.M. Johnst.

Hierba. Perenne. Endémica.

Distribución: ANT, ATA.

Rango altitudinal: 1000-3000 m.

Argylia farnesiana Gleisner \& Ricardi

Subarbusto. Endémico.

Distribución: ATA, COQ.

Rango altitudinal: 900-1000 m.
Argylia geranioides DC.

Hierba. Perenne. Endémica.

Distribución: ATA, COQ.

Rango altitudinal: 900-1400 m.

Argylia glutinosa Phil.

Hierba. Perenne. Endémica.

Distribución: ANT, ATA.

Rango altitudinal: 1400-2900 m.

Argylia potentillifolia DC.

Sinónimos: Argylia potentillaefolia DC. var. beta Clos

Hierba. Perenne. Endémica.

Distribución: ATA, COQ.

Rango altitudinal: 200-3500 m.

Argylia radiata (L.) D. Don

Sinónimos: Bignonia radiata L., Argylia canescens D. Don, Argylia puberula DC., Argylia feuillie DC., Argylia tenuifolia C. Presl, Oxymitus argylioides C. Presl, Argylia chrysantha Phil., Argylia eremophila Phil., Argylia glabriuscula Phil., Argylia villosa Phil., Argylia digitalina Phil., Argylia viridis Phil. var. digitalina (Phil.) Reiche

Hierba. Perenne. Nativa.

Distribución: TAR, ANT, ATA, COQ, VAL, RME.

Rango altitudinal: 0-800 m.

Países limítrofes: Perú.

Nombre vulgar: Flor del jote, cartucho, terciopelo.

Argylia tomentosa Phil.

Sinónimos: Argylia tomentosa Phil. var. tenella (Phil.)

Reiche, Argylia tenella Phil.

Hierba. Perenne. Endémica.

Distribución: ANT, ATA.

Rango altitudinal: 2400-2900 m.

Argylia uspallatensis DC.

Sinónimos: Argylia trifoliata DC., Tecoma uspallatensis Mart. ex DC.

Hierba. Perenne. Nativa.

Distribución: ANT, VAL.

Rango altitudinal: 1700-4100 m.

Países limítrofes: Argentina.

\section{Campsidium}

Campsidium valdivianum (Phil.) Skottsb.

Sinónimos: Campsidium chilense Reissek \& Seem., Tecoma valdiviana Phil.

Arbusto trepador. Nativo.

Distribución: MAU, NUB, BIO, ARA, LRI, LLA, AIS, MAG.

Rango altitudinal: 0-800 m. 
Países limítrofes: Argentina.

Nombre vulgar: Pilpilvoqui blanco, voqui bejuco, voqui de canasta.

\section{Eccremocarpus}

Eccremocarpus scaber Ruiz \& Pav.

Sinónimos: Calampelis scaber (Ruiz \& Pav.) D. Don, comb. illeg., Calampelis scaber (Ruiz \& Pav.) Sweet, Eccremocarpus scaber Ruiz \& Pav. var. sepium Bertero ex A.DC., Eccremocarpus sepium Bertero

Arbusto trepador. Nativo.

Distribución: VAL, RME, LBO, MAU, NUB, BIO, ARA, LRI.

Rango altitudinal: 200-2400 m.

Países limítrofes: Argentina.

Nombre vulgar: Chupa-chupa, chupapoto.

\section{Tecoma}

Tecoma fulva (Cav.) D. Don

Sinónimos: Bignonia fulva Cav., Tecomaria fulvum (Cav.)

Seem., Bignonia meyeniana Schauer, Stenolobium fulvum

(Cav.) Sprague

Arbusto. Nativo.

Distribución: AYP, TAR.

Rango altitudinal: 200-2300 m.

Países limítrofes: Bolivia y Perú.

Nombre vulgar: Chuvé.

\section{BORAGINACEAE}

\section{Amsinckia}

Amsinckia calycina (Moris) Chater

Sinónimos: Lithospermum calycinum Moris, Amsinckia angustifolia Lehm., Amsinckia angustifolia Lehm. var. pseudolycopsioides Clos, Lithospermum chilense Colla

Hierba. Anual. Nativa.

Distribución: TAR, ANT, COQ, VAL, RME, LBO, MAU, NUB, BIO, ARA, LLA, AIS, MAG.

Rango altitudinal: 0-4500 m.

Países limítrofes: Argentina y Bolivia.

Nombre vulgar: Hierba rocilla.

Amsinckia tessellata A. Gray

Hierba. Anual. Nativa.

Distribución: RME.

Rango altitudinal: 0-500 m.

Países limítrofes: Argentina.

\section{Asperugo}

Asperugo procumbens L.

Hierba. Anual. Introducida.

Distribución: MAG.

\section{Borago}

\section{Borago officinalis L.}

Hierba. Anual. Introducida.

Distribución: ATA, COQ, VAL, RME, LBO, MAU, NUB, BIO, ARA, LRI, LLA.

\section{Buglossoides}

Buglossoides arvensis (L.) I.M. Johnst.

Hierba. Anual. Introducida.

Distribución: AIS.

\section{Cordia}

Cordia decandra Hook. \& Arn.

Arbusto o árbol pequeño. Endémico.

Distribución: ANT, ATA, COQ.

Rango altitudinal: 0-1200 m.

Nombre vulgar: Carbón, carbonillo.

\section{Cryptantha}

Cryptantha alfalfalis (Phil.) I.M. Johnst.

Sinónimos: Eritrichium alfalfalis Phil., Eritrichium rigidum

Phil.

Hierba. Anual. Endémica.

Distribución: RME, LBO.

Rango altitudinal: 700-1100 m.

Cryptantha alyssoides (A. DC.) Reiche

Sinónimos: Eritrichium alyssoides A. DC., Eritrichium gilliesii Phil., Eritrichium talquinum Phil., Cryptantha talquina (Phil.) Brand

Hierba. Perenne. Endémica.

Distribución: VAL, RME, LBO, MAU.

Rango altitudinal: 1000-2700 m.

Cryptantha aprica (Phil.) Reiche

Sinónimos: Eritrichium apricum Phil., Eritrichium bridgesii Phil., Eritrichium lignosum Phil., Eritrichium denudatum Phil., Eritrichium closii Phil., Eritrichium rengifoanum Phil., Cryptantha candelabrum Brand

Hierba. Anual. Endémica.

Distribución: ATA, COQ, VAL, RME, LBO.

Rango altitudinal: 400-2400 m. 
Cryptantha argentea I.M. Johnst.

Hierba. Perenne. Endémica.

Distribución: ANT, ATA.

Rango altitudinal: 0-500 m.

Cryptantha aspera (Phil.) Grau

Sinónimos: Eritrichium asperum Phil.

Hierba. Anual. Endémica.

Distribución: ATA, COQ.

Rango altitudinal: 0-600 m.

Cryptantha calycina (Phil.) Reiche

Sinónimos: Eritrichium calycinum Phil.

Hierba. Anual. Endémica.

Distribución: TAR, ANT, ATA, COQ.

Rango altitudinal: 3100-3800 m.

Cryptantha calycotricha I.M. Johnst.

Hierba. Anual. Endémica.

Distribución: COQ, VAL, RME.

Rango altitudinal: 0-1000 m.

Cryptantha capituliflora (Clos) Reiche

Sinónimos: Eritrichium capituliflorum Clos, Eritrichium cephalanthum Phil.

Hierba. Perenne. Nativa.

Distribución: COQ, VAL, RME.

Rango altitudinal: 2000-3500 m.

Países limítrofes: Argentina.

Cryptantha chaetocalyx (Phil.) I.M. Johnst.

Sinónimos: Eritrichium chaetocalyx Phil., Cryptantha divaricata Reiche, Eritrichium pustulosum Phil., Eritrichium divaricatum Phil.

Hierba. Anual. Endémica.

Distribución: ANT, ATA.

Rango altitudinal: 0-800 m.

\section{Cryptantha chispae Grau}

Sinónimos: Eritrichium affine Phil.

Hierba. Anual. Endémica.

Distribución: COQ.

Rango altitudinal: 0-500 m.

Cryptantha clandestina (Trevir.) I.M. Johnst.

Sinónimos: Lithospermum clandestinum Trevir., Cryptantha philippiana Brand

Hierba. Anual. Endémica.

Distribución: ANT, COQ, VAL, RME, LBO, MAU.

Cryptantha cynoglossoides (Phil.) I.M. Johnst.

Sinónimos: Eritrichium cynoglossoides Phil., Eritrichium uspallatense Phil., Cryptantha phacelioides auct. non (Clos) Reiche
Hierba. Anual. Nativa.

Distribución: COQ.

Rango altitudinal: 700-4000 m.

Países limítrofes: Argentina.

Cryptantha dichita (Phil.) I.M. Johnst.

Sinónimos: Eritrichium dichita Phil.

Hierba. Anual. Endémica.

Distribución: ATA.

Nombre vulgar: Papur.

Cryptantha diffusa (Phil.) I.M. Johnst.

Sinónimos: Eritrichium diffusum Phil., Eritrichium debile Phil., Cryptantha debilis (Phil.) Reiche, Cryptantha famatinae Brand, Cryptantha borchersii (Phil.) Hauman, Eritrichium borchersii Phil., Eritrichium micranthum Phil.

Hierba. Anual. Nativa.

Distribución: AYP, TAR, ANT, ATA, COQ.

Rango altitudinal: 2000-4100 m.

Países limítrofes: Argentina.

Nombre vulgar: Chapinqhora macho.

Cryptantha dimorpha (Phil.) Greene

Sinónimos: Eritrichium dimorphum Phil.

Hierba. Anual. Endémica.

Distribución: ATA, COQ, VAL, RME.

Rango altitudinal: 600-2000 m.

Cryptantha diplotricha (Phil.) Reiche

Sinónimos: Eritrichium diplotrichum Phil., Eritrichium diplotrichum Phil. var. humilis Phil., Eritrichium axillare Phil., Cryptantha hossei Brand, Cryptantha modesta Brand, Cryptantha capituliflora (Clos) Reiche var. compacta Brand, Cryptantha axillaris (Phil.) Reiche, Cryptantha diplotricha (Phil.) Reiche var. humilis (Phil.) Reiche

Hierba. Anual. Nativa.

Distribución: AYP.

Rango altitudinal: 2000-4500 m.

Países limítrofes: Argentina.

Cryptantha dolichophylla (Phil.) Reiche

Sinónimos: Eritrichium dolichophyllum Phil.

Hierba. Anual. Endémica.

Distribución: ATA, COQ.

Rango altitudinal: 100-1200 m.

Cryptantha filaginea (Phil.) Reiche

Sinónimos: Eritrichium filagineum Phil.

Hierba. Anual. Nativa.

Distribución: ANT, ATA, COQ.

Rango altitudinal: 0-2600 m.

Países limítrofes: Perú. 
Cryptantha filiformis (Phil.) Reiche

Sinónimos: Eritrichium filiforme Phil., Eritrichium mite Phil. Hierba. Anual. Endémica.

Distribución: TAR, ANT, COQ.

Rango altitudinal: 0-700 m.

Cryptantha gayi I.M. Johnst.

Hierba. Anual. Endémica.

Distribución: ATA, COQ.

Rango altitudinal: 0-900 m.

Cryptantha globulifera (Clos) Reiche

Sinónimos: Eritrichium globuliferum Clos, Eritrichium floribundum Phil., Cryptantha floribunda (Phil.) Reiche, Eritrichium carrizalense Phil., Eritrichium glareosum Phil., Eritrichium oliganthum Phil., Eritrichium parvulum Phil., Eritrichium sphaerophorum Phil.

Hierba. Anual. Nativa.

Distribución: AYP, TAR, ATA, COQ, VAL, RME.

Rango altitudinal: 0-1500 m.

Países limítrofes: Argentina.

Cryptantha glomerata Lehm. ex Fisch. \& C.A. Mey. subsp. glomerata

Sinónimos: Eritrichium strictum Phil., Eritrichium longisetum Phil., Eritrichium diplasianthum Phil., Eritrichium foliosum Phil., Cryptantha candolleana Brand Hierba. Anual. Endémica.

Distribución: TAR, ANT, COQ, VAL, RME, LBO, NUB, BIO, ARA.

Rango altitudinal: 0-2800 m.

Cryptantha glomerata Lehm. ex Fisch. \& C.A. Mey. subsp. quadrinuculata Grau

Sinónimos: Eritrichium vidali Phil., Cryptantha vidali (Phil.) Reiche

Hierba. Anual. Endémica.

Distribución: COQ, VAL.

Rango altitudinal: 0-600 m.

Cryptantha glomerulifera (Phil.) I.M. Johnst.

Sinónimos: Eritrichium glomeruliferum Phil.

Hierba. Perenne. Nativa.

Distribución: AYP, TAR, ATA, COQ, VAL, RME.

Rango altitudinal: 2000-3500 m.

Países limítrofes: Argentina.

Cryptantha gnaphalioides (A. DC.) Reiche

Sinónimos: Eritrichium gnaphalioides A. DC., Eritrichium

fruticosum Phil.

Hierba. Perenne. Endémica.

Distribución: ANT, ATA, COQ.

Rango altitudinal: 0-2900 m.

Nombre vulgar: Té de burro.
Cryptantha haplostachya (Phil.) I.M. Johnst.

Sinónimos: Eritrichium haplostachyum Phil.

Hierba. Anual. Endémica.

Distribución: ATA.

Rango altitudinal: $200 \mathrm{~m}$.

Cryptantha hispida (Phil.) Reiche

Sinónimos: Eritrichium hispidum Phil.

Hierba. Anual. Endémica.

Distribución: ANT, ATA.

Rango altitudinal: 2700-3800 m.

Nombre vulgar: Itallapa.

Cryptantha involucrata (Phil.) Reiche

Sinónimos: Eritrichium involucratum Phil.

Hierba. Anual. Endémica.

Distribución: ATA, COQ, RME.

Rango altitudinal: 1300-3500 m.

Cryptantha kingii (Phil.) Reiche

Sinónimos: Eritrichium kingii Phil., Eritrichium virens

Phil., Eritrichium macrocalyx Phil., Cryptantha virens

(Phil.) Reiche, Cryptantha macrocalyx (Phil.) Reiche

Hierba. Anual. Endémica.

Distribución: ATA, COQ.

Rango altitudinal: 0-600 m.

Cryptantha limensis (A. DC.) I.M. Johnst.

Sinónimos: Eritrichium limense A. DC.

Hierba. Anual. Nativa.

Distribución: ANT.

Rango altitudinal: $3800 \mathrm{~m}$.

Países limítrofes: Perú.

Cryptantha linearis (Colla) Greene

Sinónimos: Eritrichium lineare (Colla) DC., Myosotis linearis Colla, Eritrichium minutiflorum Phil., Cryptantha minutiflora (Phil.) Brand, Eritrichium gracile Phil., Cryptantha gracilis (Phil.) Reiche, Eritrichium fallax Phil., Cryptantha fallax (Phil.) Reiche

Hierba. Anual. Endémica.

Distribución: ANT, COQ, VAL, RME, LBO, MAU.

Rango altitudinal: 0-1200 m.

Nombre vulgar: Sobaquillo.

Cryptantha longifolia (Phil.) Reiche

Sinónimos: Eritrichium longifolium Phil.

Hierba. Perenne. Endémica.

Distribución: COQ.

Cryptantha marioricardiana Teillier

Subarbusto. Endémico.

Distribución: ATA.

Rango altitudinal: 0-100 m. 
Cryptantha marticorenae Grau

Hierba. Anual. Endémica.

Distribución: ATA, COQ.

Rango altitudinal: 300-900 m.

Cryptantha phaceloides (Clos) Reiche

Sinónimos: Eritrichium phaceloides Clos

Hierba. Anual. Endémica.

Distribución: ANT, ATA.

Rango altitudinal: $3300 \mathrm{~m}$.

Cryptantha romanii I.M. Johnst.

Hierba. Anual. Endémica.

Distribución: ANT, ATA.

Rango altitudinal: $500 \mathrm{~m}$.

Cryptantha spathulata (Phil.) Reiche

Sinónimos: Eritrichium spathulatum Phil.

Hierba. Perenne. Endémica.

Distribución: LBO.

Cryptantha subamplexicaulis (Phil.) Reiche

Sinónimos: Eritrichium subamplexicaule Phil.

Hierba. Anual o perenne. Endémica.

Distribución: TAR, ANT.

Rango altitudinal: 0-500 m.

Cryptantha taltalensis I.M. Johnst.

Hierba. Anual. Endémica.

Distribución: ANT, ATA, COQ.

Rango altitudinal: 0-400 m.

Cryptantha volckmannii (Phil.) I.M. Johnst.

Sinónimos: Eritrichium volckmannii Phil., Eritrichium chrysanthum Phil., Cryptantha chrysantha (Phil.) Reiche

Hierba. Anual. Endémica.

Distribución: COQ.

Rango altitudinal: 600-2900 m.

Cryptantha werdermanniana I.M. Johnst.

Hierba. Anual. Endémica.

Distribución: ANT.

Rango altitudinal: $2300 \mathrm{~m}$.

\section{Cynoglossum}

\section{Cynoglossum creticum Mill.}

Hierba. Bienal. Introducida.

Distribución: ATA, COQ, VAL, RME, LBO, MAU, NUB, BIO, ARA, LRI, LLA, JFE.

Cynoglossum zeylanicum (Vahl ex Hornem.) Thunb. ex Lehm. Hierba. Anual. Introducida.

Distribución: MAU, ARA, LLA.

\section{Echium}

Echium plantagineum L.

Hierba. Anual o bienal. Introducida.

Distribución: LBO, MAU, NUB, BIO, ARA.

Echium vulgare L.

Hierba. Bienal. Introducida.

Distribución: COQ, VAL, RME, LBO, MAU, NUB, BIO, ARA, LRI, LLA, AIS, MAG.

\section{Johnstonella}

Johnstonella parviflora (Phil.) Hasenstab \& M.G. Simpson Sinónimos: Cryptantha parviflora (Phil.) Reiche, Eritrichium parviflorum Phil., Eritrichium microphyllum Phil., Cryptantha microphylla (Phil.) Reiche Hierba. Anual. Nativa.

Distribución: AYP, TAR, ANT, ATA.

Países limítrofes: Perú.

\section{Lappula}

Lappula redowskii (Hornem.) Greene

Sinónimos: Myosotis redowskii Hornem.

Hierba. Anual o bienal. Nativa.

Distribución: MAG.

Rango altitudinal: 100-150 m.

Países limítrofes: Argentina.

Myosotis

Myosotis albiflora Banks \& Sol. ex Hook.f. Sinónimos: Eritrichium albiflorum Griseb.

Hierba. Perenne. Nativa.

Distribución: AIS, MAG.

Rango altitudinal: 0-200 m.

Países limítrofes: Argentina.

Myosotis antarctica Hook. f.

Hierba. Anual o perenne. Endémica.

Distribución: MAG.

Rango altitudinal: 0-500 m.

Myosotis arvensis (L.) Hill

Hierba. Anual. Introducida.

Distribución: VAL, RME, LBO, MAU, NUB, BIO, ARA, LRI, LLA, MAG, JFE.

Myosotis azorica H.C. Watson ex Hook.

Hierba. Anual. Introducida.

Distribución: LLA. 
Myosotis discolor Pers. subsp. canariensis (Pit.) Grau Hierba. Anual. Introducida.

Distribución: AIS, MAG.

Myosotis discolor Pers. subsp. discolor

Hierba. Anual. Introducida.

Distribución: MAU, ARA, LRI, MAG.

Myosotis latifolia Poir.

Hierba. Perenne. Introducida.

Distribución: ATA, RME, NUB, BIO, LRI.

Myosotis laxa Lehm.

Hierba. Anual. Introducida.

Distribución: LBO, MAU, NUB, BIO, ARA, LRI, LLA, AIS, JFE.

Myosotis ramosissima Rochel

Hierba. Anual. Introducida.

Distribución: MAG.

\section{Myosotis scorpioides L.}

Hierba. Perenne. Introducida.

Distribución: RME, ARA, LLA, AIS, MAG.

Myosotis stricta Link ex Roem. \& Schult.

Hierba. Anual o perenne. Introducida.

Distribución: AIS, MAG.

Myosotis sylvatica Ehrh. ex Hoffm.

Hierba. Bienal. Introducida.

Distribución: JFE.

\section{Nama}

Nama dichotomum (Ruiz \& Pav.) Choisy

Sinónimos: Nama stricta Phil., Nama dichotomum (Ruiz \& Pav.) Choisy fma. amplifolia Brand, Nama dichotomum (Ruiz \& Pav.) Choisy var. amplifolia (Brand) C.L. Hitchc., Nama dichotomum (Ruiz \& Pav.) Choisy var. stricta (Phil.) Brand, Hydrolea dichotoma Ruiz \& Pav., Marylaunidium dichotomum (Ruiz \& Pav.) Kuntze

Hierba. Anual. Nativa.

Distribución: AYP, TAR, ANT, RME.

Rango altitudinal: 1000-4000 m.

Países limítrofes: Argentina y Bolivia.

Nama undulatum Kunth var. australe C.L. Hitchc.

Hierba. Anual. Nativa.

Distribución: ATA.

Rango altitudinal: 1000-3000 m.

Países limítrofes: Argentina.

\section{Nesocaryum}

Nesocaryum stylosum (Phil.) I.M. Johnst.

Sinónimos: Heliotropium stylosum Phil.

Arbusto. Endémico.

Distribución: IDE.

Rango altitudinal: 0-200 m.

\section{Omphalodes}

Omphalodes linifolia (L.) Moench

Hierba. Anual. Introducida.

Distribución: ARA.

\section{Pectocarya}

Pectocarya anomala I.M. Johnst.

Hierba. Anual o bienal. Nativa.

Distribución: AYP, TAR.

Rango altitudinal: 2300-2600 m.

Países limítrofes: Perú.

Pectocarya dimorpha (I.M. Johnst.) I.M. Johnst.

Sinónimos: Pectocarya gracilis (Ruiz \& Pav.) I.M. Johnst. var. dimorpha I.M. Johnst.

Hierba. Anual o bienal. Endémica.

Distribución: ANT, ATA, COQ.

Rango altitudinal: 0-1500 m.

Pectocarya linearis (Ruiz \& Pav.) DC.

Hierba. Anual. Introducida.

Distribución: ANT, COQ, VAL, RME, LBO, MAU, BIO, AIS.

Pectocarya pusilla (A. DC.) A. Gray

Sinónimos: Gruvelia pusilla A. DC.

Hierba. Anual. Endémica.

Distribución: VAL, LBO.

Rango altitudinal: 0-500 m.

\section{Phacelia}

Phacelia brachyantha Benth.

Sinónimos: Phacelia brachyantha Benth. var. paniculata A.DC., Phacelia clinopodioides Bertero ex Brand, Phacelia simplicifolia Colla

Hierba. Perenne. Nativa.

Distribución: COQ, VAL, RME, LBO, MAG.

Rango altitudinal: 1500-4500 m.

Países limítrofes: Argentina.

Phacelia cumingii (Benth.) A. Gray

Sinónimos: Eutoca cumingii Benth., Microgenetes cumingii

A.DC., Phacelia cumingii (Benth.) A. Gray var. pusilla 
(Phil.) Reiche, Phacelia cumingii (Benth.) A. Gray var. litoralis (Phil.) Reiche, Phacelia cumingii (Benth.) A. Gray var. grandis (Phil.) Reiche, Phacelia cumingii (Benth.) A. Gray var. frigida (Phil.) Brand, Eutoca frigida Phil., Eutoca peraltae Phil., Phacelia frigida (Phil.) Reiche, Eutoca litoralis Phil., Eutoca grandis Phil., Eutoca pinnatifida Phil., Eutoca pusilla Phil.

Hierba. Anual. Nativa.

Distribución: AYP, TAR, ANT, ATA, COQ, VAL, RME, LBO.

Rango altitudinal: 3200-3800 m.

Países limítrofes: Argentina.

Phacelia nana Wedd.

Sinónimos: Eutoca lomarifolia Phil.

Hierba. Anual. Nativa.

Distribución: TAR, ANT.

Rango altitudinal: 3500-4700 m.

Países limítrofes: Argentina y Bolivia.

Phacelia pinnatifida Griseb. ex Wedd.

Sinónimos: Phacelia boliviana Brand, Phacelia pinnatifida Griseb. ex Wedd. var. lobulata Hicken, Phacelia pinnatifida Griseb. ex Wedd. var. decumbens Brand, Phacelia pinnatifida Griseb. ex Wedd. var. elatior Griseb., Phacelia pinnatifida Griseb. ex Wedd. var. foliosa Reiche, Phacelia pinnatifida Griseb. ex Wedd. var. robusta Wedd., Phacelia viscosa Phil., Phacelia foliosa Phil.

Hierba. Perenne. Nativa.

Distribución: AYP, TAR, ANT, ATA, COQ.

Rango altitudinal: 1000-4600 m.

Países limítrofes: Argentina, Bolivia y Perú.

Phacelia secunda J.F. Gmel. var. pinnata (Vahl) Deginani Sinónimos: Heliotropium pinnatum Vahl, Phacelia magellanica (Lam.) Coville fma. robusta Brand, Phacelia pinnata (Ruiz \& Pav.) J.F. Macbr. var. robusta (Brand) J.F. Macbr., Phacelia secunda J.F. Gmel. subsp. pinnata (Ruiz \& Pav.) Constance, Phacelia magellanica (Lam.) Coville fma. amoena Brand, Phacelia pinnata (Ruiz \& Pav.) J.F. Macbr., Aldea pinnata Ruiz \& Pav., Phacelia magellanica (Lam.) Coville fma. pinnata (Vahl) Brand

Hierba. Perenne. Nativa.

Distribución: MAU, MAG.

Rango altitudinal: 1500-3500 m.

Países limítrofes: Argentina.

Phacelia secunda J.F. Gmel. var. secunda

Sinónimos: Phacelia magellanica (Lam.) Coville fma. plantaginea Brand, Phacelia magellanica (Lam.) Coville fma. andina Brand, Phacelia magellanica (Lam.) Coville fma. genuina Brand, nom. illeg., Aldea circinata Willd., Phacelia parviflora Phil., Phacelia circinata (Willd.) Jacq., Phacelia circinata (Willd.) Jacq. var. acutiloba DC.,
Phacelia circinata (Willd.) Jacq. var. paniculata DC., Phacelia circinata (Willd.) Jacq. var. obtusiloba DC., Phacelia secunda J.F. Gmel. subsp. plantaginea (Brand) Constance, Phacelia secunda J.F. Gmel. subsp. parviflora (Phil.) Constance, Hydrophyllum magellanicum Lam., Phacelia magellanica (Lam.) Coville

Hierba. Perenne. Nativa.

Distribución: AYP, TAR, ATA, COQ, VAL, RME, LBO, MAU, NUB, BIO, ARA, LRI, LLA, AIS, MAG.

Rango altitudinal: 0-4000 m.

Países limítrofes: Argentina, Bolivia y Perú.

Phacelia setigera Phil.

Sinónimos: Phacelia pinnatifida Griseb. var. setigera (Phil.) Reiche

Hierba. Anual. Nativa.

Distribución: AYP, TAR, ANT, ATA.

Rango altitudinal: 4000-4800 m.

Países limítrofes: Argentina.

Phacelia sinuata Phil.

Hierba. Perenne. Nativa.

Distribución: TAR, ANT, COQ.

Rango altitudinal: 1000-4000 m.

Países limítrofes: Argentina.

\section{Plagiobothrys}

Plagiobothrys armeriifolius (Phil.) I.M. Johnst.

Sinónimos: Eritrichium armeriifolius Phil.

Hierba. Anual. Endémica.

Distribución: LBO.

Plagiobothrys calandrinioides (Phil.) I.M. Johnst.

Sinónimos: Eritrichium calandrinioides Phil., Eritrichium albiflorus Griseb., Eritrichium uliginosum auct. non Phil., Plagiobothrys lechleri I.M. Johnst., Allocarya alternifolia Brand, Allocarya humilis Brand, Plagiobothrys albiflorus (Griseb.) R.L. Pérez-Mor. ex D.M. Moore, Eritrichium nubigenum Phil. ex F. Meigen

Hierba. Anual. Nativa.

Distribución: VAL, RME, MAG.

Rango altitudinal: 2000-2500 m.

Países limítrofes: Argentina y Bolivia.

Plagiobothrys collinus (Phil.) I.M. Johnst.

Sinónimos: Eritrichium collinum Phil., Cryptantha collina (Phil.) Reiche, Eritrichium inconspicuum Phil., Cryptantha inconspicua (Phil.) Reiche

Hierba. Perenne. Endémica.

Distribución: COQ.

Rango altitudinal: 100-500 m. 
Plagiobothrys corymbosus (Ruiz \& Pav.) I.M. Johnst. Sinónimos: Myosotis corymbosa Ruiz \& Pav., Allocarya sessilifolia Greene, Allocarya sessiliflora Reiche, Allocarya corymbosa (Ruiz \& Pav.) Brand, Eritrichium sessiliflorum A.DC., Cryptantha corymbosa (Ruiz \& Pav.) I.M. Johnst., Allocarya tenuifolia (Schlecht. ex Phil.) Greene, Allocarya tenuifolia (Schlecht. ex Phil.) Greene var. pulchella (Phil.) Reiche, Eritrichium tenuifolium Schlecht. ex Phil., Eritrichium tenuifolium Schlecht. ex Phil. var. pulchellum Phil., Plagiobothrys tenuifolius (Schlecht. ex Phil.) I.M.Johnst.

Hierba. Anual. Nativa.

Distribución: BIO, ARA, LRI, LLA.

Rango altitudinal: 0-1500 m.

Países limítrofes: Argentina.

Plagiobothrys foliosus I.M. Johnst.

Hierba. Perenne. Endémica.

Distribución: NUB, ARA.

Plagiobothrys fulvus (Hook. \& Arn.) I.M. Johnst.

Sinónimos: Myosotis fulva Hook. \& Arn., Eritrichium laxiflorum Phil., Eritrichium fulvum Hook. \& Arn. var. pinguis Phil.

Hierba. Anual. Endémica.

Distribución: COQ, VAL, RME, LBO, MAU, NUB, BIO, ARA, LLA.

Rango altitudinal: 0-1000 m.

Plagiobothrys germainii (Phil.) I.M. Johnst.

Sinónimos: Eritrichium germainii Phil., Allocarya germainii (Phil.) Reiche

Hierba. Perenne. Endémica.

Distribución: BIO, ARA.

Rango altitudinal: 200-300 m.

Plagiobothrys gracilis (Ruiz \& Pav.) I.M. Johnst.

Sinónimos: Myosotis gracilis Ruiz \& Pav., Echinospermum gracile (Ruiz \& Pav.) Lehm., Rochelia gracilis (Ruiz \& Pav. ex G. Don) J.F. Macbr.

Hierba. Anual. Endémica.

Distribución: COQ, RME, MAU, BIO.

Plagiobothrys myosotoides (Lehm.) Brand

Sinónimos: Plagiobothrys tinctorius (Ruiz \& Pav.) A. Gray, Eritrichium tinctorium A. DC., Eritrichium pugae Phil.

Hierba. Anual. Nativa.

Distribución: AYP, COQ, VAL, RME, LBO, MAU, NUB, BIO, ARA.

Rango altitudinal: 0-3500 m.

Países limítrofes: Bolivia y Perú.

Plagiobothrys oppositifolius (Phil.) I.M. Johnst.

Sinónimos: Eritrichium oppositifolius Phil., Eritrichium limonium Phil., Eritrichium cinereum Phil.

Hierba. Anual. Endémica.

Distribución: ARA.

Plagiobothrys pedicellaris (Phil.) I.M. Johnst.

Sinónimos: Allocarya capitata (Clos) Brand var. longipes (Phil. ex Reiche) Brand, Allocarya tenuifolia (Schlecht. ex Phil.) Greene var. longipes Phil. ex Reiche, Eritrichium tenuifolium Schlecht. ex Phil. var. longipes Phil.

Hierba. Perenne. Endémica.

Distribución: ARA.

Plagiobothrys polycaulis (Phil.) I.M. Johnst.

Sinónimos: Eritrichium polycaule Phil., Eritrichium delicatulum Phil., Eritrichium graminifolium Phil., Eritrichium bracteatum Phil., Eritrichium vernum Phil., Eritrichium flavicans Phil.

Hierba. Anual. Endémica.

Distribución: RME, MAU, NUB, BIO, ARA, LLA.

Rango altitudinal: 0-300 m.

Plagiobothrys pratensis (Phil.) I.M. Johnst.

Sinónimos: Eritrichium pratense Phil.

Hierba. Anual o perenne. Endémica.

Distribución: ARA, LLA.

Rango altitudinal: 100-300 m.

Plagiobothrys procumbens (Colla) A. Gray

Sinónimos: Allocarya procumbens (Colla) Greene, Myosotis procumbens Colla, Eritrichium illapelinum Phil., Eritrichium tenuicaule Phil.

Hierba. Anual. Nativa.

Distribución: COQ, VAL, RME, LBO, MAU, NUB, BIO, ARA.

Rango altitudinal: 0-1200 m.

Países limítrofes: Argentina.

Plagiobothrys pulchellus (Phil.) I.M. Johnst. Sinónimos: Eritrichium pulchellum Phil.

Hierba. Anual. Endémica.

Distribución: BIO, ARA.

Rango altitudinal: 0-200 m.

Plagiobothrys uliginosus (Phil.) I.M. Johnst.

Sinónimos: Eritrichium uliginosum Phil., Allocarya uliginosa (Phil.) Greene, Eritrichium pedicellare Phil., Allocarya pedicellaris (Phil.) Reiche

Hierba. Anual. Endémica.

Distribución: NUB, ARA.

Rango altitudinal: 0-100 m.

Plagiobothrys verrucosus (Phil.) I.M. Johnst.

Sinónimos: Eritrichium verrucosum Phil., Plagiobothrys patagonicus I.M. Johnst., Plagiobothrys myosotoides 
(Lehm.) Brand var. patagonicus (I.M. Johnst.) Brand Hierba. Anual. Nativa.

Distribución: VAL, RME, LBO, MAU, AIS.

Rango altitudinal: 500-1000 m.

Países limítrofes: Argentina.

\section{Selkirkia}

Selkirkia berteroi (Colla) Hemsl.

Sinónimos: Cynoglossum berteroi Colla

Arbusto. Endémico.

Distribución: JFE.

Rango altitudinal: 0-600 m.

Selkirkia limense (Willd.) Holstein \& Weigend Sinónimos: Cynoglossum limense Willd., Cynoglossum decurrens var. limense (Willd.) DC., Cynoglossum decurrens Ruiz \& Pav., Cynoglossum alatum Molina

Hierba. Perenne. Endémica.

Distribución: MAU, BIO, ARA, LRI.

Selkirkia pauciflora (Ruiz \& Pav.) Holstein \& Weigend Sinónimos: Cynoglossum pauciflorum Ruiz \& Pav., Cynoglossum paniculatum Hook. \& Arn., Mapuchea paniculata (Hook. \& Arn.) M. Serrano, R. Carbajal \& S. Ortiz, Cynoglossum azocartii Phil., Cynoglossum paniculatum var. azocartii (Phil.) Reiche, Cynoglossum paniculatum fma. azocartii (Phil.) Brand, Cynoglossum paniculatum fma. philippianum Brand

Subarbusto. Endémico.

Distribución: VAL, LBO, MAU, NUB, BIO, ARA, LRI.

Rango altitudinal: 100-1100 m.

Nombre vulgar: No me olvides.

\section{Tiquilia}

Tiquilia atacamensis (Phil.) A.T. Richardson

Sinónimos: Coldenia atacamensis Phil.

Subarbusto. Endémico.

Distribución: AYP, TAR, ANT, ATA.

Rango altitudinal: 0-3500 $\mathrm{m}$.

Nombre vulgar: Káuchal.

Tiquilia grandiflora (Phil.) A.T. Richardson

Sinónimos: Coldenia grandiflora Phil.

Subarbusto. Nativo.

Distribución: AYP, TAR, ANT, ATA.

Rango altitudinal: $1400 \mathrm{~m}$.

Países limítrofes: Perú.

Tiquilia litoralis (Phil.) A.T. Richardson

Sinónimos: Coldenia littoralis Phil.

Subarbusto. Nativo.

Distribución: AYP, TAR, ANT, ATA.
Rango altitudinal: 0-1300 m.

Países limítrofes: Perú.

Tiquilia paronychioides (Phil.) A.T. Richardson Sinónimos: Coldenia paronychioides Phil.

Subarbusto. Nativo.

Distribución: AYP, TAR, ANT, ATA.

Rango altitudinal: 0-3300 m.

Países limítrofes: Bolivia y Perú.

Tiquilia tacnensis A.T. Richardson

Subarbusto. Nativo.

Distribución: AYP, TAR, ANT.

Rango altitudinal: 1900-2000 m.

Países limítrofes: Perú.

\section{BRASSICACEAE}

\author{
Alshehbazia \\ Alshehbazia hauthalii (Gilg \& Muschl.) Salariato \& \\ Zuloaga \\ Sinónimos: Eudema hauthalii Gilg \& Muschl., Onuris \\ hauthalii (Gilg \& Muschl.) Al-Shehbaz, Brayopsis hauthalii \\ (Gilg \& Muschl.) Skottsb., Brayopsis skottsbergii Gilg ex \\ Skottsb. \\ Hierba. Perenne. Nativa. \\ Distribución: MAG. \\ Rango altitudinal: 300-4000 m. \\ Países limítrofes: Argentina.
}

\section{Alyssum}

Alyssum alyssoides (L.) L.

Hierba. Anual. Introducida.

Distribución: BIO, MAG.

\section{Arabidopsis}

Arabidopsis thaliana (L.) Heynh.

Hierba. Anual. Introducida.

Distribución: BIO, ARA, LLA, AIS.

\author{
Atacama \\ Atacama nivea (Phil.) Toro, Mort \& Al-Shehbaz \\ Sinónimos: Sisymbrium niveum Phil., Mathewsia nivea \\ (Phil.) O.E. Schulz \\ Hierba. Perenne. Endémica. \\ Distribución: ANT, ATA. \\ Rango altitudinal: 2500-3500 m.
}




\section{Barbarea}

Barbarea verna (Mill.) Asch.

Hierba. Bienal. Introducida.

Distribución: RME, MAU, NUB, BIO, ARA, LRI, LLA.

\section{Brassica}

\section{Brassica napus L.}

Hierba. Anual o bienal. Introducida.

Distribución: ATA, COQ, RME, LBO, NUB, BIO, ARA, LLA, MAG, JFE.

Brassica nigra (L.) W.D.J. Koch

Hierba. Anual. Introducida.

Distribución: ANT, ATA, COQ, VAL, RME, BIO, JFE.

Brassica oleracea L.

Hierba. Bienal. Introducida.

Distribución: LLA, MAG, JFE, IPA.

\section{Brassica rapa L.}

Hierba. Anual o bienal. Introducida.

Distribución: AYP, ANT, COQ, VAL, RME, LBO, MAU, NUB, BIO, ARA, LRI, LLA, AIS, MAG, JFE.

\section{Brassica tournefortii Gouan}

Hierba. Anual. Introducida.

Distribución: VAL.

\section{Camelina}

Camelina microcarpa Andrz. ex DC.

Hierba. Anual. Introducida.

Distribución: RME.

\section{Capsella}

Capsella bursa-pastoris (L.) Medik.

Hierba. Anual o bienal. Introducida.

Distribución: AYP, ANT, COQ, VAL, RME, LBO, MAU, NUB, BIO, ARA, LRI, LLA, AIS, MAG, IPA.

\section{Cardamine}

\section{Cardamine africana $\mathrm{L}$.}

Hierba. Perenne. Introducida.

Distribución: LLA, AIS.

\section{Cardamine bonariensis Pers.}

Sinónimos: Cardamine alsophila Phil. var. pusilla (Phil.) Reiche, Cardamine nasturtioides Bertero ex Barnéoud, Cardamine andicola Phil., Cardamine nemophila Phil., Cardamine pusilla Phil., Cardamine ramosissima Steud.,
Cardamine tridens Phil., Cardamine bracteata Phil., Cardamine caespitosa Phil., Cardamine alsophila Phil., Cardamine alsophila Phil. var. bracteata (Phil.) Reiche, Cardamine alsophila Phil. var. caespitosa (Phil.) Reiche, Cardamine alsophila Phil. var. tridens (Phil.) Reiche

Hierba. Perenne. Nativa.

Distribución: AYP, TAR, ANT, COQ, VAL, RME, LBO, MAU, NUB, BIO, ARA, LRI, LLA, AIS, MAG, JFE.

Rango altitudinal: 0-4500 m.

Países limítrofes: Argentina, Bolivia y Perú.

Nombre vulgar: Berro picante.

\section{Cardamine chenopodiifolia Pers.}

Sinónimos: Arabis commersonii DC., Arabis spathulata (Poir.) DC., Sisymbrium bellidifolium Poir., Sisymbrium spathulatum Poir., Heterocarpus fernandezianus Phil., Cardamine fernandeziana (Phil.) Johow

Hierba. Anual. Nativa.

Distribución: JFE.

Rango altitudinal: 0-800 m.

Países limítrofes: Argentina y Bolivia.

\section{Cardamine chilensis DC.}

Sinónimos: Cardamine valdiviana Phil., Cardamine chilensis DC. var. angustifolia O.E. Schulz, Cardamine solisii Phil., Cardamine valdiviana Phil. var. callitrichoides (Speg.) O.E. Schulz, Cardamine vulgaris Phil. var. micropetala (Phil.) O.E. Schulz, Cardamine chilensis DC. var. valdiviana (Phil.) Reiche, Cardamine nana Barnéoud, Cardamine micropetala Phil., Cardamine ramosissima Steud. var. micropetala (Phil.) Reiche

Hierba. Anual o perenne. Nativa.

Distribución: VAL, RME, LBO, MAU, NUB, BIO, ARA, LRI.

Rango altitudinal: 0-1000 m.

Países limítrofes: Argentina.

\section{Cardamine cordata Barnéoud}

Sinónimos: Cardamine cordata Barnéoud var. decumbens (Barnéoud) O.E. Schulz, Cardamine nivalis Gillies ex Hook. \& Arn. subsp. andina (Phil.) O.E. Schulz, Cardamine calbucana Phil., Cardamine monticosa Phil., Cardamine decumbens Barnéoud, Cardamine peteroana Phil., Cardamine andina Phil.

Hierba. Perenne. Nativa.

Distribución: COQ, VAL, RME, LBO, MAU, NUB, BIO, ARA, LRI, LLA.

Rango altitudinal: 700-2900 m.

Países limítrofes: Argentina.

Cardamine geraniifolia (Poir.) DC

Sinónimos: Dentaria geraniifolia (Poir.) Reiche, Sisymbrium geraniifolium Poir.

Hierba. Perenne. Nativa. 
Distribución: AIS, MAG.

Rango altitudinal: 0-600 m.

Países limítrofes: Argentina.

Cardamine glacialis (G. Forst.) DC.

Sinónimos: Cardamine glacialis (G. Forst.) DC. var. pubescens Phil. ex O.E. Schulz, Cardamine antiscorbutica Banks \& Sol. ex Griseb., Cardamine strictula Steud., Sisymbrium glaciale G. Forst., Cardamine ciliata Phil., Cardamine gongylodes Phil., Cardamine litoralis Phil., Cardamine magellanica Phil., Cardamine palenae Phil., Cardamine soehrensii Phil., Cardamine pratensis L. var. minor Barnéoud, Cardamine glacialis (G. Forst.) DC. var. pumila A. Gray, Cardamine glacialis (G. Forst.) DC. var. elatior A. Gray, Cardamine hirsuta L. var. antiscorbutica (Banks \& Sol. ex Griseb.) Reiche, Cardamine glacialis (G. Forst.) DC. subsp. litoralis (Phil.) O.E. Schulz, Cardamine hirsuta L. var. magellanica (Phil.) Reiche, Cardamine hirsuta L. var. soehrensii (Phil.) Reiche, Cardamine glacialis (G. Forst.) DC. var. soehrensii (Phil.) O.E. Schulz, Sisymbrium grandiflorum Molina

Hierba. Perenne. Nativa.

Distribución: ATA, RME, MAU, ARA, LRI, LLA, AIS, MAG.

Rango altitudinal: 0-1500 m.

Países limítrofes: Argentina.

Cardamine hirsuta $\mathrm{L}$.

Hierba. Anual. Introducida.

Distribución: VAL, LBO, MAU, NUB, BIO, ARA, LLA, MAG, JFE.

Cardamine kruesselii Johow ex Reiche

Hierba. Perenne. Endémica.

Distribución: JFE.

\section{Cardamine marginata Phil.}

Sinónimos: Cardamine vulgaris Phil. var. marginata (Phil.) O.E. Schulz

Hierba. Perenne. Endémica.

Distribución: NUB, ARA.

Cardamine rostrata Griseb.

Sinónimos: Cardamine rostrata Griseb. var. reniformis (Phil.) O.E. Schulz, Cardamine reniformis Phil., Cardamine lechleriana Steud.

Hierba. Perenne. Nativa.

Distribución: NUB, BIO, ARA, LRI, LLA.

Rango altitudinal: 0-1600 m.

Países limítrofes: Argentina.

Cardamine tenuirostris Hook. \& Arn.

Sinónimos: Cardamine tenuirostris Hook. \& Arn. subsp. affinis (Hook. \& Arn.) O.E. Schulz, Cardamine tenuirostris
Hook. \& Arn. subsp. reicheana O.E. Schulz, Cardamine flavescens Phil., Cardamine affinis Hook. \& Arn.

Hierba. Perenne. Nativa.

Distribución: COQ, VAL, RME, LBO, MAU, NUB, BIO, ARA, LRI, LLA.

Rango altitudinal: 0-1700 m.

Países limítrofes: Argentina.

\section{Cardamine tuberosa DC.}

Sinónimos: Cardamine tuberosa DC. subsp. cognata (Steud.) O.E. Schulz, Cardamine granulata Phil., Cardamine cognata Steud., Cardamine tuberosa DC. var. granulata (Phil.) Reiche, Cardamine thyrsoidea O.E. Schulz

Hierba. Perenne. Nativa.

Distribución: COQ, VAL, RME, LBO, MAU, NUB, BIO, ARA, AIS.

Rango altitudinal: 0-2700 m.

Países limítrofes: Argentina.

Cardamine variabilis Phil.

Sinónimos: Cardamine integrifolia Phil. var. diversifolia O.E. Schulz, Cardamine variabilis Phil. var. pinnatisecta O.E. Schulz, Cardamine thermarum Martic., Cardamine triphylla Phil., Sisymbrium simpsonii Phil.

Hierba. Perenne. Nativa.

Distribución: MAU, NUB, BIO, ARA, LRI, LLA, AIS.

Rango altitudinal: 0-1800 m.

Países limítrofes: Argentina.

Cardamine volckmannii Phil.

Sinónimos: Cardamine nivalis Gillies ex Hook. \& Arn., Cardamine petiolulata Phil. ex O.E. Schulz, Cardamine stricta Phil., Cardamine hirsuta L. var. nivalis (Gillies ex Hook. \& Arn.) Hook.f.

Hierba. Perenne. Nativa.

Distribución: ATA, COQ, VAL, RME, LBO.

Rango altitudinal: 2000-3800 m.

Países limítrofes: Argentina.

Cardamine vulgaris Phil.

Sinónimos: Cardamine garaventae O.E. Schulz, Cardamine grandjotii O.E. Schulz, Cardamine macrostachya Phil., Cardamine vulgaris Phil. var. oligozyga O.E. Schulz, Cardamine hirsuta L. var. vulgaris (Phil.) Reiche, Cardamine intermedia Steud.

Hierba. Perenne. Nativa.

Distribución: VAL, RME, LBO, MAU, NUB, BIO, ARA, LRI, LLA, AIS, MAG, JFE.

Rango altitudinal: 0-1600 m.

Países limítrofes: Argentina. 


\section{Chorispora}

Chorispora tenella (Pall.) DC.

Hierba. Anual. Introducida.

Distribución: RME.

\section{Cremolobus}

Cremolobus chilensis (Lag. ex DC.) DC.

Sinónimos: Urbanodoxa tarapacana Ricardi \& Martic., Biscutella chilensis Lag. ex DC., Cremolobus sinuatus Hook., Cremolobus pinnatifidus Hook.

Hierba. Anual. Nativa.

Distribución: AYP.

Rango altitudinal: 0-4400 m.

Países limítrofes: Argentina, Bolivia y Perú.

\section{Descurainia}

Descurainia antarctica (E. Fourn.) O.E. Schulz

Sinónimos: Descurainia argentea O.E. Schulz, Hesperis antarctica (E. Fourn.) Kuntze

Hierba. Anual o bienal. Nativa.

Distribución: MAG.

Rango altitudinal: 0-600 m.

Países limítrofes: Argentina.

Descurainia depressa (Phil.) Prantl ex Reiche

Sinónimos: Descurainia brachycarpa (Phil.) Prantl ex Reiche, Sisymbrium brachycarpum Phil., nom. illeg., Sisymbrium depressum Phil.

Hierba. Bienal o perenne. Nativa.

Distribución: AYP, TAR, ANT, ATA.

Rango altitudinal: 3500-5000 m.

Países limítrofes: Argentina, Bolivia y Perú.

Descurainia erodiifolia (Phil.) Prantl ex Reiche

Sinónimos: Sisymbrium erodiifolium Phil.

Hierba. Bienal. Nativa.

Distribución: ATA, COQ, VAL, RME, MAU.

Rango altitudinal: 200-3200 m.

Países limítrofes: Argentina y Bolivia.

Descurainia myriophylla (Willd. ex DC.) R.E. Fr. Sinónimos: Sisymbrium myriophyllum Willd. ex DC.

Hierba. Anual. Nativa.

Distribución: AYP, TAR, ANT, ATA.

Rango altitudinal: 1900-4600 m.

Países limítrofes: Argentina, Bolivia y Perú.

Nombre vulgar: Qasabe.

Descurainia nuttallii (Colla) O.E. Schulz

Sinónimos: Descurainia cumingiana (Fisch. \& C.A. Mey.) Prantl var. elegantula (Phil.) O.E. Schulz, Descurainia cumingiana (Fisch. \& C.A. Mey.) Prantl var. tenuissima (Phil.) Reiche, Sisymbrium tenuissimum Phil., Sophia tenuissima (Phil.) Macloskie, Sisymbrium elegantulum Phil., Sisymbrium nuttalli Colla, Sisymbrium macrophyllum Barnéoud, Descurainia sophia (L.) Webb ex Prantl var. macrophylla (Barnéoud) Prantl ex Reiche

Hierba. Anual. Nativa.

Distribución: ANT, ATA, COQ, VAL, RME, LBO, MAU, LLA, MAG.

Rango altitudinal: 0-3200 m.

Países limítrofes: Argentina.

Descurainia pimpinellifolia (Barnéoud) O.E. Schulz

Sinónimos: Descurainia glaucescens (Phil.) Prantl ex Reiche, Descurainia stricta (Phil.) Prantl ex Reiche fma. umbellifera (Phil.) O.E. Schulz, Descurainia pimpinellifolia (Barnéoud) O.E. Schulz var. glaucescens (Phil.) O.E. Schulz, Sisymbrium pimpinellifolium Barnéoud, Sisymbrium umbelliferum Phil., Descurainia canescens (Nutt.) Prantl var. pimpinellifolium (Barnéoud) Reiche, Sophia glaucescens (Phil.) Macloskie

Hierba. Anual. Nativa.

Distribución: ANT, ATA, COQ, VAL, RME, LBO, MAU.

Rango altitudinal: 1500-4000 m.

Países limítrofes: Argentina.

Descurainia sophia (L.) Webb ex Prantl

Hierba. Anual. Introducida.

Distribución: RME, MAG.

Descurainia stricta (Phil.) Prantl ex Reiche

Sinónimos: Descurainia stricta (Phil.) Prantl ex Reiche var. minutiflora (Prantl ex Reiche) O.E. Schulz, Descurainia stricta (Phil.) Prantl ex Reiche var. rubescens (Phil.) O.E. Schulz, Descurainia stricta (Phil.) Prantl ex Reiche var. florida (Phil.) O.E. Schulz, Descurainia minutiflora Prantl ex Reiche var. florida (Phil.) Reiche, Sisymbrium rubescens Phil., Descurainia rubescens (Phil.) Reiche, Sisymbrium strictum Phil., Sisymbrium floridum Phil., Hesperis florida (Phil.) Kuntze, Descurainia minutiflora Prantl ex Reiche Hierba. Anual. Nativa.

Distribución: AYP, TAR, ANT, ATA, COQ.

Rango altitudinal: 3200-4700 m.

Países limítrofes: Argentina y Bolivia.

Nombre vulgar: Kasawi.

\section{Diplotaxis}

Diplotaxis muralis (L.) DC.

Hierba. Anual o bienal. Introducida.

Distribución: ATA, COQ, RME. 
Draba

Draba funiculosa Hook.f.

Hierba. Perenne. Nativa.

Distribución: MAG.

Rango altitudinal: 0-1100 m.

Países limítrofes: Argentina.

Draba gilliesii Hook. \& Arn.

Sinónimos: Draba davilae Phil., Draba gilliesii Hook. \& Arn. var. davilae (Phil.) O.E. Schulz, Draba gilliesii Hook. \& Arn. var. rosulata (Phil.) Reiche, Draba gilliesii Hook. \& Arn. var. stolonifera (Barnéoud) Reiche, Draba rosulata Phil., Draba stolonifera Barnéoud, Draba araucana Phil., Draba colchaguensis Phil., Draba gilliesii Hook. \& Arn. fma. araucana (Phil.) O.E. Schulz, Draba gilliesii Hook. \& Arn. var. rosulata (Phil.) Reiche

Hierba. Perenne. Nativa.

Distribución: COQ, VAL, RME, LBO, MAU, NUB, BIO, ARA, LLA, AIS, MAG.

Rango altitudinal: 400-4000 m.

Países limítrofes: Argentina.

Draba macleanii Hook.f.

Sinónimos: Draba atacamensis Gilg

Hierba. Perenne. Nativa.

Distribución: AYP.

Rango altitudinal: 3900-4900 m.

Países limítrofes: Argentina, Bolivia y Perú.

Draba magellanica Lam.

Sinónimos: Draba magellanica Lam. var. saffordii (Phil.) O.E. Schulz, Draba saffordii Phil., Draba incana L. var. magellanica (Lam.) Hook.f.

Hierba. Perenne. Nativa.

Distribución: AIS, MAG.

Rango altitudinal: 0-3400 m.

Países limítrofes: Argentina.

Draba pusilla F. Phil.

Sinónimos: Draba schoenleinii F. Meigen

Hierba. Perenne. Nativa.

Distribución: COQ, RME, LBO, MAU, MAG.

Rango altitudinal: 500-3400 m.

Países limítrofes: Argentina.

Draba thlaspiformis (Phil.) Al-Shehbaz

Sinónimos: Draba philippii O.E. Schulz, Eudema thlaspiforme Phil.

Hierba. Perenne. Endémica.

Distribución: RME.

Draba verna L.

Hierba. Anual. Introducida.
Distribución: RME, BIO, AIS, MAG.

Eruca

Eruca vesicaria (L.) Cav. subsp. sativa (Mill.) Thell.

Hierba. Anual. Introducida.

Distribución: VAL.

Eruca vesicaria (L.) Cav. subsp. versicaria

Hierba. Anual. Introducida.

Distribución: VAL.

\section{Hesperis}

Hesperis matronalis L.

Hierba. Bienal. Introducida.

Distribución: MAG.

\section{Hirschfeldia}

Hirschfeldia incana (L.) Lagr.-Fossat

Hierba. Anual o bienal. Introducida.

Distribución: ATA, COQ, VAL, RME, LBO, BIO, ARA, JFE, IPA.

\section{Hollermayera}

Hollermayera valdiviana (Phil.) Ravenna

Sinónimos: Hollermayera sylvatica O.E. Schulz, Armoracia valdiviana Phil.

Hierba. Perenne. Endémica.

Distribución: ARA, LLA.

Rango altitudinal: 600-700 m.

\section{Hornungia}

Hornungia procumbens (L.) Hayek

Hierba. Anual. Introducida.

Distribución: AYP, TAR, ATA, COQ, MAG.

Isatis

Isatis tinctoria $\mathrm{L}$.

Hierba. Anual. Introducida.

Distribución: VAL, RME, LBO, MAU.

\section{Ivania}

Ivania cremnophila (I.M. Johnst.) O.E. Schulz

Sinónimos: Cardamine cremnophila I.M. Johnst.

Hierba. Perenne. Endémica.

Distribución: ATA.

Rango altitudinal: 2700-3300 m.

Nombre vulgar: Hierba del gato. 
Ivania juncalensis Al-Shehbaz

Hierba. Perenne. Endémica.

Distribución: VAL.

Rango altitudinal: 2400-2600 m.

\section{Lepidium}

Lepidium angustissimum Phil.

Sinónimos: Lepidium tayloriae Al-Shehbaz

Hierba. Anual. Endémica.

Distribución: ATA, COQ.

Rango altitudinal: 1900-2400 m.

Lepidium auriculatum Regel \& Körn.

Sinónimos: Lepidium araucanum Phil., Lepidium bipinnatifidium Desv. var. araucanum (Phil.) Reiche

Hierba. Anual. Nativa.

Distribución: ANT, COQ, VAL, RME, LBO, MAU, NUB, BIO, ARA, LRI, LLA, AIS, MAG.

Rango altitudinal: 0-2000 m.

Países limítrofes: Argentina y Bolivia.

Lepidium bipinnatifidum Desv.

Hierba. Perenne. Nativa.

Distribución: VAL, LBO, MAU, BIO, LLA.

Rango altitudinal: 0-500 m.

Países limítrofes: Bolivia y Perú.

Nombre vulgar: Mosquetón, picantilla.

Lepidium bonariense L.

Sinónimos: Thlaspi multifidum Poir., Lepidium mendocinum Phil.

Hierba. Anual. Nativa.

Distribución: AYP, TAR, ANT, ATA, COQ, VAL, RME, BIO, JFE, IPA.

Rango altitudinal: 0-3300 m.

Países limítrofes: Argentina y Bolivia.

Nombre vulgar: Hierba del tapón.

Nota: Introducida en el Archipiélago Juan Fernández y en la Isla de Pascua.

Lepidium campestre (L.) W.T. Aiton

Hierba. Anual. Introducida.

Nota: Al-Shehbaz (2010) señala su presencia en Chile, sin mencionar región.

Lepidium chichicara Desv.

Hierba. Perenne. Nativa.

Distribución: AYP, TAR, ANT, ATA, COQ.

Rango altitudinal: 0-700 m.

Países limítrofes: Perú.

Lepidium coronopus (L.) Al-Shehbaz

Hierba. Anual. Introducida.

Distribución: LLA.
Lepidium cumingianum Fisch. \& C.A. Mey.

Sinónimos: Lepidium cumingianum Fisch. \& C.A. Mey. subsp. berteroanum Thell., Lepidium cumingianum Fisch. \& C.A. Mey. subsp. orbiculatum Thell., Lepidium cumingianum Fisch. \& C.A. Mey. var. canescens Thell., Lepidium cumingianum Fisch. \& C.A. Mey. var. subsagittatum Thell.

Hierba. Perenne. Endémica.

Distribución: TAR, VAL, RME, LBO, BIO.

Rango altitudinal: 0-500 m.

Lepidium didymum L.

Sinónimos: Coronopus didymus (L.) Sm., Senebiera didyma (L.) Pers.

Hierba. Anual o bienal. Nativa.

Distribución: AYP, TAR, ANT, ATA, COQ, VAL, RME, LBO, MAU, NUB, BIO, ARA, LRI, LLA, MAG, IPA.

Rango altitudinal: 0-2900 m.

Países limítrofes: Argentina, Bolivia y Perú.

Nota: Introducida en la Isla de Pascua.

Lepidium draba L.

Hierba. Perenne. Introducida.

Distribución: TAR, ATA, COQ, VAL, RME, AIS, MAG.

Lepidium heterophyllum Benth.

Hierba. Perenne. Introducida.

Distribución: ARA.

Lepidium horstii Johow ex Skottsb.

Hierba. Perenne. Endémica.

Distribución: IDE.

Rango altitudinal: $300 \mathrm{~m}$.

Lepidium johnstonii C.L. Hitchc.

Hierba. Anual. Nativa.

Distribución: ANT.

Rango altitudinal: 700-1500 m.

Países limítrofes: Argentina.

Lepidium latifolium L.

Hierba. Perenne. Introducida.

Distribución: ANT, COQ, MAU.

Lepidium myrianthum Phil.

Sinónimos: Lepidium ruderale L. var. myrianthum (Phil.)

Reiche

Hierba. Anual. Nativa.

Distribución: ANT.

Rango altitudinal: 200-3400 m.

Países limítrofes: Argentina. 
Lepidium nitidum Nutt. ex Torr. \& A. Gray

Sinónimos: Lepidium curicoanum Phil., Lepidium chilense Kunze, Lepidium bipinnatifidum Desv. var. curicoanum (Phil.) Reiche, Lepidium tenuifolium Phil., Lepidium bipinnatifidum Desv. var. tenuifolium (Phil.) Reiche, Lepidium tenuissimum Steud.

Hierba. Anual. Nativa.

Distribución: VAL, LBO, MAU, NUB.

Rango altitudinal: 0-200 m.

Nota: Según Al-Shehbaz (2010), esta especie se distribuye en Chile y disyunto en California, Norte América.

Lepidium philippianum (Kuntze) Thell.

Sinónimos: Nasturtium philippianum Kuntze, Lepidium philippianum (Kuntze) Thell. var. brachystylum Thell., Onuris reichei Gilg \& Muschl.

Hierba. Perenne. Endémica.

Distribución: RME.

Rango altitudinal: 2400-3000 m.

Lepidium pseudodidymum Thell. ex Druce

Sinónimos: Coronopus pinnatifidus (DC.) Gaertn. var. australis (Hook.f.) Reiche

Hierba. Anual. Nativa.

Distribución: VAL, RME, LBO, MAU, NUB, BIO, ARA, LRI, LLA, AIS, MAG.

Rango altitudinal: 0-400 m.

Países limítrofes: Argentina.

Lepidium rahmeri Phil.

Hierba. Anual. Nativa.

Distribución: AYP, TAR, ANT, VAL.

Rango altitudinal: 2600-4200 m.

Países limítrofes: Argentina.

Nombre vulgar: Kolka.

Lepidium raimondii O.E. Schulz

Hierba. Anual. Nativa.

Distribución: AYP, TAR, ATA.

Rango altitudinal: 3000-4500 m.

Países limítrofes: Perú.

Lepidium reichei Phil. ex Reiche

Sinónimos: Lepidium morrisonii C.L. Hitchc., Nasturtium brevicaule (Barnéoud) Kuntze

Hierba. Perenne. Nativa.

Distribución: ATA, COQ, VAL, RME.

Rango altitudinal: 2500-3600 m.

Países limítrofes: Argentina.

Lepidium sativum L.

Hierba. Anual. Introducida.

Distribución: BIO, ARA.
Lepidium spathulatum Phil.

Hierba. Perenne. Endémica.

Distribución: ANT, ATA.

Rango altitudinal: 0-1600 m.

Lepidium spicatum Desv.

Sinónimos: Lepidium spicatum Desv. var. calyx-persistente

Boelcke, Lepidium spicatum Desv. var. racemosum

(Griseb.) Boelcke, Lepidium racemosum Griseb.

Hierba. Perenne. Nativa.

Distribución: LLA, MAG.

Rango altitudinal: 0-3300 m.

Países limítrofes: Argentina.

Lepidium strictum (S. Watson) Rattan ex B.L. Rob.

Sinónimos: Lepidium oxycarpum Torr. \& A. Gray var. strictum S. Watson

Hierba. Anual. Endémica.

Distribución: AYP, TAR, ANT, ATA, COQ, VAL, RME, MAU, NUB, BIO, ARA, LLA, MAG.

Rango altitudinal: 0-3800 m.

Lepidium virginicum L.

Hierba. Anual. Introducida.

Distribución: VAL, IDE.

\section{Lobularia}

Lobularia maritima (L.)

Hierba. Perenne. Introducida.

Distribución: TAR, ANT, COQ, VAL, RME, LBO, MAU, BIO, ARA, LRI, LLA.

\section{Mancoa}

Mancoa hispida Wedd.

Sinónimos: Mancoa minima Rollins, Radicula scabra Rusby

Hierba. Perenne. Nativa.

Distribución: AYP, TAR, ANT.

Rango altitudinal: 3400-4800 m.

Países limítrofes: Argentina, Bolivia y Perú.

\section{Mathewsia}

Mathewsia auriculata Phil.

Subarbusto. Endémico.

Distribución: TAR, ATA, COQ.

Rango altitudinal: 100-2700 m.

Mathewsia foliosa Hook. \& Arn.

Hierba. Perenne. Endémica.

Distribución: ATA, COQ, VAL, RME.

Rango altitudinal: 0-1500 m. 
Mathewsia incana Phil.

Subarbusto. Endémico.

Distribución: ANT, ATA.

Rango altitudinal: 0-1300 m.

Mathewsia linearifolia Turcz.

Sinónimos: Mathewsia collina I.M. Johnst., Mathewsia laciniata Phil.

Hierba. Perenne. Endémica.

Distribución: ANT, ATA, COQ.

Rango altitudinal: 0-300 $\mathrm{m}$.

\section{Matthiola}

Matthiola incana (L.) R.Br.

Hierba. Perenne. Introducida.

Distribución: ANT, JFE.

\section{Menonvillea}

Menonvillea chilensis (Turcz.) B.D. Jacks.

Sinónimos: Menonvillea chilensis (Turcz.) B.D. Jacks. var. aptera (Phil.) Rollins, Menonvillea parviflora Phil., Menonvillea orbiculata Phil. var. parviflora (Phil.) Reiche, Menonvillea parvula Phil., Cymatoptera chilensis Turcz., Menonvillea aptera Phil., Menonvillea media Turcz., Menonvillea parviflora Phil. var. aptera (Phil.) I.M. Johnst., Menonvillea pinnatifida Barnéoud var. parvula (Phil.) Gilg \& Muschl., Menonvillea orbiculata Phil. fma. glabra Gilg \& Muschl.

Hierba. Anual. Endémica.

Distribución: ANT, ATA, COQ, VAL.

Rango altitudinal: 0-800 m.

Menonvillea cicatricosa (Phil.) Rollins

Sinónimos: Hexaptera cicatricosa Phil.

Subarbusto. Nativo.

Distribución: LBO, MAU.

Rango altitudinal: 1800-2800 m.

Países limítrofes: Argentina.

Menonvillea comberi Sandwith

Sinónimos: Menonvillea scapigera (Phil.) Rollins subsp.

hirsuta (Rollins) Prina, Menonvillea hirsuta Rollins

Hierba. Anual. Nativa.

Distribución: ARA.

Rango altitudinal: 1000-1700 m.

Países limítrofes: Argentina.

Menonvillea constitutionis (F. Phil.) Rollins

Sinónimos: Hexaptera constitutionis F. Phil.

Hierba. Perenne. Endémica.

Distribución: VAL, RME, MAU.

Rango altitudinal: 0-200 m.
Menonvillea cuneata (Gillies \& Hook.) Rollins

Sinónimos: Hexaptera cuneata Gillies \& Hook., Hexaptera cuneata Gillies \& Hook. var. violacea (Phil.) Reiche, Hexaptera jussiaei Barnéoud, Hexaptera violacea Phil., Hexaptera jussiaei Barnéoud var. tridens (Phil.) Reiche, Hexaptera tridens Phil., Decaptera trifida Turcz.

Hierba. Perenne. Nativa.

Distribución: ATA, COQ, VAL, RME, LBO.

Rango altitudinal: 1700-4600 m.

Países limítrofes: Argentina.

Menonvillea filifolia Fisch. \& C.A. Mey.

Sinónimos: Menonvillea linearis DC. var. filifolia (Fisch. \& C.A. Mey.) Rollins, Menonvillea angustifolia C. Pres1

Hierba. Anual. Endémica.

Distribución: ATA, COQ, VAL, RME, LBO.

Rango altitudinal: 0-1200 m.

Menonvillea flexuosa Phil.

Sinónimos: Menonvillea crassa Rollins, Menonvillea falcata Reiche, Menonvillea flexuosa Phil. fma. tomentosa Gilg \& Muschl.

Hierba. Perenne. Endémica.

Distribución: ATA, COQ, VAL, RME.

Rango altitudinal: 0-3700 m.

Menonvillea frigida (Phil.) Rollins

Sinónimos: Hexaptera frigida Phil.

Hierba. Perenne. Endémica.

Distribución: ANT.

Rango altitudinal: 3900-4700 m.

Menonvillea linearis DC.

Sinónimos: Menonvillea robustula Steud., Menonvillea trifida Phil., Menonvillea linearis DC. var. trifida (Phil.) Reiche, Menonvillea virgata Phil., Menonvillea linearis DC. var. virgata (Phil.) Reiche, Dispeltophorus crassifolius Lehm. Hierba. Anual. Endémica.

Distribución: COQ, VAL, RME, LBO, MAU, BIO.

Rango altitudinal: 0-2000 m.

Menonvillea litoralis (Barnéoud) Rollins

Sinónimos: Menonvillea gayi Phil., Hexaptera litoralis Barnéoud, Menonvillea arachnoidea O.E. Schulz

Hierba. Anual. Endémica.

Distribución: ATA, COQ.

Rango altitudinal: 200-1100 m.

Menonvillea macrocarpa (I.M. Johnst.) Rollins

Sinónimos: Hexaptera macrocarpa I.M. Johnst.

Hierba. Perenne. Endémica.

Distribución: ATA. 
Menonvillea marticorenae (Al-Shehbaz) Salariato \& AlShehbaz

Sinónimos: Menonvillea filifolia Fisch. \& C.A. Mey. subsp. marticorenae Al-Shehbaz

Hierba. Anual. Endémica.

Distribución: ANT, ATA, COQ, VAL.

Rango altitudinal: 0-900 m.

\section{Menonvillea minima Rollins}

Hierba. Anual. Endémica.

Distribución: ATA, COQ.

Rango altitudinal: 0-200 m.

Menonvillea nordenskjoeldii (Dusén) Rollins

Sinónimos: Hexaptera cuneata Gillies \& Hook. var. nordenskjoeldii (Dusén) Gilg \& Muschl., Hexaptera nordenskjoeldii Dusén

Hierba. Perenne. Nativa.

Distribución: AIS, MAG.

Rango altitudinal: 500-2100 m.

Países limítrofes: Argentina.

Menonvillea orbiculata Phil.

Sinónimos: Menonvillea orbiculata Phil. var. perplexa Rollins, Menonvillea alata Rollins

Hierba. Bienal. Endémica.

Distribución: ANT, ATA, COQ.

Rango altitudinal: 0-1300 m.

Menonvillea pinnatifida Barnéoud

Hierba. Perenne. Endémica.

Distribución: ANT, ATA, COQ, RME.

Rango altitudinal: 800-3000 m.

Menonvillea purpurea (Hastings) Rollins

Sinónimos: Hexaptera purpurea Hastings, Hexaptera linearis Barnéoud

Hierba. Perenne. Endémica.

Distribución: COQ, VAL, RME, LBO, MAU.

Rango altitudinal: 0-2800 $\mathrm{m}$.

Menonvillea rollinsii Al-Shehbaz \& Martic.

Sinónimos: Aimara rollinsii (Al-Shehbaz \& Martic.)

Salariato \& Al-Shehbaz

Subarbusto. Endémico.

Distribución: TAR, ANT, ATA.

Rango altitudinal: 2600-3400 m.

Menonvillea scapigera (Phil.) Rollins subsp. longipes (Rollins) Prina

Sinónimos: Menonvillea hookeri Rollins, Menonvillea perstylosa Rollins, Menonvillea longipes Rollins, Hexaptera pinnatifida Gillies \& Hook.

Hierba. Perenne. Nativa.
Distribución: ATA, COQ, RME, LBO, MAU, NUB.

Rango altitudinal: 1100-3300 m.

Países limítrofes: Argentina.

Menonvillea spathulata (Gillies \& Hook.) Rollins

Sinónimos: Hexaptera pusilla Phil., Hexaptera spathulata Gillies \& Hook., Hexaptera spathulata Gillies \& Hook. subsp. pusilla (Phil.) Gilg \& Muschl., Hexaptera spathulata Gillies \& Hook. var. pusilla (Phil.) Reiche, Hexaptera cuneata (Gillies \& Hook.) Rollins var. edentata Kuntze Hierba. Perenne. Nativa.

Distribución: VAL, RME.

Rango altitudinal: 2200-4100 m.

Países limítrofes: Argentina.

Menonvillea virens (Phil.) Rollins

Sinónimos: Hexaptera virens Phil.

Hierba. Perenne. Nativa.

Distribución: TAR, ANT, ATA.

Rango altitudinal: 2000-5000 m.

Países limítrofes: Argentina.

\section{Mostacillastrum}

Mostacillastrum andinum (Phil.) Al-Shehbaz

Sinónimos: Sisymbrium corymbosum Phil., Sisymbrium corymbosum Phil. var. consanguineum (Phil. ex Reiche) O.E. Schulz, Hesperis andina (Phil.) Kuntze, Sisymbrium andinum Phil. fma. dolichocarpum Hauman, Sisymbrium andinum Phil. var. latifolium Phil., Sisymbrium andinum Phil. var. morenoanum (Chodat \& Wilczek) O.E. Schulz, Sisymbrium sagittatum Hook. \& Arn. var. andinum (Phil.) Speg., Sisymbrium sagittatum Hook. \& Arn. var. latifolium (Phil.) Speg., Sisymbrium andinum Phil., Sisymbrium amplexicaule Phil. var. corymbosum (Phil.) Reiche, Hesperis corymbosa (Phil.) Kuntze, Sisymbrium consanguineum Phil. ex Reiche

Hierba. Perenne. Nativa.

Distribución: COQ, VAL, RME, MAU.

Rango altitudinal: 1800-3300 m.

Países limítrofes: Argentina.

Mostacillastrum commune (Speg.) Al-Shehbaz

Sinónimos: Sisymbrium sagittatum var. commune Speg.

Hierba. Anual. Nativa.

Distribución: COQ, VAL, RME.

Rango altitudinal: 100-3300 m.

Países limítrofes: Argentina.

Mostacillastrum dianthoides (Phil.) Al-Shehbaz

Sinónimos: Sisymbrium dianthoides Phil., Sisymbrium arequipanum Al-Shehbaz

Hierba. Perenne. Nativa.

Distribución: TAR, ANT. 
Rango altitudinal: 3200-4400 m.

Países limítrofes: Argentina y Perú.

Mostacillastrum ferreyrae (Förther \& Weigend) AlShehbaz

Sinónimos: Sisymbrium ferreyrae Förther \& Weigend

Hierba. Anual. Nativa.

Distribución: TAR.

Rango altitudinal: 300-1000 m.

Países limítrofes: Perú.

Mostacillastrum gracile (Wedd.) Al-Shehbaz

Sinónimos: Heterothrix gracilis (Wedd.) O.E. Schulz, Pennellia gracilis (Wedd.) O.E. Schulz, Sisymbrium gracile Wedd.

Hierba. Perenne. Nativa.

Distribución: AYP, TAR, ANT, COQ.

Rango altitudinal: 1800-3900 m.

Países limítrofes: Perú.

Mostacillastrum leptocarpum (Hook. \& Arn.) Al-Shehbaz Sinónimos: Sisymbrium andinum Phil. var. hastatum (Phil.) O.E. Schulz, Sisymbrium andinum Phil. var. juncalense O.E. Schulz, Hesperis leptocarpa (Hook. \& Arn.) Kuntze, Sisymbrium hastatum Phil., Sisymbrium leptocarpum Hook. \& Arn., Sisymbrium gayanum Barnéoud, Nasturtium hastatum Phil.

Hierba. Perenne. Nativa.

Distribución: COQ, VAL, RME.

Rango altitudinal: 1800-3200 m.

Países limítrofes: Argentina.

Mostacillastrum pectinifolium (Al-Shehbaz) Al-Shehbaz Sinónimos: Sisymbrium pectinitifolium Al-Shehbaz Hierba. Perenne. Nativa.

Distribución: AYP, TAR, ANT.

Rango altitudinal: 2300-3800 m.

Países limítrofes: Perú.

Mostacillastrum sagittatum (Hook. \& Arn.) Al-Shehbaz Sinónimos: Sisymbrium sagittatum Hook. \& Arn. var. ciliatum (Phil.) Speg., Sisymbrium sagittatum Hook. \& Arn., Hesperis sagittata (Hook. \& Arn.) Kuntze, Sophia sagittata (Hook. \& Arn.) Macloskie, Sisymbrium ciliatum Phil., Sisymbrium fruticosum Reiche, Sisymbrium volckmannii Phil.

Hierba. Perenne. Endémica.

Distribución: ANT, ATA, COQ, VAL, RME.

Rango altitudinal: 100-3700 m.

\section{Nasturtium}

Nasturtium microphyllum Boenn. ex Rchb. Hierba. Perenne. Introducida. Distribución: VAL, LBO.
Nasturtium officinale $\mathrm{R}$. Br.

Hierba. Perenne. Introducida.

Distribución: AYP, TAR, ATA, COQ, VAL, RME, LBO, MAU, NUB, BIO, ARA, LRI, LLA, AIS, JFE.

\section{Neuontobotrys}

Neuontobotrys berningeri O.E. Schulz

Hierba. Perenne. Endémica.

Distribución: AYP, TAR.

Rango altitudinal: 0-3200 m.

Neuontobotrys elloanensis Al-Shehbaz

Hierba. Perenne. Endémica.

Distribución: ANT.

Rango altitudinal: $3500 \mathrm{~m}$.

Neuontobotrys grayana (Baehni \& J.F.Macbr.) Al-Shehbaz Sinónimos: Sisymbrium grayanum Baehni \& J.F. Macbr.

Hierba. Perenne. Nativa.

Distribución: AYP, TAR, ANT.

Rango altitudinal: 2600-3300 m.

Países limítrofes: Perú.

Neuontobotrys intricatissima (Phil.) Al-Shehbaz

Sinónimos: Draba intricatissima Phil., Sisymbrium intricatissimum (Phil.) Reiche, Hesperis intricatissima (Phil.)

Kuntze, Eremodraba intricatissima (Phil.) O.E. Schulz

Hierba. Anual. Nativa.

Distribución: TAR.

Rango altitudinal: 1400-2900 m.

Países limítrofes: Perú.

Neuontobotrys lanata (Walp.) Al-Shehbaz

Sinónimos: Sisymbrium lanatum (Walp.) O.E. Schulz, Sisymbrium foliosum Phil., nom. illeg., Sisymbrium pubescens (Phil. ex Reiche) O.E. Schulz var. glabrescens O.E. Schulz, Sisymbrium pubescens (Phil. ex Reiche) O.E. Schulz, Sisymbrium donnarosae Martic., Hesperis foliosa (Phil.) Kuntze, Sisymbrium andinum Phil. var. pubescens Phil. ex Reiche

Hierba. Perenne. Nativa.

Distribución: AYP, TAR, ANT, ATA, COQ, RME.

Rango altitudinal: 2400-4100 m.

Países limítrofes: Perú.

Nombre vulgar: Chuchar.

Neuontobotrys linearifolia (Kuntze) Al-Shehbaz Sinónimos: Neuontobotrys linifolia O.E. Schulz, Hesperis linearifolia Kuntze

Hierba. Perenne. Endémica.

Distribución: AYP, TAR, ATA.

Rango altitudinal: 100-3800 m. 
Neuontobotrys mendocina (Romanczuk) Al-Shehbaz Sinónimos: Sisymbrium mendocinum Romanczuk Hierba. Perenne. Nativa.

Distribución: RME.

Rango altitudinal: 2200-3000 m.

Países limítrofes: Argentina.

Neuontobotrys polyphylla (Phil.) Al-Shehbaz

Sinónimos: Sisymbrium polyphyllum Phil.

Hierba. Perenne. Nativa.

Distribución: ANT.

Rango altitudinal: 3500-4500 m.

Países limítrofes: Argentina.

Neuontobotrys tarapacana (Phil.) Al-Shehbaz

Sinónimos: Sisymbrium philippianum I.M. Johnst., Sisymbrium tarapacanum Phil., Cardamine deserticola Phil., Neuontobotrys desericola (Phil.) Al-Shehbaz, Arabis tarapacana Phil.

Hierba. Perenne. Nativa.

Distribución: AYP, TAR, ANT, ATA.

Rango altitudinal: 1700-4600 m.

Países limítrofes: Argentina y Bolivia.

Nombre vulgar: kamatokamata.

\section{Noccaea}

Noccaea magellanica (Comm. ex Poir.) Holub

Sinónimos: Thlaspi alpestre L. var. gracile (Phil.) Gilg \& Muschl., Thlaspi andicola Hook. \& Arn., Thlaspi glaucophyllum Barnéoud, Thlaspi gracile Phil., Thlaspi magellanicum Comm. ex Poir. var. andicola (Hook. \& Arn.) O.E. Schulz, Thlaspi magellanicum Comm. ex Poir., Draba depilis Phil., Thlaspi exile Phil.

Hierba. Perenne. Nativa.

Distribución: VAL, RME, MAU, NUB, BIO, ARA, AIS, MAG.

Rango altitudinal: 0-4000 m.

Países limítrofes: Argentina.

\section{Onuris}

Onuris alismatifolia Gilg ex Skottsb.

Hierba. Perenne. Nativa.

Distribución: MAG.

Rango altitudinal: 500-1100 m.

Países limítrofes: Argentina.

Onuris graminifolia Phil.

Sinónimos: Onuris oligosperma (Speg.) Gilg \& Muschl.

Hierba. Perenne. Nativa.

Distribución: MAG.

Rango altitudinal: 1100-2300 m.

Países limítrofes: Argentina.
Onuris hatcheriana (Gilg ex Macloskie) Gilg \& Muschl. Sinónimos: Draba hatcheriana Gilg ex Macloskie

Hierba. Perenne. Nativa.

Distribución: MAG.

Rango altitudinal: 900-1800 m.

Países limítrofes: Argentina.

Onuris papillosa O.E. Schulz

Hierba. Perenne. Nativa.

Distribución: MAG.

Rango altitudinal: 100-1200 m.

Países limítrofes: Argentina.

Onuris spegazziniana Gilg \& Muschl.

Sinónimos: Draba graminifolia Speg.

Hierba. Perenne. Nativa.

Distribución: MAG.

Rango altitudinal: 600-1800 m.

Países limítrofes: Argentina.

\section{Pennellia}

Pennellia lechleri (E. Fourn.) Al-Shehbaz \& C.D. Bailey Sinónimos: Stenodraba lechleri (E. Fourn.) Ravenna, Pennellia petraea (Kuntze) O.E. Schulz, Sisymbrium petraeum Phil., nom. illeg., Stenodraba glareosa Ravenna, Heterothrix petraea (Kuntze) O.E. Schulz, Sisymbrium caespitosum Phil., Sisymbrium fastigiatum Phil., Stenodraba fastigiata (Phil.) Ravenna, Sisymbrium lechleri E. Fourn., Weberbauera lechleri (E. Fourn.) Al-Shehbaz, Hesperis lechleri (E. Fourn.) Kuntze, Hesperis petraea Kuntze

Hierba. Perenne. Nativa.

Distribución: RME, LBO, NUB, ARA.

Rango altitudinal: 300-2100 m.

Países limítrofes: Argentina.

Pennellia parvifolia (Phil.) Al-Shehbaz \& C.D. Bailey Sinónimos: Sisymbrium parvifolium Phil., Sisymbrium vestitum (Ravenna) Al-Shehbaz, Stenodraba parvifolia (Phil.) O.E. Schulz, Stenodraba vestita Ravenna, Weberbauera parvifolia (Phil.) Al-Shehbaz

Hierba. Perenne. Nativa.

Distribución: RME, LBO, MAU.

Rango altitudinal: 1500-2300 m.

Países limítrofes: Argentina.

\section{Petroravenia}

Petroravenia friesii (O.E. Schulz) Al-Shehbaz

Sinónimos: Eudema friesii O.E. Schulz

Hierba. Perenne. Nativa.

Distribución: AYP, TAR, ANT.

Rango altitudinal: 2800-5000 m.

Países limítrofes: Argentina y Bolivia. 
Petroravenia werdermannii (O.E. Schulz) Al-Shehbaz

Sinónimos: Eudema werdermannii O.E. Schulz

Hierba. Perenne. Nativa.

Distribución: ATA.

Rango altitudinal: 3800-4700 m.

Países limítrofes: Argentina.

\section{Polypsecadium}

Polypsecadium litorale (Phil.) Al-Shehbaz

Sinónimos: Sisymbrium litorale Phil., Sisymbrium litorale Phil. var. virgatum O.E. Schulz, Hesperis litoralis (Phil.)

Kuntze

Hierba. Perenne. Endémica.

Distribución: ANT, BIO.

Rango altitudinal: 0-1000 m.

Polypsecadium magellanicum (Juss. ex Pers.) Al-Shehbaz Sinónimos: Brassica antarctica Molina, Brassica magellanica Juss. ex Pers., Sisymbrium magellanicum (Juss. ex Pers.) Hook.f.

Hierba. Perenne. Nativa.

Distribución: MAG.

Rango altitudinal: 0-1100 m.

Países limítrofes: Argentina.

Polypsecadium zoellneri Al-Shehbaz

Hierba. Perenne. Endémica.

Distribución: ATA.

\section{Raphanus}

\section{Raphanus raphanistrum $\mathrm{L}$.}

Hierba. Anual o bienal. Introducida.

Distribución: ANT, ATA, COQ, VAL, RME, LBO, MAU, NUB, BIO, ARA, LLA.

\section{Raphanus sativus L.}

Hierba. Anual o bienal. Introducida.

Distribución: ANT, ATA, COQ, VAL, RME, LBO, MAU, NUB, BIO, ARA, LRI, LLA, MAG, JFE.

\section{Rapistrum}

Rapistrum rugosum (L.) All.

Hierba. Anual. Introducida.

Distribución: ATA, COQ, VAL, RME, LBO, MAU, NUB, BIO, ARA, LRI, IPA.

\section{Rorippa}

Rorippa austroamericana Mart.-Laborde Hierba. Perenne. Nativa. Distribución: VAL, RME, LLA.
Rango altitudinal: 2000-4300 m.

Países limítrofes: Argentina.

Rorippa bonariensis (Poir.) Macloskie

Sinónimos: Nasturtium bonariense (Poir.) DC., Sisymbrium

bonariense Poir., Cardamine indica (L.) Kuntze var. bonariensis (Poir.) Kuntze, Nasturtium indicum (L.) DC. subsp. bonariense (Poir.) Kuntze \& Muschl., Nasturtium tweediei O.E. Schulz, Nasturtium macrorrhizum Steud.

Hierba. Anual o bienal. Nativa.

Distribución: RME.

Rango altitudinal: 0-2400 m.

Países limítrofes: Argentina.

Rorippa coxii (F. Phil. ex Phil.) L.E. Navas

Sinónimos: Nasturtium coxi F. Phil. ex Phil., Sisymbrium laciniosum Phil., Nasturtium patens Phil., Turritis chilensis Phil. ex Reiche

Hierba. Perenne. Nativa.

Distribución: VAL, RME, ARA.

Rango altitudinal: 100-300 m.

Países limítrofes: Argentina.

Rorippa mandonii (E. Fourn.) Mart.-Laborde

Sinónimos: Sisymbrium mandonii E. Fourn., Diplotaxis vernalis Phil., Hesperis mandonii (E. Fourn.) Kuntze, Nasturtium eggersii O.E. Schulz

Hierba. Anual. Nativa.

Distribución: VAL, LBO, MAU.

Rango altitudinal: 100-3000 m.

Países limítrofes: Argentina y Bolivia.

Rorippa palustris (L.) Besser

Hierba. Anual. Introducida.

Distribución: BIO, ARA, LRI, LLA.

Rorippa philippiana Macloskie

Sinónimos: Nasturtium bonariense (Poir.) DC. var. micranthum (Phil.) Reiche

Hierba. Anual. Nativa.

Distribución: COQ, VAL, RME, LBO, MAU, NUB, BIO, ARA, LLA, AIS.

Rango altitudinal: 0-2900 m.

Países limítrofes: Argentina y Perú.

Rorippa sarmentosa (Sol. ex G. Forst.) J.F. Macbr. Hierba. Anual o perenne. Introducida.

Distribución: IPA.

Rorippa sylvestris (L.) Besser

Hierba. Perenne. Introducida.

Distribución: RME, LBO, MAU, NUB, BIO, ARA, LRI. 


\section{Sarcodraba}

Sarcodraba dusenii (O.E. Schulz) Al-Shehbaz

Sinónimos: Grammosperma dusenii O.E. Schulz

Hierba. Perenne. Nativa.

Distribución: MAG.

Rango altitudinal: 500-1000 m.

Países limítrofes: Argentina.

\section{Schizopetalon}

Schizopetalon arcuatum Al-Shehbaz

Hierba. Anual. Endémica.

Distribución: ATA.

Rango altitudinal: 200-400 m.

Schizopetalon bipinnatifidum Phil.

Hierba. Anual. Endémica.

Distribución: ATA, COQ.

Rango altitudinal: 300-2400 m.

\section{Schizopetalon biseriatum Phil.}

Hierba. Anual. Endémica.

Distribución: ATA, COQ, VAL.

Rango altitudinal: 0-600 m.

Schizopetalon brachycarpum Al-Shehbaz

Hierba. Anual. Endémica.

Distribución: RME.

Rango altitudinal: 2100-2300 m.

Schizopetalon corymbosum Al-Shehbaz

Hierba. Anual. Endémica.

Distribución: COQ, VAL.

Schizopetalon dentatum (Barnéoud) Gilg \& Muschl.

Sinónimos: Diplotaxis chilensis Barnéoud, Perreymondia dentata Barnéoud, Perreymondia multifida Barnéoud, Perreymondia viridis Phil., Schizopetalon viride (Phil.) Reiche

Hierba. Anual. Endémica.

Distribución: ATA, COQ, VAL, RME.

Rango altitudinal: 600-2300 m.

\section{Schizopetalon maritimum Barnéoud}

Sinónimos: Schizopetalon gayanum Barnéoud

Hierba. Anual. Endémica.

Distribución: ATA, COQ.

Rango altitudinal: 0-200 m.

Schizopetalon rupestre (Barnéoud) Reiche

Sinónimos: Perreymondia rupestris Barnéoud, Perreymondia brongniartii Barnéoud, Schizopetalon brongniartii (Barnéoud) Reiche, Schizopetalon walkeri Sims var. brongniartii (Barnéoud) Gilg \& Muschl., Schizopetalon san-romanii Phil., Schizopetalon dentatum (Barnéoud) Gilg \& Muschl. var. san-romanii (Phil.) Gilg \& Muschl.

Hierba. Anual. Nativa.

Distribución: ATA, COQ, VAL.

Rango altitudinal: 1900-4000 m.

Países limítrofes: Argentina.

\section{Schizopetalon tenuifolium Phil.}

Hierba. Anual. Endémica.

Distribución: ATA.

Rango altitudinal: 0-500 m.

Schizopetalon walkeri Sims

Hierba. Anual. Endémica.

Distribución: COQ, VAL.

Rango altitudinal: 0-1500 m.

\section{Sibara}

Sibara anethifolia (Phil.) Al-Shehbaz

Sinónimos: Werdermannia anethifolia (Phil.) I.M. Johnst., Nasturtium anethifolium Phil., Heterothrix anethifolia (Phil.) O.E. Schulz, Sisymbrium carnosulum Phil.

Hierba. Perenne. Endémica.

Distribución: TAR, ANT, ATA.

Rango altitudinal: 0-800 m.

Sibara dilloniorum Al-Shehbaz

Hierba. Anual. Endémica.

Distribución: ANT.

Rango altitudinal: 0-800 m.

Sibara macrostachya (Phil.) Al-Shehbaz

Sinónimos: Sisymbrium macrostachyum Phil., Werdermannia macrostachya (Phil.) O.E. Schulz, Nasturtium macrostachyum Phil., Sisymbrium pectinatum Reiche, Sisymbrium larranagae Phil.

Hierba. Perenne. Endémica.

Distribución: ANT.

Rango altitudinal: 0-100 m.

Sibara pinnata (Barnéoud) Al-Shehbaz

Sinónimos: Werdermannia pinnata (Barnéoud) O.E. Schulz, Sisymbrium pinnatum Barnéoud, Sisymbrium pinnatum Barnéoud var. pubescens Barnéoud, Nasturtium deserticola Phil.

Hierba. Perenne. Endémica.

Distribución: ANT, ATA.

Rango altitudinal: $2800 \mathrm{~m}$. 


\section{Sinapis}

Sinapis arvensis L.

Hierba. Anual. Introducida.

Distribución: COQ.

\section{Sisymbrium}

\section{Sisymbrium altissimum L.}

Hierba. Anual. Introducida.

Distribución: BIO.

Sisymbrium austriacum Jacq.

Hierba. Bienal. Introducida.

Distribución: COQ, VAL, RME, LBO, ARA, LLA.

\section{Sisymbrium irio L.}

Hierba. Anual. Introducida.

Distribución: AYP, ANT, ATA, VAL, RME, LBO, MAU, MAG.

Sisymbrium officinale (L.) Scop.

Hierba. Anual. Introducida.

Distribución: ATA, COQ, VAL, RME, LBO, MAU, NUB, BIO, ARA, LRI, LLA, JFE.

Sisymbrium orientale L.

Hierba. Anual. Introducida.

Distribución: ANT, COQ, VAL, RME, LBO, MAU, NUB, BIO, ARA, LRI, MAG.

\section{Teesdalia}

Teesdalia nudicaulis (L.) W.T. Aiton

Hierba. Anual. Introducida.

Distribución: MAG.

\section{Thlaspi}

Thlaspi arvense L.

Hierba. Anual. Introducida.

Distribución: ANT, MAG.

\section{Tomostima}

Tomostima australis (R. Br.) Al-Shehbaz, M. Koch \& Jordon-Thaden

Sinónimos: Draba australis R. Br.

Hierba. Anual. Nativa.

Distribución: COQ, MAG.

Rango altitudinal: 0-1800 m.

Países limítrofes: Argentina.

\section{Tropidocarpum}

Tropidocarpum lanatum (Barnéoud) Al-Shehbaz \& R.A. Price

Sinónimos: Agallis montana Phil., Agallis lanata (Barnéoud) Gilg \& Muschl. ex O.E. Schulz, Lepidium lanatum Barnéoud

Hierba. Anual. Endémica.

Distribución: COQ, VAL, RME.

Rango altitudinal: 200-900 m.

\section{Weberbauera}

Weberbauera chillanensis (Phil.) Al-Shehbaz

Sinónimos: Draba chillanensis Phil., Stenodraba chillanensis (Phil.) O.E. Schulz

Hierba. Perenne. Nativa.

Distribución: MAU, NUB, BIO, ARA.

Rango altitudinal: 2000-2900 m.

Países limítrofes: Argentina.

Weberbauera colchaguensis (Barnéoud) Al-Shehbaz

Sinónimos: Cardamine colchaguensis Barnéoud, Draba andina Phil., Draba patagonica Phil., Sisymbrium colchaguensis (Barnéoud) Wedd. ex E. Fourn., Stenodraba andina (Phil.) O.E. Schulz, Stenodraba andina (Phil.) O.E. Schulz var. hirticaulis O.E. Schulz, Stenodraba colchaguensis (Barnéoud) O.E. Schulz, Stenodraba patagonica (Phil.) Ravenna, Arabis drabaeformis Schltdl., Arabis colchaguensis (Barnéoud) Turcz., Hesperis colchaguensis (Barnéoud) Kuntze, Braya pusilla A. Gray, Hesperis pusilla (A. Gray) Kuntze, Weberbauera pusilla (A. Gray) O.E. Schulz

Hierba. Perenne. Nativa.

Distribución: COQ, VAL, RME, MAU, LLA, AIS, MAG.

Rango altitudinal: 500-3700 m.

Países limítrofes: Argentina.

Weberbauera imbricatifolia (Barnéoud) Al-Shehbaz Sinónimos: Draba imbricatifolia Barnéoud, Sisymbrium imbricatifolium (Barnéoud) Wedd., Hesperis imbricatifolia (Barnéoud) Kuntze, Stenodraba imbricatifolia (Barnéoud) O.E. Schulz, Stenodraba imbricatifolia (Barnéoud) O.E. Schulz var. glabrata O.E. Schulz, Braya imbricatifolia (Barnéoud) A. Gray

Hierba. Perenne. Nativa.

Distribución: ATA, COQ, VAL, RME, LBO.

Rango altitudinal: 2800-4200 m.

Países limítrofes: Argentina.

Weberbauera lagunae (O.E. Schulz) Al-Shehbaz

Sinónimos: Stenodraba suffruticosa (Barnéoud) O.E. Schulz var. lagunae O.E. Schulz

Hierba. Perenne. Endémica. 
Distribución: ATA.

Rango altitudinal: 3800-4000 m.

Weberbauera stenophylla (Leyb.) Al-Shehbaz

Sinónimos: Draba stenophylla Leyb., Draba cauquensis Phil., Draba leyboldii Phil., Stenodraba stenophylla (Leyb.) O.E. Schulz, Stenodraba stenophylla (Leyb.) O.E. Schulz var. leyboldii (Phil.) O.E. Schulz

Hierba. Perenne. Endémica.

Distribución: RME, MAU.

Rango altitudinal: 2000-4000 m.

Weberbauera suffruticosa (Barnéoud) Al-Shehbaz

Sinónimos: Draba suffruticosa Barnéoud, Sisymbrium suffruticosum (Barnéoud) E. Fourn., Hesperis suffruticosa (Barnéoud) Kuntze, Stenodraba suffruticosa (Barnéoud) O.E. Schulz, Draba imbricatifolia Barnéoud var. suffruticosa (Barnéoud) Reiche

Hierba. Perenne. Endémica.

Distribución: COQ.

Rango altitudinal: $3300-4100 \mathrm{~m}$.

\section{Xerodraba}

Xerodraba lycopodioides (Speg.) Skottsb.

Sinónimos: Xerodraba pectinata (Speg.) Skottsb., Eudema lycopodioides (Speg.) Gilg \& Muschl., Eudema pectinata (Speg.) Gilg \& Muschl.

Subarbusto. Nativo.

Distribución: MAG.

Rango altitudinal: 0-1400 m.

Países limítrofes: Argentina.

Xerodraba patagonica (Speg.) Skottsb.

Sinónimos: Braya patagonica Speg., Eudema patagonica (Speg.) Gilg \& Muschl., Draba monantha Gilg ex Kuntze var. microphylla Gilg, nom. nud.

Subarbusto. Nativo.

Distribución: MAG.

Rango altitudinal: 0-1100 m.

Países limítrofes: Argentina.

\section{CACTACEAE}

\section{Austrocactus}

Austrocactus patagonicus (F.A.C. Weber) Backeb. Sinónimos: Cereus patagonicus F.A.C. Weber, Echinocactus intertextus Phil.

Subarbusto. Nativo.

Distribución: ARA, AIS.

Rango altitudinal: 0-1000 m.

Países limítrofes: Argentina.
Austrocactus philippii (Regel \& E. Schmidt) Buxb.

Sinónimos: Austrocactus hibernus F. Ritter, Erdisia philippii (Regel \& E. Schmidt) Britton \& Rose, Cereus philippi Regel \& Schmidt, Echinocactus philippii (Regel \& E. Schmidt) K. Schum., Echinopsis philippii (Regel \& E. Schmidt) G. Nicholson

Subarbusto suculento. Nativo.

Distribución: MAU.

Rango altitudinal: $2000 \mathrm{~m}$.

Países limítrofes: Argentina.

Austrocactus spiniflorus (Phil.) F. Ritter

Sinónimos: Erdisia spiniflora (Phil.) Britton \& Rose, Opuntia spiniflora Phil., Corryocactus spiniflorus (Phil.) Hutchison, Opuntia bicolor Phil., Opuntia clavata Phil., Cereus hypogaeus F.A.C. Weber ex Regel, Echinocereus hypogaeus Rümpler, Eulychnia clavata Phil., Echinocereus clavata K. Schum.

Subarbusto suculento. Endémico.

Distribución: RME, LBO.

Rango altitudinal: 1500-2500 m.

\section{Browningia}

Browningia candelaris (Meyen) Britton \& Rose

Sinónimos: Cereus candelaris Meyen, Cactus candelaris (Meyen) Meyen

Árbol suculento. Nativo.

Distribución: AYP, TAR.

Rango altitudinal: 2000-3000 m.

Países limítrofes: Perú.

Nombre vulgar: Candelabro, cardón, sabaya.

\section{Copiapoa}

Copiapoa ahremephiana N.P. Taylor \& G.J. Charles

Arbusto suculento. Endémico.

Distribución: ANT.

Rango altitudinal: 0-100 m.

Copiapoa boliviana (Pfeiff.) F. Ritter

Sinónimos: Copiapoa atacamensis Middled., Echinocactus bolivianus Pfeiff., Copiapoa calderana F. Ritter subsp. atacamensis (Middled.) D.R. Hunt

Subarbusto suculento. Endémico.

Distribución: ANT.

Rango altitudinal: 0-1000 m.

Copiapoa calderana F. Ritter

Sinónimos: Copiapoa atacamensis Middled. var. calderana (F. Ritter) A.E. Hoffm., Copiapoa calderana F. Ritter var. spinosior F. Ritter, Copiapoa lembckei Backeb., nom. illeg. Subarbusto suculento. Endémico. 
Distribución: ATA.

Rango altitudinal: 0-200 m.

Copiapoa cinerascens (Salm-Dyck) Britton \& Rose

Sinónimos: Copiapoa applanata Backeb., nom. illeg., Copiapoa cinerascens (Salm-Dyck) Britton \& Rose var. intermedia F. Ritter, Echinocactus cinerascens Salm-Dyck, Copiapoa cinerascens (Salm-Dyck) Britton \& Rose var. applanata F. Ritter, Echinocactus ambiguus Hildm. ex K. Schum.

Arbusto suculento. Endémico.

Distribución: ANT, ATA.

Rango altitudinal: 0-200 m.

Copiapoa cinerea (Phil.) Britton \& Rose var. cinerea

Sinónimos: Copiapoa tenebrosa F. Ritter, Copiapoa cinerea (Phil.) Britton \& Rose var. tenebrosa (F. Ritter) A.E. Hoffm., Echinocactus cinereus Phil.

Arbusto suculento. Endémico.

Distribución: ANT.

Rango altitudinal: 0-1000 m.

Copiapoa cinerea (Phil.) Britton \& Rose var. columnaalba (F. Ritter) Backeb.

Sinónimos: Copiapoa columna-alba F. Ritter var. nuda F. Ritter, Copiapoa columna-alba F. Ritter, Copiapoa melanohystrix F. Ritter

Subarbusto suculento. Endémico.

Distribución: ANT, ATA.

Rango altitudinal: 0-1000 m.

Copiapoa cinerea (Phil.) Britton \& Rose var. gigantea (Backeb.) N.P. Taylor

Sinónimos: Copiapoa gigantea Backeb. var. haseltoniana (Backeb.) F. Ritter, Copiapoa gigantea Backeb., Copiapoa haseltoniana Backeb., Copiapoa albispina Backeb., nom. nud., Copiapoa cinerea (Phil.) Britton \& Rose var. haseltoniana (Backeb.) N.P. Taylor

Arbusto suculento. Endémico.

Distribución: ANT.

Rango altitudinal: 700-1000 m.

Copiapoa coquimbana (Rümpler) Britton \& Rose var. coquimbana

Sinónimos: Copiapoa alticostata F. Ritter, Copiapoa coquimbana (Rümpler) Britton \& Rose var. alticostata (F. Ritter) A.E. Hoffm., Copiapoa coquimbana (Rümpler) Britton \& Rose var. armata F. Ritter, Copiapoa coquimbana (Rümpler) Britton \& Rose var. pendulina (F. Ritter) A.E. Hoffm., Copiapoa coquimbana (Rümpler) Britton \& Rose var. pseudocoquimbana (F. Ritter) A.E. Hoffm., Copiapoa coquimbana (Rümpler) Britton \& Rose var. vallenarensis (F. Ritter) A.E. Hoffm., Copiapoa coquimbana (Rümpler)
Britton \& Rose var. wagenknechtii F. Ritter, Copiapoa pendulina F. Ritter, Copiapoa pseudocoquimbana F. Ritter, Copiapoa pseudocoquimbana F. Ritter var. chaniarensis F. Ritter, Copiapoa pseudocoquimbana F. Ritter var. domeykoensis F. Ritter, Copiapoa pseudocoquimbana F. Ritter var. vulgata F. Ritter, Copiapoa vallenarensis F. Ritter, Copiapoa serenana Voldan, Echinocactus coquimbanus Rümpler, Copiapoa wagenknechtii F. Ritter

Arbusto suculento. Endémico.

Distribución: ATA, COQ.

Rango altitudinal: 0-1000 m.

Copiapoa coquimbana (Rümpler) Britton \& Rose var. fiedleriana (K. Schum.) A.E. Hoffm.

Sinónimos: Copiapoa fiedleriana (K. Schum.) Backeb., Copiapoa pepiniana (K. Schum.) Backeb. var. fiedleriana Backeb., Echinocactus fieldlerianum K. Schum.

Subarbusto suculento. Endémico.

Distribución: ATA.

Rango altitudinal: 0-200 m.

\section{Copiapoa dealbata F. Ritter}

Sinónimos: Copiapoa carrizalensis F. Ritter, Copiapoa carrizalensis F. Ritter var. gigantea F. Ritter, Copiapoa dealbata F. Ritter var. carrizalensis (F. Ritter) A.E. Hoffm., Copiapoa dealbata F. Ritter fma. gigantea (F. Ritter) A.E. Hoffm., Copiapoa cinerea (Phil.) Britton \& Rose var. dealbata (F. Ritter) Backeb.

Arbusto suculento. Endémico.

Distribución: ATA.

Rango altitudinal: 0-200 m.

Copiapoa decorticans N.P. Taylor \& G.J. Charles

Subarbusto suculento. Endémico.

Distribución: ANT.

Rango altitudinal: 0-200 m.

Copiapoa echinata F. Ritter

Sinónimos: Copiapoa echinata F. Ritter fma. pulla F. Ritter, Copiapoa echinata F. Ritter var. borealis F. Ritter, Copiapoa megarhiza Britton \& Rose var. echinata (F. Ritter) A.E. Hoffm., Copiapoa totoralensis F. Ritter

Subarbusto suculento. Endémico.

Distribución: ATA.

Rango altitudinal: 0-200 m.

Copiapoa echinoides (Lem. ex Salm-Dyck) Britton \& Rose Sinónimos: Copiapoa cuprea F. Ritter, Copiapoa dura F. Ritter, Copiapoa echinoides (Lem. ex Salm-Dyck) Britton \& Rose var. cuprea (F. Ritter) A.E. Hoffm., Echinocactus echinoides Lem. ex Salm-Dyck

Subarbusto suculento. Endémico.

Distribución: ATA. 
Copiapoa eremophila F. Ritter

Sinónimos: Copiapoa cinerea (Phil.) Britton \& Rose var. eremophila (F. Ritter) A.E. Hoffm., Copiapoa cinerea (Phil.) Britton \& Rose fma. albispina F. Ritter

Arbusto suculento. Endémico.

Distribución: TAR.

Rango altitudinal: 400-1000 m.

\section{Copiapoa grandiflora F. Ritter}

Sinónimos: Copiapoa cinerascens (Salm-Dyck) Britton \& Rose var. grandiflora (F. Ritter) A.E. Hoffm.

Subarbusto suculento. Endémico.

Distribución: ANT, ATA.

Copiapoa humilis (Phil.) Hutchison var. esmeraldana (F. Ritter) A.E. Hoffm.

Sinónimos: Copiapoa esmeraldana F. Ritter

Subarbusto suculento. Endémico.

Distribución: ANT.

Rango altitudinal: 200-500 m.

Copiapoa humilis (Phil.) Hutchison var. humilis

Sinónimos: Copiapoa humilis (Phil.) Hutchison var. paposoensis (F. Ritter) A. Hoffm., nom. illeg., Copiapoa paposoensis F. Ritter, nom. illeg., Echinocactus humilis Phil.

Subarbusto suculento. Endémico.

Distribución: ANT.

Rango altitudinal: 200-1000 m.

Copiapoa humilis (Phil.) Hutchison var. longispina (F. Ritter) A.E. Hoffm.

Sinónimos: Copiapoa longispina F. Ritter

Subarbusto suculento. Endémico.

Distribución: ATA.

Copiapoa humilis (Phil.) Hutchison var. taltalensis (Werderm.) A.E. Hoffm.

Sinónimos: Copiapoa chaniaralensis F. Ritter, Copiapoa taltalensis (Werderm.) Looser, Echinocactus taltalensis Werderm.

Subarbusto suculento. Endémico.

Distribución: ANT.

Copiapoa humilis (Phil.) Hutchison var. tenuissima (F. Ritter) G. Charles

Sinónimos: Copiapoa tenuissima F. Ritter

Subarbusto suculento. Endémico.

Distribución: ANT.

Rango altitudinal: 600-800 m.

Copiapoa humilis (Phil.) Hutchison var. tocopillana (F. Ritter) G. Charles

Sinónimos: Copiapoa tocopillana F. Ritter
Subarbusto suculento. Endémico.

Distribución: ANT.

Copiapoa humilis (Phil.) Hutchison var. varispinata (F. Ritter) G. Charles

Sinónimos: Copiapoa varispinata F. Ritter

Subarbusto suculento. Endémico.

Distribución: ANT.

Copiapoa hypogaea $\mathrm{F}$. Ritter var. hypogaea

Sinónimos: Copiapoa hypogaea F. Ritter var. barquitensis

F. Ritter, Copiapoa mollicula F. Ritter

Subarbusto suculento. Endémico.

Distribución: ANT, ATA.

Rango altitudinal: 400-500 m.

Copiapoa hypogaea F. Ritter var. montana (F. Ritter) G. Charles

Sinónimos: Copiapoa olivana F. Ritter, Copiapoa montana

F. Ritter

Subarbusto suculento. Endémico.

Distribución: ANT.

Copiapoa krainziana F. Ritter

Sinónimos: Copiapoa krainziana F. Ritter var. scopulina F. Ritter, Copiapoa cinerea (Phil.) Britton \& Rose var. krainziana (F. Ritter) Slaba

Subarbusto suculento. Endémico.

Distribución: ANT.

Rango altitudinal: 300-900 m.

Copiapoa laui L. Diers

Sinónimos: Copiapoa hypogaea F. Ritter var. laui (L. Diers)

A. Hoffm.

Subarbusto suculento. Endémico.

Distribución: ANT, ATA.

Rango altitudinal: 100-700 m.

Copiapoa longistaminea F. Ritter

Sinónimos: Copiapoa cinerea (Phil.) Britton \& Rose var. longistaminea (F. Ritter) Slaba

Arbusto suculento. Endémico.

Distribución: ANT.

Rango altitudinal: 0-200 m.

Copiapoa marginata (Salm-Dyck) Britton \& Rose var. bridgesii (Pfeiff.) A.E. Hoffm.

Sinónimos: Echinocactus bridgesii Pfeiff., Copiapoa bridgesii (Pfeiff.) Backeb.

Subarbusto suculento. Endémico.

Distribución: ANT, ATA.

Rango altitudinal: 200-700 m. 
Copiapoa marginata (Salm-Dyck) Britton \& Rose var. marginata

Sinónimos: Echinocactus marginatus Salm-Dyck, Echinocactus columnaris Pfeiff., Echinocactus streptocaulon Hook., Copiapoa streptocaulon (Hook.) Oosten

Subarbusto suculento. Endémico.

Distribución: ATA.

Rango altitudinal: 0-700 m.

Copiapoa megarhiza Britton \& Rose

Sinónimos: Copiapoa megarhiza Britton \& Rose var. microrhiza F. Ritter

Subarbusto suculento. Endémico.

Distribución: ATA.

Rango altitudinal: 200-800 m.

Copiapoa rarissima F. Ritter

Subarbusto suculento. Endémico.

Distribución: ANT.

\section{Copiapoa rupestris F. Ritter}

Sinónimos: Copiapoa desertorum F. Ritter var. hornilloensis (F. Ritter) A.E. Hoffm., Copiapoa desertorum F. Ritter var. rupestris (F. Ritter) A.E. Hoffm., Copiapoa desertorum F. Ritter, Copiapoa desertorum F. Ritter var. rubriflora (F. Ritter) A.E. Hoffm., Copiapoa hornilloensis F. Ritter, Copiapoa rubriflora F. Ritter

Arbusto suculento. Endémico.

Distribución: ANT.

Rango altitudinal: 0-500 m.

\section{Copiapoa serpentisulcata F. Ritter}

Sinónimos: Copiapoa serpentisulcata F. Ritter var. castanea F. Ritter

Arbusto suculento. Endémico.

Distribución: ATA.

Rango altitudinal: 0-300 m.

Copiapoa solaris (F. Ritter) F. Ritter

Sinónimos: Copiapoa conglomerata (Phil.) Lembcke, Copiapoa ferox Lembcke \& Backeb., nom. illeg., Echinocactus conglomeratus Phil., Pilocopiapoa solaris F. Ritter

Arbusto suculento. Endémico.

Distribución: ANT.

Rango altitudinal: 0-1000 m.

\section{Corryocactus}

Corryocactus brevistylus (K. Schum. ex Vaupel) Britton \& Rose

Sinónimos: Corryocactus krausii Backeb., Cereus brevistylus K. Schum.

Arbusto suculento. Nativo.
Distribución: AYP, TAR.

Rango altitudinal: 2000-3500 m.

Países limítrofes: Perú.

Nombre vulgar: Guacalla.

\section{Cumulopuntia}

Cumulopuntia dactylifera (Vaupel) E.F. Anderson

Sinónimos: Cumulopuntia pentlandii (Salm-Dyck) F. Ritter var. dactylifera (Vaupel) F. Ritter, Opuntia dactylifera Vaupel

Subarbusto suculento. Nativo.

Distribución: ANT.

Países limítrofes: Perú.

Cumulopuntia echinacea (Ritter) Ritter

Sinónimos: Tephrocactus echinaceus F. Ritter, Opuntia echinacea (F. Ritter) A.E. Hoffm., Cumulopuntia boliviana (Salm-Dyck) F. Ritter subsp. echinacea (F. Ritter) D.R. Hunt, Maihueniopsis boliviana (Salm-Dyck) R. Kiesling subsp. echinacea (Ritter) Faúndez \& R. Kiesling

Arbusto suculento. Nativo.

Distribución: TAR.

Rango altitudinal: 2600-4000 m.

Países limítrofes: Perú.

Cumulopuntia ignescens (Vaup.) Ritter

Sinónimos: Tephrocactus ignescens (Vaupel) Backeb., Opuntia ignescens Vaupel, Cumulopuntia boliviana (SalmDyck) F. Ritter subsp. ignescens (Vaupel) D.R. Hunt, Maihuenipsis boliviana (Salm-Dyck) R. Kiesling subsp. ignescens (Vaup.) Faúndez \& R. Kiesling

Arbusto suculento. Nativo.

Distribución: TAR, ANT.

Rango altitudinal: 3300-4500 m.

Países limítrofes: Argentina, Bolivia y Perú.

Nombre vulgar: Piskayu.

Cumulopuntia sphaerica (C.F. Först.) E.F. Anderson

Sinónimos: Opuntia leucophaea Phil., Cumulopuntia tubercularis F. Ritter, Opuntia sphaerica C.F. Först., Echinocactus berteri auct. non (Colla) Gay

Subarbusto suculento. Nativo.

Distribución: TAR, ANT, ATA, COQ, VAL.

Rango altitudinal: 0-3500 m.

Países limítrofes: Perú.

Nombre vulgar: Jalajala, puskaye.

\section{Cylindropuntia}

Cylindropuntia tunicata (Lehm.) F.M. Knuth

Arbusto suculento. Introducido.

Distribución: TAR, ANT, ATA, COQ. 


\section{Echinopsis}

Echinopsis atacamensis (Phil.) Friedrich \& G.D. Rowley Sinónimos: Cereus atacamensis Phil., Trichocereus atacamensis (Phil.) Beckeb., Helianthocereus atacamensis (Phil.) Backeb.

Árbol suculento. Nativo.

Distribución: ANT.

Rango altitudinal: 2000-3800 m.

Países limítrofes: Argentina y Bolivia.

Nombre vulgar: Pasakana.

Echinopsis chiloensis (Colla) Friedrich \& G.D. Rowley subsp. chiloensis

Sinónimos: Trichocereus chiloensis (Colla) Britton \& Rose, Trichocereus chiloensis (Colla) Britton \& Rose var. australis F. Ritter, Trichocereus chiloensis (Colla) Britton \& Rose var. borealis F. Ritter, Trichocereus chiloensis (Colla) Britton \& Rose var. conjungens F. Ritter, Trichocereus chiloensis (Colla) Britton \& Rose var. eburneus F. Ritter, nom. illeg., Trichocereus chiloensis (Colla) Britton \& Rose var. panhoplites (K. Schum.) F. Ritter, nom. illeg., Cactus chiloensis Colla, Cereus chiloensis (Colla) DC., Cereus quisco J. Remy ex Gay

Arbusto suculento. Endémico.

Distribución: ANT, ATA, COQ, VAL, RME, LBO, MAU.

Rango altitudinal: 0-1700 m.

Echinopsis chiloensis (Colla) Friedrich \& G.D. Rowley subsp. litoralis (Johow) Lowry

Sinónimos: Echinopsis litoralis (Johow) Friedrich \& G.D. Rowley, Trichocereus chiloensis (Colla) Britton \& Rose subsp. litoralis (Johow) Lowry, Cereus litoralis Johow, Trichocereus litoralis (Johow) Looser, Echinopsis bolligeriana Mächler \& H.E. Walter

Arbusto suculento. Endémico.

Distribución: COQ, VAL, LBO, MAU.

Rango altitudinal: 0-200 m.

Echinopsis coquimbana (Molina) Friedrich \& G.D. Rowley Sinónimos: Trichocereus coquimbana (Molina) Britton \& Rose, Cactus coquimbanus Molina, Cereus coquimbanus (Molina) K. Schum.

Arbusto suculento. Endémico.

Distribución: ATA, COQ.

Rango altitudinal: 0-500 m.

Echinopsis deserticola (Werderm.) Friedrich \& G.D. Rowley

Sinónimos: Echinopsis deserticola (Werderm.) Friedrich \& G.D. Rowley var. fulvilana (F. Ritter) A.E. Hoffm., Echinopsis spinibarbis (Pfeiff.) A.E. Hoffm., Trichocereus deserticola (Werderm.) Looser, Trichocereus fulvilanus F. Ritter, Eulychnia spinibarbis (Pfeiff.) Britton \& Rose,
Cereus deserticola Werderm., Trichocereus spinibarbis (Pfeiff.) F. Ritter, Cereus spinibarbis Pfeiff.

Arbusto suculento. Endémico.

Distribución: ANT, ATA.

Rango altitudinal: 400-800 m.

Echinopsis ferox (Britton \& Rose) Backeb.

Sinónimos: Lobivia ferox Britton \& Rose, Pseudolobivia

ferox (Britton \& Rose) Backeb.

Subarbusto suculento. Nativo.

Distribución: TAR.

Rango altitudinal: 2000-3800 m.

Países limítrofes: Argentina, Bolivia y Perú.

Echinopsis formosa (Pfeiff.) Jacobi ex Salm-Dyck

Sinónimos: Echinocactus formosa Pfeiff., Acanthocalycium formosum (Pfeiff.) Backeb., Soehrencia formosa (Pfeiff.) Backeb., Trichocereus formosus (Pfeiff.) F. Ritter, Lobivia longispina Britton \& Rose

Arbusto suculento. Nativo.

Distribución: ANT.

Países limítrofes: Argentina.

Echinopsis glauca (F. Ritter) Friedrich \& G.D. Rowley fma. pendens (F. Ritter) Friedrich \& G.D. Rowley

Sinónimos: Trichocereus glaucus F. Ritter fma. pendens F.

Ritter

Arbusto suculento. Endémico.

Distribución: TAR.

Rango altitudinal: 400-600 m.

Echinopsis nigripilis (Phil.) Friedrich \& G.D. Rowley

Sinónimos: Cereus nigripilis Phil., Trichocereus nigripilis (Phil.) Baker, Trichocereus coquimbanus (Molina) Britton \& Rose var. nigripilis (Phil.) Borg

Arbusto suculento. Endémico.

Distribución: COQ.

Rango altitudinal: 0-500 m.

Echinopsis skottsbergii (Backeb.) Friedrich \& G.D. Rowley Sinónimos: Trichocereus skottsbergii Backeb.

Arbusto suculento. Endémico.

Distribución: COQ.

Rango altitudinal: 0-500 m.

\section{Eriosyce}

Eriosyce aspillagae (Söhrens) Katt.

Sinónimos: Pyrrhocactus aspillagae (Söhrens) F. Ritter, Neoporteria horrida (Gay) D.R. Hunt var. aspillagae (Söhrens) A.E. Hoffm., Neoporteria aspillagae (Söhrens) Backeb., Echinocactus aspillagae Söhrens, Eriosyce aspillagae (Söhrens) Katt. subsp. maechleri H.E. Walter Subarbusto suculento. Endémico. 
Distribución: LBO, MAU.

Rango altitudinal: 0-200 m.

Eriosyce aurata (Pfeiff.) Backeb. var. aurata

Sinónimos: Eriosyce algarrobensis F. Ritter, Eriosyce ceratistes Britton \& Rose, Eriosyce ihotzkyana F. Ritter var. ausseliana (F. Ritter) F. Ritter, Eriosyce sandillon (Gay) Phil., Eriosyce sandillon (Gay) Phil. var. algarrobensis (F. Ritter) A.E. Hoffm., Eriosyce sandillon (Gay) Phil. var. mollensis (Backeb.) A.E. Hoffm., Eriosyce sandillon (Gay) Phil. var. vallenarensis (Backeb.) A.E. Hoffm., Echinocactus auratus Pfeiff., Echinocactus ceratistes Otto ex Pfeiff., Echinocactus sandillon Gay

Arbusto suculento. Endémico.

Distribución: ATA, COQ, VAL, RME.

Rango altitudinal: 1500-2500 m.

Eriosyce aurata (Pfeiff.) Backeb. var. spinibarbis (F. Ritter) Katt.

Sinónimos: Eriosyce spinibarbis F. Ritter

Arbusto suculento. Endémico.

Distribución: ATA.

Rango altitudinal: 2000-2500 m.

Eriosyce caligophila R. Pinto

Sinónimos: Islaya caligophila (R. Pinto) Faúndez \& R. Kiesling

Subarbusto suculento. Endémico.

Distribución: TAR.

Rango altitudinal: 600-700 m.

Eriosyce chilensis (Hildm. ex K. Schum.) Katt. var. albidiflorus (F. Ritter) Katt.

Sinónimos: Pyrrhocactus chilensis (Hildm. ex K. Schum.)

Katt. var. albidiflorus F. Ritter

Arbusto suculento. Endémico.

Distribución: COQ.

Rango altitudinal: 0-100 m.

Eriosyce chilensis (Hildm. ex K. Schum.) Katt. var. chilensis

Sinónimos: Pyrrhocactus chilensis (Hildm. ex K. Schum.) F. Ritter, Pyrrhocactus krausii F. Ritter, Neoporteria chilensis (Hildm. ex K. Schum.) Britton \& Rose, Echinocactus chilensis Hildm. ex K. Schum., Neochilenia chilensis (Hildm. ex K. Schum.) Backeb.

Arbusto suculento. Endémico.

Distribución: COQ, VAL.

Rango altitudinal: 0-100 m.

Eriosyce confinis (F. Ritter) Katt.

Sinónimos: Pyrrhocactus confinis F. Ritter, Neoporteria confinis (F. Ritter) Donald \& G.D. Rowley, Neoporteria kunzei (C.F. Först.) Backeb. var. confinis (F. Ritter) A.E. Hoffm., Neochilenia confinis (F. Ritter) Backeb.

Subarbusto suculento. Endémico.

Distribución: ATA.

Rango altitudinal: 0-500 m.

Eriosyce crispa (F. Ritter) Katt.

Sinónimos: Pyrrhocactus crispus F. Ritter, Neoporteria crispa (F. Ritter) Donald \& G.D. Rowley, Neoporteria vallenarensis (F. Ritter) A.E. Hoffm. var. crispa (F. Ritter) A.E. Hoffm.,Horridocactus crispus (F. Ritter) Backeb.

Arbusto suculento. Endémico.

Distribución: ATA.

Rango altitudinal: 0-300 m.

Eriosyce curvispina (Bertero ex Colla) Katt. subsp. curvispina var. curvispina

Sinónimos: Pyrrhocactus curvispinus (Bertero ex Colla) A. Berger ex Backeb., Pyrrhocactus andicola (F. Ritter) F. Ritter, Pyrrhocactus andicola (F. Ritter) F. Ritter var. descendens (F. Ritter) F. Ritter, Pyrrhocactus andicola (F. Ritter) F. Ritter var. mollensis (F. Ritter) F. Ritter, Pyrrhocactus andicola (F. Ritter) F. Ritter var. robustus (F. Ritter) F. Ritter, Pyrrhocactus coliguayensis F. Ritter, Pyrrhocactus grandiflorus F. Ritter, Pyrrhocactus horridus (Gay) Backeb. var. aconcaguensis (F. Ritter) F. Ritter, Pyrrhocactus horridus (Gay) Backeb. var. orientalis (F. Ritter) F. Ritter, Pyrrhocactus limariensis F. Ritter, Pyrrhocactus lissocarpus F. Ritter, Pyrrhocactus pamaensis F. Ritter, Neoporteria choapensis (F. Ritter) Donald \& G.D. Rowley, Neoporteria curvispina (Bertero ex Colla) Donald \& G.D. Rowley, Neoporteria horrida (Gay) D.R. Hunt var. coliguayensis (F. Ritter) A.E. Hoffm., Neoporteria horrida (Gay) D.R. Hunt var. limariensis (F. Ritter) A.E. Hoffm., Neoporteria litoralis F. Ritter, Eriosyce curvispina (Bertero ex Colla) Katt. var. aconcaguensis (F. Ritter) Katt., Eriosyce curvispina (Bertero ex Colla) Katt. var. choapensis (F. Ritter) Katt., Eriosyce limariensis (F. Ritter) Katt., Eriosyce marksiana (F. Ritter) Katt. var. gracilis (F. Ritter) Katt., Eriosyce marksiana (F. Ritter) Katt. var. lissocarpa (F. Ritter) Katt., Cactus curvispinus Bertero ex Colla, Horridocactus curvispinus (Bertero ex Colla) Backeb., Pyrrhocactus choapensis F. Ritter, Horridocactus choapensis (F. Ritter) Backeb., Pyrrhocactus aconcaguensis F. Ritter, Horridocactus aconcaguensis (F. Ritter) Backeb., Neoporteria curvispina (Bertero ex Colla) Donald \& G.D. Rowley var. aconcaguensis (F. Ritter \&, Eriosyce curvispina (Bertero ex Colla) Katt. var. limariensis (F. Ritter) A. Hoffm. \& H., Pyrrhocactus lissocarpus F. Ritter var. gracilis F. Ritter Arbusto suculento. Endémico.

Distribución: ATA, COQ, VAL, RME, LBO, MAU.

Rango altitudinal: 200-2000 m. 
Eriosyce curvispina (Bertero ex Colla) Katt. subsp. curvispina var. tuberisulcata (Jacobi) Katt.

Sinónimos: Pyrrhocactus tuberisulcatus (Jacobi) A. Berger, Pyrrhocactus armatus F. Ritter, Pyrrhocactus horridus Backeb., nom. illeg., Pyrrhocactus horridus (Gay) Backeb. fma. vegasanus (F. Ritter) F. Ritter, Pyrrhocactus horridus (Gay) Backeb. var. mutabilis F. Ritter, Pyrrhocactus horridus (Gay) Backeb. var. robustus (F. Ritter) F. Ritter, Pyrrhocactus odoriflorus F. Ritter, Neoporteria horrida (Gay) D.R. Hunt, Neoporteria horrida (Gay) D.R. Hunt var. armata (F. Ritter) A.E. Hoffm., Neoporteria horrida (Gay) D.R. Hunt var. odoriflora (F. Ritter) A.E. Hoffm., Neoporteria tuberisulcata (Jacobi) Donald \& G.D. Rowley, Eriosyce curvispina (Bertero ex Colla) Katt. var. armata (F. Ritter) Katt., Echinocactus tuberisulcatus Jacobi, Eriosyce curvispina (Bertero ex Colla) Katt. var. robusta (F. Ritter) Katt., Cactus horridus Bertero ex Colla, nom. illeg., Eriosyce curvispina (Bertero ex Colla) Katt. var. mutabilis (F. Ritter) Katt., Pyrrhocactus robustus F. Ritter, Echinocactus horridus (Bertero ex Colla) J. Remy ex Gay

Arbusto suculento. Endémico.

Distribución: RME, LBO.

Rango altitudinal: 0-600 m.

Eriosyce curvispina (Bertero ex Colla) Katt. subsp. marksiana (Ritter) R. Ferryman

Sinónimos: Pyrrhocactus marksianus F. Ritter, Pyrrhocactus marksianus F. Ritter var. tunensis F. Ritter, Pyrrhocactus truncatipetalus F. Ritter, Neoporteria curvispina (Bertero ex Colla) Donald \& G.D. Rowley var. lissocarpa (F. Ritter) A.E. Hoffm., Neoporteria curvispina (Bertero ex Colla) Donald \& G.D. Rowley var. marksiana (F. Ritter) A.E. Hoffm., Neoporteria marksiana (F. Ritter) Donald \& G.D. Rowley, Eriosyce marksiana (F. Ritter) Katt.

Arbusto suculento. Endémico.

Distribución: LBO, MAU.

Rango altitudinal: 200-500 m.

Eriosyce engleri (F. Ritter) Katt.

Sinónimos: Pyrrhocactus engleri (F. Ritter) F. Ritter, Neoporteria curvispina (Bertero ex Colla) Donald \& G.D. Rowley var. engleri (F. Ritter) A.E. Hoffm., Neoporteria engleri (F. Ritter) Donald \& G.D. Rowley, Horridocactus engleri $\mathrm{F}$. Ritter

Arbusto suculento. Endémico.

Distribución: VAL, RME.

Rango altitudinal: $1900 \mathrm{~m}$.

Eriosyce eriosyzoides (F. Ritter) Ferryman

Sinónimos: Pyrrhocactus eriosyzoides (F. Ritter) F. Ritter, Pyrrhocactus atroviridis F. Ritter, Pyrrhocactus eriosyzoides (F. Ritter) F. Ritter var. domeykoensis F. Ritter, Pyrrhocactus transiens F. Ritter, Neoporteria carrizalensis (F. Ritter) A.E. Hoffm., Neoporteria carrizalensis (F. Ritter)
A.E. Hoffm. var. totoralensis (F. Ritter) A.E. Hoffm., Neoporteria eriosyzoides (F. Ritter) Donald \& G.D. Rowley, Neoporteria huascensis (F. Ritter) Donald \& G.D. Rowley, Neoporteria jussieui (Monv. ex Salm-Dyck) Britton \& Rose var. huascensis (F. Ritter) A.E. Hoffm., Neoporteria kunzei (C.F. Först.) Backeb., Neoporteria totoralensis (F. Ritter) Donald \& G.D. Rowley, Neoporteria vallenarensis (F. Ritter) A.E. Hoffm. var. domeykoensis (F. Ritter) A.E. Hoffm., Neoporteria vallenarensis (F. Ritter) A.E. Hoffm. var. transitensis (F. Ritter) A.E. Hoffm., Neoporteria vallenarensis (F. Ritter) A. Hoffm., comb. illeg., Neochilenia transitensis (F. Ritter) Backeb., Eriosyce crispa (F. Ritter) Katt. subsp. atroviridis (F. Ritter) Katt., Eriosyce crispa (F. Ritter) Katt. var. carrizalensis (F. Ritter) Katt., Eriosyce crispa (F. Ritter) Katt. var. huascensis (F. Ritter) Katt., Eriosyce crispa (F. Ritter) Katt. var. totoralensis (F. Ritter) Katt., Eriosyce kunzei (C.F. Först.) Katt. var. transitensis (F. Ritter) Katt., Eriosyce eriosyzoides (F. Ritter) Ferryman, Horridocactus eriosyzoides F. Ritter, Eriosyce kunzei auct. non (C.F. Först.) Katt., Eriosyce eriosyzoides (F. Ritter) Ferryman var. transitensis (F. Ritter) A. Hoffm. \& H. Walter, Eriosyce eriosyzoides (F. Ritter) Ferryman subsp. atroviridis (F. Ritter) Ferryman, Horridocactus atroviridis (F. Ritter) Backeb., Neoporteria vallenarensis (F. Ritter) A.E. Hoffm. var. atroviridis (F. Ritter) A.E. Hoffm., Neoporteria atroviridis (F. Ritter) Ferryman, Eriosyce eriosyzoides (F. Ritter) Ferryman var. carrizalensis (F. Ritter) A. Hoffm. \& H. Walter, Pyrrhocactus carrizalensis F. Ritter, Horridocactus carrizalensis (F. Ritter) Backeb., Neoporteria totoralensis (F. Ritter) Donald \& G.D. Rowley var. carrizalensis (F. Ritter) Ferryman, Eriosyce eriosyzoides (F. Ritter) Ferryman var. huascensis (F. Ritter) A. Hoffm. \& H. Walter, Pyrrhocactus huascensis F. Ritter, Neochilenia huascensis (F. Ritter) Backeb., Eriosyce eriosyzoides (F. Ritter) Ferryman var. totoralensis (F. Ritter) A. Hoffm. \& H. Walter, Pyrrhocactus totoralensis F. Ritter, Neochilenia totoralensis (F. Ritter) Backeb., Pyrrhocactus kunzei (C.F. Först.) Y. Ito

Arbusto suculento. Endémico.

Distribución: ATA, COQ.

Rango altitudinal: 0-1800 m.

Eriosyce esmeraldana (F. Ritter) Katt.

Sinónimos: Neoporteria esmeraldana (F. Ritter) Donald \& G.D. Rowley, Thelocephala esmeraldana (F. Ritter) F. Ritter, Chileorebutia esmeraldana F. Ritter, Neochilenia esmeraldana (F. Ritter) Backeb.

Subarbusto suculento. Endémico.

Distribución: ANT, ATA.

Rango altitudinal: 100-200 m.

Eriosyce garaventae (F. Ritter) Katt.

Sinónimos: Pyrrhocactus garaventai (F. Ritter) F. Ritter, Horridocactus garaventai F. Ritter, Neoporteria subaiana (Backeb.) Donald \& G.D. Rowley, Neoporteria garaventae 
(F. Ritter) Ferryman, Neoporteria curvispina (Bertero ex Colla) Donald \& G.D. Rowley var. garaventae (F. Ritter) Donald \& G.D. Rowley

Arbusto suculento. Endémico.

Distribución: VAL.

Rango altitudinal: 1000-3000 m.

Eriosyce heinrichiana (Backeb.) Katt.

Sinónimos: Pyrrhocactus heinrichianus (Backeb.) F. Ritter, Pyrrhocactus chaniarensis F. Ritter, Pyrrhocactus jussieui (Monv. ex Salm-Dyck) Britton \& Rose var. australis F. Ritter, Pyrrhocactus jussieui (Monv. ex Salm-Dyck) Britton \& Rose var. spinosior F. Ritter, Pyrrhocactus setosiflorus F. Ritter var. intermedius F. Ritter, Pyrrhocactus trapichensis F. Ritter, Pyrrhocactus wagenknechtii F. Ritter, Neoporteria chorosensis (F. Ritter) Donald \& G.D. Rowley, Neoporteria deherdtiana (Backeb.) Donald \& G.D. Rowley, nom. illeg., Neoporteria dimorpha (F. Ritter) Donald \& G.D. Rowley, Neoporteria jussieui (Monv. ex Salm-Dyck) Britton \& Rose, Neoporteria jussieui (Monv. ex Salm-Dyck) Britton \& Rose var. chaniarensis (F. Ritter)A.E. Hoffm., Neoporteriajussieui (Monv. ex Salm-Dyck) Britton \& Rose var. chorosensis (F. Ritter) A.E. Hoffm., Neoporteria jussieui (Monv. ex SalmDyck) Britton \& Rose var. dimorpha (F. Ritter) A.E. Hoffm., Neoporteria jussieui (Monv. ex Salm-Dyck) Britton \& Rose var. setosiflora (F. Ritter) A.E. Hoffm., Neoporteria jussieui (Monv. ex Salm-Dyck) Britton \& Rose var. trapichensis (F. Ritter) A.E. Hoffm., Neoporteria jussieui (Monv. ex Salm-Dyck) Britton \& Rose var. wagenknechtii (F. Ritter) A.E. Hoffm., Neoporteria occulta (Phil.) Britton \& Rose, Neoporteria ritteri Donald \& G.D. Rowley, Neoporteria setosiflora (F. Ritter) Donald \& G.D. Rowley, Eriosyce heinrichiana (Backeb.) Katt. subsp. intermedia (F. Ritter) Katt., Eriosyce heinrichiana (Backeb.) Katt. var. setosiflora (F. Ritter) Katt., Pyrrhocactus setosiflorus F. Ritter, Eriosyce heinrichiana (Backeb.) Katt., Chilenia occulta (Phil.) Backeb., Echinocactus occultus Phil., Chilenia jussieui (Monv. ex Salm-Dyck) Backeb.

Subarbusto suculento. Endémico.

Distribución: ATA, COQ.

Rango altitudinal: 0-500 $\mathrm{m}$.

Eriosyce ihotzkyana F. Ritter

Arbusto suculento. Endémico.

Distribución: COQ.

Rango altitudinal: 0-1500 m.

Eriosyce iquiquensis (F. Ritter) Ferryman

Sinónimos: Pyrrhocactus saxifragus F. Ritter, Neoporteria aricensis (F. Ritter) Donald \& G.D. Rowley, Neoporteria aricensis (F. Ritter) Donald \& G.D. Rowley var. floribunda (Backeb.) A.E. Hoffm., Neoporteria aricensis (F. Ritter) Donald \& G.D. Rowley var. saxifraga (F. Ritter) A.E. Hoffm., Neoporteria iquiquensis (F. Ritter) Donald \& G.D.
Rowley, Neoporteria recondita (F. Ritter) Donald \& G.D. Rowley var. residua (F. Ritter) A.E. Hoffm., Neoporteria residua (F. Ritter \& Buining) Donald \& G.D. Rowley, Islaya iquiquensis (F. Ritter) Faúndez \& R. Kiesling, Neochilenia iquiquensis (F. Ritter) Backeb., Pyrrhocactus aricensis (F. Ritter) Backeb., Pyrrhocactus residuus F. Ritter \& Buining, Eriosyce recondita (F. Ritter) Katt. subsp. iquiquensis (F. Ritter) Katt.

Arbusto suculento. Endémico.

Distribución: TAR, ANT.

Rango altitudinal: 600-1000 m.

Eriosyce islayensis (C.F. Först.) Katt.

Sinónimos: Islaya islayensis (C.F. Först.) Backeb., Echinocactus islayensis C.F. Först.

Arbusto suculento. Nativo.

Distribución: TAR.

Países limítrofes: Perú.

Eriosyce krausii (F. Ritter) Katt.

Sinónimos: Neoporteria esmeraldana (F. Ritter) Donald \& G.D. Rowley var. malleolata (F. Ritter) A.E. Hoffm., Thelocephala krausii (F. Ritter) F. Ritter, Thelocephala longirapa F. Ritter, Thelocephala malleolata (F. Ritter) F. Ritter, Thelocephala malleolata (F. Ritter) F. Ritter var. solitaria (F. Ritter) F. Ritter, Chileorebutia kraussii Ritter, Neochilenia kraussii (Ritter) Backeb., Neoporteria odieri (Lem. ex Salm-Dyck) Backeb. var. kraussii (Ritter) Hoffman, Eriosyce odieri (Lem. ex Salm-Dyck) Katt. subsp. malleolata Hoffman \& Walter, Chileorebutia malleolata Ritter, Neochilenia malleolata (Ritter) Backeb., Thelocephala malleolata (Ritter) Ritter, Neoporteria odieri (Lem. ex Salm-Dyck) Backeb.(Lem. ex SalmDyck) Backeb. var. malleolata, Eriosyce odieri (Lem. ex Salm-Dyck) Katt. subsp. malleolata Hoffman \& Walter var. weisserii Hoffman \& Walter, Thelocephala weisserii (Hoffman \& Walter) Faúndez \& Saldivia

Arbusto suculento. Endémico.

Distribución: TAR, ANT, ATA.

Rango altitudinal: 0-200 $\mathrm{m}$.

Eriosyce lapampaensis F. Ritter

Subarbusto suculento. Endémico.

Distribución: ATA.

Rango altitudinal: 200-2500 m.

Eriosyce laui Luthy

Sinónimos: Islaya laui (Luthy) Faúndez \& R. Kiesling,

Rimacactus laui (Luthy) Mottram

Arbusto suculento. Endémico.

Distribución: ANT.

Rango altitudinal: 500-700 m. 
Eriosyce megacarpa F. Ritter

Subarbusto suculento. Endémico.

Distribución: ATA.

Rango altitudinal: 0-100 m.

Eriosyce napina (Phil.) Katt.

Sinónimos: Neoporteria napina (Phil.) Backeb., Neoporteria napina (Phil.) Backeb. fma. nuda (F. Ritter) A.E. Hoffm., Neoporteria napina (Phil.) Backeb. var. duripulpa (F. Ritter) A.E. Hoffm., Neoporteria napina (Phil.) Backeb. var. lembckei (Backeb.) A.E. Hoffm., Neoporteria napina (Phil.) Backeb. var. glabrescens (F. Ritter) A.E. Hoffm., Neochilenia lembckei Backeb., Eriosyce aerocarpa (F. Ritter) Katt., Eriosyce napina (Phil.) Katt. var. duripulpa (F. Ritter) Katt., Eriosyce napina (Phil.) Katt. subsp. lembckei Katt., Eriosyce odieri (Lem. ex Salm-Dyck) Katt. subsp. fulva (F. Ritter) Katt., Thelocephala aerocarpa (F. Ritter) F. Ritter, Thelocephala duripulpa (F. Ritter) F. Ritter, Thelocephala fulva F. Ritter, Thelocephala nuda F. Ritter, Echinocactus napinus Phil., Thelocephala napina (Phil.) Y. Ito, Chileorebutia napina (Phil.) F. Ritter, Neochilenia napina (Phil.) Backeb., Neochilenia napina (Phil.) Backeb. var. mitis (Phil.) Backeb., Eriosyce napina (Phil.) Katt. subsp. aerocarpa (F. Ritter) Ferryman, Chileorebutia aerocarpa F. Ritter, Neochilenia aerocarpa (F. Ritter) Backeb., Neoporteria napina (Phil.) Backeb. var. aerocarpa (F. Ritter) A.E. Hoffm., Thelocephala lembckei (Backeb.) F. Ritter, Chileorebutia duripulpa F. Ritter, Neochilenia duripulpa (F. Ritter) Backeb., Eriosyce napina (Phil.) Katt. subsp. challensis R. Keim \& I. Schaub, Eriosyce spectabilis A.E. Hoffm. \& H.E. Walter, nom. nud.

Subarbusto suculento. Endémico.

Distribución: ATA.

Rango altitudinal: 100-600 m.

\section{Eriosyce occulta Katt.}

Sinónimos: Pyrrhocactus philippianus Faúndez, Pyrrhocactus occultus F. Ritter, nom. illeg., Pyrrhocactus occultus F. Ritter var. spinosior F. Ritter, nom. illeg.

Subarbusto suculento. Endémico.

Distribución: ANT.

Rango altitudinal: 0-500 m.

Eriosyce odieri (Lem. ex Salm-Dyck) Katt. subsp. glabrescens (F. Ritter) Katt.

Sinónimos: Thelocephala glabrescens (F. Ritter) F. Ritter

Subarbusto suculento. Endémico.

Distribución: ATA.

Rango altitudinal: 0-200 m.

Eriosyce odieri (Lem. ex Salm-Dyck) Katt. subsp. malleolata (F. Ritter) A.E. Hoffm. \& H. Walter var. weisseri A.E. Hoffm. \& H. Walter

Sinónimos: Thelocephala weisseri (A. Hoffmman \& H.
Walter) Faúndez \& Saldivia

Subarbusto suculento. Endémico.

Distribución: ANT.

Eriosyce odieri (Lem. ex Salm-Dyck) Katt. subsp. odieri Sinónimos: Neoporteria monte-amargensis (Backeb.) Donald \& G.D. Rowley, nom. illeg., Neoporteria odieri (Lem. ex Salm-Dyck) Backeb., Neoporteria reichei (K. Schum.) Backeb., Eriosyce odieri (Lem. ex Salm-Dyck) Katt. var. monte-amargensis Katt., Thelocephala odieri (Lem. ex Salm-Dyck) F. Ritter, Neochilenia odieri (Lem. ex Salm-Dyck) Backeb., Chileorebutia odieri (Lem. ex SalmDyck) F. Ritter, Echinocactus odieri Lem. ex Salm-Dyck Subarbusto suculento. Endémico.

Distribución: ATA.

Rango altitudinal: 0-400 m.

Eriosyce paucicostata (F. Ritter) Ferryman subsp. echinus (Ritter) R. Ferryman

Sinónimos: Pyrrhocactus echinus F. Ritter, Eriosyce taltalensis (Hutchison) Katt. subsp. echinus (F. Ritter) Katt., Neoporteria paucicostata (F. Ritter) Donald \& G.D. Rowley var. echinus (F. Ritter) A.E. Hoffm., Neoporteria paucicostata (F. Ritter) Donald \& G.D. Rowley var. glaucescens (F. Ritter) A.E. Hoffm., Pyrrhocactus glaucescens F. Ritter

Arbusto suculento. Endémico.

Distribución: ANT.

Rango altitudinal: 400-800 m.

Eriosyce paucicostata (F. Ritter) Ferryman subsp. floccosa (Ritter) R. Ferryman

Sinónimos: Pyrrhocactus floccosus F. Ritter, Eriosyce taltalensis (Hutchison) Katt. var. floccosa (F. Ritter) Katt., Pyrrhocactus floccosus F. Ritter var. minor (F. Ritter) F. Ritter, Neoporteria eriocephala (Backeb.) Donald \& G.D. Rowley, nom. illeg., Neoporteria paucicostata (F. Ritter) Donald \& G.D. Rowley var. floccosa (F. Ritter) A.E. Hoffm. Arbusto suculento. Endémico.

Distribución: ANT.

Rango altitudinal: 200-600 m.

Eriosyce paucicostata (F. Ritter) Ferryman subsp. paucicostata

Sinónimos: Pyrrhocactus paucicostatus (F. Ritter) F. Ritter, Pyrrhocactus neohankeanus F. Ritter, Pyrrhocactus neohankeanus F. Ritter var. densispinus F. Ritter, Pyrrhocactus neohankeanus F. Ritter var. elongatus F. Ritter, Pyrrhocactus neohankeanus F. Ritter var. flaviflorus F. Ritter, Pyrrhocactus paucicostatus (F. Ritter) F. Ritter var. viridis (F. Ritter) F. Ritter, Neoporteria fusca (Muehlenpf.) Britton \& Rose, Neoporteria haenkeana (C.F. Först.) Donald \& G.D. Rowley, Neoporteria paucicostata (F. Ritter) Donald \& G.D. Rowley, Neoporteria paucicostata 
(F. Ritter) Donald \& G.D. Rowley var. neohankeana (F. Ritter) A.E. Hoffm., Neoporteria paucicostata (F. Ritter) Donald \& G.D. Rowley var. viridis (F. Ritter) A.E. Hoffm., Neoporteria woutersiana (Backeb.) Donald \& G.D. Rowley, nom. illeg., Delaetia woutersiana Backeb., nom. illeg., Eriosyce taltalensis (Hutchinson) Katt. subsp. paucicostata (F. Ritter) Katt., Horridocactus paucicostatus F. Ritter, Neoporteria neohankeana (F. Ritter) Ferryman, Neochilenia paucicostata (F. Ritter) Backeb.

Arbusto suculento. Perenne. Endémica.

Distribución: ANT.

Rango altitudinal: 0-600 m.

Eriosyce recondita (F. Ritter) Katt.

Sinónimos: Pyrrhocactus reconditus F. Ritter, Pyrrhocactus vexatus F. Ritter, Neoporteria recondita (F. Ritter) Donald \& G.D. Rowley, Neoporteria recondita (F. Ritter) Donald \& G.D. Rowley var. vexata (F. Ritter) A.E. Hoffm., Neochilenia recondita (F. Ritter) Backeb.

Subarbusto suculento. Endémico.

Distribución: ANT.

Rango altitudinal: 400-1000 m.

Eriosyce rodentiophila $\mathrm{F}$. Ritter

Sinónimos: Eriosyce rodentiophila F. Ritter var. lanata $\mathrm{F}$. Ritter

Arbusto suculento. Endémico.

Distribución: ANT, ATA.

Rango altitudinal: 100-600 m.

Eriosyce senilis (Backeb.) Katt.

Sinónimos: Neoporteria nidus (Söhrens ex K. Schum.) Britton \& Rose, Neoporteria coimasensis F. Ritter, Neoporteria coimasensis F. Ritter fma. crassispina F. Ritter, Neoporteria coimasensis F. Ritter fma. tenuispina F. Ritter, Neoporteria coimasensis F. Ritter var. robusta (F. Ritter) F. Ritter, Neoporteria multicolor F. Ritter, Neoporteria nidus (Söhrens) Britton \& Rose var. coimasensis (F. Ritter) A.E. Hoffm., Neoporteria nidus (Söhrens) Britton \& Rose var. gerocephala (Y. Ito) F. Ritter, Neoporteria nidus (Söhrens) Britton \& Rose var. matancillana F. Ritter, Neoporteria nidus (Söhrens) Britton \& Rose var. multicolor (F. Ritter) A.E. Hoffm., Neoporteria robusta F. Ritter, Neoporteria subgibbosa (Haw.) Britton \& Rose var. robusta (F. Ritter) A.E. Hoffm., Eriosyce senilis (Backeb.) Katt. subsp. coimasensis (F. Ritter) Katt., Eriosyce senilis (Backeb.) Katt. subsp. elquiensis Katt., Echinocactus senilis Phil., nom. illeg., Neoporteria gerocephala Y. Ito, Neoporteria senilis Backeb., Echinocactus nidus Söhrens ex K. Schum. Arbusto suculento. Endémico.

Distribución: COQ.

Rango altitudinal: 200-500 m. Nombre vulgar: Viejito.
Eriosyce simulans (F. Ritter) Katt.

Sinónimos: Pyrrhocactus simulans F. Ritter, Neoporteria simulans (F. Ritter) Donald \& G.D. Rowley, Eriosyce heinrichiana (Backeb.) Katt. subsp. simulans (F. Ritter) Katt., Neochilenia simulans (F. Ritter) Backeb.

Arbusto suculento. Endémico.

Distribución: COQ.

Rango altitudinal: 100-400 m.

Eriosyce sociabilis (F. Ritter) Katt.

Sinónimos: Neoporteria sociabilis F. Ritter, Neoporteria sociabilis F. Ritter var. napina F. Ritter

Arbusto suculento. Endémico.

Distribución: ATA.

Eriosyce subgibbosa (Haw.) Katt. subsp. clavata (Söhrens ex K. Schum.) Katt.

Sinónimos: Neoporteria clavata (Söhrens ex K. Schum.) Werderm., Neoporteria clavata (Söhrens ex K. Schum.) Werderm. fma. grandiflora F. Ritter, Neoporteria clavata (Söhrens ex K. Schum.) Werderm. var. nigrihorrida (Backeb.) A.E. Hoffm., Neoporteria clavata (Söhrens ex K. Schum.) Werderm. var. parviflora F. Ritter, Neoporteria clavata (Söhrens ex K. Schum.) Werderm. var. procera F. Ritter, Neoporteria microsperma F. Ritter, Neoporteria microsperma F. Ritter var. graciana F. Ritter, Neoporteria microsperma F. Ritter var. serenana F. Ritter, Neoporteria nigrihorrida Backeb., Neoporteria nigrihorrida (Backeb.) Backeb. fma. crassispina F. Ritter, Neoporteria wagenknechtii F. Ritter, Neoporteria wagenknechtii F. Ritter var. microsperma (F. Ritter) A.E. Hoffm., Neoporteria wagenknechtii F. Ritter var. napina F. Ritter, Neoporteria wagenknechtii F. Ritter var. vallenarensis (F. Ritter) A.E. Hoffm., Eriosyce subgibbosa (Haw.) Katt. var. nigrihorrida (Backeb.) Katt., Eriosyce subgibbosa (Haw.) Katt. var. vallenarensis (F. Ritter) Katt., Eriosyce subgibbosa (Haw.) Katt. var. wagenknechtii (F. Ritter) Katt., Eriosyce subgibbosa (Haw.) Katt. subsp. clavata (Söhrens ex K. Schum.) Katt.

Arbusto suculento. Endémico.

Distribución: COQ.

Rango altitudinal: 0-800 m.

Eriosyce subgibbosa (Haw.) Katt. subsp. subgibosa var. castanea (F. Ritter) Katt.

Sinónimos: Neoporteria castanea F. Ritter

Arbusto suculento. Endémico.

Distribución: LBO, MAU.

Eriosyce subgibbosa (Haw.) Katt. subsp. subgibosa var. subgibosa

Sinónimos: Neoporteria subgibosa (Haw.) Britton \& Rose, Neoporteria castanea F. Ritter var. tunensis F. Ritter, Neoporteria litoralis F. Ritter var. intermedia F. Ritter, Neoporteria subgibbosa (Haw.) Britton \& Rose var. 
intermedia (F. Ritter) A.E. Hoffm., Neoporteria subgibbosa (Haw.) Britton \& Rose var. litoralis (F. Ritter) A.E. Hoffm., Neoporteria subgibbosa (Haw.) Britton \& Rose var. orientalis F. Ritter, Eriosyce subgibbosa (Haw.) Katt. var. litoralis (F. Ritter) Katt., Echinocactus subgibbosus Haw., Cereus dichroacanthus Mart. ex Pfeiff., Echinocactus acutissima Otto \& Dietr., Echinocactus castaneoides Cels ex Salm-Dyck, Cactus berteri Colla

Arbusto suculento. Endémico.

Distribución: ATA, COQ, VAL, RME, LBO, MAU, BIO.

Rango altitudinal: 0-500 m.

Eriosyce taltalensis (Hutchison) Katt. subsp. pilispina (F. Ritter) Katt.

Sinónimos: Pyrrhocactus pilispina Ritter, Neoporteria intermedia (F. Ritter) Donald \& G.D. Rowley var. pilispina (F. Ritter) A.E. Hoffm., Neoporteria pilispina (F. Ritter) Donald \& G.D. Rowley

Arbusto suculento. Endémico.

Distribución: ATA.

Rango altitudinal: 0-600 m.

Eriosyce taltalensis (Hutchison) Katt. subsp. pygmaea R. Ferryman

Sinónimos: Pyrrhocactus pygmaeus F. Ritter, Pyrrhocactus gracilis F. Ritter, Pyrrhocactus pulchellus F. Ritter, Neoporteria calderana (F. Ritter) Donald \& G.D. Rowley, Neoporteria intermedia (F. Ritter) Donald \& G.D. Rowley, Neoporteria intermedia (F. Ritter) Donald \& G.D. Rowley fma. gracilis (F. Ritter) A.E. Hoffm., Neoporteria intermedia (F. Ritter) Donald \& G.D. Rowley fma. pygmaea (F. Ritter) A.E. Hoffm., Neoporteria intermedia (F. Ritter) Donald \& G.D. Rowley var. calderana (F. Ritter) A.E. Hoffm., Neoporteria intermedia (F. Ritter) Donald \& G.D. Rowley var. pulchella (F. Ritter) A.E. Hoffm., Neoporteria intermedia (F. Ritter) Donald \& G.D. Rowley var. scoparia (F. Ritter) A.E. Hoffm., Neoporteria scoparia (F. Ritter) Donald \& G.D. Rowley, Neoporteria taltalensis Hutchison var. transiens (F. Ritter) A.E. Hoffm., Eriosyce taltalensis (Hutchison) Katt. var. pygmaea (F. Ritter) Katt.

Subarbusto suculento. Endémico.

Distribución: ANT, ATA.

Rango altitudinal: 0-400 m.

Eriosyce taltalensis (Hutchison) Katt. subsp. taltalensis Sinónimos: Pyrrhocactus taltalensis (Hutchison) F. Ritter, Eriosyce taltalensis (Hutchison) Katt., Pyrrhocactus tenuis F. Ritter, Neoporteria rupicola (F. Ritter) Donald \& G.D. Rowley, Neoporteria taltalensis Hutchison, Neochilenia taltalensis (Hutchison) Backeb., Pyrrhocactus rupiculus F. Ritter

Arbusto suculento. Endémico. Distribución: ANT, ATA.

Rango altitudinal: 500-700 m.
Eriosyce tenebrica (F. Ritter) Katt.

Sinónimos: Neoporteria napina (Phil.) Backeb. var. fankhauseri (F. Ritter) A.E. Hoffm., Thelocephala fankhauseri F. Ritter, Thelocephala tenebrica F. Ritter

Subarbusto suculento. Endémico.

Distribución: ATA, COQ.

Rango altitudinal: 100-600 m.

Eriosyce villosa (Monv.) Katt.

Sinónimos: Neoporteria villosa (Monv.) A. Berger, Neoporteria laniceps F. Ritter, Neoporteria villosa (Monv.) A. Berger var. laniceps (F. Ritter) A.E. Hoffm., Cactus villosus Monv., Neoporteria atrispinosa Backeb., Echinocactus villosus (Monv.) Labour.

Arbusto suculento. Endémico.

Distribución: ATA, COQ.

Rango altitudinal: 0-900 m.

Nombre vulgar: Quisco.

\section{Eulychnia}

Eulychnia acida Phil.

Sinónimos: Eulychnia acida Phil. var. elata F. Ritter, Eulychnia acida Phil. var. procumbens F. Ritter

Árbol suculento. Endémico.

Distribución: ATA, COQ.

Rango altitudinal: 0-1300 m.

Nombre vulgar: Copao.

Eulychnia aricensis F. Ritter

Árbol suculento. Endémico.

Distribución: TAR.

Rango altitudinal: 400-700 m.

Eulychnia breviflora Phil.

Sinónimos: Eulychnia barquitensis F. Ritter, Eulychnia breviflora Phil. var. taltalensis F. Ritter, Eulychnia breviflora Phil. var. tenuis F. Ritter, Eulychnia saint-pieana F. Ritter var. barquitensis (F. Ritter) A.E. Hoffm., Cereus panoplaeatus Monv.

Árbol suculento. Endémico.

Distribución: ANT, ATA, COQ.

Rango altitudinal: $0-200 \mathrm{~m}$.

Nombre vulgar: Copao.

\section{Eulychnia castanea Phil.}

Sinónimos: Cereus castaneus (Phil.) K. Schum., Philippicereus castaneus (Phil.) Backeb.

Arbusto suculento. Endémico.

Distribución: COQ, VAL.

Rango altitudinal: 0-200 m. 
Eulychnia iquiquensis (K. Schum.) Britton \& Rose

Sinónimos: Eulychnia iquiquensis (K. Schum.) Britton \& Rose var. pullilana F. Ritter, Cereus iquiquensis K. Schum., Eulychnia breviflora Phil. subsp. iquiquensis (K. Schum.) D.R. Hunt

Árbol suculento. Endémico.

Distribución: TAR, ANT, ATA.

Rango altitudinal: 0-1000 m.

Nombre vulgar: Copao.

Eulychnia saint-pieana F. Ritter

Árbol suculento. Endémico.

Distribución: ANT, ATA.

Rango altitudinal: 0-700 m.

\section{Haageocereus}

Haageocereus australis Backeb.

Sinónimos: Haageocereus australis Backeb. fma. subtilispinus F. Ritter, Haageocereus multicolorspinus Buining

Arbusto suculento. Nativo.

Distribución: TAR.

Rango altitudinal: 0-500 m.

Países limítrofes: Perú.

Haageocereus fascicularis (Meyen) F. Ritter

Sinónimos: Cereus fascicularis Meyen, Trichocereus fascicularis (Meyen) Britton \& Rose, Weberbauerocereus fascicularis (Meyen) Backeb.

Arbusto suculento. Endémico.

Distribución: AYP, TAR.

Rango altitudinal: 2000-3000 m.

Nombre vulgar: Chikachika.

\section{Maihuenia}

Maihuenia patagonica (Phil.) Britton \& Rose

Sinónimos: Opuntia patagonica Phil.

Subarbusto suculento. Nativo.

Distribución: LLA, AIS, MAG.

Rango altitudinal: 0-500 m.

Países limítrofes: Argentina.

Maihuenia poeppigii (Otto ex Pfeiff.) K. Schum.

Sinónimos: Opuntia poeppigii Otto \& Pfeiff., Maihuenia philippii (F.A.C. Weber) K. Schum., Pereskia philippii F.A.C. Weber, Pereskia poeppigii Salm-Dyck, Opuntia maihuen J. Remy

Subarbusto suculento. Nativo.

Distribución: MAU, NUB, BIO, ARA.

Rango altitudinal: 500-1000 m.

Países limítrofes: Argentina.

Nombre vulgar: Maihuén.

\section{Maihueniopsis}

Maihueniopsis archiconoidea $\mathrm{F}$. Ritter

Sinónimos: Opuntia archiconoidea (F. Ritter) D.R. Hunt

Subarbusto suculento. Endémico.

Distribución: ATA.

Rango altitudinal: 1200-1800 m.

Maihueniopsis atacamensis (Phil.) F. Ritter

Sinónimos: Opuntia atacamensis Phil., Tephrocactus atacamensis (Phil.) F. Ritter

Subarbusto suculento. Endémico.

Distribución: ANT.

Rango altitudinal: $4100 \mathrm{~m}$.

Nombre vulgar: Chuchampe.

Maihueniopsis camachoi (Espinosa) F. Ritter

Sinónimos: Tephrocactus camachoi (Espinosa) Backeb., Opuntia camachoi Espinosa, Tephrocactus chilensis

Backeb.

Subarbusto suculento. Endémico.

Distribución: ANT.

Rango altitudinal: $3900 \mathrm{~m}$.

Nombre vulgar: Kume.

Maihueniopsis colorea (F. Ritter) F. Ritter

Sinónimos: Tephrocactus coloreus F. Ritter, Opuntia colorea (F. Ritter) D.R. Hunt

Subarbusto suculento. Endémico.

Distribución: ATA.

Rango altitudinal: 1300-3500 m.

Maihueniopsis crassispina F. Ritter

Sinónimos: Opuntia crassispina (F. Ritter) D.R. Hunt

Subarbusto suculento. Endémico.

Distribución: ATA.

Rango altitudinal: $200 \mathrm{~m}$.

Maihueniopsis darwinii (Hensl.) F. Ritter

Sinónimos: Opuntia darwinii Hensl., Tephrocactus darwinii

(Hensl.) Backeb. ex Fric

Subarbusto suculento. Nativo.

Distribución: AIS.

Rango altitudinal: 0-500 m.

Países limítrofes: Argentina.

Maihueniopsis domeykoensis F. Ritter

Sinónimos: Opuntia domeykoensis (F. Ritter) D.R. Hunt

Subarbusto suculento. Endémico.

Distribución: ATA.

Rango altitudinal: 0-500 m. 
Maihueniopsis glomerata (Haw.) R. Kiesling

Sinónimos: Opuntia glomerata Haw., Maihueniopsis tarapacana (Phil.) F. Ritter, Tephrocactus glomeratus (Haw.) Backeb., Opuntia conoidea (F. Ritter ex Backeb.) G.D. Rowley, Tephrocactus conoideus F. Ritter ex Backeb., Tephrocactus reicheanus (Espinosa)Backeb., Maihueniopsis conoidea (F. Ritter ex Backeb.) F. Ritter, Opuntia ovallei Gay, Opuntia tarapacana Phil., Tephrocactus tarapacanus (Phil.) Backeb.

Subarbusto suculento. Nativo.

Distribución: ANT, ATA, COQ.

Rango altitudinal: 2000-4000 m.

Países limítrofes: Argentina y Bolivia.

Maihueniopsis grandiflora F. Ritter

Subarbusto suculento. Endémico.

Distribución: COQ.

Rango altitudinal: $1700 \mathrm{~m}$.

Maihueniopsis nigrispina (K. Schum.) R. Kiesling

Sinónimos: Opuntia nigrispina K. Schum., Tephrocactus nigrispinus (K. Schum.) Backb.

Subarbusto suculento. Nativo.

Distribución: TAR.

Rango altitudinal: 2500-3500 m.

Países limítrofes: Argentina y Bolivia.

Maihueniopsis ovata (Pfeiff.) F. Ritter

Sinónimos: Opuntia ovata Pfeiff., Tephrocactus ovatus (Pfeiff.) Backeb.

Subarbusto suculento. Nativo.

Distribución: VAL, RME.

Rango altitudinal: 1000-2000 m.

Países limítrofes: Argentina.

Nombre vulgar: Gatito, perrito.

Maihueniopsis rahmeri (Phil.) F. Ritter

Sinónimos: Opuntia rahmerii Phil.

Subarbusto suculento. Endémico.

Distribución: TAR.

Maihueniopsis wagenknechtii F. Ritter

Sinónimos: Opuntia wagenknechtii (F. Ritter) D.R. Hunt

Subarbusto suculento. Endémico.

Distribución: COQ.

Rango altitudinal: $2000 \mathrm{~m}$.

\section{Miqueliopuntia}

Miqueliopuntia miquelii (Monv.) F. Ritter

Sinónimos: Opuntia miquelii Monv., Cylindropuntia miquelii (Monv.) Backeb., Opuntia geissei Phil., Austrocilindropuntia miquelii (Monv.) Backb.

Arbusto suculento. Endémico.
Distribución: ATA, COQ.

Rango altitudinal: 0-500 m.

\section{Neowerdermannia}

Neowerdermannia chilensis Backeb.

Sinónimos: Weingartia chilensis (Backeb.) Backeb., Sulcorebutia chilensis (Backeb.) F.H. Brandt

Subarbusto suculento. Endémico.

Distribución: AYP, TAR.

Rango altitudinal: 3000-3500 m.

\section{Oreocereus}

Oreocereus hempelianus (Gürke) D.R. Hunt

Sinónimos: Arequipa australis F. Ritter, Arequipa hempeliana (Gürke) Kreuz. \& Buining, Echinopsis hempelianus Gürke, Oreocereus australis (F. Ritter) A.E. Hoffm.

Arbusto suculento. Nativo.

Distribución: AYP.

Rango altitudinal: 2400-3700 m.

Países limítrofes: Perú.

Nombre vulgar: Achacaño.

Oreocereus leucotrichus (Phil.) Wagenkn. ex F. Ritter

Sinónimos: Oreocereus variicolor Backeb., Arequipa leucotricha (Phil.) Britton \& Rose, Echinocactus leucotrichus Phil., Borzicactus leucotrichus (Phil.) Kimnach Arbusto suculento. Nativo.

Distribución: AYP, TAR, ANT.

Rango altitudinal: 2400-3500 m.

Países limítrofes: Perú.

Nombre vulgar: Pichaja, chastudo.

\section{Pterocactus}

Pterocactus australis (F.A.C. Weber) Backeb. Sinónimos: Opuntia australis F.A.C. Weber

Subarbusto suculento. Nativo.

Distribución: AIS.

Rango altitudinal: 0-500 m.

Países limítrofes: Argentina.

Pterocactus hickenii Britton \& Rose

Sinónimos: Opuntia skottsbergii Britton \& Rose, Pterocactus skottsbergii (Britton \& Rose) Backeb.

Subarbusto suculento. Nativo.

Distribución: AIS.

Rango altitudinal: 0-500 m.

Países limítrofes: Argentina. 
Tunilla

Tunilla soehrensii (Britton \& Rose) Hunt \& Iliff

Sinónimos: Platyopuntia chilensis Ritt., Tunilla chilensis (Ritt.) D. Hunt \& J. Iliff, Airampoa chilensis (Ritt.) Doweld. Arbusto suculento. Nativo.

Distribución: TAR.

Rango altitudinal: $3500 \mathrm{~m}$.

Países limítrofes: Argentina, Bolivia y Perú.

\section{CALCEOLARIACEAE}

\section{Calceolaria}

Calceolaria aiseniana Ehrh.

Hierba. Perenne. Endémica.

Distribución: AIS.

Rango altitudinal: 0-500 m.

Calceolaria alba Ruiz \& Pav.

Subarbusto. Endémico.

Distribución: MAU, NUB, BIO, ARA.

Rango altitudinal: 0-1200 m.

Calceolaria andina Benth.

Sinónimos: Calceolaria secunda Witasek

Subarbusto. Endémico.

Distribución: COQ, VAL, RME, LBO, MAU.

Rango altitudinal: 800-3000 m.

Calceolaria angustifolia (Lind1.) Sweet

Sinónimos: Calceolaria berteri Colla, Calceolaria salicariifolia Phil., Calceolaria integrifolia L. var. angustifolia Lindl.

Arbusto o subarbusto. Endémico.

Distribución: VAL, RME, LBO, MAU.

Rango altitudinal: 0-2600 m.

Calceolaria arachnoidea Graham subsp. arachnoidea

Hierba. Perenne. Endémica.

Distribución: RME, LBO, MAU.

Rango altitudinal: 1900-2600 m.

Nombre vulgar: Relbún de la cordillera.

Calceolaria arachnoidea Graham subsp. nubigena (Poepp.) C. Ehrh.

Sinónimos: Calceolaria nubigena Poepp., Calceolaria arachnoidea Graham var. lanata Meyen ex Walp. \& Schauer, Calceolaria arachnoidea Graham var. viridis Benth.

Hierba. Perenne. Endémica.

Distribución: ATA, COQ, VAL, RME, LBO, MAU.

Rango altitudinal: 2000-3000 m.
Nombre vulgar: Relbún de la cordillera.

Calceolaria ascendens Lindl. subsp. ascendens

Sinónimos: Calceolaria uspallatensis Kraenzl.

Subarbusto. Endémico.

Distribución: COQ, VAL, RME.

Rango altitudinal: 0-1900 m.

Calceolaria ascendens Lindl. subsp. exigua (Witasek) Nic. García

Sinónimos: Calceolaria exigua Witasek, Calceolaria miserrima Kraenzl., Calceolaria parvifolia Phil., nom. illeg.

Subarbusto. Endémico.

Distribución: VAL, RME.

Rango altitudinal: 1600-2100 m.

Calceolaria ascendens Lindl. subsp. glandulifera (Witasek) C. Ehrh.

Sinónimos: Calceolaria bipartita Phil., Calceolaria glandulifera Witasek

Subarbusto. Endémico.

Distribución: COQ, VAL, RME, LBO, MAU.

Rango altitudinal: 800-2000 m.

Calceolaria ascendens Lindl. subsp. pristiphylla (Phil.) C. Ehrh.

Sinónimos: Calceolaria pristiphylla Phil., Calceolaria ascendens Lindl. var. pristiphylla (Phil.) Kraenzl.

Subarbusto. Endémico.

Distribución: COQ, RME.

Rango altitudinal: 500-1800 m.

\section{Calceolaria asperula Phil.}

Hierba. Perenne. Endémica.

Distribución: RME, LBO.

Rango altitudinal: 900-2000 m.

Calceolaria auriculata Phil.

Subarbusto. Endémico.

Distribución: LBO, MAU.

Rango altitudinal: $200 \mathrm{~m}$.

Calceolaria biflora Lam.

Sinónimos: Calceolaria plantaginea Sm., Calceolaria falklandica (S. Moore) Kraenzl., Fagelia falklandica S. Moore

Hierba. Perenne. Nativa.

Distribución: RME, MAU, NUB, BIO, ARA, LRI, LLA, AIS, MAG.

Rango altitudinal: 0-1000 m.

Países limítrofes: Argentina. 
Calceolaria caleuana Muñoz-Schick \& Moreira

Hierba. Perenne. Endémica.

Distribución: VAL, RME.

Rango altitudinal: 2100-2300 m.

Calceolaria campanae Phil.

Sinónimos: Calceolaria gnaphaliifolia Kraenzl.

Hierba. Perenne. Endémica.

Distribución: VAL.

Rango altitudinal: 1500-2000 m.

\section{Calceolaria cana Cav.}

Hierba. Perenne. Endémica.

Distribución: COQ, VAL, RME, LBO, MAU, NUB, BIO, ARA.

Rango altitudinal: 600-2500 m.

Calceolaria cavanillesii Phil.

Sinónimos: Calceolaria recta Witasek

Hierba. Perenne. Nativa.

Distribución: MAU, NUB, BIO, ARA.

Rango altitudinal: 500-2100 m.

Países limítrofes: Argentina.

Calceolaria collina Phil. subsp. collina

Sinónimos: Calceolaria coquimbensis (Benth.) Kraenzl., Calceolaria ascendens Lindl. var. coquimbensis Benth.

Arbusto o subarbusto. Endémico.

Distribución: ATA, COQ.

Rango altitudinal: 0-500 m.

Calceolaria collina Phil. subsp. conferta (Witasek) C. Ehrh.

Sinónimos: Calceolaria conferta Witasek, Calceolaria fulva Witasek fma. viscosa Witasek

Arbusto o subarbusto. Endémico.

Distribución: COQ.

Rango altitudinal: 400-1600 m.

Calceolaria collina Phil. subsp. subincisa (Benth.) C. Ehrh. Sinónimos: Calceolaria abscondita Witasek, Calceolaria dentata Ruiz \& Pav. var. subincisa Benth., Calceolaria quadriradiata Phil.

Arbusto o subarbusto. Endémico.

Distribución: ATA, COQ.

Rango altitudinal: 200-800 m.

Calceolaria corymbosa Ruiz \& Pav. subsp. corymbosa

Sinónimos: Calceolaria herbertiana Lindl., Calceolaria cordata Phil., Calceolaria herbertiana Lindl. var. parviflora Lindl.

Subarbusto. Endémico.

Distribución: COQ, VAL, RME, LBO, MAU, NUB, BIO, ARA, LLA.
Rango altitudinal: 0-1300 m.

Nombre vulgar: Arguenita del cerro.

Calceolaria corymbosa Ruiz \& Pav. subsp. floccosa (Witasek) C. Ehrh.

Sinónimos: Calceolaria floccosa Witasek

Hierba. Perenne. Nativa.

Distribución: MAU.

Rango altitudinal: 2200-2700 m.

Países limítrofes: Argentina.

Calceolaria corymbosa Ruiz \& Pav. subsp. mimuloides (Clos) C. Ehrh.

Sinónimos: Calceolaria mimuloides Clos, Calceolaria oligantha Phil.

Hierba. Perenne. Endémica.

Distribución: COQ, VAL, RME.

Rango altitudinal: 2200-3500 m.

Calceolaria corymbosa Ruiz \& Pav. subsp. montana (Cav.)

C. Ehrh.

Sinónimos: Calceolaria montana Cav., Calceolaria villosa

Phil.

Hierba. Perenne. Endémica.

Distribución: LBO, MAU.

Rango altitudinal: 2200-3100 m.

Calceolaria corymbosa Ruiz \& Pav. subsp. santiagina C.

Ehrh.

Hierba. Perenne. Endémica.

Distribución: VAL, RME, LBO.

Rango altitudinal: $700-2300 \mathrm{~m}$.

Calceolaria corymbosa Ruiz \& Pav. subsp. tetraphylla (Phil.) C. Ehrh.

Sinónimos: Calceolaria tetraphylla Phil.

Hierba. Perenne. Endémica.

Distribución: NUB, BIO, ARA.

Rango altitudinal: $700-1600 \mathrm{~m}$.

Calceolaria crenatiflora Cav.

Sinónimos: Calceolaria hollermayeri Kraenzl., Calceolaria cunninghamii Vatke, Calceolaria pendula Sweet

Hierba. Perenne. Nativa.

Distribución: LBO, ARA, LRI, LLA, AIS.

Rango altitudinal: 0-1000 m.

Países limítrofes: Argentina.

Calceolaria densifolia Phil. subsp. densifolia

Subarbusto. Endémico.

Distribución: COQ, VAL.

Rango altitudinal: 1200-1300 m. 
Calceolaria densifolia Phil. subsp. laxa C. Ehrh.

Subarbusto. Endémico.

Distribución: VAL, RME.

Rango altitudinal: 1300-1700 m.

Calceolaria dentata Ruiz \& Pav. subsp. araucana (Phil.)

C. Ehrh.

Sinónimos: Calceolaria araucana Phil.

Hierba. Perenne. Nativa.

Distribución: BIO, ARA, LLA.

Rango altitudinal: 200-1000 m.

Países limítrofes: Argentina.

Calceolaria dentata Ruiz \& Pav. subsp. cumingiana (Witasek) C. Ehrh.

Sinónimos: Calceolaria dentata Ruiz \& Pav. var. cumingiana (Witasek) Reiche, Calceolaria cummingiana Witasek

Arbusto o subarbusto. Endémico.

Distribución: LBO, MAU.

Rango altitudinal: 0-600 m.

Calceolaria dentata Ruiz \& Pav. subsp. dentata

Sinónimos: Calceolaria dentata Ruiz \& Pav. var. compacta (Phil.) Reiche, Calceolaria laetevirens Kraenzl., Calceolaria compacta Phil., Calceolaria chiloensis Lindl., Calceolaria ascendens Lindl. var. chiloensis (Lindl.) Kraenzl.

Arbusto o subarbusto. Nativo.

Distribución: VAL, RME, LBO, MAU, NUB, BIO, ARA, LRI, LLA.

Rango altitudinal: 0-2000 m.

Países limítrofes: Argentina.

\section{Calceolaria filicaulis Clos subsp. filicaulis}

Sinónimos: Calceolaria flabellifolia Kraenzl., Calceolaria palenae Phil.

Hierba. Perenne. Nativa.

Distribución: RME, MAU, NUB, BIO, ARA, LRI.

Rango altitudinal: 1400-2700 m.

Países limítrofes: Argentina.

Calceolaria filicaulis Clos subsp. luxurians (Witasek) C. Ehrh.

Sinónimos: Calceolaria luxurians Witasek, Calceolaria cana Cav. var. pannosa (Phil.) Reiche, Calceolaria pannosa Phil.

Hierba. Perenne. Nativa.

Distribución: ATA, COQ, VAL, RME, LBO, MAU.

Rango altitudinal: 2200-3100 m.

Países limítrofes: Argentina.

Calceolaria flavovirens C. Ehrh.

Arbusto o subarbusto. Endémico.

Distribución: ATA, COQ.
Rango altitudinal: 2200-3000 m.

Calceolaria georgiana F. Phil.

Arbusto o subarbusto. Endémico.

Distribución: COQ.

Rango altitudinal: 400-700 m.

Calceolaria germainii Witasek

Hierba. Perenne. Nativa.

Distribución: MAU.

Rango altitudinal: 600-2000 m.

Países limítrofes: Argentina.

Calceolaria glandulosa Poepp. ex Benth. subsp. alicahuensis (Muñoz-Schick) C. Ehrh.

Sinónimos: Calceolaria alicahuensis Muñoz-Schick, Calceolaria dumetorum Phil., Calceolaria glutinosa

Meigen, nom. illeg.

Hierba. Perenne. Endémica.

Distribución: COQ, VAL.

Rango altitudinal: $700-2100 \mathrm{~m}$.

Calceolaria glandulosa Poepp. ex Benth. subsp. glandulosa Sinónimos: Calceolaria kingii Phil., Calceolaria atrovirens Witasek

Hierba. Perenne. Endémica.

Distribución: ATA, COQ, VAL, RME, LBO, MAU.

Rango altitudinal: 0-1500 m.

Calceolaria hypericina Poepp. ex Benth.

Arbusto o subarbusto. Endémico.

Distribución: COQ, VAL, RME, LBO.

Rango altitudinal: 1800-3000 m.

Calceolaria inamoena Kraenzl.

Sinónimos: Calceolaria aberrans Kraenzl.

Arbusto o subarbusto. Nativo.

Distribución: AYP, TAR.

Rango altitudinal: 3500-3800 m.

Países limítrofes: Perú.

Nombre vulgar: Kukumelo.

Calceolaria integrifolia $\mathrm{L}$.

Sinónimos: Calceolaria rugosa Ruiz \& Pav.

Arbusto o subarbusto. Nativo.

Distribución: COQ, VAL, RME, LBO, MAU, NUB, BIO,

ARA, LRI, LLA.

Rango altitudinal: 0-1500 m.

Países limítrofes: Argentina.

Calceolaria lanigera Phil.

Hierba. Perenne. Endémica.

Distribución: LBO, MAU.

Rango altitudinal: 900-1500 m. 
Calceolaria latifolia Benth.

Sinónimos: Calceolaria latifolia Benth. var. longepetiolata (Phil.) Reiche, Calceolaria longepetiolata Phil., Calceolaria stachydifolia Phil.

Hierba. Perenne. Endémica.

Distribución: COQ, VAL, LBO.

Rango altitudinal: 500-1100 m.

\section{Calceolaria lepida Phil.}

Subarbusto. Endémico.

Distribución: ATA, COQ, VAL, RME.

Rango altitudinal: $1800 \mathrm{~m}$.

Calceolaria meyeniana Phil. subsp. cheiranthoides (Witasek) C. Ehrh.

Sinónimos: Calceolaria cheiranthoides Reiche ex Witasek Arbusto o subarbusto. Endémico.

Distribución: MAU.

Rango altitudinal: $500 \mathrm{~m}$.

Calceolaria meyeniana Phil. subsp. glabrata (Phil.) C. Ehrh. Sinónimos: Calceolaria glabrata Phil.

Arbusto o subarbusto. Endémico.

Distribución: MAU, NUB, BIO.

Rango altitudinal: 1000-2000 m.

Calceolaria meyeniana Phil. subsp. meyeniana

Sinónimos: Calceolaria glabrata Phil. var. meyeniana (Phil.) Reiche, Calceolaria landbecki Phil., Calceolaria andicola Witasek, Calceolaria crocea Phil.

Arbusto o subarbusto. Endémico.

Distribución: VAL, RME, LBO, MAU, ARA.

Rango altitudinal: 600-2300 m.

Calceolaria meyeniana Phil. subsp. nahuelbutae (Phil.) C. Ehrh.

Sinónimos: Calceolaria vernicosa Phil., Calceolaria nahuelbutae Phil.

Arbusto o subarbusto. Endémico.

Distribución: BIO, ARA.

Rango altitudinal: 800-1300 m.

Calceolaria morisii Walp.

Sinónimos: Calceolaria polyphylla Kraenzl., Calceolaria hypoleuca Kuntze, nom. nud., Calceolaria wettsteiniana Witasek, Calceolaria salviaefolia Colla, nom. illeg.

Arbusto o subarbusto. Endémico.

Distribución: COQ, VAL, RME, MAU.

Rango altitudinal: 0-500 m.

\section{Calceolaria nitida Colla}

Sinónimos: Calceolaria pseudoglandulosa Clos

Subarbusto. Endémico.

Distribución: RME, LBO, MAU.
Rango altitudinal: 400-500 m.

Calceolaria nudicaulis Benth.

Sinónimos: Calceolaria pratensis Phil.

Hierba. Perenne. Endémica.

Distribución: VAL, RME, LBO.

Rango altitudinal: 500-1800 m.

Nombre vulgar: Topatopa.

Calceolaria pallida Phil.

Arbusto o subarbusto. Endémico.

Distribución: LBO, MAU.

Rango altitudinal: 1600-2200 m.

Calceolaria paposana Phil.

Subarbusto. Endémico.

Distribución: ANT, ATA, COQ.

Rango altitudinal: 200-600 m.

Calceolaria paralia Cav.

Hierba. Perenne. Endémica.

Distribución: LBO, MAU.

Rango altitudinal: 600-2300 m.

Calceolaria petioalaris Cav.

Sinónimos: Calceolaria petioalaris Cav. var. cuspidata (Phil.) Reiche, Calceolaria cuspidata Phil., Calceolaria effusa Phil., Calceolaria connata Hook. ex Graham, Calceolaria petioalaris Cav. var. oblongifolia Clos, Calceolaria petioalaris Cav. var. latifolia Clos

Hierba. Perenne. Endémica.

Distribución: ATA, COQ, VAL, RME, LBO, MAU.

Rango altitudinal: 0-1800 m.

Calceolaria philippii Eyz.

Subarbusto. Endémico.

Distribución: RME, LBO.

Rango altitudinal: $1300 \mathrm{~m}$.

Calceolaria picta Phil.

Hierba. Perenne. Endémica.

Distribución: COQ.

Rango altitudinal: 0-500 m.

Calceolaria pinifolia Cav.

Hierba. Perenne. Nativa.

Distribución: ATA, COQ, VAL.

Rango altitudinal: 2600-4300 m.

Países limítrofes: Argentina.

Calceolaria pinnata $\mathrm{L}$.

Sinónimos: Calceolaria bipinnatifida Phil.

Hierba. Anual. Nativa.

Distribución: ANT. 
Rango altitudinal: 0-500 m.

Países limítrofes: Bolivia y Perú.

Calceolaria poikilanthes Sandwith

Hierba. Perenne. Nativa.

Distribución: ARA.

Rango altitudinal: 1300-2000 m.

Países limítrofes: Argentina.

Calceolaria polifolia Hook.

Sinónimos: Calceolaria spatellifolia Kraenzl.

Arbusto o subarbusto. Endémico.

Distribución: COQ, VAL, RME, LBO.

Rango altitudinal: 0-2300 m.

Nombre vulgar: Té de burro.

\section{Calceolaria polyrrhiza Cav.}

Sinónimos: Calceolaria lanceolata Cav., Calceolaria prichardii (Rendle) Kraenzl., Fagelia prichardii Rendle, Calceolaria acutifolia Witasek, Calceolaria chubutensis Skottsb., Calceolaria mendocina Phil., Calceolaria cymbiflora Sandwith, Calceolaria lanceolata Cav. var. acutifolia (Witasek) Reiche, Calceolaria lanceolata Cav. var. pusilla (Witasek) Reiche, Calceolaria pusilla Witasek, Calceolaria lanceolata Cav. fma. acutifolia (Witasek) W. Bowden, Calceolaria patagonica Kraenzl.

Hierba. Perenne. Nativa.

Distribución: MAU, NUB, BIO, ARA, AIS, MAG.

Rango altitudinal: 500-2000 m.

Países limítrofes: Argentina.

Calceolaria purpurea Graham

Hierba. Perenne. Endémica.

Distribución: VAL, RME, LBO, MAU.

Rango altitudinal: 900-2300 m.

Calceolaria rinconada Ehrh.

Subarbusto. Endémico.

Distribución: ANT.

Rango altitudinal: 200-600 m.

Calceolaria rubiginosa C. Ehrh.

Subarbusto. Endémico.

Distribución: COQ, VAL.

Rango altitudinal: 400-700 m.

\section{Calceolaria segethii Phil.}

Subarbusto. Endémico.

Distribución: COQ, VAL, RME.

Rango altitudinal: 800-2200 m.

Calceolaria spathulata Witasek

Hierba. Perenne. Endémica.

Distribución: BIO, ARA.
Rango altitudinal: 1900-2000 m.

Calceolaria stellariifolia Phil.

Sinónimos: Calceolaria rupicola F. Meigen

Subarbusto. Endémico.

Distribución: AYP, TAR, ANT, RME.

Rango altitudinal: 2700-4300 m.

Nombre vulgar: Zapatilla, willjaya.

Calceolaria talcana Grau \& Ehr. Bayer

Arbusto o subarbusto. Endémico.

Distribución: LBO, MAU, NUB, BIO, ARA.

Rango altitudinal: 500-1300 m.

Calceolaria tenella Poepp. \& Endl.

Sinónimos: Calceolaria skottsbergii Gand.

Hierba. Perenne. Nativa.

Distribución: NUB, BIO, ARA, LRI, LLA, AIS, MAG.

Rango altitudinal: 0-1500 m.

Países limítrofes: Argentina.

\section{Calceolaria thyrsiflora Graham}

Sinónimos: Calceolaria thyrsiflora Graham var. alliacea

Phil., Calceolaria bridgesii Kunze

Arbusto o subarbusto. Endémico.

Distribución: VAL, RME, LBO, MAU, BIO.

Rango altitudinal: 0-2000 m.

Nombre vulgar: Hierba dulce, palqui, palo dulce.

Calceolaria tripartita Ruiz \& Pav.

Hierba. Anual. Nativa.

Distribución: COQ, VAL.

Rango altitudinal: 0-3900 m.

Países limítrofes: Argentina y Perú.

Calceolaria undulata Benth.

Sinónimos: Calceolaria foliosa Phil., Calceolaria brevistyla

Clos

Arbusto o subarbusto. Nativo.

Distribución: MAU, BIO.

Rango altitudinal: 1300-2200 m.

Países limítrofes: Argentina.

Calceolaria uniflora Lam.

Sinónimos: Calceolaria nana Sm., Calceolaria darwinii Benth., Calceolaria uniflora Lam. var. darwinii (Kuntze) Witasek ex Reiche, Fagelia darwinii Kuntze, Calceolaria minima Witasek

Hierba. Perenne. Nativa.

Distribución: RME, AIS, MAG.

Rango altitudinal: 0-500 m.

Países limítrofes: Argentina. 
Calceolaria valdiviana Phil. subsp. crassifolia (Phil.) C. Ehrh.

Sinónimos: Calceolaria crassifolia Phil.

Hierba. Perenne. Endémica.

Distribución: BIO, ARA, LRI.

Rango altitudinal: 0-500 m.

Calceolaria valdiviana Phil. subsp. valdiviana

Sinónimos: Calceolaria llaimae Kraenzl., Calceolaria plantaginea Sm. var. obtusifolia Clos, Calceolaria obtusifolia (Clos) Witasek, Calceolaria tenera Phil., Calceolaria werdermannii Kraenzl., Calceolaria tenerifolia Phil.

Hierba. Perenne. Nativa. Distribución: MAU, NUB, BIO, ARA, LRI.

Rango altitudinal: 600-1800 m.

Países limítrofes: Argentina.

Calceolaria verbascifolia Bertero ex Phil.

Sinónimos: Calceolaria borchersi Phil., Calceolaria oreas Phil.

Arbusto o subarbusto. Endémico.

Distribución: VAL, LBO.

Rango altitudinal: 500-1300 m.

Calceolaria viscosissima (Hook.) Lindl.

Sinónimos: Calceolaria pubescens Phil., Calceolaria robusta A. Dietr., Calceolaria integrifolia L. var. viscosissima Hook., Calceolaria gmelinii Phil.

Subarbusto. Endémico.

Distribución: COQ, VAL, LBO.

Rango altitudinal: 0-500 m.

Calceolaria volckmannii Phil.

Sinónimos: Calceolaria benthami Phil., Calceolaria bigemina Phil., Calceolaria poeppigiana Phil.

Hierba. Perenne. Nativa.

Distribución: MAU, NUB, BIO.

Rango altitudinal: 1000-2500 m.

Países limítrofes: Argentina.

Calceolaria williamsii Phil.

Hierba. Perenne. Endémica.

Distribución: MAU, BIO.

Rango altitudinal: 2400-2700 m.

\section{Jovellana}

Jovellana guentheri Kraenzl.

Hierba. Perenne. Endémica.

Distribución: LLA.

Rango altitudinal: 0-500 m.
Jovellana punctata Ruiz \& Pav.

Sinónimos: Calceolaria puncticulata Phil.

Arbusto. Endémico.

Distribución: VAL, RME, MAU, NUB, BIO, ARA, LRI.

Rango altitudinal: 0-2000 m.

Jovellana violacea (Cav.) G. Don

Sinónimos: Calceolaria violacea Cav.

Arbusto. Endémico.

Distribución: MAU, NUB, BIO, ARA, LRI.

Rango altitudinal: 0-600 m.

\section{CALYCERACEAE}

\section{Boopis}

Boopis australis Decne.

Sinónimos: Acarpha australis (Decne.) Griseb.

Hierba. Perenne. Nativa.

Distribución: AIS, MAG.

Rango altitudinal: 0-1000 m.

Países limítrofes: Argentina.

Boopis filifolia Speg.

Sinónimos: Boopis prichardii S. Moore

Hierba. Perenne. Nativa.

Distribución: MAG.

Rango altitudinal: 0-1000 m.

Países limítrofes: Argentina.

Boopis gracilis Phil.

Sinónimos: Boopis pozoaeformis Phil., Boopis gracilis

Phil. var. decumbens Chodat \& Wilczek, Boopis gracilis

Phil. var. pozoaeformis (Phil.) Hicken, Boopis bicolor Phil.

Hierba. Anual. Nativa.

Distribución: RME, MAU.

Rango altitudinal: 0-2000 m.

Países limítrofes: Argentina.

Boopis graminea Phil.

Hierba. Perenne. Nativa.

Distribución: MAU, NUB, BIO, ARA.

Rango altitudinal: 1500-2000 m.

Países limítrofes: Argentina.

Boopis multicaulis Phil.

Hierba. Perenne. Nativa.

Distribución: MAU, ARA.

Países limítrofes: Argentina.

Boopis patagonica Speg.

Hierba. Perenne. Nativa.

Distribución: MAG. 
Rango altitudinal: 0-1000 m.

Países limítrofes: Argentina.

Boopis pusilla Phil.

Hierba. Anual. Endémica.

Distribución: RME.

Rango altitudinal: $1600 \mathrm{~m}$.

\section{Calycera}

Calycera eryngioides J. Remy

Sinónimos: Anomocarpus eryngioides (J. Remy) Miers

Hierba. Anual. Endémica.

Distribución: COQ, RME, LBO.

Rango altitudinal: 1500-2500 m.

Nombre vulgar: Repollito de cordillera.

\section{Calycera herbacea Cav. var. herbacea}

Sinónimos: Calycera herbacea Cav. var. viridiflora (Phil.) Pontiroli, Calycera viridiflora (Phil.) Miers, Calycera nudicaulis Phil., Boopis viridiflora Miers, Chodat \& Hassl., Calycera viridiflora (Phil.) Miers fma. squarrosa (Miers) Hicken, Gymnocaulus viridiflorus Phil., Boopis australis Decne. var. squarrosa (Miers) Reiche, Boopis squarrosa Miers

Hierba. Perenne. Nativa.

Distribución: COQ, VAL, RME, MAU, ARA.

Rango altitudinal: 2200-3000 m.

Países limítrofes: Argentina.

Calycera herbacea Cav. var. sinuata (Miers) Pontiroli Sinónimos: Calycera sinuata Miers, Calycera viridiflora (Phil.) Miers fma. sinuata (Miers) Hicken, Calycera intermedia Phil., Calycera involucrata Phil., Calycera crenata R.E. Fr.

Hierba. Perenne. Nativa.

Distribución: ANT.

Rango altitudinal: 2500-4900 m.

Países limítrofes: Argentina.

Calycera leucanthema (Poepp. ex Less.) Kuntze

Sinónimos: Calycera integrifolia (Phil.) Reiche, Boopis integrifolia Phil., Boopis leucanthema Poepp. ex Less., Acicarpha lanata Lag., Anomocarpus leucanthemus (Poepp. ex Less.) Miers, Anomocarpus tenuifolius Miers, Anomocarpus tenuis Miers, Leucocera annua Turcz., Calycera lanata Benth. \& Hook.f.

Hierba. Anual. Endémica.

Distribución: LBO, MAU, NUB, BIO, ARA, LLA.

Rango altitudinal: 300-700 m.

Calycera sessiliflora Phil.

Sinónimos: Calycera sessiliflora Phil. var. axillaris (Miers) Reiche, Anomocarpus axillaris Miers, Anomocarpus subsessiliflorus Miers, nom. illeg.

Hierba. Anual. Endémica.

Distribución: COQ, VAL, RME.

Rango altitudinal: 700-1900 m.

Calycera sympaganthera (Ruiz \& Pav.) Kuntze

Sinónimos: Calycera balsamitaefolia (Juss.) Rich., nom. illeg., Calycera sympaganthera (Ruiz \& Pav.) Martic. \& Quezada, comb. illeg., Scabiosa sympaganthera Ruiz \& Pav., Boopis balsamitaefolia Juss., nom. illeg.

Hierba. Perenne. Endémica.

Distribución: BIO, ARA.

Rango altitudinal: $1300 \mathrm{~m}$.

\section{Gamocarpha}

Gamocarpha alpina (Poepp. ex Less.) H.V. Hansen

Sinónimos: Boopis alpina Poepp. ex Less., Gamocarpha poeppigii DC. var. angustifolia (Phil.) Reiche, Boopis angustifolia Phil., Gamocarpha ligulata Miers

Hierba. Perenne. Nativa.

Distribución: LBO, MAU, NUB, BIO, ARA.

Rango altitudinal: 1500-3000 m.

Países limítrofes: Argentina.

Gamocarpha dentata Phil.

Hierba. Perenne. Nativa.

Distribución: BIO, ARA.

Rango altitudinal: $1500-2500 \mathrm{~m}$.

Países limítrofes: Argentina.

Gamocarpha gilliesii Miers

Sinónimos: Gamocarpha breviscapa Phil., Boopis gilliesi

(Miers) Hauman, Boopis breviscapa Phil.

Hierba. Perenne. Nativa.

Distribución: TAR, VAL, LBO.

Rango altitudinal: 200-2500 m.

Países limítrofes: Argentina.

Gamocarpha polycephala Phil.

Hierba. Perenne. Endémica.

Distribución: NUB.

Gamocarpha pumila Miers

Hierba. Perenne. Endémica.

Distribución: MAU.

Gamocarpha selliana Reiche

Sinónimos: Gamocarpha patagonica Speg., Gamocarpha selliana Reiche var. multicaulis Dusén

Hierba. Perenne. Nativa.

Distribución: LLA, AIS, MAG.

Rango altitudinal: 500-1500 m.

Países limítrofes: Argentina. 


\section{Moschopsis}

Moschopsis leyboldii Phil.

Hierba. Perenne. Nativa.

Distribución: RME.

Rango altitudinal: 3000-4500 m.

Países limítrofes: Argentina.

Moschopsis monocephala (Phil.) Reiche

Sinónimos: Boopis monocephala Phil.

Hierba. Anual. Nativa.

Distribución: AYP, TAR, ANT, ATA.

Rango altitudinal: 4000-5000 m.

Países limítrofes: Argentina, Bolivia y Perú.

Nombre vulgar: Waje, anukaylla.

Moschopsis rosulata (N.E. Br.) Dusén

Sinónimos: Acicarpha rosulata N.E. Br., Moschopsis spathulata Dusén, Gamocarpha rosulata (N.E. Br.) Skottsb.

Hierba. Perenne. Nativa.

Distribución: MAG.

Rango altitudinal: 700-2500 m.

Países limítrofes: Argentina.

Moschopsis subandina (Speg.) Dusén

Sinónimos: Gamocarpha subandina Speg.

Hierba. Perenne. Nativa.

Distribución: ARA, LRI.

Rango altitudinal: 1500-2500 m.

Países limítrofes: Argentina.

Moschopsis trilobata Dusén

Hierba. Perenne. Nativa.

Distribución: MAG.

Rango altitudinal: 500-1500 m.

Países limítrofes: Argentina.

\section{Nastanthus}

Nastanthus caespitosus (Phil.) Reiche

Sinónimos: Boopis caespitosa Phil.

Hierba. Perenne. Endémica.

Distribución: ANT, ATA, MAU.

Rango altitudinal: 500-4300 m.

Nombre vulgar: Chicorea.

Nastanthus compactus (Phil.) Miers

Sinónimos: Nastanthus diazi (Phil.) Phil. ex Reiche, Boopis

diazi Phil., Boopis compacta Phil.

Hierba. Bienal. Nativa.

Distribución: ANT, ATA, COQ, RME, MAU.

Rango altitudinal: 3000-3700 m.

Países limítrofes: Argentina.
Nastanthus scapigerus (J. Remy) Miers

Sinónimos: Nastanthus laciniatus Miers, Boopis laciniata (Miers) Ball, Boopis scapigera J. Remy, Boopis miersii Phil., Nastanthus spathulatus (Phil.) Miers var. spathulatus, Boopis spathulata Phil., Boopis bellidifolia Phil., Nastanthus bellidifolius (Phil.) Reiche, Boopis dubia Phil., Boopis reichei Phil., Boopis araucana Phil., Nastanthus araucanus (Phil.) Reiche, Nastanthus scapiger Miers

Hierba. Perenne. Nativa.

Distribución: VAL, RME, LBO, MAU, NUB, BIO, MAG.

Rango altitudinal: 500-3000 m.

Países limítrofes: Argentina.

Nastanthus ventosus (Meyen) Miers

Sinónimos: Calycera andina Miers, nom. nud., Nastanthus agglomeratus Miers var. pinnatifidus (Miers) Reiche, Nastanthus pinnatifidus Miers, Nastanthus agglomeratus Miers var. laciniatus (Miers) Reiche, Calycera ventosa Meyen, Boopis ventosa (Meyen) Kuntze, Boopis scapigera J. Remy var. ventosus (Meyen) Wedd., Nastanthus caespitosus (Phil.) Reiche var. ventosus (Meyen) Pontiroli, Nastanthus agglomeratus Miers var. agglomeratus, Nastanthus agglomeratus Miers var. breviflorus (Phil.) Reiche, Nastanthus agglomeratus Miers var. gayanus (Phil.) Reiche, Nastanthus agglomeratus Miers var. gilliesii (Miers) Reiche, Boopis breviflora Phil., Boopis gayana Phil., Nastanthus gilliesii Miers, Nastanthus gayanus (Phil.) Miers

Hierba. Perenne. Nativa.

Distribución: COQ, VAL, RME, MAU, BIO.

Rango altitudinal: 1500-3200 m.

Países limítrofes: Argentina.

\section{CAMPANULACEAE}

\section{Campanula}

Campanula rapunculoides $\mathrm{L}$.

Hierba. Perenne. Introducida.

Distribución: JFE.

\section{Cyphocarpus}

Cyphocarpus innocuus Sandwith

Hierba. Anual. Endémica.

Distribución: COQ.

Rango altitudinal: $1000 \mathrm{~m}$.

Cyphocarpus psammophilus Ricardi

Hierba. Anual. Endémica.

Distribución: ATA, COQ.

Rango altitudinal: $800 \mathrm{~m}$. 
Cyphocarpus rigescens Miers

Sinónimos: Cyphocarpus rigescens Miers fma. glabratus Phil. ex E. Wimm.

Hierba. Anual. Endémica.

Distribución: ATA, COQ.

Rango altitudinal: 500-1000 m.

Nombre vulgar: Pata de pajarito.

\section{Downingia}

Downingia pusilla (G. Don ex A. DC.) Torr.

Sinónimos: Bolelia humilis Greene, Clintonia pusilla G. Don ex A. DC., Downingia humilis (Greene) Greene, Lobelia pusilla Poepp., Bolelia pusilla (Poepp.) Greene

Hierba. Anual. Nativa.

Distribución: COQ, VAL, RME, LBO, MAU, NUB, BIO, ARA.

Rango altitudinal: 0-3200 m.

Países limítrofes: Argentina.

\section{Legenere}

Legenere valdiviana (Phil.) E. Wimm.

Sinónimos: Howellia limosa Greene, Howellia valdiviana (Phil.) E. Wimm., Legenere limosa (Greene) McVaugh, Lobelia valdiviana (Phil.) Vatke, Mezleria valdiviana Phil., Dortmannia valdiviana (Phil.) Kuntze

Hierba. Anual. Nativa.

Distribución: LLA.

Rango altitudinal: 0-200 m.

Países limítrofes: Argentina.

\section{Lobelia}

Lobelia anceps L.f.

Hierba. Anual. Introducida.

Distribución: ANT, VAL, RME, LBO, MAU, NUB, BIO, ARA, LRI, LLA, JFE.

Lobelia bridgesii Hook. \& Arn.

Sinónimos: Tupa bridgesii (Hook. \& Arn.) A. DC., Rapuntium bridgesii (Hook. \& Arn.) C. Presl, Dortmanna bridgesii (Hook. \& Arn.) Kuntze, Lobelia blanda (D. Don) Heynh., Tupa blanda D. Don, Rapuntium blandum (D. Don) C. Presl, Rapuntium lucaeanum C. Presl, Lobelia lucaeana (C. Presl) A. DC., Dortmanna blanda (D. Don) Kuntze, Dortmanna lucaeana (C. Presl) Kuntze

Subarbusto. Endémica.

Distribución: LRI.

Rango altitudinal: 0-200 m.

Nombre vulgar: Tupa rosada.
Lobelia excelsa Bonpl.

Sinónimos: Lobelia salicifolia Sweet, Tupa salicifolia (Sweet) G. Don, Tupa glaucescens Phil., Rapuntium excelsum (Bonpl.) C. Presl, Dortmanna excelsa (Bonpl.) Kuntze, Lobelia gigantea auct. non Cav., Lobelia arguta Lindl., Tupa arguta (Lindl.) G. Don, Dortmanna arguta (Lindl.) Kuntze, Lobelia neriifolia Moris, Tupa kingi Phil. Arbusto. Endémico.

Distribución: COQ, VAL, RME, LBO, MAU.

Rango altitudinal: 0-1200 m.

Nombre vulgar: Tupa.

Lobelia oligophylla (Wedd.) Lammers

Sinónimos: Pratia repens Gaudich., Hypsela reniformis (Kunth) C. Presl, Pratia longiflora Hook.f., Hypsela oligophylla (Wedd.) Benth. \& Hook.f. ex Zahlbr., Lobelia pratiana Gaudich. ex Lammers, Lysipomia reniformis Kunth, Pratia atacamensis Phil., Pratia oligophylla Wedd., Pratia pencana Phil., Pratia subsessilis Wedd., Hypsela longiflora (Hook.f.) F. Phil., Hypsela subsessilis (Wedd.) Benth. \& Hook.f. ex Zahlbr., Hypsela atacamensis (Phil.) F. Phil.

Hierba. Perenne. Nativa.

Distribución: AYP, TAR, ANT, ATA, COQ, VAL, RME, LBO, MAU, NUB, BIO, ARA, LLA, AIS, MAG.

Rango altitudinal: 0-4000 m.

Países limítrofes: Argentina y Bolivia.

Nombre vulgar: Qatari.

Lobelia polyphylla Hook. \& Arn.

Sinónimos: Lobelia ovata Reiche, Tupa polyphylla (Hook. \& Arn.) G. Don, Rapuntium polyphyllum (Hook. \& Arn.) C. Presl, Dortmanna polyphylla (Hook. \& Arn.) Kuntze, Tupa ovata Phil., Rapuntium subdentatum C. Presl, Lobelia polyphylla Hook. \& Arn. fma. subdentata (C. Presl) E. Wimm., Tupa subdentata (C. Presl) A. DC., Dortmanna subdentata (C. Presl) Kuntze, Lobelia polyphylla Hook. \& Arn. var. besseriana (C. Presl) Reiche, Tupa polyphylla (Hook. \& Arn.) G. Don var. besseriana (C. Presl) Vatke, Tupa besseriana (C. Presl) A. DC., Tupa purpurea G. Don, Tupa serrata Phil., Rapuntium besserianum C. Presl, Rapuntium purpureum (G. Don) C. Presl, Dortmanna besseriana (C. Presl) Kuntze, Dortmanna purpurea (G. Don) Kuntze, Rapuntium bracteosum C. Presl, Lobelia polyphylla Hook. \& Arn. fma. bracteosa (C. Presl) E. Wimm., Lobelia polyphylla Hook. \& Arn. var. bracteosa (C. Presl) Reiche, Tupa bracteosa (C. Presl) A. DC., Dortmanna bracteosa (C. Presl) Kuntze, Lobelia polyphylla Hook. \& Arn. var. angustifolia Hook. \& Arn. ex A. DC., Tupa polyphylla (Hook. \& Arn.) G. Don var. angustifolia (Hook. \& Arn.) A. DC., Lobelia polyphylla Hook. \& Arn. var. coquimbana (Vatke) Reiche, Tupa coquimbana Phil., Lobelia polyphylla Hook. \& Arn. fma. linearifolia (Phil.) E. Wimm., Tupa linearifolia Phil., Tupa axilliflora Phil., 
Lobelia axilliflora (Phil.) Reiche, Lobelia polyphylla Hook. \& Arn. fma. hyssopifolia (C. Presl) E. Wimm., Rapuntium hyssopifolium C. Presl, Tupa hyssopifolia (C. Presl) A. DC., Dortmanna hyssopifolia (C. Presl) Kuntze, Tupa gayana Phil., Lobelia polyphylla Hook. \& Arn. var. latifolia (A. DC.) Heynh., Tupa polyphylla (Hook. \& Arn.) G. Don var. latifolia A. DC., Lobelia poeppigiana Kunze ex A. DC., Rapuntium poeppigianum (Kunze ex A. DC.) C. Presl, Tupa polyphylla (Hook. \& Arn.) G. Don var. bracteosa (C. Presl) Vatke, Lobelia hyssopifolia (C. Presl) Gay, Lobelia polyphylla Hook. \& Arn. var. angustifolia (Hook. \& Arn. ex A. DC.) Heynh., Tupa atropurpurea Vis., Tupa polyphylla (Hook. \& Arn.) G. Don var. coquimbana Vatke, Tupa poeppigiana Phil.

Arbusto. Endémico.

Distribución: ATA, COQ, VAL, RME, LBO.

Rango altitudinal: 0-1200 m.

Nombre vulgar: Tupa.

\section{Lobelia tupa L.}

Sinónimos: Lobelia mucronata Cav. var. berteroi (A. DC.) E. Wimm., Lobelia mucronata Cav. fma. hookeri (A. DC.) E. Wimm., Lobelia mucronata Cav., Lobelia mucronata Cav. fma. ovalifolia E. Wimm., Lobelia tupa L. var. bicalcarata (Kuntze) E. Wimm., Lobelia tupa L. var. montana Reiche, Lobelia tupa L. var. pavonii E. Wimm., Lobelia serrata Meyen, Tupa feuillei G. Don, Tupa feuillei G. Don var. macrophylla Vatke, Rapuntium tupa (L.) C. Presl, Dortmanna tupa (L.) Kuntze, Dortmanna philippiana Kuntze, Lobelia bicalcarata (Kuntze) Zahlbr. ex K. Schum., Dortmanna bicalcarata Kuntze, Lobelia tupa L. var. mucronata (Cav.) Reiche, Tupa mucronata (Cav.) A. DC., Tupa cavanillesiana G. Don, nom. illeg., Tupa feuillei G. Don var. mucronata (Cav.) Vatke, Rapuntium mucronatum (Cav.) C. Presl, Tupa mucronata (Cav.) A. DC. var. hookeri A. DC., Tupa berteroi A. DC., Tupa feuillei G. Don var. berteroi (A. DC.) Vatke, Dortmanna berteroi (A. DC.) Kuntze, Lobelia tupa L. var. berteroi (A. DC.) Reiche, Lobelia feuillei (G. Don) Voss, nom. illeg., Dortmanna mucronata (Cav.) Kuntze

Hierba. Perenne. Endémica.

Distribución: VAL, LBO, MAU, NUB, BIO, ARA, LRI, LLA, JFE.

Rango altitudinal: 0-1000 m.

Nombre vulgar: Tupa, tabaco del diablo.

Nota: Introducida en el Archipiélago Juan Fernández.

\section{Triodanis}

Triodanis perfoliata (L.) Nieuwl. subsp. biflora (Ruiz \& Pav.) Lammers

Sinónimos: Triodanis biflora (Ruiz \& Pav.) Greene, Campanula biflora Ruiz \& Pav., Pentagonia biflora (Ruiz \& Pav.) Kuntze, Specularia biflora (Ruiz \& Pav.) Fisch. \&
A. Gray, Triodanis perfoliata (L.) Nieuwl. var. biflora (Ruiz \& Pav.) T.R. Bradley

Hierba. Anual. Nativa.

Distribución: ANT, VAL, RME, LLA.

Rango altitudinal: 0-1000 m.

Países limítrofes: Argentina, Bolivia y Perú.

\section{Wahlenbergia}

Wahlenbergia berteroi Hook. \& Arn.

Subarbusto. Endémico.

Distribución: JFE.

Rango altitudinal: 0-600 m.

Wahlenbergia fernandeziana A. DC. Arbusto o subarbusto. Endémico.

Distribución: JFE.

Rango altitudinal: 0-600 m.

Wahlenbergia grahamae Hemsl.

Subarbusto. Endémico.

Distribución: JFE.

Rango altitudinal: 400-600 m.

Wahlenbergia linarioides (Lam.) A. DC.

Sinónimos: Campanula arida Kunth, Campanula chilensis Molina, Campanula linarioides Lam., Wahlenbergia arida (Kunth) Griseb., Wahlenbergia linarioides (Lam.) A. DC. var. arida (Kunth) A. DC., Wahlenbergia linarioides (Lam.) A. DC. var. micrantha Phil.

Hierba. Perenne. Nativa.

Distribución: COQ, VAL, RME, LBO, MAU, NUB, BIO, ARA, LLA.

Rango altitudinal: 0-1000 m.

Países limítrofes: Argentina, Bolivia y Perú.

Nombre vulgar: Uño-perquén.

Wahlenbergia masafuerae (Phil.) Skottsb.

Sinónimos: Euphorbia masafuerae Phil.

Subarbusto. Endémico.

Distribución: JFE.

Rango altitudinal: 0-1100 m.

Wahlenbergia tuberosa Hook.f.

Subarbusto. Nativo.

Distribución: JFE.

Rango altitudinal: 0-300 m.

Países limítrofes: Perú. 


\section{CAPRIFOLIACEAE}

\section{Centranthus}

Centranthus ruber (L.) DC.

Hierba. Perenne. Introducida.

Distribución: JFE.

\section{Dipsacus}

Dipsacus sativus (L.) Honck.

Hierba. Bienal. Introducida.

Distribución: VAL, RME, LBO, MAU, NUB, BIO, ARA, LRI, JFE.

\section{Knautia}

Knautia integrifolia Bertol.

Hierba. Anual. Introducida.

Distribución: ARA.

\section{Sambucus}

\section{Sambucus nigra L.}

Arbusto o árbol pequeño. Introducido.

Distribución: MAU, NUB, BIO, ARA, LRI, LLA, MAG.

\section{Scabiosa}

\section{Scabiosa atropurpurea L.}

Hierba o subarbusto. Perenne. Introducida.

Distribución: ANT, COQ, VAL, RME, LBO, MAU, NUB, BIO, ARA, JFE.

\section{Stangea}

Stangea paulae Graebn.

Hierba. Perenne. Nativa.

Distribución: TAR.

Rango altitudinal: 4700-5200 m.

Países limítrofes: Perú.

\section{Valeriana}

\section{Valeriana aequiloba Clos}

Hierba. Anual. Endémica.

Distribución: COQ.

Rango altitudinal: 0-200 m.

Valeriana atacamensis Borsini

Sinónimos: Valeriana pubescens Phil.

Hierba. Perenne. Endémica.

Distribución: ANT, ATA, COQ.

Rango altitudinal: 0-1000 m.
Valeriana boelckei Rossow

Hierba. Perenne. Nativa.

Distribución: MAU, ARA.

Rango altitudinal: 1500-2000 m.

Países limítrofes: Argentina.

Valeriana bracteosa Phil.

Sinónimos: Valeriana rupestris Phil.

Hierba. Perenne. Endémica.

Distribución: VAL, RME, LBO, NUB.

Rango altitudinal: 1000-1600 m.

Valeriana bridgesii Hook. \& Arn.

Sinónimos: Valeriana regularis Clos, Valeriana simplex Clos, Valeriana phellocarpa Phil.

Hierba. Perenne. Endémica.

Distribución: COQ, VAL, RME, LBO.

Rango altitudinal: 200-900 m.

Valeriana carnosa $\mathrm{Sm}$.

Sinónimos: Valeriana magellanica Lam.

Hierba. Perenne. Nativa.

Distribución: LBO, MAU, NUB, BIO, ARA, LLA, AIS, MAG.

Rango altitudinal: 0-2700 m.

Países limítrofes: Argentina.

Valeriana castellanosii Borsini

Hierba. Perenne. Nativa.

Distribución: ANT.

Rango altitudinal: 4200-5000 m.

Países limítrofes: Argentina.

Valeriana chilensis Borsini

Hierba. Perenne. Nativa.

Distribución: MAU.

Rango altitudinal: 1000-2000 m.

Países limítrofes: Argentina.

Valeriana clarionifolia Phil.

Sinónimos: Valeriana spegazzini Skottsb., Valeriana sarcophylla Stuck. \& Briq., Phyllactis clarionifolia (Phil.) Speg.

Hierba. Perenne. Nativa.

Distribución: MAU, AIS.

Rango altitudinal: 0-2000 m.

Países limítrofes: Argentina.

Valeriana crispa Ruiz \& Pav.

Sinónimos: Valeriana oreocharis Phil., Valeriana floribunda Phil., Valeriana lobata (Hook. \& Arn.) Höck, Astrephia lobata Hook. \& Arn., Valeriana excelsa Reiche

Hierba. Anual. Nativa.

Distribución: COQ, VAL, RME, LBO, MAU, NUB, BIO, 
ARA.

Rango altitudinal: 1000-2500 m.

Países limítrofes: Argentina.

Valeriana fonckii Phil.

Sinónimos: Valeriana crenata Phil.

Hierba. Perenne. Nativa.

Distribución: MAU, NUB, BIO, ARA, LLA, AIS.

Rango altitudinal: 1000-2500 m.

Países limítrofes: Argentina.

Valeriana fragilis Clos

Sinónimos: Betckea heterophylla Phil., Valeriana heterophylla Phil., Valeriana integrifolia Phil.

Hierba. Perenne. Endémica.

Distribución: ANT, ATA, COQ.

Rango altitudinal: 0-1000 m.

Valeriana graciliceps Clos

Sinónimos: Valeriana lutescens Phil.

Arbusto. Endémico.

Distribución: COQ, VAL, RME, LBO, MAU.

Rango altitudinal: 2000-2500 m.

Valeriana grandifolia Phil.

Hierba. Anual. Endémica.

Distribución: VAL, RME, MAU, NUB, BIO, ARA.

Rango altitudinal: 0-2000 m.

Valeriana hebecarpa DC.

Sinónimos: Valeriana columbaria Phil.

Hierba. Perenne. Nativa.

Distribución: NUB, BIO, ARA.

Rango altitudinal: 1000-2000 m.

Países limítrofes: Argentina.

Valeriana hornschuchiana Walp.

Sinónimos: Valeriana glauca auct. non DC., Valeriana rotundiloba Clos, Valeriana bustillosii Phil.

Hierba. Perenne. Nativa.

Distribución: VAL, RME, LBO, MAU.

Rango altitudinal: 2500-3000 m.

Países limítrofes: Argentina.

Valeriana hyalinorrhiza Ruiz \& Pav.

Hierba. Perenne. Nativa.

Distribución: VAL, RME, LBO, MAU, BIO.

Rango altitudinal: 0-500 m.

Países limítrofes: Bolivia.

Valeriana interrupta Ruiz \& Pav.

Hierba. Perenne. Nativa.

Distribución: AYP.

Rango altitudinal: $3500-4000 \mathrm{~m}$.
Países limítrofes: Perú.

Valeriana lapathifolia Vahl

Sinónimos: Valeriana cordata Griseb., Valeriana cordata

Griseb. var. dentata Phil., Valeriana andonaegui Phil.

Hierba. Perenne. Nativa.

Distribución: ARA, LRI, LLA, AIS, MAG.

Rango altitudinal: 0-1500 m.

Países limítrofes: Argentina.

Nombre vulgar: Hualhuilque, gualhuilque.

Valeriana laxiflora DC.

Sinónimos: Valeriana laxa Phil., Valeriana rupicola Poepp. \& Endl., Valeriana sparsiflora Clos, Valeriana foliosa Phil., Valeriana lyrata Phil., Valeriana pearcei Phil., Valeriana laxiflora DC. var. cardaminifolia Poepp. \& Endl.

Hierba. Perenne. Nativa.

Distribución: VAL, RME, LBO, NUB, BIO, ARA, LLA, AIS, MAG.

Rango altitudinal: 100-2000 m.

Países limítrofes: Argentina.

Valeriana lepidota Clos

Sinónimos: Valeriana colchaguensis Phil., Valeriana maipoana Ravenna

Hierba. Perenne. Endémica.

Distribución: VAL, RME, LBO.

Rango altitudinal: 1000-2300 m.

Valeriana leucocarpa DC.

Hierba. Perenne. Nativa.

Distribución: LBO, MAU, NUB, BIO, ARA, MAG.

Rango altitudinal: $900-2000 \mathrm{~m}$.

Países limítrofes: Argentina.

Valeriana macrorhiza DC.

Sinónimos: Phyllactis macrorhiza (DC.) Wedd., Phyllactis gilliesii (Hook. \& Arn.) Wedd., Valeriana gilliesii (Hook. \& Arn.) Stuck. \& Briq., Betckea gilliesii Hook. \& Arn.

Hierba. Perenne. Nativa.

Distribución: LBO, MAU, NUB, BIO, ARA, LLA.

Rango altitudinal: 1500-2700 m.

Países limítrofes: Argentina.

Nombre vulgar: Triaca del cerro.

Valeriana moyanoi Speg.

Sinónimos: Valeriana fonckii Phil. var. spiciformis Dusén, Valeriana radicalis Clos var. patagonica Hicken

Hierba. Perenne. Nativa.

Distribución: AIS.

Rango altitudinal: 1000-2500 m.

Países limítrofes: Argentina. 
Valeriana nivalis Wedd.

Sinónimos: Valeriana altoandina Cabrera

Hierba. Perenne. Nativa.

Distribución: AYP, TAR, ANT, ATA.

Rango altitudinal: 3600-4800 m.

Países limítrofes: Argentina y Perú.

Nombre vulgar: Waji.

\section{Valeriana obtusifolia DC.}

Sinónimos: Valeriana obovata Clos, Valeriana aegilitis Phil., Valeriana araucana Phil., Valeriana crassicaulis Phil., Valeriana compacta Phil., nom. illeg.

Hierba. Perenne. Endémica.

Distribución: VAL, NUB, BIO, ARA, LRI.

Rango altitudinal: 0-1100 m.

Valeriana papilla Bertero ex DC.

Sinónimos: Valeriana berterii Colla, Valeriana papilla

Bertero ex DC. var. andicola Clos

Hierba. Perenne. Endémica.

Distribución: COQ, VAL, RME, LBO.

Rango altitudinal: 200-2000 m.

Nombre vulgar: Papilla.

\section{Valeriana peltata $\mathrm{Clos}$}

Sinónimos: Valeriana pterocarpa Hook. \& Arn.

Hierba. Perenne. Endémica.

Distribución: ATA, COQ, VAL, RME.

Rango altitudinal: 0-500 m.

Valeriana petersenii Weberling \& Reese

Hierba. Perenne. Nativa.

Distribución: AYP.

Rango altitudinal: 3000-5000 m.

Países limítrofes: Bolivia.

Valeriana philippiana Briq.

Sinónimos: Valeriana pulchella Phil.

Hierba. Perenne. Nativa.

Distribución: LLA, AIS, MAG.

Rango altitudinal: 1000-2400 m.

Países limítrofes: Argentina.

Valeriana polemoniifolia Phil.

Sinónimos: Valeriana pugae Phil., Valeriana caudata Phil., Valeriana germainii Briq.

Hierba. Anual. Nativa.

Distribución: COQ, RME, MAU, NUB, BIO, ARA, LRI,

LLA.

Rango altitudinal: 0-1500 m.

Países limítrofes: Argentina.

Valeriana pycnantha A. Gray

Hierba. Perenne. Nativa.
Distribución: AYP, TAR, ANT.

Rango altitudinal: 4000-4900 m.

Países limítrofes: Argentina, Bolivia y Perú.

Valeriana radicalis $\mathrm{Clos}$

Sinónimos: Valeriana andina F. Meigen

Hierba. Perenne. Endémica.

Distribución: RME.

Rango altitudinal: 2000-3400 m.

Valeriana samolifolia (DC.) Colla

Sinónimos: Plectritis congesta (Lindl.) DC., Betckea samolifolia DC., Valerianella samolifolia (DC.) A. Gray, Plectritis samolifolia (DC.) Höck

Hierba. Perenne. Nativa.

Distribución: VAL, RME, LBO, MAU, NUB, BIO, ARA.

Rango altitudinal: $500-1000 \mathrm{~m}$.

Países limítrofes: Argentina.

Valeriana sedifolia d'Urv.

Sinónimos: Phyllactis sedifolia (d’Urv.) Wedd., Valeriana sedoides Hombr. \& Jacq., Aretiastrum sedifolium (d'Urv.) Graebn., Macloskie, Valeriana magellanica Hombr. \& Jacquinot ex Decne

Hierba. Perenne. Nativa.

Distribución: MAG.

Rango altitudinal: 500-1500 m.

Países limítrofes: Argentina.

Valeriana senecioides Phil.

Arbusto. Endémico.

Distribución: ATA, COQ.

Rango altitudinal: 0-1000 m.

Valeriana sphaerocarpa Phil.

Hierba. Anual. Endémica.

Distribución: VAL.

Valeriana stricta Clos

Sinónimos: Valeriana glauca DC., Valeriana glauca DC. var. elegans (Clos) Reiche, Valeriana elegans Clos

Subarbusto. Nativo.

Distribución: ATA, COQ, VAL, RME, LBO, MAU.

Rango altitudinal: 1000-3300 m.

Países limítrofes: Argentina.

Valeriana urbanii Phil.

Hierba. Perenne. Nativa.

Distribución: AYP, TAR, ANT.

Rango altitudinal: 3500-5000 m.

Países limítrofes: Argentina.

Nombre vulgar: Waje. 
Valeriana vaga $\mathrm{Clos}$

Sinónimos: Valeriana muriculata Phil.

Hierba. Perenne. Endémica.

Distribución: ATA, COQ, VAL, RME.

Rango altitudinal: 1000-2800 m.

Valeriana valdiviana Phil.

Hierba. Anual. Endémica.

Distribución: VAL, MAU, NUB, BIO, ARA, LLA.

Rango altitudinal: 0-700 m.

Valeriana velutina Clos

Hierba. Perenne. Endémica.

Distribución: COQ, VAL.

Rango altitudinal: 1500-2200 m.

Valeriana verticillata $\mathrm{Clos}$

Hierba. Perenne. Endémica.

Distribución: VAL, RME, LBO, MAU.

Rango altitudinal: 1500-2000 m.

\section{Valeriana virescens $\mathrm{Clos}$}

Sinónimos: Valeriana montteana Phil., Valeriana virescens

Clos var. montteana (Phil.) Reiche

Hierba. Anual. Nativa.

Distribución: MAU, NUB, BIO, ARA, LRI, LLA, AIS.

Rango altitudinal: 0-1000 m.

Países limítrofes: Argentina.

\section{Valerianella}

Valerianella eriocarpa Desv.

Hierba. Anual. Introducida.

Distribución: BIO, ARA, LRI.

Valerianella locusta (L.) Laterr.

Hierba. Anual. Introducida.

Distribución: LBO, MAU, NUB, BIO, ARA, LRI, LLA.

Valerianella rimosa Bast

Hierba. Anual. Introducida.

Distribución: ARA.

\section{CARDIOPTERIDACEAE}

\section{Citronella}

Citronella mucronata (Ruiz \& Pav.) D. Don

Sinónimos: Villaresia mucronata Ruiz \& Pav., Villaresia gongonha (Mart.) Miers var. pungens (Miers) Engl., Villaresia chilensis Stuntz, Villaresia pungens Miers, Villaresia mucronata Ruiz \& Pav. var. laeta Miers, Patagua chilensis Poepp. ex Neger
Árbol. Endémico.

Distribución: COQ, VAL, RME, LBO, MAU, NUB, BIO, ARA, LLA.

Rango altitudinal: 0-700 m.

Nombre vulgar: Huillipatagua, naranjillo.

\section{CARICACEAE}

\section{Carica}

Carica chilensis (Planch. ex A. DC.) Solms

Sinónimos: Vasconcellea chilensis Planch. ex A. DC., Papaya chilensis (Planch. ex A. DC.) Kuntze, Carica pyriformis Hook. \& Arn.

Arbusto. Endémico.

Distribución: ATA, COQ, VAL.

Rango altitudinal: 0-500 m.

Nombre vulgar: Palo gordo, monte gordo.

\section{CARYOPHYLLACEAE}

\section{Agrostemma}

Agrostemma githago L.

Hierba. Anual. Introducida.

Distribución: BIO, ARA.

\section{Arenaria}

Arenaria digyna D.K.F. Schltdl.

Sinónimos: Arenaria serpylloides Gay

Hierba. Perenne. Nativa.

Distribución: AYP, TAR, ANT, ATA, COQ, VAL, RME, LBO, MAU, NUB, BIO, ARA, LLA, AIS, MAG.

Rango altitudinal: 500-4200 m.

Países limítrofes: Bolivia y Perú.

Arenaria fastigiata Phil.

Hierba. Perenne. Endémica.

Distribución: MAU.

Arenaria oligosperma Naudin

Hierba. Anual. Endémica.

Distribución: COQ.

Arenaria pleurantha Phil.

Hierba. Perenne. Endémica.

Distribución: LLA, AIS.

Arenaria rivularis Phil.

Hierba. Perenne. Nativa.

Distribución: AYP, TAR, ANT, ATA, COQ. 
Rango altitudinal: 3200-4700 m.

Países limítrofes: Argentina y Bolivia.

\section{Arenaria serpens Kunth}

Sinónimos: Arenaria microphylla Phil., Arenaria andicola Gillies, Arenaria andicola Gillies var. caespitosa (Phil.) Hauman, Arenaria caespitosa Phil., Arenaria palustris Naudin, Arenaria palustris Naudin var. patagonica (Phil.) Reiche, Arenaria patagonica Phil., Arenaria serpens Kunth var. andicola (Gillies) Rohrb., Arenaria serpens Kunth var. caespitosa (Phil.) Hauman, Arenaria serpens Kunth var. microphylla (Phil.) Speg., Arenaria serpens Kunth var. palustris (Naudin) Speg., Arenaria serpens Kunth var. patagonica (Phil.) Speg., Arenaria serpylloides Naudin var. andicola (Gillies) Reiche

Hierba. Perenne. Nativa.

Distribución: AYP, TAR, ANT, ATA, COQ, VAL, RME, LBO, MAU, NUB, BIO, ARA, LRI, LLA, AIS, MAG.

Rango altitudinal: 3000-4500 m.

Países limítrofes: Argentina, Bolivia y Perú.

\section{Arenaria serpyllifolia $\mathrm{L}$.}

Hierba. Anual o bienal. Introducida.

Distribución: COQ, RME, LBO, MAU, BIO, AIS, MAG.

\section{Augustea}

Augustea coquimbensis (Gereau \& Martic.) Iamonico Sinónimos: Polycarpon coquimbense Gereau \& Martic. Arbusto. Endémico.

Distribución: COQ.

Rango altitudinal: 1200-1700 m.

\section{Cardionema}

Cardionema andinum (Phil.) A. Nelson \& J.F. Macbr. Sinónimos: Pentacaena andina Phil.

Hierba. Perenne. Endémica.

Distribución: AYP, TAR.

Rango altitudinal: 3000-3500 m.

Cardionema kurtzii Subils

Hierba. Perenne. Nativa.

Distribución: COQ.

Rango altitudinal: 1500-2600 m.

Países limítrofes: Argentina.

Cardionema ramosissima (Weinm.) A. Nelson \& J.F. Macbr.

Sinónimos: Acanthonychia ramosissima (Weinm.) A. Nelson \& J.F. Macbr., Loeflingia ramosissima Weinm., Paronychia ramosissima (Weinm.) DC., Pentacaena ramosissima (Weinm.) Hook. \& Arn.

Hierba. Perenne. Nativa.
Distribución: AYP, TAR, ANT, ATA, COQ, VAL, RME, LBO, NUB, BIO, ARA.

Rango altitudinal: 500-3600 m.

Países limítrofes: Argentina, Bolivia y Perú.

Nombre vulgar: Jaramilla.

\section{Cerastium}

\section{Cerastium arvense $\mathrm{L}$.}

Hierba. Perenne. Introducida.

Distribución: ANT, ATA, COQ, VAL, RME, LBO, MAU, NUB, BIO, ARA, LRI, LLA, AIS, MAG.

Cerastium fontanum Baumg. subsp. vulgare (Hartmann) Greuter \& Burdet

Hierba. Perenne. Introducida.

Distribución: ATA, COQ, VAL, RME, LBO, MAU, NUB, BIO, ARA, LRI, LLA, AIS, MAG, JFE.

Cerastium glomeratum Thuill.

Hierba. Anual. Introducida.

Distribución: COQ, VAL, RME, LBO, MAU, NUB, BIO, ARA, LRI, LLA, AIS, MAG, JFE, IPA.

Cerastium humifusum Cambess.

Sinónimos: Cerastium montioides Naudin

Hierba. Perenne. Nativa.

Distribución: ANT, COQ, VAL, RME, AIS, MAG.

Rango altitudinal: 0-3800 m.

Países limítrofes: Argentina, Bolivia y Perú.

Cerastium mucronatum Wedd.

Hierba. Perenne. Nativa.

Distribución: AYP.

Rango altitudinal: 4300-4400 m.

Países limítrofes: Bolivia y Perú.

\section{Colobanthus}

Colobanthus lycopodioides Griseb.

Sinónimos: Colobanthus lechleri Phil., Drudea lycopodioides (Griseb.) Griseb.

Subarbusto. Nativo.

Distribución: RME, MAG.

Rango altitudinal: 0-2300 m.

Países limítrofes: Argentina.

Colobanthus quitensis (Kunth) Bartl.

Sinónimos: Colobanthus cherlerioides Hook.f., Colobanthus crassifolius (d'Urv.) Hook.f., Colobanthus meigeni Phil., Sagina crassifolia d'Urv., Sagina quitensis Kunth, Colobanthus saginoides Bartl.

Hierba. Perenne. Nativa.

Distribución: AYP, TAR, ANT, ATA, COQ, VAL, RME, 
MAU, NUB, BIO, ARA, LLA, AIS, MAG.

Rango altitudinal: 0-3800 m.

Países limítrofes: Argentina, Bolivia y Perú.

Colobanthus subulatus (d'Urv.) Hook.f.

Sinónimos: Colobanthus subulatus (d'Urv.) Hook.f. var.

darwinii Hook.f., Sagina subulata d'Urv.

Hierba. Perenne. Nativa.

Distribución: RME, AIS, MAG.

Rango altitudinal: 0-3700 m.

Países limítrofes: Argentina.

\section{Corrigiola}

Corrigiola crassifolia Chaudhri

Hierba. Perenne. Endémica.

Distribución: COQ, RME.

\section{Corrigiola propinqua Gay}

Hierba. Perenne. Endémica.

Distribución: COQ, VAL, LBO.

Rango altitudinal: 0-500 m.

Corrigiola squamosa Hook. \& Arn. var. latifolia (Gay) Skottsb.

Sinónimos: Corrigiola latifolia Gay

Hierba. Perenne. Endémica.

Distribución: COQ, VAL.

Rango altitudinal: 0-500 m.

Corrigiola squamosa Hook. \& Arn. var. poeppigii Chaudhri Sinónimos: Corrigiola glomeruliflora Steud.

Hierba. Perenne. Endémica.

Distribución: COQ, VAL, RME, LBO, MAU, BIO.

Rango altitudinal: 0-700 m.

Corrigiola squamosa Hook. \& Arn. var. squamosa

Hierba. Perenne. Endémica.

Distribución: COQ, VAL, RME.

Rango altitudinal: 0-500 m.

\section{Dianthus}

Dianthus armeria L.

Hierba. Anual o bienal. Introducida.

Distribución: ARA.

\section{Drymaria}

Drymaria cordata (L.) Willd. ex Roem. \& Schult. Sinónimos: Drymaria cordata (L.) Willd. ex Roem. \& Schult. var. pacifica Mizush., Holosteum cordatum L. Hierba. Anual. Nativa.

Distribución: ANT.
Rango altitudinal: 0-2000 m.

Países limítrofes: Argentina, Bolivia y Perú.

Drymaria engleriana (Muschl.) Baehni \& J.F. Macbr. var. devia (Baehni \& J.F. Macbr.) J.A. Duke

Sinónimos: Drymaria devia Baehni \& J.F. Macbr.

Hierba. Anual. Nativa.

Distribución: AYP.

Rango altitudinal: $3500 \mathrm{~m}$.

Países limítrofes: Perú.

Drymaria paposana Phil.

Hierba. Anual. Nativa.

Distribución: ANT.

Países limítrofes: Bolivia y Perú.

Herniaria

Herniaria cinerea DC.

Hierba. Anual. Introducida.

Distribución: COQ.

\section{Lychnis}

Lychnis coronaria (L.) Desr.

Hierba. Perenne. Introducida.

Distribución: BIO, ARA.

\section{Microphyes}

Microphyes litoralis Phil.

Hierba. Anual. Nativa.

Distribución: TAR, ANT, ATA, COQ.

Rango altitudinal: 0-800 $\mathrm{m}$.

Países limítrofes: Bolivia.

Microphyes minima (Miers ex Colla) Briq.

Sinónimos: Microphyes lanuginosus Phil., Talinum minimum Miers ex Colla

Hierba. Anual. Endémica.

Distribución: COQ, VAL, RME, NUB, BIO.

Rango altitudinal: 0-2000 m.

Microphyes robustus Ricardi var. pallidus Ricardi

Hierba. Anual. Endémica.

Distribución: ATA.

Rango altitudinal: 500-900 m.

Microphyes robustus Ricardi var. robustus

Hierba. Anual. Endémica.

Distribución: ATA, COQ.

Rango altitudinal: $800-1000 \mathrm{~m}$. 


\section{Paronychia}

Paronychia chilensis DC. subsp. chilensis var. chilensis Hierba. Perenne. Nativa.

Distribución: ANT, ATA, COQ, VAL, RME, LBO, MAU, BIO, JFE.

Rango altitudinal: 0-200 m.

Países limítrofes: Argentina, Bolivia y Perú.

Paronychia chilensis DC. subsp. chilensis var. mutica (Phil.) Reiche

Sinónimos: Paronychia mutica Phil.

Hierba. Perenne. Endémica.

Distribución: COQ, VAL, BIO.

Paronychia chilensis DC. subsp. subandina (Phil.) Chaudhri

Sinónimos: Paronychia subandina Phil., Paronychia chilensis DC. var. subandina (Phil.) Reiche

Hierba. Perenne. Endémica.

Distribución: COQ.

Paronychia coquimbensis Gay var. appressa (Phil.) Chaudhri

Sinónimos: Paronychia appressa Phil.

Hierba. Perenne. Endémica.

Distribución: COQ.

Paronychia coquimbensis Gay var. coquimbensis Sinónimos: Paronychia chilensis DC. var. coquimbensis (Gay) Reiche

Hierba. Perenne. Endémica.

Distribución: COQ, VAL.

Paronychia franciscana Eastw.

Hierba. Perenne. Nativa.

Distribución: COQ, VAL, JFE.

Rango altitudinal: 100-1500 m.

Nota: Introducida en el Archipiélago de Juan Fernandez.

Paronychia johnstonii Chaudhri var. johnstonii

Hierba. Perenne. Endémica.

Distribución: ANT.

Paronychia johnstonii Chaudhri var. scabrida Chaudhri Hierba. Perenne. Endémica.

Distribución: ANT.

\section{Paronychia microphylla Phil.}

Subarbusto. Nativo.

Distribución: AYP, TAR.

Rango altitudinal: 2200-3500 m.

Países limítrofes: Bolivia y Perú.

Nombre vulgar: Té de burro.
Paronychia setigera (Gillies ex Hook. \& Arn.) F. Herm. Sinónimos: Herniaria setigera Gillies ex Hook. \& Arn., Paronychia chilensis DC. var. andina (Phil.) Reiche, Paronychia subandina Gand., nom. illeg., Paronychia andina Phil., nom. illeg., Paronychia australis Gillies

Hierba. Perenne. Nativa.

Distribución: VAL, RME, MAU, BIO.

Rango altitudinal: 200-2500 m.

Países limítrofes: Argentina.

\section{Petrorhagia}

Petrorhagia dubia (Raf.) G. López \& Romo

Hierba. Anual. Introducida.

Distribución: VAL, LBO, MAU, NUB, BIO, ARA, MAG.

Petrorhagia prolifera (L.) P.W. Ball \& Heyw.

Hierba. Anual. Introducida.

Distribución: LBO, NUB, BIO, ARA.

Philippiella

Philippiella patagonica Speg.

Subarbusto. Nativo.

Distribución: MAG.

Rango altitudinal: 0-500 m.

Países limítrofes: Argentina.

Polycarpon

Polycarpon moreiranum Muñoz-Schick

Subarbusto. Endémico.

Distribución: COQ.

Rango altitudinal: $774 \mathrm{~m}$.

Polycarpon tetraphyllum (L.) L.

Hierba. Anual. Introducida.

Distribución: COQ, VAL, RME, LBO, MAU, BIO, ARA, LRI, LLA, JFE, IPA.

\section{Pycnophyllopsis}

Pycnophyllopsis lanatum (Phil.) M. E. Timaná

Sinónimos: Pycnophyllum lanatum Phil.

Arbusto. Endémico.

Distribución: COQ, VAL.

Rango altitudinal: 1550-2600 m.

\section{Pycnophyllum}

Pycnophyllum bryoides (Phil.) Rohrb. Sinónimos: Stichophyllum bryoides Phil. Hierba. Perenne. Nativa.

Distribución: AYP, TAR, ANT. 
Rango altitudinal: 4100-4500 m.

Países limítrofes: Argentina, Bolivia y Perú.

Nombre vulgar: Yaretilla.

Pycnophyllum glomeratum Mattf.

Hierba. Perenne. Nativa.

Distribución: AYP, TAR.

Rango altitudinal: 4200-4500 m.

Países limítrofes: Perú.

Pycnophyllum macropetalum Mattf.

Hierba. Perenne. Nativa.

Distribución: AYP, TAR, ANT.

Rango altitudinal: 4000-4800 m.

Países limítrofes: Argentina, Bolivia y Perú.

Nombre vulgar: Ayro macho.

Pycnophyllum molle J. Remy

Hierba. Perenne. Nativa.

Distribución: AYP, TAR, ANT.

Rango altitudinal: 3500-4800 m.

Países limítrofes: Argentina, Bolivia y Perú.

Nombre vulgar: Yaretilla.

Pycnophyllum spathulatum Mattf.

Hierba. Perenne. Nativa.

Distribución: AYP, TAR, ANT.

Rango altitudinal: 4000-5000 m.

Países limítrofes: Bolivia.

\section{Reicheella}

Reicheella andicola (Phil.) Pax

Sinónimos: Lyallia andicola Phil., Bryopsis andicola Reiche

Hierba. Perenne. Endémica.

Distribución: AYP, TAR, ANT.

Nombre vulgar: Yaretilla de agua.

\section{Sabulina}

Sabulina acutiflora (Fenzl ex Endl.) Dillenb. \& Kadereit Sinónimos: Minuartia acutiflora (Fenzl ex Endl.) Mattf., Alsine acutiflora Fenzl ex Endl., Alsine minuta (Naudin) Rohrb., Arenaria minuta Naudin, Minuartia minuta (Naudin) Roquero

Hierba. Anual. Endémica.

Distribución: VAL, RME, LBO, MAU, NUB.

Rango altitudinal: 0-500 m.

\section{Sagina}

Sagina apetala Ard. var. apetala Hierba. Anual. Introducida.
Distribución: VAL, RME, LBO, MAU, NUB, BIO, ARA, LLA.

Sagina apetala Ard. var. pachyrrhiza (Phil.) Reiche Sinónimos: Sagina pachyrrhiza Phil.

Hierba. Anual. Endémica.

Distribución: RME.

Sagina apetala Ard. var. valdiviana (Phil.) Reiche

Sinónimos: Sagina valdiviana Phil.

Hierba. Anual. Endémica.

Distribución: LLA.

Sagina chilensis Naudin

Hierba. Anual. Nativa.

Distribución: RME, LBO, JFE.

Rango altitudinal: 0-500 m.

Países limítrofes: Argentina.

Nota: Introducida en el Archipiélago Juan Fernández.

\section{Sagina procumbens L.}

Hierba. Perenne. Introducida.

Distribución: MAU, NUB, BIO, ARA, LRI, LLA, AIS, MAG.

\section{Saponaria}

Saponaria officinalis L.

Hierba. Perenne. Introducida.

Distribución: VAL, RME, LBO, MAU, NUB, BIO, ARA, LRI, LLA, AIS.

\section{Scleranthus}

\section{Scleranthus annuus L.}

Hierba. Anual. Introducida.

Distribución: LBO, MAU, NUB, BIO, ARA.

\section{Silene}

Silene andicola Gillies ex Hook. \& Arn.

Sinónimos: Melandrium andicolum (Gillies ex Hook. \& Arn.) Rohrb., Melandrium chilense (Naudin) Rohrb. var. cucubaloides (Fenzl) Hosseus, Melandrium cucubaloides Fenzl ex Rohrb., Lychnis andicola (Gillies ex Hook. \& Arn.) Rusby

Hierba. Perenne. Nativa.

Distribución: LBO, NUB, BIO, ARA, LLA, MAG.

Rango altitudinal: 1500-2000 m.

Países limítrofes: Argentina y Bolivia.

Silene antarctica (Kuntze) Pedersen

Sinónimos: Lychnis antarctica Kuntze

Hierba. Perenne. Nativa. 
Distribución: MAG.

Rango altitudinal: 1000-1500 m.

Países limítrofes: Argentina.

Silene armeria L.

Hierba. Anual o bienal. Introducida.

Distribución: BIO, ARA.

Silene chilensis (Naudin) Bocquet

Sinónimos: Lychnis chilensis Naudin, Lychnis terminalis Naudin, Melandrium andicolum (Gillies ex Hook. \& Arn.) Rohrb. var. nubigenum (Phil.) Reiche, Melandrium chilense (Naudin) Rohrb., Silene nubigena Phil., Melandrium terminale (Naudin) Reiche

Hierba. Perenne. Nativa.

Distribución: COQ, RME, LBO, MAU, NUB, BIO, ARA, LRI, LLA, MAG.

Rango altitudinal: 2000-3000 m.

Países limítrofes: Argentina y Bolivia.

Silene chubutensis (Speg.) Bocquet

Sinónimos: Lychnis chubutensis Speg., Melandrium chubutense (Speg.) Speg.

Hierba. Perenne. Nativa.

Distribución: AIS.

Rango altitudinal: 0-1500 m.

Países limítrofes: Argentina.

\section{Silene gallica $\mathrm{L}$.}

Hierba. Anual. Introducida.

Distribución: ANT, COQ, VAL, RME, LBO, MAU, NUB, BIO, ARA, LRI, LLA, JFE.

\section{Silene magellanica (Desr.) Bocquet}

Sinónimos: Lychnis magellanica Desr., Melandrium magellanicum (Desr.) Fenzl ex Rohrb., Lychnis graminea Molina, nom. nud.

Hierba. Perenne. Nativa.

Distribución: AIS, MAG.

Rango altitudinal: 0-1500 m.

Países limítrofes: Argentina.

Silene mandonii (Rohrb.) Bocquet

Sinónimos: Melandrium mandonii Rohrb., Melandrium rimbachii Mattf.

Hierba. Perenne. Nativa.

Distribución: AYP, TAR, ANT.

Rango altitudinal: 1500-4700 m.

Países limítrofes: Argentina, Bolivia y Perú.

Silene patagonica (Speg.) Bocquet

Sinónimos: Silene densifolia (Dusén) Bocquet, Lychnis patagonica Speg., Melandrium densifolium Dusén, Melandrium patagonicum (Speg.) Speg., Lychnis patagonica Speg. fma. glabriuscula H. Ross

Hierba. Perenne. Nativa.

Distribución: AIS, MAG.

Rango altitudinal: 1000-1500 m.

Países limítrofes: Argentina.

Silene plutonica Naudin

Sinónimos: Melandrium chilense (Naudin) Rohrb. var. plutonicum (Naudin) Hosseus, Melandrium plutonicum (Naudin) Reiche, Silene glutinosa Walp., nom. nud.

Hierba. Perenne. Nativa.

Distribución: RME, LBO, ARA, LLA.

Rango altitudinal: 1000-2000 m.

Países limítrofes: Argentina.

Silene vulgaris (Moench) Garcke

Hierba. Perenne. Introducida.

Distribución: RME, ARA.

\section{Spergula}

Spergula arvensis L.

Hierba. Anual. Introducida.

Distribución: COQ, VAL, RME, LBO, MAU, NUB, BIO, ARA, LRI, LLA, MAG.

Spergula bocconii (Scheele) Pedersen

Hierba. Anual o bienal. Introducida.

Distribución: COQ, VAL, RME, NUB, BIO, ARA, LRI, MAG, JFE, IDE.

Spergula cerviana (Cham. \& Schltdl.) D. Dietr.

Sinónimos: Arenaria cerviana Cham. \& Schltdl., Spergularia cerviana (Cham. \& Schltdl.) G. Don, Lepigonum purpureum Kindb. var. firmum Kindb., Spergularia firma (Kindb.) Rohrb., Spergularia polyantha Phil., Arenaria polyantha Phil.

Hierba. Perenne. Endémica.

Distribución: ATA, RME, MAU, NUB, BIO, ARA.

Rango altitudinal: 0-500 $\mathrm{m}$.

Spergula depauperata (Naudin) Pedersen

Sinónimos: Spergularia depauperata (Naudin) Rohrb., Arenaria depauperata Naudin, Lepigonum depauperatum (Naudin) Kindb., Spergularia depauperata (Naudin) Rohrb. var. tenella (Phil.) Hauman \& Irigoyen, Spergularia tenella Phil., Tissa depauperata (Naudin) Reiche, Tissa depauperata (Naudin) Reiche var. tenella (Phil.) Hauman, Lepigonum grandiflorum Kindb., Spergularia grandiflora (Kindb.) Rohrb., Spergularia rengifoi Phil.

Hierba. Perenne. Nativa.

Distribución: VAL, RME, NUB, ARA, LLA.

Rango altitudinal: 500-3800 m.

Países limítrofes: Argentina. 
Spergula pissisi (Phil.) Volponi

Sinónimos: Spergularia pissisii (Phil.) I.M. Johnst., Arenaria pissisi Phil., Tissa pissisi (Phil.) Reiche

Hierba. Perenne. Nativa.

Distribución: ATA, COQ.

Rango altitudinal: 2500-4000 m.

Países limítrofes: Argentina.

Spergula platensis (Cambess.) Shinners

Sinónimos: Balardia platensis Cambess.

Hierba. Anual o bienal. Nativa.

Distribución: RME, BIO, ARA.

Países limítrofes: Argentina.

Spergula rubra (L.) D. Dietr.

Hierba. Anual o perenne. Introducida.

Distribución: COQ, RME, LBO, MAU, NUB, BIO, ARA, JFE.

Spergula villosa Pers.

Sinónimos: Spergularia villosa (Pers.) Cambess., Arenaria berteroana Phil., Spergularia villosa (Pers.) Cambess. var. berteroana (Phil.) Rohrb.

Hierba. Perenne. Nativa.

Distribución: COQ, VAL, RME, LBO, MAU, BIO, LLA.

Rango altitudinal: 0-1000 m.

Países limítrofes: Argentina y Perú.

\section{Spergularia}

Spergularia aberrans I.M. Johnst.

Hierba. Perenne. Endémica.

Distribución: ANT.

Spergularia arbuscula (Gay) I.M. Johnst.

Sinónimos: Paronychia arbuscula Gay, Arenaria teretifolia Phil., Arenaria lignosa Phil., Spergularia lignosa (Phil.) Rohrb., Spergularia fruticosa Phil., Spergularia teretifolia (Phil.) Phil., Tissa lignosa (Phil.) Reiche, Tissa teretifolia (Phil.) Reiche

Subarbusto. Endémico.

Distribución: AYP, TAR, ANT, ATA, COQ.

Rango altitudinal: 0-100 m.

\section{Spergularia confertiflora Steud.}

Sinónimos: Spergularia confertiflora Steud. var. polyphylla (Phil.) Skottsb., Spergularia polyphylla (Phil.) Rohrb., Tissa polyphylla (Phil.) Reiche, Arenaria rubra L. var. polyphylla Phil.

Hierba. Perenne. Endémica.

Distribución: JFE, IDE.

Rango altitudinal: 0-100 m.
Spergularia cremnophila I.M. Johnst.

Hierba. Perenne. Endémica.

Distribución: ANT, ATA.

Rango altitudinal: 0-500 m.

Spergularia denticulata (Phil.) Phil.

Sinónimos: Arenaria denticulata Phil., Tissa denticulata (Phil.) Reiche

Hierba. Anual. Endémica.

Distribución: ANT, ATA.

Rango altitudinal: 0-100 m.

Spergularia dillenii Lebel

Hierba. Anual o bienal. Introducida.

Distribución: COQ, RME, MAU.

Spergularia fasciculata Phil.

Sinónimos: Tissa stuebellii Hieron., Tissa fasciculata (Phil.)

Reiche, Spergularia stuebellii (Hieron.) I.M. Johnst.

Hierba. Perenne. Nativa.

Distribución: AYP, TAR, ANT.

Rango altitudinal: 3000-3800 m.

Países limítrofes: Bolivia y Perú.

Nombre vulgar: Alhucema.

Spergularia floribunda (Gay) Rohrb.

Sinónimos: Arenaria floribunda Gay, Spergularia coquimbensis Phil., Tissa floribunda (Gay) Reiche, Lepigonum floribundum (Gay) Kindb.

Hierba. Perenne. Endémica.

Distribución: ATA, COQ.

Rango altitudinal: 0-100 m.

Spergularia manicata (Skottsb.) Kool \& Thulin

Sinónimos: Sanctambrosia manicata (Skottsb.) Skottsb., Paronychia manicata Skottsb.

Arbusto. Endémico.

Distribución: IDE.

Spergularia marina (L.) Griseb.

Hierba. Anual o bienal. Introducida.

Distribución: COQ, VAL, RME, BIO, LLA, AIS, MAG.

Spergularia masafuerana Skottsb.

Hierba. Perenne. Endémica.

Distribución: JFE.

Rango altitudinal: 0-800 m.

Spergularia media (L.) C. Presl

Hierba. Perenne. Introducida.

Distribución: ANT, COQ, VAL, RME, LBO, MAU, NUB, BIO, ARA, LRI, LLA, AIS, MAG. 
Spergularia pycnantha $\mathrm{R}$. Rossbach

Hierba. Perenne. Endémica.

Distribución: ATA, COQ, VAL, RME.

Rango altitudinal: 0-500 m.

Spergularia stenocarpa (Phil.) I.M. Johnst.

Sinónimos: Arenaria stenocarpa Phil., Spergularia larrañagae Phil., Spergularia borchersi Phil., Tissa borchersi (Phil.) Reiche

Hierba. Perenne. Endémica.

Distribución: AYP, TAR, ANT, ATA.

Rango altitudinal: 0-500 m.

\section{Stellaria}

Stellaria alsine Grimm

Hierba. Perenne. Introducida.

Distribución: AIS, MAG.

Stellaria arvalis Fenzl ex F. Phil.

Sinónimos: Stellaria cuspidata Schltdl. var. alsineformis Naudin

Hierba. Perenne. Nativa.

Distribución: TAR, VAL, RME, LBO, MAU, NUB, BIO, ARA, LRI, LLA, AIS, MAG.

Rango altitudinal: 0-1500 m.

Países limítrofes: Argentina.

\section{Stellaria chilensis Pedersen}

Sinónimos: Stellaria concinna Ravenna, Stellaria circinata Ravenna, Stellaria celsa Ravenna

Hierba. Perenne. Endémica.

Distribución: AYP, TAR, ANT, COQ, VAL, RME, LBO, MAU, NUB, BIO, ARA, LLA, JFE.

Rango altitudinal: 0-3400 $\mathrm{m}$.

Nota: Introducida en el Archipiélago Juan Fernández.

\section{Stellaria debilis d'Urv.}

Sinónimos: Alsine axillaris (Phil.) Macloskie, Alsine chubutensis (Speg.) Macloskie, Alsine debile (d'Urv.) Macloskie, Stellaria axillaris Phil., Stellaria chubutensis Speg., Stellaria debilis d'Urv. var. condensata (A. Gray ex Macloskie) Hauman \& Irigoyen, Stellaria stenopetala Phil., Stellaria stenopetala Phil. var. axillaris (Phil.) Hauman, Stellaria stenopetala Phil. var. chubutensis (Speg.) Hauman, Stellaria stenopetala Phil. var. magellanica Phil., Stellaria stenopetala Phil. var. typica Hauman, nom. illeg., Stellaria xanthospora Chodat \& Wilczek

Hierba. Perenne. Nativa.

Distribución: ATA, COQ, MAG.

Rango altitudinal: 0-3500 m.

Países limítrofes: Argentina.

Stellaria media (L.) Vill.

Hierba. Anual. Introducida.
Distribución: ANT, ATA, COQ, VAL, RME, LBO, MAU, NUB, BIO, ARA, LRI, LLA, AIS, MAG, JFE.

Stellaria pallida (Dumort.) Crép.

Hierba. Anual. Introducida.

Distribución: RME, MAG.

Stellaria parviflora Banks \& Sol. ex Hook.f. subsp. ignis Pedersen

Hierba. Perenne. Nativa.

Distribución: MAG.

Rango altitudinal: 0-500 m.

Países limítrofes: Argentina.

Stellaria weddellii Pedersen

Sinónimos: Stellaria cuspidata Schltdl. var. sessilifolia Wedd.

Hierba. Perenne. Nativa.

Distribución: AYP.

Rango altitudinal: 3100-4500 m.

Países limítrofes: Argentina y Bolivia.

\section{CELASTRACEAE}

\section{Lepuropetalon}

Lepuropetalon spathulatum Muhl. ex Elliott

Sinónimos: Pyxidanthera spathulata Muhl., Cryptopetalum pussillum Hook. \& Arn., Lepuropetalon pusillum (Hook. \& Arn.) Gay

Hierba. Anual. Nativa.

Distribución: VAL, RME, LBO, MAU, NUB, BIO, ARA, LLA.

Rango altitudinal: 0-500 m.

Países limítrofes: Argentina.

\section{Maytenus}

\section{Maytenus boaria Molina}

Sinónimos: Maytenus boaria Molina var. angustifolia Turcz., Maytenus chilensis DC., Maytenus chilensis DC. var. angustifolius DC., Celastrus uncinatus Ruiz \& Pav., Maytenus crenulatus C. Presl, Boaria molinae A. DC., Maytenus magellanica auct. non (Lam.) Hook.f., Maytenus uncinatus (Ruiz \& Pav.) G. Don, Senacia maytenus Lam., Celastrum maytenus Willd.

Árbol. Nativo.

Distribución: ATA, COQ, VAL, RME, LBO, MAU, NUB, BIO, ARA, LRI, LLA, AIS, MAG.

Rango altitudinal: 0-4000 m.

Países limítrofes: Argentina y Bolivia.

Nombre vulgar: Maitén. 
Maytenus chubutensis (Speg.) Lourteig, O'Donell \& Sleumer

Sinónimos: Pernettya chubutensis Speg.

Arbusto o subarbusto. Nativo.

Distribución: MAU, NUB, BIO, ARA, LLA, AIS.

Rango altitudinal: 500-2000 m.

Países limítrofes: Argentina.

Maytenus disticha (Hook.f.) Urb.

Sinónimos: Myginda disticha Hook.f., Rhacoma disticha (Hook.f.) Loes.

Arbusto o subarbusto. Nativo.

Distribución: MAU, NUB, BIO, ARA, LRI, LLA, AIS, MAG.

Rango altitudinal: 0-2000 m.

Países limítrofes: Argentina.

Maytenus magellanica (Lam.) Hook.f.

Sinónimos: Cassine magellanica Lam., Celastrus megellanicus (Lam.) DC., Maytenus andina Phil., Euthalis lucida Banks \& Sol. ex Hook.f.

Árbol. Nativo.

Distribución: LBO, MAU, NUB, BIO, ARA, LRI, LLA, AIS, MAG.

Rango altitudinal: 0-2000 m.

Países limítrofes: Argentina.

Nombre vulgar: Leña dura.

\section{CERATOPHYLLACEAE}

\section{Ceratophyllum}

\section{Ceratophyllum demersum L.}

Sinónimos: Ceratophyllum tricuspidatum Dumort., Ceratophyllum oxyacanthum Cham., Ceratophyllum tuberculatum Cham., Ceratophyllum apiculatum Cham., Ceratophyllum chilense Leyb., Ceratophyllum aquaticum H.C. Watson, Ceratophyllum australis Griseb.

Hierba acuática. Perenne. Nativa.

Distribución: VAL, RME, NUB.

Rango altitudinal: 0-1300 m.

Países limítrofes: Argentina, Bolivia y Perú.

Nombre vulgar: Cola de zorro, lila de agua, pelo de agua, baba de sapo, hilo de agua.

\section{CHENOPODIACEAE}

\section{Atriplex}

Atriplex atacamensis Phil.

Arbusto. Endémico.

Distribución: AYP, TAR, ANT, ATA.

Rango altitudinal: 200-3000 m.
Nombre vulgar: Cachiyuyo.

Atriplex chapinii I.M. Johnst.

Arbusto. Endémico.

Distribución: IDE.

Rango altitudinal: 0-500 m.

Atriplex chilensis Colla

Hierba. Anual. Endémica.

Distribución: VAL, LBO, BIO, ARA, LLA, MAG.

Rango altitudinal: 0-100 m.

Atriplex chizae Rosas

Arbusto. Endémico.

Distribución: AYP, TAR.

Rango altitudinal: 0-1100 m.

Atriplex clivicola I.M. Johnst.

Sinónimos: Atriplex clivicola I.M. Johnst. var. lopholepis

I.M. Johnst., Obione clivicola (I.M. Johnst.) Ulbr.

Arbusto. Endémico.

Distribución: ANT, ATA, COQ.

Rango altitudinal: 200-700 m.

Atriplex coquimbana Phil.

Arbusto. Endémico.

Distribución: ATA, COQ.

Rango altitudinal: 300-500 m.

Atriplex costellata Phil.

Arbusto. Endémico.

Distribución: COQ, VAL.

Rango altitudinal: 0-200 m.

Atriplex deserticola Phil.

Sinónimos: Atriplex podocarpa Phil., Atriplex retusa Gay,

Obione retusa (Gay) Ulbr.

Subarbusto. Nativo.

Distribución: AYP, TAR, ANT, ATA, COQ.

Rango altitudinal: 1500-3000 m.

Países limítrofes: Argentina.

Nombre vulgar: Cachiyuyo.

Atriplex glaucescens Phil.

Sinónimos: Atriplex polyphylla Phil.

Arbusto. Endémico.

Distribución: AYP, TAR, ANT, ATA.

Rango altitudinal: 1300-3700 m.

Nombre vulgar: Juirajuira.

Atriplex hortensis L.

Hierba. Anual. Introducida.

Distribución: COQ, RME. 
Atriplex hystrix Phil.

Sinónimos: Atriplex mucronata Phil., nom. illeg., Obione hystrix (Phil.) Ulbr., Obione mucronata (Phil.) Ulbr.

Arbusto. Endémico.

Distribución: ANT, ATA, COQ.

Rango altitudinal: 0-600 m.

Atriplex imbricata (Moq.) D. Dietr. var. foliolosa (Phil.) Rosas

Sinónimos: Atriplex foliolosum Phil., Atriplex sanambrosiana Sparre

Arbusto o subarbusto. Endémico.

Distribución: IDE.

Rango altitudinal: 0-100 m.

Atriplex imbricata (Moq.) D. Dietr. var. imbricata

Sinónimos: Atriplex axillaris Phil., Atriplex microphylla Phil., Obione imbricata Moq., Atriplex salaris Phil., Obione axillaris (Phil.) Ulbr.

Arbusto o subarbusto. Nativo.

Distribución: AYP, TAR, ANT, ATA.

Rango altitudinal: 3500-3800 m.

Países limítrofes: Argentina, Bolivia y Perú.

Nombre vulgar: Cachiyuyo, chókel, ojalar, kopakopa macho, pilaya.

Atriplex leuca Phil.

Sinónimos: Atriplex densifolia Phil.

Hierba. Perenne. Endémica.

Distribución: ATA, COQ.

Rango altitudinal: 0-800 m.

Atriplex madariagae Phil.

Arbusto. Endémico.

Distribución: AYP, TAR, ANT, ATA.

Rango altitudinal: 200-2700 m.

Nombre vulgar: Cachial, kachiyuyo, kórial, chókel, juirajuira.

Atriplex myriophylla Phil.

Sinónimos: Atriplex pusilla (Wedd.) Phil., comb. illeg., Obione pusilla Wedd., hom. illeg., Obione myriophylla (Phil.) Ulbr.

Hierba. Anual. Nativa.

Distribución: AYP, TAR.

Rango altitudinal: 2000-4000 m.

Países limítrofes: Argentina y Bolivia.

Atriplex nummularia Lindl.

Arbusto. Introducido.

Distribución: ANT, COQ.

Atriplex oreophila Phil.

Sinónimos: Atriplex humilis Phil., hom. illeg., Atriplex hypsophila I.M. Johnst.
Hierba. Anual. Nativa.

Distribución: TAR, ATA, COQ.

Rango altitudinal: 3500-4000 m.

Países limítrofes: Argentina.

Atriplex patula L.

Hierba. Anual. Introducida.

Distribución: RME, BIO, ARA, LLA, MAG.

Atriplex peruviana Moq.

Hierba. Perenne. Nativa.

Distribución: AYP.

Rango altitudinal: 0-1900 m.

Países limítrofes: Perú.

Atriplex philippii R.E. Fr.

Sinónimos: Atriplex prostrata Phil., hom. illeg.

Hierba. Anual. Endémica.

Distribución: RME.

Rango altitudinal: 100-1000 m.

Nombre vulgar: Pasto cenizo.

Atriplex prostrata Boucher ex DC.

Hierba. Anual. Introducida.

Distribución: COQ, RME, MAU, BIO, ARA, LRI, LLA, MAG.

Atriplex repanda Phil.

Sinónimos: Atriplex angustifolia Phil.

Arbusto. Endémico.

Distribución: ATA, COQ, RME.

Rango altitudinal: 0-1500 m.

Nombre vulgar: Sereno.

Atriplex rosea L.

Hierba. Anual. Introducida.

Distribución: COQ.

Atriplex semibaccata $\mathrm{R}$. Br.

Hierba. Perenne. Introducida.

Distribución: ANT, ATA, COQ, VAL, RME.

Atriplex suberecta I. Verd.

Hierba. Anual. Introducida.

Distribución: ATA, COQ.

Atriplex taltalensis I.M. Johnst.

Subarbusto. Endémico.

Distribución: TAR, ANT, ATA.

Rango altitudinal: 0-100 m.

Atriplex tatarica L.

Hierba. Anual. Introducida.

Distribución: RME. 
Atriplex vallenarensis Rosas

Arbusto. Endémico.

Distribución: ATA, COQ.

Rango altitudinal: 0-600 m.

Atriplex vulgatissima Speg.

Arbusto. Nativo.

Distribución: MAG.

Rango altitudinal: 0-500 m.

Países limítrofes: Argentina.

Bassia

Bassia hyssopifolia (Pall.) Kuntze

Hierba. Anual. Introducida.

Distribución: ANT, ATA, VAL, RME.

\section{Beta}

Beta vulgaris L. subsp. maritima (L.) Arcang.

Hierba. Perenne. Introducida.

Distribución: ATA, VAL, RME.

Beta vulgaris L. subsp. vulgaris

Hierba. Perenne. Introducida.

Distribución: TAR, JFE.

\section{Chenopodiastrum}

Chenopodiastrum murale (L.) S. Fuentes, Uotila \& Borsch Hierba. Anual. Introducida.

Distribución: AYP, TAR, ANT, ATA, COQ, VAL, RME, LBO, MAU, BIO, ARA, LRI, LLA, JFE, IDE.

\section{Chenopodium}

\section{Chenopodium album L.}

Hierba. Anual. Introducida.

Distribución: AYP, TAR, ANT, ATA, COQ, VAL, RME, LBO, MAU, NUB, BIO, ARA, LRI, LLA, AIS, MAG, JFE.

Chenopodium antarcticum (Hook.f.) Benth. \& Hook.f.

Sinónimos: Blitum antarcticum Hook.f., Chenopodium antarcticum (Hook.f.) Speg., comb. illeg.

Hierba. Anual. Nativa.

Distribución: MAG.

Rango altitudinal: 0-500 m.

Países limítrofes: Argentina.

Chenopodium carnosulum Moq.

Hierba. Anual. Introducida.

Distribución: VAL, LLA, AIS, MAG.
Chenopodium crusoeanum Skottsb.

Subarbusto. Endémico.

Distribución: JFE.

Rango altitudinal: 0-500 m.

Chenopodium ficifolium $\mathrm{Sm}$.

Hierba. Anual. Introducida.

Distribución: VAL, LLA, MAG.

Chenopodium frigidum Phil.

Hierba. Anual. Nativa.

Distribución: AYP, TAR, ANT, ATA, COQ, RME.

Rango altitudinal: 3200-4000 m.

Países limítrofes: Argentina.

Nombre vulgar: Chápir, yuyo, quínoa chica, illankoma.

Chenopodium glaucum L.

Hierba. Anual. Nativa.

Distribución: IPA.

Países limítrofes: Argentina.

Nombre vulgar: Huataru (Rapa Nui).

Chenopodium hircinum Schrad.

Sinónimos: Chenopodium hircinum Schrad. var. typicum A.

Ludw. \& Aellen, nom. illeg.

Hierba. Anual. Nativa.

Distribución: AYP, TAR, ANT, ATA, COQ, VAL, RME, LBO, NUB, LRI.

Rango altitudinal: 0-1400 m.

Países limítrofes: Argentina, Bolivia y Perú.

Nombre vulgar: Yuyo, quinoa, illinkoma, ajara, quinoa de los abuelos.

Chenopodium mandonii (S. Watson) Aellen

Sinónimos: Teloxys mandonii S. Watson

Hierba. Anual. Nativa.

Distribución: ANT, VAL.

Rango altitudinal: 2000-4000 m.

Países limítrofes: Argentina y Bolivia.

Chenopodium nesodendron Skottsb.

Arbusto. Endémico.

Distribución: JFE.

Rango altitudinal: 300-500 m.

Chenopodium papulosum Moq.

Hierba. Anual. Nativa.

Distribución: ATA, COQ, VAL, BIO, LLA.

Rango altitudinal: 0-1000 m.

Países limítrofes: Argentina.

Chenopodium petiolare Kunth

Sinónimos: Chenopodium sparsiflorum Phil., Chenopodium hastatum Phil. 
Hierba. Perenne. Nativa.

Distribución: AYP, TAR, ANT, ATA, COQ, VAL.

Rango altitudinal: 2000-3000 m.

Países limítrofes: Argentina.

Nombre vulgar: Yuyo, kañawe, juirajuira, obleo, kantalo.

Chenopodium philippianum Aellen

Hierba. Anual. Nativa.

Distribución: COQ, VAL, RME, LBO, MAU.

Rango altitudinal: 2000-2500 m.

Países limítrofes: Argentina.

Chenopodium quinoa Willd.

Sinónimos: Chenopodium quinoa Willd. fma. purpurascens Aellen

Hierba. Anual. Nativa.

Distribución: TAR, ANT, NUB, LLA.

Rango altitudinal: 0-3800 m.

Países limítrofes: Argentina, Bolivia y Perú.

Nombre vulgar: Quínoa, quingua, quinua, chula, ch'iva, ch'ivaqhora.

Chenopodium sanctae-clarae Johow

Arbusto. Endémico.

Distribución: JFE.

Rango altitudinal: 0-100 m.

Chenopodium sancti-ambrosii Skottsb.

Arbusto. Endémico.

Distribución: IDE.

Rango altitudinal: 300-500 m.

Chenopodium trifurcatum Phil.

Hierba. Anual. Endémica.

Distribución: ATA, COQ.

Rango altitudinal: 350-2900 m.

Chenopodium vulvaria L.

Hierba. Anual. Introducida.

Distribución: TAR, ANT, VAL, RME, LBO, MAU.

\section{Dysphania}

Dysphania ambrosioides (L.) Mosyakin \& Clemants Sinónimos: Ambrina parvula Phil., Ambrina ambrosioides (L.) Spach, Teloxys ambrosioides (L.) W.A. Weber, Chenopodium ambrosioides L., Ambrina incisa Phil.

Hierba. Perenne. Nativa.

Distribución: AYP, TAR, ANT, ATA, COQ, VAL, RME, LBO, MAU, NUB, BIO, ARA, LRI, LLA, JFE, IDE.

Rango altitudinal: 0-2000 m.

Países limítrofes: Argentina y Bolivia.

Nombre vulgar: Paico, arka, toronjil dulce.

Nota: Introducida en el Archipiélago Juan Fernández.
Dysphania chilensis (Schrad.) Mosyakin \& Clemants Sinónimos: Ambrina andicola Phil., Ambrina denudata Phil., Chenopodium ambrosioides L. var. euchilense Aellen, Chenopodium ambrosioides L. fma. denudatum (Phil.) Aellen, Chenopodium ambrosioides L. var. andicola (Phil.) Aellen, Chenopodium ambrosioides L. var. chilense (Schrad.) Griseb., Chenopodium anthelminticum L. var. chilense (Schrad.) Griseb., Chenopodium ambrosioides L. subsp. chilense (Schrad.) Aellen, Ambrina chilensis (Schrad.) Spach, Chenopodium vagans Standl., Chenopodium chilense Schrad.

Hierba. Perenne. Nativa.

Distribución: ANT, ATA, COQ, VAL, RME, LBO, MAU, NUB, BIO, LLA.

Rango altitudinal: 0-1500 m.

Países limítrofes: Argentina y Bolivia.

Nombre vulgar: Paico.

Dysphania microcarpa (Phil.) Mosyakin \& Clemants

Sinónimos: Roubieva microcarpa Phil., Chenopodium zoellneri Aellen, Chenopodium multifidum L. var. microcarpum (Phil.) Reiche, Chenopodium microcarpum (Phil.) A. Troncoso

Hierba. Anual. Endémica.

Distribución: VAL, RME.

Dysphania multifida L.

Hierba. Perenne. Introducida.

Distribución: AYP, TAR, ANT, ATA, COQ, VAL, RME, LBO, MAU, NUB, BIO, ARA, LRI, LLA, JFE.

\section{Maireana}

Maireana brevifolia (R. Br.) Paul G. Wilson

Arbusto. Introducido.

Distribución: IDE.

\section{Nitrophila}

Nitrophila atacamensis (Phil.) Hieron. ex Ulbr. Sinónimos: Glaux atacamensis Phil. Hierba. Anual. Endémica.

Distribución: ANT.

Rango altitudinal: 2300-4000 m.

\section{Oxybasis}

Oxybasis glauca (L.) S. Fuentes, Uotila \& Borsch Hierba. Anual. Introducida.

Distribución: VAL, LLA, AIS, MAG. 
Oxybasis macrosperma (Hook.f.) S. Fuentes, Uotila \& Borsch

Sinónimos: Chenopodium halophilum Phil., Chenopodium macrospermum Hook.f. subsp. macrospermum, Chenopodium macrospermum Hook.f. subsp. salsum (Phil.) A. Troncoso, Blitum salsum Phil., Chenopodium macrospermum Hook.f. subsp. halophilum (Phil.) Aellen, Chenopodium macrospermum Hook.f. var. halophilum (Phil.) Standl.

Hierba. Anual. Nativa.

Distribución: ANT, ATA, VAL, RME, LBO, MAU, BIO, LLA, AIS.

Rango altitudinal: 0-100 m.

Países limítrofes: Argentina y Bolivia.

Oxybasis urbica (L.) S. Fuentes, Uotila \& Borsch

Hierba. Anual. Introducida.

Distribución: JFE.

\section{Salsola}

Salsola kali L.

Hierba. Anual. Introducida.

Distribución: ATA, COQ, VAL, RME, LBO, MAU, NUB, BIO, ARA, LRI, LLA.

\section{Sarcocornia}

Sarcocornia andina (Phil.) Freitag, M.A. Alonso \& M.B. Crespo

Sinónimos: Salicornia andina Phil., Salicornia fruticosa var. andina (Phil.) Gunckel, Salicornia peruviana var. andina (Phil.) Reiche

Arbusto. Nativo.

Distribución: ANT.

Rango altitudinal: 2300-4200 m.

Países limítrofes: Argentina, Bolivia y Perú.

Sarcocornia magellanica (Phil.) M.A. Alonso \& M.B. Crespo Sinónimos: Salicornia magellanica Phil.

Arbusto. Nativo.

Distribución: MAG.

Rango altitudinal: 0-500 m.

Países limítrofes: Argentina.

Sarcocornia neei (Lag.) M.A. Alonso \& M.B. Crespo

Sinónimos: Salicornia peruviana Kunth var. corticosa (Meyen) Reiche, Salicornia peruviana Kunth var. doeringii (Lorentz \& Niederl.) Reiche, Salicornia copiapina Phil.,

Salicornia neei Lag.

Arbusto. Nativo.

Distribución: ANT, ATA, COQ, VAL, LBO, MAU, NUB, BIO, ARA, LLA, JFE.

Rango altitudinal: 0-2500 m.
Países limítrofes: Argentina y Perú.

Nombre vulgar: Sosa, hierba sosa, hierba del salitre.

Nota: Introducida en Archipiélago de Juan Fernández. Alonso \& Crespo (2008) excluyen a Sarcocornia fruticosa de las Américas, creando la combinación Sarcocornia neei, sin ser su sinónimo.

Sarcocornia pulvinata (R.E. Fr.) A.J. Scott

Sinónimos: Salicornia pulvinata R.E. Fr.

Hierba. Perenne. Nativa.

Distribución: TAR, ANT.

Rango altitudinal: 3600-4200 m.

Países limítrofes: Argentina, Bolivia y Perú.

Nombre vulgar: Janki, jankijanki, champa, yaretilla de la vega.

\section{Suaeda}

Suaeda argentinensis A. Soriano

Arbusto. Nativo.

Distribución: MAG.

Rango altitudinal: 0-500 m.

Países limítrofes: Argentina.

Suaeda foliosa Moq.

Sinónimos: Suaeda foliosa Moq. var. tenuifolia (Phil.) Standl., Suaeda brevifolia Phil., Suaeda divaricata Moq. var. brevifolia (Phil.) Reiche, Suaeda divaricata Moq. var. parvifolia (Phil.) Reiche, Suaeda divaricata Moq. var. tenuifolia (Phil.) Reiche, Suaeda tenuifolia Phil., Suaeda parvifolia Phil.

Subarbusto. Nativo.

Distribución: TAR, ANT, ATA, COQ.

Rango altitudinal: 0-700 m.

Países limítrofes: Bolivia.

Suaeda multiflora Phil.

Arbusto. Endémico.

Distribución: ATA.

Rango altitudinal: 0-900 m.

Suaeda nesophila I.M. Johnst.

Sinónimos: Suaeda divaricata Moq. var. microphylla F.

Phil.

Arbusto. Endémico.

Distribución: IDE.

Rango altitudinal: 0-100 m.

Suaeda patagonica Speg.

Sinónimos: Lerchea patagonica (Speg.) Speg.

Hierba. Anual. Nativa.

Distribución: MAG.

Rango altitudinal: 0-500 m.

Países limítrofes: Argentina. 


\section{CLEOMACEAE}

\section{Cleome}

Cleome chilensis DC.

Sinónimos: Cleome chilensis DC. var. pubescens DC.

Hierba. Anual. Nativa.

Distribución: TAR, ANT, ATA.

Rango altitudinal: 300-700 m.

Países limítrofes: Bolivia y Perú.

Nombre vulgar: Hierba de los dedos, flor de la abeja, tacma.

\section{COLUMELLIACEAE}

\section{Desfontainia}

Desfontainia fulgens D. Don

Sinónimos: Desfontainia chilensis Gay, Desfontainia novemdentata Gand., Desfontainia ilicifolia Phil., Desfontainia hookeri Dunal, Desfontainia spinosa Ruiz \& Pav. var. hookeri (Dunal) Reiche, Desfontainia spinosa Ruiz \& Pav. var. chilensis (Gay) Reiche, Desfontainia spinosa Ruiz \& Pav. var. parvifolia (D. Don) Hook., Desfontainia acutangula Dunal, Desfontainia costaricensis Wooson, Desfontainia spinosa Ruiz \& Pavon, Desfontainia obovata Kraenzl., Desfontainia parvofolia D. Don, Desfontainia pulchera Mold., Desfontainia splendens Humb. \& Bonpl., Desfontainia steyemarkii Mold., Linkia peruviana Pers., Linkia spinosa (Ruiz \& Pav.) Poiret, Linkia splandens (Humb. \& Bonpl.) Poiret

Arbusto o árbol pequeño. Nativo.

Distribución: MAU, NUB, BIO, ARA, LRI, LLA, AIS, MAG.

Rango altitudinal: 0-1200 m.

Países limítrofes: Argentina, Bolivia y Perú.

Nombre vulgar: Chapico, michai blanco, taique, trautrau.

\section{CONVOLVULACEAE}

\section{Calystegia}

Calystegia sepium (L.) R.Br.

Arbusto trepador. Introducido.

Distribución: VAL, RME, LBO, MAU, NUB, BIO, ARA, LRI, LLA, AIS, JFE, IPA.

Calystegia soldanella (L.) Roem. \& Schult.

Hierba. Perenne. Introducida.

Distribución: VAL, LBO, MAU, NUB, BIO, ARA, LRI, LLA.

Rango altitudinal: 3-280 m.
Calystegia tuguriorum $\mathrm{R}$. Br. ex Hook. $\mathrm{f}$.

Hierba trepadora. Perenne. Nativa.

Distribución: LRI, AIS, JFE.

Rango altitudinal: $30-150 \mathrm{~m}$.

Países limítrofes: Argentina.

\section{Convolvulus}

Convolvulus arvensis $\mathrm{L}$.

Hierba trepadora. Perenne. Introducido.

Distribución: AYP, ANT, ATA, COQ, VAL, RME, LBO, MAU, NUB, BIO, ARA, LRI, LLA, MAG, JFE.

\section{Convolvulus bonariensis Cav.}

Sinónimos: Aniseia diversifolia Walp., Convolvulus bonariensis Cav. var. multiflorus Phil., Convolvulus dissectus Cav. var. diversifolius (Walp.) Reiche, Convolvulus triflorus Phil.

Hierba trepadora. Perenne. Nativa.

Distribución: VAL, RME.

Rango altitudinal: 0-3000 m.

Países limítrofes: Argentina.

Nombre vulgar: Correhuela, bocina.

Convolvulus chilensis Pers.

Sinónimos: Convolvulus dissectus Cav., nom. illeg., Convolvulus canescens Phil., nom. illeg., Convolvulus dissectus Cav. var. canescens (Phil.) Reiche

Hierba trepadora. Perenne. Endémica.

Distribución: ANT, ATA, COQ, VAL, RME, LBO, MAU, NUB.

Rango altitudinal: 0-1800 m.

Nombre vulgar: Correhuela, bocina.

Convolvulus demissus Choisy

Sinónimos: Convolvulus andinus Phil., Convolvulus demissus Choisy var. andinus (Phil.) Reiche, Convolvulus demissus Choisy var. ovatus (Phil.) Reiche, Convolvulus ovatus Phil.

Hierba. Perenne. Nativa.

Distribución: COQ, RME, LBO, MAU.

Rango altitudinal: 1500-3000 m.

Países limítrofes: Argentina.

\section{Convolvulus hermanniae L'Hér.}

Sinónimos: Aniseia costata (Meyen) Walp., Convolvulus costatus Meyen, Convolvulus crenatus Jacq., Convolvulus erosus Desr., Convolvulus hermanniae L'Hér. var. elongatus Choisy, Convolvulus hermanniae L'Hér. var. viridis Meisn., Convolvulus incanus Vahl, Ipomoea hermanniae (L'Hér.) G. Don

Hierba trepadora. Perenne. Nativa. Distribución: COQ, VAL, MAU, NUB, BIO, ARA. 
Rango altitudinal: 0-2500 m.

Países limítrofes: Argentina, Bolivia y Perú.

Convolvulus laciniatus Desr. var. hirsutus Desr.

Sinónimos: Convolvulus lasianthus Cav.

Hierba. Perenne. Nativa.

Distribución: ATA, COQ.

Rango altitudinal: 0-500 m.

Países limítrofes: Argentina.

Convolvulus laciniatus Desr. var. laciniatus

Sinónimos: Convolvulus geranioides Phil., Ipomoea polymorpha Riedel ex Meisn. var. glabra Griseb., Convolvulus laciniatus Desr. var. peduncularis Meisn.

Hierba. Perenne. Nativa.

Distribución: ATA, COQ, VAL.

Rango altitudinal: 0-3000 m.

Países limítrofes: Argentina, Bolivia y Perú.

\section{Cressa}

Cressa truxillensis Kunth

Sinónimos: Cressa australis R. Br. var. petiolata Meisn., Cressa cretica L. var. truxillensis (Kunth) Choisy

Hierba. Perenne. Nativa.

Distribución: TAR, ANT, ATA, COQ, RME.

Rango altitudinal: 0-2000 m.

Países limítrofes: Argentina, Bolivia y Perú.

\section{Cuscuta}

Cuscuta andina Phil.

Sinónimos: Cuscuta racemosa Mart. var. andina (Phil.)

Reiche

Hierba parásita. Anual. Nativa.

Distribución: MAU.

Países limítrofes: Argentina.

Nombre vulgar: Cabello de ángel.

Cuscuta campestris Yunck.

Hierba parásita. Anual. Introducida.

Distribución: TAR, RME, LBO, MAU, NUB, BIO, ARA, LRI.

Cuscuta chilensis Ker Gawl.

Sinónimos: Cuscuta aurea Phil.

Hierba parásita. Anual. Nativa.

Distribución: TAR, ANT, ATA, COQ, VAL, RME, LBO,

MAU, NUB, BIO, ARA, LLA.

Rango altitudinal: 1000-2300 m.

Países limítrofes: Argentina.

Nombre vulgar: Cabello de ángel, cúscuta.
Cuscuta epithymum (L.) Murray ex L. var. angustissima (Engelm.) Yunck.

Hierba parásita. Anual. Introducida.

Distribución: RME, ARA.

Cuscuta micrantha Choisy var. holwayi Yunck.

Hierba parásita. Anual. Endémica.

Distribución: MAU.

Nombre vulgar: Cabello de ángel.

Cuscuta micrantha Choisy var. latiflora Engelm.

Hierba parásita. Anual. Endémica.

Distribución: ATA.

Nombre vulgar: Cabello de ángel.

\section{Cuscuta micrantha Choisy var. micrantha}

Sinónimos: Cuscuta micrantha Choisy var. typica Yunck., nom. illeg.

Hierba parásita. Anual. Endémica.

Distribución: ANT, ATA, COQ, VAL, RME, BIO.

Rango altitudinal: $3000 \mathrm{~m}$.

Nombre vulgar: Cabello de ángel.

Cuscuta microstyla Engelm. var. bicolor (Hunz.) Hunz.

Sinónimos: Cuscuta bicolor Hunz.

Hierba parásita. Anual. Nativa.

Distribución: RME.

Rango altitudinal: 2000-2500 m.

Países limítrofes: Argentina.

Nombre vulgar: Cabello de ángel.

Cuscuta microstyla Engelm. var. microstyla

Sinónimos: Cuscuta microstyla Engelm. var. typica Hunz., nom. illeg.

Hierba parásita. Anual. Endémica.

Distribución: RME, BIO.

Rango altitudinal: 1600-3100 m.

Nombre vulgar: Cabello de ángel.

Cuscuta odorata Ruiz \& Pav.

Hierba parásita. Anual. Nativa.

Distribución: ANT, ATA, COQ, LBO.

Rango altitudinal: 600-1500 m.

Países limítrofes: Bolivia y Perú.

Nombre vulgar: Cabello de ángel.

Cuscuta pauciflora Phil.

Hierba parásita. Anual. Nativa.

Distribución: MAU, LRI.

Rango altitudinal: 0-500 m.

Países limítrofes: Argentina.

Nombre vulgar: Cabello de ángel. 
Cuscuta purpurata Phil.

Hierba parásita. Anual. Endémica.

Distribución: TAR, ANT, ATA, COQ.

Rango altitudinal: 0-300 m.

Nombre vulgar: Cabello de ángel.

Cuscuta pusilla Phil.

Hierba parásita. Anual. Endémica.

Distribución: LLA.

Nombre vulgar: Cabello de ángel.

\section{Cuscuta rustica Hunz.}

Hierba parásita. Anual. Endémica.

Distribución: COQ.

Rango altitudinal: $4000 \mathrm{~m}$.

Nombre vulgar: Cabello de ángel.

\section{Cuscuta suaveolens Ser.}

Sinónimos: Cuscuta racemosa Mart. var. chiliana Engelm., Cuscuta floribunda Phil.

Hierba parásita. Anual. Nativa.

Distribución: AYP, TAR, ATA, COQ, VAL, RME, LBO,

MAU, NUB, BIO, ARA, LRI, LLA.

Rango altitudinal: 0-2500 m.

Países limítrofes: Argentina.

Nombre vulgar: Cabello de ángel.

Cuscuta werdermannii Hunz.

Hierba parásita. Anual. Endémica.

Distribución: COQ.

Rango altitudinal: $300 \mathrm{~m}$.

Nombre vulgar: Cabello de ángel.

\section{Dichondra}

Dichondra microcalyx (Hallier f.) Fabris

Sinónimos: Dichondra repens J.R. Forst. \& G. Forst. var. microcalyx Hallier f., Dichondra repens auct. non J.R. Forst. \& G. Forst., Dichondra sericea Sw. var. microcalyx (Hallier f.) H.T. Buck

Hierba. Perenne. Nativa.

Distribución: COQ, ARA.

Rango altitudinal: 0-900 m.

Países limítrofes: Argentina, Bolivia y Perú.

Dichondra sericea Sw. var. holosericea (O'Donell) Fabris Sinónimos: Dichondra repens J.R. Forst. \& G. Forst. var. holosericea O'Donell

Hierba. Perenne. Nativa.

Distribución: COQ, VAL, MAU, NUB, BIO, ARA.

Rango altitudinal: 0-1000 m.

Países limítrofes: Argentina.
Dichondra sericea Sw. var. sericea

Sinónimos: Dichondra repens J.R. Forst. \& G. Forst. var. sericea (Sw.) Choisy, Dichondra parviflora Meisn.

Hierba. Perenne. Nativa.

Distribución: ANT, ATA, COQ, VAL, RME, LBO, MAU, NUB, BIO, ARA, LLA, JFE.

Rango altitudinal: 0-500 m.

Países limítrofes: Argentina y Bolivia.

\section{Evolvulus}

Evolvulus sericeus Sw. var. elongatus (Choisy) O'Donell Sinónimos: Evolvulus incanus Pers. var. elongatus Choisy, Leucomalla lanuginosa Phil.

Hierba. Perenne. Nativa.

Distribución: RME.

Rango altitudinal: 0-2000 m.

Países limítrofes: Argentina.

Evolvulus sericeus Sw. var. sericeus

Sinónimos: Evolvulus araucanus Phil.

Hierba. Perenne. Nativa.

Distribución: BIO.

Rango altitudinal: 0-3500 m.

Países limítrofes: Argentina, Bolivia y Perú.

\section{Ipomoea}

Ipomoea dumetorum Willd. ex Roem. \& Schult.

Sinónimos: Convolvulus dumetorum Kunth, Convolvulus pauciflorus Roem. \& Schult., Convolvulus pauciflorus Roem. \& Schult. var. chilensis (A. Braun \& Bouché) Kuntze, Ipomoea chilensis A. Braun \& Bouché, Ipomoea paposana Phil.

Hierba trepadora. Perenne. Nativa.

Distribución: ANT.

Rango altitudinal: 900-3000 m.

Países limítrofes: Argentina, Bolivia y Perú.

Ipomoea indica (Burm. f.) Merr.

Hierba trepadora. Perenne. Introducida.

Distribución: JFE.

Rango altitudinal: 0-1000 m.

Nota: Introducida en el Archipiélago Juan Fernández.

Ipomoea pes-caprae (L.) R. Br.

Hierba. Perenne. Nativa.

Distribución: IPA.

Nombre vulgar: Tanoa, tano’a.

Ipomoea purpurea (L.) Roth

Sinónimos: Convolvulus purpureus L.

Hierba trepadora. Anual. Introducida.

Distribución: VAL, RME.

Rango altitudinal: 0-2000 m. 


\section{CORIARIACEAE}

\section{Coriaria}

Coriaria ruscifolia L.

Arbusto. Nativo.

Distribución: MAU, NUB, BIO, ARA, LRI, LLA, AIS.

Rango altitudinal: 500-1600 m.

Países limítrofes: Argentina y Perú.

Nombre vulgar: Deu, huique, huiqui, matarratones.

\section{CRASSULACEAE}

\section{Crassula}

Crassula closiana (Gay) Reiche

Sinónimos: Tillaea closiana Gay

Hierba. Anual. Nativa.

Distribución: ATA, COQ, VAL, RME, LBO.

Rango altitudinal: 0-700 m.

Países limítrofes: Bolivia y Perú.

Crassula connata (Ruiz \& Pav.) A. Berger var. connata

Sinónimos: Crassula erecta (Hook. \& Arn.) Berger, Tillaea connata Ruiz \& Pav., Tillaeae erecta Hook. \& Arn., Tillaeae minima Gay

Hierba. Anual. Nativa.

Distribución: AYP, TAR, ANT, ATA, COQ, VAL, RME, LBO, MAU, NUB, LLA.

Rango altitudinal: 0-3300 m.

Países limítrofes: Argentina, Bolivia y Perú.

Crassula connata (Ruiz \& Pav.) A. Berger var. erectoides M. Bywater \& Wickens

Hierba. Anual. Nativa.

Distribución: VAL, RME, MAU.

Nota: Presente en Arizona, California y México.

Crassula connata (Ruiz \& Pav.) A. Berger var. muscoides M. Bywater \& Wickens

Hierba. Anual. Endémica.

Distribución: LLA.

Crassula decumbens Thunb.

Sinónimos: Crassula ovallei (Phil.) Reiche, Crassula radicans (Phil.) Reiche, Tillaea ovallei Phil., Tillaea radicans Phil., Tillaea rencana Phil.

Hierba. Anual. Nativa.

Distribución: VAL.

Crassula drummondii (Torr. \& A. Gray) Fedde Sinónimos: Tillaea drummondii Torr. \& A. Gray Hierba. Anual. Nativa.
Distribución: RME, MAU.

Rango altitudinal: 0-3000 m.

Países limítrofes: Argentina.

Crassula moschata G. Forst.

Sinónimos: Bulliarda magellanica DC., nom. nud., Crassula magellanica (Willd. ex Schult.) Macloskie, Tillaea magellanica Willd. ex Schult., Tillaea moschata (G. Forst.) DC., Tillaea chiloensis Gay

Hierba. Anual. Nativa.

Distribución: LRI, LLA, AIS, MAG.

Rango altitudinal: 0-100 m.

Países limítrofes: Argentina.

Crassula peduncularis (Sm.) F. Meigen

Sinónimos: Crassula paludosa (Schltdl.) Reiche, Tillaea paludosa Schltdl. ex Lechl., nom. nud., Tillaea peduncularis Sm.

Hierba. Anual. Nativa.

Distribución: COQ, VAL, RME, LBO, NUB, BIO, ARA, LRI, LLA, AIS.

Rango altitudinal: 0-2500 m.

Países limítrofes: Argentina.

Crassula solieri (Gay) F. Meigen

Sinónimos: Tillaea solierii Gay, Tillaea andicola Phil., Crassula andicola (Phil.) Meigen

Hierba. Anual. Nativa.

Distribución: RME, MAU, NUB, BIO.

Rango altitudinal: 100-500 m.

Nota: También en Norteamérica.

Crassula tillaea Lest.-Garl.

Hierba. Anual. Introducida.

Distribución: COQ, VAL, RME, LBO, MAU, NUB, BIO.

Sedum

Sedum acre L.

Hierba. Perenne. Introducida.

Distribución: ARA, LLA, AIS, MAG.

\section{CUCURBITACEAE}

\section{Sicyos}

Sicyos baderoa Hook. \& Arn. var. ambrosianus (Skottsb.) Martic. \& Quezada

Sinónimos: Sicyos bryoniaefolius Moris var. ambrosianus Skottsb.

Hierba trepadora. Anual. Endémica.

Distribución: IDE.

Rango altitudinal: 400-500 m. 
Sicyos baderoa Hook. \& Arn. var. baderoa

Sinónimos: Sicyos bryoniaefolius Moris

Hierba trepadora. Anual. Nativa.

Distribución: AYP, TAR, ANT, ATA, COQ, VAL, RME, JFE.

Rango altitudinal: 0-900 m.

Países limítrofes: Bolivia y Perú.

Nombre vulgar: Brionia, calabacillo, tupac-llanco.

\section{CUNONIACEAE}

\section{Caldcluvia}

Caldcluvia paniculata (Cav.) D. Don

Sinónimos: Weinmannia paniculata Cav., Dieterica paniculata (Cav.) Ser. ex A. DC., Caldcluvia paniculata (Cav.) D. Don var. mochaena Kunke, Weinmannia corymbosa Ruiz \& Pav., Weinmannia chilensis DC.

Árbol. Nativo.

Distribución: MAU, NUB, BIO, ARA, LRI, LLA, AIS.

Rango altitudinal: 0-500 m.

Países limítrofes: Argentina.

Nombre vulgar: Tiaca, triaca, quiaca.

\section{Eucryphia}

Eucryphia cordifolia Cav.

Sinónimos: Pellinia cordifolia (Cav.) Molina

Árbol. Nativo.

Distribución: BIO, ARA, LRI, LLA, AIS.

Rango altitudinal: 0-1000 $\mathrm{m}$.

Países limítrofes: Argentina.

Nombre vulgar: Ulmo, muermo.

Eucryphia glutinosa (Poepp. \& Endl.) Baill.

Sinónimos: Eucryphia pinnatifolia Gay, Fagus glutinosa

Poepp. \& Endl., Eucryphia glandulosa Reiche

Arbusto o árbol pequeño. Endémico.

Distribución: MAU, NUB, BIO, ARA.

Nombre vulgar: Guindo santo.

\section{Weinmannia}

Weinmannia trichosperma Cav.

Sinónimos: Weinmannia dentata Ruiz \& Pav., Windmannia trichosperma (Cav.) Kuntze

Árbol. Nativo.

Distribución: MAU, NUB, BIO, ARA, LRI, LLA, AIS, MAG.

Rango altitudinal: 0-1000 m.

Países limítrofes: Argentina.

Nombre vulgar: Tineo, palo santo, teñiu, tinel, maden.

\section{DROSERACEAE}

\section{Drosera}

Drosera uniflora Willd.

Sinónimos: Drosera macloviana Gand.

Hierba. Perenne. Nativa.

Distribución: ARA, LRI, LLA, AIS, MAG.

Rango altitudinal: 0-600 m.

Países limítrofes: Argentina.

Nombre vulgar: Atrapa-moscas.

\section{ELAEOCARPACEAE}

\section{Aristotelia}

Aristotelia chilensis (Molina) Stuntz

Sinónimos: Aristotelia glandulosa Ruiz \& Pav., nom. illeg., Aristotelia macqui L'Hér., Aristotelia macqui L'Hér. var. alpestris Reiche, Aristotelia macqui L'Hér. var. andina Phil., Cornus chilensis Molina, Aristotelia glabra Miers

Árbol. Nativo.

Distribución: COQ, VAL, RME, LBO, MAU, NUB, BIO, ARA, LRI, LLA, AIS, JFE.

Rango altitudinal: 0-1500 m.

Países limítrofes: Argentina.

Nombre vulgar: Maqui, clon.

Nota: Introducida en el Archipiélago Juan Fernández.

\section{Crinodendron}

\section{Crinodendron hookerianum Gay}

Sinónimos: Tricuspidaria hookeriana (Gay) A. Cunn., Tricuspidaria lanceolata Miq., Crinodendron eriocladum Gand.

Árbol. Endémico.

Distribución: ARA, LRI, LLA.

Rango altitudinal: 0-1100 m.

Nombre vulgar: Chaquihue, chequehue, polizón, olivillo.

Crinodendron patagua Molina

Sinónimos: Tricuspidaria dependens Ruiz \& Pav., Crinodendron dependens (Ruiz \& Pav.) Kuntze, Tricuspidaria hexapetala Turcz., Tricuspidaria patagua (Molina) Miers Árbol. Endémico.

Distribución: VAL, RME, LBO, MAU, NUB, BIO, JFE.

Rango altitudinal: 0-1800 m.

Nombre vulgar: Patagua, patahua.

Nota: Introducida en el Archipiélago Juan Fernández. 


\section{ELATINACEAE}

\section{Elatine}

Elatine triandra Schkuhr

Sinónimos: Elatine chilensis Naudin, Elatine nivalis Speg., Elatine hydropiper L. var. triandra (Schkuhr) Fiori

Hierba. Anual. Nativa.

Distribución: RME, LBO, MAU, NUB, BIO, ARA, LRI, LLA.

Rango altitudinal: 0-1000 m.

Países limítrofes: Argentina, Bolivia y Perú.

Nombre vulgar: Yerbilla, hierbilla.

\section{ERICACEAE}

\section{Empetrum}

Empetrum rubrum Vahl ex Willd.

Sinónimos: Empetrum nigrum L. var. andinum DC., Empetrum maclovianum Gand.

Arbusto. Nativo.

Distribución: VAL, RME, LBO, MAU, NUB, BIO, ARA, LRI, LLA, AIS, MAG, JFE.

Países limítrofes: Argentina.

Nombre vulgar: Brecillo, murtilla de Magallanes.

\section{Gaultheria}

Gaultheria antarctica Hook.f.

Sinónimos: Pernettya serpyllifolia (Lam.) DC., Arbutus serpyllifolia Lam., Gaultheria microphylla Hook.f., Gaultheria serpyllifolia (Lam.) Skottsb., Pernettya hookeri Nied.

Subarbusto. Nativo.

Distribución: ARA, LRI, LLA, AIS, MAG.

Rango altitudinal: 0-500 m.

Países limítrofes: Argentina.

Gaultheria caespitosa Poepp. \& Endl.

Sinónimos: Pernettya minima Phil., Gaultheria minima (Phil.) Sandwith

Arbusto o subarbusto. Nativo.

Distribución: VAL, LBO, MAU, NUB, BIO, ARA, LLA, AIS.

Rango altitudinal: 1500-2500 m.

Países limítrofes: Argentina.

Gaultheria insana (Molina) D.J. Middleton

Sinónimos: Hippomanica insana Molina, Pernettya furiens (Hook. \& Arn.) Klotzsch, Pernettya insana (Molina) Gunckel, Gaultheria furiens (Hook. \& Arn.) Hook. \& Arn., Arbutus furiens Hook. \& Arn., Arbutus punctata Hook. \& Arn., Gaultheria punctata (Hook. \& Arn.) Hook. \& Arn.,
Pernettya punctata (Hook. \& Arn.) Klotzsch, Arbutus vernalis Poepp. \& Endl., Gaultheria vernalis (Poepp. \& Endl.) Kunze, Pernettya vernalis (Poepp. \& Endl.) Phil., Pernettya melanocarpa Phil.

Arbusto. Nativo.

Distribución: TAR, ANT, MAU, NUB, BIO, ARA, LRI, LLA, AIS, MAG.

Rango altitudinal: 0-600 m.

Países limítrofes: Argentina.

Nombre vulgar: Hued-hued.

Gaultheria linifolia (Phil.) Teillier \& R.A. Rodr.

Sinónimos: Pernettya linifolia Phil., Pernettya mucronata (L.f.) Gaudich. ex Spreng. var. linifolia (Phil.) Reiche, Pernettya prostrata (Cav.) DC. var. linifolia (Phil.) Sleumer, Pernettya myrtilloides Zucc. ex Steud. var. linifolia (Phil.) Kausel, Pernettya poeppigii (DC.) Klotzsch var. linifolia (Phil.) Sleumer, Gaultheria poeppigii DC. var. linifolia (Phil.) D.J. Middleton

Arbusto. Endémico.

Distribución: RME, ARA, LRI, LLA.

Gaultheria marticorenae Teillier \& P.W. Fritsch

Sinónimos: Pernettya angustifolia Lindl., Pernettya mucronata (L.f.) Gaudich. ex Spreng. var. angustifolia (Lindl.) Reiche, Gaultheria mucronata (L.f.) Hook. var. angustifolia (Lindl.) D.J. Middleton, Pernettya leucocarpa DC. var. linearis Reiche, Gaultheria angustifolia (Lindl.) Teillier

Arbusto. Nativo.

Distribución: MAU, NUB, BIO, ARA, LRI, LLA.

Países limítrofes: Argentina.

Nombre vulgar: Chaura.

Gaultheria mucronata (L.f.) Hook. \& Arn.

Sinónimos: Gaultheria mucronata (L.f.) Hook. \& Arn. var. microphylla (Hombr.) D.J. Middleton, Pernettya mucronata (L.f.) Gaudich. ex Spreng. var. microphylla Decne., Pernettya mucronata (L.f.) Gaudich. ex Spreng., Pernettya mucronata (L.f.) Gaudich. ex Spreng. var. parvifolia (Phil.) Skottsb., Pernettya rupicola Phil., Arbutus mucronata L.f., Arbutus rigida Banks \& Sol. ex Hook.f., Pernettya ovalifolia Hombr. \& Jacq., Pernettya oblongifolia Hombr. \& Jacq., Pernettya mucronata DC. var. rupicola (Phil.) Reiche, Pernettya litoralis Phil., Gaultheria myrtilloides Hook. \& Arn. var. minor Hook. \& Arn., Pernettya parvifolia Phil.

Arbusto. Nativo.

Distribución: MAU, NUB, BIO, ARA, LRI, LLA, AIS, MAG.

Rango altitudinal: 0-1100 m.

Países limítrofes: Argentina.

Nombre vulgar: Chaura. 
Gaultheria nubigena (Phil.) B.L. Burtt \& Sleumer

Sinónimos: Pernettya nubigena Phil.

Arbusto. Nativo.

Distribución: ARA, LLA.

Rango altitudinal: 1000-1500 m.

Países limítrofes: Argentina.

\section{Gaultheria phillyreifolia (Pers.) Sleumer}

Sinónimos: Pernettya palenae Phil., Pernettya philippii Gand., Pernettya phillyreifolia (Pers.) DC., Arbutus phillyreifolia Pers., Gaultheria florida Phil., Gaultheria myrtilloides Hook. \& Arn., Gaultheria phillyreifolia (Pers.) Sleumer var. florida (Phil.) Kausel, Gaultheria lanceolata Phil., Gaultheria myrtilloides Hook. \& Arn. var. racemosa Phil. ex Reiche

Arbusto. Nativo.

Distribución: LBO, MAU, NUB, BIO, ARA, LRI, LLA, AIS, MAG.

Rango altitudinal: 0-1500 m.

Países limítrofes: Argentina.

Nombre vulgar: Chaura.

\section{Gaultheria poeppigii DC.}

Sinónimos: Gaultheria poeppigii DC. var. nana (Sleumer) D.J. Middleton, Pernettya myrtilloides Zucc. ex Steud. var. myrtilloides, Pernettya myrtilloides Zucc. ex Steud. var. nana (Sleumer) Sleumer, Pernettya poeppigii (DC.) Klotzsch, Gaultheria myrtilloides Poepp. \& Endl., nom. illeg., Pernettya poeppigii (DC.) Klotzsch var. nana Sleumer, Pernettya buxifolia Phil., Pernettya leucocarpa DC. var. buxifolia (Phil.) Reiche, Pernettya phillyreifolia (Pers.) DC. var. araucana Kuntze

Arbusto. Nativo.

Distribución: MAU, NUB, BIO, ARA, LRI, LLA, AIS.

Rango altitudinal: 0-2500 m.

Países limítrofes: Argentina.

Nombre vulgar: Chaura, chal, cheúkk, gus, amain-ngush.

Gaultheria pumila (L.f.) D.J. Middleton var. leucocarpa (DC.) D.J. Middleton

Sinónimos: Gaultheria pumila (L.f.) D.J. Middleton var. crassifolia (Phil.) D.J. Middleton, Pernettya pumila (L.f.) Hook. var. crassifolia (Phil.) Sleumer, Pernettya pumila (L.f.) Hook. var. leucocarpa (DC.) Kausel, Pernettya breviflora Phil., Pernettya crassifolia Phil., Pernettya empetrifolia (Lam.) Gaudich. var. leucocarpa (DC.) Wedd., Pernettya leucocarpa DC., Pernettya trinervia Gand., Pernettya leucocarpa DC. var. gayana DC., Pernettya gayana (DC.) Decne.

Arbusto. Nativo.

Distribución: VAL, RME, LBO, MAU, NUB, BIO, ARA, LRI, LLA, AIS, MAG.

Rango altitudinal: 600-3200 m.

Países limítrofes: Argentina.
Gaultheria pumila (L.f.) D.J. Middleton var. pumila

Sinónimos: Pernettya pumila (L.f.) Hook., Arbutus pumila L.f., Arbutus empetrifolia Lam., Pernettya empetrifolia (Lam.) Gaudich., Pernettya pumila (L.f.) Hook. var. empetrifolia (Lam.) Hook.f.

Arbusto. Nativo.

Distribución: VAL, RME, MAU, NUB, BIO, ARA, LRI, LLA, AIS, MAG.

Rango altitudinal: 0-1000 m.

Países limítrofes: Argentina.

Nombre vulgar: Chaura, chal, chan ámain.

Gaultheria racemulosa (DC.) D.J. Middleton

Sinónimos: Pernettya rigida (Bertero ex Colla) DC., Pernettya mucronata (L.f.) Gaudich. ex Spreng. var. mutica Hook. \& Arn., Pernettya bridgesii Phil., Pernettya racemulosa DC.

Arbusto. Endémico.

Distribución: JFE.

Rango altitudinal: 100-1400 m.

Nombre vulgar: Murtillo de Juan Fernández.

Gaultheria renjifoana Phil.

Arbusto. Endémico.

Distribución: BIO.

Gaultheria tenuifolia (Phil.) Sleumer

Sinónimos: Pernettya elegans Phil., Pernettya reticulata Phil., Pernettya tenuifolia Phil., Gaultheria tenuifolia (Phil.) Sleumer var. elegans (Phil.) Kausel, Pernettya promaucana Phil., Gaultheria elegans (Phil.) Reiche, Gaultheria salicifolia Phil., Gaultheria tenuifolia (Phil.) Sleumer var. promaucana (Phil.) Kausel

Arbusto. Nativo.

Distribución: MAU, NUB, BIO, ARA, LRI.

Rango altitudinal: 500-1000 m.

Países limítrofes: Argentina.

\section{Lebetanthus}

Lebetanthus myrsinites (Lam.) Dusén

Sinónimos: Prionotes americana Hook., Lebetanthus americanus (Hook.) Endl., Jacquinotia myrsinites Hombr. \& Jacq., Jacquinotia prostrata Hombr. \& Jacq., Jacquinotia volubilis Hombr. \& Jacq., Prionotes myrsinites (Lam.) Skottsb.

Subarbusto epífito o terrestre. Nativo.

Distribución: LLA, AIS, MAG.

Países limítrofes: Argentina. 


\section{ESCALLONIACEAE}

\section{Escallonia}

Escallonia alpina Poepp. ex DC. var. alpina

Sinónimos: Escallonia araucana Phil., Escallonia fonckii Phil., Escallonia fonckii Phil. var. araucana (Phil.) Reiche, Escallonia alpina Poepp. ex DC. var. glaberrima Phil., Escallonia sparsiflora Phil.

Arbusto. Nativo.

Distribución: VAL, RME, LBO, MAU, NUB, BIO, ARA, LRI, LLA, AIS, MAG.

Rango altitudinal: 200-2300 m.

Países limítrofes: Argentina.

Escallonia alpina Poepp. ex DC. var. carmelitana (Meyen) Acevedo \& Kausel

Sinónimos: Escallonia carmelitana Meyen, Escallonia flavescens $\mathrm{C}$. Presl

Arbusto. Nativo.

Distribución: VAL, RME, LBO, MAU, NUB, MAG.

Rango altitudinal: 0-3000 m.

Países limítrofes: Argentina.

Escallonia alpina Poepp. ex DC. var. glabrata (Phil.) Sleumer Sinónimos: Escallonia glabrata Phil.

Arbusto. Endémico.

Distribución: NUB, BIO, ARA.

Rango altitudinal: 600-2000 m.

Escallonia angustifolia C. Presl

Sinónimos: Escallonia coquimbensis J. Remy, Escallonia angustifolia C. Presl var. coquimbensis (J. Remy) Acevedo \& Kausel, Escallonia coquimbensis J. Remy var. salicifolia Reiche

Arbusto o árbol pequeño. Nativo.

Distribución: AYP, TAR, ATA, COQ, MAU.

Rango altitudinal: 0-3300 $\mathrm{m}$.

Países limítrofes: Argentina y Perú.

Nombre vulgar: Ñipa, q'ero.

Escallonia callcottiae Hook. \& Arn.

Sinónimos: Escallonia callcottiae Hook. \& Arn. var. fernandeziana (Phil.) Engl., Escallonia rubricaulis Colla, Escallonia fernandeziana Phil.

Arbusto o árbol pequeño. Endémico.

Distribución: JFE.

Rango altitudinal: 0-800 m.

Escallonia florida Poepp. ex DC.

Arbusto. Endémico.

Distribución: MAU, NUB, BIO, ARA.

Rango altitudinal: 500-2000 m.

Nombre vulgar: Sauco cimarrón.
Escallonia gayana Acevedo \& Kausel

Arbusto. Endémico.

Distribución: BIO, ARA, LLA.

Rango altitudinal: 0-400 $\mathrm{m}$.

Escallonia illinita C. Presl var. illinita

Sinónimos: Escallonia glandulosa Lodd. non Sm., Escallonia rubra Bertero non Ruiz \& Pav., Escallonia grahamiana Hook. \& Arn., Escallonia viscosa Forbes

Arbusto. Endémico.

Distribución: COQ, VAL, RME, LBO, MAU, NUB, BIO.

Rango altitudinal: 0-3000 m.

Nombre vulgar: Corontillo, ñipa, barraco, siete camisas.

Escallonia illinita C. Presl var. pubicalycina Briq.

Sinónimos: Escallonia illinita C. Presl var. stenopetala (Kunze) Acevedo \& Kausel, Escallonia stenopetala Kunze, Escallonia illinita C. Presl var. beta Hook. \& Arn.

Arbusto. Endémico.

Distribución: COQ, VAL, RME, LBO, MAU, NUB, BIO, ARA.

Rango altitudinal: 100-3000 m.

Escallonia leucantha J. Remy

Sinónimos: Escallonia bellidifolia Phil., Escallonia pycnantha Briq., Escallonia modesta Briq.

Arbusto. Nativo.

Distribución: MAU, NUB, BIO, ARA, LRI, LLA.

Rango altitudinal: 0-1500 m.

Países limítrofes: Argentina.

Nombre vulgar: Luncillo, siete camisas.

Escallonia myrtoidea Bertero ex DC.

Sinónimos: Escallonia arguta C. Presl, Escallonia reflexa Gillies, Escallonia andina Phil., Escallonia illinita C. Presl var. andina (Phil.) Reiche, Escallonia claudii Killip, Escallonia microcarpa Gillies ex Hook. \& Arn., nom. nud.

Arbusto o árbol pequeño. Nativo.

Distribución: COQ, VAL, RME, LBO, MAU, NUB, BIO.

Rango altitudinal: 100-3000 m.

Países limítrofes: Argentina.

Nombre vulgar: Luncalun.

Escallonia pulverulenta (Ruiz \& Pav.) Pers. var. glabra Engl.

Sinónimos: Escallonia resinosa auct. non Ruiz \& Pav., Escallonia berteriana DC., Escallonia resiniflua Walp., Escallonia pulverulenta (Ruiz \& Pav.) Pers. var. berteriana (DC.) Pamp., Escallonia pulverulenta (Ruiz \& Pav.) Pers. var. resiniflua (Walp.) Pamp.

Arbusto o árbol pequeño. Endémico.

Distribución: COQ, VAL, RME, LBO, MAU, NUB, BIO.

Rango altitudinal: 0-1300 m.

Nombre vulgar: Corontillo, mardoño. 
Escallonia pulverulenta (Ruiz \& Pav.) Pers. var. pulverulenta

Sinónimos: Stereoxylon pulverulentum Ruiz \& Pav., Escallonia spinulosa Kunth ex Engl., nom. nud.

Arbusto o árbol pequeño. Endémico.

Distribución: COQ, VAL, RME, LBO, MAU, NUB, BIO, ARA.

Rango altitudinal: 0-2000 m.

Nombre vulgar: Corontillo, mardoño.

Escallonia revoluta (Ruiz \& Pav.) Pers.

Sinónimos: Stereoxylon revolutum Ruiz \& Pav., Escallonia thyrsoidea Bertero, nom. nud., Escallonia hirsuta C. Presl, Escallonia affinis Rupr. ex A. Gray, nom. nud.

Árbol. Endémico.

Distribución: COQ, VAL, RME, MAU, NUB, BIO, ARA, LRI.

Rango altitudinal: 0-1800 m.

Nombre vulgar: Lun, siete camisas.

\section{Escallonia rosea Griseb.}

Sinónimos: Escallonia pterocladon Hook., Escallonia rupestris Phil., Escallonia chonotica Phil., Escallonia montana Phil., Escallonia longidens Phil., Escallonia rosea Griseb. var. rupestris (Phil.) Reiche

Arbusto. Nativo.

Distribución: MAU, NUB, BIO, ARA, LRI, LLA, AIS, MAG.

Rango altitudinal: 0-1500 m.

Países limítrofes: Argentina.

Nombre vulgar: Siete camisas, siete camisas colorado.

Escallonia rubra (Ruiz \& Pav.) Pers. var. dumetorum (Phil.) Acevedo \& Kausel

Sinónimos: Escallonia berberifolia auct. non (Humb. \& Bonpl.) Kunth, Escallonia dumetorum Phil.

Arbusto. Nativo.

Distribución: ARA, LRI, LLA.

Rango altitudinal: 0-1300 m.

Países limítrofes: Argentina.

Escallonia rubra (Ruiz \& Pav.) Pers. var. glutinosa (Phil.) Reiche

Sinónimos: Escallonia glutinosa Phil.

Arbusto. Endémico.

Distribución: LBO, MAU, NUB, BIO.

Rango altitudinal: $100-2100 \mathrm{~m}$.

Escallonia rubra (Ruiz \& Pav.) Pers. var. macrantha (Hook. \& Arn.) Reiche

Sinónimos: Escallonia macrantha Hook. \& Arn.

Arbusto. Endémico.

Distribución: NUB, ARA, LRI, LLA, AIS.

Rango altitudinal: 0-1000 m.
Escallonia rubra (Ruiz \& Pav.) Pers. var. rubra

Sinónimos: Stereoxylon rubrum Ruiz \& Pav., Escallonia poeppigiana DC., Escallonia poeppigiana DC. var. longifolia DC., Escallonia punctata DC., Escallonia duplicato-serrata J. Remy, Escallonia littoralis Phil., Escallonia littoralis Phil. var. concinna (Phil.) Reiche, Escallonia concinna Phil., Escallonia macrantha Hook. \& Arn. var. duplicato-serrata (J. Remy) Engl., Escallonia rubra (Ruiz \& Pav.) Pers. var. punctata (DC.) Hook.f., Escallonia rahmeri Phil., Escallonia rubra (Ruiz \& Pav.) Pers. var. glabriuscula Hook. \& Arn., Escallonia rubra (Ruiz \& Pav.) Pers. var. uniflora Poepp. \& Endl., Escallonia rubra (Ruiz \& Pav.) Pers. var. multiflora Poepp. \& Endl., Escallonia commutata Regel

Arbusto. Nativo.

Distribución: COQ, VAL, RME, LBO, MAU, NUB, BIO, ARA, LRI, LLA, AIS, MAG.

Rango altitudinal: 0-2300 m.

Países limítrofes: Argentina.

Nombre vulgar: Ñipa, siete camisas colorado, möki, müki.

Escallonia rubra (Ruiz \& Pav.) Pers. var. thalassica Kausel Arbusto. Endémico.

Distribución: COQ, VAL, RME, MAU.

Rango altitudinal: 0-400 m.

Escallonia serrata $\mathrm{Sm}$.

Sinónimos: Celastrus venustus Banks \& Sol. ex Hook.f., Stereoxylon serratum (Sm.) Poir.

Arbusto. Nativo.

Distribución: LLA, AIS, MAG.

Rango altitudinal: 0-400 $\mathrm{m}$.

Países limítrofes: Argentina.

Escallonia virgata (Ruiz \& Pav.) Pers.

Sinónimos: Stereoxylon virgatum Ruiz \& Pav., Escallonia stricta J. Remy, Escallonia patagonica Gand., Escallonia virgata (Ruiz \& Pav.) Pers. var. philippiana Engl., Escallonia virgata (Ruiz \& Pav.) Pers. var. pavoniana Pamp., Escallonia philippiana (Engl.) Mast., Escallonia stenophylla Phil., Escallonia angustifolia Phil.

Arbusto. Nativo.

Distribución: RME, MAU, NUB, BIO, ARA, LRI, LLA, AIS, MAG.

Rango altitudinal: 0-3000 m.

Países limítrofes: Argentina.

Nombre vulgar: Mata negra, meki.

\section{Tribeles}

Tribeles australis Phil.

Sinónimos: Chalepoa magellanica Hook.f., Tribeles philippii Macloskie

Subarbusto. Nativo. 
Distribución: LRI, LLA, AIS, MAG.

Rango altitudinal: 0-1000 m.

Países limítrofes: Argentina.

\section{Valdivia}

Valdivia gayana J. Remy

Sinónimos: Valdivia gayana Remy var. hollermayeri Gunckel, Valdivia gayana Remy var. robusta Gunckel

Subarbusto. Endémico.

Distribución: LRI.

Rango altitudinal: 0-300 m.

\section{EUPHORBIACEAE}

\section{Adenopeltis}

Adenopeltis serrata (W.T. Aiton) I.M. Johnst.

Sinónimos: Excoecaria marginata (Baill.) Griseb., Adenopeltis colliguaya Bertero ex A. Juss., Excoecaria serrata W.T. Aiton, Excoecaria colliguaya (Bertero ex A. Juss.) Baill., Stillingia glandulosa Dombey ex Baill.

Arbusto. Endémico.

Distribución: COQ, VAL, RME, LBO, MAU, NUB, BIO.

Nombre vulgar: Colliguay macho, lechón.

\section{Avellanita}

Avellanita bustillosii Phil.

Arbusto. Endémico.

Distribución: VAL, RME, LBO.

Rango altitudinal: 300-800 m.

Nombre vulgar: Avellanita.

\section{Chiropetalum}

Chiropetalum berterianum Schltdl. var. berterianum

Sinónimos: Argythamnia berteriana (Schltdl.) Müll. Arg., Chiropetalum berterianum Schltdl. fma. macrantha Skottsb.

Subarbusto. Endémico.

Distribución: ATA, COQ, VAL, RME, LBO, MAU, ARA.

Rango altitudinal: 200-1800 m.

Chiropetalum berterianum Schltdl. var. psiladenium Skottsb.

Sinónimos: Argythamnia berteriana (Schltdl.) Müll. Arg. var. psiladenia (Skottsb.) J.W. Ingram

Subarbusto. Endémico.

Distribución: ATA, COQ, VAL.

Rango altitudinal: $600 \mathrm{~m}$.
Chiropetalum canescens Phil.

Sinónimos: Argythamnia canescens (Phil.) F. Phil., Argythamnia sponiella Müll. Arg., Chiropetalum gigouxii Espinosa, Chiropetalum sponiella (Müll. Arg.) Pax

Subarbusto. Endémico.

Distribución: ANT, ATA.

Rango altitudinal: 0-200 m.

Chiropetalum cremnophilum I.M. Johnst.

Sinónimos: Argythamnia cremnophila (I.M. Johnst.) J.W. Ingram

Subarbusto. Endémico.

Distribución: ANT, ATA, COQ.

Rango altitudinal: $200 \mathrm{~m}$.

Chiropetalum tricuspidatum (Lam.) A. Juss.

Sinónimos: Croton tricuspidatus Lam., Argythamnia tricuspidata (Lam.) Müll. Arg. var. lanceolata (Cav.) Müll. Arg., Chiropetalum lanceolatum (Cav.) A. Juss., Croton lanceolatum Cav., Chiropetalum tricuspidatum (Lam.) A. Juss. var. lanceolatum (Cav.) Pax \& K. Hoffm., Chiropetalum ovatum Phil., Argythamnia tricuspidata (Lam.) Müll. Arg.

Subarbusto. Nativo.

Distribución: ATA, COQ, VAL, RME, LBO, MAU, NUB, BIO, ARA, LRI.

Rango altitudinal: 0-1500 m.

Países limítrofes: Argentina.

Nombre vulgar: Ventosilla.

\section{Colliguaja}

Colliguaja dombeyana A. Juss.

Arbusto. Endémico.

Distribución: COQ, RME, LBO, MAU, NUB, BIO.

Rango altitudinal: 0-2700 m.

Nombre vulgar: Colliguay.

Colliguaja integerrima Gillies \& Hook.

Arbusto. Nativo.

Distribución: COQ, VAL, RME, LBO, MAU, NUB, AIS, MAG.

Rango altitudinal: 500-1500 m.

Países limítrofes: Argentina.

Nombre vulgar: Colliguay.

\section{Colliguaja odorifera Molina}

Sinónimos: Colliguaja triquetra Gillies \& Hook., Colliguaja obtusa Regel, Croton colliguay Molina

Arbusto. Endémico.

Distribución: ANT, ATA, COQ, VAL, RME, LBO, MAU, BIO.

Rango altitudinal: 0-1300 m.

Nombre vulgar: Colliguay. 
Colliguaja salicifolia Gillies \& Hook.

Sinónimos: Colliguaja dombeyana Gay, nom. illeg. Arbusto. Endémico.

Distribución: COQ, VAL, RME, LBO, MAU, BIO.

Rango altitudinal: 200-1800 m.

Nombre vulgar: Colliguay.

\section{Croton}

Croton chilensis Müll. Arg.

Arbusto. Endémico.

Distribución: ANT.

Rango altitudinal: 300-800 m.

Nombre vulgar: Higuerilla.

Croton setiger Hook

Hierba. Anual. Introducida.

Distribución: VAL, RME, MAU, BIO.

Dysopsis

Dysopsis glechomoides (A. Rich.) Müll. Arg.

Sinónimos: Hydrocotyle glechomoides A. Rich., Dysopsis gayana Baill., Dysopsis glechomoides (A. Rich.) Müll. Arg. var. genuina Müll. Arg., Molina chilensis Gay

Hierba. Perenne. Nativa.

Distribución: COQ, BIO, ARA, LRI, LLA, AIS, MAG.

Rango altitudinal: 0-1300 m.

Países limítrofes: Argentina y Bolivia.

Dysopsis hirsuta (Müll. Arg.) Skottsb.

Sinónimos: Dysopsis glechomoides (A. Rich.) Müll. Arg. var. hirsuta Müll. Arg.

Hierba. Perenne. Endémica.

Distribución: JFE.

\section{Euphorbia}

Euphorbia amandi Oudejans

Sinónimos: Euphorbia ovalifolia (Klotzsch \& Garcke) Boiss. var. dentata R.E. Fr.

Hierba. Anual. Nativa.

Distribución: AYP, TAR, ANT.

Rango altitudinal: 1500-4000 m.

Países limítrofes: Argentina.

Nombre vulgar: J'alpa.

\section{Euphorbia araucana Phil.}

Hierba. Perenne. Endémica.

Distribución: ARA.

Euphorbia besseri (Klotzsch \& Garcke) Boiss. Sinónimos: Anisophyllum besseri Klotzsch \& Garcke Hierba. Perenne. Endémica.
Nota: Distribución desconocida.

Euphorbia collina Phil. var. andina (Phil.) Subils

Sinónimos: Euphorbia andina Phil., Euphorbia dasyclada

Dusén, Euphorbia portulacoides L. var. andensis Croizat

Hierba. Perenne. Nativa.

Distribución: MAU, ARA, MAG.

Rango altitudinal: 500-1000 m.

Países limítrofes: Argentina.

Euphorbia collina Phil. var. collina

Sinónimos: Euphorbia portulacoides L. subsp. collina (Phil.) Croizat

Hierba. Perenne. Nativa.

Distribución: COQ, RME, LBO, MAU, NUB, BIO, ARA, MAG.

Rango altitudinal: 0-3100 m.

Países limítrofes: Argentina.

Euphorbia collina Phil. var. minor (Hicken) Subils

Sinónimos: Euphorbia portulacoides L. var. minor Hicken

Hierba. Perenne. Nativa.

Distribución: MAG.

Rango altitudinal: 2000-2500 m.

Países limítrofes: Argentina.

Euphorbia collina Phil. var. spathulata (Chodat \& Wilczek) Subils

Sinónimos: Euphorbia portulacoides L. var. spathulata Chodat \& Wilczek

Hierba. Perenne. Nativa.

Distribución: AIS.

Rango altitudinal: 0-2500 m.

Países limítrofes: Argentina.

Euphorbia copiapina Phil.

Sinónimos: Euphorbia calderensis Phil.

Hierba. Perenne. Endémica.

Distribución: ANT, ATA.

Euphorbia cyathophora Murray

Hierba. Anual. Introducida.

Distribución: ANT.

Euphorbia elquiensis Phil.

Hierba. Perenne. Endémica.

Distribución: ATA, COQ.

Euphorbia engelmannii Boiss.

Sinónimos: Euphorbia rotundifolia Hook. \& Arn., nom. illeg., Euphorbia hortensis Engelm. ex Boiss., nom. nud., Euphorbia engelmannii Boiss. var. depressa Boiss., Euphorbia inclinata Boiss., nom. nud., Chamaesaracha engelmannii (Boiss.) Soják 
Hierba. Anual. Endémica.

Distribución: ATA, COQ, VAL, RME, LBO.

Rango altitudinal: 900-2000 m.

\section{Euphorbia falcata L.}

Hierba. Anual. Introducida.

Distribución: RME.

\section{Euphorbia germainii Phil.}

Hierba. Anual. Endémica.

Distribución: COQ, RME.

Rango altitudinal: 1600-3200 m.

\section{Euphorbia helioscopia L.}

Hierba. Anual o bienal. Introducida.

Distribución: TAR, ATA, COQ, VAL, RME, BIO, ARA, LLA.

\section{Euphorbia hirta L.}

Hierba. Anual. Introducida.

Distribución: AYP, TAR, IPA.

\section{Euphorbia hypericifolia L.}

Hierba. Perenne. Introducida.

Distribución: VAL, IPA.

Euphorbia klotzschii Oudejans var. argentina (Müll. Arg. ex Griseb.) Oudejans

Sinónimos: Euphorbia ovalifolia (Klotzsch \& Garcke) Boiss. var. argentina Müll. Arg. ex Griseb.

Hierba. Anual. Nativa.

Distribución: MAU.

Rango altitudinal: 0-500 m.

Países limítrofes: Argentina.

Euphorbia klotzschii Oudejans var. klotzschii

Sinónimos: Anisophyllum ovalifolium Klotzsch \& Garcke, Chamaesyce ovalifolia (Klotzsch \& Garcke) Croizat

Hierba. Anual. Nativa.

Distribución: AYP, TAR, ANT, ATA, COQ, VAL, RME, LBO, MAU, NUB, BIO, ARA.

Rango altitudinal: 0-1000 m.

Países limítrofes: Argentina y Bolivia.

Euphorbia klotzschii Oudejans var. schizosepala (Engelm. ex Boiss.) Oudejans

Sinónimos: Euphorbia ovalifolia (Klotzsch \& Garcke)

Boiss. var. schizosepala Engelm. ex Boiss.

Hierba. Anual. Nativa.

Distribución: MAU, NUB, BIO, ARA, LRI, LLA, JFE.

Rango altitudinal: 0-1000 m.

Países limítrofes: Argentina.
Euphorbia lactiflua Phil.

Arbusto. Endémico.

Distribución: ANT, ATA.

Rango altitudinal: 0-700 m.

Nombre vulgar: Lechero.

Euphorbia lathyris L.

Hierba. Anual o bienal. Introducida.

Distribución: VAL, RME, LBO, MAU, NUB, BIO, ARA, LRI, LLA, JFE.

Euphorbia macraulonia Phil.

Hierba. Perenne. Endémica.

Distribución: RME.

Euphorbia maculata L.

Hierba. Perenne. Introducida.

Distribución: ATA, COQ, VAL, RME, LBO, MAU, NUB, BIO.

Euphorbia meyeniana Klotzsch

Sinónimos: Chamaesyce meyeniana (Klotzsch) Croizat

Hierba. Anual. Nativa.

Distribución: AYP, TAR, ATA.

Rango altitudinal: 0-500 m.

Países limítrofes: Bolivia.

Euphorbia ovalleana Phil.

Hierba. Perenne. Endémica.

Distribución: COQ.

Euphorbia peplus L.

Hierba. Anual. Introducida.

Distribución: AYP, TAR, ANT, ATA, COQ, VAL, RME, LBO, MAU, NUB, BIO, ARA, LRI, LLA, JFE, IPA.

Euphorbia philippiana (Klotzsch \& Garcke) Boiss. Sinónimos: Tithymalus philippianus Klotzsch \& Garcke Hierba. Anual. Endémica.

Distribución: BIO.

Euphorbia platyphyllos L.

Hierba. Anual. Introducida.

Distribución: VAL, RME, LBO, MAU, NUB, BIO.

Euphorbia porphyrantha Phil.

Hierba. Perenne. Nativa.

Distribución: ANT, ATA.

Países limítrofes: Perú.

Euphorbia portulacoides L.

Sinónimos: Euphorbia chilensis Gay, Euphorbia portulacoides L. subsp. normalis (Kuntze) Croizat, Euphorbia portulacoides L. var. normalis Kuntze 
Hierba. Perenne. Nativa. Distribución: COQ, VAL, RME, LBO, MAU, NUB, BIO, ARA, LRI, LLA, AIS, MAG.

Rango altitudinal: 0-1700 m.

Países limítrofes: Argentina y Bolivia.

Euphorbia raphilippii Oudejans

Hierba. Perenne. Endémica.

Distribución: COQ.

Euphorbia serpens Kunth

Sinónimos: Chamaesyce serpens (Kunth) Small

Hierba. Perenne. Nativa.

Distribución: AYP, TAR, ANT, COQ, VAL, RME, MAU, NUB, BIO, ARA, IPA.

Rango altitudinal: 0-900 m.

Países limítrofes: Argentina, Bolivia y Perú.

Nombre vulgar: Pato (Rapa Nui).

Nota: Introducida en la Isla de Pascua.

\section{Euphorbia tarapacana Phil.}

Hierba. Anual. Endémica.

Distribución: AYP, TAR, ANT.

Rango altitudinal: 100-1300 m.

\section{Euphorbia terracina L.}

Hierba. Perenne. Introducida.

Distribución: VAL.

Euphorbia thinophila Phil.

Hierba. Perenne. Endémica.

Distribución: ANT, ATA, COQ.

Rango altitudinal: 0-300 m.

\section{Euphorbia verna Phil.}

Hierba. Anual. Endémica.

Distribución: BIO.

Rango altitudinal: 0-500 m.

Ficus

Ficus carica L.

Árbol. Introducido.

Distribución: ANT, JFE.

Nombre vulgar: Higuera.

\section{Mercurialis}

Mercurialis annua L.

Hierba. Anual. Introducida.

Distribución: ANT, VAL.

\section{Ricinus}

Ricinus communis L.

Hierba o subarbusto. Perenne. Introducida.

Distribución: AYP, ANT, ATA, COQ, VAL, RME, BIO, LLA, JFE, IPA.

\section{FABACEAE}

\section{Acacia}

Acacia aroma Gillies ex Hook. \& Arn.

Arbusto o árbol pequeño. Introducido.

Distribución: AYP, TAR.

Acacia caven (Molina) Molina

Sinónimos: Acacia cavenia (Molina) Hook. \& Arn., Acacia farnesiana (L.) Willd. fma. cavenia (Molina) E.C. Clos, Mimosa cavenia Molina, Mimosa caven Molina, Vachellia caven (Molina) Seigler \& Ebinger, Vachellia caven (Molina) Seigler \& Ebinger var. caven (Molina) Molina, Vachellia caven (Molina) Seigler \& Ebinger var. dehiscens Ciald., Acacia caven (Molina) Molina var. dehiscens Burkart ex Ciald.

Árbol. Nativo.

Distribución: ATA, COQ, VAL, RME, LBO, MAU, NUB, BIO, ARA, LRI.

Rango altitudinal: 0-3000 m.

Países limítrofes: Argentina y Bolivia.

Nombre vulgar: Espino.

Acacia dealbata Link

Arbusto o árbol pequeño. Introducido.

Distribución: VAL, RME, LBO, MAU, NUB, BIO, ARA, LRI, LLA, JFE.

Nombre vulgar: Aromo.

Acacia horrida (L.) Willd.

Árbol. Introducido.

Distribución: ATA, RME.

Acacia karroo Hayne

Arbusto o árbol pequeño. Introducido.

Distribución: TAR, RME.

Acacia macracantha Humb. \& Bonpl. ex Willd.

Arbusto o árbol pequeño. Nativo.

Distribución: AYP, TAR.

Rango altitudinal: 0-100 m.

Países limítrofes: Bolivia y Perú.

Acacia melanoxylon $\mathrm{R}$. Br.

Árbol. Introducido. 
Distribución: VAL, RME, LBO, MAU, NUB, BIO, ARA, LRI, LLA, JFE.

Nombre vulgar: Aromo australiano.

Acacia paradoxa DC.

Arbusto. Introducido.

Distribución: VAL.

Acacia visco Lorentz ex Griseb.

Sinónimos: Acacia concinna Phil., hom. illeg.

Árbol. Nativo.

Distribución: AYP, TAR, ANT, ATA.

Rango altitudinal: 0-2500 m.

Países limítrofes: Argentina, Bolivia y Perú.

\section{Adesmia}

Adesmia aegiceras Phil.

Sinónimos: Adesmia glanduligera I.M. Johnst., Adesmia remyana Phil., Adesmia subumbellata Phil., Adesmia trijuga Gillies ex Hook. \& Arn. var. remyana (Phil.) Burkart, Adesmia trijuga Gillies ex Hook. \& Arn. var. robustior Hook. \& Arn., Patagonium aegiceras (Phil.) Kuntze, Patagonium aegiceras (Phil.) Reiche, comb. illeg., Patagonium trijugum (Gillies ex Hook. \& Arn.) Kuntze var. remyanum (Phil.) Reiche Subarbusto. Nativo.

Distribución: TAR, ATA, COQ, VAL, RME.

Rango altitudinal: 1500-4000 m.

Países limítrofes: Argentina.

Nombre vulgar: Cuerno de cabra, jarilla.

Adesmia aphylla Clos

Sinónimos: Patagonium aphyllum (Clos) Kuntze

Arbusto. Endémico.

Distribución: ATA, COQ.

Rango altitudinal: 1800-3000 m.

Nombre vulgar: Panza de burro.

\section{Adesmia arachnipes Clos}

Sinónimos: Adesmia oresigena Phil., Patagonium arachnipes (Clos) Kuntze, Patagonium oresigenum (Phil.)

Kuntze

Hierba. Perenne. Endémica.

Distribución: COQ, VAL, RME.

Rango altitudinal: 1600-3500 m.

\section{Adesmia araucana Phil.}

Sinónimos: Patagonium araucanum (Phil.) Kuntze

Hierba. Perenne. Endémica.

Distribución: COQ, VAL, LBO, MAU, NUB, BIO, ARA.

Rango altitudinal: 800-1500 m.

Adesmia argentea Meyen

Sinónimos: Adesmia cinerea Clos, Patagonium argenteum
(Meyen) Kuntze, Patagonium cinereum (Clos) Kuntze

Arbusto. Endémico.

Distribución: TAR, ATA, COQ, VAL.

Rango altitudinal: 0-2000 m.

Nombre vulgar: Jarilla, varilla blanca, varilla mansa.

Adesmia argyrophylla Phil.

Sinónimos: Adesmia kingii Phil., Adesmia sessiliflora Phil., Adesmia furcata Phil., Adesmia divaricata (Phil. ex Reiche) Dyer, Patagonium argyrophyllum (Phil.) Kuntze, Patagonium kingii (Phil.) Kuntze, Patagonium sessiliflorum (Phil.) Kuntze

Arbusto. Endémico.

Distribución: ATA, COQ.

Rango altitudinal: 200-2800 m.

Adesmia aromatica Burkart

Arbusto. Endémico.

Distribución: COQ.

Rango altitudinal: 1100-1300 m.

Adesmia aspera Gillies ex Hook. \& Arn.

Sinónimos: Patagonium asperum (Gillies ex Hook. \& Arn.) Kuntze, Patagonium mucronatum (Hook. \& Arn.) Kuntze var. asperum (Gillies ex Hook. \& Arn.) Reiche

Hierba. Perenne. Nativa.

Distribución: COQ, VAL, RME, LBO, MAU, BIO.

Rango altitudinal: 1000-3000 m.

Países limítrofes: Argentina.

Adesmia atacamensis Phil.

Sinónimos: Adesmia glandulosa Phil., Patagonium atacamense (Phil.) Kuntze, Patagonium glandulosum (Phil.)

Kuntze

Arbusto. Endémico.

Distribución: AYP, TAR, ANT, ATA, COQ.

Rango altitudinal: 2000-4000 m.

Nombre vulgar: Allaval, jarilla, pasto de huanaco.

Adesmia aurantiaca (Dusén) Burkart

Sinónimos: Adesmia pumila Hook.f. var. aurantiaca Dusén Hierba. Perenne. Nativa.

Distribución: MAG.

Rango altitudinal: 0-500 m.

Países limítrofes: Argentina.

Adesmia balsamica Bertero ex Colla

Sinónimos: Patagonium balsamicum (Bertero ex Colla)

Kuntze

Arbusto. Endémico.

Distribución: VAL, RME.

Rango altitudinal: 0-1000 m.

Nombre vulgar: Jarilla. 
Adesmia bedwellii Skottsb.

Arbusto. Endémico.

Distribución: COQ, RME.

Rango altitudinal: 200-700 m.

Nombre vulgar: Varilla brava.

Adesmia bicolor (Poir.) DC.

Sinónimos: Hedysarum bicolorum Poir., Hedysarum pendulum Poir., Adesmia glabriuscula Vogel, Adesmia pendula Poir., Adesmia radicans Clos, Patagonium glabriusculum (Vogel) Kuntze, Patagonium radicans (Clos) Kuntze, Patagonium bicolor (Poir.) Kuntze

Hierba. Perenne. Nativa.

Distribución: VAL, RME, BIO, ARA.

Rango altitudinal: 0-2200 m.

Países limítrofes: Argentina.

Adesmia bijuga Phil.

Sinónimos: Patagonium bijugum (Phil.) Reiche

Arbusto. Endémico.

Distribución: MAU.

Adesmia boronioides Hook.f.

Sinónimos: Patagonium boronioides (Hook.f.) Kuntze

Arbusto. Nativo.

Distribución: AIS, MAG.

Rango altitudinal: 0-1500 m.

Países limítrofes: Argentina.

Nombre vulgar: Paramela.

Adesmia brachysemeon Phil.

Sinónimos: Patagonium bracteatum (Hook. \& Arn.) Kuntze Hierba. Perenne. Endémica.

Distribución: RME, LBO, MAU, BIO.

Rango altitudinal: 0-2200 m.

Adesmia bracteata Hook. \& Arn.

Arbusto. Endémico.

Distribución: ATA, COQ, VAL, RME.

Rango altitudinal: 1200-2600 m.

Adesmia brevivexillata Burkart

Hierba. Perenne. Endémica.

Distribución: VAL, RME, BIO, ARA.

Rango altitudinal: 1500-2500 m.

\section{Adesmia burkartii M.N. Correa}

Hierba. Perenne. Nativa.

Distribución: MAG.

Rango altitudinal: 1200-1500 m.

Países limítrofes: Argentina.

Adesmia calycicomosa Burkart

Arbusto. Endémico.
Distribución: COQ.

Rango altitudinal: 1100-1400 m.

Adesmia capitellata (Clos) Hauman

Sinónimos: Adesmia oligophylla Phil., Lotus capitellatus

Clos, Patagonium oligophyllum (Phil.) Kuntze, Hosackia

capitellata (Clos) Brand

Hierba. Anual. Nativa.

Distribución: ATA, COQ, VAL, RME.

Rango altitudinal: 2300-4200 m.

Países limítrofes: Argentina.

Adesmia colinensis (Phil. ex Reiche) Martic.

Sinónimos: Patagonium colinense Phil. ex Reiche

Arbusto. Endémico.

Distribución: COQ, VAL, RME.

Rango altitudinal: 1000-2000 m.

Adesmia concinna Phil.

Arbusto. Endémico.

Distribución: MAU, NUB, BIO, ARA.

Rango altitudinal: 200-1400 m.

Adesmia conferta Hook. \& Arn.

Sinónimos: Adesmia brachycarpa Phil., Adesmia izquierdi Phil. ex Reiche, Adesmia stipulacea Clos, Adesmia venosa Phil., Patagonium brachycarpum (Phil.) Kuntze, Patagonium confertum (Hook. \& Arn.) Kuntze, Patagonium stipulaceum (Clos) Kuntze, Patagonium venosum (Phil.) Reiche

Hierba. Perenne. Endémica.

Distribución: COQ, VAL, RME, LBO, MAU, BIO.

Rango altitudinal: 100-1800 m.

Adesmia confusa Ulibarri

Sinónimos: Patagonium arboreum (Bertero ex Clos) Kuntze, Adesmia arborea Bertero ex Clos, hom. illeg., Adesmia berteroniana Steud., nom. nud.

Arbusto. Endémico.

Distribución: COQ, VAL, RME, LBO.

Rango altitudinal: 0-1800 m.

Nombre vulgar: Palhuén, espinillo, varilla brava.

Adesmia coquimbensis Burkart

Arbusto. Endémico.

Distribución: ATA, COQ.

Rango altitudinal: $1900 \mathrm{~m}$.

Adesmia coronilloides Gillies ex Hook. \& Arn.

Sinónimos: Adesmia codonocalyx G.F. Grandjot \& K. Grandjot, Adesmia germainii Phil., Adesmia glauca Phil., Patagonium coronilloides (Gillies ex Hook. \& Arn.) Kuntze, Patagonium coronilloides (Gillies ex Hook. \& Arn.) Reiche, comb. illeg., Patagonium germainii (Phil.) Kuntze, Patagonium germainii (Phil.) Reiche, comb. illeg., 
Patagonium coronilloides (Gillies ex Hook. \& Arn.) Kuntze var. glaucum (Phil.) Reiche, comb. illeg., Patagonium glaucum (Phil.) Kuntze

Hierba. Perenne. Nativa.

Distribución: RME, MAU.

Rango altitudinal: 2200-3000 m.

Países limítrofes: Argentina.

\section{Adesmia corymbosa Clos}

Sinónimos: Adesmia palenae Phil., Adesmia fernandezii Phil., Adesmia tenuis Phil., Adesmia vallis-pulchrae Phil., nom. nud., Patagonium vallis-pulchrae Reiche, Patagonium corymbosum (Clos) Kuntze, Patagonium palenae (Phil.) Reiche

Hierba. Perenne. Nativa.

Distribución: VAL, LBO, MAU, NUB, BIO, ARA, AIS, MAG.

Rango altitudinal: 200-3500 m.

Países limítrofes: Argentina.

Adesmia cuneata Meyen ex Vogel

Sinónimos: Patagonium cuneatum (Meyen ex Vogel) Kuntze

Hierba. Perenne. Endémica.

Distribución: RME, LBO.

Rango altitudinal: 2100-2800 m.

\section{Adesmia curvifolia Clos}

Sinónimos: Patagonium curvifolium (Clos) Kuntze

Arbusto. Endémico.

Distribución: ATA, COQ.

Rango altitudinal: 1000-1500 m.

Adesmia darapskyana (Phil. ex Reiche) Martic.

Sinónimos: Patagonium darapskyanum Phil. ex Reiche

Hierba o subarbusto. Perenne. Endémica.

Distribución: VAL, RME, LBO.

Rango altitudinal: 2300-2800 m.

Adesmia davilae Phil.

Sinónimos: Patagonium davilae (Phil.) Kuntze

Hierba. Perenne. Endémica.

Distribución: RME, MAU, NUB, BIO, ARA.

Rango altitudinal: $2000 \mathrm{~m}$.

\section{Adesmia denticulata Clos}

Sinónimos: Patagonium denticulatum (Clos) Kuntze

Subarbusto. Endémico.

Distribución: COQ, MAU, NUB, BIO, ARA.

Rango altitudinal: 0-1600 m.

Adesmia denudata Phil.

Sinónimos: Patagonium denudatum (Phil.) Kuntze

Hierba. Perenne. Endémica.
Distribución: ATA, COQ.

Rango altitudinal: $2300 \mathrm{~m}$.

Adesmia dessaueri (Phil. ex Reiche) Ulibarri

Sinónimos: Patagonium dessaueri Phil. ex Reiche

Arbusto. Endémico.

Distribución: ATA, LBO.

Adesmia dichotoma Clos

Sinónimos: Patagonium dichotomum (Clos) Kuntze, Patagonium cinereum (Clos) Kuntze var. dichotomum (Clos) Reiche

Arbusto. Endémico.

Distribución: ATA, COQ, VAL.

Rango altitudinal: 900-2800 m.

Adesmia disperma Phil.

Sinónimos: Patagonium dispermum (Phil.) Reiche

Hierba. Perenne. Endémica.

Distribución: ANT, ATA, COQ, VAL.

Rango altitudinal: 200-300 m.

Adesmia dumosa Phil.

Sinónimos: Patagonium dumosum (Phil.) Reiche

Arbusto. Endémico.

Distribución: ATA, COQ, RME.

Adesmia echinus C. Presl

Sinónimos: Adesmia gayana Phil., Patagonium echinus (C.

Presl) Kuntze, Patagonium gayanum (Phil.) Kuntze

Subarbusto. Nativo.

Distribución: ANT, ATA, COQ, MAU.

Rango altitudinal: $2800-4400 \mathrm{~m}$.

Países limítrofes: Argentina.

Adesmia elata Clos

Sinónimos: Patagonium elatum (Clos) Kuntze, Patagonium leiocarpum (Hook. \& Arn.) Kuntze var. elatum (Clos) Reiche, Patagonium leiocarpum (Hook. \& Arn.) Kuntze var. macrostachyum Phil. ex Reiche

Hierba. Perenne. Endémica.

Distribución: ATA, COQ, MAU, NUB, BIO, ARA, LRI, AIS.

Rango altitudinal: 700-1300 m.

Adesmia elegans Clos

Sinónimos: Patagonium elegans (Clos) Kuntze

Arbusto. Endémico.

Distribución: ANT, ATA, COQ, MAU.

Adesmia emarginata Clos

Sinónimos: Patagonium emarginatum (Clos) Kuntze

Subarbusto. Nativo.

Distribución: ATA, MAU, NUB, BIO, ARA, LLA, AIS. 
Rango altitudinal: 200-2700 m.

Países limítrofes: Argentina.

Nombre vulgar: Paramela, paramilla.

Adesmia eremophila Phil.

Sinónimos: Adesmia latistipula Phil. ex Reiche, Patagonium eremophilum (Phil.) Kuntze, Patagonium latistipula Phil. ex Reiche

Hierba. Perenne. Endémica.

Distribución: TAR, ANT, ATA, COQ.

Rango altitudinal: 0-1800 m.

Adesmia erinacea Phil.

Sinónimos: Adesmia senticula Phil., Patagonium erinaceum (Phil.) Kuntze, Patagonium erinaceum (Phil.) Reiche, comb. illeg., Patagonium senticulum (Phil.) Reiche

Arbusto. Nativo.

Distribución: TAR, ANT, ATA, MAU.

Rango altitudinal: 2500-4400 m.

Países limítrofes: Argentina.

\section{Adesmia exilis Clos}

Sinónimos: Adesmia berteroi Phil. ex Kuntze, nom. nud., Adesmia decumbens Phil., Adesmia decumbens Phil. var. berteroi Phil. ex G.F. Grandjot \& K. Grandjot, Adesmia humifusa Phil., Adesmia valdesia Clos, Patagonium decumbens (Phil.) Kuntze, Adesmia inconspicua Phil., Patagonium exile (Clos) Kuntze, Patagonium inconspicum (Phil.) Kuntze, Patagonium valdesium (Clos) Kuntze, Patagonium humifusum Kuntze

Hierba. Perenne. Nativa.

Distribución: COQ, VAL, RME, LBO, MAU.

Rango altitudinal: 1400-3300 m.

Países limítrofes: Argentina.

Adesmia filicaulis Phil.

Sinónimos: Patagonium filicaule (Phil.) Kuntze, Patagonium radicans (Clos) Kuntze var. filicaule (Phil.)

Reiche

Hierba. Perenne. Endémica.

Distribución: NUB, ARA.

Rango altitudinal: 500-1500 m.

\section{Adesmia filifolia Clos}

Sinónimos: Patagonium filifolium (Clos) Kuntze

Hierba. Anual. Endémica.

Distribución: ANT, ATA, COQ, VAL, RME, LBO.

Rango altitudinal: 0-1800 m.

Adesmia frigida Phil.

Sinónimos: Adesmia adenophora Phil., Patagonium frigidum (Phil.) Kuntze, Patagonium adenophorum (Phil.) Reiche

Subarbusto. Endémico.
Distribución: ANT, ATA.

Rango altitudinal: 1900-4500 m.

Adesmia fuentesii G.F. Grandjot

Hierba. Perenne. Endémica.

Distribución: COQ, VAL, RME.

Rango altitudinal: $2000-3500 \mathrm{~m}$.

Adesmia glaucescens Phil.

Sinónimos: Patagonium araucanum (Phil.) Kuntze var. glaucescens (Phil.) Reiche, Patagonium glaucescens (Phil.)

Kuntze

Hierba. Perenne. Endémica.

Distribución: BIO, ARA.

Rango altitudinal: 0-1000 m.

Adesmia glomerula Clos var. australior Burkart

Hierba. Perenne. Nativa.

Distribución: RME, MAU, NUB, BIO, ARA.

Rango altitudinal: 1700-2700 m.

Países limítrofes: Argentina.

\section{Adesmia glomerula Clos var. glomerula}

Sinónimos: Adesmia compacta Phil., Adesmia humilis Phil., Patagonium compactum (Phil.) Kuntze, Patagonium glomerulum (Clos) Kuntze, Patagonium humile (Phil.) Kuntze

Hierba. Perenne. Nativa.

Distribución: RME, MAU, NUB, BIO, ARA.

Rango altitudinal: 2000-4000 m.

Países limítrofes: Argentina.

Adesmia glutinosa Hook. \& Arn.

Sinónimos: Patagonium glutinosum (Hook. \& Arn.) Kuntze Arbusto. Endémico.

Distribución: ATA, COQ, VAL.

Rango altitudinal: 700-3000 m.

Adesmia godoyae (Phil. ex Reiche) Martic.

Sinónimos: Patagonium godoyae Phil. ex Reiche

Arbusto. Endémico.

Distribución: ATA, RME.

Rango altitudinal: $700-1000 \mathrm{~m}$.

Adesmia gracilis Meyen ex Vogel

Sinónimos: Patagonium gracile (Meyen ex Vogel) Kuntze Arbusto. Nativo.

Distribución: COQ, RME, MAU.

Rango altitudinal: 200-3000 m.

Países limítrofes: Argentina.

Adesmia gracillima I.M. Johnst.

Hierba. Perenne. Endémica.

Distribución: ANT, RME. 
Adesmia hemisphaerica Hauman

Subarbusto. Nativo.

Distribución: TAR, ANT, COQ, RME.

Rango altitudinal: 3200-3600 m.

Países limítrofes: Argentina.

Adesmia hirsuta Phil.

Sinónimos: Patagonium hirsutum (Phil.) Kuntze

Arbusto. Endémico.

Distribución: ANT, ATA, COQ, RME.

Adesmia horrida Gillies ex Hook. \& Arn.

Sinónimos: Adesmia leucopogon Phil., Patagonium horridum (Gillies ex Hook. \& Arn.) Kuntze, Patagonium leucopogon (Phil.) Kuntze, Patagonium horridum (Gillies ex Hook. \& Arn.) Kuntze var. minor Reiche

Arbusto. Nativo.

Distribución: TAR, ANT, ATA, COQ.

Rango altitudinal: 2800-4000 m.

Países limítrofes: Argentina y Bolivia.

Nombre vulgar: Cuerno de cabra.

\section{Adesmia hystrix Phil.}

Sinónimos: Adesmia sentis Phil., Adesmia villanuevae Phil. ex Reiche, nom. nud., Patagonium hystrix (Phil.) Kuntze, Patagonium sentis (Phil.) Reiche, Patagonium villanuevae Reiche

Arbusto. Endémico.

Distribución: ANT, ATA, COQ.

Rango altitudinal: 2000-4100 m.

Adesmia jilesiana Burkart

Hierba. Perenne. Nativa.

Distribución: ATA, COQ.

Rango altitudinal: 3000-4200 m.

Países limítrofes: Argentina.

Adesmia lanata Hook.f.

Sinónimos: Patagonium lanatum (Hook.f.) Kuntze

Hierba. Perenne. Nativa.

Distribución: ARA, MAG.

Rango altitudinal: 100-900 m.

Países limítrofes: Argentina.

Adesmia landbecki Phil.

Sinónimos: Patagonium landbecki (Phil.) Kuntze, Patagonium longisetum (DC.) Kuntze var. landbeckii (Phil.) Reiche

Hierba. Perenne. Endémica.

Distribución: VAL, RME, LBO, MAU, NUB, BIO, ARA.

Rango altitudinal: 0-500 m.

Adesmia laxa Clos

Sinónimos: Patagonium laxum (Clos) Kuntze
Hierba. Perenne. Endémica.

Distribución: COQ, RME.

Rango altitudinal: 0-200 m.

Adesmia leiocarpa Hook. \& Arn.

Sinónimos: Adesmia psilocarpa Phil., Patagonium psilocarpum (Phil.) Kuntze, Patagonium leiocarpum (Hook. \& Arn.) Kuntze

Hierba. Anual. Endémica.

Distribución: ATA, COQ, VAL, RME.

Rango altitudinal: 0-1300 m.

Adesmia littoralis Burkart

Subarbusto. Endémico.

Distribución: ATA, COQ.

Rango altitudinal: 0-100 m.

Adesmia longipes Phil.

Sinónimos: Patagonium longipes (Phil.) Kuntze

Hierba. Perenne. Nativa.

Distribución: RME, LBO, MAU, NUB, BIO, ARA, LRI, LLA.

Rango altitudinal: 1300-3200 m.

Países limítrofes: Argentina.

Adesmia longiseta DC.

Sinónimos: Patagonium longisetum (DC.) Kuntze

Hierba. Perenne. Endémica.

Distribución: COQ, RME, LBO, ARA.

Rango altitudinal: 2000-3200 m.

Adesmia lotoides Hook.f.

Sinónimos: Adesmia lotoides Hook.f. var. vaginata Hook.f., Adesmia unifoliolata Skottsb., Patagonium lotoides (Hook.f.) Kuntze, Patagonium lotoides (Hook.f.) Reiche, comb. illeg. Hierba. Perenne. Nativa.

Distribución: AIS, MAG.

Rango altitudinal: 0-1500 m.

Países limítrofes: Argentina.

Adesmia loudonia Hook. \& Arn.

Sinónimos: Patagonium loudonii (Hook. \& Arn.) Kuntze, Patagonium loudonii (Hook. \& Arn.) Reiche, comb. illeg.

Arbusto. Endémico.

Distribución: COQ, VAL, RME, LBO.

Rango altitudinal: 0-1200 m.

Adesmia medinae (Phil. ex Reiche) Ulibarri

Sinónimos: Patagonium medinae (Phil. ex Reiche) Reiche

Hierba. Perenne. Endémica.

Distribución: RME, LBO, MAU. 
Adesmia melanocaulos Phil.

Sinónimos: Adesmia diaziana I.M. Johnst., Patagonium melanocaulon (Phil.) Reiche

Arbusto. Endémico.

Distribución: ANT, ATA.

Rango altitudinal: 0-1100 m.

Adesmia melanthes Phil.

Sinónimos: Patagonium melanthes (Phil.) Reiche

Arbusto. Nativo.

Distribución: AYP, TAR, ANT.

Rango altitudinal: 3700-4200 m.

Países limítrofes: Perú.

Adesmia micrantha Phil.

Sinónimos: Patagonium micranthum (Phil.) Kuntze, Patagonium parviflorum (Clos) Kuntze var. micranthum (Phil.) Reiche

Hierba. Anual. Endémica.

Distribución: ATA.

Adesmia microcalyx Phil. var. calvescens Burkart

Hierba. Perenne. Endémica.

Distribución: NUB, ARA.

Rango altitudinal: 0-1100 m.

Adesmia microcalyx Phil. var. microcalyx

Sinónimos: Patagonium microcalyx (Phil.) Reiche

Hierba. Perenne. Endémica.

Distribución: BIO, ARA.

Rango altitudinal: 0-1100 m.

Adesmia microphylla Hook. \& Arn.

Sinónimos: Adesmia spinosa A. Lesson, Patagonium microphyllum (Hook. \& Arn.) Kuntze

Arbusto. Endémico.

Distribución: ATA, COQ, VAL, RME.

Rango altitudinal: 0-1500 m.

Nombre vulgar: Palhuén.

Adesmia minor (Hook. \& Arn.) Burkart var. caespitosa (Phil.) Ulibarri \& Burkart

Sinónimos: Adesmia caespitosa Phil., Patagonium caespitosum (Phil.) Reiche

Subarbusto. Nativo.

Distribución: ANT.

Rango altitudinal: 3800-4400 m.

Países limítrofes: Argentina.

Nombre vulgar: Cuerno de cabra.

Adesmia monosperma Clos

Sinónimos: Adesmia calycosa Phil., Patagonium monospermum (Clos) Kuntze, Patagonium calycosum (Phil.) Reiche
Arbusto. Endémico.

Distribución: ATA, COQ.

Rango altitudinal: 200-2600 m.

Adesmia montana Phil.

Sinónimos: Patagonium montanum (Phil.) Kuntze

Hierba. Perenne. Endémica.

Distribución: COQ, RME.

Rango altitudinal: 2100-2800 m.

Adesmia mucronata Hook. \& Arn.

Sinónimos: Adesmia closii Phil., Patagonium mucronatum (Hook. \& Arn.) Kuntze, Patagonium closii (Phil.) Kuntze

Hierba. Perenne. Endémica.

Distribución: COQ, VAL, RME, LBO, MAU, NUB, BIO.

Rango altitudinal: 0-2600 m.

Adesmia multicuspis Clos

Sinónimos: Adesmia oxalidophylla Phil., Adesmia melanocarpa (Phil. ex Reiche) Dyer, Patagonium oxalidophyllum (Phil.) Kuntze, Patagonium multicuspe (Clos) Kuntze, Patagonium oxalidophyllum (Phil.) Kuntze var. melanocarpum Phil. ex Reiche

Hierba. Anual. Endémica.

Distribución: ATA, COQ.

Rango altitudinal: 1100-2300 m.

Adesmia obcordata $\mathrm{Clos}$

Sinónimos: Patagonium obovatum (Clos) Kuntze, Patagonium obcordatum (Clos) Kuntze

Arbusto. Nativo.

Distribución: RME, LBO.

Rango altitudinal: 200-2500 m.

Países limítrofes: Argentina.

Adesmia obovata $\mathrm{Clos}$

Sinónimos: Adesmia leptacantha Phil., Patagonium obovatum (Clos) Kuntze, Patagonium leptacanthum (Phil.)

Kuntze

Arbusto. Nativo.

Distribución: RME, LBO, MAU, AIS.

Rango altitudinal: 200-2500 m.

Países limítrofes: Argentina.

Nombre vulgar: Cuerno de cabra, jarilla.

Adesmia obscura Clos

Sinónimos: Adesmia graveolens Phil., Adesmia villosa Phil., hom. illeg., Patagonium obscurum (Clos) Kuntze, Patagonium graveolens (Phil.) Kuntze, Patagonium obscurum (Clos) Kuntze var. graveolens (Phil.) Reiche, Patagonium villosum (Phil.) Reiche

Arbusto. Endémico.

Distribución: ATA, COQ.

Rango altitudinal: 2000-3400 m. 
Adesmia occulta (R.E. Fr.) Burkart

Sinónimos: Patagonium occultum R.E. Fr.

Subarbusto. Nativo.

Distribución: AYP, TAR, ANT.

Rango altitudinal: 3000-4400 m.

Países limítrofes: Argentina y Bolivia.

Adesmia odontophylla Phil.

Sinónimos: Patagonium odontophyllum (Phil.) Kuntze

Arbusto. Endémico.

Distribución: ATA.

Adesmia ovallensis Ulibarri

Arbusto. Endémico.

Distribución: COQ.

Rango altitudinal: 200-300 m.

Adesmia papposa (Lag.) DC. var. papposa

Sinónimos: Adesmia arvensis Phil., Adesmia chillanensis Phil., Adesmia elongata Phil., Aeschynomene papposa Lag., Patagonium papposum (Lag.) Kuntze, Patagonium chillanense (Phil.) Reiche, Patagonium arvense (Phil.) Kuntze, Patagonium elongatum (Phil.) Kuntze, Patagonium leiocarpum (Hook. \& Arn.) Kuntze var. elongatum (Phil.) Reiche

Hierba. Perenne. Nativa.

Distribución: COQ, VAL, RME, LBO, MAU, NUB, BIO, ARA.

Rango altitudinal: 0-2500 m.

Países limítrofes: Argentina.

Adesmia papposa (Lag.) DC. var. radicifolia (Clos) M.N. Correa

Sinónimos: Adesmia radicifolia Clos, Patagonium radicifolium (Clos) Kuntze

Hierba. Perenne. Nativa.

Distribución: COQ, VAL, RME, LBO, MAU, BIO.

Rango altitudinal: 0-3100 m.

Países limítrofes: Argentina.

\section{Adesmia parviflora $\mathrm{Clos}$}

Sinónimos: Patagonium parviflorum (Clos) Kuntze, Patagonium parviflorum (Clos) Kuntze var. diffusum Bertero ex Reiche

Hierba. Anual. Endémica.

Distribución: ANT, ATA, COQ, VAL, RME, LBO, MAG.

Rango altitudinal: 0-2600 m.

\section{Adesmia parvifolia Phil.}

Sinónimos: Adesmia axillaris Phil., Adesmia parvifolia Phil. var. axillaris (Phil.) Reiche, Patagonium parvifolium (Phil.) Reiche, Patagonium parvifolium (Phil.) Reiche var. axillare (Phil.) Reiche, Patagonium axillare (Phil.) Kuntze, Patagonium lanatum (Hook.f.) Kuntze var. axillaris (Phil.) Speg.

Hierba. Perenne. Nativa.

Distribución: MAU, NUB, BIO, ARA, LLA, AIS, MAG.

Rango altitudinal: 0-2600 m.

Países limítrofes: Argentina.

Adesmia pauciflora Vogel

Sinónimos: Patagonium pauciflorum (Vogel) Kuntze

Arbusto. Endémico.

Distribución: RME.

Adesmia pearcei Phil.

Sinónimos: Patagonium pearcei (Phil.) Kuntze

Arbusto. Endémico.

Distribución: BIO.

Adesmia pedicellata Hook. \& Arn.

Sinónimos: Adesmia genistoides C. Presl, Adesmia ulicina C. Presl, Adesmia calopogon Phil., Adesmia deserticola Phil., Patagonium pedicellatum (Hook. \& Arn.) Kuntze, Patagonium deserticolum (Phil.) Kuntze, Patagonium genistoides (C. Presl) Kuntze, Patagonium genistoides (C. Presl) Reiche, comb. illeg., Patagonium ulicinum (C. Presl) Kuntze, Patagonium calopogon Phil. ex Reiche

Arbusto. Endémico.

Distribución: ATA, COQ.

Rango altitudinal: 0-2800 m.

Adesmia pentaphylla Phil.

Sinónimos: Patagonium pentaphyllum (Phil.) Reiche

Arbusto. Nativo.

Distribución: RME.

Rango altitudinal: 2200-3000 m.

Países limítrofes: Argentina.

Adesmia peraltae (Phil. ex Reiche) Ulibarri

Sinónimos: Patagonium peraltae Phil. ex Reiche

Arbusto. Endémico.

Distribución: ATA, COQ.

Nombre vulgar: Varilla.

Adesmia phylloidea Clos

Sinónimos: Adesmia virgata Bertero ex Steud., nom. nud., Patagonium phylloideum (Clos) Kuntze

Arbusto. Endémico.

Distribución: COQ, VAL, RME.

Rango altitudinal: 100-1400 m.

Adesmia pinifolia Gillies ex Hook. \& Arn.

Sinónimos: Patagonium pinifolium (Gillies ex Hook. \& Arn.) Kuntze ex Taub.

Arbusto. Nativo.

Distribución: RME.

Rango altitudinal: 1500-3700 m. 
Países limítrofes: Argentina y Bolivia.

Nombre vulgar: Leña amarilla.

Adesmia pirionii I.M. Johnst.

Arbusto. Endémico.

Distribución: COQ, VAL.

Rango altitudinal: 100-900 m.

Adesmia polyphylla Phil.

Sinónimos: Patagonium polyphyllum (Phil.) Reiche

Arbusto. Nativo.

Distribución: AYP, TAR, ANT.

Rango altitudinal: 3200-4500 m.

Países limítrofes: Bolivia.

Adesmia propinqua Clos

Sinónimos: Adesmia dendroides Phil., Patagonium propinquum (Clos) Kuntze, Patagonium dendrodes (Phil.)

Kuntze

Arbusto. Endémico.

Distribución: NUB, BIO, ARA.

Rango altitudinal: 100-1500 m.

Adesmia prostrata Clos var. eglandulosa Burkart

Sinónimos: Adesmia coluteoides Phil., Patagonium coluteoides (Phil.) Kuntze

Hierba. Perenne. Endémica.

Distribución: COQ, RME, LBO, MAU.

Rango altitudinal: 500-1500 m.

Adesmia prostrata Clos var. prostrata

Sinónimos: Patagonium prostratum (Clos) Kuntze, Adesmia meyeniana Phil., Patagonium meyenianum (Phil.) Kuntze

Hierba. Perenne. Endémica.

Distribución: RME, LBO, MAU.

Rango altitudinal: 1000-1500 m.

Adesmia pumila Hook.f.

Sinónimos: Patagonium pumilum (Hook.f.) Kuntze

Hierba. Perenne. Nativa.

Distribución: MAG.

Rango altitudinal: 0-900 m.

Países limítrofes: Argentina.

\section{Adesmia pungens Clos}

Sinónimos: Adesmia intricata Phil. ex Reiche, nom. nud., Patagonium intricatum Phil., Patagonium pungens (Clos) Kuntze

Arbusto. Endémico.

Distribución: ANT, ATA, COQ.

Rango altitudinal: 0-2100 m.

Adesmia pusilla Phil.

Sinónimos: Patagonium pusillum (Phil.) Kuntze
Hierba. Anual. Endémica.

Distribución: TAR, ANT, ATA.

Rango altitudinal: 100-600 m.

Adesmia quadripinnata (Hicken) Burkart

Sinónimos: Adesmia oligophyla Phil. var. quadripinnata

Hicken

Hierba. Anual. Nativa.

Distribución: MAU.

Rango altitudinal: 800-2600 m.

Países limítrofes: Argentina.

Adesmia rahmeri Phil.

Sinónimos: Patagonium rahmeri (Phil.) Reiche

Hierba. Anual o bienal. Nativa.

Distribución: TAR, ANT, ATA.

Rango altitudinal: 2600-4400 m.

Países limítrofes: Argentina.

Adesmia ramosissima Phil.

Sinónimos: Patagonium ramosissimum (Phil.) Kuntze

Hierba. Perenne. Endémica.

Distribución: COQ, LBO.

Rango altitudinal: 500-1000 m.

Adesmia reclinata Muñoz

Hierba. Perenne. Endémica.

Distribución: COQ.

Rango altitudinal: 0-1000 m.

Nombre vulgar: Lentejilla.

Adesmia renjifoana (Phil. ex Reiche) Ulibarri

Sinónimos: Adesmia renjifoana Phil., nom. nud., Patagonium renjifoanum Phil. ex Reiche

Arbusto. Nativo.

Distribución: LBO.

Rango altitudinal: 1500-2600 m.

Países limítrofes: Argentina.

Adesmia resinosa (Phil. ex Reiche) Martic.

Sinónimos: Patagonium resinosum Phil. ex Reiche

Arbusto o árbol pequeño. Endémico.

Distribución: VAL, RME.

Rango altitudinal: 1700-2000 m.

Adesmia retusa Griseb.

Sinónimos: Adesmia grisebachii Phil., Patagonium retusum (Griseb.) Kuntze var. grisebachii (Phil.) Reiche, Patagonium retusum (Griseb.) Kuntze

Hierba. Perenne. Nativa.

Distribución: ARA, LLA.

Rango altitudinal: 0-1800 m.

Países limítrofes: Argentina. 
Adesmia rubroviridis Burkart

Arbusto. Endémico.

Distribución: COQ.

Rango altitudinal: 2200-2600 m.

Adesmia salicornioides Speg.

Sinónimos: Patagonium salicornioides (Speg.) Speg.

Subarbusto. Nativo.

Distribución: MAG.

Rango altitudinal: 0-1500 m.

Países limítrofes: Argentina.

Adesmia sandwithii Burkart

Hierba. Perenne. Nativa.

Distribución: MAG.

Rango altitudinal: 1000-2000 m.

Países limítrofes: Argentina.

Adesmia schneideri Phil.

Sinónimos: Adesmia rigida Skottsb., Patagonium schneideri (Phil.) Kuntze, Patagonium schneideri (Phil.)

Reiche, comb. illeg.

Arbusto. Nativo.

Distribución: ATA, RME, LBO.

Rango altitudinal: 200-3300 m.

Países limítrofes: Argentina.

Adesmia spinosissima Meyen

Sinónimos: Adesmia rupicola Wedd., Patagonium spinosissimum (Meyen) Kuntze

Arbusto. Nativo.

Distribución: AYP, TAR, ANT, ATA.

Rango altitudinal: 2700-4300 m.

Países limítrofes: Argentina, Bolivia y Perú.

Adesmia spuma Werderm. ex Burkart

Hierba. Perenne. Nativa.

Distribución: ATA, COQ.

Rango altitudinal: 2000-4600 m.

Países limítrofes: Argentina.

Adesmia subterranea Clos

Sinónimos: Patagonium subterraneum (Clos) Kuntze

Subarbusto. Nativo.

Distribución: ATA, COQ, VAL.

Rango altitudinal: 1200-4300 m.

Países limítrofes: Argentina.

Nombre vulgar: Cuerno de cabra.

Adesmia tenella Hook. \& Arn. var. macrocarpa Ulibarri Sinónimos: Patagonium angustifolium (Hook. \& Arn.) Reiche, comb. illeg.

Hierba. Anual. Endémica.

Distribución: ATA.
Adesmia tenella Hook. \& Arn. var. misera (Phil.) Skottsb. Sinónimos: Adesmia smithiae DC. var. misera Phil.

Hierba. Anual. Endémica.

Distribución: ATA, COQ, VAL, RME, LBO.

Rango altitudinal: 0-1000 m.

Adesmia tenella Hook. \& Arn. var. tenella

Sinónimos: Adesmia angustifolia Hook. \& Arn., Adesmia vesicaria Bertero ex Colla, Adesmia parvula Phil., Adesmia tenuicaulis Phil., Patagonium parvulum (Phil.) Kuntze, Patagonium tenuicaule (Phil.) Reiche, Patagonium vesicarium (Bertero ex Colla) Reiche, Patagonium vesicarium (Bertero ex Colla) Kuntze, comb. illeg.

Hierba. Anual. Endémica.

Distribución: ANT, ATA, COQ, VAL, RME, LBO.

Rango altitudinal: 0-1300 m.

Adesmia tomentosa Meyen

Hierba. Perenne. Endémica.

Distribución: VAL, MAU.

Rango altitudinal: 200-300 m.

Adesmia torcaea Phil.

Sinónimos: Patagonium torcaeum (Phil.) Reiche

Hierba. Perenne. Endémica.

Distribución: COQ, VAL.

Rango altitudinal: 200-3200 m.

Adesmia trifoliata Phil.

Sinónimos: Adesmia philippiana (Hosseus) Burkart, Patagonium philippianum Hosseus, Patagonium triphyllum Speg., Patagonium trifoliatum (Phil.) Kuntze

Arbusto. Endémico.

Distribución: VAL, RME.

Rango altitudinal: $2000 \mathrm{~m}$.

Adesmia trifoliolata Gillies ex Hook. \& Arn.

Sinónimos: Patagonium trifoliolatum (Gillies ex Hook. \& Arn.) Kuntze ex Taub.

Hierba. Anual o bienal. Nativa.

Distribución: VAL, RME.

Rango altitudinal: 200-2300 m.

Países limítrofes: Argentina.

Adesmia uspallatensis Gillies ex Hook. \& Arn.

Sinónimos: Patagonium uspallatense (Gillies ex Hook. \& Arn.) Kuntze

Arbusto. Nativo.

Distribución: VAL, RME.

Rango altitudinal: 1900-3000 m.

Países limítrofes: Argentina. 
Adesmia verrucosa Meyen

Arbusto. Nativo.

Distribución: AYP.

Rango altitudinal: 1700-3600 m.

Países limítrofes: Perú.

Adesmia villosa Hook.f.

Hierba. Perenne. Nativa.

Distribución: MAG.

Rango altitudinal: 0-2400 m.

Países limítrofes: Argentina.

Adesmia viscida Bertero ex Colla

Sinónimos: Adesmia aprica Phil., Adesmia simonsi Phil., Patagonium apricum (Phil.) Kuntze, Patagonium mucronatum (Hook. \& Arn.) Kuntze var. apricum (Phil.) Reiche, Patagonium simonsii (Phil.) Kuntze

Hierba. Perenne. Endémica.

Distribución: COQ, VAL, RME, LBO, MAU, NUB, BIO, ARA.

Rango altitudinal: 0-3000 m.

Adesmia viscidissima I.M. Johnst.

Hierba. Perenne. Endémica.

Distribución: ANT.

Rango altitudinal: 700-800 m.

Adesmia viscosa Gillies ex Hook. \& Arn.

Sinónimos: Adesmia pulchra Phil., Patagonium pulchrum (Phil.) Kuntze, Patagonium viscosum (Gillies ex Hook. \& Arn.) Kuntze

Arbusto. Endémico.

Distribución: LBO, ARA.

Rango altitudinal: 300-800 m.

Adesmia volckmannii Phil.

Sinónimos: Patagonium campestre Rendle, Patagonium volckmannii (Phil.) Kuntze, Adesmia quadrijuga Phil., Patagonium quadrijugum (Phil.) Kuntze, Patagonium volckmannii (Phil.) Reiche, comb. illeg.

Arbusto. Nativo.

Distribución: RME, MAU, NUB, BIO, ARA, LLA, AIS, MAG.

Rango altitudinal: 200-2200 m.

Países limítrofes: Argentina.

Adesmia zoellneri Ulibarri

Arbusto. Endémico.

Distribución: COQ, VAL.

Albizia

Albizia lophantha (Willd.) Benth.

Árbol. Introducido.
Distribución: VAL, RME, MAU, BIO, JFE.

\section{Anarthrophyllum}

Anarthrophyllum andicolum (Gillies ex Hook. \& Arn.) F. Phil.

Sinónimos: Anarthrophyllum andicolum (Gillies ex Hook. \& Arn.) F. Phil. var. bridgesii Chodat \& Wilcz., Anarthrophyllum juniperinum (Meyen) F. Phil., Genista andicola Gillies ex Hook. \& Arn., Genista juniperina Meyen

Arbusto. Endémico.

Distribución: VAL, RME, LBO.

Rango altitudinal: 0-1800 m.

Nombre vulgar: Pichi-romero.

Anarthrophyllum cumingii (Hook. \& Arn.) F. Phil.

Sinónimos: Genista cumingii Hook. \& Arn., Anarthrophyllum cumingii (Hook. \& Arn.) F. Phil. var. angustifolia Chodat \& Wilcz.

Arbusto. Endémico.

Distribución: COQ, VAL, RME, LBO, MAU.

Rango altitudinal: 1800-3000 m.

Anarthrophyllum desideratum (DC.) Benth. var. desideratum

Sinónimos: Genista desiderata DC., Anarthrophyllum desideratum Neger, nom. illeg.

Subarbusto. Nativo.

Distribución: AIS, MAG.

Rango altitudinal: 0-1000 m.

Países limítrofes: Argentina.

Anarthrophyllum desideratum (DC.) Benth. var. morenonis (Kuntze) Speg.

Sinónimos: Anarthrophyllum morenonis Kuntze

Subarbusto. Nativo.

Distribución: MAG.

Rango altitudinal: 0-1000 m.

Países limítrofes: Argentina.

Anarthrophyllum elegans (Gillies ex Hook. \& Arn.) F. Phil.

Sinónimos: Genista elegans Gillies ex Hook. \& Arn., Anarthrophyllum pungens Chodat

Arbusto. Nativo.

Distribución: VAL.

Rango altitudinal: 1000-2500 m.

Países limítrofes: Argentina.

Anarthrophyllum gayanum (A. Gray) B.D. Jacks.

Sinónimos: Genista gayana A. Gray, Genista umbellata Clos, Anarthrophyllum umbellatum (Clos) F. Phil.

Subarbusto. Nativo. 
Distribución: COQ, RME.

Rango altitudinal: 2000-3700 m.

Países limítrofes: Argentina.

Anarthrophyllum rigidum (Gillies ex Hook. \& Arn.) Hieron.

Sinónimos: Genista rigida Gillies ex Hook. \& Arn., Anarthrophyllum brevistipula Phil.

Arbusto. Nativo.

Distribución: MAU, MAG.

Rango altitudinal: 200-2500 m.

Países limítrofes: Argentina.

\section{Astragalus}

\section{Astragalus amatus Clos}

Sinónimos: Astragalus procumbens Hook. \& Arn., Phaca tricolor Clos, Astragalus tricolor (Clos) Reiche, Astragalus ferrugineus Clos, Astragalus leucomallus Phil., Phaca brachyptera Phil., Astragalus brachypterus (Phil.) Reiche, Astragalus litoreus Phil., Tragacantha brevialata Kuntze, Astragalus subandinus Speg., Astragalus chilensis E. Sheld. Hierba. Perenne. Nativa.

Distribución: ATA, COQ, VAL, RME, LBO, MAU, NUB, BIO, ARA.

Rango altitudinal: 2-2600 m.

Países limítrofes: Bolivia y Perú.

\section{Astragalus arequipensis Vogel}

Sinónimos: Astragalus bolivianus Phil.

Hierba. Perenne. Nativa.

Distribución: AYP, TAR, ANT.

Rango altitudinal: $450-4500 \mathrm{~m}$.

Países limítrofes: Argentina, Bolivia y Perú.

Astragalus arnottianus (Gillies ex Hook. \& Arn.) Reiche Sinónimos: Phaca arnottiana Gillies ex Hook. \& Arn., Phaca uspallatensis Phil., Phaca reedi Phil., Astragalus reedii (Phil.) Hauman, Phaca nana Phil., Astragalus nanus (Phil.) Reiche, Astragalus philippi Speg.

Hierba. Perenne. Nativa.

Distribución: COQ, VAL, RME, LBO.

Rango altitudinal: 1620-3200 m.

Países limítrofes: Argentina.

Astragalus bellus (Kuntze) R.E. Fr.

Sinónimos: Phaca pulchella Clos, Astragalus pulchellus (Clos) Reiche, Tragacantha bella Kuntze

Hierba. Perenne. Nativa.

Distribución: COQ.

Países limítrofes: Argentina.

Astragalus berteri Colla

Sinónimos: Astragalus prostratus Hook. \& Arn., Astragalus alberjilla Steud., Phaca grata Clos, Astragalus gratus (Clos) Reiche, Astragalus filifolius Clos, Astragalus elongatus (Phil.) Reiche, Phaca concinna Phil., Astragalus concinnus (Phil.) Reiche, Astragalus cauquenensis Phil., Astragalus pencanus Phil., Tragacantha longior Kuntze, Astragalus rhudolphi Speg., Phaca elongata Phil.

Hierba. Perenne. Endémica.

Distribución: ATA, COQ, VAL, RME, LBO, MAU, NUB, BIO, ARA.

Astragalus berterianus (Moris) Reiche

Sinónimos: Phaca berteriana Moris, Phaca canescens Hook. \& Arn., Astragalus canescens (Hook. \& Arn.) Gray, nom. illeg., Astragalus oblongifolius Clos, Astragalus sphaerocarpus Clos, Astragalus placens Clos var. oblongifolius (Clos) Reiche, Phaca laxiflora Phil., Astragalus laxiflorus (Phil.) Reiche, Phaca dolichostachya Phil., Astragalus dolichostachys (Phil.) Reiche, Phaca dissitiflora Phil., Astragalus laxiflorus (Phil.) Reiche var. dissitiflora (Phil.) Reiche, Astragalus aconcaguensis Speg. Hierba. Anual. Endémica.

Distribución: COQ, VAL, RME, LBO, MAU, BIO.

Rango altitudinal: 0-3000 m.

Astragalus bustillosii Clos

Sinónimos: Phaca depauperata Phil., Astragalus depauperatus (Phil.) Reiche, Phaca saxifraga Phil., Astragalus brachycalyx Phil., Tragacantha atacamensis Kuntze, Astragalus atacamensis (Kuntze) R.E. Fr., Astragalus tarapacanus Speg.

Hierba. Perenne. Nativa.

Distribución: AYP, TAR, ANT, ATA, COQ.

Rango altitudinal: 1900-4870 m.

Países limítrofes: Argentina.

Nombre vulgar: Garbanzo silvestre.

Astragalus cachinalensis Phil.

Sinónimos: Tragacantha cachinalensis (Phil.) Kuntze

Hierba. Anual o bienal. Endémica.

Distribución: ANT, ATA.

Rango altitudinal: 800-800 m.

Astragalus chamissonis (Vogel) Reiche

Sinónimos: Phaca chamissonis Vogel, Phaca ochroleuca Hook. \& Arn., Astragalus ochroleucus (Hook. \& Arn.) Gray, nom. illeg., Astragalus ovallensis Clos, Astragalus chilensis (Nees) Reiche, hom. illeg., Astragalus placens Clos, Astragalus volckmannii Phil., Astragalus araucanus (F. Phil.) Reiche, Astragalus monospermus Phil., Astragalus laetevirens Phil., Phaca chilensis Nees, Phaca araucana F. Phil.

Hierba. Perenne. Nativa.

Distribución: ATA, COQ, VAL, RME, LBO, MAU, NUB, BIO, ARA. 
Rango altitudinal: 10-3000 m.

Países limítrofes: Argentina.

Nombre vulgar: Hierba loca.

Astragalus confinis I.M. Johnst.

Hierba. Perenne. Nativa.

Distribución: TAR.

Países limítrofes: Perú.

Astragalus coquimbensis (Hook. \& Arn.) Reiche

Sinónimos: Phaca coquimbensis Hook. \& Arn., Astragalus vasticola I.M. Johnst., Phaca carrizalensis Phil., Phaca atacamensis Phil.

Hierba. Anual. Endémica.

Distribución: ANT, ATA, COQ.

Rango altitudinal: 0-510 $\mathrm{m}$.

Astragalus cruckshanksii (Hook. \& Arn.) Griseb.

Sinónimos: Phaca cruckshanksii Hook. \& Arn., Astragalus amunategui Phil., Tragacantha cruckshanksii (Hook. \&

Arn.) Kuntze var. glabrescens Kuntze, Astragalus landbecki (Phil.) Reiche, Phaca landbecki Phil.

Hierba. Perenne. Nativa.

Distribución: ATA, COQ, VAL, RME, LBO, MAU.

Rango altitudinal: 1200-3700 m.

Países limítrofes: Argentina.

Astragalus cryptanthus Wedd.

Sinónimos: Phaca clandestina Phil.

Hierba. Perenne. Nativa.

Distribución: AYP, TAR.

Rango altitudinal: 3850-4150 m.

Países limítrofes: Bolivia.

Astragalus cryptobotrys I.M. Johnst.

Sinónimos: Phaca cryptantha Phil., Astragalus clandestinus (Phil.) Hieron.

Hierba. Perenne. Nativa.

Distribución: AYP, TAR, ANT.

Rango altitudinal: $3815-4550 \mathrm{~m}$.

Países limítrofes: Argentina.

Astragalus curvicaulis (Clos) Reiche

Sinónimos: Phaca curvicaulis Clos, Astragalus elatus

(Hook. \& Arn.) Reiche, comb. illeg., Phaca elata Hook. \&

Arn., Tragacantha curvicaulis (Clos) Kuntze

Hierba. Perenne. Endémica.

Distribución: COQ, VAL, RME, LBO.

Rango altitudinal: $1900-2800 \mathrm{~m}$.

Nombre vulgar: Hierba loca.

Astragalus darumbium (Bertero ex Colla) Clos

Sinónimos: Sutherlandia darumbium Bertero ex Colla, Phaca macrophysa Phil., Astragalus macrophysus (Phil.) Reiche,
Phaca robusta Phil., Astragalus macrophysus (Phil.) Reiche var. robustus (Phil.) Reiche, Tragacantha firma Kuntze

Hierba. Perenne. Nativa.

Distribución: RME, LBO.

Rango altitudinal: 900-3200 m.

Países limítrofes: Argentina.

Astragalus diminutivus (Phil.) Gómez-Sosa

Sinónimos: Astragalus deminutivus I.M. Johnst., Phaca diminutiva Phil.

Hierba. Perenne. Nativa.

Distribución: TAR.

Países limítrofes: Argentina y Bolivia.

Astragalus dodtii Phil.

Sinónimos: Astragalus rengifoi Phil., Astragalus melanogonatus I.M. Johnst., Tragacantha dodtii (Phil.)

Kuntze

Hierba. Anual. Endémica.

Distribución: ANT, ATA, COQ.

Rango altitudinal: 0-800 m.

Astragalus domeykoanus (Phil.) Reiche

Sinónimos: Phaca domeykoana Phil., Phaca orites Phil., Astragalus orites (Phil.) Reiche

Hierba. Perenne. Nativa.

Distribución: MAU, NUB, BIO, ARA.

Rango altitudinal: 1380-1380 m.

Países limítrofes: Argentina.

Astragalus edmonstonei (Hook.) B.L. Rob.

Sinónimos: Phaca edmonstonei Hook., Astragalus flavus

(Hook. \& Arn.) E. Sheld., Astragalus chrysanthus (Moris)

Reiche, nom. illeg., Phaca flava Hook. \& Arn., Phaca chrysantha Moris, Astragalus affinis Steud., Phaca podocarpa Phil., Phaca acutidens Phil., Astragalus hohenacheri Speg., Tragacantha flava (Hook. \& Arn.) Kuntze, Tragacantha chrysantha (Moris) Kuntze

Hierba. Perenne. Endémica.

Distribución: ATA, COQ, VAL, LBO, MAU.

Rango altitudinal: 5-200 m.

Nombre vulgar: Hierba loca.

Astragalus germainii Phil.

Sinónimos: Astragalus segethi Phil., Astragalus dilectus Phil., Astragalus closianus Phil., Astragalus dessaueri Phil., Astragalus alfalfalis Phil., Astragalus azureus Phil. ex Reiche, Astragalus germaini Phil. var. azureus Phil. ex Fr., Tragacantha germaini (Phil.) Kuntze, Tragacantha closiana (Phil.) Kuntze, Tragacantha dilecta (Phil.) Kuntze, Tragacantha segethii (Phil.) Kuntze

Subarbusto. Endémico.

Distribución: VAL, RME, LBO, MAU.

Rango altitudinal: 2200-2950 m. 
Astragalus johnstonii Gómez-Sosa

Hierba. Perenne. Endémica.

Distribución: VAL, RME.

Rango altitudinal: 1250-1350 m.

Astragalus limariensis Muñoz

Hierba. Perenne. Endémica.

Distribución: ANT, COQ.

Rango altitudinal: 0-3960 m.

Nombre vulgar: Tetilla.

Astragalus looseri I.M. Johnst.

Hierba. Perenne. Nativa.

Distribución: COQ, VAL, RME, LBO, MAU.

Rango altitudinal: 1500-3000 m.

Países limítrofes: Argentina.

Astragalus magellanicus Gómez-Sosa

Hierba. Perenne. Nativa.

Distribución: AIS, MAG.

Rango altitudinal: 250-250 m.

Países limítrofes: Argentina.

Astragalus maulensis Speg.

Sinónimos: Phaca brachytropis Phil., hom. illeg., Astragalus brachytropis (Phil.) Reiche, comb. illeg.

Hierba. Perenne. Endémica.

Distribución: MAU.

Astragalus micranthellus Wedd.

Sinónimos: Tragacantha micranthella (Wedd.) Kuntze

Hierba. Perenne. Nativa.

Distribución: AYP, TAR, ANT.

Rango altitudinal: 4000-4250 m.

Países limítrofes: Argentina, Bolivia y Perú.

Astragalus minimus Vogel

Hierba. Perenne. Nativa.

Distribución: AYP.

Rango altitudinal: 4300-4300 m.

Países limítrofes: Argentina, Bolivia y Perú.

Astragalus minutissimus Wedd.

Sinónimos: Tragacantha minutissima (Wedd.) Kuntze

Hierba. Perenne. Nativa.

Distribución: AYP, TAR.

Rango altitudinal: 3720-4400 m.

Países limítrofes: Bolivia y Perú.

Astragalus monteroi I.M. Johnst.

Hierba. Perenne. Endémica.

Distribución: ARA.

Rango altitudinal: 1-3 m.
Astragalus monticola Phil.

Sinónimos: Astragalus barceloi Phil., Tragacantha monticola (Phil.) Kuntze

Hierba. Perenne. Nativa.

Distribución: RME.

Rango altitudinal: 2500-3500 m.

Países limítrofes: Argentina.

Astragalus nivicola Gómez-Sosa

Hierba. Perenne. Nativa.

Distribución: MAG.

Rango altitudinal: 90-1300 m.

Países limítrofes: Argentina.

Astragalus nudus Clos

Sinónimos: Tragacantha nuda (Clos) Kuntze

Hierba. Perenne. Endémica.

Distribución: ATA, COQ, VAL.

Rango altitudinal: 2-1350 m.

Nombre vulgar: Alfalfillo.

Astragalus orthocarpus I.M. Johnst.

Sinónimos: Astragalus oliganthus (Phil.) Reiche, nom.

illeg., Phaca oligantha Phil., Tragacantha oligantha (Phil.)

Kuntze

Hierba. Perenne. Endémica.

Distribución: LBO.

Rango altitudinal: 380-1750 m.

Astragalus palenae (Phil.) Reiche

Sinónimos: Phaca palenae Phil., Phaca rahmeri Phil., Astragalus rahmeri (Phil.) Reiche, Astragalus pallens Reiche, Phaca oreophila Phil., Tragacantha oreophila (Phil.) Kuntze

Hierba. Perenne. Nativa.

Distribución: MAU, ARA, LLA, AIS, MAG.

Rango altitudinal: 10-900 m.

Países limítrofes: Argentina.

Astragalus paposanus I.M. Johnst.

Hierba. Perenne. Endémica.

Distribución: ANT, COQ.

Rango altitudinal: 100-2600 m.

Astragalus patagonicus (Phil.) Speg.

Sinónimos: Phaca patagonica Phil.

Hierba. Perenne. Nativa.

Distribución: AIS, MAG.

Rango altitudinal: 150-380 m.

Países limítrofes: Argentina.

Astragalus pehuenches Niederl.

Sinónimos: Phaca inflata Gillies ex Hook. \& Arn., Astragalus inflatus (Gillies ex Hook. \& Arn.) Steud., Phaca 
striata Clos, Astragalus striatus (Clos) Reiche, Phaca macrocarpa Phil., Astragalus macrocarpus (Phil.) Reiche, nom. illeg., Tragacantha bisinflata Kuntze, Tragacantha grandis Kuntze, Astragalus grandis (Kuntze) Speg., Tragacantha striata (Clos) Kuntze

Hierba. Perenne. Nativa.

Distribución: COQ, VAL, RME, LBO, MAU.

Rango altitudinal: 700-3000 m.

Países limítrofes: Argentina.

Astragalus pissisii (Phil.) I.M. Johnst.

Sinónimos: Astragalus canescens (Hook. \& Arn.) Reiche var. pissisii (Phil.) Reiche, Phaca pissisii Phil., Tragacantha pissisii (Phil.) Kuntze

Hierba. Anual. Endémica.

Distribución: ATA, COQ, VAL, RME, MAU.

Rango altitudinal: 350-3100 m.

Astragalus pusillus Vogel

Hierba. Perenne. Nativa.

Distribución: AYP, TAR, ANT, ATA.

Rango altitudinal: 3650-4500 m.

Países limítrofes: Argentina, Bolivia y Perú.

Astragalus reichei Speg.

Sinónimos: Phaca compacta Phil., Astragalus compactus (Phil.) Reiche

Hierba. Perenne. Nativa.

Distribución: TAR, ANT.

Países limítrofes: Bolivia.

Astragalus schinetorum Barneby

Hierba. Perenne. Endémica.

Distribución: COQ.

Rango altitudinal: 2800-2800 m.

Astragalus tacorensis Gómez-Sosa

Hierba. Perenne. Nativa.

Distribución: AYP, TAR.

Países limítrofes: Argentina.

Astragalus triflorus (DC.) A. Gray

Sinónimos: Phaca triflora DC., Tragacantha triflora (DC.)

Kuntze

Hierba. Anual. Nativa.

Distribución: TAR, ANT.

Rango altitudinal: 100-700 m.

Países limítrofes: Perú.

Astragalus trifoliatus Phil.

Sinónimos: Astragalus valparadisiensis Speg., Tragacantha trifoliata (Phil.) Kuntze

Hierba. Perenne. Endémica.

Distribución: VAL.
Rango altitudinal: 5-5 m.

Astragalus vagus (Clos) Reiche

Sinónimos: Phaca vaga Clos, Astragalus san-romani (Phil.)

Reiche, Phaca san-romani Phil., Tragacantha vaga (Clos)

Kuntze

Hierba. Perenne. Endémica.

Distribución: ATA, COQ.

Rango altitudinal: 450-4300 m.

Astragalus valerianensis I.M. Johnst.

Hierba. Perenne. Endémica.

Distribución: ATA.

Astragalus verticillatus (Phil.) Reiche

Sinónimos: Phaca verticillata Phil.

Hierba. Perenne. Endémica.

Distribución: VAL, LBO, MAU, BIO.

Rango altitudinal: 250-1800 m.

Astragalus vesiculosus Clos

Sinónimos: Phaca nubigena Meyen ex Vogel, Astragalus nubigenus (Meyen ex Vogel) Taub., Astragalus meyenianus Speg., Phaca bustillosi Phil., Tragacantha andina Kuntze, Astragalus rupestris Reiche

Hierba. Perenne. Nativa.

Distribución: COQ, VAL, RME, LBO, MAU.

Rango altitudinal: 2250-3410 m.

Países limítrofes: Argentina.

Astragalus werdermannii I.M. Johnst.

Hierba. Perenne. Nativa.

Distribución: TAR.

Países limítrofes: Argentina y Bolivia.

\section{Balsamocarpon}

Balsamocarpon brevifolium $\mathrm{Clos}$

Sinónimos: Caesalpinia brevifolia (Clos) Benth.

Arbusto. Endémico.

Distribución: ATA, COQ.

Rango altitudinal: 0-1900 m.

Nombre vulgar: Algarrobilla.

\section{Caesalpinia}

Caesalpinia angulata (Hook. \& Arn.) Baill.

Sinónimos: Caesalpinia angulicaulis Clos, Zuccagnia angulata Hook. \& Arn., Sophora angulata (Hook. \& Arn.) Ravenna

Arbusto. Endémico.

Distribución: ATA, COQ.

Rango altitudinal: 0-1900 m.

Nombre vulgar: Retamo. 
Caesalpinia gilliesii (Wall. ex Hook.) D. Dietr.

Sinónimos: Poinciana gilliesii Wall. ex Hook., Caesalpinia gilliesii (Wall. ex Hook.) Benth., nom. illeg., Erythrostemon gilliesii (Wall. ex Hook.) Klotzsch

Arbusto. Nativo.

Distribución: AYP, TAR, ATA, COQ, VAL, RME.

Rango altitudinal: 0-2500 $\mathrm{m}$.

Países limítrofes: Argentina y Bolivia.

Caesalpinia major (Medik.) Dandy \& Exell

Arbusto. Nativo.

Distribución: IPA.

Nombre vulgar: Ngaoho, naoho (Rapa Nui).

Caesalpinia spinosa (Molina) Kuntze

Sinónimos: Poinciana spinosa Molina, Caesalpinia tinctoria (Kunth) Benth. ex Reiche, Tara spinosa (Molina)

Britton \& Rose, Caesalpinia chilensis DC.

Árbol. Nativo.

Distribución: AYP, TAR, COQ, VAL.

Rango altitudinal: 0-3000 m.

Países limítrofes: Bolivia y Perú.

Nombre vulgar: Tara.

\section{Calliandra}

Calliandra chilensis Benth.

Sinónimos: Feuilleea chilensis (Benth.) Kuntze, Acacia nigra Clos

Arbusto. Endémico.

Distribución: ATA, COQ.

Rango altitudinal: $1100 \mathrm{~m}$.

\section{Crotalaria}

Crotalaria grahamiana Wight \& Arn.

Hierba. Perenne. Introducida.

Distribución: IPA.

Crotalaria incana $\mathrm{L}$.

Hierba. Perenne. Introducida.

Distribución: AYP.

Rango altitudinal: 40-60 m.

\section{Crotalaria pallida Aiton}

Hierba o subarbusto. Perenne. Introducida.

Distribución: IPA.

Nombre vulgar: Nga ehe ehe (Rapa Nui).

\section{Cytisus}

Cytisus scoparius (L.) Link

Arbusto. Introducido.

Distribución: MAU, BIO, ARA, LRI, LLA, AIS, MAG.
Cytisus striatus Rothm.

Arbusto. Introducido.

Distribución: MAU, NUB, BIO, ARA.

Dalea

Dalea azurea (Phil.) Reiche

Sinónimos: Parosela azurea (Phil.) J.F. Macbr., Psoralea azurea Phil., Lotodes azureum (Phil.) Kuntze

Subarbusto. Endémico.

Distribución: ANT.

Rango altitudinal: 0-500 m.

Dalea moquehuana J.F. Macbr.

Hierba. Perenne. Nativa.

Distribución: AYP, TAR.

Rango altitudinal: 1900-2700 m.

Países limítrofes: Perú.

Dalea pennellii (J.F. Macbr.) J.F. Macbr. var. chilensis Barneby

Subarbusto. Endémico.

Distribución: AYP, TAR.

Rango altitudinal: 2500-3300 m.

\section{Desmanthus}

Desmanthus virgatus (L.) Willd.

Hierba. Perenne. Introducida.

Distribución: AYP.

Dipogon

Dipogon lignosus (L.) Verdc.

Arbusto trepador. Introducido.

Distribución: TAR.

\section{Errazurizia}

Errazurizia multifoliolata (Clos) I.M. Johnst.

Sinónimos: Errazurizia glandulifera Phil., Psoralea multifoliolata Clos, Dalea multifoliolata (Clos) Reiche, Parosela multifoliolata (Clos) J.F. Macbr.

Arbusto. Endémico.

Distribución: ANT, ATA, COQ.

Rango altitudinal: 0-1400 m.

\section{Galega}

Galega officinalis L.

Hierba. Perenne. Introducida.

Distribución: ANT, VAL, RME, LBO, MAU, NUB, BIO, ARA, LLA, JFE. 


\section{Geoffroea}

Geoffroea decorticans (Gillies ex Hook. \& Arn.) Burkart Sinónimos: Gourliea decorticans Gillies ex Hook. \& Arn., Lucuma spinosa Molina, Gourliea chilensis Clos, Gourliea spinosa (Molina) Skeels

Árbol. Nativo.

Distribución: AYP, TAR, ANT, ATA, COQ.

Rango altitudinal: 100-2600 m.

Países limítrofes: Argentina y Bolivia.

Nombre vulgar: Chañar.

\section{Glycyrrhiza}

Glycyrrhiza astragalina Gillies ex Hook. \& Arn.

Subarbusto. Nativo.

Distribución: VAL, BIO.

Rango altitudinal: 1000-2500 m.

Países limítrofes: Argentina.

\section{Hoffmannseggia}

Hoffmannseggia aphylla (Phil.) G.P. Lewis \& Sotuyo Sinónimos: Caesalpinia aphylla Phil.

Arbusto. Endémico.

Distribución: AYP, TAR.

Rango altitudinal: 0-3200 m.

Hoffmannseggia doellii Phil.

Hierba. Perenne. Endémica.

Distribución: TAR, ANT, ATA.

Rango altitudinal: 2300-3500 m.

Hoffmannseggia eremophila (Phil.) Burkart ex Ulibarri Sinónimos: Hoffmannseggia andina Miers var. eremophila (Phil.) Reiche, Hoffmannseggia andina Miers, nom. nud., Hoffmannseggia andina Phil., Zuccagnia eremophila Phil.

Hierba. Perenne. Nativa.

Distribución: ANT, ATA.

Rango altitudinal: 3000-4000 m.

Países limítrofes: Argentina.

Hoffmannseggia glauca (Ortega) Eifert

Sinónimos: Hoffmannseggia falcaria Cav., nom. illeg., Larrea glauca Ortega, Caesalpinia glauca (Ortega) Kunth, Caesalpinia falcaria (Cav.) L. Fisher

Hierba. Perenne. Nativa.

Distribución: ATA, COQ, VAL, RME.

Rango altitudinal: 0-4000 m.

Países limítrofes: Argentina y Bolivia.

Nombre vulgar: Porotillo, culchao.

Hoffmannseggia minor (Phil.) Ulibarri

Sinónimos: Hoffmannseggia doellii Phil. var. minor Phil.
Hierba. Perenne. Nativa.

Distribución: AYP, TAR, ANT.

Rango altitudinal: 800-4000 m.

Países limítrofes: Argentina y Bolivia.

Hoffmannseggia prostrata Lag. ex DC.

Sinónimos: Hoffmannseggia gracilis (Ruiz \& Pav.) Hook. \& Arn., Caesalpinia prostrata (Lag. ex DC.) J.F. Macbr., Larrea gracilis Ruiz \& Pav.

Hierba. Perenne. Nativa.

Distribución: AYP, TAR, ANT, ATA.

Rango altitudinal: 0-2700 m.

Países limítrofes: Bolivia y Perú.

Nombre vulgar: Ají.

\section{Hoffmannseggia trifoliata Cav.}

Sinónimos: Hoffmannseggia trifoliata Cav. var. microphylla Speg., Hoffmannseggia trifoliata Cav. var. glandulosa Speg., Hoffmannseggia trifoliata Cav. fma. normalis Speg., Hoffmannseggia trifoliata Cav. fma. microphylla Speg.

Hierba. Perenne. Nativa.

Distribución: AIS.

Rango altitudinal: 0-600 m.

Países limítrofes: Argentina.

Hoffmannseggia viscosa (Ruiz \& Pav.) Hook.

Sinónimos: Caesalpinia ternata (Phil.) J.F. Macbr., Larrea viscosa Ruiz \& Pav., Caesalpinia viscosa (Ruiz \& Pav.) Fisch., Hoffmannseggia ternata Phil.

Hierba. Perenne. Nativa.

Distribución: AYP, TAR.

Rango altitudinal: 1500-3000 m.

Países limítrofes: Bolivia y Perú.

\section{Indigofera}

Indigofera truxillensis Kunth

Hierba. Perenne. Nativa.

Distribución: AYP.

Países limítrofes: Perú.

\section{Lablab}

Lablab purpureus (L.) Sweet Hierba. Perenne. Introducida. Distribución: IPA.

\section{Lathyrus}

Lathyrus berteroanus Colla ex Savi Sinónimos: Lathyrus gracilis Phil., Lathyrus debilis Vogel var. berteroanum (Colla ex Savi) Reiche Hierba trepadora. Perenne. Endémica. 
Distribución: COQ, VAL, RME, LBO, MAU, NUB, BIO, ARA.

Lathyrus cabrerianus Burkart

Sinónimos: Lathyrus pubescens Clos, hom. illeg., Lathyrus dumetorum Burkart, hom. illeg.

Hierba. Perenne. Nativa.

Distribución: NUB, BIO, ARA, LLA, AIS.

Países limítrofes: Argentina.

Lathyrus campestris Phil.

Sinónimos: Lathyrus debilis Vogel var. campestris (Phil.)

Reiche, Lathyrus gracillimus Reiche

Hierba. Anual. Nativa.

Distribución: MAU, LLA.

Países limítrofes: Argentina.

Lathyrus cicera $\mathrm{L}$.

Hierba. Anual. Introducida.

Distribución: VAL.

Lathyrus crassipes Gillies ex Hook. \& Arn.

Hierba. Anual. Nativa.

Distribución: RME, BIO, LLA.

Países limítrofes: Argentina.

Lathyrus hookeri G. Don

Sinónimos: Lathyrus sessilifolius Hook. \& Arn., Lathyrus chilensis Steud., Lathyrus epetiolaris Clos, Lathyrus pisaster Clos, Lathyrus roseus Phil., Lathyrus litoralis Phil., Lathyrus ovalifolius Phil., Lathyrus trichocalyx Phil., Lathyrus magellanicus Lam. var. araucanus Phil., Lathyrus heterocirrus Phil., Lathyrus magellanicus Lam. var. heterocirrus (Phil.) Reiche, Lathyrus sessilifolius Hook. \& Arn. fma. trichocalyx (Phil.) Burkart, Lathyrus hookeri G. Don var. trichocalyx (Phil.) Burkart

Hierba trepadora. Perenne. Nativa.

Distribución: RME, LBO, BIO.

Países limítrofes: Argentina.

Lathyrus japonicus Willd. var. aleuticus (Greene) Fernald Hierba. Perenne. Introducida.

Distribución: AIS.

Lathyrus japonicus Willd. var. japonicus

Hierba. Perenne. Introducida.

Distribución: BIO, ARA, LLA.

Lathyrus lomanus I.M. Johnst.

Hierba trepadora. Perenne. Endémica.

Distribución: ANT.

Lathyrus macropus Gillies ex Hook. \& Arn.

Sinónimos: Lathyrus linearifolius Griseb., nom. illeg.
Hierba. Perenne. Nativa.

Distribución: VAL, RME, ARA.

Países limítrofes: Argentina.

Lathyrus magellanicus Lam. var. glaucescens Speg.

Sinónimos: Lathyrus magellanicus Lam. var. oxyphylla

Speg., Lathyrus magellanicus Lam. var. campestris Dusén

Hierba. Perenne. Nativa.

Distribución: AIS, MAG.

Países limítrofes: Argentina.

Nombre vulgar: Arvejilla.

Lathyrus magellanicus Lam. var. longipes (Phil.) Burkart

Sinónimos: Lathyrus longipes Phil., Lathyrus dumetorum

Phil. var. longipes (Phil.) Reiche

Hierba. Perenne. Nativa.

Distribución: RME, LBO.

Países limítrofes: Argentina.

Nombre vulgar: Arvejilla.

\section{Lathyrus magellanicus Lam. var. magellanicus}

Sinónimos: Lathyrus magellanicus Lam. var. subsessilifolius Kuntze, Lathyrus magellanicus D. Don, nom. illeg., Lathyrus patagonicus Hauman, Lathyrus pterocaulos Phil.

Hierba trepadora. Perenne. Nativa.

Distribución: COQ, VAL, RME, LBO, MAU, NUB, BIO, ARA, AIS, MAG.

Países limítrofes: Argentina, Bolivia y Perú.

Nombre vulgar: Arvejilla.

Lathyrus magellanicus Lam. var. tucumanensis Burkart

Hierba trepadora. Perenne. Nativa.

Distribución: LRI.

Países limítrofes: Argentina.

\section{Lathyrus multiceps Clos}

Sinónimos: Lathyrus multiceps Clos var. setiger (Phil.) Acevedo, Lathyrus setiger Phil., Lathyrus eurypetalus Phil., Lathyrus setiger Phil. var. eurypetalus (Phil.) Reiche, Lathyrus ecirrhosus Phil.

Hierba. Perenne. Nativa.

Distribución: VAL, RME, LBO, MAU, NUB, BIO, ARA.

Países limítrofes: Argentina.

Lathyrus nervosus Lam.

Sinónimos: Lathyrus trigonus Vogel, Lathyrus ovalifolius

Phil. var. mucronatus Phil.

Hierba. Perenne. Nativa.

Distribución: ARA, AIS, MAG.

Países limítrofes: Argentina.

Lathyrus pubescens Hook. \& Arn.

Sinónimos: Lathyrus petiolaris Vogel, Lathyrus acutifolius Vogel, Lathyrus andicolus Gand., Lathyrus dumetorum Phil. 
Hierba. Perenne. Nativa.

Distribución: COQ, VAL, RME, BIO, ARA, LRI.

Países limítrofes: Argentina y Bolivia.

Lathyrus pusillus Elliott

Sinónimos: Lathyrus stipularis J. Presl, Lathyrus montevidensis Vogel, Lathyrus arvensis Phil., Lathyrus debilis Vogel var. arvensis (Phil.) Reiche, Lathyrus crassipes Phil., nom. illeg., Lathyrus dicirrhus Clos

Hierba. Anual. Nativa.

Distribución: LLA.

Países limítrofes: Argentina y Perú.

Lathyrus sativus L.

Hierba. Anual. Introducida.

Distribución: LBO, MAU, NUB, BIO.

Lathyrus subandinus Phil.

Hierba. Perenne. Endémica.

Distribución: VAL, RME, LBO, MAU, NUB, BIO, ARA.

\section{Leucaena}

Leucaena leucocephala (Lam.) de Wit

Arbusto o árbol pequeño. Introducido.

Distribución: IPA.

\section{Lotus}

Lotus corniculatus L.

Hierba. Perenne. Introducida.

Distribución: ATA, RME, LBO, MAU, NUB, BIO, ARA, LRI, LLA, MAG.

\section{Lotus pedunculatus Cav.}

Hierba. Perenne. Introducida.

Distribución: MAU, NUB, BIO, ARA, LRI, LLA, AIS, IPA.

Lotus subpinnatus Lag.

Sinónimos: Hosackia subpinnata (Lag.) Torr. \& A. Gray

Hierba. Anual. Endémica.

Distribución: ANT, ATA, COQ, VAL, RME, LBO, MAU, NUB, BIO, ARA, LRI, LLA.

Rango altitudinal: 0-2300 m.

Lotus tenuis Waldst. \& Kit. ex Willd.

Hierba. Perenne. Introducida.

Distribución: VAL, RME, NUB, BIO, ARA, LLA.

\section{Lupinus}

Lupinus albus $\mathrm{L}$.

Hierba. Anual. Introducida.

Distribución: BIO, ARA.
Lupinus angustifolius L.

Hierba. Anual. Introducida.

Distribución: NUB, BIO.

Lupinus arboreus Sims

Arbusto. Introducido.

Distribución: COQ, VAL, LBO, MAU, BIO, ARA, LRI, LLA, MAG, JFE.

Lupinus luteus L.

Hierba. Anual. Introducida.

Distribución: VAL.

Lupinus microcarpus Sims

Sinónimos: Lupinus comberanus C.P. Sm., Lupinus fischeranus C.P. Sm., Lupinus verticillatus C.P. Sm.

Hierba. Anual. Nativa.

Distribución: TAR, ANT, ATA, COQ, VAL, RME, LBO, MAU, NUB, BIO, ARA, LLA.

Rango altitudinal: 0-2500 $\mathrm{m}$.

Países limítrofes: Argentina y Perú.

Nombre vulgar: Altramuz, hierba del traro.

Lupinus oreophilus Phil.

Sinónimos: Lupinus oreophilus Greene, nom. illeg.

Hierba. Perenne. Endémica.

Distribución: AYP, TAR, ANT.

Rango altitudinal: 2700-4400 m.

Lupinus polyphyllus Lindl.

Hierba. Perenne. Introducida.

Distribución: LLA, AIS, MAG.

Lupinus subacaulis Griseb.

Sinónimos: Lupinus chilensis C.P. Sm.

Hierba. Perenne. Nativa.

Distribución: AYP, TAR, ANT.

Rango altitudinal: 3000-4500 m.

Países limítrofes: Argentina, Bolivia y Perú.

Lupinus subinflatus C.P. Sm.

Hierba. Perenne. Nativa.

Distribución: AYP, TAR, ANT.

Rango altitudinal: 2500-4000 m.

Países limítrofes: Argentina y Bolivia.

Lupinus tarapacensis C.P. Sm.

Arbusto. Nativo.

Distribución: AYP, TAR.

Países limítrofes: Perú.

Lupinus werdermannianus C.P. Sm.

Arbusto. Endémico.

Distribución: TAR. 


\section{Macroptilium}

Macroptilium lathyroides (L.) Urban

Hierba. Anual. Introducida.

Distribución: IPA.

\section{Medicago}

Medicago arabica (L.) Huds.

Hierba. Anual. Introducida.

Distribución: COQ, VAL, RME, LBO, MAU, NUB, BIO, ARA, LRI, LLA, JFE.

Medicago arborea L.

Arbusto. Introducido.

Distribución: RME, MAU.

\section{Medicago lupulina L.}

Hierba. Anual o bienal. Introducida.

Distribución: ANT, ATA, COQ, VAL, RME, LBO, MAU, NUB, BIO, ARA, LRI, LLA, AIS, JFE, IPA.

Medicago minima (L.) Bartal.

Hierba. Anual. Introducida.

Distribución: COQ, VAL, RME, LBO, ARA, MAG.

Medicago polymorpha L. var. confinis (Koch) Ooststr. \& B. Reichg.

Hierba. Anual. Introducida.

Distribución: ANT, ATA, COQ, VAL, RME, LBO, MAU, NUB, BIO, ARA, JFE.

\section{Medicago polymorpha L. var. polymorpha}

Hierba. Anual. Introducida.

Distribución: AYP, ANT, ATA, COQ, VAL, RME, LBO, MAU, NUB, BIO, ARA, LRI, JFE.

Medicago polymorpha L. var. vulgaris (Benth.) Shinners Hierba. Anual. Introducida.

Distribución: VAL, RME, NUB, BIO, ARA, LRI, JFE.

\section{Medicago sativa $\mathrm{L}$.}

Hierba o subarbusto. Perenne. Introducida.

Distribución: AYP, TAR, ANT, ATA, COQ, VAL, RME, LBO, MAU, NUB, BIO, ARA, LRI, LLA, AIS, MAG, JFE.

\section{Melilotus}

Melilotus albus Medik.

Hierba o subarbusto. Bienal. Introducida.

Distribución: AYP, TAR, ATA, COQ, VAL, RME, LBO, MAU, NUB, BIO, AIS, MAG.
Melilotus indicus (L.) All.

Hierba o subarbusto. Anual. Introducida.

Distribución: AYP, TAR, ANT, ATA, COQ, VAL, RME, LBO, MAU, NUB, BIO, ARA, LRI, LLA, AIS, MAG, JFE, IPA.

Melilotus officinalis (L.) Lam.

Hierba o subarbusto. Anual o bienal. Introducida.

Distribución: VAL, RME, LBO, MAG.

\section{Ornithopus}

Ornithopus compressus L.

Hierba. Anual. Introducida.

Distribución: BIO.

Ornithopus pinnatus (Mill.) Druce

Hierba. Anual o perenne. Introducida.

Distribución: BIO.

Ornithopus sativus Brot.

Hierba. Anual. Introducida.

Distribución: BIO.

\section{Otholobium}

Otholobium glandulosum (L.) J.W. Grimes

Sinónimos: Psoralea glandulosa L., Lotodes glandulosum (L.) Kuntze, Hoita glandulosa (L.) Rydb.

Arbusto o árbol pequeño. Nativo.

Distribución: AYP, TAR, COQ, VAL, RME, LBO, MAU, NUB, BIO, ARA, LRI.

Rango altitudinal: 600-1400 m.

Países limítrofes: Bolivia y Perú.

\section{Prosopis}

Prosopis alba Griseb.

Sinónimos: Prosopis siliquastrum (Cav. ex Lag.) DC. var. longisiliqua Phil., Prosopis atacamensis Phil.

Árbol. Nativo.

Distribución: AYP, TAR, ANT, ATA.

Rango altitudinal: 0-2500 m.

Países limítrofes: Argentina, Bolivia y Perú.

Nombre vulgar: Algarrobo blanco.

\section{Prosopis burkartii Muñoz}

Arbusto. Endémico.

Distribución: TAR.

Prosopis chilensis (Molina) Stuntz emend. Burkart Sinónimos: Prosopis siliquastrum (Cav. ex Lag.) DC., Ceratonia chilensis Molina, Acacia siliquastrum Cav. ex Lag., Prosopis schinopoma Stuck. 
Árbol. Nativo.

Distribución: TAR, ANT, ATA, COQ, VAL, RME, LBO.

Rango altitudinal: 500-2500 m.

Países limítrofes: Argentina, Bolivia y Perú.

Nombre vulgar: Algarrobo del centro.

Prosopis flexuosa DC. var. flexuosa

Arbusto. Nativo.

Distribución: TAR, ANT, ATA, COQ.

Países limítrofes: Argentina y Bolivia.

Prosopis flexuosa DC. var. fruticosa (Meyen) F.A. Roig

Sinónimos: Prosopis fruticosa Meyen

Arbusto. Endémico.

Distribución: AYP, TAR, ATA, COQ.

Rango altitudinal: 100-800 m.

Prosopis strombulifera (Lam.) Benth.

Sinónimos: Strombocarpa strombulifera (Lam.) A. Gray, Acacia strombulifera (Lam.) Willd., Spirolobium australe Orb., Mimosa circinalis Cav., nom. illeg., Mimosa strombulifera Lam., Prosopis reptans Benth. var. chilensis Zoellner

Arbusto. Nativo.

Distribución: TAR, ANT, ATA, COQ, VAL, LBO.

Rango altitudinal: 0-1600 m.

Países limítrofes: Argentina y Perú.

Nombre vulgar: Espinillo, retortón.

Prosopis tamarugo Phil.

Árbol. Endémico.

Distribución: AYP, TAR, ANT.

\section{Rhynchosia}

Rhynchosia minima (L.) DC.

Arbusto trepador. Introducido.

Distribución: AYP.

\section{Robinia}

\section{Robinia pseudoacacia L.}

Árbol. Introducido.

Distribución: VAL, RME, LBO, MAU, NUB, BIO, JFE, IPA.

\section{Senna}

Senna arnottiana (Gillies ex Hook.) H.S. Irwin \& Barneby Sinónimos: Cassia arnottiana Gillies ex Hook., Cassia andina Phil., Cassia arnottiana Gillies ex Hook. var. andina (Phil.) Reiche

Arbusto o subarbusto. Nativo.
Distribución: COQ, VAL, RME, LBO, MAU, NUB.

Rango altitudinal: 800-2800 m.

Países limítrofes: Argentina.

Senna birostris (Dombey ex Vogel) H.S. Irwin \& Barneby var. arequipensis (Meyen ex Vogel) H.S. Irwin \& Barneby Sinónimos: Cassia arequipensis Meyen ex Vogel, Cassia tarapacana Phil.

Arbusto. Nativo.

Distribución: AYP, TAR.

Rango altitudinal: 2200-3900 m.

Países limítrofes: Perú.

Senna brongniartii (Gaudich.) H.S. Irwin \& Barneby

Sinónimos: Cassia misera Phil., Cassia brongniartii Gaudich.

Arbusto o subarbusto. Nativo.

Distribución: AYP, TAR, ANT.

Rango altitudinal: 100-1100 m.

Países limítrofes: Perú.

Senna candolleana (Vogel) H.S. Irwin \& Barneby

Sinónimos: Cassia closiana Phil., Cassia obtusa Clos, Cassia candolleana Vogel, Cassia emarginata Clos, nom. illeg., Cassia bicapsularis L. var. chilensis Benth.

Arbusto. Endémico.

Distribución: COQ, VAL, RME, LBO.

Rango altitudinal: 0-800 m.

Senna cruckshanksii (Hook. \& Arn.) H.S. Irwin \& Barneby Sinónimos: Cassia stipulacea Aiton var. tenuistipula Bertero ex Vogel, Cassia campanae Phil., Cassia confusa Phil. var. campanae (Phil.) Reiche, Cassia cruckshanksii Hook. \& Arn.

Arbusto. Endémico.

Distribución: COQ, VAL, RME.

Rango altitudinal: 400-600 m.

Senna cumingii (Hook. \& Arn.) H.S. Irwin \& Barneby var. alcaparra (Phil.) H.S. Irwin \& Barneby

Sinónimos: Cassia alcaparra Phil.

Arbusto. Endémico.

Distribución: COQ, VAL.

Rango altitudinal: 0-1800 m.

Senna cumingii (Hook. \& Arn.) H.S. Irwin \& Barneby var. coquimbensis (Vogel) H.S. Irwin \& Barneby

Sinónimos: Cassia coquimbensis Vogel, Cassia flaccida Clos

Arbusto. Endémico.

Distribución: ANT, ATA, COQ.

Rango altitudinal: 0-400 m. 
Senna cumingii (Hook. \& Arn.) H.S. Irwin \& Barneby var. cumingii

Sinónimos: Cassia cumingii Hook. \& Arn.

Arbusto. Endémico.

Distribución: ANT, ATA, COQ.

Rango altitudinal: 0-1000 m.

Senna cumingii (Hook. \& Arn.) H.S. Irwin \& Barneby var. eremobia (Phil.) H.S. Irwin \& Barneby

Sinónimos: Cassia eremobia Phil.

Arbusto. Endémico.

Distribución: ANT.

Rango altitudinal: 0-200 m.

Senna huidobriana (Phil.) Zoellner \& San Martin

Sinónimos: Cassia huidobriana Phil.

Arbusto. Endémico.

Distribución: COQ.

Rango altitudinal: 0-300 m.

Senna paposana (Phil.) Zoellner \& San Martin

Sinónimos: Cassia paposana Phil.

Arbusto. Endémico.

Distribución: ANT.

Senna septemtrionalis (Viv.) H.S. Irwin \& Barneby

Árbol. Introducido.

Distribución: LBO.

Senna stipulacea (Aiton) H.S. Irwin \& Barneby var. anglorum $\mathrm{H}$.S. Irwin \& Barneby

Arbusto. Endémico.

Distribución: COQ, VAL, RME, MAU, NUB.

Rango altitudinal: 0-500 m.

Senna stipulacea (Aiton) H.S. Irwin \& Barneby var. stipulacea

Sinónimos: Cassia stipulacea Aiton, Cassia foetida Ruiz \& Pav. ex G. Don, Cassia myrtifolia Phil. ex Reiche, Cassia stipulacea Willd., nom. illeg., Cassia pencana Phil. ex sched.

Arbusto. Endémico.

Distribución: VAL, LBO, MAU, NUB, BIO, ARA, LRI, LLA.

Rango altitudinal: 0-1000 m.

Nombre vulgar: Quebracho, alcaparra.

Senna urmenetae (Phil.) H.S. Irwin \& Barneby

Sinónimos: Cassia urmenetae Phil., Cassia glaucescens

Benth., Cassia oreades Phil.

Arbusto. Endémico.

Distribución: ATA, COQ, RME.

Rango altitudinal: 0-2500 m.

\section{Sophora}

Sophora cassioides (Phil.) Sparre

Sinónimos: Edwardsia cassioides Phil.

Árbol. Endémico.

Distribución: MAU, NUB, BIO, ARA, LRI, LLA, AIS.

Rango altitudinal: 0-900 m.

Nombre vulgar: Pilo, pelú.

Sophora fernandeziana (Phil.) Skottsb. var. fernandeziana Sinónimos: Sophora tetraptera J.S. Muell. subsp. fernandeziana Skottsb.

Árbol. Endémico.

Distribución: JFE.

Nombre vulgar: Mayu-monte, mayu del monte.

Sophora fernandeziana (Phil.) Skottsb. var. reedeana (Phil.) Skottsb.

Sinónimos: Edwardsia reedeana Phil., Sophora reediana (Phil.) Yakovlev

Árbol. Endémico.

Distribución: JFE.

Sophora macrocarpa $\mathrm{Sm}$.

Sinónimos: Sophora donihuensis Ravenna

Arbusto o árbol pequeño. Endémico.

Distribución: COQ, VAL, RME, LBO, MAU, NUB, BIO, ARA.

Nombre vulgar: Mayu, mayo.

Sophora masafuerana (Phil.) Skottsb.

Sinónimos: Edwardsia masafuerana Phil.

Árbol. Endémico.

Distribución: JFE.

Nombre vulgar: Pelú de Juan Fernández, leña dura, madera dura.

Sophora toromiro (Phil.) Skottsb.

Sinónimos: Edwardsia toromiro Phil., Sophora tetraptera auct., non J. Mill.

Arbusto o árbol pequeño. Endémico.

Distribución: IPA.

Nombre vulgar: Toromiro.

Nota: Extinto en estado silvestre.

\section{Spartium}

Spartium junceum L.

Arbusto. Introducido.

Distribución: AYP, ANT, VAL, RME, LBO, MAU, NUB, BIO, ARA. 
Teline

Teline monspessulana (L.) K. Koch

Arbusto. Introducido.

Distribución: VAL, RME, LBO, MAU, NUB, BIO, ARA, LRI, LLA, JFE.

Nombre vulgar: Retamilla.

\section{Trifolium}

Trifolium angustifolium L.

Hierba. Anual. Introducida.

Distribución: VAL, RME, LBO, MAU, NUB, BIO, ARA.

Trifolium antucoense D. Heller

Sinónimos: Trifolium circumdatum Kunze, nom. illeg., Lupinaster circumdatus (Kunze) C. Presl, Trifolium inconspicuum Poepp. ex D. Heller, nom. nud.

Hierba. Anual. Endémica.

Distribución: LBO, BIO, LLA.

\section{Trifolium arvense $\mathrm{L}$.}

Hierba. Anual. Introducida.

Distribución: LBO, MAU, NUB, BIO, ARA, LRI, AIS, MAG.

Trifolium aureum Pollich

Hierba. Anual o bienal. Introducida.

Distribución: MAG.

Trifolium campestre Schreb.

Hierba. Anual o bienal. Introducida.

Distribución: COQ, VAL, LBO, MAU, NUB, BIO, ARA, LRI, LLA, MAG.

Trifolium cernuum Brot.

Hierba. Anual. Introducida.

Distribución: LBO, MAU.

Trifolium chilense Hook. \& Arn.

Sinónimos: Lupinaster ochreatus (Kunze ex Steud.) C. Presl, Trifolium ochreatum Kunze ex Steud.

Hierba. Anual. Endémica.

Distribución: VAL, RME, LBO, BIO, LLA.

Rango altitudinal: 600-900 m.

\section{Trifolium depauperatum Desv.}

Sinónimos: Lupinaster depauperatus (Desv.) C. Presl

Hierba. Anual. Nativa.

Distribución: VAL, RME, LBO, MAU, NUB, BIO, ARA.

Rango altitudinal: 100-1000 m.

Países limítrofes: Perú.
Trifolium dubium Sibth.

Hierba. Anual. Introducida.

Distribución: VAL, RME, LBO, MAU, NUB, BIO, ARA, LRI, LLA, AIS, MAG, JFE.

Trifolium fragiferum L.

Hierba. Perenne. Introducida.

Distribución: MAG.

\section{Trifolium glomeratum L.}

Hierba. Anual. Introducida.

Distribución: VAL, RME, LBO, MAU, NUB, BIO, ARA, LLA.

\section{Trifolium hybridum L.}

Hierba. Perenne. Introducida.

Distribución: BIO, LLA, MAG.

Trifolium incarnatum L.

Hierba. Anual o bienal. Introducida.

Distribución: VAL, RME, MAU, BIO, ARA, LRI, LLA.

Trifolium macraei Hook. \& Arn.

Sinónimos: Trifolium bicephalum Elmer, Trifolium

catalinae S. Watson, Trifolium mercedense P.B. Kenn, Trifolium traskae P.B. Kenn

Hierba. Anual. Nativa.

Distribución: RME, LBO, MAU.

Rango altitudinal: 0-600 m.

Nota: Se encuentra también en California.

Trifolium microdon Hook. \& Arn.

Sinónimos: Trifolium lechleri Phil., Trifolium chrysanthum Hook. \& Arn., Trifolium microdon Hook. \& Arn. var. pilosum Eastw., Trifolium tricuspidatum Bertero ex Steud.

Hierba. Anual. Nativa.

Distribución: RME, BIO, ARA, LLA.

Rango altitudinal: 0-500 m.

Nota: Se encuentra también en Estados Unidos y Canadá.

Trifolium physanthum Hook. \& Arn.

Sinónimos: Trifolium valdivianum Phil. ex D. Heller \& Zohary, nom. nud.

Hierba. Anual. Endémica.

Distribución: VAL, LBO, MAU, BIO, LLA.

Trifolium polymorphum Poir. var. grandiflorum Parodi Hierba. Anual. Nativa.

Distribución: RME, MAU, NUB, BIO.

Rango altitudinal: 0-500 m.

Países limítrofes: Argentina.

Trifolium polymorphum Poir. var. polymorphum

Sinónimos: Trifolium grandiflorum Hook. \& Arn., Amoria 
polymorpha (Poir.) C. Presl, Trifolium rivale Closs, non Steud., Trifolium crosnierii Clos, Trifolium indecorum Clos, Trifolium simplex Clos, Trifolium brevipes Phil., Trifolium concinum Phil., Trifolium amphicarpum Phil., Trifolium rubrum Larrañaga

Hierba. Perenne. Nativa.

Distribución: ANT, ATA, COQ, VAL, RME, LBO, MAU, NUB, BIO, ARA, LRI.

Rango altitudinal: 0-2700 m.

Países limítrofes: Argentina, Bolivia y Perú.

Trifolium pratense $\mathrm{L}$.

Hierba. Perenne. Introducida.

Distribución: COQ, VAL, RME, LBO, MAU, NUB, BIO, ARA, LRI, LLA, AIS, MAG, JFE.

Trifolium repens L.

Hierba. Perenne. Introducida.

Distribución: COQ, VAL, RME, LBO, MAU, NUB, BIO, ARA, LRI, LLA, AIS, MAG, JFE, IPA.

\section{Trifolium spadiceum L.}

Hierba. Anual o bienal. Introducida.

Distribución: MAG.

Trifolium striatum L.

Hierba. Anual o bienal. Introducida.

Distribución: RME, LBO, MAU, NUB, BIO, ARA.

\section{Trifolium subterraneum L.}

Hierba. Anual. Introducida.

Distribución: COQ, LBO, MAU, BIO, ARA.

\section{Trifolium suffocatum L.}

Hierba. Anual. Introducida.

Distribución: RME, LBO.

\section{Trifolium tomentosum L.}

Hierba. Anual. Introducida.

Distribución: VAL, RME, LBO, BIO.

Trifolium triaristatum Bertero ex Colla

Hierba. Anual. Nativa.

Distribución: VAL, LBO, BIO, LLA.

Nota: Se encuentra también en México y Estados Unidos.

\section{Trifolium vernum Phil.}

Hierba. Anual. Endémica.

Distribución: VAL, LBO.

Rango altitudinal: 1500-2000 m.

Trifolium vestitum D. Heller \& Zohary Sinónimos: Trifolium volekmanni Phil. Hierba. Perenne. Endémica.
Distribución: COQ, RME.

Rango altitudinal: 2000-3000 m.

\section{Trigonella}

Trigonella monspeliaca L.

Hierba. Anual. Introducida.

Distribución: VAL, RME, LBO.

Ulex

Ulex europaeus L.

Arbusto. Introducido.

Distribución: VAL, LBO, MAU, NUB, BIO, ARA, LRI, LLA, MAG.

Vicia

Vicia araucana Phil.

Hierba. Anual o bienal. Endémica.

Distribución: MAU, NUB.

Vicia benghalensis L.

Hierba. Anual. Introducida.

Distribución: AYP, COQ, VAL, RME, LBO, MAU, NUB, BIO, ARA, LRI, MAG.

Vicia berteroana Phil.

Hierba. Anual. Endémica.

Distribución: RME, LBO.

Vicia bijuga Gillies ex Hook. \& Arn.

Sinónimos: Lathyrus anomalus Phil., Vicia solisii Phil., Vicia saffordii Phil., Vicia sericella Speg., Vicia sericella Speg. var. glabrata Speg.

Hierba. Anual o bienal. Nativa.

Distribución: RME, NUB, LLA, AIS, MAG.

Rango altitudinal: 0-1000 m.

Países limítrofes: Argentina.

Vicia coquimbensis Martic.

Sinónimos: Vicia truncata Phil., hom. illeg.

Hierba. Anual o perenne. Endémica.

Distribución: COQ.

\section{Vicia diversifolia Phil.}

Hierba. Anual. Endémica.

Distribución: LLA.

Vicia graminea $\mathrm{Sm}$.

Sinónimos: Vicia graminea Sm. var. heterophyla Kuntze, Vicia graminea Sm. var. multiflora Hook. \& Arn., Vicia grata Phil.

Hierba. Anual o bienal. Nativa. 
Distribución: RME, AIS, MAG.

Rango altitudinal: 0-500 m.

Países limítrofes: Argentina, Bolivia y Perú.

Vicia hirsuta (L.) Gray

Hierba. Anual. Introducida.

Distribución: LBO, MAU, NUB, BIO, ARA, LRI, LLA, MAG.

Vicia inconspicua Phil.

Hierba. Anual. Endémica.

Distribución: ARA, LLA.

Rango altitudinal: 0-400 m.

Vicia lanceolata Phil.

Hierba. Anual o bienal. Endémica.

Distribución: MAU.

Vicia linearifolia Hook. \& Arn.

Sinónimos: Vicia hookeri G. Don, Vicia micrantha Hook.

\& Arn.

Hierba trepadora. Anual. Nativa.

Distribución: VAL, BIO, ARA, LLA, AIS.

Rango altitudinal: 0-500 m.

Países limítrofes: Argentina.

Vicia magellanica Hook.f. var. dianthes (Phil.) Reiche

Sinónimos: Vicia dianthes Phil.

Hierba. Anual o bienal. Endémica.

Distribución: ARA.

Vicia magellanica Hook.f. var. magellanica

Sinónimos: Vicia graminea auct. non Sm., Vicia kingii Hook.f., Vicia patagonica Hook.f., Vicia depauperata Clos, Vicia patagonica Hook.f. var. depauperata (Clos) Speg., Vicia andicola Phil. non Kunth

Hierba. Anual o bienal. Nativa.

Distribución: COQ, RME, LBO, MAU, NUB, BIO, ARA, AIS, MAG.

Rango altitudinal: 0-500 m.

Países limítrofes: Argentina y Bolivia.

Vicia modesta Phil.

Hierba. Anual o bienal. Endémica.

Distribución: ANT, VAL.

\section{Vicia mucronata Clos}

Hierba. Anual o bienal. Endémica.

Distribución: VAL, RME, LBO, ARA, LLA.

Rango altitudinal: 0-800 m.

Vicia nana Vogel

Sinónimos: Vicia dentata Gillies ex Hook. \& Arn., Vicia valdiviana Phil., Vicia leptantha Phil.
Hierba trepadora. Anual. Nativa.

Distribución: BIO, LLA.

Rango altitudinal: 0-500 $\mathrm{m}$.

Países limítrofes: Argentina.

Vicia nigricans Hook. \& Arn.

Sinónimos: Vicia macraei Hook. \& Arn., Vicia coxii Phil., Vicia darapskiana Phil., Vicia andina Phil., Vicia leyboldii Phil., Vicia magnifolia Clos, Vicia moorei Phil., Vicia speciosa Phil., Vicia commutata Phil., Vicia fodinarum Phil., Vicia apiculata Phil., Vicia apiculata Phil. var. parvifolia Phil.

Hierba. Perenne. Nativa.

Distribución: VAL, RME, LBO, MAU, NUB, BIO, ARA, LRI, LLA, AIS.

Rango altitudinal: 0-500 m.

Países limítrofes: Argentina.

Vicia pallida Hook. \& Arn.

Hierba. Anual o bienal. Endémica.

Distribución: COQ, VAL, RME, LBO.

Vicia parviflora Cav.

Arbusto trepador. Introducido.

Distribución: ARA.

Vicia sativa L. subsp. nigra (L.) Ehrh.

Hierba. Anual. Introducida.

Distribución: RME, BIO, ARA, LLA.

Vicia sativa L. subsp. sativa

Hierba. Anual. Introducida.

Distribución: COQ, VAL, RME, LBO, MAU, NUB, BIO, ARA, LRI, LLA, AIS.

Vicia sessiliflora Clos

Hierba. Anual o bienal. Endémica.

Distribución: LLA.

Vicia setifolia Kunth

Sinónimos: Vicia graminea Sm. var. setifolia (Kunth) Kuntze, Vicia acerosa Clos, Vicia acerosa Clos var. angustifolia (Clos) Reiche, Vicia angustifolia Clos, hom. illeg.

Hierba. Anual. Nativa.

Distribución: RME, LLA.

Rango altitudinal: 0-1600 m.

Países limítrofes: Argentina.

Vicia subserrata Phil.

Hierba. Anual. Endémica.

Distribución: COQ, RME.

Rango altitudinal: 100-200 m. 
Vicia tetrasperma (L.) Schreb.

Hierba. Anual. Introducida.

Distribución: AYP, VAL, RME, LBO, MAU, AIS, MAG.

Vicia vicina Clos

Hierba. Anual o bienal. Endémica.

Distribución: AYP, TAR, ANT, COQ, VAL, RME, LBO, MAU, NUB, BIO, ARA.

Rango altitudinal: 0-1800 m.

Vicia villosa Roth

Hierba. Anual. Introducida.

Distribución: RME, LBO, MAU, NUB, BIO, ARA.

\section{Weberbauerella}

Weberbauerella chilensis Faúndez \& Saldivia

Hierba. Perenne. Endémica.

Distribución: TAR, ATA.

Rango altitudinal: 2500-3600 m.

\section{FAGACEAE}

\section{Quercus}

Quercus robur L.

Árbol. Introducido.

Distribución: NUB, BIO, ARA, LRI, JFE.

Nombre vulgar: Encino, roble europeo.

\section{FRANCOACEAE}

\section{Araeoandra}

Araeoandra tenuicaulis (Barnéoud) Lefor Sinónimos: Viviania tenuicaulis Barnéoud Hierba. Anual. Endémica.

Distribución: COQ.

Rango altitudinal: 0-600 m.

\section{Balbisia}

Balbisia gracilis (Meyen) Hunz. \& Ariza

Sinónimos: Wendtia gracilis Meyen, Wendtia gracilis Meyen var. typica Knuth, nom. illeg., Wendtia reynoldsii Endl. ex Walp., Wendtia trigyna (Kunze) Kuntze, Wendtia trigyna (Kunze) Kuntze var. poeppigiana Kuntze

Subarbusto. Nativo.

Distribución: COQ, VAL, RME, LBO, MAU, NUB, BIO, ARA, AIS.

Rango altitudinal: 0-1500 m.

Países limítrofes: Argentina.
Balbisia microphylla (Phil.) Reiche

Sinónimos: Ledocarpon microphylla Phil.

Subarbusto. Endémico.

Distribución: AYP, TAR, ATA.

Rango altitudinal: 3000-3500 m.

Nombre vulgar: Purisa, pupuñía.

Balbisia peduncularis (Lindl.) D. Don

Sinónimos: Ledocarpon pedunculare Lindl., Cruckshanksia cistiflora Hook. \& Arn., Ledocarpon cistiflorum Meyen, nom. nud.

Subarbusto. Nativo.

Distribución: AYP, ANT, ATA, COQ.

Rango altitudinal: 200-500 m.

Países limítrofes: Perú.

Nombre vulgar: Flor de San José, amancai, palo negro, copa

de oro, mancay.

Balbisia stitchkinii Ricardi

Subarbusto. Endémico.

Distribución: AYP.

Rango altitudinal: 3800-4000 m.

\section{Cissarobryon}

Cissarobryon elegans Kunze ex Poepp.

Sinónimos: Cissarobryon aristulatum Phil., Cissarobryon macrophyllum Phil., Cissarobryon parvifolium Phil.

Hierba. Perenne. Endémica.

Distribución: VAL, RME, LBO, MAU, NUB, BIO, ARA.

Rango altitudinal: 200-2500 m.

\section{Francoa}

Francoa appendiculata Cav. var. appendiculata

Hierba. Perenne. Endémica.

Distribución: VAL, RME, LBO, MAU, NUB, BIO, ARA, LRI, LLA.

Rango altitudinal: 800-1500 m.

Francoa appendiculata Cav. var. ramosa (D. Don) Rolfe Sinónimos: Francoa ramosa D. Don

Hierba. Perenne. Endémica.

Distribución: VAL, RME, MAU, NUB, BIO, ARA, LLA.

Francoa appendiculata Cav. var. sonchifolia (Cav.) Rolfe Sinónimos: Francoa sonchifolia Cav.

Hierba. Perenne. Endémica.

Distribución: MAU, NUB, BIO, ARA, LRI, LLA.

Rango altitudinal: 0-500 m.

Nombre vulgar: Hierba del pasmo, llaupangue. 
Tetilla

Tetilla hydrocotylifolia DC.

Hierba. Perenne. Endémica.

Distribución: COQ, VAL, RME, LBO, MAU, ARA.

\section{Viviania}

Viviania crenata (Hook.) G. Don

Sinónimos: Macraea crenata Hook.

Arbusto. Endémico.

Distribución: COQ, VAL, RME, LBO.

Rango altitudinal: 0-2300 m.

Nombre vulgar: Oreganillo.

Viviania marifolia Cav.

Sinónimos: Viviania rosea (Lindl.) Klotzsch, Macraea rosea Lindl., Viviania brevipedunculata Phil., Viviania laxa Phil.

Arbusto. Nativo.

Distribución: ATA, COQ, VAL, RME, LBO, MAU.

Rango altitudinal: 3200-4000 m.

Países limítrofes: Argentina.

Nombre vulgar: Oreganillo, té de burro.

Viviania ovata Phil.

Sinónimos: Viviania bernalesii Phil., Viviania rosea (Lindl.) Klotzsch var. ovata (Phil.) Reiche, Viviania viridis Phil. ex Reiche

Arbusto. Nativo.

Distribución: VAL, RME, LBO, MAU, NUB.

Rango altitudinal: 2000-2500 m.

Países limítrofes: Argentina.

\section{FRANKENIACEAE}

\section{Frankenia}

Frankenia chilensis K. Presl

Sinónimos: Frankenia campestris Schauer, Frankenia chilensis K. Presl var. campestris (Schauer) Gunckel, Frankenia erecta Gay, Frankenia nicolletiana Gay, Frankenia farinosa J. Remy, Frankenia aspera Phil., Frankenia chilensis K. Presl var. aspera (Phil.) I.M. Johnst., Frankenia florida Phil., Frankenia nicolletiana Gay var. florida (Phil.) Reiche, Frankenia glabrata Phil., Frankenia chilensis K. Presl var. florida (Phil.) Gunckel, Coldenia glabra Phil.

Arbusto. Nativo.

Distribución: TAR, ANT, ATA, COQ, RME.

Países limítrofes: Perú.
Frankenia microphylla Cav.

Sinónimos: Franca microphylla (Cav.) Vis., Frankenia microphylla Cav. var. relaxata Speg., Niederleinia microphylla (Cav.) Hieron. ex Nied.

Subarbusto. Nativo.

Distribución: MAG.

Rango altitudinal: 0-500 $\mathrm{m}$.

Países limítrofes: Argentina.

Frankenia salina (Molina) I.M. Johnst.

Sinónimos: Frankenia berteroana Gay, Frankenia micrantha Gay, Frankenia salina (Molina) I.M. Johnst. var. micrantha (Gay) Gunckel, Franca grandifolia (Cham. \& Schltdl.) Greene, Frankenia campestris (Gay) Tidestrom, Frankenia grandifolia Cham. \& Schltdl. var. micrantha (Gay) W.L. Bray, Frankenia grandifolia Cham. \& Schltdl., Frankenia grandifolia Cham. \& Schltdl. var. campestris Gray, Frankenia latifolia K. Presl, Frankenia micrantha Gay var. berteroana (Gay) W.L. Bray, Ocymum salinum Molina, Velezia latifolia Eschsch.

Subarbusto. Endémico.

Distribución: ATA, COQ, VAL, RME, LBO, MAU, NUB.

Rango altitudinal: 0-500 m.

Nombre vulgar: Hierba del salitre, salitre, vichilla, dichilla.

Frankenia triandra J. Remy

Sinónimos: Anthobryum triandrum (J. Remy) Surgis, Anthobryum aretioides Phil., Anthobryum clarenii (R.E. Fr.) Cabrera, Anthobryum tetragonum Phil., Frankenia clarenii R.E. Fries, Pycnophyllum sulcatum Griseb., Anthobryum aretoides Phil.

Subarbusto. Nativo.

Distribución: AYP, TAR, ANT.

Rango altitudinal: $3300-4800 \mathrm{~m}$.

Países limítrofes: Argentina, Bolivia y Perú.

Nombre vulgar: Llaretilla.

Frankenia vidalii $\mathrm{F}$. Phil.

Arbusto o subarbusto. Endémico.

Distribución: IDE.

Rango altitudinal: 200-500 m.

\section{GENTIANACEAE}

\section{Centaurium}

Centaurium cachanlahuen (Molina) B.L. Rob.

Sinónimos: Gentiana cachanlahuen Molina, Gentiana peruviana Lam., Chironia chilensis Willd., nom. illeg., Erythraea chilensis (Willd.) Pers., Centaurium chilense (Willd.) Druce, nom. illeg., Erythraea chilensis (Willd.) Pers. var. humilis Phil. ex Reiche

Hierba. Anual. Nativa. 
Distribución: ANT, ATA, COQ, VAL, RME, LBO, MAU, NUB, BIO, ARA, LRI, LLA, AIS, JFE.

Rango altitudinal: 0-1700 m.

Países limítrofes: Argentina.

Nombre vulgar: Canchanlahue, canchanlahuen, cachén, canchanlahua.

Nota: Introducida en el Archipiélago Juan Fernández.

\section{Centaurium erythraea Rafn}

Hierba. Anual o perenne. Introducida.

Distribución: LLA, AIS.

Centaurium littorale (Turner) Gilmour

Hierba. Anual. Introducida.

Distribución: ARA, LLA, AIS.

Centaurium pulchellum (Sw.) Druce

Hierba. Anual. Introducida.

Distribución: LRI, LLA.

Centaurium spicatum (L.) Fritsch ex Janch.

Hierba. Anual o perenne. Nativa.

Distribución: IPA.

\section{Cicendia}

Cicendia quadrangularis (Lam.) Griseb.

Sinónimos: Microcala quadrangularis (Dombey ex Lam.) Griseb., Gentiana quadrangularis Lam., Exacum quadrangulare (Lam.) Willd., Exacum chilense Bertero, nom. nud., Exacum inflatum Hook. \& Arn.

Hierba. Anual. Nativa.

Distribución: ANT, COQ, VAL, RME, LBO, MAU, NUB, BIO, ARA, LRI, LLA.

Rango altitudinal: 0-1000 m.

Países limítrofes: Argentina, Bolivia y Perú.

\section{Gentiana}

\section{Gentiana prostrata Haenke}

Sinónimos: Gentiana sedifolia Kunth, Gentiana gayi Griseb., Gentiana podocarpa (Phil.) Griseb., Gentiana prostrata Haenke var. podocarpa (Phil.) Kusn., Gentiana ramosissima Phil., Varasia podocarpa Phil., Gentiana sedifolia Kunth var. lineata Phil., Gentiana minima Phil., Varasia sessilis Phil.

Hierba. Anual. Nativa.

Distribución: AYP, TAR, ANT, ATA, COQ, RME, LBO, MAU, NUB, BIO, ARA, MAG.

Rango altitudinal: $1800-4500 \mathrm{~m}$.

Países limítrofes: Argentina y Bolivia.

Nombre vulgar: Mamañika.

\section{Gentianella}

Gentianella coquimbensis (Briq.) Martic. \& Quezada Sinónimos: Gentiana coquimbensis Briq., Gentianella coquimbensis (Briq.) T.N. Ho \& S.W. Liu, comb. illeg.

Hierba. Perenne. Endémica.

Distribución: ATA, COQ.

Rango altitudinal: 1600-3500 m.

Gentianella magellanica (Gaudich.) Fabris ex D.M. Moore Sinónimos: Gentiana lactea Phil., Gentiana pearcei Phil., Gentiana valdiviana Phil., Gentiana magellanica Gaudich., Gentiana araucana Phil., Gentiana modesta Phil.

Hierba. Anual. Nativa.

Distribución: MAU, NUB, BIO, ARA, LRI, LLA, AIS, MAG.

Rango altitudinal: 0-2000 m.

Países limítrofes: Argentina.

Gentianella multicaulis (Gillies ex Griseb.) Fabris

Sinónimos: Gentianella gilliesii (Gilg) Martic. \& Arroyo, nom. illeg., Gentiana gilliesii Gilg, nom. illeg.

Hierba. Bienal. Nativa.

Distribución: ATA, COQ.

Rango altitudinal: 1500-4000 m.

Países limítrofes: Argentina y Bolivia.

Gentianella ottonis (Phil.) Muñoz

Sinónimos: Gentiana ottonis Phil., Gentiana hexamera Phil., Gentiana ottonis Phil. var. hexamera (Phil.) Reiche

Hierba. Perenne. Nativa.

Distribución: COQ, VAL, RME, MAU.

Rango altitudinal: 2400-3200 m.

Países limítrofes: Argentina.

Gentianella tarapacana (Gilg) T.N. Ho \& S.W. Liu

Sinónimos: Gentiana tarapacana Gilg

Hierba. Bienal. Endémica.

Distribución: TAR, ANT.

Rango altitudinal: $3800 \mathrm{~m}$.

\section{GERANIACEAE}

\section{Erodium}

Erodium botrys (Cav.) Bertol.

Hierba. Anual. Introducida.

Distribución: COQ, VAL, RME, NUB, BIO, ARA, LRI.

Erodium cicutarium (L.) L'Hér. ex Aiton

Hierba. Anual o bienal. Introducida.

Distribución: AYP, TAR, ANT, ATA, COQ, VAL, RME, LBO, MAU, NUB, BIO, ARA, LRI, LLA, AIS, MAG, JFE. 
Erodium geoides A. St.-Hil.

Sinónimos: Erodium botrys auct. non (Cav.) Bertol.

Hierba. Anual o bienal. Introducida.

Distribución: COQ, VAL, ARA.

Rango altitudinal: 0-800 m.

Erodium malacoides (L.) L'Hér. ex Aiton var. malacoides Hierba. Anual o bienal. Introducida.

Distribución: ANT, ATA, COQ, VAL, RME.

Erodium malacoides (L.) L'Hér. ex Aiton var. ribifolium (Jacq.) DC.

Hierba. Anual o bienal. Introducida.

Distribución: COQ, VAL, RME.

Erodium moschatum (L.) L'Hér. ex Aiton

Hierba. Anual o bienal. Introducida.

Distribución: ANT, ATA, COQ, VAL, RME, LBO, MAU, NUB, BIO, ARA, LRI, LLA, JFE.

\section{Geranium}

\section{Geranium berteroanum Colla}

Sinónimos: Geranium andinum Phil., Geranium proximum Steud., Geranium patagonicum Hook.f., Geranium apricum Phil., Geranium chilense Aedo \& Muñoz Garm., Geranium collae Aedo, Muñoz Garm. \& Pando, Geranium neohispidum Aedo \& Muñoz Garm., Geranium submolle Steud., Geranium columbinum auct. non L., Geranium berteroanum Colla var. apricum (Phil.) Reiche, Geranium berteroanum Colla var. caespitosum Reiche, Geranium berteroanum Colla var. hispidum Reiche

Hierba. Perenne. Nativa.

Distribución: COQ, VAL, RME, LBO, MAU, NUB, BIO, ARA, LRI, LLA, AIS, MAG.

Rango altitudinal: 0-2100 m.

Países limítrofes: Argentina.

Geranium core-core Steud.

Sinónimos: Geranium argentinum R. Knuth, Geranium moorei Phil., Geranium commutatum Steud., Geranium ochsenii Phil., Geranium squamosum Phil., Geranium subsericeum R. Knuth, Geranium rapulum A. St.-Hil. \& Naudin, Geranium columbinum auct. non L., Geranium commutatum Steud. var. oschsenii (Phil.) Reiche

Hierba. Perenne. Nativa.

Distribución: AYP, TAR, ANT, ATA, COQ, VAL, RME, LBO, MAU, NUB, BIO, ARA, LRI, LLA, AIS, MAG, JFE. Rango altitudinal: 0-4000 m.

Países limítrofes: Argentina y Bolivia.

Nombre vulgar: Core-core.

Nota: Introducida en el Archipiélago Juan Fernández.

\section{Geranium dissectum L.}

Hierba. Anual. Introducida.

Distribución: VAL, RME, LBO, MAU, NUB, BIO, ARA, LLA, JFE.

Geranium magellanicum Hook.f.

Sinónimos: Geranium magellanicum Hook.f. var. typicum

R. Knuth, nom. illeg.

Hierba. Perenne. Nativa.

Distribución: BIO, ARA, LLA, AIS, MAG.

Rango altitudinal: 0-1200 m.

Países limítrofes: Argentina.

Geranium molle L.

Hierba. Anual. Introducida.

Distribución: COQ, VAL, RME, LBO, MAU, NUB, BIO, ARA, LLA, MAG.

Geranium purpureum Vill.

Hierba. Anual. Introducida.

Distribución: VAL, MAU, NUB, BIO, ARA, LRI.

Geranium pusillum L.

Hierba. Anual. Introducida.

Distribución: RME, MAU, AIS, MAG, JFE.

Geranium robertianum $\mathrm{L}$.

Hierba. Anual. Introducida.

Distribución: COQ, VAL, RME, LBO, MAU, NUB, BIO, ARA, LRI, JFE.

\section{Geranium sessiliflorum Cav.}

Sinónimos: Geranium acaule auct. non Willd., Geranium sessiliflorum Cav. fma. albiflorum Kuntze, nom. nud.

Hierba. Perenne. Nativa.

Distribución: AYP, TAR, COQ, RME, MAU, NUB, BIO, ARA, LLA, AIS, MAG.

Rango altitudinal: 0-4800 m.

Países limítrofes: Argentina, Bolivia y Perú.

\section{Geranium skottsbergii R. Knuth}

Sinónimos: Geranium columbinum auct. non L., Geranium philippii J.F. Macbr., Geranium berteroanum Colla var. ciliatum Reiche, Geranium berteroanum Colla var. philippi (J.F. Macbr.) L.E. Navas

Hierba. Perenne. Endémica.

Distribución: COQ, VAL, RME, LBO, MAU, ARA, AIS.

Rango altitudinal: 0-1300 m. 


\section{GESNERIACEAE}

\section{Asteranthera}

Asteranthera ovata (Cav.) Hanst.

Sinónimos: Asteranthera chiloensis Hanst., Columnea ovata Cav.

Hierba epífita. Perenne. Nativa.

Distribución: MAU, NUB, BIO, ARA, LRI, LLA, AIS, MAG.

Rango altitudinal: 1000-2000 m.

Países limítrofes: Argentina.

Nombre vulgar: Estrellita, estrellita del bosque, voqui.

\section{Mitraria}

Mitraria coccinea Cav.

Sinónimos: Gesneria chilensis Molina

Arbusto trepador. Nativo.

Distribución: COQ, VAL, MAU, NUB, BIO, ARA, LRI, LLA, AIS, MAG.

Rango altitudinal: 500-2000 m.

Países limítrofes: Argentina.

Nombre vulgar: Botellita, chilca, voquivoqui, vochi-vochi.

\section{Sarmienta}

Sarmienta scandens (J.D. Brandis ex Molina) Pers.

Sinónimos: Sarmienta repens Ruiz \& Pavón, nom. illeg., Urceolaria scandens J.D. Brandis ex Molina, Urceolaria chilensis Molina, Ulceolaria chilensis Roemer. \& Schultes Subarbusto epífito. Endémico.

Distribución: COQ, MAU, NUB, BIO, ARA, LRI, LLA, AIS.

Rango altitudinal: 0-1400 m.

Nombre vulgar: Italahuén, votri, medallita, habaslahuén, canucán.

\section{GOMORTEGACEAE}

\section{Gomortega}

Gomortega keule (Molina) Baill.

Sinónimos: Lucuma keule Molina, Gomortega nitida Ruiz \& Pav., Keulia chilensis Molina, Adenostemum nitidum (Ruiz \& Pav.) Pers.

Árbol. Endémico. Distribución: MAU, NUB, BIO.

Rango altitudinal: 0-700 m.

Nombre vulgar: Queule, keule.

\section{GOODENIACEAE}

\section{Selliera}

Selliera radicans Cav.

Sinónimos: Goodenia radicans (Cav.) Pers., Goodenia repens Labill., Selliera fasciculata Buchenan, Selliera herpystica Schltdl., Selliera microphylla Colenso, Selliera repens de Vriese

Hierba. Perenne. Endémica.

Distribución: ATA, COQ, VAL, RME, LBO, MAU, NUB, BIO, ARA, LRI, LLA, AIS.

Rango altitudinal: 0-900 $\mathrm{m}$.

Nombre vulgar: Roseta nudosa de los pantanos, maleza de las marismas.

\section{GRISELINIACEAE}

\section{Griselinia}

Griselinia carlomunozii M.O. Dillon \& Muñoz-Schick

Arbusto. Endémico.

Distribución: ANT.

Rango altitudinal: 200-500 m.

Griselinia jodinifolia (Griseb.) Taub.

Sinónimos: Decostea jodinifolia Griseb.

Arbusto. Endémico.

Distribución: MAU, NUB, BIO, ARA, LRI, LLA.

Rango altitudinal: 0-800 m.

Griselinia racemosa (Phil.) Taub.

Sinónimos: Decostea racemosa Phil.

Arbusto. Nativo.

Distribución: ARA, LRI, LLA, AIS.

Rango altitudinal: 0-1300 m.

Países limítrofes: Argentina.

Nombre vulgar: Lamulahuen.

Griselinia ruscifolia (Clos) Ball

Sinónimos: Decostea ruscifolia Clos, Griselinia ruscifolia (Clos) Taub., comb. illeg.

Arbusto. Nativo.

Distribución: LRI, LLA, AIS, MAG.

Rango altitudinal: 500-2000 m.

Países limítrofes: Argentina.

Nombre vulgar: Lilinquen.

Griselinia scandens (Ruiz \& Pav.) Taub.

Sinónimos: Decostea scandens Ruiz \& Pav., Griselinia alata Ball

Arbusto. Endémico. 
Distribución: COQ, VAL, LBO, MAU, NUB, BIO, LLA, AIS.

Rango altitudinal: 0-800 m.

Nombre vulgar: Yelmo.

\section{GROSSULARIACEAE}

\section{Ribes}

Ribes bicolor Phil.

Sinónimos: Ribes glandulosum Ruiz \& Pav., Ribes ruizii Rehder

Arbusto. Endémico.

Distribución: COQ, VAL, RME, LBO, NUB, BIO, ARA.

Rango altitudinal: $1700 \mathrm{~m}$.

Ribes cucullatum Hook. \& Arn.

Sinónimos: Ribes lacarense Phil., Ribes nubigenum Phil., Ribes nebularum Phil., Ribes montanum Phil., Ribes brachystachya Phil.

Arbusto. Nativo.

Distribución: VAL, RME, LBO, MAU, NUB, BIO, ARA, LLA, AIS, MAG.

Rango altitudinal: 0-3000 m.

Países limítrofes: Argentina.

Nombre vulgar: Zarzaparrilla.

Ribes densiflorum Phil.

Sinónimos: Ribes cucullatum Hook. \& Arn. var. densiflorum (Phil.) Sparre, Ribes nitidissimum Neger

Arbusto. Nativo.

Distribución: NUB, BIO, ARA, LLA.

Rango altitudinal: 1000-2000 m.

Países limítrofes: Argentina.

Ribes integrifolium Phil.

Arbusto. Endémico.

Distribución: BIO, ARA.

Rango altitudinal: 1100-1400 m.

Nombre vulgar: Parrilla falsa.

Ribes magellanicum Poir.

Sinónimos: Ribes ovallei Phil., Ribes parviflorum Phil., Ribes parvifolium Phil., Ribes ahrendsii Phil., Ribes palenae Phil., Ribes micranthum Phil., Ribes magellanicum Poir. subsp. parviflorum (Phil.) Sparre

Arbusto. Nativo.

Distribución: VAL, RME, LBO, MAU, NUB, BIO, ARA, LRI, LLA, AIS, MAG.

Rango altitudinal: 0-2000 m.

Países limítrofes: Argentina.

Nombre vulgar: Zarzaparrilla, parrilla.
Ribes nemorosum Phil.

Sinónimos: Ribes polyanthes Phil., Ribes rupicola Phil., Ribes stolpi Phil.

Arbusto. Endémico.

Distribución: COQ, VAL, RME, LBO, MAU, NUB, BIO, ARA.

Rango altitudinal: 1400-1800 m.

Nombre vulgar: Zarzaparrilla.

Ribes punctatum Ruiz \& Pav.

Sinónimos: Rebis punctata (Ruiz \& Pav.) Spach, Rebis ebracteolata Spach, Ribes ebracteolatum (Spach) Gay, Ribes sublobatum Phil., Ribes collinum Phil., Ribes berteroanum Phil., Ribes heterophyllum Phil., Ribes georgianum F. Phil. Arbusto. Nativo.

Distribución: COQ, VAL, RME, LBO, MAU, NUB, BIO, ARA, LLA.

Rango altitudinal: 500-2000 m.

Países limítrofes: Argentina.

Nombre vulgar: Brevilla, zarzaparrilla, parrilla, uvilla.

Ribes trilobum Meyen

Sinónimos: Rebis gayanum (Spach) Reiche, Ribes villosum Gay

Arbusto. Endémico.

Distribución: COQ, VAL, RME, LBO, MAU, NUB, BIO, ARA.

Rango altitudinal: 0-2400 m.

Nombre vulgar: Parrilla, muhul.

Ribes valdivianum Phil.

Sinónimos: Ribes valdivianum Phil. var. sessiliflorum Phil. Arbusto. Nativo.

Distribución: RME, LBO, NUB, BIO, ARA, LRI, LLA, AIS.

Rango altitudinal: 0-1700 m.

Países limítrofes: Argentina.

\section{GUNNERACEAE}

\section{Gunnera}

Gunnera berteroi Phil.

Sinónimos: Gunnera laxiflora Phil.

Hierba. Perenne. Nativa.

Distribución: LBO, MAU.

Rango altitudinal: 2700-3100 m.

Países limítrofes: Argentina y Bolivia.

Gunnera bracteata Steud. ex G. Benn.

Sinónimos: Gunnera glabra Phil., Gunnera insularis Phil., Gunnera pyramidalis Schindl.

Hierba. Perenne. Endémica. 
Distribución: JFE.

Rango altitudinal: 0-500 m.

Nombre vulgar: Pangue.

Gunnera lobata Hook.f.

Hierba. Perenne. Nativa.

Distribución: LLA, AIS, MAG.

Rango altitudinal: 0-500 m.

Países limítrofes: Argentina.

Gunnera magellanica Lam.

Sinónimos: Dysemone integrifolia Banks ex Blume, Misandra magellanica J.F. Gmel., Gunnera plicata Vahl, Gunnera falklandica Hook.f., Gunnera reichei Schindl., Gunnera integrifolia Blume

Hierba. Perenne. Nativa.

Distribución: RME, LBO, MAU, NUB, BIO, ARA, LRI, LLA, AIS, MAG.

Rango altitudinal: 0-1800 m.

Países limítrofes: Argentina, Bolivia y Perú.

Gunnera masafuerae Skottsb.

Hierba. Perenne. Endémica.

Distribución: JFE.

Rango altitudinal: 0-500 m.

Nombre vulgar: Pangue.

Gunnera peltata Phil.

Hierba. Perenne. Endémica.

Distribución: JFE.

Rango altitudinal: 0-500 m.

Nombre vulgar: Pangue.

Gunnera tinctoria (Molina) Mirb. var. meyerii (L.E. Mora) L.E. Mora, Pabón-Mora \& F. González

Sinónimos: Gunnera chilensis Lam. var. meyerii L.E. Mora Hierba. Perenne. Nativa.

Distribución: COQ, VAL, LBO, MAU, NUB, BIO, ARA, LRI, LLA, AIS, MAG.

Rango altitudinal: 0-1500 m.

Países limítrofes: Argentina.

Nombre vulgar: Pangue, nalca.

Gunnera tinctoria (Molina) Mirb. var. tinctoria

Sinónimos: Panke tinctoria Molina, Gunnera chilensis Lam., Gunnera scabra Ruiz \& Pav., Panke anapodophyllifolia Feuille, Panke chilensis Oersted, Panke caulescens J.F. Gmelin

Hierba. Perenne. Nativa.

Distribución: COQ, VAL, LBO, MAU, NUB, BIO, ARA, LLA, AIS, MAG, JFE.

Rango altitudinal: 0-1000 m.

Países limítrofes: Argentina.

Nombre vulgar: Pangue, nalca.
Gunnera tinctoria (Molina) Mirb. var. valdiviensis (L.E. Mora) L.E. Mora, Pabón-Mora \& F. González

Sinónimos: Gunnera chilensis Lam. var. valdiviensis L.E. Mora

Hierba. Perenne. Endémica.

Distribución: LLA.

Rango altitudinal: 0-600 m.

Nombre vulgar: Pangue, nalca.

\section{HALORAGACEAE}

\section{Haloragis}

Haloragis masafuerana Skottsb. var. asperrima (Skottsb.) Orchard

Sinónimos: Haloragis asperrima Skottsb.

Subarbusto. Endémico.

Distribución: JFE.

Haloragis masafuerana Skottsb. var. masafuerana

Subarbusto. Endémico.

Distribución: JFE.

Rango altitudinal: 0-600 m.

Haloragis masatierrana Skottsb.

Subarbusto. Endémico.

Distribución: JFE.

\section{Myriophyllum}

Myriophyllum aquaticum (Vell.) Verdc.

Sinónimos: Myriophyllum proserpinacoides Gillies ex Hook. \& Arn.

Hierba acuática. Perenne. Nativa.

Distribución: AYP, TAR, ANT, ATA, COQ, VAL, RME, LBO, MAU, NUB, BIO, ARA, LRI, LLA, AIS, MAG.

Rango altitudinal: 0-2000 m.

Países limítrofes: Argentina, Bolivia y Perú.

Nombre vulgar: Lima, lima trencilla, wakalima, loroma, aguasana.

Myriophyllum quitense Kunth

Sinónimos: Myriophyllum elatinoides Gaudich. var. ternatum (Gaudich.) Reiche, Myriophyllum ternatum Gaudich., Myriophyllum ternatum Gaudich. var. tetraphyllum Hook. \& Arn.

Hierba acuática. Perenne. Nativa.

Distribución: AYP, TAR, ANT, ATA, COQ, VAL, RME, MAU, NUB, BIO, ARA, LLA, AIS, MAG.

Rango altitudinal: 0-4500 m.

Países limítrofes: Argentina, Bolivia y Perú.

Nombre vulgar: Loroma, aguasana, loroma hembra. 


\section{HELIOTROPIACEAE}

\section{Heliotropium}

Heliotropium amplexicaule Vahl

Hierba o subarbusto. Perenne. Introducida.

Distribución: RME.

Rango altitudinal: 550-600 m.

\section{Heliotropium angiospermum Murray}

Hierba o subarbusto. Anual o perenne. Introducida.

Distribución: TAR.

Heliotropium chenopodiaceum (A. DC.) Clos var. chenopodiaceum

Sinónimos: Heliophytum chenopodiaceum A. DC., Cochranea chenopodiacea (A. DC.) Miers

Arbusto. Endémico.

Distribución: ANT, ATA, COQ.

Rango altitudinal: 200-1700 m.

Heliotropium chenopodiaceum (A. DC.) Clos var. ericoideum (Miers) Reiche

Sinónimos: Cochlearia ericoidea Miers, Heliotropium pearcei Phil., Eritrichium glabratum Phil.

Arbusto. Endémico.

Distribución: ANT, ATA, COQ.

Rango altitudinal: 0-2300 m.

\section{Heliotropium curassavicum L.}

Sinónimos: Heliotropium curassavicum L. var. parviflorum Ball, Heliotropium curassavicum L. var. genuinum I.M. Johnst., nom. illeg.

Hierba. Perenne. Nativa.

Distribución: AYP, TAR, ANT, ATA, COQ, VAL, RME, LBO.

Rango altitudinal: 0-2000 m.

Países limítrofes: Argentina, Bolivia y Perú.

Heliotropium eremogenum I.M. Johnst.

Arbusto. Endémico.

Distribución: TAR, ANT.

Rango altitudinal: 0-300 m.

Heliotropium filifolium (Miers) I.M. Johnst.

Sinónimos: Cochranea filifolia Miers, Heliotropium chenopodiaceum (A. DC.) Clos var. filifolium (Miers) Reiche, Cochranea kingi Phil., Heliotropium kingi (Phil.) Reiche

Arbusto. Endémico.

Distribución: ATA.

Rango altitudinal: 0-400 m.
Heliotropium floridum (A. DC.) Clos

Sinónimos: Heliophytum floridum A.DC., Cochranea florida (A. DC.) Miers, Heliotropium floridum (A. DC.) Clos var. latifolium Phil.

Arbusto. Endémico.

Distribución: ANT, ATA.

Rango altitudinal: 0-600 m.

Heliotropium geissei F. Phil.

Hierba. Anual. Nativa.

Distribución: COQ, VAL, RME.

Rango altitudinal: 1000-1200 m.

Países limítrofes: Argentina.

\section{Heliotropium glutinosum Phil.}

Sinónimos: Cochranea glutinosa (Phil.) Phil.

Arbusto. Endémico.

Distribución: ATA.

Rango altitudinal: 1100-1500 m.

Heliotropium huascoense I.M. Johnst.

Arbusto. Endémico.

Distribución: ATA, COQ.

Rango altitudinal: 0-500 m.

Heliotropium inconspicuum Reiche

Sinónimos: Cochranea parviflora Phil.

Arbusto. Endémico.

Distribución: ANT, ATA.

Rango altitudinal: 1000-1200 m.

Heliotropium jaffuelii I.M. Johnst.

Arbusto. Endémico.

Distribución: ANT.

Rango altitudinal: 0-1000 m.

Heliotropium krauseanum Fedde

Arbusto. Nativo.

Distribución: TAR.

Rango altitudinal: $700 \mathrm{~m}$.

Países limítrofes: Perú.

Heliotropium linariifolium Phil.

Sinónimos: Heliotropium linearifolium F. Phil., Heliotropium longiflorum Phil.

Arbusto. Endémico.

Distribución: TAR, ANT, ATA.

Rango altitudinal: 0-1300 m.

Heliotropium longistylum Phil.

Sinónimos: Cochranea longistyla (Phil.) Phil., Heliotropium vernicosum Phil.

Arbusto. Endémico.

Distribución: ATA, COQ, VAL. 
Heliotropium megalanthum I.M. Johnst.

Sinónimos: Cochranea corymbosa Miers, Heliotropium corymbosum (Miers) Reiche, Heliotropium crassifolium Phil., Cochranea crassifolia (Phil.) Phil.

Subarbusto. Endémico.

Distribución: ATA, COQ.

Rango altitudinal: 0-700 m.

Heliotropium myosotifolium (A. DC.) Reiche

Sinónimos: Heliotropium stenophyllum Hook. \& Arn. var. myosotifolium (A. DC.) Clos, Heliophytum stenophyllum (Hook. \& Arn.) A. DC. var. myosotifolium A. DC., Cochranea myosotifolia (A. DC.) Miers, Cochranea hebecula Miers, Cochranea hispidula Miers, Heliotropium hispidulum (Miers) Reiche, Cochranea sentis Phil., Heliotropium canum Phil., Heliotropium hispidulum Phil.

Arbusto. Endémico.

Distribución: TAR, ATA.

Rango altitudinal: 0-2400 m.

\section{Heliotropium paronychioides A. DC.}

Hierba. Anual. Nativa.

Distribución: COQ, VAL, RME, LBO, MAU, NUB, BIO, ARA, LLA.

Rango altitudinal: 100-3100 m.

Países limítrofes: Argentina.

Heliotropium philippianum I.M. Johnst.

Arbusto. Endémico.

Distribución: ANT, ATA.

Rango altitudinal: 0-300 m.

\section{Heliotropium pycnophyllum Phil.}

Sinónimos: Cochranea pycnophylla (Phil.) F. Phil. ex Reiche, Heliotropium breanum Phil., Heliotropium brevifolium Phil.

Arbusto. Endémico.

Distribución: ANT, ATA.

Rango altitudinal: 0-1100 m.

\section{Heliotropium sclerocarpum Phil.}

Sinónimos: Cochranea sclerocarpa Phil., Heliotropium chenopodiaceum (A. DC.) Clos var. sclerocarpa (Phil.) Reiche

Arbusto. Endémico.

Distribución: ATA.

Rango altitudinal: 0-800 m.

Heliotropium sinuatum (Miers) I.M. Johnst. Sinónimos: Cochranea sinuata Miers, Heliotropium izagae Phil., Heliotropium rosmarinifolium Phil.

Arbusto. Endémico.

Distribución: AYP, TAR, ANT, ATA, COQ.

Rango altitudinal: 0-1300 m.
Heliotropium stenophyllum Hook. \& Arn.

Sinónimos: Heliophytum stenophyllum (Hook. \& Arn.) A. DC., Cochranea stenophylla (Hook. \& Arn.) Miers, Meladendron chilense Molina, Heliotropium rosmarinifolium Bertero ex Steud., nom. nud., Heliotropium rosmarinifolium Bertero ex A.DC., Heliotropium stenophyllum (Hook. \& Arn.) A. DC. var. rosmarinifolium (Bertero ex A. DC.) Clos, Cochranea conferta Miers, nom. nud., Cochranea congesta Miers

Arbusto. Endémico.

Distribución: ATA, COQ, VAL.

Rango altitudinal: 0-1000 m.

Heliotropium taltalense (Phil.) I.M. Johnst.

Sinónimos: Cochranea taltalensis Phil., Heliotropium rugosum Phil., Cochranea rugosa (Phil.) Phil.

Arbusto. Endémico.

Distribución: ANT, ATA.

Rango altitudinal: 0-700 m.

\section{HYDRANGEACEAE}

\section{Hydrangea}

Hydrangea serratifolia (Hook. \& Arn.) F. Phil. Sinónimos: Cornidia serratifolia Hook. \& Arn., Cornidia integerrima Hook. \& Arn., Hydrangea integerrima (Hook. \& Arn.) Engl., Hydrangea scandens Poepp.

Arbusto trepador. Nativo.

Distribución: VAL, RME, LBO, MAU, NUB, BIO, ARA, LRI, LLA, AIS.

Rango altitudinal: 500-1500 m.

Países limítrofes: Argentina.

Nombre vulgar: Canelilla, pehuelden, voqui naranjo, laurela.

\section{HYPERICACEAE}

\section{Hypericum}

\section{Hypericum androsaemum $\mathrm{L}$.}

Hierba. Perenne. Introducida.

Distribución: LBO, MAU, LRI, LLA.

Hypericum caespitosum Cham. \& Schltdl.

Sinónimos: Hypericum chilense Gay, Hypericum muscoides Phil., Hypericum chilense Gay var. muscoides (Phil.) Reiche, Hypericum uliginosum Kunth var. prostratum R. Keller, Hypericum brevistylum auct. non Choisy

Hierba. Anual o perenne. Endémica.

Distribución: MAU, NUB, BIO, ARA, LRI, LLA.

Nombre vulgar: Nanco. 
Hypericum perforatum $\mathrm{L}$.

Hierba. Perenne. Introducida.

Distribución: VAL, RME, LBO, MAU, NUB, BIO, ARA,

LRI, LLA, JFE.

Hypericum silenoides Juss.

Sinónimos: Hypericum paposanum I.M. Johnst., Hypericum indecorum Kunth, Hypericum multiflorum Kunth

Hierba. Anual o perenne. Nativa.

Distribución: ANT, ARA, LRI.

Países limítrofes: Argentina, Bolivia y Perú.

Hypericum $x$ inodorum $\mathrm{L}$.

Hierba o subarbusto. Anual o perenne. Introducida.

Distribución: VAL, MAU, ARA, LLA, AIS.

\section{KRAMERIACEAE}

\section{Krameria}

Krameria cistoidea Hook. \& Arn.

Arbusto. Endémico.

Distribución: ANT, ATA, COQ, VAL, RME.

Rango altitudinal: 0-2500 m.

Nombre vulgar: Pacul, chañarcillo.

Krameria lappacea (Dombey) Burdet \& B.B. Simpson Sinónimos: Landia lappacea Dombey, Krameria triandra Ruiz \& Pav. var. humboldtiana Chodat, Krameria iluca Phil., Krameria pentapetala Ruiz \& Pav.

Arbusto. Nativo.

Distribución: AYP, TAR, ANT, ATA, COQ.

Rango altitudinal: 300-4500 m.

Países limítrofes: Argentina, Bolivia y Perú.

\section{LAMIACEAE}

\section{Cuminia}

Cuminia eriantha (Benth.) Benth.

Sinónimos: Bystropogon erianthus Benth., Cuminia fernandezia Colla, Johowia fernandezia (Colla) Epling \& Looser, Cuminia brevidens Benth., Skottsbergiella fernandezia (Colla) Epling, Cuminia eriantha (Benth.) Benth. var. fernandezia (Colla) Harley

Arbusto. Endémico.

Distribución: JFE.

Rango altitudinal: 200-500 m.

\section{Galeopsis}

Galeopsis tetrahit L.
Hierba. Anual. Introducida.

Distribución: LLA.

\section{Gardoquia}

Gardoquia gilliesii Graham

Sinónimos: Satureja gilliesii (Graham) Briq., Gardoquia chilensis Benth., Satureja chilensis (Benth.) Briq., Clinopodium chilense (Benth.) Govaerts

Arbusto. Endémico.

Distribución: COQ, VAL, RME, LBO, MAU, NUB, BIO, ARA.

Rango altitudinal: 0-1000 m.

Nombre vulgar: Oreganillo.

Gardoquia multiflora Ruiz \& Pav.

Sinónimos: Satureja multiflora (Ruiz \& Pav.) Briq., Clinopodium multiflorum (Ruiz \& Pav.) Kuntze, Rizoa ovatifolia Cav.

Arbusto. Endémico.

Distribución: MAU, NUB, BIO, ARA, LRI, LLA.

Rango altitudinal: 0-1700 m.

Nombre vulgar: Menta de árbol.

\section{Glechoma}

Glechoma hederacea L.

Hierba. Perenne. Introducida.

Distribución: ARA, LRI, LLA, MAG.

\section{Kurzamra}

Kurzamra pulchella (Clos) Kuntze

Sinónimos: Soliera pulchella Clos, Micromeria pulchella (Clos) Wedd.

Hierba. Perenne. Nativa.

Distribución: ATA, COQ.

Rango altitudinal: $3500-4100 \mathrm{~m}$.

Países limítrofes: Argentina.

Nombre vulgar: Poleo de cordillera.

\section{Lamium}

Lamium amplexicaule L.

Hierba. Anual. Introducida.

Distribución: ANT, ATA, COQ, VAL, RME, LBO, MAU, NUB, BIO, ARA, LLA, MAG.

Lamium purpureum L.

Hierba. Anual. Introducida.

Distribución: MAG. 


\section{Lepechinia}

Lepechinia chilensis (Molina) R. Morales Sinónimos: Lepechinia chamaedryoides (Balb.) Epling, Rosmarinus chilensis Molina, Sphacele chilense (Molina) Briq., Sphacele chamaedryoides (Balb.) Briq., Sphacele campanulata Benth., Dracocephalum chamaedryoides Balb., Phytoxis sidertifolia Molina, Phytoxis acidissima Molina, Alguelagum chilense (Molina) Kuntze

Arbusto. Endémico.

Distribución: COQ, VAL, LBO, MAU, NUB, BIO, ARA, LRI, LLA.

Rango altitudinal: 0-1600 m.

Nombre vulgar: Salvia, salvia macho, lahuén, alhuelaluén.

Lepechinia salviae (Lindl.) Epling

Sinónimos: Sphacele salviae (Lindl.) Briq., Sphacele lindleyi Benth., Stachys salviae Lindl., Gardoquia salviaefolia Colla, Alguelagum salviae (Lindl.) Kuntze Arbusto. Endémico.

Distribución: COQ, VAL, RME.

Rango altitudinal: 0-900 m.

Nombre vulgar: Salvia, salvia blanca, lahuenlahuén.

Lepechinia subhastata (Benth.) Epling

Sinónimos: Sphacele subhastata Benth., Alguelagum subhastatum (Benth.) Kuntze

Arbusto. Endémico.

Distribución: VAL.

Rango altitudinal: 0-1500 m.

\section{Lycopus}

Lycopus europaeus L.

Hierba. Perenne. Introducida.

Distribución: LRI, LLA.

\section{Marrubium}

Marrubium vulgare L.

Hierba. Perenne. Introducida.

Distribución: ANT, ATA, COQ, VAL, RME, LBO, MAU, NUB, BIO, ARA, LRI, AIS, JFE.

\section{Melissa}

\section{Melissa officinalis L.}

Hierba. Perenne. Introducida.

Distribución: COQ, VAL, RME, LBO, MAU, NUB, BIO, ARA, LLA, JFE.

\section{Mentha}

\section{Mentha aquatica L.}

Hierba. Perenne. Introducida.

Distribución: ANT, COQ, VAL, RME, LBO, MAU, NUB, BIO, ARA, JFE.

\section{Mentha pulegium L.}

Hierba. Perenne. Introducida.

Distribución: COQ, VAL, RME, LBO, MAU, NUB, BIO, ARA, LRI, LLA, JFE.

\section{Mentha suaveolens Ehrh.}

Hierba. Perenne. Introducida.

Distribución: ANT, ATA, VAL, RME, LBO, NUB, BIO, ARA, LRI, LLA, JFE.

\section{Mentha $x$ piperita L.}

Hierba. Perenne. Introducida.

Distribución: ANT, ATA, COQ, VAL, RME, LBO, MAU, NUB, BIO, ARA, LRI, LLA, AIS, MAG.

\section{Micromeria}

Micromeria darwinii Benth.

Sinónimos: Clinopodium darwinii (Benth.) Kuntze, Clinopodium darwinii (Benth.) Kuntze var. pusilla (Phil.) Epling, Satureja darwinii (Benth.) Briq., Satureja pusilla Macloskie, Micromeria darwinii Benth. var. pusilla (Phil.) Speg., Micromeria pusilla Phil.

Subarbusto. Nativo.

Distribución: MAG

Rango altitudinal: 0-1000 m.

Países limítrofes: Argentina.

Micromeria gilliesii Benth.

Sinónimos: Clinopodium gilliesii (Benth.) Kuntze, Satureja parvifolia (Phil.) Epling, Satureja gilliesii (Benth.) Briq., Oreosphacus parvifolia Phil.

Arbusto. Nativo.

Distribución: AYP, TAR, ANT.

Rango altitudinal: 1200-4000 m.

Países limítrofes: Argentina y Bolivia.

Nombre vulgar: Muña.

\section{Molucella}

Molucella laevis L.

Hierba. Anual. Introducida.

Distribución: VAL.

\section{Prunella}

Prunella vulgaris L.

Hierba. Perenne. Introducida.

Distribución: COQ, VAL, RME, LBO, MAU, NUB, BIO, ARA, LRI, LLA, AIS, MAG, JFE. 


\section{Salvia}

Salvia gilliesii Benth.

Sinónimos: Salvia cuspidata Ruiz et Pav. subsp. gilliesii (Benth.) J.R.I. Wood, Salvia gilliesii Benth. var. glandulosa Griseb.

Arbusto. Nativo.

Distribución: TAR, ANT.

Rango altitudinal: 500-4000 m.

Países limítrofes: Argentina y Bolivia.

Salvia rhombifolia Ruiz \& Pav.

Sinónimos: Salvia pilosa Vahl, Salvia foliosa Benth., Salvia tafallae Benth., Salvia paposana Phil.

Hierba. Anual. Nativa.

Distribución: TAR, ANT.

Rango altitudinal: 0-4000 m.

Países limítrofes: Perú.

Salvia tubiflora Sm.

Sinónimos: Salvia biflora Ruiz \& Pav., Salvia excisa Ruiz \& Pav., Salvia scrobiculata Meyen, Salvia biflora Ruiz \& Pav. var. glabrata Benth.

Hierba. Perenne. Nativa.

Distribución: ANT, ATA.

Rango altitudinal: 0-3000 m.

Países limítrofes: Perú.

Salvia verbenaca $\mathrm{L}$.

Hierba. Perenne. Introducida.

Distribución: RME.

\section{Scutellaria}

Scutellaria nummulariifolia Hook.f.

Sinónimos: Cruzia serpyllacea Phil.

Hierba. Perenne. Nativa.

Distribución: AIS, MAG.

Rango altitudinal: 0-900 m.

Países limítrofes: Argentina.

Scutellaria racemosa Pers.

Sinónimos: Scutellaria rojasii Briq., Scutellaria rumicifolia

Kunth, Scutellaria hastata Larrañaga, Scutellaria heterophylla Willd. ex Benth., Scutellaria bonariensis Willd. ex Benth.

Hierba. Perenne. Nativa.

Distribución: VAL, RME, MAU, NUB, BIO, ARA, LRI, LLA.

Rango altitudinal: 0-1500 m.

Países limítrofes: Argentina y Bolivia.

Scutellaria valdiviana (Clos) Epling

Sinónimos: Theresa valdiviana Clos
Arbusto. Endémico.

Distribución: MAU, BIO, LRI.

Rango altitudinal: 0-200 m.

\section{Stachys}

Stachys albicaulis Lindl.

Sinónimos: Stachys eriophylla Briq.

Hierba. Perenne. Nativa.

Distribución: VAL, RME, LBO, MAU, NUB, BIO, ARA.

Rango altitudinal: 1000-2000 m.

Países limítrofes: Argentina.

Nombre vulgar: Hierba de Santa María.

Stachys arvensis L.

Hierba. Anual. Introducida.

Distribución: VAL, LLA, JFE, IPA.

Stachys bridgesii Benth.

Hierba. Perenne. Endémica.

Distribución: COQ, RME, LBO, MAU, LRI, LLA.

Rango altitudinal: 0-2300 m.

Nombre vulgar: Hierba de Santa Rosa.

Stachys eremicola Epling

Hierba. Anual. Endémica.

Distribución: ANT, ATA, COQ.

Rango altitudinal: 0-600 m.

Stachys gilliesii Benth.

Sinónimos: Stachys petiolosa Briq.

Hierba. Perenne. Nativa.

Distribución: COQ, VAL, RME, LBO, MAU, NUB, BIO.

Rango altitudinal: 0-2300 m.

Países limítrofes: Argentina y Bolivia.

Stachys grandidentata Lindl.

Sinónimos: Stachys toronjicillo Phil., Stachys closi Phil., Stachys serrata Clos

Hierba. Perenne. Endémica.

Distribución: ANT, ATA, COQ, VAL, RME, LBO, MAU, NUB, BIO, ARA, LLA.

Rango altitudinal: 0-2900 m.

Nombre vulgar: Hierba santa.

Stachys macraei Benth.

Sinónimos: Stachys chonotica Hook.f.

Hierba. Perenne. Endémica.

Distribución: COQ, VAL, RME, LBO, MAU, NUB, BIO, ARA, LRI, LLA, AIS.

Rango altitudinal: 0-2000 m. 
Stachys ochroleuca Phil.

Sinónimos: Stachys litoralis Phil., Stachys dubia Briq., Stachys rupestris Phil., Stachys meyeniana Phil.

Hierba. Perenne. Endémica.

Distribución: COQ, VAL, LBO, MAU, NUB, BIO, ARA.

Rango altitudinal: 0-3000 m.

\section{Stachys pannosa Phil.}

Hierba. Perenne. Endémica.

Distribución: ANT, ATA, COQ, VAL, NUB, BIO.

Rango altitudinal: 0-700 m.

Stachys philippiana Vatke

Sinónimos: Stachys andina Phil.

Hierba. Perenne. Endémica.

Distribución: COQ, VAL, RME, MAU, NUB, BIO, ARA.

Rango altitudinal: 2000-3000 m.

\section{Stachys sericea Cav.}

Sinónimos: Stachys glabrata Phil., Stachys sidertidoides

Gillies ex Benth., Stachys candidissima Phil.

Hierba. Perenne. Endémica.

Distribución: VAL, RME, LBO, MAU, NUB, BIO, ARA,

LLA.

Rango altitudinal: 500-2500 m.

Stachys truncata Kunze ex Benth.

Hierba. Anual. Endémica.

Distribución: COQ, VAL, MAU, AIS.

Rango altitudinal: 0-600 m.

\section{Teucrium}

\section{Teucrium bicolor $\mathrm{Sm}$.}

Sinónimos: Teucrium orchideum Lindl., Teucrium cavanilliesii Bertero ex Steud., nom. nud., Teucrium chilense Desf. ex Steud., nom. nud., Teucrium heterophyllum Cav. Arbusto. Endémico.

Distribución: COQ, VAL, RME, LBO, MAU, NUB, BIO, ARA, LRI, LLA.

Rango altitudinal: 0-2100 m.

Nombre vulgar: Oreganillo.

Teucrium nudicaule Hook.

Sinónimos: Teucrium leucanthum Phil., Teucrium nudicaule Hook. var. leucanthum (Phil.) Epling, Teucrium tripartitum Meyen

Arbusto. Endémico.

Distribución: ANT, ATA, COQ.

Rango altitudinal: 0-2100 m.

\section{LARDIZABALACEAE}

\section{Boquila}

Boquila trifoliolata (DC.) Decne.

Sinónimos: Lardizabala trifoliolata DC., Lardizabala funaria (Molina) Looser, Cogylia ternata Molina, Dolichos funarius Molina, Boissiera trifoliata Dombey ex DC., nom. nud., Boquila discolor Decne., Lardizabala discolor Kunze ex Poepp. \& Endl.

Arbusto trepador. Nativo.

Distribución: MAU, NUB, BIO, ARA, LRI, LLA.

Rango altitudinal: 0-1700 m.

Países limítrofes: Argentina.

Nombre vulgar: Pilpilvoqui, voqui blanco, voqui pil-pil.

\section{Lardizabala}

Lardizabala biternata Ruiz \& Pav.

Sinónimos: Cogylia biternata (Ruiz \& Pav.) Molina, Boissiera triternata Dombey ex DC., nom. nud., Lardizabala triternata Ruiz \& Pav., Lardizabala infuscata Miers, Lardizabala sylvicola Miers, Cogylia triternata (Ruiz \& Pav.) Molina

Arbusto trepador. Endémico.

Distribución: VAL, RME, LBO, MAU, NUB, BIO, ARA, LRI, JFE.

Rango altitudinal: 0-1500 m.

Nombre vulgar: Cóguil, coguilera, voqui-cóguil, collivoqui, voqui blanco, huipinga, coile.

Nota: Introducida en el Archipiélago Juan Fernández.

\section{LAURACEAE}

\section{Beilschmiedia}

Beilschmiedia berteroana (Gay) Kosterm.

Sinónimos: Cryptocarya berteroana Gay, Bellota nitida Phil., Cryptocarya nitida Phil., Boldu chilanum Nees ex Meisn., Boldu nitidum (Phil.) Meisn., Bellota pauciflora Phil.

Árbol. Endémico.

Distribución: RME, LBO, MAU, NUB.

Rango altitudinal: 0-1300 m.

Nombre vulgar: Belloto, belloto del centro.

Beilschmiedia miersii (Gay) Kosterm. Sinónimos: Bellota miersii Gay, Boldu chilanum Nees

Árbol. Endémico.

Distribución: VAL, RME.

Rango altitudinal: 0-1500 m.

Nombre vulgar: Belloto, belloto del norte. 


\section{Cryptocarya}

Cryptocarya alba (Molina) Looser

Sinónimos: Peumus rubra Molina, Peumus alba Molina, Cryptocarya rubra (Molina) Skeels, Peumus mammosa Molina, Laurus peumus Molina, Cryptocarya peumus Nees, Icosandra rufescens Phil., Cryptocarya stenantha Phil., Cryptocarya peumus Nees var. stenantha (Phil.) Mez, Cryptocarya peumus Nees var. laxiflora Phil. ex Mez, Cryptocarya laxiflora Phil., Cryptocarya peumo (Dombey ex Lam.) Kosterm., Cryptocarya mammosa (Molina) Kosterm., Laurus peumo Dombey ex Lam.

Árbol. Endémico.

Distribución: COQ, VAL, RME, LBO, MAU, NUB, BIO, ARA.

Rango altitudinal: 0-1500 m.

Nombre vulgar: Peumo.

\section{Persea}

Persea lingue (Ruiz \& Pav.) Nees

Sinónimos: Persea meyeniana Nees, Laurus linguy Miers ex Bertero, Persea lingue (Ruiz \& Pav.) Nees var. canescens Nees, Persea lingue (Ruiz \& Pav.) Nees var. palustris Nees, Persea intermedia Phil., Nothaphoebe lingue Baeza, Nothaphoebe meyeniana Baeza, Laurus lingue Ruiz \& Pav. Árbol. Nativo.

Distribución: VAL, RME, LBO, MAU, NUB, BIO, ARA, LRI, LLA.

Rango altitudinal: 0-900 m.

Países limítrofes: Argentina.

Nombre vulgar: Lingue.

\section{LENTIBULARIACEAE}

\section{Pinguicula}

\section{Pinguicula antarctica Vahl}

Sinónimos: Pinguicula magellanica Comm. ex Franch. Hierba. Perenne. Nativa.

Distribución: ARA, LRI, LLA, AIS, MAG.

Rango altitudinal: 0-1000 m.

Países limítrofes: Argentina.

Nombre vulgar: Flor de pantano, violeta cimarrona, violeta de pantano, grasilla.

\section{Pinguicula chilensis Gay}

Sinónimos: Pinguicula antarctica Donat, hom. illeg.

Hierba. Perenne. Nativa.

Distribución: MAU, NUB, BIO, ARA, LRI, LLA.

Rango altitudinal: 1500-3000 m.

Países limítrofes: Argentina.

\section{Utricularia}

Utricularia gibba $\mathrm{L}$.

Sinónimos: Utricularia gayana A.DC., Utricularia tenuis Cav., Utricularia tenuis Cav. var. poeppigii A. DC.

Hierba acuática. Perenne. Nativa.

Distribución: ATA, COQ, MAU, NUB, BIO, ARA, LRI.

Rango altitudinal: 0-2500 m.

Países limítrofes: Argentina, Bolivia y Perú.

Nombre vulgar: Chupa bichos, bolsita de agua, manguera.

\section{LINACEAE}

\section{Cliococca}

Cliococca selaginoides (Lam.) C.M. Rogers \& Mildner Sinónimos: Linum selaginoides Lam., Cliococca tenuifolia Bab., Linum babingtonii Planch., Linum selaginoides Lam. var. chilense Planch., Linum microphyllum Larrañaga

Hierba. Perenne. Nativa.

Distribución: VAL, MAU, NUB, BIO, ARA, LRI.

Rango altitudinal: 0-1300 m.

Países limítrofes: Argentina y Bolivia.

Nombre vulgar: Merulahuén.

\section{Linum}

\section{Linum bienne Mill.}

Hierba. Perenne. Introducida.

Distribución: ANT, ATA, COQ, VAL, RME, LBO, MAU, NUB, BIO, ARA, LRI, LLA.

\section{Linum catharticum $\mathrm{L}$.}

Hierba. Perenne. Introducida.

Distribución: MAG.

\section{Linum chamissonis Schiede}

Sinónimos: Linum aquilinum Molina var. grandiflorum Hook. \& Arn., Linum oligophyllum Hook. \& Arn., nom. illeg., Linum macraei Benth. var. cumingii Urban

Hierba. Perenne. Endémica.

Distribución: MAU, NUB, BIO, ARA.

Rango altitudinal: 0-800 $\mathrm{m}$.

Nombre vulgar: Ñanco, ñancolahuén, retamilla, nanco, nancolahuén.

Linum cremnophilum I.M. Johnst.

Hierba. Perenne. Endémica.

Distribución: ANT, ATA.

Rango altitudinal: 0-500 m.

Linum macraei Benth. var. macraei

Sinónimos: Linum aquilinum Molina, Mesynium chilense 
Raf., Linum chironioides Griseb., Linum macraei Benth. var. olygophyllum (Hook. \& Arn.) Reiche, Linum cumingii Lodd.

Hierba. Perenne. Endémica.

Distribución: COQ, VAL, RME, LBO, MAU, NUB, BIO, ARA.

Rango altitudinal: 0-1000 m.

Nombre vulgar: Nancolahuén.

Linum macraei Benth. var. marticorenae Mildner Hierba. Perenne. Endémica.

Distribución: VAL, LBO, MAU, NUB, BIO.

Rango altitudinal: 0-300 m.

Linum prostratum Dombey ex Lam.

Sinónimos: Linum paposanum Phil.

Hierba. Perenne. Nativa.

Distribución: ANT.

Rango altitudinal: 200-1000 m.

Países limítrofes: Bolivia y Perú.

\section{Linum ramosissimum Gay}

Sinónimos: Linum obtusifolium Phil., Linum chamissonis Schiede var. obtusifolium (Phil.) Reiche, Linum chamissonis Schiede var. ramosissimum (Gay) Reiche

Hierba. Perenne. Endémica.

Distribución: COQ.

Rango altitudinal: 0-600 m.

\section{Linum usitatissimum L.}

Hierba. Anual. Introducida.

Distribución: ATA, VAL, NUB, BIO, ARA, JFE.

\section{LINDERNIACEAE}

\section{Lindernia}

Lindernia dubia (L.) Pennell

Sinónimos: Gratiola dubia L., Lindernia dubia (L.) Pennell var. anagallidea (Michx.) Cooperr.

Hierba. Anual. Nativa.

Distribución: RME, MAU, NUB, BIO, ARA, LRI.

Países limítrofes: Argentina, Bolivia y Perú.

\section{LOASACEAE}

\section{Blumenbachia}

Blumenbachia dissecta (Hook. \& Arn.) Weigend \& Grau Sinónimos: Loasa dissecta Hook. \& Arn., Caiophora espigneira (Gay) Urb. \& Gilg, Blumenbachia espigneira Gay, Caiophora dissecta (Hook. \& Arn.) Urb. \& Gilg,
Loasa microcalyx Phil.

Hierba. Perenne. Nativa.

Distribución: VAL, RME, LBO, MAU.

Países limítrofes: Argentina.

Blumenbachia prietea Gay

Sinónimos: Caiophora prietea (Gay) Urb. \& Gilg

Hierba. Perenne. Nativa.

Distribución: LBO, MAU, NUB, BIO, ARA.

Países limítrofes: Argentina.

Blumenbachia silvestris Poepp.

Sinónimos: Caiophora silvestris (Poepp.) Urb. \& Gilg, Caiophora scandens Meyen \& Klotzsch ex Walp., Caiophora silvestris (Poepp.) Urb. \& Gilg var. mitis (Phil.) Urb. \& Gilg, Caiophora tomentosula Urb. \& Gilg, Blumenbachia mitis Phil., Blumenbachia domeykoana Phil., Loasa ochagaviae Phil., Loasa volckmanni Phil., Blumenbachia nemorosa Phil., Blumenbachia scandens Meyen

Hierba. Bienal o perenne. Nativa.

Distribución: VAL, RME, LBO, MAU, NUB, BIO, ARA.

Países limítrofes: Argentina.

Nombre vulgar: Ortiga caballuna.

\section{Caiophora}

Caiophora chuquitensis (Meyen) Urb. \& Gilg

Sinónimos: Loasa chuquitensis Meyen, Blumenbachia chuquitensis (Meyen) Hook. f., Caiophora superba Phil.

Hierba o subarbusto. Perenne. Nativa.

Distribución: AYP, TAR, ANT.

Países limítrofes: Argentina, Bolivia y Perú.

Caiophora cirsiifolia C. Presl

Sinónimos: Caiophora sepiaria (Ruiz \& Pav. ex G. Don) J.F. Macbr., Blumenbachia sepiaria Ruiz \& Pav. ex G. Don Hierba trepadora. Perenne. Nativa.

Distribución: AYP, TAR.

Países limítrofes: Perú.

Caiophora coronata (Gillies ex Arn.) Hook. \& Arn.

Sinónimos: Loasa coronata Gillies ex Arn., Blumenbachia coronata (Gillies ex Arn.) Hieron., Caiophora absinthiifolia C. Presl

Hierba. Perenne. Nativa.

Distribución: AYP, TAR, ANT, ATA, COQ, VAL, RME.

Países limítrofes: Argentina y Bolivia.

Nombre vulgar: Ortiguilla.

Caiophora deserticola Weigend \& M. Ackermann

Hierba o subarbusto. Perenne. Nativa.

Distribución: TAR.

Países limítrofes: Perú. 
Caiophora rosulata (Wedd.) Urb. \& Gilg

Sinónimos: Loasa rosulata Wedd., Caiophora anemonoides

Urb. \& Gilg, Caiophora rahmeri Phil.

Hierba. Perenne. Nativa.

Distribución: AYP, TAR, ANT.

Países limítrofes: Bolivia.

\section{Grausa}

Grausa gayana (Urb. \& Gilg) Weigend \& R.H. Acuña Sinónimos: Loasa sagittata auct. non Hook. \& Arn., Loasa gayana Urb. \& Gilg

Hierba trepadora. Perenne. Endémica.

Distribución: ARA, LRI, LLA.

Grausa lateritia (Gillies ex Arn.) Weigend \& R.H. Acuña Sinónimos: Loasa acaulis (Phil.) Urb. \& Gilg, Blumenbachia acaulis Phil., Loasa lateritia Gillies ex Arn.

Hierba. Perenne. Nativa.

Distribución: COQ, MAU, NUB, BIO, ARA.

Países limítrofes: Argentina.

Grausa martinii (Phil.) Weigend \& R.H. Acuña

Sinónimos: Loasa martinii Phil.

Hierba. Anual. Endémica.

Distribución: ARA, LRI, LLA.

Grausa micrantha (Poepp.) Weigend \& R.H. Acuña

Sinónimos: Loasa remyi Gay, Loasa micrantha Poepp.

Hierba. Anual. Endémica.

Distribución: RME, LBO, MAU, NUB, BIO, ARA.

Grausa sagittata (Hook. \& Arn.) Weigend \& R.H. Acuña

Sinónimos: Loasa sagittata Hook. \& Arn.

Hierba. Perenne. Endémica.

Distribución: LLA.

\section{Huidobria}

\section{Huidobria chilensis Gay}

Sinónimos: Loasa chilensis (Gay) Urb. \& Gilg

Arbusto. Endémico.

Distribución: ANT, ATA.

Huidobria fruticosa Phil.

Sinónimos: Loasa fruticosa (Phil.) Urb. \& Gilg

Arbusto. Endémico.

Distribución: AYP, TAR, ANT, ATA.

\section{Loasa}

Loasa acanthifolia Desr.

Sinónimos: Loasa punicea Phil.

Hierba. Perenne. Nativa.
Distribución: MAU, NUB, BIO, ARA, LRI, LLA.

Países limítrofes: Argentina.

Nombre vulgar: Ortiga brava.

Loasa acerifolia Dombey ex Juss.

Sinónimos: Loasa furcata Phil., Loasa solaniifolia Gay,

Loasa williamsi Phil.

Hierba. Anual. Nativa.

Distribución: COQ, LBO, MAU, NUB, BIO, ARA, LRI, LLA.

Países limítrofes: Argentina.

Nombre vulgar: Ortiga brava.

Loasa argentina Urb. \& Gilg

Sinónimos: Loasa patagonica Urb. \& Gilg, nom. nud.

Hierba. Perenne. Nativa.

Distribución: AIS, MAG.

Países limítrofes: Argentina.

Loasa arnottiana Gay

Hierba. Anual. Endémica.

Distribución: COQ.

Loasa caespitosa Phil.

Hierba. Perenne. Endémica.

Distribución: ATA, COQ, VAL, RME.

Loasa elongata Hook. \& Arn.

Sinónimos: Loasa bertrandii Phil., Loasa urmenetae Phil.

Hierba. Anual. Endémica.

Distribución: ANT, ATA, COQ.

Loasa floribunda Hook. \& Arn.

Sinónimos: Loasa floribunda Hook. \& Arn. var. brachysepala Urb. \& Gilg

Hierba. Anual. Endémica.

Distribución: COQ, VAL, RME.

Loasa heterophylla Hook. \& Arn.

Sinónimos: Loasa aphanantha Urb. \& Gilg, Loasa parviflora Phil., hom. illeg., Loasa insons Poepp. var. prostrata Poepp., Loasa barneoudii Gay, Loasa elongata Phil., nom. nud., Loasa subandina Phil.

Hierba. Anual. Nativa.

Distribución: COQ, VAL, RME, MAU.

Países limítrofes: Argentina.

Loasa humilis Phil.

Hierba. Perenne. Endémica.

Distribución: MAU.

Loasa illapelina Phil.

Sinónimos: Loasa illapelina Phil. var. laciniata (Phil.) Urb. \& Gilg, Loasa leucantha Phil. 
Hierba. Anual. Endémica.

Distribución: ATA, COQ.

Loasa insons Poepp.

Sinónimos: Loasa intricata Gay, Loasa tricolor Ker Gawl. var. insons (Poepp.) Urb. \& Gilg, Loasa meyeniana Walp.

Hierba. Anual. Nativa.

Distribución: COQ, VAL, RME, LBO, MAU.

Países limítrofes: Argentina.

Loasa mollensis Muñoz-Schick \& Trenqualye Hierba. Anual. Endémica.

Distribución: VAL.

Loasa multifida Gay

Hierba. Anual. Endémica.

Distribución: ATA, COQ.

Loasa nitida Desr.

Hierba. Anual. Introducida.

Distribución: TAR, ANT.

Loasa pallida Gillies ex Arn.

Sinónimos: Loasa aldunatea Gay

Subarbusto. Endémico.

Distribución: ATA, COQ, VAL, RME, LBO.

Nombre vulgar: Ortiga caballuna.

Loasa paradoxa Urb. \& Gilg

Hierba. Perenne. Endémica.

Distribución: VAL, RME.

Loasa placei Lindl.

Sinónimos: Loasa tricolor Ker Gawl. var. placei (Lindl.)

Urb. \& Gilg

Hierba. Anual. Endémica.

Distribución: ATA, COQ, VAL, RME, LBO, MAU.

Loasa prostrata Gillies ex Arn.

Sinónimos: Loasa tricolor Ker Gawl. var. prostrata (Gillies ex Arn.) Urb. \& Gilg, Loasa prostrata Gillies ex Arn. var. cumingii Hook. \& Arn., Loasa alba D. Don

Hierba. Anual. Endémica.

Distribución: COQ, VAL, RME, LBO.

Loasa sclareifolia Juss.

Sinónimos: Loasa sclareifolia Juss. var. brachycarpa Urb. \& Gilg, Loasa sclareifolia Juss. var. inermis Urb. \& Gilg, Loasa sclareifolia Juss. var. nemoralis (Phil.) Urb. \& Gilg, Loasa nemoralis Phil.

Hierba. Bienal o perenne. Nativa.

Distribución: ATA, COQ, VAL, RME, LBO, MAU, NUB, BIO, ARA.

Países limítrofes: Argentina.
Nombre vulgar: Ortiga brava.

Loasa sigmoidea Urb. \& Gilg

Hierba. Perenne. Nativa.

Distribución: ATA, COQ, VAL, RME, MAU.

Países limítrofes: Argentina.

Loasa tricolor Ker Gawl.

Sinónimos: Loasa bryoniaefolia Schrad. ex DC.

Hierba. Anual. Nativa.

Distribución: ATA, COQ, VAL, RME, MAU.

Países limítrofes: Argentina.

Nombre vulgar: Cardito.

Loasa triloba Dombey ex Juss.

Hierba. Anual. Endémica.

Distribución: ATA, COQ, VAL, RME, LBO, MAU, NUB, BIO, ARA, LRI.

\section{Mentzelia}

Mentzelia albescens (Gillies ex Arn.) Griseb.

Sinónimos: Bartonia albescens Gillies ex Arn., Bartonia

sinuata C. Presl, Nuttallia albescens (Gillies ex Arn.)

Standl.

Hierba. Bienal. Nativa.

Distribución: ATA, COQ, VAL, RME.

Países limítrofes: Argentina.

Mentzelia bartonioides (C. Presl) Urb. \& Gilg

Sinónimos: Mentzelia andina I.M. Johnst., hom. illeg., Mentzelia pinnatifida Sleumer, hom. illeg., Acrolasia bartonioides C. Presl, Acrolasia solieri Gay, Mentzelia solieri (Gay) Urb. \& Gilg ex Urb., Mentzelia pinnatifida (Phil.) Urb. \& Gilg, Mentzelia andina Urb. \& Gilg, Acrolasia bartonioides Gay, hom. illeg., Acrolasia pinnatifida Phil.

Hierba. Anual. Nativa.

Distribución: ATA, COQ.

Países limítrofes: Argentina.

Mentzelia scabra Kunth subsp. atacamensis (Urb. \& Gilg) Weigend

Sinónimos: Mentzelia chilensis Gay var. atacamensis Urb. \& Gilg

Subarbusto. Endémico.

Distribución: AYP, ANT, COQ.

Mentzelia scabra Kunth subsp. chilensis (Gay) Weigend Sinónimos: Mentzelia ignea (Phil.) Urb. \& Gilg, Mentzelia chilensis Gay, Loasa ignea Phil.

Arbusto o subarbusto. Nativo.

Distribución: ANT, ATA, COQ.

Países limítrofes: Bolivia. 
Nasa

Nasa urens (Jacq.) Weigend

Sinónimos: Loasa urens Jacq.

Hierba. Anual. Nativa.

Distribución: ANT.

Países limítrofes: Perú.

\section{Pinnasa}

Pinnasa bergii (Hieron.) Weigend \& R.H. Acuña

Sinónimos: Loasa bergii Hieron.

Hierba. Perenne. Nativa.

Distribución: AIS, MAG.

Países limítrofes: Argentina.

Pinnasa nana (Phil.) Weigend \& R.H. Acuña

Sinónimos: Loasa nana Phil.

Hierba. Perenne. Nativa.

Distribución: RME, ARA, LLA.

Países limítrofes: Argentina.

Pinnasa pinnatifida (Gillies ex Arn.) Weigend \& R.H. Acuña

Sinónimos: Loasa pinnatifida (Gillies ex Arn., Loasa bridgesii Urb. \& Gilg, Loasa chillana Urb. \& Gilg, Loasa filicifolia Poepp., Loasa acutiloba Urb. \& Gilg, Loasa poeppigiana Urb. \& Gilg, Loasa tripartita Urb. \& Gilg Hierba. Perenne. Nativa.

Distribución: RME, LBO, MAU, NUB, BIO, ARA, LRI.

Países limítrofes: Argentina.

Pinnasa volubilis (Dombey ex Juss.) Weigend \& R.H. Acuña

Sinónimos: Loasa volubilis Dombey ex Juss., Loasa artemisiifolia Poepp. ex Urb. \& Gilg, Loasa volubilis Dombey ex Juss. var. alpina Poepp.

Hierba. Perenne. Endémica.

Distribución: VAL, RME, LBO, MAU, NUB, BIO, ARA, LRI.

\section{Presliophytum}

Presliophytum malesherbioides (Phil.) R.H. Acuña \& Weigend

Sinónimos: Loasa malesherbioides Phil., Loasa longiseta Phil.

Hierba. Anual. Nativa.

Distribución: ANT, ATA, COQ.

Países limítrofes: Argentina.

Presliophytum sessiliflorum (Phil.) R.H. Acuña \& Weigend Hierba. Anual. Endémica.

Distribución: ATA.

\section{Scyphanthus}

Scyphanthus elegans Sweet

Sinónimos: Grammatocarpus volubilis C. Presl, Scyphanthus stenocarpus (Poepp.) Urb. \& Gilg, Grammatocarpus cumingii C. Presl

Hierba trepadora. Anual o bienal. Endémica.

Distribución: COQ, VAL, RME, LBO, MAU, NUB, BIO, ARA.

Nombre vulgar: Monjita.

\section{LORANTHACEAE}

\section{Desmaria}

Desmaria mutabilis (Poepp. \& Endl.) Tiegh. ex T. Durand \& B.D. Jacks.

Sinónimos: Loranthus mutabilis Poepp. \& Endl., Phrygilanthus mutabilis (Poepp. \& Endl.) Eichl., Gaiandendron mutabile (Poepp. \& Endl.) Engl. \& Prantl.

Arbusto parásito. Endémico.

Distribución: LBO, MAU, NUB, BIO, ARA, LRI, LLA.

Rango altitudinal: 0-1700 m.

\section{Ligaria}

Ligaria cuneifolia (Ruiz \& Pav.) Tiegh.

Sinónimos: Loranthus cuneifolius Ruiz \& Pav., Ligaria coronata Tiegh., Loranthus linearifolius Bertero

Arbusto parásito. Nativo.

Distribución: COQ, VAL, RME, LBO, NUB.

Rango altitudinal: 0-3000 m.

Países limítrofes: Argentina, Bolivia y Perú.

\section{Notanthera}

Notanthera heterophylla (Ruiz \& Pav.) G. Don

Sinónimos: Loranthus heterophyllus Ruiz \& Pav., Phrygilanthus berteroi (Hook. \& Arn.) Eichler, Loranthus buxifolius Cham. \& Schltdl., Loranthus eschscholzianus Mart. ex Schult. \& Schult.f., Loranthus valdivianus Miq., Loranthus berteroi Hook. \& Arn., Psittacanthus berteroi (Hook. \& Arn.) G. Don, Phrygilanthus heterophyllus (Ruiz \& Pav.) Eichler

Arbusto parásito. Endémico.

Distribución: VAL, RME, LBO, MAU, NUB, BIO, ARA, LRI, LLA, AIS, JFE.

Rango altitudinal: 0-1500 m.

Nombre vulgar: Quintral del boldo. 


\section{Tristerix}

Tristerix aphyllus (DC.) Barlow \& Wiens

Sinónimos: Phrygilanthus aphyllus (DC.) Eichler fma. luteus Follmann, Loranthus aphyllus DC., Loranthus cactorum Hook. \& Arn., Phrygilanthus aphyllus ( DC.) Eichler, Loranthus pumilus Miers ex Schult. \& Schult.f.

Arbusto parásito. Endémico.

Distribución: ATA, COQ, VAL, RME, LBO.

Rango altitudinal: 0-1800 m.

Nombre vulgar: Quintral del quisco.

Tristerix corymbosus (L.) Kuijt

Sinónimos: Phrygilanthus tetrandus (Ruiz \& Pav.) Eichler, Loranthus tetrandus Ruiz \& Pav., Lonicera corymbosa L., Tristerix tetrandrus (Ruiz \& Pav.) Mart., Loranthus corymbosus (L.) Desr., Loranthus utui Molina

Arbusto parásito. Nativo.

Distribución: ATA, COQ, VAL, RME, LBO, MAU, NUB, BIO, ARA, LLA, JFE.

Rango altitudinal: 0-2400 m.

Países limítrofes: Argentina.

Nombre vulgar: Quintral.

Nota: Introducida en el Archipiélago Juan Fernández.

Tristerix verticillatus (Ruiz \& Pav.) Barlow \& Wiens Sinónimos: Phrygilanthus verticillatus (Ruiz \& Pav.) Eichler, Loranthus verticillatus Ruiz \& Pav., Metastachys verticillata (Ruiz \& Pav.) Tiegh., Notanthera verticillata (Ruiz \& Pav.) G. Don, Loranthus sternbergianus Schult. \& Schult.f., Notanthera sternbergianus (Schult. f.) G. Don, Phrygilanthus sternbergianus (Schult. f.) Reiche, Loranthus poeppigii DC., Notanthera poeppigii (DC.) G. Don

Arbusto parásito. Nativo.

Distribución: ATA, COQ, VAL, RME, LBO, MAU, NUB, BIO, ARA, LRI, LLA.

Rango altitudinal: 0-3500 m.

Países limítrofes: Argentina y Bolivia.

Nombre vulgar: Quintral.

\section{LYTHRACEAE}

\section{Ammannia}

Ammannia coccinea Rottb. Hierba. Anual. Introducida. Distribución: MAU.

Ammannia latifolia L.

Hierba. Anual. Introducida. Distribución: MAU.
Lythrum

Lythrum hyssopifolia L.

Hierba. Anual. Introducida.

Distribución: TAR, ATA, COQ, VAL, RME, LBO, MAU, NUB, BIO, ARA, LRI, LLA, JFE.

Lythrum maritimum Kunth

Sinónimos: Lythrum album auct. non Kunth, Lythrum

albicaule Bertero

Hierba. Perenne. Nativa.

Distribución: AYP, TAR, ATA, VAL, RME, JFE.

Rango altitudinal: 0-2000 m.

Países limítrofes: Argentina, Bolivia y Perú.

Lythrum portula (L.) D.A. Webb

Hierba. Anual. Introducida.

Distribución: ARA, LLA.

Lythrum salicaria L.

Hierba. Perenne. Introducida.

Distribución: RME, LLA.

\section{Pleurophora}

Pleurophora polyandra Hook. \& Arn.

Sinónimos: Pleurophora polyandra Hook. \& Arn. fma. squarrosa (Steud.) Koehne, Pleurophora uncinata Phil.

Hierba. Anual. Endémica.

Distribución: COQ, VAL, RME, LBO.

Rango altitudinal: 200-2000 m.

\section{Pleurophora pungens D. Don}

Sinónimos: Pleurophora pungens D. Don fma. imbricata Koehne

Subarbusto. Endémico.

Distribución: ANT, ATA, COQ, VAL, RME, LBO.

Rango altitudinal: 500-1000 m.

Nombre vulgar: Lengua de gallina.

Pleurophora pusilla Hook. \& Arn.

Sinónimos: Pleurophora pusilla Hook. \& Arn. fma. vestita Koehne, Pleurophora pilosiuscula Gay var. glabra Phil.

Hierba. Anual. Endémica.

Distribución: ATA, COQ, VAL, RME, LBO.

Rango altitudinal: 0-900 m. 


\section{MALPIGHIACEAE}

\section{Dinemagonum}

Dinemagonum gayanum A. Juss.

Sinónimos: Dinemagonum bridgesianum A. Juss., Dinemagonum maculigerum Phil., Dinemagonum albicaule Phil., Dinemagonum gayanum A. Juss. var. albicaule (Phil.) Reiche, Dinemagonum gayanum A. Juss. var. bridgesianum (A. Juss.) Reiche, Dinemagonum bridgesianum A. Juss. fma. glanduloso-bracteolata Nied., Dinemagonum bridgesianum A. Juss. var. parvifolium Nied.

Arbusto o subarbusto. Endémico.

Distribución: TAR, ATA, COQ, VAL.

Rango altitudinal: 0-2600 m.

Nombre vulgar: Té de burro, pingo blanco.

\section{Dinemandra}

Dinemandra ericoides A. Juss.

Sinónimos: Dinemandra glaberrima A. Juss., Dinemandra strigosa Phil., Dinemandra ramosissima Phil., Dinemandra subaptera Phil., Dinemandra glauca Baill., Dinemandra ericoides A. Juss. var. triandra Nied., Dinemandra glaberrima A. Juss.

Arbusto o subarbusto. Endémico.

Distribución: TAR, ANT, ATA.

Rango altitudinal: 0-2800 m.

Nombre vulgar: Té de burro, té bravo, colorado.

\section{MALVACEAE}

\section{Abutilon}

Abutilon grandifolium (Willd.) Sweet

Arbusto o subarbusto. Introducido.

Distribución: ANT.

\section{Andeimalva}

Andeimalva chilensis (Gay) J.A. Tate

Sinónimos: Malacothamnus chilensis (Gay) Krapov., Sphaeralcea glabrata Phil., Sphaeralcea grandifolia Phil., Sphaeralcea capitata Phil., Sphaeralcea viridis Phil., Sphaeralcea peteroana Phil., Sphaeralcea chilensis Gay, Sphaeroma chilense (Gay) Kuntze, Sphaeroma glabratum (Phil.) Kuntze

Arbusto. Endémico.

Distribución: ATA, COQ, VAL, RME, LBO, MAU.

Rango altitudinal: 300-3000 m.

\section{Anoda}

Anoda cristata (L.) Schltdl.

Hierba. Perenne. Introducida.

Distribución: TAR, ANT, ATA, COQ, VAL, RME, LBO, MAU, NUB, BIO, ARA, JFE.

\section{Corynabutilon}

Corynabutilon bicolor (Phil. ex K. Schum.) Kearney

Sinónimos: Abutilon bicolor Phil. ex K. Schum.

Arbusto. Nativo.

Distribución: COQ, RME.

Rango altitudinal: 200-2200 m.

Países limítrofes: Argentina.

Nombre vulgar: Matamora, malva.

Corynabutilon ceratocarpum (Hook. \& Arn.) Kearney

Sinónimos: Sida ceratocarpa Hook. \& Arn., Abutilon ceratocarpum (Hook. \& Arn.) Gay

Arbusto. Endémico.

Distribución: VAL, RME, LBO.

Rango altitudinal: 700-2400 m.

Nombre vulgar: Huella.

Corynabutilon hirsutum (Phil.) A.E. Martic.

Sinónimos: Anoda hirsuta Phil., Abutilon hirsutum (Phil.)

Reiche

Arbusto. Endémico.

Distribución: BIO, ARA.

Rango altitudinal: 300-500 m.

Corynabutilon ochsenii (Phil.) Kearney

Sinónimos: Anoda ochsenii Phil., Abutilon ochsenii (Phil.)

Phil. ex F. Phil., Abutilon ochsenii (Phil.) Phil. ex F. Phil.

var. stellaris Reiche, Abutilon garckei Baker f.

Arbusto. Endémico.

Distribución: ARA, LRI.

Rango altitudinal: 0-500 m.

Corynabutilon salicifolium (Reiche) Krapov.

Sinónimos: Abutilon salicifolium Reiche

Arbusto. Endémico.

Distribución: BIO, ARA.

Rango altitudinal: 0-200 m.

Corynabutilon viride (Phil.) A.E. Martic.

Sinónimos: Abutilon viride Phil.

Arbusto. Endémico.

Distribución: LBO, MAU, NUB, BIO.

Rango altitudinal: 1000-1800 m. 
Corynabutilon vitifolium (Cav.) Kearney

Sinónimos: Sida vitifolia Cav., Abutilon vitifolium (Cav.) D. Don, Sidalcea triloba Turcz.

Arbusto o árbol pequeño. Endémico.

Distribución: VAL, BIO, ARA, LRI, LLA.

Rango altitudinal: 0-1400 m.

Nombre vulgar: Huella.

\section{Cristaria}

Cristaria adenophora I.M. Johnst.

Hierba. Anual o perenne. Endémica.

Distribución: ANT, ATA.

Rango altitudinal: 2400-3300 m.

\section{Cristaria andicola Gay}

Hierba. Perenne. Nativa.

Distribución: ANT, ATA, COQ.

Rango altitudinal: 2000-4700 m.

Países limítrofes: Argentina.

Nombre vulgar: Malvilla, primavera.

Cristaria argyliifolia Phil.

Sinónimos: Cristaria aspera Gay var. pilosa (Phil.) Reiche, Cristaria pilosa Phil.

Hierba. Anual. Endémica.

Distribución: ATA.

Rango altitudinal: 300-700 m.

\section{Cristaria aspera Gay var. aspera}

Sinónimos: Cristaria intermedia Gay, Cristaria urmenetae Phil., Cristaria lata Turcz.

Hierba. Perenne. Endémica.

Distribución: TAR, ANT, ATA, COQ.

Rango altitudinal: 0-800 m.

Cristaria aspera Gay var. formosula (I.M. Johnst.) MuñozSchick

Sinónimos: Cristaria formosula I.M. Johnst.

Hierba. Anual. Nativa.

Distribución: ANT, ATA.

Rango altitudinal: 0-700 m.

Cristaria aspera Gay var. sadae (Phil.) Muñoz-Schick

Sinónimos: Cristaria sadae Phil.

Hierba. Perenne. Endémica.

Distribución: ANT, ATA.

Rango altitudinal: 0-700 m.

\section{Cristaria calderana Muñoz-Schick}

Hierba. Anual o perenne. Endémica.

Distribución: ATA.

Rango altitudinal: 0-100 m.
Cristaria cordato-rotundifolia Gay

Hierba. Perenne. Endémica.

Distribución: ATA.

Rango altitudinal: 1300-2500 m.

Cristaria cyanea Phil. ex Baker f.

Sinónimos: Cristaria cyanea Phil.

Hierba. Anual. Endémica.

Distribución: TAR, ATA, COQ.

Rango altitudinal: 1000-2400 m.

Nombre vulgar: Malvilla negra.

Cristaria dissecta Hook. \& Arn. var. dissecta

Sinónimos: Lecanophora dissecta (Hook. \& Arn.) Speg., Cristaria flexuosa Phil., Cristaria ovallea Gay, Cristaria univittata Hochr., Cristaria glandulosa Phil. non Cristaria Phil. 1864non C. glandulosa Phil. 1864

Hierba. Anual o perenne. Nativa.

Distribución: AYP, TAR, ANT, ATA, COQ, VAL, RME, LBO.

Rango altitudinal: 100-3700 m.

Países limítrofes: Argentina.

Nombre vulgar: Malvavisco, malva.

Cristaria dissecta Hook. \& Arn. var. glandulosa (Phil.) Muñoz-Schick

Sinónimos: Cristaria glandulosa Phil., Cristaria glomerulata I.M. Johnst., Cristaria saniculaefolia Phil. ex Baker f., Cristaria saniculifolia Phil.

Hierba. Anual o perenne. Nativa.

Distribución: ATA, COQ.

Rango altitudinal: $300-2800 \mathrm{~m}$.

Países limítrofes: Argentina.

Cristaria dissecta Hook. \& Arn. var. inconspicua (F. Phil.) Muñoz-Schick

Sinónimos: Cristaria inconspicua F. Phil.

Hierba. Anual o perenne. Nativa.

Distribución: COQ.

Rango altitudinal: 2700-3500 m.

Países limítrofes: Argentina.

Cristaria fuentesiana I.M. Johnst.

Hierba. Perenne. Endémica.

Distribución: ANT, ATA.

Rango altitudinal: 100-800 m.

Cristaria glaucophylla Cav. var. eriantha (Hook. \& Arn.) Muñoz-Schick

Sinónimos: Cristaria australis Phil., Cristaria eriantha Hook. \& Arn., Sida eriantha (Hook. \& Arn.) Steud.

Hierba. Perenne. Endémica.

Distribución: COQ, VAL, RME, MAU.

Rango altitudinal: 0-100 m. 
Cristaria glaucophylla Cav. var. glaucophylla

Sinónimos: Lecanophora glaucophylla (Cav.) Speg., Cristaria betonicaefolia Pers., Cristaria carrizalensis Phil., Cristaria glaucophylla Cav. var. simplex Reiche, Cristaria haenkeana C. Presl, Cristaria hirsuta C. Presl, Cristaria hispida Phil., hom. illeg., Cristaria pannosa Phil. ex Reiche, Cristaria trichocaula Phil.

Hierba. Perenne. Endémica.

Distribución: ATA, COQ, VAL.

Rango altitudinal: 0-600 m.

\section{Cristaria gracilis Gay}

Sinónimos: Cristaria divaricata Phil. ex Baker f., Cristaria humilis Phil., Cristaria patens Phil., Cristaria ranunculifolia Phil. ex Baker f., Cristaria divaricata Phil. var. hirsuta Phil., Cristaria divaricata Phil., hom. illeg., Cristaria ranunculifolia Phil.

Hierba. Anual o perenne. Nativa.

Distribución: AYP, TAR, ANT, ATA, COQ.

Rango altitudinal: 1000-4200 m.

Países limítrofes: Perú.

Nombre vulgar: Malvilla.

Cristaria insularis F. Phil. var. insularis

Hierba. Anual. Endémica.

Distribución: IDE.

Cristaria insularis F. Phil. var. johowii (Skottsb.) MuñozSchick

Sinónimos: Cristaria johowii Skottsb.

Hierba. Anual. Endémica.

Distribución: IDE.

\section{Cristaria integerrima Phil. var. integerrima}

Sinónimos: Cristaria diaziana I.M. Johnst., Cristaria foliosa Phil., Cristaria grandidentata Phil. ex Baker f., Cristaria intonsa I.M. Johnst., Cristaria oxyptera Phil., Cristaria paposana I.M. Johnst., Cristaria rotundifolia Phil., Cristaria borchersii Phil., Cristaria setosa Phil., Cristaria larrañagae Phil., Cristaria grandidentata Phil.

Hierba. Anual o perenne. Endémica.

Distribución: TAR, ANT, ATA.

Rango altitudinal: 0-1500 m.

Cristaria integerrima Phil. var. lobulata (Phil.) MuñozSchick

Sinónimos: Cristaria lobulata Phil.

Hierba. Anual o perenne. Endémica.

Distribución: ANT, ATA.

Rango altitudinal: 200-500 m.

Cristaria leucantha I.M. Johnst.

Hierba. Perenne. Endémica.
Distribución: ANT.

Rango altitudinal: 0-200 m.

Cristaria molinae Gay

Sinónimos: Cristaria diversifolia Phil. fma. parvula (Phil.) I.M. Johnst., Cristaria grandiflora Turcz., Cristaria heterophylla Phil., hom. illeg., Cristaria trifida Phil., Cristaria parvula Phil., Cristaria diversifolia Phil.

Hierba. Anual. Endémica.

Distribución: TAR, ANT, ATA, COQ.

Rango altitudinal: 0-800 $\mathrm{m}$.

\section{Cristaria multiflora Gay}

Sinónimos: Cristaria glabrata Phil.

Hierba. Perenne. Endémica.

Distribución: TAR, ATA, COQ, VAL.

Rango altitudinal: 0-2200 m.

Cristaria ovata Muñoz-Schick

Hierba. Perenne. Endémica.

Distribución: ANT, ATA, COQ.

Rango altitudinal: 0-100 m.

Cristaria tenuissima Muñoz-Schick

Hierba. Anual. Endémica.

Distribución: TAR, ANT.

Rango altitudinal: 0-300 m.

Cristaria viridiluteola Gay var. pinnata (Phil.) MuñozSchick

Sinónimos: Cristaria pinnata Phil., Cristaria thinophila I.M. Johnst.

Hierba. Anual o perenne. Endémica.

Distribución: TAR, ANT, ATA.

Rango altitudinal: 0-300 $\mathrm{m}$.

Cristaria viridiluteola Gay var. viridiluteola

Sinónimos: Cristaria bipinnatifida Phil., Cristaria viridiluteola Gay var. geraniifolia (C. Presl) Reiche, Cristaria seselifolia Turcz., Cristaria bipinnata Phil.

Hierba. Anual o perenne. Endémica.

Distribución: AYP, TAR, ANT, ATA, COQ.

Rango altitudinal: 0-800 $\mathrm{m}$.

Nombre vulgar: Malvilla, malvilla salada.

\section{Gossypium}

Gossypium barbadense L.

Arbusto. Introducido.

Distribución: AYP, TAR, ANT, ATA, COQ, IPA. 
Hibiscus

Hibiscus trionum L.

Hierba. Anual. Introducida.

Distribución: MAU, BIO.

\section{Lecanophora}

Lecanophora subacaulis Krapov.

Hierba. Perenne. Nativa.

Distribución: MAG.

Rango altitudinal: 0-300 m.

Países limítrofes: Argentina.

Malva

Malva assurgentiflora (Kellogg) M.F. Ray

Arbusto. Introducido.

Distribución: AYP, ANT, ATA, COQ, VAL, MAU, JFE.

Malva dendromorpha M.F. Ray

Subarbusto. Introducido.

Distribución: AYP, TAR, ANT, COQ, VAL, LBO, MAU, LLA.

Malva moschata L.

Hierba. Anual. Introducida.

Distribución: LLA, AIS.

Malva neglecta Wallr.

Hierba. Perenne. Introducida.

Distribución: VAL, RME, ARA.

\section{Malva nicaeensis All.}

Hierba. Perenne. Introducida.

Distribución: ANT, ATA, COQ, VAL, RME, LBO, MAU, NUB, BIO, ARA, LRI, JFE.

Malva parviflora $\mathrm{L}$.

Hierba. Perenne. Introducida.

Distribución: AYP, ANT, ATA, COQ, VAL, RME, LBO, MAU, NUB, BIO, ARA, LLA, JFE.

Malva sylvestris L.

Hierba. Anual. Introducida.

Distribución: ANT, VAL, RME, AIS.

Malva verticillata $\mathrm{L}$.

Arbusto. Introducido.

Distribución: ANT.

\section{Malvastrum}

Malvastrum coromandelianum (L.) Garcke
Subarbusto. Introducido.

Distribución: TAR, RME, IPA.

\section{Malvella}

Malvella leprosa (Ortega) Krapov.

Sinónimos: Malva albifolia Larrañaga, Malva leprosa Ortega, Malva sulphurea Gillies ex Hook. \& Arn., Malvastrum sulfureum (Gillies ex Hook. \& Arn.) Griseb., Sida hederacea (Douglas) Torr., Sida hederacea (Douglas) Torr. var. sulphurea (Gillies ex Hook. \& Arn.) Baker f., Sida leprosa (Ortega) K. Schum., Sida leprosa (Ortega) K. Schum. var. sulphurea (Hook. \& Arn.) Hochr., Sida sulphurea (Gillies ex Hook. \& Arn.) A. Gray, Disella hederacea (Douglas ex Hook.) Greene, Malva hederacea Douglas ex Hook.

Hierba. Perenne. Nativa.

Distribución: TAR, ANT, ATA, COQ, VAL, RME.

Rango altitudinal: 0-2000 m.

Países limítrofes: Argentina, Bolivia y Perú.

\section{Modiola}

Modiola caroliniana (L.) G. Don

Hierba. Perenne. Introducida.

Distribución: ATA, COQ, VAL, RME, LBO, MAU, NUB, BIO, ARA, LRI, LLA, JFE.

\section{Nototriche}

Nototriche alternata A.W. Hill

Sinónimos: Nototriche sajamensis (Hieron.) A.W. Hill, Malvastrum sajamense Hieron.

Hierba. Perenne. Nativa.

Distribución: AYP.

Rango altitudinal: 4000-5000 m.

Países limítrofes: Perú.

Nototriche anthemidifolia (J. Remy) A.W. Hill

Sinónimos: Malvastrum anthemidifolium (J. Remy) A. Gray, Sida anthemidifolia J. Remy

Hierba. Perenne. Nativa.

Distribución: AYP, TAR.

Rango altitudinal: 3500-4800 m.

Países limítrofes: Argentina, Bolivia y Perú.

Nototriche argentea A.W. Hill

Hierba. Perenne. Nativa.

Distribución: AYP, TAR, ANT.

Rango altitudinal: 3300-4500 m.

Países limítrofes: Perú.

Nototriche auricoma (Phil.) A.W. Hill

Sinónimos: Malvastrum auricomum Phil., Malvastrum 
auricomum Phil. ex Baker f.

Hierba. Perenne. Endémica.

Distribución: AYP, TAR, ANT.

Rango altitudinal: 4200-4700 m.

Nototriche clandestina (Phil.) A.W. Hill

Sinónimos: Malvastrum clandestinum (Phil.) Baker f., Sida clandestina Phil.

Hierba. Perenne. Nativa.

Distribución: ANT, ATA.

Rango altitudinal: 3000-5100 m.

Países limítrofes: Argentina.

Nombre vulgar: Altea.

Nototriche compacta (A. Gray) A.W. Hill

Sinónimos: Malvastrum compactum A. Gray, Malvastrum megalorrhizum (Phil.) Baker f., Sida compacta Gay, hom. illeg., Sida macrorhiza Phil. ex Baker f., nom. nud., Sida megalorrhiza Phil., Nototriche holosericea A.W. Hill, Nototriche megalorrhiza Phil.

Hierba. Perenne. Nativa.

Distribución: AYP, TAR, ANT, ATA, COQ, VAL, RME, LBO.

Rango altitudinal: 1900-4500 m.

Países limítrofes: Argentina.

Nombre vulgar: Mostaza.

Nototriche diminutiva (Phil.) I.M. Johnst.

Sinónimos: Malva diminutiva Phil., Malvastrum diminutivum (Phil.) Baker f.

Hierba. Anual. Endémica.

Distribución: TAR, ANT.

Rango altitudinal: 3800-4000 m.

Nototriche estipulata A.W. Hill ex B.L. Burtt

Hierba. Perenne. Nativa.

Distribución: AYP, TAR, ANT.

Rango altitudinal: $3000-4700 \mathrm{~m}$.

Países limítrofes: Perú.

Nombre vulgar: Oqelatalata, tanitani, psike de cordillera.

Nototriche hillii Krapov.

Hierba. Perenne. Nativa.

Distribución: AYP, TAR, ATA.

Rango altitudinal: 4000-4700 m.

Países limítrofes: Argentina y Bolivia.

Nototriche leucosphaera A.W. Hill

Hierba. Perenne. Nativa.

Distribución: AYP, TAR, ANT.

Rango altitudinal: 4300-4600 m.

Países limítrofes: Bolivia.
Nototriche meyenii Ulbr.

Sinónimos: Sida borussica Meyen

Hierba. Perenne. Nativa.

Distribución: AYP.

Rango altitudinal: 4000-4800 m.

Países limítrofes: Perú.

Nototriche nana A.W. Hill

Hierba. Anual. Endémica.

Distribución: AYP, TAR, ANT.

Rango altitudinal: 3700-4600 m.

Nototriche obcuneata (Baker f.) A.W. Hill var. cinerea A.W. Hill

Hierba. Perenne. Nativa.

Distribución: AYP.

Rango altitudinal: 4400-4900 m.

Países limítrofes: Bolivia.

Nototriche obcuneata (Baker f.) A.W. Hill var. obcuneata Sinónimos: Malvastrum obcuneatum Baker f.

Hierba. Perenne. Nativa.

Distribución: AYP.

Rango altitudinal: 4000-4400 m.

Países limítrofes: Perú.

Nototriche orbignyana (Wedd.) A.W. Hill

Sinónimos: Malvastrum orbignyanum Wedd.

Hierba. Perenne. Nativa.

Distribución: AYP.

Rango altitudinal: 4400-4500 m.

Países limítrofes: Bolivia y Perú.

Nototriche ovata Krapov.

Hierba. Perenne. Nativa.

Distribución: ATA.

Rango altitudinal: 3800-4100 m.

Países limítrofes: Argentina.

Nototriche parviflora (Phil.) A.W. Hill

Sinónimos: Malvastrum parviflorum Phil.

Hierba. Perenne. Nativa.

Distribución: AYP, TAR, ANT.

Rango altitudinal: 4100-5000 m.

Países limítrofes: Argentina y Bolivia.

Nombre vulgar: Layo.

Nototriche philippii A.W. Hill

Hierba. Perenne. Nativa.

Distribución: AYP, ANT, ATA.

Rango altitudinal: 3200-4500 m.

Países limítrofes: Argentina y Perú. 
Nototriche pulverulenta B.L. Burtt \& A.W. Hill

Hierba. Perenne. Nativa.

Distribución: AYP, TAR.

Rango altitudinal: 4200-4500 m.

Países limítrofes: Argentina y Bolivia.

Nototriche pulvinata A.W. Hill

Hierba. Perenne. Nativa.

Distribución: AYP.

Rango altitudinal: 4000-4900 m.

Países limítrofes: Bolivia.

Nototriche pusilla A.W. Hill

Hierba. Anual. Nativa.

Distribución: AYP, TAR, ANT.

Rango altitudinal: 3800-4800 m.

Países limítrofes: Argentina, Bolivia y Perú.

Nototriche pygmaea (J. Remy) A.W. Hill

Sinónimos: Malvastrum pygmaeum (J. Remy) A. Gray, Nototriche werdermannii Ulbr., Sida pygmaea J. Remy

Hierba. Anual. Nativa.

Distribución: AYP, TAR.

Rango altitudinal: $3500-4600 \mathrm{~m}$.

Países limítrofes: Argentina, Bolivia y Perú.

Nototriche rugosa (Phil.) A.W. Hill

Sinónimos: Malvastrum pedicularifolium (Meyen) A. Gray var. rugosum (Phil.) Reiche, Malvastrum rugosum Phil.

Hierba. Perenne. Nativa.

Distribución: AYP, TAR, ANT, ATA.

Rango altitudinal: 1900-4600 m.

Países limítrofes: Argentina, Bolivia y Perú.

Nombre vulgar: Malva.

Nototriche stipularis (Phil.) A.E. Martic.

Sinónimos: Malvastrum stipulare Phil.

Hierba. Perenne. Nativa.

Distribución: TAR, ANT.

Rango altitudinal: 3200-4400 m.

Países limítrofes: Bolivia.

Nototriche turritella A.W. Hill

Hierba. Perenne. Nativa.

Distribución: AYP, TAR.

Rango altitudinal: 3600-4600 m.

Países limítrofes: Bolivia y Perú.

\section{Palaua}

Palaua concinna (Phil.) I.M. Johnst.

Sinónimos: Sida concinna Phil.

Arbusto. Endémico.

Distribución: ANT.
Rango altitudinal: 0-600 m.

Palaua dissecta Benth.

Sinónimos: Palaua bipinnatifida Reiche

Hierba. Anual. Nativa.

Distribución: TAR, ANT.

Rango altitudinal: 100-400 m.

Países limítrofes: Perú.

Palaua inconspicua I.M. Johnst.

Hierba. Anual. Nativa.

Distribución: ANT.

Rango altitudinal: 0-200 m.

Países limítrofes: Perú.

Palaua modesta (Phil.) Reiche

Sinónimos: Sida modesta Phil.

Hierba. Anual. Endémica.

Distribución: ANT.

Rango altitudinal: 300-400 m.

Sida

Sida rhombifolia L.

Hierba o subarbusto. Anual o perenne. Introducida.

Distribución: COQ, IPA.

Sida spinosa L.

Subarbusto. Introducido.

Distribución: AYP, ATA.

Sphaeralcea

Sphaeralcea obtusiloba (Hook.) G. Don

Sinónimos: Malva obtusiloba Hook., Sphaeralcea gayana Phil., Sphaeralcea berteroana Phil., Sphaeralcea collina

Phil., Sphaeralcea floribunda Phil., Sphaeralcea rupestris

Phil., Sphaeralcea coquimbana Phil., Sphaeralcea vidali

Phil., Sphaeralcea circinata Phil., Sphaeroma obtusilobum

(Gay) Kuntze, Sphaeroma rupestre (Phil.) Kuntze, Sphaeroma valparadiseum (Phil.) Kuntze, Sphaeroma berteroana (Phil.) Kuntze, Sphaeroma collinum (Phil.) Kuntze, Sphaeroma coquimbarum (Phil.) Kuntze, Sphaeroma gayanum (Phil.) Kuntze, Sphaeralcea arenaria Phil., Sphaeralcea valparadisea Phil.

Subarbusto. Endémico.

Distribución: ATA, COQ, VAL, RME, LBO, ARA.

Rango altitudinal: 0-2000 m.

Nombre vulgar: Malvavisca, malva del cerro.

Sphaeralcea purpurata (Lindl.) Krapov.

Sinónimos: Malva belloa Gay, Malva purpurata Lindl., Malva purpurea Gay, Malva tenuifolia Hook. \& Arn., Malvastrum belloum (Gay) A. Gray, Malvastrum 
purpuratum (Lindl.) G. Nicholson, Malvastrum tenuifolium (Hook. \& Arn.) Baker f., Malva laeta Phil.

Hierba. Perenne. Nativa.

Distribución: COQ, LBO, MAU, NUB, BIO, ARA.

Rango altitudinal: 0-300 m.

Países limítrofes: Argentina.

Nombre vulgar: Malva loca.

\section{Tarasa}

Tarasa antofagastana (Phil.) Krapov.

Sinónimos: Malva antofagastana Phil., Malvastrum antofagastanum (Phil.) Baker f., Malveopsis antofagastana (Phil.) Kuntze

Hierba. Anual. Nativa.

Distribución: ANT, ATA.

Rango altitudinal: 1500-3600 m.

Países limítrofes: Argentina y Bolivia.

Tarasa congestiflora (I.M. Johnst.) Krapov.

Sinónimos: Malvastrum congestiflorum I.M. Johnst.

Hierba. Anual. Nativa.

Distribución: AYP, TAR, ANT.

Rango altitudinal: 2000-3800 m.

Países limítrofes: Perú.

Tarasa humilis (Gillies ex Hook. \& Arn.) Krapov.

Sinónimos: Malva humilis Gillies ex Hook. \& Arn., Malva subacaulis Phil., Malvastrum humile (Gillies ex Hook. \& Arn.) A. Gray, Malvastrum humile (Gillies ex Hook. \& Arn.) A. Gray var. subacaule (Phil.) Reiche, Malvastrum subacaule (Phil.) Baker f.

Hierba. Perenne. Nativa.

Distribución: RME, MAU, NUB, BIO, ARA.

Rango altitudinal: 900-3300 m.

Países limítrofes: Argentina.

Tarasa martiniana Krapov.

Hierba. Anual. Endémica.

Distribución: ANT.

Rango altitudinal: $3000 \mathrm{~m}$.

Tarasa operculata (Cav.) Krapov.

Sinónimos: Malvastrum plumosum (C. Presl) A. Gray, Malva operculata Cav., Tarasa rahmeri Phil., Malvastrum operculatum (Cav.) Hochr., Malva plumosa C. Presl, Malvastrum plumosum (C. Presl) A. Gray var. atacamensis Baker f., Tarasa rahmeri Phil. var. atacamensis (Baker f.) Bruns

Subarbusto. Nativo.

Distribución: AYP, TAR, ANT.

Rango altitudinal: 1500-3800 m.

Países limítrofes: Perú.

Nombre vulgar: Malva, canchalahua.
Tarasa pediculata Krapov.

Hierba. Anual. Endémica.

Distribución: AYP, TAR, ANT.

Rango altitudinal: 1800-3700 m.

Tarasa reichei (Phil.) Krapov.

Sinónimos: Malva reichei Phil., Sida reichei (Phil.) Reiche

Arbusto. Endémico.

Distribución: LBO, MAU.

Rango altitudinal: 0-100 m.

Tarasa tarapacana (Phil.) Krapov.

Sinónimos: Malva tarapacana Phil., Malvastrum tarapacanum (Phil.) Baker f.

Hierba. Anual. Nativa.

Distribución: AYP, TAR, ANT.

Rango altitudinal: 3000-4000 m.

Países limítrofes: Argentina y Bolivia.

Tarasa tenella (Cav.) Krapov.

Sinónimos: Malva tenella Cav., Malvastrum tenellum (Cav.) Hieron.

Hierba. Anual o bienal. Nativa.

Distribución: AYP, TAR, ANT.

Rango altitudinal: 2500-3800 m.

Países limítrofes: Argentina, Bolivia y Perú.

Nombre vulgar: Malvilla, malva.

Tarasa umbellata Krapov.

Arbusto. Endémico.

Distribución: VAL, MAU.

\section{Thespesia}

Thespesia populnea (L.) Sol. ex Corrêa

Árbol. Nativo.

Distribución: IPA.

Nombre vulgar: Makoi (Rapa Nui).

\section{Triumfetta}

Triumfetta semitriloba Jacq.

Arbusto o árbol pequeño. Nativo.

Distribución: IPA.

Países limítrofes: Argentina.

Nombre vulgar: Hau hau (Rapa Nui).

\section{Urocarpidium}

Urocarpidium albiflorum Ulbr.

Hierba. Anual. Nativa.

Distribución: AYP.

Rango altitudinal: $2600 \mathrm{~m}$.

Países limítrofes: Perú. 
Urocarpidium chilensis (A. Braun \& C.D. Bouché) Krapov. Sinónimos: Fuertesimalva chilensis (A. Braun \& C.D. Bouché) Fryxell, Malva chilensis A. Braun \& C.D. Bouché Hierba. Anual. Nativa.

Distribución: AYP, ANT, ATA, COQ.

Rango altitudinal: 400-2200 m.

Países limítrofes: Perú.

Urocarpidium mathewsii (Turcz.) Krapov.

Sinónimos: Malva mathewsii Turcz.

Hierba. Anual. Nativa.

Distribución: ANT, ATA, COQ.

Rango altitudinal: 0-600 m.

Países limítrofes: Perú.

Urocarpidium peruvianum (L.) Krapov.

Sinónimos: Malva peruviana L., Malvastrum peruvianum (L.) A. Gray, Fuertesimalva peruviana (L.) Fryxell

Hierba. Anual. Nativa.

Distribución: AYP, TAR, ANT, COQ.

Rango altitudinal: 100-2300 m.

Países limítrofes: Bolivia y Perú.

Urocarpidium sanambrosianum D.M. Bates

Sinónimos: Fuertesimalva sanambrosiana (D.M. Bates) Fryxell

Hierba. Anual. Endémica.

Distribución: IDE.

Rango altitudinal: 200-500 m.

\section{Waltheria}

Waltheria indica L.

Subarbusto. Introducido.

Distribución: AYP, IPA.

\section{MELIACEAE}

Melia

Melia azedarach L.

Árbol. Introducido.

Distribución: IPA.

Nombre vulgar: Miro tahiti (Rapa Nui).

\section{MISODENDRACEAE}

\section{Misodendrum}

Misodendrum angulatum Phil.

Subarbusto parásito. Nativo.

Distribución: NUB, ARA, LRI, LLA, AIS, MAG.
Países limítrofes: Argentina.

Misodendrum brachystachium DC.

Sinónimos: Archiphyllum brachystachium (DC.) Tiegh., Archiphyllum macrophyllum (Phil.) Tiegh., Misodendrum macrophyllum Phil.

Subarbusto parásito. Nativo.

Distribución: MAU, NUB, BIO, ARA, LRI, LLA, AIS, MAG.

Países limítrofes: Argentina.

Nombre vulgar: Cabello de ángel.

Misodendrum gayanum Tiegh.

Sinónimos: Misodendrum imbricatum Hook.f., non Poepp.

\& Endl.

Subarbusto parásito. Nativo.

Distribución: BIO, ARA, LRI, LLA, AIS.

Países limítrofes: Argentina.

Misodendrum linearifolium DC.

Sinónimos: Angelopogon linearifolium (DC.) Poepp. ex Tiegh., Misodendrum microphyllum Hook. \& Arn.

Subarbusto parásito. Nativo.

Distribución: VAL, RME, LBO, MAU, NUB, BIO, ARA, LRI, LLA, AIS, MAG.

Países limítrofes: Argentina.

Misodendrum macrolepis Phil.

Subarbusto parásito. Endémico.

Distribución: LLA, AIS.

Misodendrum oblongifolium DC.

Sinónimos: Archiphyllum oblongifolium (DC.) Tiegh.

Subarbusto parásito. Nativo.

Distribución: MAU, NUB, BIO, ARA, LRI, LLA, AIS, MAG.

Países limítrofes: Argentina.

Nombre vulgar: Cabello de ángel.

Misodendrum punctulatum DC.

Sinónimos: Misodendrum imbricatum Poepp. \& Endl., Misodendrum punctulatum DC. var. magellanicum DC.

Subarbusto parásito. Nativo.

Distribución: MAU, NUB, BIO, ARA, LRI, LLA, AIS, MAG.

Países limítrofes: Argentina.

Nombre vulgar: Injerto.

Misodendrum quadriflorum DC.

Sinónimos: Telophyllum quadriflorum (DC.) Tiegh.

Subarbusto parásito. Nativo.

Distribución: MAU, NUB, BIO, ARA, AIS, MAG.

Países limítrofes: Argentina. 


\section{MOLLUGINACEAE}

Glinus

Glinus radiatus (Ruiz \& Pav.) Rohrb.

Sinónimos: Mollugo radiata Ruiz \& Pav., Mollugo araucana Phil.

Hierba. Anual. Nativa.

Distribución: COQ, VAL, RME, LBO, MAU, NUB, BIO, ARA.

Rango altitudinal: 0-500 m.

Países limítrofes: Argentina, Bolivia y Perú.

Nombre vulgar: Hierba del pollo.

\section{MONIMIACEAE}

\section{Laurelia}

Laurelia sempervirens (Ruiz \& Pav.) Tul.

Sinónimos: Pavonia sempervirens Ruiz \& Pav., Laurelia serrata Bertero, Laurelia aromatica Juss. ex Poir., Atherosperma sempervirens (Ruiz \& Pav.) Baill., Thiga chilensis Molina

Árbol. Endémico.

Distribución: LBO, MAU, NUB, BIO, ARA, LRI, LLA.

Rango altitudinal: 0-1000 m.

Nombre vulgar: Laurel.

\section{Laureliopsis}

Laureliopsis philippiana (Looser) Schodde

Sinónimos: Laurelia philippiana Looser

Árbol. Nativo.

Distribución: MAU, NUB, BIO, ARA, LRI, LLA, AIS.

Rango altitudinal: 0-1000 m.

Países limítrofes: Argentina.

Nombre vulgar: Tepa, huahuán, laurela.

\section{Peumus}

Peumus boldus Molina

Sinónimos: Ruizia fragrans Ruiz \& Pav., Peumus fragrans (Ruiz \& Pav.) Pers., Boldoa fragrans (Ruiz \& Pav.) Gay, Boldea boldus (Molina) Looser, Boldus chilensis Molina, Boldu chilanum Nees

Árbol. Endémico.

Distribución: COQ, VAL, RME, LBO, MAU, NUB, BIO, ARA, LRI, LLA.

Rango altitudinal: 0-1500 m.

Nombre vulgar: Boldo, boldu.

\section{MONTIACEAE}

\section{Calandrinia}

Calandrinia acaulis Kunth

Sinónimos: Calandrinia megarhiza Hemsl.

Hierba. Perenne. Nativa.

Distribución: AYP, TAR, ATA.

Países limítrofes: Argentina, Bolivia y Perú.

Calandrinia affinis Gillies ex Arn.

Hierba. Perenne. Nativa.

Distribución: COQ, VAL, RME, LBO, MAU.

Países limítrofes: Argentina.

Nombre vulgar: Quiaca.

Calandrinia caespitosa Gillies ex Arn.

Sinónimos: Calandrinia diffusa Gillies ex Arn., Calandrinia rupestris Barnéoud, Calandrinia densa Phil., nom. illeg., Calandrinia rupestris Barnéoud var. skottsbergii (Gand.) Skottsb., Calandrinia caespitosa Gillies ex Arn. var. skottsbergii (Gand.) Añon, Calandrinia densa Reiche ex Peralta \& D.I. Ford, nom. illeg., Calandrinia gayana Barnéoud var. glomerata Reiche, Claytonia caespitosa (Gillies ex Arn.) Kuntze, Claytonia diffusa (Gillies \& Hook.) Kuntze, Claytonia rupestris (Barnéoud) Kuntze Hierba. Perenne. Nativa.

Distribución: ATA, COQ, VAL, RME, MAU, ARA, MAG. Países limítrofes: Argentina.

Calandrinia ciliata (Ruiz \& Pav.) DC.

Sinónimos: Talinum ciliatum Ruiz \& Pav., Calandrinia caulescens Kunth, Calandrinia feltonii Skottsb.

Hierba. Anual. Nativa.

Distribución: VAL, RME, LBO, BIO, LLA.

Países limítrofes: Argentina, Bolivia y Perú.

Calandrinia colchaguensis Barnéoud

Hierba. Perenne. Nativa.

Distribución: RME, LBO, MAU, NUB, BIO, ARA, LRI.

Países limítrofes: Argentina y Bolivia.

Calandrinia compacta Barnéoud

Sinónimos: Calandrinia occulta Phil., Calandrinia armeriifolia Phil.

Hierba. Perenne. Nativa.

Distribución: AYP, TAR, ANT, ATA, COQ, RME.

Países limítrofes: Argentina.

Calandrinia compressa Schrad. ex DC.

Sinónimos: Calandrinia gaudichaudii Barnéoud, Calandrinia macilenta Barnéoud, Calandrinia procumbens Moris, Calandrinia virgata Phil., Calandrinia tenella Hook. \& Arn. 
Hierba. Anual. Nativa.

Distribución: AYP, TAR, ANT, COQ, VAL, RME, LBO, MAU, NUB, BIO, ARA, LRI.

Países limítrofes: Bolivia.

Calandrinia fuegiana Gand.

Sinónimos: Calandrinia caespitosa Gillies ex Arn. var. australis Skottsb.

Hierba. Perenne. Nativa.

Distribución: MAG.

Países limítrofes: Argentina.

Calandrinia graminifolia Phil.

Sinónimos: Calandrinia affinis Gillies ex Arn. var. graminifolia (Phil.) Reiche

Hierba. Perenne. Nativa.

Distribución: MAU, NUB, BIO, ARA.

Países limítrofes: Argentina y Bolivia.

Calandrinia monandra (Ruiz \& Pav.) DC.

Sinónimos: Talinum monandrum Ruiz \& Pav., Monocosmia corrigioloides Fenzl, Corrigiola deltoides Hook. \& Arn., Monocosmia monandra (Ruiz \& Pav.) Baill.

Hierba. Anual. Nativa.

Distribución: VAL, RME, LBO, MAU, NUB, BIO, ARA, LLA, AIS, MAG, JFE.

Países limítrofes: Argentina.

Nota: Introducida en el Archipiélago Juan Fernández.

Calandrinia nitida (Ruiz \& Pav.) DC.

Sinónimos: Calandrinia multicaulis Phil., Calandrinia axilliflora Barnéoud, Talinum diffusum Colla, Talinum nitidum Ruiz \& Pav.

Hierba. Anual. Endémica.

Distribución: VAL, RME, LBO, LRI.

Calandrinia ranunculina J.M. Watson, A.R. Flores \& Elvebakk

Hierba. Perenne. Nativa.

Distribución: MAG.

Países limítrofes: Argentina.

Calandrinia skottsbergii Gand.

Hierba. Perenne. Nativa.

Distribución: ARA, AIS.

Países limítrofes: Argentina.

\section{Cistanthe}

Cistanthe amarantoides (Phil.) Carolin ex Hershkovitz Sinónimos: Philippiamra amaranthoides (Phil.) Kuntze, Silvaea amarantoides Phil., Silvaea corrigioloides Phil. Hierba. Perenne. Endémica.

Distribución: AYP, TAR, ANT, ATA, COQ.
Nombre vulgar: Anojarjinchu.

Cistanthe arancioana Peralta

Hierba. Anual. Endémica.

Distribución: ANT.

Cistanthe arenaria (Cham.) Carolin ex Hershkovitz

Sinónimos: Calandrinia arenaria Cham., Calandrinia chamissoi Barnéoud, Calandrinia arenaria Cham. var. chamissoi (Barnéoud) Reiche, Calandrinia arenaria Cham. var. subverticillata (Phil.) Reiche, Calandrinia arenaria Cham. var. vicina (Phil.) Reiche, Calandrinia solisii Phil., Calandrinia nana Phil., Calandrinia subverticillata Phil., Talinum trigonum Colla, Calandrinia venulosa Hook. \& Arn., Claytonia trigona (Colla) Kuntze

Hierba. Anual. Nativa.

Distribución: ATA, COQ, VAL, RME, LBO, MAU, NUB, BIO, ARA.

Países limítrofes: Argentina.

Cistanthe cabrerae (Añon) Peralta

Sinónimos: Calandrinia cabrerae Añon

Hierba. Perenne. Nativa.

Distribución: ANT, ATA.

Países limítrofes: Argentina.

Cistanthe cachinalensis (Phil.) Peralta \& D.I. Ford

Sinónimos: Calandrinia taltalensis I.M. Johnst., Calandrinia cachinalensis Phil.

Hierba suculenta. Perenne. Endémica.

Distribución: ANT, ATA, COQ.

Cistanthe calycina (Phil.) Carolin ex Hershkovitz

Sinónimos: Calandrinia calycina Phil., Calandrinia bochersii Phil., nom. illeg.

Hierba. Anual. Endémica.

Distribución: ANT, ATA, COQ.

Cistanthe celosioides (Phil.) Carolin ex Hershkovitz

Sinónimos: Philippiamra celosioides (Phil.) Kuntze, Philippiamra fastigiata (Phil.) Pax \& K. Hoffm., Philippiamra pachyphylla (Phil.) Kuntze, Silvaea capitata Phil., Silvaea celosioides Phil., Silvaea fastigiata Phil., Silvaea pachyphylla Phil.

Hierba. Anual. Nativa.

Distribución: AYP, TAR, ANT, ATA.

Países limítrofes: Perú.

Nombre vulgar: Básal.

Cistanthe cephalophora (I.M. Johnst.) Carolin ex Hershkovitz

Sinónimos: Calandrinia cephalophora I.M. Johnst.

Hierba. Anual. Endémica.

Distribución: TAR, ANT, ATA. 
Cistanthe chrysantha (I.M. Johnst.) Peralta \& D.I. Ford Sinónimos: Calandrinia chrysantha I.M. Johnst. Hierba. Anual. Endémica.

Distribución: ANT.

Cistanthe coquimbensis (Barnéoud) Carolin ex Hershkovitz Sinónimos: Calandrinia coquimbensis Barnéoud Hierba. Anual. Endémica. Distribución: ATA, COQ.

Cistanthe cymosa (Phil.) Hershkovitz Sinónimos: Calandrinia cymosa Phil. Hierba. Anual. Endémica. Distribución: TAR, ANT, ATA, COQ.

Cistanthe densiflora (Barnéoud) Hershkovitz Sinónimos: Calandrinia densiflora Barnéoud, Calandrinia barneoudii Phil., Calandrinia fasciculata Phil., Calandrinia viridis Phil., Calandrinia spicata Phil.

Hierba. Anual. Nativa.

Distribución: TAR, ANT, ATA, COQ.

Países limítrofes: Argentina.

Nombre vulgar: Pata de guanaco.

Cistanthe fenzlii (Barnéoud) Carolin ex Hershkovitz Sinónimos: Calandrinia fenzlii Barnéoud, Calandrinia lancifolia Phil., Calandrinia sanguinea Phil.

Hierba. Perenne. Endémica.

Distribución: LBO, BIO, ARA.

Cistanthe frigida (Barnéoud) Peralta

Sinónimos: Calandrinia frigida Barnéoud, Cistanthe picta (Gillies ex Arn.) Carolin ex Hershkovitz var. frigida (Barnéoud) Hershkovitz, Calandrinia picta Gillies ex Arn. var. frigida (Barnéoud) Reiche

Hierba. Perenne. Nativa.

Distribución: ATA, COQ, VAL, RME.

Países limítrofes: Argentina.

Cistanthe grandiflora (Lindl.) Schltdl.

Sinónimos: Cistanthe discolor (Schrad.) Spach, Calandrinia grandiflora Lindl., Calandrinia speciosa Lehm., Cistanthe grandiflora (Lindl.) Carolin ex Hershkovitz, comb. illeg., Calandrinia spectabilis Otto \& Dietr., Calandrinia discolor Schrad., Cistanthe speciosa (Lehm.) Lilja, Calandrinia glauca Schrad.

Hierba. Perenne. Endémica.

Distribución: ANT, ATA, COQ, VAL, RME, LBO, MAU, NUB, BIO, ARA.

Nombre vulgar: Doquilla, hierba del corrimiento, mármol, pata de guanaco, renilla.

Cistanthe humilis (Phil.) Peralta

Sinónimos: Calandrinia humilis Phil., Calandrinia oblongifolia Barnéoud var. humilis (Phil.) Reiche

Hierba. Perenne. Nativa.

Distribución: ATA, COQ.

Países limítrofes: Argentina.

Cistanthe lamprosperma (I.M. Johnst.) Peralta \& D.I. Ford Sinónimos: Calandrinia lamprosperma I.M. Johnst.

Hierba. Perenne. Endémica.

Distribución: ANT.

Cistanthe laxiflora (Phil.) Peralta \& D.I. Ford

Sinónimos: Calandrinia aegilitis F. Phil., Calandrinia laxiflora Phil.

Hierba suculenta. Perenne. Endémica.

Distribución: COQ, VAL.

Cistanthe longiscapa (Barnéoud) Carolin ex Hershkovitz

Sinónimos: Calandrinia litoralis Phil., Calandrinia

longiscapa Barnéoud

Hierba. Anual. Endémica.

Distribución: ANT, ATA, COQ.

Cistanthe minuscula (Añon) Peralta

Sinónimos: Calandrinia minuscula Añon

Hierba. Anual. Nativa.

Distribución: TAR, ANT, ATA.

Países limítrofes: Argentina.

Cistanthe picta (Gillies ex Arn.) Carolin ex Hershkovitz Sinónimos: Calandrinia picta Gillies ex Arn., Calandrinia picta Gillies ex Arn. var. portulacifolia (Phil.) Hicken, Calandrinia portulacifolia Phil., Calandrinia villanuevae Phil.

Hierba. Perenne. Nativa.

Distribución: ANT, ATA, COQ, VAL, RME, LBO.

Países limítrofes: Argentina.

Cistanthe salsoloides (Barnéoud) Carolin ex Hershkovitz Sinónimos: Calandrinia salsoloides Barnéoud, Calandrinia calocephala Phil., Calandrinia spicigera Phil., Calandrinia acuminata Phil.

Hierba. Anual. Nativa.

Distribución: AYP, TAR, ANT, ATA, COQ.

Países limítrofes: Argentina.

Nombre vulgar: Congonilla, kámin.

Cistanthe stricta (Phil.) Peralta

Sinónimos: Calandrinia stricta Phil.

Hierba. Anual. Nativa.

Distribución: ATA.

Países limítrofes: Argentina. 
Cistanthe thyrsoidea (Reiche) Peralta \& D.I. Ford

Sinónimos: Calandrinia thyrsoidea Reiche

Hierba. Anual. Endémica.

Distribución: AYP, TAR, ATA, COQ.

\section{Lenzia}

Lenzia chamaepitys Phil.

Hierba. Perenne. Nativa.

Distribución: ANT, ATA, COQ.

Países limítrofes: Argentina.

\section{Montia}

\section{Montia fontana L.}

Sinónimos: Montia linearifolia d'Urv., Calandrinia pusilla Barnéoud, Monocosmia verrucosa Phil.

Hierba. Anual. Nativa.

Distribución: COQ, VAL, RME, LBO, MAU, NUB, BIO, ARA, LRI, LLA, MAG.

Países limítrofes: Argentina, Bolivia y Perú.

\section{Montiopsis}

Montiopsis andicola (Gillies) D.I. Ford

Sinónimos: Calandrinia andicola Gillies, Calandrinia denticulata Gillies, Calandrinia denticulata Gillies var. andicola (Gillies) Reiche, Calandrinia denticulata Gillies var. echinata Barnéoud, Calandrinia oligantha Phil., Calandrinia saxifraga Barnéoud, Calandrinia saxifraga Barnéoud var. oligantha (Phil.) Reiche, Calandrinia tricolor Phil.

Hierba. Perenne. Nativa.

Distribución: COQ, VAL, RME, LBO, MAU, NUB.

Países limítrofes: Argentina.

Montiopsis berteroana (Phil.) D.I. Ford

Sinónimos: Calandrinia berteroana Phil., Calandrinia floribunda Phil., Calandrinia rosea Phil.

Hierba. Anual. Nativa.

Distribución: COQ, VAL, RME, LBO, MAU, NUB, BIO, ARA.

Países limítrofes: Argentina.

Montiopsis capitata (Hook. \& Arn.) D.I. Ford

Sinónimos: Calandrinia capitata Hook. \& Arn., Calandrinia capituligera Phil., Calandrinia erithrichioides Phil., Calandrinia erythrocoma Phil., Calandrinia petiolata Phil., Calandrinia prostrata Phil.

Hierba. Anual. Nativa.

Distribución: AYP, ATA, COQ, VAL, RME, LBO, MAU, AIS.

Países limítrofes: Argentina.
Montiopsis cistiflora (Gillies ex Arn.) D.I. Ford

Sinónimos: Calandrinia dianthoides Phil., Calandrinia splendens Barnéoud, Calandrinia splendens Barnéoud var. dianthoides (Phil.) Reiche, Calandrinia cistiflora Gillies ex Arn.

Hierba. Perenne. Nativa.

Distribución: VAL, RME, LBO, MAU, NUB, BIO, ARA.

Países limítrofes: Argentina.

Montiopsis copiapina (Phil.) D.I. Ford

Sinónimos: Calandrinia copiapina Phil., Calandrinia polia

Phil.

Hierba. Perenne. Nativa.

Distribución: ANT, ATA, COQ.

Países limítrofes: Argentina.

Montiopsis cumingii (Hook. \& Arn.) D.I. Ford Sinónimos: Calandrinia cumingii Hook. \& Arn.

Hierba. Anual. Nativa.

Distribución: AYP, TAR, ANT, COQ, VAL, RME, MAU.

Países limítrofes: Argentina, Bolivia y Perú.

Montiopsis demissa (Phil.) D.I. Ford

Sinónimos: Calandrinia demissa Phil., Calandrinia depressa Phil.

Hierba. Anual. Endémica.

Distribución: TAR, ATA, COQ, VAL, RME.

Montiopsis gayana (Barnéoud) D.I. Ford

Sinónimos: Calandrinia gayana Barnéoud, Calandrinia tenuifolia Phil., Calandrinia rahmeri Phil., Calandrinia vidali Phil., Calandrinia glandulifera Phil., Calandrinia conferta Gillies ex Arn., Calandrinia hirtella Phil., Calandrinia calycotricha Phil., Calandrinia gayana Barnéoud var. hirtella (Phil.) Reiche

Hierba. Perenne. Nativa.

Distribución: COQ, RME, LBO, MAU, NUB, BIO, ARA, LRI.

Países limítrofes: Argentina.

Montiopsis gilliesii (Hook. \& Arn.) D.I. Ford

Sinónimos: Calandrinia gilliesii Hook. \& Arn., Calandrinia canescens Phil., Calandrinia sessiliflora Phil., Calandrinia sericea Hook. \& Arn. var. sessiliflora (Phil.) Hauman, Calandrinia setosa Phil. var. longifolia Phil., Calandrinia leucotricha Phil.

Hierba. Perenne. Nativa.

Distribución: COQ, VAL, RME, LBO, MAU.

Países limítrofes: Argentina.

Montiopsis glomerata (Phil.) D.I. Ford

Sinónimos: Calandrinia glomerata Phil., Calandrinia callithrix Phil., Calandrinia leucocephala Phil.

Hierba. Anual. Nativa. 
Distribución: ATA, COQ.

Países limítrofes: Argentina.

Montiopsis modesta (Phil.) D.I. Ford

Sinónimos: Calandrinia modesta Phil.

Hierba. Anual. Nativa.

Distribución: ANT, ATA, COQ.

Países limítrofes: Argentina.

Montiopsis parviflora (Phil.) D.I. Ford

Sinónimos: Calandrinia bandurriae Phil., Calandrinia parviflora Phil.

Hierba. Anual. Endémica.

Distribución: AYP, ATA, COQ.

Montiopsis polycarpoides (Phil.) Peralta

Sinónimos: Calandrinia polycarpoides Phil.,

Calandriniopsis polycarpoides (Phil.) R. Franz

Hierba. Anual. Nativa.

Distribución: ANT, VAL.

Países limítrofes: Argentina y Bolivia.

Montiopsis potentilloides (Barnéoud) D.I. Ford

Sinónimos: Calandrinia potentilloides Barnéoud, Calandrinia uspallatensis Phil., Montiopsis uspallatensis (Phil.) D.I. Ford, Calandrinia nivalis Phil., Calandrinia sericea Hook. \& Arn. var. uspallatensis (Phil.) Reiche, Calandrinia setosa Phil.

Hierba. Perenne. Nativa.

Distribución: COQ, VAL, RME.

Países limítrofes: Argentina.

Montiopsis ramosissima (Hook. \& Arn.) D.I. Ford

Sinónimos: Calandrinia landbeckii Phil., Calandrinia poeppigiana Walp., Calandrinia ramosissima Hook. \& Arn. Hierba. Anual. Endémica.

Distribución: COQ, VAL, RME, LBO, MAU.

Montiopsis sericea (Hook. \& Arn.) D.I. Ford

Sinónimos: Calandrinia argentea Phil., Calandrinia ferruginea Barnéoud, Calandrinia potentilloides Barnéoud var. minor Barnéoud, Calandrinia sericea Hook. \& Arn., Calandriniopsis sericea (Hook. \& Arn.) R. Franz, Calandrinia sericea Hook. \& Arn. var. longipes Hook. \& Arn.

Hierba. Perenne. Endémica.

Distribución: COQ, VAL, RME, MAU, NUB.

Nombre vulgar: Hierba del chancho.

Montiopsis trifida (Hook. \& Arn.) D.I. Ford

Sinónimos: Calandrinia aurea Barnéoud, Calandrinia capitata Hook. \& Arn. var. prolifera (Phil.) Reiche, Calandrinia involucrata Phil., Calandrinia leucopogon Phil., Calandrinia montana Phil., Calandrinia prolifera
Phil., Calandrinia trifida Hook. \& Arn., Calandriniopsis montana (Phil.) R. Franz

Hierba. Anual. Endémica.

Distribución: AYP, TAR, ANT, ATA, COQ, VAL, RME, LBO.

Montiopsis umbellata (Ruiz \& Pav.) D.I. Ford

Sinónimos: Talinum umbellatum Ruiz \& Pav., Calandrinia umbellata (Ruiz \& Pav.) DC., Calandrinia hispida Phil., Calandrinia phalacra Phil., Calandrinia sanfurgi Phil., Calandrinia sericea Hook. \& Arn. var. phalacra (Phil.) Reiche, Calandriniopsis umbellata (Ruiz \& Pav.) R. Franz, Calandrinia sericea Hook. \& Arn. var. aequipes Hook. \& Arn.

Hierba. Perenne. Nativa.

Distribución: COQ, VAL, RME, LBO, MAU, NUB, BIO, ARA, LLA.

Países limítrofes: Argentina.

Nombre vulgar: Flor de la mistela.

\section{MORACEAE}

\section{Broussonetia}

Broussonetia papyrifera (L.) L'Hér. ex Vent.

Arbusto o árbol pequeño. Introducido.

Distribución: IPA.

Nombre vulgar: Mahute (Rapa Nui) (Rapa Nui).

\section{MYRICACEAE}

\section{Morella}

Morella pavonis (C. DC.) Parra-O

Sinónimos: Myrica pavonis C. DC.

Arbusto o árbol pequeño. Nativo.

Distribución: AYP, TAR.

Países limítrofes: Perú.

\section{MYRTACEAE}

\section{Amomyrtus}

Amomyrtus luma (Molina) D. Legrand \& Kausel

Sinónimos: Eugenia darwinii Hook.f., Myrtus luma Molina, Myrtus multiflora Juss. ex J. St.-Hil., Myrtus darwinii (Hook.f.) Barnéoud, Myrcia lechleriana Miq., Myrtus valdiviana Phil., Pseudocaryophyllus darwinii (Hook.f.) Burret

Árbol. Nativo.

Distribución: MAU, NUB, BIO, ARA, LRI, LLA, AIS. 
Rango altitudinal: 0-800 m.

Países limítrofes: Argentina.

Nombre vulgar: Luma.

Amomyrtus meli (Phil.) D. Legrand \& Kausel

Sinónimos: Myrtus meli Phil., Pseudocaryophyllus meli (Phil.) Burret

Árbol. Endémico.

Distribución: BIO, ARA, LRI, LLA.

Rango altitudinal: 0-600 m.

Nombre vulgar: Meli.

\section{Blepharocalyx}

Blepharocalyx cruckshanksii (Hook. \& Arn.) Nied. Sinónimos: Eugenia cruckshanksii Hook. \& Arn., Eugenia divaricatum O. Berg, Luma cruckshanksii (Hook. \& Arn.) A. Gray, Eugenia divaricatum O. Berg var. obovata O. Berg, Eugenia divaricatum O. Berg var. ovalis O. Berg, Eugenia divaricatum $\mathrm{O}$. Berg var. pauciflora $\mathrm{O}$. Berg, Blepharocalyx divaricatus (O. Berg) Nied., Blepharocalyx divaricatus (O. Berg) Nied. var. obovatus (O. Berg) Reiche, Blepharocalyx divaricatus (O. Berg) Nied. var. ovalis (O. Berg) Reiche, Blepharocalyx divaricatus (O. Berg) Nied. var. pauciflorus (O. Berg) Reiche, Temu divaricatum (O. Berg) O. Berg Árbol. Endémico.

Distribución: VAL, RME, LBO, MAU, NUB, BIO, ARA, LRI, LLA.

Rango altitudinal: 0-200 m.

Nombre vulgar: Temu, palo colorado.

\section{Eucalyptus}

\section{Eucalyptus camaldulensis Dehnh.}

Árbol. Introducido.

Distribución: COQ, VAL, RME, LBO, MAU.

Eucalyptus globulus Labill.

Árbol. Introducido.

Distribución: VAL, LBO, MAU, NUB, BIO, ARA, LRI, JFE, IPA.

\section{Legrandia}

Legrandia concinna (Phil.) Kausel Sinónimos: Eugenia concinna Phil. Arbusto o árbol pequeño. Endémico.

Distribución: MAU, NUB.

Rango altitudinal: 500-1000 m.

Nombre vulgar: Luma.
Luma

Luma apiculata (DC.) Burret

Sinónimos: Eugenia apiculata DC., Eugenia proba O. Berg, Myrceugenella apiculata (DC.) Kausel, Myrceugenia apiculata (DC.) Nied., Eugenia gilliesi Hook. \& Arn., Eugenia affinis Gillies ex Hook. \& Arn., Eugenia hookeri Steud., Eugenia apiculata DC. var. arnyan Hook.f., Eugenia barneoudii O. Berg, Eugenia spectabilis Phil., Eugenia modesta Phil., Eugenia mucronata Phil., Eugenia palenae Phil., Eugenia cuspidata Phil., Eugenia ebracteata F. Phil., Myrtus chequenilla Kuntze, Luma gilliesi (Hook. \& Arn.) Burret, Luma spectabilis (Phil.) Burret, Luma hookeri (Steud.) Burret, Myrceugenella apiculata (DC.) Kausel var. australis Kausel, Myrceugenella grandjotii Kausel, Myrceugenella apiculata (DC.) Kausel var. spectabilis (Phil.) Kausel

Árbol. Nativo.

Distribución: COQ, VAL, RME, LBO, MAU, NUB, BIO, ARA, LRI, LLA, AIS.

Rango altitudinal: 500-1000 m.

Países limítrofes: Argentina.

Nombre vulgar: Arrayán, palo colorado.

Luma chequen (Molina) A. Gray

Sinónimos: Eugenia chequen Molina, Myrtus chequen (Molina) Spreng., Eugenia gayana Barnéoud, Myrtus uliginosa Miq., Myrtus uliginosa Miq. fma. major Miq., Myrtus gayana (Barnéoud) O. Berg, Eugenia bella Phil., Eugenia pulchra O. Berg, Eugenia myrtomimeta Diels, Luma gayana (Barnéoud) Burret, Myrceugenella chequen (Molina) Kausel, Myrceugenella gayana (Barnéoud) Kausel, Myrceugenella langerfeldtii Kausel, Myrceugenella chequen (Molina) Kausel var. myrtomimeta (Diels) Kausel Arbusto o árbol pequeño. Endémico.

Distribución: COQ, VAL, RME, LBO, MAU, NUB, BIO, ARA, LRI, LLA.

Rango altitudinal: 0-1100 m.

Nombre vulgar: Chequén, arrayán blanco.

\section{Myrceugenia}

Myrceugenia chrysocarpa (O. Berg) Kausel

Sinónimos: Luma chrysocarpa (O. Berg) Burret, Eugenia chrysocarpa O. Berg, Eugenia philippii O. Berg, Eugenia buxifolia Phil., Eugenia patagonica Phil., Eugenia petiolata Phil., Myrceugenia buxifolia (Phil.) Reiche, Luma philippii (O. Berg) Burret

Arbusto o árbol pequeño. Nativo.

Distribución: LBO, MAU, NUB, BIO, ARA, LRI, LLA, AIS.

Rango altitudinal: 500-1200 m.

Países limítrofes: Argentina.

Nombre vulgar: Luma blanca, pitrilla. 
Myrceugenia colchaguensis (Phil.) L.E. Navas

Sinónimos: Eugenia colchaguensis Phil., Myrceugenia malvillana Kausel

Arbusto. Endémico.

Distribución: VAL, RME, LBO, MAU, NUB, BIO, ARA.

Rango altitudinal: 0-400 $\mathrm{m}$.

Myrceugenia correifolia (Hook. \& Arn.) O. Berg

Sinónimos: Eugenia correifolia Hook. \& Arn., Eugenia maritima Barnéoud, Luma correifolia (Hook. \& Arn.) A. Gray, Eugenia thalassaia O. Berg, Myrceugenia johowi Gusinde, Myrceugenia thalassaia (O. Berg) Gusinde ex Fuentes, Myrceugenia maritima (Barnéoud) Kausel

Arbusto o árbol pequeño. Endémico.

Distribución: COQ, VAL, LBO, MAU.

Rango altitudinal: 0-700 m.

Nombre vulgar: Petrillo, petrilla.

Myrceugenia exsucca (DC.) O. Berg

Sinónimos: Luma exsucca (DC.) Burret, Eugenia exsucca DC., Myrcengenia multiflora (Hook. \& Arn.) Kausel, Eugenia temu Hook. \& Arn., Luma temu (Hook. \& Arn.) Gray, Myrceugenia lechleriana O. Berg, Myrcengenia camphorata O. Berg, Eugenia exsucca DC. var. patagua O. Berg, Eugenia pitra O. Berg, Eugenia exsucca DC. var. temu (Hook. \& Arn.) O. Berg, Eugenia exsucca DC. var. apiculata O. Berg, Eugenia corralensis Phil., Luma pitra (O. Berg) Burret, Luma corralensis (Phil.) Burret

Árbol. Nativo.

Distribución: COQ, VAL, RME, LBO, MAU, NUB, BIO, ARA, LRI, LLA, AIS.

Rango altitudinal: 0-1000 m.

Países limítrofes: Argentina.

Nombre vulgar: Pitra, petra, patagua.

Myrceugenia lanceolata (Juss. ex J. St.-Hil.) Kausel Sinónimos: Myrtus lanceolata Juss. ex J. St.-Hil., Eugenia dombeyana DC., Myrtus gudilla Colla, Eugenia stenophylla Hook. \& Arn., Eugenia gudilla (Colla) Barnéoud, Luma stenophylla (Hook. \& Arn.) Gray, Eugenia stenophylla Hook. \& Arn. var. latifolia Hook. ex O. Berg, Myrceugenia stenophylla (Hook. \& Arn.) O. Berg, Luma dombeyana (DC.) Burret

Arbusto. Endémico.

Distribución: VAL, RME, LBO, MAU, NUB, BIO, ARA.

Rango altitudinal: 200-800 m.

Nombre vulgar: Arrayancillo, ñipa.

Myrceugenia leptospermoides (DC.) Kausel

Sinónimos: Eugenia leptospermoides DC., Eugenia leptospermoides DC. var. microphylla O. Berg, Eugenia leptospermoides DC. var. latifolia O. Berg, Eugenia leptospermoides DC. var. longifolia O. Berg, Eugenia thymifolia Phil. ex Reiche
Arbusto. Endémico.

Distribución: MAU, NUB, BIO, ARA.

Rango altitudinal: $0-400 \mathrm{~m}$.

Nombre vulgar: Macella, petrillo.

Myrceugenia obtusa (DC.) O. Berg

Sinónimos: Eugenia obtusa DC., Myrtus raran Colla, Eugenia raran (Colla) Barnéoud, Luma obtusa (DC.) A. Gray, Myrceugenia chilensis O. Berg, Eugenia polyantha Phil., Myrceugenia obtusa (DC.) O. Berg var. raran (Colla) O. Berg, Myrcengenia obtusa (DC.) O. Berg var. berteroana O. Berg, Myrcengenia obtusa (DC.) O. Berg var. polyantha (Phil.) O. Berg

Arbusto o árbol pequeño. Endémico.

Distribución: COQ, VAL, RME, LBO, MAU, NUB, BIO, ARA.

Rango altitudinal: 0-1400 m.

Nombre vulgar: Rarán.

Myrceugenia ovata (Hook. \& Arn.) O. Berg var. nannophylla (Burret) Landrum

Sinónimos: Myrceugenia montana Kausel, Myrceugenia nannophylla (Burret) Kausel, Luma nannophylla Burret, Myrceugenia valientei Kausel

Arbusto. Nativo.

Distribución: MAU, NUB, BIO, ARA, LRI, LLA.

Rango altitudinal: 500-1000 m.

Países limítrofes: Argentina.

Myrceugenia ovata (Hook. \& Arn.) O. Berg var. ovata Sinónimos: Eugenia ovata Hook. \& Arn., Eugenia cumingii Hook. \& Arn., Eugenia trichocarpa Phil., Luma ovata (Hook. \& Arn.) Burret, Luma cumingii (Hook. \& Arn.) Burret

Arbusto o árbol pequeño. Endémico.

Distribución: BIO, ARA, LRI, LLA.

Rango altitudinal: 0-100 m.

Nombre vulgar: Huillipeta.

Myrceugenia parvifolia (DC.) Kausel

Sinónimos: Eugenia parvifolia DC., Luma baeckeoides Griseb.

Arbusto o árbol pequeño. Endémico.

Distribución: MAU, NUB, BIO, ARA, LRI, LLA.

Rango altitudinal: 0-200 m.

Nombre vulgar: Chequén, chilquilco.

Myrceugenia pinifolia (F. Phil.) Kausel

Sinónimos: Eugenia pinifolia F. Phil., Myrcengenia stenophylla (Hook. \& Arn.) O. Berg var. pinifolia (F. Phil.) Reiche

Arbusto. Endémico.

Distribución: MAU, NUB, BIO.

Rango altitudinal: 0-100 m. 
Myrceugenia planipes (Hook. \& Arn.) O. Berg

Sinónimos: Myrceugenia distoma (O. Berg) Kausel, Eugenia planipes Hook. \& Arn., Myrcia planipes (Hook. \& Arn.) Kiaersk., Eugenia planipes Hook. \& Arn. var. genuina O. Berg, nom. illeg., Eugenia planipes Hook. \& Arn. var. grandifolia O. Berg, Eugenia distoma O. Berg Árbol. Nativo.

Distribución: NUB, BIO, ARA, LRI, LLA, AIS.

Rango altitudinal: 500-1000 m.

Países limítrofes: Argentina.

Nombre vulgar: Pitra.

Myrceugenia rufa (Colla) Skottsb. ex Kausel

Sinónimos: Myrtus rufa Colla, Eugenia ferruginea Hook. \& Arn., Eugenia rufa (Colla) Barnéoud, Luma ferruginea (Hook. \& Arn.) A. Gray, Myrcengenia ferruginea (Hook. \& Arn.) Reiche, Luma rufa (Colla) Burret

Arbusto. Endémico.

Distribución: COQ, VAL.

Rango altitudinal: 0-200 m.

Myrceugenia schulzei Johow

Sinónimos: Luma schulzei (Johow) Burret

Árbol. Endémico.

Distribución: JFE.

Rango altitudinal: $400 \mathrm{~m}$.

Nombre vulgar: Luma de Más Afuera.

\section{Myrcianthes}

Myrcianthes coquimbensis (Barnéoud) Landrum \& Grifo Sinónimos: Reichea coquimbensis (Barnéoud) Kausel, Myrtus coquimbensis Barnéoud, Aspidogenia coquimbensis (Barnéoud) Burret

Arbusto. Endémico.

Distribución: COQ.

Rango altitudinal: 0-200 m.

Nombre vulgar: Lucumillo, lucumilla.

\section{Myrteola}

Myrteola nummularia (Poir.) O. Berg

Sinónimos: Eugenia humifusa Phil., Myrteola barneoudii (O. Berg) O. Berg var. humifusa (Phil.) Reiche, Myrteola bullata O. Berg, Myrteola humifusa (Phil.) O. Berg, Myrteola leucomyrtillus (Griseb.) Reiche, Myrteola nummularia (Poir.) O. Berg var. barneoudii (O. Berg) Kausel, Myrteola nummularia (Poir.) O. Berg var. repens (Phil.) Reiche, Myrteola repens (Phil.) O. Berg, Myrtus barneoudii O. Berg, Myrtus leucomyrtillus Griseb., Myrtus nummularia Poir., Myrtus nummularia Poir. var. major Hook.f., Myrtus repens Phil., Myrteola barneoudii (O. Berg) O. Berg, Myrteola bullata O. Berg var. pentamera O. Berg, Myrteola bullata O. Berg var. tetramera O. Berg, Eugenia humilis Phil.
Arbusto o subarbusto. Nativo.

Distribución: NUB, BIO, ARA, LRI, LLA, AIS, MAG, JFE.

Rango altitudinal: 100-1500 m.

Países limítrofes: Argentina, Bolivia y Perú.

Nombre vulgar: Daudapo, huarapo, naurapo.

\section{Nothomyrcia}

Nothomyrcia fernandeziana (Hook. \& Arn.) Kausel

Sinónimos: Myrceugenia fernandeziana (Hook. \& Arn.) Johow, Myrtus fernandeziana Hook. \& Arn., Eugenia lumilla Phil., Eugenia fernandeziana (Hook. \& Arn.) Barnéoud, Myrcengenia luma O. Berg, Luma fernandeziana (Hook. \& Arn.) Burret

Árbol. Endémico.

Distribución: JFE.

Rango altitudinal: 0-300 m.

Nombre vulgar: Luma de Juan Fernández, lumilla.

\section{Psidium}

Psidium guajava $\mathrm{L}$.

Arbusto. Introducido.

Distribución: IPA.

Nombre vulgar: Guayaba, tuaba (Rapa Nui).

\section{Syzygium}

Syzygium jambos (L.) Alston

Árbol. Introducido.

Distribución: IPA.

\section{Tepualia}

Tepualia stipularis (Hook. \& Arn.) Griseb.

Sinónimos: Metrosideros stipularis (Hook. \& Arn.) Hook.f., Myrtus stipularis Hook. \& Arn., Tepualia patagonica Phil., Tepualia philippiana Griseb., Tepualia stipularis (Hook. \& Arn.) Griseb. var. patagonica (Phil.) Reiche, Tepualia stipularis (Hook. \& Arn.) Griseb. var. philippiana (Griseb.) Speg.

Arbusto o árbol pequeño. Nativo.

Distribución: MAU, NUB, BIO, ARA, LRI, LLA, AIS, MAG.

Rango altitudinal: 0-1000 m.

Países limítrofes: Argentina.

Nombre vulgar: Tepu, tepú.

\section{Ugni}

Ugni candollei (Barnéoud) O. Berg

Sinónimos: Myrtus candollei Barnéoud, Myrtus krausei Phil., Ugni krausei (Phil.) O. Berg, Ugni candollei (Barnéoud) O. Berg fma. litoralis Kausel, Ugni candollei (Barnéoud) O. Berg fma. monticola Kausel 
Arbusto. Endémico.

Distribución: MAU, NUB, BIO, ARA, LRI, LLA.

Rango altitudinal: 100-800 m.

Nombre vulgar: Murta, murta blanca, tautau, chauchau, trautrau.

\section{Ugni molinae Turcz.}

Sinónimos: Eugenia ugni (Molina) Hook. \& Arn., Myrtus ugni Molina, Ugni myrtus Macloskie, Ugni ugni (Molina) Macloskie, nom. illeg., Ugni poeppigii O. Berg, Myrtus molinae Barnéoud, Ugni philippii O. Berg

Arbusto. Nativo.

Distribución: LBO, MAU, NUB, BIO, ARA, LRI, LLA, AIS, JFE.

Rango altitudinal: 700-1500 m.

Países limítrofes: Argentina.

Nombre vulgar: Murtilla, murta, murtillo, uñi.

Nota: Introducida en el Archipiélago Juan Fernández.

Ugni selkirkii (Hook. \& Arn.) O. Berg

Sinónimos: Eugenia selkirkii Hook. \& Arn., Myrtus berteroi Phil., Ugni berteroi (Phil.) F. Phil.

Arbusto. Endémico.

Distribución: JFE.

Rango altitudinal: 400-800 m.

Nombre vulgar: Murtillo.

\section{NOTHOFAGACEAE}

\section{Nothofagus}

Nothofagus alessandrii Espinosa

Sinónimos: Fuscospora alessandri (Espinosa) Heenan \& Smissen

Árbol. Endémico.

Distribución: MAU.

Rango altitudinal: 100-500 m.

Nombre vulgar: Ruil.

Nothofagus alpina (Poepp. \& Endl.) Oerst.

Sinónimos: Nothofagus nervosa (Phil.) Dimitri \& Milano, comb. illeg., Fagus alpina Poepp. \& Endl., Fagus nervosa Phil., Nothofagus procera (Poepp. \& Endl.) Oerst., comb. illeg., Nothofagus nervosa (Phil.) Krasser, Lophozonia alpina (Poepp. \& Endl.) Heenan \& Smissen

Árbol. Nativo.

Distribución: MAU, NUB, BIO, ARA, LRI, LLA.

Rango altitudinal: 200-1200 m.

Países limítrofes: Argentina.

Nombre vulgar: Raulí.

Nothofagus antarctica (G. Forst.) Oerst.

Sinónimos: Fagus antarctica G. Forst., Fagus antarctica G.
Forst. var. sublobata A. DC., Fagus antarctica G. Forst. var. uliginosa A. DC., Calucechinus antactica Hombr. \& Jacq., Calucechinus montagni Hombr. \& Jacq., Fagus antarctica G. Forst. var. microphylla Phil., Nothofagus montagnei (Hombr. \& Jacq.) Krasser

Árbol. Nativo.

Distribución: MAU, NUB, BIO, ARA, LRI, LLA, AIS, MAG.

Rango altitudinal: 0-1500 m.

Países limítrofes: Argentina.

Nombre vulgar: Ñirre, ñire.

Nothofagus betuloides (Mirb.) Oerst.

Sinónimos: Fagus betuloides Mirb., Nothofagus patagonica Gand., Betula antarctica G. Forst., nom. nud., Betula antarctica G. Forst. ex Willd., Fagus dubia Mirb., Fagus forsteri Hook., Calusparassus forsteri Hombr. \& Jacq., Calusparassus betuloides Hombr. \& Jacq.

Árbol. Nativo.

Distribución: LRI, LLA, AIS, MAG.

Rango altitudinal: 0-1500 m.

Países limítrofes: Argentina.

Nombre vulgar: Coigüe de Magallanes, guindo.

Nothofagus dombeyi (Mirb.) Oerst.

Sinónimos: Fagus dombeyi Mirb., Fagus dombeyi Mirb. var. microphylla Phil.

Árbol. Nativo.

Distribución: LBO, MAU, NUB, BIO, ARA, LRI, LLA, AIS.

Rango altitudinal: 0-1000 m.

Países limítrofes: Argentina.

Nombre vulgar: Coigüe, coihue.

Nothofagus glauca (Phil.) Krasser

Sinónimos: Fagus glauca Phil., Nothofagus obliqua (Mirb.)

Oerst. var. glauca (Phil.) Reiche, Nothofagus megalocarpa

Reiche, Lophozonia glauca (Phil.) Heenan \& Smissen

Árbol. Endémico.

Distribución: RME, LBO, MAU, NUB, BIO.

Rango altitudinal: 100-1500 m.

Nombre vulgar: Roble maulino, hualo, roble colorado.

Nothofagus macrocarpa (A. DC.) F.M. Vázquez \& R.A. Rodr.

Sinónimos: Nothofagus obliqua (Mirb.) Oerst. var. macrocarpa (A. DC.) Reiche, Fagus obliqua Mirb. var. macrocarpa A.DC., Lophozonia macrocarpa (A. DC.) Heenan \& Smissen

Árbol. Endémico.

Distribución: VAL, RME, LBO.

Rango altitudinal: $800-2200 \mathrm{~m}$.

Nombre vulgar: Roble, roble blanco, roble de Santiago. 
Nothofagus nitida (Phil.) Krasser

Sinónimos: Fagus nitida Phil.

Árbol. Nativo.

Distribución: LRI, LLA, AIS, MAG.

Rango altitudinal: 0-900 m.

Países limítrofes: Argentina.

Nombre vulgar: Coigüe de Chiloé, roble de Chiloé.

\section{Nothofagus obliqua (Mirb.) Oerst.}

Sinónimos: Fagus obliqua Mirb., Lophozonia heterocarpa Turcz., Fagus obliqua Mirb. var. macranthera A. DC., Fagus obliqua Mirb. var. dentatosquamata Kuntze, Nothofagus leoni Espinosa, Fagus obliqua (Mirb.) Oerst. var. valdiviana (Phil.) A. DC., Fagus valdiviana Phil., Fagus obliqua Mirb. var. integrisquamata Kuntze, Nothofagus obliqua (Mirb.) Oerst. subsp. valdiviana (Phil.) F.M. Vázquez \& R.A. Rodr., Nothofagus obliqua (Mirb.) Oerst. subsp. andina F.M. Vázquez \& R.A. Rodr., Lophozonia obliqua (Mirb.) Heenan \& Smissen, Lophozonia obliqua (Mirb.) Heenan \& Smissen subsp. andina (F.M. Vázquez \& R. Rodr.) Heenan \& Smissen, Lophozonia obliqua (Mirb.) Heenan \& Smissen subsp. valdiviana (Phil.) Heenan \& Smissen

Árbol. Nativo.

Distribución: VAL, RME, LBO, MAU, NUB, BIO, ARA, LRI, LLA.

Rango altitudinal: 0-2500 m.

Países limítrofes: Argentina.

Nombre vulgar: Hualle, roble, coyán, roble-pellín.

Nothofagus pumilio (Poepp. \& Endl.) Krasser

Sinónimos: Fagus antarctica G. Forst. var. bicrenata A. DC., Fagus pumilio Poepp. \& Endl., Calusparassus pumilio Hombr. \& Jacq., Fagus antarctica G. Forst. var. pumilio (Poepp. \& Endl.) Kuntze

Árbol. Nativo.

Distribución: MAU, NUB, BIO, ARA, LRI, LLA, AIS, MAG.

Rango altitudinal: 0-2000 m.

Países limítrofes: Argentina.

Nombre vulgar: Lenga.

\section{NYCTAGINACEAE}

\section{Allionia}

\section{Allionia incarnata L.}

Sinónimos: Allionia puberula Phil., Wedeliela incarnata (L.) Cockerell, Wedelia incarnata (L.) Kuntze, Allionia bandurriae Phil., Allionia jarae Phil.

Hierba. Perenne. Nativa.

Distribución: AYP, TAR, ANT, ATA.

Rango altitudinal: 0-3000 m.

Países limítrofes: Argentina, Bolivia y Perú.

\section{Boerhavia}

Boerhavia diffusa $\mathrm{L}$.

Hierba. Perenne. Introducida.

Distribución: AYP, TAR, ATA, COQ, VAL, RME, LBO, MAU, BIO, IPA.

\section{Mirabilis}

Mirabilis acuta (Reiche) Heimerl

Sinónimos: Oxybaphus ovatus (Ruiz \& Pav.) Vahl var. acutus Reiche

Hierba. Perenne. Endémica.

Distribución: AYP, TAR, ANT, ATA, COQ.

Rango altitudinal: 500-2900 m.

Nombre vulgar: Tapahua.

Mirabilis cordifolia (Kunze ex Choisy) Heimerl

Sinónimos: Oxybaphus cordifolius Kunze ex Choisy, Allione cordifolia (Kunze ex Choisy) Kuntze

Hierba. Perenne. Nativa.

Distribución: COQ, VAL, RME, LBO, MAU.

Rango altitudinal: 0-900 $\mathrm{m}$.

Países limítrofes: Perú.

Mirabilis elegans (Choisy) Heimerl

Sinónimos: Oxybaphus elegans Choisy, Allionia elegans (Choisy) Kuntze, Oxybaphus dichotumus Phil., Oxybaphus san-romani Phil., Mirabilis elegans (Choisy) Heimerl var. dichotoma (Phil.) Heimerl

Hierba. Perenne. Nativa.

Distribución: AYP, TAR, ANT, ATA, COQ, VAL, RME.

Rango altitudinal: 0-3000 m.

Países limítrofes: Perú.

Mirabilis expansa (Ruiz \& Pav.) Standl.

Sinónimos: Calyxhymenia expansa Ruiz \& Pav., Allionia expansa (Ruiz \& Pav.) Kuntze, Oxybaphus expansa (Ruiz \& Pav.) Vahl

Hierba. Perenne. Nativa.

Distribución: AYP, TAR, VAL.

Rango altitudinal: 100-3600 m.

Países limítrofes: Bolivia y Perú.

\section{Mirabilis jalapa L.}

Hierba. Perenne. Introducida.

Distribución: ANT, BIO, JFE, IPA.

Mirabilis ovata (Ruiz \& Pav.) F. Meigen

Sinónimos: Oxybaphus campestris Griseb., Allionia ovata (Ruiz \& Pav.) Standl., Calyxhymenia ovata Ruiz \& Pav., Mirabilis campestris (Griseb.) I.M. Johnst., Oxybaphus ovatus (Ruiz \& Pav.) Vahl

Hierba. Perenne. Nativa. 
Distribución: ATA, COQ, VAL, RME, LBO.

Rango altitudinal: 0-3200 m.

Países limítrofes: Argentina y Perú.

Mirabilis prostrata (Ruiz \& Pav.) Heimerl

Sinónimos: Oxybaphus micranthus Choisy, Oxybaphus prostratus (Ruiz \& Pav.) Vahl, Allionia micrantha (Choisy) Molfino, Calyxhymenia prostrata Ruiz \& Pav., Allionia excelsa (Willd.) kuntze, Allionia prostrata (Ruiz \& Pav.) Kuntze

Hierba. Perenne. Nativa.

Distribución: ANT, ATA, COQ, VAL, RME, LBO, MAU.

Rango altitudinal: 0-1400 m.

Países limítrofes: Argentina, Bolivia y Perú.

Mirabilis trollii Heimerl

Hierba. Perenne. Endémica.

Distribución: TAR.

Rango altitudinal: $2200 \mathrm{~m}$.

\section{NYMPHAEACEAE}

\section{Nymphaea}

Nymphaea alba L.

Hierba acuática. Perenne. Introducida.

Distribución: MAU, NUB, BIO, ARA, LLA.

\section{OLEACEAE}

\section{Fraxinus}

Fraxinus excelsior L.

Árbol. Introducido.

Distribución: BIO.

\section{Ligustrum}

Ligustrum ovalifolium Hassk.

Arbusto o árbol pequeño. Introducido.

Distribución: JFE.

Nombre vulgar: Ligustrina.

\section{Menodora}

Menodora linoides Phil.

Arbusto. Endémico.

Distribución: COQ, VAL.

Rango altitudinal: 1200-1800 m.

Nombre vulgar: Linacillo.

\section{ONAGRACEAE}

\section{Camissonia}

Camissonia dentata (Cav.) Reiche subsp. dentata

Sinónimos: Oenothera dentata Cav., Oenothera contorta Douglas var. divaricata (Gay) Munz, Chamissonia tenuifolia (Spach) Reiche, Camissonia flava Link, Oenothera chamissonis Link, Holostigma argutum Spach, Holostigma heterophyllum Spach, Sphaerostigma chamissonis (Link) Fisch. \& C.A. Mey., Oenothera minutiflora D. Dietr., Sphaerostigma dentatum (Cav.) Gay, Sphaerostigma divaricatum Gay, Sphaerostigma ramosissimum Phil., Chamissonia acuminata (Phil.) Reiche, Chamissonia paradoxa (Spach) Reiche var. divaricata (Gay) Reiche, Oenothera torulosa H. Lév. fma. chilensis (D. Dietr.) H. Lév., Oenothera micrantha Spreng. var. acuminata (Phil.) Munz, Sphaerostigma heterophylla (Spach) Gay

Hierba. Anual. Nativa.

Distribución: AYP, TAR, ATA, COQ, VAL, RME, LBO, MAU, NUB, BIO, ARA, AIS.

Rango altitudinal: 0-3500 m.

Países limítrofes: Argentina y Perú.

Camissonia dentata (Cav.) Reiche subsp. littoralis P.H. Raven \& D.M. Moore

Sinónimos: Sphaerostigma acuminatum Phil.

Hierba. Anual. Endémica.

Distribución: MAU, BIO.

Rango altitudinal: 0-200 m.

\section{Clarkia}

Clarkia tenella (Cav.) F.H. Lewis \& M.R. Lewis subsp. ambigua (Phil.) D.M. Moore \& F.H. Lewis ex Martic.

Sinónimos: Clarkia tenella (Cav.) F.H. Lewis \& M.R. Lewis subsp. ambigua (Phil.) D.M. Moore \& F.H. Lewis, comb. illeg., Godetia ambigua Phil.

Hierba. Anual. Endémica.

Distribución: NUB, BIO, ARA.

Clarkia tenella (Cav.) F.H. Lewis \& M.R. Lewis subsp. araucana D.M. Moore \& F.H. Lewis

Hierba. Anual. Endémica.

Distribución: NUB, BIO, ARA, LLA.

Rango altitudinal: 0-300 m.

Clarkia tenella (Cav.) H.F. Lewis \& M.R. Lewis subsp. tenella

Sinónimos: Oenothera tenella Cav., Godetia cavanillesii Spach, Godetia tenella (Cav.) Steud., Oenothera auricula H. Lév. var. tenella (Cav.) H. Lév., Godetia dasycarpa Phil., Godetia tenella (Cav.) Steud. var. dasycarpa (Phil.) Munz, Oenothera quadrivulnera Douglas var. dasycarpa 
(Cav.) Thell. ex Probst, Godetia quadrivulnera (Douglas) Spach var. tenella Jeps., Oenothera prismatica H. Lév. var. dasycarpa H. Lév.

Hierba. Anual. Nativa.

Distribución: COQ, VAL, RME, LBO, MAU, NUB, BIO, ARA, LRI, LLA.

Rango altitudinal: 0-3200 m.

Países limítrofes: Argentina.

Clarkia tenella (Cav.) F.H. Lewis \& M.R. Lewis subsp. tenuifolia (Cav.) D.M. Moore \& F.H. Lewis

Sinónimos: Oenothera tenuifolia Cav., Godetia tenuifolia (Cav.) Spach, Oenothera tenella Cav. var. tenuifolia (Cav.) Lindl., Godetia gayana Spach, Oenothera gayana (Spach) Steud., Oenothera prismatica H. Lév. var. tenuifolia (Cav.) H. Lév.

Hierba. Anual. Endémica.

Distribución: COQ, VAL, RME.

Rango altitudinal: 0-200 m.

Nombre vulgar: Inuil, sangre de toro, sangre de buey, huasita.

\section{Epilobium}

Epilobium australe Poepp. \& Hausskn. ex Hausskn.

Sinónimos: Epilobium lechleri Phil. \& Hausskn. ex Hausskn., Epilobium australe Poepp. \& Hausskn. ex Hausskn. var. andinum (Phil.) Sam., Epilobium australe Poepp. \& Hausskn. ex Hausskn. var. lechleri (Phil. \& Hausskn. ex Hausskn.) Sam., Epilobium australe Poepp. \& Hausskn. ex Hausskn. var. interruptum (Sam.) Sam., Epilobium australe Poepp. \& Hausskn. ex Hausskn. var. pumilum Sam., Epilobium interruptum Sam., Epilobium deflexum Sam., Epilobium tetragonum L. var. antarcticum Hook.f., Epilobium antarcticum (Hook.f.) Kuntze, Epilobium transandinum Sam.

Hierba. Perenne. Nativa.

Distribución: RME, LBO, MAU, NUB, BIO, ARA, LLA, AIS, MAG.

Rango altitudinal: 0-4000 m.

Países limítrofes: Argentina.

Epilobium barbeyanum H. Lév.

Hierba. Perenne. Nativa.

Distribución: ATA, COQ, VAL, RME, LBO, MAU, BIO.

Rango altitudinal: 1000-3500 m.

Países limítrofes: Argentina.

Epilobium brachycarpum C. Presl

Hierba. Anual. Introducida.

Distribución: BIO.

Epilobium campestre (Jeps.) Hoch \& W.L. Wagner

Hierba. Anual. Introducida.

Distribución: RME.
Rango altitudinal: 1700-1900 m.

Epilobium ciliatum Raf.

Sinónimos: Epilobium hookerianum Hausskn. ex Skottsb., Epilobium valdivense Hausskn. var. alboffii Macloskie, Epilobium tetragonum auct. non L., Epilobium valdiviense Hausskn., Epilobium magellanicum Phil. \& Hausskn. ex Hausskn., Epilobium longipes Sam., Epilobium chilense Hausskn., Epilobium constrictum Sam., Epilobium cunninghami Hausskn., Epilobium pedicellare J. Presl var. latifolium Walp., Epilobium aconcaguinum Phil., Epilobium albiflorum Phil., Epilobium chilense Hausskn. var. latifolium Sam., Epilobium chilense Hausskn. var. macrum Sam., Epilobium leiophyton Sam.

Hierba. Perenne. Nativa.

Distribución: ATA, COQ, VAL, RME, LBO, MAU, NUB, BIO, ARA, LLA, AIS, MAG.

Rango altitudinal: 0-3200 m.

Países limítrofes: Argentina.

Epilobium conjugens Skottsb.

Hierba. Perenne. Nativa.

Distribución: AIS, MAG.

Rango altitudinal: 0-1000 m.

Países limítrofes: Argentina.

Epilobium densifolium Hausskn.

Sinónimos: Epilobium nivale Meyen var. lignosum (F. Phil.) Hosseus, Epilobium lignosum F. Phil.

Hierba. Perenne. Nativa.

Distribución: VAL, RME, LBO, MAU, NUB, BIO, ARA, MAG.

Rango altitudinal: 500-3300 m.

Países limítrofes: Argentina.

Epilobium denticulatum Ruiz \& Pav.

Sinónimos: Epilobium andicolum Hausskn., Epilobium caesium Hausskn.

Hierba. Perenne. Nativa.

Distribución: AYP, TAR, ANT, COQ, BIO.

Rango altitudinal: 1500-4500 m.

Países limítrofes: Argentina, Bolivia y Perú.

Nombre vulgar: Tuari.

Epilobium fragile Sam.

Hierba. Perenne. Nativa.

Distribución: AYP, TAR, ANT.

Rango altitudinal: 3300-4200 m.

Países limítrofes: Bolivia y Perú.

Epilobium glaucum Phil.

Sinónimos: Epilobium glaucum Phil. var. stenophyllum Macloskie \& Dusén, Epilobium patagonicum Rendle, Epilobium nubigenum Phil. 
Hierba. Perenne. Nativa.

Distribución: COQ, VAL, RME, LBO, MAU, NUB, BIO, ARA, LLA, AIS, MAG.

Rango altitudinal: 0-3000 m.

Países limítrofes: Argentina.

\section{Epilobium nivale Meyen}

Sinónimos: Epilobium andinum Phil.

Hierba. Perenne. Nativa.

Distribución: COQ, VAL, RME, LBO, MAU, NUB, BIO, ARA.

Rango altitudinal: 300-4000 m.

Países limítrofes: Argentina.

Epilobium obscurum Schreb.

Hierba. Perenne. Introducida.

Distribución: RME, NUB, BIO, ARA, LRI, LLA.

Epilobium puberulum Hook. \& Arn.

Sinónimos: Epilobium pedunculatum Phil.

Hierba. Perenne. Nativa.

Distribución: VAL, RME, LBO, MAU, NUB, BIO, ARA, LRI, LLA, AIS.

Rango altitudinal: 0-1000 m.

Países limítrofes: Argentina.

Epilobium subdentatum (Meyen) Lievens \& Hoch

Sinónimos: Boisduvalia subulata (Ruiz \& Pav.) Raim., Boisduvalia volckmannii Phil., Oenothera gauroides Kuntze, Boisduvalia tocornalii Gay, Nierembergia subdentata Meyen, Oenothera uniflora Gillies ex Hook. \& Arn., nom. nud., Boisduvalia concinna (D. Don) Spach, Oenothera subulata Ruiz \& Pav., Oenothera concinna D. Don, Epilobium concinnum (D. Don) Hoch \& P.H. Raven Hierba. Anual. Nativa.

Distribución: COQ, VAL, RME, LBO, MAU, NUB, BIO, ARA.

Rango altitudinal: 0-1800 m.

Países limítrofes: Argentina.

Epilobium tetragonum L. subsp. lamyi (F.W. Schultz) Nyman

Hierba. Perenne. Introducida.

Distribución: RME, MAU, BIO, ARA, LLA.

\section{Fuchsia}

Fuchsia lycioides Andrews

Sinónimos: Fuchsia rosea Ruiz \& Pav.

Arbusto. Endémico.

Distribución: ATA, COQ, VAL, RME.

Rango altitudinal: 0-1500 m.

Nombre vulgar: Palo falso, palo de yegua, coralito, palo blanco.
Fuchsia magellanica Lam.

Sinónimos: Fuchsia magellanica Lam. var. macrostema (Ruiz \& Pav.) Munz, Fuchsia araucana F. Phil., Fuchsia coccinea Dryand. var. robustior Hook.f., Fuchsia gracilis Lindl. var. macrostema (Ruiz \& Pav.) Lindl., Fuchsia gracilis Lindl., Fuchsia macrostema Ruiz \& Pav., Fuchsia coccinea auct. non Dryand., Dorvalla eucharis Comm. ex Lam., Thilcum tinctorium Molina, Fuchsia magellanica Lam. var. typica Munz, nom. illeg., Fuchsia macrostema Ruiz \& Pav. var. grandiflora Hook., Fuchsia coccinea Dryand. var. macrostema (Ruiz \& Pav.) Hook., Fuchsia magellanica Lam. var. gracilis (Lindl.) L.H. Bailey, Fuchsia conica Lindl., Fuchsia macrostema Ruiz \& Pav. var. conica (Lindl.) Sweet, Fuchsia gracilis Lindl. var. multiflora Lindau, Fuchsia discolor Lindl., Fuchsia magellanica Lam. var. discolor (Lindl.) L.H. Bailey, Fuchsia chonotica Phil., Fuchsia coccinea Dryand. var. chonotica (Phil.) Reiche, Fuchsia magellanica Lam. var. molinae Espinosa, Fuchsia magellanica Lam. var. eburnea Pisano, Fuchsia magellanica Lam. var. conica (Lindl.) L.H. Bailey, Fuchsia gracilis Lindl. var. tenella Lindl., Fuchsia macrostema Ruiz \& Pav. var. tenella (Lindl.) DC., Fuchsia macrostema Ruiz \& Pav. var. gracilis (Lindl.) Sweet

Arbusto. Nativo.

Distribución: VAL, RME, LBO, MAU, NUB, BIO, ARA, LRI, LLA, AIS, MAG, JFE.

Rango altitudinal: 0-2000 m.

Países limítrofes: Argentina.

Nombre vulgar: Chilco, chilca, palo blanco.

Nota: Introducida en el Archipiélago Juan Fernández.

\section{Gayophytum}

Gayophytum humile A. Juss.

Sinónimos: Gayophytum densifolium Phil., Gayophytum minutum Phil., Gayophytum humile A. Juss. var. densifolium (Phil.) Reiche, Gayophytum nuttallii Torr. \& A. Gray, Gayophytum humile A. Juss. var. robustum (Phil.) Reiche Hierba. Anual. Nativa.

Distribución: ATA, COQ, RME, LBO, MAU.

Rango altitudinal: 500-3600 m.

Países limítrofes: Argentina.

Nombre vulgar: Quinchamalí.

Gayophytum micranthum Hook. \& Arn.

Sinónimos: Gayophytum gracile Phil., Gayophytum robustum Phil., Gayophytum humile A. Juss. var. gracile (Phil.) Reiche, Sphaerostigma paradoxum (Spach) Gay, Oenothera gracilis (Phil.) H. Lév.

Hierba. Anual. Nativa.

Distribución: ANT, ATA, COQ, VAL, RME, LBO, MAU.

Rango altitudinal: 1200-4300 m.

Países limítrofes: Argentina. 


\section{Ludwigia}

Ludwigia grandiflora (Michx.) Greuter \& Burdet subsp. hexapetala (Hook. \& Arn.) G.L. Nesom \& Kartesz

Sinónimos: Jussiaea hexapetala Hook. \& Arn., Ludwigia hexapetala (Hook. \& Arn.) Zardini, A.G. Gu \& P.H. Raven Hierba acuática. Perenne. Nativa.

Distribución: RME, LBO, MAU, BIO.

Rango altitudinal: 10-500 m.

Países limítrofes: Argentina.

Ludwigia octovalvis (Jacq.) P.H. Raven

Hierba. Perenne. Introducida.

Distribución: AYP, TAR.

Rango altitudinal: $10-270 \mathrm{~m}$.

Ludwigia peploides (Kunth) P.H. Raven subsp. montevidensis (Spreng.) P.H. Raven

Sinónimos: Jussiaea montevidensis Spreng., Jussiaea repens

L. var. montevidensis (Spreng.) Munz, Jussiaea repens L., Ludwigia adscendens (L.) H. Hara var. montevidensis (Spreng.) H. Hara, Jussiaea glandulosa Larrañaga

Hierba acuática. Perenne. Nativa.

Distribución: ATA, COQ, VAL, RME, LBO, MAU, NUB, BIO, ARA, LRI, LLA.

Rango altitudinal: 0-1000 m.

Países limítrofes: Argentina y Perú.

Nombre vulgar: Pasto de la rana.

Ludwigia peruviana (L.) H. Hara

Hierba acuática. Perenne. Introducida.

Distribución: LBO, BIO.

Rango altitudinal: 100-360 m.

\section{Oenothera}

Oenothera acaulis Cav.

Sinónimos: Lavauxia mutica Spach, Oenothera mutica (Spach) Gay

Hierba. Perenne. Endémica.

Distribución: COQ, VAL, RME, LBO, MAU, NUB, BIO, ARA, LRI.

Rango altitudinal: 0-1100 m.

Nombre vulgar: Colsilla, hierba de la apostema, rodalán.

\section{Oenothera affinis Cambess.}

Sinónimos: Oenothera berteriana Spach, Oenothera chilensis Fisch. \& C.A. Mey., Raimannia berteriana (Spach) Sprague \& Riley

Hierba. Anual. Nativa.

Distribución: ATA, COQ, VAL, RME, JFE.

Rango altitudinal: 0-4000 m.

Países limítrofes: Argentina y Bolivia.

Nombre vulgar: Flor de San José, metrón, metrún, Don
Diego de la noche.

Nota: Introducida en el Archipiélago Juan Fernández.

Oenothera arequipensis Munz \& I.M. Johnst.

Hierba. Anual. Nativa.

Distribución: ANT.

Rango altitudinal: 0-2700 m.

Países limítrofes: Perú.

Oenothera biennis L.

Hierba. Bienal. Introducida.

Distribución: VAL.

\section{Oenothera coquimbensis Gay}

Sinónimos: Oenothera grandidentata Phil., Oenothera coquimbensis Gay var. grandidentata (Phil.) Reiche

Hierba. Anual. Endémica.

Distribución: ANT, ATA, COQ, VAL.

Rango altitudinal: 0-700 $\mathrm{m}$.

Oenothera glazioviana Micheli

Hierba. Bienal. Introducida.

Distribución: LBO, LLA.

Oenothera grisea W. Dietr.

Hierba. Anual. Endémica.

Distribución: VAL.

Rango altitudinal: 0-100 m.

Oenothera magellanica Phil.

Sinónimos: Oenothera magellanica Phil. var. chubutensis

Macloskie, Oenothera polymorpha H. Lév. var. magellanica

(Phil.) H. Lév.

Hierba. Anual o bienal. Nativa.

Distribución: AIS, MAG.

Rango altitudinal: 0-3000 m.

Países limítrofes: Argentina.

Oenothera nana Griseb.

Hierba. Anual o bienal. Nativa.

Distribución: TAR, ANT.

Rango altitudinal: 2500-4500 m.

Países limítrofes: Argentina, Bolivia y Perú.

Oenothera odorata Jacq.

Sinónimos: Oenothera odorata Jacq. fma. glabrescens Speg., Oenothera odorata Jacq. fma. media Speg., Oenothera odorata Jacq. fma. undulata Speg., Oenothera ibarii Phil., Raimannia odorata (Jacq.) Sprague \& Riley, Onagra undulata Moench, Oenothera undulata Aiton, Oenothera odorata Jacq. var. virescens Ser., Oenothera odorata Jacq. var. glaucescens Ser., Oenothera odoratissima Tausch, Oenothera mollissima L. subsp. odorata (Jacq.) Thell. 
Hierba. Anual. Nativa.

Distribución: AIS, MAG.

Rango altitudinal: 0-2800 m.

Países limítrofes: Argentina.

Oenothera peruana W. Dietr.

Hierba. Anual o bienal. Nativa.

Distribución: TAR.

Rango altitudinal: 2500-3300 m.

Países limítrofes: Perú.

Oenothera picensis Phil.

Hierba. Anual. Nativa.

Distribución: ANT, ATA, COQ, VAL, RME, LBO, BIO,

JFE.

Rango altitudinal: 0-2000 m.

Países limítrofes: Argentina.

Nota: Introducida en el Archipiélago Juan Fernández.

Oenothera ravenii W. Dietr. subsp. chilensis W. Dietr.

Hierba. Anual o bienal. Endémica.

Distribución: VAL, BIO, ARA, LRI, LLA.

Rango altitudinal: 0-300 m.

Oenothera rosea L'Hér. ex Aiton

Hierba. Perenne. Introducida.

Distribución: AYP, COQ, VAL, RME, LBO, MAU, NUB, BIO, ARA, JFE, IPA.

Oenothera sandiana Hassk.

Sinónimos: Oenothera rubida Rusby

Hierba. Anual. Nativa.

Distribución: AYP, TAR.

Rango altitudinal: 2000-4000 m.

Países limítrofes: Bolivia y Perú.

Oenothera stricta Ledeb. ex Link

Sinónimos: Oenothera propinqua Spach, Oenothera bracteata Phil., Oenothera propinqua Spach var. sparsiflora Phil., Oenothera valdiviana Phil., Oenothera glabrescens Phil., Oenothera brachysepala Spach, Oenothera arguta Greene, Onagra arguta (Greene) Small, Oenothera bracteata Phil. var. glabrescens (Phil.) Reiche, Oenothera mollissima L. var. valdiviana (Phil.) Reiche, Oenothera mollissima L. subsp. propinqua (Spach) Thell., Oenothera stricta Ledeb. ex Link var. propinqua (Spach) Reiche Hierba. Anual o bienal. Nativa.

Distribución: ATA, COQ, VAL, RME, LBO, MAU, NUB, BIO, ARA, LRI, LLA, AIS, MAG, IPA.

Rango altitudinal: 0-1000 m.

Países limítrofes: Argentina.

Nombre vulgar: Don Diego de la noche, flor de San José.

Nota: Introducida en la Isla de Pascua.
Oenothera villaricae W. Dietr.

Hierba. Anual o bienal. Nativa.

Distribución: ARA, LRI, LLA.

Rango altitudinal: 0-1000 m.

Países limítrofes: Argentina.

\section{OROBANCHACEAE}

\section{Agalinis}

Agalinis linarioides (Cham. \& Schltdl.) D’Arcy

Sinónimos: Gerardia linarioides Cham. \& Schltdl.

Hierba. Perenne. Nativa.

Distribución: ATA, COQ.

Rango altitudinal: 0-2000 m.

Países limítrofes: Bolivia.

Nombre vulgar: Cartucho.

Agalinis meyeniana (Benth.) Barringer

Sinónimos: Gerardia rigida Gillies ex Benth. var. meyeniana Benth.

Hierba. Perenne. Endémica.

Distribución: ATA.

Rango altitudinal: 800-1300 m.

\section{Bellardia}

Bellardia trixago (L.) All.

Hierba. Anual. Introducida.

Distribución: VAL, MAU, NUB, BIO, ARA, AIS.

Bellardia viscosa (L.) Fisch. \& C.A. Mey

Hierba. Anual. Introducida.

Distribución: RME, LBO, MAU, NUB, BIO, ARA, LRI, LLA, AIS.

\section{Castilleja}

Castilleja attenuata (A. Gray) T.I. Chuang \& Heckard

Hierba. Anual. Introducida.

Distribución: VAL, RME, LBO, MAU, NUB, BIO.

Castilleja laciniata Hook. \& Arn.

Sinónimos: Orthocarpus australis Benth., Orthocarpus laciniatus (Hook. \& Arn.) D.D. Keck

Hierba. Anual. Nativa.

Distribución: COQ, VAL, RME, MAU, BIO.

Rango altitudinal: $300-700 \mathrm{~m}$.

Países limítrofes: Perú. 
Castilleja pumila (Benth.) Wedd. ex Herrera

Sinónimos: Castilleja nubigena Kunth var. pumila Benth., Castilleja fissifolia L. subsp. pumila (Benth.) Wedd., Castilleja fissifolia L.f. var. pumila (Benth.) Wedd.

Hierba parásita. Perenne. Nativa.

Distribución: AYP, TAR.

Rango altitudinal: 3000-4000 m.

Países limítrofes: Argentina, Bolivia y Perú.

Nombre vulgar: Albahaca.

\section{Euphrasia}

Euphrasia adenonota I.M. Johnst.

Hierba. Anual. Endémica.

Distribución: ATA, COQ.

Rango altitudinal: 2800-3200 m.

Euphrasia andicola Benth.

Hierba. Perenne. Endémica.

Distribución: LBO, MAU, ARA.

Euphrasia antarctica Benth.

Hierba. Anual. Nativa.

Distribución: NUB, BIO, ARA, LLA, AIS, MAG.

Rango altitudinal: 0-2500 m.

Países limítrofes: Argentina.

Euphrasia chrysantha Phil.

Hierba. Perenne. Nativa.

Distribución: LBO, MAU, NUB, BIO, ARA, LRI, LLA.

Rango altitudinal: 1000-3000 m.

Países limítrofes: Argentina.

\section{Euphrasia cockayniana Petrie}

Hierba. Anual. Endémica.

Distribución: AIS, MAG.

Rango altitudinal: 0-820 m.

Euphrasia flavicans Phil.

Hierba. Perenne. Endémica.

Distribución: ARA, LRI, LLA, AIS.

Rango altitudinal: 0-1500 m.

Euphrasia formosissima Skottsb.

Subarbusto. Endémico.

Distribución: JFE.

Rango altitudinal: 0-500 m.

Euphrasia intricata Phil.

Hierba. Perenne. Endémica.

Distribución: BIO.

Rango altitudinal: 0-500 m.
Euphrasia meiantha Clos

Hierba. Anual. Nativa.

Distribución: MAU, NUB, BIO, ARA, LRI, LLA, AIS.

Rango altitudinal: 1000-2000 m.

Países limítrofes: Argentina.

Euphrasia muscosa Phil.

Hierba. Perenne. Endémica.

Distribución: LLA, AIS.

Rango altitudinal: $1200 \mathrm{~m}$.

Euphrasia perpusilla Phil.

Hierba. Anual. Endémica.

Distribución: LLA.

Rango altitudinal: 200-300 m.

Euphrasia philippii Wettst.

Sinónimos: Euphrasia picta Phil., Euphrasia montana Phil.

Hierba. Anual. Endémica.

Distribución: BIO, ARA.

Rango altitudinal: 0-1300 m.

Euphrasia subexserta Benth

Hierba. Perenne. Nativa.

Distribución: RME, LBO, MAU, NUB, BIO, ARA, LLA, AIS.

Rango altitudinal: 500-3000 m.

Países limítrofes: Argentina.

Euphrasia trifida Poepp. ex Benth.

Sinónimos: Euphrasia aurea F. Phil., Euphrasia spectabilis

Phil., Euphrasia caespitosa Phil.

Hierba. Perenne. Nativa.

Distribución: LBO, MAU, NUB, BIO, ARA, LRI, LLA.

Rango altitudinal: 1000-2200 m.

Países limítrofes: Argentina.

Euphrasia villaricensis Phil.

Hierba. Perenne. Endémica.

Distribución: LLA.

\section{Neobartsia}

Neobartsia chilensis (Benth.) Uribe-Convers \& Tank Sinónimos: Bartsia chilensis Benth.

Hierba. Anual. Endémica.

Distribución: COQ, VAL.

Rango altitudinal: 300-600 m.

Neobartsia peruviana (Walp.) Uribe-Convers \& Tank

Sinónimos: Bartsia peruviana Walp., Bartsia meyeniana

Benth.

Hierba. Perenne. Nativa.

Distribución: AYP. 
Rango altitudinal: 1100-4900 m.

Países limítrofes: Argentina, Bolivia y Perú.

Neobartsia serrata (Molau) Uribe-Convers \& Tank Sinónimos: Bartsia serrata Molau

Subarbusto. Nativo.

Distribución: AYP, TAR.

Rango altitudinal: 2300-3600 m.

Países limítrofes: Perú.

\section{Orobanche}

Orobanche chilensis (Phil.) Beck

Sinónimos: Myzorrhiza chilensis Phil.

Hierba parásita. Perenne. Nativa.

Distribución: ATA, COQ, VAL, RME.

Rango altitudinal: 0-1800 m.

Países limítrofes: Argentina.

Nombre vulgar: Orobanca.

\section{Orobanche minor $\mathrm{Sm}$.}

Hierba parásita. Anual. Introducida.

Distribución: MAU, NUB, BIO, ARA.

\section{Orobanche ramosa $\mathrm{L}$.}

Hierba parásita. Anual. Introducida.

Distribución: COQ, RME, MAU, NUB, BIO, ARA.

Orobanche tarapacana Phil.

Hierba parásita. Perenne. Endémica.

Distribución: AYP, TAR.

Rango altitudinal: 0-2800 m.

\section{Parentucellia}

Parentucellia latifolia Caruel

Hierba. Anual. Introducida.

Distribución: VAL, RME, LBO, MAU, NUB, BIO, ARA.

\section{OXALIDACEAE}

\section{Oxalis}

Oxalis adenophylla Gillies ex Hook. \& Arn.

Sinónimos: Acetosella adenophylla (Gillies ex Hook. \& Arn.) Kuntze, Acetosella bustillosii (Phil.) Kuntze, Oxalis bustillosii Phil., Oxalis bustillosii Phil. var. biflora Phil.

Hierba. Perenne. Nativa.

Distribución: RME, LBO, MAU, NUB, BIO, ARA, LRI, LLA, AIS.

Rango altitudinal: 0-2600 m.

Países limítrofes: Argentina.
Oxalis arbuscula Barnéoud

Sinónimos: Oxalis fruticula Phil., Acetosella arbuscula (Barnéoud) Kuntze, Acetosella fruticula (Phil.) Kuntze

Subarbusto. Endémico.

Distribución: ANT, ATA.

Rango altitudinal: 600-1200 m.

Oxalis arenaria Bertero ex Colla

Sinónimos: Oxalis araucana Reiche, Oxalis biglandulosa

Steud., Oxalis hyalinorhiza Poepp. ex R. Knuth

Hierba. Perenne. Endémica.

Distribución: COQ, VAL, RME, LBO, MAU, NUB, BIO, ARA, LLA, MAG.

Rango altitudinal: 0-1100 m.

Oxalis articulata Savigny

Hierba. Perenne. Introducida.

Distribución: RME, BIO.

Oxalis atacamensis Reiche

Sinónimos: Acetosella trichocalyx (Phil.) Kuntze

Hierba. Perenne. Endémica.

Distribución: ANT, ATA.

Rango altitudinal: 400-600 m.

Oxalis aureoflava Steud.

Sinónimos: Oxalis corniculata L. var. aureoflava (Steud.) Gunckel, Acetosella aureoflava (Steud.) Kuntze, Xanthoxalis aureoflava (Steud.) Holub

Hierba. Perenne. Endémica.

Distribución: MAU, NUB, BIO, ARA, LRI, LLA, AIS.

Rango altitudinal: 0-1000 m.

\section{Oxalis berteroana Barnéoud}

Sinónimos: Oxalis compacta Gillies ex Hook. \& Arn. subsp. berteroana (Barnéoud) Lourteig, Oxalis falconiana Steud. berteroana (Barnéoud) Lourteig, Oxalis chaetocalyx Phil., Oxalis josephii R. Knuth, Oxalis pachyphylla Phil., Oxalis peraltae Phil., Acetosella berteroana (Barnéoud) Kuntze, Acetosella falconiana (Steud.) Kuntze, Acetosella pachyphylla (Phil.) Kuntze, Oxalis berteroana Barnéoud var. uniflora Phil.

Hierba. Anual. Nativa.

Distribución: COQ, VAL, RME, LBO, MAU.

Rango altitudinal: 1100-1700 m.

Países limítrofes: Argentina.

Oxalis bulbocastanum Phil.

Sinónimos: Oxalis breana Phil., Oxalis thyrsoidea Reiche, Oxalis occidentalis R. Knuth

Hierba. Perenne. Endémica.

Distribución: AYP, TAR, ANT, ATA.

Rango altitudinal: 200-700 m. 
Oxalis caesia Phil.

Arbusto. Endémico.

Distribución: ANT, ATA.

Rango altitudinal: 0-1000 m.

Oxalis campanensis Lourteig

Hierba. Perenne. Endémica.

Distribución: VAL, RME.

Rango altitudinal: 1500-1800 m.

Oxalis cinerea Zucc.

Sinónimos: Oxalis alfalfalis Phil., Oxalis lineata Gillies ex Hook. \& Arn., Oxalis niveiphylla R. Knuth, Oxalis pearcei Phil., Oxalis spodiophylla Walp. var. microphylla Walp., Oxalis spodiophylla Walp., Oxalis fernandensis R. Knuth, Oxalis besseri R. Knuth, Acetosella haenkeana (Zucc.) Kuntze, Acetosella lineata (Gillies ex Hook. \& Arn.) Kuntze, Acetosella pearcei (Phil.) Kuntze, Acetosella spodiophylla (Walp.) Kuntze

Subarbusto. Nativo.

Distribución: COQ, VAL, RME, LBO, MAU, ARA.

Rango altitudinal: 1000-2700 m.

Países limítrofes: Argentina y Perú.

Oxalis clandestina Phil.

Hierba. Anual o bienal. Endémica.

Distribución: VAL, LBO, MAU, NUB, BIO, ARA, LLA.

Rango altitudinal: 0-200 m.

Oxalis colchaguensis Lourteig

Hierba. Perenne. Endémica.

Distribución: ATA, COQ, VAL, RME, LBO, MAU.

Oxalis compacta Gillies ex Hook. \& Arn.

Sinónimos: Oxalis gilliesii Phil., Oxalis landbeckii Phil., Oxalis platypila Gillies ex Hook. \& Arn., Oxalis reichei R. Knuth, Oxalis uspallatensis R. Knuth, Acetosella compacta (Gillies ex Hook. \& Arn.) Kuntze, Acetosella gayana (Phil.) Kuntze, Acetosella platypila (Gillies ex Hook. \& Arn.) Kuntze, Oxalis gayana Phil.

Hierba. Anual. Nativa.

Distribución: ANT, ATA, COQ, VAL, RME, LBO, MAU, BIO.

Rango altitudinal: 1600-4300 m.

Países limítrofes: Argentina.

Oxalis corniculata L. var. atropurpurea Planch.

Sinónimos: Oxalis corniculata L. var. purpurascens Speg.

Hierba. Perenne. Introducida.

Distribución: COQ, RME, JFE.

Rango altitudinal: 0-500 m.

Oxalis corniculata L. var. corniculata

Hierba. Perenne. Introducida.
Distribución: COQ, VAL, RME, LBO, MAU, NUB, BIO, ARA, LRI, LLA, MAG, JFE, IPA.

Oxalis debilis Kunth

Hierba. Anual. Introducida.

Distribución: JFE.

Oxalis dumetorum Barnéoud

Sinónimos: Oxalis prorepens Phil., Oxalis hookeriana Pohl ex Progel, Oxalis lechleri Steud., Acetosella dumetorum (Barnéoud) Kuntze

Hierba. Perenne. Endémica.

Distribución: VAL, LBO, MAU, NUB, BIO, ARA, LRI, LLA.

Rango altitudinal: 0-200 m.

Oxalis enneaphylla Cav.

Sinónimos: Oxalis cunninghamii R. Knuth, Oxalis enneaphylla Cav. subsp. ibari (Phil.) Lourteig, Oxalis patagonica Speg., Acetosella enneaphylla (Cav.) Kuntze, Oxalis enneaphylla Cav. var. patagonica (Speg.) Skottsb., Oxalis frigida R. Knuth, Oxalis ibari Phil., Oxalis pumila d'Urv., Oxalis enneaphylla Cav. var. pumila (d’Urv.) Hook. Hierba. Perenne. Nativa.

Distribución: MAG.

Rango altitudinal: 0-2600 m.

Países limítrofes: Argentina.

Oxalis eremobia Phil.

Sinónimos: Oxalis inesitae Phil.

Hierba. Perenne. Endémica.

Distribución: ANT, ATA.

Rango altitudinal: 2100-3300 m.

Oxalis ericoides R. Knuth

Subarbusto. Endémico.

Distribución: ANT.

Rango altitudinal: 1500-3000 m.

Oxalis erythrorhiza Gillies ex Hook. \& Arn.

Sinónimos: Oxalis bryoides Phil., Oxalis guessfeldtii R.

Knuth, Acetosella bryoides (Phil.) Kuntze, Acetosella erythrorhiza (Gillies ex Hook. \& Arn.) Kuntze

Hierba. Perenne. Nativa.

Distribución: ANT, ATA, COQ, RME, LBO, MAU.

Rango altitudinal: 1500-4300 m.

Países limítrofes: Argentina.

Oxalis gigantea Barnéoud

Arbusto. Endémico.

Distribución: ANT, ATA, COQ.

Rango altitudinal: 0-1000 m.

Nombre vulgar: Churco, churqui. 
Oxalis gyrorhiza Bertero ex Colla

Sinónimos: Oxalis radicans Ruiz \& Pav. ex R. Knuth, Acetosella gyrorhiza (Bertero ex Colla) Kuntze, Oxalis autumnalis Poepp. ex Progel, nom. illeg.

Hierba. Perenne. Endémica.

Distribución: VAL, RME, LBO, MAU, NUB, BIO, ARA, LRI, LLA.

Rango altitudinal: 0-400 m.

\section{Oxalis holosericea Phil.}

Sinónimos: Acetosella holosericea (Phil.) Kuntze

Hierba. Perenne. Nativa.

Distribución: LBO, MAU.

Rango altitudinal: 2500-2700 m.

Países limítrofes: Argentina.

Oxalis hypsophila Phil.

Sinónimos: Oxalis exigua Phil., Oxalis coyensis R. Knuth, Oxalis fluehmannii Phil., Oxalis gracilinervosa R. Knuth, Oxalis leptocaulos Phil., Oxalis microphylla Phil.

Hierba. Perenne. Nativa.

Distribución: ANT, ATA, COQ, VAL, RME, LBO.

Rango altitudinal: 2600-5000 m.

Países limítrofes: Argentina.

Oxalis incana Phil.

Subarbusto. Endémico.

Distribución: RME.

Rango altitudinal: 0-2000 m.

Oxalis johnstonii R. Knuth

Hierba. Perenne. Endémica.

Distribución: ANT, ATA.

Rango altitudinal: 0-900 m.

Oxalis laciniata Cav.

Sinónimos: Oxalis squamoso-radicosa Steud., Acetosella laciniata (Cav.) Kuntze, Acetosella squamoso-radicosa (Steud.) Kuntze, Oxalis prichardii Rendle, Oxalis squamoso-radicosa Steud. var. pubescens Skottsb., Oxalis laciniata Cav. var. pubescens (Skottsb.) J.M.H. Shaw

Hierba. Perenne. Nativa.

Distribución: MAG.

Rango altitudinal: 0-2600 m.

Países limítrofes: Argentina.

Oxalis laxa Hook. \& Arn. var. hispidissima Barnéoud

Sinónimos: Oxalis laxa Hook. \& Arn. var. violacea R. Knuth, Oxalis micrantha Bertero ex Colla var. setifera R. Knuth, Acetosella platycaulis (Steud.) Kuntze, Oxalis chosicensis R. Knuth, Oxalis platycaulis Steud., Oxalis umbellata Kuntze ex R. Knuth, nom. nud.

Hierba. Anual. Nativa.

Distribución: ANT, ATA, COQ, VAL, RME, LBO.
Rango altitudinal: 0-1600 m.

Países limítrofes: Argentina y Perú.

Oxalis laxa Hook. \& Arn. var. laxa

Sinónimos: Oxalis deflexa Poepp. ex Progel, Oxalis dichotomiflora Steud., Oxalis geranioides R. Knuth, Oxalis laxa Hook. \& Arn. var. major R. Knuth, Oxalis laxa Hook. \& Arn. var. minor Barnéoud, Oxalis micrantha Bertero ex Colla var. alsinoides (Walp.) R. Knuth, Oxalis micrantha Bertero ex Colla var. purpurea R. Knuth, Oxalis brevicaulis Steud., Oxalis alsinoides Walp.

Hierba. Anual. Nativa.

Distribución: ANT, COQ, VAL, RME, LBO, MAU, BIO.

Rango altitudinal: 0-1200 m.

Países limítrofes: Perú.

Oxalis leucophylla Phil.

Hierba. Perenne. Endémica.

Distribución: ATA.

Rango altitudinal: 0-200 m.

Oxalis loricata Dusén

Hierba. Perenne. Nativa.

Distribución: AIS, MAG.

Rango altitudinal: 0-1500 m.

Países limítrofes: Argentina.

Oxalis magellanica G. Forst.

Sinónimos: Oxalis carnosa Molina, Oxalis modesta Phil., Acetosella modesta (Phil.) Kuntze, Oxalis cataractae A. Cunn., Oxalis lactea Hook.

Hierba. Perenne. Nativa.

Distribución: ARA, LLA, AIS, MAG.

Rango altitudinal: 0-2000 m.

Países limítrofes: Argentina.

Nombre vulgar: Ojos de agua.

Oxalis matancillae Lourteig

Hierba. Perenne. Endémica.

Distribución: ANT.

Rango altitudinal: 100-400 m.

Oxalis megalorrhiza Jacq.

Sinónimos: Oxalis ornata Phil., Oxalis paposana Phil., Oxalis borchersii Phil., Oxalis darapskyi Phil. ex Reiche, Oxalis paniculata Reiche, Oxalis paposana Phil. var. hirta R. Knuth, Oxalis succulenta Barnéoud, Oxalis tarapacana Phil., Oxalis reticulata Steud., Oxalis illapelina Phil., Oxalis brevis Phil., Oxalis carnosa Molina var. incana Reiche Hierba. Perenne. Nativa.

Distribución: AYP, TAR, ANT, ATA, COQ, VAL, RME, LBO, MAU, NUB, BIO.

Rango altitudinal: 0-3200 m.

Países limítrofes: Perú. 
Oxalis micrantha Bertero ex Colla

Sinónimos: Oxalis cumingii Herb., Acetosella cumingii (Herb.) Kuntze, Acetosella micrantha (Bertero ex Colla) Kuntze, Acetosella pygmaea (Phil.) Kuntze, Acetosella vinagrillo (Steud.) Kuntze, Oxalis micrantha Bertero ex Colla var. major R. Knuth, Oxalis pygmaea Phil., Oxalis vinaqrillo Steud., Xanthoxalis micrantha (Bertero ex Colla) Holub

Hierba. Anual. Nativa.

Distribución: ANT, ATA, COQ, VAL, RME, LBO, MAU, NUB, BIO, ARA, LRI, LLA, JFE.

Rango altitudinal: 0-1300 m.

Países limítrofes: Argentina.

Nota: Introducida en el Archipiélago Juan Fernández.

Oxalis mira Lourteig

Hierba. Anual. Endémica.

Distribución: COQ.

Rango altitudinal: 400-600 m.

Oxalis morenoensis Lourteig

Hierba. Perenne. Endémica.

Distribución: ANT.

Rango altitudinal: 0-1000 m.

Oxalis nahuelhuapiensis Speg.

Sinónimos: Oxalis comberi R. Knuth

Hierba. Perenne. Nativa.

Distribución: RME, ARA.

Rango altitudinal: 1500-2500 m.

Países limítrofes: Argentina.

Oxalis novemfoliolata Heibl \& Martic.

Subarbusto. Endémica.

Distribución: ATA

Rango altitudinal: 100-450 m.

Oxalis ornithopus Phil.

Sinónimos: Acetosella ornithopus (Phil.) Kuntze

Hierba. Perenne. Endémica.

Distribución: ANT, ATA.

Rango altitudinal: 0-600 m.

Oxalis ovalleana Phil.

Hierba suculenta. Anual. Endémica.

Distribución: ANT, ATA, COQ.

Rango altitudinal: 0-600 m.

Oxalis pachyrrhiza Wedd.

Hierba. Perenne. Nativa.

Distribución: AYP, TAR, ANT, ATA, COQ, VAL, RME, MAU.

Rango altitudinal: 3500-4000 m.

Países limítrofes: Argentina, Bolivia y Perú.
Oxalis penicillata Phil.

Hierba. Perenne. Nativa.

Distribución: VAL, RME, LBO.

Rango altitudinal: 2000-3700 m.

Países limítrofes: Argentina.

Oxalis perdicaria (Molina) Bertero

Sinónimos: Oxalis delicatula Phil., Oxalis lobata Sims,

Oxalis mallobolba Cav., Acetosella eriorrhiza (Zucc.)

Kuntze, Acetosella lobata (Sims) Kuntze, Acetosella

mallobolba (Cav.) Kuntze, Acetosella perdicaria (Molina)

Kuntze, Oxalis autumnalis A. St.-Hil., Oxalis eriorhiza

Zucc., Oxalis tenera Spreng., Sassia perdicaria Molina

Hierba. Perenne. Nativa.

Distribución: COQ, VAL, RME, LBO, MAU, NUB, BIO, ARA, LRI, LLA.

Rango altitudinal: 0-500 m.

Países limítrofes: Argentina.

Nombre vulgar: Flor de mayo, flor de la perdiz, mayo, rimu.

Oxalis pes-caprae L.

Hierba. Perenne. Introducida.

Distribución: COQ, VAL, RME, BIO, LLA, JFE.

Oxalis purpurea L.

Hierba. Perenne. Introducida.

Distribución: JFE.

Oxalis pycnophylla Wedd.

Sinónimos: Oxalis hauthalii R. Knuth

Hierba. Perenne. Nativa.

Distribución: ANT.

Rango altitudinal: 2200-5000 m.

Países limítrofes: Argentina y Bolivia.

Oxalis ricardii Lourteig

Hierba. Perenne. Endémica.

Distribución: ANT.

Rango altitudinal: 0-1000 m.

Oxalis rigida (Barnéoud) Lourteig

Sinónimos: Oxalis adenocaulos Phil., Oxalis puberula Phil., Oxalis san-romanii Phil., Oxalis torcana Phil., Acetosella puberula (Phil.) Kuntze, Oxalis laxa Hook. \& Arn. var. rigida Barnéoud

Hierba. Perenne. Nativa.

Distribución: ANT, ATA, COQ, RME, LBO.

Rango altitudinal: 800-2700 m.

Países limítrofes: Argentina.

Oxalis rosea Jacq.

Sinónimos: Oxalis rosea Jacq. var. simplex Reiche

Hierba. Anual. Endémica.

Distribución: COQ, VAL, RME, LBO, MAU, NUB, BIO, 
ARA, LRI, LLA, AIS.

Rango altitudinal: $0-1500 \mathrm{~m}$.

Nombre vulgar: Culle colorado.

Oxalis squamata Zucc.

Sinónimos: Oxalis chilensis R. Knuth, Oxalis geminata Hook. \& Arn., Oxalis hirthii Phil., Oxalis macropus Phil., Oxalis polyantha Walp., Acetosella geminata (Gillies ex Hook. \& Arn.) Kuntze, Acetosella macropus (Phil.) Kuntze, Acetosella polyantha (Walp.) Kuntze, Acetosella squamata (Zucc.) Kuntze, Oxalis trichocalyx Steud., Xanthoxalis polyantha (Walp.) Holub

Hierba. Perenne. Nativa. Distribución: VAL, RME, LBO, MAU, BIO.

Rango altitudinal: 1000-3200 m.

Países limítrofes: Argentina.

Oxalis squarrosa Barnéoud

Sinónimos: Oxalis briquetii R. Knuth, Oxalis coquimbana Phil., Oxalis glutinosa Phil., Acetosella squarrosa (Barnéoud) Kuntze, Acetosella glutinosa (Phil.) Kuntze, Acetosella coquimbana (Phil.) Kuntze

Subarbusto. Endémico.

Distribución: ATA, COQ.

Rango altitudinal: 1000-2800 m.

Oxalis strictula Steud.

Sinónimos: Oxalis aberrans Reiche

Hierba. Perenne. Endémica.

Distribución: VAL, RME, LBO.

Rango altitudinal: 500-1200 m.

Oxalis tacorensis B.L. Burtt

Hierba. Perenne. Nativa.

Distribución: AYP, TAR, ANT.

Rango altitudinal: 4200-5100 m.

Países limítrofes: Bolivia.

Nombre vulgar: Chincura.

Oxalis tortuosa Lindl.

Sinónimos: Oxalis gaudichaudii Barnéoud, Oxalis maritima Barnéoud, Oxalis glomerata Hook. \& Arn., Oxalis bridgesii Bertero ex Colla, Oxalis zonata Liebm.

Hierba suculenta. Perenne. Endémica.

Distribución: ATA, COQ, VAL, LBO, JFE.

Rango altitudinal: 0-300 m.

\section{Oxalis tuberosa Molina}

Hierba suculenta. Perenne. Nativa.

Países limítrofes: Argentina, Bolivia y Perú.

Nota: Descrita para Chile por Molina (1782) y citada para Chile por Lourteig (2000), sin mencionar la localidad o material de referencia.
Oxalis valdiviensis Barnéoud

Sinónimos: Oxalis berningeri R. Knuth, Oxalis hapalconidea Barnéoud, Oxalis tolguacensis R. Knuth, Acetosella antucensis (Phil.) Kuntze, Acetosella hapalconidea (Barnéoud) Kuntze, Acetosella valdiviensis (Barnéoud) Kuntze, Oxalis antucensis Phil., Oxalis capillipes R. Knuth, Oxalis tinctoria Poepp. ex Progel, Oxalis valdiviensis Barnéoud var. antucensis (Phil.) Reiche, Oxalis valdiviana Vilm., Oxalis valdiviensis Barnéoud var. humilis Speg., Xanthoxalis valdiviensis (Barnéoud) Holub

Hierba. Perenne. Nativa.

Distribución: VAL, LBO, MAU, NUB, BIO, ARA, LRI, LLA.

Rango altitudinal: 1000-1500 m.

Países limítrofes: Argentina.

Oxalis virgosa Molina

Sinónimos: Oxalis subcarnosa Klotzsch ex Walp., Acetosella virgosa (Molina) Kuntze, Acetosella subcarnosa (Klotzsch ex Walp.) Kuntze

Arbusto. Endémico.

Distribución: ATA, COQ, VAL.

Rango altitudinal: 0-100 m.

\section{PAPAVERACEAE}

\section{Argemone}

Argemone crassifolia G.B. Ownbey

Hierba. Perenne. Endémica.

Distribución: ATA.

Rango altitudinal: $1300 \mathrm{~m}$.

Argemone hunnemannii Otto \& A. Dietr.

Sinónimos: Argemone mexicana L. var. grandiflora auct. non (Sweet) Reiche, Argemone platyceras Link \& Otto var. chilensis Prain, Argemone platyceras Link \& Otto var. hunnemannii (Otto \& A. Dietr.) Fedde, Argemone mexicana sensu Gay, non L.

Hierba. Anual. Nativa.

Distribución: ANT, ATA, COQ, VAL, RME, LBO, MAU.

Rango altitudinal: 0-2500 m.

Países limítrofes: Argentina.

Nombre vulgar: Cardo blanco.

Argemone rosea Hook.

Sinónimos: Argemone mexicana L. var. rosea (Hook.) Reiche, Argemone mexicana L. var. spinosa Barnéoud ex Reiche, Argemone mexicana $\mathrm{L}$. var. tomentosa Barnéoud ex Reiche, Argemone platyceras Link \& Otto var. hispido-rosea Fedde Hierba. Anual. Endémica.

Distribución: ATA, COQ.

Rango altitudinal: 0-900 m. 
Argemone subfusiformis G.B. Ownbey

Sinónimos: Argemone mexicana L. var. ochroleuca auct. non (Sweet) Lindl., Argemone mexicana auct. non L., Argemone mexicana L. var. glauca Barnéoud ex Reiche Hierba. Anual. Nativa.

Distribución: AYP, TAR, ANT, ATA, COQ, VAL, RME. Rango altitudinal: 0-2000 m.

Países limítrofes: Argentina, Bolivia y Perú.

Nombre vulgar: Cardo blanco.

\section{Eschscholzia}

Eschscholzia californica Cham.

Hierba. Perenne. Introducida.

Distribución: COQ, VAL, RME, LBO, MAU, NUB, BIO, ARA.

\section{Fumaria}

Fumaria agraria Lag.

Hierba. Anual. Introducida.

Distribución: ANT, ATA, COQ, VAL, RME, LBO, MAU, NUB, BIO, ARA, LRI, LLA.

Fumaria capreolata L.

Hierba. Anual. Introducida.

Distribución: ATA, COQ, VAL, RME, LBO, MAU, NUB, BIO, ARA, LRI, LLA, JFE, IPA.

\section{Fumaria officinalis L.}

Hierba. Anual. Introducida.

Distribución: VAL.

Fumaria parviflora Lam.

Hierba. Anual. Introducida.

Distribución: COQ, VAL, RME, LBO, BIO.

\section{Papaver}

Papaver dubium L.

Hierba. Anual. Introducida.

Distribución: MAG.

Papaver hybridum L.

Hierba. Anual. Introducida.

Distribución: VAL, RME.

\section{Papaver rhoeas L.}

Hierba. Anual. Introducida.

Distribución: RME, LBO, LLA.

\section{Papaver somniferum L.}

Hierba. Anual. Introducida.

Distribución: ANT, COQ, VAL, RME, LBO, MAU, BIO,
LRI, MAG, JFE.

\section{PASSIFLORACEAE}

\author{
Malesherbia \\ Malesherbia auristipulata Ricardi \\ Subarbusto. Endémico. \\ Distribución: AYP, TAR. \\ Rango altitudinal: 1800-2100 m. \\ Malesherbia campanulata Ricardi \\ Hierba. Perenne. Endémica. \\ Distribución: COQ. \\ Rango altitudinal: 3300-4000 m.
}

Malesherbia corallina Muñoz-Schick \& R. Pinto

Subarbusto. Endémico.

Distribución: TAR.

Rango altitudinal: 2700-2800 m.

Malesherbia densiflora Phil.

Hierba. Perenne. Endémica.

Distribución: ATA.

Rango altitudinal: 2500-3100 m.

Malesherbia deserticola Phil.

Sinónimos: Malesherbia borchersi Phil.

Subarbusto. Endémico.

Distribución: ANT, ATA.

Rango altitudinal: 3400-3500 m.

Malesherbia fasciculata D. Don var. fasciculata

Sinónimos: Malesherbia thyrsoidea Bertero ex Steud., Gynopleura fascicula (D. Don) Roem.

Subarbusto. Endémico.

Distribución: COQ, VAL, RME, LBO.

Rango altitudinal: 400-1000 m.

Malesherbia fasciculata D. Don var. glandulosa Ricardi Subarbusto. Endémico.

Distribución: COQ.

Malesherbia humilis Poepp. var. gabrielae (Ricardi) Gengler Sinónimos: Malesherbia gabrielae Ricardi

Hierba. Anual. Endémica.

Distribución: COQ.

Rango altitudinal: 700-2600 m.

Malesherbia humilis Poepp. var. humilis

Sinónimos: Gynopleura humilis (D. Don) Roem., Gynopleura dilatata Walp., Malesherbia dilatata (Walp.) F. Phil. 
Hierba. Anual. Nativa.

Distribución: ANT, ATA, COQ, VAL, RME, MAU.

Rango altitudinal: 0-1800 m.

Países limítrofes: Argentina.

Nombre vulgar: Piojito, piojillo.

Malesherbia humilis Poepp. var. parviflora (Phil.) Ricardi Sinónimos: Malesherbia multiflora Ricardi, Malesherbia parviflora Phil.

Hierba. Anual. Endémica.

Distribución: TAR, ANT, ATA, COQ.

Rango altitudinal: 0-2900 m.

Malesherbia humilis Poepp. var. propinqua (Gay) Ricardi Sinónimos: Malesherbia propinqua Gay, Malesherbia humilis D. Don var. propinqua (Gay) Reiche

Hierba. Anual. Endémica.

Distribución: COQ.

Rango altitudinal: 600-2000 m.

Malesherbia humilis Poepp. var. taltalina (Ricardi) Gengler Sinónimos: Malesherbia taltalina Ricardi

Hierba. Anual. Endémica.

Distribución: ANT.

Rango altitudinal: 0-200 m.

Malesherbia lactea Phil.

Sinónimos: Malesherbia rosulata Werderm.

Hierba. Perenne. Nativa.

Distribución: ANT, ATA.

Rango altitudinal: 2500-3900 m.

Países limítrofes: Argentina.

Malesherbia lanceolata Ricardi

Hierba. Perenne. Endémica.

Distribución: ATA, COQ.

Rango altitudinal: 2900-3300 m.

Malesherbia linearifolia (Cav.) Pers.

Sinónimos: Gynopleura linearifolia Cav., Malesherbia linearifolia (Cav.) Poir., comb. illeg., Malesherbia coronota D. Don, Malesherbia subalpina Poepp. ex Walp., Gynopleura coronata (D. Don) Roem., Malesherbia humilis D. Don var. subalpina (Poepp.) Gay

Subarbusto. Endémico.

Distribución: COQ, VAL, RME, LBO.

Rango altitudinal: 400-3200 m.

Malesherbia lirana Gay var. bracteata (Phil.) Ricardi

Sinónimos: Malesherbia bracteata Phil., Malesherbia oblongifolia auct. non Phil.

Hierba. Perenne. Endémica.

Distribución: ATA, COQ.

Rango altitudinal: 3000-3500 m.
Malesherbia lirana Gay var. lirana

Sinónimos: Malesherbia hieronymi Harms, Malesherbia lirana Gay var. hieronymi (Harms) Ricardi, Malesherbia cuneata Phil., Malesherbia serpyllifolia Phil., Malesherbia lirana Gay var. sepyllifolia (Phil.) Reiche, Malesherbia lirana Gay var. subtomentosa Kuntze, Malesherbia incana Werderm.

Hierba. Perenne. Nativa.

Distribución: ANT, ATA, COQ, VAL, RME.

Rango altitudinal: 2000-4000 m.

Países limítrofes: Argentina.

Malesherbia obtusa Phil. var. johnstonii (Werderm.) Ricardi

Sinónimos: Malesherbia johnstonii Werderm.

Subarbusto. Endémico.

Distribución: ATA.

Rango altitudinal: $2500 \mathrm{~m}$.

Malesherbia obtusa Phil. var. obtusa

Sinónimos: Malesherbia breviflora Phil.

Subarbusto. Endémico.

Distribución: ATA.

Rango altitudinal: $500 \mathrm{~m}$.

Malesherbia paniculata D. Don

Sinónimos: Gynopleura coerulea C. Presl, Malesherbia linearifolia (Cav.) Pers. var. paniculata (D. Don) Reiche

Subarbusto. Endémico.

Distribución: ATA, COQ, VAL, RME, LBO.

Rango altitudinal: 400-2500 m.

Nombre vulgar: Farolito.

Malesherbia rugosa Gay var. pseudopulverulenta Ricardi Subarbusto. Endémico.

Distribución: ATA.

Rango altitudinal: $2000 \mathrm{~m}$.

Malesherbia rugosa Gay var. rugosa

Sinónimos: Malesherbia ovata Phil., Malesherbia oblongifolia Phil., Malesherbia foliosa Phil., Malesherbia prolifera Phil., Malesherbia serrata Phil., Malesherbia brevipedunculata Werderm., Malesherbia glandulifera Werderm.

Subarbusto. Endémico.

Distribución: ATA.

Rango altitudinal: 1000-3000 m.

Malesherbia tenuifolia D. Don

Sinónimos: Gynopleura tenuifolia (D. Don) Roem., Malesherbia pulchra Phil.

Subarbusto. Endémico.

Distribución: TAR.

Rango altitudinal: $2500 \mathrm{~m}$. 
Malesherbia tocopillana Ricardi

Subarbusto. Endémico.

Distribución: ANT.

Rango altitudinal: 0-200 m.

\section{Passiflora}

\section{Passiflora foetida L.}

Arbusto trepador. Nativo.

Distribución: AYP.

Rango altitudinal: 20-50 m.

Países limítrofes: Bolivia y Perú.

Passiflora pinnatistipula Cav.

Sinónimos: Passiflora chilensis Miers, Tacsonia pinnatistipula (Cav.) Juss.

Arbusto trepador. Nativo.

Distribución: COQ, VAL.

Rango altitudinal: 2500-3000 m.

Países limítrofes: Bolivia y Perú.

Nombre vulgar: Flor de la pasión, flor de la corona de Cristo, pasionaria, granadilla.

\section{PHRYMACEAE}

\section{Erythranthe}

Erythranthe bridgesii (Benth.) G.L. Nesom

Sinónimos: Mimulus parviflorus Lindl. var. bridgesii Benth., Mimulus longipes Phil., Mimulus bridgesii (Benth.) Clos var. integrifolia Clos, Mimulus bridgesii (Benth.) Clos var. stoloniformis Clos, Mimulus bridgesii (Benth.) Clos, Mimulus acutidens Reiche

Hierba. Anual. Nativa.

Distribución: VAL, RME, LBO, MAU, NUB, BIO, ARA, LRI, LLA.

Rango altitudinal: 0-500 m.

Países limítrofes: Argentina.

Nombre vulgar: Placa, berro.

Erythranthe cuprea (Dombrain) G.L. Nesom

Sinónimos: Mimulus luteus L. var. cuprea Hook., Mimulus cupreus Dombrain

Hierba. Anual. Nativa.

Distribución: LBO, MAU, NUB, BIO, ARA.

Rango altitudinal: 900-2100 m.

Países limítrofes: Argentina.

Nombre vulgar: Placa, berro.

Erythranthe depressa (Phil.) G.L. Nesom var. ciminum (C. Bohlen) J.M. Watson \& A.R. Flores

Sinónimos: Mimulus depressus Phil. var. ciminum C. Bohlen
Hierba. Perenne. Endémica.

Distribución: ATA.

Rango altitudinal: 2900-3100 m.

Erythranthe depressa (Phil.) G.L. Nesom var. depressa Sinónimos: Mimulus pissisi Phil., Mimulus acaulis Phil., Mimulus depressus Phil. var. acaulis (Phil.) Reiche, Mimulus depressus Phil. var. pissisi (Phil.) Reiche, Mimulus depressus Phil.

Hierba. Anual o Perenne. Endémica.

Distribución: ANT, ATA, COQ.

Rango altitudinal: 2000-4500 m.

Erythranthe glabrata (Kunth) G.L. Nesom

Sinónimos: Mimulus andicolus Kunth, Mimulus parviflorus Lindl., Mimulus glabratus Kunth var. parviflorus (Lindl.) Grant, Mimulus sylvaticus Phil., Mimulus kingii Phil., Mimulus tener Phil., Mimulus parviflorus Lindl. var. externa Skottsb., Mimulus glabratus Kunth var. externus (Skottsb.) Skottsb., Mimulus pilosiusculus Kunth, Mimulus propinquus Lindl., Mimulus parviflorus Lindl. var. nana Wedd., Mimulus glabratus Kunth

Hierba. Anual. Nativa.

Distribución: AYP, TAR, ANT, ATA, COQ, VAL, RME, LBO, MAU, NUB, BIO, ARA, LRI, LLA, AIS, MAG, JFE.

Rango altitudinal: 0-4500 m.

Países limítrofes: Argentina, Bolivia y Perú.

Nombre vulgar: Oqororo.

Erythranthe lutea (L.) G.L. Nesom var. lutea

Sinónimos: Mimulus punctatus Miers ex Bertero, Mimulus luteus L. var. nummularius Clos, Mimulus luteus L. var. micranthus Phil., Mimulus glabratus Kunth var. micranthus (Phil.) Boivin, Mimulus luteus L. var. rivularis (Lodd.) Lindl., Mimulus rivularis Lodd., Mimulus luteus L. fma. macrophyllus Clos, Mimulus punctatus Miers ex Bertero, Mimulus luteus L.

Hierba. Anual o Perenne. Nativa.

Distribución: ATA, COQ, VAL, RME, LBO, MAU, NUB, BIO, ARA, LRI, LLA, AIS.

Rango altitudinal: 0-3700 m.

Países limítrofes: Argentina.

Erythranthe lutea (L.) G.L. Nesom var. variegata (Lodd.) Hook.

Sinónimos: Mimulus variegatus Lodd., Mimulus naiandinus J.M. Watson \& C. Bohlen, Mimulus luteus L. var. variegatus (Lodd.) Hook.

Hierba. Anual o Perenne. Endémica.

Distribución: LBO, MAU.

Rango altitudinal: 500-2700 m. 
Erythranthe minima (C. Bohlen) J.M. Watson \& A.R. Flores

Sinónimos: Mimulus minimus C. Bohlen, Mimulus depressus Phil. var. nanus (Phil.) Reiche, Mimulus nanus auct. non Phil.

Hierba. Anual. Endémica.

Distribución: ATA.

\section{PHYTOLACCACEAE}

\section{Anisomeria}

Anisomeria coriacea D. Don

Sinónimos: Anisomeria drastica (Bertero) Moq., Pircunia drastica Bertero, Phytolacca drastica (Bertero) Poepp. \& Endl.

Hierba. Perenne. Endémica.

Distribución: COQ, VAL, RME, LBO, MAU.

Rango altitudinal: 500-2600 m.

Nombre vulgar: Pircún, pirco, congrio.

Anisomeria littoralis (Poepp. \& Endl.) Moq.

Sinónimos: Phytolacca chilensis Miers, nom. nud., Phytolacca littoralis Poepp. \& Endl., Anisomeria chilensis (Miers) H. Walter, Anisomeris fruticosa Phil.

Arbusto. Endémico.

Distribución: ANT, ATA, COQ, VAL, RME, MAU.

Rango altitudinal: 0-1300 m.

\section{Ercilla}

Ercilla spicata (Bertero) Moq.

Sinónimos: Ercilla volubilis A. Juss., Galvezia spicata Bertero, Suriana volubilis (A. Juss.) Dombey \& Cav. ex D. Don, Bridgesia spicata (Bertero) Hook. \& Arn., Apodostachys densiflora Turcz., Phytolacca volubilis (A. Juss.) Heimerl, Ercilla spicata (Hook. \& Arn.) Moq.

Arbusto trepador. Endémico.

Distribución: VAL, RME, LBO, MAU, NUB, BIO, ARA, LRI.

Rango altitudinal: 0-3000 m.

Nombre vulgar: Coralillo, siete huiras, voqui-auca, voquitraro.

Ercilla syncarpellata Nowicke

Arbusto trepador. Endémico.

Distribución: MAU, LRI, LLA, AIS.

Rango altitudinal: 0-300 m.

Nombre vulgar: Coralillo, siete huiras, voqui-auca, voquitraro.
Phytolacca

Phytolacca bogotensis Kunth

Sinónimos: Phytolacca australis Phil., Phytolacca bogotensis Kunth var. australis (Phil.) Hauman, comb. illeg., Phytolacca micrantha H. Walter, Phytolacca parviflora Hauman

Hierba. Perenne. Nativa.

Distribución: BIO, ARA, LRI, LLA.

Rango altitudinal: 0-3000 m.

Países limítrofes: Argentina, Bolivia y Perú.

Nombre vulgar: Carmín.

Phytolacca chilensis (Miers ex Moq.) H. Walter

Sinónimos: Pircunia chilensis Miers ex Moq.

Subarbusto. Endémico.

Distribución: VAL, RME, LBO.

\section{PIPERACEAE}

\section{Peperomia}

Peperomia berteroana Miq.

Sinónimos: Peperomia tristanensis Christoph., Peperomia berteroana Miq. subsp. tristanensis (Christoph.) Valdeb.

Hierba. Perenne. Nativa.

Distribución: JFE.

Rango altitudinal: 0-600 m.

Nota: También presente en Isla Inaccesible e Isla Tristan da Cunha.

Peperomia coquimbensis Skottsb.

Hierba epífita. Perenne. Endémica.

Distribución: COQ.

Rango altitudinal: $500 \mathrm{~m}$.

Nombre vulgar: Congonilla.

Peperomia doellii Phil.

Hierba suculenta. Perenne. Endémica.

Distribución: ANT, ATA, COQ.

Rango altitudinal: 0-700 m.

Peperomia fernandeziana Miq.

Sinónimos: Peperomia fernandeziana Miq. fma. oblongifolia Skottsb., Peperomia chilensis C. DC.

Hierba epífita o terrestre. Perenne. Endémica.

Distribución: COQ, VAL, LRI, LLA, JFE.

Rango altitudinal: 0-600 m.

Nombre vulgar: Congonilla.

Peperomia margaritifera Bertero ex Hook.

Sinónimos: Peperomia margaritifera Bertero ex Hook. var. umbraticola Skottsb. ex Yunck. 
Hierba. Perenne. Endémica.

Distribución: JFE.

Rango altitudinal: 200-400 m.

Peperomia nummularioides Griseb.

Sinónimos: Peperomia australis Phil., Peperomia nummulariifolia Kunth

Hierba. Perenne. Endémica.

Distribución: COQ, LRI, LLA, AIS.

Rango altitudinal: 0-500 m.

Nombre vulgar: Congonilla del monte.

Peperomia skottsbergii C. DC. Hierba. Perenne. Endémica.

Distribución: JFE.

Rango altitudinal: 100-600 m.

\section{PITTOSPORACEAE}

\section{Pittosporum}

Pittosporum crassifolium Banks \& Sol. ex A. Cunn. Arbusto o árbol pequeño. Introducido.

Distribución: LBO, MAU, NUB, BIO, JFE.

Pittosporum undulatum Vent.

Arbusto. Introducido.

Distribución: VAL.

Nombre vulgar: Pitosporo.

\section{PLANTAGINACEAE}

\section{Bacopa}

Bacopa monnieri (L.) Pennell

Sinónimos: Lysimachia monnieri L., Herpestis monnieri (L.) Kunth, Bacopa monnieri (L.) Wettst., nom. illeg., Bramia indica Lam.

Hierba. Anual. Nativa.

Distribución: AYP, TAR, ANT, ATA, COQ, MAU.

Rango altitudinal: 0-3500 m.

Países limítrofes: Argentina y Bolivia.

\section{Callitriche}

\section{Callitriche albomarginata Fassett}

Hierba. Anual. Endémica.

Distribución: RME.

Rango altitudinal: $2700 \mathrm{~m}$.

Callitriche antarctica Engelm. ex Hegelm.

Hierba acuática. Anual. Nativa.
Distribución: RME, AIS, MAG.

Rango altitudinal: 0-500 m.

Países limítrofes: Argentina.

Callitriche deflexa A. Braun ex Hegelm.

Hierba. Anual. Nativa.

Distribución: COQ, LBO, MAU, NUB, BIO, ARA.

Rango altitudinal: 0-500 m.

Países limítrofes: Argentina.

Callitriche heterophylla Pursh

Hierba acuática. Anual. Nativa.

Distribución: BIO, ARA, LLA.

Rango altitudinal: 0-500 m.

Países limítrofes: Argentina.

Callitriche lechleri (Hegelm.) Fassett var. berteroana (Hegelm.) Fassett

Sinónimos: Callitriche marginata Torr. var. berteroana Hegelm., Callitriche berteroniana Steud.

Hierba. Anual. Nativa.

Distribución: VAL, LBO, AIS.

Países limítrofes: Argentina.

Callitriche lechleri (Hegelm.) Fassett var. lechleri

Sinónimos: Callitriche marginata Torr. var. lechleri Hegelm., Callitriche oblongicarpa Fassett

Hierba acuática. Anual. Nativa.

Distribución: VAL, RME, LBO, MAU, NUB, BIO, ARA, LRI, LLA, AIS, MAG, JFE.

Rango altitudinal: 0-2000 m.

Países limítrofes: Argentina.

Nota: Introducida en el Archipiélago Juan Fernández.

Callitriche terrestris Raf. subsp. turfosa (Bertero emend. Hegelm.) Bacigalupo

Sinónimos: Callitriche turfosa Bertero

Hierba. Anual. Nativa.

Distribución: ANT, VAL, RME, NUB, BIO, ARA, LRI, LLA, AIS.

Rango altitudinal: 0-1000 m.

Países limítrofes: Argentina.

Callitriche truncata Guss.

Hierba acuática. Anual. Introducida.

Distribución: ARA, MAG.

\section{Cymbalaria}

Cymbalaria muralis P. Gaertn., B. Mey. \& Scherb.

Hierba. Perenne. Introducida.

Distribución: VAL, RME, MAU, BIO, JFE. 
Digitalis

Digitalis purpurea L.

Hierba. Perenne. Introducida.

Distribución: ATA, VAL, MAU, NUB, BIO, ARA, LRI, LLA, AIS, MAG, JFE.

\section{Fonkia}

Fonkia uliginosa Phil.

Sinónimos: Gratiola uliginosa (Phil.) F. Phil., Gratiola peruviana L. var. uliginosa (Phil.) Reiche

Hierba. Perenne. Nativa.

Distribución: ARA, LRI, LLA.

Rango altitudinal: 0-1000 m.

Países limítrofes: Argentina.

\section{Gratiola}

Gratiola peruviana L.

Hierba. Perenne. Nativa.

Distribución: ATA, LBO, MAU, NUB, BIO, ARA, LRI, LLA.

Rango altitudinal: 0-1500 m.

Países limítrofes: Argentina y Bolivia.

Hebe

Hebe elliptica (G. Forst.) Pennell

Sinónimos: Hebe magellanica J.F. Gmel., Veronica elliptica

G. Forst., Veronica simpsoni Phil.

Arbusto. Nativo.

Distribución: AIS, MAG.

Rango altitudinal: 0-500 m.

Países limítrofes: Argentina.

Hebe salicifolia (G. Forst.) Pennell

Sinónimos: Veronica salicifolia G. Forst., Veronica fonki Phil.

Arbusto. Nativo.

Distribución: LLA, AIS, MAG.

Rango altitudinal: 0-200 m.

Países limítrofes: Bolivia.

\section{Hippuris}

\section{Hippuris vulgaris L.}

Hierba. Perenne. Nativa.

Distribución: BIO, LLA, AIS, MAG.

Rango altitudinal: 0-500 m.

Países limítrofes: Argentina.

Nombre vulgar: Pinito de agua.

\section{Kickxia}

Kickxia elatine (L.) Dumort.

Hierba. Anual. Introducida.

Distribución: RME, NUB, BIO, ARA, JFE.

\section{Limosella}

Limosella australis $\mathrm{R}$. Br.

Sinónimos: Limosella aquatica L. var. tenuifolia (Nutt.) Hook.f., Limosella aquatica auct. non L., Limosella tenuifolia Nutt.

Hierba. Anual. Nativa.

Distribución: ANT, COQ, VAL, RME, LBO, MAU, NUB, BIO, ARA, LRI, LLA, AIS, MAG.

Rango altitudinal: 0-4500 m.

Países limítrofes: Argentina y Bolivia.

\section{Linaria}

Linaria canadensis (L.) Dum. Cours.

Hierba. Perenne. Introducida.

Distribución: ANT, ATA, COQ, VAL, RME, MAU, BIO, ARA, LRI.

\section{Linaria vulgaris Mill.}

Hierba. Perenne. Introducida.

Distribución: VAL, LBO, NUB, BIO, ARA, AIS.

\section{Littorella}

Littorella australis Griseb. ex Benth. \& Hook.f.

Sinónimos: Plantago araucana Rahn

Hierba. Perenne. Nativa.

Distribución: ARA, LRI, LLA, AIS, MAG.

Rango altitudinal: 0-500 m.

Países limítrofes: Argentina.

\section{Mecardonia}

Mecardonia procumbens (Mill.) Small var. flagellaris (Cham. \& Schltdl.) V.C. Souza

Sinónimos: Herpestis flagellaris Cham. \& Schltdl., Moniera flagellaris (Cham. \& Schltdl.) Kuntze, Bacopa flagellaris (Cham. \& Schltdl.) Wettst., Moniera procumbens (Mill.) Kuntze var. flagellaris (Cham. \& Schltdl.) Kuntze, Mecardonia flagellaris (Cham. \& Schltdl.) Rossow, Bacopa chamaedryoides (Kunth) Wettst. var. flagellaris (Cham. \& Schltdl.) Chodat \& Hassl.

Hierba. Anual. Nativa.

Distribución: LBO, MAU.

Rango altitudinal: 0-1000 m.

Países limítrofes: Argentina. 
Mecardonia procumbens (Mill.) Small var. procumbens Sinónimos: Erinus procumbens Mill., Herpestis chamaedryoides Kunth, Bacopa procumbens (Mill.) Greenm.

Hierba. Anual. Nativa.

Distribución: MAU.

Rango altitudinal: 0-1000 m.

Países limítrofes: Argentina, Bolivia y Perú.

\section{Melosperma}

Melosperma andicola Benth.

Sinónimos: Melosperma glabra Phil., Herpestis andicola Gillies ex Benth.

Subarbusto. Nativo.

Distribución: COQ, VAL, RME, LBO, MAU, NUB.

Rango altitudinal: 2300-2700 m.

Países limítrofes: Argentina.

\section{Melosperma angustifolia Phil.}

Sinónimos: Melosperma andicola Benth. var. angustifolia (Phil.) Rossow

Hierba. Anual. Nativa.

Distribución: COQ, VAL, RME, LBO, MAU, NUB, BIO, ARA.

Rango altitudinal: 2500-4500 m.

Países limítrofes: Argentina.

\section{Monttea}

Monttea chilensis Gay var. chilensis

Arbusto o árbol pequeño. Endémico.

Distribución: COQ, VAL.

Rango altitudinal: 0-500 m.

Nombre vulgar: Uvillo.

Monttea chilensis Gay var. taltalensis Reiche

Arbusto o árbol pequeño. Endémico.

Distribución: ANT, COQ.

Rango altitudinal: 0-700 m.

\section{Ourisia}

Ourisia alpina Poepp. \& Endl.

Sinónimos: Ourisia pallens Poepp. \& Endl., Ourisia alpina Poepp. \& Endl. var. pallens (Poepp. \& Endl.) Benth., Ourisia rosea Phil., Ourisia alpina Poepp. \& Endl. var. glabra Phil., Ourisia rancoana Phil.

Hierba. Perenne. Nativa.

Distribución: MAU, NUB, BIO, ARA, LLA.

Rango altitudinal: 1000-2700 m.

Países limítrofes: Argentina.
Ourisia breviflora Benth. subsp. breviflora

Sinónimos: Ourisia antarctica Hook.f.

Hierba. Perenne. Nativa.

Distribución: AIS, MAG.

Rango altitudinal: 0-1200 m.

Países limítrofes: Argentina.

Ourisia breviflora Benth. subsp. uniflora (Phil.) Meudt Sinónimos: Ourisia uniflora Phil., Ourisia breviflora Benth. var. uniflora (Phil.) Reiche

Hierba. Perenne. Nativa.

Distribución: NUB, BIO, LLA.

Rango altitudinal: 500-2000 m.

Países limítrofes: Argentina.

Ourisia coccinea (Cav.) Pers. subsp. coccinea

Sinónimos: Dichroma coccinea Cav., Ourisia villosa Molina, Ourisia pearcei Phil.

Hierba. Perenne. Nativa.

Distribución: MAU, NUB, BIO, ARA, LRI, LLA, AIS.

Rango altitudinal: 0-1600 m.

Países limítrofes: Argentina.

Ourisia coccinea (Cav.) Pers. subsp. elegans (Phil.) Meudt Sinónimos: Ourisia coccinea (Cav.) Pers. var. minor Benth., Ourisia coccinea (Cav.) Pers. var. elegans (Phil.) Reiche, Ourisia elegans Phil.

Hierba. Perenne. Endémica.

Distribución: COQ, LBO, MAU, NUB, BIO, ARA, LRI.

Rango altitudinal: 100-2600 m.

Ourisia fragrans Phil.

Hierba. Perenne. Nativa.

Distribución: LLA.

Rango altitudinal: 1300-2200 m.

Países limítrofes: Argentina.

Ourisia fuegiana Skottsb.

Sinónimos: Ourisia muscosa auct. non Benth.

Hierba. Perenne. Nativa.

Distribución: AIS, MAG.

Rango altitudinal: 0-1200 m.

Países limítrofes: Argentina.

Ourisia microphylla Poepp. \& Endl.

Sinónimos: Ourisia polyantha auct. non Poepp. \& Endl.

Subarbusto. Nativo.

Distribución: MAU, NUB, BIO.

Rango altitudinal: 800-2200 m.

Países limítrofes: Argentina.

Ourisia muscosa Benth.

Hierba. Perenne. Nativa.

Distribución: AYP, TAR. 
Rango altitudinal: 3800-5000 m.

Países limítrofes: Bolivia y Perú.

Ourisia polyantha Poepp. \& Endl.

Sinónimos: Ourisia diazii Phil.

Subarbusto. Endémico.

Distribución: RME, LBO.

Rango altitudinal: 1300-2400 m.

Ourisia pygmaea Phil.

Sinónimos: Ourisia uniflora auct. non Phil.

Hierba. Perenne. Nativa.

Distribución: MAU, NUB, BIO, ARA, LRI, LLA.

Rango altitudinal: 1400-2200 m.

Países limítrofes: Argentina.

Ourisia ruelloides (L.f.) Kuntze

Sinónimos: Ourisia poeppigii Benth., Ourisia racemosa Clos, Ourisia magellanica C.F. Gaertn., Ourisia glabra Molina, Chelone ruelloides L.f.

Hierba. Perenne. Nativa.

Distribución: LBO, MAU, NUB, BIO, ARA, LRI, LLA, AIS, MAG.

Rango altitudinal: 0-2600 m.

Países limítrofes: Argentina.

Ourisia serpyllifolia Benth.

Sinónimos: Ourisia melospermoides Phil.

Subarbusto. Endémico.

Distribución: VAL, RME, MAU.

Rango altitudinal: 1000-2200 m.

\section{Plantago}

Plantago australis Lam. subsp. australis

Sinónimos: Plantago candollei Raf., Plantago accrescens Pilg., Plantago kurtzii Pilg., Plantago refracta Pilg., Plantago stuckertii Pilg., Plantago leptophylla Decne., Plantago cantagallensis Zahlbr., Plantago bicallosa Decne., Plantago australis Lam. subsp. angustifolia (Pilg.) Rahn, Plantago bicallosa Decne. var. angustifolia Pilg., Plantago gigantea Decne., Plantago durvillei Fisch. \& C.A. Mey.

Hierba. Perenne. Nativa.

Distribución: TAR, VAL, BIO, ARA, LRI, LLA, AIS, MAG, JFE.

Rango altitudinal: 0-3500 m.

Países limítrofes: Argentina y Bolivia.

Plantago australis Lam. subsp. cumingiana (Fisch. \& C.A. Mey.) Rahn

Sinónimos: Plantago cumingiana Fisch. \& C.A. Mey., Plantago pugae Phil., Plantago calbucana Phil., Plantago foncki Phil., Plantago tomentosa Lam. var. foncki (Phil.)
Reiche, Plantago laevigata Phil., Plantago ovata Phil., Plantago julieti Phil.

Hierba. Perenne. Nativa.

Distribución: VAL, NUB, BIO, ARA, LRI, LLA, AIS, MAG.

Rango altitudinal: 0-2000 m.

Países limítrofes: Argentina.

Plantago barbata G. Forst. subsp. austroandina Rahn

Hierba. Perenne. Nativa.

Distribución: AIS, MAG.

Rango altitudinal: 100-1800 m.

Países limítrofes: Argentina.

Plantago barbata G. Forst. subsp. barbata

Sinónimos: Plantago andicola Gillies ex Hook.f., Plantago imberbis Hook.f., Plantago pauciflora Lam., Plantago barbata G. Forst. var. pauciflora (Gay) Pilg., Plantago andicola Decne. ex Barnéoud, Plantago pauciflora Lam. var. major Barnéoud, Plantago barbata G. Forst. var. imberbis Hook.f., Plantago caespitosa Phil., Plantago barbata G. Forst. var. caespitosa (Phil.) Pilg., Plantago pachyrrhiza Phil.

Hierba. Perenne. Nativa.

Distribución: ATA, COQ, VAL, RME, LBO, MAU, NUB, BIO, ARA, LLA, AIS, MAG.

Rango altitudinal: 500-3600 m.

Países limítrofes: Argentina.

Plantago barbata G. Forst. subsp. monanthos (d'Urv.) Rahn

Sinónimos: Plantago monanthos d'Urv., Plantago polymorpha Banks \& Sol. ex Hook.f., Plantago barbata G. Forst. var. elongata Hook.f., Plantago barbata G. Forst. var. monanthos (d’Urv.) Pilg.,

Hierba. Perenne. Nativa.

Distribución: RME, MAG.

Rango altitudinal: 0-200 m.

Países limítrofes: Argentina.

Plantago barbata G. Forst. subsp. muscoides (Hook.f.) Rahn

Sinónimos: Plantago monanthos d'Urv. var. muscoides Hook.f., Plantago monanthos d'Urv. var. abbreviata Hook.f., Plantago barbata G. Forst. fma. muscoides (Hook.f.) Pilg., Plantago barbata G. Forst. fma. abbreviata (Hook.f.) Pilg.

Hierba. Perenne. Nativa.

Distribución: MAG.

Rango altitudinal: 0-200 m.

Países limítrofes: Argentina. 


\section{Plantago brasiliensis Sims}

Sinónimos: Plantago brasiliensis Sims var. gayana (Decne. ex Barnéoud) Pilg., Plantago obtusata Decne., Plantago chilensis Rapin, Plantago decaisnei Barnéoud, Plantago gayana Decne. ex Barnéoud, Plantago lasiothrix Kunze ex Decne., Plantago brasiliensis Sims var. chilensis (Rapin) Pilg., Plantago sericea Ruiz \& Pav. var. decaisnei (Barnéoud) Wedd., Plantago brasiliensis Sims var. decaisnei (Barnéoud) Pilg., Plantago brasiliensis Sims var. lasiothrix (Decne.) Pilg., Plantago dolichophylla Phil., Plantago vidali Phil.

Hierba. Perenne. Nativa.

Distribución: RME, LBO, MAU, NUB, BIO, ARA, LLA.

Rango altitudinal: 0-2200 m.

Países limítrofes: Argentina.

\section{Plantago coronopus L.}

Hierba. Anual. Introducida.

Distribución: COQ, LBO, NUB, BIO, ARA.

Plantago fernandezia Bertero ex Barnéoud

Sinónimos: Robinsonia nervosa Phil.

Arbusto. Endémico.

Distribución: JFE.

Rango altitudinal: 500-600 m.

Plantago firma Kunze ex Walp.

Sinónimos: Plantago brachystachys Walp., Plantago virginica L. var. firma (Walp.) Reiche, Plantago truncata Cham. \& Schltdl. var. canohirsuta Pilg., Plantago leonensis Steud., Plantago clausa Steud., Plantago marginata Steud., Plantago skottsbergii Pilg., Plantago truncata Cham. \& Schltdl. subsp. skottsbergii (Pilg.) Pilg., Plantago truncata Cham. \& Schltdl. subsp. firma (Kuntze ex Walp.) Pilg.

Hierba. Anual. Endémica.

Distribución: COQ, VAL, RME, LBO, MAU, NUB, BIO, ARA, LRI, JFE.

Rango altitudinal: 0-1000 m.

\section{Plantago grandiflora Meyen}

Sinónimos: Plantago macrantha Decne. ex Barnéoud, Plantago macrantha Decne. ex Barnéoud var. nitidifolia Barnéoud, Plantago macrantha Decne. ex Barnéoud var. trichophylla Phil., Plantago macrantha Decne. ex Barnéoud var. hirsuta Phil., Plantago macrantha Decne. ex Barnéoud var. argentea Phil.

Hierba. Perenne. Nativa.

Distribución: VAL, RME, LBO, MAU, NUB, BIO, ARA.

Rango altitudinal: 1300-2800 m.

Países limítrofes: Argentina.

Plantago hispidula Ruiz \& Pav.

Sinónimos: Plantago callosa Colla, Plantago macrosperma Steud., Plantago subtrinervis Phil., Plantago stenopetala
Phil., Plantago disticha Phil., Plantago albida Phil., Plantago steinheilii Barnéoud, Plantago heterophylla Phil., nom. illeg., Plantago stenopetala Phil. var. stricta Phil., Plantago tumida Link

Hierba. Anual. Endémica.

Distribución: AYP, TAR, ANT, ATA, COQ, VAL, RME, LBO, MAU, NUB, BIO, ARA.

Rango altitudinal: 0-200 m.

Nombre vulgar: Llantén.

Plantago johnstonii Pilg.

Hierba. Anual. Endémica.

Distribución: ANT.

Plantago lanceolata L.

Hierba. Perenne. Introducida.

Distribución: ANT, ATA, COQ, VAL, RME, LBO, MAU, NUB, BIO, ARA, LRI, LLA, AIS, MAG, JFE, IPA.

Plantago litorea Phil.

Sinónimos: Plantago philippiana Vatke, Plantago glabriuscula Phil., Plantago oligantha Phil.

Hierba. Anual. Endémica.

Distribución: AYP, TAR, ANT, ATA, COQ, VAL.

Rango altitudinal: 0-3600 m.

Plantago lundborgii Sparre

Hierba. Anual. Endémica.

Distribución: IDE.

Rango altitudinal: 0-200 m.

\section{Plantago major L.}

Hierba. Perenne. Introducida.

Distribución: AYP, ANT, COQ, VAL, RME, LBO, MAU, NUB, BIO, ARA, LRI, LLA, AIS, MAG, JFE, IPA.

Plantago maritima L.

Sinónimos: Plantago juncoides Lam., Plantago maritima

L. var. juncoides (Lam.) A. Gray

Hierba. Perenne. Nativa.

Distribución: MAG.

Rango altitudinal: 0-500 m.

Países limítrofes: Argentina.

Plantago pachyneura Steud.

Sinónimos: Plantago durvillei Fisch. \& C.A. Mey. subsp. eupachyneura (Pilg.) Pilg., nom. illeg., Plantago australis Lam. subsp. pachyneura (Steud.) Rahn, Plantago pachyneura Steud. subsp. eupachyneura Pilg., Plantago hygrophila Steud., Plantago pachyneura Steud. var. hygrophila (Steud.) Pilg., Plantago durvillei Fisch. \& C.A. Mey. var. hygrophila (Steud.) Pilg., Plantago berteroi Steinh. ex Decne., Plantago pachystachys Phil.

Hierba. Perenne. Nativa. 
Distribución: ANT, ATA, COQ, VAL, RME, LBO, MAU, NUB, BIO, ARA, LRI, LLA, MAG.

Rango altitudinal: 1300-2500 m.

Países limítrofes: Argentina.

Plantago pulvinata Speg.

Hierba. Perenne. Nativa.

Distribución: AIS.

Rango altitudinal: 0-400 m.

Países limítrofes: Argentina.

Plantago rancaguae Steud.

Sinónimos: Plantago quillota Vatke, Plantago deserticola Phil., Plantago steinheilii Barnéoud, Plantago brachyantha Phil., Plantago bracteosa Phil.

Hierba. Anual. Endémica.

Distribución: ANT, ATA, COQ, VAL, RME, LBO.

Rango altitudinal: 0-200 m.

\section{Plantago sempervivoides Dusén}

Hierba. Perenne. Nativa.

Distribución: MAG.

Rango altitudinal: 700-1600 m.

Países limítrofes: Argentina.

Plantago sericea Ruiz \& Pav. subsp. araucana Rahn

Hierba. Anual. Endémica.

Distribución: MAU, BIO.

Rango altitudinal: $1200 \mathrm{~m}$.

Plantago sericea Ruiz \& Pav. subsp. sericans (Pilg.) Rahn Sinónimos: Plantago monticola Decne., Plantago monticola Decne. subsp. sericans Pilg., Plantago monticola Decne. subsp. eumonticola Pilg., nom. illeg.

Hierba. Anual o bienal. Nativa.

Distribución: AYP.

Rango altitudinal: 2900-4400 m.

Países limítrofes: Argentina y Perú.

Plantago tehuelcha Speg.

Hierba. Perenne. Nativa.

Distribución: BIO, MAG.

Rango altitudinal: 0-900 m.

Países limítrofes: Argentina.

Plantago truncata Cham. \& Schltdl.

Sinónimos: Plantago australis Lam. subsp. truncata (Cham. \& Schltdl.) Rahn, Plantago eschscholtziana Fisch. \& C.A. Mey., Plantago truncata Cham. \& Schltdl. subsp. escscholtziana (Fisch. \& C.A. Mey.) Pilg., Plantago berteroniana Steud., Plantago obscura Steud., Plantago bridgesii Decne., Plantago valparadisiaca Decne., Plantago amphibola Phil., Plantago angustifolia Phil., Plantago tomentosa Lam. subsp. angustifolia (Phil.)
Reiche, Plantago truncata Cham. \& Schltdl. var. philippii Pilg.

Hierba. Perenne. Endémica.

Distribución: VAL, RME, LBO, MAU, NUB, BIO, ARA, LRI, LLA.

Rango altitudinal: 0-800 m.

Plantago tubulosa Decne.

Hierba. Perenne. Nativa.

Distribución: AYP, TAR, ANT.

Rango altitudinal: 2900-5000 m.

Países limítrofes: Argentina, Bolivia y Perú.

Nombre vulgar: Psike.

Plantago uniglumis Wallr. ex Walp.

Sinónimos: Plantago coelorhiza Morris \& Macloskie, Plantago barbata G. Forst. var. uncialis Wedd., Plantago uncialis Decne. ex Barnéoud, Plantago barbata G. Forst. fma. uncialis (Decne. ex Barnéoud) Pilg., Plantago uniglumis Wallr. ex Walp. fma. maxima Pilg.

Hierba. Perenne. Nativa.

Distribución: COQ, VAL, RME, LBO, MAU, NUB, AIS, MAG.

Rango altitudinal: 200-3200 m.

Países limítrofes: Argentina.

\section{Stemodia}

Stemodia durantifolia (L.) Sw. var. chilensis (Benth.) C.C. Cowan

Sinónimos: Stemodia chilensis Benth., Stemodiacra chilensis Kuntze

Hierba acuática. Perenne. Nativa.

Distribución: ANT, ATA, COQ, VAL, RME, LBO, MAU, NUB, BIO, ARA.

Rango altitudinal: 0-500 m.

Países limítrofes: Argentina.

Nombre vulgar: Contrayerba.

\section{Veronica}

Veronica anagallis-aquatica $\mathrm{L}$.

Hierba. Anual. Introducida.

Distribución: AYP, TAR, ATA, COQ, VAL, RME, LBO, MAU, NUB, BIO, ARA, LRI, LLA, AIS, JFE.

\section{Veronica arvensis L.}

Hierba. Anual. Introducida.

Distribución: ATA, VAL, RME, LBO, MAU, NUB, BIO, ARA, LRI, LLA, MAG, JFE.

Veronica beccabunga $\mathrm{L}$.

Hierba. Perenne. Introducida.

Distribución: LLA. 
Veronica chamaedrys L.

Hierba. Anual. Introducida.

Distribución: LRI.

Veronica officinalis L.

Hierba. Perenne. Introducida.

Distribución: ARA, LRI.

Veronica peregrina L. subsp. xalapensis (Kunth) Pennell Hierba. Anual. Introducida.

Distribución: COQ, RME, LBO, MAU, NUB, BIO, ARA, LRI, AIS, MAG.

Veronica persica Poir.

Hierba. Anual. Introducida.

Distribución: ANT, ATA, COQ, VAL, RME, LBO, MAU, NUB, BIO, ARA, LRI, LLA, JFE.

\section{Veronica scutellata L.}

Hierba. Perenne. Introducida.

Distribución: LRI, LLA.

Veronica serpyllifolia L.

Hierba. Perenne. Introducida.

Distribución: VAL, RME, LBO, MAU, NUB, BIO, ARA, LRI, LLA, AIS, MAG.

\section{PLUMBAGINACEAE}

\section{Armeria}

Armeria maritima (Mill.) Willd.

Sinónimos: Armeria maritima (Mill.) Willd. subsp. andina (Poepp. ex Boiss.) D.M. Moore \& Yates, Armeria andina Poepp. ex Boiss., Armeria macloviana Cham., Armeria curvifolia Bertero, Armeria chilensis Boiss., Armeria androsacea Boiss., Armeria brachyphylla Boiss., Armeria delfinii Phil., Armeria tenuifolia Phil., Armeria patagonica Phil., Armeria exaristata Phil., Armeria aegialea Phil., Armeria bella Albov., Statice punicea Rendle, Statice macloviana Mackloskie, Statice maritima Mill.

Hierba. Perenne. Nativa.

Distribución: COQ, VAL, RME, LBO, MAU, NUB, BIO, ARA, LLA, AIS, MAG.

Rango altitudinal: 0-3200 m.

Países limítrofes: Argentina.

Nota: Para una completa sinonimia, ver E. Ruiz, Flora de Chile 2(3): 2. 2005.

\section{Bakerolimon}

Bakerolimon plumosum (Phil.) O.A. Lincz.

Sinónimos: Limonium plumosum (Phil.) Kuntze, Statice plumosa Phil.

Arbusto. Endémico.

Distribución: ANT, ATA, COQ.

Rango altitudinal: 0-1000 m.

\section{Limonium}

Limonium guaicuru (Molina) Kuntze

Sinónimos: Plegorrhiza guaicura Molina, Statice chilensis Phil., Plegorrhiza adstringens Willd.

Hierba. Perenne. Endémica.

Distribución: ATA, COQ, VAL.

Rango altitudinal: 0-200 m.

Nombre vulgar: Guaicurú.

Plumbago

Plumbago caerulea Kunth

Arbusto o subarbusto. Nativo.

Distribución: ANT, ATA, COQ.

Rango altitudinal: 0-2500 m.

Países limítrofes: Argentina, Bolivia y Perú.

\section{POLEMONIACEAE}

\section{Bryantiella}

Bryantiella glutinosa (Phil.) J.M. Porter

Sinónimos: Gilia glutinosa Phil.

Hierba. Anual. Nativa.

Distribución: AYP, TAR, ANT, ATA.

Rango altitudinal: 0-3700 m.

Países limítrofes: Perú.

Nombre vulgar: Lipelipe, pachareke, alhucema del campo, pasto de lluvia.

\section{Collomia}

Collomia biflora (Ruiz \& Pav.) Brand

Sinónimos: Gilia biflora (Ruiz \& Pav.) J.F. Macbr., Phlox biflora Ruiz \& Pav., Collomia cavanillesii Hook. \& Arn., Collomia cavanillesii Hook. \& Arn. fma. coccinea (Lehm. ex Lindl.) Wherry, Collomia coccinea Lehm. ex Lindl., Collomia soehrensi Phil., Collomia stenosiphon Kunze, Collomia lateritia Don, Collomia biflora (Ruiz \& Pav.) Brand var. lateritia (Don) Brand, Collomia cavanillesii Hook. \& Arn. fma. lateritia (Don) Wherry, Collomia cavanillesii Hook. \& Arn. fma. soehrensi (Phil.) Wherry, Collomia cavanillesii Hook. \& Arn. fma. stenosiphon (Kunze) Wherry, Phlox unidentata Bertero

Hierba. Anual. Nativa.

Distribución: VAL, RME, LBO, MAU, NUB, BIO, ARA, LRI, LLA, AIS, MAG. 
Rango altitudinal: 200-1300 m.

Países limítrofes: Argentina.

\section{Gilia}

Gilia crassifolia Benth.

Sinónimos: Gilia crassifolia Benth. var. andicola (Phil.) Brand, Gilia lanigera Phil., Gilia andicola Phil., Gilia intermedia Phil.

Hierba. Anual. Nativa.

Distribución: ANT, ATA, COQ, VAL, RME, LBO.

Rango altitudinal: 0-4000 m.

Países limítrofes: Argentina.

Gilia laciniata Ruiz \& Pav.

Hierba. Anual. Nativa.

Distribución: AYP, TAR, ANT, ATA, COQ, VAL, RME, LBO, MAU, NUB, BIO, ARA, LRI, LLA, AIS, JFE.

Rango altitudinal: 0-4300 $\mathrm{m}$.

Países limítrofes: Argentina, Bolivia y Perú.

Nombre vulgar: Latalata, comino del campo.

Gilia valdiviensis Griseb.

Hierba. Anual. Nativa.

Distribución: COQ, VAL, RME, LBO, LLA, JFE.

Rango altitudinal: 0-3000 m.

Países limítrofes: Argentina.

Nota: Introducida en la isla Más Afuera (Archipiélago Juan Fernández).

\section{Ipomopsis}

Ipomopsis gossypifera (Gillies ex Benth.) V.E. Grant Sinónimos: Gilia gossypifera Gillies ex Benth., Gilia involucrata Phil.

Hierba. Anual. Nativa.

Distribución: TAR, ANT, ATA.

Rango altitudinal: 2400-4500 m.

Países limítrofes: Argentina y Bolivia.

\section{Leptosiphon}

Leptosiphon pusillus (Benth.) J.M. Porter \& L.A. Johnson Sinónimos: Linanthus pusillus (Benth.) Greene, Gilia pusilla Benth.

Hierba. Anual. Endémica.

Distribución: COQ, VAL, RME, LBO.

Rango altitudinal: 0-800 m.

\section{Microsteris}

Microsteris gracilis (Hook.) Greene

Sinónimos: Gilia gracilis Hook., Collomia gracilis (Hook.) Douglas ex Benth., Gilia gracilis Hook. var. minuartioides (Franch.) Borsini, comb. illeg., Collomia gracilis (Hook.)
Douglas ex Benth. var. minuartioides Franch., Collomia eritrichoides Griseb., Gilia gracilis Hook. var. eritrichoides (Griseb.) Brand, Polemonium morenonis Kuntze, Navarretia gracilis (Hook.) Kuntze, Phlox gracilis (Hook.) Greene, Gilia gracilis Phil., hom. illeg.

Hierba. Anual. Nativa.

Distribución: AYP, TAR, COQ, VAL, RME, LBO, MAU, NUB, BIO, ARA, LLA, AIS, MAG, JFE.

Rango altitudinal: 0-4100 m.

Países limítrofes: Argentina, Bolivia y Perú.

Nota: Introducida en el Archipiélago Juan Fernández.

\section{Navarretia}

Navarretia involucrata Ruiz \& Pav.

Sinónimos: Gilia berterii DC., Gilia navarettia Steud., Gilia mucronata Lehm., Gilia eryngoides Lehm., Collomia navarretia $\mathrm{G}$. Don

Hierba. Anual. Nativa.

Distribución: VAL, RME, LBO, MAU, NUB, BIO, ARA, LRI, LLA, MAG.

Rango altitudinal: 1000-2000 m.

Países limítrofes: Argentina.

\section{Polemonium}

Polemonium micranthum Benth.

Sinónimos: Polemonium antarcticum Griseb., Polemonium gayanum (Wedd.) Brand, Gilia gayana Wedd., Gilia diffusa Phil., Gilia johowi F. Meigen, Polemoniella antarctica (Griseb.) A. Nelson \& J.F. Macbr. fma. diffusa (Phil.) Wherry, Polemoniella antarctica (Griseb.) A. Nelson \& J.F. Macbr. fma. gayana (Wedd.) Wherry, Polemoniella antarctica (Griseb.) A. Nelson \& J.F. Macbr. fma. johowi (F. Meigen) Wherry

Hierba. Anual. Nativa.

Distribución: COQ, VAL, RME, AIS, MAG.

Rango altitudinal: 0-2000 m.

Países limítrofes: Argentina.

\section{POLYGALACEAE}

\section{Monnina}

Monnina linearifolia Ruiz \& Pav.

Sinónimos: Pteromonnina linearifolia (Ruiz \& Pav.) B.

Eriksen

Hierba. Perenne. Nativa.

Distribución: COQ, VAL, RME, LBO, MAU, NUB, BIO, ARA.

Rango altitudinal: 0-1000 m.

Países limítrofes: Argentina.

Nombre vulgar: Agua-rica, quelén-quelén. 
Monnina philippiana Chodat

Sinónimos: Monnina pterocarpa Ruiz \& Pav. var. angustifolia (DC.) Hook. \& Arn., Pteromonnina philippiana (Chodat) B. Eriksen, Monnina angustifolia auct. non DC.

Hierba. Perenne. Nativa.

Distribución: COQ, VAL, RME, LBO.

Rango altitudinal: 100-1600 m.

Países limítrofes: Argentina.

\section{Polygala}

Polygala darwiniana A.W. Benn.

Sinónimos: Acanthocladus tehuelchum Speg., Polygala tehuelchum (Speg.) Speg.

Hierba. Anual o bienal. Nativa.

Distribución: MAG.

Rango altitudinal: 0-500 m.

Países limítrofes: Argentina.

Polygala gayi A.W. Benn.

Hierba. Anual o bienal. Endémica.

Distribución: VAL, RME, LBO, MAU, NUB, BIO, ARA, LLA.

Rango altitudinal: 0-1600 m.

Polygala gnidioides Willd.

Sinónimos: Polygala thesioides Willd., Polygala pratensis Phil., Polygala eutaxoides Turcz.

Hierba. Bienal o perenne. Nativa.

Distribución: COQ, VAL, RME, LBO, MAU, NUB, BIO,

ARA, LRI, LLA, AIS.

Rango altitudinal: 0-1800 m.

Países limítrofes: Argentina.

Nombre vulgar: Chin-chín, quelén-quelén, clinclín, quelulahuén.

Polygala persistens A.W. Benn.

Sinónimos: Polygala paradoxa Chodat

Hierba. Bienal o perenne. Nativa.

Distribución: MAU.

Rango altitudinal: 0-2000 m.

Países limítrofes: Argentina.

Polygala salasiana Gay

Hierba. Perenne. Nativa.

Distribución: ATA, COQ, RME, LBO, MAU, NUB, BIO,

ARA, AIS, MAG.

Rango altitudinal: 0-2600 m.

Países limítrofes: Argentina.

Polygala solieri Gay

Hierba. Perenne. Endémica.

Distribución: ATA.

Rango altitudinal: 2800-3000 m.
Polygala subandina Phil.

Sinónimos: Polygala oxyantha Phil., Polygala philippiana

Chodat, Polygala mendocina Phil.

Hierba. Perenne. Nativa.

Distribución: RME, LBO, BIO, ARA.

Rango altitudinal: 0-4500 m.

Países limítrofes: Argentina y Bolivia.

\section{POLYGONACEAE}

\section{Chorizanthe}

Chorizanthe commissuralis J. Remy

Hierba. Anual. Nativa.

Distribución: AYP, TAR, ANT, ATA, COQ.

Rango altitudinal: 0-1300 m.

Países limítrofes: Argentina.

Nombre vulgar: Pegadera, kinchanlawa.

Chorizanthe dasyantha Phil.

Sinónimos: Chorizanthe fasciculata Phil., Chorizanthe humilis Phil., Chorizanthe illapelina Phil., Chorizanthe intricata Phil., Chorizanthe parviflora Phil., Chorizanthe tenuis Phil., hom. illeg.

Subarbusto. Endémico.

Distribución: ATA, COQ, VAL.

Chorizanthe densa Phil.

Subarbusto. Endémico.

Distribución: VAL.

Rango altitudinal: 800-900 m.

Chorizanthe deserticola Phil.

Subarbusto. Endémico.

Distribución: ANT, ATA, COQ.

Rango altitudinal: 0-500 m.

Chorizanthe flavescens Phil.

Subarbusto. Endémico.

Distribución: COQ.

Rango altitudinal: 0-500 m.

Chorizanthe frankenioides J. Remy

Subarbusto. Endémico.

Distribución: ATA, COQ.

Rango altitudinal: 0-500 m.

Chorizanthe gajardoi Teillier \& Macaya

Hierba. Perenne. Endémica.

Distribución: COQ.

Rango altitudinal: 1850-1950 m. 
Chorizanthe glabrescens Benth.

Sinónimos: Chorizanthe tenuis Phil., Chorizanthe vaginata

Benth. var. arida J. Remy

Subarbusto. Endémico.

Distribución: COQ.

Chorizanthe kingii Phil.

Sinónimos: Chorizanthe pauciflora Phil.

Subarbusto. Endémico.

Distribución: ATA, COQ.

Rango altitudinal: 0-500 m.

Chorizanthe mieresii Teillier \& Macaya

Subarbusto. Endémico.

Distribución: ATA, COQ.

Rango altitudinal: 3-260 m.

Chorizanthe navasiae Teillier \& Macaya

Hierba. Perenne. Endémica.

Distribución: COQ.

Rango altitudinal: 5-280 m.

Chorizanthe novoana Teillier \& Macaya

Hierba. Perenne. Endémica.

Distribución: VAL.

Rango altitudinal: 0-100 m.

Chorizanthe paniculata Benth.

Sinónimos: Chorizanthe macraei Benth., Chorizanthe macraei Benth. var. humilis Benth., Chorizanthe ramosissima Benth., Chorizanthe rosea Phil.

Subarbusto. Endémico.

Distribución: COQ, VAL, RME, LBO.

Nombre vulgar: Sanguinaria.

Chorizanthe peduncularis Benth.

Sinónimos: Chorizanthe umbellata Phil.

Subarbusto. Endémico.

Distribución: ATA, COQ.

Chorizanthe rosasii Teillier \& Macaya

Hierba. Perenne. Endémica.

Distribución: COQ.

Rango altitudinal: 1700-2600 m.

\section{Chorizanthe vaginata Benth.}

Sinónimos: Chorizanthe vaginata Benth. var. maritima J. Remy

Subarbusto. Endémico.

Distribución: ATA, COQ, VAL, LBO, MAU.

Rango altitudinal: 0-200 m.
Chorizanthe virgata Benth.

Sinónimos: Chorizanthe virgata Benth. var. tomentosa Benth.

Subarbusto. Endémico.

Distribución: ATA, COQ, VAL, RME, LBO.

Rango altitudinal: $900 \mathrm{~m}$.

Chorizanthe viridis Phil.

Subarbusto. Endémico.

Distribución: COQ, VAL.

Rango altitudinal: 800-1100 m.

\section{Emex}

Emex spinosa (L.) Campd.

Hierba. Anual. Introducida.

Distribución: COQ.

Fallopia

Fallopia japonica (Houtt.) Ronse Decr.

Hierba. Perenne. Introducida.

Distribución: LLA, AIS.

Fallopia sachalinensis (F. Schmidt)

Hierba. Perenne. Introducida.

Distribución: LLA.

\section{Koenigia}

Koenigia islandica L.

Hierba. Anual. Introducida.

Distribución: MAG.

\section{Lastarriaea}

Lastarriaea chilensis J. Remy

Sinónimos: Lastarriaea linearis Phil. ex Parry, Lastarriaea stricta Phil., Chorizanthe chilensis (J. Remy) Goodman, Chorizanthe lastarriaea Parry, nom. illeg.

Hierba. Anual. Endémica.

Distribución: ATA, COQ, VAL, RME, LBO.

Rango altitudinal: 0-200 m.

\section{Muehlenbeckia}

Muehlenbeckia fruticulosa (Walp.) Standl. Sinónimos: Polygonum fruticulosum Walp.

Arbusto. Nativo.

Distribución: AYP.

Rango altitudinal: 3400-3500 m.

Países limítrofes: Bolivia y Perú.

Nombre vulgar: Visvisa. 
Muehlenbeckia hastulata (Sm.) I.M. Johnst. var. fascicularis (Meisn.) Brandbyge

Sinónimos: Muehlenbeckia chilensis Meisn. var. fascicularis Meisn.

Arbusto. Nativo.

Distribución: VAL, LBO, MAU, NUB, BIO, ARA, LRI, LLA.

Rango altitudinal: 0-500 m.

Países limítrofes: Argentina.

Muehlenbeckia hastulata (Sm.) I.M. Johnst. var. hastulata Sinónimos: Muehlenbeckia chilensis Meisn., Muehlenbeckia chilensis Meisn. var. brachybotrys Meisn., Muehlenbeckia chilensis Meisn. var. injucunda (Lindl.) Meisn., Polygonum hastulatum (Sm.) Kuntze, Polygonum injucunda Lindl., Rumex hastulatus Sm., Karkinetron undulatum Raf., Calacinum chilense (Meisn.) J.F. Macbr.

Arbusto. Nativo.

Distribución: AYP, TAR, ATA, COQ, VAL, RME, LBO, MAU, NUB, BIO, ARA, LRI, LLA.

Rango altitudinal: 0-2700 m.

Países limítrofes: Argentina.

Nombre vulgar: Mollaca, quilo, voqui negro.

Muehlenbeckia hastulata (Sm.) I.M. Johnst. var. rotundata (Phil.) Brandbyge

Sinónimos: Muehlenbeckia rotundata Phil.

Arbusto. Nativo.

Distribución: NUB, AIS, MAG.

Rango altitudinal: 0-1000 m.

Países limítrofes: Argentina.

\section{Oxytheca}

Oxytheca dendroidea Nutt. subsp. chilensis (J. Remy) Ertter

Sinónimos: Brisegnoa chilensis J. Remy, Oxytheca apiculata Miers ex Benth., nom. nud., Oxytheca spiculata Miers

Hierba. Anual. Nativa.

Distribución: ANT, ATA, COQ, VAL, RME.

Rango altitudinal: 2100-3500 m.

Países limítrofes: Argentina.

\section{Persicaria}

\section{Persicaria maculosa Gay}

Hierba. Anual. Introducida.

Distribución: AYP, TAR, ATA, COQ, VAL, RME, LBO, MAU, NUB, BIO, ARA, LRI, LLA, AIS, MAG.
Polygonum

Polygonum acuminatum Kunth

Hierba. Perenne. Introducida.

Distribución: VAL, LBO, MAU, NUB, BIO, IPA.

Nombre vulgar: Tavari (Rapa Nui).

Polygonum aviculare L.

Hierba. Anual o bienal. Introducida.

Distribución: AYP, TAR, ANT, ATA, COQ, VAL, RME, LBO, MAU, NUB, BIO, ARA, LRI, LLA, AIS, MAG, JFE.

Polygonum bowenkampii Phil.

Hierba. Perenne. Endémica.

Distribución: RME.

Polygonum brasiliense K. Koch

Hierba. Perenne. Introducida.

Distribución: AIS, MAG.

Polygonum campanulatum Hook. f.

Hierba. Perenne. Introducida.

Distribución: LLA, AIS.

Polygonum convolvulus L.

Hierba. Anual. Introducida.

Distribución: COQ, VAL, RME, LBO, NUB, BIO, ARA, LRI, LLA, AIS.

Polygonum hydropiper L.

Hierba. Anual. Introducida.

Distribución: MAU, NUB, BIO, LLA.

Polygonum hydropiperoides Michx.

Hierba. Perenne. Introducida.

Distribución: AYP, TAR, ATA, VAL, RME, LBO, MAU, NUB, BIO, ARA, LRI, JFE.

Polygonum lapathifolium L.

Hierba. Perenne. Introducida.

Distribución: ATA, RME, LBO, MAU, NUB, BIO, ARA, LRI, LLA, JFE.

Polygonum maritimum L.

Hierba. Perenne. Introducida.

Distribución: COQ, VAL, NUB, BIO, LRI, LLA, AIS, MAG.

Polygonum mite Schrank

Hierba. Anual. Introducida.

Distribución: VAL.

Polygonum orientale L.

Hierba. Anual. Introducida.

Distribución: RME, BIO, ARA. 
Polygonum sanguinaria J. Remy

Subarbusto. Endémico.

Distribución: COQ, VAL, RME, BIO, AIS.

Rango altitudinal: 0-2200 m.

Nombre vulgar: Sanguinaria.

\section{Rumex}

Rumex acetosa L.

Hierba. Perenne. Introducida.

Distribución: MAG.

Rumex acetosella $\mathrm{L}$.

Hierba. Perenne. Introducida.

Distribución: AYP, TAR, ANT, COQ, VAL, RME, LBO, MAU, NUB, BIO, ARA, LRI, LLA, AIS, MAG, JFE.

Rumex conglomeratus Murray var. vulgaris Wallr.

Hierba. Perenne. Introducida.

Distribución: ATA, COQ, VAL, RME, LBO, MAU, NUB,

BIO, ARA, LRI, LLA, AIS, JFE.

Rumex crispissimus Kuntze

Sinónimos: Rumex decumbens Dusén

Hierba. Perenne. Nativa.

Distribución: VAL, MAG.

Rango altitudinal: 0-800 m.

Países limítrofes: Argentina.

Rumex crispus L.

Hierba. Perenne. Introducida.

Distribución: ANT, ATA, COQ, VAL, RME, LBO, MAU, NUB, BIO, ARA, LRI, LLA, AIS, MAG, JFE, IPA.

Rumex cristatus DC.

Hierba. Perenne. Introducida.

Distribución: RME, LLA.

Rumex cuneifolius Campd.

Hierba. Perenne. Nativa.

Distribución: ATA, VAL, RME, BIO, ARA, LLA, AIS.

Rango altitudinal: 0-4000 m.

Países limítrofes: Argentina, Bolivia y Perú.

Rumex darwinianus Rech. f.

Hierba. Perenne. Nativa.

Distribución: LLA.

Rango altitudinal: 0-500 m.

Países limítrofes: Argentina.

Rumex longifolius DC.

Hierba. Perenne. Introducida.

Distribución: RME, LBO, MAU, BIO, ARA, LLA, MAG.
Rumex magellanicus Campd.

Sinónimos: Rumex hippiatricus J. Remy, Rumex magellanicus Griseb., hom. illeg., Rumex magellanicus Campd. var. dusenii Rech.f., Rumex erosus Phil.

Hierba. Perenne. Nativa.

Distribución: COQ, AIS, MAG.

Rango altitudinal: 1000-4000 m.

Países limítrofes: Argentina.

Nombre vulgar: Huaicrahu.

Rumex maricola J. Remy

Sinónimos: Rumex cuneifolius Campd. var. maricola (J. Remy) Rech.f., Rumex arenarius Poepp. ex Endl.

Hierba. Perenne. Endémica.

Distribución: COQ, VAL, RME, LBO, MAU, NUB, BIO, ARA, LRI, LLA, AIS.

Rango altitudinal: 0-500 $\mathrm{m}$.

Rumex maritimus L.

Hierba. Anual o bienal. Introducida.

Distribución: VAL, RME, MAG.

Rumex obtusifolius L.

Hierba. Perenne. Introducida.

Distribución: RME, LBO, BIO, ARA, LRI, LLA, AIS, MAG.

Rumex patagonicus Rchb.f.

Sinónimos: Rumex chiloensis Rchb.f.

Hierba. Perenne. Endémica.

Distribución: ARA, LLA, AIS.

Rango altitudinal: 0-500 m.

Rumex pulcher L.

Hierba. Perenne. Introducida.

Distribución: COQ, VAL, RME, LBO, MAU, NUB, BIO, ARA, LLA, MAG, JFE.

Rumex romassa J. Remy

Sinónimos: Rumex asplundii Rech.f.

Hierba. Perenne. Nativa.

Distribución: BIO, ARA, LRI, LLA, AIS.

Rango altitudinal: 1000-3500 m.

Países limítrofes: Argentina.

\section{PORTULACACEAE}

Portulaca

Portulaca oleracea L.

Hierba. Anual. Introducida.

Distribución: AYP, TAR, ATA, COQ, VAL, RME, LBO, MAU, BIO, ARA, LLA, JFE, IPA. 
Portulaca philippii I.M. Johnst.

Hierba. Perenne. Nativa.

Distribución: AYP, TAR, ANT, ATA.

Rango altitudinal: 500-3600 m.

Países limítrofes: Bolivia.

\section{PRIMULACEAE}

\section{Anagallis}

Anagallis alternifolia Cav. var. alternifolia

Sinónimos: Anagallis alternifolia Cav. var. minor R. Knuth, Anagallis alternifolia Cav. var. tenelliformis R. Knuth fma. laxa R. Knuth

Hierba. Perenne. Nativa.

Distribución: ANT, ATA, COQ, VAL, RME, LBO, MAU, NUB, BIO, ARA, LRI, LLA, AIS, MAG.

Rango altitudinal: 0-2500 m.

Países limítrofes: Argentina.

Anagallis alternifolia Cav. var. repens (d'Urv.) Knuth Sinónimos: Lysimachia repens d'Urv., Anagallis alternifolia Cav. var. densifolia Hook.f., Euparea chilensis Baudo, Anagallis alternifolia Cav. var. angustifolia Phil.

Hierba. Perenne. Nativa.

Distribución: ATA, COQ, VAL, RME, LBO, MAU, NUB, BIO, ARA, LRI, LLA, AIS, MAG.

Rango altitudinal: 0-3500 m.

Países limítrofes: Argentina.

Anagallis arvensis L.

Hierba. Anual. Introducida.

Distribución: AYP, TAR, ATA, COQ, VAL, RME, LBO, MAU, NUB, BIO, ARA, LLA, JFE, IPA.

\section{Androsace}

\section{Androsace salasii Kurtz}

Sinónimos: Collomia pusilla Dusén, Androsace pusilla (Dusén) Lourteig

Hierba. Anual. Nativa.

Distribución: AIS, MAG.

Rango altitudinal: 0-2500 m.

Países limítrofes: Argentina.

\section{Centunculus}

Centunculus minimus L.

Sinónimos: Anagallis minima (L.) E.H.L. Krause

Hierba. Anual. Introducida.

Distribución: ANT, COQ, RME, LBO, MAU, NUB, BIO, ARA, LLA, JFE.

\section{Lysimachia}

Lysimachia sertulata Baudo

Sinónimos: Lysimachia chilensis (Griseb.) Knuth, Lysimachia marginata Macloskie, Lysimachia umbellata Phil., Theopyxis chilensis Griseb.

Hierba. Perenne. Nativa.

Distribución: MAU, NUB, BIO, ARA, LRI, LLA.

Rango altitudinal: 0-2000 m.

Países limítrofes: Argentina.

Nombre vulgar: Melilukul.

\section{Pelletiera}

Pelletiera verna A. St.-Hil.

Sinónimos: Pelletiera serpyllifolia (Poir.) Kuntze, Asterolinon serpyllifolium (Poir.) Ball, Asterolinon trinum Baudo

Hierba. Anual. Nativa.

Distribución: VAL, RME, LBO, BIO, LLA.

Rango altitudinal: 0-1000 m.

Países limítrofes: Argentina.

\section{Primula}

Primula comberi W.W. Sm.

Hierba. Perenne. Nativa.

Distribución: ARA.

Rango altitudinal: 1500-2000 m.

Países limítrofes: Argentina.

Primula magellanica Lehm.

Sinónimos: Primula decipiens Duby, Primula farinosa L. var. magellanica (Lehm.) Hook.f., Primula farinosa L. subsp. magellanica (Lehm.) W.W. Sm. \& Forrest

Hierba. Perenne. Nativa.

Distribución: ARA, LLA, AIS, MAG.

Rango altitudinal: 0-1800 m.

Países limítrofes: Argentina.

Nombre vulgar: Primula, oreja de oso.

\section{Samolus}

Samolus latifolius Duby

Hierba. Perenne. Endémica.

Distribución: VAL, MAU, NUB, BIO, ARA, LRI, LLA.

Samolus repens (J.R. Forst. \& G. Forst.) Pers.

Hierba. Perenne. Nativa.

Distribución: BIO.

Nota: Se encuentra también en Australia.

Samolus spathulatus (Cav.) Duby

Sinónimos: Androsace spathulata Cav., Primula pistiifolia 
Griseb., Steirostemon spathulatus Phil.

Hierba. Perenne. Nativa.

Distribución: AIS, MAG.

Países limítrofes: Argentina.

Samolus valerandi $\mathrm{L}$.

Hierba. Perenne. Introducida.

Distribución: ATA, COQ, VAL.

Rango altitudinal: 10-2500 m.

\section{PROTEACEAE}

\section{Embothrium}

Embothrium coccineum J.R. Forst. \& G. Forst. Sinónimos: Embothrium coccineum J.R. Forst. \& G. Forst. var. cavanillesii Kuntze, Embothrium coccineum J.R. Forst. \& G. Forst. var. oblanceolatum Kuntze, Embothrium coccineum J.R. Forst. \& G. Forst. var. lanceolatum (Ruiz \& Pav.) Kuntze, Embothrium coccineum J.R. Forst. \& G. Forst. var. obovatum Kuntze, Embothrium coccineum J.R. Forst. \& G. Forst. fma. lanceolatum (Ruiz \& Pav.) R.L. PérezMor., Embothrium lanceolatum Ruiz \& Pav., Embothrium valdivianum Gand., Embothrium gilliesii Meisn.

Árbol. Nativo.

Distribución: MAU, NUB, BIO, ARA, LRI, LLA, AIS, MAG.

Rango altitudinal: 0-1500 m.

Países limítrofes: Argentina.

Nombre vulgar: Notro, notru, ciruelillo, fosforito, treumún.

\section{Gevuina}

Gevuina avellana Molina

Sinónimos: Quadria heterophylla Ruiz \& Pav., Quadria avellana (Molina) Gaertn.

Árbol. Nativo.

Distribución: MAU, NUB, BIO, ARA, LRI, LLA.

Rango altitudinal: $100-700 \mathrm{~m}$.

Países limítrofes: Argentina.

Nombre vulgar: Avellano, Gevuín.

\section{Lomatia}

Lomatia dentata (Ruiz \& Pav.) R. Br.

Sinónimos: Embothrium dentatum Ruiz \& Pav., Tricondylus dentatus (Ruiz \& Pav.) Kuntze, Lomatia dentata (Ruiz \& Pav.) R. Br. var. acutifolia Meisn., Lomatia dentata (Ruiz \& Pav.) R. Br. var. obtusifolia Meisn.

Árbol. Nativo.

Distribución: COQ, VAL, LBO, MAU, NUB, BIO, ARA, LRI, LLA.

Rango altitudinal: 0-1800 m.
Países limítrofes: Argentina.

Nombre vulgar: Avellanillo, piñol, guardafuego, palo negro.

Lomatia ferruginea (Cav.) R. Br.

Sinónimos: Embothrium ferrugineum Cav., Tricondylus ferrugineus (Cav.) Salisb., Lomatia pinnatifida Hort ex Thornton, nom. nud.

Árbol. Nativo.

Distribución: MAU, NUB, BIO, ARA, LRI, LLA, AIS, MAG.

Rango altitudinal: 0-800 m.

Países limítrofes: Argentina.

Nombre vulgar: Fuinque, romerillo, huinque, piuné, moré.

Lomatia hirsuta (Lam.) Diels subsp. obliqua (Ruiz \& Pav.) R.T. Penn.

Sinónimos: Lomatia obliqua (Ruiz \& Pav.) R. Br., Tricondylus obliqua (Ruiz \& Pav.) Kuntze, Lomatia obliqua (Ruiz \& Pav.) R. Br. var. alnifolia (Poepp. ex Meisn.) Meisn., Lomatia obliqua (Ruiz \& Pav.) R. Br. var. subintegrifolia Meisn., Embothrium obliquum Ruiz \& Pav. Árbol. Nativo.

Distribución: COQ, VAL, RME, LBO, MAU, NUB, BIO, ARA, LRI, LLA.

Rango altitudinal: 0-1000 m.

Países limítrofes: Argentina.

Nombre vulgar: Radal, raral, nogal silvestre.

\section{Orites}

Orites myrtoidea (Poepp. \& Endl.) Benth. \& Hook.f. ex B.D. Jacks.

Sinónimos: Lomatia chilensis Gay, Roupala myrtoidea Poepp. \& Endl., Lomatia alpina Phil., nom. nud., Embothrium myrtifolium Poepp. ex Meisn., Tricondylus chilensis (Gay) Kuntze

Arbusto. Nativo.

Distribución: MAU, NUB, BIO, ARA.

Rango altitudinal: $700-1500 \mathrm{~m}$.

Países limítrofes: Argentina.

Nombre vulgar: Radal enano.

\section{QUILLAJACEAE}

\section{Quillaja}

\section{Quillaja saponaria Molina}

Sinónimos: Quillaja molinae DC., Quillaja poeppigii Walp., Smegmadermos emarginatus Ruiz \& Pav., Smegmaria emarginata (Ruiz \& Pav.) Willd.

Árbol. Nativo.

Distribución: COQ, VAL, RME, LBO, MAU, NUB, BIO, ARA. 
Países limítrofes: Argentina.

Nombre vulgar: Quillay.

\section{RAFFLESIACEAE}

\section{Pilostyles}

Pilostyles berteroi Guill.

Sinónimos: Apodanthes berteroi (Guill.) Gardner, Frostia berteroi $\mathrm{H}$. Karst.

Hierba parásita. Perenne. Nativa.

Distribución: ANT, ATA, COQ, VAL, RME, NUB.

Rango altitudinal: 0-3700 m.

Países limítrofes: Argentina y Bolivia.

\section{RANUNCULACEAE}

\section{Anemone}

Anemone antucensis Poepp.

Hierba. Perenne. Nativa.

Distribución: MAU, NUB, BIO, ARA, LRI, LLA, MAG.

Rango altitudinal: 100-1800 m.

Países limítrofes: Argentina.

Anemone decapetala Ard. var. decapetala

Sinónimos: Anemone trilobata Juss., Anemone chilensis Spreng. ex Pritz., nom. nud., Anemone decapetala Ard. fma. primaria Eichler, Anemone chilensis Spreng. ex Eichler, nom. nud., Anemone decapetala Ard. var. grandifolia Eichler, Anemone polypetala Larrañaga, Anemone bilobata Phil., Anemone chilensis Spreng. ex Eichler, Anemone chilensis Spreng. ex Pritzel, Anemone macrorhiza Dombey ex Eichler

Hierba. Perenne. Nativa.

Distribución: COQ, VAL, RME, LBO, MAU, NUB, BIO, ARA, LRI, LLA, AIS, MAG, JFE.

Rango altitudinal: 0-3000 $\mathrm{m}$.

Países limítrofes: Argentina, Bolivia y Perú.

Nombre vulgar: Centella.

Nota: Introducida en el Archipiélago Juan Fernández.

Anemone decapetala Ard. var. foliolosa Eichler

Sinónimos: Anemone cicutifolia I.M. Johnst., Anemone triternata Vahl, Anemone decapetala Ard. var. triloba Juss. ex Lorentz, Anemone fumariaefolia Juss., Anemone decapetala Ard. var. triternata (Vahl) Kuntze, Anemone decapetala Niederl., Anemone tridentata Britton

Hierba. Perenne. Nativa.

Distribución: VAL, RME, LBO, MAU, NUB, BIO, ARA, LRI, LLA, AIS, MAG.

Rango altitudinal: 0-2500 m.
Países limítrofes: Argentina, Bolivia y Perú.

Nombre vulgar: Centella, flor de la esperanza.

Anemone hepaticifolia Hook.

Hierba. Perenne. Endémica.

Distribución: LRI, LLA.

Rango altitudinal: 0-1000 m.

Nombre vulgar: Flor de la estrella.

Anemone moorei Espinosa

Subarbusto. Endémico.

Distribución: MAU.

Rango altitudinal: $500 \mathrm{~m}$.

Nombre vulgar: Pata de león.

Anemone multifida Poir.

Sinónimos: Anemone multifida Poir. var. grandiflora Rendle, Anemone multifida Poir. var. lanigera (Gay) Ulbr., Anemone commersoniana Richardson ex Spreng., Anemone multifida Poir. var. magellanica DC., Anemone multifida Poir. var. commersoniana (Richardson ex Spreng.) Ulbr., Anemone multifida Poir. var. hudsoniana DC., Anemone lanigera Gay, Anemone multifida Poir. var. uniflora DC.

Hierba. Perenne. Nativa.

Distribución: MAU, NUB, BIO, ARA, LRI, LLA, AIS, MAG.

Rango altitudinal: 0-2000 m.

Países limítrofes: Argentina.

Anemone rigida Gay

Subarbusto. Endémico.

Distribución: RME, LBO, MAU.

Rango altitudinal: 1000-1500 m.

\section{Aquilegia}

Aquilegia vulgaris L.

Hierba. Perenne. Introducida.

Distribución: NUB, BIO, ARA, LRI, LLA.

\section{Barneoudia}

Barneoudia balliana Britton

Hierba. Perenne. Nativa.

Distribución: COQ, RME.

Rango altitudinal: 3000-5000 m.

Países limítrofes: Argentina.

\section{Barneoudia chilensis Gay}

Sinónimos: Barneoudia cyanoleuca Leyb., Barneoudia domeykoana Leyb., Anemone chilensis (Gay) Kurtz, Anemone chilensis (Gay) Reiche, comb. illeg., Anemone barneoudia Kuntze, Anemone gayana R. Wagner Hierba. Perenne. Nativa. 
Distribución: COQ, VAL, RME.

Rango altitudinal: 2000-4000 m.

Países limítrofes: Argentina.

Barneoudia major Phil.

Sinónimos: Anemone major (Phil.) F. Meigen, Anemone major (Phil.) Reiche, comb. illeg., Barneoudia maxima Leyb.

Hierba. Perenne. Nativa.

Distribución: COQ, VAL, RME, LBO.

Rango altitudinal: 1000-4000 m.

Países limítrofes: Argentina.

\section{Callianthemoides}

Callianthemoides semiverticillata (Phil.) Tamura

Sinónimos: Anemone myriophylla Speg., Ranunculus pseudosemiverticillatus Espinosa \& C. Rudolph, Ranunculus semiverticillatus Phil.

Hierba. Perenne. Nativa.

Distribución: LLA.

Rango altitudinal: 100-2500 m.

Países limítrofes: Argentina.

\section{Caltha}

Caltha appendiculata Pers.

Sinónimos: Caltha appendiculata Pers. var. chilensis Huth, Caltha limbata Schltdl., Caltha paradoxa Sol. ex T.F. Forst., Psychrophila appendiculata (Pers.) Gay, Caltha holophylla Leyb., Psychrophila holophylla Leyb.

Hierba. Perenne. Nativa.

Distribución: LBO, MAU, NUB, BIO, ARA, LRI, LLA, AIS, MAG.

Rango altitudinal: 0-2000 m.

Países limítrofes: Argentina.

Caltha dioneifolia Hook.f.

Sinónimos: Psychrophila dioneifolia (Hook.f.) Gay

Hierba. Perenne. Nativa.

Distribución: AIS, MAG

Rango altitudinal: 0-1100 m.

Países limítrofes: Argentina.

Caltha sagittata Cav.

Sinónimos: Caltha involuta A.W. Hill, Caltha alata A.W. Hill, Caltha sagittata Cav. var. latifolia Huth, Psychrophila sagittata (Cav.) Gay, Psychrophila andicola Gay, Caltha multicapsularis Sol. ex T.F. Forst., Caltha andicola (Gay) Walp., Caltha de ranco Steud., Caltha digitata A. Cunn. Hierba. Perenne. Nativa.

Distribución: COQ, RME, LBO, MAU, NUB, BIO, ARA, LLA, AIS, MAG

Rango altitudinal: 0-3500 m.
Países limítrofes: Argentina, Bolivia y Perú.

Nombre vulgar: Maillico.

\section{Clematis}

Clematis bonariensis Juss. ex DC.

Arbusto trepador. Introducido.

Distribución: BIO, ARA.

Rango altitudinal: 120-320 m.

Clematis montevidensis Spreng.

Arbusto trepador. Introducido.

Distribución: ATA.

\section{Halerpestes}

Halerpestes cymbalaria (Pursh) Greene

Sinónimos: Ranunculus microcarpus J. Presl, Ranunculus tridentatus Kunth ex DC., Ranunculus pozoaefolius Gay, Ranunculus minutus Gay, Ranunculus hemignostus Steud., Ranunculus maritimus Phil., Ranunculus minutus Gay var. microphylla Phil. ex Reiche, Ranunculus cymbalaria Pursh, Ranunculus cymbalaria Pursh var. americanus DC., Ranunculus tridentatus Kunth ex DC. var. major DC., Ranunculus tridentatus Kunth ex DC. var. minor DC., Ranunculus microcarpus J. Presl var. maritima Phil., Halerpestes tridentata (Kunth ex DC.) Greene

Hierba. Perenne. Nativa.

Distribución: AYP, TAR, ANT, ATA, COQ, VAL, RME, LBO, MAU, AIS, MAG.

Rango altitudinal: 0-4500 m.

Países limítrofes: Argentina y Bolivia.

Halerpestes exilis (Phil.) Tamura

Sinónimos: Ranunculus cymbalaria Pursh fma. exilis (Phil.) Lourteig, Ranunculus cymbalaria Pursh var. exilis (Phil.) R.E. Fr., Ranunculus exilis Phil., Ranunculus minutus Gay var. exilis (Phil.) Reiche, Ranunculus minutiusculus Ulbr.

Hierba. Anual. Nativa.

Distribución: AYP, TAR, ANT, ATA, COQ.

Rango altitudinal: $2000-4300 \mathrm{~m}$.

Países limítrofes: Argentina.

Halerpestes uniflora (Phil. ex Reiche) Emadzade, Lehnebach, P. Lockh. \& Hörandl

Sinónimos: Ranunculus pseudocaltha Chodat \& Wilczek, Ranunculus pseudocaltha Chodat \& Wilczek fma. minor Chodat \& Wilczek, Ranunculus uniflorus Phil. ex Reiche, Ranunculus uniflorus Phil. ex Reiche fma. bolivianus (Phil.) Lourteig, Ranunculus bolivianus Phil.

Hierba. Perenne. Nativa.

Distribución: AYP, TAR, ANT, ATA, MAU, AIS, MAG.

Rango altitudinal: 0-4500 m.

Países limítrofes: Argentina. 


\section{Hamadryas}

Hamadryas delfinii Phil. ex Reiche

Hierba. Perenne. Nativa.

Distribución: MAG.

Rango altitudinal: 0-1100 m.

Países limítrofes: Argentina.

Hamadryas kingii Hook.f.

Hierba. Perenne. Nativa.

Distribución: MAG.

Rango altitudinal: 500-2000 m.

Países limítrofes: Argentina.

Hamadryas magellanica Lam.

Sinónimos: Hamadryas tomentosa DC., Hamadryas magellanica Lam. var. tomentosa (DC.) Hook.f., Hamadryas magellanica Franchet, Hamadryas paniculata Hook.f.

Hierba. Perenne. Nativa.

Distribución: MAG.

Rango altitudinal: 0-1000 m.

Países limítrofes: Argentina.

Hamadryas sempervivoides Sprague

Hierba. Perenne. Nativa.

Distribución: MAG.

Rango altitudinal: 700-1300 m.

Países limítrofes: Argentina.

\section{Myosurus}

\section{Myosurus apetalus Gay}

Sinónimos: Myosurus gracilis (Speg.) Macloskie, Myosurus aristatus Benth. ex Hook.f. var. apetalus (Gay) Huth, Myosurus aristatus Benth. ex Hook.f. var. gracilis Speg., Myosurus aristatus Benth. ex Hook.f. var. brachypoda Speg., Myosurus aristatus Benth. ex Hook.f.

Hierba. Anual. Nativa.

Distribución: COQ, RME, MAG.

Rango altitudinal: 0-4000 m.

Países limítrofes: Argentina, Bolivia y Perú.

Myosurus patagonicus Speg.

Sinónimos: Myosurus minimus auct. non L.

Hierba. Anual. Nativa.

Distribución: RME, NUB, BIO, MAG.

Rango altitudinal: 0-500 m.

Países limítrofes: Argentina.

\section{Ranunculus}

Ranunculus acaulis Banks \& Sol. ex DC.

Sinónimos: Ranunculus skottsbergii Gand., Ranunculus stenopetalus Hook., Ranunculus litoralis Schltdl. ex Lechl., nom. nud., Ranunculus litoralis Phil., Ranunculus biternatus Vallentin \& Cotton, Ranunculus uniflorus Colenso

Hierba. Anual. Nativa.

Distribución: LLA, AIS, MAG.

Rango altitudinal: 0-1000 m.

Países limítrofes: Argentina.

Ranunculus apiifolius Pers.

Sinónimos: Ranunculus sceleratus auct. non L., Aphanostemma apiifolium (Pers.) A. St.-Hil.

Hierba. Anual. Nativa.

Distribución: VAL, LBO, MAU, NUB, BIO, ARA, LLA.

Rango altitudinal: 0-500 m.

Países limítrofes: Argentina.

Nombre vulgar: Apio cimarrón.

\section{Ranunculus aquatilis L.}

Hierba acuática. Perenne. Introducida.

Distribución: AYP, NUB, BIO, ARA, LLA, MAG.

Ranunculus arvensis L.

Hierba. Anual. Introducida.

Distribución: MAU, NUB, BIO.

Ranunculus biternatus Sm.

Sinónimos: Ranunculus exiguus d'Urv., Ranunculus commersonii DC. ex Poir., Ranunculus montteanus Phil., Ranunculus crassipes Hook.f., Ranunculus flaccidus Banks \& Sol. ex Hook.f., Ranunculus montteanus Phil. var. obtusilobus Phil. ex Reiche

Hierba. Anual. Nativa.

Distribución: LLA, AIS, MAG.

Rango altitudinal: 0-900 m.

Países limítrofes: Argentina.

Ranunculus bonariensis Poir. var. trisepalus (Gillies ex Hook. \& Arn.) Lourteig

Sinónimos: Ranunculus trisepalus Gillies ex Hook. \& Arn., Ranunculus obtusatus Poepp., Ranunculus bonariensis Poir. var. beta Eichler, Ranunculus humilis Collie ex Hook. \& Arn., Ranunculus berteronianus Steud., nom. nud.

Hierba. Anual. Nativa.

Distribución: COQ, VAL, RME, LBO, MAU, NUB, BIO, ARA, LRI.

Rango altitudinal: 0-900 m.

Países limítrofes: Argentina.

Ranunculus caprarum Skottsb.

Hierba. Perenne. Endémica.

Distribución: JFE.

Rango altitudinal: $1200 \mathrm{~m}$. 
Ranunculus chilensis DC.

Sinónimos: Ranunculus sericans Steud., Ranunculus protractus Steud., Ranunculus elatus Steud., Ranunculus berteroanus Phil., Ranunculus chilensis DC. var. lasius Phil. ex Reiche, Ranunculus chilensis DC. var. gayi Phil. ex Reiche, Ranunculus valdivianus Phil. ex Reiche, Ranunculus chilensis DC. var. alpha Poepp., Ranunculus chilensis DC. var. beta Poepp.

Hierba. Anual. Nativa.

Distribución: COQ, VAL, RME, LBO, MAU, NUB, BIO, ARA, LRI, LLA, AIS, MAG.

Rango altitudinal: 0-3600 m.

Países limítrofes: Argentina y Perú.

Nombre vulgar: Cáustico de vega, ranunculo.

Ranunculus flagelliformis Sm.

Sinónimos: Casalea flagelliformis (Sm.) A. St.-Hil., Casalea flagelliformis (Sm.) A. St.-Hil. var. lutescenes A. St.-Hil., Casalea hederacea Mart. ex Eichler

Hierba. Anual. Nativa.

Distribución: COQ, VAL, RME, MAU, NUB, BIO, ARA, LRI, LLA.

Rango altitudinal: 0-2500 m.

Países limítrofes: Argentina, Bolivia y Perú.

Ranunculus fuegianus Speg.

Sinónimos: Ranunculus biternatus Wild.

Hierba. Perenne. Nativa.

Distribución: COQ, AIS, MAG.

Rango altitudinal: 0-3700 m.

Países limítrofes: Argentina.

Ranunculus hydrophilus Gaudich.

Hierba. Anual. Nativa.

Distribución: BIO, ARA, LLA, AIS, MAG.

Rango altitudinal: 0-1500 m.

Países limítrofes: Argentina.

Ranunculus maclovianus d'Urv.

Sinónimos: Ranunculus colliguensis Steud.

Hierba. Anual. Nativa.

Distribución: LLA, MAG.

Rango altitudinal: 0-1000 m.

Países limítrofes: Argentina.

Ranunculus minutiflorus Bertero ex Phil.

Sinónimos: Ranunculus savatieri Franch., Ranunculus aysenensis Gand., Ranunculus chilensis auct. non DC., Casalea chilensis A. St.-Hil., Ranunculus saxifragaefolius Steud., Ranunculus miser Phil., Ranunculus minutiflorus Bertero ex Phil. var. miser (Phil.) Reiche, Hydrocotyle pauciflora Phil., Ranunculus berteroanus Presl

Hierba. Perenne. Nativa.

Distribución: COQ, RME, LBO, MAU, NUB, BIO, ARA,
LRI, LLA, AIS, MAG.

Rango altitudinal: 0-1800 m.

Países limítrofes: Argentina.

Ranunculus muricatus L.

Hierba. Anual. Introducida.

Distribución: COQ, VAL, RME, LBO, MAU, NUB, ARA, LRI, MAG, JFE.

Ranunculus parviflorus $\mathrm{L}$.

Hierba. Anual. Introducida.

Distribución: NUB, BIO, ARA.

Ranunculus peduncularis Sm. var. erodiifolius (Gay) Reiche

Sinónimos: Ranunculus erodiifolius Gay, Ranunculus peduncularis Sm. var. polypetalus (Gillies ex Hook. \& Arn.) Macloskie, Ranunculus polypetalus Gillies ex Hook. $\&$ Arn., hom. illeg., Ranunculus andinus Phil., Ranunculus polypetalus Gillies ex Hook. \& Arn. var. acaulis Gillies

Hierba. Perenne. Nativa.

Distribución: COQ, RME, LBO, MAU, NUB, BIO, ARA, LRI, LLA, AIS, MAG.

Rango altitudinal: 0-3500 m.

Países limítrofes: Argentina.

\section{Ranunculus peduncularis Sm. var. peduncularis}

Sinónimos: Ranunculus alboffii Macloskie, Ranunculus glandulifer Poepp., Ranunculus patagonicus Poepp., Ranunculus peduncularis Sm. var. alboffiana Speg., Ranunculus peduncularis Sm. var. glandulifer (Poepp.) Reiche, Ranunculus peduncularis Sm. var. patagonicus (Poepp.) Reiche, Ranunculus peduncularis Sm. var. minor Wedd. ex Franch., Ranunculus gilliesii Steud., Ranunculus talquinus Phil. ex Reiche, Ranunculus peduncularis Sm. var. glabrata Reiche, Ranunculus peduncularis Sm. var. saffordi Phil. ex Reiche, Ranunculus peduncularis Sm. var. longavinus Phil. ex Reiche, Ranunculus peduncularis Sm. var. chillanensis Phil. ex Reiche, Ranunculus polypetalus Steud. nom. nud., Ranunculus pratensis Phil.

Hierba. Perenne. Nativa.

Distribución: COQ, VAL, RME, LBO, MAU, NUB, BIO, ARA, LLA, AIS, MAG.

Rango altitudinal: 0-3000 m.

Países limítrofes: Argentina.

Ranunculus pseudotrullifolius Skottsb.

Sinónimos: Ranunculus dusenii Lourteig, Ranunculus caespitosus Dusén, Ranunculus trullifolius Dusén, hom. illeg.

Hierba. Anual. Nativa.

Distribución: LLA, MAG.

Rango altitudinal: 0-500 $\mathrm{m}$.

Países limítrofes: Argentina. 
Ranunculus repens L. var. flore-pleno DC.

Hierba. Perenne. Introducida.

Distribución: COQ, VAL, NUB, BIO, ARA, LRI, LLA.

Ranunculus repens L. var. repens

Hierba. Perenne. Introducida.

Distribución: ATA, COQ, VAL, RME, LBO, MAU, NUB, BIO, ARA, LRI, LLA, AIS, MAG.

Ranunculus sceleratus L.

Hierba. Anual. Introducida.

Distribución: VAL, RME, LBO.

Ranunculus sericocephalus Hook.f.

Sinónimos: Ranunculus fueginos Phil. ex Reiche, Ranunculus sericocephalus Hook.f. var. major Albov, Ranunculus phillipianus De Wild.

Hierba. Perenne. Nativa.

Distribución: MAG.

Rango altitudinal: 0-1000 m.

Países limítrofes: Argentina.

Ranunculus spegazzinii Lourteig

Sinónimos: Ranunculus oligocarpus Speg., hom. illeg.

Hierba. Perenne. Nativa.

Distribución: ARA, AIS, MAG.

Rango altitudinal: 1000-1500 m.

Países limítrofes: Argentina.

\section{Ranunculus trichophyllus Chaix}

Sinónimos: Ranunculus aquatilis auct. non L., Ranunculus aquatilis L. var. caespitosa auct. non DC., Ranunculus aquatilis L. var. capillacea auct. non DC., Ranunculus fluitans Lam. fma. minor auct. non Gelert, Ranunculus fluitans Lam. var. fluviatilis auct. non (G. Weber ex F.H.

Wigg.) Gelert, Ranunculus curvirostris Freyn

Hierba acuática. Anual. Nativa.

Distribución: LLA, MAG.

Rango altitudinal: 0-4000 m.

Países limítrofes: Argentina, Bolivia y Perú.

Ranunculus trullifolius Hook.f.

Sinónimos: Ranunculus monanthos Phil., Ranunculus monanthos Phil. var. chiloensis Phil. ex Reiche

Hierba. Anual. Nativa.

Distribución: COQ, ARA, LLA, AIS, MAG.

Rango altitudinal: 0-1000 m.

Países limítrofes: Argentina.

\section{RESEDACEAE}

\section{Reseda}

Reseda decursiva Forssk.

Hierba. Anual o bienal. Introducida.

Distribución: VAL.

Reseda lutea L.

Arbusto. Introducido.

Distribución: NUB, BIO.

Reseda luteola L.

Hierba. Anual o perenne. Introducida.

Distribución: VAL, BIO.

Reseda odorata L.

Hierba. Anual. Introducida.

Distribución: ATA.

Reseda phyteuma L.

Hierba. Anual o perenne. Introducida.

Distribución: ATA, BIO.

\section{RHAMNACEAE}

\section{Colletia}

\section{Colletia hystrix Clos}

Sinónimos: Colletia valdiviana Phil., Colletia spinosa Lam. var. armata (Miers) Reiche, Colletia armata Miers, Colletia pungens Miers, Colletia spinosa Lam. var. valdiviana (Phil.) Reiche, Colletia spinosissima J.F. Gmel. var. valdiviana (Phil.) Escal., Colletia aciculata Miers, Colletia armata Miers var. insularis Miers, Colletia brevispina Phil., Colletia cataphracta Miers, Colletia ferox Gillies \& Hook. var. veprecula (Miers) Suess., Colletia hystrix Clos var. bresvispina (Phil.) Reiche, Colletia spinosa Lam., Colletia tomentosa Phil., Colletia spinosa Lam. var. cataphracta (Miers) Reiche, Colletia ferox Gillies \& Hook. var. dumosa (Miers) Suess., Colletia spinosa Lam. var. pungens (Miers) Reiche, Colletia veprecula Miers, Colletia spinosa Lam. var. veprecula (Miers) Reiche

Arbusto. Nativo.

Distribución: ATA, COQ, VAL, RME, LBO, MAU, NUB, BIO, ARA, LRI, LLA, AIS.

Rango altitudinal: 0-2000 m.

Países limítrofes: Argentina.

Nombre vulgar: Crucero, yaquil.

Colletia spartioides Bertero ex Colla

Arbusto. Endémico.

Distribución: JFE. 
Rango altitudinal: 0-600 m.

Nombre vulgar: Yaquil.

Colletia ulicina Gillies \& Hook.

Sinónimos: Colletia valenzuela Bertero ex Steud., nom. nud.

Arbusto. Endémico.

Distribución: COQ, VAL, RME, LBO, MAU, BIO.

Rango altitudinal: 0-1400 m.

Nombre vulgar: Crucero, junco minero, yaquil.

\section{Discaria}

Discaria articulata (Phil.) Miers

Sinónimos: Colletia articulata Phil., Retamilia articulata (Phil.) Miers

Arbusto. Nativo.

Distribución: RME, LBO, MAU, NUB, BIO, ARA.

Rango altitudinal: 0-2000 m.

Países limítrofes: Argentina.

Nombre vulgar: Crucero, yaquil.

Discaria chacaye (G. Don) Tortosa

Sinónimos: Colletia chacaye G. Don, Colletia discolor Hook., Colletia crenata Clos, Colletia serratifolia Vent. var. foliosa Hook. \& Arn., Notophaena magellanica Miers, Notophaena cognata Miers, Discaria cognata (Miers) Reiche, Colletia montana Phil., Colletia dumosa Phil., Discaria magellanica (Miers) Reiche, Colletia nivalis Phil., Discaria foliosa (Hook. \& Arn.) Reiche, Discaria crenata (Clos) Regel, Colletia serratifolia auct. non Vent., Discaria dumosa (Phil.) Reiche, Discaria montana (Phil.) Reiche, Notophaena discolor (Hook.) Miers, Notophaena foliosa (Hook. \& Arn.) Miers, Discaria discolor (Hook.) Reiche, comb. illeg.

Arbusto o árbol pequeño. Nativo.

Distribución: VAL, RME, LBO, MAU, NUB, BIO, ARA, LRI, LLA, AIS, MAG.

Rango altitudinal: 0-2300 m.

Países limítrofes: Argentina.

Nombre vulgar: Chacaye.

Discaria nana (Clos) Benth. \& Hook. ex Weberb.

Sinónimos: Colletia nana Clos, Ochetophila parvifolia Miers, Ochetophila prostrata Miers, nom. illeg., Colletia stipellacea Phil., Discaria prostrata (Miers) Reiche, nom. illeg., Discaria nana (Clos) Benth. \& Hook. ex Weberb. var. inermis Kuntze, Discaria prostrata (Miers) Reiche var. inermis Chodat \& Wilczek, nom. nud., Ochetophila nana (Clos) J. Kellerm., Medán \& Aagesen

Arbusto. Nativo.

Distribución: COQ, VAL, RME, LBO, MAU, NUB, BIO, ARA.

Rango altitudinal: 1000-3800 m.
Países limítrofes: Argentina.

Discaria trinervis (Gillies ex Hook. \& Arn.) Reiche Sinónimos: Sageretia trinervis Gillies ex Hook. \& Arn., Ochetophila hookeriana Reissek ex Clos, nom. illeg., Colletia doniana Clos, Discaria doniana (Clos) Weberb., Rhamnus linearis Clos, Ochetophila trinervis (Gillies ex Hppk.) Poepp. ex Miers

Arbusto o árbol pequeño. Nativo.

Distribución: ATA, COQ, VAL, RME, LBO, MAU, NUB, BIO, ARA, AIS.

Rango altitudinal: 0-3500 m.

Países limítrofes: Argentina.

Nombre vulgar: Chacay.

\section{Retanilla}

Retanilla ephedra (Vent.) Brongn.

Sinónimos: Retanilla ephedra (Vent.) Brongn. var. crassa (Phil.) Reiche, Colletia ephedra Vent., Colletia obcordata Vent., Retanilla obcordata (Vent.) Brongn., Retanilla crassa Phil., Retanilla moelleri Phil.

Arbusto. Endémico.

Distribución: VAL, RME, LBO, MAU, NUB, BIO, ARA.

Rango altitudinal: 0-1500 m.

Nombre vulgar: Retamilla, coquilla, camán, yaquil.

Retanilla stricta Hook. \& Arn.

Sinónimos: Trevoa frutilla Steud., nom. nud., Retanilla affinis Clos

Arbusto. Endémico.

Distribución: COQ, VAL, RME, LBO, MAU.

Rango altitudinal: 200-1500 m.

Nombre vulgar: Frutilla del campo.

Retanilla trinervia (Gillies \& Hook.) Hook. \& Arn.

Sinónimos: Trevoa trinervia Gillies \& Hook., Colletia trebu Bertero ex Colla, Trevoa trinervis Miers, nom. nud.

Arbusto. Endémico.

Distribución: COQ, VAL, RME, LBO, MAU.

Rango altitudinal: 0-1700 m.

Nombre vulgar: Trevu, trevo.

\section{Rhamnus}

Rhamnus diffusus Clos

Sinónimos: Colletia maytenioides Griseb., Sciadophila maytenoides Phil.

Arbusto. Endémico.

Distribución: MAU, NUB, BIO, ARA, LRI.

Rango altitudinal: 0-1200 m.

Nombre vulgar: Murta negra, palo negro, molfuenmamel. 


\section{Trevoa}

Trevoa quinquenervia Gillies \& Hook.

Sinónimos: Talguenea quinquenervia (Gillies \& Hook.) I.M. Johnst., Talguenea costata Miers, Colletia tralhuen Bertero ex Colla, Talguenea costata Hook. \& Arn., nom. illeg., Talguenea mollis Miers, nom. illeg.

Arbusto. Endémico.

Distribución: COQ, VAL, RME, LBO, MAU, NUB.

Rango altitudinal: 0-2200 m.

Nombre vulgar: Tralhuén, talguén, tulahuén.

\section{ROSACEAE}

\section{Acaena}

Acaena alpina Poepp. ex Walp.

Sinónimos: Acaena digitata Phil., Acaena digitata Phil. var. latifoliolata Bitter, Acaena digitata Phil. var. subpinnata Bitter

Hierba. Perenne. Nativa.

Distribución: VAL, RME, LBO, MAU, NUB, BIO, ARA, LLA.

Rango altitudinal: 2200-2500 m.

Países limítrofes: Argentina.

Acaena antarctica Hook.f.

Sinónimos: Acaena microcephala Schltdl., Acaena pearcei Phil., Acaena pumila Phil., hom. illeg., Acaena tenuifolia Bitter, Acaena pearcei Phil. var. glabrinervis Bitter

Hierba. Perenne. Nativa.

Distribución: BIO, ARA, LLA, AIS, MAG.

Rango altitudinal: 1000-1600 m.

Países limítrofes: Argentina.

Acaena argentea Ruiz \& Pav.

Sinónimos: Acaena argentea Ruiz \& Pav. var. breviscapa Bitter, Acaena argentea Ruiz \& Pav. fma. nigricans Bitter, Acaena argentea Ruiz \& Pav. fma. viridis Bitter, Acaena argentea Ruiz \& Pav. var. coriacea Bitter, Acaena argentea Ruiz \& Pav. var. grandiceps Bitter, Acaena argentea Ruiz \& Pav. var. interrrupte-pinnata Bitter, Acaena argentea Ruiz \& Pav. var. lanigera Bitter, Acaena argentea Ruiz \& Pav. var. subcalvescens Bitter, Acaena argentea Ruiz \& Pav. fma. epargyrea Bitter

Hierba. Perenne. Nativa.

Distribución: LBO, MAU, NUB, BIO, ARA, LLA, JFE.

Rango altitudinal: 700-1000 m.

Países limítrofes: Argentina y Perú.

Nombre vulgar: Cadillo, trun, amor seco, zarzaparrilla, proquín.

Nota: Introducida en el Archipiélago Juan Fernández.
Acaena caespitosa Gillies ex Hook. \& Arn.

Hierba. Perenne. Nativa.

Distribución: MAG.

Rango altitudinal: 0-3000 m.

Países limítrofes: Argentina.

Acaena integerrima Gillies ex Hook. \& Arn.

Sinónimos: Acaena integerrima Gillies ex Hook. \& Arn. var. oligantha Bitter, Acaena integerrima Gillies ex Hook. \& Arn. var. subpilosicupula Bitter

Hierba. Perenne. Nativa.

Distribución: RME, LBO, MAU, NUB, BIO, ARA, AIS, MAG.

Rango altitudinal: 0-2000 m.

Países limítrofes: Argentina.

Acaena leptacantha Phil.

Sinónimos: Acaena capitata Phil., Acaena leptacantha Phil. var. conferta Bitter, Acaena leptacantha Phil. subsp. connectens Bitter, Acaena leptacantha Phil. var. longissima Bitter, Acaena leptacantha Phil. var. negeri (E. Duse) Bitter, Acaena macrocephala Poepp. var. negeri E. Duse

Hierba. Perenne. Nativa.

Distribución: RME, LBO, MAU, NUB, BIO, ARA, LLA.

Rango altitudinal: 1000-1700 m.

Países limítrofes: Argentina.

Nombre vulgar: Pimpinela.

Acaena lucida (Aiton) Vahl

Sinónimos: Ancistrum lucidum Aiton, Acaena parvifolia Phil., Acaena lucida (Lam.) Vahl, nom. illeg., Acaena lucida (Lam.) Vahl var. parvifolia (Phil.) Reiche, Ancistrum lucidum Lam., nom. illeg.

Hierba. Perenne. Nativa.

Distribución: MAG.

Rango altitudinal: 700-1100 m.

Países limítrofes: Argentina.

Acaena macrocephala Poepp.

Sinónimos: Acaena macrocephala Poepp. var. caputmedusae Bitter, nom. illeg.

Hierba. Perenne. Nativa.

Distribución: MAU, NUB, BIO, ARA, LRI.

Rango altitudinal: 900-2000 m.

Países limítrofes: Argentina.

Acaena magellanica (Lam.) Vahl

Sinónimos: Acaena canescens Phil., Acaena glandulifera Bitter, Acaena glaucella Bitter, Acaena krausei Phil., Acaena laevigata Aiton, Acaena macropoda Bitter, Ancistrum magellanicum Lam., Acaena adscendens (Lam.) Vahl, Acaena acutifida Bitter, Acaena brachyglochin Bitter, Acaena colchaguensis Bitter, Acaena hirsuta Phil., Acaena cadilla Hook.f., Acaena closiana Gay, Acaena coxi Phil., 
Acaena petiolulata Phil., Acaena macrostemon Hook.f., Acaena depauperata Bitter, Acaena exaltata Bitter, Acaena grandistipula Bitter, Acaena grossifolia Bitter, Acaena hirta Citerne, Acaena humilis Bitter, Acaena ischnostemom Bitter, Acaena krausei Phil. var. hirsuta (Phil.) Reiche, Acaena krausei Phil. var. massonandra Bitter, Acaena krausei Phil. var. meionandra Bitter, Acaena laevigata Aiton var. venulosa (Griseb.) Reiche, Acaena longiaristata H. Ross, Acaena longistipula Bitter, Acaena macrophyes Bitter, Acaena macrostemon Hook.f. subsp. closiana (Gay) Bitter, Acaena macrostemon Hook.f. var. basipilosa Bitter, Acaena macrostemon Hook.f. subsp. longiaristata (H. Ross) Bitter, Acaena magellanica (Lam.) Vahl subsp. pygmaea Bitter, Acaena magellanica (Lam.) Vahl var. glabrescens Bitter, Acaena magellanica (Lam.) Vahl subsp. venulosa (Griseb.) Bitter, Acaena neglecta Bitter, Acaena obtusiloba Bitter, Acaena oligoglochin Bitter, Acaena plioglochin Bitter, Acaena rubescens Bitter, Acaena subflaccida Bitter, Acaena venulosa Griseb.

Hierba. Perenne. Nativa.

Distribución: AYP, TAR, ANT, ATA, COQ, VAL, RME, LBO, MAU, NUB, BIO, ARA, LRI, LLA, AIS, MAG.

Rango altitudinal: 100-3500 m.

Países limítrofes: Argentina.

Nombre vulgar: Amor seco, cadilla, trun, sítor.

Acaena masafuerana Bitter

Hierba. Perenne. Endémica.

Distribución: JFE.

Rango altitudinal: 1000-1100 m.

Acaena ovalifolia Ruiz \& Pav.

Sinónimos: Acaena elegans Gay, Acaena micranthera Bitter, Acaena ovalifolia Ruiz \& Pav. subsp. elegans (Gay) Bitter, Acaena ovalifolia Ruiz \& Pav. var. elegans (Gay) Reiche, Acaena tenuipila Bitter

Hierba. Perenne. Nativa.

Distribución: COQ, RME, LBO, MAU, NUB, BIO, ARA, LRI, LLA, AIS, MAG, JFE.

Rango altitudinal: 500-2500 m.

Países limítrofes: Argentina, Bolivia y Perú.

Nombre vulgar: Cadillo.

Nota: Introducida en el Archipiélago Juan Fernández.

Acaena patagonica A.E. Martic.

Hierba. Perenne. Nativa.

Distribución: RME, MAG.

Rango altitudinal: 0-1100 m.

Países limítrofes: Argentina.

Acaena pinnatifida Ruiz \& Pav.

Sinónimos: Acaena multifida Hook.f., Acaena multifida Hook.f. var. utriquepilosa Bitter, Acaena pinnatifida Ruiz \& Pav. subsp. pliacantha Bitter, Acaena pinnatifida Ruiz
\& Pav. var. depauperata Bitter, Acaena calcitrapa Phil., Acaena euacantha Phil., Acaena leptophylla Phil., Acaena longifolia Phil., Acaena multifida Hook.f. subsp. intercedens Bitter, Acaena multifida Hook.f. subsp. quinquefida Bitter, Acaena oligacantha Phil., Acaena pinnatifida Ruiz \& Pav. var. macrura Bitter, Acaena pinnatifida Ruiz \& Pav. subsp. heterotricha Bitter, Acaena pinnatifida Ruiz \& Pav. var. parvifrons Bitter, Acaena pinnatifida Ruiz \& Pav. subsp. hypoleuca Bitter, Acaena pinnatifida Ruiz \& Pav. subsp. liocarpa Bitter, Acaena pinnatifida Ruiz \& Pav. subsp. longifolia (Phil.) Bitter, Acaena pinnatifida Ruiz \& Pav. subsp. nudiscapa Bitter, Acaena pinnatifida Ruiz \& Pav. subsp. oligacantha (Phil.) Bitter, Acaena pinnatifida Ruiz \& Pav. var. intermedia Bitter, Acaena pinnatifida Ruiz \& Pav. var. uspallatensis Bitter, Acaena pinnatifida Ruiz \& Pav. var. calcitrapa (Phil.) Reiche, Acaena pinnatifida Ruiz \& Pav. var. eucantha (Phil.) Reiche, Acaena pinnatifida Ruiz \& Pav. var. leptophylla (Phil.) Reiche, Acaena pinnatifida Ruiz \& Pav. var. longifolia (Phil.) Reiche, Acaena pinnatifida Ruiz \& Pav. var. oligacantha (Phil.) Reiche

Hierba. Perenne. Nativa.

Distribución: COQ, VAL, RME, LBO, MAU, NUB, BIO, ARA, LRI, LLA, AIS, MAG.

Rango altitudinal: 1300-4000 m.

Países limítrofes: Argentina.

Nombre vulgar: Cadillo, amor seco, pimpinela, pimpinela cimarrona, cepacaballo.

\section{Acaena platyacantha Speg.}

Hierba. Perenne. Nativa.

Distribución: NUB, ARA, AIS, MAG.

Rango altitudinal: 900-2000 m.

Países limítrofes: Argentina.

\section{Acaena poeppigiana Gay}

Hierba. Perenne. Nativa.

Distribución: COQ, VAL, RME, LBO, MAU, AIS, MAG.

Rango altitudinal: $2400-3500 \mathrm{~m}$.

Países limítrofes: Argentina.

\section{Acaena pumila Vahl}

Sinónimos: Acaena pumila Vahl var. acrocoma Bitter, Acaena glaberrima Phil., Acaena pumila Vahl var. glaberrima (Phil.) Bitter

Hierba. Perenne. Nativa.

Distribución: LRI, LLA, AIS, MAG.

Rango altitudinal: 900-1100 m.

Países limítrofes: Argentina.

Acaena sericea J. Jacq.

Sinónimos: Acaena fuegina Phil., Acaena cuneata Hook. \& Arn.

Hierba. Perenne. Nativa.

Distribución: VAL, RME, LBO, MAG. 
Rango altitudinal: 0-1000 m.

Países limítrofes: Argentina.

Acaena splendens Hook. \& Arn.

Sinónimos: Acaena splendens Hook. \& Arn. var. gracilis Bitter, Acaena splendens Hook. \& Arn. var. brachyphylla Bitter, Acaena splendens Hook. \& Arn. var. brevisericea Bitter, Acaena splendens Hook. \& Arn. var. macrophylla Bitter

Hierba. Perenne. Nativa.

Distribución: COQ, VAL, RME, LBO, MAU, NUB, BIO.

Rango altitudinal: 0-3000 m.

Países limítrofes: Argentina.

Nombre vulgar: Abrojo, cadillo, choncli, amores secos, cepacaballo.

Acaena tenera Albov

Sinónimos: Acaena antarctica Hook.f. var. laxiuscula Bitter Hierba. Perenne. Nativa.

Distribución: MAG.

Rango altitudinal: 100-1000 m.

Países limítrofes: Argentina.

Acaena trifida Ruiz \& Pav. var. glabrescens Regel \& Körn. Hierba. Perenne. Endémica.

Distribución: ANT, ATA, RME.

Rango altitudinal: 0-1800 m.

Acaena trifida Ruiz \& Pav. var. trifida

Sinónimos: Acaena trifida Ruiz \& Pav. var. quinquefida (Phil.) Reiche, Acaena quinquefida Phil., Acaena trifida Ruiz \& Pav. var. mollisima Bitter, Acaena trifida Ruiz \& Pav. var. nanodes Bitter, Acaena trifida Ruiz \& Pav. var. robusta Bitter, Acaena trifida Ruiz \& Pav. var. argentella Bitter, Acaena trifida Ruiz \& Pav. var. plurifoliolata Bitter, Acaena trifida Ruiz \& Pav. var. brachyphylla Bitter

Hierba. Perenne. Endémica.

Distribución: COQ, VAL, RME, LBO, MAU, NUB, BIO, ARA.

Rango altitudinal: 0-1300 m.

Nombre vulgar: Pimpinela, amores secos.

\section{Aphanes}

Aphanes arvensis L.

Hierba. Anual. Introducida.

Distribución: ANT, COQ, RME, LBO, ARA, LLA.

Aphanes berteroana Rothm. fma. berteroana

Hierba. Anual. Endémica.

Distribución: LBO.

Rango altitudinal: 200-900 m.
Aphanes berteroana Rothm. fma. vegeta Rothm.

Hierba. Anual. Endémica.

Distribución: LBO.

Rango altitudinal: 200-900 m.

Aphanes looseri (Rothm.) Rothm.

Sinónimos: Alchemilla looseri Rothm.

Hierba. Anual. Endémica.

Distribución: RME.

Rango altitudinal: 500-700 m.

Aphanes neglecta (Rothm.) Rothm.

Sinónimos: Alchemilla neglecta Rothm.

Hierba. Anual. Endémica.

Distribución: RME, ARA, LRI, LLA, AIS.

Rango altitudinal: 0-1000 m.

\section{Cotoneaster}

Cotoneaster francheti Bois.

Arbusto. Introducido.

Distribución: VAL.

Nombre vulgar: Cotoneaster.

\section{Duchesnea}

Duchesnea indica (Andrews) Focke

Hierba. Perenne. Introducida.

Distribución: VAL, RME, LBO, MAU, ARA, LRI, LLA.

Fragaria

Fragaria chiloensis (L.) Mill.

Sinónimos: Fragaria chilensis Ehrh., Fragaria vesca L. var. chiloensis L., Fragaria chilensis Ehrh. var. tincta Ser., Fragaria chiloensis (L.) Mill., Fragaria chiloensis (L.) Duchesne, nom. illeg., Potentilla chiloensis (L.) Mabb.

Hierba. Perenne. Nativa.

Distribución: LBO, MAU, NUB, BIO, ARA, LRI, LLA, AIS, MAG, JFE.

Rango altitudinal: 0-1800 m.

Países limítrofes: Argentina.

Nombre vulgar: Frutilla, lahueñe.

\section{Geum}

Geum andicola (Phil.) Reiche

Sinónimos: Sierversia andicola Phil.

Hierba. Perenne. Nativa.

Distribución: LLA.

Rango altitudinal: 0-2000 m.

Países limítrofes: Argentina. 
Geum involucratum Pers.

Sinónimos: Oncostylus involucratus (Pers.) F. Bolle, Geum parviflorum Comm. ex Sm.

Hierba. Perenne. Nativa.

Distribución: LLA, AIS, MAG.

Rango altitudinal: 0-1200 m.

Países limítrofes: Argentina.

Geum lechlerianum Schltdl.

Sinónimos: Oncostylus lechlerianus (Schltdl.) F. Bolle

Hierba. Perenne. Endémica.

Distribución: ARA, LLA.

Rango altitudinal: 0-500 m.

Geum magellanicum Comm. ex Pers.

Sinónimos: Geum chiloense auct. non Balb. ex Ser.

Hierba. Perenne. Nativa.

Distribución: LBO, ARA, LRI, LLA, AIS, MAG.

Rango altitudinal: 0-1700 m.

Países limítrofes: Argentina.

\section{Geum quellyon Sweet}

Sinónimos: Geum coccineum Lindl., hom. illeg., Geum grandiflorum Steud., Geum chiloense Balb. ex Ser., Geum coccineum Sibth. \& Sm.

Hierba. Perenne. Endémica.

Distribución: VAL, RME, LBO, MAU, NUB, BIO, ARA, LRI, LLA, AIS, MAG.

Rango altitudinal: 0-2600 m.

Nombre vulgar: Yerba del clavo, llallante, quillón.

\section{Kageneckia}

\section{Kageneckia angustifolia D. Don}

Árbol. Endémico.

Distribución: COQ, VAL, RME, LBO, MAU.

Rango altitudinal: 0-3200 m.

Nombre vulgar: Olivillo, pulpica, frangel.

Kageneckia oblonga Ruiz \& Pav.

Sinónimos: Kageneckia crataegoides D. Don, Kageneckia crataegifolia Lindl., Kageneckia ovata Colla, Lydaea lyday Molina

Árbol. Endémico.

Distribución: COQ, VAL, RME, LBO, MAU, NUB, BIO, ARA.

Rango altitudinal: 300-600 m.

Nombre vulgar: Huayu, huayu colorado, bollén.

\section{Lachemilla}

Lachemilla diplophylla (Diels) Rothm. Sinónimos: Alchemilla diplophylla Diels Hierba. Perenne. Nativa.
Distribución: AYP, TAR, ANT.

Rango altitudinal: 3900-4500 m.

Países limítrofes: Bolivia y Perú.

Nombre vulgar: Pasto, champa del bofedal.

Lachemilla pinnata (Ruiz \& Pav.) Rothm.

Sinónimos: Alchemilla calchaquina Lillo, Alchemilla pinnata Ruiz \& Pav., Alchemilla alata Ruiz \& Pav. ex Steud., Aphanes alata Steud., Aphanes pinnata Pers., Zygalchemilla pinnata (Ruiz \& Pav.) Rydb.

Hierba. Perenne. Nativa.

Distribución: AYP, TAR, ANT.

Rango altitudinal: 3600-4500 m.

Países limítrofes: Argentina y Bolivia.

Lachemilla sandiensis (Pilg.) Rothm.

Sinónimos: Alchemilla sandiensis Pilg.

Hierba. Perenne. Endémica.

Distribución: AYP.

Rango altitudinal: 4500-4700 m.

\section{Margyracaena}

Margyracaena x skottsbergii Bitter

Subarbusto. Endémico.

Distribución: JFE.

Rango altitudinal: 200-400 m.

Nota: Extinta en estado silvestre. Origen híbrido entre Acaena argentea y Margyricarpus dyginus.

\section{Margyricarpus}

Margyricarpus digynus (Bitter) Skottsb.

Sinónimos: Margyricarpus setosus Ruiz \& Pav. var. digynus Bitter

Subarbusto. Endémico.

Distribución: JFE.

Rango altitudinal: 100-500 m.

Nombre vulgar: Hierba de la perlilla, perla, romerillo, sabinilla.

Margyricarpus pinnatus (Lam.) Kuntze

Sinónimos: Empetrum pinnatum Lam., Margyricarpus setosus Ruiz \& Pav., Margyricarpus imberbis C. Presl

Arbusto o subarbusto. Nativo.

Distribución: ANT, COQ, VAL, RME, LBO, MAU, NUB, BIO, ARA, LRI, LLA.

Rango altitudinal: 0-3000 m.

Países limítrofes: Argentina, Bolivia y Perú.

Nombre vulgar: Perlilla, perla, sabinilla, romerillo. 


\section{Polylepis}

Polylepis rugulosa Bitter

Sinónimos: Polylepis tenuiruga Bitter

Árbol. Nativo.

Distribución: AYP.

Rango altitudinal: 3000-4000 m.

Países limítrofes: Perú.

Nombre vulgar: Keñoa, keñua.

Polylepis tarapacana Phil.

Sinónimos: Polylepis tarapacana Phil. var. multisquamata Bitter, Polylepis tarapacana Phil. var. brevifilamentosa Bitter, Polylepis tarapacana Phil. var. pycnolopha Bitter, Polylepis tarapacana Phil. var. sajamensis Bitter

Árbol. Nativo.

Distribución: AYP, TAR, ANT.

Rango altitudinal: 3900-4700 m.

Países limítrofes: Argentina, Bolivia y Perú.

Nombre vulgar: Queñoa, queñua.

\section{Potentilla}

Potentilla anserina $\mathrm{L}$.

Hierba. Perenne. Introducida.

Distribución: VAL, MAU, NUB, BIO, ARA, LRI, LLA, AIS, MAG.

\section{Potentilla reptans $\mathrm{L}$.}

Hierba. Perenne. Introducida.

Distribución: RME.

\section{Prunus}

Prunus cerasus L.

Árbol. Introducido.

Distribución: JFE.

Nombre vulgar: Cerezo.

Rosa

Rosa canina L.

Arbusto. Introducido.

Distribución: RME, MAU, BIO, LLA.

Rosa rubiginosa L.

Arbusto. Introducido.

Distribución: VAL, RME, LBO, MAU, NUB, BIO, ARA, LLA, AIS, MAG.

\section{Rubus}

Rubus constrictus P.J. Müll. \& Lefèvre Arbusto. Introducido.
Distribución: COQ, BIO, ARA, LRI, LLA.

Nombre vulgar: Mora, murra.

Rubus geoides $\mathrm{Sm}$.

Hierba. Perenne. Nativa.

Distribución: BIO, ARA, LRI, LLA, AIS, MAG, JFE.

Rango altitudinal: 0-1800 m.

Países limítrofes: Argentina.

Nombre vulgar: Miñe miñe, frutilla.

Rubus praecox Bertol.

Arbusto. Introducido.

Distribución: VAL, RME, LBO, MAU, NUB, BIO, ARA, LLA, JFE.

Nombre vulgar: Mora.

Rubus radicans Cav.

Hierba. Perenne. Nativa.

Distribución: ARA, LLA, AIS, MAG.

Rango altitudinal: 900-1500 m.

Países limítrofes: Argentina.

Nombre vulgar: Frutilla, miñemiñe.

Rubus ulmifolius Schott

Arbusto. Introducido.

Distribución: COQ, VAL, RME, LBO, MAU, NUB, BIO, ARA, LLA, JFE.

Nombre vulgar: Mora.

Sanguisorba

Sanguisorba minor Scop.

Hierba. Perenne. Introducida.

Distribución: COQ, VAL, RME, LBO, MAU, NUB, BIO, ARA.

\section{Tetraglochin}

Tetraglochin acanthocarpum (Speg.) Speg.

Sinónimos: Margyricarpus acanthocarpus Speg., Tetraglochin acanthocarpus (Speg.) Speg. fma. macropoda Speg., Tetraglochin acanthocarpus (Speg.) Speg. var. typica Speg., nom. illeg.

Subarbusto. Nativo.

Distribución: MAG.

Rango altitudinal: 0-500 m.

Países limítrofes: Argentina.

Tetraglochin alatum (Gillies ex Hook. \& Arn.) Kuntze Sinónimos: Margyricarpus alatus Gillies ex Hook. \& Arn., Tetraglochin strictum Poepp., Tetraglochin microphyllum Phil., Margyricarpus strictus (Poepp.) J. F. Macbride Arbusto. Nativo. 
Distribución: ATA, COQ, VAL, RME, LBO, MAU, NUB, BIO.

Rango altitudinal: 0-4000 m.

Países limítrofes: Argentina.

Nombre vulgar: Pimpinela, horizonte, caulia, caulla.

Tetraglochin cristatum (Britton) Rothm.

Sinónimos: Tetraglochin acanthocarpus (Speg.) Speg. fma. leiocarpum Speg., Margyricarpus cristatus Britton

Arbusto o subarbusto. Nativo.

Distribución: AYP, TAR.

Rango altitudinal: 3000-4500 m.

Países limítrofes: Argentina, Bolivia y Perú.

Nombre vulgar: Caulla, cailla, queiña, sangia, canela, añawaya.

\section{RUBIACEAE}

\section{Coprosma}

\section{Coprosma oliveri Fosberg}

Arbusto o árbol pequeño. Endémico.

Distribución: JFE.

Rango altitudinal: 0-500 m.

Nombre vulgar: Olivo, olivillo.

Coprosma pyrifolia (Hook. \& Arn.) Skottsb.

Sinónimos: Psychotria pyrifolia Hook. \& Arn.

Árbol. Endémico.

Distribución: JFE.

Rango altitudinal: 0-500 m.

Nombre vulgar: Peralillo.

\section{Cruckshanksia}

Cruckshanksia hymenodon Hook. \& Arn.

Sinónimos: Cruckshanksia bustillosii Phil., Cruckshanksia hymenodon Hook. \& Arn. var. bustillosii (Phil.) Ricardi \& Quezada, Rotheria lanceolata Meyen

Hierba. Perenne. Nativa.

Distribución: ANT, ATA, COQ, VAL, RME.

Rango altitudinal: 1000-3500 m.

Países limítrofes: Argentina.

Nombre vulgar: Rosa del campo.

\section{Cruckshanksia lithiophila Ricardi}

Hierba. Perenne. Endémica.

Distribución: ATA.

Rango altitudinal: 3000-3600 m.

\section{Cruckshanksia macrantha Phil.}

Sinónimos: Oreopolus macranthus (Phil.) Ricardi

Hierba. Perenne. Nativa.
Distribución: ATA, COQ, VAL.

Rango altitudinal: 1000-4500 m.

Países limítrofes: Argentina.

Cruckshanksia montiana Clos

Sinónimos: Cruckshanksia capitata Phil., Cruckshanksia

densifolia Phil.

Hierba. Perenne. Endémica.

Distribución: ATA, COQ.

Rango altitudinal: 0-500 m.

Cruckshanksia palmae Clos

Sinónimos: Oreopolus palmae (Clos) Ricardi

Hierba. Perenne. Nativa.

Distribución: COQ, VAL, RME.

Rango altitudinal: 2000-4000 m.

Países limítrofes: Argentina.

Cruckshanksia pumila Clos

Sinónimos: Cruckshanksia tripartita Phil., Cruckshanksia chrysantha Phil., Cruckshanksia geisseana Phil., Cruckshanksia darapskyana Phil.

Hierba. Anual o bienal. Endémica.

Distribución: ANT, ATA, COQ.

Rango altitudinal: 800-2300 m.

Nombre vulgar: Rosa, rosita.

Cruckshanksia verticillata Phil.

Sinónimos: Cruckshanksia paradoxa Phil., Cruckshanksia capitata Phil. var. paradoxa (Phil.) Reiche

Hierba. Perenne. Endémica.

Distribución: ANT, ATA, COQ.

Rango altitudinal: 100-1000 m.

\section{Galium}

Galium antarcticum Hook.f.

Sinónimos: Galium debile Banks \& Sol., Galium trifidum auct. non L.

Hierba. Anual. Nativa.

Distribución: AIS, MAG.

Rango altitudinal: 0-500 m.

Países limítrofes: Argentina.

Galium aparine L.

Hierba. Anual. Introducida.

Distribución: AYP, TAR, ANT, ATA, COQ, VAL, RME, LBO, MAU, NUB, BIO, ARA, LRI, LLA, AIS, MAG, JFE.

Galium araucanum Phil.

Sinónimos: Galium suffruticosum Hook. \& Arn. var. araucanum (Phil.) Reiche

Hierba. Perenne. Endémica.

Distribución: COQ, VAL, RME, LBO, MAU, NUB, BIO, 
ARA, LLA, AIS, MAG.

Rango altitudinal: 0-1900 m.

Galium corymbosum Ruiz \& Pav.

Hierba. Perenne. Nativa.

Distribución: AYP, TAR, ANT, COQ.

Rango altitudinal: 2000-5000 m.

Países limítrofes: Argentina, Bolivia y Perú.

Galium cotinoides Cham. \& Schltdl.

Hierba. Perenne. Endémica.

Distribución: LBO, MAU, NUB.

Rango altitudinal: 0-500 m.

Galium diffusoramosum Dempster \& Ehrend.

Sinónimos: Galium diffusum Clos

Hierba. Anual. Endémica.

Distribución: ANT, ATA, COQ, MAU.

Rango altitudinal: 100-700 m.

Galium divaricatum Pourr. ex Lam.

Hierba. Anual. Introducida.

Nota: Dempster (1982) señala que Gay lo habría encontrado en algún lugar de Chile.

Galium eriocarpum Bartl. ex DC.

Sinónimos: Galium brevifolium Phil., Galium eriocarpum Bartl. ex DC. var. normale Kuntze, Galium eriocarpum Bartl. ex DC. var. leiocarpum Kuntze, Galium philippii Briq.

Subarbusto. Nativo.

Distribución: COQ, VAL, RME, LBO, MAU, NUB.

Rango altitudinal: 1000-3000 m.

Países limítrofes: Argentina.

Galium fuegianum Hook.f.

Hierba. Anual. Nativa.

Distribución: LBO, MAU, NUB, BIO, ARA, AIS, MAG.

Rango altitudinal: 0-2000 m.

Países limítrofes: Argentina.

Galium gilliesii Hook. \& Arn. subsp. gilliesii

Sinónimos: Galium lanatum Kuntze

Hierba. Perenne. Nativa.

Distribución: ATA, COQ, VAL, RME, LBO.

Rango altitudinal: 2000-4000 m.

Países limítrofes: Argentina y Perú.

Galium gilliesii Hook. \& Arn. subsp. telanthos (Phil.) Dempster

Sinónimos: Galium telanthos Phil., Galium trichocarpum

DC. var. telanthos (Phil.) Reiche, Galium volckmanni Phil.

Hierba. Perenne. Nativa.

Distribución: COQ, RME, LBO, MAU.

Rango altitudinal: 1500-3500 m.
Países limítrofes: Argentina.

Galium hypocarpium (L.) Endl. ex Griseb.

Sinónimos: Relbunium hypocarpium (L.) Hemsl., Valantia hypocarpia L., Rubia relbun Cham. \& Schltdl., Galium relbun (Cham. \& Schltdl.) Clos

Hierba. Perenne. Nativa.

Distribución: ANT, COQ, VAL, RME, LBO, MAU, NUB, BIO, ARA, LRI, LLA, AIS.

Rango altitudinal: 0-4000 m.

Países limítrofes: Argentina, Bolivia y Perú.

Nombre vulgar: Relbún, kantoría.

Galium inconspicuum Phil.

Sinónimos: Galium hypnoides Clos var. inconspicuum (Phil.) Reiche

Hierba. Perenne. Nativa.

Distribución: MAU, NUB, BIO, ARA.

Rango altitudinal: 1000-2000 m.

Países limítrofes: Argentina.

Galium leptum Phil.

Hierba. Perenne. Endémica.

Distribución: COQ, RME.

Rango altitudinal: $1800 \mathrm{~m}$.

Galium magellanicum Hook.f.

Sinónimos: Galium chonoense Hook.f. var. chonoense, Galium nigricans Clos, Galium forsteri Phil., Galium valdivianum Phil., Galium chonoense Hook.f. var. valdivianum Reiche

Hierba. Perenne. Nativa.

Distribución: VAL, MAU, NUB, BIO, ARA, LRI, LLA, AIS, MAG.

Rango altitudinal: 0-1500 m.

Países limítrofes: Argentina.

Galium masafueranum Skottsb.

Hierba. Perenne. Endémica.

Distribución: JFE.

Rango altitudinal: 1100-1400 m.

Galium murale (L.) All.

Hierba. Anual. Introducida.

Distribución: COQ, VAL, RME, LBO, MAU, BIO.

Galium ovalleanum Phil.

Subarbusto. Endémico.

Distribución: COQ.

Rango altitudinal: 1100-2600 m.

Galium parisiense L.

Hierba. Anual. Introducida.

Distribución: RME. 
Galium philippianum Dempster

Sinónimos: Galium dasycarpon Kunze ex Walp.

Subarbusto. Endémico.

Distribución: COQ, VAL, RME, LBO.

Rango altitudinal: 1200-2200 m.

Galium suffruticosum Hook. \& Arn.

Sinónimos: Galium andinum Phil., Galium peteroanum

Phil., Rubia margaritifera Reiche

Subarbusto. Nativo.

Distribución: ATA, COQ, VAL, RME, LBO, MAU.

Rango altitudinal: 0-2700 m.

Países limítrofes: Argentina.

Galium trichocarpum DC.

Sinónimos: Galium eriocarpum Bartl. ex DC. var. trichocarpum (DC.) Wedd. ex Hauman, Galium chamissonis Hook. \& Arn., Galium lasiocarpum Phil., Galium scandens Phil., Galium laxum Phil.

Hierba. Perenne. Endémica.

Distribución: VAL, RME, LBO, MAU, BIO.

Rango altitudinal: 400-2200 m.

Galium tricornutum Dandy

Hierba. Anual. Introducida.

Distribución: NUB, BIO.

Galium werdermannii Standl.

Sinónimos: Galium hypnoides Clos var. hypnoides, Galium closianum Briq.

Hierba. Perenne. Endémica.

Distribución: BIO, ARA.

Rango altitudinal: $1100 \mathrm{~m}$.

\section{Leptostigma}

Leptostigma arnottianum Walp.

Sinónimos: Nertera arnottiana (Walp.) B.L. Rob., Hedyotis repens Clos, Coprosma calycina Gray, Oldenlandia uniflora Ruiz \& Pav. var. repens (Clos) Reiche, nom. illeg.

Hierba. Perenne. Nativa.

Distribución: NUB, BIO, ARA, LRI, LLA.

Rango altitudinal: 0-500 m.

Países limítrofes: Argentina.

\section{Nertera}

Nertera granadensis (Mutis ex L.f.) Druce

Sinónimos: Gomozia granadensis Mutis ex L.f., Nertera depressa Banks \& Sol. ex Gaertn., Cunina sanfuentesii Clos Hierba. Perenne. Nativa.

Distribución: COQ, VAL, MAU, NUB, BIO, ARA, LRI, LLA, AIS, MAG, JFE.

Rango altitudinal: 500-3500 m.
Países limítrofes: Argentina.

Nombre vulgar: Coralito, chaquirita del monte, rucachucao, coralillo.

\section{Oldenlandia}

Oldenlandia brachypetala (Phil.) E.L. Cabral \& Bacigalupo Sinónimos: Hedyotis brachypetala Phil., Hedyotis minuta Phil. ex Benth. \& Hook., nom. nud.

Hierba. Perenne. Endémica.

Distribución: AIS.

Oldenlandia salzmannii (DC.) Benth. \& Hook.

Sinónimos: Anotis salzmannii DC., Hedyotis salzmannii (DC.) Steud., Oldenlandia uniflora Ruiz \& Pav., Hedyotis uniflora DC., Hedyotis pilosa Poepp., Hedyotis chiloensis Phil., Hedyotis inconspicua F. Phil.

Hierba. Anual. Nativa.

Distribución: MAU, NUB, BIO, ARA, LLA, JFE.

Rango altitudinal: 0-1300 m.

Países limítrofes: Argentina.

\section{Oreopolus}

Oreopolus glacialis (Poepp.) Ricardi

Sinónimos: Cruckshanksia glacialis Poepp., Oreopolus patagonicus Speg., Cruckshanksia patagonica (Speg.) Macloskie, Oreopolus glacialis (Poepp.) Ricardi var. pilosus Ricardi, Oreopolus citrinus Schltdl., Oreocaryon nivalis Kuntze ex K. Schum.

Hierba. Anual. Nativa.

Distribución: RME, LBO, MAU, NUB, BIO, ARA, LRI, LLA, AIS, MAG.

Rango altitudinal: 300-3500 m.

Países limítrofes: Argentina.

\section{Rubia}

Rubia tinctorum L.

Hierba. Perenne. Introducida.

Distribución: RME.

\section{Sherardia}

Sherardia arvensis L.

Hierba. Anual. Introducida.

Distribución: COQ, VAL, RME, LBO, MAU, NUB, BIO, ARA, LRI, LLA, JFE. 


\section{RUTACEAE}

\section{Fagara}

Fagara externa Skottsb.

Sinónimos: Zanthoxylum externum (Skottsb.) Stuessy

Árbol. Endémico.

Distribución: JFE.

Nombre vulgar: Naranjillo.

Fagara mayu (Bertero ex Colla) Engl.

Sinónimos: Zanthoxylum mayu Bertero ex Colla, Zanthoxylon mayu Hook. \& Arn., Xanthoxylon mayu Bertero ex Colla

Árbol. Endémico.

Distribución: JFE.

Nombre vulgar: Mayu, naranjillo, palo amarillo.

\section{Pitavia}

Pitavia punctata (Ruiz \& Pav.) Molina

Sinónimos: Galvezia punctata Ruiz \& Pav.

Árbol. Endémico.

Distribución: MAU, NUB, BIO, ARA.

Rango altitudinal: 0-800 m.

Nombre vulgar: Pitao.

\section{Ruta}

Ruta chalepensis L.

Arbusto. Introducido.

Distribución: ANT, COQ, VAL, RME, LBO, MAU, NUB, BIO, ARA, JFE.

\section{SALICACEAE}

\section{Azara}

Azara alpina Poepp. \& Endl.

Arbusto. Nativo.

Distribución: LBO, MAU, NUB, BIO, ARA.

Rango altitudinal: 1000-2000 m.

Países limítrofes: Argentina.

Azara celastrina D. Don

Sinónimos: Azara sparsiflora Steud., nom. nud., Azara lilen

Bertero, nom. nud.

Arbusto o árbol pequeño. Endémico.

Distribución: COQ, VAL, RME, LBO, MAU, NUB, BIO.

Rango altitudinal: 0-1000 m.

Nombre vulgar: Lilén.
Azara dentata Ruiz \& Pav.

Sinónimos: Azara tomentosa Bertero ex Steud., Azara celastrina D. Don var. tomentosa (Steud.) Reiche

Arbusto. Endémico.

Distribución: COQ, VAL, RME, LBO, MAU, NUB, BIO, ARA.

Rango altitudinal: 500-1500 m.

Nombre vulgar: Corcolén.

Azara integrifolia Ruiz \& Pav.

Sinónimos: Azara intermedia Gay, Azara hirtella Miq., Azara berteroniana Steud., Azara lechleriana Steud., Azara pycnophylla Phil., Azara browneae F. Phil., Azara integrifolia Ruiz \& Pav. var. pycnophylla (Phil.) Reiche, Azara integrifolia Ruiz \& Pav. var. browneae (F. Phil.) Reiche

Arbusto. Endémico.

Distribución: VAL, RME, LBO, MAU, NUB, BIO, ARA, LRI.

Rango altitudinal: 200-2000 m.

Nombre vulgar: Corcolén, aromo, chin-chin.

Azara lanceolata Hook.f.

Sinónimos: Azara chiloensis Hook.f., Azara serrata Ruiz \& Pav. var. chiloensis (Hook.f.) Reiche, Azara brumalis Gand., Azara lanceolata Hook.f. var. chiloensis (Hook.f.) Reiche Arbusto o árbol pequeño. Nativo.

Distribución: NUB, BIO, ARA, LRI, LLA, AIS.

Rango altitudinal: 0-1000 m.

Países limítrofes: Argentina.

Azara microphylla Hook.f.

Sinónimos: Azara borealis F. Phil., Azara valdiviae Lechl. ex Steud., Myrtophyllum chilense Turcz.

Arbusto o árbol pequeño. Nativo.

Distribución: COQ, MAU, NUB, BIO, ARA, LRI, LLA.

Rango altitudinal: 0-1500 m.

Países limítrofes: Argentina.

Nombre vulgar: Chinchín.

Azara petiolaris (D. Don) I.M. Johnst.

Sinónimos: Azara gilliesii Hook. \& Arn., Quillaja petiolaris D. Don, Azara crassifolia Hort., Azara gilliesi Hook. \& Arn. var. minor Reiche

Arbusto o árbol pequeño. Endémico.

Distribución: COQ, VAL, RME, LBO, MAU, NUB.

Rango altitudinal: 600-1500 m.

Nombre vulgar: Maqui blanco, maquicillo, lilén, corcolén.

Azara serrata Ruiz \& Pav. var. fernandeziana (Gay) Reiche Sinónimos: Azara fernandeziana Gay

Arbusto. Endémico.

Distribución: JFE.

Rango altitudinal: 300-400 m. 
Azara serrata Ruiz \& Pav. var. serrata

Sinónimos: Azara umbellata Phil., Azara dubia Steud., Azara bergii Phil., Azara subandina Phil., Azara serrata Ruiz \& Pav. var. bergii (Phil.) Reiche

Arbusto o árbol pequeño. Endémico.

Distribución: COQ, VAL, RME, LBO, MAU, NUB, BIO, ARA, LRI, LLA.

Rango altitudinal: 200-2000 m.

Nombre vulgar: Corcolén, aromo de castilla.

\section{Populus}

Populus nigra L.

Árbol. Introducido.

Distribución: BIO.

Salix

Salix alba L.

Árbol. Introducido.

Distribución: BIO.

Salix babylonica L.

Árbol. Introducido.

Distribución: COQ, RME, NUB, BIO, ARA, JFE.

Salix caprea L.

Arbusto. Introducido.

Distribución: NUB, BIO.

Salix humboldtiana Willd.

Sinónimos: Salix chilensis Molina, Salix magellanica Lam. Árbol. Nativo.

Distribución: AYP, TAR, ANT, ATA, COQ, VAL, RME, LBO, MAU, NUB, BIO, ARA.

Rango altitudinal: 0-3900 m.

Países limítrofes: Argentina, Bolivia y Perú.

Nombre vulgar: Sauce amargo, sauce chileno.

Nota: Existen híbridos naturales de Salix humboldtiana y

S. babylonica.

Salix viminalis L.

Arbusto o árbol pequeño. Introducido.

Distribución: RME, LBO, NUB, BIO, ARA, LRI, AIS, MAG.

\section{SANTALACEAE}

\section{Antidaphne}

Antidaphne punctulata (Clos) Kuijt

Sinónimos: Eremolepis punctulata (Clos) Griseb., Lepidoceras punctulatum Clos, Eremolepis verrucosa Griseb.
Arbusto parásito. Endémico.

Distribución: BIO, ARA, LRI, LLA.

Rango altitudinal: 0-1500 m.

\section{Lepidoceras}

Lepidoceras chilense (Molina) Kuijt

Sinónimos: Lepidoceras kingii Hook.f., Lepidoceras dombei Hook.f., Lepidoceras squamifer Clos, Myrtobium microphyllum Miq., Viscum chilense Molina

Arbusto parásito. Endémico.

Distribución: VAL, MAU, NUB, BIO, ARA, LRI, LLA.

Rango altitudinal: 0-2000 m.

Nombre vulgar: Chiuchiu, quintral del temu.

\section{Myoschilos}

Myoschilos oblongum Ruiz \& Pav.

Sinónimos: Miyoschilos angusta Phil., Myoschilos oblongum Ruiz \& Pav. var. angusta (Phil.) Macloskie

Arbusto. Nativo.

Distribución: COQ, VAL, RME, LBO, MAU, NUB, BIO, ARA, LRI, LLA, AIS, MAG.

Países limítrofes: Argentina.

Nombre vulgar: Orocoi, orocoipo.

\section{Nanodea}

Nanodea muscosa Banks ex C.F. Gaertn.

Hierba. Perenne. Nativa.

Distribución: LLA, AIS, MAG.

Rango altitudinal: 0-1000 m.

Países limítrofes: Argentina.

\section{Santalum}

Santalum fernandezianum F. Phil.

Árbol. Endémico.

Distribución: JFE.

Nombre vulgar: Sándalo de Juan Fernández.

Nota: Extinta.

\section{SAPINDACEAE}

\section{Bridgesia}

Bridgesia incisifolia Bertero ex Cambess.

Sinónimos: Bridgesia incisifolia Bertero ex Cambess. var. parvifolia Barnéoud

Arbusto. Endémico.

Distribución: ATA, COQ, VAL, RME.

Rango altitudinal: 0-1000 m.

Nombre vulgar: Rumpiata, rumpaito, rumpe-ato. 


\section{Dodonaea}

Dodonaea viscosa Jacq. Arbusto. Introducido.

Distribución: COQ, IPA.

\section{Guindilia}

Guindilia trinervis Gillies ex Hook. \& Arn.

Sinónimos: Valenzuelia trinervis Bertero ex Cambess. Arbusto. Nativo.

Distribución: COQ, VAL, RME, LBO, MAU.

Rango altitudinal: 200-3000 m.

Países limítrofes: Argentina.

Nombre vulgar: Guindillo.

\section{Llagunoa}

Llagunoa glandulosa (Hook. \& Arn.) G. Don

Sinónimos: Amirola glandulosa Hook. \& Arn., Orbignya trifolia Bertero

Arbusto. Endémico.

Distribución: ANT, ATA, COQ, VAL, RME, LBO.

Rango altitudinal: 0-1500 m.

Nombre vulgar: Árbol de cuentas, atutemo.

\section{Sapindus}

\section{Sapindus saponaria L.}

Árbol. Introducido.

Distribución: AYP, IPA.

Nombre vulgar: Marikuru (Rapa Nui).

Nota: Los Rapanui la consideran como nativa.

\section{SAPOTACEAE}

\section{Pouteria}

Pouteria lucuma (Ruiz \& Pav.) Kuntze

Sinónimos: Achras lucuma Ruiz \& Pav., Richardella lucuma (Ruiz \& Pav.) Aubrév.

Árbol. Nativo.

Distribución: ATA.

Países limítrofes: Bolivia y Perú.

Nota: Sólo hay un ejemplar que respalda la distribución natural en Chile (ATA). Aún es dudoso su origen.

\section{Pouteria splendens (A. DC.) Kuntze}

Sinónimos: Lucuma valparadisea Molina, Lucuma splendens A. DC., Gayella valparadisaea (Molina) Pierre, Vitellaria valparadisaea (Molina) Radlk. ex Dubard, Gayella splendens (A. DC.) Aubrév.

Arbusto o árbol pequeño. Endémico.
Distribución: COQ, VAL.

Rango altitudinal: 0-500 m.

Nombre vulgar: Palo colorado, lúcuma silvestre.

\section{SAXIFRAGACEAE}

\section{Chrysosplenium}

Chrysosplenium macranthum Hook.

Hierba. Perenne. Nativa.

Distribución: MAG.

Rango altitudinal: 0-100 m.

Países limítrofes: Argentina.

Chrysosplenium valdivicum Hook.

Hierba. Perenne. Nativa.

Distribución: ARA, LRI, LLA.

Rango altitudinal: 0-1600 m.

Países limítrofes: Argentina.

\section{Saxifraga}

Saxifraga magellanica Poir.

Sinónimos: Saxifraga cordillerana C. Presl var. magellanica (Poir.) Dusén, Saxifraga cordillerana C. Presl

Hierba. Perenne. Nativa.

Distribución: MAU, NUB, BIO, ARA, AIS, MAG.

Rango altitudinal: 0-3000 m.

Países limítrofes: Argentina y Perú.

Saxifraga umbrosa L.

Hierba. Perenne. Introducida.

Distribución: MAG.

\section{Saxifragella}

Saxifragella bicuspidata (Hook.f.) Engl. Sinónimos: Saxifraga bicuspidata Hook.f.

Hierba. Perenne. Nativa.

Distribución: LLA, MAG.

Rango altitudinal: 500-1500 m.

Países limítrofes: Argentina.

\section{Saxifragodes}

Saxifragodes albowiana (Kurtz ex Albov) D.M. Moore Sinónimos: Saxifraga albowiana Kurtz ex Albov, Saxifragella albowiana (Kurtz ex Albov) Engl.

Hierba. Perenne. Nativa.

Distribución: LLA, AIS, MAG.

Rango altitudinal: 0-1000 m.

Países limítrofes: Argentina. 


\section{SCHOEPFIACEAE}

Arjona

Arjona patagonica Hombr. \& Jacq. ex Decne.

Sinónimos: Arjona andina Phil., Arjona rigida Miers, Arjona ruscifolia Poepp., Arjona tuberosa Cav. var. patagonica DC.

Hierba. Perenne. Nativa.

Distribución: COQ, VAL, LBO, NUB, ARA, MAG.

Países limítrofes: Argentina.

Arjona pusilla Hook.f.

Hierba. Perenne. Nativa.

Distribución: AIS, MAG.

Países limítrofes: Argentina, Bolivia y Perú.

Arjona tuberosa Cav.

Sinónimos: Arjona apressa Phil., Arjona pungens Phil., Arjona tuberosa Cav. var. lanata Macloskie

Hierba. Perenne. Nativa.

Distribución: AIS, MAG.

Países limítrofes: Argentina.

\section{Quinchamalium}

\section{Quinchamalium chilense Molina}

Sinónimos: Quichamalium procumbens Ruiz \& Pav., Quinchamalium chilense Molina var. gracile Hook. \& Arn., Quinchamalium gracile (Hook. \& Arn.) Brongn., Quinchamalium chilense Molina var. robustior Hook. \& Arn., Quinchamalium majus Brongn., Quinchamalium ericoides Brongn. ex Gay, Quinchamalium elegans C. Presl, Quinchamalium brevifolium C. Presl, Quinchamalium andinum Phil., Quinchamalium platense Phil., Quinchamalium excrescens Phil., Quinchamalium purpureum Phil., Quinchamalium linarioides Phil., Quinchamalium berteroanum Phil., Quinchamalium bracteosum Phil., Quinchamalium carnosum Phil., Quinchamalium parviflorum Phil., Quinchamalium chilense Molina var. parviflorum (Phil.) L.E. Navas, Quinchamalium thesioides Phil., Quinchamalium thesioides Phil. var. flaccidum Phil., Quinchamalium minutum Phil., Quinchamalium rugosum Phil., Quinchamalium litorale Phil., Quinchamalium tarapacanum Phil., Quinchamalium araucanum $\mathrm{F}$. Meigen

Hierba. Perenne. Nativa.

Distribución: AYP, TAR, ANT, ATA, COQ, VAL, RME, LBO, MAU, NUB, BIO, ARA, LRI, LLA, AIS.

Países limítrofes: Argentina, Bolivia y Perú.

Nombre vulgar: Quinchamalí.

\section{SCROPHULARIACEAE}

\author{
Alonsoa \\ Alonsoa honoraria Grau \\ Subarbusto. Endémico. \\ Distribución: COQ. \\ Rango altitudinal: 300-400 m.
}

Alonsoa meridionalis (L.f.) Kuntze

Sinónimos: Scrophularia meridionalis L.f., Alonsoa urticifolia Steud., Alonsoa incisifolia Ruiz \& Pav.

Hierba. Perenne. Nativa.

Distribución: COQ, VAL, RME, LBO, MAU, NUB, BIO.

Países limítrofes: Bolivia y Perú.

Nombre vulgar: Flor del soldado, ajicillo.

\section{Buddleja}

Buddleja araucana Phil.

Sinónimos: Buddleja globosa Hope var. araucana (Phil.)

Reiche

Arbusto. Nativo.

Distribución: ATA, COQ, VAL, BIO.

Rango altitudinal: $300-1600 \mathrm{~m}$.

Países limítrofes: Argentina.

Buddleja globosa Hope

Sinónimos: Buddleja capitata Jacq., Buddleja connata Ruiz \& Pav.

Arbusto. Nativo.

Distribución: AYP, COQ, VAL, RME, LBO, MAU, NUB, BIO, ARA, LRI, LLA.

Rango altitudinal: 0-2000 m.

Países limítrofes: Argentina.

Nombre vulgar: Matico, pañil, palquil, palguín.

Buddleja suaveolens Kunth \& Bouché Sinónimos: Buddleja gayana Benth.

Arbusto. Endémico.

Distribución: ANT, ATA, COQ, VAL.

Rango altitudinal: 500-2900 m.

Nombre vulgar: Acerillo.

\section{Myoporum}

Myoporum laetum G. Forst.

Arbusto o árbol pequeño. Introducido.

Distribución: COQ, VAL, MAU. 


\section{Scrophularia}

Scrophularia auriculata L.

Hierba. Perenne. Introducida.

Distribución: RME, MAU, ARA.

\section{Verbascum}

Verbascum densiflorum Bertol.

Hierba. Bienal. Introducida.

Distribución: ARA.

Verbascum thapsus L.

Hierba. Bienal. Introducida.

Distribución: VAL, RME, LBO, MAU, NUB, BIO, ARA, LLA, AIS, JFE.

Verbascum virgatum Stokes

Hierba. Bienal. Introducida.

Distribución: ATA, COQ, VAL, RME, LBO, MAU, NUB, BIO, ARA, LLA, JFE, IPA.

\section{SIMAROUBACEAE}

\section{Ailanthus}

Ailanthus altissima (Mill.) Swingle

Árbol. Introducido.

Distribución: RME, BIO, JFE.

\section{SOLANACEAE}

\section{Benthamiella}

Benthamiella azorella (Skottsb.) A.Soriano

Sinónimos: Saccardophyton azorella Skottsb.

Subarbusto. Nativo.

Distribución: MAG.

Rango altitudinal: 500-1200 m.

Países limítrofes: Argentina.

Benthamiella lanata A. Soriano

Subarbusto. Nativo.

Distribución: MAG.

Rango altitudinal: 0-500 m.

Países limítrofes: Argentina.

Benthamiella nordenskioldii Dusén ex N.E. Br.

Subarbusto. Nativo.

Distribución: MAG.

Rango altitudinal: 0-1000 m.

Países limítrofes: Argentina.
Benthamiella patagonica Speg.

Sinónimos: Benthamiella aurea Skottsb., Benthamiella intermedia Skottsb., Benthamiella abietina Skottsb.

Subarbusto. Nativo.

Distribución: MAG.

Rango altitudinal: 500-1500 m.

Países limítrofes: Argentina.

\section{Calibrachoa}

Calibrachoa parviflora (Juss.) D’Arcy

Sinónimos: Nicotiana parviflora (Juss.) Lehm., Petunia parviflora Juss.

Hierba. Anual. Nativa.

Distribución: VAL.

Rango altitudinal: 0-300 m.

Países limítrofes: Argentina.

\section{Cestrum}

Cestrum parqui L'Hér.

Sinónimos: Cestrum campestre Griseb., Cestrum parqui L'Hér. var. glabriusculum Kuntze, Cestrum parqui L'Hér. var. longiflorum Francey, Cestrum parqui L'Hér. var. poepigii Dunal, Cestrum virgatum Ruiz \& Pav.

Arbusto. Nativo.

Distribución: AYP, TAR, ANT, ATA, COQ, VAL, RME, LBO, MAU, NUB, BIO, ARA, LRI, JFE.

Rango altitudinal: 0-2500 m.

Países limítrofes: Argentina y Bolivia.

Nombre vulgar: Palqui, parqui, hediondilla.

Nota: Introducida en el Archipiélago Juan Fernández.

\section{Combera}

Combera minima (Phil.) Sandwith

Sinónimos: Nicotiana minima Phil., Petunia minima (Phil.)

Reiche

Hierba. Perenne. Endémica.

Distribución: LLA.

Rango altitudinal: $1800 \mathrm{~m}$.

Combera paradoxa Sandwith

Hierba. Perenne. Nativa.

Distribución: NUB, AIS.

Rango altitudinal: 1800-3200 m.

Países limítrofes: Argentina.

\section{Datura}

Datura ferox L.

Hierba. Anual. Introducida.

Distribución: ATA, COQ, RME, LBO, MAU, NUB, BIO, LLA. 
Datura inoxia Mill.

Hierba. Anual. Introducida.

Distribución: ANT, ATA.

Datura stramonium L.

Hierba. Anual. Introducida.

Distribución: AYP, TAR, ANT, ATA, COQ, VAL, RME, LBO, MAU, NUB, BIO, ARA, JFE.

\section{Dunalia}

Dunalia spinosa (Meyen) Dammer

Sinónimos: Dunalia lycioides Miers, Atropa spinosa Meyen, Dierbachia lyciodes (Miers) Kuntze

Arbusto. Nativo.

Distribución: AYP, TAR.

Rango altitudinal: $3500 \mathrm{~m}$.

Países limítrofes: Bolivia y Perú.

Nombre vulgar: Chañar silvestre, chilka.

\section{Exodeconus}

Exodeconus flavus (I.M. Johnst.) Axelius \& D'Arcy

Sinónimos: Cacabus flavus I.M. Johnst.

Hierba. Anual. Nativa.

Distribución: AYP, TAR.

Rango altitudinal: 2000-2500 m.

Países limítrofes: Perú.

Exodeconus integrifolius (Phil.) Axelius

Sinónimos: Cacabus integrifolius Phil.

Hierba. Anual. Nativa.

Distribución: AYP, TAR, ANT, ATA.

Rango altitudinal: 2300-4000 m.

Países limítrofes: Argentina.

Nombre vulgar: Oreja de ratón.

Exodeconus pusillus (Bitter) Axelius

Sinónimos: Cacabus pusillus Bitter

Hierba. Anual. Nativa.

Distribución: AYP, TAR.

Rango altitudinal: 2500-3000 m.

Países limítrofes: Perú.

\section{Fabiana}

Fabiana bryoides Phil.

Arbusto. Nativo.

Distribución: AYP, ANT, ATA, COQ.

Rango altitudinal: 2900-4900 m.

Países limítrofes: Argentina y Bolivia.

Nombre vulgar: Pata de perdiz, pata de pizaca.
Fabiana densa J. Remy

Sinónimos: Fabiana clarenii Dammer

Arbusto. Nativo.

Distribución: AYP, TAR, ATA.

Rango altitudinal: 2700-4500 m.

Países limítrofes: Argentina, Bolivia y Perú.

Nombre vulgar: Khachukipa.

Fabiana denudata Miers

Sinónimos: Fabiana hieronymi Niederl.

Arbusto. Nativo.

Distribución: AYP, TAR, ANT.

Rango altitudinal: 300-3700 m.

Países limítrofes: Argentina.

Nombre vulgar: Tolilla, alma tola.

Fabiana imbricata Ruiz \& Pav.

Sinónimos: Fabiana araucana Phil., Fabiana biflora J.

Remy, Fabiana imbricata Ruiz \& Pav. var. biflora (J.

Remy) Reiche, Fabiana lutescens Phil.

Arbusto. Nativo.

Distribución: ATA, COQ, VAL, RME, LBO, MAU, NUB, BIO, ARA, LRI.

Rango altitudinal: 2600-3200 m.

Países limítrofes: Argentina.

Nombre vulgar: Pichi, peta, romero.

Fabiana ramulosa (Wedd.) Hunz. \& Barboza

Sinónimos: Fabiana densa J. Remy var. ramulosa Wedd., Fabiana deserticola Reiche

Arbusto. Endémico.

Distribución: AYP, TAR, ANT.

Rango altitudinal: 3200-4000 m.

Nombre vulgar: Kipa, tara macho.

Fabiana squamata Phil.

Arbusto. Nativo.

Distribución: TAR, ANT.

Rango altitudinal: 3000-4400 m.

Países limítrofes: Bolivia.

Nombre vulgar: Koba.

Fabiana stephanii Hunz. \& Barboza

Arbusto. Nativo.

Distribución: AYP, TAR.

Rango altitudinal: 3000-3900 m.

Países limítrofes: Perú.

Fabiana viscosa Hook. \& Arn.

Sinónimos: Fabiana coridifolia Dunal, Fabiana ericoides Dunal, Fabiana barriosi Phil.

Arbusto. Endémico.

Distribución: ANT, ATA, COQ. 
Rango altitudinal: 100-2200 m.

Nombre vulgar: Pichinilla, copatola, husillo, pichanilla.

\section{Jaborosa}

Jaborosa caulescens Gillies \& Hook. var. bipinnatifida (Dunal) Reiche

Sinónimos: Lonchestigma caulescens (Gillies \& Hook.) Dunal var. bipinnatifidum Dunal, Jaborosa bipinnatifida (Dunal) Meigen, Lonchestigma bipinnatifidum (Dunal) Phil., Trechonaetes bipinnatifida Phil.

Hierba. Perenne. Nativa.

Distribución: ANT, ATA, COQ, RME.

Rango altitudinal: $3000-4500 \mathrm{~m}$.

Países limítrofes: Argentina.

Jaborosa caulescens Gillies \& Hook. var. caulescens Sinónimos: Dorystigma caulescens (Gillies \& Hook.) Miers, Lonchestigma caulescens (Gillies \& Hook.) Dunal Hierba. Perenne. Nativa.

Distribución: AYP, TAR, ATA, COQ, VAL, RME, MAU.

Rango altitudinal: 2000-4000 m.

Países limítrofes: Argentina.

Nombre vulgar: Teqerere.

Jaborosa laciniata (Miers) Hunz. \& Barboza

Sinónimos: Trechonaetes laciniata Miers, Trechonaetes bridgesii Dunal

Hierba. Perenne. Nativa.

Distribución: ATA, COQ, VAL, RME, MAU.

Rango altitudinal: 2500-4000 m.

Países limítrofes: Argentina.

\section{Jaborosa magellanica (Griseb.) Dusén}

Sinónimos: Himeranthus magellanicus Griseb., Jaborosa magellanica Phil.

Hierba. Perenne. Nativa.

Distribución: AIS, MAG.

Rango altitudinal: 0-500 m.

Países limítrofes: Argentina.

Jaborosa parviflora (Phil.) Hunz. \& Barboza

Sinónimos: Trechonaetes parviflora Phil., Lonchestigma parviflorum (Phil.) Cabrera, Jaborosa crispa auct. non Benth. \& Hook., Trechonaetes machucana Phil.

Hierba. Perenne. Nativa.

Distribución: AYP, TAR, ANT, ATA.

Rango altitudinal: 3700-4500 m.

Países limítrofes: Argentina y Bolivia.

Nombre vulgar: Psike.

Jaborosa pinnata Phil.

Hierba. Perenne. Endémica.

Distribución: RME, LBO, MAU.
Jaborosa reflexa Phil.

Sinónimos: Jaborosa araucana Phil.

Hierba. Perenne. Nativa.

Distribución: RME, LBO, MAU, NUB, BIO, ARA.

Rango altitudinal: 200-2000 m.

Países limítrofes: Argentina.

Jaborosa riojana Hunz. \& Barboza

Hierba. Perenne. Nativa.

Distribución: ANT.

Rango altitudinal: 3000-4300 m.

Países limítrofes: Argentina.

Jaborosa squarrosa (Miers) Hunz. \& Barboza

Sinónimos: Dorystigma squarrosum Miers, Lonchestigma squarrosum (Miers) Dunal

Hierba. Perenne. Nativa.

Distribución: AYP, TAR, ATA.

Rango altitudinal: 3000-4700 m.

Países limítrofes: Argentina, Bolivia y Perú.

Jaborosa volkmannii (Phil.) Reiche

Sinónimos: Dolichosiphon volkmanni Phil.

Hierba. Perenne. Nativa.

Distribución: BIO, ARA.

Rango altitudinal: 1500-2000 m.

Países limítrofes: Argentina.

\section{Latua}

Latua pubiflora (Griseb.) Baill.

Sinónimos: Lycioplesium pubiflorum Griseb., Latua venenosa Phil.

Arbusto o árbol pequeño. Endémico.

Distribución: LRI, LLA.

Rango altitudinal: 300-900 m.

Nombre vulgar: Latúe, palo de los brujos, latué, palo mato.

\section{Lycium}

Lycium boerhaviaefolium L.f.

Sinónimos: Grabowskia boerhaviifolia (L.f.) Schltdl., Grabowskia glauca (Phil.) I.M. Johnst., Lycium glaucum Phil.

Arbusto. Nativo.

Distribución: TAR, ANT.

Rango altitudinal: 300-2500 m.

Países limítrofes: Argentina y Perú.

Lycium bridgesii (Miers) R.A. Levin, Jill S. Mill. \& G. Bernardello

Sinónimos: Phrodus bridgesii Miers, Phrodus microphyllus (Miers) Miers, Phrodus pendulus (Phil.) Phil., Alona microphylla Miers, Phrodus nodosus Miers, Phrodus 
breviflorus Phil., Phrodus thymifolius (Phil.) Phil.

Arbusto. Endémico.

Distribución: ATA, COQ.

Rango altitudinal: 500-2900 m.

Lycium carolinianum Walter var. sandwicense (A. Gray)

C.L. Hitchc.

Arbusto. Nativo.

Distribución: IPA.

Nombre vulgar: Pua nako nako (Rapa Nui).

Lycium chilense Miers ex Bertero var. chilense

Sinónimos: Lycium chilense Miers ex Bertero var. petiolatum Phil., Lycium scoparium Miers, Lycium chilense Miers ex Bertero subsp. normale Reiche, Lycium chilense Miers ex Bertero var. tomentosulum Phil., Lycium salsum Ruiz \& Pav. var. chilense (Bertero) Kuntze, Lycium chilense Miers ex Bertero var. ovatum Phil.

Arbusto. Nativo.

Distribución: ATA, COQ, VAL, RME, LBO, MAU.

Rango altitudinal: 0-4500 m.

Países limítrofes: Argentina y Bolivia.

Nombre vulgar: Coralillo.

Lycium chilense Miers ex Bertero var. confertifolium (Miers) F.A. Barkley

Sinónimos: Lycium scoparium Miers var. confertifolium Miers

Arbusto. Nativo.

Distribución: COQ, VAL, RME.

Rango altitudinal: 0-1500 m.

Países limítrofes: Argentina.

Lycium chilense Miers ex Bertero var. filifolium (Gillies ex Miers) Bernardello

Sinónimos: Lycium filifolium Gillies ex Miers, Lycium chilense Miers ex Bertero var. capillare (Miers) A. Terracc. Arbusto. Nativo.

Distribución: ATA, COQ.

Rango altitudinal: 0-1500 m.

Países limítrofes: Argentina.

Lycium chilense Miers ex Bertero var. glaberrimum Phil. Sinónimos: Lycium chilense Miers ex Bertero subsp. gracile (Meyen) Reiche, Lycium sessiliflorum Phil., Lycium rhadinum Phil., Lycium gracile Meyen, Lycium venosum Phil., Lycium chilense Miers ex Bertero fma. glaberrimum (Phil.) A. Terracc., Lycium chilense Miers ex Bertero var. gracile (Meyen) A. Terracc., Lycium chilense Miers ex Bertero var. glabriusculum Phil., Lycium salsum Ruiz \& Pav. var. gracile (Meyen) Kuntze, Lycium chilense Miers ex Bertero var. venosum (Phil.) Reiche, Lycium chilense Miers ex Bertero var. rhadinum (Phil.) Reiche

Arbusto. Nativo.
Distribución: ATA, COQ, VAL.

Rango altitudinal: 500-2000 m.

Países limítrofes: Argentina.

Lycium chilense Miers ex Bertero var. minutifolium (Miers) F.A. Barkley

Sinónimos: Lycium filifolium Gillies ex Miers var. minutifolium Miers, Lycium minutifolium Phil., Lycium chilense Miers ex Bertero fma. minutifolium (Miers) A. Terracc.

Arbusto. Nativo.

Distribución: ATA, COQ.

Rango altitudinal: 0-2500 m.

Países limítrofes: Argentina.

Lycium chilense Miers ex Bertero var. vergarae (Phil.)

Bernardello

Sinónimos: Lycium vergarae Phil.

Arbusto. Nativo.

Distribución: TAR, ATA, COQ.

Rango altitudinal: 2000-4000 m.

Países limítrofes: Argentina.

Lycium deserti Phil.

Sinónimos: Lycium breanum Phil., Lycium pachyclados Phil.

Arbusto. Endémico.

Distribución: TAR, ANT, ATA.

Rango altitudinal: 500-3200 m.

Lycium distichum Meyen

Sinónimos: Grabowskia disticha (Meyen) Nees ex Dunal

Arbusto. Nativo.

Distribución: TAR.

Rango altitudinal: $2000 \mathrm{~m}$.

Países limítrofes: Perú.

Lycium humile Phil.

Sinónimos: Lycium chilense Miers ex Bertero var. deserticum A. Terracc.

Arbusto. Nativo.

Distribución: TAR, ANT, ATA, RME.

Rango altitudinal: 2000-4000 m.

Países limítrofes: Argentina.

Nombre vulgar: Jume, june, wicha.

Lycium leiostemum Wedd.

Sinónimos: Lycium biesei F.A. Barkley

Arbusto. Nativo.

Distribución: AYP, TAR, ANT, ATA.

Rango altitudinal: $1000 \mathrm{~m}$.

Países limítrofes: Perú. 
Lycium minutifolium J. Remy

Sinónimos: Lycium implexum Miers, Lycium horridum Phil., Lycium rhudolphi Speg., Lycium chilense Miers ex Bertero var. deserticum A. Terracc., Lycium chilense Miers ex Bertero var. implexum (Miers) A. Terracc.

Arbusto. Endémico.

Distribución: ANT, ATA, COQ.

Rango altitudinal: 1000-3200 m.

Nombre vulgar: Calpiche, coralillo.

Lycium rachidocladum Dunal

Sinónimos: Lycium chilense Miers ex Bertero var. rachidocladum (Dunal) A. Terracc., Lycium chilense Miers ex Bertero subsp. rachidocladum (Dunal) Reiche

Arbusto. Endémico.

Distribución: ATA, COQ.

Rango altitudinal: 0-3500 m.

Lycium stenophyllum J. Remy

Sinónimos: Lycium fragosum Miers

Arbusto. Nativo.

Distribución: TAR, ANT, ATA, COQ.

Rango altitudinal: 0-2500 m.

Países limítrofes: Perú.

Lycium tenuispinosum Miers var. calycinum (Griseb.) Bernardello

Sinónimos: Lycium scoparium Miers var. calycinum Griseb., Lycium ovalilobum C.L. Hitchc.

Arbusto. Nativo.

Distribución: LLA.

Rango altitudinal: 0-2000 m.

Países limítrofes: Argentina.

\section{Nicandra}

Nicandra physalodes (L.) Gaertn.

Sinónimos: Atropa physalodes L.

Hierba. Anual. Nativa.

Distribución: AYP, TAR, COQ, VAL, RME.

Rango altitudinal: 0-2500 m.

Países limítrofes: Argentina, Bolivia y Perú.

\section{Nicotiana}

Nicotiana acuminata (Graham) Hook. var. acuminata

Sinónimos: Petunia acuminata Graham, Nicotiana longiflora Cav. var. oligantha (Phil.) Millán, Nicotiana uspallatensis Phil., Nicotiana oligantha Phil., Nicotiana copiapina Phil., Nicotiana modesta Phil.

Hierba. Perenne. Nativa.

Distribución: TAR, ANT, ATA, COQ, VAL, RME, LBO, MAU, NUB, BIO.

Rango altitudinal: 100-3400 m.
Países limítrofes: Argentina.

Nombre vulgar: Tabaco del campo, tabaco cimarrón.

Nicotiana acuminata (Graham) Hook. var. compacta Goodsp.

Hierba. Anual. Endémica.

Distribución: COQ.

Rango altitudinal: 2700-3500 m.

Nicotiana acuminata (Graham) Hook. var. multiflora (Phil.) Reiche

Sinónimos: Nicotiana angustifolia Ruiz \& Pav., Nicotiana heterophylla Phil., Nicotiana multiflora Phil.

Hierba. Anual. Endémica.

Distribución: ANT, ATA, COQ, VAL, RME, MAU, NUB, BIO, ARA, LLA.

Rango altitudinal: 100-3100 m.

Nicotiana cordifolia Phil. subsp. cordifolia

Arbusto. Endémico.

Distribución: JFE.

Rango altitudinal: 0-200 m.

Nicotiana cordifolia Phil. subsp. sanctaclarae Danton

Arbusto. Endémico.

Distribución: JFE.

Nicotiana corymbosa J. Remy

Sinónimos: Nicotiana monticola Dunal, Nicotiana scapigera Phil., Nicotiana oulophylla Dunal

Hierba. Anual. Nativa.

Distribución: ANT, ATA, COQ, VAL, RME, LBO, MAU, MAG.

Rango altitudinal: 700-3700 m.

Países limítrofes: Argentina.

Nicotiana glauca Graham

Arbusto o subarbusto. Nativo.

Distribución: AYP, TAR, ANT, ATA, COQ, VAL, RME.

Rango altitudinal: 0-3000 m.

Países limítrofes: Argentina, Bolivia y Perú.

Nombre vulgar: Palqui inglés, palqui extranjero, belénbelén.

Nicotiana linearis Phil.

Hierba. Anual. Nativa.

Distribución: COQ, MAU.

Rango altitudinal: 200-2100 m.

Países limítrofes: Argentina.

Nicotiana longibracteata Phil.

Sinónimos: Nicotiana frigida Phil.

Hierba. Anual. Nativa.

Distribución: TAR, ANT, ATA. 
Rango altitudinal: 3400-3700 m.

Países limítrofes: Argentina.

Nombre vulgar: Palpapalpa.

Nicotiana miersii J. Remy var. lychnoides (J. Remy) Goodsp.

Sinónimos: Nicotiana floribunda (Phil.) Reiche, Nicotiana lychnoides J. Remy, Waddingtonia floribunda Phil.

Hierba. Anual. Endémica.

Distribución: ATA, COQ.

Rango altitudinal: 0-1400 m.

Nicotiana miersii J. Remy var. miersii

Sinónimos: Nicotiana collae Phil., Nicotiana coquimbana Phil.

Hierba. Anual. Endémica.

Distribución: ATA, COQ, VAL, RME.

Rango altitudinal: 0-1400 m.

Nicotiana paa Mart. Crov.

Sinónimos: Nicotiana noctiflora Hook. var. albiflora Comes, Nicotiana cavanillesii Dunal var. albiflora (Comes) Millán

Hierba. Perenne. Nativa.

Distribución: ATA.

Rango altitudinal: 100-1600 m.

Países limítrofes: Argentina.

Nicotiana pauciflora J. Remy

Sinónimos: Nicotiana longiflora Cav. var. pauciflora (J.

Remy) Comes, Nicotiana caudigera Phil.

Hierba. Anual. Endémica.

Distribución: ATA, COQ.

Rango altitudinal: 500-2500 m.

Nicotiana petunioides (Griseb.) Millán

Sinónimos: Fabiana petunioides Griseb., Nicotiana pampasana Kuntze, Nicotiana philippii Millán

Hierba. Anual. Nativa.

Distribución: ANT, ATA.

Rango altitudinal: 3700-4600 m.

Países limítrofes: Argentina.

Nicotiana solanifolia Walp.

Sinónimos: Nicotiana breviloba Phil., Nicotiana cardiophylla Phil.

Subarbusto. Endémico.

Distribución: TAR, ANT, ATA, COQ.

Rango altitudinal: 0-1000 m.

\section{Nicotiana tabacum $\mathrm{L}$.}

Hierba. Anual o perenne. Introducida.

Distribución: JFE, IPA.

Nombre vulgar: Tabaco, aba aba (Rapa Nui).
Nicotiana undulata Ruiz \& Pav.

Sinónimos: Nicotiana chilensis Millán nom. illeg., Nicotiana brachysolen Phil.

Hierba. Anual. Nativa.

Distribución: AYP, TAR, ANT.

Rango altitudinal: $2700-4200 \mathrm{~m}$.

Países limítrofes: Argentina, Bolivia y Perú.

Nombre vulgar: Lipelipe.

\section{Nierembergia}

Nierembergia repens Ruiz \& Pav.

Hierba. Perenne. Nativa.

Distribución: MAU, NUB, BIO, ARA, LRI.

Rango altitudinal: 0-500 m.

Nota: Presente también en Ecuador.

\section{Nolana}

Nolana acuminata (Miers) Miers ex Dunal

Sinónimos: Sorema lanceolata Miers, Sorema acuminata

Miers, Sorema longifolia auct. non (Lindl.) Miers, Nolana

lanceolata (Miers) Miers ex Dunal, Nolana angustifolia

Phil., Nolana navarri Phil., Nolana rupestris Phil.

Hierba. Anual. Endémica.

Distribución: ANT, ATA, COQ, VAL.

Rango altitudinal: 0-900 $\mathrm{m}$.

Nolana adansonii (Roem. \& Schult.) I.M. Johnst.

Sinónimos: Tula adansonii Roem. \& Schult.

Hierba. Anual. Nativa.

Distribución: TAR.

Rango altitudinal: 0-800 m.

Países limítrofes: Perú.

Nolana albescens (Phil.) I.M. Johnst.

Sinónimos: Dolia albescens Phil. ex Wettst., Bargemontia albescens (Phil.) I.M. Johnst., Dolia albescens Phil.

Arbusto. Endémico.

Distribución: ANT, ATA, COQ.

Rango altitudinal: 0-1300 m.

Nolana aplocaryoides (Gaudich.) I.M. Johnst.

Sinónimos: Nolana sedifolia Poepp. var. aplocaryoides

(Gaudich.) Mesa, Leloutrea aplocaryoides Gaudich., Bargemontia aplocaryoides (Gaudich.) I.M. Johnst., Alona pusilla Phil.

Hierba. Anual. Nativa.

Distribución: AYP, TAR, ANT, ATA.

Rango altitudinal: 0-1300 m.

Países limítrofes: Perú. 
Nolana arenicola I.M. Johnst.

Hierba. Anual. Nativa.

Distribución: TAR.

Rango altitudinal: 200-700 m.

Países limítrofes: Perú.

Nolana baccata (Lindl.) Dunal

Sinónimos: Alona baccata Lindl., Sorema linearis Miers, Gubleria baccata Gaudich., Nolana linearis (Miers) Miers ex Dunal, Nolana stans Phil., Nolana carrera Phil., Nolana leucantha Phil., Nolana carrera Phil. var. leucantha (Phil.) Reiche, Periloba stans (Phil.) I.M. Johnst., Nolana alba Phil.

Hierba. Anual. Endémica.

Distribución: ANT, ATA, COQ.

Rango altitudinal: 0-800 m.

Nolana balsamiflua (Gaudich.) Mesa

Sinónimos: Alona balsamiflua Gaudich.

Subarbusto. Endémico.

Distribución: ANT.

Rango altitudinal: $500 \mathrm{~m}$.

Nolana carnosa (Lindl.) Miers ex Dunal

Sinónimos: Alona carnosa Lindl., Nolana rostrata (Lindl.) Miers ex Dunal var. carnosa (Lindl.) Mesa, Alona vernicosa Phil., Alona sedifolia Phil., Osteocarpus lepidophyllus Phil., Alona lepidophylla (Phil.) Reiche

Subarbusto. Endémico.

Distribución: TAR, ATA.

Rango altitudinal: 0-200 m.

Nolana clivicola (I.M. Johnst.) I.M. Johnst.

Sinónimos: Bargemontia clivicola I.M. Johnst.

Arbusto. Endémico.

Distribución: ANT, ATA.

Rango altitudinal: 0-800 m.

Nolana coelestis (Lindl.) Miers ex Dunal

Sinónimos: Alona coelestis Lind1., Alona ericifolia Miers, Nolana ericifolia (Miers) Miers ex Dunal, Alona floribunda Phil., Alona coelestis Lindl. var. ericifolia (Miers) F.H. Brandt

Subarbusto. Endémico.

Distribución: ATA, COQ.

Rango altitudinal: 100-800 m.

\section{Nolana crassulifolia Poepp.}

Sinónimos: Alona tomentosa Lindl., Alibrexia rupicola Miers, Nolana grossulifolia Kunze ex Gay, Dolia clavata auct. non Miers, Alona micrantha Phil., Dolia tomentosa (Lindl.) Benth., Dolia rupicola (Miers) Benth. \& Hook. ex Wettst., Dolia canescens Phil., Dolia eremobia Phil., Dolia grandiflora Phil., Dolia crassifolia Kuntze, Bargemontia crassulifolia (Poepp.) I.M. Johnst., Bargemontia micrantha (Phil.) I.M. Johnst., Bargemontia eremobia (Phil.) I.M. Johnst., Dolia philippi (Braun) F.H. Brandt, Dolia atacamensis F.H. Brandt, Alibrexia philipii A. Braun

Arbusto o subarbusto. Endémico.

Distribución: ATA, COQ, VAL.

Rango altitudinal: 0-1500 m.

Nolana deflexa (I.M. Johnst.) I.M. Johnst.

Sinónimos: Bargemontia deflexa I.M. Johnst.

Arbusto. Endémico.

Distribución: ANT, ATA.

Nolana dianae M.O. Dillon

Hierba. Anual. Endémica.

Distribución: ANT.

Rango altitudinal: 300-600 m.

Nolana diffusa I.M. Johnst.

Arbusto. Endémico.

Distribución: ANT.

Rango altitudinal: 0-500 m.

Nolana divaricata (Lindl.) I.M. Johnst.

Sinónimos: Nolana peruviana (Gaudich.) I.M. Johnst. subsp. divaricata (Lindl.) Mesa, Aplocarya divaricata Lindl., Dolia clavata Miers, Alona xerophila Phil., Dolia divaricata (Lindl.) Hook. \& Arn. ex W. Brandt, Alona rigida Phil., Dolia puberula Phil., Dolia hirsutula Phil., Dolia clavata Miers var. puberula (Phil.) Reiche, Bargemontia divaricata (Lindl.) I.M. Johnst., Bargemontia clavata (Miers) I.M. Johnst., Osteocarpus clavatus Phil.

Subarbusto. Endémico.

Distribución: ANT, ATA, COQ.

Rango altitudinal: 0-4100 m.

Nolana elegans (Phil.) Reiche

Sinónimos: Sorema elegans Phil.

Hierba. Anual. Endémica.

Distribución: ANT, ATA, VAL.

Rango altitudinal: 0-600 m.

Nolana filifolia (Hook. \& Arn.) I.M. Johnst.

Sinónimos: Alona filifolia (Hook. \& Arn.) I.M. Johnst., Convolvulus filifolius Hook. \& Arn., Nolana chastenayana Gaudich., Alona glandulosa Lindl., Ipomoea cruckshanskii Choisy, Fabiana grandiflora Dunal, Nolana glandulosa (Lindl.) Miers ex Dunal, Osteocarpus foliolosus Phil., Alona chastenayana (Gaudich.) Gaudich. ex Wettst.

Subarbusto. Endémico.

Distribución: ATA, COQ.

Rango altitudinal: 0-1300 m. 
Nolana foliosa (Phil.) I.M. Johnst.

Sinónimos: Dolia foliosa Phil., Bargemontia foliosa (Phil.)

I.M. Johnst.

Hierba. Perenne. Endémica.

Distribución: TAR.

Nolana glauca (I.M. Johnst.) I.M. Johnst.

Sinónimos: Bargemontia glauca I.M. Johnst., Nolana peruviana (Gaudich.) I.M. Johnst. var. glauca (I.M. Johnst.) Mesa

Subarbusto. Endémico.

Distribución: ANT, ATA, COQ.

Rango altitudinal: 0-1000 m.

Nolana gracillima (I.M. Johnst.) I.M. Johnst.

Sinónimos: Nolana sedifolia Poepp. subsp. confinis (I.M. Johnst.) Mesa, Bargemontia gracillima I.M. Johnst.

Hierba. Anual. Nativa.

Distribución: AYP, TAR, ANT.

Rango altitudinal: 0-2400 $\mathrm{m}$.

Países limítrofes: Perú.

Nolana incana (Phil.) I.M. Johnst.

Sinónimos: Alibrexia incana Phil., Dolia incana (Phil.) Wettst., Dolia incana (Phil.) Benth. \& Hook. ex F.H. Brandt Arbusto. Endémico.

Distribución: ANT, ATA.

Rango altitudinal: 0-800 m.

Nolana inconspicua (I.M. Johnst.) I.M. Johnst.

Sinónimos: Bargemontia inconspicua I.M. Johnst.

Arbusto. Endémico.

Distribución: ANT.

Rango altitudinal: 0-1000 m.

Nolana intonsa I.M. Johnst.

Hierba. Perenne. Endémica.

Distribución: TAR.

Rango altitudinal: 200-800 m.

Nolana jaffuelii I.M. Johnst.

Hierba. Anual. Nativa.

Distribución: TAR, ANT.

Rango altitudinal: 0-1000 m.

Países limítrofes: Perú.

Nolana lachimbensis M.O. Dillon \& Luebert

Arbusto. Endémico.

Distribución: ANT.

Rango altitudinal: $500 \mathrm{~m}$.

Nolana leptophylla (Miers) I.M. Johnst.

Sinónimos: Dolia leptophylla Miers, Velpeaulia alibrexioides Gaudich., Alona deserticola Phil., Alona dubia Phil., Bargemontia leptophylla (Miers) I.M. Johnst., Bargemontia deserticola (Phil.) I.M. Johnst., Dolia deserticola (Phil.) W. Brandt

Hierba. Perenne. Endémica.

Distribución: TAR, ANT, ATA.

Rango altitudinal: 0-4200 m.

Nolana linearifolia Phil.

Sinónimos: Nolana decemloba Herzog, Bargemontia linearifolia (Phil.) I.M. Johnst.

Hierba. Perenne. Endémica.

Distribución: ANT, ATA.

Rango altitudinal: 0-1000 m.

Nolana lycioides I.M. Johnst.

Sinónimos: Nolana sedifolia Poepp. subsp. confinis (I.M. Johnst.) Mesa

Hierba. Perenne. Nativa.

Distribución: AYP, TAR, ANT.

Rango altitudinal: 200-2100 m.

Países limítrofes: Perú.

Nolana mollis (Phil.) I.M. Johnst.

Sinónimos: Nolana leptophylla (Miers) I.M. Johnst. subsp. mollis (Phil.) Mesa, Alona mollis Phil., Dolia macrocalyx Phil., Bargemontia mollis (Phil.) I.M. Johnst.

Hierba. Perenne. Endémica.

Distribución: ANT, ATA.

Rango altitudinal: 0-700 m.

Nolana onoana M.O. Dillon \& M. Nakaz.

Hierba. Anual. Endémica.

Distribución: ANT.

Rango altitudinal: 100-600 m.

Nolana paradoxa Lindl.

Sinónimos: Nolana paradoxa Lindl. subsp. atriplicifolia (D. Don) Mesa, Periloba paradoxa (Lindl.) Raf., Sorema paradoxa (Lindl.) Lindl., Sorema litoralis Miers, Nolana litoralis (Miers) Dunal, Nolana paradoxa Lindl. var. glaberrima Dunal, Nolana atriplicifolia D. Don var. cuneifolia Dunal, Nolana paradoxa Lindl. var. violacea Van Houtte, Sorema petiolata Phil., Nolana ochrocarpa Phil. ex Wettst., Nolana geminiflora Phil., Nolana petiolata (Phil.) Reiche, Nolana atriplicifolia D. Don, Nolana grandiflora Lehm. ex G. Don, Sorema atriplicifolia (D. Don) Lindl., Sorema paradoxa (Lindl.) Lindl. var. atriplicifolia (D. Don) Miers, Nolana napiformis Phil., Nolana grandiflora Herzog Hierba. Anual. Endémica.

Distribución: ATA, COQ, VAL, MAU, NUB, BIO, ARA, LRI, LLA.

Rango altitudinal: 0-300 m.

Nombre vulgar: Suspiro del campo. 
Nolana parviflora (Phil.) Phil.

Sinónimos: Sorema parviflora Phil., Periloba parviflora (Phil.) I.M. Johnst.

Hierba. Anual. Endémica.

Distribución: ANT, ATA.

Rango altitudinal: 0-800 m.

Nolana patula (Phil.) Mesa ex M.O. Dillon

Sinónimos: Alona patula Phil., Nolana patula (Phil.) Mesa, comb. illeg.

Hierba. Perenne. Endémica.

Distribución: ATA.

Nolana peruviana (Gaudich.) I.M. Johnst.

Sinónimos: Bargemontia peruviana Gaudich., Dolia macrocalyx Phil. ex Herzog

Subarbusto. Endémico.

Distribución: TAR, ANT, ATA.

Rango altitudinal: 0-1000 m.

Nombre vulgar: Suspiro.

Nolana philippiana M.O. Dillon \& Luebert

Hierba. Anual. Endémica.

Distribución: ANT.

Rango altitudinal: 700-1600 m.

Nolana pterocarpa Phil. ex Wettst.

Sinónimos: Nolana pterosperma Phil., Nolana debilis Phil., Nolana pulchella Phil. ex Reiche, Periloba pterosperma (Phil.) I.M. Johnst.

Hierba. Anual. Endémica.

Distribución: TAR, ATA.

Rango altitudinal: 0-800 m.

Nolana ramosissima I.M. Johnst.

Sinónimos: Dolia salsoloides auct. non Lindl.

Arbusto. Endémico.

Distribución: ANT.

Rango altitudinal: 0-700 m.

Nolana reichei M.O. Dillon \& Arancio

Hierba. Perenne. Endémica.

Distribución: COQ.

Rango altitudinal: 0-100 m.

Nolana rhombifolia Martic. \& Quezada

Hierba. Anual. Endémica.

Distribución: AYP.

Rango altitudinal: 1800-1900 m.

Nolana rostrata (Lindl.) Miers ex Dunal

Sinónimos: Alona rostrata Lindl., Alona obtusa Lindl., Nolana obtusa (Lindl.) Miers ex Dunal, Alona miersii Phil., Alona phylicifolia Phil., Alona fonckii Phil., Rayera teretifolia Gaudich., Osteocarpus brevifolius Phil., Nolana lepidophylla (Phil.) I.M. Johnst., Osteocarpus rostratus (Lindl.) Phil.

Subarbusto. Endémico.

Distribución: TAR, ANT, ATA, COQ.

Rango altitudinal: 500-4100 m.

Nolana rupicola Gaudich.

Sinónimos: Alona longifolia Lindl., Sorema longifolia (Lindl.) Miers, Nolana longifolia (Lindl.) Miers ex Dunal, Nolana triquetra Koch \& Bouché, Sorema glutinosa Phil., Sorema bracteosa Phil., Nolana lanceolata auct. non (Miers) Miers ex Dunal, Nolana glutinosa (Phil.) Reiche, Nolana bracteosa (Phil.) Reiche, Periloba longifolia (Lindl.) I.M. Johnst.

Hierba. Perenne. Endémica.

Distribución: ANT, ATA, COQ, VAL.

Rango altitudinal: 0-900 $\mathrm{m}$.

Nombre vulgar: Suspiro.

Nolana salsoloides (Lindl.) I.M. Johnst.

Sinónimos: Dolia salsoloides Lindl., Osteocarpus spathulatus Phil., Dolia micrantha (Phil.) Reiche

Arbusto. Endémico.

Distribución: ANT, ATA, COQ.

Rango altitudinal: 0-900 $\mathrm{m}$.

Nolana sedifolia Poepp.

Sinónimos: Fabiana lanuginosa Hook. \& Arn., Salsola glomerulata Meyen, Dolia vermiculata Lindl., Alibrexia brevifolia Phil., Dolia brevifolia (Phil.) Phil. ex Wettst., Bargemontia sedifolia (Poepp.) I.M. Johnst.

Subarbusto. Endémico.

Distribución: TAR, ANT, ATA, COQ, VAL.

Rango altitudinal: 0-1000 m.

Nolana sessiliflora Phil.

Sinónimos: Nolana sessilifolia Phil. ex I.M. Johnst., Periloba sessiliflora (Phil.) I.M. Johnst.

Hierba. Anual. Endémica.

Distribución: ANT, ATA.

Rango altitudinal: 2000-2100 m.

Nolana sphaerophylla (Phil.) Mesa ex M.O. Dillon Sinónimos: Nolana flaccida (Phil.) I.M. Johnst., Alona sphaerophylla Phil., Bargemontia sphaerophylla (Phil.) I.M. Johnst., Alona flaccida Phil., Bargemontia flaccida (Phil.) I.M. Johnst.

Subarbusto. Endémico.

Distribución: ANT, ATA.

Rango altitudinal: 0-800 m. 
Nolana stenophylla I.M. Johnst.

Sinónimos: Alona stenophylla (I.M. Johnst.) I.M. Johnst.

Arbusto. Endémico.

Distribución: ANT, ATA.

Rango altitudinal: 0-600 m.

Nolana tarapacana (Phil.) I.M. Johnst.

Sinónimos: Dolia tarapacana Phil.

Hierba. Perenne. Endémica.

Distribución: AYP, TAR, ANT, ATA.

Rango altitudinal: 1000-3000 m.

Nombre vulgar: Deditos.

Nolana tocopillensis (I.M. Johnst.) I.M. Johnst.

Sinónimos: Bargemontia tocopillensis I.M. Johnst.

Arbusto. Endémico.

Distribución: ANT.

Rango altitudinal: 0-300 m.

Nolana villosa (Phil.) I.M. Johnst.

Sinónimos: Alibrexia villosa Phil., Dolia villosa (Phil.)

Reiche

Arbusto. Endémico.

Distribución: ANT, ATA.

Rango altitudinal: 0-1700 m.

Nolana werdermannii I.M. Johnst.

Hierba. Perenne. Endémica.

Distribución: ATA, COQ.

Rango altitudinal: $800 \mathrm{~m}$.

\section{Physalis}

\section{Physalis peruviana L.}

Hierba. Perenne. Nativa.

Distribución: AYP, COQ, VAL, RME, LBO, JFE.

Países limítrofes: Perú.

Nombre vulgar: Capulí, amor en bolsa, bolsa de amor.

Nota: Introducida en el Archipiélago Juan Fernández.

Physalis viscosa L.

Sinónimos: Physalis mendocina Phil.

Hierba. Perenne. Nativa.

Distribución: TAR, ATA, COQ, VAL, RME, BIO, ARA, IPA.

Rango altitudinal: 0-2000 m.

Países limítrofes: Argentina, Bolivia y Perú.

Nota: Introducida en la Isla de Pascua. Probablemente introducida en regiones del centro y sur.

\section{Reyesia}

Reyesia cactorum (I.M. Johnst.) D’Arcy

Sinónimos: Salpiglossis cactorum I.M. Johnst.
Hierba. Perenne. Endémica.

Distribución: ANT, ATA.

Rango altitudinal: 2900-3500 m.

Reyesia chilensis Gay

Sinónimos: Pteroglossis laxa Miers, Salpiglossis chilensis

(Gay) Wettst., Salpiglossis brachysiphon I.M. Johnst., Reyesia laxa (Miers) D’Arcy

Hierba. Perenne. Endémica.

Distribución: AYP, TAR, ANT, ATA, COQ.

Rango altitudinal: 0-1000 m.

Reyesia juniperoides (Werderm.) D'Arcy

Sinónimos: Salpiglossis juniperoides Werderm.

Hierba. Perenne. Endémica.

Distribución: AYP, TAR.

Rango altitudinal: $2500 \mathrm{~m}$.

Nombre vulgar: Canchanlahua.

Reyesia parviflora (Phil.) Hunz.

Sinónimos: Salpiglossis parviflora Phil.

Hierba. Anual. Nativa.

Distribución: TAR, ANT, ATA, COQ, RME.

Rango altitudinal: 2900-3500 m.

Países limítrofes: Argentina.

\section{Salpichroa}

Salpichroa origanifolia (Lam.) Baill.

Hierba. Perenne. Introducida.

Distribución: VAL, BIO.

Rango altitudinal: 900-1000 m.

\section{Salpichroa scandens Dammer}

Arbusto. Nativo.

Distribución: AYP.

Rango altitudinal: 2000-3600 m.

Países limítrofes: Argentina y Bolivia.

Salpichroa tristis Miers var. lehmanni (Dammer) Keel

Arbusto o árbol pequeño. Nativo.

Distribución: TAR.

Rango altitudinal: 3500-4500 m.

Países limítrofes: Argentina, Bolivia y Perú.

\section{Salpiglossis}

Salpiglossis sinuata Ruiz \& Pav.

Sinónimos: Salpiglossis purpurea Miers, Salpiglossis fulva Courtois, Salpiglossis picta Sweet, Salpiglossis purpurea Miers var. atropurpurea (Graham) Miers, Salpiglossis straminea Hook., Salpiglossis straminea Hook. var. picta (Sweet) Hook.

Hierba. Perenne. Nativa. 
Distribución: COQ, VAL, RME, LBO, MAU, NUB, BIO, ARA, LLA.

Rango altitudinal: 500-2000 m.

Países limítrofes: Argentina.

Nombre vulgar: Panza de burro.

Salpiglossis spinescens Clos

Arbusto. Endémico.

Distribución: ATA, COQ.

Rango altitudinal: 700-2800 m.

Nombre vulgar: Panza de burro.

\section{Schizanthus}

Schizanthus alpestris Poepp.

Sinónimos: Schizanthus angustifolius Phil., Schizanthus glanduliferus Phil., Schizanthus alpestris Poepp. var. glandulifera Phil.

Hierba. Anual. Endémica.

Distribución: ATA, COQ, VAL, RME.

Rango altitudinal: 900-2900 m.

Schizanthus candidus Lindl.

Sinónimos: Schizanthus albiflorus Phil.

Hierba. Anual. Endémica.

Distribución: ATA, COQ.

Rango altitudinal: 0-500 m.

Nombre vulgar: Mariposa blanca, cacatúa.

Schizanthus coccineus (Phil.) J.M. Watson

Sinónimos: Schizanthus grahamii Gill. var. coccinea Phil.

Hierba. Anual o bienal. Endémica.

Distribución: RME.

Rango altitudinal: 2600-2800 m.

Nombre vulgar: Mariposita roja.

Schizanthus grahamii Gillies ex Hook.

Sinónimos: Schizanthus retusus Hook., Schizanthus incanus Hort. ex C. Morr., Schizanthus gilliesii Phil., Schizanthus araucanus Phil., Schizanthus diazii Phil.

Hierba. Anual o bienal. Nativa.

Distribución: VAL, RME, LBO, MAU, BIO.

Rango altitudinal: 1200-2500 m.

Países limítrofes: Argentina.

Schizanthus hookeri Gillies ex Graham

Sinónimos: Schizanthus calycosus Phil.

Hierba. Anual o bienal. Nativa.

Distribución: COQ, VAL, RME, LBO, MAU, NUB, BIO,

ARA.

Rango altitudinal: 1300-3000 m.

Países limítrofes: Argentina.
Schizanthus integrifolius Phil.

Hierba. Anual. Endémica.

Distribución: ATA, COQ.

Rango altitudinal: $700-1500 \mathrm{~m}$.

Nombre vulgar: Palito.

Schizanthus lacteus Phil.

Sinónimos: Schizanthus sanromanii Phil.

Hierba. Anual. Endémica.

Distribución: ANT, ATA.

Rango altitudinal: 0-700 m.

Schizanthus laetus Phil.

Sinónimos: Schizanthus fallax I.M. Johnst.

Hierba. Anual. Endémica.

Distribución: AYP, TAR, ANT, ATA.

Rango altitudinal: 0-500 m.

Schizanthus litoralis Phil.

Sinónimos: Schizanthus splendens Sudzuki

Hierba. Anual. Endémica.

Distribución: ANT, ATA, COQ, VAL.

Rango altitudinal: 100-800 m.

Schizanthus parvulus Sudzuki

Hierba. Anual. Endémica.

Distribución: COQ.

Rango altitudinal: 300-600 m.

Schizanthus pinnatus Ruiz \& Pav.

Sinónimos: Schizanthus gayanus Phil., Schizanthus gracilis

Clos, Schizanthus humilis Phil., Schizanthus laciniosus

Phil., Schizanthus latifolius Phil., Schizanthus lilacinus

Kunze, Schizanthus heterophyllus Phil., Schizanthus tenuifolius Phil., Schizanthus tenuis Phil.

Hierba. Anual. Endémica.

Distribución: COQ, VAL, RME, LBO, MAU, NUB, BIO, ARA, LRI.

Rango altitudinal: $100-1500 \mathrm{~m}$.

Nombre vulgar: Pajarito.

Schizanthus porrigens Graham

Sinónimos: Schizanthus floribundus Phil.

Hierba. Anual. Endémica.

Distribución: COQ, VAL, RME, LBO.

Rango altitudinal: 0-500 m.

Schizanthus tricolor Grau \& Gronbach

Sinónimos: Schizanthus pinnatus Ruiz \& Pav. var. humilis

Lindl.

Hierba. Anual. Endémica.

Distribución: VAL, RME.

Rango altitudinal: 0-500 m. 


\section{Solanum}

Solanum alphonsei Dunal

Sinónimos: Solanum alphonsei Dunal var. taguatagua Dunal, Solanum germainii Phil., Solanum tenuicaule Phil. Arbusto. Endémico.

Distribución: LBO, MAU.

Rango altitudinal: 0-3000 m.

\section{Solanum americanum Mill.}

Sinónimos: Solanum nigrum L. var. americanum (Mill.) O.E. Schulz

Subarbusto. Nativo.

Distribución: ANT, COQ, VAL, RME, LBO.

Rango altitudinal: 0-1200 m.

Países limítrofes: Argentina, Bolivia y Perú.

Nombre vulgar: Hierba mora.

\section{Solanum argenteum Dunal}

Arbusto. Introducido.

Distribución: JFE.

\section{Solanum brachyantherum Phil.}

Sinónimos: Solanum geissei Phil.

Hierba. Perenne. Endémica.

Distribución: AYP, TAR, ANT, ATA, COQ, IDE.

Rango altitudinal: 100-700 m.

Solanum bridgesii Phil. var. bridgesii

Subarbusto. Endémico.

Distribución: RME, LBO, ARA.

Solanum bridgesii Phil. var. ocellatum (Phil.) Witasek ex Reiche

Sinónimos: Solanum ocellatum Phil.

Subarbusto. Endémico.

Distribución: RME.

Solanum chilense (Dunal) Reiche

Sinónimos: Lycopersicon chilense Dunal, Lycopersicon atacamense Phil., Lycopersicon bipinnatifidum Phil., Lycopersicon puberulum Phil.

Hierba. Perenne. Endémica.

Distribución: TAR, ANT.

Rango altitudinal: 0-1500 m.

Nombre vulgar: Tomatillo, tomate silvestre.

Solanum coxii Phil.

Arbusto. Endémico.

Distribución: LLA.

Solanum crispum Ruiz \& Pav.

Sinónimos: Solanum ligustrinum Lodd., Solanum congestiflorum Dunal, Solanum gayanum (J. Remy) F. Phil.,
Solanum pannosum Phil., Solanum pyrrhocarpum Phil., Witheringia crispa (Ruiz \& Pav.) J. Remy, Witheringia tomatillo J. Remy, Solanum crispum Ruiz \& Pav. var. ligustrinum (Lodd.) Dunal, Solanum tomatillo (J. Remy) F. Phil., Solanum concavum Lindl., Solanum syringaefolium Kunth \& Bouché, Witheringia berteroana J. Remy, Witheringia gayana J. Remy, Solanum congestiflorum Dunal var. longifolium Dunal, Solanum crispum Ruiz \& Pav. var. elaeagnifolium Dunal, Solanum sadae Phil., Solanum landbeckii Phil., Solanum angustifolium Lam. var. brevifolium Dunal, Solanum congestiflorum Dunal var. pannosum (Phil.) Reiche, Solanum congestiflorum Dunal var. syringaefolium (Kunth \& Bouché) Reiche, Solanum izquierdii Phil., Solanum pugae Phil., Solanum tagua Kuntze

Arbusto. Nativo.

Distribución: COQ, VAL, RME, LBO, MAU, NUB, BIO, ARA, LRI, LLA, AIS, JFE.

Rango altitudinal: 0-2500 m.

Países limítrofes: Argentina.

Nombre vulgar: Hierba del chabalongo, huevil, natri.

Solanum echegarayi Hieron.

Sinónimos: Solanum juncalense Reiche, Solanum juncalense Reiche subsp. aconcaguae Bitter

Hierba. Perenne. Nativa.

Distribución: VAL, MAU, NUB, BIO, ARA, LLA.

Rango altitudinal: 2000-3000 m.

Países limítrofes: Argentina.

Solanum elaeagnifolium Cav.

Hierba. Perenne. Nativa.

Distribución: AYP, TAR, ANT, ATA, COQ, VAL, RME.

Rango altitudinal: 200-3300 m.

Países limítrofes: Argentina.

Nombre vulgar: Tomatillo.

Solanum etuberosum Lindl.

Sinónimos: Solanum bustillosii Phil., Solanum subandinum F. Meigen, Solanum looseri Juz., Solanum tuberosum L. var. polemoniifolium Hook.f., Solanum kunzei Phil., Solanum etuberosum Lindl. var. antucense Bitter, Solanum etuberosum Lindl. var. bustillosii (Phil.) Witasek, Solanum etuberosum Lindl. var. chillanense Bitter

Hierba. Perenne. Endémica.

Distribución: VAL, RME, LBO, MAU, NUB, BIO, ARA. Rango altitudinal: 400-3000 m.

Solanum fernandezianum Phil.

Sinónimos: Solanum brevistylum Wittm., nom. nud., Solanum tuberosum L. var. fernandezianum (Phil.) Reiche Hierba. Perenne. Endémica.

Distribución: JFE.

Rango altitudinal: 100-1700 m. 
Solanum forsteri Seem.

Hierba o subarbusto. Perenne. Nativa.

Distribución: IPA.

Nombre vulgar: Poporo (Rapa Nui).

Solanum fragile Wedd.

Sinónimos: Solanum grandidentatum Phil., Solanum tarapacanum Phil.

Hierba. Perenne. Nativa.

Distribución: AYP, TAR.

Rango altitudinal: 3500-4000 m.

Países limítrofes: Bolivia y Perú.

Nombre vulgar: Nuñumaya.

Solanum furcatum Dunal

Sinónimos: Solanum tredecimgranum Bitter, Solanum andinum Reiche, Solanum crenato-dentatum Dunal, Solanum furcatum Dunal var. acutedentatum Nees, Solanum furcatum Dunal var. obtusedentatum Nees, Solanum furcatum Dunal var. subintegerrimum Nees, Solanum rancaguense Dunal, Solanum robinsonianum Bitter, Witheringia furcata (Dunal) J. Rémy

Hierba. Perenne. Nativa.

Distribución: AYP, TAR, ANT, ATA, COQ, VAL, RME, LBO, MAU, NUB, BIO, ARA, LLA, AIS, JFE.

Rango altitudinal: 200-1900 m.

Países limítrofes: Argentina y Perú.

Nombre vulgar: Hierba mora.

Nota: Introducida en el Archipiélago Juan Fernández.

Solanum gaudichaudii Dunal

Hierba. Anual. Endémica.

Distribución: COQ, VAL.

Rango altitudinal: 0-600 m.

Solanum herba-bona Reiche

Hierba. Anual. Endémica.

Distribución: ATA.

Nombre vulgar: Hierba mora.

Solanum heterantherum Witasek ex Reiche

Sinónimos: Solanum tomentosum (J. Remy) F. Phil., Witheringia tomentosa J. Remy

Hierba. Anual. Endémica.

Distribución: ATA, COQ, VAL.

Rango altitudinal: 0-100 m.

Solanum infundibuliforme Phil.

Sinónimos: Solanum infundibuliforme Phil. var. angustepinnatum Bitter, Solanum infundibuliforme Phil. var. albiflorum Ochoa

Hierba. Perenne. Nativa.

Distribución: TAR.

Rango altitudinal: 2500-4000 m.
Países limítrofes: Argentina y Bolivia.

Nombre vulgar: Aparuma.

Solanum lycopersicoides Dunal

Arbusto. Nativo.

Distribución: AYP, TAR.

Rango altitudinal: 1500-3600 m.

Países limítrofes: Perú.

Solanum maglia Schltdl.

Sinónimos: Solanum collinum Dunal, Solanum maglia Schltdl. var. collinum (Dunal) Bitter, Solanum maglia Schltdl. var. witasekianum Bitter, Solanum maglia Molina, nom. nud., Solanum tuberosum L. var. maglia (Schltdl.) A. DC., Solanum maglia Schltdl. var. brevifrons Bitter

Hierba. Perenne. Nativa.

Distribución: COQ, VAL, MAU, NUB, BIO, ARA, LLA.

Rango altitudinal: 0-1800 m.

Países limítrofes: Argentina.

Nombre vulgar: Papa cimarrona, papa de zorro.

\section{Solanum marginatum L.f.}

Arbusto. Introducido.

Distribución: VAL, MAU, BIO, JFE.

Rango altitudinal: 5-450 m.

Solanum medians Bitter

Hierba. Perenne. Nativa.

Distribución: AYP, TAR, ANT.

Rango altitudinal: 3100-3600 m.

Países limítrofes: Perú.

Solanum montanum L.

Sinónimos: Solanum phyllanthum Cav. var. crassipes (Phil.)

Witasek ex Reiche, Solanum crassipes Phil.

Hierba. Perenne. Nativa.

Distribución: AYP, TAR, ANT, ATA, COQ.

Países limítrofes: Perú.

Solanum nigrum $\mathrm{L}$.

Hierba. Anual. Introducida.

Distribución: AYP, TAR, ANT, ATA, COQ, VAL, RME, LBO, MAU, NUB, BIO, ARA, LRI, LLA, AIS.

Solanum nitidibaccatum Bitter

Sinónimos: Solanum physalifolium Rusby var. nitidibaccatum (Bitter) Edmonds

Hierba. Anual. Nativa.

Distribución: MAG.

Rango altitudinal: 0-2500 m.

Países limítrofes: Argentina. 
Solanum nitidum Ruiz \& Pav.

Arbusto. Nativo.

Distribución: AYP, TAR.

Rango altitudinal: 3000-3500 m.

Países limítrofes: Bolivia y Perú.

Nombre vulgar: Ñuñmaya.

\section{Solanum palustre Schltdl.}

Sinónimos: Solanum brevidens Phil., Solanum palustre Schltdl. var. glabrescens Walp., Solanum brevidens Phil. var. glabrescens (Dunal) Hawkes, Solanum tuberosum L. var. brevidens (Phil.) Reiche, Solanum tuberosum L. var. pearcei (Phil.) Reiche

Hierba. Perenne. Nativa.

Distribución: VAL, LBO, BIO, ARA, LLA.

Rango altitudinal: 0-1200 m.

Países limítrofes: Argentina.

Nombre vulgar: Papa de monte.

Solanum paposanum Phil.

Sinónimos: Solanum aberrans Phil., Solanum crassipes Phil. var. aberrans (Phil.) Bitter, Solanum phyllanthum Cav. var. aberrans (Phil.) Witasek ex Reiche

Hierba. Anual. Endémica.

Distribución: AYP, TAR, ANT, COQ.

Solanum pennellii Correll var. elachistus Martic. \& Quezada

Arbusto. Endémico.

Distribución: AYP, TAR.

Rango altitudinal: $1500 \mathrm{~m}$.

Solanum pentlandii Dunal subsp. interandinum (Bitter) Edmonds

Sinónimos: Solanum masafueranum Bitter \& Scottsb., Solanum interandinum Bitter

Subarbusto. Nativo.

Distribución: JFE.

Nota: Presente también en Ecuador.

Solanum pentlandii Dunal subsp. pentlandii

Subarbusto. Nativo.

Distribución: TAR.

Países limítrofes: Bolivia y Perú.

Solanum peruvianum L.

Sinónimos: Lycopersicon peruvianum (L.) Mill.

Hierba. Perenne. Nativa.

Distribución: AYP, TAR.

Rango altitudinal: 0-400 m.

Países limítrofes: Perú.

Solanum pimpinellifolium L.

Sinónimos: Lycopersicon pimpinellifolium (L.) Mill.,
Lycopersicon pissisi Phil., Solanum pissisi (Phil.) Reiche

Arbusto. Nativo.

Distribución: ATA.

Rango altitudinal: 0-500 m.

Países limítrofes: Perú.

Solanum pinnatum Cav.

Sinónimos: Solanum maritimum Meyen ex Nees, Solanum albiflorum Phil., Solanum feuillei Dunal, Solanum novemlobum Dunal, Solanum novemlobum Dunal var. pauciflorum Dunal, Solanum pinnatum Cav. var. subintegrifolium (Dunal) Reiche, nom. illeg., Solanum pinnatum Cav. var. tomentosum Reiche, Solanum runcinatum Ruiz \& Pav., Solanum cavanillesii Dunal var. subintegrifolium Dunal, Solanum gaudichaudiana (J. Remy) Phil., Witheringia gaudichaudiana J. Remy, Solanum gaudichaudii Dunal var. viride Dunal, Witheringia pinnata (Cav.) J. Remy

Subarbusto. Endémico.

Distribución: ANT, ATA, COQ, VAL, RME, LBO, MAU, JFE.

Rango altitudinal: 100-800 m.

Nombre vulgar: Hierba del chabalongo, serilla.

Solanum polyphyllum Phil.

Hierba. Perenne. Endémica.

Distribución: TAR.

\section{Solanum pseudocapsicum L.}

Subarbusto. Nativo.

Distribución: ANT, COQ, VAL, RME, BIO, JFE.

Rango altitudinal: 0-2600 m.

Países limítrofes: Argentina, Bolivia y Perú.

\section{Solanum radicans L.f.}

Sinónimos: Solanum ruderale (J. Remy) F. Phil., Witheringia ruderalis J. Remy

Subarbusto. Nativo.

Distribución: AYP, TAR, ATA, COQ, LBO.

Rango altitudinal: 500-2800 m.

Países limítrofes: Bolivia y Perú.

Solanum remyanum Phil.

Sinónimos: Solanum flexuosum (J. Remy) Phil., Witheringia

flexuosa J. Remy

Hierba. Perenne. Endémica.

Distribución: ANT, ATA, COQ.

Rango altitudinal: 0-700 m.

Solanum sanfurgoi Phil.

Arbusto. Endémico.

Distribución: MAU. 
Solanum sarrachoides Sendtn. Sinónimos: Solanum styleanum Dunal Hierba. Anual. Nativa. Distribución: VAL, LBO, MAU. Rango altitudinal: 200-2300 m. Países limítrofes: Argentina y Perú.

Nombre vulgar: Mora.

\section{Solanum sinuatirecurvum Bitter}

Sinónimos: Solanum metarsium C.V. Morton

Hierba. Perenne. Nativa.

Distribución: ANT.

Rango altitudinal: 3000-4500 m.

Países limítrofes: Argentina y Bolivia.

\section{Solanum sisymbriifolium Lam.}

Hierba. Perenne. Nativa.

Distribución: VAL, NUB.

Rango altitudinal: 0-1700 m.

Países limítrofes: Argentina, Bolivia y Perú.

Solanum sitiens I.M. Johnst.

Sinónimos: Solanum rickii Correll

Arbusto. Endémico.

Distribución: ANT.

Rango altitudinal: 2500-3400 m.

\section{Solanum tuberosum L.}

Sinónimos: Solanum chiloense (A. DC.) Berthault, Solanum molinae Juz., Solanum oceanicum Brücher, Solanum tuberosum L. var. chiloense A.DC., Solanum tuberosum L. var. cultum A. DC., Solanum tuberosum L. var. vulgare Hook.f., Solanum fonckii Phil. ex Reiche, nom. nud., nom. nud., Solanum chilotanum Hawkes, nom. nud., Solanum zykinii Lechn.

Hierba. Perenne. Nativa.

Distribución: ANT, VAL, RME, LBO, BIO, ARA, LLA, AIS.

Rango altitudinal: 500-3000 m.

Países limítrofes: Perú.

Nombre vulgar: Papa, poñi.

\section{Solanum tweedianum Hook.}

Hierba. Perenne. Nativa.

Distribución: VAL.

Rango altitudinal: 0-2500 m.

Países limítrofes: Argentina y Bolivia.

Solanum valdiviense Dunal

Sinónimos: Solanum cyrtopodium Dunal, Solanum krauseanum Phil., Solanum puberulum Phil., Solanum poeppigianum Dunal, nom. nud., Solanum sembarto Kuntze, Solanum sembarto Kuntze var. pubescens Kuntze,
Solanum sembarto Kuntze var. varians Kuntze, Solanum spiraeoides Dunal, Solanum subenervium Dunal

Arbusto. Nativo.

Distribución: RME, MAU, NUB, BIO, ARA, LRI, LLA, AIS.

Rango altitudinal: 100-2000 m.

Países limítrofes: Argentina.

Nombre vulgar: Huevil, llaguecillo.

Solanum weddellii Phil.

Hierba. Perenne. Endémica.

Distribución: TAR, ANT.

Rango altitudinal: 4000-4200 m.

Vestia

Vestia foetida Hoffmanns.

Sinónimos: Vestia lycioides Willd.

Arbusto. Endémico.

Distribución: VAL, LBO, NUB, BIO, ARA, LRI.

Rango altitudinal: $200 \mathrm{~m}$.

Nombre vulgar: Chuplín, echuelcúb, huevil.

\section{STYLIDIACEAE}

\section{Donatia}

Donatia fascicularis J.R. Forst. \& G. Forst.

Sinónimos: Donatia magellanica Lam., Polycarpon magellanicum L.f.

Hierba. Perenne. Nativa.

Distribución: ARA, LRI, LLA, AIS, MAG.

Rango altitudinal: 0-1000 m.

Países limítrofes: Argentina.

Nombre vulgar: Hierba de Donati, donacia.

\section{Phyllachne}

Phyllachne uliginosa J.R. Forst. \& G. Forst.

Sinónimos: Forstera muscifolia Willd., Forstera uliginosa (J.R. Forst. \& G. Forst.) Hombr. \& Jacquinot

Hierba. Perenne. Nativa.

Distribución: LLA, AIS, MAG.

Rango altitudinal: 0-700 m.

Países limítrofes: Argentina.

Nombre vulgar: Musguillo. 


\section{TETRACHONDRACEAE}

\section{Tetrachondra}

Tetrachondra patagonica Skottsb.

Sinónimos: Tetrachondra patagonica Skottsb. subsp. fuegiana D.M. Moore

Hierba. Perenne. Nativa.

Distribución: MAG.

Rango altitudinal: 0-1000 m.

Países limítrofes: Argentina.

Nombre vulgar: Tetracondra.

\section{THYMELAEACEAE}

\section{Drapetes}

Drapetes muscosus Lam.

Sinónimos: Drapetes muscoides Lam.

Hierba. Perenne. Nativa.

Distribución: LLA, AIS, MAG.

Rango altitudinal: 0-1000 m.

Países limítrofes: Argentina.

\section{Ovidia}

Ovidia andina (Poepp. \& Endl.) Meisn.

Sinónimos: Daphne andina Poepp. \& Endl., Daphne tenera Phil., Ovidia tenera (Phil.) Macloskie

Arbusto. Nativo.

Distribución: MAU, NUB, BIO, ARA, LRI, LLA, AIS.

Rango altitudinal: 700-2300 m.

Países limítrofes: Argentina.

Nombre vulgar: Traro-voqui.

Ovidia pillo-pillo (Gay) Meisn.

Sinónimos: Daphne pillo-pillo Gay, Ovidia parviflora Meisn.

Arbusto. Endémico.

Distribución: BIO, ARA, LRI, LLA, AIS.

Nombre vulgar: Lloime, palo hediondo, pillopillo.

\section{TROPAEOLACEAE}

\section{Tropaeolum}

Tropaeolum austropurpureum (J.M. Watson \& A.R. Flores) J.M. Watson \& A.R. Flores

Sinónimos: Tropaeolum hookerianum Barnéoud subsp. austropurpureum J.M. Watson \& A.R. Flores

Hierba. Perenne. Endémica.

Distribución: COQ.
Rango altitudinal: 0-200 m.

Tropaeolum azureum Bertero ex Colla

Sinónimos: Rixea azurea (Colla) Morren, Tropaeolum aureum C.A. Muell., Tropaeolum azureum Bertero ex Colla var. oblongilobum Buchenau, Tropaeolum violaeflorum A. Dietr., Tropaeolum azureum Bertero ex Colla var. angustilobum Buchenau, Tropaeolum azureum Bertero ex Colla var. grandiflorum Van Houtte, Tropaeolum lepidum Phil. ex Buchenau, Tropaeolum lepidum Phil. ex Buchenau var. luteum Reiche, Tropaeolum reicheanum Buchenau ex Reiche, Tropaeolum luteum (Reiche) Buchenau

Hierba. Perenne. Endémica.

Distribución: ANT, ATA, COQ, VAL, RME.

Rango altitudinal: 0-2500 m.

Nombre vulgar: Pajarito azul.

Tropaeolum beuthii Klotzsch

Sinónimos: Tropaeolum leptoceras I.M. Johnst., Tropaeolum benthamii Van Houtte

Hierba. Perenne. Endémica.

Distribución: AYP, TAR, ANT.

Rango altitudinal: $300-1000 \mathrm{~m}$.

Tropaeolum brachyceras Hook. \& Arn.

Sinónimos: Tropaeolum chilense Bertero ex Colla, Chymocarpus brachyceras (Hook. \& Arn.) Heynh., Tropaeolum brachyceras Hook. \& Arn. var. genuinum Buchenau, Tropaeolum minimum Miers, Tropaeolum brachyceras Hook. \& Arn. var. grandiflorum Reinecke ex Walp., Tropaeolum brachyceras Hook. \& Arn. var. sulphureum Walp., Tropaeolum tenellum G. Don

Hierba. Perenne. Endémica.

Distribución: COQ, VAL, RME, LBO, MAU.

Rango altitudinal: 0-1400 m.

Nombre vulgar: Malla, pajarito.

Tropaeolum ciliatum Ruiz \& Pav. subsp. ciliatum Hierba trepadora. Perenne. Endémica.

Distribución: VAL, RME, MAU, NUB, BIO, ARA.

Rango altitudinal: 400-1000 m.

Tropaeolum ciliatum Ruiz \& Pav. subsp. septentrionale Sparre

Sinónimos: Tropaeolum venosum Phil. ex Buchenau

Hierba trepadora. Perenne. Endémica.

Distribución: VAL, RME, LBO, MAU, NUB.

Rango altitudinal: 400-2000 m.

Tropaeolum hookerianum Barnéoud subsp. hookerianum Sinónimos: Tropaeolum brachyceras Hook. \& Arn. var. hookerianum (Barnéoud) Buchenau

Hierba. Perenne. Endémica.

Distribución: COQ. 
Rango altitudinal: 0-700 m.

Nombre vulgar: Mastuerzo.

Tropaeolum hookerianum Barnéoud subsp. pilosum J.M. Watson \& A.R. Flores

Hierba. Perenne. Endémica.

Distribución: COQ.

Rango altitudinal: 0-500 m.

\section{Tropaeolum incisum (Speg.) Sparre}

Sinónimos: Tropaeolum polyphyllum Cav. var. incisum Speg., Tropaeolum polyphyllum Cav. fma. schizophyllum H. Ross ex Neger, nom. nud.

Hierba. Perenne. Nativa.

Distribución: ATA, LBO, MAU, NUB, BIO, ARA, LLA.

Rango altitudinal: 1000-3000 m.

Países limítrofes: Argentina.

Tropaeolum jilesii Sparre

Hierba. Perenne. Endémica.

Distribución: COQ, VAL.

Rango altitudinal: 2000-2500 m.

Tropaeolum kingii Phil.

Sinónimos: Tropaeolum buchenaui Phil.

Hierba. Perenne. Endémica.

Distribución: ATA, COQ.

Rango altitudinal: 900-1500 m.

Tropaeolum leptophyllum G. Don subsp. gracile (Hook. \& Arn.) Sparre

Sinónimos: Tropaeolum gracile (Hook. \& Arn.) Sparre, Tropaeolum polyphyllum Cav. var. gracile Hook. \& Arn.

Hierba. Perenne. Endémica.

Distribución: MAU, NUB, BIO, ARA.

Rango altitudinal: 0-1900 m.

Tropaeolum leptophyllum G. Don subsp. leptophyllum Sinónimos: Tropaeolum chilense Bertero ex Colla var. eximium Steud., Tropaeolum edule Bridges, Tropaeolum bridgesii Field \& Gardner, Tropaeolum linearifolium Steud. Hierba. Perenne. Nativa.

Distribución: VAL, RME, LBO, MAU, NUB, BIO, ARA.

Rango altitudinal: 1000-2500 m.

Países limítrofes: Argentina.

Nombre vulgar: Púa.

\section{Tropaeolum looseri Sparre}

Hierba. Perenne. Endémica.

Distribución: COQ.

Rango altitudinal: 800-2400 m.

Tropaeolum majus L.

Hierba. Perenne. Introducida.
Distribución: VAL, RME, BIO, JFE.

Tropaeolum myriophyllum (Poepp. \& Endl.) Sparre

Sinónimos: Tropaeolum polyphyllum Cav. var. myriophyllum

Poepp. \& Endl.

Hierba. Perenne. Endémica.

Distribución: MAU, BIO.

Rango altitudinal: 400-3500 m.

Tropaeolum nubigenum Phil.

Hierba. Perenne. Endémica.

Distribución: RME.

Rango altitudinal: 3000-4000 m.

Tropaeolum nuptae-jucundae Sparre

Hierba. Perenne. Endémica.

Distribución: MAU, NUB, BIO, ARA.

Rango altitudinal: 0-300 m.

Tropaeolum polyphyllum Cav.

Sinónimos: Chymocarpus polyphyllus (Cav.) Heynh., Tropaeolum prostratum Miers, Tropaeolum paniculatum Meyen, Tropaeolum floribundum Turcz.

Hierba. Perenne. Nativa.

Distribución: COQ, VAL, RME, LBO, MAU.

Rango altitudinal: 2000-3700 m.

Países limítrofes: Argentina.

Tropaeolum porifolium (Cav.) L. Andersson \& S. Andersson

Sinónimos: Magallana porrifolia Pers., Magallana cavanillesii Scala, Magallana porifolia Cav.

Hierba. Perenne. Nativa.

Distribución: AIS.

Rango altitudinal: 0-2000 m.

Países limítrofes: Argentina.

Tropaeolum rhomboideum Lem.

Sinónimos: Tropaeolum tenuirostre Steud. var. majus Buchenau

Hierba. Perenne. Endémica.

Distribución: RME.

Rango altitudinal: 1000-2000 m.

Tropaeolum sessilifolium Poepp. \& Endl.

Hierba. Perenne. Endémica.

Distribución: COQ, VAL, RME, LBO.

Rango altitudinal: 1500-3400 m.

Tropaeolum speciosum Poepp. \& Endl.

Sinónimos: Chymocarpus speciosus (Poepp. \& Endl.) Walp., Tropaeolum lechleri Steud., Anisocentra cardiopetala Turcz.

Hierba. Perenne. Endémica. 
Distribución: BIO, ARA, LRI, LLA, AIS.

Rango altitudinal: 0-1500 m.

Nombre vulgar: Martillo del carpintero, pajarito, voqui, quintralito.

\section{Tropaeolum tricolor Sweet}

Sinónimos: Chymocarpus tricolor (Sweet) Heynh., Tropaeolum coccineum Miers, Tropaeolum elegans G. Don, Tropaeolum tricolor Sweet var. majus Marnock, Tropaeolum jarrattii Youell ex Paxton, Tropaeolum tricolor Sweet var. jarrattii (Paxton) Lem., Tropaeolum subincrassatum Steud., Tropaeolum incrassatum Steud., Tropaeolum tricolor Sweet var. grandiflorum Reinecke ex Walp., Tropaeolum tricolor Sweet var. splendens Reinecke ex Walp., Tropaeolum tricolor Sweet var. pallescens Barnéoud, Tropaeolum tricolor Sweet var. aurantiacum Morren, Tropaeolum tricolor Sweet var. grandiflorum Morren, Tropaeolum tricolor Sweet var. versicolor Morren, Tropaeolum tricolor Sweet var. venustum Paxton ex Otto, Tropaeolum violaceum Steud., Tropaeolum tricolor Sweet var. regelianum Möhring ex Regel, Tropaeolum tricolor Sweet var. schultzii Regel Hierba. Perenne. Endémica.

Distribución: ANT, ATA, COQ, VAL, RME, LBO, MAU, NUB, BIO, ARA, LLA.

Rango altitudinal: 0-2800 m.

Nombre vulgar: Relicario, soldadillo, chupa-chupa, gargantilla, arguenita.

\section{ULMACEAE}

\section{Ulmus}

Ulmus minor Mill.

Árbol. Introducido.

Distribución: RME.

\section{URTICACEAE}

\section{Boehmeria}

Boehmeria excelsa (Bertero ex Steud.) Wedd.

Sinónimos: Splitgerbera denudata Gay, Procris excelsa

Bertero ex Steud.

Árbol. Endémico.

Distribución: JFE.

Rango altitudinal: 0-400 m.

Nombre vulgar: Manzano.

\section{Parietaria}

Parietaria debilis G. Forst. Hierba. Anual. Nativa.
Distribución: TAR, ANT, ATA, COQ, VAL, RME, LBO, JFE.

Parietaria feliciana Phil.

Hierba. Anual. Endémica.

Distribución: IDE.

\section{Parietaria judaica L.}

Hierba. Anual. Introducida.

Distribución: VAL, RME.

\section{Pilea}

\section{Pilea elegans Gay}

Sinónimos: Pilea elliptica Hook.f. var. gayana Wedd.

Subarbusto. Endémico.

Distribución: BIO, ARA, LRI.

Rango altitudinal: 0-700 $\mathrm{m}$.

Nombre vulgar: Coyanlahuén, mellahuvilu.

Pilea elliptica Hook.f.

Sinónimos: Pilea chilensis Wedd., Pilea pedunculata

Blume, Pilea uliginosa Phil.

Hierba. Perenne. Endémica.

Distribución: ARA, LRI, LLA, AIS.

Rango altitudinal: 0-1100 m.

Pilea hyalina Fenzl

Sinónimos: Pilea hyalina Fenzl var. longipes Miq.

Hierba. Anual. Nativa.

Distribución: LBO.

Rango altitudinal: 0-1500 m.

Países limítrofes: Argentina, Bolivia y Perú.

\section{Soleirolia}

Soleirolia soleirolii (Req.) Dandy

Hierba. Perenne. Introducida.

Distribución: COQ, VAL, RME, BIO, ARA, LRI.

\section{Urtica}

Urtica berteroana Phil.

Sinónimos: Urtica echinata Benth. var. berteroana (Phil.)

Wedd.

Hierba. Perenne. Endémica.

Distribución: COQ, VAL, RME.

Rango altitudinal: 0-600 m.

Urtica dioica $\mathrm{L}$.

Arbusto. Introducido.

Distribución: BIO, ARA, LLA. 
Urtica echinata Benth.

Sinónimos: Urtica echinata Benth. var. punctulata Hauman, Urtica andicola Wedd.

Hierba. Perenne. Nativa.

Distribución: AYP, TAR, ANT.

Rango altitudinal: 3600-4500 m.

Países limítrofes: Argentina, Bolivia y Perú.

\section{Urtica flabellata Kunth}

Hierba. Anual. Nativa.

Distribución: AYP.

Rango altitudinal: 4000-4500 m.

Países limítrofes: Argentina, Bolivia y Perú.

Urtica glomeruliflora Steud.

Sinónimos: Urtica fernandeziana (Gay) H. Ross ex Skottsb., comb. illeg., Boehmeria fernandeziana Gay

Hierba. Perenne. Endémica.

Distribución: JFE.

Rango altitudinal: 200-1300 m.

Urtica gracilis Aiton subsp. mollis (Steud.) Weigend

Sinónimos: Urtica buchtienii R. Ross, Urtica mollis

Steud., Urtica dioica L. var. mollis (Steud.) Wedd., Urtica

diplotricha Phil., Urtica dioica L. var. diplotricha (Phil.)

Wedd.

Hierba. Perenne. Nativa.

Distribución: ANT, ATA, COQ, VAL, RME, LBO, MAU, ARA, LLA, AIS, MAG.

Rango altitudinal: 0-3500 m.

Países limítrofes: Argentina.

Urtica magellanica Poir.

Sinónimos: Urtica darwinii Hook.f., Urtica magellanica Poir. subsp. bracteata (Steud.) Geltman, Urtica pseudodioica Steud., Urtica bracteata Steud., Urtica magellanica Poir. var. bracteata (Steud.) Wedd.

Hierba. Perenne. Nativa.

Distribución: COQ, VAL, RME, LBO, MAU, NUB, BIO,

ARA, LRI, LLA, AIS, MAG.

Rango altitudinal: 0-1300 m.

Países limítrofes: Argentina, Bolivia y Perú.

Nombre vulgar: Ortiga caballuna.

Urtica masafuerae Phil.

Hierba. Perenne. Endémica.

Distribución: JFE.

Rango altitudinal: 0-500 m.

Urtica trichantha (Wedd.) Acevedo \& L.E. Navas

Sinónimos: Urtica echinata Benth. var. trichantha Wedd.

Hierba. Perenne. Nativa.

Distribución: AYP, TAR, ANT.

Rango altitudinal: 3400-4500 m.
Países limítrofes: Bolivia y Perú.

Nombre vulgar: Itapilla.

Urtica urens $\mathrm{L}$.

Hierba. Anual. Introducida.

Distribución: AYP, ANT, ATA, COQ, VAL, RME, LBO, MAU, NUB, BIO, ARA, LRI, LLA, AIS, MAG, JFE.

\section{VERBENACEAE}

\section{Aloysia}

Aloysia deserticola (Phil.) Lu-Irving \& O'Leary

Sinónimos: Acantholippia deserticola (Phil.) Moldenke, Acantholippia punensis Botta, nom. illeg., Lippia deserticola Phil., Lippia microphylla Phil., nom. illeg.

Arbusto. Nativo.

Distribución: AYP, TAR, ANT.

Rango altitudinal: 2300-3500 m.

Países limítrofes: Argentina y Bolivia.

Nombre vulgar: Kore.

Aloysia gratissima (Gillies \& Hook. ex Hook.) Tronc.

Sinónimos: Verbena gratissima Gillies \& Hook.

Arbusto. Nativo.

Distribución: VAL.

Países limítrofes: Argentina y Bolivia.

Nota: Moroni et al. 2016 sólo cita un ejemplar para Chile en Valparaíso, Limache recolectado por Garaventa 7092 (SI). No existen otros materiales.

Aloysia salviifolia (Hook. \& Arn.) Moldenke

Sinónimos: Aloysia chilensis (Schauer) Moldenke, Verbena salviifolia Hook. \& Arn., Lippia chilensis Schauer

Arbusto. Endémico.

Distribución: ATA, COQ.

Rango altitudinal: 0-1600 m.

Nombre vulgar: Salvia blanca, salvia.

Aloysia tarapacana (Botta) Lu-Irving \& O'Leary

Sinónimos: Acantholippia tarapacana Botta

Arbusto. Endémico.

Distribución: AYP.

Rango altitudinal: 2800-3300 m.

Aloysia trifida (Gay) Lu-Irving \& O’Leary

Sinónimos: Aloysia fonckii (Phil.) Moldenke, Aloysia reichei Moldenke var. reichei, Aloysia reichei Moldenke var. trilobata Moldenke, Acantholippia trifida (Gay) Moldenke, Lippia trifida Gay, Aloysia gracilis (Phil.) Acevedo, comb. illeg., Lippia trifida Gay var. gracilis (Phil.) Reiche, Lippia fonckii Phil., Acantholippia trifida (Gay) Moldenke var. reichei Moldenke 
Arbusto. Nativo.

Distribución: TAR, ANT, ATA, COQ.

Rango altitudinal: 1500-2500 m.

Países limítrofes: Argentina.

\section{Diostea}

Diostea juncea (Gillies \& Hook.) Miers

Sinónimos: Verbena juncea Gillies \& Hook., Lippia juncea (Gillies \& Hook.) Schauer, Bailloniajuncea Benth. \& Hook.f., Dipyrena spartioides Ravenna, Dipyrena juncea (Gillies \& Hook.) Ravenna, Dipyrena valdiviana Phil., Diostea valdiviana (Phil.) Miers, Dipyrena dentata Phil., Diostea infuscata Miers, Dipyrena infuscata (Miers) Ravenna, Citharexylum germaini Briq., Diostea chamaedryfolia Hort ex Hook.f., nom. illeg.

Arbusto. Nativo.

Distribución: COQ, VAL, RME, LBO, MAU, NUB, BIO, ARA, LRI.

Rango altitudinal: 0-2500 m.

Países limítrofes: Argentina.

Nombre vulgar: Retama.

\section{Glandularia}

Glandularia araucana (Phil.) Botta

Sinónimos: Verbena araucana Phil., Verbena chilensis Moldenke, Verbena glabrata Phil., nom. illeg.

Subarbusto. Nativo.

Distribución: RME, MAU, NUB, BIO, ARA.

Rango altitudinal: 900-3000 m.

Países limítrofes: Argentina.

Glandularia atacamensis (Reiche) J.M. Watson \& A. Hoffm.

Sinónimos: Verbena atacamensis Reiche, Verbena trifida Kunth var. deserticola Moldenke

Hierba. Perenne. Endémica.

Distribución: TAR, ANT, ATA.

Rango altitudinal: 0-700 m.

Glandularia berteroi (Schauer) Muñoz-Schick

Sinónimos: Glandularia reichei (Acevedo) L.E. Navas, Verbena berteroi Schauer fma. albiflora Moldenke, Verbena reichei Acevedo, Shuttleworthia berteroi Meisn., Verbena berteroi Schauer

Hierba. Perenne. Endémica.

Distribución: ANT, ATA, COQ, VAL, RME, LBO, MAU, NUB, BIO, ARA, LLA.

Rango altitudinal: 100-3400 m.

Glandularia corymbosa (Ruiz \& Pav.) N. O'Leary \& P. Peralta

Sinónimos: Verbena corymbosa Ruiz \& Pav.
Hierba. Perenne. Nativa.

Distribución: LBO, BIO, ARA, LLA.

Rango altitudinal: 0-700 $\mathrm{m}$.

Nombre vulgar: Corre-caballito, verbena.

Nota: Se encuentra también en Brasil y Uruguay.

Glandularia gynobasis (Wedd.) N. O’Leary \& P. Peralta Sinónimos: Verbena bella Phil., Verbena gynobasis Wedd. var. strigosa Phil., Verbena gynobasis Wedd.

Hierba. Perenne. Endémica.

Distribución: AYP, TAR.

Rango altitudinal: 1900-4000 m.

Glandularia laciniata (L.) Schnack \& Covas

Sinónimos: Verbena laciniata (L.) Briq., Verbena trachea Phil., Erinus laciniatus L., Verbena odorata Meyen

Hierba. Perenne. Nativa.

Distribución: COQ, VAL, RME, LBO, MAU, NUB, BIO, ARA.

Rango altitudinal: 0-2100 m.

Países limítrofes: Bolivia y Perú.

Glandularia landbeckii (Phil.) P. Peralta

Sinónimos: Verbena landbeckii Phil.

Hierba. Perenne. Endémica.

Distribución: COQ, VAL.

Rango altitudinal: 300-1500 m.

Glandularia lipozygioides (Walp.) L.E. Navas

Sinónimos: Verbena lipozygioides Walp., Verbena lipozygoides Walp. var. minima Walp.

Hierba. Perenne. Endémica.

Distribución: COQ, RME.

Rango altitudinal: 1200-1400 m.

Glandularia macrosperma (Speg.) Tronc.

Sinónimos: Glandularia sulphurea (D. Don) Schnack \& Covas var. intermedia (Kuntze) L.E. Navas, Verbena sulphurea D. Don var. intermedia Kuntze, Verbena macrosperma Speg.

Hierba. Perenne. Nativa.

Distribución: COQ, VAL.

Rango altitudinal: 2800-3100 m.

Países limítrofes: Argentina.

Glandularia multiglandulosa (Moldenke) P. Peralta Sinónimos: Verbena multiglandulosa Moldenke

Hierba. Perenne. Endémica.

Distribución: COQ.

Rango altitudinal: $1300 \mathrm{~m}$.

Glandularia porrigens (Phil.) J.M. Watson \& A. Hoffm. Sinónimos: Verbena cumingii Moldenke, Verbena paulsenii Phil., Verbena porrigens Phil. 
Subarbusto. Endémico. Distribución: ANT, ATA, COQ, VAL, RME.

Rango altitudinal: 0-1000 m.

Glandularia ribifolia (Walp.) P. Peralta Sinónimos: Verbena ribifolia Walp., Verbena ribifolia Walp. var. foetida (Phil.) Acevedo, Verbena ribifolia Walp. fma. alba Acevedo, Verbena ribifolia Walp. fma. longavina (Phil.) Acevedo, Verbena foetida Phil., Verbena longavina Phil.

Hierba. Perenne. Endémica.

Distribución: RME, LBO, MAU.

Rango altitudinal: 500-2500 m.

Glandularia sulphurea (D. Don) Schnack \& Covas var. pedunculata (Clos) L.E. Navas

Sinónimos: Verbena sulphurea D. Don var. fuscorubra Skottsb., Verbena sulphurea D. Don var. pedunculata Clos, Verbena sulphurea D. Don fma. alba Moldenke ex Skottsb.

Hierba. Perenne. Endémica.

Distribución: ATA, COQ, VAL, RME.

Rango altitudinal: 0-1000 m.

Glandularia sulphurea (D. Don) Schnack \& Covas var. sulphurea

Sinónimos: Verbena sulphurea D. Don var. taltalensis Moldenke, Verbena sulphurea D. Don, Verbena sulphurea D. Don var. longituba Kuntze, Verbena sulphurea D. Don var. scabra Acevedo, Shuttleworthia sulphurea (D. Don) Meisn., Uwarowia sulphurea (D. Don) Meisn.

Hierba. Perenne. Nativa.

Distribución: ATA, COQ, VAL, RME, ARA.

Rango altitudinal: 2600-3300 m.

Países limítrofes: Argentina.

Nombre vulgar: Hierba del incordio.

\section{Junellia}

Junellia aretioides (R.E. Fr.) Moldenke

Sinónimos: Verbena aretioides R.E. Fr.

Arbusto. Nativo.

Distribución: AYP, TAR.

Rango altitudinal: 2700-4400 m.

Países limítrofes: Argentina y Bolivia.

Junellia bryoides (Phil.) Moldenke

Sinónimos: Verbena bryoides Phil.

Arbusto. Endémico.

Distribución: AYP, TAR.

Rango altitudinal: 3100-3900 m.

Nombre vulgar: Culesoro, pata de perdiz.

Junellia caespitosa (Gillies \& Hook.) Moldenke Sinónimos: Verbena caespitosa Gillies \& Hook.
Arbusto. Nativo.

Distribución: ATA, COQ.

Rango altitudinal: 1400-3600 m.

Países limítrofes: Argentina.

Junellia crithmifolia (Gillies \& Hook.) N. O’Leary \& P. Peralta

Sinónimos: Verbena crithmifolia Gillies \& Hook., Glandularia crithmifolia (Gillies \& Hook.) Schnack \& Covas

Arbusto. Nativo.

Distribución: COQ.

Rango altitudinal: 0-2500 m.

Países limítrofes: Argentina.

Junellia digitata (Phil.) Moldenke var. digitata

Sinónimos: Verbena triternata Phil., Junellia tridactyla (Phil.) Moldenke, Junellia punctulata Hieron. ex Moldenke, Verbena digitata Phil., Verbena tridactyla Phil.

Arbusto. Nativo.

Distribución: AYP, TAR, ANT.

Rango altitudinal: 3500-4700 m.

Países limítrofes: Argentina.

Nombre vulgar: Altea.

Junellia digitata (Phil.) Moldenke var. integerrima (Botta) Botta

Sinónimos: Verbena digitata Phil. var. integerrima Botta

Hierba. Perenne. Nativa.

Distribución: TAR, ANT.

Rango altitudinal: 3200-4500 m.

Países limítrofes: Argentina.

Junellia juniperina (Lag.) Moldenke

Sinónimos: Verbena juniperina Lag.

Arbusto. Nativo.

Distribución: AYP, TAR, RME.

Rango altitudinal: 1900-3600 m.

Países limítrofes: Argentina, Bolivia y Perú.

Nombre vulgar: Tola.

Junellia lavandulaefolia (Phil.) Moldenke

Sinónimos: Junellia lavandulaefolia (Phil.) Moldenke var. colchaguensis (Phil.) Moldenke, Verbena lavandulaefolia Phil., Verbena colchaguensis Phil., Verbena lavandulaefolia Phil. var. colchaguensis (Phil.) Reiche

Arbusto. Endémico.

Distribución: COQ, VAL, RME, LBO, MAU.

Rango altitudinal: 1000-3200 m.

Junellia micrantha (Phil.) Múlgura

Sinónimos: Junellia micrantha (Phil.) Moldenke, nom. illeg., Verbena ramulosa Phil., Verbena micrantha Phil. Arbusto. Nativo. 
Distribución: RME, LBO.

Rango altitudinal: 0-3500 m.

Países limítrofes: Argentina.

Junellia minima (Meyen) Moldenke

Sinónimos: Junellia minima (Meyen) Moldenke var. strigosa Moldenke, Junellia stragulosoides Moldenke, Verbena minima Meyen, Verbena straguloides (Moldenke)

Arbusto. Nativo.

Distribución: AYP, TAR.

Países limítrofes: Argentina, Bolivia y Perú.

\section{Junellia odonellii Moldenke}

Sinónimos: Verbena o'donelli (Moldenke) Tronc., comb. illeg.

Arbusto. Nativo.

Distribución: AIS, MAG.

Rango altitudinal: 0-1000 m.

Países limítrofes: Argentina.

Junellia origenes (Phil.) N. O’Leary \& P. Peralta

Sinónimos: Verbena origenes Phil., Verbena origenes Phil. var. glabriflora Moldenke, Verbena deserticola Phil., Verbena origenes Phil. var. semperi Moldenke, Verbena palmata Reiche, Glandularia origenes (Phil.) Schnack \& Covas

Hierba. Perenne. Nativa.

Distribución: ANT, ATA, COQ.

Rango altitudinal: 0-4000 m.

Países limítrofes: Argentina.

Nombre vulgar: Rica-rica, core, costilla.

Junellia pappigera (Phil.) N. O’Leary \& P. Peralta

Sinónimos: Urbania egañioides Phil., Urbania pappigera Phil.

Arbusto. Nativo.

Distribución: TAR, ANT, ATA.

Rango altitudinal: 3100-4800 m.

Países limítrofes: Argentina y Bolivia.

Junellia pseudojuncea (Gay) Moldenke

Sinónimos: Verbena pseudojuncea Gay, Verbena spathulata Gillies \& Hook. var. pseudojuncea (Gay) Reiche, Thryothamnus junciformis Phil., Verbena junciformis (Phil.) Reiche

Arbusto. Endémico.

Distribución: ATA, COQ.

Rango altitudinal: 2000-2500 m.

Junellia selaginoides (Kunth ex Walp.) Moldenke var. illapelina (Phil.) Botta

Sinónimos: Junellia illapelina (Phil.) Moldenke, Verbena illapelina Phil., Verbena selaginoides Kunth ex Walp. var. illapelina (Phil.) Reiche
Arbusto. Endémico.

Distribución: ANT, ATA, COQ.

Rango altitudinal: 600-1500 m.

Junellia selaginoides (Kunth ex Walp.) Moldenke var. selaginoides

Sinónimos: Verbena polycephala Turcz., Verbena selaginoides Kunth ex Walp., Verbena alternifolia Hort ex Schauer

Arbusto. Endémico.

Distribución: ANT, COQ.

Rango altitudinal: 0-500 m.

Junellia seriphioides (Gillies \& Hook.) Moldenke

Sinónimos: Verbena echinata Phil., Verbena seriphioides

Gillies \& Hook.

Arbusto. Nativo.

Distribución: AYP, TAR, ANT.

Rango altitudinal: 1300-4200 m.

Países limítrofes: Argentina y Bolivia.

Nombre vulgar: Rosa de la cordillera, kaylla.

Junellia silvestrii (Speg.) Moldenke

Sinónimos: Verbena silvestrii Speg.

Arbusto. Nativo.

Distribución: MAG.

Rango altitudinal: 0-200 m.

Países limítrofes: Argentina.

Junellia spathulata (Gillies \& Hook.) Moldenke var. glauca (Gillies \& Hook.) Botta

Sinónimos: Junellia glauca (Gillies \& Hook.) Moldenke, Verbena glauca Gillies \& Hook.

Arbusto. Nativo.

Distribución: COQ, VAL, RME, MAU.

Rango altitudinal: $500-2700 \mathrm{~m}$.

Países limítrofes: Argentina.

Junellia spathulata (Gillies \& Hook.) Moldenke var. spathulata

Sinónimos: Verbena spathulata Gillies \& Hook.

Arbusto. Nativo.

Distribución: COQ, RME, LBO, MAU.

Rango altitudinal: 1900-2200 m.

Países limítrofes: Argentina.

Junellia thymifolia (Lag.) Moldenke

Sinónimos: Verbena thymifolia Lag.

Arbusto. Nativo.

Distribución: MAG.

Rango altitudinal: 0-500 m.

Países limítrofes: Argentina. 
Junellia tridactylites (Lag.) Moldenke

Sinónimos: Junellia minutifolia (Phil.) Moldenke, Verbena minutifolia Phil., Verbena philippiana Kuntze, nom. illeg., Verbena tridactylites Lag.

Arbusto. Nativo.

Distribución: MAG.

Rango altitudinal: 2300-2400 m.

Países limítrofes: Argentina.

Junellia trifurcata (Phil.) Moldenke

Sinónimos: Verbena trifurcata Phil.

Subarbusto. Endémico.

Distribución: RME.

Rango altitudinal: 2300-3400 m.

Junellia ulicina (Phil.) Moldenke

Sinónimos: Verbena ulicina Phil.

Arbusto. Nativo.

Distribución: ATA, COQ, VAL, RME, LBO.

Rango altitudinal: 0-1800 m.

Países limítrofes: Argentina.

Junellia uniflora (Phil.) Moldenke

Sinónimos: Verbena uniflora Phil., Lycium nanum Phil.

Arbusto. Nativo.

Distribución: ATA, COQ, VAL, RME, MAU.

Rango altitudinal: 2500-4000 m.

Países limítrofes: Argentina.

\section{Lampayo}

Lampayo hieronymi K. Schum. ex Moldenke

Arbusto. Nativo.

Distribución: ANT.

Rango altitudinal: 2500-4000 m.

Países limítrofes: Argentina.

Nombre vulgar: Lampaya macho.

Nota: El nombre de género Lampaya es considerado inválido.

\section{Lampayo medicinalis Phil.}

Arbusto. Nativo.

Distribución: AYP, TAR, ANT.

Rango altitudinal: 2000-4500 m.

Países limítrofes: Bolivia.

Nombre vulgar: Lampaya hembra.

Nota: El nombre de género Lampaya es considerado inválido.

\section{Lantana}

\section{Lantana camara L.}

Arbusto. Introducido.

Distribución: VAL, IPA.

\section{Lippia}

Lippia fragrans Turcz.

Sinónimos: Lippia geisseana (Phil.) Soler., Buddleja geisseana Phil.

Arbusto. Endémico.

Distribución: ANT, ATA, COQ.

Rango altitudinal: 0-1400 m.

Nombre vulgar: Orégano.

Lippia turbinata Griseb.

Sinónimos: Lippia aprica Phil., Lippia disepala Phil.

Arbusto. Nativo.

Distribución: ATA.

Rango altitudinal: 0-1500 m.

Países limítrofes: Argentina y Bolivia.

\section{Mulguraea}

Mulguraea arequipensis (Botta) N. O'Leary \& P. Peralta Sinónimos: Verbena arequipense Botta, Junellia arequipense (Botta) Botta, Dipyrena arequipensis (Botta) Ravenna

Arbusto. Nativo.

Distribución: AYP, TAR.

Rango altitudinal: 2200-4300 m.

Países limítrofes: Perú.

Mulguraea asparagoides (Gillies \& Hook.) N. O’Leary \& P. Peralta

Sinónimos: Verbena asparagoides Gillies \& Hook., Junellia asparagoides (Gillies \& Hook.) Moldenke

Arbusto. Nativo.

Distribución: ATA, COQ, VAL.

Rango altitudinal: 2000-2800 m.

Países limítrofes: Argentina y Bolivia.

Mulguraea cinerascens (Schauer) N. O'Leary \& P. Peralta Sinónimos: Diostea cinerascens (Schauer) Moldenke, Verbena cinerascens Schauer, Junellia cinerascens (Schauer) Botta, Dipyrena cinerascens (Schauer) Ravenna Arbusto. Endémico.

Distribución: COQ, VAL.

Rango altitudinal: 1000-1500 m.

Mulguraea hystrix (Phil.) N. O’Leary \& P. Peralta Sinónimos: Verbena hystrix Phil., Junellia hystrix (Phil.) Moldenke

Arbusto. Nativo.

Distribución: ANT, ATA.

Rango altitudinal: 2600-3700 m.

Países limítrofes: Argentina. 
Mulguraea scoparia (Gillies \& Hook.) N. O'Leary \& P. Peralta

Sinónimos: Verbena scoparia Gillies \& Hook., Diostea scoparia (Gillies \& Hook.) Miers, Diostea scirpea (Phil.) Miers, Lippia aphylla Phil., Lippia scirpea Phil., Verbena scoparia Gillies \& Hook. var. aphylla (Phil.) Acevedo, comb. illeg., Junellia scoparia (Gillies \& Hook.) Botta, Dipyrena scoparia (Hook.) Ravenna

Arbusto. Nativo.

Distribución: COQ, VAL, RME.

Rango altitudinal: 1800-3000 m.

Países limítrofes: Argentina.

Mulguraea tridens (Lag.) N. O'Leary \& P. Peralta Sinónimos: Verbena tridens Lag., Junellia tridens (Lag.) Moldenke

Arbusto. Nativo.

Distribución: MAG.

Rango altitudinal: 0-800 m.

Países limítrofes: Argentina.

\section{Phyla}

Phyla nodiflora (L.) Greene var. minor (Gillies \& Hook.) N. O'Leary \& P. Peralta

Sinónimos: Phyla canescens (Kunth) Greene, Lippia canescens Kunth, Lippia nodiflora (L.) Michx. var. minor Gillies \& Hook., Lippia litoralis Phil., Phyla nodiflora (L.) Greene fma. copiapina Acevedo

Hierba. Perenne. Nativa.

Distribución: ATA, COQ, VAL, RME, LBO, MAU, BIO, ARA, LRI, LLA.

Rango altitudinal: 0-1100 m.

Países limítrofes: Argentina.

Phyla nodiflora (L.) Greene var. nodiflora

Sinónimos: Lippia nodiflora (L.) Michx., Verbena nodiflora

L.

Hierba. Perenne. Nativa.

Distribución: TAR, ATA.

Países limítrofes: Argentina, Bolivia y Perú.

Nombre vulgar: Hierba de la virgen María, tiqui-tiqui, tiquil-tiquil.

\section{Pitraea}

\section{Pitraea cuneato-ovata (Cav.) Caro}

Sinónimos: Castelia cuneato-ovata Cav., Pitraea chilensis Turcz., Priva cuneato-ovata (Cav.) Rusby, Bouchea copiapensis Gay

Hierba. Perenne. Nativa.

Distribución: AYP, TAR, ANT, ATA, COQ, VAL, RME.

Rango altitudinal: 0-3000 m.

Países limítrofes: Argentina y Perú.
Nombre vulgar: Chámen.

\section{Rhaphithamnus}

Rhaphithamnus spinosus (Juss.) Moldenke

Sinónimos: Volkameria spinosa Juss., Duranta umbilicata Miers, Duranta umbellata Miers, Citharexylum cyanocarpum Hook. \& Arn., Citharexylum ovatum Turcz., Rhaphithamnus cyanocarpum (Hook. \& Arn.) Miers, Rhaphithamnus amoenus Miers, Rhaphithamnus buxifolius Miers, Rhaphithamnus parvifolius Miers, Rhaphithamnus macranthus Gand., Rhaphithamnus spinosus (Juss.) Moldenke fma. albiflorus G. Kunkel, Rhaphithamnus spinosus (Juss.) Moldenke var. inermis G. Kunkel, Rhaphithamnus spinosus (Juss.) Moldenke fma. microphyllus G. Kunkel

Arbusto. Nativo.

Distribución: COQ, VAL, RME, LBO, MAU, NUB, BIO, ARA, LRI, LLA, AIS.

Rango altitudinal: 0-1000 m.

Países limítrofes: Argentina.

Nombre vulgar: Arrayán macho, espino negro, arrayán de espino, huayún, espino blanco, hayún, repu, arrayancillo.

Rhaphithamnus venustus (Phil.) B.L. Rob.

Sinónimos: Citharexylum venustum Phil., Rhaphithamnus longiflorus Miers, Rhaphithamnus serratifolius Miers, Rhaphithamnus venustus (Phil.) Skottsb., comb. illeg.

Árbol. Endémico.

Distribución: JFE.

Rango altitudinal: 0-1000 m.

Nombre vulgar: Juan bueno.

\section{Verbena}

Verbena bonariensis L.

Hierba. Anual o bienal. Nativa.

Distribución: AYP, TAR, ANT, ATA, COQ, VAL, RME, LBO, MAU, NUB, BIO, ARA, LRI, LLA.

Rango altitudinal: 0-2100 m.

Países limítrofes: Argentina y Bolivia.

Nombre vulgar: Verbena.

Verbena cuneifolia Ruiz \& Pav.

Hierba. Perenne. Nativa.

Distribución: RME.

Rango altitudinal: 2000-4000 m.

Países limítrofes: Perú.

Verbena hispida Ruiz \& Pav.

Hierba. Perenne. Nativa.

Distribución: AYP, TAR, VAL, RME, LBO, NUB, BIO.

Rango altitudinal: 0-3500 m.

Países limítrofes: Argentina, Bolivia y Perú. 
Verbena litoralis Kunth

Hierba. Perenne. Nativa.

Distribución: AYP, ATA, COQ, VAL, RME, LBO, MAU, NUB, BIO, ARA, LRI, LLA, JFE, IPA.

Rango altitudinal: 0-2000 m.

Países limítrofes: Argentina, Bolivia y Perú.

Nombre vulgar: Verbena.

Nota: Introducida en el Archipiélago Juan Fernández y en la Isla de Pascua.

Verbena officinalis L.

Hierba. Perenne. Introducida.

Distribución: COQ, MAU, BIO, ARA, LRI.

\section{VIOLACEAE}

\section{Pombalia}

Pombalia parviflora (Mutis ex L.f.) Paula-Souza

Sinónimos: Hybanthus parviflorus (Mutis ex L.f.) Baill., Viola parviflora Mutis ex L.f., Hybanthus parviflorus (Mutis ex L.f.) Baill. var. latifolius (Eichler) Hassl., Hybanthus parviflorus (Mutis ex L.f.) Baill. var. argentinensis Sparre, Hybanthus parviflorus (Mutis ex L.f.) Baill. var. glutinosus (Vent.) Hassl., Ionidium parviflorum (Mutis ex L.f.) Vent., Ionidium glutinosum Vent., Hybanthus glutinosus (Vent.) Taub., Hybanthus parviflorus (Mutis ex L.f.) Baill. var. typicus Hassl., nom. illeg., Hybanthus parviflorus (Mutis ex L.f.) Baill. fma. membranaceus Schulze-Menz, Calceolaria bangii Rusby, Hybanthus parviflorus (Mutis ex L.f.) Baill. var. chamaedrifolius (C. Presl) Sparre, Ionidium chamaedryfolium Poepp. ex Walp., Solea parviflora (Mutis ex L.f.) Spreng., Ionidium glutinosum Vent. var. latifolium Eichler, Ionidium glutinosum Vent. var. angustifolium Eichler, Ionidium glutinosum Vent. var. paraguayense Chodat, Hybanthus parviflorus (Mutis ex L.f.) Baill. var. bangii (Rusby) Sparre, Hybanthus maytencillo Baill., Hybanthus microphyllus (Willd. ex Schult.) Baill., Ionidium microphyllum (Willd. ex Schult.) Kunth, Solea glutinosa (Vent.) Spreng., Viola glutinosa (Vent.) Poir., Viola microphylla Willd. ex Schult., nom. illeg., Viola parvifolia Schult., Viola venezuelensis Steyerm.

Hierba. Anual o perenne. Nativa.

Distribución: LBO, BIO.

Rango altitudinal: 0-3500 m.

Países limítrofes: Argentina y Bolivia.

\section{Viola}

Viola acanthophylla Leyb. ex Reiche

Hierba. Perenne. Endémica.

Distribución: RME.
Viola aizoon Reiche

Hierba. Perenne. Endémica.

Distribución: NUB, ARA.

Viola angustifolia Phil.

Hierba. Perenne. Endémica.

Distribución: RME, LBO.

Viola araucaniae W. Becker

Hierba. Anual. Endémica.

Distribución: ARA.

Viola arvensis Murray

Hierba. Anual o bienal. Introducida.

Distribución: NUB, BIO, ARA, LRI, LLA.

Viola atropurpurea Leyb.

Hierba. Perenne. Nativa.

Distribución: VAL, RME, LBO, MAU.

Rango altitudinal: 2500-4000 m.

Países limítrofes: Argentina.

Nombre vulgar: Escarapela, carabello.

Viola aurantiaca Leyb.

Hierba. Perenne. Endémica.

Distribución: RME.

Rango altitudinal: 2600-3000 m.

Viola aurata Phil.

Hierba. Anual. Endémica.

Distribución: COQ.

Rango altitudinal: 900-1100 m.

Nombre vulgar: Estrellita.

Viola auricolor Skottsb.

Hierba. Perenne. Nativa.

Distribución: AIS.

Rango altitudinal: 780-1200 m.

Países limítrofes: Argentina.

Viola auricula Leyb.

Hierba. Anual. Endémica.

Distribución: RME.

Rango altitudinal: 2200-2500 m.

Viola brachypetala Gay

Hierba. Anual. Endémica.

Distribución: VAL.

Viola bustillosia Gay

Hierba. Perenne. Endémica.

Distribución: LBO.

Rango altitudinal: 2100-2400 m. 
Viola calderensis W. Becker

Sinónimos: Viola pseudasterias Reiche, Viola pseudasterias Reiche var. psammophila (Phil.) Reiche, Viola psammophila Phil.

Hierba. Anual. Endémica.

Distribución: ANT, ATA.

Rango altitudinal: 0-500 m.

Viola cano-barbata Leyb.

Hierba. Perenne. Nativa.

Distribución: COQ, VAL, RME, LBO.

Rango altitudinal: 2500-4000 m.

Países limítrofes: Argentina.

Viola capillaris Pers. var. araucana (Phil.) Reiche

Subarbusto. Endémico.

Distribución: NUB, BIO, ARA.

Viola capillaris Pers. var. capillaris

Sinónimos: Viola stipularis Cav.

Subarbusto. Nativo.

Distribución: LBO, MAU, NUB, BIO, ARA, LRI, LLA.

Rango altitudinal: 0-300 m.

Países limítrofes: Perú.

Viola capillaris Pers. var. dumetorum (Phil.) Reiche Sinónimos: Viola dumetorum Phil., Viola dumetorum Phil. var. araucana Phil.

Subarbusto. Endémico.

Distribución: BIO.

Viola chamaedrys Leyb.

Hierba. Anual. Endémica.

Distribución: VAL, RME.

Rango altitudinal: 1500-1900 m.

Viola columnaris Skottsb.

Hierba. Perenne. Nativa.

Distribución: AIS.

Rango altitudinal: 800-1000 m.

Países limítrofes: Argentina.

Viola commersonii DC. ex Ging.

Hierba. Perenne. Nativa.

Distribución: AIS, MAG.

Rango altitudinal: 0-700 m.

Países limítrofes: Argentina.

Viola congesta Gillies ex Hook. \& Arn.

Hierba. Perenne. Endémica.

Distribución: RME, MAU.

Viola corralensis Phil.

Hierba. Perenne. Endémica.
Distribución: LRI.

Rango altitudinal: 0-500 m.

Viola cotyledon Ging.

Hierba. Perenne. Nativa.

Distribución: RME, LBO, MAU, NUB, BIO, ARA.

Rango altitudinal: 900-3300 m.

Países limítrofes: Argentina.

Nombre vulgar: Hierba del corazón.

Viola curicoensis W. Becker

Hierba. Perenne. Endémica.

Distribución: MAU.

Rango altitudinal: 2000-2500 m.

Viola cyathiformis W. Becker

Hierba. Perenne. Endémica.

Distribución: NUB.

Rango altitudinal: 600-700 m.

Viola decipiens Reiche

Hierba. Perenne. Endémica.

Distribución: COQ, VAL, RME, NUB.

Rango altitudinal: 2700-3500 m.

Viola domeykoana Gay

Hierba. Anual. Nativa.

Distribución: ATA, COQ, VAL, RME, LBO.

Rango altitudinal: 3000-4100 m.

Países limítrofes: Argentina.

Viola escarapela J.M. Watson \& A.R. Flores Sinónimos: Viola pulchella Leyb. ex Reiche Hierba. Anual. Endémica.

Distribución: COQ, VAL, MAU.

Rango altitudinal: 0-2000 m.

Viola farkasiana J.M. Watson \& A.R. Flores

Hierba. Perenne. Nativa.

Distribución: BIO.

Rango altitudinal: 1400-1500 m.

Países limítrofes: Argentina.

Viola flühmannii Phil.

Hierba. Perenne. Nativa.

Distribución: BIO, ARA, LRI.

Rango altitudinal: 1500-2500 m.

Países limítrofes: Argentina.

Viola friderici $\mathrm{W}$. Becker

Hierba. Perenne. Endémica.

Distribución: RME. 
Viola frigida Phil.

Sinónimos: Viola frigida Phil. var. borchersii (Phil.) Reiche, Viola borchersi Phil.

Hierba. Anual. Nativa.

Distribución: ANT, ATA, COQ, VAL.

Rango altitudinal: 3000-4100 m.

Países limítrofes: Argentina.

\section{Viola germainii Sparre}

Sinónimos: Viola nivalis Phil.

Hierba. Perenne. Endémica.

Distribución: RME.

Rango altitudinal: $3000 \mathrm{~m}$.

Viola glacialis Poepp. \& Endl.

Hierba. Perenne. Endémica.

Distribución: RME, LBO, MAU, BIO.

Rango altitudinal: $2500 \mathrm{~m}$.

Viola glechomoides Leyb.

Hierba. Anual. Endémica.

Distribución: RME.

Rango altitudinal: 2200-2800 m.

Viola godoyae Phil.

Hierba. Anual. Endémica.

Distribución: ATA.

Viola granulosa Wedd.

Hierba. Perenne. Nativa.

Distribución: AYP.

Rango altitudinal: 4000-4500 m.

Países limítrofes: Bolivia y Perú.

Viola huesoensis Martic.

Sinónimos: Viola litoralis Phil., nom. illeg.

Hierba. Anual. Endémica.

Distribución: ANT.

Rango altitudinal: 0-500 m.

\section{Viola huidobrii Gay}

Sinónimos: Viola lechlerii Griseb.

Hierba. Perenne. Nativa.

Distribución: BIO, ARA, LLA.

Rango altitudinal: 100-2500 m.

Países limítrofes: Argentina.

Viola johnstonii W. Becker

Hierba. Perenne. Endémica.

Distribución: ANT.

Viola karlreicheana Sanso, Seo \& Xifreda

Hierba. Anual. Endémica.

Distribución: RME.
Viola lanifera W. Becker

Hierba. Perenne. Endémica.

Distribución: COQ.

Rango altitudinal: 3000-3200 m.

Viola leyboldiana Phil.

Hierba. Perenne. Endémica.

Distribución: VAL, MAU.

Viola llullaillacoensis W. Becker

Hierba. Anual. Endémica.

Distribución: ANT, ATA.

Rango altitudinal: 4000-4200 m.

Viola maculata Cav. var. maculata

Sinónimos: Viola maculata Cav. var. pubescens Reiche, Viola valdiviana Kalela, Viola buchtienii Gand., Viola maculata Cav. fma. chilensis Weibel, Viola maculata Cav. fma. chillanensis Sparre, Viola maculata Cav. fma. constitucionensis Sparre, Viola maculata Cav. fma. munozii Sparre, Viola maculata Cav. fma. valdiviana (Kalela) Weibel, Viola maculata Cav. var. buchtienii (Gand.) Weibel Hierba. Perenne. Nativa.

Distribución: RME, LBO, MAU, NUB, BIO, ARA, LRI, LLA, AIS, MAG.

Rango altitudinal: 0-2000 m.

Países limítrofes: Argentina.

Nombre vulgar: Pilludén, violeta del monte.

Viola maculata Cav. var. microphyllos (Poir.) DC. ex Ging. Sinónimos: Viola microphyllos Poir., Viola maculata Cav. subsp. microphyllos (Poir.) Weibel

Hierba. Perenne. Nativa.

Distribución: AIS, MAG.

Rango altitudinal: 0-2000 m.

Países limítrofes: Argentina.

Viola maculata Cav. var. popetae Sparre

Hierba. Perenne. Endémica.

Distribución: LBO.

Viola magellanica G. Forst.

Sinónimos: Viola magniflora Molina

Hierba. Perenne. Nativa.

Distribución: LLA, MAG.

Rango altitudinal: 0-700 m.

Países limítrofes: Argentina.

Viola minutiflora Phil.

Hierba. Anual. Endémica.

Distribución: BIO, ARA.

Rango altitudinal: 0-500 m. 
Viola montagnei Gay var. glandulosa Phil.

Hierba. Perenne. Endémica.

Distribución: COQ, RME.

Rango altitudinal: 2600-4100 m.

Viola montagnei Gay var. montagnei

Hierba. Perenne. Nativa.

Distribución: ATA, COQ, VAL, RME, LBO, MAU.

Rango altitudinal: 2900-4200 m.

Países limítrofes: Argentina.

Viola muscoides Phil.

Hierba. Perenne. Endémica.

Distribución: AIS.

Rango altitudinal: $700 \mathrm{~m}$.

Viola nassauvioides Phil.

Hierba. Perenne. Nativa.

Distribución: RME.

Viola nubigena Leyb.

Hierba. Anual. Endémica.

Distribución: RME.

Rango altitudinal: 2500-3000 m.

\section{Viola odorata L.}

Hierba. Perenne. Introducida.

Distribución: VAL, LBO, BIO.

Viola ovalleana Phil.

Hierba. Anual. Endémica.

Distribución: COQ.

Rango altitudinal: 2600-2800 m.

Viola philippii Leyb. var. arbuscula (Phil.) Reiche

Sinónimos: Viola arbuscula Phil.

Hierba. Perenne. Endémica.

Distribución: RME.

Rango altitudinal: 2000-4000 m.

Viola philippii Leyb. var. philippii

Sinónimos: Viola microphylla Phil.

Hierba. Perenne. Nativa.

Distribución: VAL, RME, LBO, MAU.

Rango altitudinal: 2500-4000 m.

Países limítrofes: Argentina.

Viola polypoda Turcz.

Hierba. Anual. Endémica.

Distribución: TAR, ANT, ATA, COQ.

Rango altitudinal: 0-3500 m.

Viola portalesia Gay var. integerrima (Phil.) Reiche Sinónimos: Viola integerrima Phil.
Subarbusto. Endémico.

Distribución: COQ, VAL, LBO, MAU.

Rango altitudinal: 0-3000 m.

Viola portalesia Gay var. portalesia

Sinónimos: Viola rubella auct. non Cav.

Subarbusto. Endémico.

Distribución: VAL, LBO, MAU, NUB, BIO, ARA, LRI, LLA.

Rango altitudinal: 0-1800 m.

Viola portulacea Leyb.

Hierba. Perenne. Nativa.

Distribución: RME, LBO.

Rango altitudinal: 2500-4500 m.

Países limítrofes: Argentina.

Viola pulvinata Reiche

Hierba. Anual. Endémica.

Distribución: RME.

Rango altitudinal: 1900 m.

Viola pusilla Poepp.

Sinónimos: Viola asterias Hook. \& Arn., Viola miersii Bertero ex Steud., Viola stellata Miers, Viola asterias Hook. \& Arn. var. genuina Reiche

Hierba. Anual. Endémica.

Distribución: ANT, ATA, COQ, VAL, RME, LBO, MAU, NUB, BIO.

Rango altitudinal: 0-2700 m.

Viola reichei Skottsb.

Sinónimos: Viola maculata Cav. subsp. reichei (Skottsb.)

Weibel, Viola reichei Skottsb. fma. gunckelii Sparre

Hierba. Perenne. Nativa.

Distribución: MAU, NUB, BIO, ARA, LRI, LLA, AIS, MAG.

Rango altitudinal: 0-2000 m.

Países limítrofes: Argentina.

Viola rhombifolia Leyb.

Hierba. Anual. Endémica.

Distribución: ATA, COQ, VAL, RME.

Rango altitudinal: 1500-2000 m.

Viola rosulata Poepp. \& Endl.

Hierba. Perenne. Endémica.

Distribución: LBO, MAU, NUB.

Rango altitudinal: 2000-2200 m.

Viola rubella Cav.

Sinónimos: Viola rubella Cav. var. angustifolia Ging., Viola rubella Cav. var. latifolia Ging.

Subarbusto. Endémico. 
Distribución: BIO, ARA, LRI, LLA.

Rango altitudinal: 0-300 m.

Viola rudolphii Sparre

Hierba. Perenne. Endémica.

Distribución: LRI, LLA.

Rango altitudinal: $1100 \mathrm{~m}$.

Viola rugosa Phil. ex W. Becker

Hierba. Perenne. Endémica.

Distribución: MAU.

Viola sacculus Skottsb.

Hierba. Perenne. Nativa.

Distribución: AIS.

Rango altitudinal: 1000-1300 m.

Países limítrofes: Argentina.

Viola santiagoensis W. Becker

Hierba. Perenne. Endémica.

Distribución: RME.

\section{Viola sempervivum Gay}

Hierba. Perenne. Nativa.

Distribución: COQ, VAL, RME.

Rango altitudinal: 2000-3500 m.

Países limítrofes: Argentina.

Viola skottsbergiana W. Becker

Hierba. Perenne. Endémica.

Distribución: LBO, MAU, BIO.

Rango altitudinal: 2000-3000 m.

Viola subandina J.M. Watson

Sinónimos: Viola pusilla Hook. \& Arn. ex Hook.

Hierba. Anual. Nativa.

Distribución: RME, LBO, MAU, NUB.

Rango altitudinal: $2000 \mathrm{~m}$.

Países limítrofes: Argentina.

Viola taltalensis W. Becker var. glaberrima W. Becker Hierba. Anual. Endémica.

Distribución: ANT.

Rango altitudinal: 0-500 m.

Viola taltalensis $\mathrm{W}$. Becker var. taltalensis

Hierba. Anual. Endémica.

Distribución: ANT.

Rango altitudinal: 0-500 m.

Viola toroensis Martic.

Sinónimos: Viola chrysantha Phil., nom. illeg.

Hierba. Anual. Endémica.

Distribución: COQ.
Viola tricolor L.

Hierba. Anual o bienal. Introducida.

Distribución: VAL, RME, LBO, MAU, NUB, BIO, ARA, LRI, LLA.

Viola tridentata Menzies ex Ging.

Hierba. Perenne. Nativa.

Distribución: LLA, AIS, MAG.

Rango altitudinal: 0-1000 m.

Países limítrofes: Argentina.

Viola truncata Meyen var. glaberrima W. Becker

Hierba. Perenne. Endémica.

Distribución: RME.

Viola truncata Meyen var. glandulifera W. Becker

Hierba. Perenne. Nativa.

Distribución: MAU.

Rango altitudinal: 2000-2500 m.

Países limítrofes: Argentina.

Viola truncata Meyen var. truncata

Hierba. Perenne. Endémica.

Distribución: RME, LBO.

Rango altitudinal: 300-2300 m.

Viola vallenarensis $\mathrm{W}$. Becker

Hierba. Anual. Endémica.

Distribución: ATA.

Rango altitudinal: $4000 \mathrm{~m}$.

Viola volcanica Gillies ex Hook. \& Arn. var. chillanensis (Phil.) Reiche

Sinónimos: Viola chillanensis Phil.

Hierba. Perenne. Endémica.

Distribución: NUB.

Rango altitudinal: 1300-1400 m.

Viola volcanica Gillies ex Hook. \& Arn. var. exilis (Phil.)

Reiche

Sinónimos: Viola exilis Phil.

Hierba. Perenne. Endémica.

Distribución: RME.

Viola volcanica Gillies ex Hook. \& Arn. var. volcanica Sinónimos: Viola congesta auct. non Gillies

Hierba. Perenne. Nativa.

Distribución: LBO, MAU, NUB, BIO.

Rango altitudinal: 1200-4000 m.

Países limítrofes: Argentina.

Nombre vulgar: Marmo. 
Viola werdermannii $\mathrm{W}$. Becker var. glaberrima W. Becker Hierba. Anual. Endémica.

Distribución: TAR, ANT.

Rango altitudinal: $700 \mathrm{~m}$.

Viola werdermannii $\mathrm{W}$. Becker var. werdermannii

Hierba. Anual. Endémica.

Distribución: ANT.

Rango altitudinal: 0-500 m.

\section{VITACEAE}

\section{Cissus}

Cissus striata Ruiz \& Pav.

Sinónimos: Cissus deficiens Hook. \& Arn., Adenopetalum palmatum Turcz., Cissus striata Ruiz \& Pav. var. chilensis Suess., Cissa striata Ruiz \& Pav. var. deficiens (Hook. \& Arn.) Reiche, Cissus striata Bertero ex Steud., Cissus stricta Bertero ex Steud., Cissus violacaea Meyen, Vitis straita E.G. Baker, Cissus bonariensis Hook \& Arn.

Arbusto trepador. Nativo.

Distribución: COQ, VAL, RME, LBO, MAU, NUB, BIO, ARA, LRI, LLA, AIS, MAG.

Rango altitudinal: 0-1700 m.

Países limítrofes: Argentina.

Nombre vulgar: Pilpilvoqui, voqui colorado.

\section{Vitis}

Vitis vinifera $\mathrm{L}$.

Arbusto trepador. Introducido.

Distribución: LBO, MAU, NUB, BIO, JFE.

Nombre vulgar: Vid, parra.

\section{WINTERACEAE}

\section{Drimys}

Drimys andina (Reiche) R. A. Rodr. \& Quezada

Sinónimos: Drimys winteri J.R. Forst. \& G. Forst. var. andina Reiche, Drimys winteri J.R. Forst. \& G. Forst. var. chilensis (DC.) A. Gray fma. andina (Reiche) Hauman, Drimys winteri J.R. Forst. \& G. Forst. var. quinoensis Kuntze

Arbusto. Endémico.

Distribución: BIO, ARA, LRI, LLA.

Rango altitudinal: 800-1500 m.

Nombre vulgar: Canelo enano.
Drimys confertifolia Phil.

Sinónimos: Drimys fernandeziana Steud., Drimys fernandezianus Miers, Drimys winteri J.R. Forst. \& G.

Forst. var. fernandeziana (Steud.) Reiche, Drimys winteri

J.R. Forst. \& G. Forst. var. confertifolia (Phil.) Johow

Árbol. Endémico.

Distribución: JFE.

Rango altitudinal: 100-1200 m.

Nombre vulgar: Canelo de Juan Fernández.

Drimys winteri J.R. Forst. \& G. Forst. var. chilensis (DC.) A. Gray

Sinónimos: Drimys paniculata Steud., Drimys chilensis DC. var. latifolia Miers, Drimys winteri J.R. Forst. \& G. Forst. fma. chilensis Eichler, Drimys chilensis DC.

Árbol. Endémico.

Distribución: COQ, VAL, RME, LBO, MAU, NUB, BIO, ARA, LRI, LLA, AIS, MAG.

Rango altitudinal: 0-1700 m.

Nombre vulgar: Canelo.

Drimys winteri J.R. Forst. \& G. Forst. var. winteri

Sinónimos: Wintera aromatica Sol. ex Foth., Drimys punctata Lam., Drimys winteri J.R. Forst. \& G. Forst. var. punctata (Lam.) DC., Drimys winteri J.R. Forst. \& G. Forst. fma. magellanica Eichler, Drimys winteri J.R. Forst. $\&$ G. Forst. var. morenonis Kuntze, Drimys wintera Thell., Drimys aromatique Descourt. ex Baill.

Árbol. Nativo.

Distribución: COQ, RME, LBO, MAU, NUB, BIO, ARA, LRI, LLA, AIS, MAG.

Rango altitudinal: 0-2500 m.

Países limítrofes: Argentina.

Nombre vulgar: Canelo, foye.

\section{ZYGOPHYLLACEAE}

\section{Bulnesia}

Bulnesia chilensis Gay

Sinónimos: Gonoptera chilensis Turcz.

Arbusto. Endémico.

Distribución: ATA, COQ.

Rango altitudinal: $100-4000 \mathrm{~m}$.

Nombre vulgar: Retama, retama del cerro.

\section{Fagonia}

Fagonia chilensis Hook. \& Arn.

Sinónimos: Fagonia chilensis Hook. \& Arn. var. aspera (Gay) I.M. Johnst., Fagonia subaphylla Phil., Fagonia aspera Gay

Hierba. Perenne. Nativa. 
Distribución: AYP, TAR, ANT, ATA, COQ.

Rango altitudinal: 0-4000 m.

Países limítrofes: Perú.

Nombre vulgar: Hualputilla, rosita.

\section{Larrea}

Larrea divaricata Cav.

Sinónimos: Covillea divaricata (Cav.) Vail, Neoschroetera

divaricata (Cav.) Briq., Schroeterella divaricata (Cav.)

Briq.

Arbusto. Nativo.

Distribución: ATA, VAL, RME, BIO.

Rango altitudinal: 0-3000 m.

Países limítrofes: Argentina, Bolivia y Perú.

Nombre vulgar: Jarrilla.

Larrea nitida Cav.

Sinónimos: Larrea balsamica I.M. Johnst., Covillea nitida

(Cav.) Vail

Arbusto. Nativo.

Distribución: ATA, COQ, VAL, RME.

Rango altitudinal: 0-3400 m.

Países limítrofes: Argentina.

Nombre vulgar: Jarrilla.

\author{
Metharme \\ Metharme lanata Phil. ex Engl. \\ Sinónimos: Metharme lanata Phil. \\ Hierba. Perenne. Endémica. \\ Distribución: AYP, TAR. \\ Rango altitudinal: $2100-2200 \mathrm{~m}$.
}

\section{Pintoa}

Pintoa chilensis Gay

Arbusto. Endémico.

Distribución: ATA.

Rango altitudinal: 200-1500 m.

\section{Porlieria}

Porlieria chilensis I.M. Johnst. Arbusto o árbol pequeño. Endémico. Distribución: COQ, VAL, RME, LBO. Rango altitudinal: 0-1400 m.

Nombre vulgar: Guayacán, palo santo.

\section{Tribulus}

Tribulus terrestris L.

Hierba. Anual. Introducida.

Distribución: TAR, ANT, ATA, RME. 
ANEXo 1. Lista alfabética de géneros con su respectiva familia y clase. Los acrónimos de las clases son: LYCOP (Lycopodiopsida), POLYP (Polypodiopsida), GNETO (Gnetopsida), PINOP (Pinopsida), LILIO (Liliopsida) y MAGNO (Magnoliopsida). / Alphabetic list of genera with family and class. Each class acronym: LYCOP (Lycopodiopsida), POLYP (Polypodiopsida), GNETO (Gnetopsida), PINOP (Pinopsida), LILIO (Liliopsida) y MAGNO (Magnoliopsida).

\begin{tabular}{|c|c|c|c|c|c|}
\hline GENERO & FAMILIA & CLASE & GENERO & FAMILIA & CLASE \\
\hline Abrotanella & Asteraceae & MAGNO & Ammophila & Poaceae & LILIO \\
\hline Abutilon & Malvaceae & MAGNO & Amomyrtus & Myrtaceae & MAGNO \\
\hline Acacia & Fabaceae & MAGNO & Amphibromus & Poaceae & LILIO \\
\hline Acaena & Rosaceae & MAGNO & Amphiscirpus & Cyperaceae & LILIO \\
\hline Achillea & Asteraceae & MAGNO & Amsinckia & Boraginaceae & MAGNO \\
\hline Achyrocline & Asteraceae & MAGNO & Anagallis & Primulaceae & MAGNO \\
\hline Acmella & Asteraceae & MAGNO & Anaphalis & Asteraceae & MAGNO \\
\hline Acrisione & Asteraceae & MAGNO & Anarthrophyllum & Fabaceae & MAGNO \\
\hline Adenocaulon & Asteraceae & MAGNO & Anatherostipa & Poaceae & LILIO \\
\hline Adenopeltis & Euphorbiaceae & MAGNO & Andeimalva & Malvaceae & MAGNO \\
\hline Adesmia & Fabaceae & MAGNO & Androsace & Primulaceae & MAGNO \\
\hline Adiantum & Pteridaceae & POLYP & Anemone & Ranunculaceae & MAGNO \\
\hline Aextoxicon & Aextoxicaceae & MAGNO & Anethum & Apiaceae & MAGNO \\
\hline Agalinis & Orobanchaceae & MAGNO & Anisomeria & Phytolaccaceae & MAGNO \\
\hline Ageratum & Asteraceae & MAGNO & Anoda & Malvaceae & MAGNO \\
\hline Agoseris & Asteraceae & MAGNO & Anredera & Basellaceae & MAGNO \\
\hline Agropyron & Poaceae & LILIO & Antennaria & Asteraceae & MAGNO \\
\hline Agrostemma & Caryophyllaceae & MAGNO & Anthemis & Asteraceae & MAGNO \\
\hline Agrostis & Poaceae & LILIO & Anthoxanthum & Poaceae & LILIO \\
\hline Ailanthus & Simaroubaceae & MAGNO & Anthriscus & Apiaceae & MAGNO \\
\hline Aira & Poaceae & LILIO & Antidaphne & Santalaceae & MAGNO \\
\hline Albizia & Fabaceae & MAGNO & Apera & Poaceae & LILIO \\
\hline Aldama & Asteraceae & MAGNO & Aphanes & Rosaceae & MAGNO \\
\hline Alisma & Alismataceae & LILIO & Aphyllocladus & Asteraceae & MAGNO \\
\hline Allionia & Nyctaginaceae & MAGNO & Apium & Apiaceae & MAGNO \\
\hline Allium & Amaryllidaceae & LILIO & Apodasmia & Restionaceae & LILIO \\
\hline Alnus & Betulaceae & MAGNO & Aponogeton & Aponogetonaceae & LILIO \\
\hline Alonsoa & Scrophulariaceae & MAGNO & Aquilegia & Ranunculaceae & MAGNO \\
\hline Alopecurus & Poaceae & LILIO & Arabidopsis & Brassicaceae & MAGNO \\
\hline Aloysia & Verbenaceae & MAGNO & Arachnitis & Corsiaceae & LILIO \\
\hline Alshehbazia & Brassicaceae & MAGNO & Araeoandra & Francoaceae & MAGNO \\
\hline Alstroemeria & Alstroemeriaceae & LILIO & Araucaria & Araucariaceae & PINOP \\
\hline Alternanthera & Amaranthaceae & MAGNO & Arctium & Asteraceae & MAGNO \\
\hline Alyssum & Brassicaceae & MAGNO & Arctotheca & Asteraceae & MAGNO \\
\hline Amaranthus & Amaranthaceae & MAGNO & Arenaria & Caryophyllaceae & MAGNO \\
\hline Amaryllis & Amaryllidaceae & LILIO & Argemone & Papaveraceae & MAGNO \\
\hline Amblyopappus & Asteraceae & MAGNO & Argylia & Bignoniaceae & MAGNO \\
\hline Ambrosia & Asteraceae & MAGNO & Argyranthemum & Asteraceae & MAGNO \\
\hline Amelichloa & Poaceae & LILIO & Argyrochosma & Pteridaceae & POLYP \\
\hline Ammannia & Lythraceae & MAGNO & Aristida & Poaceae & LILIO \\
\hline Ammi & Apiaceae & MAGNO & Aristolochia & Aristolochiaceae & MAGNO \\
\hline
\end{tabular}




\begin{tabular}{|c|c|c|c|c|c|}
\hline GENERO & FAMILIA & CLASE & GENERO & FAMILIA & CLASE \\
\hline Aristotelia & Elaeocarpaceae & MAGNO & Benthamiella & Solanaceae & MAGNO \\
\hline Arjona & Schoepfiaceae & MAGNO & Berberidopsis & Berberidopsidaceae & MAGNO \\
\hline Armeria & Plumbaginaceae & MAGNO & Berberis & Berberidaceae & MAGNO \\
\hline Arnica & Asteraceae & MAGNO & Beta & Chenopodiaceae & MAGNO \\
\hline Arrhenatherum & Poaceae & LILIO & Bidens & Asteraceae & MAGNO \\
\hline Artemisia & Asteraceae & MAGNO & Bipinnula & Orchidaceae & LILIO \\
\hline Arthropteris & Oleandraceae & POLYP & Blechnum & Blechnaceae & POLYP \\
\hline Arundo & Poaceae & LILIO & Blennosperma & Asteraceae & MAGNO \\
\hline Asclepias & Apocynaceae & MAGNO & Blepharocalyx & Myrtaceae & MAGNO \\
\hline Asperugo & Boraginaceae & MAGNO & Blumenbachia & Loasaceae & MAGNO \\
\hline Asphodelus & Asphodelaceae & LILIO & Boehmeria & Urticaceae & MAGNO \\
\hline Asplenium & Aspleniaceae & POLYP & Boerhavia & Nyctaginaceae & MAGNO \\
\hline Astelia & Asteliaceae & LILIO & Bolax & Apiaceae & MAGNO \\
\hline Asteranthera & Gesneriaceae & MAGNO & Bolboschoenus & Cyperaceae & LILIO \\
\hline Asteriscium & Apiaceae & MAGNO & Bomarea & Alstroemeriaceae & LILIO \\
\hline Astragalus & Fabaceae & MAGNO & Boopis & Calyceraceae & MAGNO \\
\hline Astrolepis & Pteridaceae & POLYP & Boquila & Lardizabalaceae & MAGNO \\
\hline Atacama & Brassicaceae & MAGNO & Borago & Boraginaceae & MAGNO \\
\hline Atriplex & Chenopodiaceae & MAGNO & Bothriochloa & Poaceae & LILIO \\
\hline Augustea & Caryophyllaceae & MAGNO & Botrychium & Ophioglossaceae & POLYP \\
\hline Austrocactus & Cactaceae & MAGNO & Bouteloua & Poaceae & LILIO \\
\hline Austrocedrus & Cupressaceae & PINOP & Bowlesia & Apiaceae & MAGNO \\
\hline Austrolycopodium & Lycopodiaceae & LYCOP & Brachyclados & Asteraceae & MAGNO \\
\hline Austrostipa & Poaceae & LILIO & Brachypodium & Poaceae & LILIO \\
\hline Avellanita & Euphorbiaceae & MAGNO & Brachystele & Orchidaceae & LILIO \\
\hline Avena & Poaceae & LILIO & Brassica & Brassicaceae & MAGNO \\
\hline Avenella & Poaceae & LILIO & Bridgesia & Sapindaceae & MAGNO \\
\hline Axonopus & Poaceae & LILIO & Briza & Poaceae & LILIO \\
\hline Azara & Salicaceae & MAGNO & Bromelica & Poaceae & LILIO \\
\hline Azolla & Salviniaceae & POLYP & Bromidium & Poaceae & LILIO \\
\hline Azorella & Apiaceae & MAGNO & Bromus & Poaceae & LILIO \\
\hline Baccharis & Asteraceae & MAGNO & Broussonetia & Moraceae & MAGNO \\
\hline Bacopa & Plantaginaceae & MAGNO & Browningia & Cactaceae & MAGNO \\
\hline Bahia & Asteraceae & MAGNO & Bryantiella & Polemoniaceae & MAGNO \\
\hline Bakerolimon & Plumbaginaceae & MAGNO & Buddleja & Scrophulariaceae & MAGNO \\
\hline Balbisia & Francoaceae & MAGNO & Buglossoides & Boraginaceae & MAGNO \\
\hline Balsamocarpon & Fabaceae & MAGNO & Bulnesia & Zygophyllaceae & MAGNO \\
\hline Barbarea & Brassicaceae & MAGNO & Caesalpinia & Fabaceae & MAGNO \\
\hline Barneoudia & Ranunculaceae & MAGNO & Caiophora & Loasaceae & MAGNO \\
\hline Bassia & Chenopodiaceae & MAGNO & Calandrinia & Montiaceae & MAGNO \\
\hline Beilschmiedia & Lauraceae & MAGNO & Calceolaria & Calceolariaceae & MAGNO \\
\hline Bellardia & Orobanchaceae & MAGNO & Caldcluvia & Cunoniaceae & MAGNO \\
\hline Bellis & Asteraceae & MAGNO & Calendula & Asteraceae & MAGNO \\
\hline Belloa & Asteraceae & MAGNO & Calibrachoa & Solanaceae & MAGNO \\
\hline
\end{tabular}




\begin{tabular}{|c|c|c|c|c|c|}
\hline GENERO & FAMILIA & CLASE & GENERO & FAMILIA & CLASE \\
\hline Calliandra & Fabaceae & MAGNO & Chersodoma & Asteraceae & MAGNO \\
\hline Callianthemoides & Ranunculaceae & MAGNO & Chevreulia & Asteraceae & MAGNO \\
\hline Callitriche & Plantaginaceae & MAGNO & Chiliotrichum & Asteraceae & MAGNO \\
\hline Calopappus & Asteraceae & MAGNO & Chiropetalum & Euphorbiaceae & MAGNO \\
\hline Calotheca & Poaceae & LILIO & Chloraea & Orchidaceae & LILIO \\
\hline Caltha & Ranunculaceae & MAGNO & Chloris & Poaceae & LILIO \\
\hline Calycera & Calyceraceae & MAGNO & Chorispora & Brassicaceae & MAGNO \\
\hline Calydorea & Iridaceae & LILIO & Chorizanthe & Polygonaceae & MAGNO \\
\hline Calyptocarpus & Asteraceae & MAGNO & Chrysanthemoides & Asteraceae & MAGNO \\
\hline Calystegia & Convolvulaceae & MAGNO & Chrysanthemum & Asteraceae & MAGNO \\
\hline Camelina & Brassicaceae & MAGNO & Chrysosplenium & Saxifragaceae & MAGNO \\
\hline Camissonia & Onagraceae & MAGNO & Chuquiraga & Asteraceae & MAGNO \\
\hline Campanula & Campanulaceae & MAGNO & Chusquea & Poaceae & LILIO \\
\hline Campsidium & Bignoniaceae & MAGNO & Cicendia & Gentianaceae & MAGNO \\
\hline Capsella & Brassicaceae & MAGNO & Cichorium & Asteraceae & MAGNO \\
\hline Cardamine & Brassicaceae & MAGNO & Cirsium & Asteraceae & MAGNO \\
\hline Cardionema & Caryophyllaceae & MAGNO & Cissarobryon & Francoaceae & MAGNO \\
\hline Carduus & Asteraceae & MAGNO & Cissus & Vitaceae & MAGNO \\
\hline Carex & Cyperaceae & LILIO & Cistanthe & Montiaceae & MAGNO \\
\hline Carica & Caricaceae & MAGNO & Citronella & Cardiopteridaceae & MAGNO \\
\hline Carpha & Cyperaceae & LILIO & Cladanthus & Asteraceae & MAGNO \\
\hline Carpobrotus & Aizoaceae & MAGNO & Clarkia & Onagraceae & MAGNO \\
\hline Carthamus & Asteraceae & MAGNO & Clematis & Ranunculaceae & MAGNO \\
\hline Castilleja & Orobanchaceae & MAGNO & Cleome & Cleomaceae & MAGNO \\
\hline Catabrosa & Poaceae & LILIO & Clinanthus & Amaryllidaceae & LILIO \\
\hline Catapodium & Poaceae & LILIO & Cliococca & Linaceae & MAGNO \\
\hline Catharanthus & Apocynaceae & MAGNO & Codonorchis & Orchidaceae & LILIO \\
\hline Cenchrus & Poaceae & LILIO & Coix & Poaceae & LILIO \\
\hline Centaurea & Asteraceae & MAGNO & Coleostephus & Asteraceae & MAGNO \\
\hline Centaurium & Gentianaceae & MAGNO & Colletia & Rhamnaceae & MAGNO \\
\hline Centaurodendron & Asteraceae & MAGNO & Colliguaja & Euphorbiaceae & MAGNO \\
\hline Centella & Apiaceae & MAGNO & Collomia & Polemoniaceae & MAGNO \\
\hline Centipeda & Asteraceae & MAGNO & Colobanthus & Caryophyllaceae & MAGNO \\
\hline Centranthus & Caprifoliaceae & MAGNO & Colocasia & Araceae & LILIO \\
\hline Centunculus & Primulaceae & MAGNO & Combera & Solanaceae & MAGNO \\
\hline Cerastium & Caryophyllaceae & MAGNO & Commelina & Commelinaceae & LILIO \\
\hline Ceratophyllum & Ceratophyllaceae & MAGNO & Conanthera & Tecophilaeaceae & LILIO \\
\hline Cestrum & Solanaceae & MAGNO & Conium & Apiaceae & MAGNO \\
\hline Chaetanthera & Asteraceae & MAGNO & Convolvulus & Convolvulaceae & MAGNO \\
\hline Chaptalia & Asteraceae & MAGNO & Conyza & Asteraceae & MAGNO \\
\hline Chascolytrum & Poaceae & LILIO & Copiapoa & Cactaceae & MAGNO \\
\hline Cheilanthes & Pteridaceae & POLYP & Coprosma & Rubiaceae & MAGNO \\
\hline Chenopodiastrum & Chenopodiaceae & MAGNO & Cordia & Boraginaceae & MAGNO \\
\hline Chenopodium & Chenopodiaceae & MAGNO & Cordyline & Asparagaceae & LILIO \\
\hline
\end{tabular}




\begin{tabular}{|c|c|c|c|c|c|}
\hline GENERO & FAMILIA & CLASE & GENERO & FAMILIA & CLASE \\
\hline Coreopsis & Asteraceae & MAGNO & Datura & Solanaceae & MAGNO \\
\hline Coriandrum & Apiaceae & MAGNO & Daucus & Apiaceae & MAGNO \\
\hline Coriaria & Coriariaceae & MAGNO & Davallia & Davalliaceae & POLYP \\
\hline Correorchis & Orchidaceae & LILIO & Delairea & Asteraceae & MAGNO \\
\hline Corrigiola & Caryophyllaceae & MAGNO & Dendroseris & Asteraceae & MAGNO \\
\hline Corryocactus & Cactaceae & MAGNO & Dennstaedtia & Dennstaedtiaceae & POLYP \\
\hline Cortaderia & Poaceae & LILIO & Deschampsia & Poaceae & LILIO \\
\hline Corynabutilon & Malvaceae & MAGNO & Descurainia & Brassicaceae & MAGNO \\
\hline Corynephorus & Poaceae & LILIO & Desfontainia & Columelliaceae & MAGNO \\
\hline Cotoneaster & Rosaceae & MAGNO & Desmanthus & Fabaceae & MAGNO \\
\hline Cotula & Asteraceae & MAGNO & Desmaria & Loranthaceae & MAGNO \\
\hline Crassula & Crassulaceae & MAGNO & Deuterocohnia & Bromeliaceae & LILIO \\
\hline Cremolobus & Brassicaceae & MAGNO & Deyeuxia & Poaceae & LILIO \\
\hline Crepis & Asteraceae & MAGNO & Dianthus & Caryophyllaceae & MAGNO \\
\hline Cressa & Convolvulaceae & MAGNO & Dichanthelium & Poaceae & LILIO \\
\hline Crinodendron & Elaeocarpaceae & MAGNO & Dichelachne & Poaceae & LILIO \\
\hline Cristaria & Malvaceae & MAGNO & Dichondra & Convolvulaceae & MAGNO \\
\hline Crocosmia & Iridaceae & LILIO & Dicksonia & Dicksoniaceae & POLYP \\
\hline Crotalaria & Fabaceae & MAGNO & Dicliptera & Acanthaceae & MAGNO \\
\hline Croton & Euphorbiaceae & MAGNO & Dielsiochloa & Poaceae & LILIO \\
\hline Cruckshanksia & Rubiaceae & MAGNO & Digitalis & Plantaginaceae & MAGNO \\
\hline Cryptantha & Boraginaceae & MAGNO & Digitaria & Poaceae & LILIO \\
\hline Cryptocarya & Lauraceae & MAGNO & Dinemagonum & Malpighiaceae & MAGNO \\
\hline Cryptogramma & Pteridaceae & POLYP & Dinemandra & Malpighiaceae & MAGNO \\
\hline Cuatrecasasiella & Asteraceae & MAGNO & Dioscorea & Dioscoreaceae & LILIO \\
\hline Cuminia & Lamiaceae & MAGNO & Diostea & Verbenaceae & MAGNO \\
\hline Cumulopuntia & Cactaceae & MAGNO & Diphasium & Lycopodiaceae & LYCOP \\
\hline Cuscuta & Convolvulaceae & MAGNO & Diplachne & Poaceae & LILIO \\
\hline Cyclospermum & Apiaceae & MAGNO & Diplazium & Athyriaceae & POLYP \\
\hline Cylindropuntia & Cactaceae & MAGNO & Diplolepis & Apocynaceae & MAGNO \\
\hline Cymbalaria & Plantaginaceae & MAGNO & Diplostephium & Asteraceae & MAGNO \\
\hline Cymbopogon & Poaceae & LILIO & Diplotaxis & Brassicaceae & MAGNO \\
\hline Cynara & Asteraceae & MAGNO & Dipogon & Fabaceae & MAGNO \\
\hline Cynodon & Poaceae & LILIO & Diposis & Apiaceae & MAGNO \\
\hline Cynoglossum & Boraginaceae & MAGNO & Dipsacus & Caprifoliaceae & MAGNO \\
\hline Cynosurus & Poaceae & LILIO & Discaria & Rhamnaceae & MAGNO \\
\hline Cyperus & Cyperaceae & LILIO & Distichia & Juncaceae & LILIO \\
\hline Cyphocarpus & Campanulaceae & MAGNO & Distichlis & Poaceae & LILIO \\
\hline Cystopteris & Cystopteridaceae & POLYP & Dittrichia & Asteraceae & MAGNO \\
\hline Cytisus & Fabaceae & MAGNO & Dodonaea & Sapindaceae & MAGNO \\
\hline Dactylis & Poaceae & LILIO & Domeykoa & Apiaceae & MAGNO \\
\hline Dalea & Fabaceae & MAGNO & Donatia & Stylidiaceae & MAGNO \\
\hline Danthonia & Poaceae & LILIO & Doniophyton & Asteraceae & MAGNO \\
\hline Dasyphyllum & Asteraceae & MAGNO & Downingia & Campanulaceae & MAGNO \\
\hline
\end{tabular}




\begin{tabular}{|c|c|c|c|c|c|}
\hline GENERO & FAMILIA & CLASE & GENERO & FAMILIA & CLASE \\
\hline Draba & Brassicaceae & MAGNO & Errazurizia & Fabaceae & MAGNO \\
\hline Drapetes & Thymelaeaceae & MAGNO & Eruca & Brassicaceae & MAGNO \\
\hline Drimys & Winteraceae & MAGNO & Eryngium & Apiaceae & MAGNO \\
\hline Drosera & Droseraceae & MAGNO & Erythranthe & Phrymaceae & MAGNO \\
\hline Drymaria & Caryophyllaceae & MAGNO & Escallonia & Escalloniaceae & MAGNO \\
\hline Dryopteris & Dryopteridaceae & POLYP & Eschscholzia & Papaveraceae & MAGNO \\
\hline Duchesnea & Rosaceae & MAGNO & Eucalyptus & Myrtaceae & MAGNO \\
\hline Dunalia & Solanaceae & MAGNO & Eucryphia & Cunoniaceae & MAGNO \\
\hline Dysopsis & Euphorbiaceae & MAGNO & Eulychnia & Cactaceae & MAGNO \\
\hline Dysphania & Chenopodiaceae & MAGNO & Eupatorium & Asteraceae & MAGNO \\
\hline Eccremocarpus & Bignoniaceae & MAGNO & Euphorbia & Euphorbiaceae & MAGNO \\
\hline Echinochloa & Poaceae & LILIO & Euphrasia & Orobanchaceae & MAGNO \\
\hline Echinopsis & Cactaceae & MAGNO & Evolvulus & Convolvulaceae & MAGNO \\
\hline Echium & Boraginaceae & MAGNO & Exodeconus & Solanaceae & MAGNO \\
\hline Eclipta & Asteraceae & MAGNO & Fabiana & Solanaceae & MAGNO \\
\hline Egeria & Hydrocharitaceae & LILIO & Facelis & Asteraceae & MAGNO \\
\hline Ehrharta & Poaceae & LILIO & Fagara & Rutaceae & MAGNO \\
\hline Eichhornia & Pontederiaceae & LILIO & Fagonia & Zygophyllaceae & MAGNO \\
\hline Elaphoglossum & Dryopteridaceae & POLYP & Fallopia & Polygonaceae & MAGNO \\
\hline Elatine & Elatinaceae & MAGNO & Famatina & Amaryllidaceae & LILIO \\
\hline Eleocharis & Cyperaceae & LILIO & Fascicularia & Bromeliaceae & LILIO \\
\hline Eleusine & Poaceae & LILIO & Festuca & Poaceae & LILIO \\
\hline Elodea & Hydrocharitaceae & LILIO & Ficinia & Cyperaceae & LILIO \\
\hline Elymus & Poaceae & LILIO & Ficus & Euphorbiaceae & MAGNO \\
\hline Elytrigia & Poaceae & LILIO & Fitzroya & Cupressaceae & PINOP \\
\hline Elytropus & Apocynaceae & MAGNO & Flaveria & Asteraceae & MAGNO \\
\hline Embothrium & Proteaceae & MAGNO & Flourensia & Asteraceae & MAGNO \\
\hline Emex & Polygonaceae & MAGNO & Foeniculum & Apiaceae & MAGNO \\
\hline Empetrum & Ericaceae & MAGNO & Fonkia & Plantaginaceae & MAGNO \\
\hline Encelia & Asteraceae & MAGNO & Fragaria & Rosaceae & MAGNO \\
\hline Enneapogon & Poaceae & LILIO & Francoa & Francoaceae & MAGNO \\
\hline Ephedra & Ephedraceae & GNETO & Frankenia & Frankeniaceae & MAGNO \\
\hline Epilobium & Onagraceae & MAGNO & Fraxinus & Oleaceae & MAGNO \\
\hline Equisetum & Equisetaceae & POLYP & Fuchsia & Onagraceae & MAGNO \\
\hline Eragrostis & Poaceae & LILIO & Fumaria & Papaveraceae & MAGNO \\
\hline Ercilla & Phytolaccaceae & MAGNO & Gaillardia & Asteraceae & MAGNO \\
\hline Erechtites & Asteraceae & MAGNO & Gaimardia & Restionaceae & LILIO \\
\hline Eremium & Poaceae & LILIO & Galega & Fabaceae & MAGNO \\
\hline Eremocharis & Apiaceae & MAGNO & Galenia & Aizoaceae & MAGNO \\
\hline Eriachaenium & Asteraceae & MAGNO & Galeopsis & Lamiaceae & MAGNO \\
\hline Erigeron & Asteraceae & MAGNO & Galinsoga & Asteraceae & MAGNO \\
\hline Eriochloa & Poaceae & LILIO & Galium & Rubiaceae & MAGNO \\
\hline Eriosyce & Cactaceae & MAGNO & Gamocarpha & Calyceraceae & MAGNO \\
\hline Erodium & Geraniaceae & MAGNO & Gamochaeta & Asteraceae & MAGNO \\
\hline
\end{tabular}


Catálogo plantas vasculares de Chile: Rodríguez, R. ET AL.

\begin{tabular}{|c|c|c|c|c|c|}
\hline GENERO & FAMILIA & CLASE & GENERO & FAMILIA & CLASE \\
\hline Gardoquia & Lamiaceae & MAGNO & Hebe & Plantaginaceae & MAGNO \\
\hline Gastridium & Poaceae & LILIO & Hedera & Araliaceae & MAGNO \\
\hline Gaultheria & Ericaceae & MAGNO & Hedypnois & Asteraceae & MAGNO \\
\hline Gavilea & Orchidaceae & LILIO & Helenium & Asteraceae & MAGNO \\
\hline Gayophytum & Onagraceae & MAGNO & Helianthus & Asteraceae & MAGNO \\
\hline Gentiana & Gentianaceae & MAGNO & Helictotrichon & Poaceae & LILIO \\
\hline Gentianella & Gentianaceae & MAGNO & Heliotropium & Heliotropiaceae & MAGNO \\
\hline Geoffroea & Fabaceae & MAGNO & Helminthotheca & Asteraceae & MAGNO \\
\hline Geranium & Geraniaceae & MAGNO & Helogyne & Asteraceae & MAGNO \\
\hline Gethyum & Amaryllidaceae & LILIO & Herbertia & Iridaceae & LILIO \\
\hline Geum & Rosaceae & MAGNO & Herniaria & Caryophyllaceae & MAGNO \\
\hline Gevuina & Proteaceae & MAGNO & Herreria & Asparagaceae & LILIO \\
\hline Gilia & Polemoniaceae & MAGNO & Hesperis & Brassicaceae & MAGNO \\
\hline Gilliesia & Amaryllidaceae & LILIO & Heterosperma & Asteraceae & MAGNO \\
\hline Glandularia & Verbenaceae & MAGNO & Hibiscus & Malvaceae & MAGNO \\
\hline Glechoma & Lamiaceae & MAGNO & Hieracium & Asteraceae & MAGNO \\
\hline Glinus & Molluginaceae & MAGNO & Hippuris & Plantaginaceae & MAGNO \\
\hline Glyceria & Poaceae & LILIO & Hirschfeldia & Brassicaceae & MAGNO \\
\hline Glycyrrhiza & Fabaceae & MAGNO & Histiopteris & Dennstaedtiaceae & POLYP \\
\hline Gochnatia & Asteraceae & MAGNO & Hoffmannseggia & Fabaceae & MAGNO \\
\hline Gomortega & Gomortegaceae & MAGNO & Holcus & Poaceae & LILIO \\
\hline Gomphrena & Amaranthaceae & MAGNO & Hollermayera & Brassicaceae & MAGNO \\
\hline Gossypium & Malvaceae & MAGNO & Homalocarpus & Apiaceae & MAGNO \\
\hline Grammitis & Polypodiaceae & POLYP & Hordeum & Poaceae & LILIO \\
\hline Gratiola & Plantaginaceae & MAGNO & Hornungia & Brassicaceae & MAGNO \\
\hline Grausa & Loasaceae & MAGNO & Huidobria & Loasaceae & MAGNO \\
\hline Greigia & Bromeliaceae & LILIO & Huperzia & Lycopodiaceae & LYCOP \\
\hline Grindelia & Asteraceae & MAGNO & Hydrangea & Hydrangeaceae & MAGNO \\
\hline Griselinia & Griseliniaceae & MAGNO & Hydrocleys & Butomaceae & LILIO \\
\hline Guindilia & Sapindaceae & MAGNO & Hydrocotyle & Apiaceae & MAGNO \\
\hline Gunnera & Gunneraceae & MAGNO & Hymenoglossum & Hymenophyllaceae & POLYP \\
\hline Gutierrezia & Asteraceae & MAGNO & Hymenophyllum & Hymenophyllaceae & POLYP \\
\hline Guynesomia & Asteraceae & MAGNO & Hypericum & Hypericaceae & MAGNO \\
\hline Gymnophyton & Apiaceae & MAGNO & Hypochaeris & Asteraceae & MAGNO \\
\hline Gynerium & Poaceae & LILIO & Hypolepis & Dennstaedtiaceae & POLYP \\
\hline Gypothamnium & Asteraceae & MAGNO & Imperata & Poaceae & LILIO \\
\hline Haageocereus & Cactaceae & MAGNO & Indigofera & Fabaceae & MAGNO \\
\hline Habenaria & Orchidaceae & LILIO & Ipheion & Amaryllidaceae & LILIO \\
\hline Hainardia & Poaceae & LILIO & Ipomoea & Convolvulaceae & MAGNO \\
\hline Halerpestes & Ranunculaceae & MAGNO & Ipomopsis & Polemoniaceae & MAGNO \\
\hline Haloragis & Haloragaceae & MAGNO & Iris & Iridaceae & LILIO \\
\hline Hamadryas & Ranunculaceae & MAGNO & Isatis & Brassicaceae & MAGNO \\
\hline Haplopappus & Asteraceae & MAGNO & Isoetes & Isoetaceae & LYCOP \\
\hline Haplorhus & Anacardiaceae & MAGNO & Isolepis & Cyperaceae & LILIO \\
\hline
\end{tabular}




\begin{tabular}{|c|c|c|c|c|c|}
\hline GENERO & FAMILIA & CLASE & GENERO & FAMILIA & CLASE \\
\hline Ivania & Brassicaceae & MAGNO & Lecanophora & Malvaceae & MAGNO \\
\hline Jaborosa & Solanaceae & MAGNO & Legenere & Campanulaceae & MAGNO \\
\hline Jarava & Poaceae & LILIO & Legrandia & Myrtaceae & MAGNO \\
\hline Johnstonella & Boraginaceae & MAGNO & Lemna & Araceae & LILIO \\
\hline Jovellana & Calceolariaceae & MAGNO & Lenzia & Montiaceae & MAGNO \\
\hline Juania & Arecaceae & LILIO & Leontochir & Alstroemeriaceae & LILIO \\
\hline Jubaea & Arecaceae & LILIO & Leontodon & Asteraceae & MAGNO \\
\hline Juncus & Juncaceae & LILIO & Lepechinia & Lamiaceae & MAGNO \\
\hline Junellia & Verbenaceae & MAGNO & Lepidium & Brassicaceae & MAGNO \\
\hline Jungia & Asteraceae & MAGNO & Lepidoceras & Santalaceae & MAGNO \\
\hline Kageneckia & Rosaceae & MAGNO & Lepidophyllum & Asteraceae & MAGNO \\
\hline Kickxia & Plantaginaceae & MAGNO & Lepidothamnus & Podocarpaceae & PINOP \\
\hline Kieslingia & Asteraceae & MAGNO & Leptinella & Asteraceae & MAGNO \\
\hline Knautia & Caprifoliaceae & MAGNO & Leptocarpha & Asteraceae & MAGNO \\
\hline Koeleria & Poaceae & LILIO & Leptophyllochloa & Poaceae & LILIO \\
\hline Koenigia & Polygonaceae & MAGNO & Leptosiphon & Polemoniaceae & MAGNO \\
\hline Krameria & Krameriaceae & MAGNO & Leptostigma & Rubiaceae & MAGNO \\
\hline Kurzamra & Lamiaceae & MAGNO & Lepturus & Poaceae & LILIO \\
\hline Lablab & Fabaceae & MAGNO & Lepuropetalon & Celastraceae & MAGNO \\
\hline Lachemilla & Rosaceae & MAGNO & Leucaena & Fabaceae & MAGNO \\
\hline Lachnagrostis & Poaceae & LILIO & Leucanthemum & Asteraceae & MAGNO \\
\hline Lactoris & Aristolochiaceae & MAGNO & Leucheria & Asteraceae & MAGNO \\
\hline Lactuca & Asteraceae & MAGNO & Leucocoryne & Amaryllidaceae & LILIO \\
\hline Laennecia & Asteraceae & MAGNO & Leucojum & Amaryllidaceae & LILIO \\
\hline Lagenophora & Asteraceae & MAGNO & Leunisia & Asteraceae & MAGNO \\
\hline Lagurus & Poaceae & LILIO & Levisticum & Apiaceae & MAGNO \\
\hline Lamarckia & Poaceae & LILIO & Leymus & Poaceae & LILIO \\
\hline Lamium & Lamiaceae & MAGNO & Libertia & Iridaceae & LILIO \\
\hline Lampayo & Verbenaceae & MAGNO & Ligaria & Loranthaceae & MAGNO \\
\hline Landoltia & Araceae & LILIO & Ligustrum & Oleaceae & MAGNO \\
\hline Lantana & Verbenaceae & MAGNO & Lilaea & Juncaginaceae & LILIO \\
\hline Lapageria & Philesiaceae & LILIO & Lilaeopsis & Apiaceae & MAGNO \\
\hline Lappula & Boraginaceae & MAGNO & Limnobium & Hydrocharitaceae & LILIO \\
\hline Lapsana & Asteraceae & MAGNO & Limonium & Plumbaginaceae & MAGNO \\
\hline Lardizabala & Lardizabalaceae & MAGNO & Limosella & Plantaginaceae & MAGNO \\
\hline Larrea & Zygophyllaceae & MAGNO & Linaria & Plantaginaceae & MAGNO \\
\hline Lastarriaea & Polygonaceae & MAGNO & Lindernia & Linderniaceae & MAGNO \\
\hline Lasthenia & Asteraceae & MAGNO & Linum & Linaceae & MAGNO \\
\hline Latace & Amaryllidaceae & LILIO & Lippia & Verbenaceae & MAGNO \\
\hline Lathyrus & Fabaceae & MAGNO & Lithrea & Anacardiaceae & MAGNO \\
\hline Latua & Solanaceae & MAGNO & Littorella & Plantaginaceae & MAGNO \\
\hline Laurelia & Monimiaceae & MAGNO & Llagunoa & Sapindaceae & MAGNO \\
\hline Laureliopsis & Monimiaceae & MAGNO & Loasa & Loasaceae & MAGNO \\
\hline Lebetanthus & Ericaceae & MAGNO & Lobelia & Campanulaceae & MAGNO \\
\hline
\end{tabular}


Catálogo plantas vasculares de Chile: Rodríguez, R. ET AL.

\begin{tabular}{|c|c|c|c|c|c|}
\hline GENERO & FAMILIA & CLASE & GENERO & FAMILIA & CLASE \\
\hline Lobularia & Brassicaceae & MAGNO & Medicago & Fabaceae & MAGNO \\
\hline Logfia & Asteraceae & MAGNO & Megalachne & Poaceae & LILIO \\
\hline Lolium & Poaceae & LILIO & Megalastrum & Dryopteridaceae & POLYP \\
\hline Lomatia & Proteaceae & MAGNO & Megathyrsus & Poaceae & LILIO \\
\hline Lophopappus & Asteraceae & MAGNO & Melia & Meliaceae & MAGNO \\
\hline Lophosoria & Dicksoniaceae & POLYP & Melica & Poaceae & LILIO \\
\hline Lotus & Fabaceae & MAGNO & Melilotus & Fabaceae & MAGNO \\
\hline Lucilia & Asteraceae & MAGNO & Melinis & Poaceae & LILIO \\
\hline Ludwigia & Onagraceae & MAGNO & Melissa & Lamiaceae & MAGNO \\
\hline Luma & Myrtaceae & MAGNO & Melosperma & Plantaginaceae & MAGNO \\
\hline Lupinus & Fabaceae & MAGNO & Menodora & Oleaceae & MAGNO \\
\hline Luzula & Juncaceae & LILIO & Menonvillea & Brassicaceae & MAGNO \\
\hline Luzuriaga & Luzuriagaceae & LILIO & Mentha & Lamiaceae & MAGNO \\
\hline Lycapsus & Asteraceae & MAGNO & Mentzelia & Loasaceae & MAGNO \\
\hline Lychnis & Caryophyllaceae & MAGNO & Mercurialis & Euphorbiaceae & MAGNO \\
\hline Lycium & Solanaceae & MAGNO & Mesembryanthemum & Aizoaceae & MAGNO \\
\hline Lycopus & Lamiaceae & MAGNO & Metharme & Zygophyllaceae & MAGNO \\
\hline Lysimachia & Primulaceae & MAGNO & Microchloa & Poaceae & LILIO \\
\hline Lythrum & Lythraceae & MAGNO & Microlepia & Dennstaedtiaceae & POLYP \\
\hline Machaerina & Cyperaceae & LILIO & Micromeria & Lamiaceae & MAGNO \\
\hline Macrachaenium & Asteraceae & MAGNO & Microphyes & Caryophyllaceae & MAGNO \\
\hline Macroptilium & Fabaceae & MAGNO & Micropsis & Asteraceae & MAGNO \\
\hline Madia & Asteraceae & MAGNO & Microseris & Asteraceae & MAGNO \\
\hline Maihuenia & Cactaceae & MAGNO & Microsorum & Polypodiaceae & POLYP \\
\hline Maihueniopsis & Cactaceae & MAGNO & Microsteris & Polemoniaceae & MAGNO \\
\hline Maireana & Chenopodiaceae & MAGNO & Miersia & Amaryllidaceae & LILIO \\
\hline Malacothrix & Asteraceae & MAGNO & Mikania & Asteraceae & MAGNO \\
\hline Malesherbia & Passifloraceae & MAGNO & Miqueliopuntia & Cactaceae & MAGNO \\
\hline Malva & Malvaceae & MAGNO & Mirabilis & Nyctaginaceae & MAGNO \\
\hline Malvastrum & Malvaceae & MAGNO & Miscanthus & Poaceae & LILIO \\
\hline Malvella & Malvaceae & MAGNO & Misodendrum & Misodendraceae & MAGNO \\
\hline Mancoa & Brassicaceae & MAGNO & Mitraria & Gesneriaceae & MAGNO \\
\hline Margyracaena & Rosaceae & MAGNO & Mniodes & Asteraceae & MAGNO \\
\hline Margyricarpus & Rosaceae & MAGNO & Modiola & Malvaceae & MAGNO \\
\hline Marrubium & Lamiaceae & MAGNO & Molucella & Lamiaceae & MAGNO \\
\hline Marsilea & Marsileaceae & POLYP & Monnina & Polygalaceae & MAGNO \\
\hline Marsippospermum & Juncaceae & LILIO & Montia & Montiaceae & MAGNO \\
\hline Marticorenia & Asteraceae & MAGNO & Montiopsis & Montiaceae & MAGNO \\
\hline Mastigostyla & Iridaceae & LILIO & Monttea & Plantaginaceae & MAGNO \\
\hline Mathewsia & Brassicaceae & MAGNO & Morella & Myricaceae & MAGNO \\
\hline Matricaria & Asteraceae & MAGNO & Moscharia & Asteraceae & MAGNO \\
\hline Matthiola & Brassicaceae & MAGNO & Moschopsis & Calyceraceae & MAGNO \\
\hline Maytenus & Celastraceae & MAGNO & Mostacillastrum & Brassicaceae & MAGNO \\
\hline Mecardonia & Plantaginaceae & MAGNO & Muehlenbeckia & Polygonaceae & MAGNO \\
\hline
\end{tabular}




\begin{tabular}{|c|c|c|c|c|c|}
\hline GENERO & FAMILIA & CLASE & GENERO & FAMILIA & CLASE \\
\hline Muhlenbergia & Poaceae & LILIO & Nymphaea & Nymphaeaceae & MAGNO \\
\hline Mulguraea & Verbenaceae & MAGNO & Ochagavia & Bromeliaceae & LILIO \\
\hline Munroa & Poaceae & LILIO & Ocyroe & Asteraceae & MAGNO \\
\hline Mutisia & Asteraceae & MAGNO & Oenothera & Onagraceae & MAGNO \\
\hline Myoporum & Scrophulariaceae & MAGNO & Oldenlandia & Rubiaceae & MAGNO \\
\hline Myoschilos & Santalaceae & MAGNO & Olsynium & Iridaceae & LILIO \\
\hline Myosotis & Boraginaceae & MAGNO & Ombrophytum & Balanophoraceae & MAGNO \\
\hline Myostemma & Amaryllidaceae & LILIO & Omphalodes & Boraginaceae & MAGNO \\
\hline Myosurus & Ranunculaceae & MAGNO & Onopordum & Asteraceae & MAGNO \\
\hline Myrceugenia & Myrtaceae & MAGNO & Onuris & Brassicaceae & MAGNO \\
\hline Myrcianthes & Myrtaceae & MAGNO & Ophioglossum & Ophioglossaceae & POLYP \\
\hline Myriophyllum & Haloragaceae & MAGNO & Ophryosporus & Asteraceae & MAGNO \\
\hline Myriopteris & Pteridaceae & POLYP & Oreobolus & Cyperaceae & LILIO \\
\hline Myrosmodes & Orchidaceae & LILIO & Oreocereus & Cactaceae & MAGNO \\
\hline Myrteola & Myrtaceae & MAGNO & Oreomyrrhis & Apiaceae & MAGNO \\
\hline Nama & Boraginaceae & MAGNO & Oreopolus & Rubiaceae & MAGNO \\
\hline Nanodea & Santalaceae & MAGNO & Oriastrum & Asteraceae & MAGNO \\
\hline Nardophyllum & Asteraceae & MAGNO & Orites & Proteaceae & MAGNO \\
\hline Nasa & Loasaceae & MAGNO & Ornithopus & Fabaceae & MAGNO \\
\hline Nassauvia & Asteraceae & MAGNO & Orobanche & Orobanchaceae & MAGNO \\
\hline Nassella & Poaceae & LILIO & Ortachne & Poaceae & LILIO \\
\hline Nastanthus & Calyceraceae & MAGNO & Oryza & Poaceae & LILIO \\
\hline Nasturtium & Brassicaceae & MAGNO & Osmorhiza & Apiaceae & MAGNO \\
\hline Navarretia & Polemoniaceae & MAGNO & Otholobium & Fabaceae & MAGNO \\
\hline Neobartsia & Orobanchaceae & MAGNO & Ourisia & Plantaginaceae & MAGNO \\
\hline Neowerdermannia & Cactaceae & MAGNO & Ovidia & Thymelaeaceae & MAGNO \\
\hline Nertera & Rubiaceae & MAGNO & Oxalis & Oxalidaceae & MAGNO \\
\hline Nesocaryum & Boraginaceae & MAGNO & Oxybasis & Chenopodiaceae & MAGNO \\
\hline Neuontobotrys & Brassicaceae & MAGNO & Oxychloë & Juncaceae & LILIO \\
\hline Nicandra & Solanaceae & MAGNO & Oxyphyllum & Asteraceae & MAGNO \\
\hline Nicoraepoa & Poaceae & LILIO & Oxytheca & Polygonaceae & MAGNO \\
\hline Nicotiana & Solanaceae & MAGNO & Oziroë & Asparagaceae & LILIO \\
\hline Nierembergia & Solanaceae & MAGNO & Pachylaena & Asteraceae & MAGNO \\
\hline Nitrophila & Chenopodiaceae & MAGNO & Palaua & Malvaceae & MAGNO \\
\hline Noccaea & Brassicaceae & MAGNO & Panicum & Poaceae & LILIO \\
\hline Nolana & Solanaceae & MAGNO & Papaver & Papaveraceae & MAGNO \\
\hline Notanthera & Loranthaceae & MAGNO & Pappostipa & Poaceae & LILIO \\
\hline Nothofagus & Nothofagaceae & MAGNO & Parapholis & Poaceae & LILIO \\
\hline Notholaena & Pteridaceae & POLYP & Parastrephia & Asteraceae & MAGNO \\
\hline Nothomyrcia & Myrtaceae & MAGNO & Parentucellia & Orobanchaceae & MAGNO \\
\hline Nothoscordum & Amaryllidaceae & LILIO & Parietaria & Urticaceae & MAGNO \\
\hline Noticastrum & Asteraceae & MAGNO & Paronychia & Caryophyllaceae & MAGNO \\
\hline Notopappus & Asteraceae & MAGNO & Pascalia & Asteraceae & MAGNO \\
\hline Nototriche & Malvaceae & MAGNO & Pasithea & Asphodelaceae & LILIO \\
\hline
\end{tabular}


Catálogo plantas vasculares de Chile: Rodríguez, R. ET AL.

\begin{tabular}{|c|c|c|c|c|c|}
\hline GENERO & FAMILIA & CLASE & GENERO & FAMILIA & CLASE \\
\hline Paspalum & Poaceae & LILIO & Pitavia & Rutaceae & MAGNO \\
\hline Passiflora & Passifloraceae & MAGNO & Pitraea & Verbenaceae & MAGNO \\
\hline Pastinaca & Apiaceae & MAGNO & Pittosporum & Pittosporaceae & MAGNO \\
\hline Patosia & Juncaceae & LILIO & Placea & Amaryllidaceae & LILIO \\
\hline Pectocarya & Boraginaceae & MAGNO & Plagiobothrys & Boraginaceae & MAGNO \\
\hline Pellaea & Pteridaceae & POLYP & Plantago & Plantaginaceae & MAGNO \\
\hline Pelletiera & Primulaceae & MAGNO & Plazia & Asteraceae & MAGNO \\
\hline Pennellia & Brassicaceae & MAGNO & Pleocarphus & Asteraceae & MAGNO \\
\hline Peperomia & Piperaceae & MAGNO & Pleopeltis & Polypodiaceae & POLYP \\
\hline Perezia & Asteraceae & MAGNO & Pleurophora & Lythraceae & MAGNO \\
\hline Perityle & Asteraceae & MAGNO & Pleurosorus & Aspleniaceae & POLYP \\
\hline Persea & Lauraceae & MAGNO & Pluchea & Asteraceae & MAGNO \\
\hline Persicaria & Polygonaceae & MAGNO & Plumbago & Plumbaginaceae & MAGNO \\
\hline Petroravenia & Brassicaceae & MAGNO & Poa & Poaceae & LILIO \\
\hline Petrorhagia & Caryophyllaceae & MAGNO & Podagrostis & Poaceae & LILIO \\
\hline Petroselinum & Apiaceae & MAGNO & Podanthus & Asteraceae & MAGNO \\
\hline Peumus & Monimiaceae & MAGNO & Podocarpus & Podocarpaceae & PINOP \\
\hline Phacelia & Boraginaceae & MAGNO & Podophorus & Poaceae & LILIO \\
\hline Phalaris & Poaceae & LILIO & Polemonium & Polemoniaceae & MAGNO \\
\hline Philesia & Philesiaceae & LILIO & Polyachyrus & Asteraceae & MAGNO \\
\hline Philibertia & Apocynaceae & MAGNO & Polycarpon & Caryophyllaceae & MAGNO \\
\hline Philippiella & Caryophyllaceae & MAGNO & Polygala & Polygalaceae & MAGNO \\
\hline Phleum & Poaceae & LILIO & Polygonum & Polygonaceae & MAGNO \\
\hline Phragmites & Poaceae & LILIO & Polylepis & Rosaceae & MAGNO \\
\hline Phycella & Amaryllidaceae & LILIO & Polypodium & Polypodiaceae & POLYP \\
\hline Phyla & Verbenaceae & MAGNO & Polypogon & Poaceae & LILIO \\
\hline Phyllachne & Stylidiaceae & MAGNO & Polypsecadium & Brassicaceae & MAGNO \\
\hline Phylloscirpus & Cyperaceae & LILIO & Polystichum & Dryopteridaceae & POLYP \\
\hline Physalis & Solanaceae & MAGNO & Pombalia & Violaceae & MAGNO \\
\hline Phytolacca & Phytolaccaceae & MAGNO & Populus & Salicaceae & MAGNO \\
\hline Picradeniopsis & Asteraceae & MAGNO & Porlieria & Zygophyllaceae & MAGNO \\
\hline Picris & Asteraceae & MAGNO & Porophyllum & Asteraceae & MAGNO \\
\hline Picrosia & Asteraceae & MAGNO & Portulaca & Portulacaceae & MAGNO \\
\hline Pilea & Urticaceae & MAGNO & Potamogeton & Potamogetonaceae & LILIO \\
\hline Pilgerodendron & Cupressaceae & PINOP & Potentilla & Rosaceae & MAGNO \\
\hline Pilostyles & Rafflesiaceae & MAGNO & Pouteria & Sapotaceae & MAGNO \\
\hline Pilularia & Marsileaceae & POLYP & Pozoa & Apiaceae & MAGNO \\
\hline Pinguicula & Lentibulariaceae & MAGNO & Presliophytum & Loasaceae & MAGNO \\
\hline Pinnasa & Loasaceae & MAGNO & Primula & Primulaceae & MAGNO \\
\hline Pintoa & Zygophyllaceae & MAGNO & Prosopis & Fabaceae & MAGNO \\
\hline Pinus & Pinaceae & PINOP & Proustia & Asteraceae & MAGNO \\
\hline Piptatherum & Poaceae & LILIO & Prumnopitys & Podocarpaceae & PINOP \\
\hline Piptochaetium & Poaceae & LILIO & Prunella & Lamiaceae & MAGNO \\
\hline Pistia & Araceae & LILIO & Prunus & Rosaceae & MAGNO \\
\hline
\end{tabular}




\begin{tabular}{|c|c|c|c|c|c|}
\hline GENERO & FAMILIA & CLASE & GENERO & FAMILIA & CLASE \\
\hline Pseudognaphalium & Asteraceae & MAGNO & Rytidosperma & Poaceae & LILIO \\
\hline Psidium & Myrtaceae & MAGNO & Sabulina & Caryophyllaceae & MAGNO \\
\hline Psilocarphus & Asteraceae & MAGNO & Saccharum & Poaceae & LILIO \\
\hline Psilotum & Psilotaceae & POLYP & Sagina & Caryophyllaceae & MAGNO \\
\hline Pteris & Pteridaceae & POLYP & Sagittaria & Alismataceae & LILIO \\
\hline Pterocactus & Cactaceae & MAGNO & Salix & Salicaceae & MAGNO \\
\hline Puccinellia & Poaceae & LILIO & Salpichroa & Solanaceae & MAGNO \\
\hline Puya & Bromeliaceae & LILIO & Salpiglossis & Solanaceae & MAGNO \\
\hline Pycnophyllopsis & Caryophyllaceae & MAGNO & Salsola & Chenopodiaceae & MAGNO \\
\hline Pycnophyllum & Caryophyllaceae & MAGNO & Salvia & Lamiaceae & MAGNO \\
\hline Pyrolirion & Amaryllidaceae & LILIO & Salvinia & Salviniaceae & POLYP \\
\hline Quercus & Fagaceae & MAGNO & Sambucus & Caprifoliaceae & MAGNO \\
\hline Quillaja & Quillajaceae & MAGNO & Samolus & Primulaceae & MAGNO \\
\hline Quinchamalium & Schoepfiaceae & MAGNO & Sanguisorba & Rosaceae & MAGNO \\
\hline Ranunculus & Ranunculaceae & MAGNO & Sanicula & Apiaceae & MAGNO \\
\hline Raphanus & Brassicaceae & MAGNO & Santalum & Santalaceae & MAGNO \\
\hline Rapistrum & Brassicaceae & MAGNO & Sapindus & Sapindaceae & MAGNO \\
\hline Raukaua & Araliaceae & MAGNO & Saponaria & Caryophyllaceae & MAGNO \\
\hline Reicheella & Caryophyllaceae & MAGNO & Sarcocornia & Chenopodiaceae & MAGNO \\
\hline Relchela & Poaceae & LILIO & Sarcodraba & Brassicaceae & MAGNO \\
\hline Reseda & Resedaceae & MAGNO & Sarmienta & Gesneriaceae & MAGNO \\
\hline Retanilla & Rhamnaceae & MAGNO & Saxegothaea & Podocarpaceae & PINOP \\
\hline Reyesia & Solanaceae & MAGNO & Saxifraga & Saxifragaceae & MAGNO \\
\hline Rhamnus & Rhamnaceae & MAGNO & Saxifragella & Saxifragaceae & MAGNO \\
\hline Rhaphithamnus & Verbenaceae & MAGNO & Saxifragodes & Saxifragaceae & MAGNO \\
\hline Rhodolirium & Amaryllidaceae & LILIO & Scabiosa & Caprifoliaceae & MAGNO \\
\hline Rhodophiala & Amaryllidaceae & LILIO & Scandix & Apiaceae & MAGNO \\
\hline Rhodoscirpus & Cyperaceae & LILIO & Schinus & Anacardiaceae & MAGNO \\
\hline Rhynchosia & Fabaceae & MAGNO & Schismus & Poaceae & LILIO \\
\hline Rhynchospora & Cyperaceae & LILIO & Schizachyrium & Poaceae & LILIO \\
\hline Ribes & Grossulariaceae & MAGNO & Schizaea & Schizaeaceae & POLYP \\
\hline Ricinus & Euphorbiaceae & MAGNO & Schizanthus & Solanaceae & MAGNO \\
\hline Robinia & Fabaceae & MAGNO & Schizopetalon & Brassicaceae & MAGNO \\
\hline Romulea & Iridaceae & LILIO & Schkuhria & Asteraceae & MAGNO \\
\hline Rorippa & Brassicaceae & MAGNO & Schoenoplectus & Cyperaceae & LILIO \\
\hline Rosa & Rosaceae & MAGNO & Schoenus & Cyperaceae & LILIO \\
\hline Rostkovia & Juncaceae & LILIO & Schyzachyrium & Poaceae & LILIO \\
\hline Rostraria & Poaceae & LILIO & Scirpus & Cyperaceae & LILIO \\
\hline Rubia & Rubiaceae & MAGNO & Scleranthus & Caryophyllaceae & MAGNO \\
\hline Rubus & Rosaceae & MAGNO & Scolymus & Asteraceae & MAGNO \\
\hline Rumex & Polygonaceae & MAGNO & Scrophularia & Scrophulariaceae & MAGNO \\
\hline Rumohra & Dryopteridaceae & POLYP & Scutellaria & Lamiaceae & MAGNO \\
\hline Ruppia & Ruppiaceae & LILIO & Scyphanthus & Loasaceae & MAGNO \\
\hline Ruta & Rutaceae & MAGNO & Sedum & Crassulaceae & MAGNO \\
\hline
\end{tabular}




\begin{tabular}{|c|c|c|c|c|c|}
\hline GENERO & FAMILIA & CLASE & GENERO & FAMILIA & CLASE \\
\hline Selaginella & Selaginellaceae & LYCOP & Stenandrium & Acanthaceae & MAGNO \\
\hline Selkirkia & Boraginaceae & MAGNO & Stenotaphrum & Poaceae & LILIO \\
\hline Selliera & Goodeniaceae & MAGNO & Stevia & Asteraceae & MAGNO \\
\hline Senecio & Asteraceae & MAGNO & Sticherus & Gleicheniaceae & POLYP \\
\hline Senna & Fabaceae & MAGNO & Stuckenia & Potamogetonaceae & LILIO \\
\hline Serpyllopsis & Hymenophyllaceae & POLYP & Suaeda & Chenopodiaceae & MAGNO \\
\hline Seseli & Apiaceae & MAGNO & Symphyotrichum & Asteraceae & MAGNO \\
\hline Sesuvium & Aizoaceae & MAGNO & Synammia & Polypodiaceae & POLYP \\
\hline Setaria & Poaceae & LILIO & Syzygium & Myrtaceae & MAGNO \\
\hline Sherardia & Rubiaceae & MAGNO & Taeniatherum & Poaceae & LILIO \\
\hline Sibara & Brassicaceae & MAGNO & Tagetes & Asteraceae & MAGNO \\
\hline Sicyos & Cucurbitaceae & MAGNO & Tanacetum & Asteraceae & MAGNO \\
\hline Sida & Malvaceae & MAGNO & Tapeinia & Iridaceae & LILIO \\
\hline Sigesbeckia & Asteraceae & MAGNO & Tarasa & Malvaceae & MAGNO \\
\hline Silene & Caryophyllaceae & MAGNO & Taraxacum & Asteraceae & MAGNO \\
\hline Silybum & Asteraceae & MAGNO & Tecoma & Bignoniaceae & MAGNO \\
\hline Sinapis & Brassicaceae & MAGNO & Tecophilaea & Tecophilaeaceae & LILIO \\
\hline Sisymbrium & Brassicaceae & MAGNO & Teesdalia & Brassicaceae & MAGNO \\
\hline Sisyrinchium & Iridaceae & LILIO & Teline & Fabaceae & MAGNO \\
\hline Sium & Apiaceae & MAGNO & Tepualia & Myrtaceae & MAGNO \\
\hline Skytanthus & Apocynaceae & MAGNO & Tessaria & Asteraceae & MAGNO \\
\hline Smallanthus & Asteraceae & MAGNO & Tetilla & Francoaceae & MAGNO \\
\hline Solanum & Solanaceae & MAGNO & Tetrachondra & Tetrachondraceae & MAGNO \\
\hline Solaria & Amaryllidaceae & LILIO & Tetraglochin & Rosaceae & MAGNO \\
\hline Soleirolia & Urticaceae & MAGNO & Tetragonia & Aizoaceae & MAGNO \\
\hline Solenomelus & Iridaceae & LILIO & Tetroncium & Juncaginaceae & LILIO \\
\hline Solidago & Asteraceae & MAGNO & Teucrium & Lamiaceae & MAGNO \\
\hline Soliva & Asteraceae & MAGNO & Thamnoseris & Asteraceae & MAGNO \\
\hline Sonchus & Asteraceae & MAGNO & Thelypteris & Thelypteridaceae & POLYP \\
\hline Sophora & Fabaceae & MAGNO & Thespesia & Malvaceae & MAGNO \\
\hline Sorghum & Poaceae & LILIO & Thlaspi & Brassicaceae & MAGNO \\
\hline Spartium & Fabaceae & MAGNO & Thyrsopteris & Dicksoniaceae & POLYP \\
\hline Speea & Amaryllidaceae & LILIO & Tigridia & Iridaceae & LILIO \\
\hline Spergula & Caryophyllaceae & MAGNO & Tillandsia & Bromeliaceae & LILIO \\
\hline Spergularia & Caryophyllaceae & MAGNO & Tiquilia & Boraginaceae & MAGNO \\
\hline Sphaeralcea & Malvaceae & MAGNO & Tolpis & Asteraceae & MAGNO \\
\hline Spilanthes & Asteraceae & MAGNO & Tomostima & Brassicaceae & MAGNO \\
\hline Spinoliva & Asteraceae & MAGNO & Torilis & Apiaceae & MAGNO \\
\hline Spirodela & Araceae & LILIO & Tradescantia & Commelinaceae & LILIO \\
\hline Sporobolus & Poaceae & LILIO & Tragopogon & Asteraceae & MAGNO \\
\hline Stachys & Lamiaceae & MAGNO & Traubia & Amaryllidaceae & LILIO \\
\hline Stangea & Caprifoliaceae & MAGNO & Trevoa & Rhamnaceae & MAGNO \\
\hline Stellaria & Caryophyllaceae & MAGNO & Trianthema & Aizoaceae & MAGNO \\
\hline Stemodia & Plantaginaceae & MAGNO & Tribeles & Escalloniaceae & MAGNO \\
\hline
\end{tabular}




\begin{tabular}{|c|c|c|c|c|c|}
\hline GENERO & FAMILIA & CLASE & GENERO & FAMILIA & CLASE \\
\hline Tribulus & Zygophyllaceae & MAGNO & Valeriana & Caprifoliaceae & MAGNO \\
\hline Trichocline & Asteraceae & MAGNO & Valerianella & Caprifoliaceae & MAGNO \\
\hline Trichomanes & Hymenophyllaceae & POLYP & Verbascum & Scrophulariaceae & MAGNO \\
\hline Trichoneura & Poaceae & LILIO & Verbena & Verbenaceae & MAGNO \\
\hline Trichopetalum & Asparagaceae & LILIO & Verbesina & Asteraceae & MAGNO \\
\hline Trifolium & Fabaceae & MAGNO & Veronica & Plantaginaceae & MAGNO \\
\hline Triglochin & Juncaginaceae & LILIO & Vestia & Solanaceae & MAGNO \\
\hline Trigonella & Fabaceae & MAGNO & Vicia & Fabaceae & MAGNO \\
\hline Triodanis & Campanulaceae & MAGNO & Villanova & Asteraceae & MAGNO \\
\hline Tripleurospermum & Asteraceae & MAGNO & Vinca & Apocynaceae & MAGNO \\
\hline Tripogon & Poaceae & LILIO & Viola & Violaceae & MAGNO \\
\hline Triptilion & Asteraceae & MAGNO & Vitis & Vitaceae & MAGNO \\
\hline Trisetum & Poaceae & LILIO & Vittaria & Pteridaceae & POLYP \\
\hline Trismeria & Pteridaceae & POLYP & Viviania & Francoaceae & MAGNO \\
\hline Tristagma & Amaryllidaceae & LILIO & Volutaria & Asteraceae & MAGNO \\
\hline Tristerix & Loranthaceae & MAGNO & Vulpia & Poaceae & LILIO \\
\hline Triticum & Poaceae & LILIO & Wahlenbergia & Campanulaceae & MAGNO \\
\hline Triumfetta & Malvaceae & MAGNO & Waltheria & Malvaceae & MAGNO \\
\hline Trixis & Asteraceae & MAGNO & Weberbauera & Brassicaceae & MAGNO \\
\hline Tropaeolum & Tropaeolaceae & MAGNO & Weberbauerella & Fabaceae & MAGNO \\
\hline Tropidocarpum & Brassicaceae & MAGNO & Weinmannia & Cunoniaceae & MAGNO \\
\hline Tunilla & Cactaceae & MAGNO & Werneria & Asteraceae & MAGNO \\
\hline Tweedia & Apocynaceae & MAGNO & Wolffia & Araceae & LILIO \\
\hline Typha & Typhaceae & LILIO & Wolffiella & Araceae & LILIO \\
\hline Ugni & Myrtaceae & MAGNO & Woodsia & Woodsiaceae & POLYP \\
\hline Ulantha & Orchidaceae & LILIO & Xanthium & Asteraceae & MAGNO \\
\hline Ulex & Fabaceae & MAGNO & Xenophyllum & Asteraceae & MAGNO \\
\hline Ulmus & Ulmaceae & MAGNO & Xerodraba & Brassicaceae & MAGNO \\
\hline Uncinia & Cyperaceae & LILIO & Yunquea & Asteraceae & MAGNO \\
\hline Urmenetea & Asteraceae & MAGNO & Zameioscirpus & Cyperaceae & LILIO \\
\hline Urocarpidium & Malvaceae & MAGNO & Zannichellia & Potamogetonaceae & LILIO \\
\hline Urospermum & Asteraceae & MAGNO & Zantedeschia & Araceae & LILIO \\
\hline Urtica & Urticaceae & MAGNO & Zea & Poaceae & LILIO \\
\hline Utricularia & Lentibulariaceae & MAGNO & Zephyra & Tecophilaeaceae & LILIO \\
\hline Vahlodea & Poaceae & LILIO & Zostera & Zosteraceae & LILIO \\
\hline Valdivia & Escalloniaceae & MAGNO & & & \\
\hline
\end{tabular}

Recibido: 02.03.2018

Aceptado: 07.05.2018 